\title{
Fouilles à Marseille : la ville médiévale et moderne
}

\author{
Marc Bouiron, Françoise Paone, Bernard Sillano, Colette Castrucci et \\ Nadine Scherrer (dir.)
}

DOI : 10.4000/books.pccj. 879

Éditeur : Publications du Centre Camille Jullian, Éditions Errance

Lieu d'édition : Aix-en-Provence

Année d'édition : 2011

Date de mise en ligne : 13 février 2020

Collection : Bibliothèque d'archéologie méditerranéenne et africaine

ISBN électronique : 9782957155767

\section{Sbooks}

http://books.openedition.org

\section{Édition imprimée}

ISBN : 9782877724616

Nombre de pages : 463

\section{Référence électronique}

BOUIRON, Marc (dir.) ; et al. Fouilles à Marseille : la ville médiévale et moderne. Nouvelle édition [en ligne]. Aix-en-Provence : Publications du Centre Camille Jullian, 2011 (généré le 21 décembre 2020). Disponible sur Internet : <http://books.openedition.org/pccj/879>. ISBN : 9782957155767 . DOI : https://doi.org/10.4000/books.pccj.879.

(c) Publications du Centre Camille Jullian, 2011

Conditions d'utilisation:

http://www.openedition.org/6540 


\section{$\mathrm{B}$ ibliothèque d'Archéologie \\ Méditerranéenne et Africaine


Dans la lignée des anciens Travaux du Centre Camille Jullian, la Bibliothèque d'Archéologie Méditerranéenne et Africaine (BiAMA) regroupe des travaux (monographie, actes de colloques, ouvrages collectifs) en relation avec les programmes scientifiques du Centre Camille Jullian, sur l'histoire et l'archéologie de la Gaule méridionale, de l'Afrique du Nord et du bassin méditerranéen. La BiAMA peut comprendre des sous-séries, comme la collection Études massaliètes (EtMassa).

Responsable légal :

Dominique Garcia, Directeur du CCJ

Directeur de la publication :

Henri Tréziny

Comité de pilotage :

Xavier Delestre, Dominique Garcia, Henri Tréziny

Conception graphique et mise en page :

Véronique Gémonet

Direction scientifique des Études massaliètes :

Michel Bats, Henri Tréziny

\section{Comité de lecture :}

Ph. Borgard (CCJ, CNRS), M.-Br. Carre (CCJ, CNRS), X. Delestre (DRAC PACA), D. Garcia (CCJ, Université de Provence), M. Griesheimer (CCJ, Université de Provence), A. Hermary (CCJ, Université de Provence), Ph. Jockey (CCJ, Université de Provence), M. Lombardo (Professeur à l'Université de Lecce), T. S. Loseby (Professeur à l'Université de Sheffield), J.-M. Mignon (Service archéologique départemental du Vaucluse), P. Pomey (CCJ, CNRS), L. Rivet (CCJ, CNRS), J. Sanmarti (Professeur à l'Université de Barcelone), H. Tréziny (CCJ, CNRS), C. Virlouvet (CCJ, Université de Provence), E. Voutiras (Professeur à l'Université de Thessalonique).

Conseiller scientifique pour ce volume : L. Schneider

(C) 2011 pour tous pays,

Édition Errance, éditeur du groupe Actes Sud

7 , rue Jean Du Bellay 75004 Paris

Tél. : 0443268582

Fax : 0143293488

Courriel : contact@editions-errance.fr

http://www.libairie-epona.fr

Centre Camille Jullian

Maison Méditerranéenne des Sciences de l'Homme

5 rue du Château de l'Horloge. BP 647, 13094 Aix-en-Provence Cedex 2

ISBN : 978-2-87772-461-6

ISSN BiAMA : 2101-2849

ISSN ÉtMassa : 0986-3974

Illustrations de couverture :

Vue de la maquette de Marseille en 1350 (maquette Acte II, M. Bouiron et T. Pécout, conservée aux Archives Municipales). (cl.Odile Guillon/CICRP) Illustration 4ème de couverture

Pierre de fondation de la reconstruction de la parcelle 372 (rue des Olives) en 1744. (cl. T. Maziers/Inrap)
Publications du Centre Camille Jullian

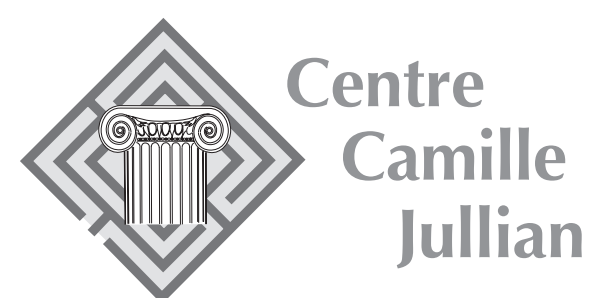

Ouvrage financé par

le Ministère de la Culture (DRAC - PACA)

et l'Institut national pour la recherche archéologique préventive
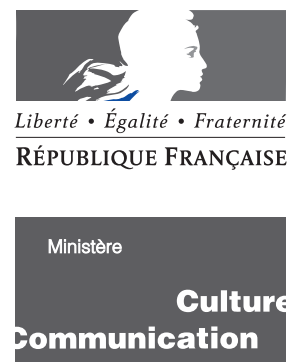

DIRECTION RÉGIONALE DES AFFAIRES CULTURELLES DE PROVENCE-ALPES-CÔTE D'AZUR

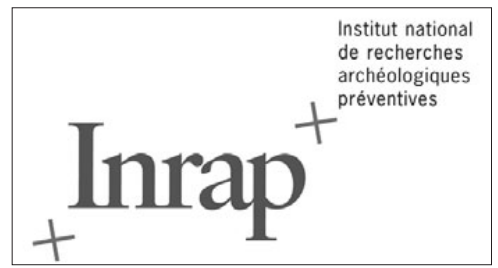

Envoyer les manuscrits à :

Henri Tréziny

Bibliothèque d'Archéologie Méditerranéenne et Africaine

Centre Camille Jullian

Maison Méditerranéenne des Sciences de l'Homme

5 rue du Château de l'Horloge. BP 647 ,

13094 Aix-en-Provence Cedex 2 


\section{FOUILLES À MARSEILLE APPROCHE DE LA VILLE MÉDIÉVALE ET MODERNE}

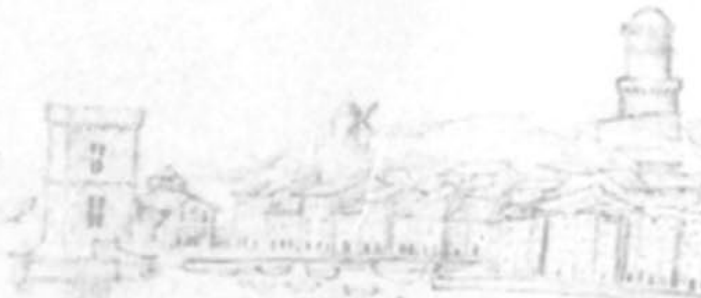

Volume collectif dirigé par Marc Bouiron, Françoise Paone, Bernard Sillano, Colette Castrucci et Nadine Scherrer

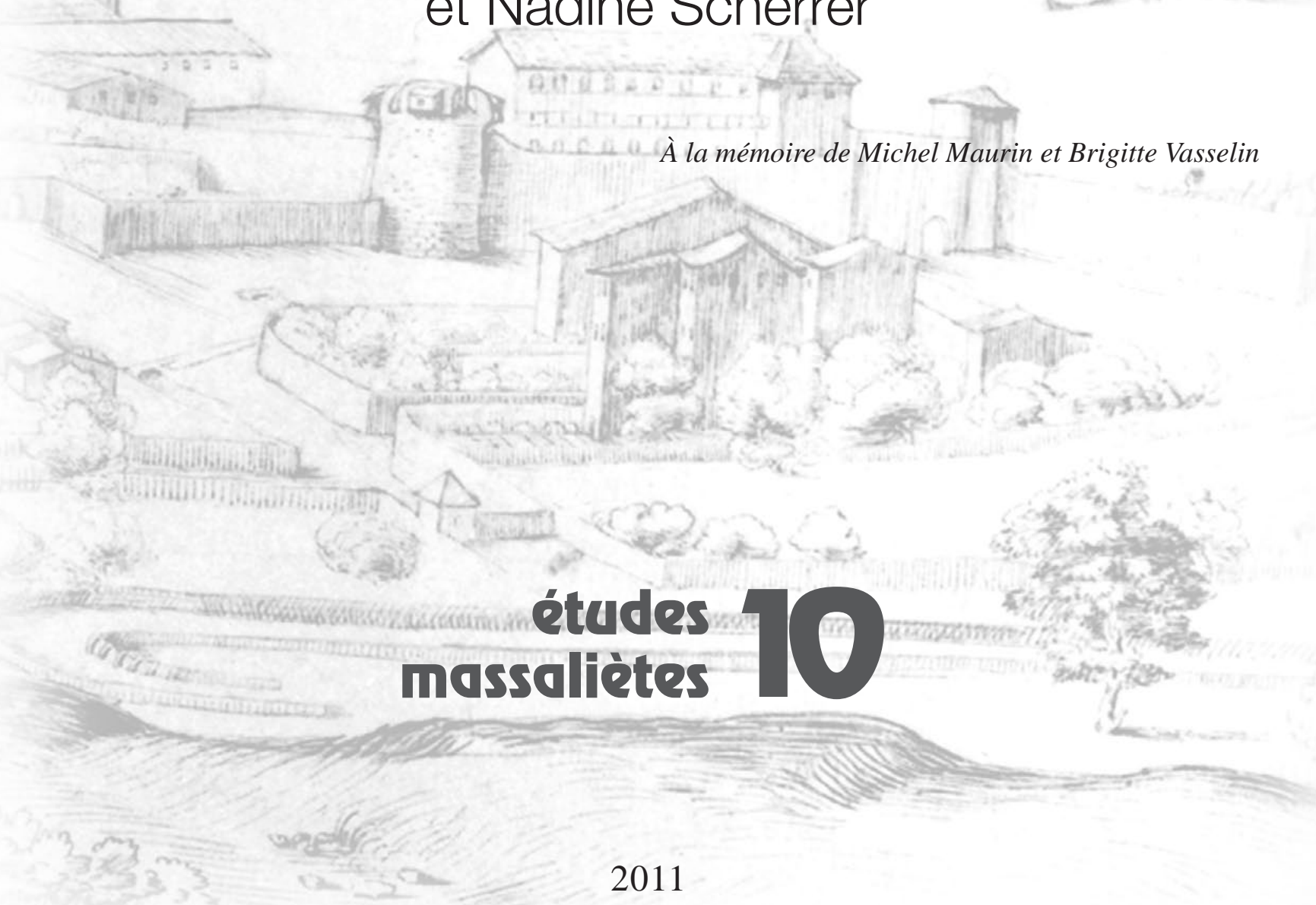




\section{Sommaire}

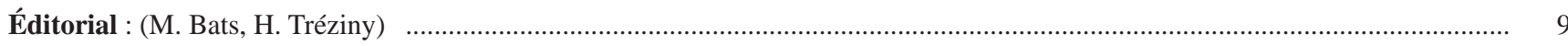

Préfaces : (X. Delestre, J.-P. Jacob) .

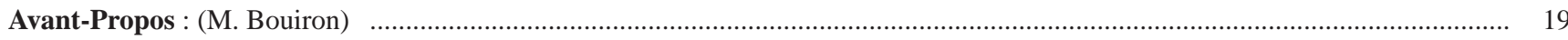

Introduction : (N. Scherrer, B. Sillano, M. Bouiron, C. Castrucci, F. Paone) .............................................................................. 21

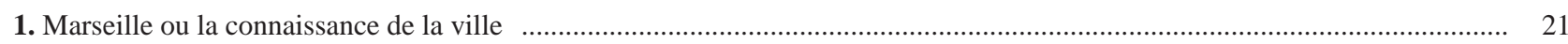

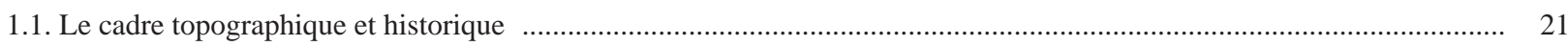

1.2. L'archéologie préventive du Moyen Âge et des Temps Modernes à Marseille ............................................................ 23

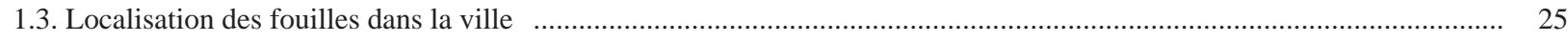

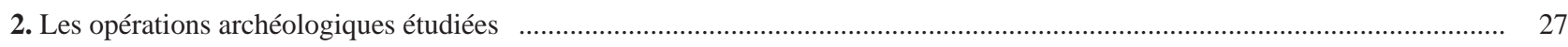

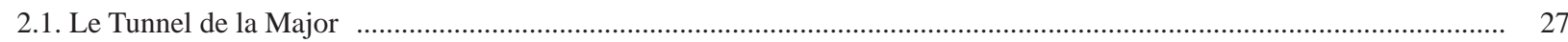

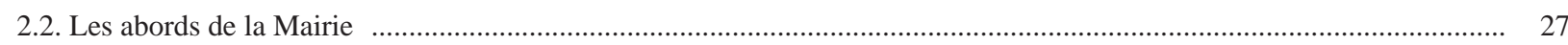

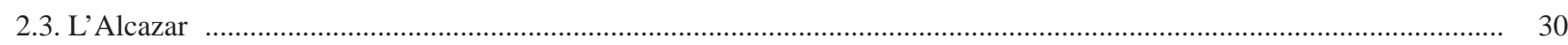

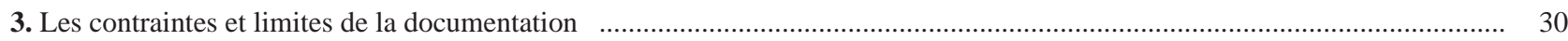

3.1. Les limites de l'archéologie du Moyen Âge et des Temps Modernes ................................................................ 30

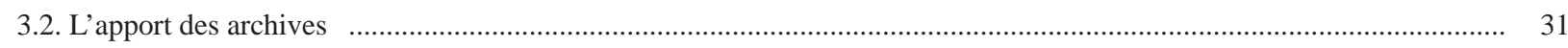

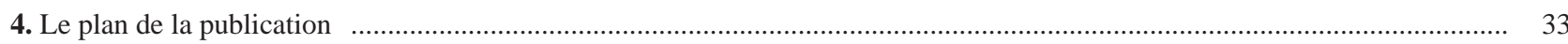

\section{PREMİ̀RE PARTIE : \\ ÉTUDE TOPOGRAPHIQUE ET MORPHOLOGIQUE D'UNE VILLE MULTIPOLAIRE}

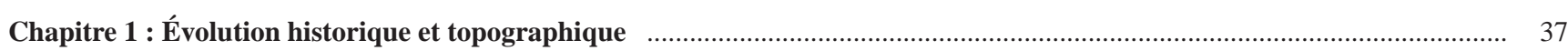

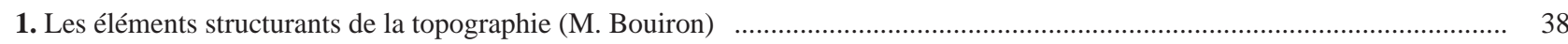

1.1. La topographie naturelle

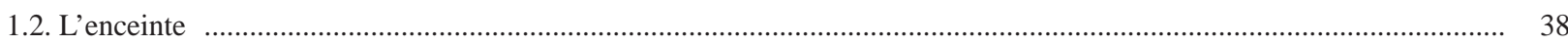

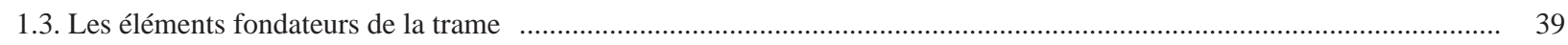

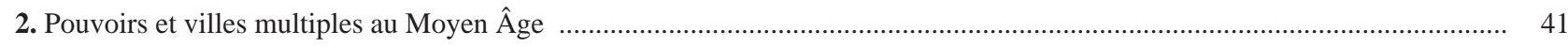

2.1. Comtes, vicomtes et pouvoir communal (M. Bouiron) ...................................................................................

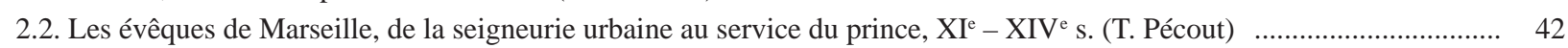

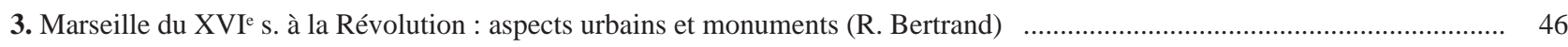

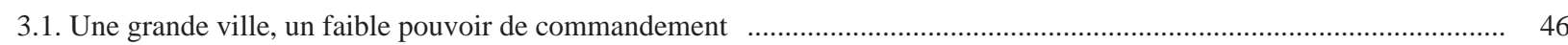

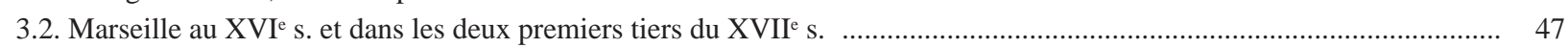

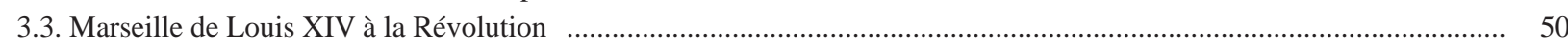

3.4. Le quartier de l'arsenal et les « embellissements » du règne de Louis XVI .............................................................. 51

3.5. Contrastes sociaux à la veille de la Révolution ............................................................................................... 52

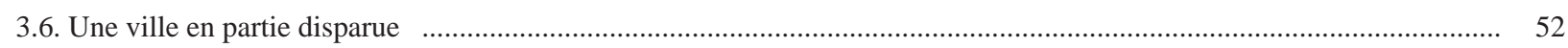

4. Le port

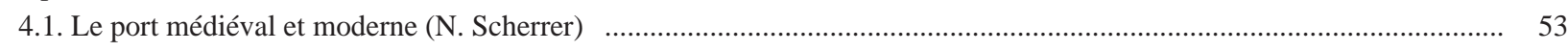

4.2. Les aménagements portuaires à la lumière des fouilles de la rue de la République (B. Sillano) ................................... 54

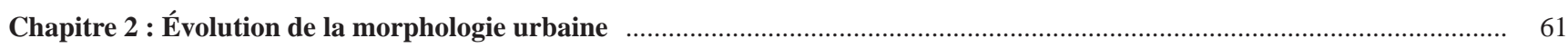

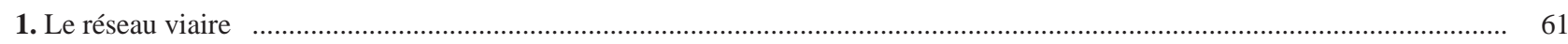

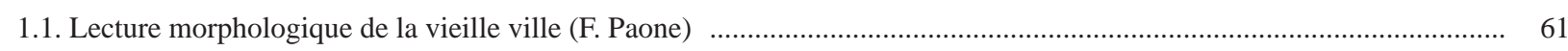

1.2. Mise en œuvre et entretien des rues aux époques médiévale et moderne (F. Paone) ................................................... 64 
1.3. Naissance de l'urbanisme moderne (B. Sillano)

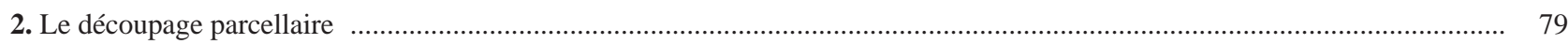

2.1. Réflexion sur le parcellaire médiéval à partir de quelques secteurs fouillés (F. Paone) ................................................. 79

2.2. L'occupation de l'espace urbain à l'Époque moderne (B. Sillano) ...........................................................................

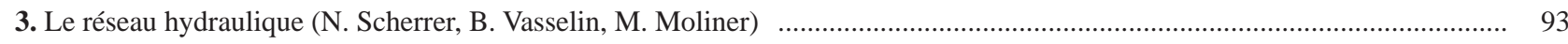

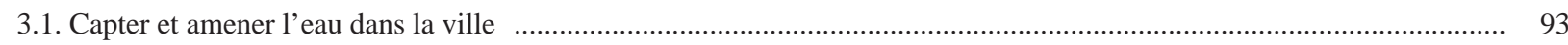

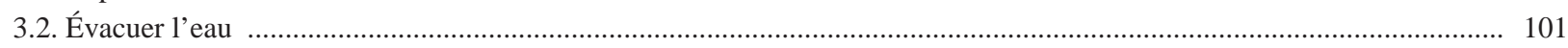

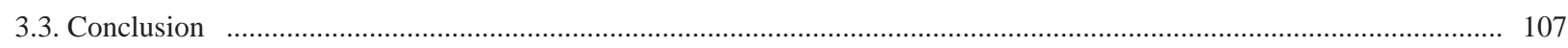

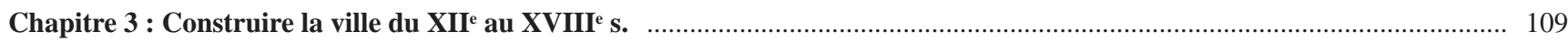

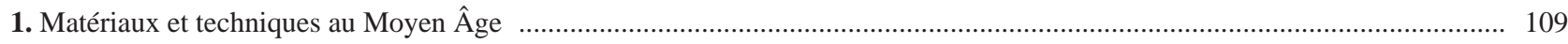

1.1. Les matériaux recensés à l'époque médiévale (A. Mezzoud, R. Thernot) …............................................................. 109

1.2. Les techniques de construction au Moyen Âge (R. Thernot) …............................................................................ 119

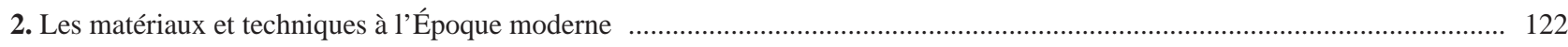

2.1. Les matériaux recensés à l'Époque moderne d'après les données de fouille et les documents d'archive

(A. Mezzoud, R. Thernot d'après M. Vacca-Goutouli) ...................................................................................... 122

2.2. Les techniques de constructions modernes (R. Thernot) ................................................................................. 127

2.3. La baie et son évolution (R. Thernot avec la coll. de M. Vacca Goutoulli et L. Duval) …........................................... 133

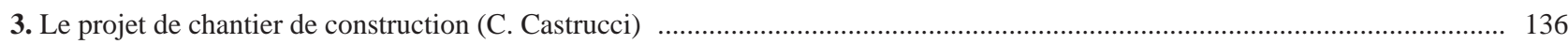

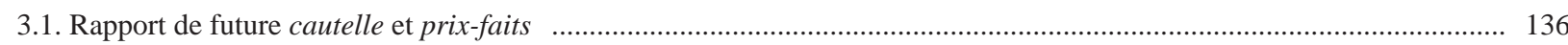

3.2. Les parties en présence lors de l'établissement du contrat : le commanditaire et l'entrepreneur ..................................... 137

3.3. Le déroulement des travaux : les tâches à accomplir par les maçons ......................................................................... 138

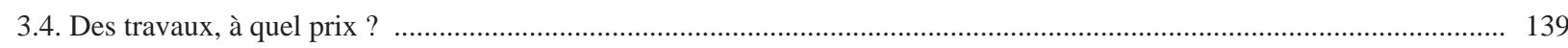

4. La pierre de taille : un élément de l'économie marseillaise (C. Castrucci) …................................................................ 140

4.1. L'utilisation de la pierre de taille : entre nécessité technique et volonté d'ostentation ................................................ 140

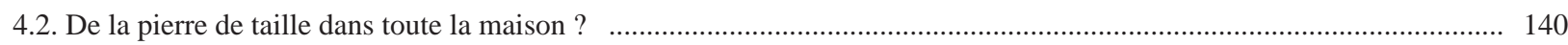

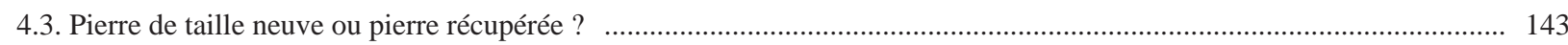

4.4. Une pierre de taille de quelle provenance et de quelle qualité ? ................................................................................ 143

4.5. De la prise en charge des enjeux économiques par les autorités communales ............................................................. 144

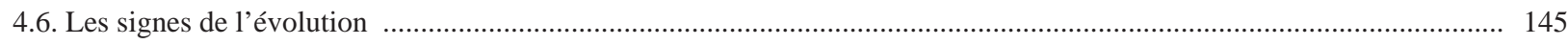

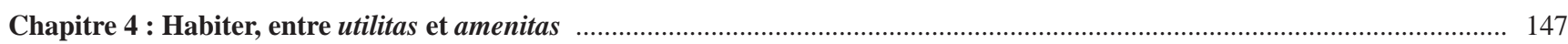

1. L'organisation spatiale des maisons médiévales (N. Scherrer, R. Thernot) …....................................................................... 147

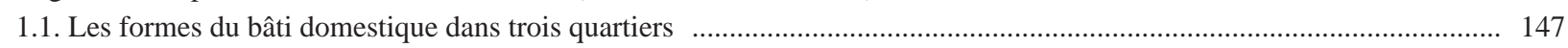

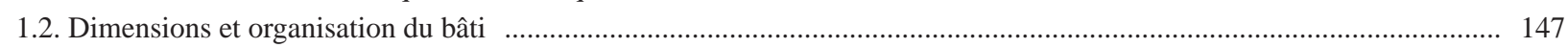

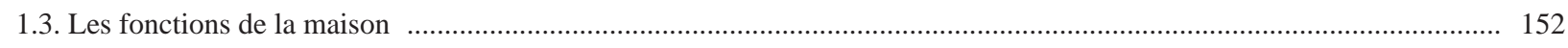

2. Manières d'habiter à Marseille : les formes de l'habitat entre la fin du XVI e et le début du XVIII ${ }^{\mathrm{e}} \mathrm{s}$. (C. Castrucci) $\quad$................. 154

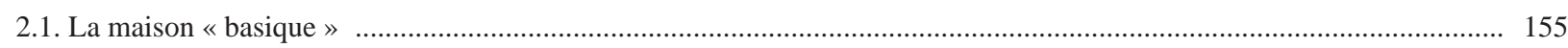

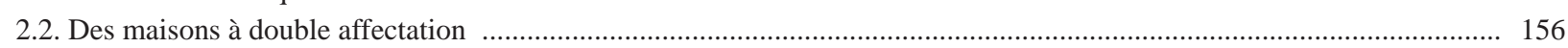

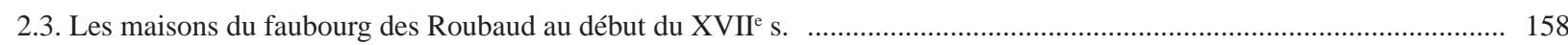

2.4. L'évolution de l'habitat vers l'immeuble d'appartement ......................................................................................... 159

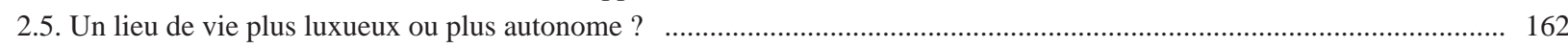

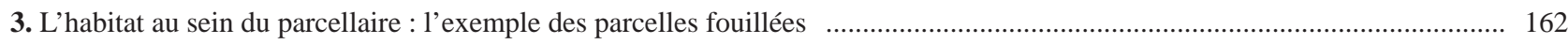

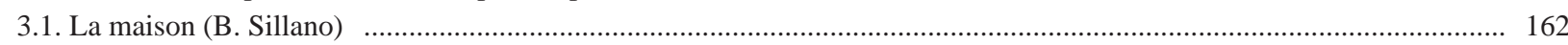

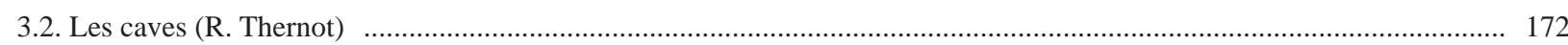

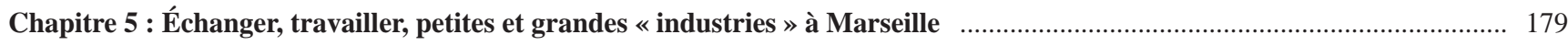

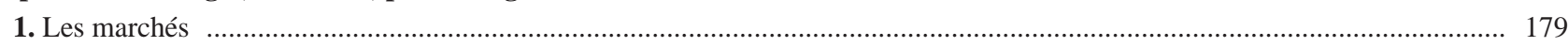

1.1. Un emplacement marchand : le macellum de Acuis (P. Rigaud) ............................................................................. 179

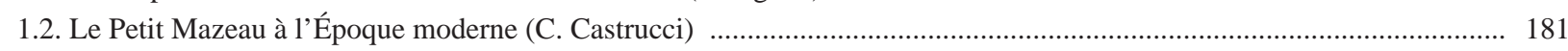

1.3. Approche archéologique des lieux de marché à l'Époque moderne (B. Sillano) …...................................................... 182

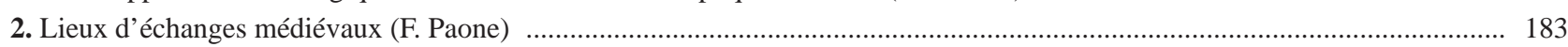

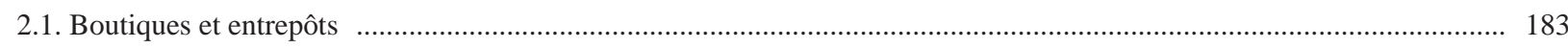


2.2. L'édifice de la rue de la Guirlande

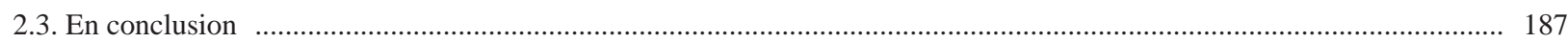

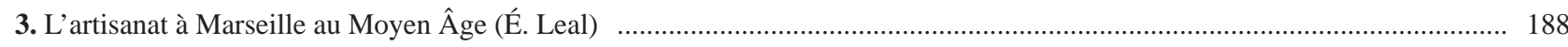

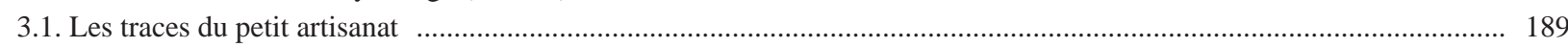

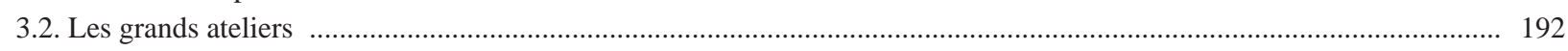

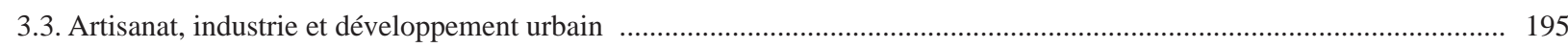

4. Témoignages archéologiques sur le commerce, l'industrie et l'artisanat à l'Époque moderne (B. Sillano) ............................. 197

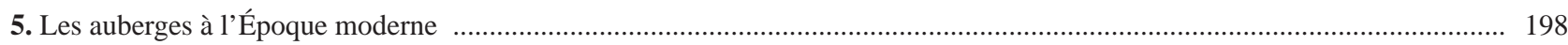

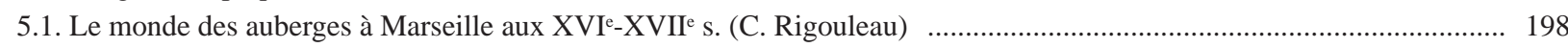

5.2. Les auberges observées en fouille (C. Castrucci, B. Sillano) …............................................................................... 203

\section{DEUXIÈME PARTIE : \\ PRÉSENTATION DE QUELQUES QUARTIERS À LA LUMIÈRE DES FOUILLES ARCHÉOLOGIQUES}

Chapitre 1 : La ville supérieure : le quartier de la Major …........................................................................................ 209

1. Le quartier de la Major à l'époque médiévale et la fortification (P. Rigaud, M. Bouiron, N. Scherrer) .................................... 209

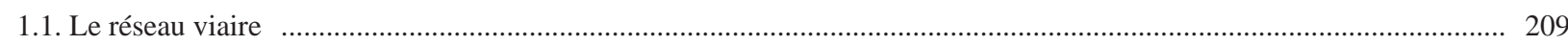

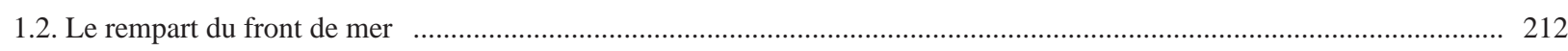

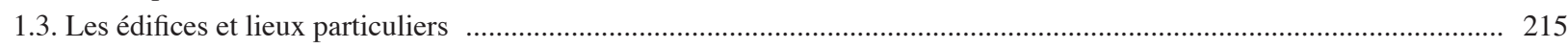

1.4. Espaces cultivés, espaces habités autour de la cathédrale ...................................................................................... 216

2. Évolution du quartier autour du groupe épiscopal (N. Scherrer, N. Valour) ......................................................................... 220

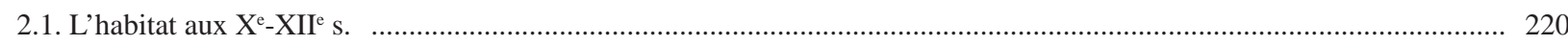

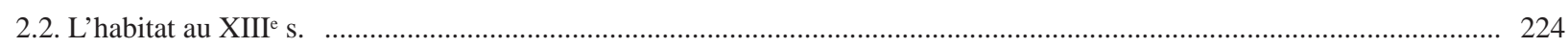

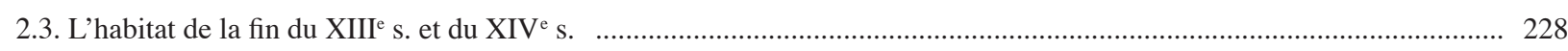

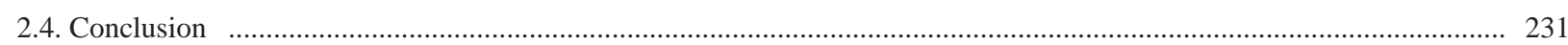

3. Les transformations durant la période moderne (N. Scherrer, N. Valour) ……..................................................................... 233

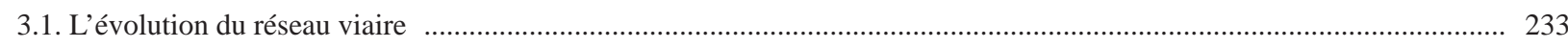

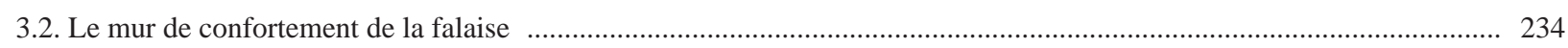

3.3. Les îlots au sud de la rue Four-du-Chapitre : de l'habitat à l'industrie ................................................................... 235

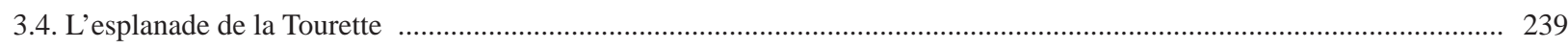

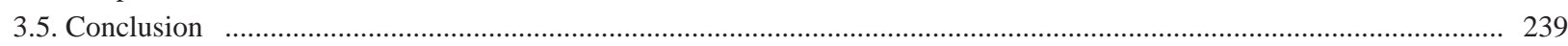

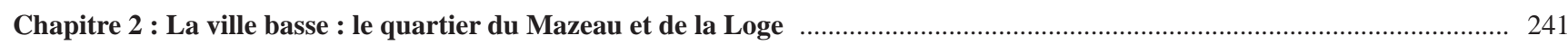

1. La ville basse à la lumière des sources écrites .......................................................................................................... 241

1.1. Les édifices et lieux majeurs du quartier (F. Paone) ....................................................................................... 241

1.2. Le quartier du Mazeau au Moyen Âge (M. Bouiron avec la coll. de P. Rigaud) .......................................................... 242

1.3. Le quartier du Corps-de-Ville à la lumière des sources écrites (C. Castrucci) .............................................................. 251

2. Mise en place et évolution du quartier au cours du Moyen Âge : l'apport de l'archéologie (F. Paone, R. Thernot) .................. 258

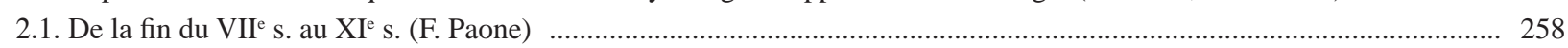

2.2. Première moitié du XII ${ }^{\mathrm{S}} \mathrm{s}$., des indices d'un travail des métaux (F. Paone) . .................................................................... 259

2.3. Création et évolution du quartier de la seconde moitié du XII s. jusqu'au XIVe s. (F. Paone, R. Thernot) ..................... 261

3. Pérennité et transformation du quartier du XVI e s. au XVIII ${ }^{\mathrm{e}}$ s. (B. Sillano, F. Paone) ………............................................. 285

3.1. La place du Petit-Mazeau et le réseau viaire (B. Sillano) ….............................................................................. 286

3.2. Îlot I : à l'est du Petit Mazeau (F. Paone) .......................................................................................................... 293

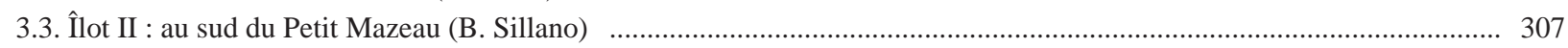

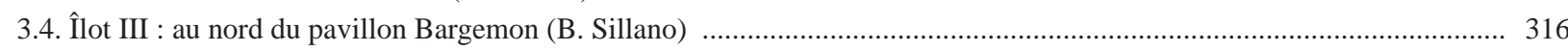

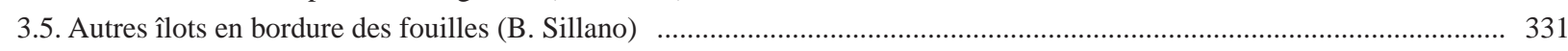

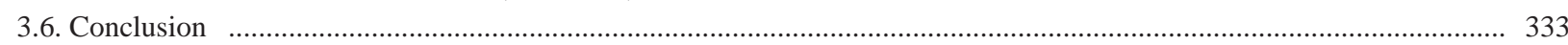

Chapitre 3 : Le faubourg et la Ville Nouvelle : du bourg de Morier au quartier de Roubaud ............................................... 337

1. Présentation du bourg à la lumière des archives .......................................................................................................... 337

1.1. Le bourg de Morier au Moyen Âge (Ph. Rigaud, M. Bouiron) ........................................................................ 337 
1.2. Du faubourg des Roubaud au quartier de Blanquerie (C. Castrucci) ...................................................................... 351

2. Le bourg de Morier médiéval ................................................................................................................................... 358

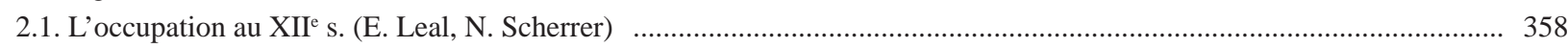

2.2. Un bourg essentiellement à vocation artisanale de la fin du XII ${ }^{\mathrm{e}} \mathrm{s}$. à la deuxième moitié du XIII' $\mathrm{s}$. (E. Leal, F. Paone) ... 362

2.3. Le faubourg médiéval (fin XIII ${ }^{\mathrm{e}}$ - début XIV e s.) (E. Leal, F. Paone, N. Scherrer) .................................................. 378

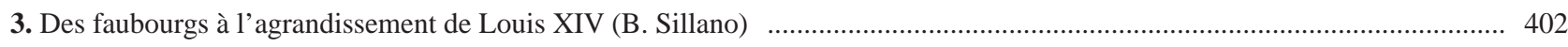

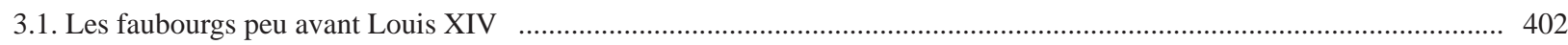

3.2. Les premières modifications liées à l'Agrandissement de Louis XIV ................................................................... 407

3.3. De l'Agrandissement à la Révolution : le lotissement de la Ville Nouvelle .................................................................. 412

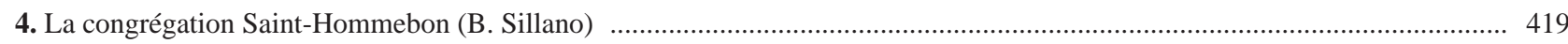

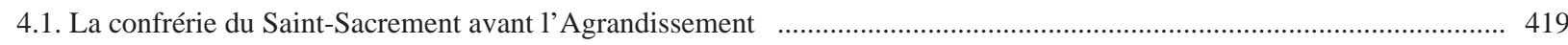

4.2. Les réaménagements liés à l'agrandissement de Louis XIV ............................................................................. 421

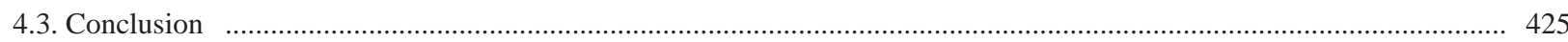

Chapitre 4 : Bilan de l'apport de l'archéologie à la connaissance de Marseille médiévale et moderne ..................................... 427

1. Synthèse chronologique (F. Paone, B. Sillano, M. Bouiron, N. Scherrer, C. Castrucci) …..................................................... 427

1.1. Un haut Moyen Âge bien peu documenté par l'archéologie ................................................................................... 429

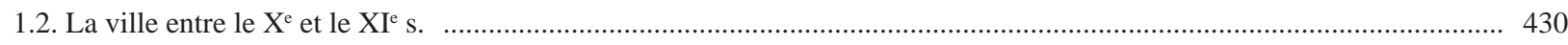

1.3. De la seconde moitié du XII è̀ la 1ère moitié du XIII' $\mathrm{s}$. : division et reconquête de l'espace urbain .................................. 431

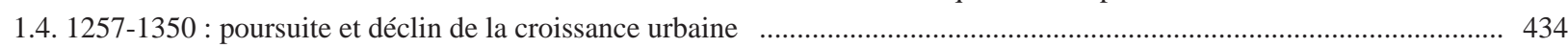

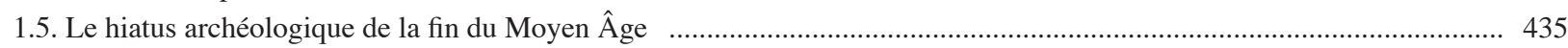

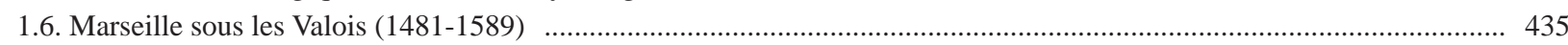

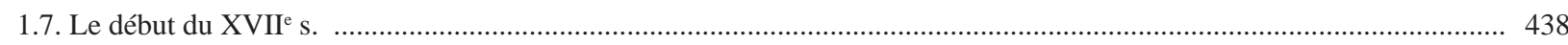

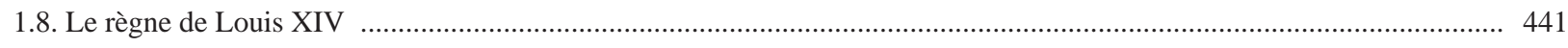

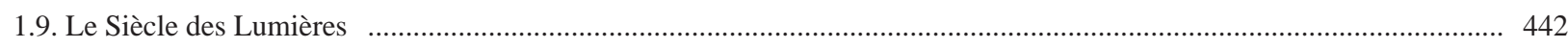

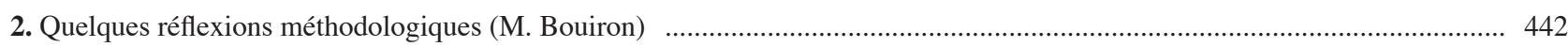

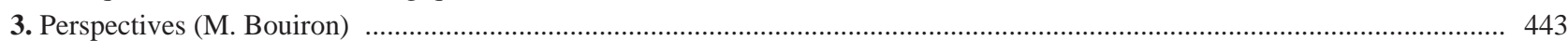

\section{ANNEXES}

1. Textes de la période médiévale : le quartier de la Major .................................................................................................

2. Textes de la période médiévale : le bourg de Roubaud ......................................................................................................... 448

2.1. Achat de cens à Bertrand de Marseille chevalier, seigneur d'Evenos et d'Olioulles, Raimond de Soliers damoiseau

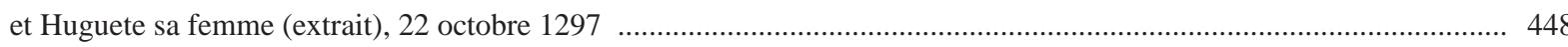

2.2. Vente de cens par Hugues de Roquefort à Raymond Viridis sur des maisons situées au bourg de Roubaud, 5 mai 1326 . 449

2.3. Vente de la directe sur une boutique d'Huguette Fausonerie par Hugues de Roquefort, 8 avril 1332 ........................... 449

2.4. Vente de cens par Hugues de Roquefort à Raymond Viridis sur des maisons situées au bourg de Roubaud

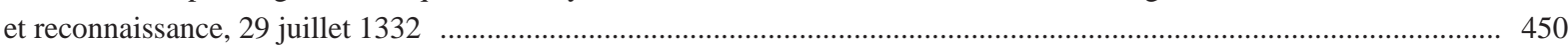

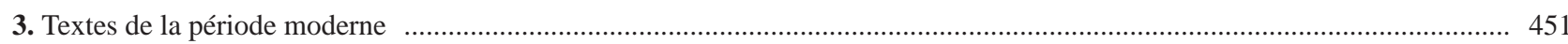

3.1. Rapport pour Jehan Boisselli contre Dangostine et demoiselle de Vento (1642, le 29 avril) .................................... 451

3.2. Prisfaict pour Pons Agnel a Jean Baptiste Gettin, Pierre Debarre, Pierre Amalbe et Michel Arnaud, maçons (1636, le 23 janvier)

3.3. Arrentement perpétuel $D^{\text {le }}$ Claire de Guérin avec Achept de place et jardin pour la Congrégation de Pères de la Mission (1636, le 22 décembre) 


\section{Éditorial}

La collection Etudes massaliètes a été créée en 1986 dans le cadre des Travaux du Centre Camille Jullian, sous la direction de Jean-Paul Morel, alors directeur du Centre Camille Jullian. Les 9 titres publiés à ce jour ont rassemblé les actes de plusieurs colloques consacrés à Marseille : Le territoire de Marseille grecque (EtMassa 1, 1986), Les amphores de Marseille grecque (EtMassa 2, 1990), Marseille grecque et la Gaule (EtMassa 3, 1992), Les cultes des cités phocéennes (EtMassa 6, 2000), Marseille. Trames et paysages urbains de Gyptis au roi René (EtMassa 7, 2001); un volume collectif de Mélanges : Sur les pas des Grecs en Occident. Hommages à André Nickels (EtMassa 4, 1995); des publications de fouilles et de matériel archéologique : Fouilles à Marseille. Les mobiliers (EtMassa 5, 1998), Lanécropole de Sainte-Barbe à Marseille (EtMassa 8, 2003), Olbia de Provence àl'époque romaine (EtMassa 9, 2007).

Vingt-cinq ans après, ce dixième fascicule paraît aujourd'hui dans la «Bibliothèque d'archéologie méditerranéenne et africaine », dont il constitue le volume 7. Consacré aux fouilles de Marseille, il s'inscrit dans la lignée des ouvrages précédents, mais constitue aussi le premier volume d'une série de publications des fouilles récentes de l'INRAP. Il s'agit de grandes opérations urbaines, par essence diachroniques, couvrant la période qui va de la naissance de la ville grecque à la période moderne. Le plan choisi par les éditeurs scientifiques est chronologique, mais il nous a semblé dommageable de publier dans des collections différentes des travaux fondamentalement unitaires. On ne s'étonnera donc pas de trouver dans les Etudes massaliètes un volume sur la ville médiévale et moderne, périodes qui ne font pas partie des préoccupations habituelles du Centre Camille Jullian. D'autres volumes suivront, consacrés aux mobiliers médiévaux et modernes, au groupe cathédral, mais aussi bien sûr à la ville grecque et romaine.

Cette ouverture chronologique des publications était nécessaire. Elle n'est d'ailleurs pas tout à fait nouvelle, puisque le volume 7 (Trames et paysages urbains) traitait de la topographie urbaine sur la longue durée, de la fondation de la ville à la fin du Moyen-Age.

Mais c'est aussi, et c'est peut-être le plus important, une ouverture institutionnelle à tous les acteurs de la recherche sur Marseille. Etudes massaliètes a toujours été une aventure commune entre chercheurs de l'Université et du CNRS, de la Culture (Service régional de l'Archéologie) et de la Ville de Marseille (Atelier du Patrimoine). Elle s'ouvre aujourd'hui à l'INRAP, qui est devenu en quelques années le principal acteur de l'archéologie urbaine à Marseille.

En fondant les Etudes massaliètes il y a un quart de siècle, nous souhaitions créer pour la communauté archéologique marseillaise une collection de référence, qui regrouperait (et susciterait ?) les principales publications sur Marseille. Avec la parution de ce dixième volume, il nous semble que le pari aura été en grande partie tenu.

Michel BATS

Henri TRÉZINY 


\title{
Préfaces
}

\author{
Xavier DELESTRE \\ Conservateur général du patrimoine \\ Conservateur régional de l'archéologie \\ Direction régionale des affaires culturelles de Provence-Alpes-Côte d'Azur
}

Jean-Paul JACOB

Président de l'Inrap 


\section{Xavier Delestre}

Depuis l'après seconde guerre mondiale, les responsables politiques et économiques lancent, pour façonner le Marseille contemporain, des chantiers d'envergure qui ne peuvent éviter une confrontation avec le passé. Parmi une longue liste, je citerai pour les exemples les plus récents, le creusement du tunnel de la Major, la construction de la bibliothèque municipale à vocation régionale de l'Alcazar ou bien encore la transformation de l'ancien Hôtel Dieu en logements et en hôtel de tourisme avec parking souterrain.

Aux côtés de ces grands chantiers coexistent de nombreux autres projets publics et privés. Ces derniers contribuent de manière plus « chirurgicale » à la transformation de la ville en restructurant des espaces plus réduits à l'intérieur d'îlots. Ces travaux amènent également leur lot de découvertes, certaines exceptionnelles, la basilique funéraire de la rue Malaval en est l'un des exemples. Ces réalisations concernent parfois aussi des lieux très symboliques comme le bâtiment de l'ancien Jeu de paume rue Thubaneau.

C'est dans ce contexte que l'archéologie marseillaise, ici comme dans bien d'autres villes françaises, s'est forgée sa place.

Au sortir des années cinquante, cette activité de terrain conduite sous l'impulsion de Fernand Benoit apporte les premières informations archéologiques sur la ville de l'Antiquité. Réalisée dans des délais très courts avec de faibles moyens, un personnel peu ou pas formé, elle ne livre que des données ponctuelles. Petit à petit, les contours de l'archéologie évoluent avec l'apparition de la notion de «fouilles de sauvetage ». Celles-ci ont été imposées par l'État (ministère de la Culture) et leurs exécutions confiées aux archéologues de l'Atelier du patrimoine de la ville de Marseille et aux personnels de l'Association pour les Fouilles Archéologiques Nationales (AFAN) créée au niveau national pour contribuer à la sauvegarde d'un patrimoine de plus en plus menacé par l'urbanisme. À partir de 2001, grâce à l'adoption de la loi relative à l'archéologie préventive et à la création d'un établissement public (Institut National de Recherches Archéologiques Préventives, INRAP) puis l'agrément du service archéologique municipal, une nouvelle étape est franchie. Il est à présent possible de considérer comme effective la mise en place d'une véritable politique de protection et d'étude du patrimoine archéologique marseillais. Cet objectif est une priorité lorsque l'on sait sa place historique prééminente et celle qu'elle a dans l'histoire de l'archéologie nationale depuis le «scandale » du Centre Bourse dans les années soixante-dix, point de départ de ce que l'on nomme depuis «l'archéologie urbaine ».

Aujourd'hui du point de vue scientifique, on ne peut qu'être satisfait du progrès spectaculaire des connaissances ${ }^{1}$ en particulier sur la topographie urbaine. Il est indiscutable que ces acquis sont dus à l'action de l'Etat (ministère de la Culture - direction régionale des affaires culturelles / service régional de l'archéologie) et à l'attention portée au dossier marseillais par les directeurs des antiquités puis les conservateurs régionaux de l'archéologie successifs et leurs collaborateurs, tout particulièrement Bruno Bizot, conservateur en chef du patrimoine. Depuis 1994, ce travail est conforté par l'expertise des membres de la commission interrégionale de la recherche archéologique Sud-Est. Elle est aussi le résultat d'une implication forte et permanente des chercheurs de l'université de Provence et des laboratoires du CNRS (Centre Camille Jullian et Laboratoire d'Archéologie Médiévale Méditerranéenne). Cet investissement intellectuel s'exprime sur le terrain aux côtés des fouilles, dans des projets collectifs de recherche, par exemple sur le thème « de la pierre de construction à Marseille des origines à l'époque moderne » (direction H. Tréziny). Toutes ces actions ont permis de poser les problématiques générales, d'en discuter les limites et d'expertiser régulièrement

1 Collectif, 2006 - Marseille, 27000 ans d'histoire, Archéologia, n 435, p. 18-75. 
les apports des fouilles, parfois même dès le moment de l'invention des vestiges par l'intermédiaire des comités scientifiques de suivi installés par le service régional de l'archéologie en accompagnement des plus grandes opérations urbaines. C'est sans nul doute ce fonctionnement collégial qui a donné du sens et sa valeur scientifique à cet enchaînement presque ininterrompu de fouilles depuis plusieurs décennies. Il me semble important de souligner cette pratique qui, avec quelques autres villes (Aix-en-Provence, Fréjus), donne aujourd'hui en Provence une place privilégiée à l'archéologie du « fait urbain ».

En revanche, le bilan reste ici plus mitigé en matière de conservation patrimoniale. Ne perdons pas de vue que cette activité soutenue d'archéologie de sauvetage puis préventive implique dans le même temps la disparition définitive d'une grande partie des «archives du sol» au point que pour certains archéologues cette idée que Marseille est « une ville antique sans antiquités » reste tristement d'actualité. Mais, nous savons tous par expérience que le pari de construire la ville du présent et celle du futur dans le respect total de sa richesse patrimoniale est une utopie. Il nous reste à faire en sorte que cet héritage puisse être capitalisé de la manière la plus méticuleuse possible pour alimenter le dossier historique. A cet égard, il ne me parait pas inutile de rappeler qu'entre 1995 et 2005 , près de $10000 \mathrm{~m}^{2}$ ont été expertisés par les équipes archéologiques sur des profondeurs qui peuvent atteindre plus de huit mètres. Ce bilan est considérable et il est certain que sans cette dynamique interinstitutionnelle, fédérée par l'État, l'archéologie marseillaise en serait restée au stade de l'archéologie « en ville », c'est-à-dire, à un archivage de données réalisé de manière plus ou moins exhaustive sur des lieux du territoire communal imposés aux archéologues par les aménageurs.

Cette perspective scientifique donnée par une action maîtrisée du terrain, soutenue par une approche collective, a été constamment discutée lors de colloques (par exemple, « Marseille, Trames et paysages urbains » en 2001). Les résultats sont livrés dans de nombreuses publications dont le volume de la carte archéologique de la Gaule paru en 2005 offre un copieux panorama pour les périodes grecques et romaines. Elle est également visible pour le public grâce à la tenue d'expositions organisées par les Musées de Marseille (par exemple «Parcours de ville » en 1999), de journées portes ouvertes sur les chantiers de fouilles, de cycles de conférences et des publications de synthèse ${ }^{2}$. Cette médiatisation des résultats de la recherche contribue sans nul doute progressivement à modifier le regard des aménageurs face à la contrainte archéologique.

L'archéologie urbaine, malgré la volonté et l'ambition des chercheurs, des institutions, la qualité des axes de recherches présentés et les priorités souhaitées, reste tributaire du contexte économique. C'est en effet ce dernier qui s'impose en permanence et biaise l'ordre d'acquisition des données archéologiques mais aussi, permet parfois l'ouverture de passionnantes études avec des apports conséquents à l'histoire, par exemple pour la thématique de la peste $^{3}$. A cette contrainte territoriale s'ajoute que pendant très longtemps l'archéologie s'est intéressée de manière privilégiée à l'Antiquité laissant hors de son champ d'expertise les niveaux archéologiques postérieurs et les vestiges en élévation à l'exception de quelques monuments insignes comme l'abbaye Saint-Victor dont Michel Fixot et Jean-Pierre Pelletier ${ }^{4}$ ont publié récemment une excellente synthèse des recherches conduites sous la responsabilité de Gabrielle Démians d'Archimbaud.

En abordant les époques médiévale et moderne dans une ville comme Marseille on pourrait penser que le dossier historique est abondant, bien documenté et que l'archéologie n'a à apporter, ici ou là, que quelques précisions. La réalité est toute autre et les travaux de ces deux dernières décennies en font la parfaite démonstration.

La consolidation du dossier archéologique est relativement récente puisque les premières données archéologiques d'importance ${ }^{5}$ datent des années 1980/1990. Elles sont enrichies dans les années suivantes par les fouilles des ateliers de potiers de l'îlot Sainte-Barbe (1991), de la place du général de Gaulle en 1992/1993 puis Jules Verne en 1995/1996 qui ont permis de reconstituer les grands traits de l'évolution d'un quartier intra muros, riverain du port, depuis sa

2 Bizot (B.), Delestre (X.), Guyon (J.), Moliner (M.), Tréziny (H.), 2007 - Marseille antique, guides archéologiques de la France, Paris.

3 Signoli (M.), Chevé (D.), Adalian (P.), Boëtsch (G.), Dutour (O.), 2007 - Peste : entre épidémies et sociétés, Firenze university Press.

4 Fixot (M.), Pelletier (J.-P.), 2009 - Saint-Victor de Marseille, Etude archéologique et monumentale, bibliothèque de l'Antiquité tardive, Paris, 2 volumes.

5 Delestre (X.), Archéologie de Marseille médiévale, des données inédites pour une histoire urbaine, La Revue culturelle de la Ville de Marseille, $\mathrm{n}^{\circ}$ 225, juin 2009, p. 9-11. 
création dans le courant du XII ${ }^{\mathrm{e}} \mathrm{s}$. La reconquête de nouveaux espaces, en périphérie du noyau urbain primitif et l'évolution du regard que les archéologues portent sur leur propre discipline ont fait que les occasions d'entrevoir Marseille médiévale et moderne se sont multipliées depuis une dizaine d'années en particulier et principalement dans les zones nord et est de la ville. Pour l'heure, le bilan que présente cette publication collective, ne peut encore trouver appui que sur une douzaine de fouilles significatives (places du Général-de-Gaulle et des Pistoles, Vieille Charité, Rue de la République-surverse du Vieux Port, Fort Saint-Jean...). Il n'en demeure pas moins essentiel de souligner que ce viatique consolide les premiers éléments archéologiques utiles pour servir d'assises à l'écriture de plusieurs siècles d'une histoire urbaine sur laquelle les sources d'archives restent souvent désespérément muettes. N'oublions pas par exemple que pour la thématique de la topographie urbaine, le premier plan connu de la ville conservé dans les archives remonte seulement au XVI ${ }^{\mathrm{e}} \mathrm{s}$.

Sans chercher ici à passer en revue de manière détaillée tous les apports de l'archéologie contemporaine à la connaissance de la vie quotidienne et de la topographie de Marseille médiévale et moderne, je mentionnerai par exemple, la mise au jour lors des fouilles de la place Général-de-Gaulle des salines de Marseille attestées en 558 et connues simplement par l'intermédiaire d'une copie du $\mathrm{X}^{\mathrm{e}} \mathrm{s}$. d'un acte du cartulaire de Notre-Dame de Paris, la localisation certaine de l'hôpital du Saint-Sépulcre, des données sur la morphologie et la densité de l'habitat intra muros dès le XII ${ }^{\mathrm{e}} \mathrm{s}$. (fouilles du site de la Major) ou sur le paysage et son évolution (fouilles de l'Alcazar).

Ce volume, le premier d'une série, a été préparé dans le cadre d'un projet collectif de recherche. Il fait suite à une publication parue en 2001 (M. Bouiron, dir., Marseille, du Lacydon au faubourg Sainte-Catherine. Ve s. av. J.-C. $\mathrm{XVIII}^{\mathrm{e}} \mathrm{s}$.) et contribue à enrichir de manière très significative l'histoire urbaine de ce très grand port méditerranéen encore largement méconnue.

Que ses auteurs soient chaleureusement félicités et remerciés pour cette somme de connaissances et en premier lieu Marc Bouiron qui a été le fer de lance du projet et a su avec compétence associer tous les chercheurs et responsables de ces opérations de fouilles successives. À n'en pas douter ce savoir archéologique, par ses implications historiques, donne un éclairage nouveau et trouvera le moment venu toute sa place dans une nouvelle « Histoire de la France urbaine». 


\section{Jean-Paul Jacob}

J'ai d'emblée accepté de préfacer ce riche ouvrage pour deux raisons essentielles. En premier lieu, durant huit années, comme conservateur régional de l'archéologie de Provence-Alpes-Côte d'Azur, j' ai eu à susciter, à négocier et à contrôler plusieurs des fouilles évoquées ici et, de fait, j'en connais et j'en apprécie tous les protagonistes. En second lieu, comme président de l'Institut national de recherches archéologiques préventives, je me réjouis que nombre de chercheurs de l'Inrap aient dirigé ou participé à ces fouilles, à l'exploitation de leurs résultats et à cette publication dans le cadre de collaborations fructueuses avec les services municipaux et les chercheurs du Service régional de l'archéologie, de l'Atelier du patrimoine de la Ville de Marseille, de l'université et du CNRS.

Marseille, ville emblématique pour l'histoire de France, pour l'histoire de la France d'avant la France. N'est-ce pas à Marseille, dans les calanques, qu' on découvrira en 1991 la grotte « Cosquer », nous obligeant à revoir les théories tentant d'expliquer l'absence d'art rupestre ancien dans le sud-est et témoignant, s'il en était encore besoin, de la formidable remontée des eaux de la Méditerranée depuis le Paléolithique supérieur. N'est-ce pas là que s'implantent les premiers colons grecs venus de Phocée en Asie mineure comme Strabon ${ }^{6}$ ou Justin ${ }^{7}$, mais aussi l'archéologie, nous le rappellent! N'est-ce pas en raison des démêlés de leurs successeurs avec les Salyens qui peuplent l'arrièrepays que les Romains prendront pied en Gaule du sud en 125 avant notre ère, pour ne plus en repartir ! César lui-même assiégea la cité en 49 pour la punir d'avoir choisi Pompée. Puis, la qualité du mouillage, le dynamisme de son port, de ses marchands, de ses édiles, de sa population en firent, malgré bien des vicissitudes, une capitale économique et, au XIX ${ }^{\mathrm{e}}$ s., la « porte de l'Orient », façon exotique ou peut-être pudique d'évoquer le commerce avec les colonies.

Ville emblématique pour l'histoire, Marseille l'est aussi pour l'archéologie. N'est-ce pas là, à quelques encablures du Vieux Port, que, en 1952, Cousteau, muni du tout nouveau scaphandre autonome, explora et «fouilla » l'épave (il serait d'ailleurs plus judicieux de dire les épaves) du Grand-Congloué, ouvrant ainsi l'ère de l'archéologie sousmarine ? N'est-ce pas à Marseille que, en 1967, eut lieu la première grande fouille « de sauvetage » en milieu urbain, liée à la menace que faisait peser sur des vestiges grecs et romains majeurs la construction des immeubles du centre commercial de La Bourse ? Une partie de ces vestiges sera d'ailleurs conservée à l'issue des fouilles dans le bien nommé « jardin des vestiges ».

Mais, paradoxalement, si l'on connaît relativement bien aujourd'hui le passé grec, romain et paléochrétien de la ville, si l'on connaît parfaitement l'urbanisation et l'activité du port aux XVIII ${ }^{\mathrm{e}}, \mathrm{XIX}^{\mathrm{e}}$ et $\mathrm{XX}^{\mathrm{e}}$ s., la longue période qui s'étend du haut Moyen Âge au siècle des Lumières est particulièrement méconnue. Elle est renseignée par des textes et des récits de voyageurs, parfois dithyrambiques, mais force est de constater qu'elle a laissé peu de vestiges et de monuments visibles. C'est presque en vain que, en flânant au gré des rues et des quartiers du centre, on cherchera les témoignages de ces périodes.

Alors l'archéologie est-elle capable de corriger une telle situation et de donner corps à une réalité dont seuls les textes rendent compte aujourd'hui ? Une récente exposition aux archives municipales de la ville, doublée de la publication d'un bel ouvrage ${ }^{\mathbf{8}}$, mêle approches archivistique et archéologique pour tenter de mieux cerner la ville au Moyen Âge, nous fournissant ainsi un début de réponse.

Géographie, IV, 4.

Histoires philippiques de Trogue Pompée, LXIII, 3, 4 et 5.

Marseille au Moyen Âge, entre Provence et Méditerranée, coordonné par Thierry Pécout, éditions Désiris, 2009. 
Cette démarche n'allait pas de soi il y a vingt ans. Il a fallu l'opiniâtreté de chercheurs comme Michel de Boüard en Normandie, Gabrielle Démians d'Archimbaud en Provence et de tant d'autres pour que, petit à petit, l'archéologie ne s'arrête plus avec les invasions du $\mathrm{V}^{\mathrm{e}} \mathrm{s}$. et la période mérovingienne. Il a fallu la lente prise de conscience par les historiens de l'évidence que les textes ne pouvaient pas tout dire et que, souvent fallacieux ou partiaux, ils pouvaientêtre réinterprétés à la lumière des faits «têtus », livrés par les fouilles. Et puis les textes concernaient surtout ceux qui avaient le pouvoir et la richesse, laissant de côté un pan entier de la cité, celle du "petit peuple», qui fait pourtant l'âme de la ville. Dans ces conditions, que dire pour les périodes, encore plus récentes, de la Renaissance et du XVII ${ }^{\mathrm{e}}$ s., encore plus abondamment fournies en documents écrits que les précédentes ? Sinon que l'apport de l'archéologie était encore moins souhaité, sollicité, attendu !

Les fouilles de la Bourse, déjà évoquées, ne livrent, pratiquement aucune information pour les périodes postérieures à l'époque romaine. J'ai dû faire face à de nombreuses critiques lorsque, à la charnière des années 1980 et 1990, j'ai prescrit des fouilles concernant ces périodes. Il fallait pourtant ne pas négliger des vestiges trop récents aux yeux de certains de mes interlocuteurs et en exiger l'étude avant destruction. Quand je vois ce que ces travaux ont apporté à la connaissance d'un passé sur lequel on croyait tout savoir, je ne regrette évidemment pas. La fouille du charnier de la peste de 1720, rue Leca, est aujourd'hui citée comme une référence, voire comme un acte fondateur des travaux qui recoupent données archéologiques et épidémiologiques. Ces nombreuses fouilles réexaminées à la lumière des archives, permettent aujourd'hui de revisiter la Marseille d'alors.

Ces connaissances, si nous n'y avions pris garde, auraient disparu à jamais et nous serions privés d'une approche matérielle, fine, intime, impartiale, de la cité et de ses habitants, qui permet la publication du présent ouvrage. Aujourd'hui, cette démarche archéologique est admise et ne fait plus débat. Elle est reconnue comme un apport essentiel à la connaissance. Je dois dire, et c'est important de le souligner ici, que j'ai toujours bénéficié, comme mes successeurs, d'une écoute attentive de la municipalité, même si ces fouilles sur des niveaux relativement récents engendraient une augmentation du coût et des délais de nos interventions.

Mais, il aura fallu que l'archéologie préventive s'impose, qu'elle affine ses méthodes d'investigation comme sa doctrine, mais aussi qu'elle élabore ses règles juridiques. Il est loin le temps où, dans des conditions difficiles, Fernand Benoît tentait d'observer et de sauver, tant bien que mal, ce qui pouvait l'être du quartier du Vieux-Port lors de sa reconstruction après son dynamitage par les Allemands en 1943. Il est loin aussi le temps où la fouille de la Bourse servait de laboratoire à des méthodes novatrices. C'est que, de 1941, date de la première loi sur l'archéologie adoptée en France (et qui d'ailleurs ne faisait pas référence à une quelconque recherche liée à des menaces de destruction) à aujourd'hui, les choses ont bien changé. Nous sommes passés d'une archéologie de "récupération », à une archéologie de «sauvetage » puis, enfin, en 2001, à une archéologie «préventive ». Ces changements lexicaux ne sont pas un jeu intellectuel, ils recouvrent une réalité épistémologique, scientifique, législative et administrative importante. Pour en mesurer l'impact il n'est qu'à regarder le formidable bond dans la connaissance du passé qu'a permis l'archéologie marseillaise depuis les années 1980.

Cette multiplication des fouilles urbaines, à Marseille comme ailleurs, et la somme des connaissances acquises ne doivent pas nous conduire à négliger deux écueils. Le premier est une consommation effrénée, trop rapide, des archives du sol. En effet la fouille, aussi bien conduite soit-elle, est un acte destructeur et nos successeurs sauront mieux fouiller que nous-mêmes et, surtout, mieux analyser et mieux interpréter les vestiges. Aussi, convient-il, dans la mesure du possible, de préserver une partie du sous-sol des centres urbains. Des techniques existent mais souvent au détriment des sacro-saints parkings souterrains dédiés à la « déesse automobile». Le second est celui de la formidable masse des informations recueillies qu'il faut impérativement traiter, synthétiser et restituer à la communauté scientifique par des ouvrages monographiques ou synthétiques, mais aussi au public le plus large, par des ouvrages de vulgarisation de qualité. L'Inrap ${ }^{9}$ s'y emploie. En effet, l'archéologie préventive ne doit pas être un simple alibi à la destruction des informations archéologiques contenues dans le sous-sol de nos villes et de nos campagnes. C'est la réponse des

9 L'Inrap est un établissement public créé par la loi de 2001, placé sous la tutelle du ministère de la Culture et de la Communication et du ministère de l'Enseignement supérieur et de la Recherche. Fort de plus de 1700 archéologues, il se substitue à l'Association pour les Fouilles Archéologiques Nationales (Afan), créée en 1975, structure devenue inadaptée en raison de la montée en puissance des opérations archéologiques préventives tout au long des trente glorieuses. 
pouvoirs publics au nécessaire équilibre entre la recherche et l'aménagement du territoire. C'est aussi la seule façon d'assurer la lecture, la compréhension et la conservation de ces « archives du sol».

A l'instar de l'histoire, l'archéologie nous aide à comprendre d'où nous venons et à penser où nous allons. C'est une noble tâche à laquelle les archéologues de tous horizons, au premier rang desquels ceux de l'Inrap, contribuent avec enthousiasme et professionnalisme. Si c'est un devoir que d'assurer cette restitution de nos travaux, c'est aussi un moment d'intense jubilation intellectuelle que de pouvoir rassembler tous les éléments du puzzle et ainsi contribuer à l'écriture ou à la réécriture de pages entières de notre histoire. Je sais que l'équipe soudée qui, durant cinq ans, à travaillé à cet ouvrage l'a ressentie, comme elle a ressenti le doute qui assaille, à un moment ou un autre, tout chercheur, comme elle à dû surmonter les obstacles inhérents à toute entreprise collective.

Alors que Marseille s'apprête à être en 2013 la capitale européenne de la culture, alors qu'elle est en pleine mutation urbaine, ce travail est un élément essentiel pour la construction de la ville de demain qui ne peut et ne veut faire table rase de son passé. C'est aussi une réponse à Chateaubriand qui écrivait : [Marseille] «Fille de l'Hellénie, institutrice de la Gaule, célébrée par Cicéron, emportée par César, n'est-ce pas réunir assez de gloire ? ${ }^{\mathbf{1 0}}$. Non ce n'était pas assez de gloire et il convenait de retisser le lien entre cette Antiquité réelle, mais aussi rêvée, et la Marseille d'aujourd'hui. Que les auteurs de cet ouvrage soient remerciés et surtout félicités de l'avoir fait aussi magistralement.

10 Mémoires d'outre-tombe, XIV, 2 


\section{Avant-Propos}

Comment publier et rendre accessible à la communauté scientifique l'abondance de documentation que génèrent les grandes opérations d'archéologie préventive en milieu urbain ? Tout directeur de fouille ayant eu à conduire ce type de chantier a été confronté à la recherche d'une solution intégrant la soif d'absolu (publier exhaustivement) et le principe de réalité (comment financer ce travail), plus ou moins éloigné de cet idéal.

Cet ouvrage est une tentative de réponse, au cœur d'un des champs d'étude urbaine peut-être parmi les plus passionnants de France, celui de la ville fondée par les Grecs d'Asie Mineure, Marseille, fille de Phocée et sœur de Vélia ou de Lampsaque. Il trouve son origine dans la mise en œuvre dans cette ville des dernières grandes opérations archéologiques du $\mathrm{XX}^{\mathrm{e}}$ s. que furent les fouilles de l'Alcazar, du Tunnel de la Major et de la place VilleneuveBargemon. La particularité de notre projet est de tenter d'aller au-delà d'une simple monographie de site, afin de montrer toutes les facettes de l'évolution d'une ville révélée par l'archéologie.

Portés par une volonté commune de tous les archéologues ayant participé à ces grandes fouilles, dont beaucoup continuent d'ailleurs à dégager le passé de Marseille, nous avons considéré que publier une seule fouille était réducteur, au vu de l'enrichissement rapide de la réflexion sur l'ensemble de l'espace urbain. Ainsi, parti d'un projet de publication centré sur la seule fouille de l'Alcazar, nous avons décidé de l'étendre en incluant d'autres sites fouillés, mettant en œuvre trois volumes distincts. Si le premier à paraître est cet ouvrage, dans l'ordre idéal plutôt le dernier de la collection, c'est qu'il nous semblait plus facile à réaliser compte tenu de la dynamique de la recherche sur les périodes médiévale et moderne à Marseille. En témoigne d'ailleurs la publication récente d'un bel ouvrage collectif coordonné par Thierry Pécout sur Marseille médiévale. Les deux autres volumes, déjà en cours de rédaction, auront pour thème les périodes antique et antique tardive pour l'un et l'étude du mobilier archéologique pour l'autre. Il restera à étudier, dans un volume distinct mais néanmoins lié aux trois précédents, l'ensemble du groupe épiscopal des origines à nos jours, sous une forme éditoriale qui reste encore à définir. Pour ce volume, nous avons pris le parti de ne pas rentrer dans le détail technique classique de l'archéologue : le lecteur ne trouvera pas ici de numéro d'unité stratigraphique ou de numérotation de mur. Nous n'avons pas souhaité simplement publier des rapports de fouille (consultables par ailleurs, comme par exemple sur l'Intranet de l'Inrap pour le rapport de l'Alcazar); seul le volume sur le mobilier pourra aller au plus près de la stratigraphie.

Un Projet Collectif de Recherche (PCR) a été constitué afin de réaliser ces études et fédérer la réflexion de tous les archéologues ayant travaillé sur Marseille. Avec mes codirecteurs de volume, Françoise Paone, Bernard Sillano, Nadine Scherrer et Colette Castrucci, nous voulons remercier tout d'abord les acteurs anonymes au nom desquels nous écrivons, usant de la truelle comme de la pelle mécanique, sous les canicules d'été ou le mistral glacial. Nous remercions également tous les partenaires ayant soutenu ce projet: le Service régional de l'Archéologie (DRACPACA) sous l'égide de Xavier Delestre, Conservateur régional, et tout particulièrement le conservateur en charge de Marseille Bruno Bizot qui n'ont eu de cesse d'aider à son aboutissement ; l'Inrap, héritier direct de l'Afan ayant réalisé les fouilles marseillaises, en la personne de son directeur interrégional François Souq et de ses présidents successifs Jean-Paul Demoule et Jean-Paul Jacob, tous convaincus de l'intérêt de notre démarche et ayant permis au personnel de leur Institut de travailler par le biais des projets d'actions scientifiques; enfin les membres du Centre Camille Jullian, Dominique Garcia son directeur, Henri Tréziny et Michel Bats, qui accueillent cet ouvrage dans les Études Massaliètes, au sein de leur nouvelle Bibliothèque d’Archéologie Méditerranéenne et Africaine.

Marc BOUIRON

Directeur du Service Archéologie de la Ville de Nice

Chercheur associé au CEPAM (UMR 6130) 


\title{
Introduction
}

\author{
N. Scherrer, B. Sillano, M. Bouiron, C. Castrucci, F. Paone
}

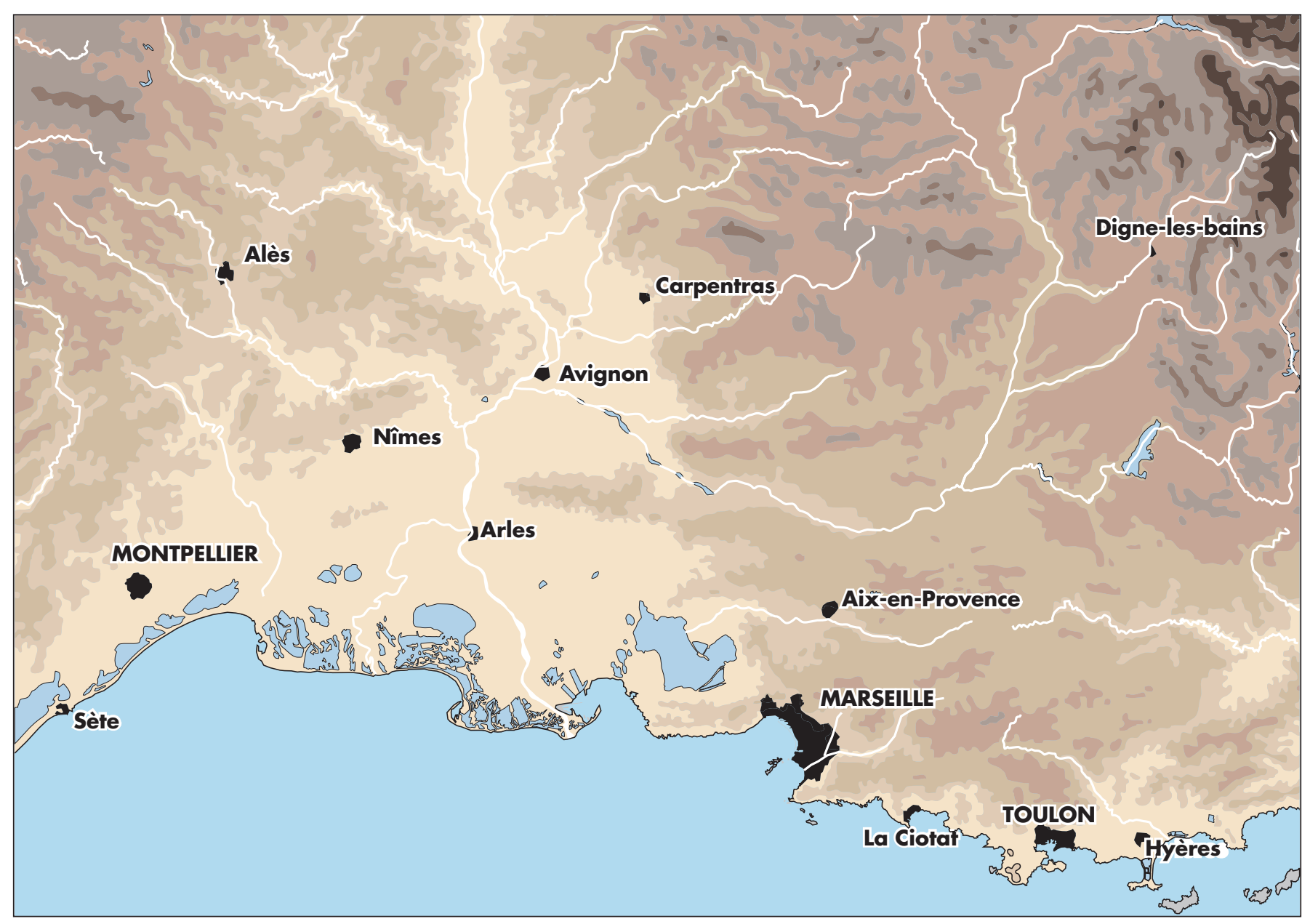

Fig. 1. La ville de Marseille et son environnement (DAO Inrap).

Avant d'entreprendre l'analyse de Marseille depuis le Moyen Âge, il importe de préciser le cadre topographique et historique, de donner le détail des fouilles qui ont servi de source à notre étude et enfin d'apprécier la relativité des sources historiques que constituent les données archéologiques et les textes d'archives.

\section{Marseille ou la connaissance de la ville}

La connaissance de l'histoire d'une ville est intimement liée à la topographie de son implantation.
Marseille, ville et port fondé par les Grecs de Phocée, marins aventuriers du Far West de l'époque archaïque, s'organise autour de la mer. Parmi les sources historique permettant de comprendre cette évolution, l'archéologie prend de plus en plus une place de choix, y compris pour les périodes les plus récentes.

\subsection{Le cadre topographique et historique}

La ville se situe dans une vaste rade du Golfe du Lion, dans la Provence méridionale calcaire qui occupe l'espace entre le Rhône et le Var (fig. 1). Elle est principalement 


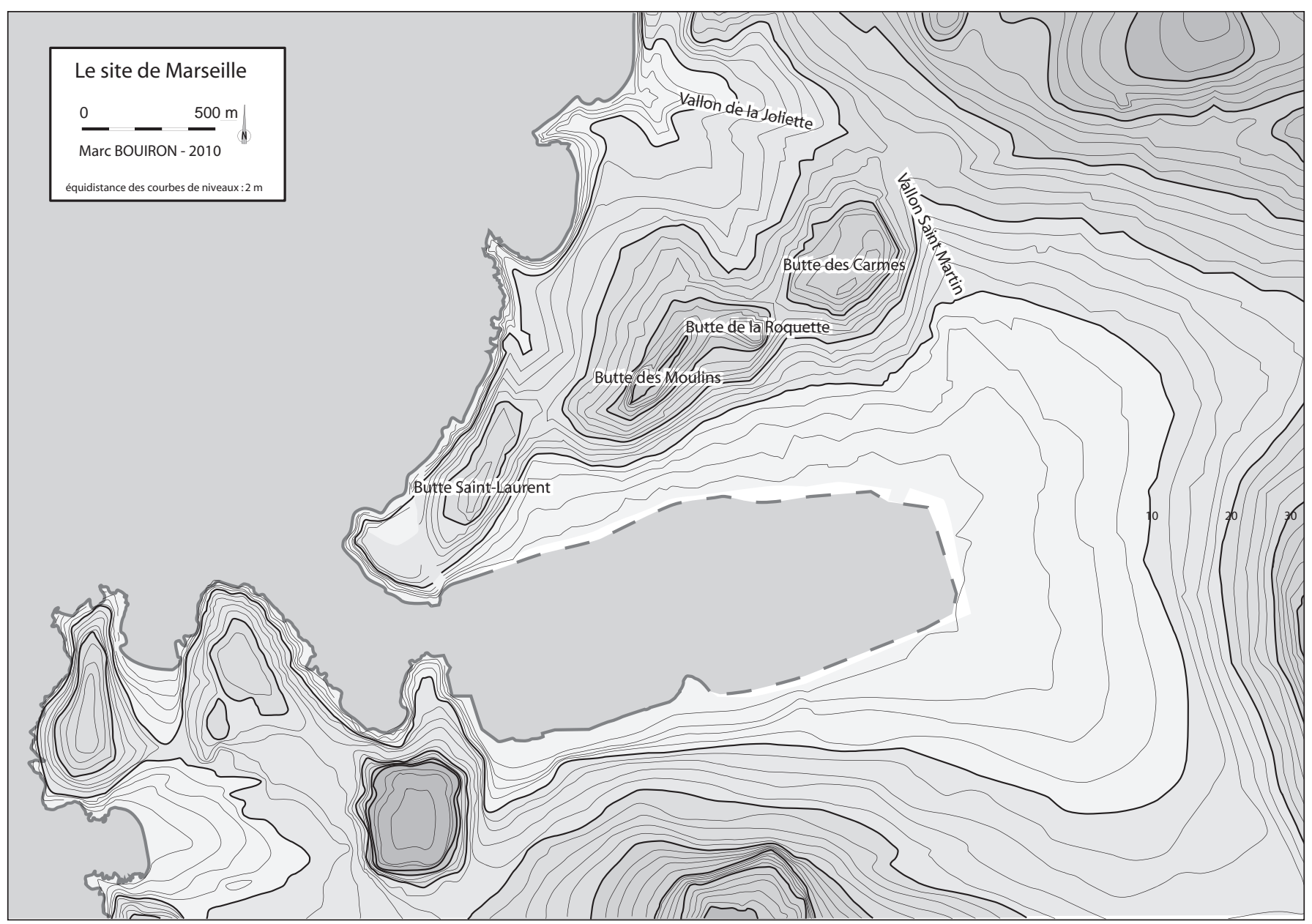

Fig. 2. Le site de Marseille (Courbes de niveaux de 1840, DAO M. Bouiron/Ville de Nice).

arrosée par le ruisseau des Aygalades au nord-ouest et par l'Huveaune et son affluent le Jarret au sud-est. Son climat méditerranéen a pu être modifié au cours des siècles par des phénomènes repérés au niveau de l'Europe, d'abord par l'optimum climatique médiéval, un réchauffement important entre l'an mil et le XIII' ${ }^{\mathrm{e}} \mathrm{s}$., puis à l'Époque moderne (du $\mathrm{XV}^{\mathrm{e}}$ au $\mathrm{XIX}^{\mathrm{e}}$ s.) lors du petit âge glaciaire.

L'atout de Marseille est avant toute chose l'emplacement de son port, le Lacydon, établi dans une calanque-estuaire ${ }^{11}$ qui s'enfonce d'un kilomètre dans les terres. Il est abrité dans une anse en eaux relativement profondes (environ $7 \mathrm{~m}$ actuellement) cernée par des collines au nord et au sud. L'embouchure, large d'environ $100 \mathrm{~m}$, s'ouvre sur la haute mer entre les avancées du fort Saint-Jean et celles du fort Saint-Nicolas et du

11 Une calanque est une crique étroite cernée de parois rocheuses escarpées. Ici, le relief, non calcaire, a été largement émoussé au fil des millénaires.
Pharo (Bouiron, Gantès 2001, p. 24). Les reliefs qui encadrent le port ont été atténués par des arasements et des remblaiements dès l'Antiquité, mais restent néanmoins encore visibles de nos jours (fig. 2).

La ville antique s'est développée au nord du plan d'eau sur trois buttes : celle de Saint-Laurent, la butte double des Moulins et de la Roquette et celle des Carmes. Au Moyen Âge, la cité s'agrandit un peu vers l'est, mais son extension territoriale reste très limitée avant l'Époque moderne (entre 50 et 70 ha) ${ }^{\mathbf{1 2}}$. Si des remparts successifs élargissent la surface de la ville intra muros au cours des siècles, ils restent relativement proches les uns des autres et l'étendue de la ville ne change guère avant le

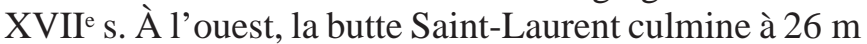
$\mathrm{NGF}$, en partie centrale celle des Moulins à $42 \mathrm{~m}$ et la Roquette à $38 \mathrm{~m}$ et enfin au nord-est la butte des Carmes se situe autour de $40 \mathrm{~m}$ (Bouiron, Gantès 2001). Les

12 La surface actuelle de la commune est de $240 \mathrm{~km}^{2}$ dont $100 \mathrm{~km}^{2}$ d'espaces naturels. 


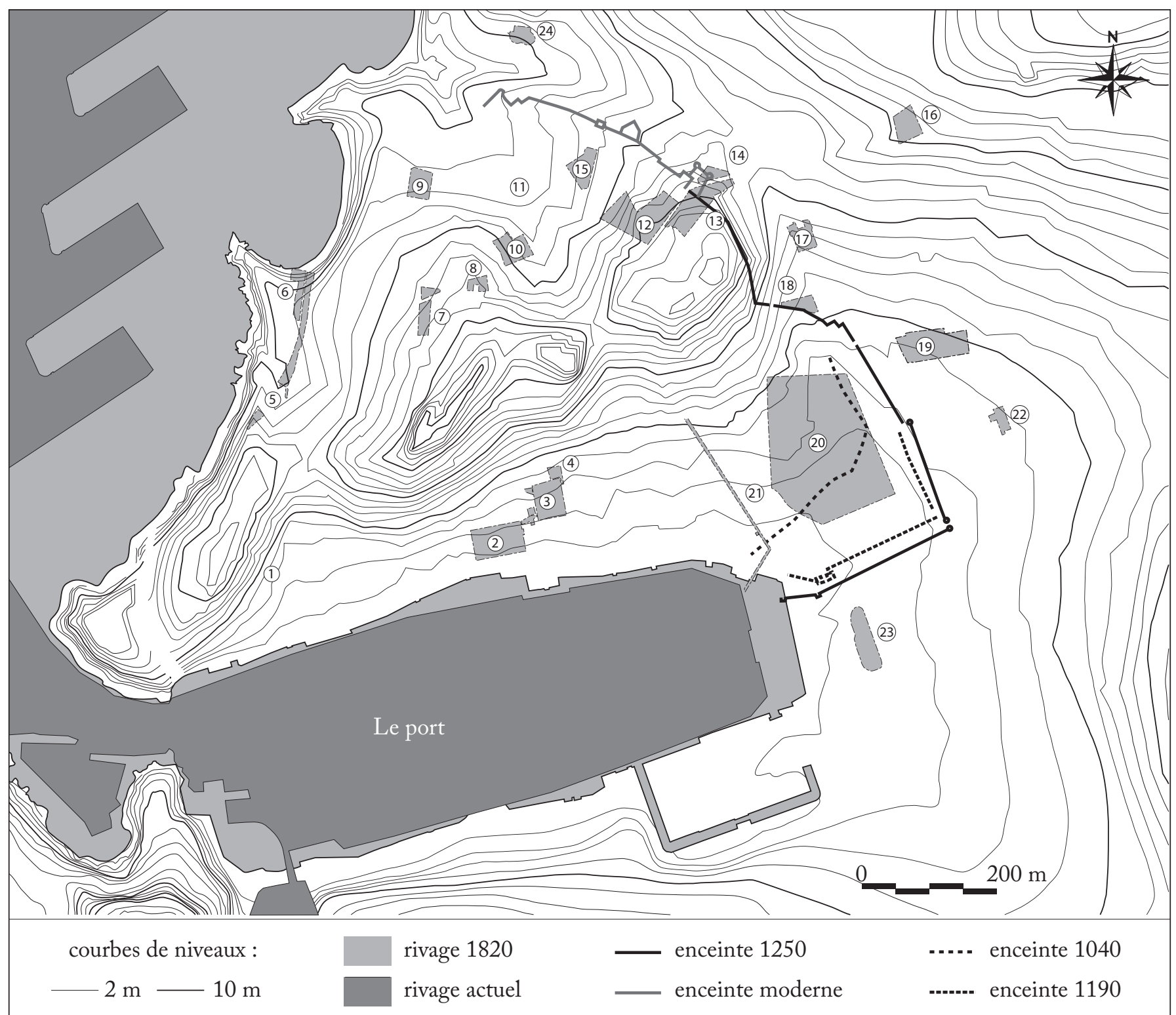

1- collège Vieux-Port, 2- place Jules-Verne, 3- place Bargemon, 4- espace Bargemon, 5- tunnel de la Major, 6- esplanade de la Major, 7- place des Pistoles, 8- RHI Bon Jésus, 9- rue Leca, 10- parking des Phocéens, 11- parking République, 12- les Carmelins, 13- les Carmes, 14- îlot N, 15- rue Trinquet, 16- Bernard Dubois, 17- Sainte-Barbe, 18- Puget III, 19- Alcazar (BMVR), 20- la Bourse, 21- République - Surverse Vieux-Port, 22- 25 rue Thubaneau - Jeu de Paume, 23- place Général-de-Gaulle, 24- Malaval.

Fig. 3. Les chantiers de fouille aechéologique dans la topographie de Marseille (DAO B. Sillano/Inrap sur fond de plan M. Bouiron).

buttes sont séparées par des talwegs dont certains ont pu être décelés en fouille par les études géomorphologiques et grâce aux aménagements visant à canaliser les eaux de ruissellement qui dévalaient ces pentes. L'importante sédimentation dans les parties basses a permis la conservation des vestiges archéologiques malgré les multiples constructions au long des siècles. La ville est entourée de vallons délimités par des collines plus ou moins hautes (du Lazaret, Saint-Charles, Saint-Michel et de la Garde).

\subsection{L'archéologie préventive du Moyen Âge et des Temps Modernes à Marseille}

Initiée dès 1967 avec les fouilles de la Bourse, l'archéologie préventive est restée présente à Marseille dans la plupart des travaux d'aménagement urbains, qu'ils soient publics ou privés. Progressivement, des fenêtres se sont ouvertes sur le passé de la ville la plus ancienne de France (fig. 3). Néanmoins, les résultats sont très 


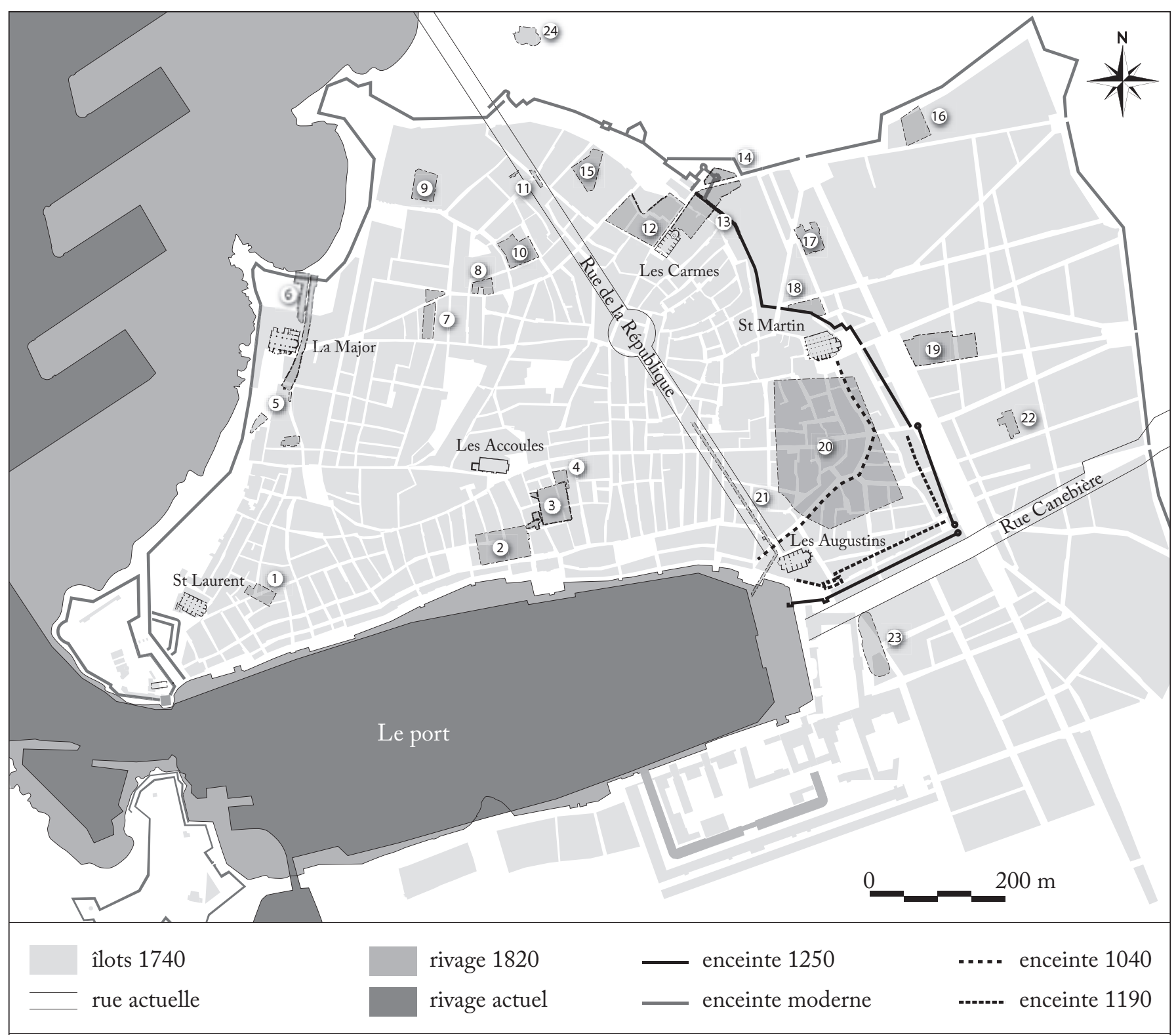

1- collège Vieux-Port, 2- place Jules-Verne, 3- place Bargemon, 4- espace Bargemon, 5- tunnel de la Major, 6- esplanade de la Major, 7- place des Pistoles, 8- RHI Bon Jésus, 9- rue Leca, 10- parking des Phocéens, 11- parking République, 12- les Carmelins, 13- les Carmes, 14- ̂̂lot N, 15- rue Trinquet, 16- Bernard Dubois, 17- Sainte-Barbe, 18- Puget III, 19- Alcazar (BMVR), 20- la Bourse, 21- République - Surverse Vieux-Port, 22- 25 rue Thubaneau - Jeu de Paume, 23- place Général-de-Gaulle, 24- Malaval.

Fig. 4. Le cadre urbain de l'Époque moderne et les opérations archéologiques (DAO B. Sillano/Inrap sur fond de plan M. Bouiron).

inégaux, en particulier en ce qui concerne les niveaux médiévaux et, à fortiori, modernes.

Inégalité dans le traitement des données tout d'abord ; pendant longtemps, l'archéologie de la période antique prédominait sur celle des niveaux plus récents, jugés peu dignes d'intérêt et suffisamment renseignés par les textes. Sur le vaste chantier de la Bourse, les vestiges médiévaux et modernes ont été éliminés, hormis quelques ensembles étudiés par des archéologues plus «sensibles» à ces problématiques. Au début des années 90, sur le chantier du parking Jules-Verne, les séquences du Moyen Âge ont été largement éradiquées et le dégagement partiel des niveaux plus récents se réduit à quelques notes non consignées dans un rapport. $\mathrm{Au}$ même moment, les niveaux médiévaux des sites comme 
le parking Sainte-Barbe (1991) ou la place Généralde-Gaulle (1993) ont donné lieu chacun à une analyse exhaustive et poussée (qui ne s'est pas faite au détriment des niveaux antiques eux-mêmes intégralement fouillés), qui a abouti à des publications monographiques importantes (Marchesi et al. 1997, Bouiron 2001a). Dans l'intervalle, plusieurs opérations de petite et moyenne envergure (Les Pistoles, Ilot 55, Parc des Phocéens, RHI Bon Jésus ${ }^{13}$ ), ont fait l'objet de publications partielles pouvant concerner l'occupation médiévale ou moderne, la priorité étant donnée bien évidemment à la période antique.

Avec la scission, en 1995, de la fouille de l'ex musée César (opération renommée par la suite en «place Villeneuve-Bargemon ») en deux opérations distinctes, «César 1 » consacrée aux périodes médiévale et moderne, et « César 2 », consacrée à l'Antiquité, la prise en compte des niveaux récents devient effective et systématique ${ }^{14}$. Désormais, le décapage préliminaire s'arrête à l'apparition des premières constructions visibles, très souvent des vestiges du siècle dernier. Il est vrai que les techniques de fouille, en particulier l'introduction systématique de la mini-pelle, ont permis de traiter les importantes séquences stratigraphiques relevées à Marseille dans un temps compatible avec les délais de fouille alors que le travail exclusivement manuel nécessitait une intervention mécanique préalable lourde qui a conduit aux impasses mentionnées.

Avec le chantier de l'Alcazar, en 2000, le rapport de fouille se complète par une étude synthétique par période, sorte de pré-publication, ainsi que d'une recherche archivistique importante. La même démarche est appliquée au chantier du Tunnel de la Major, en 2001, puis à celui de l'Espace Bargemon, en 2003, ainsi que sur les quelques opérations très récentes menées durant les trois ans de rédaction de la présente publication (Collège Vieux-Port, Rue de la République, Rue Jean Trinquet, 25 rue Thubaneau).

Afin de permettre la publication des trois grandes opérations de l'Alcazar, du Tunnel de la Major et de l'Espace Bargemon, un Projet Collectif de Recherche (PCR) «Archéologie urbaine à Marseille : publication des fouilles récentes » a été mis en place. Il est coordonné par M. Bouiron ${ }^{15}$.

13 Se référer aux notices de sites dans Bouiron et al. 2001a, p. 421, 425 et 429.

14 Il faut souligner ici le rôle joué à l'époque par le Service régional de l'Archéologie et en particulier par le conservateur en charge de Marseille, Bruno Bizot.

15 Premier triennal : 2005-2007; second triennal, en cours au moment de la publication : 2008-2010. Il convient de préciser que les fouilles réalisées autour de la Mairie ne sont étudiées, dans le cadre de cette publication, que pour le Moyen Âge et l'Époque moderne;

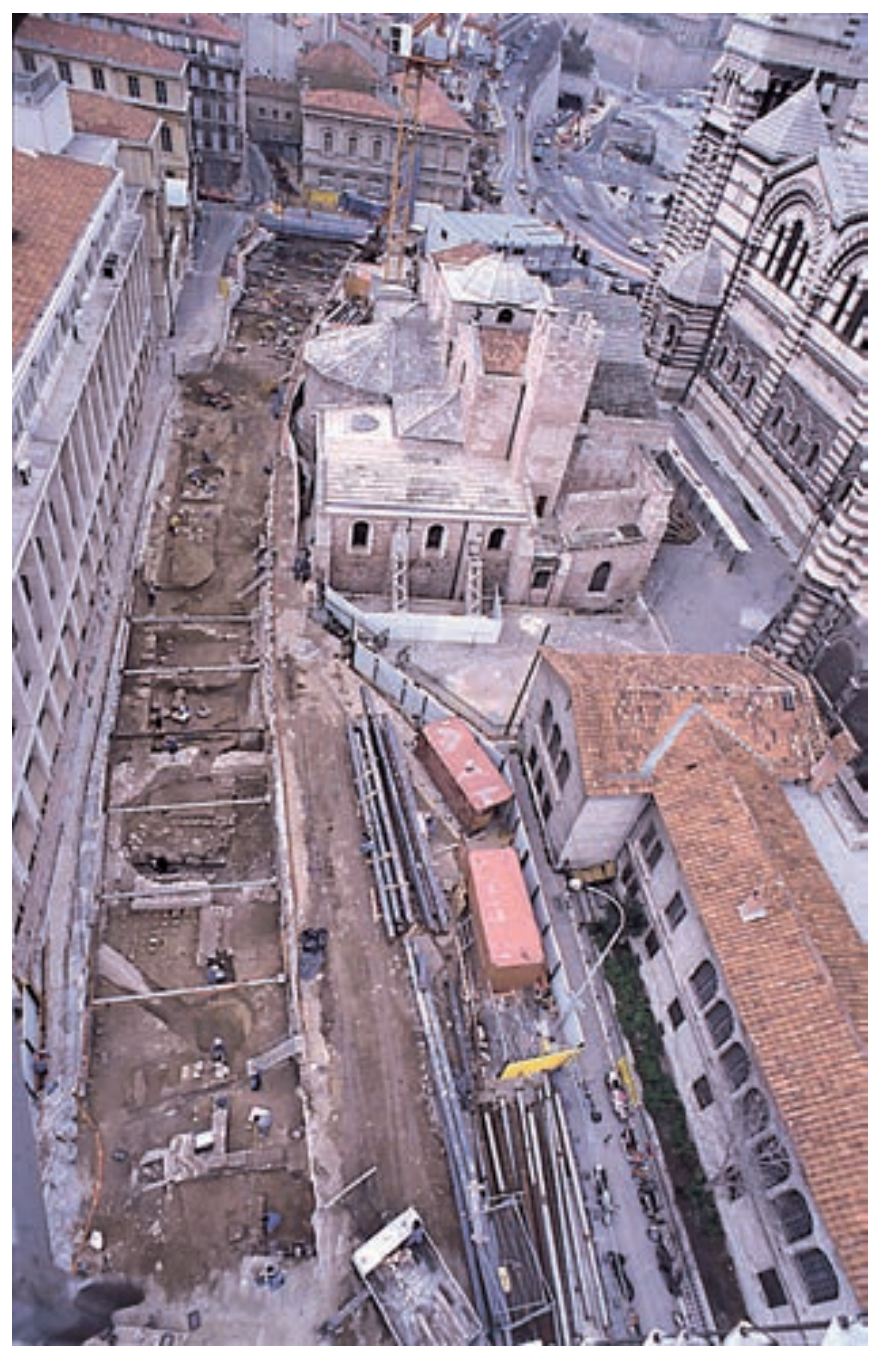

Fig. 5. La fouille du Tunnel de la Major vue du nord (cl. Maziers/Inrap).

À l'origine ambitieux, le projet de publication devait concerner toutes les opérations préventives marseillaises, mais la réduction drastique des moyens octroyés nous a conduits à nous polariser sur ces trois chantiers, pour lesquels l'étude déjà menée était suffisamment aboutie pour nous dispenser d'un retour à l'enregistrement de terrain. La question de la représentativité de ces opérations reste posée pour prétendre tirer des conclusions générales sur l'évolution de la ville; il ne s'agit ici que d'une approche.

\subsection{Localisation des fouilles dans la ville}

Les trois opérations concernées par cette publication sont localisées en trois endroits très différents de la ville (fig. 4). La première, le Tunnel de la Major, se situe à

les autres périodes seront publiées dans le cadre de l'ACR conduite par A. Hesnard. 
proximité de la cathédrale, sur le revers de la butte des Moulins et de la butte Saint-Laurent. La seconde, l'Espace Bargemon, est en bordure du port et plus exactement en son milieu, lieu stratégique où sont installées les instances décisionnelles. Et la troisième, l'Alcazar, dans les faubourgs, à proximité des remparts médiévaux.

D'emblée, l'étude exclut le terroir qui, par les échanges qu'il a avec la ville (matériaux, denrées alimentaires, journaliers, résidences secondaires), participe pourtant de la vie de la cité. Les quelques fouilles archéologiques qui l'ont concerné n'ont renseigné que l'agriculture à l'époque antique. Seule une «folie »du $\mathrm{XVII}^{\mathrm{e}}$ s., mise au jour à Saint-Jean-du-Désert (Abel 1995), montre le faste déployé par l'élite urbaine dans ses résidences secondaires, faste souvent absent de leurs demeures du centre ville. Il convient néanmoins de signaler sur une grande partie du terroir marseillais l'importance des travaux de mise en culture aux XVII et XVIII ${ }^{\mathrm{e}}$ s. qui se traduisent par la création de terrasses et des remblaiements massifs (de l'ordre du mètre d'épaisseur), systématiquement mis en évidence par les fouilles et diagnostics archéologiques et qu'il conviendra d'étudier ultérieurement. Ce terroir s'étend jusqu'à la rive sud du port qui, jusqu'à l'avènement de Louis XIV, reste extra muros et n'est pas concernée par notre étude. Mentionnons néanmoins les travaux du LAMM sur l'abbaye de Saint-Victor (Fixot, Pelletier 2009) ou encore les jardins du roi René, mis au jour sur le chantier du Quai Rive-Neuve.

En marge de la ville sans pour autant être assimilables au terroir, les faubourgs ont été largement étudiés par le biais de l'archéologie. Les chantiers de Sainte-Barbe et du parking Général-de-Gaulle, déjà publiés, ainsi que les opérations de l'îlot Puget, de l'îlot Bernard Dubois ou encore du Jeu de Paume, au 25 de la rue Thubaneau (Sillano, Scherrer 2009) ont montré le caractère à la fois urbanisé et industriel de ces quartiers au Moyen Âge et aux Temps Modernes. À la fois centrale et d'une très grande superficie, la fouille de l'Alcazar en rassemble tous les caractères et en livre une synthèse à la fois diachronique et fonctionnelle.

La ville intra muros, si elle reste une au sein de remparts dont le tracé a, somme toute, été peu modifié depuis l'Antiquité, n'en est pas moins divisée en quartiers. Depuis le début du Moyen Âge jusqu'à la fin de l'Époque moderne, ceux-ci ont réuni la population selon des groupes sociaux dont l'impact est tangible jusque dans le type d'habitation. Ville haute, dépendant de l'évêque, et ville basse, dite vicomtale, n'expriment pas qu'une réalité foncière mais bien des populations différentes. La première, pauvre et roturière, se traduit par les petites habitations qui font le charme de l'actuel quartier du Panier ; la seconde, occupée par la noblesse, les marchands et les négociants, présente une mosaïque d'habitats où se côtoient hôtels du patriciat, maisons bourgeoises, boutiques et maisons élémentaires. Au fil du temps, la dichotomie primaire s'est morcelée, les propriétés vicomtales étant rachetées par la bourgeoisie et les écuyers, pour aboutir à la création des quatre grands quartiers de l'Époque moderne : Cavaillon, Blanquerie, Corps-de-Ville et Saint-Jean. À chacun nous avons coutume d'attribuer une frange de la population soit, respectivement, les journaliers, qui travaillent dans le terroir pendant la journée, les commerçants et artisans, les nobles et bourgeois et enfin les marins. Chacun de ces quartiers a fait l'objet de fouilles archéologiques. Dans le quartier de Cavaillon, citons les fouilles des Pistoles, de l'îlot 55, de la RHI Bon Jésus, des Carmes, de la Rue Leca, du Tunnel de la Major ou, plus récemment, du Parking République, de la Rue Trinquet et de l'esplanade de la Major. Pour des raisons diverses (documentation insuffisante ou opération plus récente que le début de la rédaction de la présente publication), seule la fouille du Tunnel de la Major a retenu notre attention. Trop proche de la cathédrale, dans une zone occupée par le chapitre, les résultats de cette opération demeurent peut-être peu représentatifs de l'habitat propre au quartier. Dans le quartier de la Blanquerie, seules les fouilles de la Bourse, du bassin de stockage Sadi Carnot (République - surverse Vieux-Port) et de l'Alcazar ont été réalisées, la première vaste mais peu documentée pour les périodes récentes, l'autre extrêmement réduite. Dans le quartier Saint-Jean, la seule opération est celle du Collège Vieux-Port si l'on excepte la toute petite fouille du parvis de l'église Saint-Laurent. Notre étude n'éclaire en rien notre connaissance de ces quartiers au Moyen Âge et à l'Époque moderne. Enfin, le quartier de Corps-de-Ville est très bien illustré par les opérations successives autour de la mairie. Par chance, l'étendue de la zone fouillée et son caractère central révèle une grande variété de types d'occupations qui permet de se représenter ce qu'était la ville de Marseille intra muros au cours du Moyen Âge et des Temps Modernes.

En conclusion, nous dirons que les trois chantiers sur lesquels s'appuie notre étude n'en restent pas moins suffisamment bien placés et vastes pour être considérés comme représentatifs de l'occupation de la ville au cours du Moyen Âge et de l'Époque moderne. Notre publication, si elle ne peut prétendre à l'exhaustivité (mais peut-elle être exhaustive lorsqu'il s'agit d'archéologie ?), n'en apporte pas moins un éclairage nouveau sur l'histoire de Marseille qui, jusqu'à présent, était essentiellement alimentée par les documents écrits. 


\section{Les opérations archéologiques étudiées}

Trois chantiers font l'objet de notre étude. Nous les indiquons dans l'ordre où ils apparaissent dans la seconde partie de l'ouvrage : le Tunnel de la Major, au nord de la ville ; les fouilles autour de la Mairie, au sud de la ville ; enfin l'Alcazar, seul chantier suburbain de notre étude.

\subsection{Le Tunnel de la Major}

Le chantier archéologique du Tunnel de la Major (codé TNM 2000) s'est déroulé entre juillet 2000 et février 2001 sur le terrain et le rapport de fouille a été finalisé en 2004 (Barra et al. 2004). Il a été dirigé par F. Conche (responsable d'opération Inrap) et O. Maufras (responsable adjointe Inrap); ils ont été aidés dans leur tâche par un collège scientifique regroupant des chercheurs de la Ville de Marseille, de l'Université de Provence et du CNRS. Provoqué par le creusement d'un tunnel, il a pris la forme d'une longue bande de $350 \mathrm{~m}$ de longueur sur environ $10 \mathrm{~m}$ de large entre le pied de la butte Saint-Laurent et le tunnel de la Joliette ${ }^{16}$ (fig. 5). La fouille, entièrement réalisée par des agents de l'Inrap, a été divisée en 7 zones. La zone 1 correspond aux surveillances de détournements de réseaux effectuées sous la direction de F. Conche en 2000. La zone 2, au sud de la mairie de secteur (responsable M. Guillaume et adjoints S. Fournier et N. Scherrer), est située au pied de la butte Saint-Laurent. Les zones 3 et 7 se succèdent au nord de la mairie de secteur (responsables C. Voyez et C. Barra, adjointe N. Valour) jusqu'à la Vieille-Major. La zone 4 longe le chevet de la Vieille-Major (responsables R. Gaday et B. Vasselin). La zone 5 se situe au nord de la zone 4 jusqu'à la place du Séminaire (responsable J.-L. Blaison et L. Duval en adjoint). Enfin la zone 7, à l'est de la mairie de secteur, a été dirigée par S. Fournier.

Ce chantier a été précédé d'un sondage dans l'avenue Vaudoyer (Bouiron et al. 2001 a, p. 422), de plusieurs sondages sur le tracé du futur tunnel (Bouiron et al. 1995) et d'une fouille de $125 \mathrm{~m}^{2}$ au niveau de l'esplanade de la Tourette (Chapon 2000). Les archives ont été étudiées par P. Rigaud et J. Cuzon (Inrap).

Dans cette publication, les vestiges liés à la vie religieuse du quartier (soit le quartier canonial, le cimetière, la chapelle des Pénitents blancs de Saint-Lazare et le Grand séminaire) ne seront pas évoqués. Ils feront l'objet d'une publication centrée sur l'évolution du quartier

16 Aucune exploration archéologique n'a été réalisée sous la Mairie, le tunnel ayant été réalisé par forage. épiscopal et la création de la cathédrale de La Major, en lien avec d'autres opérations de fouille.

Les vestiges médiévaux ne sont que partiellement conservés car arasés à l'Époque moderne par diverses constructions ; la création du boulevard Robert-Schuman notamment a entamé la stratification jusqu' aux vestiges de l'Antiquité tardive. Par ailleurs, les constructions des $\mathrm{XIII}^{\mathrm{e}}$ et $\mathrm{XIV}^{\mathrm{e}} \mathrm{s}$. ont largement détruit celles des périodes précédentes, du haut Moyen Âge en particulier. Néanmoins, et malgré aussi l'étroitesse du chantier, un quartier médiéval se dessine clairement. Pour la période moderne, les vestiges archéologiques, également largement arasés, sont néanmoins bien éclairés par les données d'archives.

\subsection{Les abords de la Mairie}

Entre 1992 et 2005, la Ville de Marseille a réalisé toute une série de travaux autour de la Mairie. Un parking est creusé sous la place Jules-Verne en 1992 puis une vaste excavation au nord de la Mairie, en 1995, qui devait accueillir un musée consacré à l'artiste marseillais César. La donation de l'artiste n'ayant pu être recueillie, un nouveau projet est défini en 2004 : l'Espace Bargemon, vaste infrastructure souterraine, à la fois annexe de la Mairie et salles d'exposition ouvertes au public. Dans ce dessein, une extension de l'emprise d'origine a été nécessaire.

Ces constructions ont été systématiquement accompagnées de fouilles archéologiques qui se répartissent en quatre campagnes :

- La fouille Jules-Verne (JV 1992) : ce chantier de $3700 \mathrm{~m}^{2}$, dirigé par A. Hesnard (Centre Camille Jullian, CNRS), n'a pas donné lieu à un rapport. Les niveaux modernes et médiévaux ont été très peu étudiés, mis à part un secteur dirigé par F. Paone (rapport non abouti). Un recueil de textes d' archives a été établi par P. Bernardi (directeur de recherches au LAMOP (Paris I), CNRS). Nous n'évoquerons que très peu cette opération.

- La fouille «César 1»(CSR 1995) : ce chantier d'environ $1500 \mathrm{~m}^{2}$, dirigé par V. Abel puis R. Thernot (tous deux de l'Inrap), a été consacré à la fouille des niveaux médiévaux et modernes sur l'emprise du projet de musée César (fig. 6). Le rapport (Thernot 1997) a été réalisé en regroupant les participations des différents responsables de secteur (F. Paone, V. Rinalducci, B. Sillano et M. Vecchione) sans qu'il y ait eu assez de temps pour réaliser une synthèse. Une étude d'archives a été menée par C. Castrucci (Inrap). 


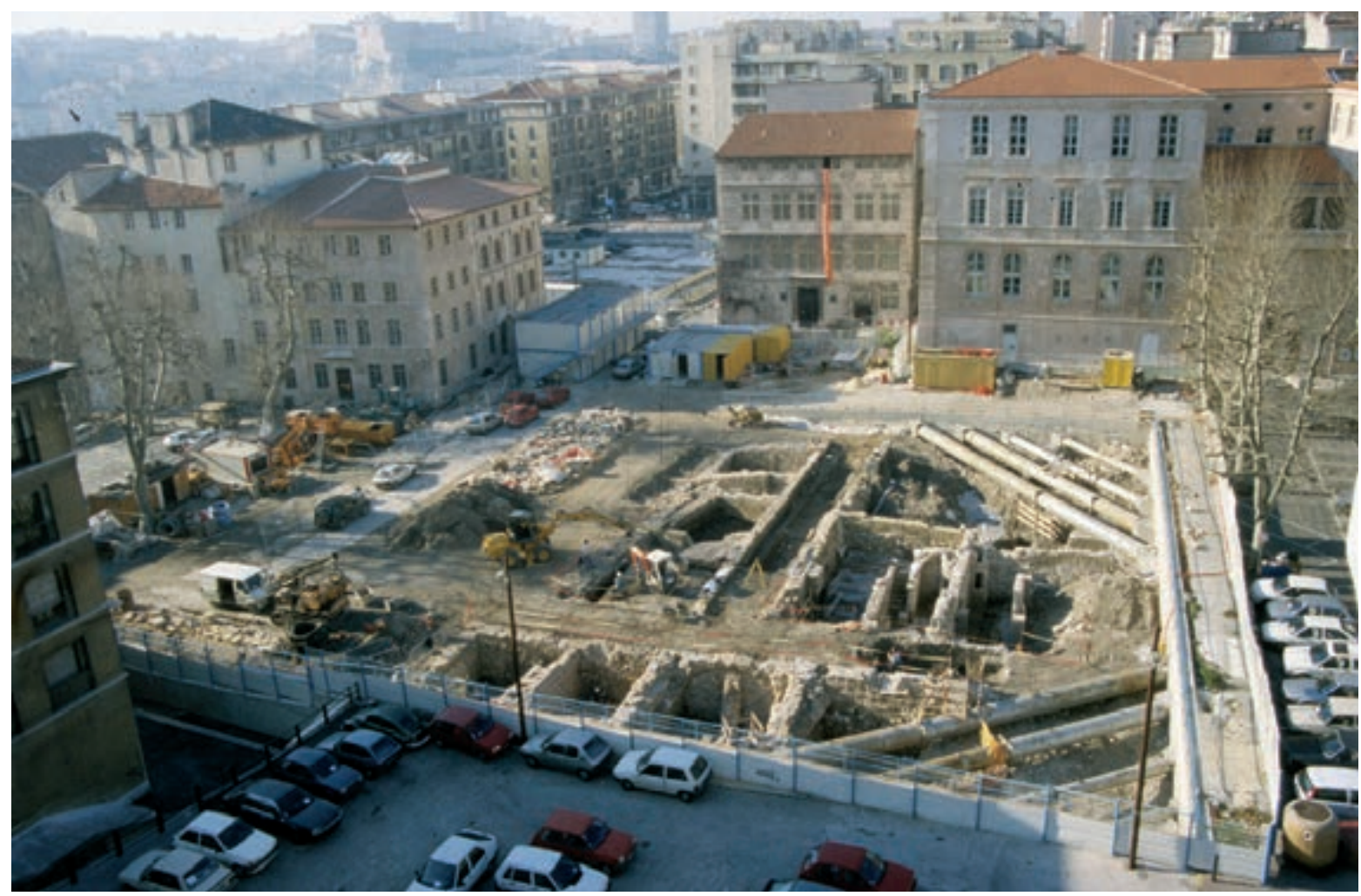

Fig. 6. Vue d'ensemble du chantier « César 1 » en 1996

Au fond, le pavillon Bargemon, la Maison Diamantée et le pavillon Daviel (cl. A. Arbion/Inrap).

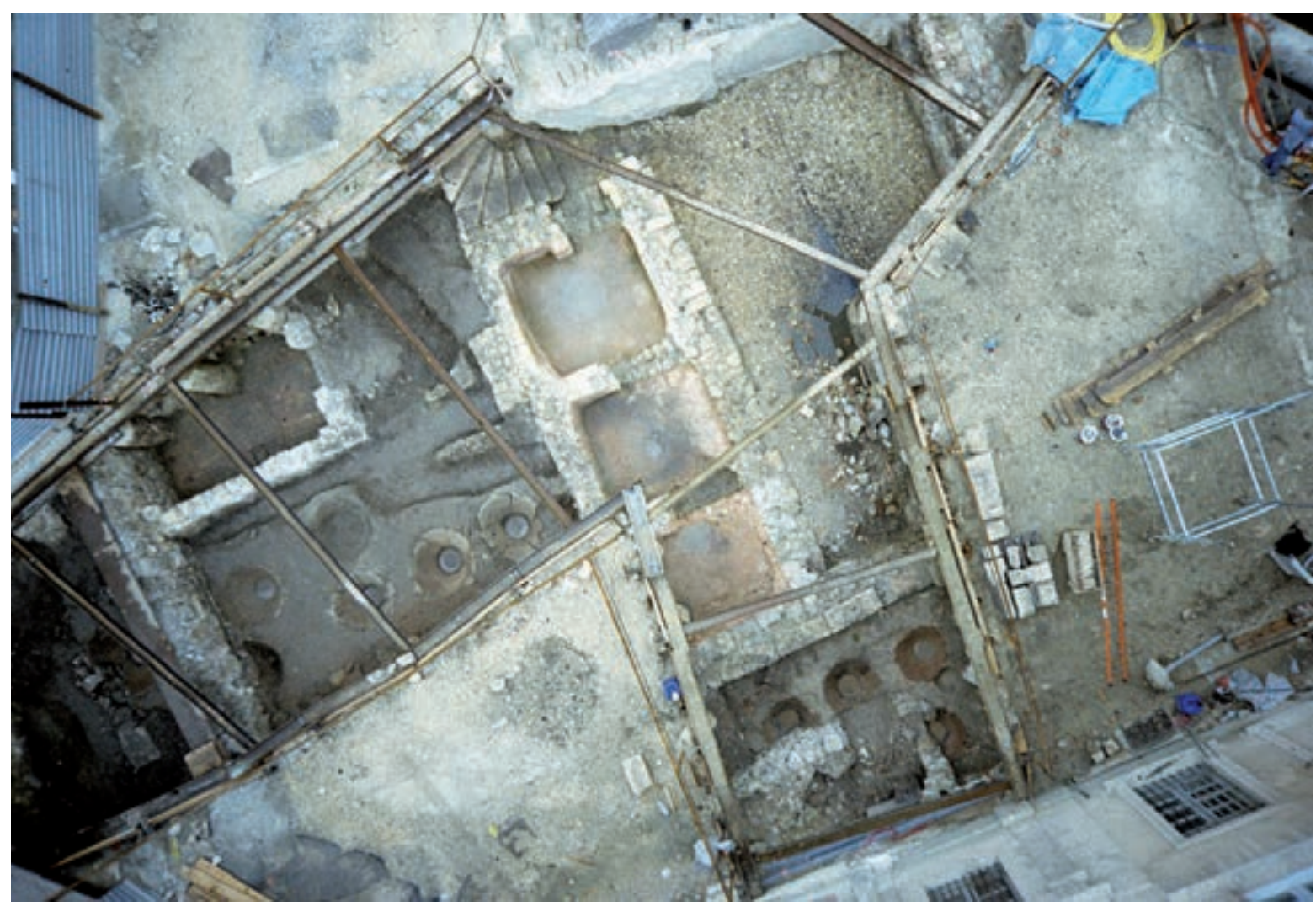

Fig. 7. La zone 3 du chantier « Espace Bargemon » (cl. T. Maziers/Inrap) 


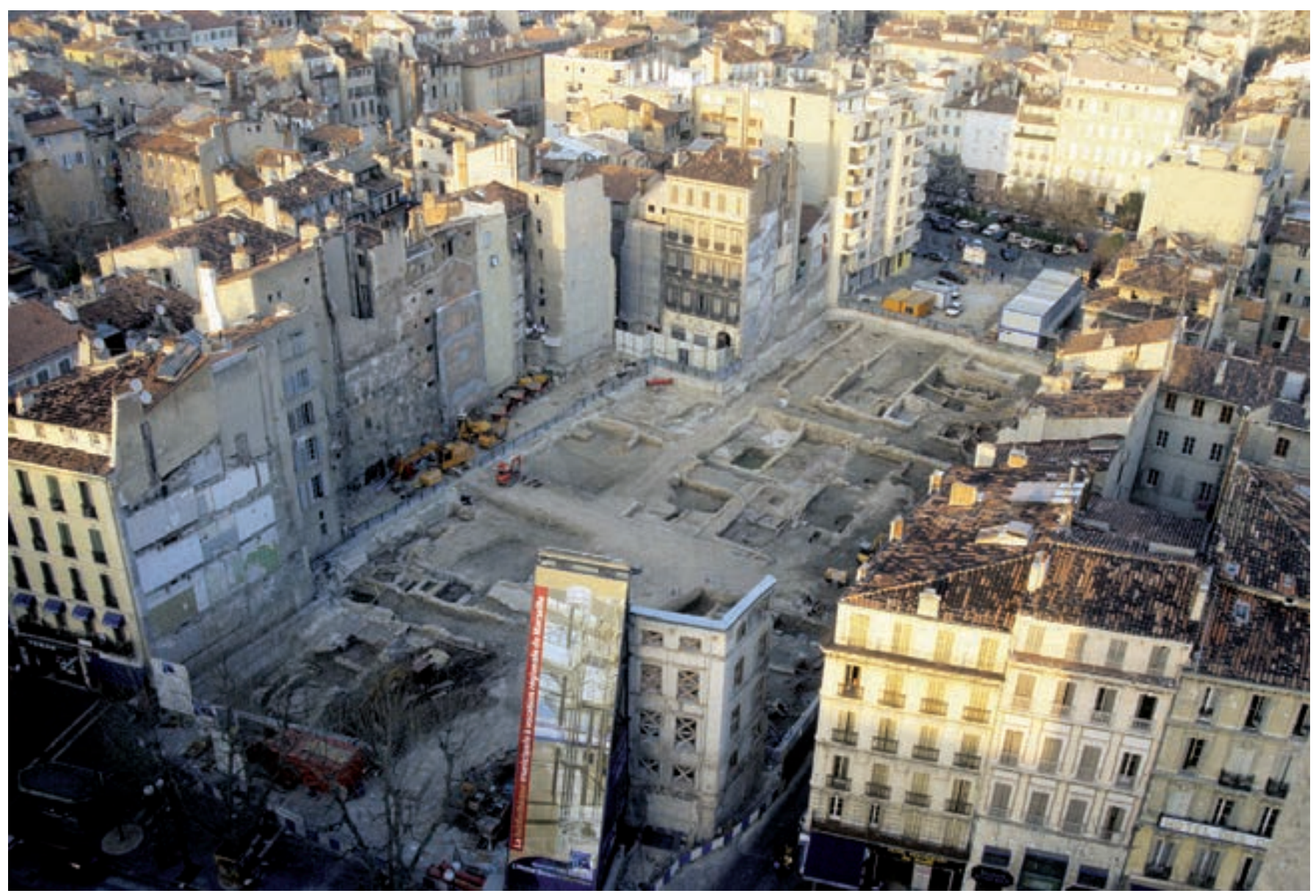

Fig. 8. Le chantier de l'Alcazar (cl. F. Parent/Inrap).

- La fouille «César 2 » (MCR 1996) : ce chantier de $2500 \mathrm{~m}^{2}$, dirigé par A. Hesnard (Centre Camille Julian) et $\mathrm{F}$. Conche (Inrap), a été consacré à la fouille des niveaux antiques sur l'emprise du musée César. Le rapport n'a pas été réalisé ; cependant, la partie des niveaux médiévaux et modernes qui n'avaient pas été fouillée, faute de temps, durant l'opération «César 1 », a pu être étudiée et les données ont été incluses dans le rapport de la fouille précédente.

- La campagne de l'Espace Bargemon (BRG 2005) : ce chantier était constitué d'une série de petites opérations en périphérie du chantier précédent (fig. 7). Ce sont la zone 1 au sud ( $40 \mathrm{~m}^{2}$, responsable M. Maurin), 2 et 3 à l'ouest $\left(60 \mathrm{~m}^{2}\right.$ et $150 \mathrm{~m}^{2}$, responsables respectifs F. Parent et B. Sillano), 4 au nord-ouest $\left(70 \mathrm{~m}^{2}\right.$, responsable M. Maurin) et 5 au nord $\left(350 \mathrm{~m}^{2}\right.$, responsables successifs F. Paone et R. Thernot). Une étude d'archives a été menée par Ph. Rigaud (Inrap) et C. Castrucci. Le rapport a donné lieu à des synthèses abouties qui ont tenté de prendre en compte l'ensemble des opérations et servent de base à la présente publication (Mellinand 2005).
Dans ce secteur, la rafle de 1943, organisée par la police française, suivie du dynamitage systématique des maisons par les Allemands a conduit à la disparition quasi-totale du quartier. Au sud de la Grand-Rue, furent seuls épargnés les bâtiments administratifs (Palais de Justice, Mairie, pavillon Bargemon, ainsi que les parcelles 384 et 370 à 374) auxquels s'ajoutent quelques édifices prestigieux (Maison Diamantée, Hôtel de Cabre). Le reste n'était qu'un champ de ruines...

L'arasement des structures archéologiques est très variable d'un secteur à l'autre, tributaire du dynamitage mais aussi des travaux de reconstruction qui ont suivi et dont nous n'avons pas le détail. Ainsi, sur l'emprise du projet du musée César, nous distinguons la moitié nord où les substructions sont conservées jusqu'au niveau du sol d'origine (rez-de-chaussée) alors que dans la moitié sud, le nivellement a surcreusé ce sol sur une profondeur de près de $1 \mathrm{~m}$. La même différence entre le nord (zones 4 et 5) et le sud (zones 1,2 et 3) a été observée pour l'opération de l'Espace Bargemon.

Les caves, creusées quasi systématiquement à partir du XVII ${ }^{e}$ s., ont aussi considérablement dégradé le 
sous-sol et nous privent d'informations essentielles comme les tranchées d'installation des murs ainsi que les sols qui leur sont contemporains. Contrairement aux époques antérieures, les vestiges d'Époque moderne consistent essentiellement en des structures bâties, pour la plupart des murs. Le corollaire est la rareté du mobilier archéologique qui nous permettrait d'établir une chronologie absolue. Paradoxalement, ce sont les niveaux les plus proches de nous dans le temps qui sont les moins bien datés; la date d'édification de nombreux murs modernes est établie avec une fourchette chronologique de deux siècles alors que la plupart des murs grecs sont datés à 25 ans près ! Les rues ont également été arasées profondément et ce d'autant plus qu'elles ont accueilli en leur axe des réseaux de canalisations successifs, les plus récents oblitérant généralement les précédents.

\subsection{L'Alcazar}

Ce chantier (BMVR 1999) de $4400 \mathrm{~m}^{2}$ a été réalisé de février 1999 à février 2000 sous la direction de M. Bouiron alors archéologue de la Ville de Marseille avec une équipe de l'Inrap (fig. 8). Il a été initié par le projet de construction de la BMVR ${ }^{17}$, sur l'emprise de l'ancien théâtre de l'Alcazar.

Onze responsables de zones et adjoints se sont répartis le travail avec une équipe d'environ 70 personnes ${ }^{18}$. L'étude d'archives a été menée par P. Rigaud (Inrap) pour la période médiévale et pour la période moderne par C. Castrucci (Inrap). Le rapport de fouille, objet d'un important travail collectif, a été rendu en 2001 (Bouiron 2001b).

L'amplitude du site a permis d'obtenir de nombreuses informations pour toutes les périodes, de l'Antiquité grecque à l'Époque moderne. Comme trop souvent, les vestiges du haut Moyen Âge n'ont pas été retrouvés, soit qu'ils n'ont pas existé, soit qu'ils aient été arasés par ceux des siècles suivants. Des traces sont conservées à partir du XII ${ }^{\mathrm{e}}$ s. et jusqu'à la destruction au milieu du $\mathrm{XIV}^{\mathrm{e}} \mathrm{s}$. du faubourg construit à la fin du XIII ${ }^{\mathrm{e}} \mathrm{s}$.

Les premières demeures de l'Époque moderne sont installées sur un apport important de remblais datés du $\mathrm{XVI}^{\mathrm{e}} \mathrm{s}$. ; elles sont légèrement antérieures à l'Agrandissement de la ville voulu par Louis XIV. À partir de la création du Cours, ces premières habitations sont réalignées et le quartier connaît un développement exponentiel de son urbanisation jusqu'au XVIII' ${ }^{\mathrm{e}}$ s., voire jusqu'à la

17 Bibliothèque Municipale à Vocation Régionale.

18 Responsables et adjoints: S. Bien, B. De Luca, M. Maurin, P. Mellinand, M. Moerman, F. Paone, F. Parent, É. Plassot, P. Reynaud, B. Sillano et C. Voyez.
Révolution. Le quartier est bouleversé par la construction de la salle de spectacle de l'Alcazar en 1857.

Les vestiges permettent de bien documenter l'évolution du quartier du XII ${ }^{\mathrm{e}} \mathrm{s}$. à la période moderne; en revanche, les élévations ne sont pas conservées.

\section{Les contraintes et limites de la documentation}

Les sources, qu'elles soient archéologiques ou archivistiques ne sont pas exhaustives sur les zones étudiées. Entre difficulté technique lors des chantiers, destruction ancienne et masse des registres de notaires à dépouiller, il faut ici préciser la représentativité de notre masse documentaire.

\subsection{Les limites de l'archéologie du Moyen Âge et des Temps Modernes}

Si l'étude des faubourgs de la ville est plus aisée en raison des phases d'abandon qui figent et scellent les différentes occupations, celle qui concerne la ville intra muros se heurte à de nombreuses difficultés. Les opérations de fouille ne concernent que les substructions d'édifices dont la destruction est parfois intervenue immédiatement avant les travaux. Aucune étude de bâti en élévation n'a encore été réalisée et la vision qui nous est restituée est extrêmement lacunaire. Le caractère figé du parcellaire durant toute cette période a pour corollaire la superposition des murs porteurs dont l'élévation toujours plus importante a souvent nécessité la démolition complète des maçonneries antérieures.

La chronologie absolue est difficile à établir en raison de la rareté du mobilier archéologique. Après les grands travaux de nivellement antiques qui ont estompé le relief très marqué à l'origine, les remblaiements associés aux constructions se font plus discrets ; or ce sont eux qui recèlent du mobilier datant. Le creusement quasi systématique des caves à partir du XVII ${ }^{\mathrm{e}}$ s. a également éliminé toute possibilité de dater les structures bâties qui les ceignent. En l'absence d'éléments datant, la chronologie relative est peu révélatrice de l'épaisseur de la séquence archéologique. Les phases constructives, de courte durée, nous livrent une grande quantité d'unités stratigraphiques (par exemple des remblais successifs préparatoires à l'établissement d'un sol) alors que les phases d'utilisation, parfois de très longue durée, ne laissent pratiquement aucune trace (le sol est balayé et entretenu régulièrement).

Deux hiatus chronologiques sont observés de manière récurrente : le premier au début de la période médiévale 
(entre le VIII et le $\mathrm{XI}^{\mathrm{e}} \mathrm{s}$.) et le second au début de la période moderne ( $\mathrm{XV}^{\mathrm{e}}$ et $\mathrm{XVI}^{\mathrm{e}} \mathrm{s}$.). Même s'il existe une importante période de récession, la ville n'a pas disparu entre le VIII et le $\mathrm{XI}^{\mathrm{e}} \mathrm{s}$. De plus, le hiatus existe aussi pour le $\mathrm{XV}^{\mathrm{e}}$ s. durant lequel le commerce reprend une activité importante ; il ne semble donc pas que le repli ou l'essor de la ville soient à l'origine de ces lacunes. Les arasements successifs des vestiges n'en sont sans doute pas non plus les seules causes. Il convient de se poser la question de la limite de nos connaissances, notamment pour ce qui concerne les éléments datant.

\subsection{L'apport des archives}

Pour la première fois à Marseille, d'importantes études d'archives, conçues comme un outil propre à confronter terrain et sources écrites, ont été conduites dans le cadre des chantiers de fouille. Portant sur les deux périodes, médiévale et moderne, les résultats sont hétérogènes du fait de l'inégalité des sources pour l'une et l'autre période.

Les archives consultées sont pour l'essentiel celles conservés aux archives municipales et départementales, dont les fonds sont parmi les plus riches de France pour la période médiévale. Rappelons que les archives municipales renferment le plus ancien registre de notaire de France (1248) et que le fonds de l'abbaye Saint-Victor, intégralement conservé aux archives départementales, est particulièrement précieux pour les historiens. Dans le cadre de l'archéologie préventive, les études d'archives sont généralement ponctuelles et liées au cadre topographique des chantiers. De ce fait, elles demeurent partielles. Elles tirent leurs informations de documents de nature différente suivant leur origine (notaires, délibérations municipales, ...) mais aussi rédigées en différentes langues. La langue d'Oc parlée à Marseille est parfois utilisée dans les actes écrits à partir du XII ${ }^{\mathrm{e}} \mathrm{s}$. Le latin reste malgré tout la langue principale des actes servant de preuve, jusqu'en 1539, date à laquelle François Ir impose la langue française (encore que cette décision mit quelques décennies à être appliquée à Marseille, Dell'Umbria 2006).

Pour la période médiévale, la thèse de doctorat de R. Pernoud sur les Statuts de la ville, les travaux de G. Rambert sur le commerce de Marseille, de M. Dupanloup sur les teinturiers, de B. Roberty sur le classement des archives..., ${ }^{19}$ sont autant de sources d'informations que nous avons pu confronter aux données de fouilles.

19 Pernoud 1949, Rambert 1951-1966, Dupanloup 1966 et 1969.
Plus récemment, le travail au long cours de M. Bouiron et celui de P. Rigaud ont permis de compléter les données du sol. Ainsi pour le site de la place Général-de-Gaulle, le nom des habitants a pu être déterminé pour un certain nombre de maisons ; l'évolution du foncier a pu être cerné dans cette zone (Bouiron 2001a, p. 242-246). L'étude de P. Rigaud pour le chantier de l'Alcazar a permis entre autres choses de cerner la mise en place de la voirie dans ce faubourg.

Pour la période moderne, les recueils successifs ont été réalisés par P. Bernardi, C. Castrucci et P. Rigaud. La carence en matière de datation absolue est compensée par l'abondance des textes d'archive ${ }^{20}$. Cependant, la majorité des textes a été rédigée entre l'extrême fin du $\mathrm{XVI}^{\mathrm{e}} \mathrm{s}$. et le début du XVIII ${ }^{\mathrm{e}} \mathrm{s}$. Leur intérêt réside donc plus particulièrement dans les descriptions qu'ils nous livrent sur l'organisation des habitats comme sur le mode de construction.

Dans tous les cas, la connaissance du positionnement exact des édifices est une dialectique délicate entre textes d'archives et archéologie. Les textes mentionnent des édifices qui sont bien évidemment connus des personnes pour qui sont écrits les actes; il n'est donc pas utile d'en préciser l'emplacement. Les fouilles archéologiques restituent des vestiges de constructions, dont on possède rarement le plan complet et dont l'interprétation même reste délicate. L'archéologue-historien doit donc confronter ces deux sources incomplètes pour essayer d'en tirer des certitudes. C'est là une œuvre de longue haleine, dont on commence à peine à bâtir les fondations.

La réunion de divers actes de vente, de location, de donation a permis de dresser outre un état de la qualité des propriétaires, l'évolution générale de la topographie du quartier et souvent une description succincte des lieux. Pour l'Époque moderne, la durée importante de ces études a permis de solliciter d'autres sources, plus rares, en relation avec le bâti : prix-faits et rapports d'expertise, actes notariés dressés à la suite d'une vente. Ces documents, très importants pour l'histoire du bâti des zones fouillées, ont fourni des éléments essentiels : la date de certaines structures découvertes en fouille, un état très détaillé de l'intérieur des habitations (indiquant à chaque fois les dimensions des pièces), l'organisation des façades, des indications sur le profil des baies, le vocabulaire des charpentes et des renseignements sur la confection des sols et des sous-sols.

Outre la restitution de structures dont il ne reste que la substruction, les rapports ont également offert la

20 Ont été consultés les fonds des Archives Départementales et des Archives Communales, ainsi que ceux de la Chambre de Commerce. 


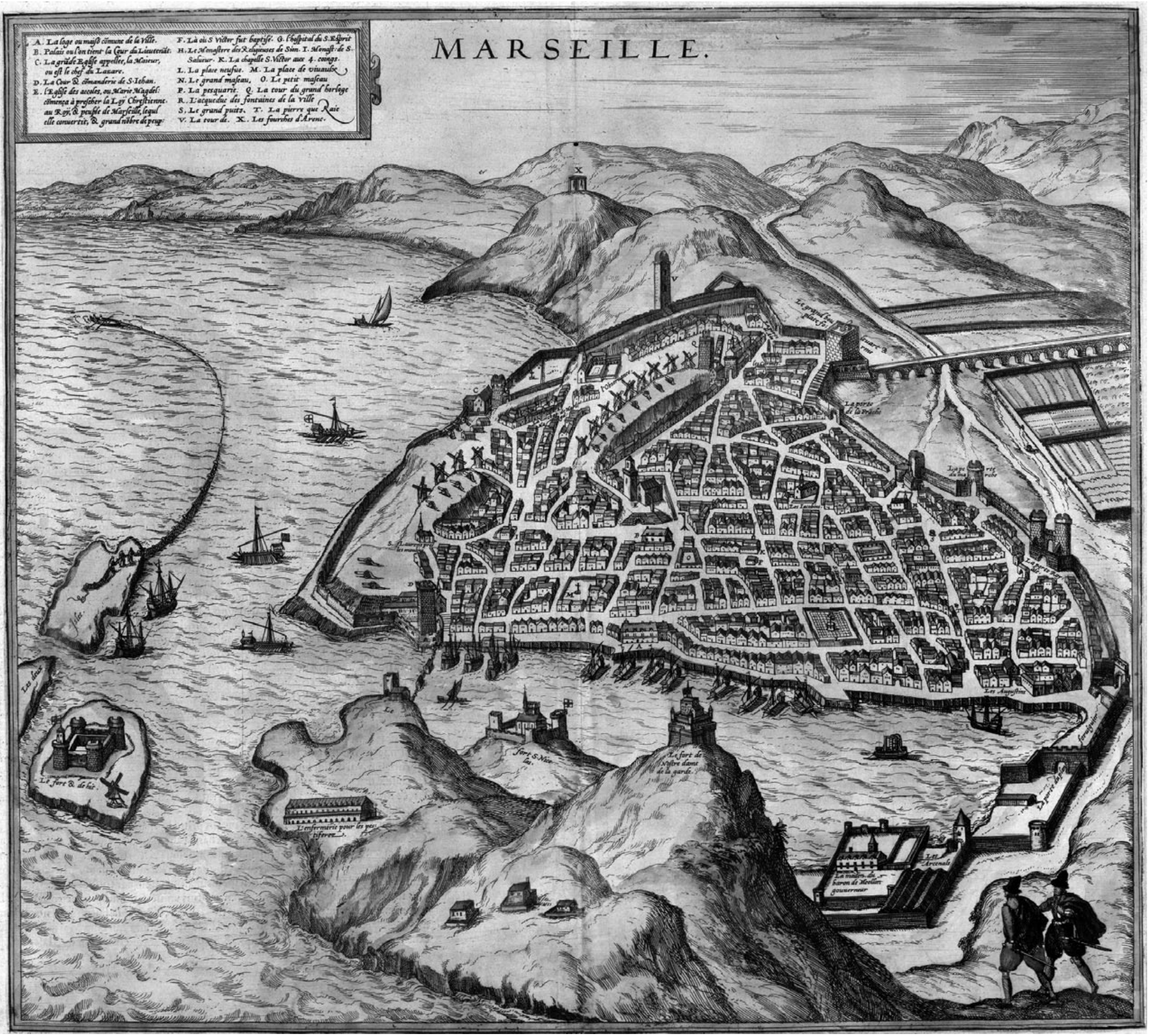

Fig. 9. Vue cavalière de Marseille à la fin du XVle $\mathrm{S}$. (plan Florini, cl. ACM).

possibilité de dresser l'état d'un bâti antérieur dont l'origine peut remonter au Moyen Âge. Les prix-faits nous ont amenés à une restitution des éléments disparus et nous ont renseignés sur des édifices en voie de construction en nous permettant d'identifier certains matériaux ou certaines structures.

Les textes permettent parfois de faire coïncider les limites des pièces mentionnées avec celles qui ont été repérées en fouille. D'autre fois, ils nous donnent une image de l'organisation interne de la parcelle avant que des travaux de plus grande envergure n'en éliminent les traces. Les rapporteurs trouvent généralement des maisons très dégradées et nous pouvons aisément supposer que leur construction est antérieure de plusieurs dizaines d'années à la date de l'expertise; il est cependant clair que les commis étant payés par l'acheteur, ils ont certainement tendance à exagérer la vétusté. Les devis, en revanche, sont établis au moment de la construction et permettent de dater précisément les structures reconnues. Ils laissent cependant planer le doute sur la réalité des travaux qui ont suivi. Par exemple, l'expérience nous a montré que quelquefois l'entrepreneur a conservé les fondations anciennes alors qu'il s'était engagé, d'après le devis, à les refaire entièrement. C'est la collecte d'un nombre important de ces 
documents, recueillis grâce au temps consacré à ces études, qui a permis la confrontation entre les sources écrites et les données issues des fouilles.

Par ailleurs, les représentations figurées de la ville forment un complément d'information non négligeable pour les périodes qui nous concernent, mais plus particulièrement pour la période moderne (fig. 9). Le plan de Pietro Angelo Pelloia, premier plan connu de Marseille récemment découvert et daté vers 1555 (Bouiron, de Candido 2009), le dessin d'Ercole Negro (1590), le tableau du Prêche de la Madeleine (du début du XVI ${ }^{\mathrm{e}} \mathrm{s}$.), le plan Demarest, le cadastre napoléonien, etc... sont autant d'éléments de comparaison avec les vestiges médiévaux ou moderne retrouvés dans le sol. Les informations concernent essentiellement la topographie, la trame urbaine, les fortifications, les édifices importants (religieux ou civils), mais certaines représentations fournissent des détails sur l'habitat, même s'ils sont à considérer avec prudence. En effet, il est possible qu'il s'agisse de représentations archétypales et non de la réalité, mais ils sont à prendre en compte.

\section{Le plan de la publication}

Nous avons volontairement choisi pour notre publication de consacrer une première partie de l'ouvrage aux études thématiques sur la topographie et la morphologie de la ville. Elles permettent d'analyser les éventuelles constantes et différences entre les quartiers et de faire des comparaisons avec d'autres villes de la région. Une seconde partie vise à présenter plus précisément les trois chantiers archéologiques qui forment le socle de cette étude. La description des vestiges suit l'ordre chronologique.

Ce plan de publication a été adopté afin de permettre un accès direct aux aspects historiques et synthétiques, et que chaque personne souhaitant plus de précisions puisse trouver les éléments objectifs sur lesquels se basent les études dans les descriptions archéologiques.

La première partie s'articule suivant un axe allant du collectif au particulier. Un premier chapitre est consacré aux éléments structurants de la topographie urbaine, divisions administratives de la ville, fortifications, édifices principaux et enfin aménagements portuaires. Le travail s'appuie à la fois sur les découvertes archéologiques et sur les textes d'archives. Le second chapitre vise à observer de plus près la trame urbaine à travers les données recueillies concernant le réseau viaire, le découpage parcellaire et le réseau hydraulique. Ensuite, l'étude s'emploie à détailler les techniques de construction et leur évolution au cours des années ; de la carrière à la mise en œuvre des matériaux, ce chapitre est une première approche synthétique sur le sujet. L'analyse de l'organisation de l'habitat à travers les fouilles archéologiques et les textes d'archives forme le quatrième chapitre. L'angle de lecture adopté s'efforce de rendre compte à la fois des aspects purement architecturaux ou techniques et des désirs humains liés au confort et à l'esthétique moins faciles à mettre en évidence. Enfin, une étude des vestiges de traces artisanales et industrielles permet d'aborder le monde du travail.

La seconde partie restitue les données archéologiques des trois chantiers (Tunnel de la Major, Espace Bargemon et Alcazar) suivant une description chronologique qui reprend le plan visant à aller du collectif vers le particulier.

Enfin une conclusion permet une autre lecture chronologique, plus synthétique, à travers laquelle se dessine l'évolution du visage de la ville au fil des siècles entre les VIII et XIX ${ }^{\mathrm{e}}$ s. Elle s'interroge sur l'apport de l'archéologie à l'écriture de l'histoire de la ville et enfin pose la question des perspectives envisageables pour de futurs travaux archéologiques. 


\section{Première Partie}

\section{ÉTUDE TOPOGRAPHIQUE ET MORPHOLOGIQUE D'UNE VILLE MULTIPOLAIRE}

La première partie de notre étude constitue le prolongement des monographies de sites qui sont données dans la seconde partie.

Seront abordées ici l'évolution générale de la Ville depuis le haut Moyen Âge, en faisant un focus particulier sur la morphologie urbaine, puis les aspects bâtis que documentent plus facilement l'archéologie.

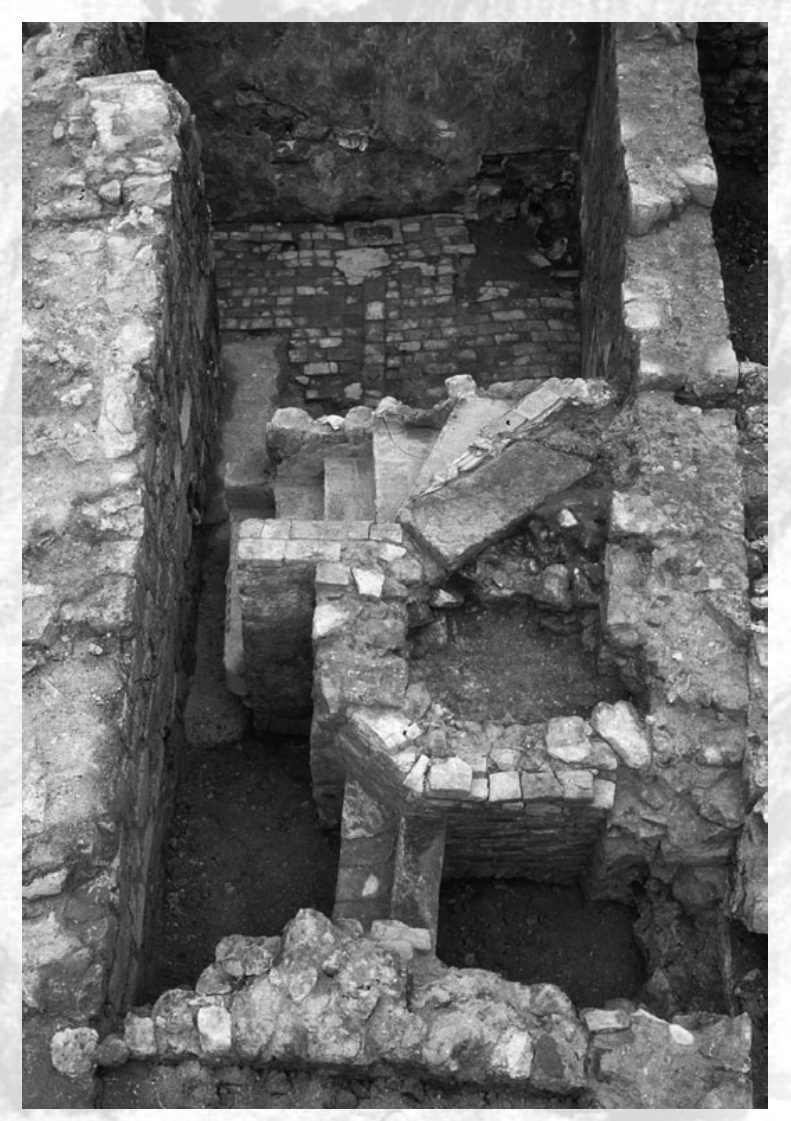




\section{Chapitre 1}

\section{Évolution historique et topographique}

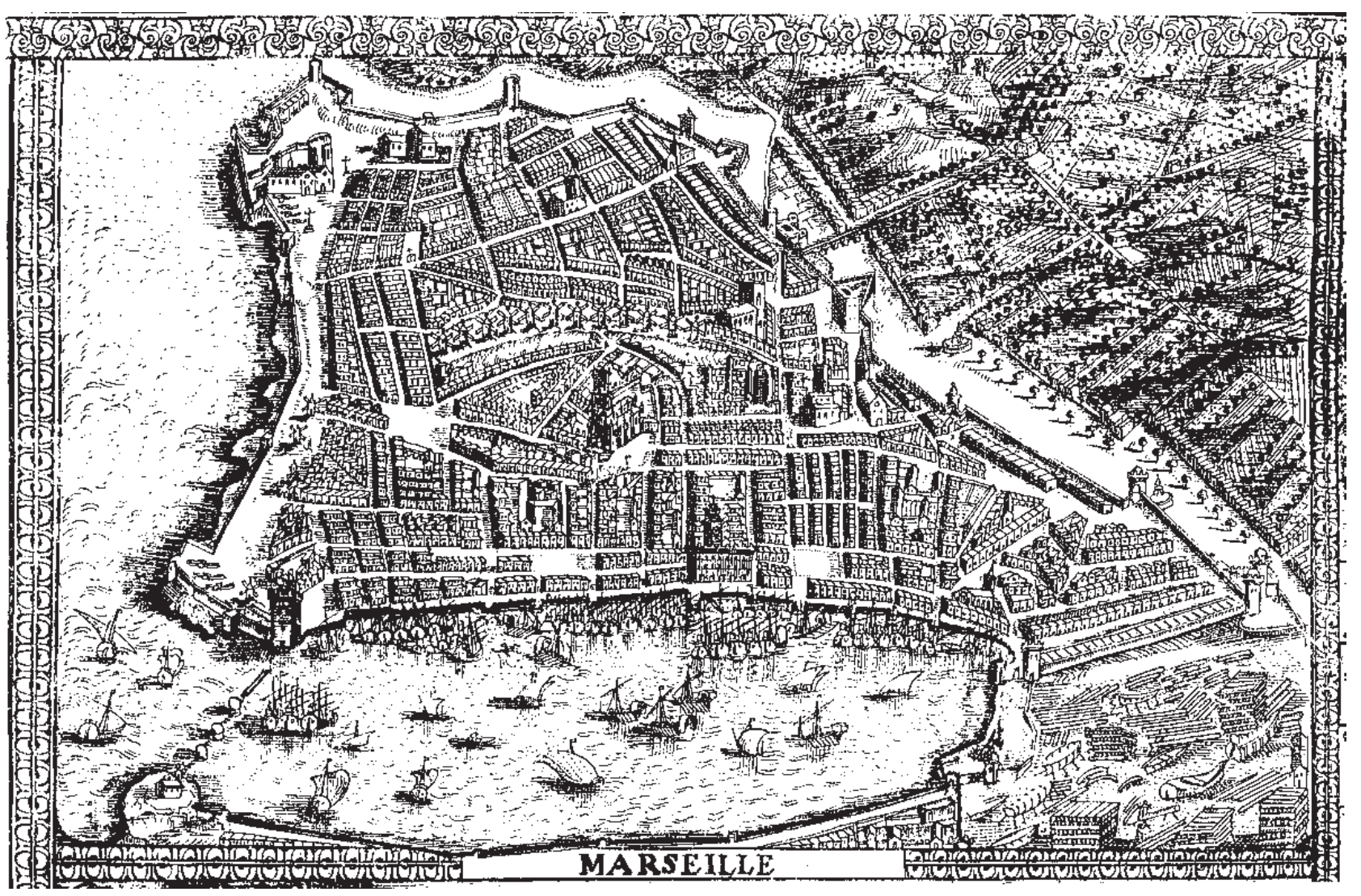

Fig. 10. Vue perspective de Marseille par Maretz (1630) (Palais du Roure/Fonds Benoit, d'après l'original conservé à la BNF).

$\mathrm{S}$ i le cadre topographique de la ville moderne n'a jamais posé de problème aux historiens, grâce aux nombreux plans et vues en perspectives des XVI'-XVIII' s. (fig. 10), il n'en a pas été de même de la ville du Moyen Âge. Plusieurs difficultés ont longtemps brouillé la compréhension de la topographie médiévale. En premier lieu les travaux d'urbanisme du $\mathrm{XIX}^{\mathrm{e}}$ s. et la destruction d'une partie de la vieille ville en 1943 nous ont privé d'une compréhension directe du tissus urbain (sans compter la large destruction des données archéologiques). Ensuite, la compréhension de la ville du début du Moyen Âge est bien évidemment étroitement liée à celle de la ville antique; or, pendant longtemps, on a hésité sur la position du rempart à l'est de la cité. Ce n'est qu'à la suite de la découverte du rempart hellénistique, sur le site de la Bourse, en 1967, que la question a été définitivement tranchée. Enfin, dernier écueil lié au précédent, l'interprétation des textes anciens a été biaisée par des lectures erronées. Les affirmations péremptoires, polémiques et souvent vindicatives d'Eugène Duprat n'ont pas aidé.

La compréhension actuelle, enfin cohérente (mais l'avenir nous le dira), de la topographie médiévale doit beaucoup aux travaux archéologiques. Pour une vision chronologique de cette évolution, nous renvoyons à la première partie de l'ouvrage coordonné par T. Pécout (Bouiron 2009b et c). La répartition des pouvoirs est détaillée ci-dessous entre autres par T. Pécout, tandis que R. Bertrand retrace l'évolution de Marseille moderne. 


\section{Les éléments structurants de la topographie (M. Bouiron)}

Nous n'aborderons ici que le cadre dans lequel s'inscrit la ville médiévale et moderne : la topographie «naturelle», les limites de la cité et les éléments fondateurs de la trame.

\subsection{La topographie naturelle}

L'extension des ports et la création de la rue de la République ont bouleversé une topographie «naturelle » de la ville que l'on perçoit maintenant difficilement. Le site urbain, on le sait (Bouiron, Gantès 2001) est constitué de trois grandes buttes successives. Avant les grandes transformations de Marseille, la butte Saint-Laurent culminait à $26 \mathrm{~m}$, la butte des Moulins ${ }^{21}$ à $42 \mathrm{~m}$ et celle des Carmes à 40 m NGF. L'actuelle plateforme du Fort Saint-Jean est totalement artificielle; seule existait une petite éminence, dans le prolongement de la butte SaintLaurent, dont le substratum atteignait 18 m NGF. Entre les buttes se trouvent des cols, d'où naissent des talwegs façonnés par les écoulements d'eau.

La topographie du sol était bien perceptible au Moyen Âge, en particulier avant que l'habitat ne recouvre la quasi totalité de l'espace urbain. La butte Saint-Laurent s'appelle le mons Babonis ${ }^{22}$, du nom de l'évêque marseillais (du VII ${ }^{e}$ s. ?) ${ }^{23}$. La butte des Moulins s'appelle Colla ${ }^{24}$, c'est-à-dire «la Colline ». Enfin la butte des Carmes est la Roquabarbara ${ }^{25}$, dont le nom subsiste encore à l'époque moderne sous le nom de Roquebarbe. Aux alentours des $\mathrm{XI}^{\mathrm{e}}$-XII ${ }^{\mathrm{e}}$ s., les hauteurs sont porteuses d'un symbole de pouvoir; on trouve ainsi l'évêque sur la butte des Carmes et les vicomtes, de façon éphémère sur la butte Saint-Laurent dans le château Babon.

L'importance dans cette topographie reste le lien avec la mer. Sur la face occidentale, la côte est plutôt escarpée, la mer ayant probablement au fil des siècles entamé le substrat «rocheux» (ou plus exactement marneux) (fig. 11). La zone de développement le plus important se concentre sur la rive nord du port, c'est-àdire sur le versant méridional des buttes. La pente douce

21 La butte des Moulins est doublée par une hauteur très proche, la butte de la Roquette à 38 m NGF.

22 GCNN Marseille $\mathrm{n}^{\circ} 1104$ (23 janvier et $1^{\text {er }}$ février 1179).

23 Sur cet évêque et le «château Babon » voir Bouiron 2009b, p. 25-26 et 28 .

24 GCNN Marseille $\mathrm{n}^{\circ} 221$ (23 janvier 1220).

25 AD13 $61 \mathrm{H} 1$ pièce 2bis (13 mars 1163) transcrit dans Bouiron 2001c, p. 79 n. 9, GCNN Marseille $\mathrm{n}^{\circ} 164$ (17 avril 1164), $\mathrm{n}^{\circ} 221$ (23 janvier 1220). jusqu'au rivage permet l'établissement d'un port qui n'a quasiment pas changé de place depuis l'Antiquité. Seule compte alors la capacité utile qui implique d'utiliser tout ou partie de la rive nord, voire de doubler le mouillage avec la rive sud, ce qui n'interviendra pas avant la fin de la période que nous étudions.

\subsection{L'enceinte}

La compréhension des limites de la ville a beaucoup progressé ces dernières années, en particulier dans les siècles de transition entre la fin de l'Antiquité et le Moyen Âge. La ville du haut Moyen Âge est bipolaire, à l'intérieur de l'emprise héritée de la fortification hellénistique. A l'ouest, une fortification entoure un espace assez large autour de la cathédrale, la butte Saint-Laurent et la partie nord de l'actuel fort Saint-Jean. L'enceinte porte au XII ${ }^{e}$ s. le nom de castrum Babonis sur la butte Saint-Laurent, et nous avons proposé d'y voir une matérialisation de la délimitation de l'episcopatus avec le comitatus à la fin du $\mathrm{VII}^{\mathrm{e}}$ s. (Bouiron 2009b, p. 28). Nous reviendrons sur ces questions dans le volume sur l'Antiquité tardive.

Nous plaçons sur la butte des Carmes une seconde fortification, plus tardive, qui appartient au pouvoir civil. La délimitation de cette enceinte ${ }^{26}$ repose encore une fois sur des textes du XII ${ }^{\mathrm{e}} \mathrm{s}$. (en particulier la délimitation de la paroisse des Accoules en 1163). Elle fait le pendant de la partie épiscopale et remploie très largement à l'est l'enceinte antique, dont on garde intactes les portes d'accès : porte d'Italie (porta romana), porte Saint-Martin et porte d'Aix.

Nous positionnons également sur la butte des Carmes le siège du pouvoir civil (palais «comtal»), peut-être dès la seconde moitié du IX ${ }^{\mathrm{e}} \mathrm{s}$. Ainsi pourrait s'expliquer la dénomination de Rocabarbara : roque (éminence fortifiée) des «Barbares », ces Bourguignons qui tiennent le pouvoir comtal et dont J.-P. Poly a bien montré combien ils étaient haïs en Provence (Poly 1976, p. 14-15). La butte a probablement été fortifiée de façon autonome ; au début du XII ${ }^{\mathrm{e}}$ s., elle est encore pourvue d'un «vallum», correspondant peut-être à une fortification de terre ${ }^{27}$. À la même époque, la nouvelle délimitation de la ville supérieure, après la fin de l'indivision entre

26 Voir pour le détail Bouiron 2009b, p. 40 et le plan p. 41. Nous incluons de manière définitive la butte des Carmes dans cette enceinte, il ne faut donc pas tenir compte du plan Bouiron 2001c, p. 79.

27 Voir Bouiron 2001c, p. 82, au plaid de la Lèque tenu entre 1122 et 1132 (d'après GCNN Marseille n ${ }^{\circ}$ 163, 21 janvier 1164). 


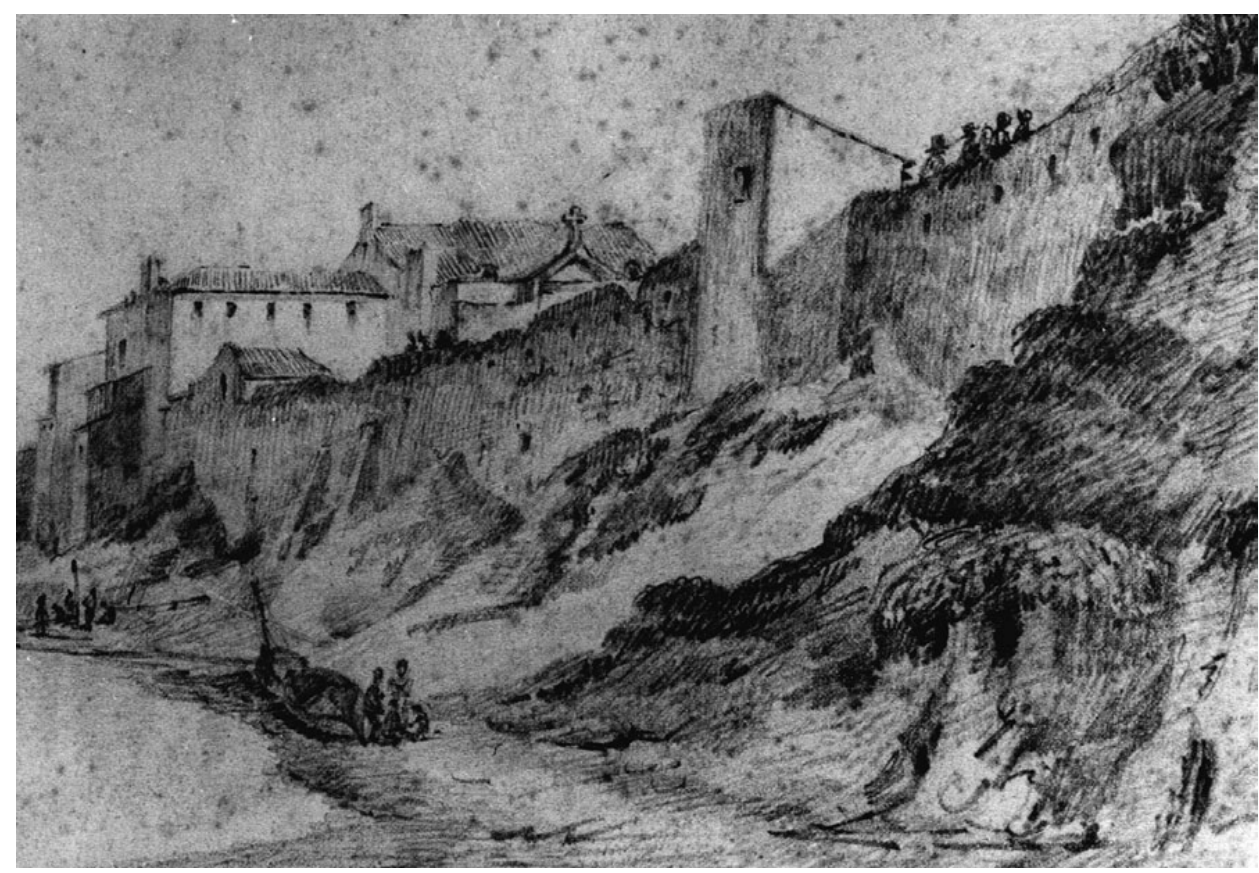

Fig. 11. Détail de l'enceinte du côté de la Tourette du côté de La Major (XVII s. ?) (cl. MHM).

vicomtes et évêques, prend alors comme repère la partie sud de la fortification de la butte des Carmes ${ }^{28}$.

Nous ne nous étendrons pas sur l'évolution de l'enceinte médiévale, maintenant bien connue. Vers 1040, la première extension de l'enceinte se place dans le cadre d'une réunification de la ville, alors que vicomtes et évêques appartiennent à la même famille. La nouvelle enceinte matérialise probablement une croissance importante de l'habitat autour de l'entrée sud-est de la ville $^{29}$. La fouille de la surverse de la rue République a recoupé le tracé probable de cette enceinte. B. Sillano propose d'attribuer à la fondation de cette fortification une série de pieux, observés très rapidement dans des conditions de chantier très difficiles; aucune maçonnerie n'a pu être réellement observée mais on imagine qu'une récupération a dû intervenir postérieurement.

Cette zone connaît une expansion quasiment sans interruption jusqu'au milieu du XIVe $\mathrm{s}$. Une extension postérieure de l'enceinte intervient encore à la fin $\mathrm{du} \mathrm{XII}^{\mathrm{e}} \mathrm{s}$. avec un doublement de la fortification vers le milieu du siècle suivant ${ }^{30}$. Nous avons proposé de

28 Il est intéressant de noter la différence de délimitation entre celle qui intervient à la fin du VII ${ }^{\mathrm{e}} \mathrm{s}$, qui laisse à l'évêque toute la partie nord-ouest de la ville, et celle de la fin du $\mathrm{XI}^{\mathrm{e}}$ s. qui se fait plutôt suivant un partage nord-sud, en suivant à peu près l'alignement des buttes.

29 Sur cette extension, voir Bouiron 2001c, p. 81 et Bouiron 2009c, p. $46-47$.

30 Détail des enceintes dans Bouiron 2001c, p. 83-87; $c f$. également Bouiron 2009c, p. 49-50. dater la fortification des alentours de $1190^{31}$; il n'est pas impossible qu'elle soit légèrement antérieure mais ne devrait pas remonter au-delà de 1180 . La création de faubourgs de plus en plus densément peuplés témoigne bien de l'attractivité de la zone de plaine située à l'est de la cité.

A l'exception de modifications de détail de la fortification (en particulier les transformations des tours en fonction de l'évolution de l'artillerie et la mise en place de bastions au XVI ${ }^{\mathrm{e}} \mathrm{s}$., dont l'étude détaillée reste à faire) (fig. 12), le tracé ne changera pas jusqu'à l'Agrandissement de Louis XIV. C'est à cette époque que sera finalement mis en œuvre un projet qui accompagnait la nouvelle donne démographique de la seconde moitié du XVII ${ }^{e}$ s. (fig. 13). L'histoire de la fortification moderne reste à entreprendre : le renforcement des bastions, scandés par les sièges de 1524,1536 et 1590 est à mettre en correspondance avec les textes d'archives et les magnifiques représentations de la ville par les ingénieurs piémontais.

\subsection{Les éléments fondateurs de la trame}

La trame urbaine médiévale dépend largement de celle de l'Antiquité. Nous l'avons montré (Bouiron 2001d, p. 156), la continuité est la règle. Dans les zones

31 Pour le détail politique et foncier entourant cette extension, voir Bouiron 2002. 


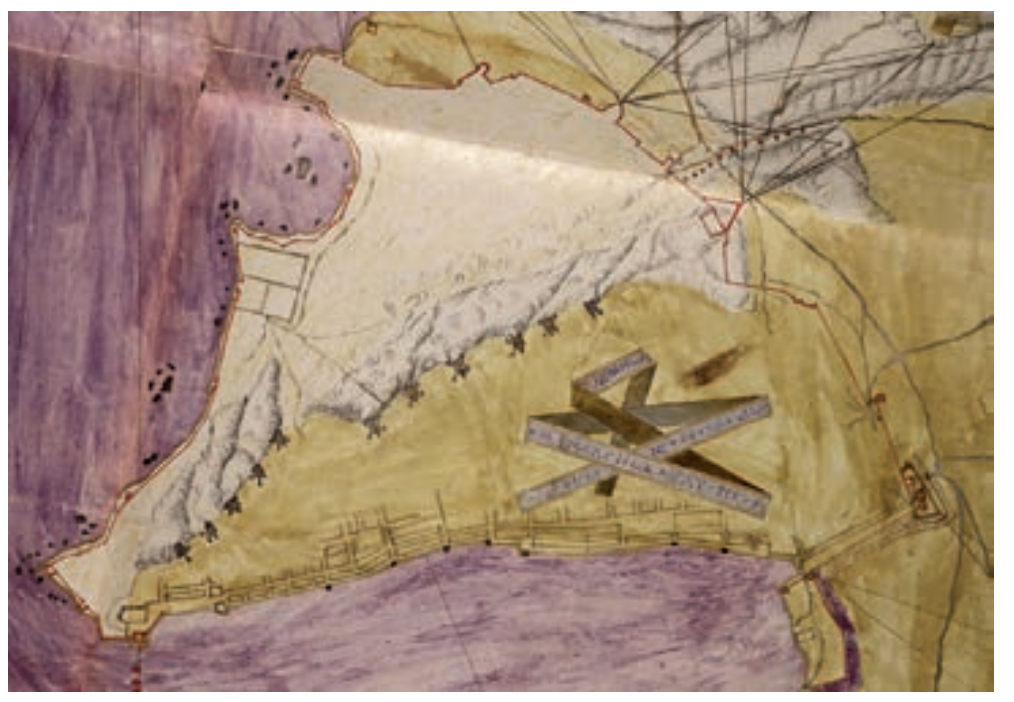

Fig. 12. Détail du plan de Marseille par Pelloia (v. 1550) (cl. AsTo).

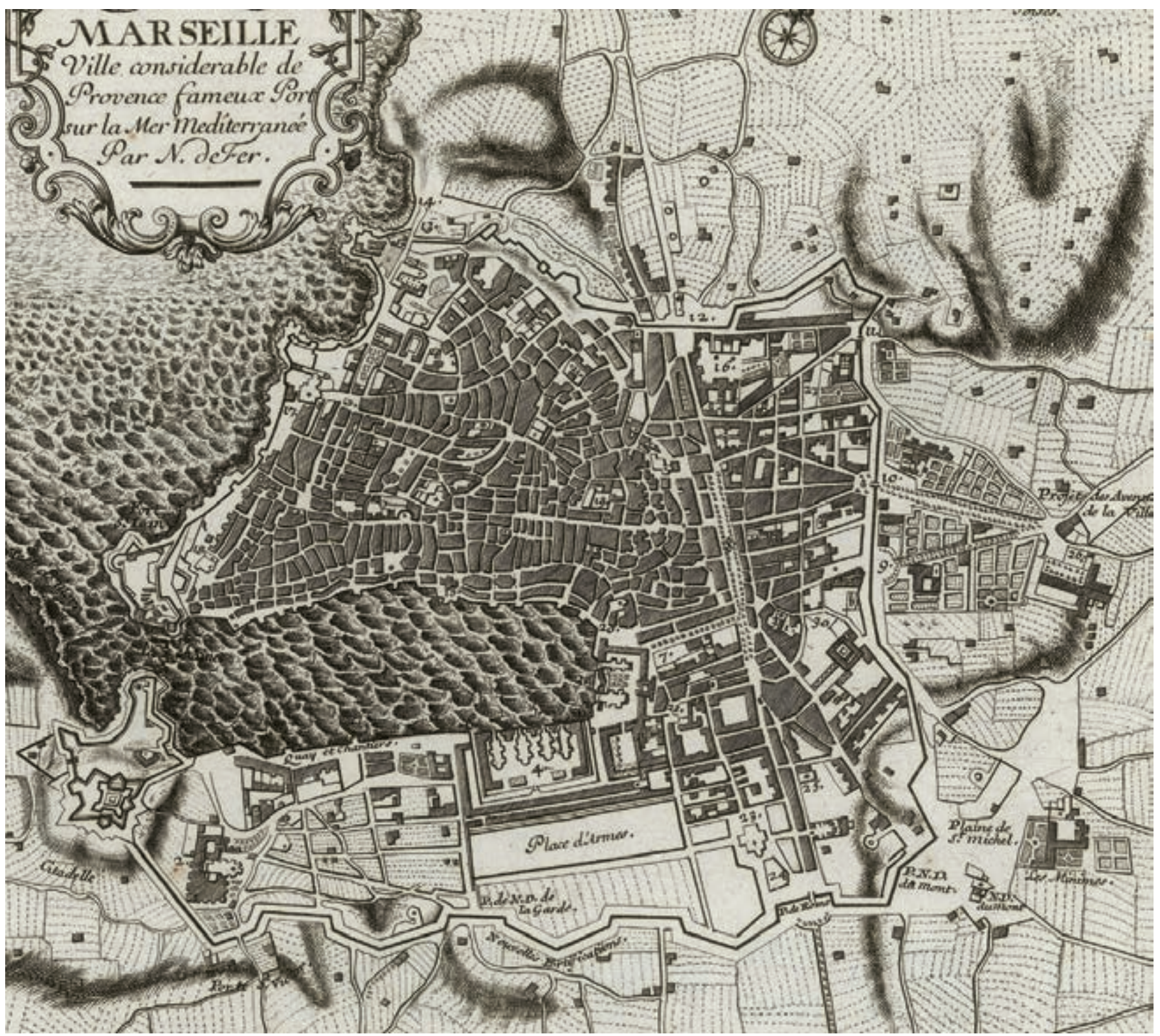


où l'habitat n'a pas disparu trop longtemps, les constructions reprennent les axes antiques. Les voies principales sont également relativement proches des anciens tracés, les portes de ville (y compris dans les enceintes réduites du haut Moyen Âge) ayant maintenu les circulations principales.

Des nouveautés sont apparues par rapport à la période romaine. Tout d'abord il faut noter les transformations que connaît la ville durant l'Antiquité tardive : en particulier la position excentrée de la cathédrale a modifié progressivement le réseau viaire. Dès cette époque, le bord de mer connaît des transformations, aperçues ponctuellement sur la fouille de la place Jules-Verne. Le démantèlement des grands édifices de l'Antiquité entraine également des ouvertures de rues; on notera toutefois que le forum ne semble pas avoir totalement disparu durant ces derniers siècles, si l'on en juge par la préservation des caves Saint-Sauveur, dans lesquelles nous avons proposé de voir le cellarium fisci de l'Antiquité tardive (Bouiron 2009b, p. 27).

Malgré la continuité, la construction des enceintes réduites à partir de la fin du $\mathrm{VII}^{\mathrm{e}} \mathrm{s}$. a entraîné des déformations importantes. Ainsi plusieurs tracés de rues semblent liés à la présence soit de l'enceinte soit de portes (rues du Poirier, de l'Éperon, des Solleillets, des Gavottes ...). Sur la butte des Moulins, la topographie d'origine est suivie par la courtine, ce qui tend à déformer le plan orthonormé antique. Pour autant, ces modifications restent relativement limitées à l'échelle de la ville.

Enfin, il faut noter l'extension sur le plan d'eau par rapport à la ligne de rivage antique. Ainsi le quartier du port a gagné une à deux files d'îlots, probablement au cours du XII ${ }^{\mathrm{e}} \mathrm{s}$.

\section{Pouvoirs et villes multiples au Moyen Âge}

On le sait, la ville médiévale est aux mains de pouvoirs multiples: pouvoir civil, pouvoir religieux se décomposent et se recomposent jusqu'au moment où les Angevins parviennent à tenir l'ensemble des droits seigneuriaux.

\subsection{Comtes, vicomtes et pouvoir communal (M. Bouiron)}

$\mathrm{Au}$ milieu du $\mathrm{X}^{\mathrm{e}}$ s., une nouvelle dynastie comtale dirige la Provence. Le premier d'entre eux, Boson, fait très certainement partie de la famille d'origine lotharingienne d'Hugues, roi d'Italie de 926 à 945, de Rodolphe et Hugues le Noir, ducs de Bourgogne, et de l'éphémère roi de Provence Boson. Si la filiation est encore hypothétique ${ }^{32}$, elle renvoie sans équivoque à cette grande famille, ces Bourguignons qui ont géré la Provence à leur profit. Dans le sillage de cette famille apparaît, quasiment au même moment, Arlulf, issu de l'entourage viennois des comtes. Boson est mentionné comme comte dès 946, Honorat, le fils d'Arlulf, est évêque de Marseille depuis au moins 948. Il est difficile de ne pas voir dans ces deux dates une réelle concomitance de la désignation de l'évêque de Marseille par le nouveau comte de Provence. Entre 972 et 977, le frère de l'évêque Honorat, Guillaume, reçoit le titre de vicomte de Marseille, qui devient avec lui héréditaire ${ }^{33}$.

Dans la situation de la ville du $\mathrm{X}^{\mathrm{e}}$ s., le comte doit disposer à Marseille de sa propre résidence. Les deux enceintes réduites, l'une à l'ouest pour l'évêque et la seconde à l'est pour le comte, délimitent les zones d'habitation. En 904, la donation d'un fisc par le comte Thibert à Saint-Victor, à l'origine de la possession de la rive sud par cette abbaye, se détermine par rapport à la porte du castrum. La connaissance de cette entité comtale repose sur très peu d'indices, le plus parlant étant la présence de « vieux murs » en 1163 qui servent de limite à la paroisse des Accoules ${ }^{34}$. Cette «ville comtale », allongée jusqu'au port au sud, est dominée par la butte des Carmes. Le tout peut donc être assimilé à un castrum, site de hauteur fortifié ; la conjonction entre la topographie et le terme de Roca Barbara, si l'on admet l'assimilation aux Bourguignons, permet de proposer une résidence des comtes « bourguignons » sur la butte des Carmes. Notons également qu'aux siècles suivants du Moyen Âge, la partie du port où se trouvent les navires les plus importants (militaires en particulier) correspond à la zone portuaire de l'ancienne ville comtale. La position de celle-ci permet également de contrôler les entrées des marchandises par la porte d'Italie ou la porte d'Aix, et de percevoir les péages correspondant (c'est le Tholonée du Moyen Âge tardif).

La possession, par une même famille, du pouvoir épiscopal et vicomtal permet d'estomper la délimitation héritée de l'Antiquité tardive. Ainsi s'explique la fondation du couvent Sainte-Marie ${ }^{35}$ en 1030, dans l'espace (neutre ou partagé ?) entre les deux enceintes réduites. Il s'agit de reconquérir cet espace devenu inoccupé. Un texte de 1073 signale que l'église Sainte-Marie

32 Voir les arbres généalogiques publiés dans Bouiron 2009b, p. 36 et 38 .

33 Sur les vicomtes de Marseille, la dernière mise est point est de Florian Mazel (2009, p. 145-166).

34 Sur tout ceci, voir Bouiron 2001c, p. 78-80 et Bouiron 2009b, p. $40-41$.

35 Le couvent Sainte-Marie, ancêtre de celui de Saint-Sauveur, a fait l'objet d'une nouvelle étude sur la base des quelques textes conservés (Bouiron à paraître). 
de las Acoas, donnée aux moniales, était auparavant une paroisse. S'agit-il d'une réminiscence d'une tentative de repeuplement au début du $\mathrm{XI}^{\mathrm{e}} \mathrm{s}$. ? On notera ici que celui-ci concerne seulement la partie sud de l'espace entre les villes, la plus proche du plan d'eau. Il faudra attendre plusieurs siècles pour que la partie au nord soit à nouveau pleinement urbanisée.

Le redécoupage de la cité entre l'évêque et les vicomtes intervient probablement de façon floue dans un premier temps comme le propose Florian Mazel (2009, p. 146). Contrairement à ce que nous pensions jusque là, il semble peu probable que nous soyons en présence d'un partage volontaire entre Pons II, dernier évêque de la famille des vicomtes, et ses frères Guillaume III et Geoffroi $\mathrm{I}^{\mathrm{er}}$. Les tentatives régulières de la famille vicomtale pour tenter de récupérer l'évêché dans la première moitié du XII ${ }^{\mathrm{e}}$ s., par le biais du prévôt Aicard, se solderont systématiquement par des échecs. La ville épiscopale acquiert une réelle existence dans les textes à partir de 1151 et est confirmée par l'empereur Frédéric $\mathrm{I}^{\mathrm{er}}$ en 1164. Le découpage qui affecte alors Marseille se fait selon une ligne globalement nord-est/sud-ouest : toute la partie sud-est relève dès lors des vicomtes, la partie nord-ouest de l'évêque. Ce partage se fait en fonction d'éléments topographiques ou de bâtiments existant à cette époque. A l'est, l'évêque prend le sommet de la butte des Carmes, en suivant la probable fortification de la partie supérieure (protégeant l'ancien palais comtal ?). La délimitation se fait ensuite en suivant à peu près la ligne de crêtes des buttes de la Roquette et des Moulins. En poursuivant vers l'ouest, sur la pente de la butte des Moulins, la ligne de partage rejoint la vieille enceinte du mons Babonis. Il s'agit donc de l'adjonction de tronçons ayant une réalité physique dans l'esprit de ceux qui partagent le territoire. Ceci explique que trois générations plus tard, l'espace s'étant transformé, la description de la limite entre les villes établies en 1220 soit beaucoup plus complexe à comprendre ${ }^{36}$.

La ville basse n'évolue que lentement à partir de ce moment-là. La multiplication des branches de la famille vicomtale, alliée aux difficultés des comtes de Provence d'origine catalane pour maintenir leur pouvoir, permet l'émergence du pouvoir communal. Au début du XIII ${ }^{\mathrm{e}}$ s., les rachats successifs des droits seigneuriaux et les conflits avec l'abbaye Saint-Victor qui cherche à tenir la ville basse, amènent la commune à une certaine liberté. C'est l'époque des podestats, le temps où l'on construit le palais communal, où la commune se donne au comte de Toulouse pour échapper au comte de Provence. Liberté de quelques décennies, difficile à

36 Cette délimitation a été étudiée de façon spécifique (Bouiron 2001c, p. 77-78). maintenir, qui ne résistera pas à la poigne du premier comte angevin, Charles $\mathrm{I}^{\mathrm{er}}$.

Dans les documents conservés du règne de ce prince, il est particulièrement important de constater la transmission des propriétés de la commune au comte ${ }^{37}$, la commune n'étant elle-même que l'héritière des droits (et possessions ?) vicomtaux.

\subsection{Les évêques de Marseille, de la seigneurie urbaine au service du prince, $\mathrm{XI}^{\mathrm{e}}-\mathrm{XIV}^{\mathrm{e}} \mathrm{s}$. (T. Pécout)}

Parmi les prélats des trois provinces ecclésiastiques d'Aix, Arles et Embrun, les évêques de Marseille se caractérisent par une puissance temporelle considérable, comparable à celle des archevêque d'Arles ou d'Aix. Pourtant, le diocèse de Marseille ne se distingue pas par son étendue ni par la densité de son peuplement. C'est avant tout à son implantation urbaine, dans une cité au notable dynamisme commercial et qui constitue la plus grande unité de Provence hormis l'Avignon pontificale du XIVe s., que l'évêque de Marseille doit son rang. Mais cette position attire aussi de nombreuses convoitises. Peu avant l'an mil, le temporel de l'évêché et celui de l'abbaye Saint-Victor restent encore largement imbriqués, sous le contrôle étroit de la famille des vicomtes de Marseille dont ils constituent l'élément principal de l'assise politique, juridictionnelle et domaniale. Dès lors que le siège épiscopal commence à s'affirmer comme puissance autonome, l'enjeu réside pour l'évêque dans sa capacité à rassembler sous son contrôle les droits susceptibles de maintenir ce rang, et d'éviter l'émergence de pouvoirs concurrents. Sur ce double plan, les prélats rencontrent des obstacles qu'ils ne parviennent pas à surmonter, et l'émergence du chapitre cathédral comme puissance seigneuriale ajoute encore à ses difficultés. De la détention par ses acteurs concurrents de nombreux droits supposant l'exercice d'une juridiction ou le contrôle d'un ressort, résulte une territorialisation progressive des dominations, et, au sein de la cité, une partition spatiale des pouvoirs seigneuriaux.

La première moitié du XII ${ }^{\mathrm{e}} \mathrm{s}$. est une période d'affirmation du pouvoir temporel des évêques de Marseille. Cette tendance est suscitée par un processus d'émancipation et de fragmentation des pouvoirs. Tandis qu'à la faveur de la réforme dite grégorienne, et de ses conséquences sur le rôle dévolu aux moines dans la société

37 Le travail d'édition en cours par Marc Bouiron et Juliette Sibon du recensement de 1265 et de l'enquête de 1298 permettra de retracer beaucoup plus précisément la localisation et les évolutions de la propriété des comtes angevins. 
chrétienne, l'abbaye de Saint-Victor échappe définitivement à leur sphère d'influence directe à la fin du XI ${ }^{\mathrm{e}} \mathrm{s}$, la famille vicomtale et sa parentèle perdent le contrôle du siège après l'épiscopat de Raymond de Solliès (1122$1151)^{38}$. Dans les années 1160 , cette évolution aboutit à la consolidation d'une seigneurie épiscopale dont le cœur est la ville haute de Marseille. Elle se maintient jusqu'à l'échange imposé par Charles d'Anjou en 1257.

Le pontificat de Pierre (1152-1170) est déterminant qui voit se structurer une seigneurie épiscopale. Depuis la ville haute, et malgré ses droits sur le port ancien, il tente de développer les échanges à partir du débarcadère de Porte Galle, dans l'anse de l'Ourse. Il contrôle aussi le monastère de moniales Saint-Sauveur. Mais l'émergence d'une seigneurie épiscopale passe par l'affrontement avec les vicomtes. Divers conflits montrent que ces derniers s'efforcent de préserver leurs prérogatives publiques et les droits qui y sont liés (albergue, questes, cavalcades, justices). Les évêques disposent en revanche du péage de Ners et Allauch, de celui de SaintJulien, ainsi que d'exemptions sur les bois proches de la ville et les taxes du port.

Ce pouvoir seigneurial grandissant s'exprime dans l'édification d'une nouvelle forteresse urbaine, aux limites de la ville, et sur les hauteurs la dominant, à Roquebarbe. Les vicomtes tentent de s'y opposer en 1151, en leur contestant le droit d'édifier des fortifications, mais le comte de Provence tranche peu après en faveur du prélat ${ }^{39}$. L'évêque Pierre prend bien soin de se faire confirmer explicitement ce droit régalien auprès de l'empereur en 1164, ce qui est également réaffirmé l'année suivante par son métropolitain, l'archevêque d'Arles. Dans les possessions les plus excentrées, le prélat mène une politique comparable de lutte et de soumission des nobles locaux. Ainsi, en 1157, les seigneurs de SaintCannat doivent accepter de lui prêter hommage ${ }^{40}$. Le pouvoir vicomtal se maintient toutefois dans les castra contrôlés par l'évêque, Aubagne, Gémenos, Cuges, Julhans, Roquefort, ou encore Saint-Marcel et Castellet. Mais ce dernier veille à s'y faire reconnaître seigneur majeur, avec l'exercice du dominium, ce qui lui permet d'imposer aux nobles serments puis hommage. Si une première forme d'allégeance des vicomtes est attestée dès $1128^{41}$, il faut attendre $1152^{42}$ pour rencontrer un

38 De rares travaux universitaires demeurés inédits (Jouve 2002, Jouvet 2006). Outre les publications de Marc Bouiron citées plus loin, c'est la publication de Florian Mazel (2002) qui propose la relecture la plus complète de la période.

39 Gérin-Ricard, Isnard 1926, ${ }^{\circ} 238$.

40 GCNN, Marseille, $\mathrm{n}^{\circ}$ 159, col. 77-78.

41 Gérin-Ricard, Isnard 1926, $n^{\circ} 224$. Pour la question de l'hommage, voir Giordanengo 1988 et Mazel 2002.

42 Gérin-Ricard, Isnard 1926, nº 241. véritable hommage, avec le vicomte Raymond Geoffroi. La cérémonie est ensuite bien attestée, avec Hugues Geoffroi en $1177^{43}$, pour la région d'Aubagne. Au XIII ${ }^{\mathrm{e}}$ s., la famille des Baux, successeurs des vicomtes, se prête aussi à ce cérémonial (Mazel 2002).

Dans leur effort de consolidation du temporel, les évêques se tournent vers les sources de toute légitimité. Ils sollicitent des confirmations des papes, mais aussi des empereurs et rois d'Arles. En cela, ils rejoignent les préoccupations des pontifes, désireux d'accroître leur emprise sur le clergé séculier, dans le sillage de la réforme dite grégorienne et du processus de centralisation qui s'ensuit, mais aussi celles des empereurs de la dynastie des Staufen, s'efforçant de restaurer leur autorité dans ce qui est devenu le royaume d'Arles. La confirmation impériale de 1164 entérine ainsi la lente gestation de la seigneurie épiscopale et donne à cette dernière la force du droit.

Déjà, en 1141, le pape Innocent II avait accordé une première bulle de confirmation qui inspire le contenu de celle d'Eugène III en $1148^{44}$. Celle d'Anastase IV, en $1153^{45}$, est en revanche plus précise dans le détail et la localisation des droits exercés. Le début des années 1160 correspond à une phase de stabilisation des juridictions spirituelles et temporelles dans la ville : tandis que les droits et limites des paroisses achèvent de se structurer, avec Saint-Cannat qui s'ajoute à Saint-Martin, SainteMarie des Accoules et Saint-Laurent, chapitre et évêque tentent de s'en partager les ressources et juridictions. Aussi, lorsque l'évêque Pierre, et peut-être aussi son chapitre, sollicitent en 1164 un diplôme de l'empereur Frédéric I Ir (1152-1190), qui s'efforce alors de reprendre le contrôle de son royaume d'Italie face aux communes urbaines, le prélat fournit à la chancellerie impériale une liste précise de ses biens et droits. Il s'efforce aussi par là de contrecarrer les résistances de la famille vicomtale qui, pour avoir longtemps partagé avec les évêques une histoire commune, dispose de droits enchevêtrés avec la seigneurie épiscopale, et qui supporte fort mal l'emprise qu'elle tente de leur imposer. Du reste, une procédure est alors en cours entre ces mêmes protagonistes, sous l'arbitrage de l'archevêque d'Arles et de l'évêque de Carpentras, depuis le début de cette année 1164 et jusqu'en octobre 1165 (Mazel 2009). La sollicitation d'une confirmation impériale s'y inscrit sans nul doute. L'évêque Pierre espère dès lors parachever la consolidation de ses droits temporels. D'ailleurs, l'archevêque d'Arles Raymond de Bollène (1163-1182) effectue la même requête auprès de l'empereur. Tous deux

43 Gérin-Ricard, Isnard 1926, nº 261.

44 GCNN, Marseille, $\mathrm{n}^{\circ}$ 146, col. 67-68, et $\mathrm{n}^{\circ}$ 147, col. 68-69.

45 AD13 6G 438, fol. 1v-2. 
obtiennent satisfaction par deux diplômes délivrés à Pavie les 16 et 17 avril 1164, et qui désormais vont figurer en bonne place parmi les titres et pièces probatoires de leurs archives et cartulaires respectifs ${ }^{46}$.

À la lecture du diplôme impérial de 1164, le pouvoir de l'évêque apparaît considérable. Ce dernier s'ancre en premier lieu dans la cité, soit à partir d'établissements ecclésiastiques, avec le monastère des bénédictines de Saint-Sauveur (en son premier emplacement, à proximité de l'église Sainte-Marie des Accoules), soit à l'appui de sa forteresse des hauteurs de Roquebarbe. Une délimitation précise et territorialisée de son ressort est donnée dans l'acte de 1164. Le contrôle du nord de la cité lui permet de s'implanter, depuis Porte Galle au nord-ouest de la ville haute, dans l'anse de l'Ourse, à l'extérieur des remparts, un petit site portuaire. Puis viennent des possessions domaniales aux abords de l'agglomération ou le long des cours d'eau irriguant le territoire marseillais, avec Plombières (quartier actuel, près de la Belle de Mai), Pratlong (au nord de la ville médiévale, près du Cannet, le long du ruisseau des Aygalades), Mont Jusiau (dans la zone de la Belle de Mai, qui comportait un cimetière juif jusqu'en 1495), le val de Saint-Just (nord-est de l'agglomération actuelle), Casau (Saint-Charles), Garbiers (au nord des précédents), le val Saint-Bauzile (vallée correspondant à l'axe de l'actuelle Canebière), le val de Morier (sud de la colline Saint-Charles), et Saint-Just, au nord-est de l'agglomération. Caldacidio, Castellum de Vier et Colonne restent en revanche non identifiés, tandis qu'Arcus renverrait à des vestiges antiques, et peut se situer dans une zone proche de l'église Saint-Saturnin, dite «dels Arcs» au XIV e s., hors des murs de la ville, ou bien encore au sud-est de celle-ci, près du Rouet. S'y ajoutent le dominium sur les massifs de Marseilleveyre, Mont Puget et Saint-Cyr, au sud de la commune actuelle (les monts « d'outre Huveaune »).

Au-delà du territoire marseillais proprement dit, l'évêque dispose de nombreux droits dans des castra qui en contrôlent les accès nord, aux Pennes-Mirabeau, nord-est, à Allauch et Ners, est, à Saint-Julien. Mais à Aubagne, ce sont les vicomtes de Marseille qui tiennent le castrum en fief de l'évêque. La seigneurie épiscopale s'exerce aussi dans les zones de salines, avec l'étang du Lion, qui se situe soit au sud de l'étang de Vacarès, en Camargue, ou bien dans l'actuelle commune de Marignane. Elle est présente sur les abords de l'Étang de Berre, le long d'axes terrestres menant à la cité, à Vitrolles, Marignane, Papia (auj. com. Marignane)

46 C'est le cas du cartulaire de l'évêché de Marseille compilé en 1356, où l'acte figure en tête avec sa confirmation de 1222: AD13 5G 91, mais pas de celui du chapitre, AD13 6G 438, où il n'apparaît qu'au folio 24 ( $65^{\mathrm{e}}$ acte). et Saint-Victor de Cella (Saint-Victoret). Quant à Bagneriis, ce toponyme non identifié renvoie peut-être au Balagnerio et Balagnier signalé au XIV ${ }^{\mathrm{e}} \mathrm{s} .{ }^{47}$, ou bien à l'étang disparu de Vagnère, près de Marignane. Enfin, le prélat contrôle quelques castra aux marges orientales du diocèse de Marseille, comme Méounes et Le Beausset. Saint-Cannat se situe dans une enclave au sein du diocèse d'Aix, tandis que Meinarguette (com. Mazaugues) est comprise dans le diocèse d'Aix, et qu'Évenos, Auroneves ainsi qu'Orvès (habitat disparu, com. Évenos) se trouvent dans celui de Toulon.

En dépit de cette considrable assise, l'évêque ne parvient nullement à prendre le contrôle de la totalité de la ville. Toute la partie basse, la plus dynamique car elle comprend aussi le port, lui échappe. Signe des limites de son rayonnement et sans doute aussi de ses capacités financières, le prélat est incapable au début du XIII ${ }^{\mathrm{e}} \mathrm{s}$. de profiter du délitement de la famille vicomtale et d'acquérir ses droits, contrairement aux élites patriciennes qui en profitent pour former un solide pouvoir communal. Le pouvoir temporel de l'Église de Marseille s'avère mal préparé à affronter le développement d'une commune. Sous l'épiscopat de Benoît d'Aligan (1229-1267) ${ }^{48}$, face au modèle d'autonomie offert aux élites urbaines par la ville basse et pour préserver son autorité sur la ville haute, il lui faut passer par l'alliance avec le comte de Provence, Raymond Bérenger V (1209-1245), puis son gendre Charles d'Anjou (1246-1285). Si au milieu du XII ${ }^{\mathrm{e}}$ s., la ville haute, qui voit grandir de nouveaux bourgs, finit par constituer une entité à part entière, dominée par la forteresse épiscopale de Roquebarbe, l'évêque s'y voit ainsi cantonner, et il doit y affronter son propre chapitre cathédral.

Ce dernier, dont les membres sont issus en grande partie de la petite noblesse urbaine et de la famille vicomtale, est d'abord au début du XII ${ }^{\mathrm{e}}$ s. un instrument entre les mains de cette dernière pour affaiblir le pouvoir épiscopal, notamment sous le prévôt Aicard (†1167). L'affirmation du chapitre, dans les années 1160, sans doute aussi de nouvelles nécessités de gestion induites par le chantier et l'Euvre de la cathédrale, conduisent à une division du temporel de l'Église, qui se traduit par une partition progressive de la ville haute. Le chapitre cathédral, installé auprès de La Major et de la maison de la prévôté, semble déjà bien contrôler leurs abords, au moins depuis janvier 1151, comme l'atteste un accord

47 AD13 5G 109 et 115

48 Moine bénédictin, abbé de Lagrasse, Benoît d'Alignan est désigné évêque de Marseille en 1229 par le pape Grégoire IX Sur ce personnage, voir Grabmann 1941 [considéré à tort par cet auteur comme un franciscain], Segonne 1964, Amargier 1966, Chiffoleau 1986, Cocci 1997 et Pécout à paraître. 
conclu avec les vicomtes ${ }^{49}$. À l'extérieur de la ville, les chanoines disposent aussi de nombreux droits, et le comte Raymond Bérenger les leur confirme en 1150, à Allauch avec un castellum à Rodimacum ${ }^{50}$, SaintJulien, les Pennes, un quart d'Orvès et d'Évenos. Un premier conflit avec le prélat débouche, en mars 1159, sur l'arbitrage des évêques de Carpentras et de Toulon, qui imposent le serment de fidélité à l'évêque ${ }^{51}$. En mai 1163, ceux d'Antibes et de Toulon prononcent une nouvelle sentence qui impose la division des menses épiscopale et canoniale ${ }^{52}$. L'ensemble des droits du chapitre est confirmé par le pape Lucius III en juin $1182^{53}$. Sous la prévôté de Guillaume de Tourtour (1173-1183), le temporel du chapitre achève ainsi de se consolider.

Il dispose ainsi d'un pouvoir seigneurial capable de rivaliser avec celui des évêques. Le Château Babon, en pariage avec les vicomtes depuis $1179^{54}$ afin de lotir la zone, et l'alleu de Sainte-Marie, mentionné en 1153 , constituent la partie de la ville haute relevant du chapitre. Ce dernier y lève des cens sur les habitants, ainsi que la moitié des dîmes de la ville entière, et la moitié de celle que perçoivent les Templiers. Dans le territoire de Marseille, ses possessions se concentrent aussi à Saint-Just, Morier, Saint-Bauzile, Archulas (Arcoles, à Fondacles, au nord de Saint-Julien), la Coufonne (Mazargues). À sa périphérie, il dispose en outre de droits et de parts de seigneuries dans les castra d'Aubagne, Gémenos, Roquefort, Julhans et Cuges, que les vicomtes tiennent en fief, ainsi qu'à Allauch, Château Gombert, Les Pennes, Saint-Julien, Évenos, Feians (près de la Couffone, Mazargues), et enfin une part de moulin sur l'Huveaune. S'y ajoutent les droits d'autel et de collation sur de très nombreuses églises.

C'est finalement le comte de Provence qui parvient à s'implanter le plus solidement dans la cité et à lancer à son profit un processus d'unification des pouvoirs qui aboutit en 1343. Dans son effort de mainmise sur la ville et ses ressources, et après avoir soumis la commune de la ville basse en 1252, Charles d'Anjou impose un échange avec Benoît d'Alignan à propos de la ville haute. Le 30 août 1257, l'évêque de Marseille abandonne toute juridiction temporelle et seigneurie. En contrepartie, il reçoit une rente annuelle de 500 livres de royaux assignées sur un ensemble de castra évalués par l'archevêque d'Aix, l'évêque de Fréjus et Barral de Baux, et sur lesquels il

49 Gérin-Ricard, Isnard 1926, ${ }^{\circ} 238$

50 Peut-être Rode ou Rodes (quartier du Lendouvier), com. Allauch.

51 Belsunce I, p. 381-383 ; ind. GCNN, Toulon, $\mathrm{n}^{\circ}$ 82, col. 69.

52 Ind. GCNN, Marseille, $\mathrm{n}^{\circ}$ 1097, col. 690

53 GCNN, Marseille, $\mathrm{n}^{\circ}$ 1108, col. 697-699.

54 GCNN, Marseille, $\mathrm{n}^{\circ}$ 1104, col. 693-696. aura toute juridiction : Châteauvert, La Roquebrussane, Néoules, les castra du Val de Signe, Mérindol, Mallemort, Alleins, Valbonnette ${ }^{55}$. S'y ajoutent tous les droits comtaux, sauf les cavalcades et l'hommage que l'évêque devra au comte, sur Saint-Cannat, Ners, Pichauris, Meinarguette, Méounes, Orvès, le Bausset ${ }^{56}$, et dans les autres lieux où l'évêque a déjà des droits, ainsi que la liberté de traversée à Mérindol ${ }^{57}$ pour ses embarcations. Le prélat recevra l'hommage des seigneurs de ses lieux, il sera défendu par les officiers comtaux face aux contestations, et pourra nommer ses propres officiers, juges et notaires sur ses terres, ainsi qu'un juge des premiers appels. L'évêque prête hommage et fidélité au comte et à la comtesse. Désormais essentiellement rural et bien que comportant d'importantes juridictions, le temporel du prélat est dispersé entre plusieurs diocèses (Aix, Cavaillon et Toulon, outre le diocèse de Marseille).

Mais l'affaiblissement des droits de l'évêque de Marseille est vigoureusement contesté par le pape Alexandre IV (1254-1261) qui y voit une aliénation imposée par le comte. Il désigne le sacriste et l'archidiacre de Maguelone vers l'automne 1258, puis l'évêque de Cavaillon Rostaing Berlinguer en décembre, afin d'examiner la conformité de cet échange. La procédure d'enquête est poursuivie par le neveu du pape, Riccardo Annibaldi, cardinal de Saint-Ange, sous les pontificats suivants, jusqu'en 1268. Le successeur de Benoît d'Alignan, Raymond de Nîmes (1267-1288), échoue enfin dans sa tentative de faire annuler l'aliénation du temporel en $1268^{58}$. Charles d'Anjou dispose ainsi d'un pouvoir considérable sur la plupart de la ville où il installe une administration. Il lui reste à acquérir les droits des moines de Saint-Victor, chose faite le 10 juin $1275^{\mathbf{5 9}}$. Sous le règne de Jeanne $\mathrm{I}^{\mathrm{re}}$ (1343-1381), le chapitre cède toutes ses juridictions sur la ville haute le $1^{\text {er }}$ décembre 1343, ainsi que ses droits de lesdes, péage et pêcherie ${ }^{60}$. À cette date, s'achève le processus d'unification des pouvoirs sur une ville qui a renoué depuis le début du siècle

55 Châteauvert, Néoules, Var ; La Roquebrussane, ch.-1. cant., Var ; les castra du Val de Signes, cant. Beausset, Var. Mallemort, Alleins, cant. Eyguières, Bouches-du-Rhône. Valbonnette, com. Lambesc, ch.-1. cant., Bouches-du-Rhône.

56 Saint-Cannat, cant. Lambesc, Bouches-du-Rhône. Ners, Pichauris, auj. com. Allauch, cant. Marseille, Bouches-du-Rhône. Meinarguette, auj. com. Mazaugues, Var. Méounes, cant. La Roquebrussane, Var. le Bausset, ch.-1. cant., Var. Orvès, auj. com. d'Évenos, Var.

57 Mérindol, cant. Cadenet, Vaucluse : il s'agit de la navigation sur la basse Durance et de sa traversée par bacs.

58 AD13 5G 12, n 81 (rouleau parchemin).

$59 \mathrm{AD} 131 \mathrm{H} 157, \mathrm{n}^{\text {os }} 772-773$. L'abbaye reçoit en compensation les revenus de l'annonerie.

60 AD13 B 529. Mabilly 1905, p. 274-283. 
avec une relative autonomie du gouvernement urbain, sous le contrôle du viguier royal et de ses officiers.

\section{Marseille du XVI ${ }^{\mathrm{e}}$ s. à la Révolution : aspects urbains et monuments (R. Bertrand)}

C'est un état provisoire des connaissances sur Marseille aux Temps modernes que l'on présentera ici, en soulignant d'emblée le long retard de l'érudition marseillaise, qui est encore loin d'être comblé. Marseille n'a pas bénéficié à la fin du XIX ${ }^{\mathrm{e}}$ puis au $\mathrm{XX}^{\mathrm{e}} \mathrm{s}$. d'une commission municipale des travaux historiques, à l'instar de celle qui est établie à Paris, ni d'un groupe associatif d'érudits s'appliquant à reconstituer l'histoire de ses monuments et de ses hôtels particuliers, comme il en a existé à Avignon ou Lyon par exemple. Bruno Roberty et les archivistes Raoul Busquet (Busquet 1955) et surtout Joseph Billioud (Billioud 1963) ont amorcé dans le second tiers du $X^{\mathrm{e}} \mathrm{s}$. les premières recherches d'archives réellement soucieuses de documenter un monument - en particulier par la découverte de prix faits. Puis dans les années 1960-1980, Jean-Jacques Gloton a contribué à réévaluer le baroque marseillais (Gloton 1980a). Les recherches d'Arnaud Ramière de Fortanier (Ramière de Fortanier 1978), d'heureux accroissements des collections municipales, tel l'achat des manuscrits de F. Michel de Léon (Bertrand 1992), et l'exposition organisée par Myriam Morel au musée d'Histoire en 2007 (La ville figurée) ont doté Marseille au cours de la dernière génération d'un corpus iconographique dont la datation a souvent été précisée.

Le progrès le plus net des connaissances est venu ces dernières années de l'extension aux Temps modernes des fouilles et relevés archéologiques. Les rapports de fouilles ont déjà permis la confrontation de plusieurs de leurs résultats aux documents écrits et iconographiques. Les archéologues ont suscité un renouveau de la recherche en archives et imposé une exigence de précisions dans son interprétation. L'archéologie contribue avant tout à apporter des données que ces autres sources ne sauraient fournir. Elle induit aussi une approche critique plus affinée des représentations iconographiques de la ville.

\subsection{Une grande ville, un faible pouvoir de commandement}

Marseille est pendant les Temps Modernes le premier foyer économique de la Provence par son activité portuaire et manufacturière et la seule cité provençale qui figure dans l'étroit peloton des grandes villes françaises de l'époque. Elle améliore sa position démographique entre $\mathrm{XVI}^{\mathrm{e}}$ et $\mathrm{XVIII}^{\mathrm{e}}$ s. alors que s'accentue son écart avec les autres villes du sud-est. Selon J. Billioud, qui a tenté d'étudier la démographie marseillaise à partir des statistiques du ravitaillement, sa population agglomérée serait vers 1520 de 14 à 15000 habitants, de 30000 vers 1554 et encore en 1599 (Rambert 1951-1966, III, 179-185). Elle est alors sans doute, par sa population, la sixième ville du royaume. Marseille aurait 40 à 45000 habitants en 1610. Elle aurait 75000 habitants en 1696, terroir compris, auxquels s'ajoute la population de cette véritable ville dans la ville qu'est l'arsenal des galères, soit 18 à 20000 personnes à la fin du XVII' s. En 1765, Marseille a perdu les pensionnaires de l'arsenal; il y aurait alors 86400 habitants dans la ville agglomérée et 19000 habitants dans le très vaste terroir. Si l'on accepte l'hypothèse tout à fait maximale de 120000 habitants en 1790 (dont 100000 dans l'agglomération et le reste dans le terroir), elle se situe alors au troisième rang français, loin derrière Paris (650 000 habitants), après Lyon (146 000 habitants), peut-être avant Bordeaux (110 000 habitants). Cette croissance démographique a des conséquences sur le développement urbain. Ce dernier est avant tout marqué par l'Agrandissement de 1666 qui triple la superficie urbaine : il dédouble la perception de la cité entre ce qui devient la «vieille ville», progressivement dépréciée, et la «Ville Nouvelle », au plan régulier, aux longues perspectives et au décor urbain de qualité, très fortement amoindri aujourd'hui (fig. 14).

L'originalité de Marseille est d'être une grande ville dont les fonctions administratives sont très réduites sous l'Ancien Régime. Le centralisme aixois n'a guère d'équivalent en France. Marseille est au XVIII' s. la seule des dix premières villes de France pour leur population qui ne soit pas le siège d'une intendance. Compte tenu de l'importance économique de la ville-port, l'intendant d'Aix doit longuement y séjourner pendant l'année. Il loue pour cela un hôtel particulier de la rue Noailles. Marseille est un port où le négoce règne en maître, ce qui n'est pas le cas de Bordeaux et Rouen, villes de parlement et d'intendance. La noblesse y est peu nombreuse. Elle est souvent récente et issue de la marchandise, les officiers des galères faisant exception (mais en 1748 les galères sont transférées à Toulon). Elle perd la direction de la ville en 1660 au profit des négociants et tend dès lors à migrer vers Aix, où la noblesse « tient le haut du pavé » et donne le ton à la ville. En 1767 cependant, une réforme du système municipal instaure un maire pris dans la noblesse locale. Les notables marseillais sont pour la plupart en phase d'accumulation du capital familial et ils sembleraient réprouver souvent l'ostentation extérieure dans les bâtiments, au contraire 


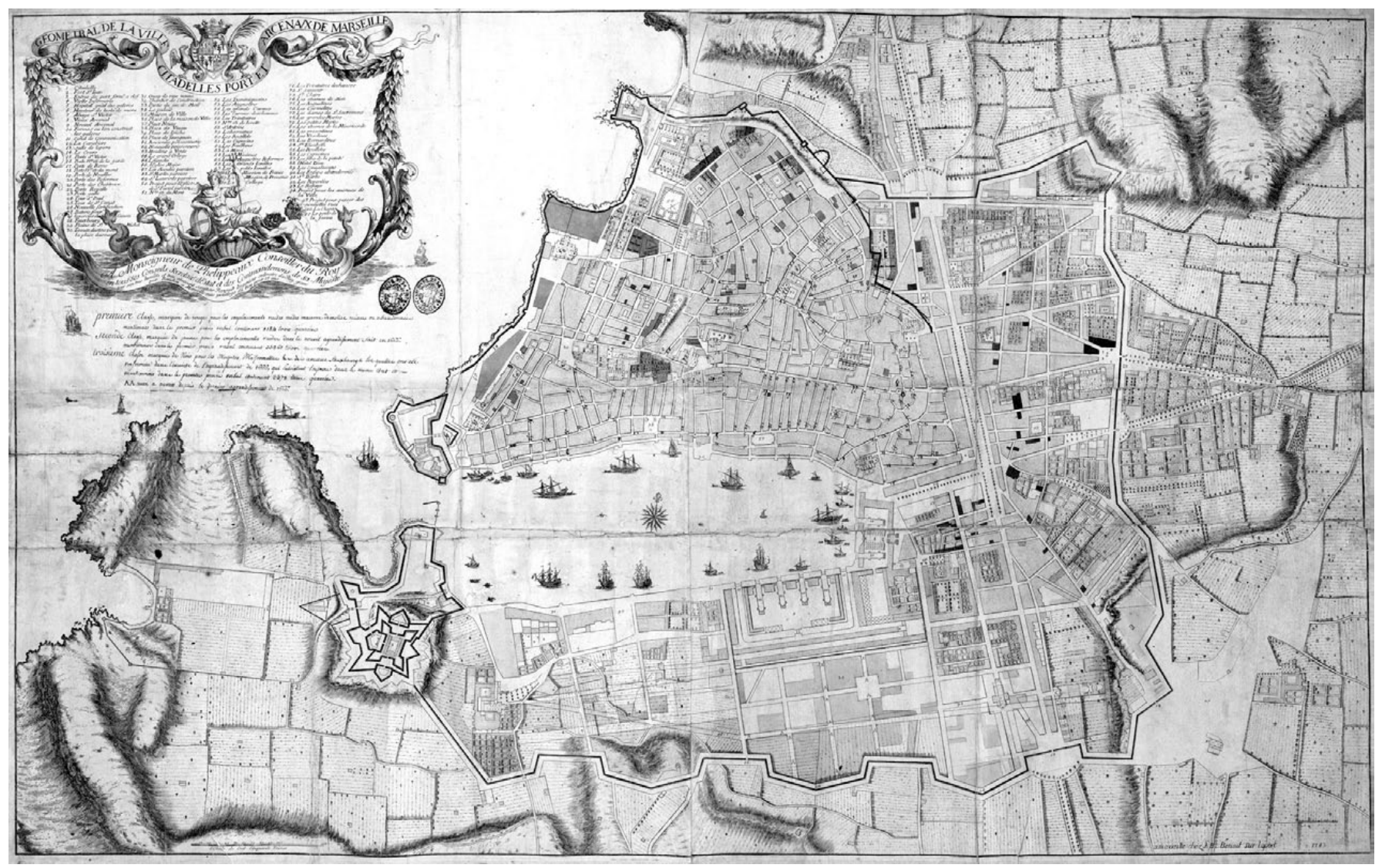

Fig. 14. Plan de Marseille par Razaud (vers 1700 ?) (cl. ACM).

de la noblesse aixoise, qui tient à accentuer sa différence d'avec les riches roturiers et est soucieuse de « tenir son rang » par ses hôtels.

\subsection{Marseille au XVI ${ }^{\mathrm{e}}$ s. et dans les deux premiers tiers du XVII ${ }^{\mathrm{e}} \mathbf{s}$.}

Quelques documents d'exception procurent des images de Marseille antérieures à l'Agrandissement de Louis XIV prises de points de vue différents. Le dessin du capitaine Ercole Nigra, vers 1591, tracé peut-être depuis le plateau Saint-Charles, «constitue la première représentation fiable de Marseille » (Ramière de Fortanier 1978, pl. 6) si l'on tient compte que son auteur, homme de guerre, est davantage soucieux de l'exactitude des remparts et fortifications que du détail de la trame urbaine dont le dédale a été transformé en damier. Non moins exceptionnels, les dessins de Cornelis Vroom, entre 1623 et 1636 (Ramière de Fortanier 1978, pl. 9) et J.-R. Werdmüller, 1662 (Bouiron et al. 2001c, p. 375-393) (fig. 15) procurent une autre vue de la ville, levée depuis le plateau Saint-Michel et centrée sur le port. Le « plan figuré » de Jacques de Maretz vers 1630 (cf. fig. 10) la montre depuis Notre-Dame de la Garde, avec des rues exagérément larges et rectilignes.

Maretz et plus encore Nigra marquent fortement l'aspect de «forteresse de mer » d'une ville qui occupe pour l'essentiel les trois buttes de son site antique et, vers l'est, la petite plaine correspondant à l'ancienne corne du port, colmatée pendant le haut Moyen Âge. Les auteurs du $\mathrm{XVI}^{\mathrm{e}}$ s. lui reconnaissent la forme d'une harpe. Sa superficie intra muros est d'environ soixantedix hectares. Marseille est protégée sur deux de ses trois côtés par son enceinte médiévale. Son contour en ligne brisée suit depuis l'entrée de la passe et la tour SaintJean le rivage escarpé, qui n'a pas encore été régularisé, jusqu'à l'anse de la Joliette, il suit approximativement l'axe de l'actuel boulevard des Dames dont la création entraînera sous le Premier Empire la disparition de cette partie de la muraille qui n'avait pas été touchée par l'Agrandissement. Au sud de la rue Sainte-Barbe, l'enceinte avait été avancée au début du XIII ${ }^{\mathrm{e}} \mathrm{s}$. presque jusqu'au niveau du futur cours Belsunce. Cette dernière portion était renforcée au XVII ${ }^{\mathrm{e}} \mathrm{s}$. par de grosses tours rondes au couronnement adapté à l'artillerie, analogue à celui du château d'If. Passé la porte Réale (angle actuel de la Canebière et du cours Belsunce), le mur 
rejoignait le fond du port, entre l'actuelle Canebière et la rue des Fabres.

L'enceinte a été renforcée dans les premières décennies du XVI ${ }^{\mathrm{e}}$ s. par des ouvrages bastionnés le long de la route d'Aix. Elle a résisté au siège de 1524 mais devient obsolète au siècle suivant face aux progrès de l'artillerie. Pas de muraille sur le quai du port, défendu par la chaîne que l'on tendait à travers la passe et par la rangée serrée des façades des maisons bordières, entrecoupées de rues étroites et de quelques «crottes » (littéralement voûtes, passages couverts, équivalents des « endrones » de la haute Provence) l'église gothique Notre-Dame des Accoules, semblerait très peuplé (plus de 6000 communiants en 1558-59 ?) et serait le quartier le plus richement habité au XVI ${ }^{\mathrm{e}} \mathrm{s}$. Robert Ruffi écrit à la fin du XVI ${ }^{\mathrm{e}}$ s. qu'y habitent «la plus part des gentilhommes et riches marchandz de la ville ». À l'est, Blanquerie où s'élève la collégiale SaintMartin, vaste édifice gothique rasé à la fin du XIX ${ }^{\mathrm{e}} \mathrm{s}$. Selon Ruffi, les habitants « sont la plusparts mesnagers et bourgeois et partie de gentilhommes ». Au nord-ouest et au nord, Cavaillon, de la Major jusqu'au couvent des Grands-Carmes, le plus éloigné du port, «où logent la plupart des laboureurs » et qui semble de façon générale

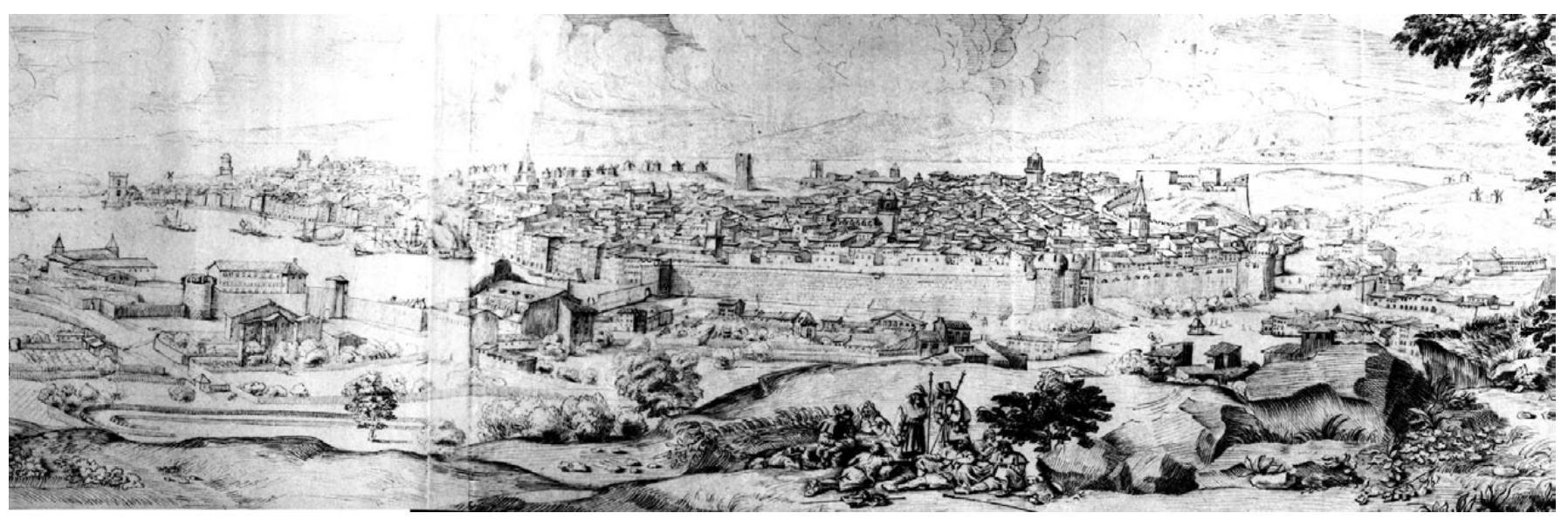

Fig. 15. Détail de la vue de Marseille par Werdmüller en 1666 (cl. Zentralbibliothek de Zürich).

Le fond du port est occupé par le « plan Fourmiguier », terrain protégé d'une muraille où se trouvent depuis le $\mathrm{XV}^{\mathrm{e}}$ s. quelques installations pour la construction des bateaux marchands et les galères. En 1512 un arsenal a été créé dans son prolongement sur la Rive Neuve. Autour de l'enceinte s'étendait une auréole faubourienne, dont des parties sont mieux connues désormais grâce aux fouilles. Particulièrement intéressante est l'évolution de son flanc oriental. Il y a là, le long des lices, entre les chemins d'Aix et d'Italie, un assez large espace, «lou grand caire » (le grand côté), glacis militaire devenu un carrefour essentiel, lieu de passage et de stationnement au contact des principales portes de l'enceinte et au débouché des chemins du terroir. Entre le dessin de Nigra et le plan de Maretz, sa bordure opposée à l'enceinte s'ourle de maisons et d'auberges. On suit aussi ses aménagements : installation de fontaines et plantation d'arbres qui préfigurent sa future transformation en Cours (Sillano 2004b).

Dans la ville murée, la division administrative et politique en «sixains » a fait place depuis le début du $\mathrm{XVI}^{\mathrm{e}}$ s. (et non en 1560 comme l'indique par erreur Ruffi) à quatre quartiers. Le cœur de la cité, Draperie ou Corps de Ville, autour de la maison commune et de un quartier socialement déprécié. À l'ouest, Saint-Jean, autour de l'église Saint-Laurent, «où sont logéz tous les pescheurs, gens de marine et quelques merchans» (Kaiser 1992, p. 81). À l'intérieur de ces quartiers, des lieux-dits aux noms assez fluctuants dans les actes pouvaient être déterminés par une rue et ses alentours (« quartier Baussenq », autour de la rue Baussenque), ou un édifice («quartier de l'observance ») (Kaiser 1992, p. 80-94). Il est couramment affirmé que les limites de ces quartiers correspondaient à celles des paroisses. W. Kayser a montré que ce n'était pas exact au XVI ${ }^{\mathrm{e}} \mathrm{s}$. pour le quartier Saint-Jean, qui se serait étendu alors jusqu'à la place de la Major ou pour la paroisse SaintMartin, qui débordait sur Cavaillon.

Depuis la suppression au milieu du $\mathrm{XV}^{\mathrm{e}} \mathrm{s}$. de la paroisse Saint-Cannat dont l'église était située sur la pente nord de la butte des Carmes, la ville est divisée en quatre paroisses. Sainte-Marie-Majeure (la Major), la cathédrale, est aussi sanctuaire paroissial, comme dans la plupart des sièges diocésains provençaux (Arles excepté). Saint-Martin est érigée en collégiale en 1536, ce qui aurait rejeté au troisième rang Notre-Dame des Accoules, qui ne devint à son tour collégiale qu'en 1560. Enfin Saint-Laurent est la dernière paroisse jusqu'à 
l'érection en 1693 de celle de Saint-Ferréol, dans la partie méridionale de l'A grandissement. La carte des limites paroissiales a été naguère réalisée par Ferréol Rebuffat par dépouillement d'un échantillon d'actes mortuaires qui précisent dans quelle artère a été « pris » le corps, et report de ces données sur les plans de Bresson (1773) et Pierron (178) qui fournissent les noms des rues (Carrière 1968, p. 25).

Ce très faible nombre de sanctuaires paroissiaux urbains est une caractéristique des villes du Midi. En fait les dévotions et les sépultures des fidèles se partagent entre les églises paroissiales et celles des couvents masculins, qui abritent également de nombreuses confréries de dévotion ou professionnelles. Au cours des XVI et XVII ${ }^{\mathrm{e}}$ s., une douzaine de chapelles de pénitents, associations pieuses de laïcs, sont édifiées, pour la plupart dans des enclos conventuels ou des cimetières paroissiaux. La ceinture conventuelle périurbaine constituée au XIII ${ }^{\mathrm{e}} \mathrm{s}$. par les ordres mendiants a disparu aux siècles suivants, ces communautés trop exposées trouvant refuge dans l'enceinte. Une seconde ceinture se formera aux XVII et XVIII' ${ }^{\mathrm{e}}$ s. à l'est et au sud; certaines de ses maisons se retrouveront dans le périmètre de l'Agrandissement de 1666 (Bertrand, Bernos 1993).

À l'intérieur de l'enceinte, un net contraste oppose depuis le Moyen Âge sinon auparavant le sud et le nord de la ville; le long d'une dorsale sud-ouest/nordest suivant approximativement le sommet des buttes et l'ancienne limite entre les villes comtale, épiscopale et prévôtale (Rambert 1934, p. 176 et sq.). Sur les versants tournés vers le port, des quartiers densément construits et peuplés, aux îlots allongés et souvent peu profonds, aux rues étroites, dont les marchés et les fontaines multipliaient les espaces de rencontre et d'échanges, qui ont une vie de sociabilité intense pouvant se muer en promiscuité. Dans ces espaces proches du port, on dénonce au $\mathrm{XVI}^{\mathrm{e}}$ les saillies des maisons sur la rue, qu'elles soient en encorbellement ou sur piliers, et l'enjambement de segments de rues par le bâti, formant les passages voûtés, les «crottes ». Les lettres patentes de 1569 donnaient pouvoir aux consuls de faire abattre «toutes les saillies et arcades ». Mais les résistances furent opiniâtres. Vers 1582 on aurait détruit plus de trois mille «auvents, crottes et saillies », ce qui n'est guère assuré (Billioud 1957, p. 67-74).

Le sommet et le revers des buttes des Moulins et de Saint-Laurent ainsi que les pentes de la butte des Carmes, zones tournées vers le terroir, connaissaient un habitat de bien moindre densité, en général modeste, voire pauvre. Le plan de Maretz comme le cadastre de 1820 y montrent des jardins et des espaces faiblement occupés, un réseau viaire marqué par les contraintes de la pente, des îlots souvent vastes, en particulier dans la partie septentrionale. Au XVII ${ }^{\mathrm{e}}$ s., de nombreux couvents, des chapelles de pénitents, des hôpitaux (la Charité, le Refuge) et des établissements artisanaux y trouveront encore des espaces où s'établir. Fait significatif, alors que les maisons religieuses situées dans les autres quartiers ne disposent d'aucun jardin et sont bordées de rues, celles de Cavaillon conservent jusqu'à la Révolution des enclos parfois vastes : on établira lors du retour de peste de 1721 des fosses communes dans celui de l'Observance. Le cimetière des protestants pourra y être à trois reprises transféré dans des jardins. Le sommet de la butte des Moulins est un espace sous-occupé, où il sera encore possible d'établir au XVIII ${ }^{\mathrm{e}} \mathrm{s}$. des cimetières.

Le percement de la rue impériale sous le second Empire a introduit un hiatus considérable dans la topographie marseillaise en passant en tranchée à l'emplacement du col situé entre les buttes des Moulins et des Carmes et en coupant les versants de ces dernières. On a souligné (Fabre 1862, p. 14-15 ; Rambert 1934, p. 184) l'importance des axes formés par des rues estouest qui suivaient les courbes de niveau et aboutissaient à une porte de l'enceinte. Ainsi la Grand-Rue, prolongée par la rue Caisserie ou l'itinéraire qui s'articule de part et autre de la rue du Panier et qui allait de la Major à SaintMartin et jusqu'à la porte de la Frache. Un autre axe a pu être important, celui formé par les rues Coutellerie, de la Loge et Lancerie : compte tenu de l'étroitesse du quai du port et des îlots à parcelles traversantes qui le bordaient, il a pu servir au charroi des magasins situés en rez-de-chaussée des maisons du port. Du sud au nord, un grand cheminement parfois raide partait du coin de la place neuve et allait par la rue Bonneterie, la rue Négrel, la rue de l'Oratoire et la rue des Grands carmes jusqu'à la porte d'Aix. En fait, ces rues situées dans la continuation des chemins royaux ont un statut spécifique au XVII ${ }^{\mathrm{e}}$ s. et sans doute auparavant: les charrettes peuvent les emprunter et leur pavement et leur entretien est, comme celui des places, entièrement à la charge de la communauté (Billioud 1957, p. 38 et sq.). Les autres rues, caladées et dites « à chaussée fendue » (à cause du ruisseau central permettant l'écoulement des eaux pluviales), sont à la charge des propriétaires riverains, chacun entretenant la portion située devant sa maison sur ordre de la ville. Elles sont très théoriquement interdites au charroi et réservées au portage au col, au brancard (de tous les malades de l'hôtel-Dieu et de tous les morts) ou bien au portage à dos d'âne et de mulet, qui sont susceptibles d'escalader celles qui sont entrecoupées de marches.

Marseille est alors une agglomération en large partie perchée, comme Nice, Gênes et bien d'autres villes et villages du pourtour méditerranéen. Elle a, jusqu'au milieu du XVII s. sn urbanisme peu différent de celui 
des autres villes provençales, voire des « villages urbanisés », les bourgs, également dotés d'enceintes. Aix fait alors exception par ses quartiers Villeneuve (1583) et Villeverte (1605) puis Mazarin (1646), agrandissements qui ont induit des tracés orthogonaux et des voies hiérarchisées. Aix a également innové en transformant en cours un segment du glacis de son enceinte, créant l'actuel cours Mirabeau (1651).

\subsection{Marseille de Louis XIV à la Révolution}

Le règne personnel de Louis XIV va transformer la physionomie de la ville. D'abord par la fortification dans les années 1660 des abords de la passe, qui répond à un double but : protéger la ville et son port d'un coup de main naval et surtout permettre aux garnisons royales de mater une éventuelle révolte urbaine, voire de bombarder la ville qui est désormais «sous le canon du roi ». La citadelle Saint-Nicolas est élevée sur un promontoire presque vierge de constructions, excepté une chapelle. Le fort Saint-Jean intègre en revanche la tour carrée du $\mathrm{XV}^{\mathrm{e}}$ s., et la tour du fanal érigée en 1646, les bâtiments de la commanderie de Malte et une partie du quartier Saint-Jean, qui est expropriée.

$\mathrm{Au}$ terme de sa construction le «Parc» (arsenal des galères) occupe à la fin du XVII ${ }^{\mathrm{e}}$ s. une superficie de près de 9 hectares sur la majeure partie de l'actuel quai des Belges et le quai de Rive-Neuve, jusqu'à la rue Fort-Notre-Dame (Zysberg 2007). On y distingue « l'ancien arsenal », édifié de 1665 à 1669 au détriment du Plan Fourmiguier, qui occupe l'essentiel du « fond du port », puis le «nouvel arsenal » construit en deux étapes (1673-1679 et 1685-1690) sur la Rive Neuve. L'ensemble présente une large ordonnance monumentale : habile scansion par les pavillons de bâtiments très longilignes ; hautes toitures à combles auxquelles répondaient alors celles de l'Hôtel de Ville. Ce couvrement jusqu'alors inusité localement semble une marque ostensible des bâtiments royaux dans la ville.

L'Agrandissement de 1666 est la plus importante opération d'urbanisme provençal des Temps modernes. Le projet décidé par lettres patentes de Louis XIV consistait en un triplement du périmètre urbain ; la nouvelle enceinte, qui se greffe à l'ancienne au pied de la butte des Carmes, près de la porte d'Aix, entoure la totalité du Lacydon puisqu'elle rejoint sur la Rive Neuve la citadelle Saint-Nicolas. Elle intègre donc à la ville, outre le « Parc », nombre de maisons religieuses périurbaines (en particulier l'abbaye Saint-Victor) et les faubourgs (excepté la Bourgade Saint-Lazare, au nord de la porte d'Aix), ainsi que le jeu de mail et de beaux jardins qui seront livrés à l'urbanisation. Le mur qui est alors construit, dont un vestige subsiste rue des Lices, ne saurait soutenir un siège. En dépit de son tracé bastionné à angles très ouverts et de ses petits orillons, il s'agit d'une simple muraille d'octroi qui n'est pas renforcée par un remblai ni précédée d'un fossé et d'ouvrages avancés. En revanche une recherche esthétique se manifeste aux angles des bastions dont les pierres d'appareil sont taillées en bossages.

Le plan d'urbanisation est fondé, suivant les canons d'esthétique urbaine du temps sur les principes du tracé rectiligne et de la largeur constante des rues, selon divers modules en fonction de leur importance. Mais il doit tenir compte des contraintes de la pente et de la présence dans la partie orientale d'un réseau préexistant de vieux chemins. Il semble un compromis imparfait entre la recherche de tracés en patte d'oie, rayonnant depuis les portes (qui font naître les maisons angulaires à pans coupés, ainsi celle construite par Pierre Puget à l'angle des rues de Rome et de la Palud) et celle d'un dessin orthogonal, qui l'emporte nettement dans le quartier de Rive Neuve (Durousseau 1990, Bonillo, Roncayolo 1996, Roncayolo 1996). Trente-huit de ces rues, plus larges, sont destinées au charroi ; elles sont dites « à dos d'âne » (bombées, avec deux ruisseaux latéraux). La ville entretient le dos d'âne, les particuliers riverains les revers.

La voie monumentale qui va être établie, le grand Cours (cours Belsunce et cours Saint-Louis aujourd'hui) constituait un «magnifique pendant au Vieux-Port, haut lieu de l'urbanisme français dont on ne regrettera jamais assez le massacre inconsidéré » (Gloton 1980b). L'inspiration vient du Cours d'Aix, promenade plantée d'arbres, agrémentée de fontaines et bordée d'hôtels aristocratiques. Mais l'originalité marseillaise est sensible : le Cours marseillais s'articule à l'axe majeur nord-sud des rues d'Aix et de Rome, soit plus d'un kilomètre de perspectives rectilignes. Il est bordé sur tous ses côtés par des îlots qui unifient par une façade ordonnancée une rangée d'immeubles de deux ou trois fenêtres construits selon un gabarit uniforme. Les voyageurs le jugent l'une des plus belles avenues de l'Europe. Une telle réalisation a été longtemps éclipsée aux yeux des historiens par les projets somptuaires et irréalistes tracés par Pierre Puget d'une place royale sur le plan Fourmiguier et dans la partie basse de l'actuelle Canebière, qui auraient impliqué la démolition de l' «ancien » arsenal qui venait d'être achevé et tenaient peu compte des contraintes du site (Drocourt 1996 ; Gloton 1996).

S'établissent au XVIII ${ }^{\mathrm{e}}$ s., au-delà de l'enceinte, outre des couvents désireux d'un relatif isolement par un enclos (les Bernardines, actuel lycée Thiers), de nouveaux faubourgs. Au nord, la Bourgade Saint-Lazare se développe le long du grand chemin d'Aix au-delà de la place pentagone aménagée entre 1726 et 1750 . 
L'urbanisation des zones plates sises à l'est des murs de la ville est réalisée dans le dernier tiers du XVIII ${ }^{\mathrm{e}} \mathrm{s}$. par lotissement par quelques propriétaires de leurs domaines (Lemaître de Beaumont crée les deux rues qui portent son nom); puis par l'aménagement en 1771-1775 des «Allées », à l'initiative de l'intendant Sénac de Meilhan (aujourd'hui allées de Meilhan et L. Gambetta, Pringle, Saba 1981). Un quartier suburbain tend à entourer le vieux sanctuaire de hauteur de Notre-Dame du Mont. $\mathrm{Au}$ sud, un faubourg s'allonge autour du vieux chemin de Rome (rue d'Italie), qui prend ce nom lorsqu'entre 1776 et 1780, la ville parvient à tracer le grand chemin de Rome, large d'une vingtaine de mètres qui s'achève par la place Castellane. Divers projets d'agrandissement de l'enceinte incluant ces nouveaux quartiers n'aboutiront pas et les murs disparaîtront au début du XIX ${ }^{\mathrm{e}} \mathrm{s}$.

C'est dans les quartiers de l'Agrandissement qu'est progressivement mis au point l'immeuble à trois fenêtres par étage (le «classique marseillais » des agents immobiliers, Rambert 1934, Bonillo 1981) et son organisation intérieure en « appartements »-pour user du terme actuel. On connaît quelques grands hôtels (Fabbri 2003) dont certains entre cour et jardin, disparus au $\mathrm{XIX}^{\mathrm{e}}$ - démolitions de la rue Noailles pour prolonger la Canebière - et au XX ${ }^{\mathrm{e}}$ s. (bombardements de 1944). En subsistent les actuels musée Cantini (fin XVII ${ }^{\mathrm{e}} \mathrm{s}$. avec modifications ultérieures) et lycée Montgrand (milieu du XVIII ${ }^{\mathrm{e}}$ s.). Un plus grand nombre d'hôtels sur rue ont des façades parfois assez simples (hôtel Pascal, 52 rue Paradis) mais ornées de mascarons sculptés à visages humains et de belles ferronneries, une des spécialités marseillaises du temps.

\subsection{Le quartier de l'arsenal et les « embellissements » du règne de Louis XVI}

À la fin de l'Ancien Régime, l'essentiel du périmètre de l'Agrandissement est construit de maisons. À l'intérieur de l'enceinte, les enclos conventuels constituent avec l'enclos de l'arsenal, le Parc, la principale réserve de terrains à bâtir. Le Parc, quasiment désaffecté et délabré, fut vendu en 1781-1784 à la ville qui céda son emplacement à une compagnie chargée des démolitions des bâtiments, de l'urbanisation et du lotissement des terrains et de la prolongation jusqu' au port de la Canebière, qui devient une large rue reliant le plan d'eau au Cours. Ainsi se crée un quartier au plan orthogonal strict et aux places régulières (place Thiars, de l'Opéra et surtout l'actuelle place de Gaulle). L'intendant Latour ordonne en 1787 que les rues nouvelles devront avoir 24 pans $(5,4 \mathrm{~m})$ de large, ce qui est inférieur à Paris (30 pieds soit 9,6 m pour Paris, Harouel 1993, p. 229). Les trottoirs, d'abord apparus sur la Canebière et la rue de Rome puis la rue Paradis, sont établis dans ces rues du lotissement de l'arsenal (Billioud 1957, p. 60).

Le long du quai de Rive Neuve et autour du canal de l'ancien arsenal (comblé pendant l'Entre-deux-guerres), de vastes immeubles fonctionnels aux façades néoclassiques, les « domaines », combinent entrepôts et ateliers en rez-de-chaussée et espaces d'habitation aux étages. La partie orientale des terrains, entre les rues Breteuil et Paradis, plus résidentielle, est articulée autour de la salle de spectacles, le Grand théâtre, actuel opéra (1787), seconde salle construite en province après le Grand théâtre de Louis à Bordeaux (1777-1780).

Louis XVI régnant, la promotion économique de la ville commence à se traduire, non sans retard, par quelques efforts d'embellissement. En 1782, le conseil de ville décida de trancher entre les variantes orales des noms de rues, afin d'indiquer leurs noms sur le nouveau plan dit de Pierron, en cours d'élaboration, qui parâ̂tra en 1785. Le conseil décida de faire graver ces noms sur les façades des maisons angulaires des carrefours. Marseille marque là un retard sur Paris, où le lieutenant de police Hérault avait commencé en 1728 de faire poser des plaques aux encoignures des voies (Bertrand 2001). L'éclairage nocturne des principales voies est réalisé entre 1786 et 1788 . Les lanternes forment de la porte d'Aix à la porte de Rome un « cordon de lumière qui est prolongé en ligne droite au milieu de la ville » selon Grosson.

Néanmoins, à la suite de la déclaration royale de 1776 qui a interdit les inhumations dans les églises et ordonné le transfert des cimetières hors de l'enceinte, seul le cimetière de la populeuse paroisse Saint-Martin a été transféré hors de la ville, formant la portion initiale du futur cimetière Saint-Charles. Ceux de la Major, des Accoules, de Saint-Laurent et de Saint-Ferréol, parfois insalubres, sont dans le périmètre des murs et ne seront fermés que dans les premières décennies du XIX ${ }^{\mathrm{e}} \mathrm{s}$.

La «vieille ville», soit les quartiers du périmètre antérieur à l'Agrandissement, achève de devenir répulsive aux yeux des visiteurs par ses rues « étroites, sales, mal habitées » et ses « tristes maisons » (Chardon 1806 : p. 126-139 ; Roncayolo 1996, p. 25-36). Jugements qui appelleraient des nuances. Se pose en particulier le problème des alignements permettant de reculer les façades et donc d'élargir progressivement les rues, qui dans la plupart des villes d'Ancien Régime accompagnent les reconstructions ponctuelles d'immeubles. L'arrêt du conseil de 29 mai 1725 a interdit de relever ou réparer les murs et maisons ainsi que de construire sur la voie publique sans autorisation des échevins (Harouel 1993, p. 203). Un plan général d'alignement est alors dressé avec «les coupements convenables pour corriger les 
défectuosités et irrégularités ». En fait, les particuliers continueraient d'agir à leur guise dans les « vieux quartiers » jusqu'à la fin de l'Ancien Régime. L'alignement commencerait alors à entrer dans les mœurs (Harouel 1993, p. 210), ce que l'archéologie pourrait aider à vérifier et préciser. S'était longtemps posé, il est vrai, le problème de l'indemnisation des pertes de terrains résultant des alignements : dans la vieille ville, elle était pour un tiers à la charge de la communauté et deux tiers des voisins ; dans la Ville Nouvelle, la communauté en payait la totalité. En 1778, trente habitants du Vieux-Marseille protestèrent auprès de Necker. Un arrêt du conseil de 1779 décida qu'à l'avenir la communauté seule procéderait au dédommagement des propriétaires de la vieille ville, au-delà d'un reculement de deux pans (Billioud 1957, p. 76 et sq; Harouel 1993, p. 208 et 305).

\subsection{Contrastes sociaux à la veille de la Révolution}

Une nouvelle répartition sociale est perceptible à la fin de l'Ancien Régime. L'élite du grand commerce, les négociants, a colonisé les zones de l'Agrandissement, en particulier les actuels quartiers Belsunce, Noailles et de Rome. $40 \%$ d'entre eux continuent cependant de résider dans la vieille ville, en très large majorité aux alentours immédiats du quai du port et de la «loge » (la bourse, au rez-de-chaussée de l'Hôtel de Ville); sauf quelques exceptions dispersées, ils ne franchissent pas vers le nord la Grand-Rue (Carrière dans Baratier et al. 1969, carte 281 ; Hénin 1983). Les hôtels où descendent les voyageurs aisés ou les négociants de passage sont pareillement presque tous situés dans l'Agrandissement, surtout aux alentours du Cours et de l'opéra (Vovelle 1980, p. 125). La cartographie des garnis de clientèle aisée révèle semblablement une double concentration dans les quartiers neufs et un semis assez dense autour de la « loge ».

Aucun négociant n'habite sur la butte des Carmes, quartier déshérité. La densité de population y est forte (plus de 1000 habitants à l'hectare, contre moins de 500 autour du Cours); à la fin du XVIII s. quelque quatrevingt «bouges » (garnis misérables) y accueillent plus du tiers du prolétariat flottant de passage à Marseille. Il s'agit aussi d'un fort noyau de prostitution dans certaines rues, ainsi la rue des Gavottes et surtout la rue de l'Echelle - où ont été signalés les premiers cas de peste en 1720 (Riani 1982). Résident sur la butte quelques artisans et surtout des matelots, ouvriers du textile, journaliers (79\% de ceux qui logent en ville), portefaix (70\%) et une population misérable : $93 \%$ des «mendiants domiciliés » habitent ce quartier (Vovelle 1980, p. 85-131).

Le quartier Saint-Jean, autour de l'église SaintLaurent, peuplé de pêcheurs et marins, est paré dès
l'Ancien Régime d'un relatif particularisme, commun aux autres quartiers de gens de mer d'Europe. Dans les premières décennies du $\mathrm{XIX}^{\mathrm{e}} \mathrm{s}$., le san-jannenque aura la réputation de sortir rarement de son quartier pour se rendre dans les autres. Enfin si l'artisanat et les fabriques restent diffus dans la cité et ses faubourgs, on note leur tendance au regroupement sur le quai de Rive Neuve, au Marquisat (entre l'arsenal et l'abbaye de Saint-Victor), puis à la fin du XVIII $s$. dans les domaines édifiés sur les terrains de l'Arsenal et aussi à proximité de la partie septentrionale de l'enceinte. Près de la porte d'Aix sont des tanneurs, savonniers et fabricants de produits chimiques, attirés sans doute par des espaces à moindre prix et, pour certains, par le bassin d'arrivée des eaux de l'aqueduc. Autour de la Charité, ateliers et fabriques vont bénéficier pendant la Révolution du lotissement de plusieurs couvents et de leurs jardins (Daumalin et al. 2003, p. 58-60).

\subsection{Une ville en partie disparue}

Une difficulté de l'étude de la ville d'Ancien Régime réside dans l'ampleur des destructions et transformations radicales subies par le bâti marseillais de la Révolution jusqu'à nos jours. Nombre de monuments religieux ont été rasés sous la Révolution et l'Empire, puis au cours du XIX ${ }^{\mathrm{e}}$ et parfois même du $\mathrm{XX}^{\mathrm{e}} \mathrm{s}$. La majeure partie de la « vieille ville», soit des quartiers urbains antérieurs à l'Agrandissement de Louis XIV, a été détruite. Sous le second Empire, le percement de la rue impériale a été suivi à la fin du siècle par la percée de la rue Colbert et la construction de la poste Colbert. Dans les premières décennies du $\mathrm{XX}^{\mathrm{e}}$ s., la démolition du «quartier derrière la Bourse » a fait disparaître l'ancien quartier de Blanquerie et défiguré irrémédiablement le Grand cours, dont la rive occidentale a été rasée. Enfin l'occupant nazi a détruit à l'explosif les quartiers de la rive septentrionale du port en 1943. Les reconstructions et modernisations d'immeubles n'ont pas cessé jusqu'à nos jours dans les autres parties de la «Ville Nouvelle». Les fouilles mettent au jour les vestiges d'un Marseille disparu, dont il n'existe souvent d'autres traces que dans les archives et les bibliothèques.

\section{Le port}

Bien qu'aucun des grands chantiers étudiés n'ait concerné réellement le port, il a semblé important, après un rappel de la place du port dans la ville médiévale et moderne, de donner les résultats principaux de l'opération de la Surverse de la rue de la République. 


\subsection{Le port médiéval et moderne (N. Scherrer)}

L'archéologie fournit peu de données sur le port aux époques médiévale et moderne, mais les archives rendent compte de son importance dans la ville ${ }^{61}$. L'étude menée par Régine Pernoud sur les archives du commerce de Marseille au Moyen Âge (Pernoud 1935) donne l'image d'un port dynamique, tourné vers l'ensemble du bassin méditerranéen (Espagne, Italie, nord de l'Afrique, Proche Orient). Les liens avec l'intérieur de la Provence (particulièrement Arles et Avignon) sont essentiels, par le couloir du Rhône, axe à travers lequel se fait un trafic de denrées constant (particulièrement les céréales, huile d'olive, le bois, ...) de la haute Provence vers la basse Provence (Stouff 1970, p. 56-60; Stouff 2009 ; Bouiron 2009c). Arles avait une place prédominante dans le commerce durant l'Antiquité, mais il semble qu'elle soit supplantée par Marseille au Moyen Âge (Pernoud 1935). Quoiqu'il en soit, le trafic entre ces deux villes concurrentes et alliées est dense.

L'importance du port est prégnante sur le dynamisme de la ville ; la santé du commerce maritime a une influence sur la prospérité de la ville et les phases de prospérité et de récession alternent durant tout le Moyen Âge et l'Époque moderne.

Le port antique visible dans le Jardin des Vestiges est largement envasé et réinvesti dès l'Antiquité tardive, les fouilles de la Bourse l'attestent; la ligne de rivage est encore mal connue pour cette période, mais des indices archéologiques permettent de la situer approximativement. Des constructions datées de l'Antiquité tardive ont pris place sur la corne du port (Bonifay 1984). Parallèlement, il semble que le niveau vertical de la mer se soit pratiquement stabilisé durant cette période après être monté régulièrement entre 2500 av. J.-C. et 500 ap. J.-C. (Morhange 2001).

Pendant le haut Moyen Âge, le commerce connaît une période de réserve due à l'insécurité de la Méditerranée ; au VIII ${ }^{e}$ s., les troubles sans doute liés au passage des troupes de Charles Martel ${ }^{62}$ contraignent la ville à se replier sur elle-même et il semble que ce soit dans l'enceinte de Babon que les habitants trouvent refuge (Bouiron 2009b ; Bouiron 2009c). Par ailleurs, l'instabilité politique provoque des désordres qui engendrent une inquiétude peu propice au développement et ce encore au IX $\mathrm{X}^{\mathrm{e}} \mathrm{s}$. avec l'attaque de la ville en 838 par les Sarrasins (Bouiron 2009b; Pernoud 1935).

61 Des découvertes récentes sur le chantier de la République donnent quelques informations sur le port médiéval qui ont été publiées dans la revue Marseille (Paone et al. 2009).

62 Il lutte contre le duc de Mauronte allié aux Sarrasins et pille Marseille (Bouiron 2009b, p. 31-34).
Avec l'installation de la famille vicomtale, la situation de la ville se stabilise et elle retrouve une période favorable aux activités commerciales (Bouiron 2009c). Lors de la première croisade à la fin du $\mathrm{XI}^{\mathrm{e}} \mathrm{s}$., sont créés les États francs de Syrie et de Palestine, ce qui favorise également les échanges entre l'Orient et l'Occident. Il en va de même lors de la troisième croisade et la prise de Saint-Jean d'Acre en 1191 par Richard Cœur de Lion. Les villes de la Méditerranée dont Marseille y établissent des comptoirs, relais importants du commerce avec le Moyen Orient.

À partir du XIVes., les luttes entre Angevins et Aragonais puis les troubles liés à la présence de bandes de routiers et enfin, la guerre de succession de la reine Jeanne perturbent à nouveau le commerce et le port est utilisé à des fins militaires; les chantiers du plan Fourmiguier se développent (Baratier, Reynaud 1951; Bouiron 2001a, p. 84-87). La peste de 1348-1349 aggrave la situation dans la ville.

Au siècle suivant, le sac des Catalans en 1423 laisse la ville exsangue, mais un renouveau s'amorce à partir du milieu du XV ${ }^{\mathrm{e}} \mathrm{s}$., notamment sous l'influence de Jacques Cœur qui établit à Marseille les galées de France. En 1481, Marseille est rattachée au royaume de France. Au $\mathrm{XVI}^{\mathrm{e}} \mathrm{s}$., le commerce se développe particulièrement avec l'empire Ottoman avec lequel François I ${ }^{\text {er }}$ entend entretenir des relations privilégiées (Joutard 1988). Thomas Lenche fonde la compagnie du corail en liaison étroite avec l'actuelle Algérie.

Les guerres de Religion secouent la région et la ville semble isolée du reste de la Provence sous le pouvoir tyrannique de Casaulx. Durant cette période sont fondés un hôtel des monnaies, la première imprimerie de la ville et $\mathrm{R}$. Ruffi est placé à la tête des toutes nouvelles Archives de la commune. Ces créations renforcent l'autonomie de la ville, mais le climat est lourd et le commerce en pâtit.

Après l'assassinat de Casaulx en 1596, Henri IV prend des mesures pour favoriser les échanges commerciaux à Marseille. La Chambre de commerce est créée en 1599. La ville subit alors des années de luttes entre factions. En 1660 Louis XIV entre à Marseille et conçoit pour la ville un projet de développement du port avec notamment la création du nouvel arsenal et en corrélation un agrandissement ambitieux de la ville hors de ses murs médiévaux. La ville connaît alors un essor important.

S'il est indéniable que le port est le pôle d'attraction principal de la ville, il est cependant attesté que, dès l'Antiquité, se développent ponctuellement hors les murs, des activités et des constructions de type artisanal ou domestique (des vestiges d'habitats datés de l'Antiquité tardive ont été observés par exemple sur le site 


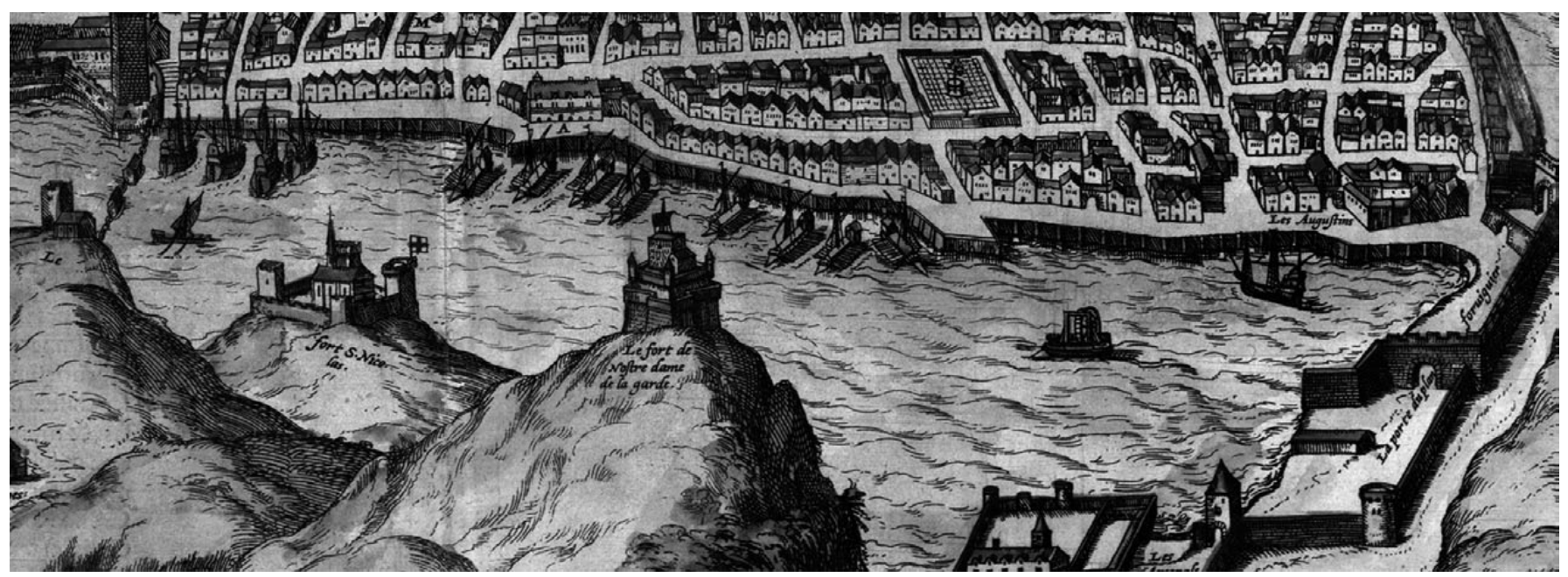

Fig. 16. Le port à la fin du XVle s. (détail du plan Florini, cl. ACM).

de l'Alcazar et lors des diagnostics de la Providence ${ }^{63}$ ). À partir du Moyen Âge, la tendance s'accentue avec la création de faubourgs. A l'Époque moderne (fig. 16), le port est actif mais se transforme largement à partir de l'Agrandissement de la ville initié par Louis XIV. L'arsenal des galères est aménagé sur la rive sud au $\mathrm{XVII}{ }^{\mathrm{e}}$ s. et le plan Fourmiguier disparaît (Bouiron 2001a, p. 321).

La voirie de ce secteur est étroitement liée à son débouché naturel que constitue le port. Si peu de données archéologiques alimentent la connaissance du réseau viaire en lisière de la rive nord, en revanche une série de recherches historiques a été entreprise sur le port et sur les nécessaires mesures d'entretien dont il était l'objet pour maîtriser l'envasement qui le menaçait. La configuration naturelle de l'anse, repliée sur elle-même, en fait un réceptacle des eaux de ruissellement des reliefs alentours. Ces écoulements naturels s'ajoutent à la négligence de la population qui déverse ses immondices dans les rues ou directement dans le port.

Animée par une dynamique marchande polarisée autour du port, la commune de Marseille doit s'assurer de l'accessibilité et de la propreté de son plan d'eau, aussi fait-elle consigner lors de la rédaction du livre 4 des Statuts les réglementations des activités et infrastructures portuaires. Les personnes chargées de l'urbanisme et de la voirie ont en charge de prévenir l'envasement effectif du Lacydon. Des mesures sont prises afin d'établir dans les rues adjacentes des réseaux d'égouts collectifs ainsi que des cuves de bois, les barquil, destinées à filtrer les eaux usées (Hesnard et al. 2001, p. 192-193). Un contrôle strict est effectué sur les navires de pêche et

63 Respectivement Bouiron 2001b et Bouiron et al. 1999. marchands pour qu'ils ne déversent leurs déchets dans le port, qui fait l'objet de curages périodiques. Les berges accueillent également des aménagements sous forme de palissages essentiellement de bois, les escars, sortes de môles contre lesquels venaient accoster les bateaux (Pernoud 1935). Ces mesures préventives ainsi que cet entretien régulier témoignent de la récurrence de cette réalité préoccupante que constitue l'envasement du port.

\subsection{Les aménagements portuaires à la lumière des fouilles de la rue de la République (B. Sillano)}

La rive nord du port n'a été atteinte par les fouilles que lors du creusement de la surverse du bassin de rétention de la place Sadi-Carnot, en 2007 (Sillano et al. 2007a). La zone se situe au fond du port, devant l'immeuble de la Samaritaine ; elle consiste en une bande de $4 \mathrm{~m}$ de large, d'abord dans l'axe de la rue de la République puis oblique en direction du plan d'eau (fig. 17). Il a semblé intéressant de présenter les résultats de l'opération dans ce volume afin de documenter archéologiquement le port.

Jusque là en effet, notre connaissance des aménagements portuaires était réduite à ce qu'Édouard Baratier résume ainsi : "Débarrassée depuis le $\mathrm{XI}^{\mathrm{e}} \mathrm{s}$. de son rempart de bordure, la rive septentrionale n'était qu'une grève aux pentes plus ou moins raides. Aucun quai n'existait encore; les premiers ne seront établis qu'au $\mathrm{XVI}^{\mathrm{e}} \mathrm{s}$. La rive est longée par une chaussée étroite et encombrée, coupée, ça et là, au débouché des ruelles transverses, de ruisseaux fangeux déversant dans le port les immondices de la cité; des palissades de pieux ou escars recevaient les alluvions aux endroits les plus ravinés, maintenaient la grève et formaient de petits môles d'embarquement » (Baratier, Reynaud 1957). 


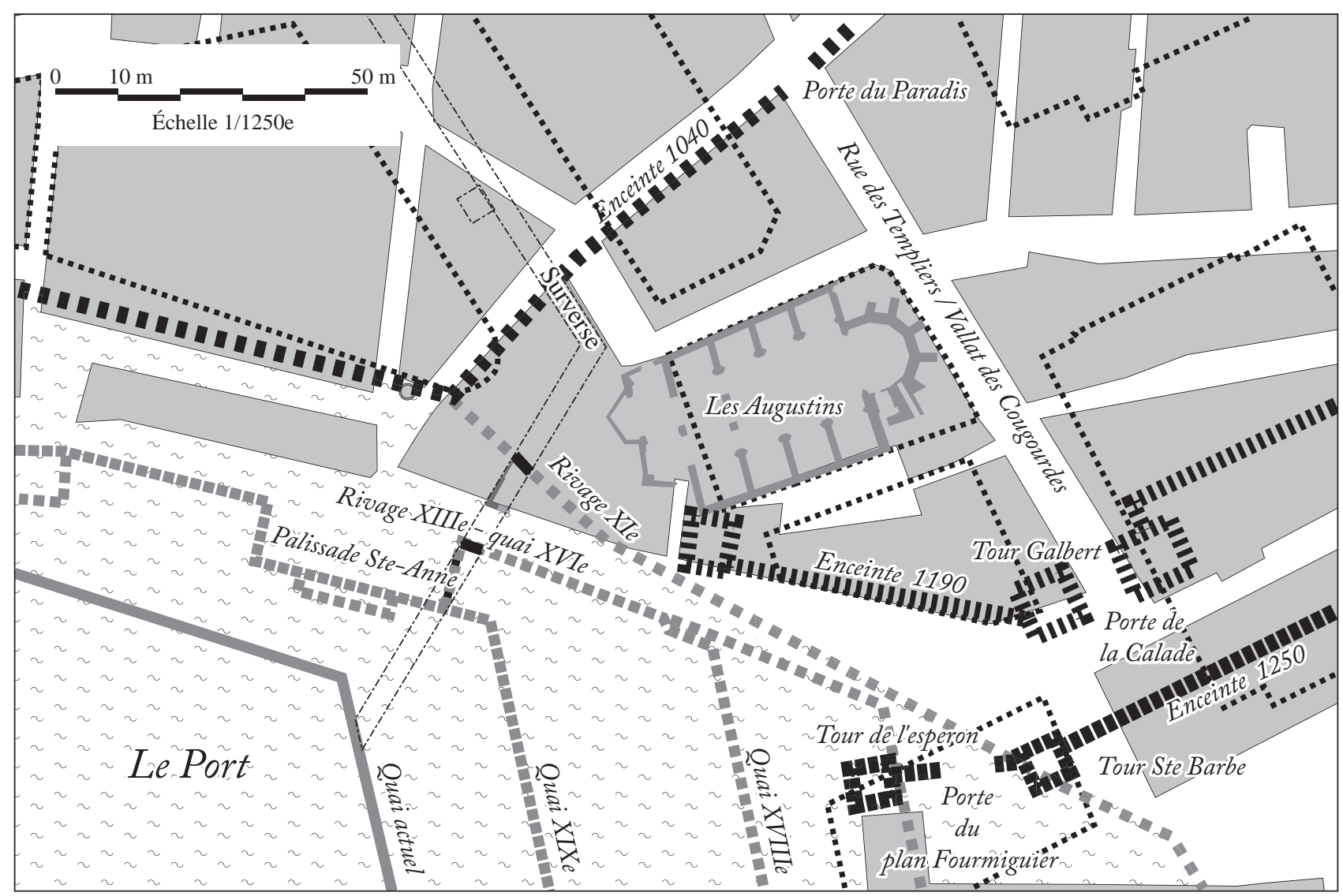

Fig. 17. Les enceintes et les lignes de rivage successives autour de l'îlot des Augustins (DAO B. Sillano/Inrap).

\subsubsection{Cale de halage et mur d'enceinte aux environs de l'an Mil}

Les quais tardifs et la corne du port antique s'envasent à partir de la fin du $\mathrm{VI}^{\mathrm{e}} \mathrm{s}$. de notre ère (Bonifay 1981). Nous avons rencontré le sommet de ces vases lors de la fouille de la surverse, face à La Samaritaine, à $200 \mathrm{~m} \mathrm{du}$ fond de la darse, sous la forme d'un niveau homogène de sable correspondant à un dépôt marin infralittoral auquel succède un dépôt de stagnation et de décantation en bordure de rivage.

À leur surface est établi un mur fait de moellons soigneusement retouchés et disposés en assises régulières, conservé sur 1,80 m de hauteur (fig. 18). Sa base, sous la cote de $-0,50 \mathrm{~m}$ NGF, possède un fruit important du côté sud tandis que les pierres, brutes de taille, et très érodées, sont recouvertes par des vases marines. Il ne fait aucun doute que ce mur marquait la ligne de rivage. Son épaisseur $(90 \mathrm{~cm})$ et son élévation permettent de l'assimiler à un mur d'enceinte. S'il ne peut être daté précisément, une chronologie relative peut se déduire des niveaux d'occupation contemporains repérés au nord-est. Sa construction remonterait au moins au $\mathrm{XI}^{\mathrm{e}}$ s., peut-être même légèrement avant. Une cale faite de blocs et pieux vient ensuite s'appuyer contre lui et éloigne la ligne de rivage. Elle a sans doute servi de halage pour des navires de petit gabarit. Les dépôts de sable et de graviers démontrent que cette cale tombe ensuite en désuétude. Un artisanat lié au travail du bois s'exerce à proximité, si ce n'est sur place, ce dont témoignent les multiples dépôts s'accumulant sur le pavage et dans une vaste fosse. On voit donc que la partie orientale de cette rive du plan d'eau ne comporte pas de quai, ni en pierre ni en bois, mais qu'il s'agit d'une grève en pente douce. Nous n'avons aucune idée de la façon dont on y accédait.

\subsubsection{Les quais entre le bas Moyen Âge et le début de l'Époque moderne}

Le mur précédent est ensuite englobé en cœur d'îlot lorsque le rivage est déplacé de plusieurs mètres vers le sud, à une époque difficile à préciser; le quai en pierre que nous avons retrouvé a subi de multiples réfections (fig. 19). Du premier état, conservé en profondeur, nous n'avons pu observer qu'une assise de blocs taillés, à $-1,07 \mathrm{~m}$ NGF, d'un module de $45 \mathrm{~cm}$ de hauteur, $50 \mathrm{~cm}$ d'épaisseur et 60 à $90 \mathrm{~cm}$ de longueur. Elle est renforcée 


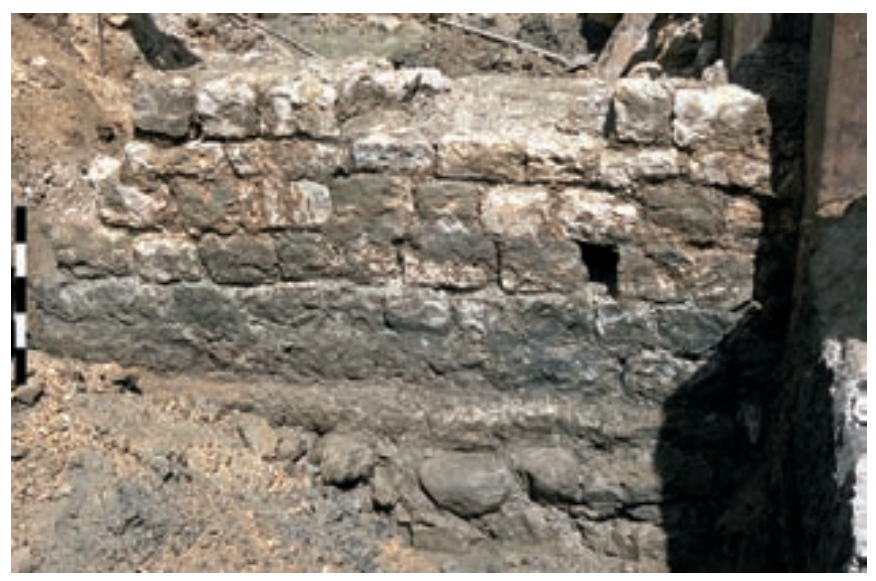

Fig. 18. Le « rempart-littoral » ( $\mathrm{Xl}^{\mathrm{e}} \mathrm{s}$. ?) près de la commanderie des Templiers (cl. FI Parent/Inrap).

par un blocage maçonné disposé en arrière. Devant, une série dense de pieux en bois de petit diamètre, 8 à $12 \mathrm{~cm}$, s'aligne contre le parement, étêtés au niveau de l'assise.

Si nous savons que l'aménagement de berge précédent est abandonné au cours du XIII ${ }^{\mathrm{e}}$ s., rien ne nous permet d'affirmer que le quai en pierre, pour lequel il n'existe pas de tranchée de fondation, a été édifié à cette époque. En revanche, la présence d'une couche de graviers caractéristique des assainissements préalables aux constructions sur les vases marines, datée de la même époque et tronquée par le quai, suppose que le rivage se situait au moins à ce niveau ou qu'il se réduisait à une grève en pente douce vers la mer. Il est vrai que, jusqu' au XVII ${ }^{\mathrm{e}}$ s., la partie orientale du port était utilisée pour mettre les bateaux en carénage, ce que confirme Arnoul en 1672 lorsqu'il écrit que « despuis la palissade de Rome qu'on apelle, jusques aux Augustins (...) est l'endroit où de tout temps on avoit acoustumé de mener les vaisseaux et barques vuydes pour se radouber et calefeutrer » (Rambert 1931, p. 326, $\left.n^{\circ} 147\right)$. Par ailleurs, nous savons qu'entre 1492 et 1495 d'importants travaux sont réalisés pour «faire la rive » depuis la tour SaintJean jusqu'à la porte de la Calade et que de «grosses pierres de quartier et de queyrons » furent employées dans ce but ${ }^{64}$. En 1509 de nouvelles réparations sont mises en œuvre «pour rabilher tous les passaiges rompus que sont sous la riba du port despuis la maison de $M^{e}$ Jehan d'Orgon sarrurier jusques au portal de la Callada ${ }^{\mathbf{6 5}}$. Pour cela on va utiliser des pierres taillées issues des carrières de Port-de-Bouc et de Martigues. Enfin, en 1511, le roi ordonne la construction d'un quai. Les travaux, confiés à l'ingénieur naval Raphaël Rostan, consistent en « une muraille de $4 \mathrm{~m}$ de hauteur et de $2 \mathrm{~m}$

64 AD13 B 1960 fol. 7v ; Hesnard et al. 2001, p. 191.

65 AD13 B 1966 fol. 251v.

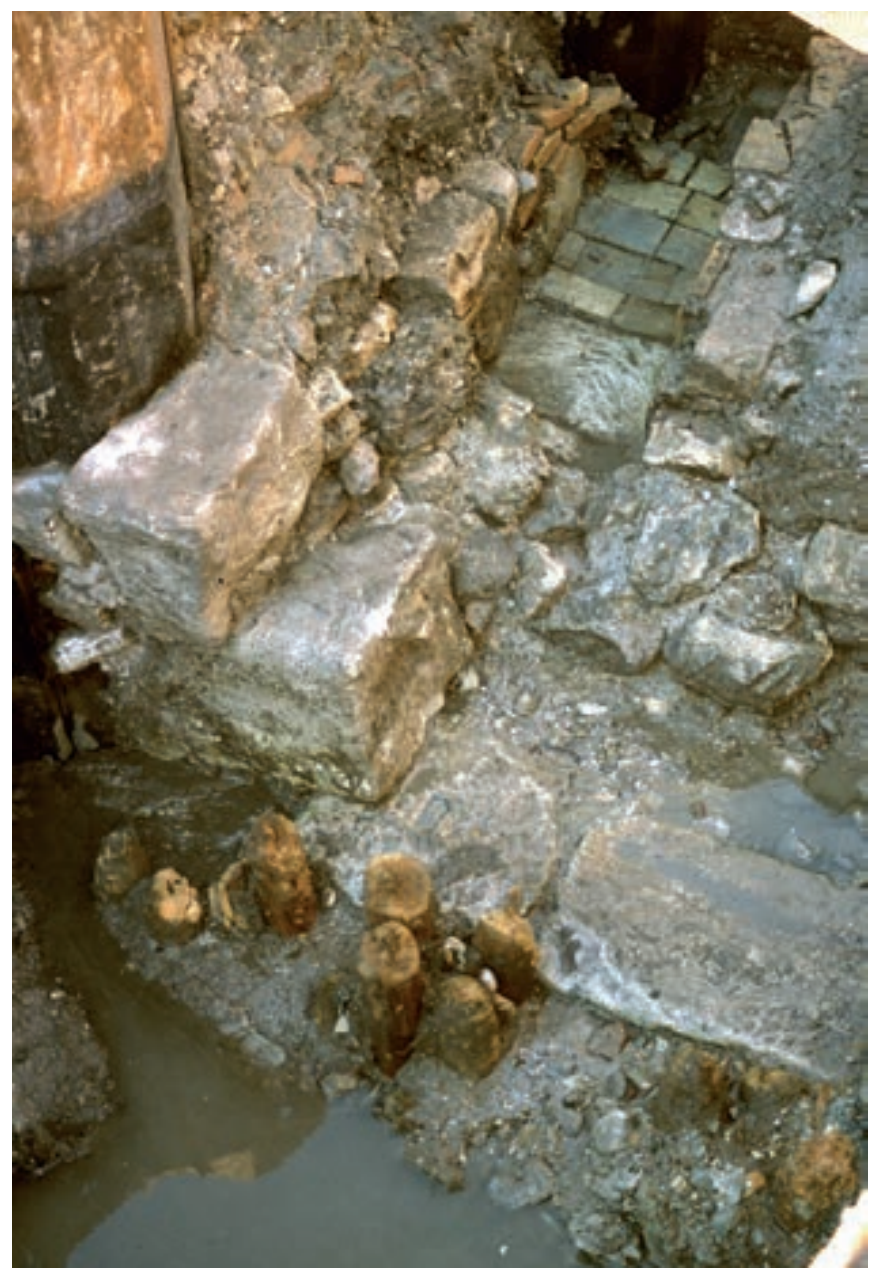

Fig. 19. Le quai du début du XVIe s. et sa réfection sous Louis XIV (cl. B. Sillano/Inrap).

de largeur sous l'eau, à la base, et revêtue de pierres de taille » (Busquet 1945, p. 166-167). Les lettres patentes fixent à 6 pans $(1,50 \mathrm{~m})$ la largeur du revêtement en pierre, au bord du quai. Il est difficile de faire la part des choses entre tous ces travaux, parfois des souhaits sans lendemain, mais il est fort probable que le quai fouillé remonte à cette période où, à la suite de l'envasement d'Aigues-Morte, Marseille devient le débouché du royaume sur la Méditerranée. Son épaisseur, 1,20 m, est certes inférieure aux 1,50 m fixés par lettres patentes, mais ce ne serait pas la première fois que nous constatons un écart entre les volontés des édiles et leur réalisation.

La largeur de la voie côtière à cet endroit, plus de $6 \mathrm{~m}$, semble contredire les études historiques qui s'accordent à dire que le quai n'était parfois pas plus large que $2 \mathrm{~m}$ (Hesnard et al. 2001, p. 187). En 1474, le voyageur allemand Hans Von Waltheym constate que «les bateaux vont jusqu'à trois aunes des murs de la ville » (Coulet 1991, 533), soit 3,50 m. Cependant, un plan de 


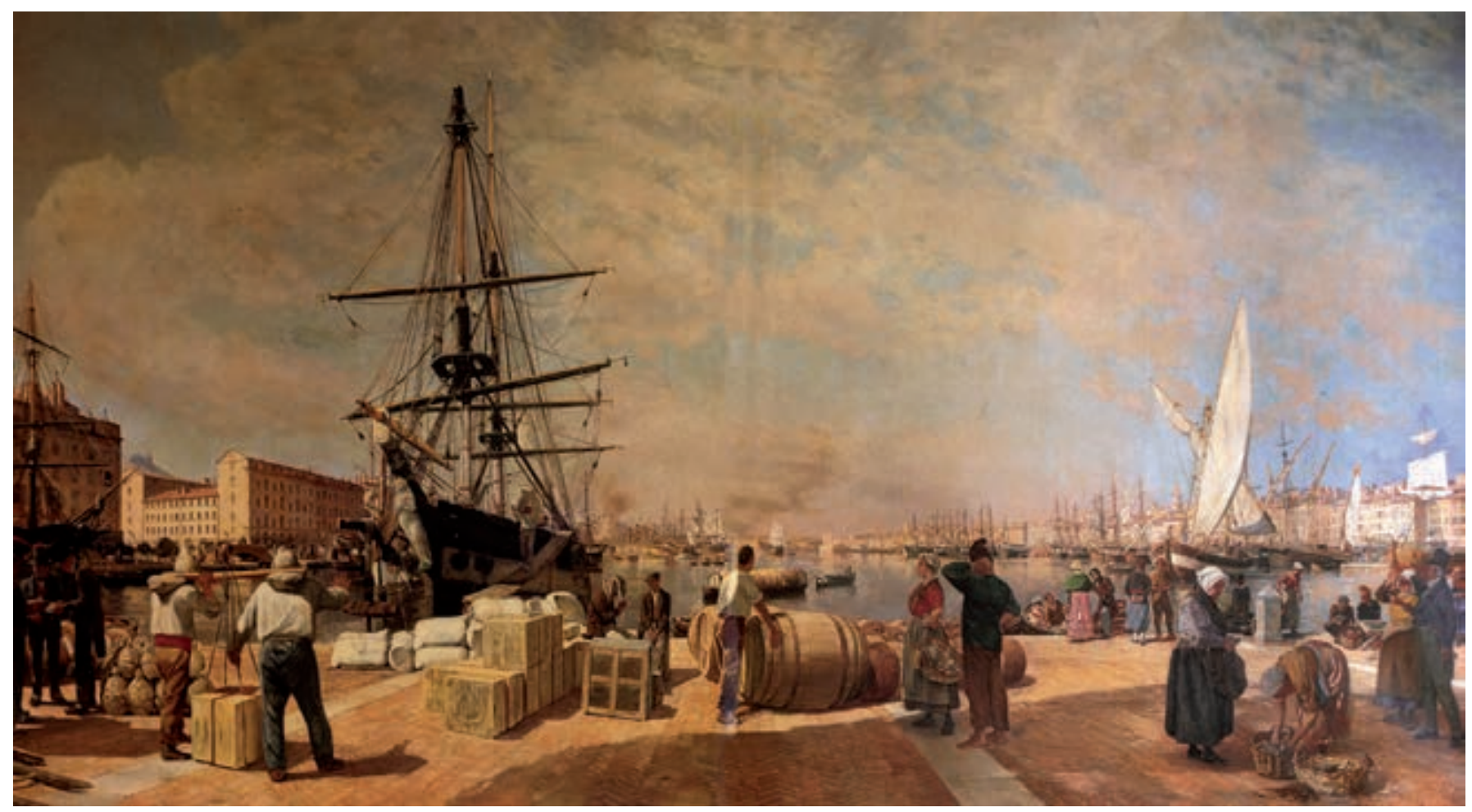

Fig. 20. Le quai de la Fraternité au début du XXe s. (J.-B. Moutte d'après Bertrand 2002, p. 149).

$1673^{66}$ met en évidence la singularité du quai devant les Augustins. Il est très large au débouché de la place Sainte-Anne et va en s'amenuisant vers l'est. La largeur que nous avons observée serait donc une particularité locale qui ne reflète pas l'ensemble des aménagements de berge de la rive nord. En revanche, nous n'avons pas observé de divergence entre les orientations du quai et de la façade recoupés par la fouille, mais il faut reconnaître qu'ils sont probablement trop fragmentaires pour pouvoir conclure.

\subsubsection{Les quais sous Louis XIV}

L'assise en pierre de taille précédente est surmontée de deux autres très différentes en raison de leur irrégularité et qui s'apparentent clairement à des réfections. Les pierres de taille, très corrodées par la mer parce que proches de la surface de l'eau, sont de dimensions trop variables pour ne pas être des remplois. Elles sont confortées, en retrait, par un mur de moellons liés par du mortier. Leur mise en place est datée du milieu du $\mathrm{XVII}^{\mathrm{e}}$ s. par la couche d'abandon d'un caniveau qu'elles recoupent.

De multiples réfections des quais sont mentionnées dans les textes entre 1670 et 1690, ainsi que d'importants

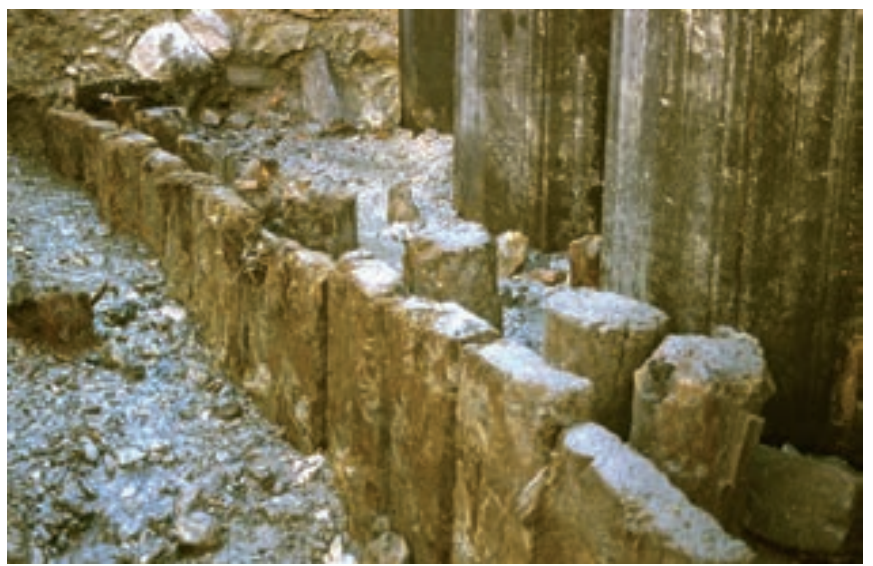

Fig. 21. La palissade Sainte-Anne en fouille (cl. B. Sillano/Inrap)

travaux de rénovation lors de la construction du Parc des galères, sous Louis XIV. Cependant, il n'est plus question dans les textes que de palissades, à priori en bois, et la nature même de cette réfection amène des interrogations. Ainsi, en 1602, il est question de «rhabiller et accoutrer 9 palissades ${ }^{67}$; or il est spécifié que les entrepreneurs «boucherons a pierre de tail, bien 
deuement, les trous de chascunes des palissades ». Le terme de palissade aurait-il prévalu à cette époque pour nommer les quais, quelle que soit leur nature ? C'est également à cette époque que le quai est recouvert de briques disposées en opus spicatum à l'intérieur de panneaux bordés de pierres de taille (fig. 20).

Un plan de 1673 est très intéressant car il s'agit de la première représentation fiable planimétrique du plan d'eau qui n'était dessiné auparavant qu'en vue cavalière. Certes, reporté sur le cadastre napoléonien, il comporte bien des erreurs d'azimut aisément compréhensibles. En revanche, en le comparant aux plans plus récents, par exemple celui de Bresson, nous constatons que les distances entre les palissades sont scrupuleusement respectées, mesurées à la chaîne d'arpenteur. Or, il apparaît clairement, à l'est du port, que la distance entre l'avant-dernière palissade et la dernière, qui deviendra la palissade Sainte-Anne, est deux fois moindre que celle qui sépare cette dernière de l'extrémité du port. Nous pressentons ainsi que le quai oriental du port a été repoussé d'une vingtaine de mètres peu après 1673 , période de reconstruction de l'Arsenal des galères, sur le périmètre du plan Fourmiguier. En 1667, les échevins se plaignent que « $M^{r}$ Arnoul continue le retraississement de nostre port et suivant les pillotins qu'il a de nouvau mis il le faict de 4 cannes donnant avec ce qu'il a faict il y a 38 cannes qui sont 228 pieds royaulx oultre le comblement qui se fera par la vase qui sera plus que $d u$ double ${ }^{6 \mathbf{6}}$. Le déplacement de la rive orientale du port ne fait donc aucun doute et le quai qui borde les Augustins aurait été plus long, d'environ $25 \mathrm{~m}$, que celui qui est dessiné sur le cadastre napoléonien.

\subsubsection{La palissade Sainte-Anne}

Nous avons eu la chance de recouper en fouille toute la bordure orientale de la palissade Sainte-Anne (fig. 21). Elle se compose de madriers de forte épaisseur ( $8 \mathrm{~cm}$ en moyenne) pour une largeur de $35 \mathrm{~cm}$ et une longueur inconnue, enfoncés côte à côte sur une distance de 9,30 m (dont seulement 3,50 m fouillés). Derrière, à $30 \mathrm{~cm}$ de distance, la palissade est bordée par un alignement de poteaux en bois d'environ $22 \mathrm{~cm}$ de diamètre séparés de $40 \mathrm{~cm}$ en moyenne. L'ensemble est découpé horizontalement à la côte - 0,60 m NGF, les pieux étant légèrement plus hauts. En arrière, l'espace est comblé par des cailloux et blocs en vrac, renforcé par des madriers en remploi coincés entre les pieux; des planches sont disposées à plat sur l'arase des pieux comme sur celle des madriers. Sur cette portion, la palissade n'a livré

68 ACM BB 251 D, fol. 579 : lettre des échevins à Bonin le 30 juillet 1667. aucun élément lapidaire taillé et tout porte à croire qu'ils ont fait l'objet d'une récupération puisque les pieux sont étêtés bien au-dessous du niveau de la mer. Les bois ont été systématiquement prélevés et ont fait l'objet d'une étude dendrochronologique. Les madriers sont en sapin, bois parfois utilisé en charpente mais plutôt réservé à la menuiserie, alors que les pieux sont tous en pin, bois courant pour ce type de structure ligneuse mais considéré comme cassant. Les sections importantes des madriers ont permis de dater l'abattage des arbres en 1728 et leur âge maximal à 63 ans.

Cette date nous permet d'établir la corrélation avec les travaux de construction de la palissade SainteAnne par Barthélemy Flotte, mentionnés en 1735. En revanche, nous n'avons pas de détails sur cet ouvrage dont « le public en a fort admiré la façon singulière de sa construction et compte beaucoup sur sa solidité ${ }^{\mathbf{6 9}}$. En 1741, lorsque le bureau d'entretien du port donne les nouvelles normes en matière de construction et réparation des quais ${ }^{\mathbf{7 0}}$, il est précisé qu'il s'agit de «la manière de bâtir dans l'eau avec béton usitée parmi les anciens grecs, les romains après eux et qu'on a commencé à pratiquer avec succès à Toulon » et que cette technique est « comme il a été fait a la palissade dite $S^{\text {te }}$ Anne». Or il s'agit là de la technique dite du «béton coulé », c'est-à-dire un mélange de pierres et mortier jetés entre des batardeaux préalablement implantés, ce que nous n'avons pas observé sauf, peut-être, sur l'autre partie de la palissade, en front de mer. Dans le cadre d'une surveillance de travaux, en effet, nous avons remarqué que la technique qui prévaut sur cette face consiste en un parement de pierres de taille renforcé par derrière par un mélange extrêmement compact de mortier et cailloutis. Le problème est que, à priori, cette face coïncide avec celle du quai napoléonien dont l'alignement se fait sur le bord externe de la palissade. Les constructeurs auraientils jugés l'œuvre de B. Flotte, réalisée près de 150 ans avant, suffisamment solide pour ne pas être refaite et servir de base ?

Un autre fait est troublant: la palissade que nous avons fouillée est en tout point similaire à celle de la Loge, mise au jour lors de travaux en 1950 et pour laquelle nous avons les textes relatifs à sa construction en $1690^{71}$ (fig. 22). La construction doit se faire « suivant le devis qui a esté fait par ledit $S^{\mathrm{r}}$ de Seguier, ingénieur pour le Roy dudit port de faire un battardeau avancé dans la mer, construire un pilotage de fondation, fonder sur ledit pilotage, un quay revestu d'un mur de pierre froide et dont le massif doit estre composé d'une bonne

69 CCIM D1.

70 CCIM D1, fol. 72-88.

71 ACM HH 449, 10 juin 1690. 
maconnerie a chaux et a sable ». La première partie est le «devis du bastardeau et pillotage » ${ }^{72}$. Le batardeau, d'une profondeur de 6 à $9 \mathrm{~m}$, est construit sur pieux (de $27 \mathrm{~cm}$ de diamètre au plus gros) au moyen de planches de 4,50 $\mathrm{m}$ à $6 \mathrm{~m}$ de long pour 7,5 $\mathrm{cm}$ d'épaisseur fixées sur des sablières de $27 \mathrm{~cm}$ par $10 \mathrm{~cm}$ de section. Le diamètre des pieux et l'épaisseur des planches qui, si elles sont fixées sur une sablière sont nécessairement verticales, concordent avec nos découvertes. Il est dit que l'entrepreneur doit ensuite vider l'eau et la vase qu'une seule rangée mais le secteur fouillé était étroit. En revanche, la distance entre les pieux était bien de 1,5 pieds $(40 \mathrm{~cm})$. Enfin, «les testes des pillotis seront esgalement razées a la ligne de fondation du mur et pour lier et fortifier l'ouvrage, on parquetera le dessus pilloté d'un plan, composé de bordages vieux de chesne de 10 pieds de longueur, jointées ensemble et arrestées sur la teste desdits pillotis avec deux cloux ou chevilles ». Nous avons aussi constaté cet arasement de la surface des pieux. Le reste, disparu, est décrit dans le «devis

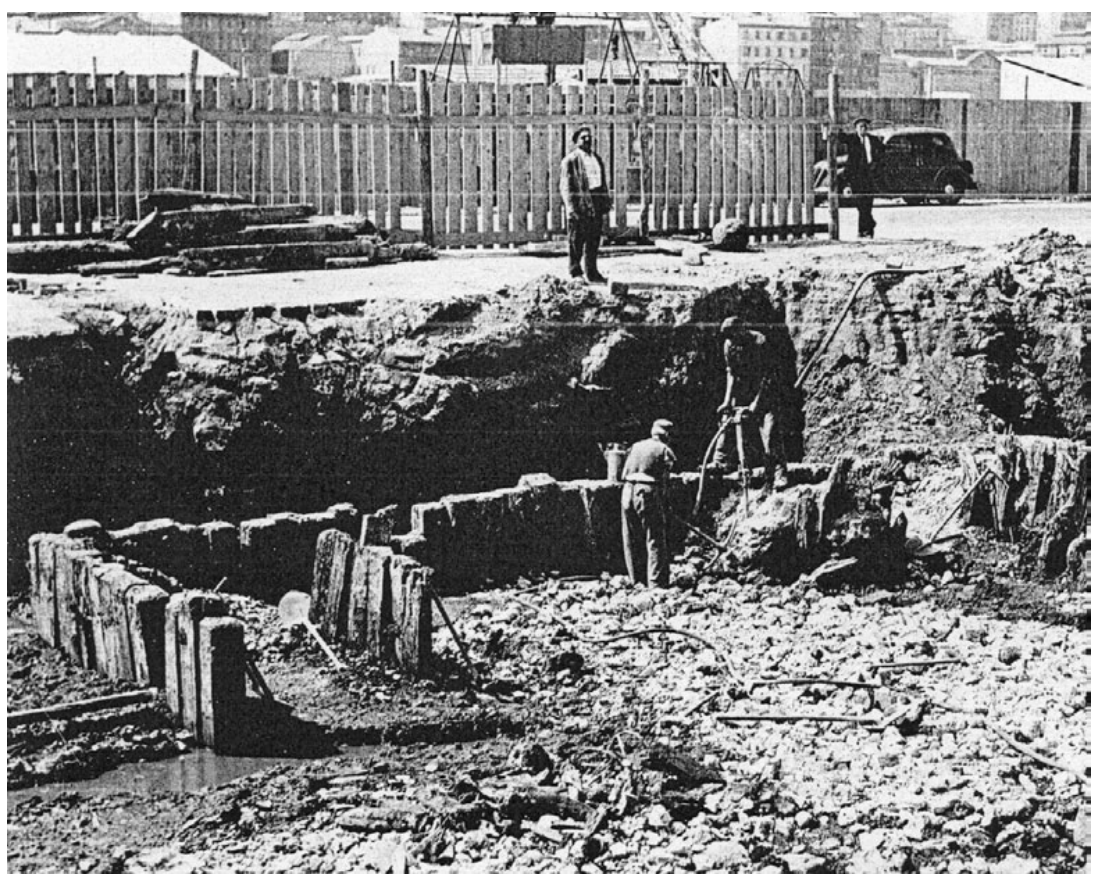

Fig. 22. La palissade de la Loge découverte en 1945 (CCIM).

«jusques a la rencontre du ferme », puis «l'espace du plan de fondation sera pavé de vieux pilotis racourcis de 9 a 10 pieds de longueur ou plus » et «l'entredeux desdits pilotis seront remplis de gros cailloux meslés que l'on battra a discrétion ". Nous avons également trouvé ces pierres entassées. Puis, «les pillotis seront jointés l'un contre l'autre du costé du battardeau et de cette manière en sera fait trois rangées. Le restant dudit plan sera composé des pilotis espacés entre eux, d'environ 1 pied et demy, franc de diamettre et seront enfoncés a la sonnette ${ }^{73}$ comme les autres ». Nous n'en avons observé

72 ACM DD 107, 16 mars et 15 avril 1690.

73 Machine dont on se sert pour enfoncer des pilotis ou des pieux. Elle comporte une lourde masse de fer ou de bois armée de fer, le «mouton », qu'on élève, et qu'on laisse retomber sur des pieux pour les enfoncer en terre. Pour lâcher le mouton, on tire sur une corde qui rappelle celles qui servent à manœuvrer les cloches, des ouvrages de pierre froide, taille et autres construction ${ }^{74}$. "Le mur du quay, du costé de la mer, sera revesteu d'une chemise de pierre froide (...) rangées par assises régulières unies, jusques au niveau de l'eau». Sur le dessus, celles-ci auront $50 \mathrm{~cm}$ de largeur, $80 \mathrm{~cm}$ de long et $25 \mathrm{~cm}$ de hauteur et seront «cramponnées et scellées en plomb». L'arrière est fait de maçonnerie « de pierre de roche de chaux et sable bien battue». Enfin « le quay aura 7 pieds par le bas et 6 par le haut, 3 toises de profondeur soubs le niveau de l'eau et sur ledit niveau s'eslevera 3 pieds », phrase difficile à comprendre, sinon que le quai dépasse de $75 \mathrm{~cm}$ au-dessus de l'eau et qu'il est profond de $5 \mathrm{~m}$.

ce qui explique l'appellation « sonnette ». On « sonne » les pieux « à refus » c'est-à-dire jusqu'à ce qu'ils refusent de s'enfoncer plus. 74 ACM DD 107, 12 mars 1690. 
PREMIÈRE PARTIE : ÉTUDE TOPOGRAPHIQUE ET MORPHOLOGIQUE D’UNE VILLE MULTIPOLAIRE

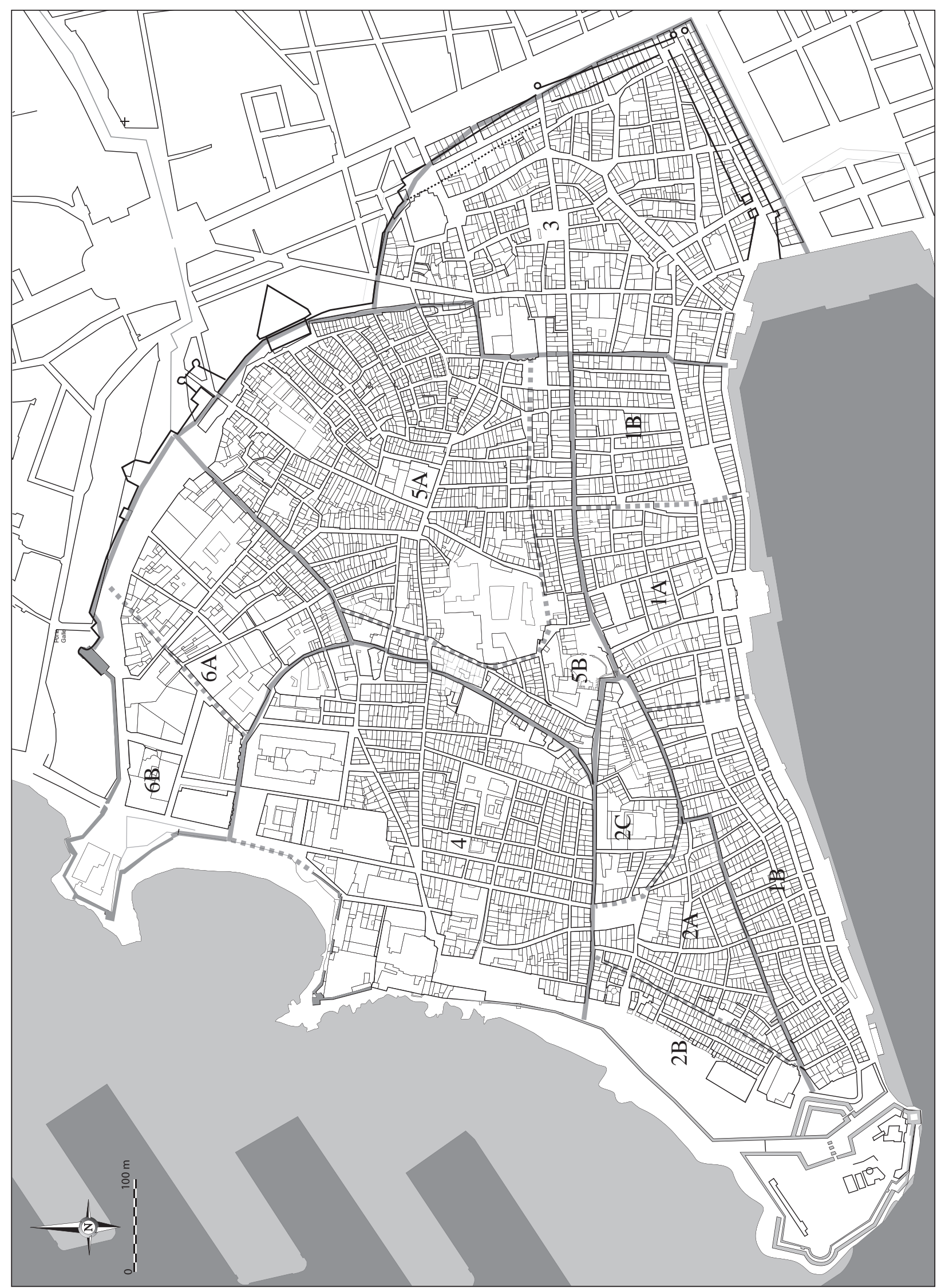

Fig. 23. Détermination des différentes unités sur fond cadastral napoléonien (DAO M. Bouiron/Ville de Nice, F. Paone/Inrap). 


\section{Chapitre 2}

\section{Évolution de la morphologie urbaine}

$\mathrm{L}$ a connaissance de la morphologie urbaine a pris un essor particulier avec les fouilles réalisées ces trente dernières années. La multiplication des «fenêtres» ouvertes dans le sous-sol a permis de mieux comprendre la trame urbaine et le réseau viaire, depuis le Moyen Âge jusqu'à nos jours.

\section{Le réseau viaire}

Le réseau viaire apparaît comme l'élément le plus important dans la structuration de la trame urbaine. Que ce soit pour la période médiévale ou pour les Temps Modernes, la fouille des voies anciennes a permis de préciser leur tracé exact, en un nombre de points suffisamment nombreux pour commencer à réfléchir à l'échelle de quartiers.

\subsection{Lecture morphologique de la vieille ville (F. Paone)}

Les différentes analyses réalisées montrent qu'à l'exception des faubourgs, la morphologie de Marseille durant la période moderne est le reflet de celle de la ville médiévale et que les principales modifications touchant le parcellaire consistent en une réunification des parcelles et une disparition de venelles de cœur d'îlot voire à l'inféodation de certaines rues ( $c f$. infra $\S \mathrm{I}, 2,2.2$.). Cependant l'implantation de couvents et hôpitaux se multiplie au cours du XVII ${ }^{e}$ s. ; ces vastes ensembles monumentaux effacent une partie des îlots anciens dans la partie septentrionale de la ville (cf. supra § I, 1, 3.2.). Pourtant le maintien généralisé du réseau viaire du Moyen Âge nous incite à proposer une analyse de la trame de la ville médiévale sur la base du cadastre napoléonien de 1820, selon une lecture régressive. Des premières lectures du tissu urbain de l'Antiquité (Moliner 2001, p. 101-120) et du Moyen Âge (Bouiron 2001d, p. 147-156) ont été proposées en 2001, mais les découvertes réalisées depuis permettent d'affiner l'évolution chronologique de la topographie marseillaise et d'en préciser les formes.

\subsubsection{Détermination des principales unités de plan}

Les différentes unités de plan sur le cadastre napoléonien sont distinguées selon plusieurs critères: l'organisation du réseau viaire, l'ordonnancement spatial, le découpage parcellaire et la détermination des rues structurantes (Gauthiez 2003).

Les principaux secteurs identifiés répondent pour l'essentiel à la topographie naturelle du site qui est caractérisée par la présence de buttes alignées selon un axe nord-est/sud-ouest (les buttes Saint-Laurent, des Moulins, de la Roquette et des Carmes) aux versants bien marqués, de vallons étendus (vallon Saint-Martin et de la Joliette) et bien sûr par l'anse profonde du Lacydon (Bouiron, Gantès 2001) (cf. fig. 2). C'est dans ce contexte que sont mises en place les trames grecques qui restent encore prégnantes aux époques médiévales et modernes (secteurs 4 et 6). Cependant, certaines zones s'affranchissent d'avantage de cet héritage (secteur 5) ou sont en lisière de la ville antique (secteur 3). Ces observations témoignent d'une réurbanisation de la ville dont l'occupation avait décliné profondément au cours du haut Moyen Âge (fig. 23).

\section{Secteur 1 : la rive nord du port}

La première unité définie concerne la rive septentrionale du port. Au nord, la rupture de pente avec les buttes des Moulins et des Carmes est matérialisée par les rues Caisserie - Grand-Rue, ancien axe grec qui correspond à une véritable structure dynamique et se prolonge à l'ouest par la rue Saint-Laurent et à l'est au delà des remparts. Au sud, le trait de côte constitue un élément déterminant. Son recul par rapport à celui de l'Antiquité offre de nouveaux espaces disponibles à bâtir; la rue de la Loge forme une parallèle à la ligne de rivage. Le long du port, l'étroitesse de l'espace laisse place à des rangées de parcelles de petites dimensions formant un cordon linéaire gagné au XIII ${ }^{\mathrm{e}} \mathrm{s}$. au-delà de la ligne de rivage du $\mathrm{XI}^{\mathrm{e}} \mathrm{s}$. Ces dernières sont doublées au nord par une seconde série d'îlots plus larges et dilatés. Ensuite, la trame est principalement structurée d'axes orientés 
globalement nord-ouest/sud-est conformément à la ligne de rivage et qui assurent la communication entre le port et l'intérieur de la ville; certaines voies ont une légère courbure et adoptent une disposition en large éventail afin de permettre au réseau de basculer progressivement à l'est du quartier du Mazeau où est établie une orientation nord/sud conformément au tracé de l'enceinte antique (secteur 3A) (fig. 24).

\section{Secteur 2 : butte Saint-Laurent-montée des Accoules}

Cet ensemble forme la transition entre la zone du port et le quartier de la Major (secteur 4), il est caractérisé par une série de pattes d'oie rayonnant de l'est à partir de la rue Caisserie vers l'ouest (2A) jusqu'à la barre nord-est/sud-ouest formée par la colline Saint-Laurent

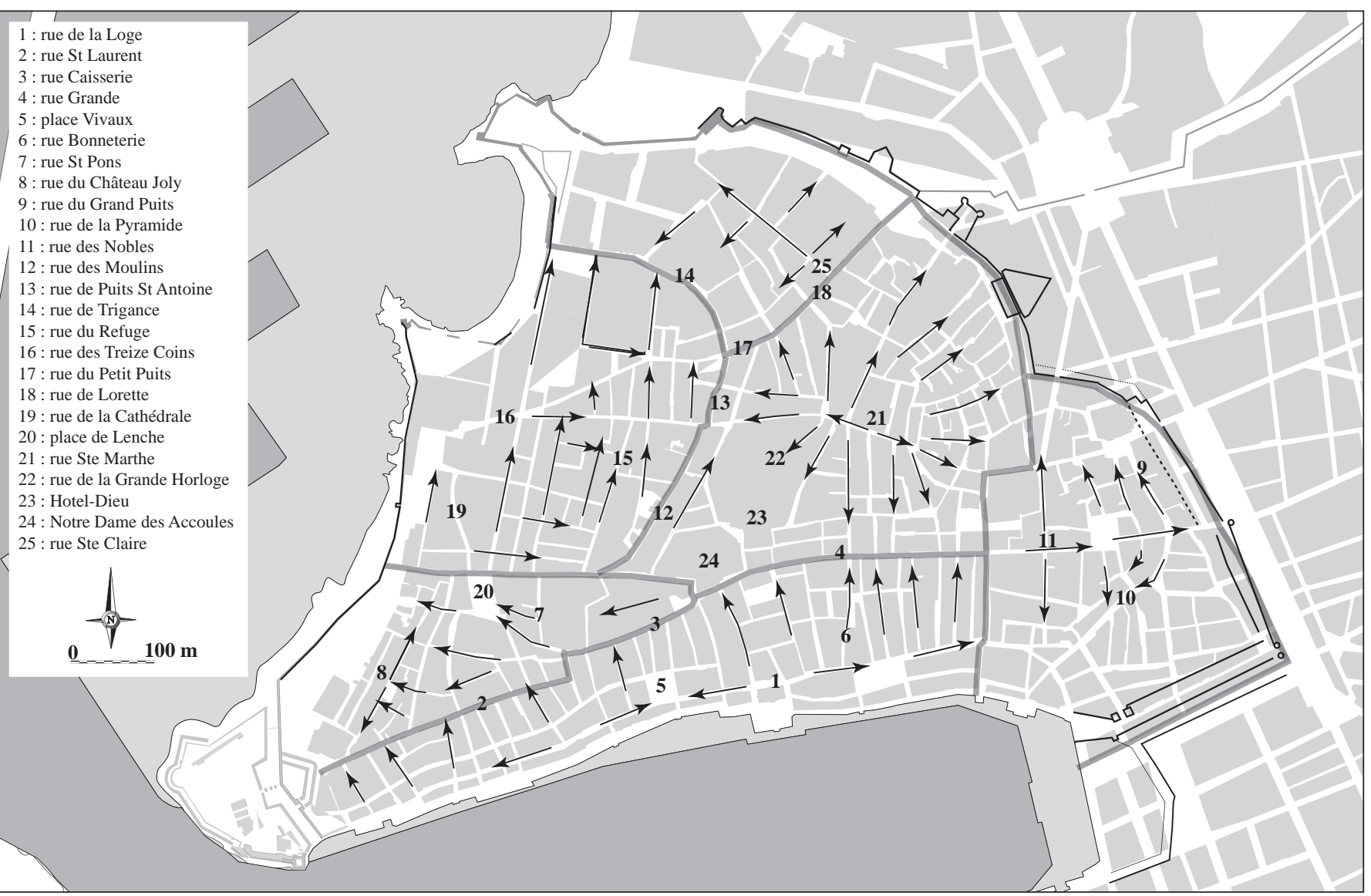

Fig. 24. Détermination des principales orientations (DAO F. Paone/Inrap sur fond de plan M. Bouiron)

Les îlots et les parcelles de plus grande envergure sont concentrés entre la place Vivaux et la rue Bonneterie (1A). La fouille de la place Bargemon a montré que lors de la création du quartier du Mazeau au XII ${ }^{\mathrm{e}}$ s., l'îlotage est d'un gabarit inférieur mais que certains lots sont plus grands que dans le secteur 1B. L'évolution morphologique s'explique en partie par la reconstruction sur ces parcelles de vastes ensembles bâtis suite à la destruction partielle du quartier médiéval lors du sac des Catalans en 1423. A l'est comme à l'ouest de cette zone (1B), la morphologie parcellaire est plus standardisée, caractérisée par des ensembles longs et étroits ainsi que par un découpage laniéré, conservant son origine médiévale. sur laquelle sont établis au XVIII ${ }^{\mathrm{e}} \mathrm{s}$. d'étroits et longilignes îlots. Ils remplacent les moulins médiévaux qui dominaient une partie de la barre rocheuse à l'extrémité de laquelle est érigée l'église Saint-Laurent (2B).

Les interventions archéologiques ont peu porté sur ce secteur de la ville, à l'exception d'une petite fouille sur le parvis de l'église Saint-Laurent. Nous connaissons fort peu l'évolution topographique du secteur qui, pourtant, accueillit le château Babon dont l'empreinte morphologique n'est plus lisible. Cette unité est, avec le secteur 3, celle qui présente la plus grande diversité dans son découpage parcellaire dont une partie est masquée par la fonderie royale établie au XVII ${ }^{e}$ s. (2C). Il semble 
cependant qu'antérieurement à sa mise en place, la rue Saint-Pons se prolongeait à l'est comme l'indique la présence d'une desserte de cœur d'îlot et pouvait déboucher au croisement de la montée des Accoules et de la rue Caisserie.

\section{Secteur 3 : autour des extensions des enceintes}

Cette partie de la ville correspond à un débordement des limites antiques et est caractérisée par des zones de croissance continue déterminées par les reculs successifs des remparts. Une des principales contraintes est due à la présence de l'enceinte antique et antique tardive composée d'une triple ligne de défense répartie autour de la porte d'Italie d'où part une voie remontant à l'époque grecque (Grand-Rue). Paradoxalement la pénétration de la corne du port présente dans le paysage jusqu'au VII ${ }^{\mathrm{e}} \mathrm{s}$. est totalement gommée, ne laissant aucune trace fossile sur le parcellaire.

La fouille de la Bourse et du Jardin des Vestiges, essentielle pour l'Antiquité, n'a pas documenté les systèmes défensifs médiévaux. La forme rémanente de l'enceinte de 1040 est perceptible dans le tracé des rues du Grand-Puits et de la Pyramide (3A) ; celle de l'enceinte de 1250 est fossilisée dans l'ordonnancement parcellaire du cordon d'îlots périphériques (Bouiron 2001d, p. 153) (3B).

\section{Secteur 4 : quartier Major, butte des Moulins}

Ce secteur se compose de plusieurs entités englobées par la couronne formée par les rues des Moulins / du Puits-Saint-Antoine / de Trigance, dont le tracé courbe se justifie à l'est par la présence de la butte des Moulins ; elle correspondrait, d'après M. Bouiron, à l'emplacement de l'enceinte réduite de La Major. La majeure partie de cet ensemble est caractérisée par une trame viaire orthogonale structurée par des axes de direction nord-nord-est/sud-sud-ouest dont certains se prolongent sur toute la longueur du secteur. Le cadastre de 1830 montre que nous sommes en présence d'un maillage régulier et linéaire qui détermine pour l'essentiel des îlots de forme rectangulaire au parcellaire laniéré. À l'est, la rue du Refuge matérialise la rupture de pente due à la présence de la butte des Moulins amorçant ainsi une inclinaison vers l'est. Au sommet de la colline, la série de moulins est en partie remplacée par une place allongée. Enfin au nord, l'espace est totalement investi au XVII ${ }^{\mathrm{e}}$ s. par plusieurs établissements religieux (le Saint-Sacrement, les Observantins) et chapelles ainsi que par des hôpitaux (la Vieille Charité, le Refuge) qui gomment toutes traces médiévales tout en respectant les orientations générales.
Les opérations du Tunnel et de l'Esplanade Major, des Pistoles, du Refuge et de la Vieille Charité ont clairement défini que les voies orthogonales sont mises en place depuis la période grecque archaïque ${ }^{75}$ mais certaines rues sont parfois légèrement décalées par rapport à celles de l'Antiquité. L'établissement du groupe épiscopal paléochrétien en lisière occidentale est intégré totalement dans le réseau viaire antique et l'impact sur la topographie du quartier de l'ensemble cathédrale médiéval, reconstruit au même emplacement que celui du $\mathrm{V}^{\mathrm{e}} \mathrm{s}$., est beaucoup plus tardif. Le percement de la rue des Treize-Coins prolongé à l'est par la rue du Petit-Puits pourrait être attribué logiquement à la nécessité de relier l'ensemble cathédral à la demeure de l'évêque établi à partir du XII' $\mathrm{s}$. sur la butte des Carmes. Or, la fouille du Tunnel a montré que c'est seulement à partir des XIII-XIV e ${ }^{\mathrm{s}}$. que cette voie apparaît clairement bordée au sud par les maisons des clercs, l'ensemble ayant amputé une partie du cimetière paroissiale. La rue des Treize-Coins / rue du Petit-Puits et, au sud, la rue de la Cathédrale adoptent donc un tracé totalement divergent de la trame grecque, permettant de faire la communication avec la rue de Lorette qui, non isocline, relève d'un réseau viaire antique distinct structurant le secteur 6. L'impact de ce percement sur la morphologie parcellaire est clairement visible sur les îlots bordiers et c'est au nord de cette limite que sont installés les ensembles monumentaux modernes. Il en est de même pour la rue de la Cathédrale, dont le tracé antique légèrement décalé par rapport à l'actuel, permettait d'après la fouille du Tunnel de la Major de relier une esplanade au forum (actuelle place de Lenche). Au Moyen Âge, elle devait assurer la communication entre le groupe épiscopal et le château Babon.

\section{Secteur 5 : butte des Carmes et butte de la Roquette}

Ce secteur se différencie de façon significative des autres unités par la forme radio-concentrique de son maillage qui s'organise à partir non pas d'un pôle mais d'une artère, -la rue Sainte-Marthe ${ }^{76}$ - qui, dans ses extrémités, se dilate pour déboucher sur un ensemble de rues rayonnantes distribuant des voies aux tracés courbes plus densément réparties dans la moitié orientale de la butte de la butte des Carmes (5A). Cette organisation spatiale aboutit à la mise en place d'îlots aux formes et dimensions extrêmement diversifiées : certains sont étroits pourvus de minuscules découpages en lanières; ils côtoient de vastes îlots pyramidaux dont les lots sont plus vastes et profonds. Le cœur de ces parcelles enclavées nécessitent la présence de dessertes voire de rues

75 Il s'agit du système S3 déterminé par M. Moliner.

76 Le long de cette rue est établi au XII' s. l'hôpital du même nom. 
inféodées durant la période moderne dont des tracés parcellaires conservent la mémoire. Le schéma général est ici principalement déterminé par une adaptation aux contraintes générées par le relief.

Malgré le peu d'informations pour le Moyen Âge fournies par les fouilles de la butte des Carmes, il semble possible de dire que le cadastre moderne reflète la morphologie médiévale. En revanche, les quelques constructions médiévales dégagées présentent des orientations distinctes des structures antiques, à l'exception bien sûr du rempart hellénistique dont le tracé et probablement une partie des substructions ont perduré. Ainsi, la morphologie générale de ce secteur trouve son origine dans l'organisation spatiale médiévale plus qu'antique.

Dans la partie sud-ouest, l'Hôtel-Dieu qui occupe essentiellement la butte de la Roquette a totalement éradiqué la trame médiévale vraisemblablement rayonnante comme le laisse pressentir l'orientation de la rue de la Grande-Horloge et ce conformément à la configuration générale du secteur.

L'église Notre-Dame des Accoules, qui relève du premier monastère marseillais Saint-Sauveur, forme un élément structurant dans l'articulation de différentes unités avec laquelle elle est en contact (secteurs 1, 2, 4 et 5). A l'est et au nord des Accoules, une zone de transition (5B) permet la liaison entre les réseaux viaires des secteurs 1 et $4 \mathrm{~B}$.

\section{Secteur 6 : versant nord de la butte des Carmes et le vallon de la Joliette}

Cette unité correspond à la partie la plus septentrionale de la ville, qui du fait qu'elle devait être moins lotie, accueillit plusieurs couvents (les Saintes-Maries et des Trinitaires) au XVII ${ }^{e}$ s. ; cependant, dès le XIV ${ }^{e} s$. y est établi le monastère des Clarisses. Le tracé de l'enceinte grecque détermine une limite nord en arc-de-cercle, conditionné par la présence des vallons de la Joliette et Saint-Martin. La trame antique a une direction nordouest/sud-est matérialisée par la rue Sainte-Claire qui forme l'épine dorsale d'un maillage orthonormé.

La partie la plus septentrionale de la ville est documentée par plusieurs opérations de fouille (la rue Leca, le parc des Phocéens, le parking République et la rue Trinquet) qui ont prouvé que la voirie médiévale conservait en la densifiant un peu la trame antique ${ }^{77}$, mais qu' au XVII ${ }^{\mathrm{e}}$ s. au moins une rue est créée. Les informations sont malgré tout ténues.

77 Il s'agit du système S5 déterminé par M. Moliner.

\subsubsection{Pour conclure}

La lecture du cadastre de 1820 montre que si Marseille médiévale est empreinte des contraintes topographiques, elle conserve en plusieurs secteurs l'héritage des tracés grecs. Elle présente des structures morphologiques extrêmement denses, aux réseaux viaires resserrés et étroits (les rues dépassent rarement une largeur de $4 \mathrm{~m}$ ), et aux constructions continues. Il semble cependant qu'une simplification de la trame soit réalisée durant l'époque moderne avec la suppression de certaines rues et dessertes de cœur d'îlot, la suppression des espaces ouverts (cours ou jardins) dont les archives nous signalent la présence au profit d'une densification de l'habitat, et la réunification de parcelles voire d'îlots primitifs au sein d'ensembles plus vastes. Cette refonte limitée du paysage résulte d'avantage d'un besoin croissant d'espaces à bâtir en réponse à la croissance démographique qu'à une véritable démarche urbanistique. Cette dernière est clairement affichée lors de l'Agrandissement planifié de la ville par Louis XIV, l'indispensable continuité territoriale s'effectuant alors grâce au maintien des voies partant des portes de la ville médiévale, qui ont perduré malgré la destruction des faubourgs au $\mathrm{XIV}^{\mathrm{e}} \mathrm{s}$.

\subsection{Mise en ouvre et entretien des rues aux époques médiévale et moderne ( $\mathrm{F}$. Paone)}

Pour l'essentiel le réseau viaire trouve son origine dans l'Antiquité ou le haut Moyen Âge. Cette longévité, propice à l'analyse topographique, est en revanche pénalisante pour l'étude de la mise en œuvre de ces voies et de leur évolution. Victime de son usage et donc de son usure, la rue est l'objet de travaux d'entretien régulier et continu jusqu'à nos jours où les chaussées déformées sont éliminées pour être remplacées par du goudron. La rue est régulièrement surcreusée car elle constitue le réceptacle naturel de toutes les infrastructures collectives d'hier comme d'aujourd'hui : arrivées d'eau, égouts, conduites de gaz et d'électricité, réseau de téléphonie. Malgré ce dédale de creusements et de remises en état successifs sont parfois miraculeusement conservés quelques lambeaux de sols antiques ou médiévaux, plus rarement modernes, qui deviennent alors autant de traces précieuses pour la connaissance de ces rues. La fouille de voies, bien que souvent partielle, permet de dater les maisons dont les sols peuvent avoir disparu, et pour ce qui nous intéresse ici de connaître la gestion, comme parfois l'absence de gestion de ces espaces de circulation. Pour les périodes médiévale et moderne, des lacunes subsistent bien sûr ; elles concernent plus particulièrement le haut Moyen Âge et les $\mathrm{XV}^{\mathrm{e}}-\mathrm{XVI}^{\mathrm{e}} \mathrm{s}$. 
C'est lors des différentes opérations au nord de la Mairie qu'a été conduite l'étude exhaustive de plusieurs axes de circulation mis en place à la fin du $\mathrm{XII}^{\mathrm{e}} \mathrm{s}$. Elle a permis de saisir leur évolution sur un peu plus d'un siècle, grâce à l'accumulation des sols et de leurs recharges ${ }^{78}$ pouvant atteindre, dans le cas de la rue du Petit-Mazeau, plus de $2 \mathrm{~m}$ de hauteur (fig. 25). L'épaisseur de cette sédimentation se justifie en partie par le manque de soin apporté à la réalisation des sols dont l'usure rapide est palliée régulièrement par des recharges de terres (Leguay 1984). Quelques aménagements attribués au $\mathrm{XVI}^{\mathrm{e}} \mathrm{s}$. sont également présents mais l'Époque moderne -et plus particulièrement le XVII s.est surtout marquée par les creusements d'extension de certaines caves qui empiètent sur la rue.

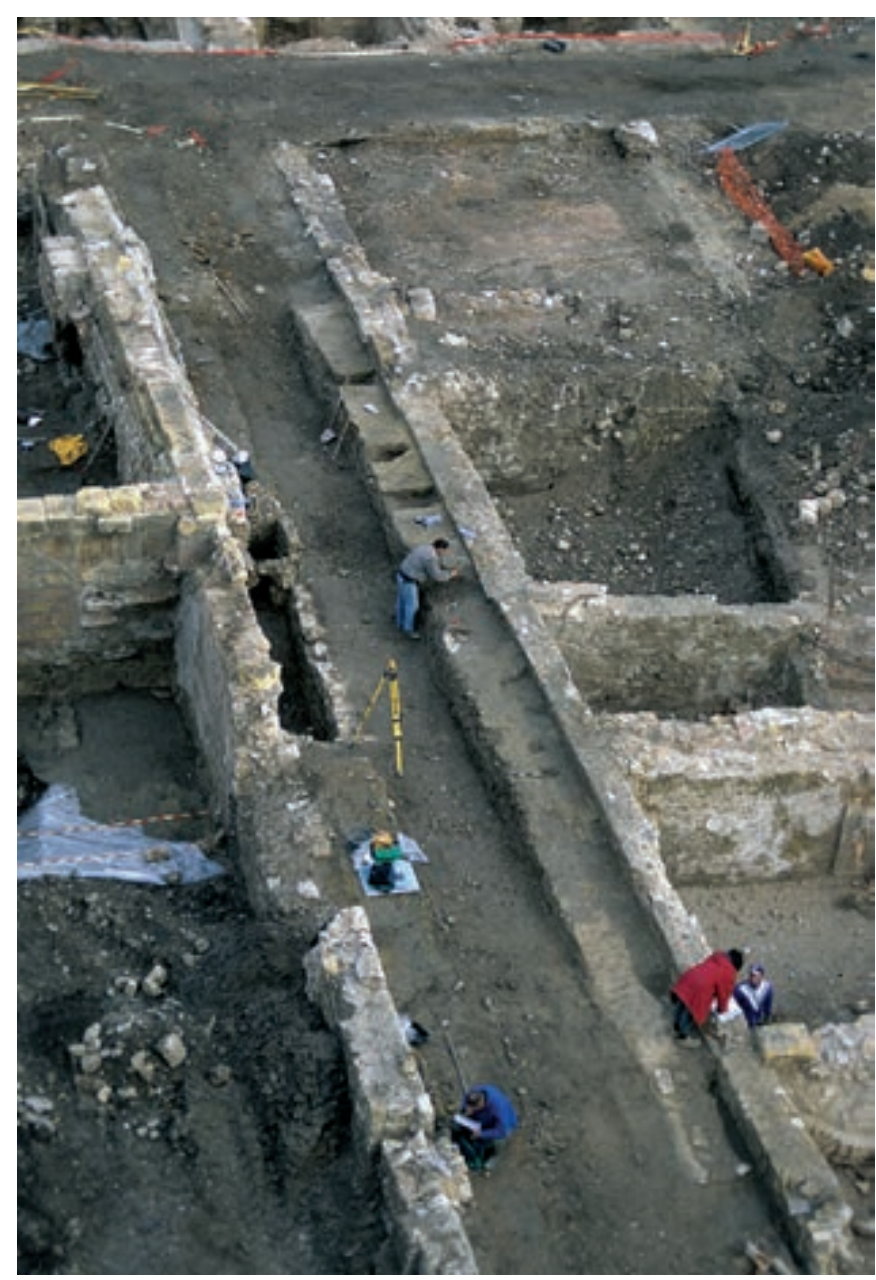

Fig. 25. La rue de la Taulisse en cours de fouille (cl. M. Derain /Inrap).

78 Les sols sont conservés sur une largeur de $1 \mathrm{~m}$ le long des façades, la partie centrale de la rue est détruite par les collecteurs contemporains qui sont systématiquement localisés là.

\subsubsection{La mise en ouvre}

La mise en œuvre des rues varie suivant les périodes : les matériaux constituant la chaussée est ainsi plus ou moins résistant et fait l'objet d'une mise en place collective ou individuelle.

\section{Durant le Moyen Âge}

Les fouilles ont permis de montrer une très grande diversité dans la composition des niveaux de circulation médiévaux mais également, dans certains cas, d'une bonne technicité (cf. infra § II, 2, 2.3.1. et II, 3, 2.3.1.). Dans le secteur du Mazeau, les plus anciennes surfaces d'utilisation les plus anciennes sont souvent marquées par des épandages de chaux ou de brasier ${ }^{79}$ en lien avec l'édification progressive des maisons. Ainsi, de façon générale, les reprises d'élévation des édifices sont l'occasion de reconstituer une surface plane, comme dans la rue de la Taulisse, où plusieurs sols chaulés tapissent les premières assises des façades nouvellement construites. Nous n'observons pas de progression significative au fil du temps dans le traitement ou le choix des matériaux, très fréquemment de simples recharges s'accumulent localement et comblent une cavité, nivellent une déclivité. Une meilleure cohésion de la couche est opérée grâce au broyage des matériaux qui la composent, alors que d'autres fois un soin particulier est apporté à la réalisation d'un sol pavé. Le déversement dans la rue de déchets alimentaires, de vidanges de foyer ou de rejets artisanaux, bien que proscrit par les Statuts municipaux, est régulièrement constaté.

Tous ces apports peuvent se superposer ou côtoyer des sols construits dont la mise en ouvre sous-tend l'emploi d'une main d'œuvre qualifiée. Des strates, formées de matériaux pilés (fragments de terres cuites) ou de petites inclusions (graviers, sable, mortier) associés à un liant argileux qui les rend particulièrement compactes, homogènes et donc plus stables, offrent ainsi une réponse provisoire à l'usure générée par la circulation et les intempéries. Moins répandus mais attestés sur différentes voies, les sols d'argile agglomérée sont formés de mottes de matière pure empilées sur deux ou trois niveaux et biseautés à leur base pour mieux s'imbriquer, l'ensemble reposant sur un lit de sable établi sur un remblai préparatoire; la surface du sol est lissée. Enfin certains sols compacts et uniformes associent petits galets, graviers, sables dans une matrice de terre battue limono-sableuse.

79 Agrégat issu de la taille des blocs. 
L'utilisation de dalles de pierres, bien que très marginale, apparaît dès le XII ${ }^{\mathrm{e}} \mathrm{s}$. devant une maison ouvrant sur la rue du Petit-Mazeau. Ces éléments de calcaire de formes variées sont liées à de l'argile plastique dans laquelle sont intégrés des morceaux de tuiles et des graviers, l'ensemble étant délimité par un alignement de pierres triangulaires formant bordure. Ce dallage s'intègre à la surface de circulation de la voie qui se compose essentiellement de terre battue et de chaux (fig. 26). La voie de la Calade qui borde le plan Fourmiguier est également pourvue dans le courant du XIII' s. d'un dallage très bien agencé et doté d'une limite nette ; sa présence seulement sur la moitié orientale de la rue a conduit les fouilleurs à l'interpréter comme un trottoir (Maurin et al. 2001a, p. 60-61).

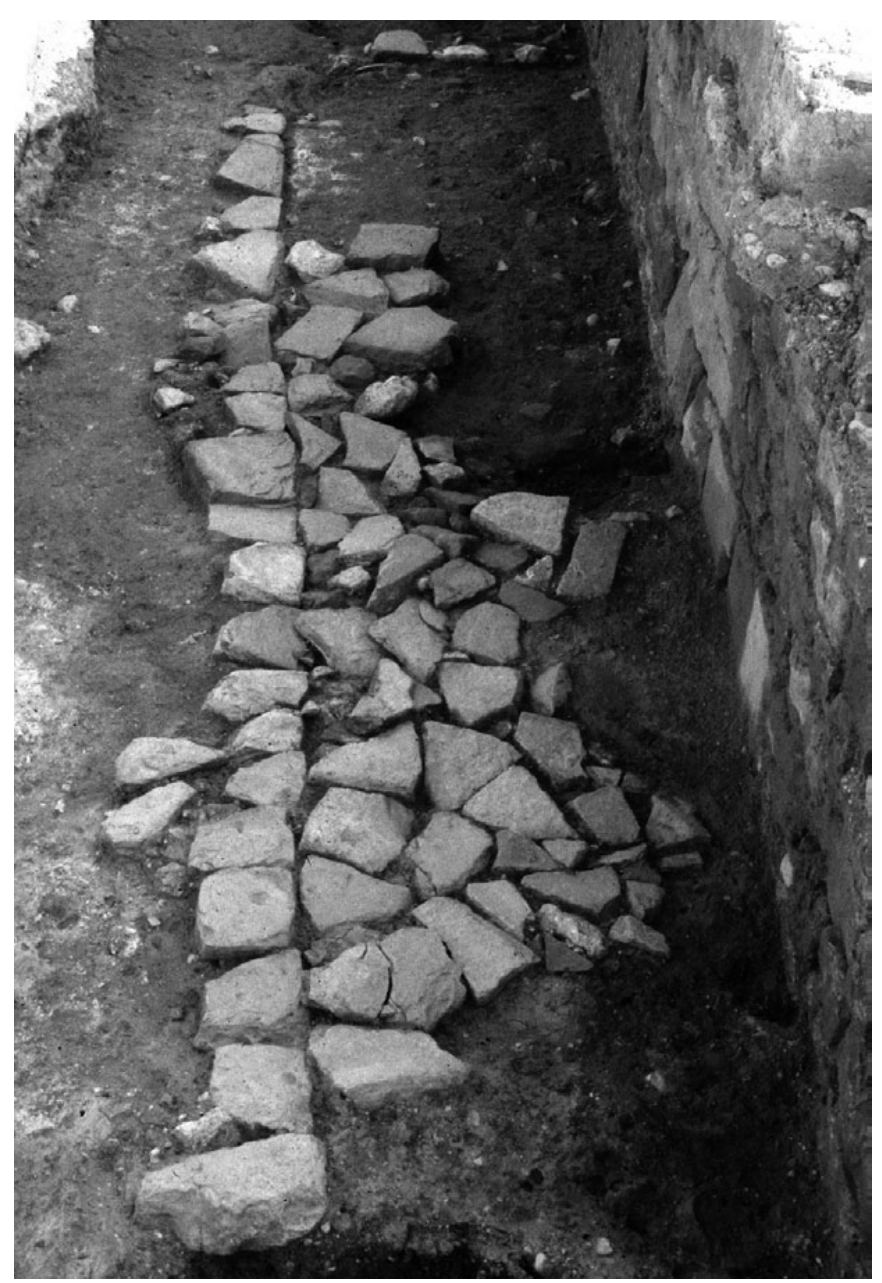

Fig. 26. Sol dallé dans la rue du Petit-Mazeau (cl. M. Derain/Inrap).

À la fin du XIII ${ }^{\mathrm{e}}$ s. et surtout au XIV ${ }^{\mathrm{e}}$ s., les revêtements de galets (appelés «calades» dans l'aire provençale) se multiplient à l'intérieur de la ville et dans les faubourgs sans toutefois se généraliser. Il est tentant d'y voir une volonté publique d'endiguer les problèmes récurrents de la voirie, de stopper l'accumulation sédimentaire générée par les multiples recharges et surtout de faciliter la circulation des piétons, comme des charrois. Établis sur une surface préalablement remblayée et nivelée, ces sols intègrent galets et pierres brutes de dix à vingt centimètres de diamètre dans le meilleur des cas, le plus souvent de dimension moindre ; l'ensemble est disposé sur un lit de limon ou de sable et parfois calé par des fragments de tuiles ou de céramiques. Les pavés s'articulent autour d'un fil d'eau central déterminé par des galets plus gros ou placés perpendiculairement à l'implantation générale des autres éléments, permettant ainsi de canaliser les écoulements. L'exemple le plus significatif a été découvert dans le bourg Sainte-Catherine où l'axe principal bien nommé via Callata est revêtu d'un pavage de galets dans lequel sont établies une série de rigoles destinées à canaliser l'eau des toitures vers un fil d'eau axial mais également le long des façades par le biais d'un empierrement en léger dévers destiné à protéger la base des murs (fig. 27). Malgré une mise en œuvre plus soignée, des matériaux plus résistants et surtout un revêtement disposé sur tout le tracé de la rue, des restaurations régulières semblent dans certains cas inéluctables comme par exemple au Petit Mazeau où quatre pavages se succèdent en un peu plus d'une cinquantaine d'années.

Les traces d'usure sont régulièrement constatées sur les surfaces de circulation, usure due au piétinement, aux lessivages par les eaux usées et pluviales ou aux activités multiples qui empiètent sur les rues. Aux fosses, crevasses, nids de poules, s'ajoutent également les ornières creusées par les passages répétés des charrois. Sur la rue de la Guirlande, dans le secteur fréquenté du Mazeau, elles sont profondes et larges d'une trentaine de centimètres, l'entraxe minimum des véhicules est estimé à $1 \mathrm{~m}$; dans le bourg Sainte-Catherine, il atteint 1,20 m.

À la lueur de l'ensemble des fouilles médiévales marseillaises, il apparaît que les rues les plus concernées par les ravinements en fonction de leur situation topographique, ou bien les plus fréquentées, ne sont pas pourvues d'un revêtement particulier. De même les environs immédiats d'établissements religieux ou de monuments en lien avec le pouvoir civil ne semblent pas avoir bénéficié de mise en œuvre plus soignée. Ainsi les voies permettant d'accéder à la cathédrale de la Major ont pour la plupart des sols en terre battue.

\section{Durant l'Époque moderne}

L'absence souvent constatée de sols de circulation d'Époque moderne s'explique naturellement par l'action dévastatrice des terrassements contemporains mais vraisemblablement aussi par la récupération massive des matériaux lors des refontes des sols pavés, répandus pour 


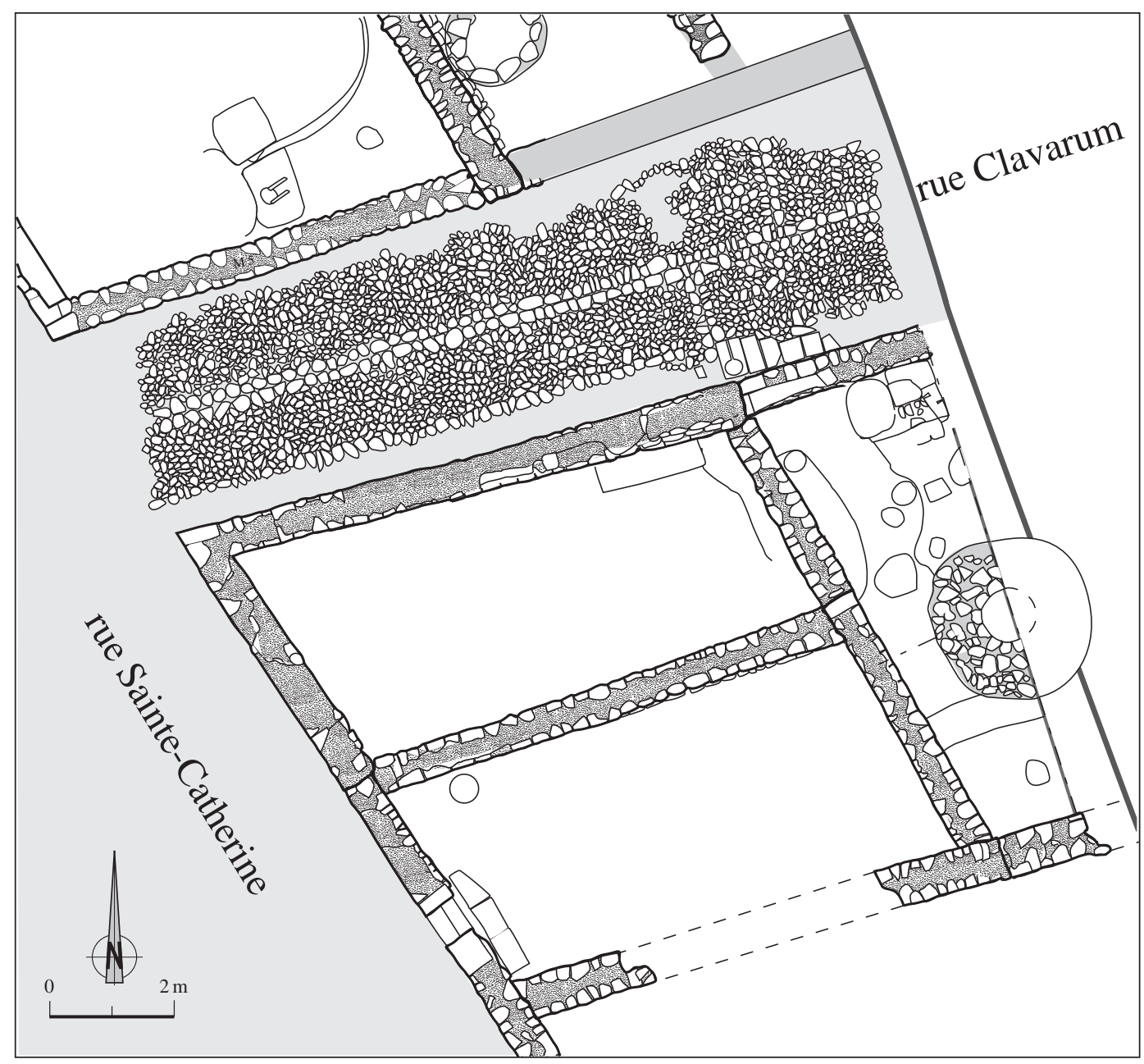

Fig. 27. La ruelle Clavarum et les îlots au nord du bourg Sainte-Catherine (DAO J. Isnard/Inrap et M. Bouiron/Ville de Nice).

cette période. Dans le quartier du Mazeau où plusieurs voies ont été étudiées, seul un témoin était préservé dans la rue du Coq-d'Inde. Dans un devis datant de 1748 , concernent la réfection du pavage de la place du Palais du Justice, il est dit que «les entrepreneurs feront tous les enlevements des anciens pavés et le transport des terres pour dresser le terrain comme il a été dit; employeront tous les cailloux qui proviendroient de l'ancien pavé, en observant d'employer les plus gros... ${ }^{80}$. S'ensuit une description technique concernant la mise en œuvre "le nouveau pavé sera assis et fiché environ un quart de pan dans le meilleur terrain et aprochant le plus de la qualité du sable et bien battu a la demoiselle apres avoir été sablé ou terrassé ». Lors de la fouille du Tunnel de la Major, les axes étudiés attestent de la mise en place généralisée entre le XVIII ${ }^{\mathrm{e}}$ et le $\mathrm{XIX}^{\mathrm{e}} \mathrm{s}$. de pavements de galets posés sur chant, après apport de remblais préparatoires pouvant atteindre, dans le cas de la rue Four-du-Chapitre, $70 \mathrm{~cm}$ d'épaisseur.

80 ACM DD 104.

\subsubsection{Les aménagements privés et collectifs}

Que ce soit pour le Moyen Âge ou l'Époque moderne, les aménagements collectifs ou privés les plus fréquents dans les rues sont naturellement liés à l'évacuation des eaux usées. Les solutions apportées semblent toutefois rudimentaires face aux problèmes récurrents générés par les écoulements, qui dans le cas de la ville basse se déversent dans le port et contribuent à son envasement. Le plus souvent, les voies adoptent une surface inclinée vers une rigole centrale qui correspond à un simple sillon ; parfois cette rigole longe un côté de la rue créant désagréments et détériorations pour les façades mais également inconfort pour les piétons et les véhicules. Ces conduits à ciel ouvert peuvent alors être comblés afin de planifier la surface comme dans la rue du Coqd'Inde. La présence d'une canalisation en terre cuite est signalée dans un chemin du bourg des Olliers (Marchesi et al. 1997, p. 117) mais l'importante quantité de tuyaux produits dans ces ateliers semble indiquer que leur usage est somme toute répandu, ce que ne confirment pas les fouilles. Enfin, quand le sol est caladé, il est de fait prévu 
un fil d'eau central auquel se raccordent ou non des rigoles secondaires réceptacles de gouttières.

La présence de conduit enterré, bien que non généralisée ${ }^{81}$, est cependant observée sur plusieurs fouilles. Dans le bourg de Morier, un caniveau suit un tracé ondulant qui longe les bâtiments répartis de façon non continue de part et d'autre de la voie. Le conduit est délimité par des piédroits non maçonnés sur lesquels reposent des dalles de couverture, le fond n'étant pas construit ; plus au sud, cet aménagement se prolonge par une rigole à ciel ouvert (fig. 28). Sur la rive nord du port, la rue de la Taulisse offre un exemple exceptionnel de réseau complexe daté du XIII ${ }^{\mathrm{e}} \mathrm{s}$., associant des conduites intégrées dans la maçonnerie d'angle des façades qui se déversent dans des caniveaux maçonnés convergeant vers un collecteur central qui a disparu. Ce dernier devait se prolonger dans les voies perpendiculaires, mais n'a pas été retrouvé. Aussi aurions-nous tendance à penser que le faible nombre d'égouts médiévaux retrouvés en fouille peut s'expliquer en partie par les creusements de collecteurs postérieurs.

Avec l'éradication quasi-totale des niveaux de voirie moderne, seuls sont conservés les aménagements enterrés comme les systèmes de collecte des eaux usées. Nous ne reviendrons pas sur les descriptifs de ces installations présentés dans le chapitre 3. mais, qu'il s'agisse de caniveaux maçonnés ou de canalisations en terres cuites, tous se déversent dans un collecteur disposé le plus souvent dans l'axe de la rue.

La vision colorée d'une rue encombrée, où la sphère privée empiète sur le domaine public, est parfois étayée par les traces matérielles trouvées en fouille (Leguay 1999). Pour les XII ${ }^{e}-X I V{ }^{e}$ s., des rejets issus d'artisanats locaux sont utilisés comme épandages de nivellement des anfractuosités des voies comme par exemple dans le bourg des Olliers où des dépotoirs de céramiques issus des ateliers de potiers comblent les ornières du chemin (Marchesi et al. 1997, p. 48). Si l'on peut considérer que ces apports participent à l'entretien des axes, en revanche certains aménagements forment clairement des obstacles. La présence d'étal est réglementée dans les axes principaux; dans les venelles et dessertes de cœur d'îlot, la découverte de foyers ou de fosses réceptacles de déchets de type scories est assez fréquemment signalée. Dans le bourg de Morier ces vestiges, témoins d'un petit artisanat des métaux, forment le prolongement des structures retrouvées à l'intérieur des pièces.

Pour l'Époque moderne, on remarque l'annexion fréquente de dessertes secondaires médiévales dans

81 On notera cependant que l'absence de caniveaux axiaux pour cette période peut s'expliquer par les creusements de collecteurs postérieurs.

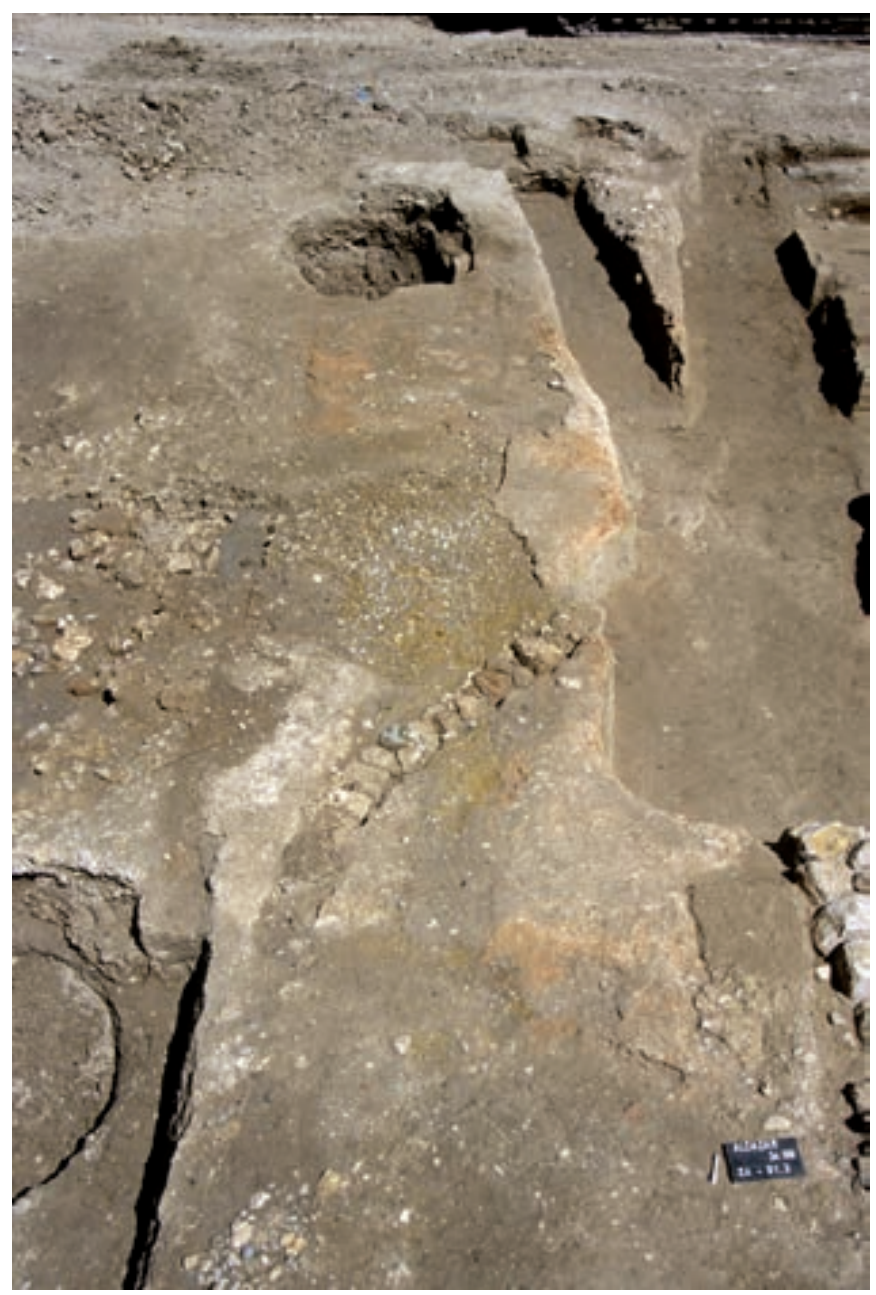

Fig. 28. Vue du caniveau de la rue de Morier (cl. F. Parent/Inrap).

les nouvelles constructions; mais cette période s'illustre surtout par des aménagements peu classiques: les extensions de caves sous la rue. Observées uniquement dans le quartier du Mazeau, les extensions de caves sous rue se généralisent au cours du XVII ${ }^{e}$ s. mais restent cependant marginales. Ces empiètements peuvent s'étendre sur la moitié de la largeur de rue, parfois moins ; leur mise en œuvre a un impact direct sur la circulation charretière qui de fait doit être interrompue le temps des travaux. Ces aménagements sont donc l'objet d'une réglementation municipale dont nous n'avons pas la trace mais à laquelle se réfèrent certains prix-faits. Dans un acte établi en 1637 il est question d'une «cave que l'entrepreneur prendra de toute part et jusques a demy rue comme il est permis ${ }^{82}$. Dans certains cas, le débordement peut atteindre $2 \mathrm{~m}$ de profondeur mais il est généralement compris entre 1 et 1,50 m. Ces extensions offrent un accès direct depuis la rue en facilitant

$82 \mathrm{AD} 13360 \mathrm{E} 72$, fol. 360 . 
ainsi la livraison de marchandises ou de combustibles. Deux systèmes d'ouvertures sont utilisés, la trémie qui forme une trappe dans la rue ou l'avaloir placé en léger débord de la façade. Ces accès fossilisent les surfaces de circulations et forment un obstacle supplémentaire aux travaux de reprises de voirie. Aussi au cours du XVIII' s. ces excroissances sont systématiquement obturées et comblées en raison vraisemblablement des désordres causés (fig. 29).

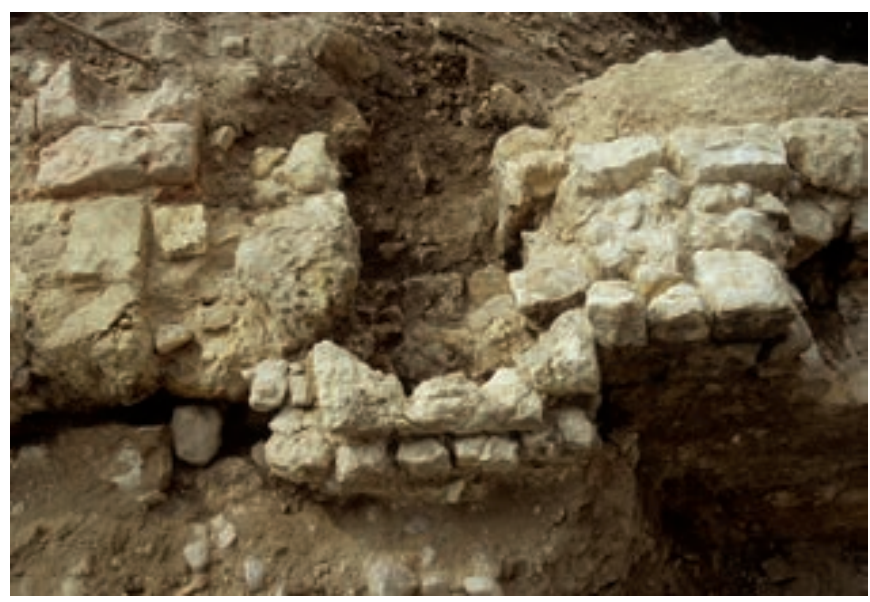

Fig. 29. Un avaloir de la rue du Mazeau (M. Derain/Inrap).

\subsubsection{Gérer les rues}

Face aux problèmes rencontrés, quelles mesures sont mises en œuvre par la puissance publique et les instances en charge de la gestion de la voirie ? Pour le Moyen Âge, les réglementations concernant l'organisation de la voirie et de l'urbanisme, et les problèmes d'hygiène publique sont consignées dans les livres des Statuts municipaux (Pernoud 1949) élaborés au cours du XIII ${ }^{\mathrm{e}} \mathrm{s}$. Six prud'hommes élus annuellement veillent à l'application des mesures prises, deux autres prud'hommes ont la charge de contrôler que les terrains vagues et enclos sont clôturés et que l'usage de dépotoirs est réservé à leurs propriétaires ${ }^{83}$. À ces derniers incombe le nettoyage hebdomadaire du tronçon de rue bordant leur maison ${ }^{84}$. La fouille du secteur du Mazeau a montré que la gestion du pas-de-porte était de mise avant même la rédaction des Statuts municipaux. Au cours du XII ${ }^{\mathrm{e}}$ s., on observe une différence dans la nature des strates selon que l'on se situe devant une façade de maison ou une autre ; un sol élaboré ou construit peut se prolonger par un apport de terre battue. De plus, la fréquence, l'aspect ponctuel des sols et recharges, la rareté des pavages semblent

83 Statuts municipaux L. V, c. 40.

84 Statuts municipaux L. IV, c. 3. indiquer que l'entretien et la remise en état de la rue incombe totalement aux propriétaires des maisons. À partir du milieu du XIII ${ }^{\mathrm{e}}$ s., la mise en place de sols caladés, bien que non systématique, se multiplie à l'intérieur de la ville comme dans les faubourgs. L'élaboration de ces sols sur l'ensemble de la voie, la technicité de leur réalisation témoignent d'une initiative communale dont le coût est vraisemblablement réparti entre les habitants. Les Statuts intègrent la gestion quotidienne des voies, de la réglementation de la circulation des animaux ${ }^{85}$ à l'interdiction de déverser les déchets et immondices dans les rues ${ }^{86}$ et la nécessité de les déposer hors les murs. La nécessaire maîtrise des espaces privés, notamment marchands, empiétant sur les voies passe par la limitation des étals à une emprise d'un mètre afin de ne pas faire obstacle à la circulation. Les problèmes d'urbanisme persistant parfois, la nécessité d'élargir les axes se fait sentir notamment dans les faubourgs où des travaux d'agrandissement sont réalisés après expropriation ${ }^{87}$.

Si certaines de ces mesures répondent à des problèmes d'hygiène publique, elles visent aussi à freiner l'engorgement du port dans lequel se déversent les ruissellements des eaux pluviales mais également des pollutions diverses. Outre le curage régulier du port trois fois par an, les rues ouvrant sur le port sont pourvues à leur débouché de barquil, sorte de cuve de bois destinée à filtrer les eaux déversées dans le port et à limiter ainsi l'envasement de la rade (Hesnard et al. 2001, p. 192).

À travers la présentation de ces rues, c'est un pan du quotidien de la ville médiévale et moderne qui se dessine. L'accumulation sédimentaire, la diversité des aménagements et leur renouvellement montrent que ces espaces publics sont rattrapés par la vie, par l'ordre et l'indiscipline, alternativement.

\subsection{Naissance de l'urbanisme moderne (B. Sillano)}

Nous distinguons ici la «vieille ville», enserrée dans les remparts médiévaux, utilisés jusqu'à la fin du XVII ${ }^{\mathrm{e}}$ s., de la Ville Nouvelle, créée par Louis XIV sur les anciens faubourgs. La première hérite d'un réseau viaire mis en place au début du Moyen Âge et qui subit, somme toute, peu de modifications, alors que l'autre voit son plan entièrement, ou presque, inventé.

85 Statuts municipaux L. V, c. 40. L. VI, c. 65, 67, 68, 80, 83.

86 Statuts municipaux L. IV, c. 3.

87 Statuts municipaux L. III, c. 8. 


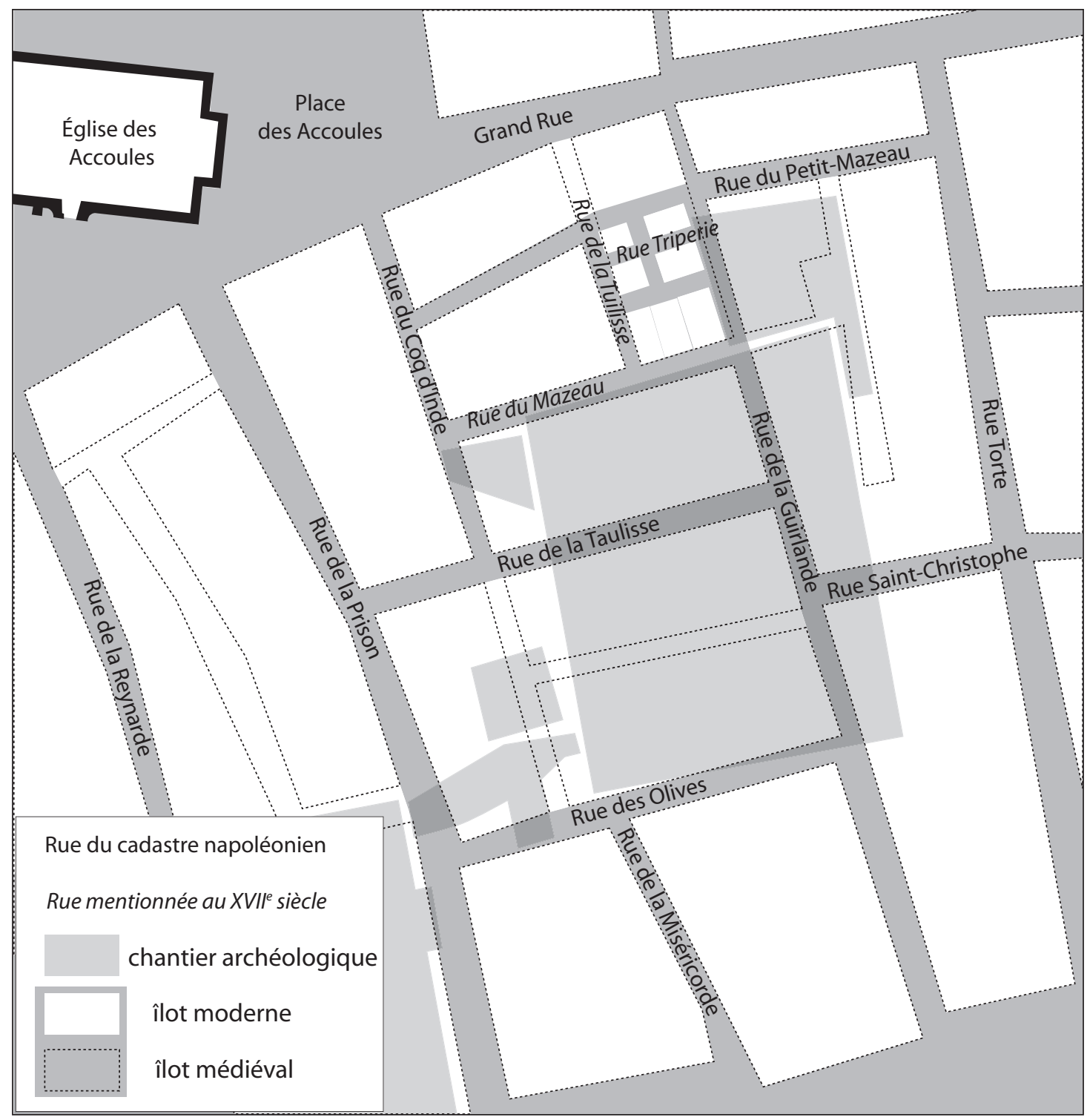

Fig. 30. Transformation des îlots médiévaux en îlotage moderne autour de la Loge (DAO B. Sillano/Inrap).

\subsubsection{Les transformations du réseau viaire intra muros à l'Époque moderne}

L'évolution du réseau viaire médiéval dans la « vieille ville» durant l'Époque moderne se résume essentiellement à la disparition des multiples traverses et impasses qui desservaient les cœurs d'îlot ( $c f$. infra § II, 2, 3.1.). Les exemples abondent, qu'ils aient été vus en fouille ou simplement suggérés par la lecture du cadastre napoléonien. Sur les chantiers à proximité de la mairie, le grand îlot à l'est de la rue de la Guirlande voit disparaitre la rue qui le pénétrait, ainsi que la placette (fig. 30). L'îlot au sud du Palais, un des plus vastes de la vieille ville, absorbe deux ruelles, l'une, du nord au sud, dans le prolongement de la rue du Coq-d'Inde, l'autre, d'est en ouest, selon la médiane de l'îlot. À l'ouest du Palais, l'îlot restitué par le cadastre de 1820 est traversé par une ruelle qui, d'après les textes ${ }^{88}$, est close. Sur la fouille du Tunnel de la Major, deux anciennes ruelles ont été mises au jour. L'une, mentionnée dans les textes comme étant celle qui «va à l'amiradour », coupe longitudinalement l'îlot, pourtant déjà très étroit, situé à l'ouest de la rue de la Cathédrale (rue de la Foire) (fig. 31). L'autre est un étroit passage qui traverse l'îlot au nord du précédent. À proximité, nous lisons sur le cadastre napoléonien, dans l'alignement de la rue Rouge, une petite impasse dans

88 «Entre la maison (...) et celle (...) il y a une petite rue de douze pans de largeur fermée par une grande porte de laquelle les $S^{r s}(. .$. ont la clef» (6 mars 1716). Traverse mentionnée au XVII ${ }^{\mathrm{e}} \mathrm{s}$. comme la «traverse perdude fermée a portes et serrures sullement puis lannee par permission de la cour des comptes » (ACM DD 107). 


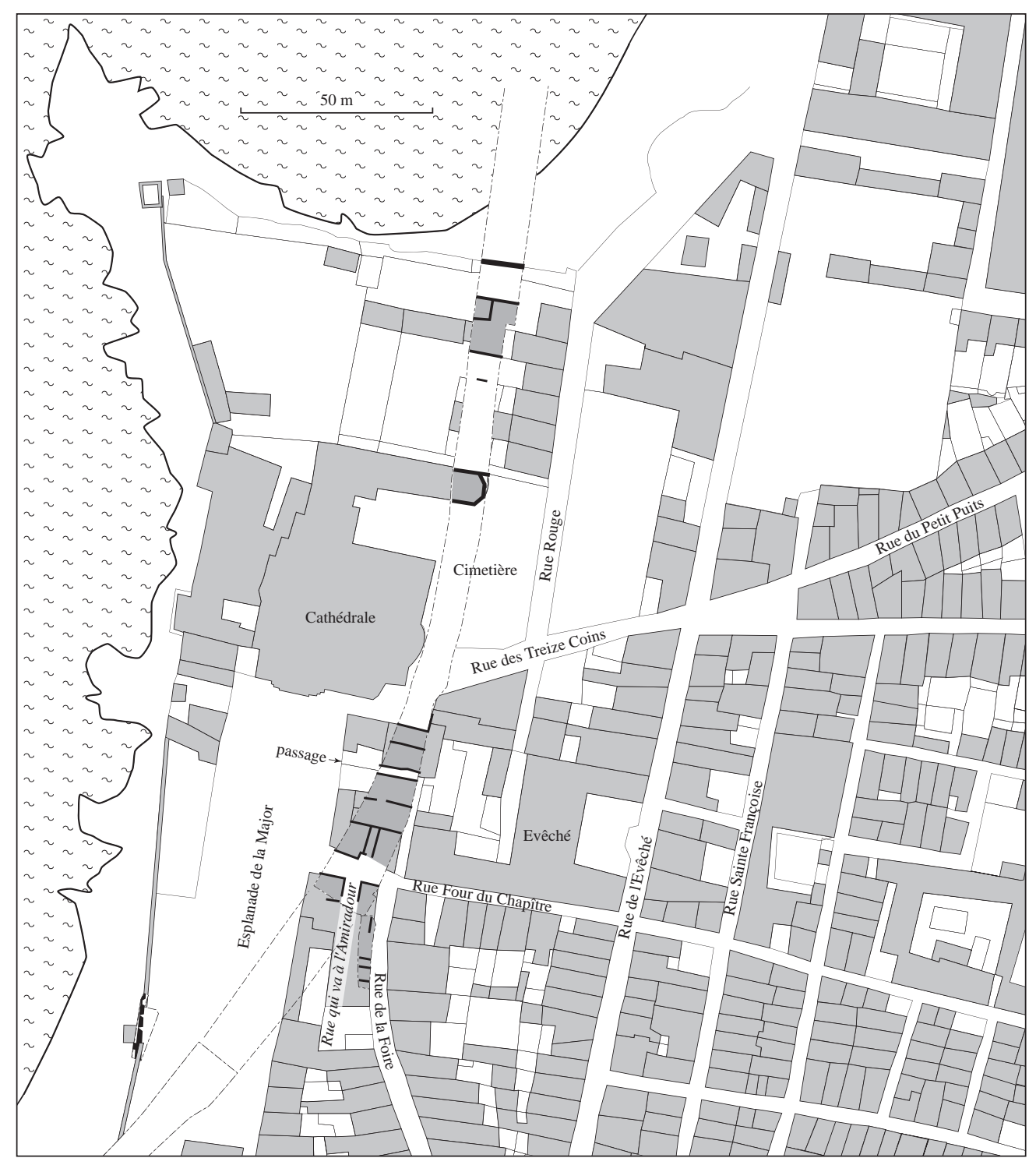

Fig. 31. Le réseau viaire autour du chantier du Tunnel de la Major (DAO M. Bouiron/Ville de Nice et F. Guériel/Inrap).

l'îlot au sud, qui se prolonge par une parcelle étroite, elle-même alignée avec une autre similaire dans l'îlot suivant. En restituant une ruelle dans cette emprise, nous retrouvons le découpage qui prévaut plus à l'est, dans le quartier du Panier. Ici, c'est la construction de l'évêché, au milieu du XVIIe s., qui a contribué à l'agrégation des îlots.

Ces transformations s'échelonnent tout au long de la période moderne, en réponse à la quête permanente de surface habitable liée à la forte croissance démographique. À l'est de la rue de la Guirlande, la ruelle semble lotie dès le $\mathrm{XIV}^{\mathrm{e}} \mathrm{s}$.; au sud de la rue de la Taulisse, l'une des anciennes ruelles est-ouest pourrait être abandonnée dès le XVI ${ }^{\mathrm{e}} \mathrm{s}$., date d'édification d'un mur qui la recoupe, l'autre plutôt au XVII ${ }^{\mathrm{e}}$ s., avec la création de la parcelle 373. À l'ouest de la rue de la Prison, la ruelle n'est abandonnée qu'au XIX ${ }^{\mathrm{e}} \mathrm{s}$. Dans le quartier de la Major, la rue qui «va à l'amiradour » est encore mentionnée au XVIII ${ }^{e}$ s., époque à laquelle le passage à travers l'îlot plus au nord est toujours utilisée.

Les rues principales, conservées au moins jusqu' aux bouleversements urbains des $\mathrm{XIX}^{\mathrm{e}}$ et $\mathrm{XX}^{\mathrm{e}}$ s., ne subissent pas, ou peu, de modification au cours de la période moderne. Au cours du XVI ${ }^{\mathrm{e}}$ s., quelques travaux d'urbanisme sont perceptibles, comme ceux qui affectent la partie septentrionale de la rue de la Guirlande. Cette artère a été nivelée, ce qui a éliminé les niveaux de voirie du bas Moyen Âge, et élargie de $1,70 \mathrm{~m}$ à 3,50 m. Ces travaux précoces, révélés uniquement par les fouilles, n'affectent pas nécessairement le plan des rues, mais ils ont laissé leur empreinte sous la forme d'un réseau de canalisations d'excellente facture ( $c f$. infra $\S$ I, 2, 3.2.2.). 
À l'inverse, alors que les archives du XVIII $s$. regorgent de plans d'alignement sur la «vieille ville», l'archéologie montre qu'ils ont été rarement suivis d'effet. Sur l'ensemble des zones fouillées, seule la rue de la Prison conserve, en négatif, la façade épierrée de la maison du roi. Ce réalignement, réalisé au XVIII ${ }^{e}$ s., ne concerne que cet édifice, dont l'état était jugé tellement déplorable qu'une démolition totale était nécessaire. En 1713, lorsque Honoré de Rome d'Ardennes veut reconstruire plusieurs bâtiments sur son emplacement, il s'adresse aux autorités communales pour leur demander de combien il est tenu de reculer sa façade ${ }^{89}$. Peu après, l'ancien hôtel de Remezan, de l'autre côté de la rue, est détruit et la façade du bâtiment qui le remplace reculée. Ces exemples montrent que les plans d'alignement n'ont pas pour but de transformer la rue en une seule fois, mais, lorsqu'une maison riveraine est détruite, de contraindre le propriétaire à s'aligner. La rareté de leur mise en œuvre met en évidence, d'une part, le blocage des propriétaires, mais également le peu de transformations du bâti dans ce secteur de la ville.

Nous pouvons mentionner quelques percements au cours du XVIII ${ }^{\text {s }}$ s. comme, par exemple, la rue Rouge, créée en $1745^{90}$, ou encore la traverse de la Charité, ouverte à travers le couvent du Petit-Puits. Mentionnons également quelques places créées en rasant des îlots entiers : place Neuve, au XVI ${ }^{\mathrm{e}}$ s., place du Petit-Mazeau, au XVIII ${ }^{e}$, place Villeneuve-Bargemon au XIX ${ }^{\mathrm{e}}$. Citons enfin le maillage serré de rues, entre les bancs de boucher du Petit Mazeau, créé à la fin du XVIe s. aux dépens d'un îlot compact dont nous avons retrouvé les extrémités des caves le long de la rue de la Guirlande.

Mais la transformation du réseau viaire à l'Époque moderne ne va pas que dans le sens d'un élargissement des voies. La portion de la rue Four-du-Chapitre fouillée sur le chantier de la Major se voit d'abord réduite du côté nord de $0,50 \mathrm{~m}$ par le déplacement de la maison du Chapitre, puis au sud lors de la création d'une usine à colle au XIX ${ }^{\mathrm{e}} \mathrm{s}$. Il semble que la municipalité ait toujours eu du mal à éclaircir l'îlotage de la " vieille ville », ce qui eut pour conséquence la démolition du quartier de la ville basse en 1943. Il est clair que la création de la Ville Nouvelle, avec ses larges rues, en attirant à elle la classe aisée, a entraîné l'asphyxie de la vieille ville qui s'est progressivement paupérisée et que la municipalité n'a plus pu (ou voulu) réhabiliter.

89 ACM BB 149, fol. 10.

9015 mai 1745 , mention d'une nouvelle rue (AD13 6 G 469, fol. 282).

\subsubsection{Des faubourgs à la Ville Nouvelle}

L'extension de la ville vers l'est, la Ville Nouvelle souhaitée par Louis XIV, a bien sûr profondément remanié les faubourgs qui occupaient la place. Pourtant ce plan prend en compte la trame viaire antérieure qui, par bien des aspects, le porte déjà en germe. Nous avons eu l'occasion d'étudier les voies de circulation situées à proximité du chantier de l'Alcazar, en partie par le biais de l'archéologie, d'avantage par l'exploitation des textes ; elles illustrent assez bien la diversité des transformations opérées sur le réseau viaire des faubourgs (fig. 32). Dans la mesure où chaque exemple est caractéristique, nous avons choisi de les traiter un après l'autre de manière diachronique.

\section{Du Grand-Caire au Cours Belsunce}

En tête des transformations du réseau viaire se trouve le Cours, symbole même de l'urbanisme moderne et reflet d'une société ayant retrouvé une paix durable après des siècles de troubles. Au cours du XVII ${ }^{\mathrm{e}}$ s., la plupart des villes du royaume s'en dotent et, à la différence des percées haussmanniennes, il ne s'agit pas de créer des axes de circulations à travers un bâti préexistant, mais d'aménager des lieux de promenade, vitrines du royaume. Selon J.-P. Gloton, à Marseille, « l'idée d'articuler la Ville Nouvelle avec l'ancienne au moyen d'une promenade aménagée sur les anciens fossés vient tout droit du cours à carrosses d'Aix-en-Provence (1651) » (Gloton 1980b, p. 171). Dans les faits, le Cours remplace un lieu qui en possède déjà les traits : le Grand-Caire.

Nous n'avons pas eu la chance de fouiller, ni même d'entrevoir, ce "Grand Côté », lice des remparts médiévaux, large de $70 \mathrm{~m}$ et qui se déploie sur $300 \mathrm{~m}$ depuis la porte Royale, au sud, jusqu'à l'inflexion que marque l'enceinte. Les plans Maretz et Auger, les plus précis en ce qui concerne les faubourgs de la ville d'avant Louis XIV, nous en donnent une image similaire ( $c f$. fig. 10 et fig. 33). C'est une place longiligne, agrémentée de fontaines et bordée d'arbres et de maisons bien alignées. Elle est appelée place du marché dans les textes car on y vendait des fruits et légumes. Au niveau du chantier de l'Alcazar, les façades ont disparu, reculées lors de la création du Cours, mais nous pouvons les restituer grâce aux murs de confins des bâtiments et aux textes d'archive. Nous constatons que l'alignement des façades était beaucoup plus oblique que celui du Cours actuel. Au nord de l'îlot de l'Alcazar, la façade était située à près de $10 \mathrm{~m}$ de l'actuelle, au sud à environ $5 \mathrm{~m}$. Elles étaient probablement parallèles aux remparts dont nous n'avons qu'une restitution en l'absence d'observation directe sur ce secteur de la ville. Ce changement 
CHAPITRE 2 - ÉVOLUTION DE LA MORPHOLOGIE URBAINE

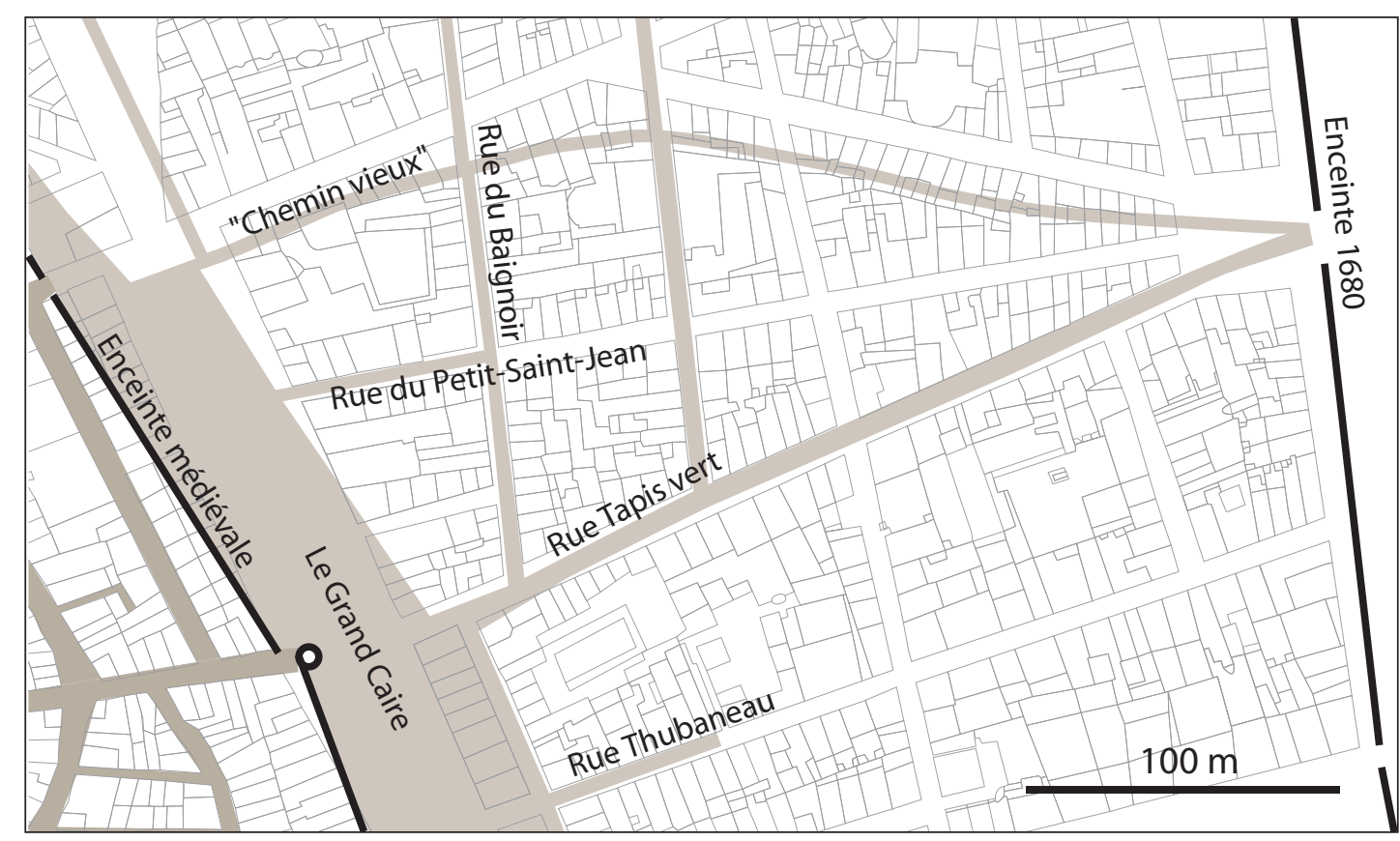

Fig. 32. Reconstitution partielle des chemins antérieurs à l'Agrandissement (DAO B. Sillano/Inrap sur fond de plan M. Bouiron).

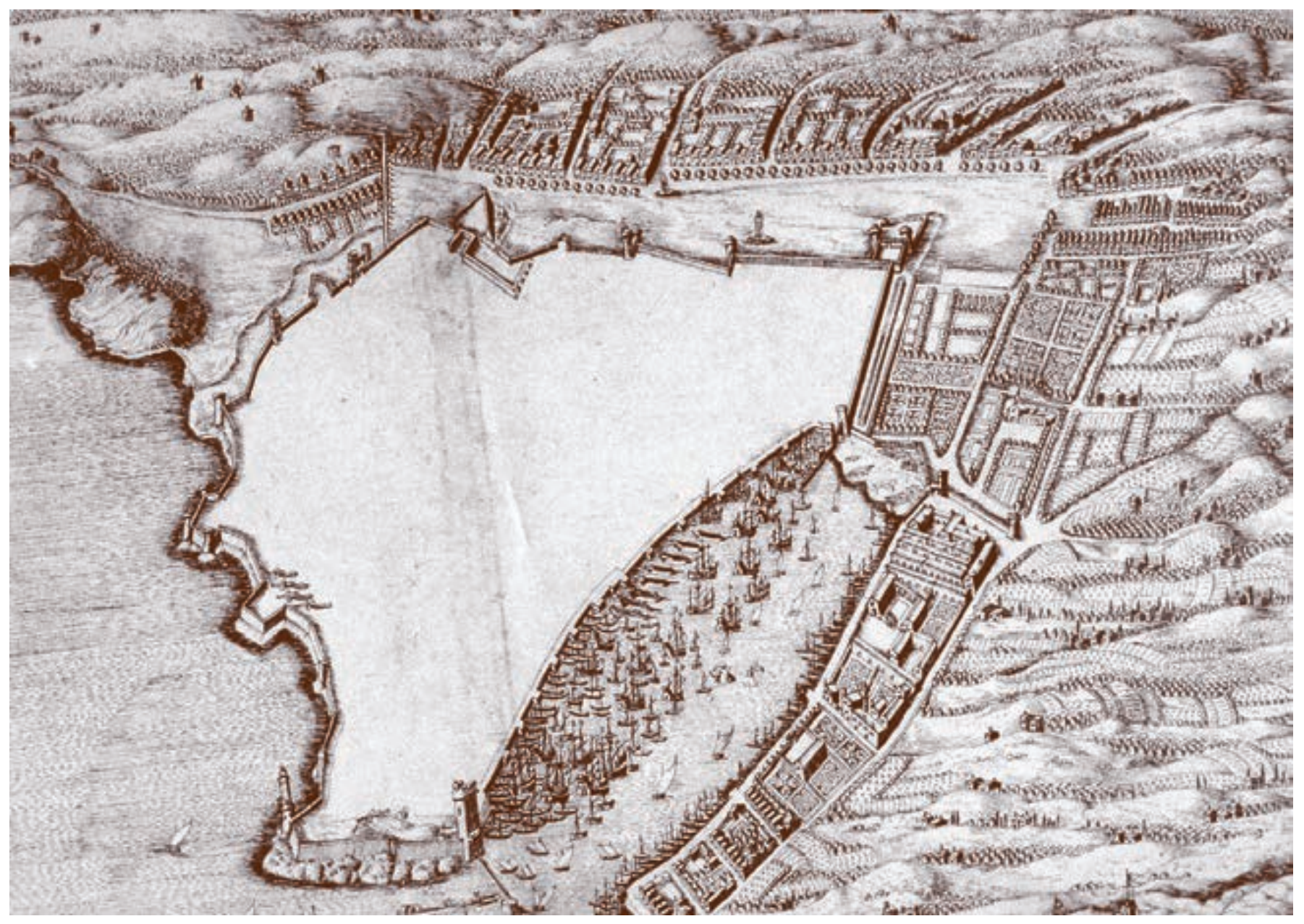

Fig. 33. Vue perspective de Marseille par Jean Auger (1652) (cl. MHM). 


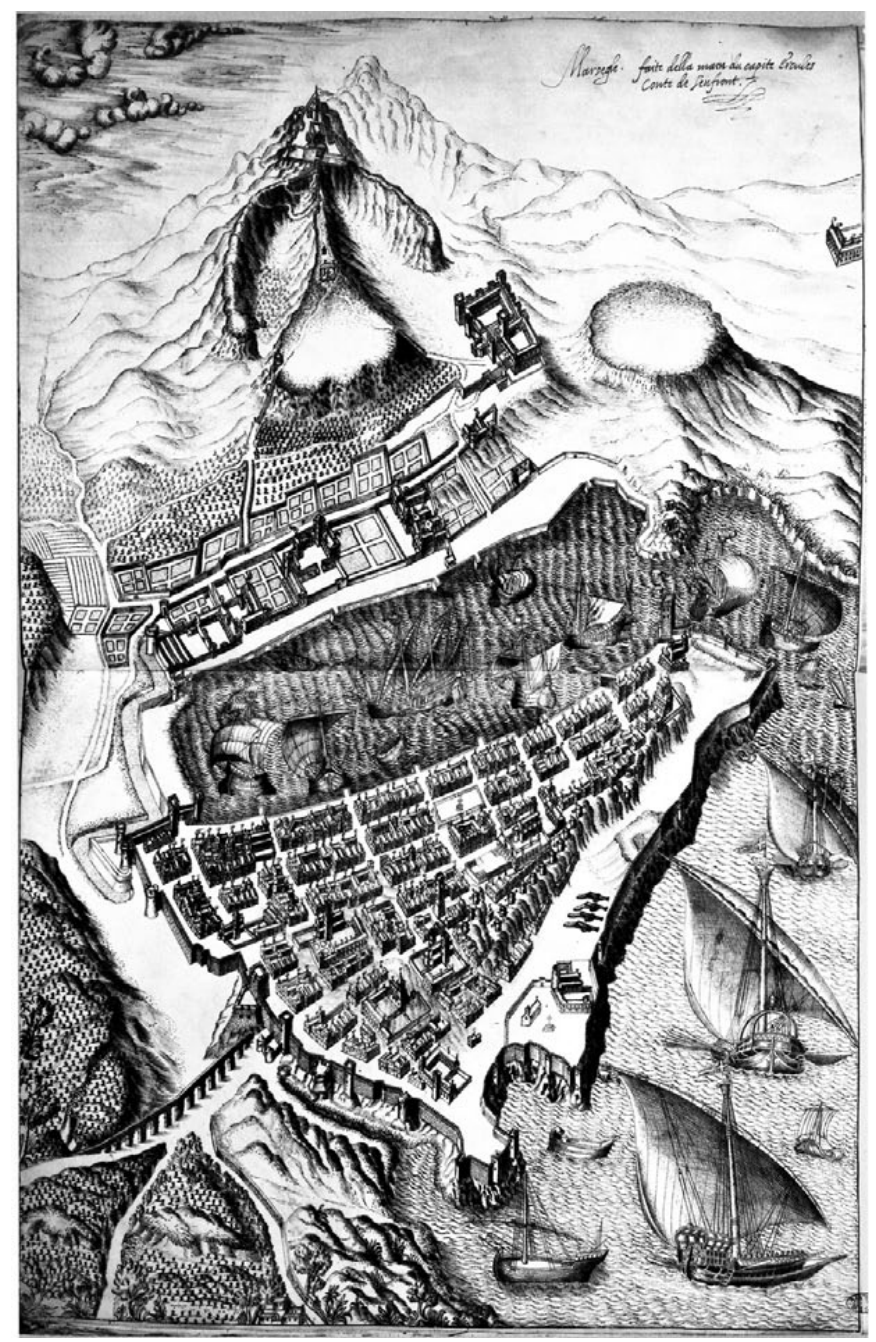

Fig. 34. Marsegle faite della main du capite Ercules, conte de Senfront (v. 1590, dessin d'Ercole Negro) (cl. ASTo).

n'est pas sans conséquence pour le parcellaire qui doit s'accommoder d'un îlot trapézoïdal, l'autre côté étant la rue du Baignoir, d'axe nord-sud. Il n'y en a pas trace sur le plan d'Ercole Nigra (fig. 34), daté de l'extrême fin du XVI ${ }^{\mathrm{e}}$ s., alors qu'un texte de $1636^{91}$ mentionne « des arbres que furent plantés après long du fossé et au devant de lad. maison (la parcelle 27) ». Nous pouvons donc aisément supposer que l'aménagement de la place remonte au tout début du XVII ${ }^{\mathrm{e}} \mathrm{s}$. Le fossé dont il est question réceptionne probablement les eaux du vallon Saint-Martin, auparavant drainées par les douves du rempart. Ces aménagements ainsi que la régularité des façades, que transcrivent bien les dessins de l'époque, traduit à l'évidence une volonté communautaire et non une somme d'intérêts privés. En cela, la création du

91 Acte d'arrentement perpétuel de demoiselle Claire de Guérin. AD13 380 E 127, fol. 1733 (cf. annexe 3.3.).
Grand-Caire constitue un des premiers actes forts d'urbanisme que connut la ville.

Plus au sud, grâce à la recherche archivistique associée à l'opération de fouille du Jeu de Paume (Sillano, Scherrer 2009), nous pouvons restituer la topographie de la place. Le logis du charbonnier, et ses dépendances, qu'achètent les religieuses en 1646 «pour faire leur esglise, habitation et monastere ${ }^{92}$ se trouve devant «le grand chemin ou grand place dentre lesd. deux portes Realle et du Marché », c'est-à-dire le long du Grand-Caire. Dans le rapport d'estime de $1683^{93}$, elles expliquent avoir beaucoup perdu avec l'Agrandissement, à cause des immeubles bâtis le long du Cours qui privent leur potager du soleil et de la création de la rue des Récollettes, devenue «une méchante rue traversse qui resoit les egouts et toutes les immondices des maisons du cours ». En revanche, il n'est nullement fait mention d'alignement ce qui prouve que cette rue reprend exactement la limite de l'ancienne place. Ces textes confirment que, comme nous le voyons sur le plan Maretz ( $c f$. fig. 10), antérieur à l'Agrandissement, l'inflexion que fait le rempart médiéval au niveau de la porte du Marché a induit un décrochement de la place à partir de la rue Tapis-Vert ; son obturation explique la présence d'îlots écrans au sud du Cours.

S'il fût décidé de créer le Cours dès 1666, sa forme définitive est restée un des sujets d'opposition entre N. Arnoul, l'Intendant des galères chargé des travaux de l'Agrandissement, et l'architecte Pierre Puget (Durousseau, 1990, p. 25-2794); elle ne sera pas fixée avant 1670. En définitive, il est curieux de constater que le Grand-Caire offre une place suffisante pour un Cours large de $40 \mathrm{~m}$; cependant, son tracé final empiète largement sur les bâtiments déjà présents dans la partie septentrionale alors que des îlots masques sont rajoutés au sud (fig. 35). Pour J.-M. Chancel, « les destructions de façade ne sont pas nécessitées par la simple logique des tracés viaires (...). Il s'agit donc moins d'un alignement nécessaire que de l'imposition d'une ville ordonnée » (Chancel 1980, p. 27). Il est vrai que l'orientation du Cours a généré celle de l'axe le plus long de la ville qui se déploie de la porte d'Aix à l'obélisque de Mazargues sur plus de $6 \mathrm{~km}$. Nous pouvons cependant voir des raisons pratiques au choix de cette orientation. Vers le nord, le passage obligé sous l'aqueduc ne pouvait se faire qu'au point le plus bas, c'est-à-dire dans l'axe vallon Saint-Martin. À l'opposé, le prolongement du Cours vers le sud, la rue de Rome, tracée à la même période,

92 AD13 357 E 137, fol. 280.

93 ACM DD 164, fol. 238 à 239.

94 Cet auteur rapproche la configuration du Cours marseillais de la Strada Nova de Gênes, ville qui a inspiré Pierre Puget. 


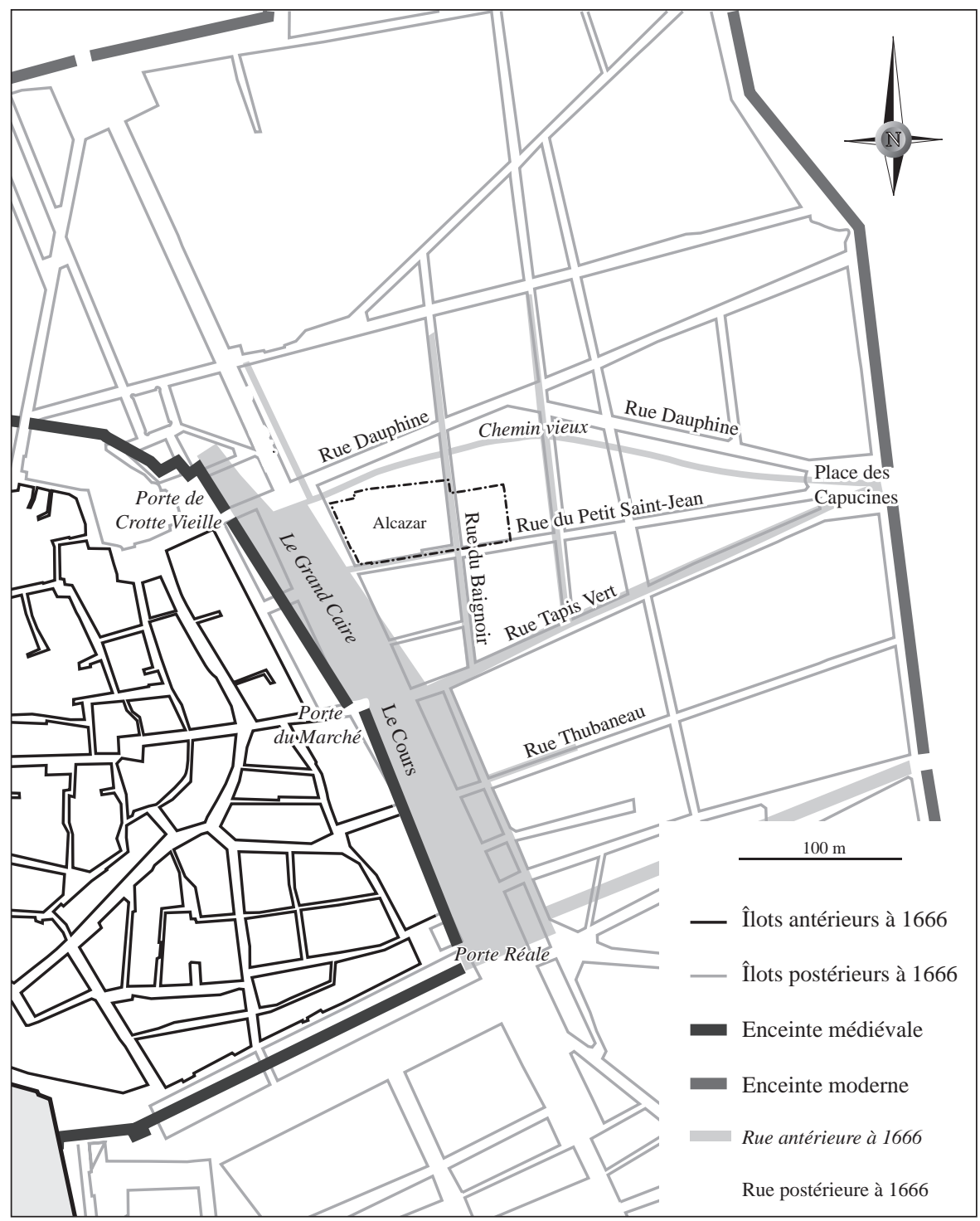

Fig. 35. Restitution du réseau viaire antérieur à l'Agrandissement (DAO Sillano/Inrap).

ne pouvait affronter la colline Saint Michel, trop escarpée, et ne pouvait que la longer. Les anciens remparts, et surtout les habitations qu'ils circonscrivent, formant une limite à l'ouest, il ne restait au tracé du Cours qu'une seule et unique solution.

À la différence du Cours d'Aix-en-Provence, celui de Marseille va chercher la régularité des édifices qui le bordent, comme nous le montre un tableau de Michel Serre (fig. 36). Les façades sont toutes conçues selon le même modèle ; un exemplaire a été conservé en façade de la bibliothèque (fig. 37). Son alignement est lourd de conséquence pour les parcelles de l'îlot de l'Alcazar; les parcelles au nord sont amputées du tiers de leur superficie totale et les bâtiments qui y prennent place ont été coupés par le milieu. La parcelle qui appartient à la congrégation Saint-Hommebon (parcelle 26), n'est pas encore lotie en 1666 et elle voit s'édifier la première façade de l'îlot sur le Cours. Elle sert ensuite de repère pour l'alignement des suivantes qui sont édifiées «suivant l'alignement fait despuis la maison bastie pour les pères missionnaires et jusque à la fassade de la Selle d'or ${ }^{95}$. Elle sert également de modèle architectural pour les autres puisqu'il est précisé dans les prix-faits que les « cosages auront la mesme hauteur que ceux de la maison desdit pères (...) la fassade de lad. maison sera bastie entièrement en pierre de taille de la mesme forme, massonerie et fasson de celle desdits pères de la mission ». Pourtant, l'immeuble qui prend place sur la parcelle 26 est peu profond et doit plutôt être considéré comme un «bâtiment-écran » dont le but est de maintenir l'unité de la façade. Situé au milieu de l'îlot,

95 AD13 390 E 236, fol. 240v. 


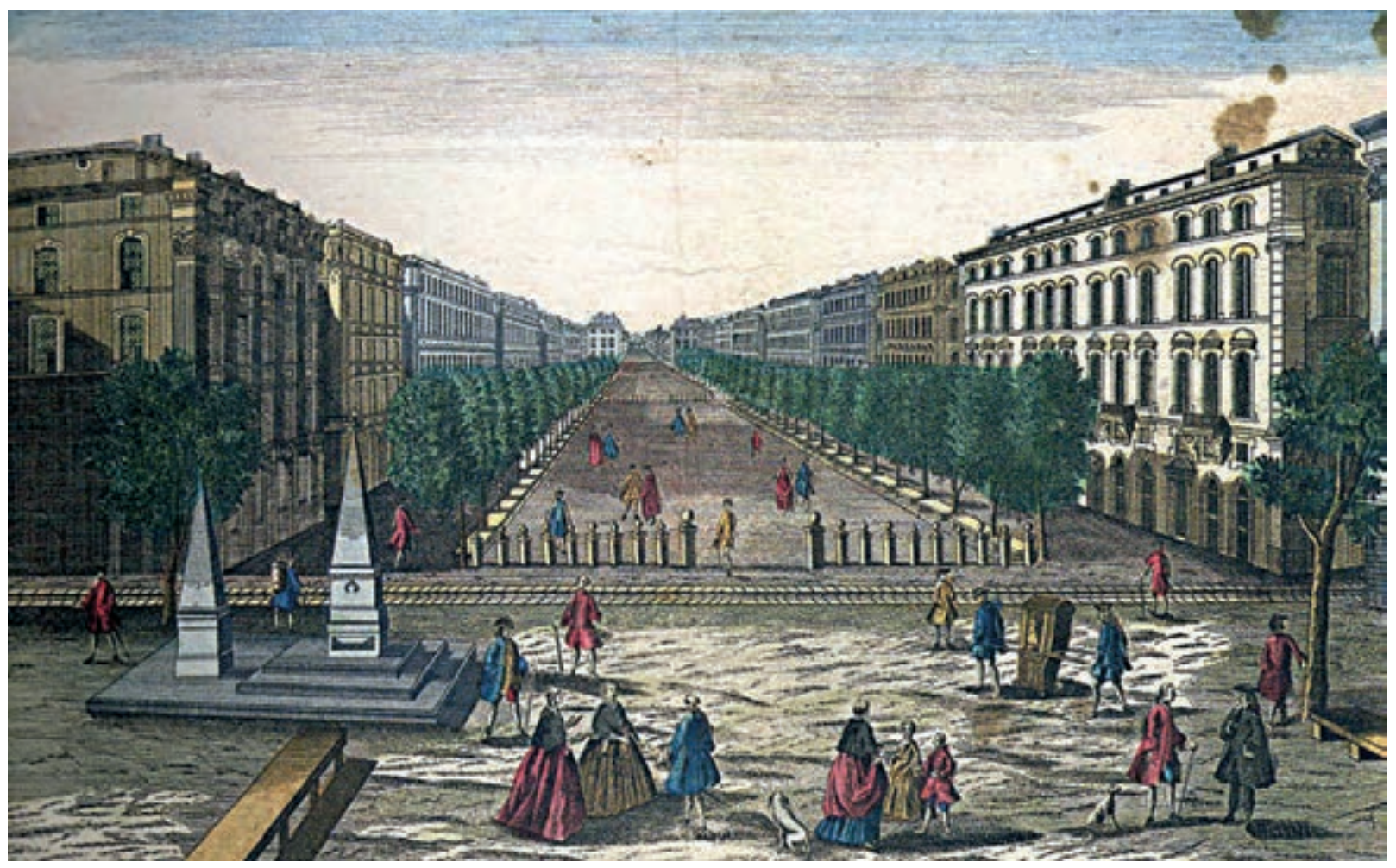

Fig. 36. Vue du Cours de Marseille par Jacques Rigaud d'après le tableau de Michel Serre (cl. Musée du Vieux Marseille).

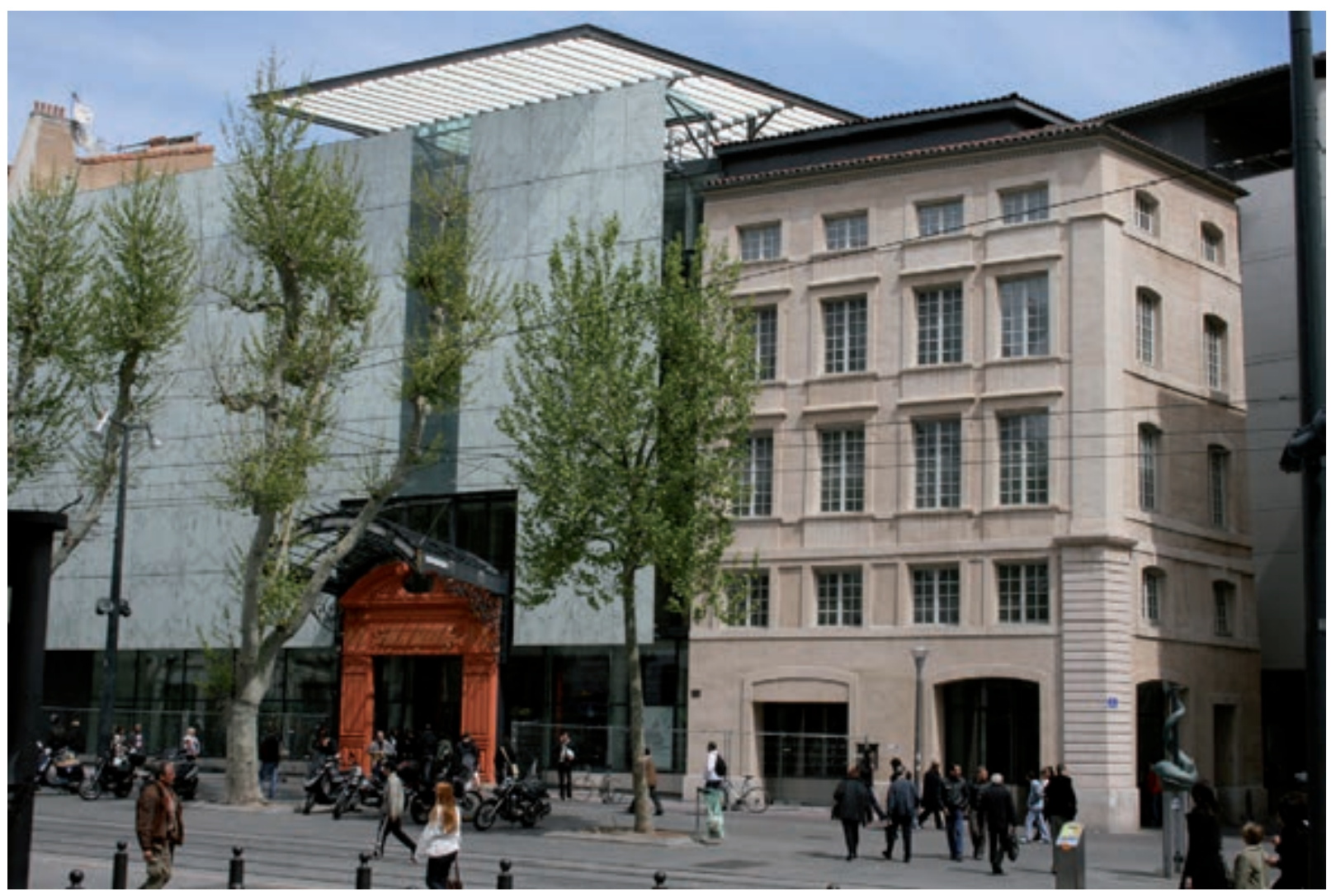

Fig. 37. La façade de l'actuelle bibliothèque de Marseille qui intègre l'ancienne façade sur le Cours (cl. B. Sillano/Inrap). 


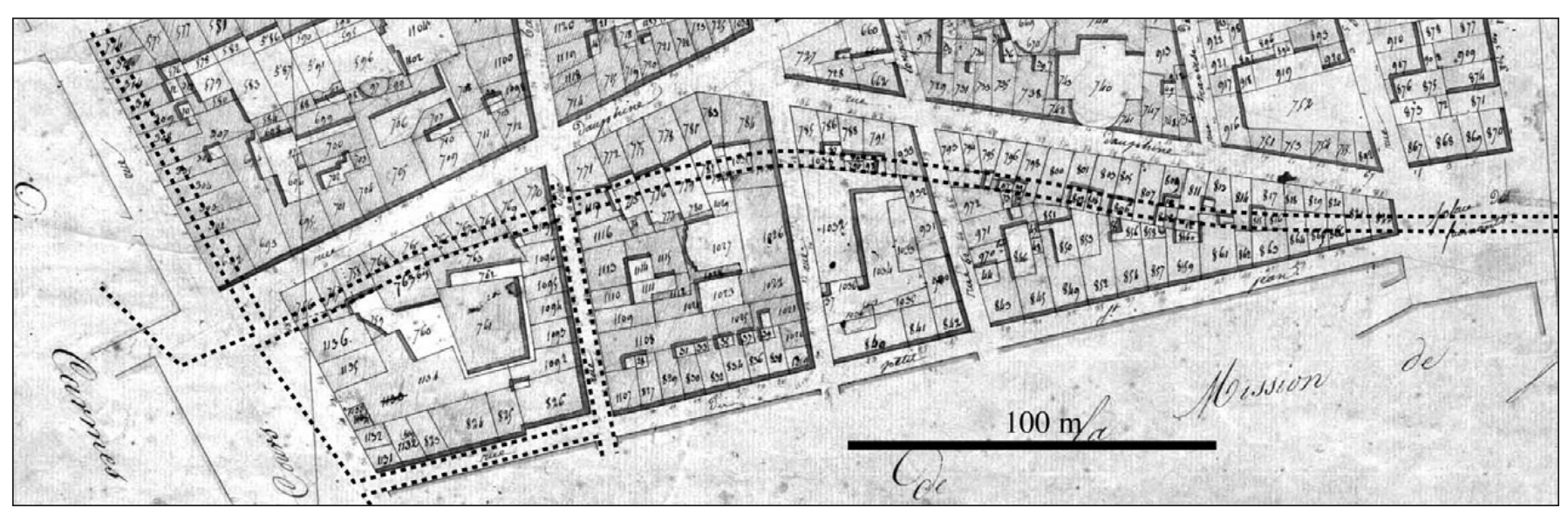

Fig. 38. Restitution du tracé du « chemin vieux » sur le cadastre napoléonien (B. Sillano/Inrap).

il accueille la porte cochère axiale présente systématiquement sur chaque îlot. Elle permet l'accès aux vastes écuries placées en cœur d'îlot.

L'aménagement du Cours lui-même comprend une allée centrale pour la promenade, en terre battue et bordée d'arbres, avec deux rues de part et d'autre ainsi qu'un trottoir le long des façades. Ces rues latérales vont rapidement être encombrées en raison des véhicules en stationnement (Tavernier, 1976, p. 67).

\section{Des rues du faubourg à celles de la Ville Nouvelle}

Comme nous l'avons constaté sur le chantier de l'Alcazar, de nombreuses rues et traverses du faubourg médiéval ont disparu au début de l'Époque moderne. Cette réduction du réseau viaire est à mettre en rapport avec un nouveau type d'habitat, au bâti plus ample tout comme le parcellaire, qui génère des îlots très vastes. À l'inverse, de nouvelles rues se créent progressivement, comme la rue du Petit-Saint-Jean, probablement en liaison avec de nouvelles demeures à desservir. Le réseau des voies radiales qui aboutissent à l'arrière-pays demeure, lui, inchangé et ce depuis l'Antiquité. Le plan de la Ville Nouvelle de Louis XIV, en introduisant des figures baroques, modifie ce réseau tout en composant avec. Des rues anciennes disparaissent alors que de simples traverses sont prolongées et élargies. Nous allons voir l'évolution des voies proches de l'îlot de l'Alcazar depuis le Moyen Âge jusqu'à l'époque actuelle. Mis à part la rue du Baignoir qui traverse le chantier, les autres sont hors d'emprise et ne sont connues que par les textes.

Le bourg de Morier médiéval se présente comme une suite d'îlots allongés du nord au sud et trois de ses rues ont été mise en évidence sur le chantier de l'Alcazar. Deux d'entre elles ont été créées en même temps que le bourg; elles disparaissent lors de la destruction de 1536. La principale, mise en place dès l'Antiquité, est la rue du Baignoir. Cet axe, orienté du nord au sud, est le reflet d'un parcellaire qui remonte à l'Antiquité grecque et a probablement transmis cette trame jusqu'à l'époque médiévale. On peut se poser des questions sur la nécessité de conserver une voie perpendiculaire aux chemins qui sortent de la ville, mais le fait est qu'elle n'a jamais cessé d'être utilisée. Arasée en surface et éventrée par les réseaux, elle n'a malheureusement pas conservé les niveaux de circulation médiévaux et modernes. En revanche, nous avons les fondations des murs de façade qui indiquent que la rue a été élargie de $4 \mathrm{~m}$ à 5,50 m, sa taille définitive. La datation de cet acte d'urbanisme qui affecte la voie de part et d'autre est difficile à établir en l'absence de tranchée de fondation et donc de comblement susceptible de livrer du mobilier datant. Cependant nous constatons, d'après l'étude de la parcelle 40 ( $c f$. infra $\S$ II, 3, 3.1.4.), qu'il se produit peu avant le lotissement de l'ensemble des parcelles qui la bordent, c'est-à-dire peu avant son intégration dans la Ville Nouvelle.

Avant l'Agrandissement, l'îlot est bordé au nord par le chemin vieux qui, partant de la porte de Crotte Vieille, abouti au couvent des Augustins, à l'emplacement de l'actuelle église des Réformés. L'étude de la trame urbaine d'époque grecque démontre l'ancienneté de cette voie appelée « chemin de Crotte Vieille » à l'époque médiévale, puis «chemin tirant aux Augustins » ${ }^{\mathbf{9 6}}$ et enfin «chemin des pères de la Mission», à l'Époque moderne. Les textes, appuyés par la fouille, nous permettent de la situer exactement à l'arrière des parcelles disposées le long de l'actuelle rue Nationale, dont les murs de confins s'alignent en oblique par rapport à la façade. Nous pouvons également en estimer la largeur à $5 \mathrm{~m}$ et restituer son tracé sur le cadastre napoléonien (fig. 38), en nous basant sur l'arrière des bâtiments, sur

96 Actuellement l'église des Réformés. 
quelques parcelles dont la forme et l'orientation sont significatives et sur le terme du chemin (le couvent des Augustins).

Il disparaît du plan de la Ville Nouvelle au profit de la rue Dauphine, qui en reproduit le tracé, en décalé. La raison est d'ordre pratique, comme le souligne T. Durousseau : «Il s'agit d'un principe simple : on ne crée de voies nouvelles qu'en évitant, durant leur mise en place, d'empêcher le fonctionnement des anciennes voies. Les ingénieurs le savent bien et les lignes de confins des parcelles donnant sur ces deux rues le montrent exactement » (Durousseau, 1990, p. 32). Ainsi, si la rue Dauphine forme un angle, c'est avant tout parce qu'elle ne pouvait croiser le chemin qu'elle remplace en coupant le virage qu'il dessine. L'avantage est double puisque, en opérant ce changement de direction, elle permet de créer la figure baroque du trident au niveau de la place des Capucines (aujourd'hui des Fainéants). Cette figure était par ailleurs en germe dans la patte d'oie que formaient à cet endroit le chemin vieux et le prédécesseur de la rue Tapis-Vert, issu de la porte du Marché. Mis à part pour les parcelles d'angle situées en bordure de ce qui deviendra la rue d'Aix ( $c f$. infra), la rue Dauphine est tracée de toutes pièces à travers des jardins ce qui en facilite la réalisation. Tout ceci tend à monter que le plan de la Ville Nouvelle est loin d'être une création pure, mais qu'il dérive de l'état précédent, tout en tenant compte du développement antérieur du bâti. À cela s'ajoutent les intérêts privés, comme le déplore N. Arnoul : «Ils font des rues tout de travers, selon leur intérêt, et quand un échevin veut une place, pour l'avoir à bon marché, il fait passer une rue qui incommode le propriétaire qui est contraint de composer. Hors cela, que les rues soient belles ou laides, ils n'y connaissent rien. $\gg{ }^{97}$. Dans le cas des jardins que traverse la rue Dauphine, ceux-ci ont été rachetés en 1670 par Couzinery, à l'époque second échevin, à André de Félix, puis revendus par lots 4 ans plus tard. Il est peu probable qu'il s'agisse d'une coïncidence. En échange de l'emprise cédée pour faire la nouvelle rue, il semble qu'il acquière l'ancienne voie puisqu'elle intègre les lots qu'il revend par la suite.

L'étude du bourg médiéval nous suggère que la rue du Petit-Saint-Jean, hors emprise de la fouille, n'existe pas au Moyen Âge. En $1636^{98}$, elle est mentionnée comme une « traverse ». À cette date, aucune habitation n'est citée au nord de la rue, en revanche, nous trouvons au sud, le Logis de la Selle d'or, à l'angle avec le Grand-Caire, puis les maisons d'Amphoux et de Barnier et, à l'angle de la rue du Baignoir, le jardin de Pagi. Ces

97 N. Arnoul, Lettre du 18 avril 1671, Tavernier, 1976, p. 67.

98 Acte d'arrentement perpétuel de demoiselle Claire de Guérin. AD13 380 E 127, fol. 1733 (cf. annexe 3.3.). habitations sont hors d'emprise et non datées, mais il est évident qu'elles doivent leur présence à celle de la traverse et réciproquement. La fouille a révélé l'existence d'une maison à l'est de la rue du Baignoir, dans le prolongement exact de la traverse, qui a peut-être généré cet axe. L'auberge du Petit Saint-Jean, construite en 1656, lui donne son nom. Avec l'agrandissement de Louis XIV, la rue est prolongée vers l'est où une porte est créée dans la nouvelle enceinte. Elle traverse alors la bâtisse révélée par les fouilles puis les jardins Barnier. Elle forme alors la sécante de la figure de trident qui prend naissance à cette porte et se prolonge extra muros par les allées de Meilhan. Nous avons ici l'illustration de la transformation d' une simple traverse en un axe important de la ville moderne. La conception de la rue Thubaneau, située plus au sud, procède de la même manière, elle a pour support une courte traverse, rallongée vers l'est à travers la propriété des pères de la Mission de France.

Les données de fouilles croisées avec celles des archives nous montrent que l'actuelle rue d'Aix est pour partie une création pure de l'Agrandissement, dans l'alignement exact du Cours. En effet, d'une manière un peu empirique, nous constatons que le plan Maretz comme celui d'Auger dessinent un angle à l'extrémité nord du Grand-Caire, angle qui n'existe pas si l'on restitue la façade sur la place et l'actuelle rue d'Aix. Il est évident qu'elle était située plus à l'ouest, par exemple dans le lit du ruisseau de la Frache, hypothèse émise lors de la fouille de l'îlot Sainte-Barbe (Marchesi et al 1997, p. 110). Vers le nord, en revanche, elle reprend une ancienne voie, peut-être le chemin d'Aix. En revanche, l'étude des archives semble indiquer qu'elle suit, au sud, l'orientation d'une traverse que bordent les quatorze parcelles vendues par André de Félix entre 1658 et 1662 et localisées à partir «du coing desd. Pères de la Mission vers les Recollets ». Nous retrouvons ces dernières sur le cadastre napoléonien, en rive orientale de l'actuelle rue d'Aix ${ }^{99}$, mais avec une longueur de $20 \mathrm{~m}$ au lieu des $12 \mathrm{~m}$ donnés par les textes. La création de la rue d'Aix a donc eu pour effet de les allonger en absorbant la ruelle ainsi probablement qu'une partie de l'îlot qui les confrontait. Curieusement, elle prend en enfilade toutes les maisons déjà construites sur la rive occidentale de la traverse préexistante. Il faut croire que la nécessité de créer la rue à cet emplacement était plus forte que celle de composer avec le bâti préexistant afin de minimiser les destructions.

Plus au sud, comme cela a été interprété à l'occasion de la fouille du Jeu de Paume (Sillano, Scherrer 2009), la rue Tapis-Vert (appelée rue Saint-Louis) existait déjà,

99 Plusieurs actes dont, par exemple AD13 362 E 116, fol. 501. 
sous le nom de «rue tirant au couvent des reverends peres augustins refformes »; elle était probablement plus tortueuse et plus étroite puisque certaines parcelles riveraines ont été agrandies alors que d'autres ont été frappées d'alignement. La rue Thubaneau existait partiellement; elle a été prolongée vers l'est à travers l'immense propriété de la Mission de France. La rue Saint-Claude (1'actuelle rue Longue-des-Capucins) a été percée à travers les jardins du sieur Simon vers 1684 .

Le site de l'Alcazar illustre bien les faubourgs modernes et leur devenir. Tout d'abord, nous voyons comment les rues du bourg médiéval ont été remembrées afin de satisfaire un parcellaire plus lâche tout en s'adaptant à la topographie de l'enceinte. Les axes anciens, les chemins qui accédaient au terroir, sont évidemment conservés. Des traverses sont créées afin de desservir des habitations disséminées au milieu de jardins. Le plan de l'agrandissement de Louis XIV prend largement en compte le réseau viaire préexistant. Si le plan baroque pouvait être l'objectif des architectes, il ne fût pas suivi d'effet. Le plan de la Ville Nouvelle, obtenu en le modifiant légèrement par de simples décalages, en profitant des espaces non bâtis, en composant également avec les intérêts privés, reflète une part d'aléatoire qui fait toute sa singularité. Des îlots immenses en côtoient d'autres minuscules, des rues (comme la rue Longuedes-Capucins) en longe d'autres à très peu de distance alors que des pans entiers ne sont desservis par aucun accès. Tout ceci traduit bien, une fois de plus, les difficultés rencontrées par un pouvoir centralisateur d'imposer sa volonté à Marseille.

\section{Le découpage parcellaire}

Le réseau viaire une fois positionné, il est possible de réfléchir au découpage des îlots en parcelles, souvent matérialisées par des murs de clôture ou de bâtiments dont l'archéologie nous livre les traces.

\subsection{Réflexion sur le parcellaire médiéval à partir de quelques secteurs fouillés ( $F$. Paone)}

Les quelques fouilles présentées ici, complétées par les données des opérations archéologiques antérieures, offrent une nouvelle lecture de Marseille médiévale et permettent de saisir quel découpage parcellaire a déterminé la micromorphologie de certains quartiers. Une approche plus pertinente du parcellaire n'est toutefois possible que lorsque l'emprise du chantier archéologique englobe un ou plusieurs îlots, mais également les rues environnantes pour pouvoir établir le rapport entre ces deux entités. L'étude morphologique du parcellaire médiéval a également pour support indispensable l'analyse régressive du cadastre napoléonien. Cependant, dans le cas de Marseille, ce document nous fournit bien peu d'information sur les faubourgs médiévaux détruits au XIV e s., et sur lesquels se développe la Ville Nouvelle de Louis XIV.

Enfin, la compréhension du parcellaire doit, dans la mesure du possible, être corrélée à la connaissance des seigneuries foncières qui se partagent la ville; au découpage maintenant bien connu entre la ville basse, dépendante du vicomte, et la ville haute, partagée en secteurs prévôtal et épiscopal, s'ajoute la multitude de propriétés éminentes.

\subsubsection{Le découpage parcellaire intra muros}

Les observations les plus exhaustives sur le parcellaire intra-muros concerne la rive nord du port, et sont limitées au quartier du Mazeau, dans une zone où les contraintes topographiques préexistantes se limitent à la pérennité de quelques axes de circulation antique. La reconstruction à partir de la fin du $\mathrm{XII}^{\mathrm{e}} \mathrm{s}$. de ce secteur en grande partie désertée au cours du haut Moyen Âge, permet alors la mise en place d'une nouvelle opération d'urbanisme dont atteste la standardisation de l'îlotage. La morphologie de ces îlots est naturellement déterminée par le quadrillage instauré par le réseau viaire qui adopte une disposition en éventail pour les axes globalement nord-sud scandé par un réseau dense mais non régulier de voies ouest-est. L'étude porte sur trois îlots, mais seul l'îlot II est observé presque intégralement.

L'îlot I de la fouille du musée César ( $c f$. infra $\S$ II. 2, 2.3.2.), de forme trapézoïdale, mesure $32,5 \mathrm{~m}$ sur sa face septentrionale pour s'amenuiser à $24 \mathrm{~m}$ au sud ; sa longueur, constante, est de $54 \mathrm{~m}$. Seules les constructions occidentales donnant sur la rue de la Guirlande sont dans l'emprise de la fouille, sur une quarantaine de mètres. Les parcelles ont une largeur standard comprise entre 4 et $5 \mathrm{~m}$ et une profondeur restituable entre 12 et $15 \mathrm{~m}$ selon qu'elles se situent dans la partie la plus large ou non de l'îlot, soit un rapport de 1/3. Elles sont disposées pour l'essentiel perpendiculairement aux rues de la Guirlande et Torte, les parcelles méridionales s'ouvrant, d'après le cadastre de 1826, vers la rue Saint-Christophe. L'acquisition de cinq à six lots a vraisemblablement été nécessaire afin d'élaborer le grand bâtiment qui pourrait correspondre à des étuves. L'étendue et la profondeur de cet ensemble nécessitent la présence d'axes de circulation permettant de desservir le cœur d'îlot. Simples venelles ou véritables rues, ces voies devaient s'articuler avec des espaces ouverts communs à différents occupants. Les traces d'un passage étroit de 1,5 m et probablement 
couvert sont apparues au nord du bâtiment $\mathrm{E}$; il mène dans une cour dotée d'un puits à godets et d'une cuve. Cet espace ouvert devait également être accessible par une voie de desserte nord-sud dont les cadastres gardent la mémoire. Son tracé serait matérialisé par l'alignement des limites occidentales de plusieurs parcelles donnant sur la rue Torte. L'existence d'autres venelles en cœur d'îlot est envisageable, leur emprise se faisant naturellement au détriment des longueurs de parcelles, profondes alors d'une dizaine de mètres. Au cours du XIV e s., l'occupation de tout ce secteur se densifie et les pressions immobilières sont perceptibles. La propriété foncière évolue et se complexifie, les espaces libres de tout bâti peuvent être lotis comme l'illustre l'établissement d'une construction sur l'emplacement de la cour centrale. La zone est en partie annexée par une maison mitoyenne, et puits et cuve sont détruits.

L'îlot II ( $c f$. infra $\S$ II, 2, 2.3.3.) a une longueur de $38 \mathrm{~m}$ pour une largeur de $16 \mathrm{~m}$. La faible distance entre les deux rues qui le délimitent a permis la mise en place de parcelles en lanières traversantes orientées nord-nordouest/sud-sud-est; seules les parcelles orientales sont disposées perpendiculairement à la rue de la Guirlande. Le découpage du sol semble être fait sur la base modulaire de $8 \mathrm{~m}$ de largeur pour une profondeur de $16 \mathrm{~m}$ soit un rapport de $1 / 2$; seul le terrain central, transitoire entre deux types de dispositions, a une largeur de $6,5 \mathrm{~m}$. Ce maillage plus lâche réunissant deux largeurs standard de $4 \mathrm{~m}$ a vraisemblablement prévalu dès l'origine sur cet îlot. La volonté d'établir des constructions plus vastes renfermant des commerces ou des auberges au plus près du Mazeau a pu conditionner le morcellement de l'îlot. Si l'établissement de parcelles de plus grande envergure à proximité des places a déjà été constaté dans diverses villes médiévales (Garrigou-Grandchamp et al. 1997, p. 124), la coexistence de maisons étroites et d'habitations plus importantes semble également être de mise dans ce quartier. Au cours du XIV ${ }^{\mathrm{e}} \mathrm{s}$. comme pour l'îlot I, le maillage se densifie; un redécoupage concerne les parcelles occidentales (A et B) alors amputées en partie nord par l'établissement d'une parcelle d'angle d'orientée ouest-est, étroite et profonde de $4 \mathrm{~m}$ sur 16,5 m.

Situé au sud du précédent ensemble, l'îlot III mesure initialement $38 \mathrm{~m}$ de long (comme l'îlot II) pour $32 \mathrm{~m}$ de largeur, soit deux fois sa largeur (cf. infra $\S \mathrm{II}, 2,2.3 .4$.). Les structures médiévales sont uniquement conservées sur la moitié nord, la partie sud ayant été totalement dérasée et remodelée par l'établissement d'hôtels particuliers au XVIII ${ }^{e}$ s. Les dimensions de cet ensemble rendent incontournable le maillage interne d'un axe secondaire, orienté est-ouest. Son tracé est matérialisé par un mur de fond de parcelle qui détermine la limite méridionale des lots disposés perpendiculairement à la rue de la Taulisse. L'emplacement de cette desserte est décalé par rapport au tracé de la rue Saint-Christophe et génère une différence de profondeur entre les parcelles nord et sud. Il semble alors concevable d'imaginer que nous soyons en présence de deux îlots distincts mais l'archéologie ne nous fournit pas d'indice dans ce sens. Le module utilisé pour les parcelles disposées perpendiculairement à la rue de la Taulisse est comparable à celui utilisé dans l'îlot I soit entre $4 \mathrm{~m}$ et $5 \mathrm{~m}$ de largeur pour une longueur se rapprochant de $12 \mathrm{~m}$. La restitution du découpage parcellaire pour la moitié méridionale de l'îlot (donnant sur la rue des Olives) n'est pas réalisable, les données archéologiques étant trop ténues. Cependant la découverte de deux murs de refends espacés de $6 \mathrm{~m}$ pourrait indiquer un découpage plus large et une profondeur de $16 \mathrm{~m}$. Enfin, sur le cadastre napoléonien apparaît, à l'ouest de la rue du Coq-d'Inde, un îlot dont les parcelles pourraient garder les traces d'un découpage médiéval. Dans un second temps, peut être à l'Époque moderne, le tronçon méridional de la rue du Coq-d'Inde et la voie est-ouest sont inféodés et on assiste à la fusion au sein d'un gros îlot de plusieurs composantes (fig. 39).

La restitution du parcellaire montre que ce quartier et probablement une grande partie de la ville basse a fait l'objet d'un plan d'urbanisme avec un découpage calibrés par et au sein de chaque îlot. Les recherches effectuées par M. Bouiron sur le monastère Saint-Sauveur ont montré que cet établissement, implanté dans la partie nord du quartier, détenait une grande partie des terres et qu'il avait joué un rôle essentiel dans la réurbanisation de ce secteur de la ville. Sur la base des registres de compte dépouillés ( $c f$. infra $\S \mathrm{II}, 2,1.1$.), les biens répertoriés pour ce secteur appartiennent à Briton Anselme et lui viennent vraisemblablement de son père Anselme Fer, qui lui-même les tenait de l'abbaye Saint-Sauveur. En 1257 ces revenus sont confisqués par Charles ${ }^{\text {er }}$ d'Anjou. Pour le XIV'e s., les registres de cens de la cour comtale mentionnent la perception de taxes sur plusieurs maisons de ce quartier autres que celles issues de la saisie des droits de Briton Anselme ; ces maisons sont localisées le long de la rue de la Guirlande, face au Petit Mazeau. Parallèlement, l'essentiel des cens reviennent à deux hôpitaux puissants, à celui du Saint-Esprit et puis à partir de 1344 à l'hôpital Saint-Jacques-de-Galice.

Pour résumer, à l'intérieur de la ville, au moins deux modules parcellaires sont perceptibles. Les dimensions standards des plus petits lots présentent une largeur comprise entre 4 et $5 \mathrm{~m}$ pour une profondeur située entre 10 et $12 \mathrm{~m}$ soit une superficie moyenne de $50 \mathrm{~m}^{2}$. Dans la partie ouest de la ville, dans le quartier de la Cathédrale, les maisons dégagées lors de la fouille du Tunnel de la Major présentent des façades de 4 à $6 \mathrm{~m}$ pour une longueur minimum de $10 \mathrm{~m}$. Les parcelles de grande 


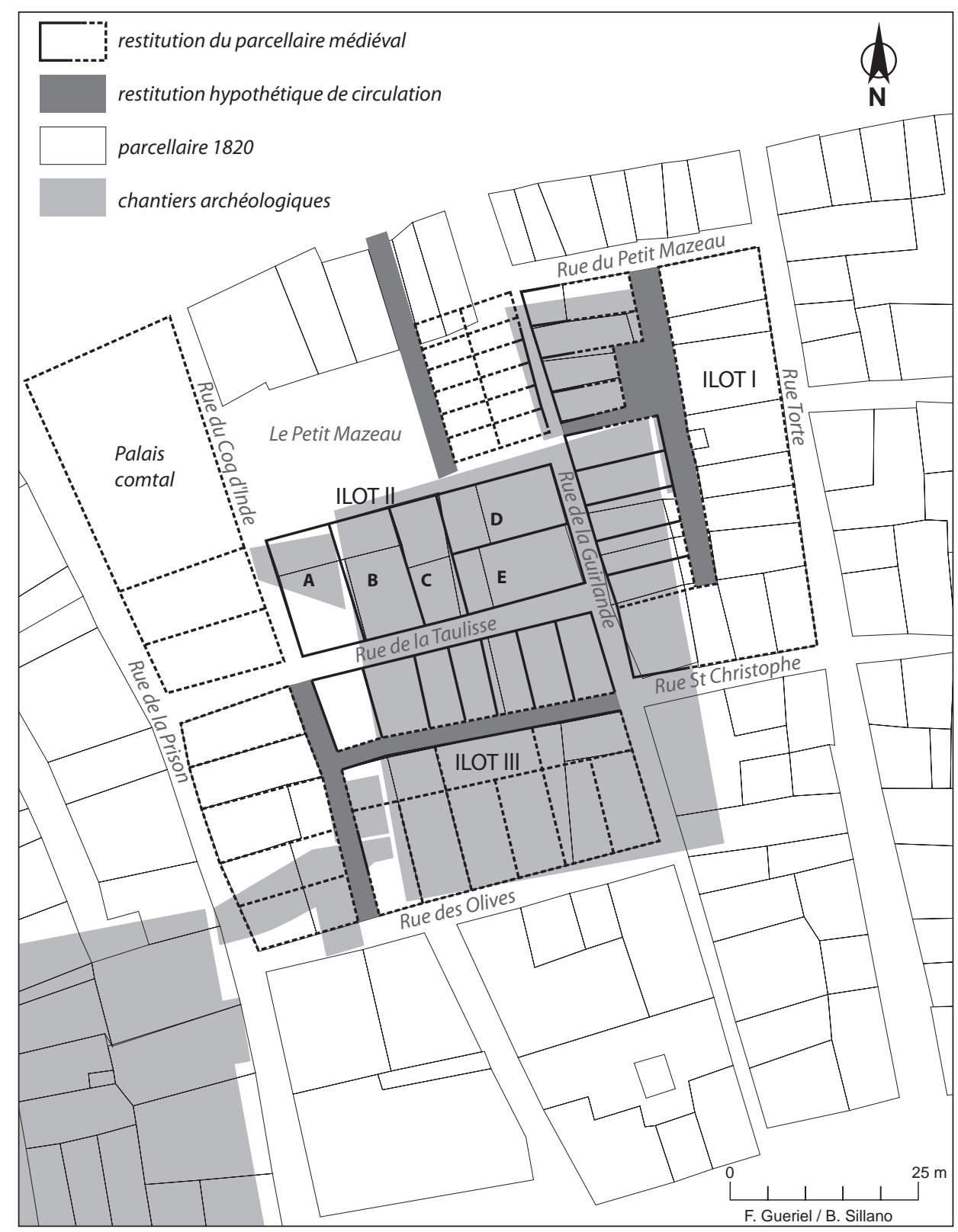

Fig. 39. Proposition de restitution du parcellaire dans le quartier du Mazeau (DAO F.Gueriel, B. Sillano/Inrap).

dimension $(8 \times 16 \mathrm{~m})$ formant le maillage de l'îlot II semblent également assez répandues si l'on en juge par la présence de ce gabarit.

\subsubsection{Les faubourgs}

Par trois fois, des fouilles archéologiques d'envergure ont porté sur le territoire périurbain de la cité médiévale. Ces opérations ont permis d'affiner notre connaissance des processus d'extension de la ville vers ces zones limitrophes généralement dévolues à l' agriculture. Il n'est toutefois pas simple de décrypter la genèse de cette urbanisation périphérique et de percevoir son évolution. De plus, la destruction des faubourgs à la fin de 1357 puis l'établissement de la Ville Nouvelle de Louis XIV atténuent, voire abolissent par endroit, les tracés médiévaux qui sont parfois encore perceptibles dans d'autres zones.

Dans le bourg de Morier ( $c f$. infra § II, 3, 2.2.), le réseau viaire détermine six îlots, dont aucun n'apparaît dans son intégralité. Avant que ne soit construit le quartier d'habitation du bourg, un quadrillage orthonormé est déjà utilisé dans le complexe artisanal accueillant la tannerie. L'ensemble des espaces (les ateliers, les réseaux hydrauliques, zones de séchages, de stockage et dépotoir) sont répartis selon un plan précis basé sur 
un rectangle modulaire de $6,5 \times 5,5 \mathrm{~m}$ et ses multiples. L'étude des registres de cens menée conjointement par M. Bouiron et P. Rigaud ( $c f$. infra § II, 3, 1.1.), a montré que les terres sur lesquelles est établie la tannerie relève du pouvoir vicomtal ; aussi est-il est possible d'attribuer aux vicomtes la création du complexe artisanal, de même que la destruction raisonnée d'une partie des bâtiments des tanneurs en vue de l'établissement d'habitations.

Lors de la mise en place du quartier d'habitation à la fin du XIII ${ }^{\mathrm{e}} \mathrm{s}$. les espaces réservés au tannage (donc les plus pollués et insalubres) sont dérasés et nivelés alors que le deuxième ensemble qui accueillait jusqu'alors probablement une unité d'habitation (ancien bâtiment 3) est complètement intégré dans le faubourg et simplement subdivisé pour s'adapter aux nouveaux besoins. Le bourg, tel qu'il se présente au cours du XIV ${ }^{\mathrm{e}} \mathrm{s}$., constitue alors un lieu de transition où se développent des habitations, des espaces artisanaux et des parcelles à vocation agricole. Le statut juridique de ces terrains révèle que le lotissement progressif du quartier est le fait de pouvoirs conjugués, celui des vicomtes, de seigneurs privés et du chapitre cathédral de La Major. Il faut ajouter le monastère des Béguines de Roubaud qui forme un facteur supplémentaire de l'expansion du faubourg.

Le nouveau découpage spatial du faubourg intègre ici plusieurs contraintes majeures: tout d'abord, le tracé du rempart et des lices qui dans ce secteur, amorce une direction nord-ouest/sud-est se répercutant sur les voies occidentales et les îlots I et II. Ensuite, on note la pérennité de la rue Crotte-Vieille qui reprend le tracé de l'ancien chemin antique et qui borde le site au nord. Une voie nouvelle, destinée à relier la rue Crotte-Vieille et celle de Morier, a un tracé oblique, formant un coude qui détermine la forme de l'îlot III. Enfin, la création de la rue des Cordiers (actuelle Baignoir) le long de laquelle s'établit le monastère des Béguines de Roubaud (hors emprise) forme un axe rectiligne à partir duquel sont disposées les parcelles cultivées (îlots V et VI). L'îlot IV adopte un plan trapézoïdal généré par l'articulation de ces différents axes.

Si le découpage parcellaire est inhérent à chaque îlot, des constantes dans les dimensions des lots apparaissent (fig. 40). L'îlot I, trop partiellement dégagé, ne peut être commenté et l'îlot III calque son découpage spatial sur le bâti préexistant. L'îlot II correspond à un ensemble hétéroclite qui intègre plusieurs anciennes maçonneries de la tannerie sous-jacente. Cet îlot se divise en plusieurs entités distinctes construites successivement. Les parcelles ne sont pas laniérées (à l'exception du lot $2 \mathrm{~F}$ ) mais contiguës et une différence de profondeur est perceptible en fonction de la rue le long desquelles elles se situent, les lots en bordure de la rue Sainte-Claire étant plus vastes. Les dimensions des façades observées sont comprises entre 7,5 m et $10 \mathrm{~m}$ et les profondeurs varient entre $6,5 \mathrm{~m}$ et 7,5 m le long de la rue de Morier et $8 \mathrm{~m}$ à $10 \mathrm{~m}$ le long de la rue Sainte-Claire. Les plus petites superficies $(2 \mathrm{H})$ font 42 à $60 \mathrm{~m}^{2}$, les plus spacieuses une centaine de mètres carrés. La parcelle traversante $2 \mathrm{~F}$, de plus grande envergure, constitue la limite entre une largeur d'îlot de $17 \mathrm{~m}$ à un rétrécissement en moitié sud à $15 \mathrm{~m}$. Toutes ces parcelles accueillent des unités d'habitations formées de deux pièces au sol. Les premiers espaces lotis sont ceux qui ouvrent sur la rue occidentale (les ensembles 2A, 2B et 2C) et contre lesquels s'accolent probablement rapidement les unités $2 \mathrm{D}$ et $2 \mathrm{E}$, puis $2 \mathrm{~F}$. Parallèlement une unité importante, $2 \mathrm{G}$, est établie plus au sud; l'espace laissé au nord de celle-ci sera lui aussi loti ultérieurement $(2 \mathrm{H})$. Cet édifice doit s'adapter à l'exiguïté de la surface restante tout en faisant le lien entre les façades non alignées des deux ensembles voisins.

Ce découpage spatial non standardisé est contemporain d'un quadrillage parcellaire régulier mis en place à l'est de la rue de Morier. La partie centrale du site est composée de deux entités distinctes, s'ouvrant respectivement à l'ouest sur la rue de Morier et la venelle nord (îlot IV) et à l'est sur la rue des Cordiers (îlot V). La limite parcellaire primitive qui sépare ces deux ensembles trouve son origine dans le tracé d'un fossé colmaté en usage avec la tannerie médiévale. L'îlot IV est celui qui présente la plus grande régularité ; un découpage rationnel du terrain a prévalu dans ce secteur et un système modulaire a été appliqué. La parcelle standard mesure $4 \mathrm{~m}$ de large pour une longueur de $11,5 \mathrm{~m}$ à $12 \mathrm{~m}$, soit un rapport de $1 / 3$, mais les subdivisions internes en deux espaces de $4 \mathrm{~m}$ ont été souvent pratiquées, dans le sens de la largeur (ensembles 4A, 4B, 4E) ou dans le sens de la longueur (ensemble $4 \mathrm{C}$, une réutilisation d'un bâtiment ancien). Les dimensions de l'îlot font que les parcelles en lanière sont disposées indifféremment le long de la rue de Morier, mais aussi de la venelle septentrionale et même perpendiculairement à la desserte de cœur d'îlot. Cette dernière ${ }^{100}$ permet d'accéder à des zones de jardins (4D) comme à des espaces construits (4E). Dans cet îlot, certaines unités d'habitations se composent d'un regroupement de plusieurs parcelles; la plus significative est l'ensemble 4A formé d'une parcelle d'angle associée à la parcelle mitoyenne. Une place assez importante est laissée aux espaces ouverts (cour, jardin ou verger) et clôturés (4A3, 4B1, 4D) qui sont toujours accessibles depuis une voie. Ceci implique que leur usage n'est pas forcément réservé aux habitants des maisons qui les jouxtent. Cette imbrication fonctionnelle

$100 \mathrm{La}$ largeur de cette desserte est réduite à $3,5 \mathrm{~m}$ du fait de l'épaisseur des murs qui la délimitent. 


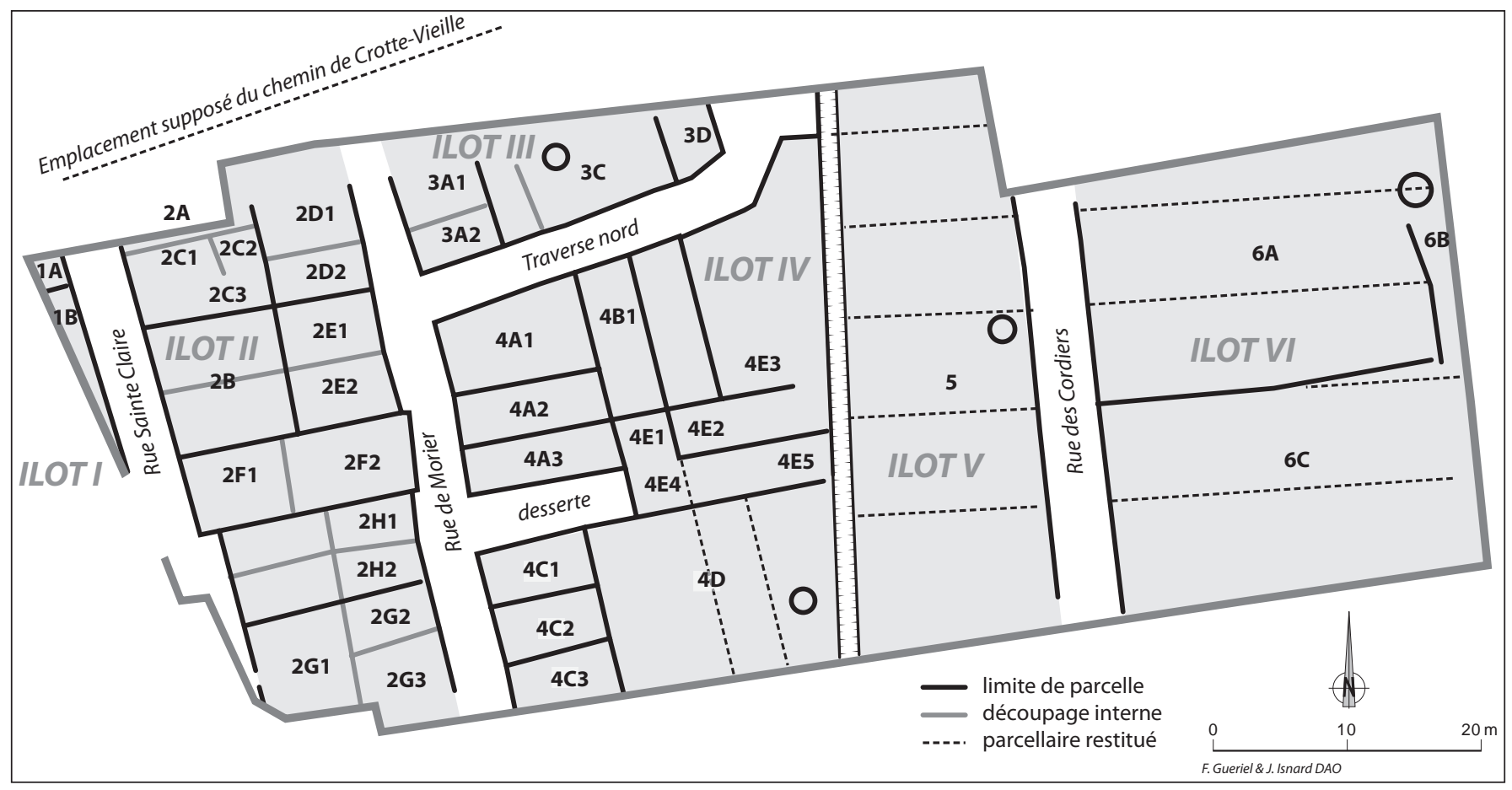

Fig. 40. Proposition de restitution du parcellaire dans le faubourg de Morier (DAO F. Gueriel, J. Isnard/Inrap).

est d'ailleurs attestée puisque l'on observe que l'activité métallurgique pratiquée dans l'immeuble $4 \mathrm{C}$ ne s'effectue pas dans le lot attenant à l'est (espace 4D) mais s'étend jusqu'en cœur d'îlot. C'est dans ce secteur que, dans un second temps, un autre découpage du terrain est réalisé en vue d'un nouveau lotissement (ensemble 4E).

L'îlot V d'une largeur moyenne de $14 \mathrm{~m}$ est, avec l'îlot VI, l'un des secteurs les moins riches en vestiges. Ceux-ci sont essentiellement conservés au nord où deux espaces d'habitation ont été découverts, auxquels s'ajoutent plus au sud un puits et un mur perpendiculaire à la rue des Cordiers. Malgré la ténuité des structures, une tentative de reconstitution du parcellaire est réalisable si l'on prolonge l'axe de certains murs au-delà de leur tracé avéré. On note par exemple que l'un des murs de l'ensemble 4E se trouve globalement dans l'alignement d'un autre mur, séparant dans l'îlot oriental, les parcelles 6A et 6B. Nous proposons donc de restituer dans l'îlot $\mathrm{V}$ un mur ou une clôture disposée selon ce tracé. La distance entre cette limite et un second mur au sud permettrait la restitution d'un module de parcelle d'une largeur de $7 \mathrm{~m}$ pour $14 \mathrm{~m}$ de long soit un rapport de 1 sur 2 . La reproduction de ce gabarit au nord aboutit jusqu'à un troisième mur qui correspond probablement à une limite de propriété.

Cette restitution hypothétique gagne en vraisemblance si on applique également son système à l'îlot VI. Pour cet îlot, la division foncière médiévale n'a pas laissé de vestige archéologique mais elle s'inscrit pourtant dans le paysage jusqu'au XVIII ${ }^{\mathrm{e}} \mathrm{s}$. comme le confirme l'examen des vestiges modernes. Le report d'une largeur de parcelle de $7 \mathrm{~m}$ semble être ici aussi la règle. Si on divise l'îlot VI en parcelles d'une largeur de $7 \mathrm{~m}$, l'extrémité d'un des murs de clôture est-ouest aboutit précisément dans la zone où l'orientation d'un mur oriental moderne diverge. En effet les deux murs de la parcelle moderne 42 reprennent exactement l'emplacement de ces enclos. Bien peu d'éléments permettent d'identifier précisément l'utilisation des parcelles de cet îlot, cependant l'importante superficie des lots dont la longueur est estimée à $24 \mathrm{~m}^{101}$ (soit une emprise de $165 \mathrm{~m}^{2}$ ) plaide vers une vocation horticole, ce secteur constituant alors la frange entre une zone rurbaine et le terroir véritable. Ceci justifie vraisemblablement la pérennisation de ce découpage spatial pendant l'Époque moderne, la destruction des faubourgs au $\mathrm{XIV}^{\mathrm{e}} \mathrm{s}$. ne concernant que les zones d'habitats.

Dans le bourg des Olliers, créé au XIII ${ }^{e}$ s., l'organisation spatiale du flanc de la colline Saint-Charles où se situe l'atelier de potiers se structure par l'intermédiaire de terrasses (Marchesi et al. 1997). Les auteurs restituent pour l'îlot occidental des parcelles en lanière de 5,5 et $6 \mathrm{~m}$ pour une longueur comprise entre 20 et $28 \mathrm{~m}$, $18 \mathrm{~m}$ pour celles formant l'îlot est. Ce découpage spatial en lien avec l'activité artisanale diffère de celle du

101 Cette mesure s'appuie également sur le parcellaire moderne. 
quartier d'habitation du bourg Sainte-Catherine où les parcelles en lanières présentent des façades de 4 à $5 \mathrm{~m}$ de large (fig. 41).

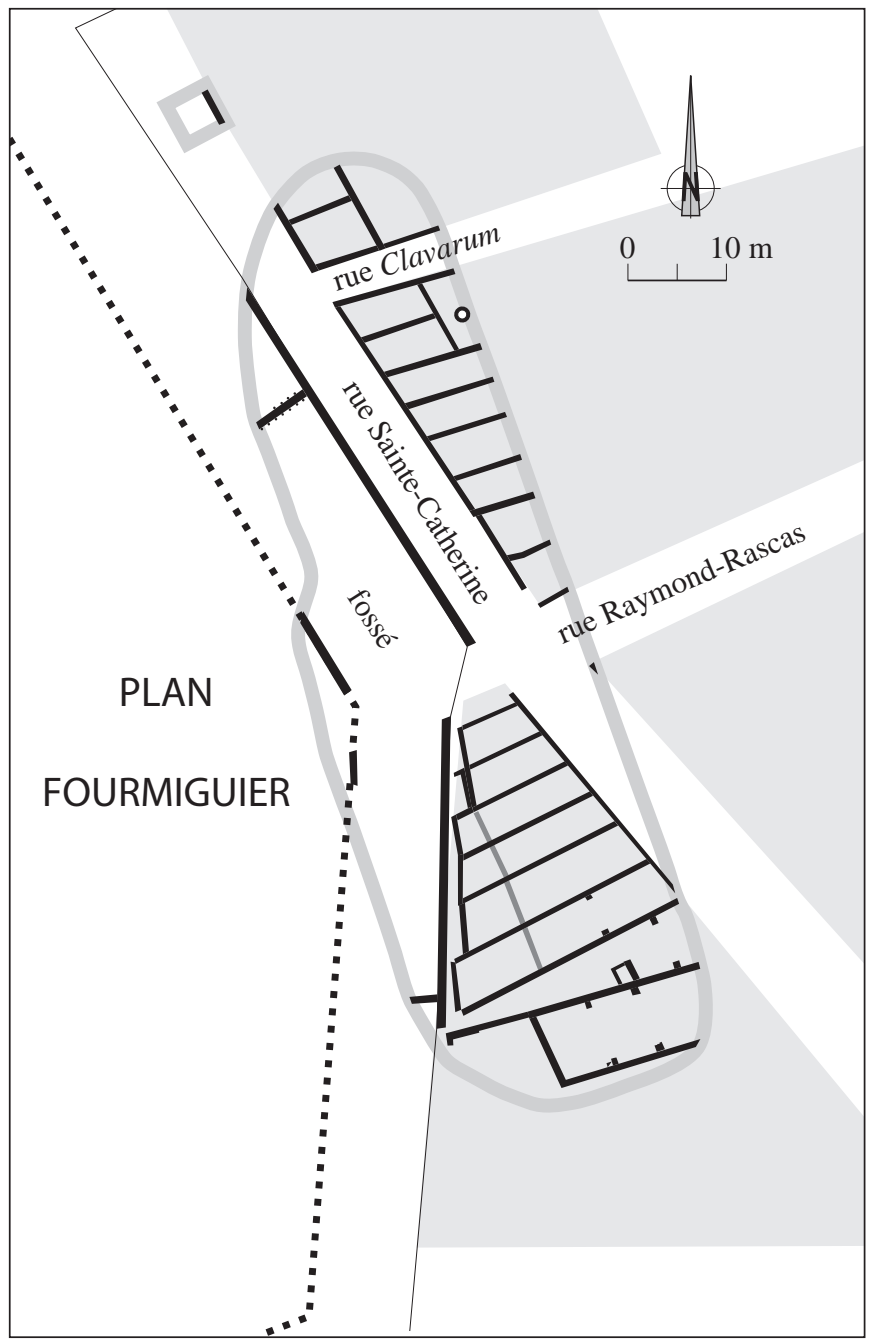

Fig. 41. Plan parcellaire du bourg Sainte-Catherine vers 1300 (DAO M. Bouiron/Ville de Nice).

\subsubsection{Conclusion}

Comme cela a déjà été mentionné, la restitution du paysage urbain médiéval est extrêmement difficile à établir. Cependant une évidence demeure : la morphologie générale de la ville intra muros, établie entre le XII ${ }^{\mathrm{e}}$ et le XIII ${ }^{\mathrm{e}}$ s., est pérennisée, la trame viaire conservée et le découpage parcellaire moderne, dont le cadastre napoléonien nous donne le témoignage, trouve sa source dans le morcellement foncier médiéval. Les autres exemples de création de quartiers à Marseille à partir du milieu du XIII ${ }^{\mathrm{e}}$ s. concernent les faubourgs, dont trois d'entre eux ont partiellement été fouillés. Malgré leur destruction au $\mathrm{XIV}^{\mathrm{e}}$ s. et le renouveau urbain initié par Louis XIV, certains tracés perdurent.
La parcelle de base qui prévaut semble là aussi basée sur un module calibré de 4 à $5 \mathrm{~m}$ de large (dimension classiquement attribué à la poutraison) pour une profondeur comprise entre 10 et $12 \mathrm{~m}$. Cependant des différences notables dans les superficies peuvent apparaître : elles résultent en premier lieu de l'adaptation à la morphologie et aux dimensions des îlots, mais varient également en fonction de la localisation dans l'îlot (les parcelles d'angle) ou de la vocation des espaces clôturés (zones à vocation agricole) (Paone 2001, p. 81-88). Une constante apparaît toutefois : les rapports pratiqués entre la largeur et la profondeur sont souvent des formules simples : 1 pour 2 ou 1 pour 3 .

D'un site à l'autre, l'observation du tissu urbain montre une diversité d'agencement des plans qui résulte d'une organisation distincte, propre à chaque îlot, mais également de la construction progressive des lots à bâtir au sein de chaque îlot. Bien que la mise en place de ces unités d'habitation se soit effectuée rapidement, d'autres éléments complexifient la lecture du découpage foncier initial : la façon dont s'agencent les murs mitoyens, les tentatives d'empiètement sur le domaine public ou sur les espaces non encore lotis, ou bien la réunification de plusieurs parcelles au sein d'une même unité, tout ce que l'on peut qualifier d' « initiative privée » constituent autant d'éléments d'irrégularité.

\subsection{L'occupation de l'espace urbain à l'Époque moderne (B. Sillano)}

S'il existe une continuité naturelle entre l'Époque moderne et la période médiévale, le parcellaire n'en connaît pas moins une réorganisation forte, en particulier dans les espaces suburbains.

\subsubsection{Le parcellaire intra muros : réorganisation du parcellaire médiéval}

D'un point de vue archéologique, le parcellaire est difficile à mettre en évidence parce que les vestiges correspondent aux bâtiments, souvent aux pièces, et que nous ne connaissons pas la manière dont ils sont regroupés, mis à part de rares cas où les circulations sont conservées. À l'inverse, le cadastre napoléonien nous donne une représentation schématique du parcellaire global, vers 1820, en gommant les espaces internes. Les quelques zones fouillées confirment qu'il reflète bien, sans trop de distorsion, le parcellaire ancien. Souvent, en effet, la contrainte de l'îlotage, très étroit en centre ville, ne permet pas au parcellaire d'évoluer au cours de la période moderne ; les études conjointes de terrain et de textes nous ont montré que, pour la plupart des 


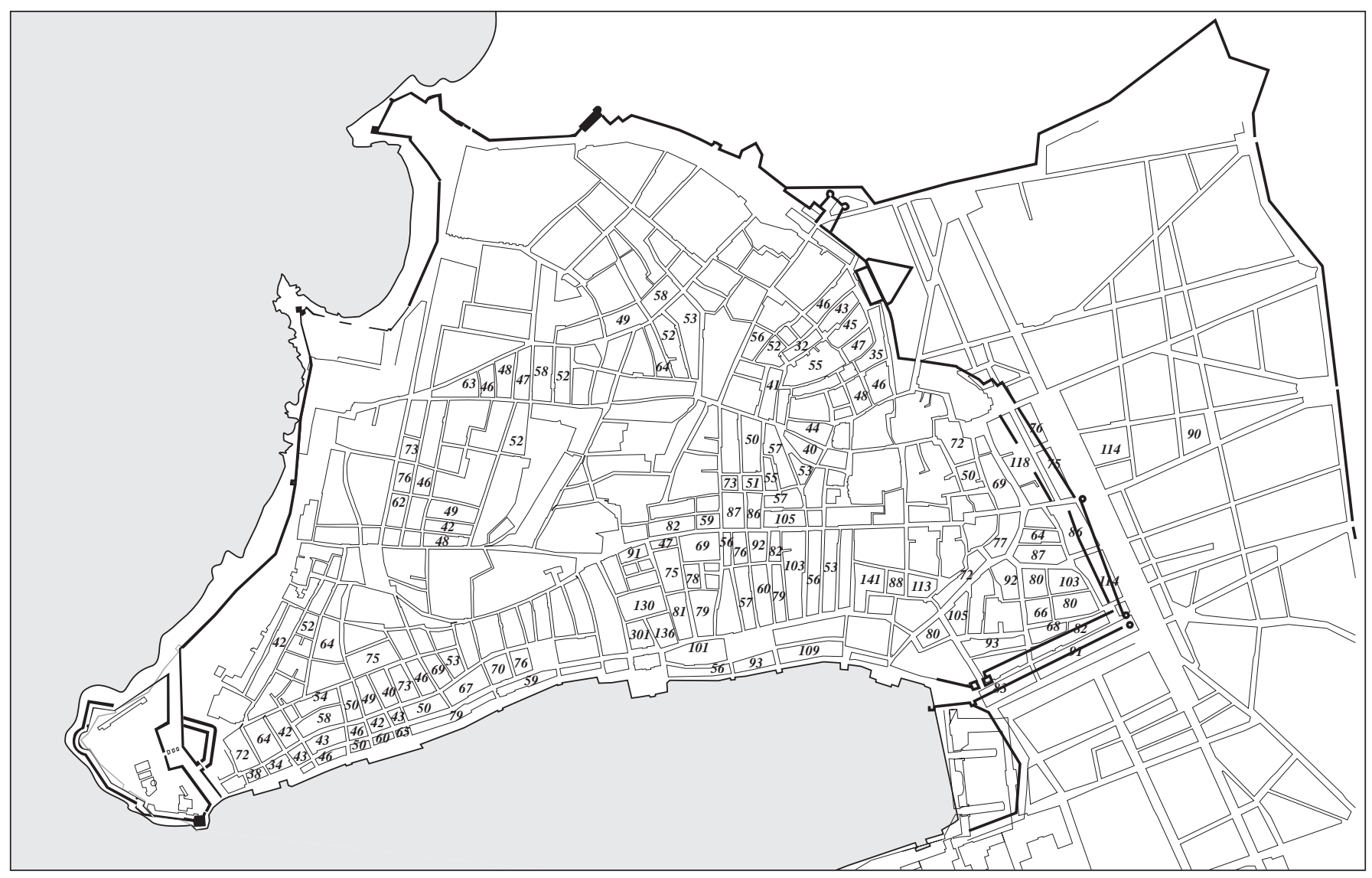

Fig. 42. Superficie moyenne des parcelles par îlot, exprimée en $\mathrm{m}^{2}$ (réalisation B. Sillano, calcul automatique Covadis/Autocad, L. Vallière/Inrap).

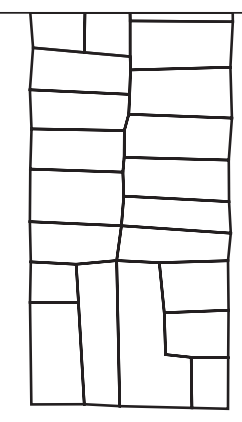

St Laurent

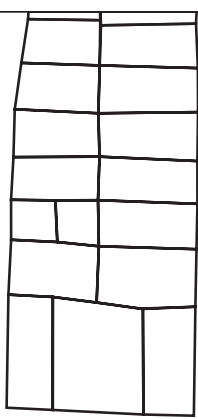

Panier

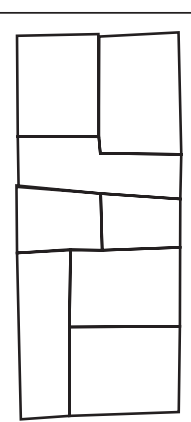

Mairie

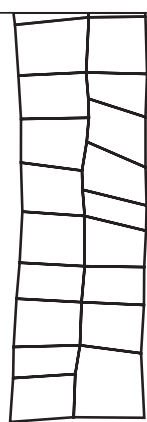

Carmes

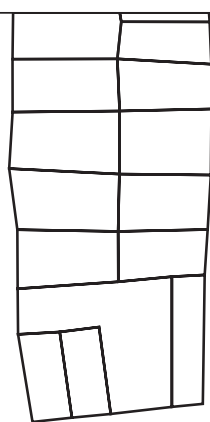

Place neuve

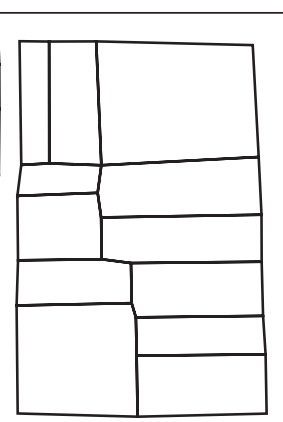

Cul de boeuf

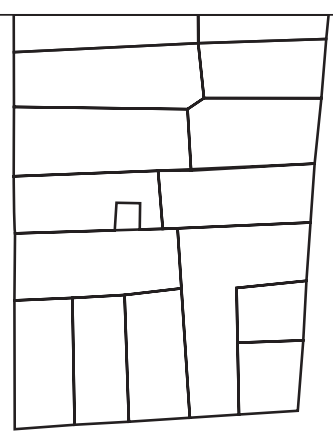

Ville nouvelle

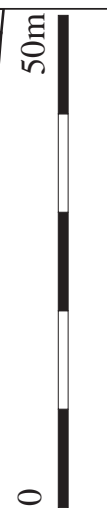

Fig. 43. Quelques îlots représentatifs de quartiers (DAO B. Sillano/Inrap).

cas, les parcelles décrites au XVII ${ }^{\mathrm{e}}$ s. coïncident avec celles qui sont dessinées sur le cadastre. Aucune modification notable du plan ne semble intervenir à l'époque contemporaine, mis à part la disparition des établissements religieux, dont les domaines sont redistribués à la Révolution, et la création d'établissements administratifs. D'autre part, bien que les contours dessinés sur le cadastre soient très simplifiés (les détails sont gommés au profit d'une représentation qui privilégie la superficie des lots, attendu que la finalité du document est la fiscalité), la largeur des parcelles, c'est-à-dire la longueur de leur façade, reste, au demi-mètre près, fiable. Le cadastre napoléonien reste donc le meilleur outil pour appréhender le parcellaire à l'échelle de la ville.

Grâce à ce document, nous avons tenté une approche statistique par échantillonnage du parcellaire; nous constatons que le module moyen des parcelles par îlot, obtenu en divisant la superficie de l'îlot par le nombre de lots, est relativement différent d'un quartier à l'autre (fig. 42 et 43). C'est sur les collines que l'on trouve 


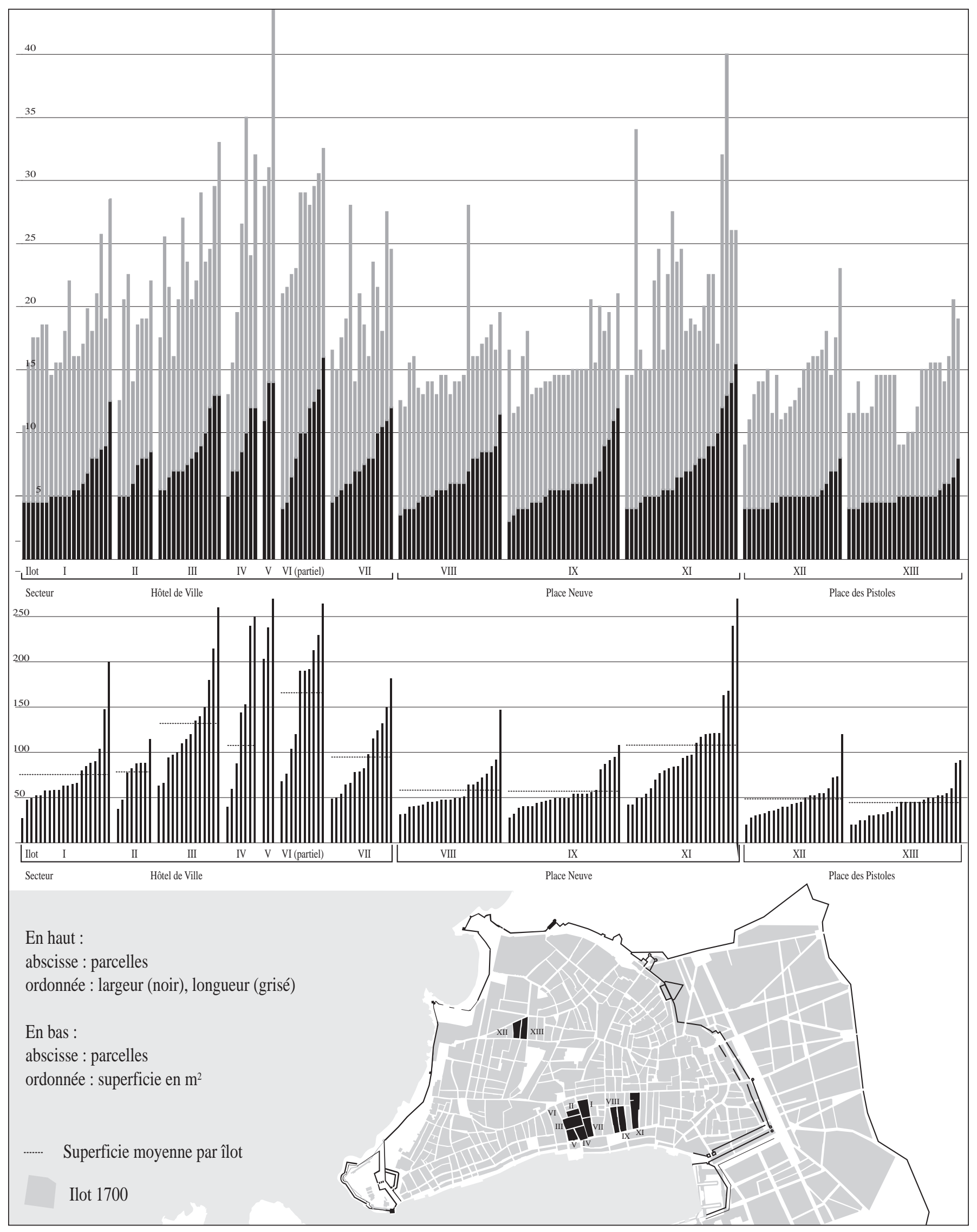

Fig. 44. Comparaison des longueurs, largeurs et superficies des parcelles pour quelques îlots (DAO B. Sillano/Inrap). 
Fig. 45. Transformation du parcellaire médiéval en parcellaire moderne dans le quartier de la Loge (DAO B. Sillano/Inrap).

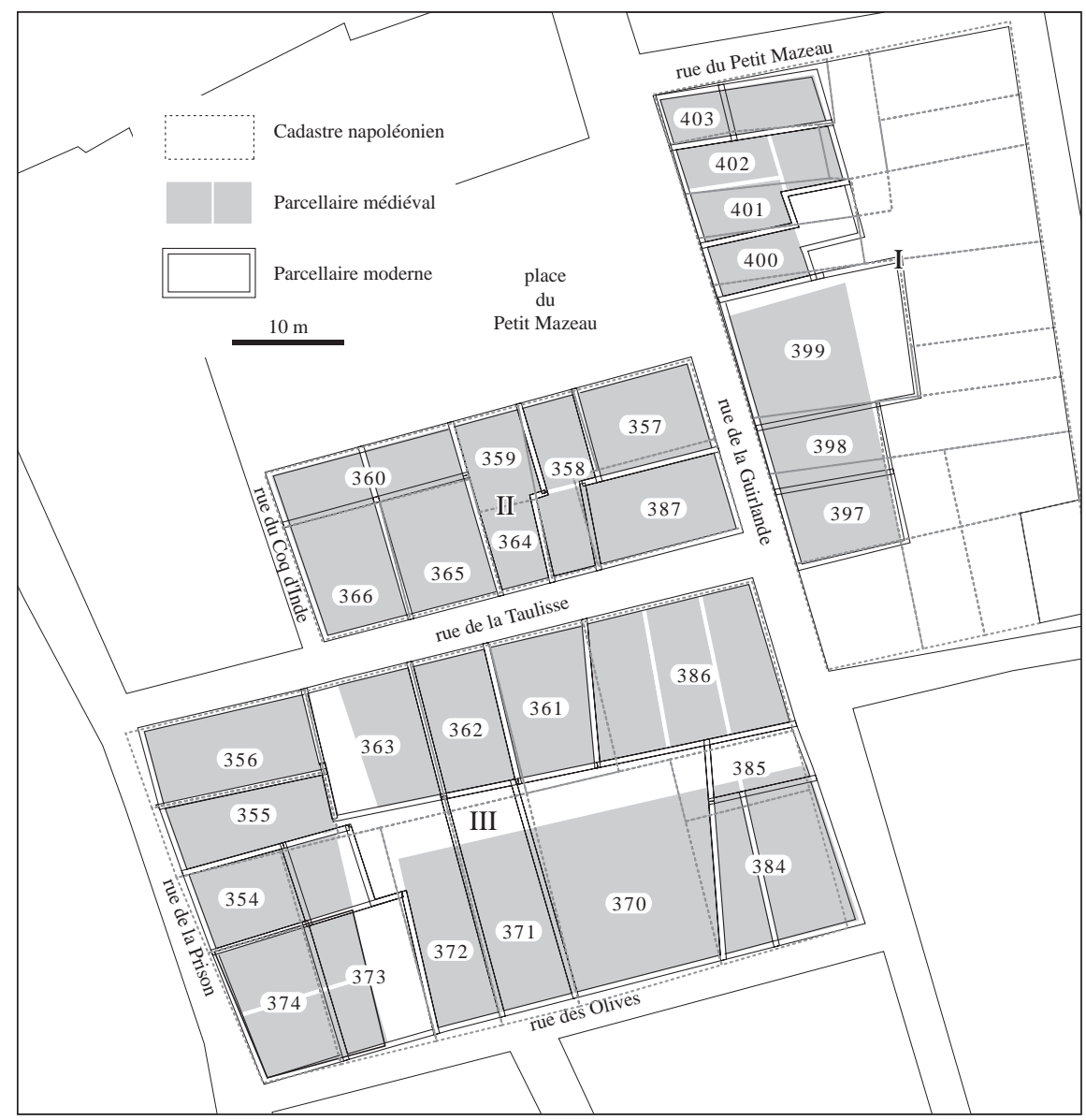

les parcelles les plus petites (butte des Moulins et butte Saint-Laurent, superficies moyennes de $54 \mathrm{~m}^{2}$, butte des Carmes, $45 \mathrm{~m}^{2}$ ), dans la ville basse les superficies moyennes (au nord de la Grand-Rue, $68 \mathrm{~m}^{2}$, au sud, $78 \mathrm{~m}^{2}$ ) et aux confins de la ville les plus vastes (entre les remparts du $\mathrm{XI}^{\mathrm{e}}$ et $\mathrm{XIV}^{\mathrm{e}} \mathrm{s}$., $85 \mathrm{~m}^{2}$ ) ainsi que près de la Loge $\left(94 \mathrm{~m}^{2}\right)$. Il existe aussi une grande disparité dans la répartition des parcelles par îlot, que nous avons essayé de traduire par un échantillonnage (fig. 44). Autour de la place Neuve (ville basse) ou de celle des Pistoles (butte des Moulins), les parcelles sont relativement homogènes. Pour le premier, celles des îlots VIII et IX ont une superficie moyenne de 56 et $58 \mathrm{~m}^{2}$, et une largeur moyenne de $6 \mathrm{~m}$ (nous ne prenons pas en compte l'îlot XIV dans lequel des parcelles traversantes perturbent les résultats). Pour l'autre, les parcelles des îlots XII et XIII ont une superficie moyenne de 44 et $48 \mathrm{~m}^{2}$ et une largeur moyenne de $5 \mathrm{~m}$. En revanche, autour de la Loge, le panel des modules est très ample. Les parcelles de l'îlot I ont une superficie moyenne de $76 \mathrm{~m}^{2}$ pour une largeur de $6,1 \mathrm{~m}$, celles de l'îlot II, $78 \mathrm{~m}^{2}$ pour $6,6 \mathrm{~m}$, celles de l'îlot VII, $94 \mathrm{~m}^{2}$ pour $7,7 \mathrm{~m}$, celles de l'îlot III, $132 \mathrm{~m}^{2}$ pour $8,5 \mathrm{~m}$, et enfin celles de l'îlot IV, $139 \mathrm{~m}^{2}$ pour $8,8 \mathrm{~m}$.
Ce rapide survol du parcellaire à l'échelle de la ville met en évidence les particularités des quartiers qui sont le reflet d'une mise en place progressive combinée à une spécificité géographique. Contraint par un îlotage étroit, le parcellaire des quartiers hauts n'a aucune marge pour s'adapter à une configuration plus «moderne » et subit très peu de modifications depuis le Moyen Âge. À l'inverse, les modifications du réseau viaire de la ville basse, c'est-à-dire le regroupement des îlots, permettent au parcellaire d'adopter un maillage plus large. À ce titre, le quartier de la Loge, disséqué grâce aux fouilles de la place Villeneuve-Bargemon, est peut-être le meilleur exemple de l'évolution du parcellaire à l'Époque moderne. En effet, les trois îlots étudiés, numérotés I, II et III, rassemblent à peu près tous les procédés de transformation du parcellaire médiéval (fig. 45).

\section{Conservation du parcellaire médiéval}

Dans de nombreux cas, le parcellaire médiéval est conservé à l'Époque moderne, tout au moins en ce qui concerne la largeur des parcelles, dont la longueur évolue parfois avec le temps aux dépens du cœur d'îlot. Ainsi avons-nous montré l'origine ancienne des façades 
des parcelles 400 à 402 de l'îlot I (face au Petit Mazeau), mais aussi des parcelles 361 et 362 , dont la grande taille mise en évidence par le cadastre napoléonien remonte au Moyen Âge ( $c f$. infra $\S$ II, 2, 3.4.9. et 10.).

\section{Extension des parcelles en cœur d'îlot}

Les parcelles 400 à 402 ont pour origine des lots de petite dimension disposés le long de la rue de la Guirlande et qui se sont ensuite étendus en cœur d'îlot (cf. infra $\S$ II, 2, 3.2.4. $\S$ II, 2, 3.2.6. et fig. 46). En retrait, les parcelles 400 et 402 ont outrepassé leurs limites pour se rejoindre derrière la parcelle 401 qui les sépare. Cette dernière voit sa petite dimension compensée par son rattachement, au XVIII ${ }^{\text {e }}$ s., à la parcelle 402. Plus tard, comme nous le voyons sur le cadastre napoléonien, elle acquiert la partie arrière de la parcelle 400.

\section{Regroupement de parcelles mitoyennes}

L'Hôtel de Remezan (parc. 374 et 373, pour partie, cf. infra $§$ II, 2, 3.4.1.) occupe toute l'extrémité méridionale d'un îlot d'axe nord-sud. Son module correspond exactement au double de celui des parcelles voisines et montre que sa construction, au $\mathrm{XV}^{\mathrm{e}}$ ou $\mathrm{XVI}^{\mathrm{e}}$ s., fait suite au regroupement de deux lots (l'arasement profond des couches superficielles nous prive des murs médiévaux). Ainsi son emprise, de 12 m par 12 m, est en vis-à-vis de trois rues. Le même processus s'est certainement déroulé sur l'îlot suivant, au nord, que le Palais a progressivement entièrement occupé. De même avons nous identifié, en fouille, trois parcelles médiévales au sein de la parcelle d'angle 386 ( $c f$. infra $\S$ II, 2, 3.4.8.), et, dans les textes, deux parcelles étroites, réunies au XVII ${ }^{\mathrm{e}} \mathrm{s}$, dans l'emprise de la parcelle 384.

\section{Regroupement de parcelles en vis-à-vis}

Nous n'avons pas de tel cas sur les trois îlots présentés, mais il est facile de les reconnaître dans les parcelles traversantes sur îlots étroits (par exemple la parcelle 394 de l'îlot VII, fig. 47).

\section{Remembrement d'un îlot}

L'îlot II est né du regroupement de deux îlots médiévaux ; à partir du $\mathrm{XVI}^{\mathrm{e}}$ s., l'espace ouvert axial est subdivisé pour créer la parcelle 359, puis fermé au sud pour créer l'autre, 364 (cf. infra $\S$ II, 2, 3.3.). À noter que l'absence d'escalier pour atteindre la cave nord suppose que ces lots sont associés durant l'Époque moderne, avant d'être individualisés comme le montre le cadastre napoléonien. Parallèlement, ou à la fin du Moyen Âge,

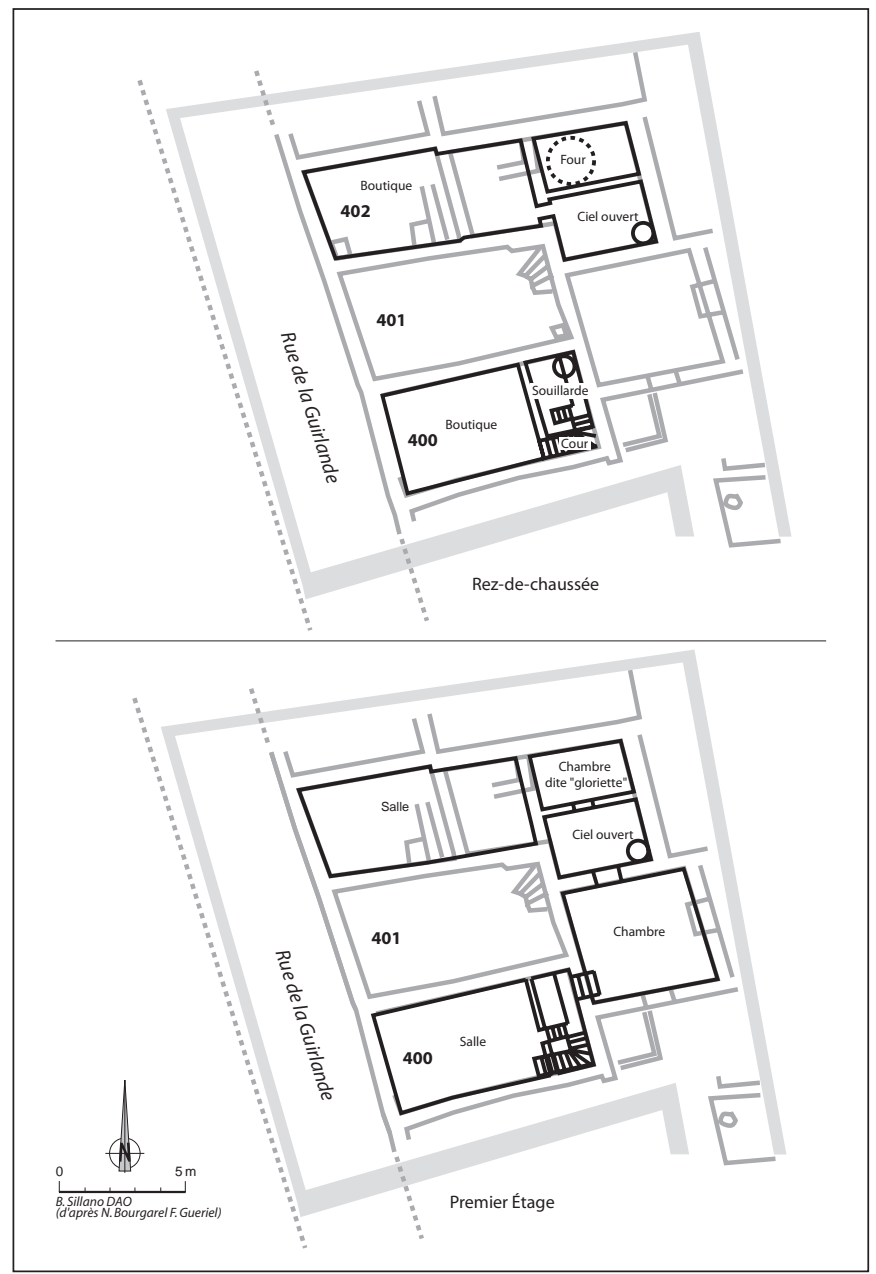

Fig. 46. Restitution de l'immeuble sur les parcelles 400, 401 et 402 (DAO B. Sillano/Inrap).

les anciens îlots sont remembrés ; à l'ouest, les quatre parcelles « en lanière » subissent une découpe transverse qui abouti à trois nouveaux lots ; à l'est, la parcelle méridionale se départit, au XVII ${ }^{\mathrm{e}}$ s., d'un espace au profit de la parcelle 358 qui devient traversante.

\section{Partage d'une grande parcelle}

Le bâtiment de bains médiéval disposé le long de la rue de la Guirlande est abandonné à l'extrême fin du Moyen Âge. Il donne naissance à trois parcelles dont l'une, $n^{\circ} 399$, occupe l'exacte moitié du bâtiment antérieur ; pour ce faire, l'ancien refend, pourtant massif, fut remplacé par un mur mitoyen à un peu plus d'un mètre vers le sud ( $c f$. infra $\S \mathrm{II}, 2,3.2 .7$.).

\section{Acquisition des espaces publics}

L'absorption des traverses se traduit par leur cession au domaine privé. L'Hôtel de Remezan, après la 


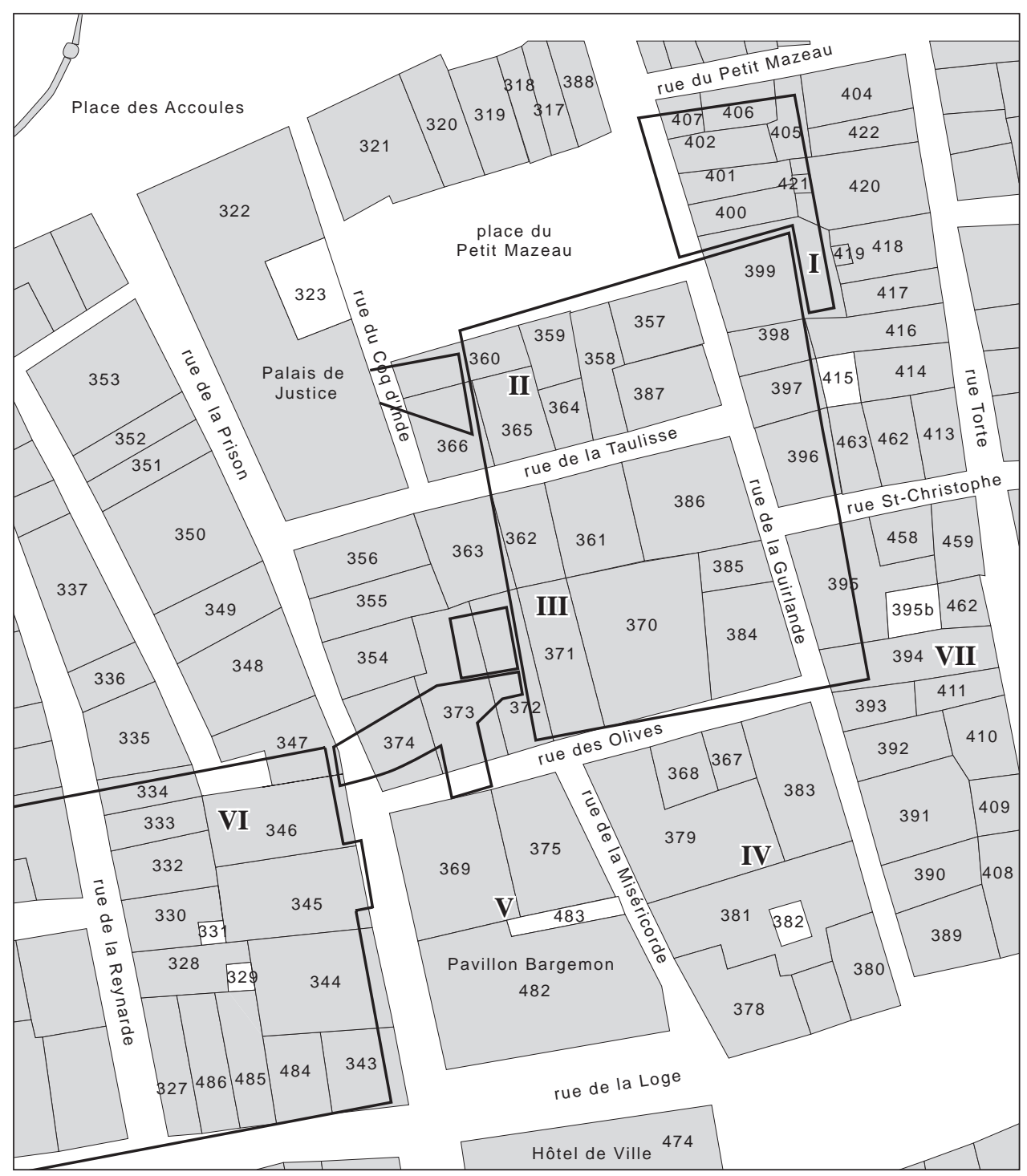

Fig. 47. Le parcellaire napoléonien autour des chantiers de la place Villeneuve-Bargemon (DAO B. Sillano/Inrap).

disparition de la ruelle qui le bordait à l'est, se départit d'un tiers de sa surface afin de créer, avec la portion de rue en vis-à-vis, la parcelle 373 ( $c f$. infra § II, 2, 3.4.3.). Cette même parcelle s'étend vers le nord où elle partage la rue avec sa voisine, $\mathrm{n}^{\circ} 372$, qui annexe ainsi, au XVIII ${ }^{\mathrm{e}}$ s., une excroissance du côté ouest. De même, la parcelle 399, déjà évoquée, s'étend vers l'est aux dépens de la ruelle qui recoupait tout l'îlot longitudinalement.

\section{Refonte totale}

Enfin, la partie méridionale de l'îlot III détient la plus grande parcelle du quartier, l'hôtel de Gérente (parcelle 370), d'une superficie de $267 \mathrm{~m}^{2}$ (cf. infra $§$ II, 2, 3.4.5.). Par malchance, toute cette zone a subi un arasement profond qui nous prive des vestiges médiévaux et donc de la filiation entre les parcellaires, mais nous remarquons que les parcelles s'établissent entre une bordure oblique à l'est (ligne qui correspond exactement à la limite occidentale des thermes romains sous-jacents, conservée pour une raison inconnue) et, à l'ouest, un passage, disparu mais attesté par un réseau de canalisations et conforme à la trame urbaine. La forme trapézoïdale qui en découle est absorbée par la parcelle 370, et plus exactement par la cour intérieure qui sépare les deux ailes bâties de part et d'autre. Cette configuration indique clairement que la parcelle a acquis son unité dès l'origine, ce qui suppose que le propriétaire, le sieur de Gérente, qui possède par ailleurs une bonne partie du reste de l'îlot, a fait table rase du parcellaire antérieur. Il est difficile de ne pas évoquer le fameux sac des Catalans en 1423 au cours duquel, selon les historiens, de nombreuses maisons situées dans le quartier de la Loge ont été détruites. Par la suite, les autorités ont incité les élites à racheter 


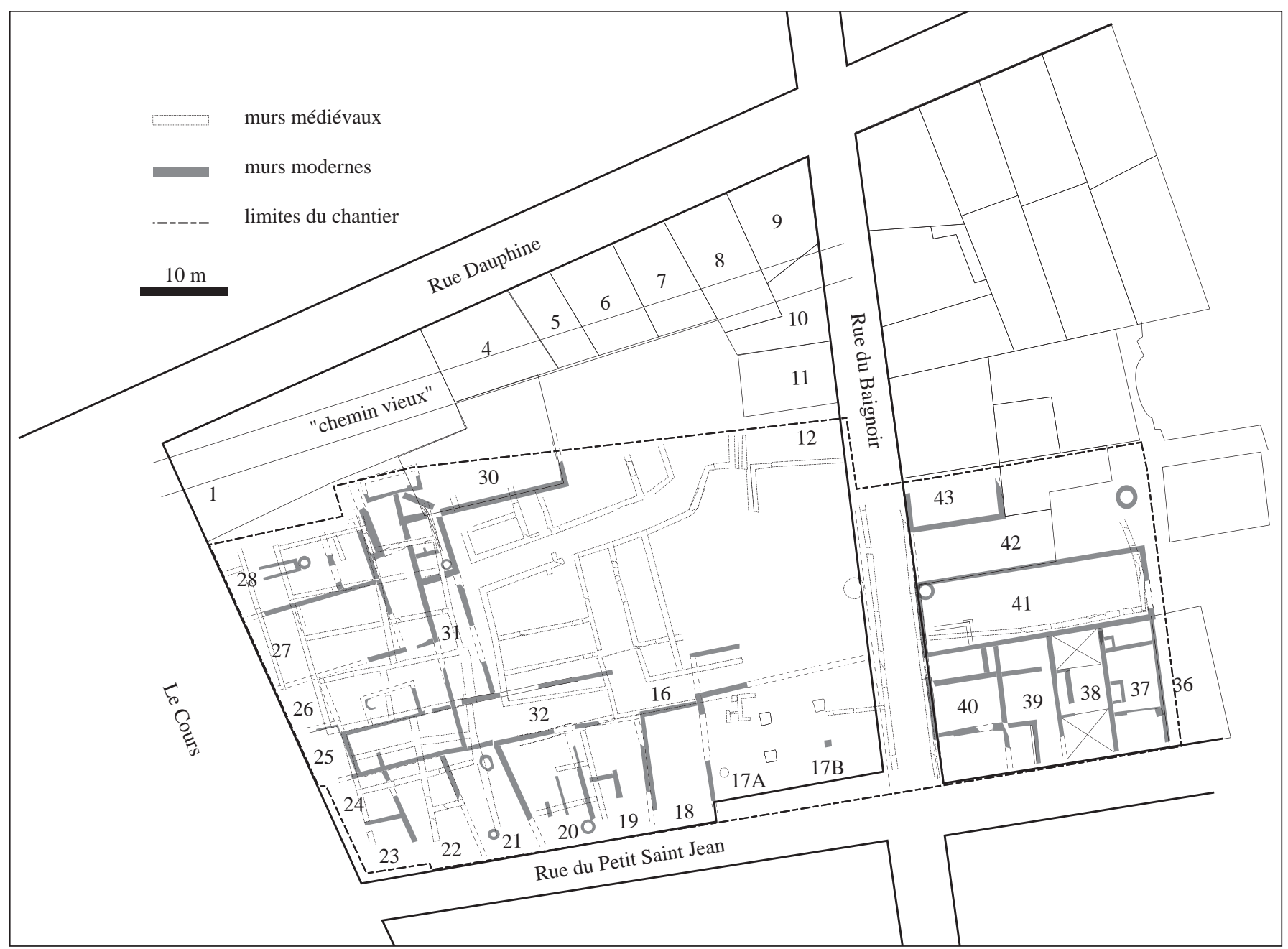

Fig. 48. Superposition des constructions médiévales et modernes sur le site de l'Alcazar avec numérotation interne des parcelles (DAO B. Sillano/Inrap).

les terrains ainsi libérés afin de hâter leurs reconstructions. Il n'est pas impossible que cet acte destructeur ait autorisé la création d'un parcellaire tout à fait différent de son prédécesseur. Ce type d'événement est, en tout cas, le seul qui puisse expliquer la transformation radicale d'un parcellaire qui, d'une manière générale, reste prisonnier de son passé.

\subsubsection{Du parcellaire des faubourgs à celui de la «Ville Nouvelle »}

Sur le secteur de la fouille de l'Alcazar, la réoccupation des faubourgs après l'arasement des habitations médiévales s'est traduite, nous l'avons vu, par la refonte du réseau viaire. Les suites sont immédiates pour le parcellaire qui, au début du XVII ${ }^{\mathrm{e}}$ s., présente d'avantage des « places à bâtir » que d'habitations proprement dites.

Le long du Grand-Caire, où nous constatons une déclinaison entre les réseaux viaires médiévaux et ceux d'Époque moderne, les parcelles (numérotées 25 à 28) se décalent également, tout en conservant certaines limites antérieures. Ainsi, la parcelle 27 occupe l'emprise de deux parcelles médiévales, d'une portion de rue et probablement des deux parcelles placées en vis-à-vis (fig. 48). La pérennité des limites reste toujours bien mystérieuse lorsque l'on sait qu'un laps de temps important s'est écoulé entre la démolition des faubourgs et les reconstructions, temps au cours duquel les murs ont été arasés, épierrés jusqu'aux fondations, puis enfouis sous un épais remblai. De même, nous constatons que les bâtiments de la confrérie Saint-Hommebon, qui occupent tout le cœur d'îlot, reprennent, à peine décalés, les limites d'un îlot médiéval et des rues voisines.

Les dimensions des parcelles avant le réalignement sur le Cours ne sont pas données par le rapport d'estime de 1668 qui ne se préoccupe que de la partie bâtie, mais elles peuvent être restituées en s'appuyant sur les données de fouille. Les parcelles 27 et 28 mesurent environ $25 \mathrm{~m}$ de long pour $8,50 \mathrm{~m}$ de large, soit une superficie supérieure à $200 \mathrm{~m}^{2}$. Immédiatement au nord, la «place 


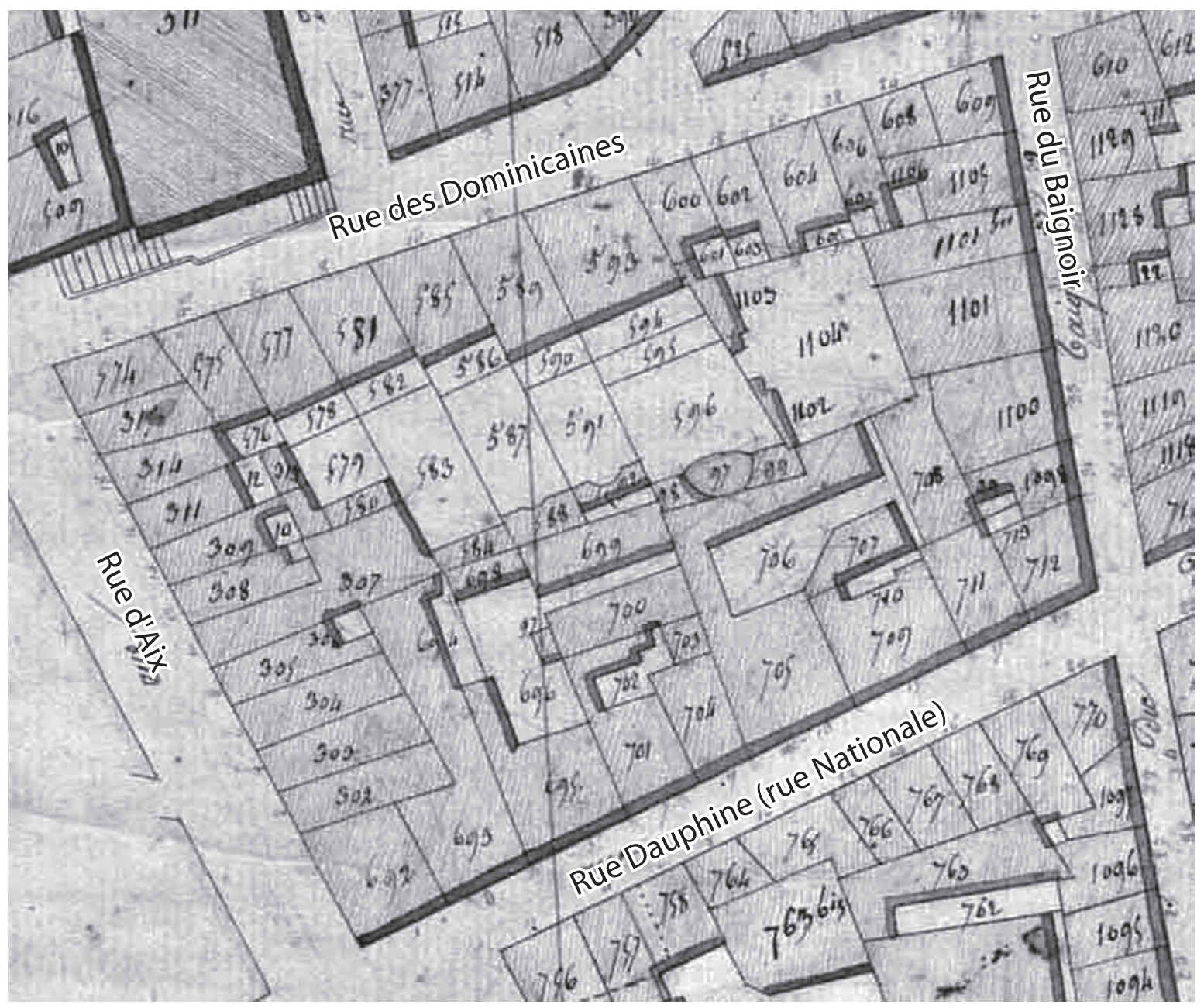

Fig. 49. L'îlot au nord de l'Alcazar où l'on distingue les parcelles vendues par le S' de Beaulieu en 1658 le long de la future rue d'Aix et celles vendus par Couzinery 15 ans plus tard le long de la rue Dauphine (extrait du cadastre napoléonien, cl. AD13).

de maison et jardin» (parcelle 1) mentionnée dans l'acte de 1636 et située à l'angle de l'îlot, hors emprise de fouille, mesure $26 \mathrm{~m}$ de long pour $9 \mathrm{~m}$ de large. À l'inverse, la parcelle 25 ne mesure que $6 \mathrm{~m}$ par $10 \mathrm{~m}$, et nous en retrouvons de plus petites encore, telles celles de Amphoux et Barnier, mentionnées dans l'acte de 1636, dans l'îlot au sud, de $6 \mathrm{~m}$ par $6 \mathrm{~m}$.

Les parcelles disposées le long de la rue du PetitSaint-Jean doivent absorber la différence d'orientation entre le Grand-Caire et la rue du Baignoir, distorsion liée à la création de cette place, qui n'existait pas aux époques antérieures; à l'extrémité ouest de la rue, les parcelles d'angle 22, 23 et 24 forment une seule unité aux contours parallèles aux deux axes ; l'autre bout de la rue (avant qu'elle ne soit prolongée), le plan de l'auberge du même nom en fait de même ; entre les deux, les parcelles 18 à 21 , mentionnées dès 1636 dans l'acte d'arrentement de la demoiselle de Guérin, adoptent un plan trapézoïdal qui répartit la déclinaison. Leurs dimensions moyennes sont de $6 \mathrm{~m}$ de large pour $12 \mathrm{~m}$ de long, environ $70 \mathrm{~m}^{2}$, c'est-à-dire un module légèrement supérieur à celui que l'on connaît dans la «vieille ville ». Les deux parcelles d'angles ont respectivement des dimensions de 19,25 m par $12 \mathrm{~m}$ et $20 \mathrm{~m}$ par $11 \mathrm{~m}$, soit des surfaces supérieures à $200 \mathrm{~m}^{2}$. Dans l'angle nord-est de l'îlot, la parcelle que se réserve la demoiselle de Guérin en 1636 a les mêmes dimensions que la première.

Dans l'îlot voisin, au nord, le long d'une ruelle, les quatorze places à bâtir que vend, en 1658, le $\mathrm{S}^{\mathrm{r}}$ de Beaulieu ${ }^{\mathbf{1 0 2}}$, sont identiques et mesurent $12 \mathrm{~m}$ de long pour $5 \mathrm{~m}$ de large, hors murs (fig. 49). Elles paraissent bien étroites, 10 ans plus tard, lorsque la traverse devient la rue d'Aix (fig. 50).

Le doublement de la superficie de la ville intra muros, sous Louis XIV, a pour effet de modifier partiellement le parcellaire des anciens faubourgs mais aussi et surtout

102 AD13 362 E 111, fol. 583. 


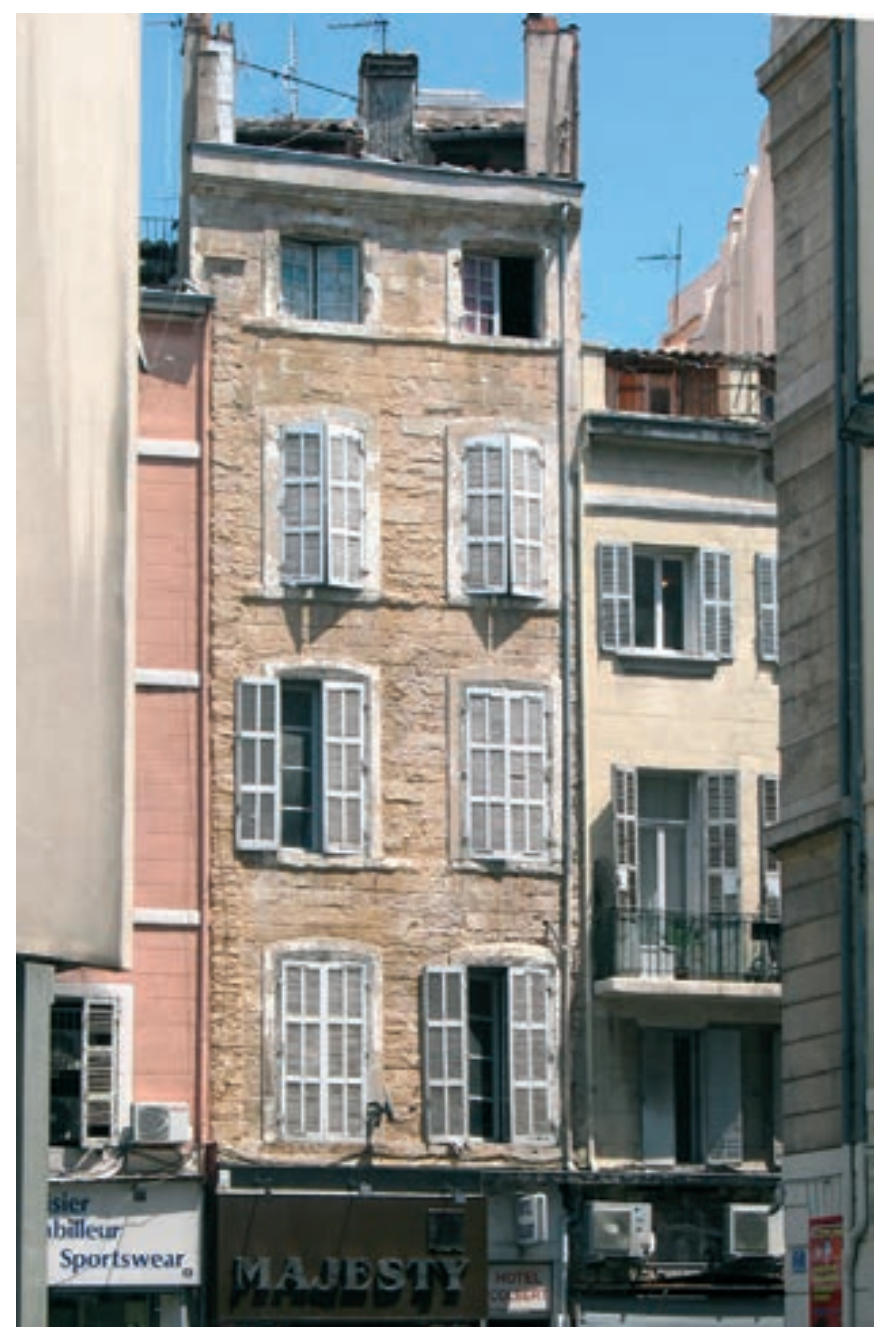

Fig. 50. Maison construite sur une des parcelles vendues par le S' de Beaulieu en 1658 (rue d'Aix, côté est) (cl. B. Sillano/Inrap).

de mettre en jeu de vastes terrains, auparavant agricoles, afin de les morceler en une multitude de « places à bâtir ». Dans le secteur de l'Alcazar, nous avons constaté que la plupart des maisons qui occupaient les faubourgs sont conservées, au moins partiellement, dans le plan de la Ville Nouvelle. Il en va ainsi des auberges disposées le long du Grand-Caire, en dépit du sérieux alignement qu'elles subissent lorsque la place devient le Cours. Les écuries alignées sur la rive nord de la partie occidentale de la rue du Petit-Saint-Jean sont transformées en auberges, mais leur emprise n'est pas modifiée. Seule la maison qui se trouve dans l'axe de cette rue (parcelle 40) est détruite lorsque la voie est prolongée vers l'est. Les parcelles vendues par le $\mathrm{S}^{\mathrm{r}}$ de Beaulieu sont, au contraire, rallongées lorsque la rue d'Aix, qui remplace la traverse qui les desservait, est tracée parallèlement à l'ancienne voie et décalée vers l'ouest.

Ce sont surtout les nouvelles parcelles qui nous intéressent ici car elles reflètent un besoin en matière d'espace qui est propre à cette époque. Nous allons voir que la manière dont ont été réalisés les lots a une incidence directe sur leur taille et leur forme.

Au nord de l'îlot, la rue Dauphine est percée à travers des jardins nouvellement acquis par Couzinery, en remplacement du «chemin vieux» situé un peu plus au sud. L'espace qui sépare ces deux voies est subdivisé au cours de plusieurs transactions qui s'échelonnent de février à juillet 1672. La première parcelle vendue, à l'angle oriental de l'îlot, possède des côtés internes à angle droit alors que les rues se recoupent à angle aigu. Cette configuration peu habituelle est traduite dans l'acte par : «laquelle place sera prise en escaire sur le dernier » ${ }^{\mathbf{0 3}}$. Les cinq parcelles suivantes sont ensuite vendues dans l'ordre, d'est en ouest, comme le précise chaque acte de vente où il est systématiquement rappelé que le lot « confronte de couchant le restant dudit jardin ». Leurs profondeurs, contraintes par la présence de la congrégation Saint-Hommebon, varient de $14 \mathrm{~m}$ à $12 \mathrm{~m}$; en revanche, leurs largeurs sont très diverses et reflètent certainement les finances de l'acquéreur. Ainsi les parcelles 4 à 7 mesurent respectivement $11 \mathrm{~m}, 5 \mathrm{~m}, 7,50 \mathrm{~m}$ et $6 \mathrm{~m}$ de large, soit un panel très varié qu'il est difficile de mettre en relation avec un type de bâti. Le même phénomène se produit au nord de la rue Dauphine, dans le sens inverse cette fois-ci ( $c f$. fig. 49). La première parcelle vendue est trassée, c'est-à-dire qu'elle s'implante sur un terrain vierge ; elle n'est pas à l'angle de la rue d'Aix puisqu'elle confronte vers l'ouest la maison acquise par Couzinery du $\mathrm{S}^{\mathrm{r}}$ de Beaulieu, antérieure à l'Agrandissement. Large de $12 \mathrm{~m}$ pour $16 \mathrm{~m}$ de profondeur, soit près de $200 \mathrm{~m}^{2}$, c'est la plus grande de la série. Puis sont vendues deux parcelles de $9 \mathrm{~m}$ de façade pour $14 \mathrm{~m}$ de profondeur et enfin, le même jour, les quatre dernières parcelles, larges de $8 \mathrm{~m}$ pour la même profondeur. Le fait que les lots soient vendus dans l'ordre indique que le choix de la dimension de la parcelle est encore dicté par l'acquéreur. En dépit des largeurs variables, il est intéressant de constater que nous avons là un module de grande taille relativement novateur.

À l'est de l'îlot, le prolongement de la rue du PetitSaint-Jean se fait à travers les jardins Barnier. Les terrains, acquis en héritage par Thomas de Riquetti, sont morcelés et vendus en 1674. Pour les parcelles qui sont dans l'emprise des fouilles, mise à part la parcelle d'angle qui a d'emblée une largeur de $8 \mathrm{~m}^{\mathbf{1 0 4}}$, deux d'entre elles ( $\mathrm{n}^{\circ} 36$ et 38), mesurent «trois canes de fassade et sept canes de proffondeur ${ }^{\mathbf{1 0 5}}$ soit $6 \mathrm{~m}$ par $14 \mathrm{~m}$, alors que deux autres ( $n^{\circ} 37$ et 39$)$ mesurent « 22 pans de fassade»,

103 AD13 362 E 125, fol. 315v.

104 AD13 380 E 171, fol. 1043v.

105 AD13 380 E 171, fol. 49 et fol. 81. 
soit $5,50 \mathrm{~m}$, pour la même profondeur ${ }^{106}$. Les quatre autres qui complètent la série vers l'est ont les mêmes caractéristiques. Cette régularité (une curieuse alternance de parcelles de largeurs sensiblement identiques) explique probablement que les ventes aient été effectuées dans le désordre. Ce ne sont donc pas les acheteurs qui ont défini les dimensions des lots mais le vendeur. Dans le même ordre d'idée pouvons-nous évoquer les parcelles, toutes identiques, loties par la congrégation Saint-Hommebon le long de la rive occidentale de la rue du Baignoir à partir de 1720.

Dans tous les cas évoqués, il est clair que la superficie de la propriété est directement liée au bâtiment qui y prend place, auquel est adjoint un petit ciel ouvert. Mais il existe également des lots de très grande dimension dans lesquels s'inscrivent un ou plusieurs bâtiments, mais aussi de vastes terrains à ciel ouvert. Citons la parcelle 41 , longue de $32 \mathrm{~m}$ et large de $8 \mathrm{~m}$, soit $328 \mathrm{~m}^{2}$. L'immeuble qui y prend place n'est pas plus grand que ceux de la rue adjacente, en revanche tout le fond de la parcelle est ouvert et fait partie du cœur d'îlot. Le partage de cet espace central, extrêmement développé dans la ville neuve, se fait de manière aléatoire, contrairement à ce qui se passe dans la « vieille ville », où, compte tenu de sa petitesse, il est très découpé et exploité au maximum, et souvent densément occupé par le bâti.

\subsubsection{Conclusion}

À l'intérieur des anciens remparts, la filiation entre les parcellaires médiévaux et modernes, très sensible, permet de considérer le cadastre napoléonien comme suffisant pour aborder la question du parcellaire moderne. Les modules moyens par quartier témoignent de leur lotissement progressif ou de leur attrait géographique. Aux intersections, autour de la Loge par exemple, quartier qui subit l'influence des commerces populaires au nord et des administrations de la ville au sud, la diversité des modules met en évidence la dualité.

Lorsque l'héritage médiéval n'est pas trop prégnant, nous pouvons espérer rencontrer des parcelles dont le module est caractéristique d'une période ou d'un niveau social du propriétaire. C'est ce que nous constatons dans la Ville Nouvelle de Louis XIV. Les parcelles créées par le $S^{r}$ de Beaulieu quelques années avant l'Agrandissement attestent de la survivance d'un module peu large, proche de celui des parcelles de la « vieille ville», alors que, au même moment, celles qui bordent le Grand-Caire, occupées par des auberges, sont de grandes dimensions et qu'un module plus large apparaît le long de la rue du

106 AD13 380 E 171, fol. 83 et fol. 1395.
Petit-Saint-Jean. Les parcelles d'angles se différencient toujours, deux à trois fois plus vastes que les autres. Le lotissement progressif de la Ville Nouvelle met en relief l'évolution du parcellaire, qui finit, vers le milieu du XVIII ${ }^{e}$ s., par atteindre un module qu'il conservera jusqu'à nos jours.

\section{Le réseau hydraulique (N. Scherrer, B. Vasselin, M. Moliner)}

Avant le XIII ${ }^{e}$ s., les textes nous manquent pour mesurer l'importance donnée dans la vie politique et sociale à la question de l'eau. Néanmoins il est vraisemblable que, comme la gestion des céréales ou du port, celle de l'eau a toujours eu une place prépondérante dans la vie publique. L'eau est utilisée pour boire, manger, laver la maison, les objets et le linge, l'hygiène corporelle (bains publics ou curatifs), travailler (artisanat, cultures, ...), pour alimenter les fossés défensifs le long des remparts; l'eau a également une importance dans le culte religieux (baptistères, ablutions, ....). À partir du XIII s., des textes, notamment les Statuts municipaux, attestent du regard porté sur la question du rejet des eaux usées (Crémieux 1917; Pernoud 1949). Les ruissellements sont un souci récurrent dans cette ville au relief escarpé ; de violents épisodes orageux ont de lourdes conséquences sur les aménagements urbains et sur l'entretien du port.

\subsection{Capter et amener l'eau dans la ville}

Les rivières, les sources, la nappe phréatique, la pluie, les marécages sont autant de sources d'eau; l'adduction se fait par captage, récupération des eaux de pluie, pompage ou forage, au moyen d'installations collectives ou individuelles. Sa qualité est menacée par un grand nombre de facteurs (fermentation, pollutions dues aux activités artisanales ou aux rejets) et les édiles cherchent à protéger les installations afin d'éviter les contaminations et de faciliter la circulation.

Le territoire de Marseille est traversé par l'Huveaune, au sud, son affluent le Jarret, à l'est, et le ruisseau des Aygalades, au nord (fig. 51). Les Statuts révisés en 1253 mentionnent la nécessité de dévier une partie des eaux du Jarret afin d'irriguer des jardins et d'alimenter des tanneries dans le quartier de la Blanquerie (Pernoud 1949; Amargier 1996). La source de la Frache, autrefois dans le vallon Saint-Martin, sous l'actuelle rue des PetitesMaries, alimentait le Grand Puits, la Font Piero que raio et sans doute le Vallat deis Cougourdos qui se jetait dans le port. Il n'est pas impossible que ce soit elle qui coule 


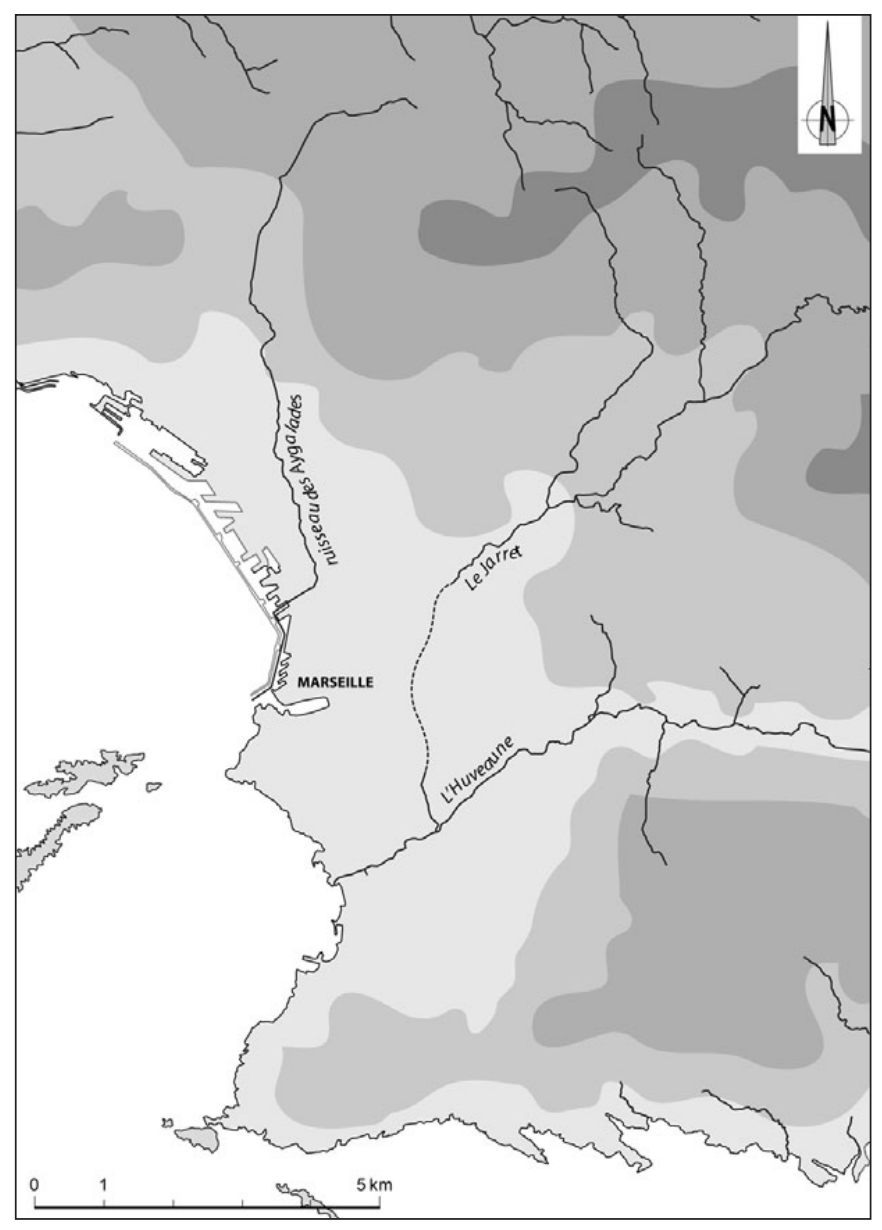

Fig. 51. Carte oro-hydrologique du bassin de Marseille (DAO F. Guériel/Inrap).

dans le fossé qui traverse le site de l'Alcazar du nord au sud. Une autre source proviendrait de l'arrière de l'actuelle église des Réformés et alimenterait une fontaine située sur la place du Cul-de-Bœuf (Chanterac 1837, p. 462).

La partie sud-est du port a été aménagée dès l'Antiquité tardive en salines, lesquelles sont sans doute abandonnées au $\mathrm{X}^{\mathrm{e}}$ ou $\mathrm{XI}^{\mathrm{e}}$ s. (Maurin, Sillano 2001, p. 38-40). Cette zone est ensuite drainée par un réseau de fossés avant l'implantation d'un faubourg (Maurin et al. 2001a, p. 44-47). Il s'agissait certainement de permettre l'extension de la ville mais aussi d'assainir ce secteur proche de la ville et de lutter contre le paludisme qui sévit au Moyen Âge dans le sud de la France.

Certaines structures sont héritées de l'Antiquité tardive, voire de l'Antiquité, mais de nouveaux aménagements sont nécessaires dès la période médiévale, tant pour l'alimentation en eau que pour le rejet des eaux usées, car les besoins s'accroissent en même temps que la ville se développe.

\subsubsection{Au Moyen Âge}

La ville basse est déjà bien pourvue en eau, mais les villes épiscopale et prévôtale semblent rencontrer quelques difficultés pour leur approvisionnement. C'est Charles Ir d'Anjou qui va imposer une politique commune de l'eau et être sans doute l'initiateur de l'aqueduc dit de l'Huveaune. Dès 1262, il demande que les pierres issues de la destruction des remparts soient utilisées pour construire des fontaines et des aqueducs. En 1310, le conseil municipal décide de la construction de neuf fontaines, six dans la ville basse (les habitants devront payer une taxe dite «fontanière ») et trois dans la ville haute. En 1318, il s'agit de créer de nouveaux abreuvoirs (Amargier 1996). Une commission de prud'hommes maçons est chargée de régler les différends autour des constructions mais aussi de l'écoulement des eaux (Pernoud 1949, p. 41). En 1332, des préposés des eaux sont nommés, un par sixain de la ville basse (Amargier 1996).

\section{Le vocabulaire des circulations et des usages hydrauliques}

Les appellations des adductions d'eau procèdent d'une certaine diversité parmi lesquelles il est parfois difficile de distinguer les particularités techniques propres à chacune, les termes utilisés étant souvent employés comme synonymes par les rédacteurs des textes latins.

Les dénominations les plus anciennes (fin du XIII ${ }^{\mathrm{e}} \mathrm{s}$.) concernant les circulations d'eau ne donnent que peu d'indications précises bien que les Statuts municipaux du milieu du siècle soient relativement explicites quant à la nécessité de procéder à des aménagements. En 1297, il est question de bedal et de giet, deux termes qui semblent pour le premier désigner le cours principal du Jarret (bedale mayrem), le deuxième une dérivation secondaire ${ }^{107}$; dans le contexte, le mot vallatum est synonyme de bedal : «...infra dictum bedale seu vallatum » ${ }^{108}$.

Les textes relatifs aux travaux d'adduction d'eaux en 1319 diversifient le lexique et introduisent la notion de conduits couverts ( crotono videlicet lausis copertis», aqueductus). Le terme crota trouve enfin une confirmation d'usage avec son synonyme aqueductum en 1474. En 1366 on mentionne «dels oydes per quos aqua decurit ad fontes hujus civitatis » ${ }^{\mathbf{1 0 9}}$. En 1396 on rapproche

107 Levy 1980, à l'entrée get, propose « rejeton, pousse... ». 108 AD13 64 H 1, n 7 ; Albanès 1879, p. 266. On distingue dans les textes le vallatum Jarretis avec le fossé de la ville appelé vallatum meniarum ou vallatum civitatis.

109 AD13 BB 25, fol. 154v. Le terme latin osdeorum est employé en 1395, AD13 1 HD B 6, fol. 80. 
Fig. 52. L'aqueduc médiéval près de la porte d'Aix (cl. M. Moliner/Atelier du Patrimoine).

deux termes génériques adayguerio sive transversia per quam ducitur seu derivatur quedam aqua... (Albanès 1879, LXIX).

On signale une carrariolo aquario (littéralement « le sentier de l'eau ») près de Crote-Vieille en $1430^{110}$. À la fin du $\mathrm{XV}^{\mathrm{e}} \mathrm{s}$. on dénomme une dérivation essugarie c'est-à-dire un ruisseau d'assèchement ${ }^{111}$. On notera en 1512 l'existence d'une martellière (porteta) servant à réguler l'arrivée de l'eau dans la rue des ateliers una porteta per ont intre l'aigua en la Curateria ${ }^{112}$.

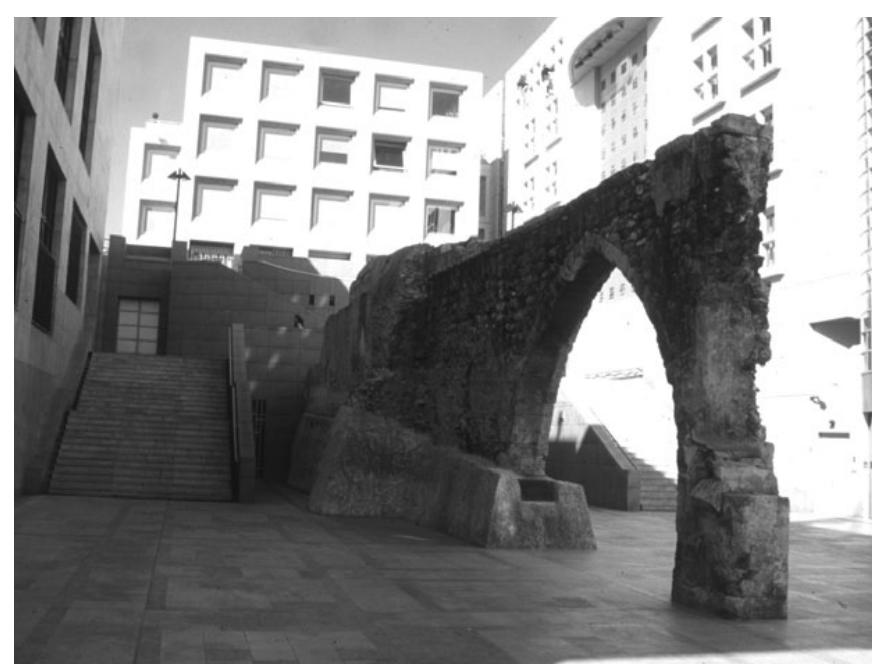

\section{L'aqueduc de l'Huveaune à la porte d'Aix}

L'achèvement du programme de travaux de l'Hôtel de région a nécessité une fouille de sauvetage ponctuelle en décembre 1988 sur le tracé de l'ancien aqueduc médiéval dit de l'Huveaune, entre le tronçon encore en élévation de nos jours, doté d'un arc brisé (fig. 52) et le départ du versant oriental de la butte des Carmes (Moerman et al. 1989). Les découvertes précisent la sortie dans la ville de cette arrivée d'eau qui franchissait d'est en ouest le col entre la butte des Carmes et la colline Saint-Charles au moyen d'une série d'arcades sur une longueur de $170 \mathrm{~m}$.

Cet aqueduc a été, jusqu'au XIX ${ }^{\mathrm{e}}$ s., l'élément principal de la distribution

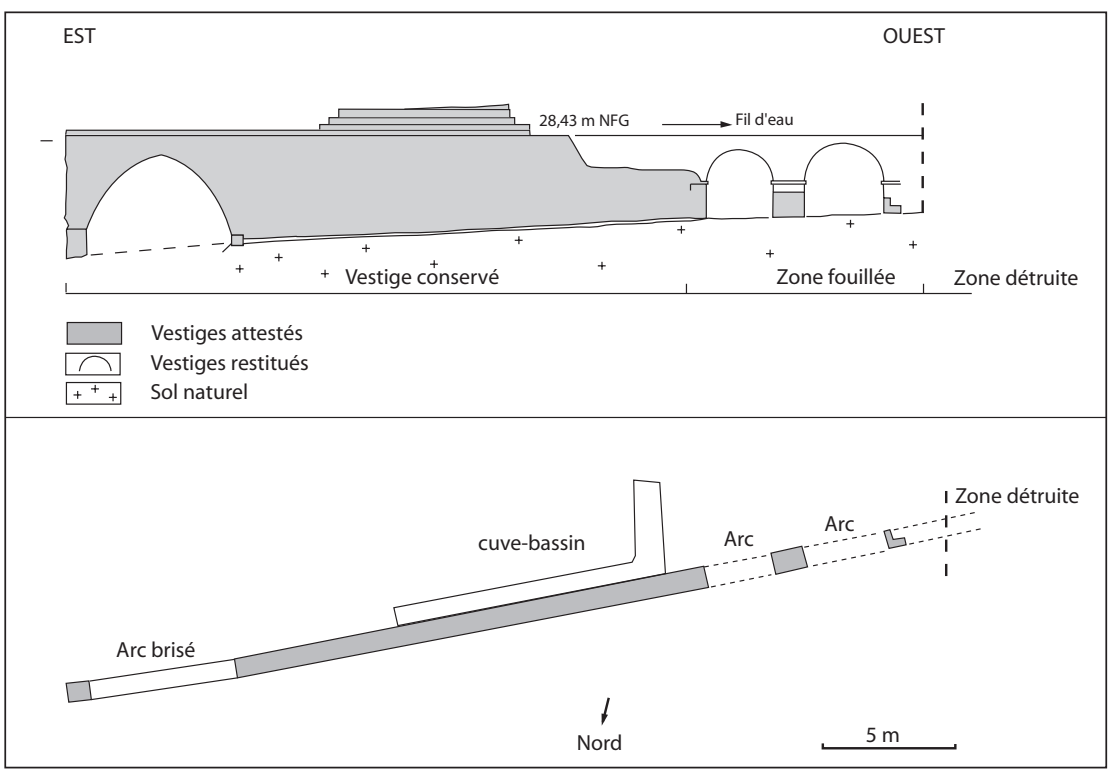

Fig. 53. Plan et élévation de l'aqueduc (DAO M. Moliner/Atelier du Patrimoine). de l'eau dans Marseille intra muros.

Construit au XIII ${ }^{e}$ s., il est alimenté à son origine par des captages divers. On possède un levé précis du parcours terminal qui franchit le vallon Sainte-Barbe ou de la Frache sur une série d'arcades bien dessinée sur les gravures anciennes (Melquiond 1882). C'est l'extrémité occidentale de cet ouvrage qui a été expertisée sur près de $300 \mathrm{~m}^{2}$ et a permis d'en préciser la structure, la chronologie et les différentes modifications jusqu'à son abandon.

Ces états témoignent de la construction et des aménagements d'une conduite d'eau aérienne, datée de la première moitié du $\mathrm{XIV}^{\mathrm{e}} \mathrm{s}$. à partir du mobilier recueilli en stratigraphie. À l'est, la partie aérienne était conservée

110 AD13 351 E 240, fol. 175v.

111 AD13 1 HD B 25, fol. 4v.

112 AD13 4 HD B 9, fol. 69. avec son arc brisé et le canal aérien où l'eau s'écoulait par gravité, encore en place, tandis qu'à l'ouest la fouille a révélé de nouvelles arcades qui avaient disparu dans le bâti moderne. Les deux arches ainsi restituées s'appuyaient à l'ouest sur une maçonnerie, ou massif de culée, à partir duquel la conduite d'eau passait en souterrain pour franchir le rempart et pénétrer en ville ${ }^{113}$ (fig. 53). Trois structures de blocs de calcaire taillés avec un blocage de moellons constituent les piédroits et le pilier de deux arches en plein cintre dont la hauteur sous claveau peut être restituée à $2,80 \mathrm{~m}$ grâce au chaînage horizontal identifié dans un piédroit. Celles-ci supportaient

113 Sur l'emprise de l'intervention, ces vestiges précis étaient détruits. L'entrée souterraine de l'aqueduc en ville aurait été repérée lors des fouilles de la butte des Carmes en 1982. 


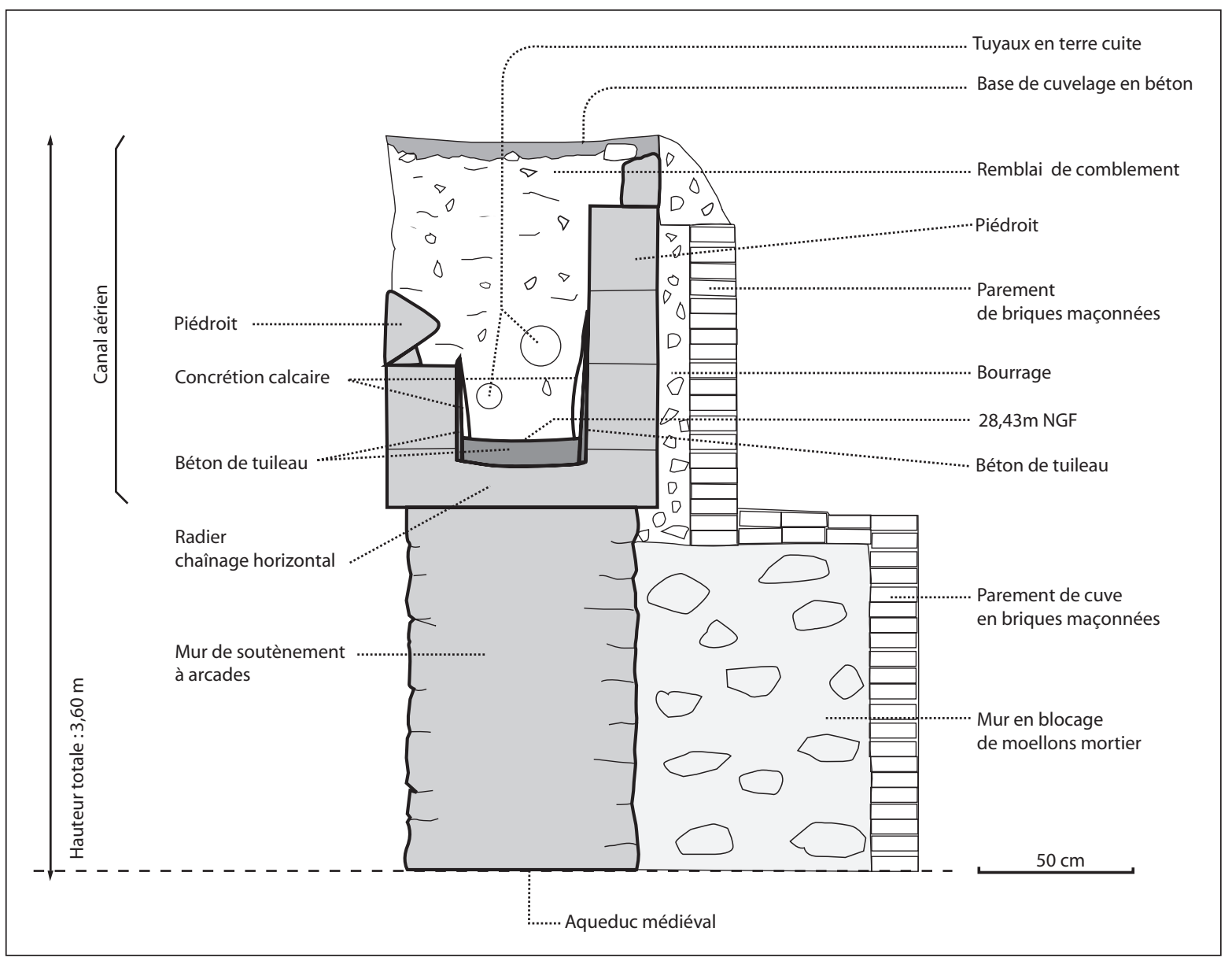

Fig. 54. Coupe de l'aqueduc (DAO M. Moliner/Atelier du Patrimoine).

le conduit aérien constitué d'un canal en pierres de taille régulièrement assisées, enduites à l'intérieur de béton hydraulique, lequel a permis de relever le fil d'eau ici à 28,43 m NGF (fig. 54). Des concrétions calcaires attestent la circulation de l'eau. La couverture, sans doute des dalles horizontales, ne nous est pas parvenue. Très rapidement, au cours du $\mathrm{XIV}^{\mathrm{e}} \mathrm{s}$. et dans la première moitié du $X^{\mathrm{e}}$ s., des remblais comblent la partie basse des arches et de petits aménagements signalent un espace de circulation. À l'Époque moderne, des remaniements ponctuels liés à la création d'îlots d'habitations affectent l'ouvrage, mais l'arrivée d'eau est maintenue. Aux $\mathrm{XVIII}^{\mathrm{e}}$ et $\mathrm{XIX}^{\mathrm{e}} \mathrm{s}$. des bassins sont accolés à l'ouvrage et l'eau est canalisée dans le conduit aérien avec la mise en place de deux conduites en terre cuite.

Sur le chantier archéologique, aucune information ne confirme la date de construction au XIII ${ }^{\mathrm{e}}$ s. proposée par les textes d'archives. Les vestiges mis au jour, massif de culée à arcades et le segment en élévation avec une arche brisée, sont peut-être une reconstruction ou une réfection dans la première moitié du $\mathrm{XIV}^{\mathrm{e}} \mathrm{s}$. d'un ouvrage hydraulique monumental capital -car unique apport extérieur- pour l'alimentation en eau potable de la ville.

\section{D’autres ouvrages collectifs}

Un autre ensemble hydraulique est construit à la fin du XII' s. sur le site de l'Alcazar en même temps qu'une importante tannerie qu'il alimente (Léal, Paone 2001b). Il se compose d'un puits-citerne, de deux tronçons d'aqueducs et d'un puits terminal qui possède un coffrage de bois derrière le cuvelage maçonné ( $c f$. infra $\S$ II, 3, 2.2.2.). Il n'a pas été possible de déterminer si l'industrie a été abandonnée du fait d'un envasement du complexe hydraulique ou si ce dernier a été abandonné suite au déplacement de la tannerie vers un autre quartier.

Sur le chantier Bargemon a été retrouvé un grand puits ${ }^{114}$ associé à une cuve (Paone 2005). La découverte de fragments de godets laisse penser qu'il s'agit d'une

114 Le diamètre de la partie conservée est de 3,30 m. 
noria qui était accessible dans le cœur d'îlot par une venelle. Ce type de puits est pourvu d'une roue verticale, munie d'une courroie dans laquelle sont insérés les godets. L'ensemble est actionné par une roue horizontale mise en mouvement à la main ou par un animal (fig. 55).

Les puits associés à une activité artisanale ou collective ont des diamètres importants $(3,30 \mathrm{~m}$ au minimum pour celui du Mazeau, $7 \mathrm{~m}$ pour le puits citerne, ou plutôt le bassin de décantation, de la tannerie). Des différents systèmes de captage (pompe à vis d'Archimède, pompe à piston, noria à chaîne) qui étaient alors essentiellement en matériaux périssables (bois et cuir), il ne nous reste quasiment rien.

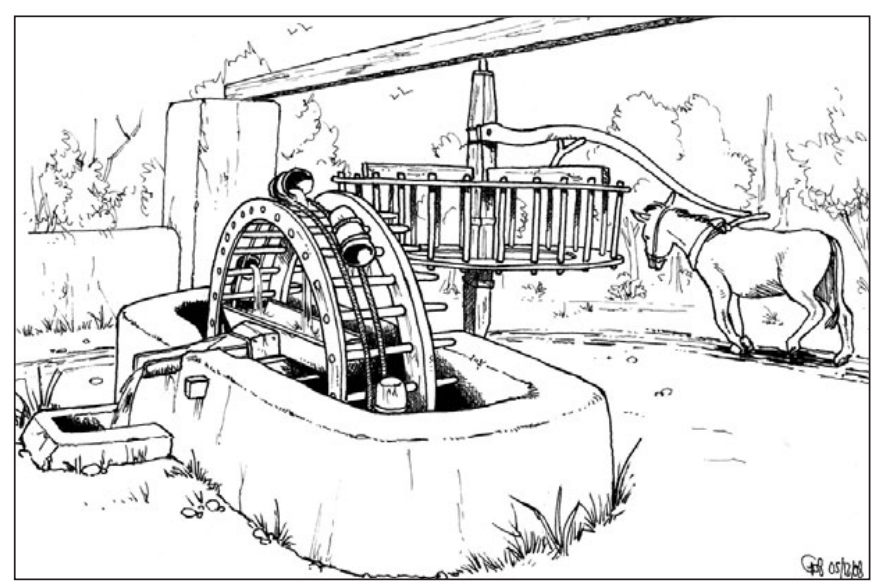

Fig. 55. Restitution d'une noria (del. F. Guériel/Inrap).

\section{Les puits}

L'étude des puits retrouvés en fouille n'est pas sans poser quelques problèmes de précision. Leur construction n'est généralement pas datée faute de mobilier dans le chemisage. En outre, il n'est pas toujours possible techniquement d'atteindre le fond du puits où se trouve logiquement le mobilier contemporain de son utilisation. Lorsque le puits n'est pas demeuré en eau, son comblement d'abandon peut être fouillé et apporte en général une datation assez basse indicatrice de sa longévité. De même les puits d'époque médiévale peuvent avoir été curés et rester en usage à l'Époque moderne. Ils peuvent aussi avoir été arasés et le niveau de leur creusement est alors perdu. Ces facteurs d'incertitudes font qu'il est parfois difficile d'établir des relations de contemporanéité entre tous les puits fouillés sur un site.

Les puits, publics ou privés, sont nombreux sur les sites de la ville basse, mais on en trouve également dans la ville haute et dans les faubourgs. Leur diamètre intérieur est habituellement plus petit que celui des puits associés à un complexe collectif ; ils oscillent généralement entre 0,80 et $1,50 \mathrm{~m}$. Leur implantation varie; ils peuvent être dans un bâtiment, parfois intégrés à la construction (un exemple de puits en angle dans l'unité $\mathrm{E}$ de l'îlot II du quartier du Mazeau), parfois mitoyens (un puits est à cheval entre les unités A et B de l'îlot II du quartier du Mazeau). Il existe aussi un exemple de puits à cheval entre un bâtiment et une rue (dans l'espace B de l'îlot III du quartier du Mazeau, $c f$. infra § II, 2, 2.3.4.). Enfin, ils peuvent être hors bâti, dans une rue, comme le puits construit au XII ${ }^{\mathrm{e}} \mathrm{s}$. dans la rue Four-du-Chapitre), à un croisement ou sur une place (le Grand Puits se situait au carrefour des rues Grand-Puits et Droite).

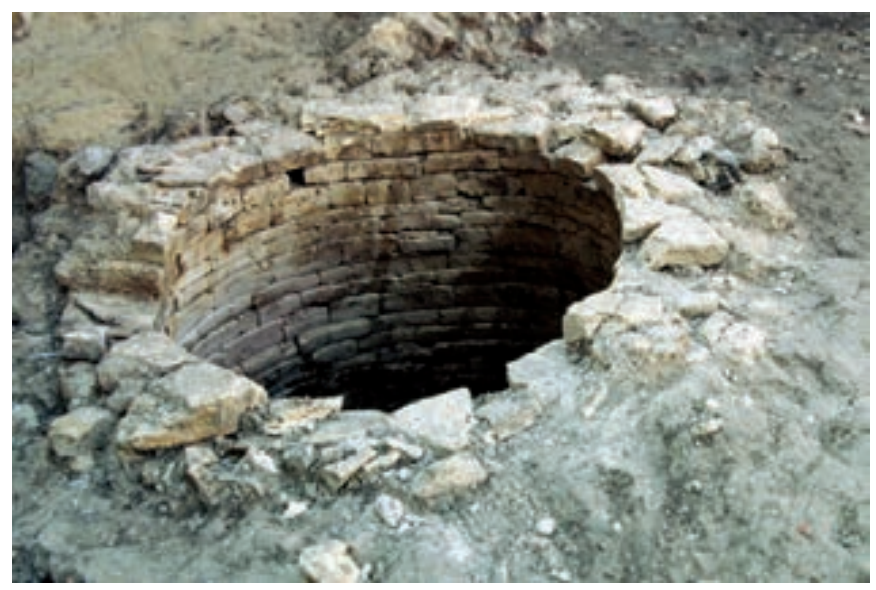

Fig. 56. Puits médiéval dans le bourg de Morier (cl. T. Maziers/Inrap).

La facture des puits médiévaux est généralement soignée, les moellons sont minutieusement disposés et jointoyés (fig. 56). Un puits observé dans la partie sud du chantier Bargemon possède un fond dallé. Les aménagements de surface liés aux puits sont rarement retrouvés en fouille, néanmoins un puits aménagé d'une rigole d'écoulement pour le trop plein des eaux a été observé en diagnostic à l'est du Centre Bourse (Scherrer, Chevillot 2006, p. 59-65).

Ce savoir-faire caractéristique de l'époque médiévale se perd à l'Époque Moderne ; il est sans doute entretenu au sein d'une corporation de puisatiers bien organisée.

\section{Les structures de stockage de l'eau}

Le stockage de l'eau s'effectue au moyen de bassins, de fontaines, d'abreuvoirs, lavoirs et de divers conteneurs (pots, tonneaux...). Les maisons sont pourvues de gouttières ou chenaux qui se déversent dans des bassins ou des tonneaux situés à leur débouché. De ces aménagements, il ne nous est quasiment rien parvenu du fait 
des arasements d'époques ultérieures (les bâtiments sont rarement conservés en élévation, les blocs sont récupérés et les éléments en bois ne sont pas conservés). L'îlot II du quartier du Mazeau a néanmoins fourni un exemple de bassin surmonté d'une voûte, situé dans un espace ouvert (fig. 57). Dans une maison mitoyenne était bâti un ensemble de deux cuves dont une était enduite. Il peut s'agir de citernes, mais des glacières ou latrines peuvent avoir les mêmes caractéristiques architecturales (cf. infra $\S$ II, 2, 2.3.3.).

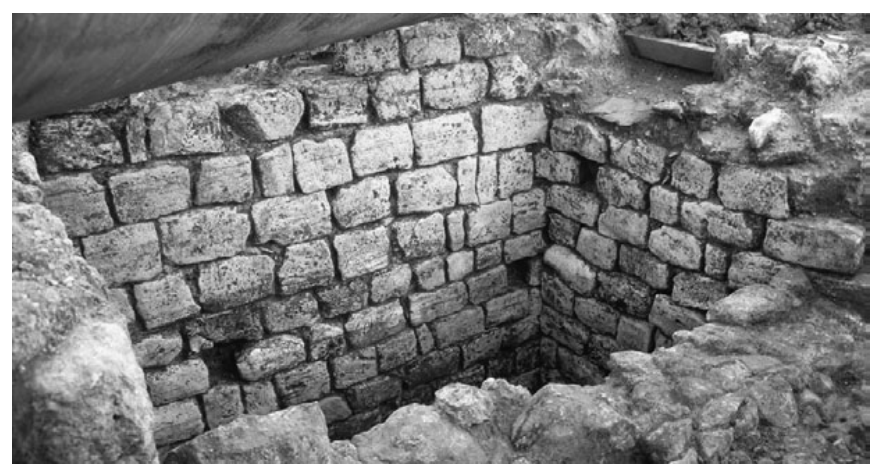

Fig. 57. Vue de la cuve d'une maison du Mazeau (cl. M. Derain/Inrap).

Les textes parlent de la création de fontaines qui, en dehors de leur aspect pratique, sont aussi un ornement de la ville et parfois le lieu de dévotions, comme la fontaine située rue Fontaine-Saint-Claude où les tanneurs avaient placé une image de leur patron. Un texte de 1296 mentionne la construction d'une fontaine à la Pierre de l'Image (cf. infra § II, 1, 1.3.3.), un autre du XIVe s. indique que l'installation de la fontaine Saint-Jacquesdes-Épées a condamné la porte d'un riverain (Amargier 1987). Des mentions concernant les abreuvoirs apparaissent dans les textes, en général pour demander que ceux-ci ne soient pas pollués par des immondices ou par le lavage du linge (Amargier 1987). Ces monuments, également lieu de sociabilité, n'ont pas été trouvés en fouille ${ }^{115}$. Citons toutefois la fontaine (ou bassin) découverte sur le chantier de la place Jules-Verne de laquelle est sortie beaucoup de vaisselle en verre.

De même, les conduites ne sont en général pas retrouvées. Elles pouvaient être en bois ou en terre ; si elles étaient en plomb ou en terre cuite, les matériaux ont été récupérés. Des canalisations de terre cuite ont néanmoins été observées, dans l'entrepôt du quartier du Mazeau (mais il s'agit de tuyaux aériques) et une autre datée du XII ${ }^{\mathrm{e}} \mathrm{s}$. bordant un mur dans un sondage de

115 Les pierres, vraisemblablement taillées, de ces constructions ont sans doute été récupérées. diagnostic au sud du jardin des vestiges (Paone 2005, Scherrer, Chevillot 2006).

\subsection{2. À l'Époque moderne}

La période moderne voit certains équipements médiévaux perdurer, les puits notamment; l'aqueduc est restructuré et les aménagements se multiplient. Les sources textuelles, beaucoup plus nombreuses qu'au Moyen Âge permettent d'appréhender plus facilement l'importance donnée aux problèmes liés à l'eau.

\section{Les adductions publiques : l'aqueduc de l'Huveaune et son réseau hydraulique}

À l'Époque moderne, la ville est déjà largement pourvue en eau grâce aux réseaux raccordés à l'aqueduc de l'Huveaune. À la fin du XIX e s., G. Melquiond, ingénieur des eaux de la ville de Marseille, dresse une carte précise de ce système hydraulique qui, depuis le Moyen Âge s'est amélioré au fil des siècles et a prévalu jusqu'à l'inauguration du canal de la Durance en 1849 (Melquiond 1882).

L'aqueduc d'origine ne prend pas sa source directement dans l'Huveaune, il draine les eaux des terrains dans lesquels il est creusé. Du XVI ${ }^{e}$ au XVIII ${ }^{e}$ s., devant l'augmentation de la population, de nouveaux captages sont installés directement sur la rivière du Jarret, puis sur l'Huveaune : le grand et le petit Béal. À l'origine des différentes branches de l'aqueduc, des bassins de décantation permettent de purifier l'eau et d'assurer un débit régulier. Des déversoirs ou cours perdus sont également installés pour purger l'eau des tronçons à réparer. Du réseau souterrain partant de l'aqueduc, G. Melquiond a examiné chaque ramification (galerie, canal ou conduite en poterie) l'une après l'autre. Aux intersections, l'eau est distribuée dans les différentes conduites grâce à des serves de partage.

De nombreuses fontaines publiques, parfois complétées par des abreuvoirs pour les animaux, sont ainsi alimentées par l'aqueduc et représentent la première source d'approvisionnement des habitants. Cependant le droit de capter l'eau directement est accordé à titre privé à certains privilégiés.

\section{Les adductions privées d'après les textes}

Les couvents, par exemple, bénéficient d'un régime spécial. Ainsi dans un acte de 1651 faisant suite à une demande des religieuses du couvent des Récollettes de capter l'eau de l'aqueduc, il est stipulé «que lesdites 
religieuses prandront la mesme quantité d'eau qui est accordée aux autres monastères et maisons religieuses de ceste ville conformément à l'ordonnance desd. sieurs consuls » ${ }^{\mathbf{1 1 6}}$.

De même dans un procès de 1638 où les pères du couvent des Grands Augustins se voient contester leurs droits « touchant l'eau qui a coustume d'estre dérivée et rejaillir dans la fonteyne de leur couvant», l'économe du monastère rappelle qu'au début du XVI ${ }^{\mathrm{e}} \mathrm{s}$. «il fust permis et octroyé ausdit pères Augustins de prandre la moitié de l'eau de la fonteyne $S^{t}$ Louis qui este hors ceste porte et icelle fere conduire dans leur couvent et dudict couvant au dehors d'icelluy pour donner une fonteyne au public pourveu qu'ils fissent les conduicts de ladite eau a leur propres cousts et despans. " ${ }^{\mathbf{1 1 7}}$. La suite de l'acte précise qu'à grands frais les deux fontaines furent construites avec en amont une serve et un cou perdu raccordés au grand puits le plus proche.

Outre certaines entreprises ou institutions, telles les congrégations religieuses, quelques privilégiés peuvent bénéficier d'un captage direct dans leur propriété des eaux de l'aqueduc par des canalisations privées comme en témoigne la déclaration suivante datant de 1685. «(...) $S^{r}$ Anthoni Simon, marchand de cette ville, lequel (...) a déclaré quil possède dans le nouveau agrandissement de cette ville un aqueduc ou bournelage dans le grand chemin après une rue tirant au couvent de Augustins Refformés pour la donnation des eaux dont sagit et que led. Simon prend dans les aqueducs de cette ville lequel aqueduc ayant environ 46 cannes de long, prenant son commencement à la sortie de la porte de la propriété de Jacques Riboution jusques dans son jardin et propriété et ce servant et conformément la permission que led. Vincent Martin (...) obtenu de messieurs les présidants et trésoriers généraux de France (...) recognaist être (...) sous la directe domaine et seigneurie du Roy (...) Declarant led. Sr Simon vouloir et devoir tenir et posséder led. acqueduc sous la directe immédiate de sa majesté » ${ }^{118}$.

Un autre exemple, daté de 1658 , se rapporte à la permission accordée à un particulier de prélever de l'eau à perpétuité pour l'usage de son terrain car il s'était engagé à exécuter à ses frais la réparation d'une rupture de l'aqueduc de l'Huveaune ayant occasionné des dégâts dans sa propriété (Melquiond 1882, p. 48).

Le privilège de posséder une conduite privée n'est donc apparemment accordé par dérogation spéciale que

116 AD13 357 E 142, fol. 240. Sillano 2001, p. 138.

117 ACM DD 275, 23 août 1638. Texte recueilli par J. Cuzon dans Sillano et al. 2007b, vol. 2, p. 123-124.

118 AD13 B 929, fol. $1208^{e}$ cahier 5, 7 mai 1685. Texte recueilli et transmis par C. Castrucci. dans des circonstances particulières et à condition d'en financer les travaux. En dépit de nombreuses fraudes perpétuées tout au long du XVIII ${ }^{\mathrm{e}}$ s., les adductions d'eau privées sont loin d'être générales. Ce n'est qu'au début du XIX ${ }^{\mathrm{e}}$ s. que des redevances commencent à être perçues pour la distribution de l'eau (Melquiond 1882, p. 45) et en corollaire que les raccordements se démocratisent et tendent à se généraliser.

\section{Les conduites d'approvisionnement en eau observées en fouille}

Les exemples d'adduction d'eau dans les fouilles archéologiques sont rares et, en outre, parfois difficiles à mettre en évidence. Les canalisations sont normalement situées dans les rues. Or les fouilles ne sont pas fréquentes sur le réseau viaire, puisqu'elles se concentrent en général sur les îlots qui le bordent. La canalisation n'est donc suivie que sur une distance réduite comprenant la plupart du temps une fraction de conduit et dans le meilleur des cas son point d'arrivée. Lorsqu'on a affaire à un tronçon de canalisation, la caractérisation de son usage comme adduction ou collecteur d'eaux usées n'est pas toujours évidente. Par exemple, nous savons par les textes que les bourneaux de terre cuite sont utilisés pour les deux fonctions. En théorie, une obturation du conduit par sédimentation d'origine hydraulique témoigne de l'évacuation d'eaux polluées chargées de différents matériaux tandis qu'un unique dépôt de concrétion calcaire devrait être caractéristique d'une adduction -Melquiond cite un cas de dépôt de calcite limitant à tel point le débit de la conduite qu'elle nécessite une réfection. En pratique, il est parfois difficile de les distinguer sur ce seul critère. Le pendage de la canalisation est déterminant pour savoir d'où provient l'eau et vers quel espace elle s'achemine et en déduire s'il s'agit d'une adduction ou non.

Sur le site de l'Alcazar, une probable canalisation d'adduction maçonnée est construite au début du XVIII ${ }^{\mathrm{e}}$ s. dans le jardin de la congrégation SaintHommebon ${ }^{119}$. Son point d'origine est la rue Nationale ; elle entre ensuite dans la parcelle du couvent où, dans un premier temps, elle se dirige vers le sud-est puis, lorsque des constructions sont établies à son emplacement, vers le sud-ouest, à travers le jardin, où elle se confond alors avec des collecteurs avant d'aboutir sur le cours Belsunce. Elle associe dans sa construction les briques au fond, les moellons de calcaire en parements et les dalles de calcaire en couverture (fig. 58). Dans ce lieu où le captage des eaux est une tradition de haute

119 Il s'agit de la canalisation CN2228 orientée nord sud et de son embranchement est-ouest CN2229. Bouiron 2001b, vol 1-2, p. 465. 


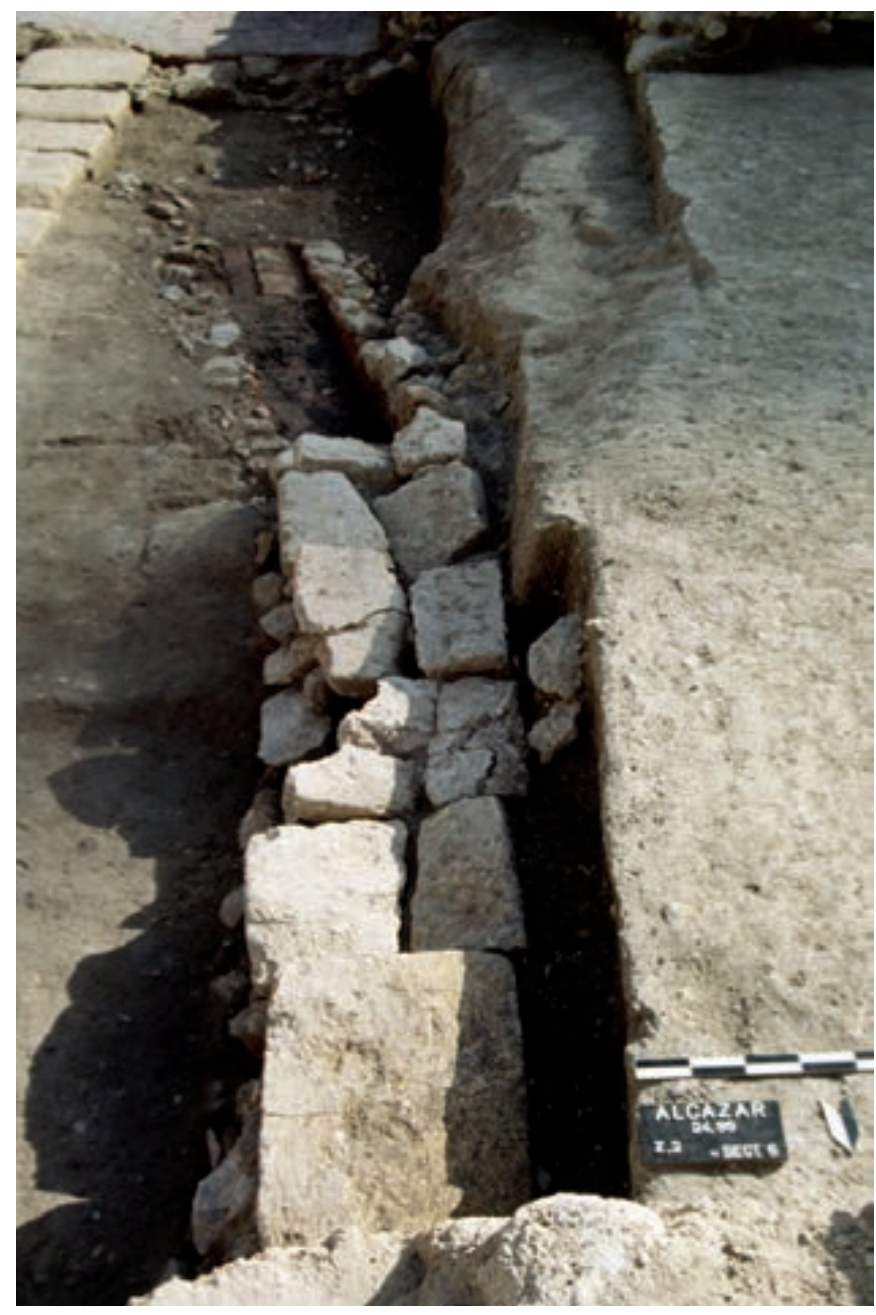

Fig. 58. Canalisation dans le bourg de Morier (cl. P. Reynaud/Inrap).

date (Bouiron 2001b, p. 92, 121, 159), il n'y aurait rien d'étonnant à ce qu'une nouvelle adduction de l'Époque moderne desserve le couvent. Il est toutefois difficile d'affirmer avec certitude que cette canalisation a bien pour fonction d'acheminer de l'eau propre à la consommation ou à l'irrigation. La présence d'un revêtement hydraulique dans le conduit plaide en faveur d'une adduction ; cependant, son comblement présente, sous une couche d'abandon, un premier niveau de remplissage riche en débris de céramique, de verre, de fer, de faune (ossements, écailles de poissons et coquillages) et de végétaux (noyaux d'olives) (Bouiron 2001b, p. 465). On peut se demander si de tels résidus peuvent s'accumuler dans une conduite d'adduction en fin de vie et ne caractérisent pas plutôt un collecteur. Aucun puits n'a été découvert sur la parcelle de la Congrégation ce qui plaiderait encore en faveur de la première hypothèse.

Sur les fouilles du Tunnel de la Major, deux canalisations de terre cuite ont été découvertes dans le passage d'accès à la chapelle des pénitents blancs de Saint-Lazare édifiée au milieu du XVI ${ }^{\mathrm{e}}$ s. et à sa sacristie construite en 1643. La relation entre l'établissement et le réseau n'a toutefois pas été établie lors de la fouille. L'une est composée de bourneaux de terre cuite de 0,55 m de long, d'un diamètre de $0,20 \mathrm{~m}$ se réduisant à $0,10 \mathrm{~m}$ à l'autre extrémité. Le sens d'écoulement de la canalisation n'a pas été déterminé lors de la fouille, mais le vernissage interne d'une des conduites et la proximité de l'établissement religieux pourraient indiquer qu'il s'agit d'une adduction d'eau.

Une autre adduction d'eau, composée d'un bournelage en terre cuite relié à un puits-citerne, a pu être mise en évidence sur la fouille de Sainte-Barbe en 1992. La partie conservée est composée de cinq tuyaux tronconiques emboîtés, d'une longueur de 0,63 m. L'extrémité de la tranchée d'installation de cette canalisation en terre cuite correspond à « un trou et à un tuyau aménagés dans la paroi du puits qui est recouvert de calcite déposée par l'eau qui circule » (Marchesi et al. 1992).

Une étude plus systématique des bourneaux pourrait peut-être permettre de déceler des productions standardisées et de les situer chronologiquement. Ces canalisations ont été remplacées, sans doute dans le courant du $\mathrm{XIX}^{\mathrm{e}}$ s., par des tuyaux de grès.

\section{Les puits}

Outre l'aqueduc, il existe d'autres moyens de s'approvisionner en eau: les sources anciennes encore présentes à Marseille à l'Époque moderne les puits artésiens et surtout les puits publics et privés dont l'usage demeure prédominant durant cette période. Sur le site de l'Alcazar, comme sur celui de la place VilleneuveBargemon, l'utilisation de puits est totalement répandue sur l'ensemble des îlots étudiés. Sur le premier site, on dénombre seize puits pour vingt unités foncières. De même, au XVII ${ }^{\mathrm{e}}$ s. sur le second site, chaque parcelle est dotée d'un puits.

Les puits du site de Bargemon sont situés en général dans les cours intérieures (les «ciels ouverts »). Lorsque les caves se généralisent, au XVII ${ }^{\mathrm{e}}$ s., ils sont prolongés. En 1603, dans la rue de la Guirlande où une maison doit être reconstruite, il est demandé au maçon de «combler le puit qui est a present a lad. maison et en creuser ung autre aud. ciel ouvert a lendroit ou sera avisé avec son vase et pille de pierre de taille bardant led. ciel ouvert de tailhe avec la gorguière pour conduire leau a la rue $\gg{ }^{\mathbf{1 2 0}}$. Nous constatons en effet que les puits successifs sont très proches les uns des autres (fig. 59). Souvent situés à

120 AD13 360 E 39, fol. 493v : prix-fait pour Jean Vinto contre Joseph Courrand et Bernard Poucard (parcelle 390), 19 mars 1603. Texte recueilli par C. Castrucci. 
proximité des escaliers, les puits s'intègrent en général à l'architecture environnante : puits d'angle ou puits adossés contre un mur. Certains d'entre eux sont également accessibles depuis le rez-de-chaussée car leur conduit est prolongé en élévation. C'est le cas du puits du Logis $d u$ Rozier où, à un mètre du sol, une fenêtre rectangulaire encadrée de blocs retaillés de calcaire de la Couronne permet de puiser l'eau depuis la cave ${ }^{121}$. Le chemisage se prolonge au-dessus et laisse imaginer qu'un semblable dispositif est construit au rez-de-chaussée (Thernot 1997, zone 5).

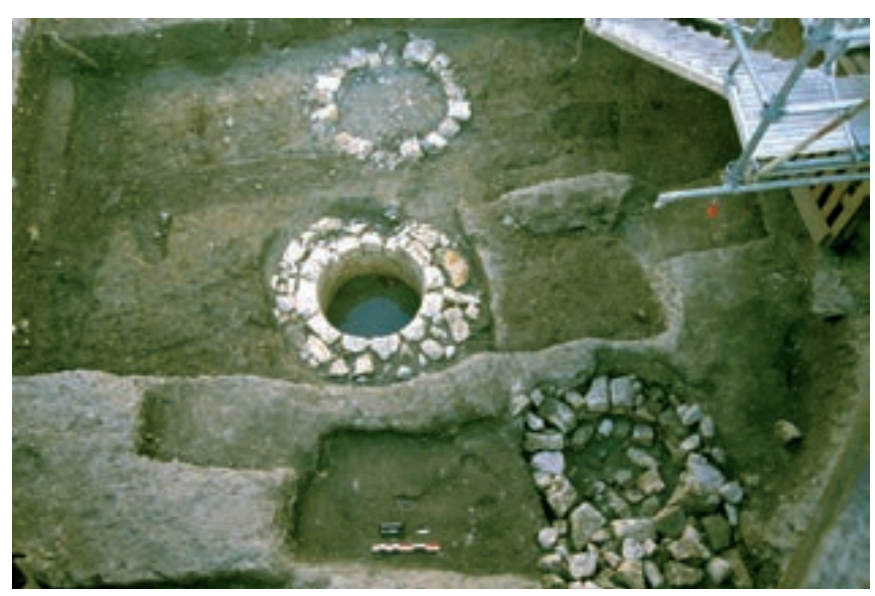

Fig. 59. Deux puits modernes et un puits médiéval (au centre) dans le quartier du Mazeau (cl. M. Derain/Inrap).

Les techniques de construction sont variées et différentes de celles des puits médiévaux dont la mise en œuvre fait l'objet d'un soin minutieux. Une majorité de cuvelages est faite d'éléments montés au mortier ou à la terre, les autres étant construits sans liant. Les matériaux sont toujours très hétérogènes : moellons, cailloux et blocs assortis de carreaux ou tuiles de terre cuite, éléments architecturaux divers en remploi (Sillano 2001, p. 138). Circulaires ou plus rarement quadrangulaires, les puits ont un diamètre interne variant entre 0,60 et $1,30 \mathrm{~m}$. Certains ont conservé leur margelle en pierres de taille (calcaire rose, pierre de Cassis, calcaire coquillier) ou en briques de terre cuite, dans les deux cas maçonnées au mortier.

Un bassin sert parfois de réceptacle pour les eaux du puits qui sont ensuite rejetées à la rue après usage comme en témoigne un prix-fait de 1675 concernant la parcelle $27 \mathrm{du}$ site de l'Alcazar située en bordure du Cours: le maçon «faira un puits de telle profondeur jusque à six pans deau, basti de pierre de roche avec sa bordure en pierres de taille avec son bassinet et jorque

121 Rinalducci 1997, p. 16 : l'îlot nord et l'îlot est, zones 5, 6 et 8. de pierre pour conduire leau à la rue » ${ }^{122}$. Aucun aménagement semblable n'a malheureusement été mis en évidence dans les fouilles de l'Alcazar ou de Bargemon.

\section{2. Évacuer l'eau}

La topographie physique de la ville induit une circulation naturelle des eaux de ruissellement avec laquelle les urbanistes durent composer de tous temps. En témoignent encore aujourd'hui les inondations du Vieux-Port lors d'orages violents.

\subsubsection{Au Moyen Âge}

L'ancien vallon de la Frache, en périphérie de la ville médiévale, devint tout naturellement la douve du rempart établi à cette époque. Il drainait les eaux de pluie captées à la fois par les versants urbanisés, à l'ouest, et ruraux, à l'est, avant de se déverser dans le talweg de la Canebière puis dans le port. Des mesures sont ordonnées dans les Statuts de la ville (XIII ${ }^{\mathrm{e}} \mathrm{s}$.) pour établir en haut des rues concernées des réservoirs destinés à retenir les eaux de pluie et les immondices qu'elles entraînent (fumier, détritus). Les Statuts stipulent en outre qu'il est interdit de rejeter les eaux du Jarret dans le port après leur traversée de la ville, notamment après les rejets des artisanats polluants telles les tanneries ou teintureries (Pernoud 1949, p. 60). L'évacuation des eaux usées drainées par les fossés aboutissaient aux fossés qui longeaient les remparts de façon à ne pas se déverser directement dans le port. De fait, la fouille du fossé sur la place Généralde-Gaulle a livré de nombreux immondices, témoignant qu'il servait de dépotoir (Bouiron et al. 2001).

Dans le bourg de Morier ${ }^{123}$, un épisode alluvial de la seconde moitié du XII ${ }^{\mathrm{e}} \mathrm{s}$. a largement incisé les vestiges de la première moitié du siècle.

La canalisation des eaux de ruissellement se faisait aussi dans les rues où des rigoles pouvaient être aménagées. Les rues qui possèdent un pavage peuvent présenter un fil d'eau central. Sur la rue Sainte-Catherine (fouille de la place Général-de-Gaulle), des fils d'eau perpendiculaires à l'axe de la rue reliaient les descentes de gouttière au fil d'eau central (Maurin et al. 2001b, p. 87-89). La rue des Cordiers (bourg de Morier) présente aussi un fil central; les restes de calade observés dans les rues Sainte-Claire et de Morier dans le bourg du même nom sont pourvus d'une évacuation axiale

122 AD13 380 E 171, fol. 1411. Texte recueilli par C. Castrucci.

123 Pour les descriptions de structures dans le quartier de la Major voir plus loin les chapitres § II, 1, pour le quartier du Mazeau § II, 2 et pour le bourg de Morier $\S$ II, 3 . 
(fil d'eau ou rigole). Par ailleurs, les niveaux de circulation en terre portent souvent trace des épisodes de ruissellement, caractérisés généralement par des flaques de gravillons et galets.

Quelques exemples d'aménagements d'évacuation des eaux de pluie ont été retrouvés en fouille ; la rue de la Guirlande est aménagée d'une rigole le long d'un bâtiment et dans la rue de la Taulisse des tuyaux de plomb ou de terre cuite intégrés dans les façades se déversent dans un égout situé au centre de la rue. La rue de Morier était dotée d'un caniveau central. Ces égouts sont des constructions en pierre avec des piédroits et des dalles de couverture, le fond étant dallé ou pas.

La question du statut des aménagements est difficile à appréhender pour le Moyen Âge. Dans la ville basse, l'entretien des rues est géré par les prud'hommes des sixains et contrôlé par deux autres prud'hommes ; les riverains doivent cependant entretenir la rue devant leur maison. Nous ne savons pas ce qu'il en est pour les égouts.

\subsubsection{L'évacuation des eaux usées ou pluviales à l'Époque moderne}

L'évacuation d'eau est souvent gérée par les pouvoirs publics, communaux en particulier. Cependant, le réseau des eaux usées part de conduites privées liées à l'habitat, et souvent retrouvées en fouille.

\section{Les conduites privées}

Les conduites d'eaux usées dans les espaces privés sont en général associées à des aires de lavage, cuisine ou buanderie. De nombreux prix-faits donnent des exemples de l'emplacement des conduites par rapport aux différentes structures hydrauliques puits, pille ou bassinet et apportent parfois des renseignements sur leur situation dans l'architecture de la maison. Ainsi en 1650, dans la maison du $\mathrm{S}^{\mathrm{r}}$ Jean Decampz le maçon devra «poser la pille à lad(ite) cuisine tout proche du puis, y mettre un canal de taille de trois pans de long allant à la rue pour donner cours aux eaux; boucher les trous que lon fera pour oster lad(ite) pille du lieu où elle est à présant, au dessoubz dicelle, fera deux murettes à fasson darmoire de mallons plats ${ }^{\mathbf{1 2 4}}$. Ou ailleurs en 1673 , «led. entrepreneur sera tenu comme promet de creuser un puids jusques a six pans deau a ch[asc]une desdittes maisons et bastira jusques au plan de la rue et sa sortie sera faicte de pierre de taille avec sa pille, bassinet,

124 AD13 360 E 80, fol. 1112 : prix-fait Jean Descampz/Cauvin, 5 décembre 1650 . Texte recueilli par C. Castrucci. gorgue et conduit jusques a la rue, le tout de taille ${ }^{\mathbf{1 2 5}}$.

À titre de comparaison, sur le site dit de la « Source du Pré » à La Ciotat, dans le faubourg de l'Escalet construit à la fin du XVII ${ }^{\mathrm{e}}$ s., deux remises situées en bordure du Port-Vieux sont dotées d'une buanderie avec bassins de lavage et canalisations. Les conduites à ciel ouvert ne sont pas en contact direct avec le bassin, l'eau polluée y est probablement déversée à l'aide de seaux. Elles se présentent comme de simples rigoles intégrées soigneusement dans la construction du sol carrelé avec les mêmes malons de terre cuite tapissant le fond et disposés de chant pour les piédroits. L'une des buanderies étant installée en fond de remise, la canalisation, d'une longueur de $7 \mathrm{~m}$, longe le mur de la pièce pour acheminer l'eau à l'extérieur, en direction du port (Mellinand 2007, p. 139 et 145).

À Marseille, la rareté de structures identiques retrouvées en fouille peut s'expliquer par l'emploi fréquent de canalisations en pierre de taille, comme l'attestent les prix-faits. Probablement apparentes, celles-ci ont pu être récupérées. À l'intérieur d'un habitat du XVI ${ }^{\mathrm{e}} \mathrm{s}$. (place Villeneuve-Bargemon), une canalisation privée d'une facture très soignée longe un mur de refend pour s'évacuer dans la rue de la Guirlande. L'eau y circulait, peut-être à ciel ouvert, sur un fond de dalles peu épaisses de calcaire lacustre sciées, de 0,60 à 0,70 m de long pour une largeur de $0,45 \mathrm{~m}$. Des dalles plus petites posées de chant délimitent le conduit de 0,20 m de large pour une hauteur de $0,16 \mathrm{~m}^{\mathbf{1 2 6}}$ (fig. 60). C'est certainement une disposition semblable de canal longeant le mur d'un espace privé qui est mise en évidence dans la partie nord-est de la même rue, par une évacuation en pierre de taille, conservée en limite d'îlot. Elle est inclinée vers le centre de la voie, vers un probable collecteur ${ }^{127}$. Un autre cas de caniveau courant au pied du mur dans un couloir est signalé sur le même site dans le logis de la Taulisse par un prix-fait de 1643 : «par moyen du tuyau de pierre de taille quy est long la muraille maistresse dans le courroir du derrière lequel a esté pareillemans reparé et remis en bon estat $\gg{ }^{\mathbf{1 2 8}}$.

Dans une autre maison de la rue de la Guirlande, l'évacuation d'eaux usées provenant de l'étage s'écoule vers une canalisation située sur la voie parallèlement au

125 AD13 380 E 169, fol. 380 : prix-fait Antoine Amalric, 1673. Texte recueilli par C. Castrucci.

126 Sillano 1997, 6 : zones 11 et 12 de l'îlot sud, p. 6.

127 Paone 1997, 6 : zone 7 et MCR zone 2, secteur 11, p. 6 (rue de la Guirlande).

128 AD13 360 E 75, fol. 561 : prix-fait Raphaël Antelme, Logis de la Taulisse (parcelle 358), 1643. Texte recueilli par C. Castrucci. 


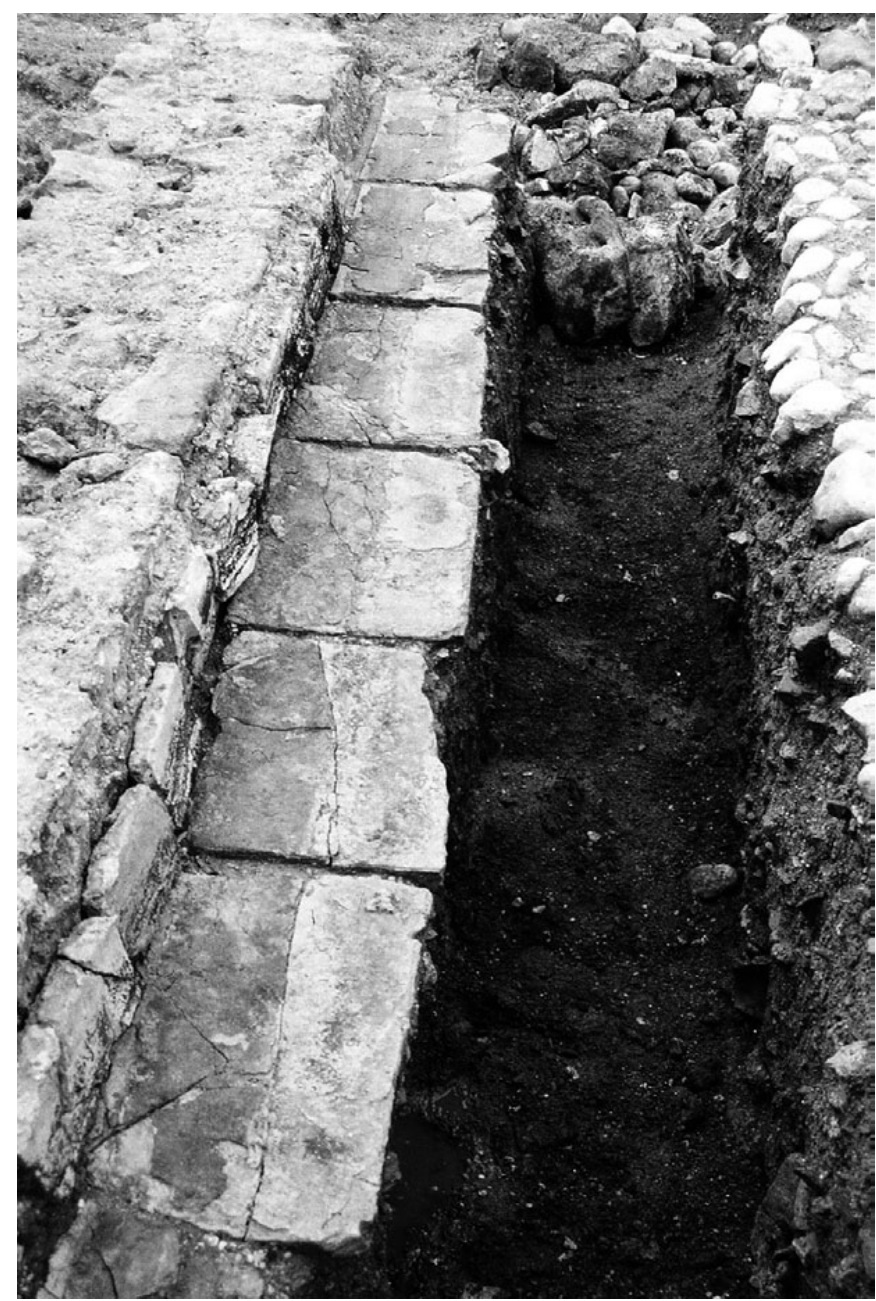

Fig. 60. Canalisation construite sur la parcelle 386 du quartier du Mazeau (cl. M. Derain/Inrap).

mur de façade ${ }^{129}$. La conduite est vraisemblablement encastrée dans le mur, car à sa base, une dalle surcreusée est intégrée dans la maçonnerie. L'aménagement de cuisines au rez-de-chaussée ou à l'étage avec leur système d'évacuation des eaux polluées inclus dans la maçonnerie est une pratique courante illustrée de manière récurrente dans les prix-faits. En 1662, on trouve ainsi témoignage de travaux d'installation d'une « pille en lad(ite) cuisine avec les bourneaux et gorgue quy se poseront dans la murailhe pour conduire leau à la rue » ${ }^{\mathbf{1 3 0}}$. De même, au premier étage d'une habitation sont construits «ung eyguier avec sa pille de taille de trois pans en carré avec

129 CN2334, Paone 1997, 6 : CSR zone 7 et MCR zone 2, secteur 11, p. 6 (rue de la Guirlande).

130 AD13 393 E 82, fol. 715 : prix-fait pour Mathieu de Madières passé avec Toussaint Simian, $\mathrm{M}^{\mathrm{e}}$ maçon ; le 10 octobre 1662. Texte recueilli par C. Castrucci. ses bourneaux pour conduire leau a la rue »131. Les canalisations raccordées à des espaces de travail peuvent recéler dans leur comblement des témoins de l'activité pratiquée. Par exemple la sédimentation d'un conduit de la rue de la Guirlande est apparue riche en écailles de poissons.

D'autres installations hydrauliques sont destinées à la canalisation des eaux de pluie. Ainsi à proximité, dans la rue de la Taulisse, des dispositifs d'évacuation des eaux de gouttière ont été observés aux angles de deux parcelles contiguës. Seul l'un d'entre eux est conservé et a pu être décrit. C'est un aménagement de briques et d'une dalle de calcaire installé sur un lit de pose de sable.

Sur le site du Tunnel de la Major, à la suite du percement d'une cave dans la maison du Chapitre à partir du deuxième quart du XVIII ${ }^{\mathrm{e}} \mathrm{s}$., une canalisation traversant la cour est installée juste au devant de l'escalier d'accès au sous-sol. Elle se présente sous forme d'un canal circulaire de $10 \mathrm{~cm}$ de diamètre, couverte par des briques ${ }^{\mathbf{1 3 2}}$. La canalisation devait avoir pour fonction de protéger l'accès à la cave du ruissellement des eaux de pluie car dans un second temps, l'entrée en est entièrement abritée par une construction.

Enfin, un réseau de caniveaux privés se raccordant à un collecteur public a été retrouvé sur le site de la place Villeneuve-Bargemon, dans un espace ouvert donnant sur la rue de la Miséricorde. Il permet l'évacuation des eaux de deux parcelles voisines. Le conduit principal situé dans le même axe que le collecteur de la rue est composé, comme lui, d'un fond de dalles de calcaire tendre et de piédroits de moellons divers liés au mortier. Il est, à l'origine, probablement recouvert de dalles. Il a été plusieurs fois repris et additionné de nouveaux embranchements. L'un de ces prolongements est formé d'un alignement de plaques de schiste sur lesquelles des traces d'oxyde de fer mêlées à des dépôts de calcites témoignent peut-être de la présence d'une canalisation métallique. Après s'être comblé progressivement, le canal principal et sa dernière ramification sont obturés vers la fin du XVII' ${ }^{\mathrm{s}}$. ${ }^{133}$.

Si la plupart des canalisations privées trouvées en fouille sont maçonnées avec des dalles de calcaire ou des briques de terre cuite et des piédroits de matériaux divers, des bourneaux ont, comme il est indiqué dans les prix-faits, également dû être employés pour l'évacuation des eaux usées en provenance des habitations. Dans les fouilles du Tunnel de la Major, rue Four-du-Chapitre, des canalisations de bourneaux de terre cuite de 0,20

131 AD13 360 E 72, fol. 360, prix-fait Jean Griffet, 1637. Texte recueilli par C. Castrucci.

132 CN7137, Barra et al. 2004, p. 346.

133 Paone 1997, 3-5 : MCR zone 2, secteurs 9, 2 et 7. 


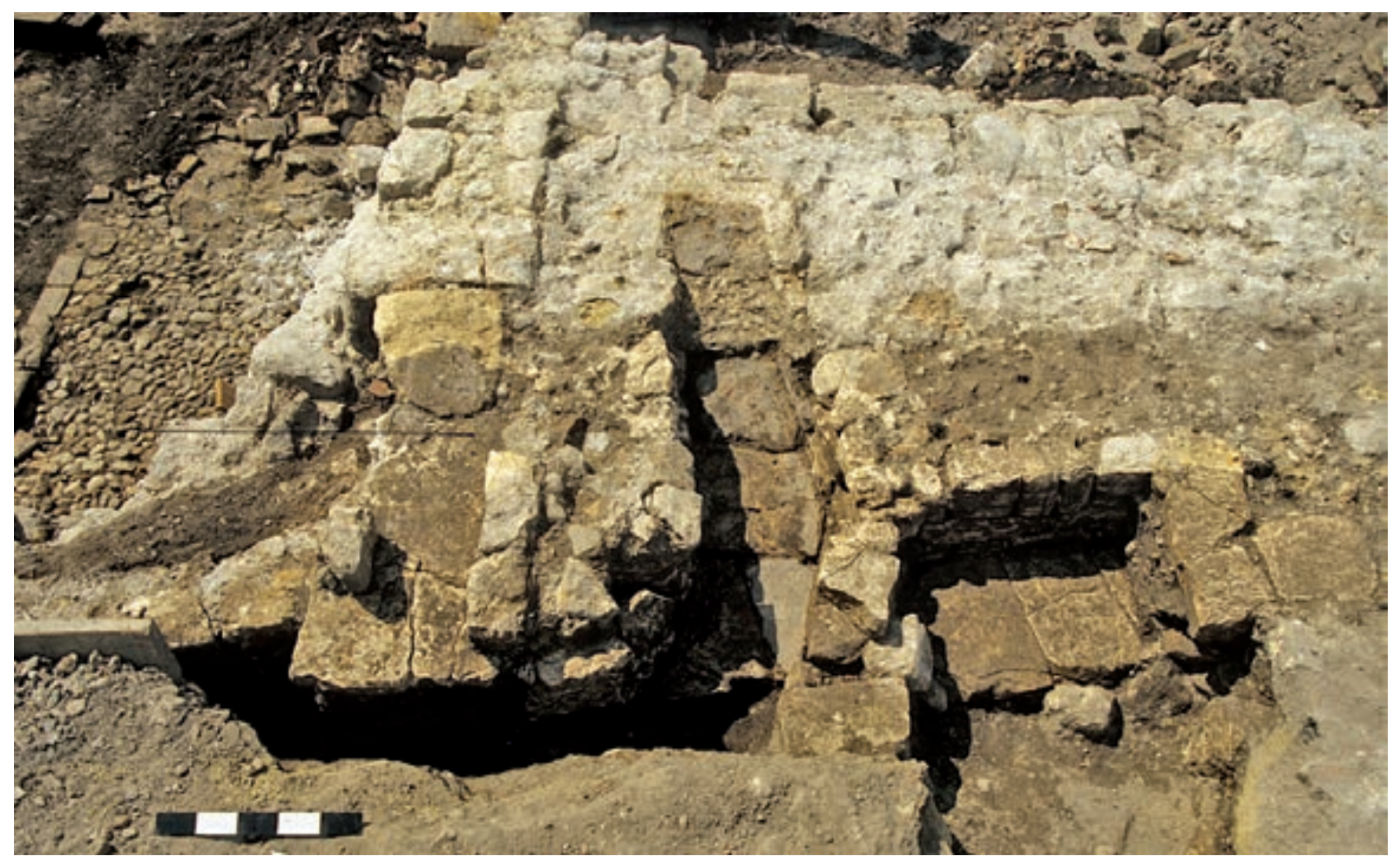

Fig. 61. Réseau de canalisation dans la rue de la Guirlande (cl. A. Arbion/Inrap).

à $0,25 \mathrm{~cm}$ de diamètre ont été interprétées comme des caniveaux. L'orientation des canalisations et le sens des bourneaux permettent en effet de supposer qu'elles proviennent d'une ou de plusieurs propriétés situées en bordure de rue (Barra et al. 2004, p. 366). Mais de nouvelles observations seraient nécessaires pour mieux comprendre l'usage qui est fait des tuyaux de terre cuite dans les espaces privés.

\section{Les collecteurs de rues}

Le plus souvent les collecteurs d'eaux usées ont évolué dans les rues jusqu'à l'Époque contemporaine, les installations les plus récentes ayant fait disparaître les plus anciennes. Cependant les caniveaux à l'Époque moderne sont assez bien documentés par les fouilles marseillaises. Le chantier de l'espace Bargemon est en particulier riche d'exemples de rues tournées vers le port qui possèdent chacune leur canalisation centrale (fig. 61).

Sur le site du Tunnel de la Major, dans l'îlot nord du vallon, une ruelle construite au plus tôt à la fin du XVII ${ }^{\text {e }}$. dessert les arrières-cours des habitations qui devaient probablement abriter certaines tâches ménagères liées à l'eau. Pour l'évacuation des eaux usées ou de l'eau de ruissellement, la ruelle, en pente douce d'est en ouest, est équipée d'un simple fil d'eau courant le

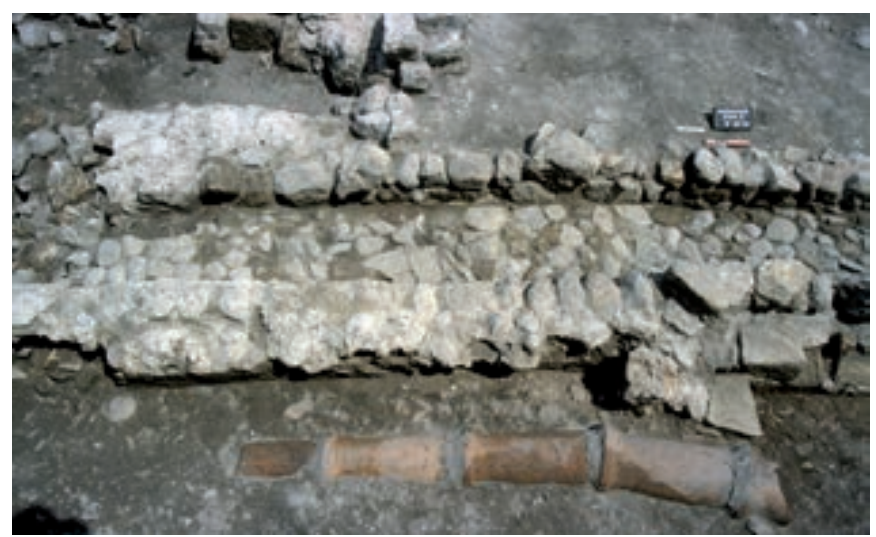

Fig. 62. Premier caniveau dans la rue de la Guirlande (XVIe s.) (cl. F. Parent/Inrap)

long de la façade sud. Il est composé d'un alignement de galets légèrement surbaissé par rapport au reste du pavement (Barra et al. 2004, p. 344).

Cet exemple demeure anecdotique car les rues sont en général équipées de collecteurs d'un gabarit beaucoup plus important. Sur le site de l'espace Bargemon, dans la rue de la Guirlande, un caniveau central en pierre de taille est aménagé au plus tôt au XVII ${ }^{\mathrm{e}} \mathrm{s}$. et reste en usage jusqu'au milieu du $\mathrm{XIX}^{\mathrm{e}}$ s. Il est constitué d'un alignement de conduites monolithiques en calcaire de Saint-Victor. Les blocs mesurent $1 \mathrm{~m}$ en moyenne pour une hauteur de $0,45 \mathrm{~m}$; ils sont creusés d'une gorge de $0,25 \mathrm{~m}$ de largeur pour une profondeur de 0,16 m. La 
couverture de dalles de calcaire blanc est calée par des assises de briques en terre cuite. Le tout est lié par un mortier hydraulique ${ }^{134}$ (fig. 62).

Mais dans la majorité des cas, les caniveaux sont maçonnés selon une technique universelle héritée de l'Antiquité. L'eau y circule sur un fond de dalles de calcaire ou de terre cuite, entre deux piédroits composés de moellons et cailloux en matériaux divers liés au mortier. La couverture est le plus souvent faite de dalles de calcaire. Dans les phases les plus récentes et dans le cas de collecteurs à grand débit, il arrive qu'elle soit voûtée. La largeur des conduits varie de 0,25 à $0,55 \mathrm{~m}$ en fonction de l'importance et de la situation de la rue dans le réseau. La hauteur est plus difficile à évaluer, la partie supérieure des caniveaux n'étant en général pas conservée. Le remplissage interne de la conduite révèle souvent un comblement progressif par sédimentation hydraulique, le mobilier céramique contenu dans les dépôts témoignant d'une date à laquelle elle a cessé d'être entretenue.

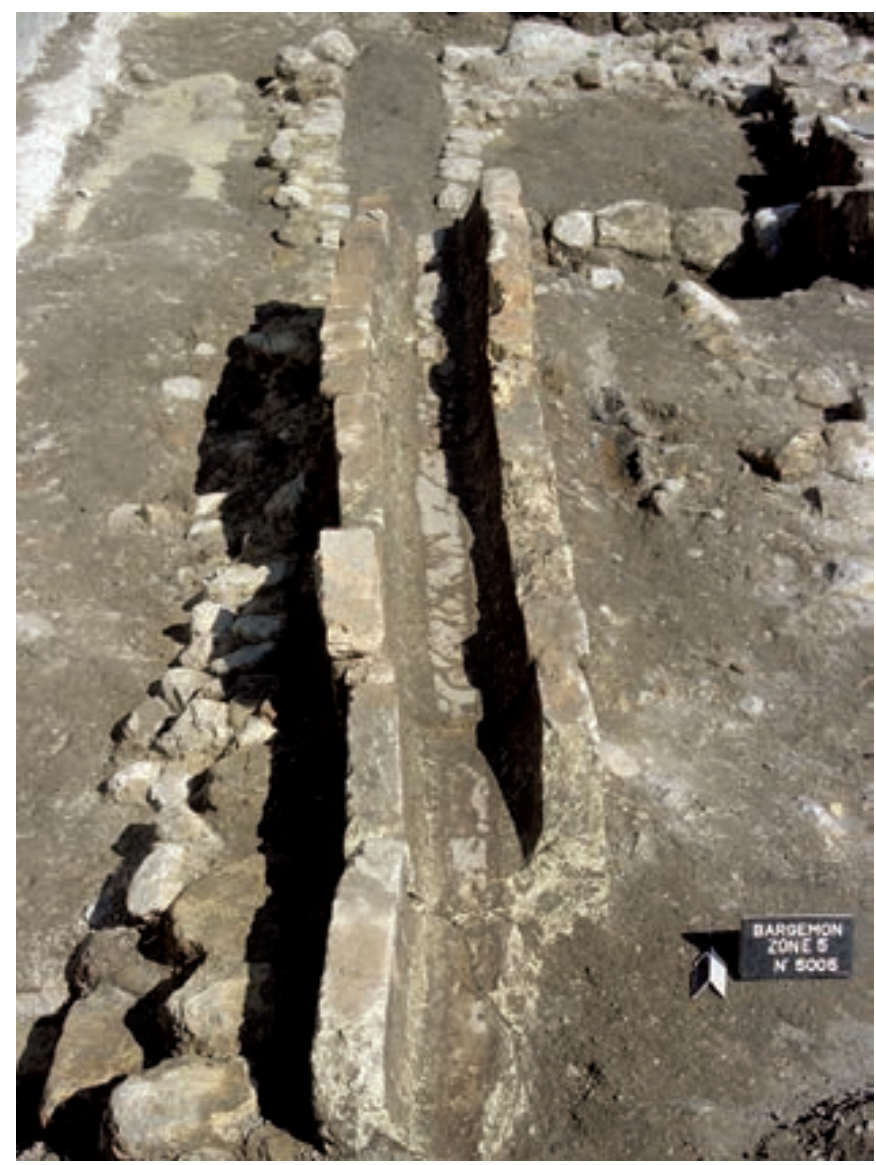

Fig. 63. Second caniveau dans la rue de la Guirlande (XVIIe-XIXe s.) (cl. F. Parent/Inrap).

134 CN5046, Mellinand 2005, p. 326-327.
Pour illustrer leurs différentes mises en œuvre, nous mentionnons quelques exemples de canalisations empruntés surtout aux fouilles de l'espace Bargemon. Dans l'axe de la rue de la Guirlande, un caniveau du $\mathrm{XVI}^{\mathrm{e}}$ s. est remarquable par sa mise en œuvre entièrement composée de galets et cailloux liés au mortier ${ }^{135}$ (fig. 63). Un peu plus loin, le caniveau de la rue de la Prison, daté entre le milieu du XVI ${ }^{\mathrm{e}}$ s. et le milieu du

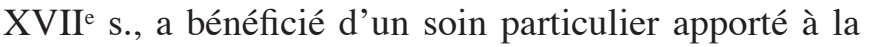
taille de ses dalles de fond légèrement surcreusées pour former un conduit ${ }^{\mathbf{1 3 6}}$ (fig. 64). Le pendage de la canalisation en direction du port est de 4 à $5 \%$. Une voie parallèle, la rue de la Miséricorde, a conservé dans son intégralité un égout abandonné au XVII ${ }^{\mathrm{e}} \mathrm{s}$. Le fond et la couverture sont composés de dalles rectangulaires de calcaire dur disposées transversalement par rapport à l'axe de l'égout. Délimitant un conduit de 0,30 à $0,40 \mathrm{~m}$ de large, deux parements d'une hauteur de 0,54 m sont construits de moellons de calcaire tendre et cailloux de poudingue liés au mortier maigre. La couverture est

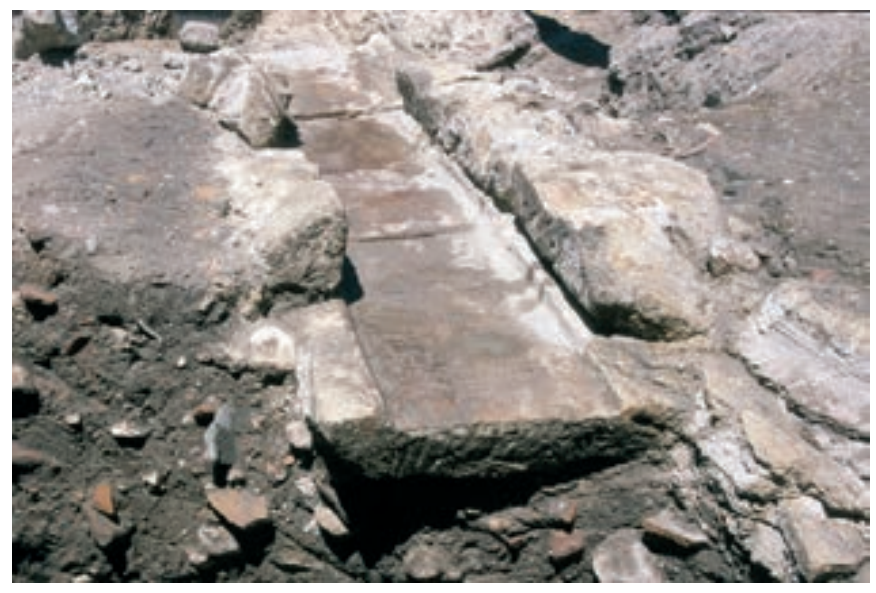

Fig. 64. Canalisation de la rue de la Prison (cl. T. Maziers/Inrap).

composée des mêmes dalles que le fond, d'une longueur moyenne de $0,70 \mathrm{~m}$ pour une largeur de 0,30 à 0,50 m et disposés transversalement également (fig. 65). Parallèlement un collecteur de construction plus récente lui est juxtaposé. Son parement oriental réutilise le parement ouest du premier égout. Il est couvert d'une voûte en plein cintre de $0,40 \mathrm{~m}$ de diamètre constituée de briques (Jandot 1996).

\section{L'écoulement des eaux dans le port}

Lorsque la place du Grand-Caire fût établie à l'emplacement de la douve du rempart, elle-même coïncidant

135 CN5006, Mellinand 2005, p. 326-327.

136 CN6020, Mellinand 2005, p. 143-145. 
avec le vallon Saint-Martin, il semble que ce soient des canaux, creusés sur sa périphérie, qui s'y substituèrent. Ainsi trouvons-nous mention d'un "fossé au devant de lad. maison ${ }^{137}$ sise sur cette place. Lorsque ce lieu devint le Cours, il n'est plus fait mention de canaux, ce qui implique l'existence d'un collecteur important sous cet axe. La réalisation de l'agrandissement de Louis XIV comporte donc un volet consacré aux eaux, usées ou pluviales, qui n'est pour l'instant abordé dans aucune étude ni encore mis en évidence par l'archéologie (Sillano 2001, p. 137). Pour la fin du XVIII ${ }^{e}$ s., un exemple d'égout de grand débit a été découvert lors des fouilles de la place Général-de-Gaulle. Il s'agit d'un conduit voûté de $1,30 \mathrm{~m}$ de hauteur sur lequel est notamment raccordé le trop plein d'une fontaine (Bouiron 2001a, p. 127).

Le port est naturellement l'exutoire de toutes ces amenées d'eau, que ce soit depuis les collines sur lesquelles est établie la ville, ou les talwegs qui drainent les collines environnantes. À l'extrémité des rues qui aboutissent au port se trouvent des «palissades » dont la fonction est notamment « de faire barrage au déversement (...) des ordures, déblais et terres de jardin qui, emportés par les eaux pluviales, dévalent les rues aux pentes abruptes. ». Sans doute pour remédier à cette nuisance, «à la fin du XVII ${ }^{\mathrm{e}}$ s., chaque palissade possède un canal d'égout voûté, construit sur le modèle de celle des oranges ${ }^{138}$, et au moins trois trappes, servant de soupiraux, pour l'entretien des canaux. Cependant, en 1774, les députés de la Chambre de Commerce se plaignent toujours des égouts, qui s'évacuent dans le port. Un plan de la fin du XVIII' ${ }^{\mathrm{e}}$ s. signale que le déversement des eaux de huit rues se conjugue vers la rue Crotte-de-Villages ${ }^{139}$.

Lors de l'opération de la rue de la République-Surverse, en 2007, l'extrémité

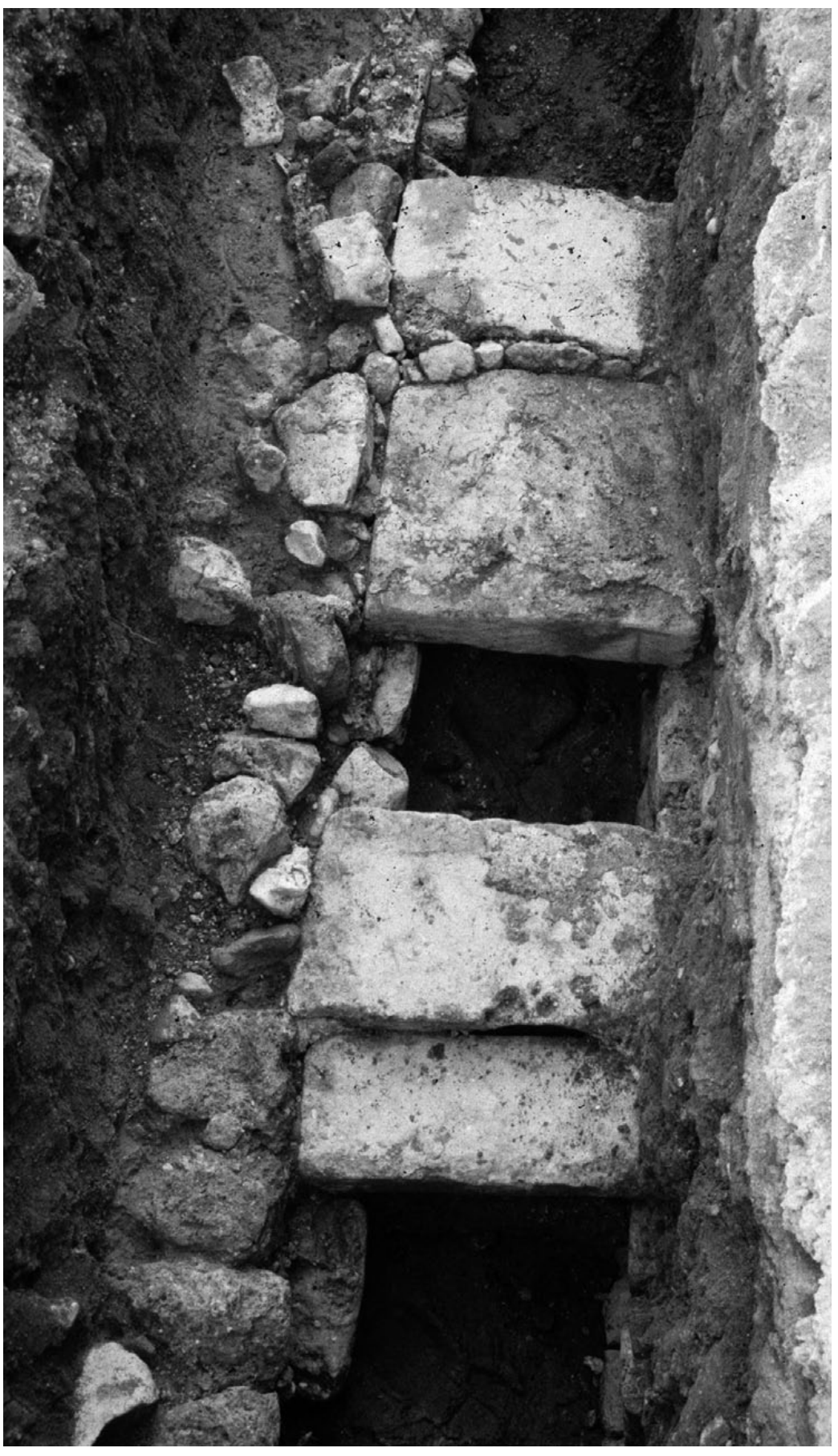

Fig. 65. Le caniveau de la rue de la Miséricorde (cl. C. Jandot/Inrap).
137 AD13 380 E 125, fol. 417.

$138 \mathrm{La}$ palissade des Oranges prolonge la ruelle de la «Place Neuve ».

139 Cuzon 2007. Les archives auxquelles se réfèrent ces renseignements sont respectivement: ACM HH 460, lettre des Consuls et Intendants du port, 10 décembre 1635 ; ACM HH 449, devis des ouvrages de maçonnerie, 10 juin 1690, et de charpente,

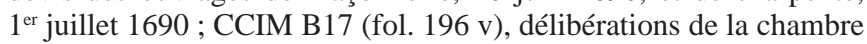
de Commerce; ACM DD 107, quai du port et rues adjacentes, 1670-1792. d'un caniveau en provenance de l'îlot des Augustins a été fouillée ( $c f$. fig. 19 et fig. 66). Le caniveau, abandonné vers le milieu du XVII ${ }^{\mathrm{e}}$ s., est perpendiculaire au quai et se déverse dans le port selon une pente de 6,5\%. Ses dimensions hors œuvre sont de $0,75 \mathrm{~m}$ de haut pour une largeur de $0,90 \mathrm{~m}$. La maçonnerie délimite un conduit de $0,45 \mathrm{~m}$ de largeur pour une hauteur de $0,40 \mathrm{~m}$. Sur la majeure partie du conduit, le fond est revêtu de rangées de carreaux de terre cuite, parfaitement ajustés. Les 
piédroits sont construits essentiellement avec des blocs de calcaire taillés en remploi, agrémentés de briques, pour le réglage de la hauteur. Les dalles de couverture, en calcaire tendre, sont très épaisses $(25 \mathrm{~cm})$.

\subsection{Conclusion}

Ce court inventaire des différentes typologies des réseaux hydrauliques de Marseille témoigne d'abord de la faible documentation archéologique. Les fouilles de rue qui permettraient de compléter la documentation sont rares. Le bâti en élévation ayant en général disparu, les canalisations privées observées sont celles qui ont été préservées de la destruction grâce à leur enfouissement après réfection tardive des sols d'habitat. Il est rare qu'elles soient suivies sur l'intégralité de leur parcours. Les adductions et évacuations publiques de la période moderne qui ont échappé à un remplacement à l'époque contemporaine sont à peine mieux connues. Pour l'étude des premières, un bon complément à la fouille est apporté par l'ouvrage de G. Melquiond qui en fait une description précise, semblable à celle d'un archéologue. Les études d'archives permettent en outre de mieux comprendre la politique de gestion de l'eau. Les extraits de prix-faits du XVII ${ }^{\mathrm{e}} \mathrm{s}$. recueillis par les archivistes à chaque campagne de fouille sont également essentiels pour suppléer au manque d'information. Ils permettent de restituer le cadre domestique des puits et canalisations particulières et parfois d'interpréter des reliquats de tuyauterie retrouvés en fouille, en marge de l'espace privé. Il ressort cependant de cette étude qu'un soin tout particulier est accordé à l'installation des ouvrages liés à l'eau.

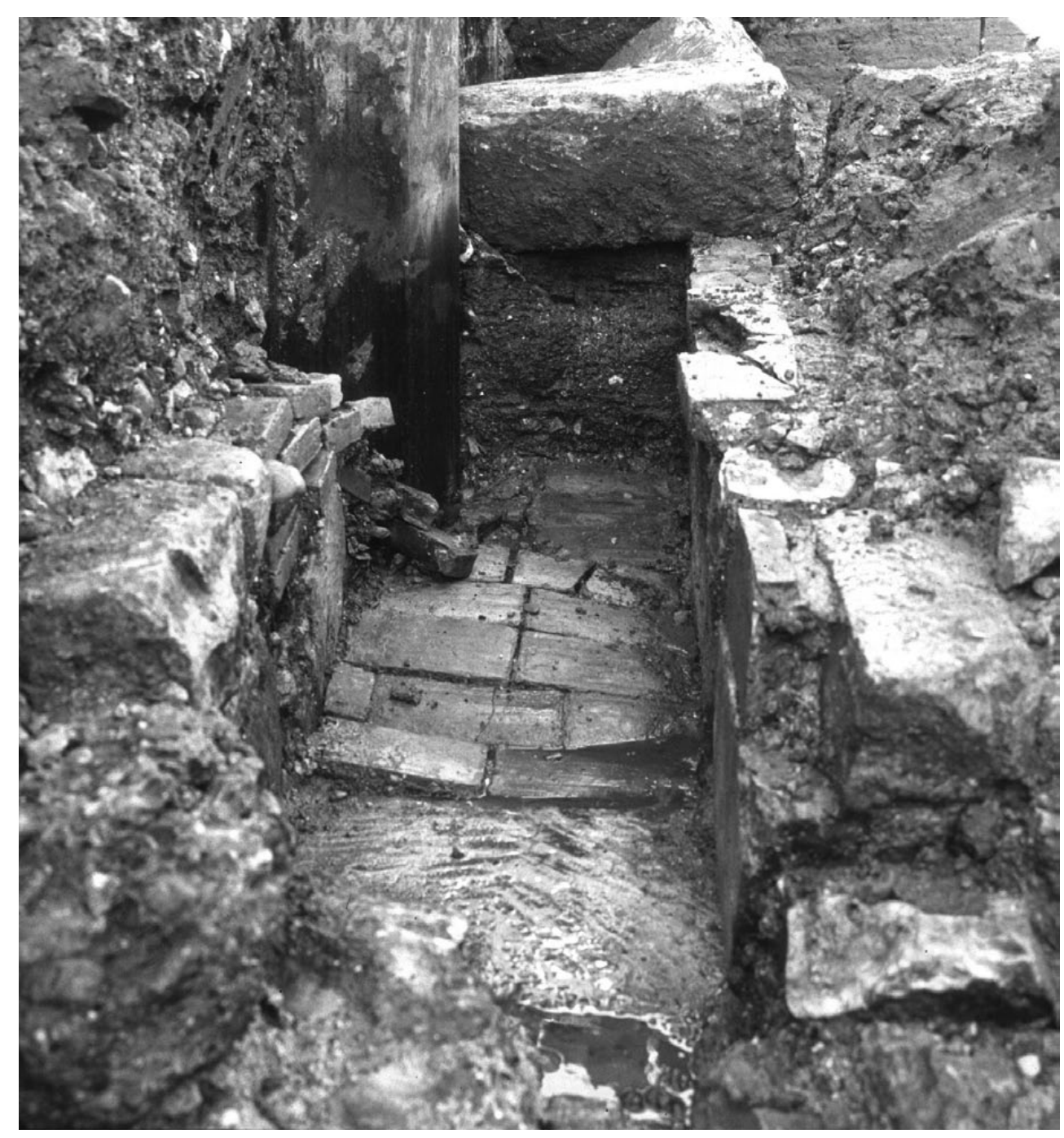

Fig. 66. Le caniveau aboutissant au quai du port sur la fouille de la Rue de la République (cl. B. Sillano/Inrap). 


\section{Chapitre 3}

\section{Construire la ville du XII ${ }^{\mathrm{e}}$ au XVIII ${ }^{\mathrm{e}}$ s.}

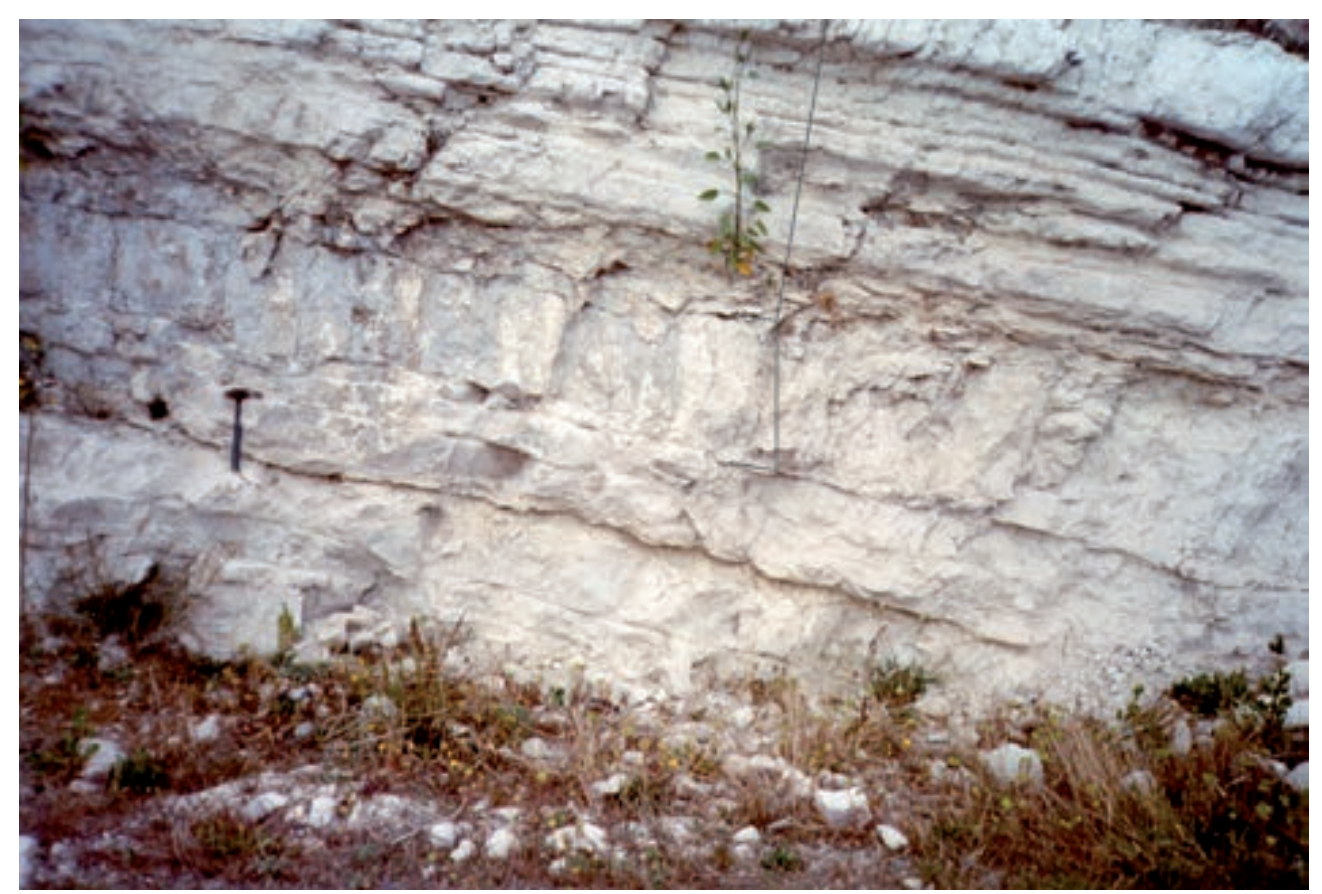

Fig. 67. Bancs de calcaires à l'ouest des quartiers de Riaux à l'Estaque (cl. A. Mezzoud/Inrap).

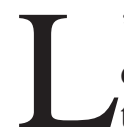

'attention portée au bâti sur les fouilles de ces dernières décennies permet de disposer maintenant de corpus assez complets documentant la construction. Le parallèle étroit avec les textes d'archives renforce la qualité des interprétations.

\section{Matériaux et techniques au Moyen Âge}

Au-delà du recensement des matériaux retrouvés dans les vestiges du Moyen Âge, ce sont les techniques même de construction qui sont perceptibles grâce aux fouilles archéologiques, les textes nous faisant largement défaut pour cette période.

\subsection{Les matériaux recensés à l'époque médiévale (A. Mezzoud, R. Thernot)}

Le recensement des matériaux utilisés à Marseille au Moyen Âge dans la construction de l'habitat est tributaire de l'état de conservation des structures mises en place au cours de cette période. La disparition de la plupart des élévations et d'une grande partie des sols de circulation prive l'enquête d'une part substantielle de son domaine d'étude. Toutefois, concentrées sur les fondations et la base des élévations associées à quelques sols en terre battue ou préparations de sol, les observations menées sur les divers chantiers, par leur caractère convergent, permettent de déterminer les principales sources d'approvisionnement en matériaux de construction. La place principale est tenue par les roches qui fournissent les matières premières de la maçonnerie : moellons, chaux et sables. La terre crue est utilisée dans les élévations comme matériau principal ou comme liant, et au sol sous la forme de terre battue. Les terres cuites architecturales restent peu représentées dans les niveaux explorés, si ce n'est à travers les fragments de tuiles et de carreaux dans les niveaux de démolition. Le bois apparaît de façon sporadique dans les niveaux résultant de l'incendie des faubourgs au XIV e s. 


\subsubsection{Les matériaux rocheux (A. Mezzoud)}

H. Tréziny a souligné la difficulté de l'étude des matériaux des monuments médiévaux de Marseille (cathédrale de La Major, église Saint-Laurent, abbaye Saint-Victor) due aux nombreuses restaurations subies par ces édifices. L'étude menée par P. Gaudon et A. Hartmann-Virnich a montré que les matériaux rocheux utilisés dans ces édifices sont pour la plupart les calcaires roses « de La Couronne » et la pierre blanche « de Saint-Victor».

L'étude des matériaux rocheux dans les constructions médiévales, menée sur les trois grands chantiers archéologiques marseillais qui font l'objet de la présente publication, s'est efforcée de rechercher l'origine géologique et géographique des matériaux et de cerner l'évolution de leur utilisation. La situation qui se dessine à l'issue de cette enquête sur l'architecture civile est différente de celle qui prévaut pour les édifices plus prestigieux. Les sources d'approvisionnement sont pour l'essentiel issues des affleurements du bassin de Marseille. Les pierres les plus fréquemment employées sont les calcaires lacustres de Saint-Victor de faciès dur et tendre. Les travertins dits aussi « tufs sédimentaires », dont les affleurements sont encore visibles au nord de la ville de Marseille, sont largement employés dans les îlots du faubourg mis au jour sur le site de l'Alcazar. À ceux-ci s'ajoutent, plus ponctuellement, des grès et poudingues dont les gisements affleurent en divers endroits de la ville. Le calcaire de La Couronne apparaît plus rarement dans les constructions civiles ordinaires des $\mathrm{XII}^{\mathrm{e}}$-XIII ${ }^{\mathrm{e}} \mathrm{s}$, mais occupe une place importante dans les édifices liés aux pouvoirs civil et religieux : palais comtal et maison canoniale. Ce matériau est toutefois présent dès le XII ${ }^{e}$ s. dans les maisons du quartier de la cathédrale. Il devient plus fréquent dans les autres secteurs au cours des siècles suivants, surtout dans les situations où l'utilisation de la pierre de taille est plus appropriée : seuils, piédroits, chaîne d'angle, parements de puits.

La présence de vestiges attestés pour les époques médiévales et modernes nous a conduit à l'étude pétrographique et géologique des matériaux naturels utilisés en construction. Notre analyse a été basée essentiellement sur une étude pétrographique préliminaire de chaque roche, c'est-à-dire sa composition minéralogique, son aspect, sa dureté, sa couleur et sa réaction à l'acide chlorhydrique.

Dans un deuxième temps, nous avons mené une étude géologique dans le bassin de Marseille et ses environs, afin de déterminer les faciès lithologiques auxquels appartenaient les différents matériaux. Nous avons effectué sur chaque site une série d'observations et d'analyses macroscopiques des différents matériaux au sein des structures mises au jour. Ces analyses ont été basées sur la composition minéralogique, physico-chimique et biologique des matériaux, afin de leur attribuer une première identification pétrographique et de les mettre en relation avec le vocabulaire déjà établi.

Enfin, nous avons tenté de réaliser des pourcentages de fréquence, en procédant à un comptage des différents matériaux dans les parements, parfois en les dénombrant sur des portions de 1 à $2 \mathrm{~m}$ de long et en les rapportant à l'ensemble de la structure. L'objectif étant d'observer la corrélation entre les matériaux et la mise en œuvre d'une part, et leur situation chronostratigraphique d'autre part, ceci dans le but de suivre l'évolution chronologique des approvisionnements.

Il importe de rappeler les principaux objectifs de notre exploration géologique dans le bassin de Marseille et de ses alentours :

- l'identification des unités géographiques pour l'ensemble des affleurements géologiques de l'aire marseillaise ;

- le prélèvement d'un grand nombre de roches susceptibles d'être utilisées comme matériaux de construction au sein des vestiges archéologiques ;

- la détermination d'un vocabulaire pétrographique, géologique et géographique plus approprié.

\section{Le cadre géographique et géologique}

Le bassin de Marseille se caractérise par une partie orientale émergée et une extension occidentale noyée dans la mer Méditerranée, dont l'étendue est difficile à préciser. La ville actuelle est à l'intérieur d'une cuvette irrégulière dont la superficie s'étend sur $180 \mathrm{~km}^{2}$. Une ceinture montagneuse discontinue borde ce bassin :

- au nord/nord-ouest, la chaîne de la Nerthe,

- au nord/nord-est, le massif d'Allauch,

- au sud-est, le massif de Carpiagne,

- au sud, le massif de Marseilleveyre.

La vallée de l'Huveaune, encastrée entre le massif d'Allauch et de Carpiagne, unit le bassin d'Aubagne à celui de Marseille. Ce dernier est drainé par trois principaux ruisseaux :

- le ruisseau des Aygalades qui prend sa source sur le versant nord-ouest de la chaîne de l'Étoile et débouche dans le bassin par le seuil de Notre-Dame-Limite ;

- le Jarret qui pénètre dans le bassin par le seuil structural liant l'Étoile au massif d'Allauch ; il provient du secteur de Pichauris (commune d'Allauch);

- l'Huveaune qui descend du massif de la SainteBaume, traverse le bassin d'Aubagne, puis la partie sud de celui de Marseille.

L'ouverture du bassin de Marseille est liée aux derniers mouvements de la phase majeure de la tectonique 
provençale (Bartonien, ère Tertiaire). Le chevauchement, vers le nord et le nord-est, d'un panneau de terrains secondaires constituant le massif de l'Étoile, a engendré une dépression dans le sillage de ces mouvements tangentiels. Cette dépression a commencé à se combler pendant l'Oligocène (Guieu 1968, 1977).

Des sédiments de type lacustre, fluvio-lacustre, torrentiel et brèchique se sont déposés dans la cuvette. La dégradation directe des reliefs nouvellement mis en place, combinée au phénomène de subsidence par failles normales liées à l'extension, se traduit par une accumulation détritique importante. La puissance de ces dépôts est indiquée par les résultats du «sondage Fournier », décrits par Ripelin en 1935. Une série de $871 \mathrm{~m}$ de marnes, sables, grès et poudingues a été traversée sans que le substratum anté-oligocène soit atteint. La sédimentation est principalement lacustre. Elle se compose de calcaires à striatelles, faciès à laminites et de calcaires dits « de l'Estaque » d'âge Sannoisien-stampien supérieur (Nury 1977, 1979).

À l'Oligocène supérieur, la sédimentation devient plus détritique. Les niveaux de conglomérats polygéniques associés à des marnes et des sables, témoignent par leur composition pétrologique d'apports lointains qui proviennent du continent « hispano-pyrénéo-corsosarde », situé au sud (Blanc 1953 ; Auzende et al. 1973). Le Miocène, connu dans le chaînon de la Nerthe et de l'Étoile, n'a été reconnu que dans le bassin du Cap Janet, et daté de l'Aquitanien basal (Catzigras et al. 1979). Le Pliocène est inconnu. La sédimentation reprend au Quaternaire avec les dépôts pléistocènes des travertins de Marseille, auxquels ont succédé les nombreuses formations bréchiques du Quaternaire moyen et supérieur.

\section{Les différents faciès rencontrés}

Le site archéologique de l'Alcazar a servi de base pour répertorier un grand nombre de matériaux utilisés dans les constructions. Nous avons remarqué que le calcaire blanc oligocène (Stampien), les grès et les poudingues de l'Oligocène supérieur, le calcaire Miocène de La Couronne ainsi que les travertins quaternaires, sont les matériaux les plus répandus au sein de ces constructions. Les formations secondaires datées du Jurassique se rencontrent rarement au sein des vestiges, ce sont le plus souvent des calcaires barrémiens à faciès Urgonien.

\section{$\square$ Les calcaires stampiens dits « calcaires blancs de Saint-Victor »}

Il s'agit de sédiments de type lacustre qui ont donné des calcaires en bancs, ou à faciès de laminites (calcaires du Stampien inférieur). Les affleurements sur le pourtour de Notre-Dame-de-la-Garde sont quasiment inexistants. Le bassin de Carénage du Vieux-Port a été creusé dans des laminites calcaires (Gaudant 1975) audessus desquelles se développent une série de marnes beiges verdâtres, de calcaires massifs et laminaires, et de lits de brèches que l'on peut observer à l'entrée du tunnel du Vieux-Port. Les calcaires subsistent seulement dans la crypte de l'abbaye Saint-Victor (Nury, Raynaud 1986). G. Démians d'Archimbaud indique que des vestiges d'extraction antique de matériaux de construction ont été reconnus dans la crypte de l'abbaye Saint-Victor (Démians d'Archimbaud et al. 1972 et 1974).

\section{$\checkmark$ Les calcaires dits «de l'Estaque » du Stampien supérieur}

À la sortie du village de l'Estaque, le long de route RN 568 longeant le littoral, à la montée des Usines (fig. 67), on aperçoit les premiers affleurements de calcaire de teinte généralement très claire (blanc jaunâtre). Ils se présentent sous forme de bancs massifs $(50 \mathrm{~cm}$ d'épaisseur) avec un pendage vers l'est; la texture est à grains fins très serrés, légèrement silicifié, crayeux. Il s'agit des «calcaires de l'Estaque » (Deperet 1889; Vasseur 1894). Dans le quartier du Marinier, au nordouest de l'Estaque, on observe une alternance de bancs calcaires de 20 à $50 \mathrm{~cm}$ d'épaisseur et des laminites calcaires à la base, sur une hauteur de 3 à 4 m (fig. 68).

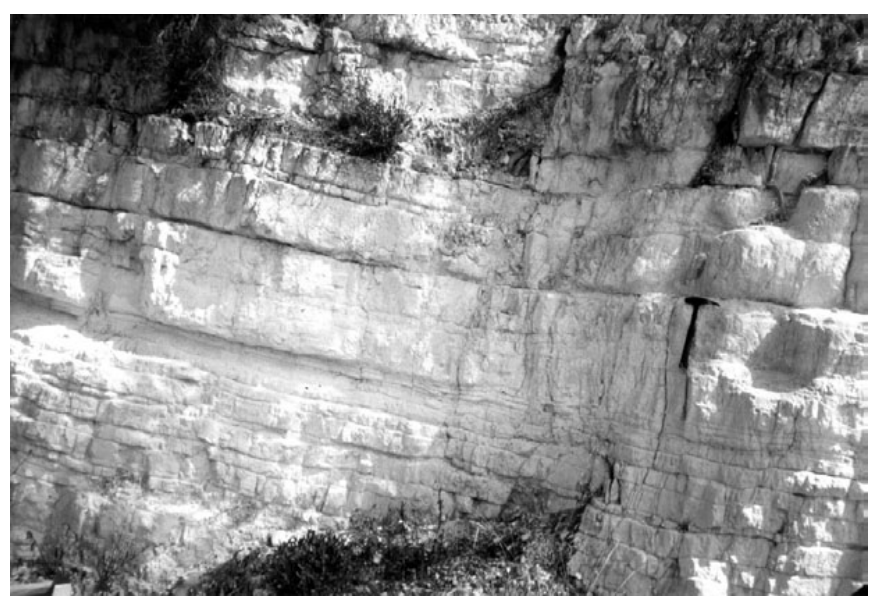

Fig. 68. Bancs de calcaires dans le quartier du Marinier à l'Estaque (cl. A. Mezzoud/Inrap)

Par sa nature et son aspect, ce calcaire ressemble à celui dit de «Saint-Victor ». Les anciens auteurs ont eu tendance à rassembler à un même niveau tous les calcaires inférieurs en une même unité (Deperet 1889 ; Vasseur 1894). Nous dirons qu'il s'agit d'un calcaire oligocène à faciès Stampien supérieur (Nury 1977; Nury 1979) 
Les calcaires stampiens n'affleurent actuellement dans le centre de Marseille que d'une façon sporadique autour du massif de Notre-Dame-de-la-Garde. Hormis les observations que nous avons faites lors de notre intervention sur un chantier de construction au 69 rue Sainte et dans la crypte de l'abbaye Saint-Victor, nous n'avons repéré aucune autre trace de ces calcaires. À l'Estaque, les bancs de calcaires de 20 à $30 \mathrm{~cm}$ d'épaisseur, observés au niveau des affleurements le long de la RN 568, au quartier de Riaux et des Maurins, laissent penser que d'éventuelles exploitations durant les périodes historiques sont envisageables. Sur les bordures du bassin de Marseille, aux Camoins, Allauch et Saint-Marcel, ils affleurent d'une façon discontinue, mais il s'agit surtout de calcaires laminitiques très altérés et très friables qui ne peuvent pas être exploités comme pierre de taille.

\section{口 Les grès et les poudingues}

À l'Oligocène supérieur, la sédimentation devient fluvio-lacustre, alternant des niveaux de grès et de poudingues, associés à des marnes sableuses, puis torrentielles et bréchiques, brèches à éléments locaux calcaires (Dupire 1985).

Les formations fluvio-lacustre, c'est-à-dire les grès et les poudingues, sont visibles à Marseille au sein d'un affleurement derrière le fort Saint-Jean. Des tranchées de 0,80 à $1 \mathrm{~m}$ de profondeur, réalisées pour des travaux de déviations de réseaux aux alentours de la

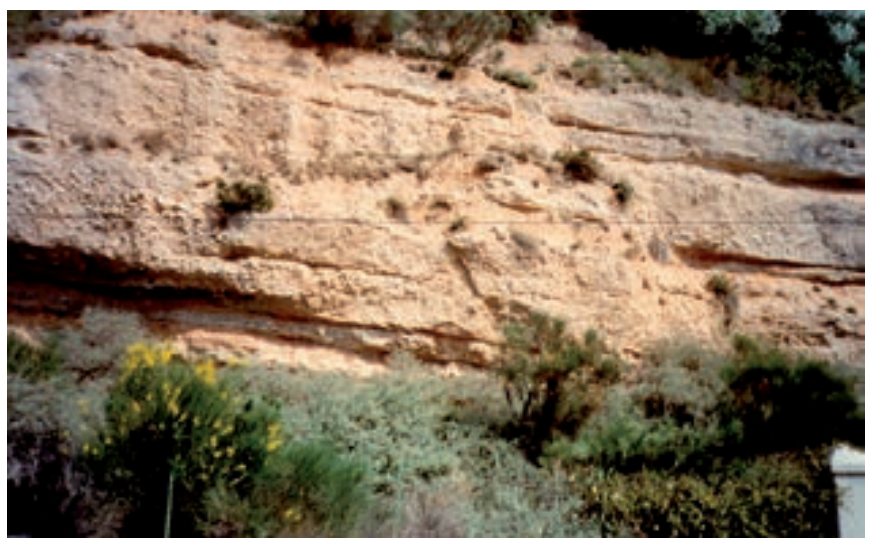

Fig. 69. Bancs de poudingues sub-horizontaux, avec intercalations de lits d'argile rouge (A. Mezzoud/Inrap).

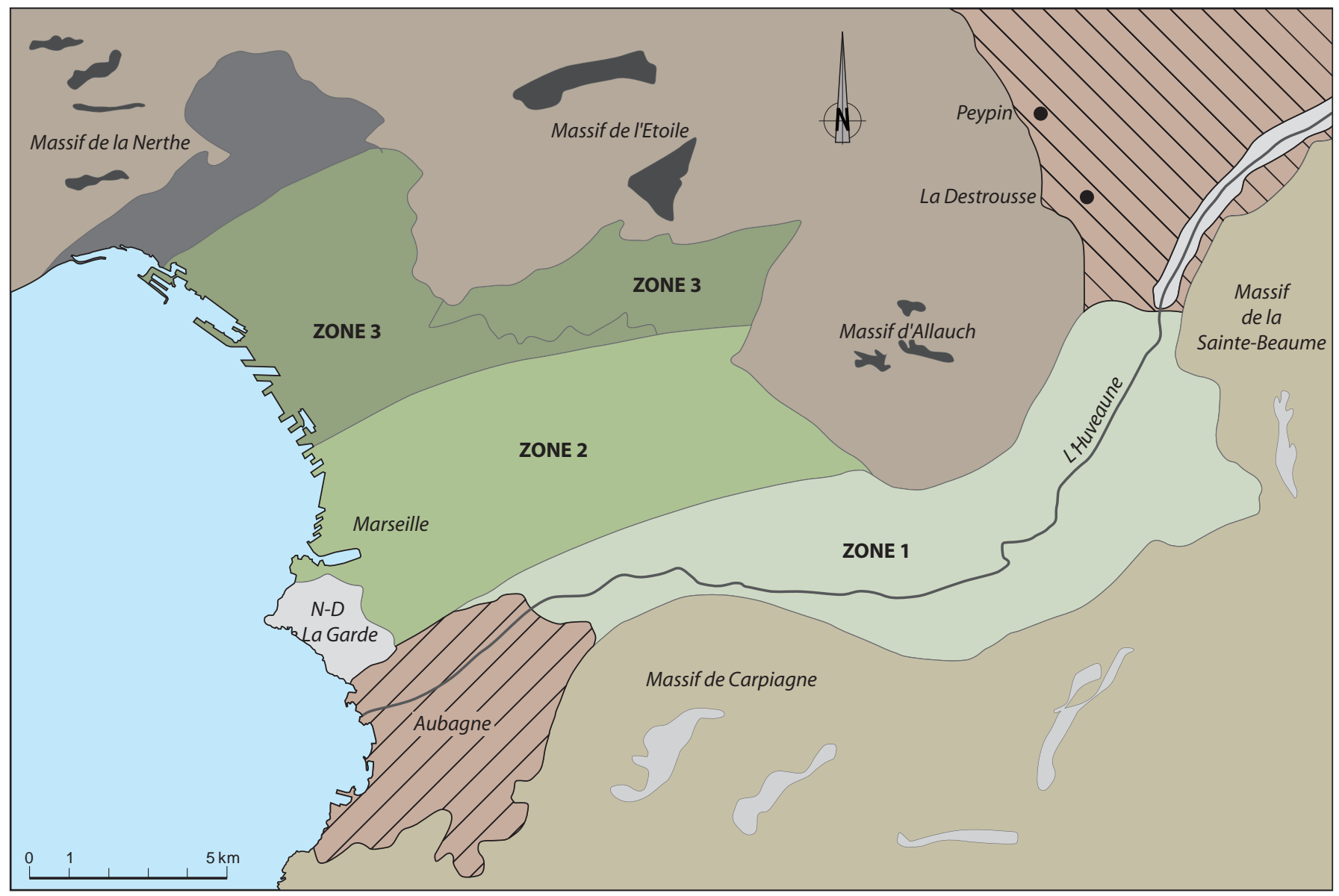

Fig. 70. Zones de répartition des grès et des poudingues dans le bassin de Marseille (les zones numérotées correspondent aux poudingues) (D. Nury). 


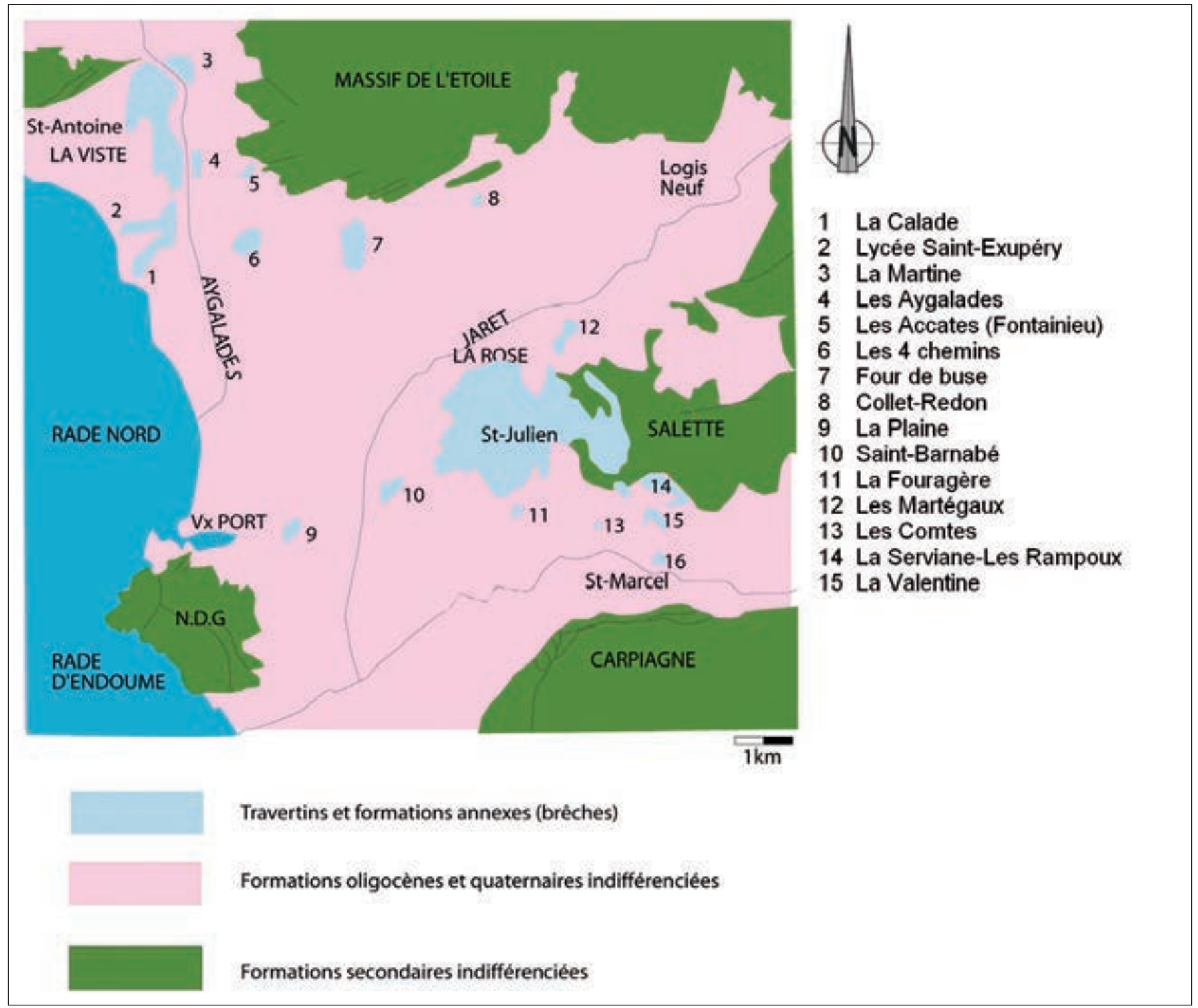

Fig. 71. Carte des principaux sites de travertins dans le bassin de Marseille (S. Dupire).

gare Saint-Charles, ont fourni des alternances de poudingues et de grès associés à des marnes sableuses. À Saint-Marcel, ces faciès peuvent affleurer sur des hauteurs assez importantes (fig. 69). À Saint-Henri et Saint-André, les poudingues visibles le long du chemin du littoral appartiennent à la formation des ArnavauxSainte-Marthe (Oligocène supérieur récent).

Denise Nury a établi une carte de répartition schématique globale des faciès de la formation des poudingues de Marseille, où elle a distingué trois zones, présentant une granulométrie fine en allant d'est en ouest (fig. 70). Les brèches à éléments calcaires du Jurassique et du Crétacé sont nommées «pseudobrèches» ou «calcaires désorganisés ». Selon elle, il s'agit de formations monogéniques (les éléments sont de même nature pétrographique) et constitués du même matériau que l'encaissant. Elles affleurent dans les massifs jurassiques et urgoniens et constituent le substratum de n'importe quel niveau de l'Oligocène. Nous les avons rencontrés dans le massif de la Nerthe. Des brèches à éléments calcaires stampiens, prises dans un ciment de même nature, ont été intercalées dans des séries oligocènes. Elles sont liées au jeu synsédimentaire de failles normales.

\section{口 Les travertins ou «tufs sédimentaires»}

Les travertins reposent en discordance sur les terrains tertiaires pour la grande majorité. Leur âge n'a jamais vraiment été élucidé ; la découverte par Gouvernet de molaires et de défenses d'un Elephas meridionalis, à la base des tufs surplombant Saint-Henri, est le seul témoin 


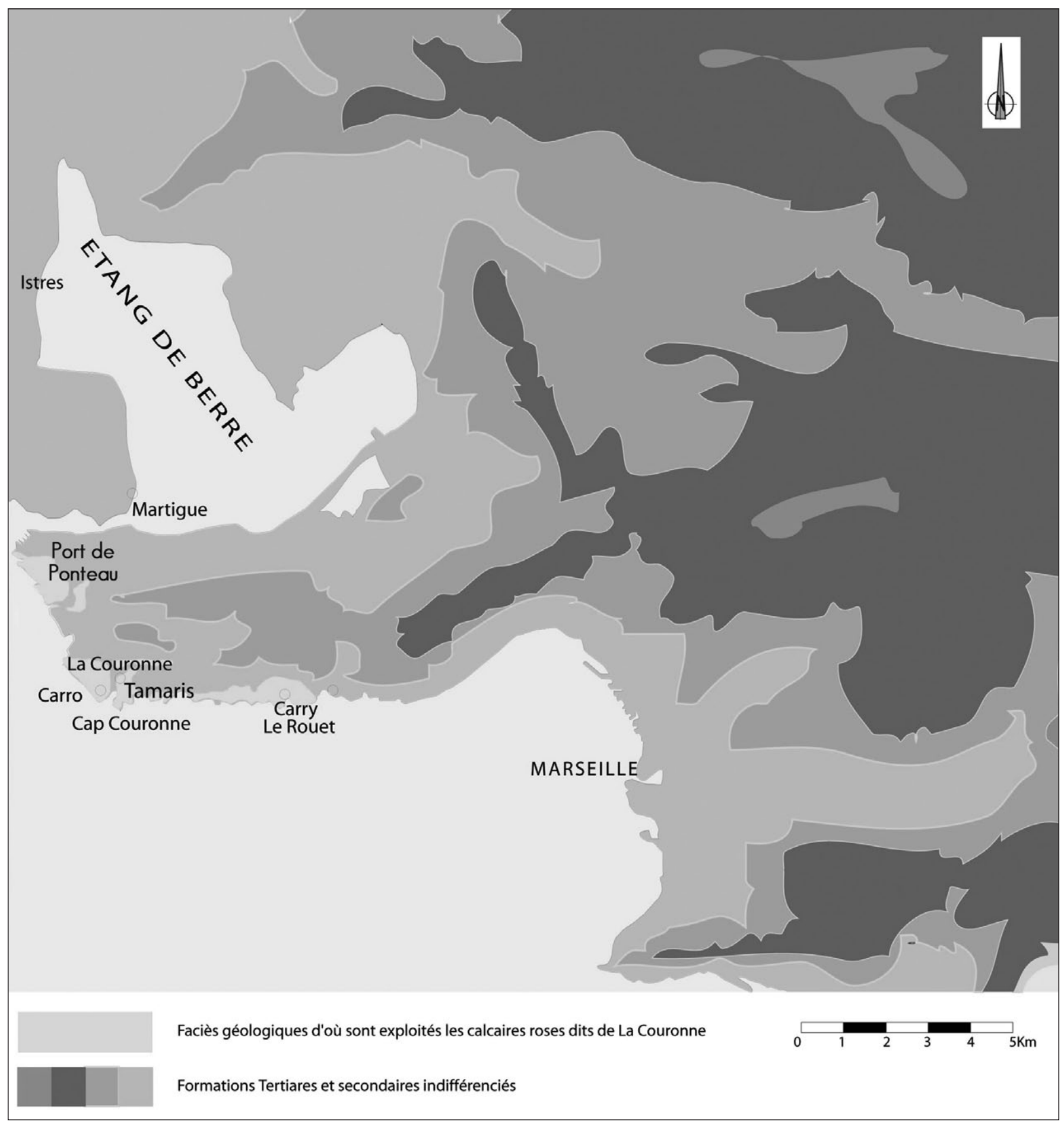

Fig. 72. Carte des principaux faciès indiquant les principales carrières de La Couronne (A. Mezzoud/Inrap).

relativement sûr. À cet endroit, l'âge serait le Pliocène supérieur.

D'après Jung, les tufs ou travertins sont des dépôts formés aux émergences de sources calcaires. Ce sont des roches grossièrement litées, vacuolaires de couleur jaunâtre et contenant souvent des débris de végétaux. Quatre facteurs (climatiques, chimiques, biologiques et mécaniques) sont nécessaires pour leur formation. Leur édification est généralement liée à un paysage calcaire karstifié et aux accidents topographiques plus au moins marqués. Dans le bassin de Marseille, bien que l'environnement soit calcaire, le lieu de dépôt est marnoargileux. L'étude de S. Dupire (Dupire 1985) a porté sur les unités (faciologiques) suivantes : les formations 
sableuses, les formations bréchiques, les roselières et les formations calcaires.

S. Dupire (fig. 71) a établi une carte de répartition des principaux sites dans le bassin de Marseille ; selon lui, ces formations constituent essentiellement deux grandes unités topographiques tabulaires, situées en position haute par rapport à leur environnement :

- l'unité des quartiers nord-ouest de Marseille: Saint-Antoine, la Viste, les Aygalades, le Cap Jannet et le Cap Pinède ;

- l'unité du centre-est : Saint-Barnabé, Saint-Jacques, Beaumont et Saint-Julien.

Nous avons assemblé ces informations et essayé de repérer le maximum d'affleurements qui peuvent nous procurer l'ensemble de ces formations travertineuses. Nous n'avons pas pu visiter tous les sites mentionnés dans les deux unités, et les affleurements que nous avons pu approcher montraient au sein de leur structure des travertins sableux, calcaires et des roselières. Les travertins bréchiques étaient absents de ces formations.

\section{$\square$ Le calcaire de La Couronne}

L'autre faciès répandu dans les monuments de Marseille, et ce depuis l'Antiquité, est le calcaire de La Couronne. Il s'agit d'un calcaire biodétritique, tertiaire, miocène, d'étage burdigalien, qui a marqué le paysage urbain de sa couleur le plus souvent rosée.

Situées à une trentaine de kilomètres de Marseille sur le territoire de Martigues, les carrières sont le plus souvent littorales ou peu éloignées du rivage (fig. 72). On connaît la préférence qui est donnée au transport par voie d'eau de ce type de matériau qui sera la règle jusqu'à la mise en place du transport par voie ferrée au $\mathrm{XIX}^{\mathrm{e}}$ s. et l'arrivée de pierres de taille d'origine plus lointaine. Cependant, les relations entre Marseille et la côte jusqu'à Fos-sur-Mer, se sont faites longtemps par mer, puisque, encore dans les années 1950, tous les transports de marchandises, de bois et de personnes se faisaient par bateaux (Vacca-Goutoulli 2001, p. 163).

\section{L'utilisation des matériaux rocheux au cours du Moyen Âge}

\section{口Le bourg de Morier}

Les matériaux utilisés au XII ${ }^{\mathrm{e}} \mathrm{s}$. dans le faubourg pour l'édification des aqueducs, des puits-citernes et des conduites sont des moellons taillés, de modules réguliers, en calcaire stampien de Saint-Victor. En relation avec ce réseau hydraulique, le bâtiment principal de la tannerie présente une prédominance du calcaire stampien au sein de sa construction. Les bâtiments extérieurs à l'ensemble artisanal affichent une prépondérance de travertin, notamment celui à aspect vacuolaire du type « roselière » de couleur ocre rouge. Ce type de roche a marqué les édifices de cette période.

À la fin du XIII ${ }^{\mathrm{e}}$ s. est mis en place le faubourg du site de l'Alcazar, réunissant six îlots d'habitation. Les murs de façade et certains murs de refend sont constitués de moellons équarris ou retouchés en travertin et en calcaire stampien. S'ajoutent parfois des blocs de poudingues et de grès employés au niveau de la première assise de certains murs de façade. Dans celui conservé en élévation dans l'îlot 6 , les proportions en matériaux rocheux utilisés au niveau des fondations sont quasiment équivalentes à celle de l'élévation. On retrouve les faciès marseillais : travertins, calcaires, poudingue et grès.

Vers la fin du XIII' ${ }^{\mathrm{e}}$ s. et le début du XIV ${ }^{\mathrm{e}}$ s., la densification du bâti garde l'héritage des modes de construction antérieurs, avec l'utilisation des mêmes faciès qu' auparavant. Néanmoins, la pierre rose de La Couronne fait son apparition dans l'habitat civil, alors qu'elle était quasiment absente des constructions précédentes du faubourg.

\section{口Le quartier de la cathédrale}

Près de la cathédrale, au sud de la rue Four-duChapitre, certains murs de façade construits au XII ${ }^{\mathrm{e}} \mathrm{s}$. mettent en œuvre des blocs et des moellons à la fois en calcaire de La Couronne et de Saint-Victor. Les réfections observées au sein des maisons situées sur la butte Saint-Laurent n'ont pas échappé à la pratique du remploi, comme en témoignent l'hétérogénéité des faciès, l'usure et le façonnage de certains matériaux rocheux utilisés. La construction de deux maisons au sud de la rue des Treize-Coins a été la seule réelle modification relevée à la fin du XIII' ${ }^{\mathrm{e}} \mathrm{s}$. et au $\mathrm{XIV}^{\mathrm{e}} \mathrm{s}$., l'occupation des autres secteurs ayant préservé une certaine continuité. Malgré la rareté des murs composant ces deux constructions, l'emploi des blocs et moellons en calcaire de La Couronne et en calcaire stampien, reste primordial. Pour la première fois des moellons de calcaire dur ont été réutilisés.

$\mathrm{Au}$ nord de la rue Four-du-Chapitre, des vestiges témoignant de l'existence d'une belle bâtisse médiévale ont été interprétés comme la maison canoniale. Le matériau rocheux le plus fréquemment utilisé dans les différents éléments architecturaux qui la composent, support de piliers, parement de murs de façade, ouvertures, est le calcaire rose de La Couronne. Des calcaires stampiens et des travertins ont été employés lors des réhabilitations postérieures.

La répartition quantitative et spatiale des matériaux employés sur le quartier de La Major suscite deux observations. Tout d'abord les matériaux rocheux employés 
dans les habitats situées aux abords du groupe cathédral et au pied nord ou à mi-pente de la butte Saint-Laurent, sont hétérogènes, sommairement taillés, liés parfois à la terre mais le plus souvent au mortier.

Cependant, pour les bâtisses situées entre la rue des Treize-Coins et la rue Four-du-Chapitre, dont l'architecture est plus soignée comme l'indiquent l'épaisseur des murs, la profondeur des fondations ou l'emploi de pierres de taille, le choix du calcaire rose de La Couronne a été privilégié.

\section{口Le quartier du Mazeau}

Dans les vestiges de l'habitat mis en place à la fin du XII ${ }^{\mathrm{e}}$ et au début du XIII ${ }^{\mathrm{e}} \mathrm{s}$. dans le quartier du Mazeau, le matériau rocheux principal est le calcaire blanc stampien, en particulier dans les murs les plus anciens. Les grès, les poudingues et ponctuellement les travertins ont été mis en œuvre en fondation dans le blocage interne des murs, et plus rarement en parements d'élévation. Le calcaire rose de La Couronne apparaît soit sporadiquement associé à d'autres roches soit de façon plus systématique dans certaines situations : cuvelages de puits, angles, piédroits, seuils, etc. Des jambages de portes mitoyennes sont formés d'une alternance de blocs taillés de Saint-Victor et de tuf. Le calcaire urgonien est peu représenté. Le palais comtal (ou un édifice voisin) dont la façade orientale a été observée, est parementé en fondation, comme en élévation, de blocs de calcaire de La Couronne.

\section{口 En conclusion}

La répartition quantitative et spatiale des matériaux employés sur les trois sites explorés a livré plusieurs informations nouvelles. Tout d'abord l'emploi du calcaire stampien dit «de Saint-Victor» dans la majorité des maçonneries au Moyen Âge accrédite l'hypothèse de sources d'approvisionnement contemporaines des constructions, telles que des carrières nouvelles, ouvertes sur le pourtour du massif de la Garde. En outre des affleurements repérés vers les quartiers de l'Estaque au nord de la ville laissent envisager que ces derniers auraient pu être aussi exploités. Les caractéristiques physiques ou mécaniques de ces faciès calcaires ont été mises en corrélation avec leur répartition au sein de la construction. L'adaptation d'une nature pétrographique à une nécessité architectonique suppose une parfaite connaissance des matériaux par les constructeurs du Moyen Âge.

Le calcaire burdigalien de La Couronne, est réservé à certains usages au Moyen Âge, alors que ses différents faciès seront très largement utilisés à l'Époque moderne. La perception de l'évolution chronologique de la prédilection pour tel ou tel faciès transparaît malgré les variations liées au statut des divers quartiers étudiés et le brouillage résultant des processus de remplois des matériaux rocheux.

La répartition des affleurements de ces matériaux nous renseigne sur les circuits commerciaux et sur le marché de la pierre en Basse-Provence. L'étude des matériaux apporte des informations sur les intentions, les connaissances théoriques et les savoir-faire techniques des bâtisseurs, et sur les conditions économiques régnant dans la région marseillaise. L'approvisionnement des chantiers de construction au Moyen Âge comme à l'Époque moderne dépend de tous ces facteurs, et l'analyse des matériaux met en évidence ces données sous un éclairage nouveau (Vacca Goutoulli 1997).

Si l'exploitation des gisements comme ceux de La Couronne, Saint-Victor ou Cassis a été attestée à diverses périodes, il n'est pas exclu que l'exploitation d'autres sites ait été également menée. Malheureusement l'urbanisation de ces dernières décennies a recouvert les traces éventuelles de ces carrières, et seuls quelques affleurements encore visibles nous permettent d'exprimer cette hypothèse.

\subsubsection{La terre crue (R. Thernot)}

La terre crue est un matériau utilisé à l'époque médiévale dans la construction de l'habitat, pour la confection des sols et pour certaines élévations.

Les sols en terre battue sont constitués d'une couche préparatoire destinée à stabiliser et assainir le sol et d'une couche d'utilisation. La première est constituée de terre limoneuse ou argileuse dans laquelle ont été incorporés des agrégats : sable, graviers, éclats calibrés de calcaire, de tuiles ou de mortier, charbons de bois, coquillages. La deuxième couche est généralement de texture plus fine et damée par la fréquentation.

Les élévations en terre crue sont représentées par l'usage de la terre massive dans le quartier du Mazeau, et de la brique crue dans les quartiers du Mazeau et de la cathédrale. Si la première technique est attestée à plusieurs reprises dans la construction de l'habitat, la seconde n'apparaît que dans deux cas d'envergure modeste.

Le mur en brique crue du quartier du Mazeau se place en façade sur rue. Il compte quatre assises de briques de terre jaune, argilo-sableuse de 5 à $10 \mathrm{~cm}$ d'épaisseur, liées par une argile grise. Le mur en briques crues du quartier de la cathédrale, daté du XII ${ }^{\mathrm{e}}$ s., est suivi sur moins d'un mètre de long, pour une largeur de $45 \mathrm{~cm}$ (Barra et al. 2004, p. 291). Sa technique de construction fait appel exclusivement à la terre, sans solin de pierre. Quelques briques, en place et dans le niveau d'effondrement, ont été repérées, mais leur modularité n'a pas pu être précisée. 
Les ouvrages en terre banchée (tapia) mis au jour sur les fouilles de la place Villeneuve-Bargemon (maisons B et E) attestent de l'utilisation de cette technique à la fin du XII ${ }^{\mathrm{e}}$ s. à Marseille dans le quartier du Mazeau alors en pleine construction. Le matériau utilisé est un limon homogène incluant quelques rares galets et cailloux de petite taille. Dans le bourg de Morier, les niveaux d'incendie sont caractérisés par la présence d'éléments provenant de la toiture (tuiles, poutres calcinées) associés à de la terre limoneuse crue et à de la terre rubéfiée, incluant des fragments de mortier et d'enduits. La relative rareté des blocs et des moellons dans ces niveaux est liée à la pratique de récupération des matériaux, mais elle est peut-être un indice de la présence d'élévations en terre.

\subsubsection{Les liants et les enduits (R. Thernot)}

Le mortier de chaux et la terre sont utilisés comme liants aussi bien des fondations que des élévations. Seul le soin apporté à la construction, donc le coût de celle-ci, semblent induire le choix de l'un ou l'autre liant. Les observations de terrain n'ont pas permis de déceler l'incorporation de chaux à la terre pour améliorer la solidité du liant, comme il en est fait mention à Aix-en-Provence dans les constructions rurales avec la terra amortayrada (Bernardi 1995, p. 160), mais cette technique connue sous le nom de «mortier d'agasse » est restée fréquente en Provence jusqu'à l'ère industrielle.

Le mortier de chaux est également utilisé comme revêtement de sol comme dans la maison $5 \mathrm{D}$ près de la cathédrale. Le mortier de chaux mis en œuvre est le plus souvent fortement dosé en chaux comme l'indiquent sa blancheur et/ou sa dureté. Les agrégats sont constitués par un sable grossier comportant des éléments roulés hétérométriques, dépassant parfois le centimètre. Utilisé comme enduit, le mortier est fait avec un sable plus fin et recouvre les murs liés à la terre et les murs en terre banchée. Dans les maçonneries parementées en petit appareil, les joints sont regarnis de mortier.

Dans les structures hydrauliques, les enduits sont destinés à constituer une couche étanche. Dans ce but, du tuileau pilé est incorporé et confère au mélange une coloration rosée. Près de la cathédrale, un petit caniveau domestique du XII s. (maison 7B - Barra et al. 2004, p. 285) reçoit pour son étanchéité un enduit de mortier de tuileau. Dans la maison 3B, les parois internes d'une latrine portent des traces du même type d'enduit de couleur rose. Pour la construction d'un aqueduc dans le bourg de Morier, l'usage du mortier hydraulique (batum) est évoqué dans un acte de $1319^{\mathbf{1 4 0}}$.

140 ACM BB12, fol. 79.
Concernant les enduits intérieurs, des fragments d'enduits peints sont signalés dans les niveaux d'abandon, mais aucun indice d'utilisation de plâtre n'a été relevé sur les structures médiévales observées.

\subsubsection{Les terres cuites architecturales (R. Thernot)}

Plusieurs types de terres cuites architecturales ont été employés, des plus fréquents (les tuiles) aux plus rares (les carreaux de pavement).

\section{Les tuiles}

Les tuiles ne sont perçues que par les éléments fragmentaires piégés dans les niveaux d'abandon ou le niveau d'incendie du bourg de Morier, détruit au milieu du XIV ${ }^{\mathrm{e}} \mathrm{s}$. Il s'agit de tuiles rondes à pâte rouge ou jaune, semblables au type fabriqué régionalement jusqu'à l'ère industrielle. Dans le bourg Sainte-Catherine, également détruit et incendié avant 1360, des tuiles canal entières de $48 \mathrm{~cm}$ de long, $22 \mathrm{~cm}$ de large et $2 \mathrm{~cm}$ d'épaisseur, parfois munies d'un trou de fixation ont été recueillies (Bouiron 1994, p. 89 ; Bouiron 2001a, p. 110).

\section{Les carreaux}

Des fragments de carreaux ou malons sont également présents dans ces niveaux d'incendie, semblables à ceux observés au bourg Sainte-Catherine. Deux modules principaux y ont été relevés : 27/14/3 ou 2 cm, et 20/14/2 cm (ibid.). Il peut s'agir des revêtements des sols des étages ou encore des malons de couvert de toiture.

Les sols de carreaux en place sont absents sur les trois chantiers. Les productions de carreaux décorés des ateliers du bourg des Olliers ne sont pas représentées, si ce n'est peut-être au bourg Sainte-Catherine par un élément particulier. Cet objet en pâte calcaire émaillée est en forme d'étoile à huit branches et porte un décor d'étoile à huit branches peinte au brun de manganèse (Richarté, Bouiron 1995). La rareté des revêtements de sol en carreaux de terre cuite avait déjà été soulignée en Provence par Philippe Bernardi et Elizabeth Sauze (Bernardi 1995, p. 365 ; Sauze 1983, p. 30).

\section{Les tuyaux}

Dans le quartier du Mazeau, en rive orientale de la rue de la Guirlande, le grand bâtiment interprété comme des bains construit à la fin du XII ${ }^{\mathrm{e}} \mathrm{s}$. ou au début du $\mathrm{XIII}^{\mathrm{e}} \mathrm{s}$. est doté d'un réseau de tuyaux en terre cuite (canons) noyé dans le blocage interne des murs (fig. 73 et $c f$. infra $\S$ II, 2, 2.3.2.). Les éléments modulaires sont tournés dans une argile rougeâtre, dont la coloration est altérée 
à cour par la cuisson en atmosphère réductrice. La pâte inclut de nombreuses particules de dégraissant, dont de la silice et un peu de mica. Les tuyaux mesurent de 28 à $34 \mathrm{~cm}$ de long, et $8,4 \mathrm{~cm}$ de diamètre extérieur maximum. Le diamètre intérieur est de l'ordre de $4,8 \mathrm{~cm}$. Ils comportent chacun un bout évasé et un autre en forme de goulot de $4 \mathrm{~cm}$ de long permettant l'emboîtement. Le mortier du blocage assure le maintien des éléments en place et l'étanchéité du dispositif. Ces modules se différencient nettement en termes de pâte, de dimensions et de forme, des tuyaux trouvés dans les ateliers du bourg des Olliers (Vallauri, Leenhardt 1997, p. 306). Ces derniers sont en pâte calcaire, atteignent $45 \mathrm{~cm}$ de long et plus de $7 \mathrm{~cm}$ de diamètre interne et leur système d'emboîtement est plus court. De plus, la datation de création des ateliers est postérieure à celle attribuée au bâtiment de la rue de la Guirlande.

Plus généralement, l'usage économe de la terre cuite est à rapprocher de la situation de pénurie évoquée par Henri Amouric, imputable d'après lui à la rareté du bois de chauffe (Amouric et al. 1997).

\subsubsection{Le bois (R. Thernot)}

L'éloignement géographique des massifs forestiers susceptibles de fournir des bois d'œuvre de section suffisante pour ménager des portées compatibles avec le fonctionnement des pièces d'habitation a vraisemblablement constitué un facteur de cherté de ce matériau dans la construction locale. En témoignent son utilisation parcimonieuse et la décision selon laquelle «(...) après le sac de Marseille, en novembre 1423, la reine Yolande accorda aux habitants de cette ville une exemption des droits de péage pour le bois d'ouvre nécessaire à la reconstruction de leurs maisons $\gg{ }^{\mathbf{1 4 1}}$.

Le bois dans le gros-œuvre est utilisé dans les planchers et les toitures, comme l'attestent les fragments calcinés retrouvés dans les niveaux d'incendie du bourg de Morier. L'utilisation de tuiles rondes en couverture laisse penser que la forme des ouvrages de charpenterie ne devait pas fortement différer de celle qui prévaut jusqu'à la fin de la période moderne. L'écartement entre les murs porteurs varie entre 4 et $5 \mathrm{~m}$. Lorsque cette portée apparaît supérieure $(8 \mathrm{~m})$, comme dans le quartier du Mazeau (unité E), il est probable que des murs de refend disparus aient divisé l'espace intérieur. Cette dimension détermine la longueur des pannes de toiture et des poutres de plancher mises en œuvre. L'étude menée par

141 ACM AA 28, 16 mars 1424, cité par Bernardi 1998, p. 317-328.

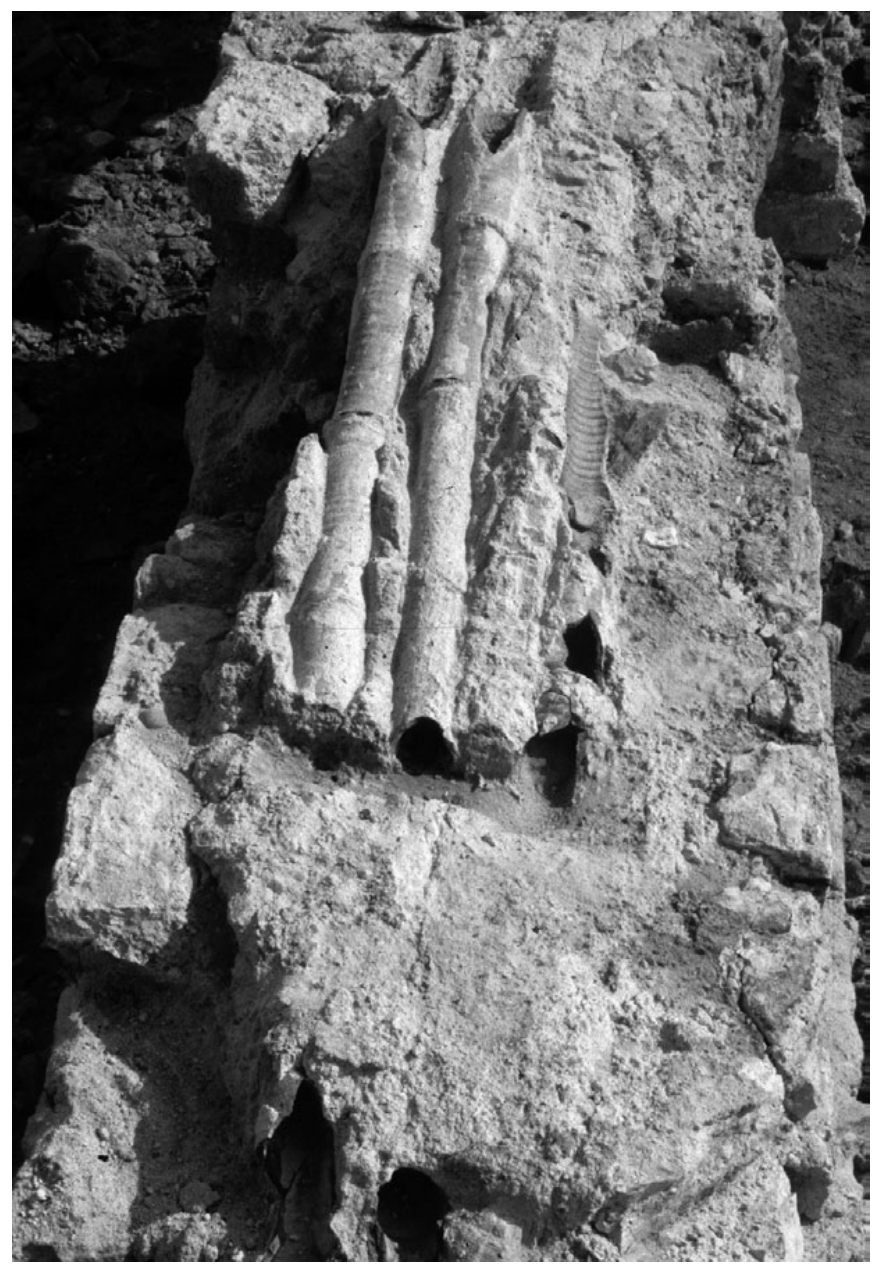

Fig. 73. Réseau de tuyaux en terre cuite noyé dans le blocage d'un mur des bains dans le quartier du Mazeau (cl. M. Derain/Inrap).

Philippe Bernardi sur les techniques de construction à Aix-en-Provence à la fin du Moyen Âge montre que les pièces de bois importées des Alpes mesuraient couramment 10 à $12 \mathrm{~m}$ de long. Les épaisseurs des pièces de section circulaire étaient comprises entre 17 et $25 \mathrm{~cm}$ et celles des pièces de section carrée atteignaient $35 \mathrm{~cm}$ (Bernardi 1995, p. 132). Les charpentiers marseillais devaient s'approvisionner auprès des mêmes filières que leurs confrères aixois. Les bois d'œuvre étaient donc coupés afin d'adapter la longueur des poutres à la résistance au fléchissement induite par le diamètre des bois disponibles. En effet, l'expérience empirique avait vraisemblablement déjà montré que le rapport entre la hauteur d'une poutre et sa longueur de portée potentielle, est de l'ordre de un à vingt. Les bois importés des Alpes permettent ainsi de réaliser des portées de 3,50 m à $7 \mathrm{~m}$, la moyenne correspondant aux écartements de 4 à $5 \mathrm{~m}$ les plus fréquents. C'est donc la section plus que la longueur des bois disponibles qui conditionne l'écartement des murs porteurs. 
L'utilisation du bois dans les supports verticaux reste marginale et ne transparaît que par les trous de poteaux dotés de calages, correspondant à des structures légères appuyées sur des murs maçonnés.

Aucun essai de détermination des espèces n'a été jusqu'ici entrepris sur les restes issus des divers secteurs fouillés, et la nature des bois utilisés n'est donc pas connue.

\subsection{Les techniques de construction au Moyen Âge (R. Thernot)}

Sur la base de ce répertoire de matériaux, les constructeurs des $\mathrm{XII}^{\mathrm{e}}-\mathrm{XV}^{\mathrm{e}}$ s. réalisent les ouvrages qui composent les diverses parties des maisons et de leurs dépendances. Les matériaux combinés entre eux génèrent un éventail technique relativement modeste, du moins tel qu'il apparaît à travers le filtre des données archéologiques. Les informations sur les élévations, les étages, les toitures, le décor des façades font défaut. La perception du bâti médiéval issue des investigations de terrain, privée d'exemples maintenus en élévation, n'est pour l'heure guère enrichie par les données d'archives. Le regard reste ainsi braqué sur le pied des murs et les sols des rez-de-chaussée, et l'attention concentrée sur les aspects techniques afférents au gros-œuvre.

\subsubsection{La maçonnerie}

Les techniques mises en œuvre sont essentiellement représentées par la maçonnerie, associant les divers modules de pierre et les liants - terre ou mortier de chaux. Les murs sont construits sur une fondation formant une semelle filante, différenciée de l'élévation par ses matériaux, sa largeur et ses modes de construction. La fondation est souvent constituée de blocs ou de moellons non retouchés ou équarris. Ces éléments sont disposés en assises plus ou moins régulièrement en fonction de leur mode de taille et de leur module. Quand les éléments sont des moellons ou des cailloux, ils peuvent être disposés en épi. Le remploi de galets de lest de bateau apparaît ponctuellement dans le quartier du Mazeau, proche du port. Un blocage interne complète le cas échéant la largeur de la structure. La fondation est débordante et comporte dans certains cas plusieurs ressauts. Elle peut être liée à la terre ou au mortier, ce dernier plus fréquemment employé dans les constructions plus soignées : maisons du quartier du Mazeau, maisons d'angle ou de grande superficie dans le faubourg. La fondation du Palais comtal près du Mazeau se distingue radicalement des autres fondations par l'utilisation de pierre de taille de La Couronne composant un moyen appareil régulier formant une série de ressauts.

Les élévations sont majoritairement formées de deux parements appareillés et d'un blocage interne. Le liant est le plus souvent le mortier de chaux dans la construction des maisons de ville. Les structures plus modestes sont liées plus volontiers à la terre. Lorsque le mur est lié à la terre, les moellons du parement peuvent être disposés en boutisse pour une meilleure adhérence, comme l'illustre le mur qui sépare les bâtiments $5 \mathrm{~A}$ et $5 \mathrm{C}$ du quartier de la cathédrale. Dans la plupart des murs, l'appareil est constitué de moellons équarris ou de blocs taillés, composant soit un petit appareil réglé avec des hauteurs d'assises de 10 à $15 \mathrm{~cm}$, soit un appareil moyen avec des blocs de 20 à $30 \mathrm{~cm}$. Dans le quartier du Mazeau, les parements des habitations courantes et ceux du grand bâtiment de la rue de la Guirlande sont en petit appareil régulier (fig. 74). Dans le faubourg ou dans le quartier de la cathédrale, l'appareil est parfois moins soigné. Dans quelques cas, un soin particulier apporté à la réalisation des parements se traduit par la taille des moellons ou des blocs mis en œuvre et les joints sont minces. Parmi ces exemples, il faut signaler les chemisages des puits et des bassins. Dans ces ouvrages plus soignés, la pierre de taille utilisée est celle de La Couronne ou de Saint-Victor(fig. 75).

\subsubsection{Le pisé et l'adobe}

La terre crue pour la confection des élévations apparaît utilisée surtout sous la forme du pisé banché (tapia), le modelage de briques semble être devenu au Moyen Âge une technique marginale, plus rarement représentée et cantonnée à des murs de clôture de cour.

Les murs en terre banchée (fig. 76) dans les habitations du quartier du Mazeau (maisons B et E) sont constitués, comme les murs en maçonnerie, d'une fondation débordante en blocs non retouchés de grès ou de poudingue, et dans certains cas (maison E) d'un solin appareillé comptant quatre assises de moellons de calcaire lacustre et de tuf, liés au mortier, de même aspect que les élévations maçonnées voisines (Thernot, Vecchione 2003, cf. infra $\S$ II, 2, 2.3.3.). L'élévation en terre massive, large de $0,55 \mathrm{~m}$, est montée par lits de damage réguliers de $8 \mathrm{~cm}$ d'épaisseur. Entre chaque lit est déposée une pellicule de mortier de chaux qui s'épaissit pour former un boudin remontant au contact des parements, afin de former l'accroche de l'enduit. L'enduit de mortier compact appliqué ensuite assure la protection de l'ensemble de la structure, y compris les assises du solin. L'accrochage des murs de refend aux murs périphériques en maçonnerie est assuré par pénétration de l'élévation en terre dans le blocage intérieur du mur. L'absence de joints verticaux traduit l'utilisation de banches sur toute la longueur, fixées de 


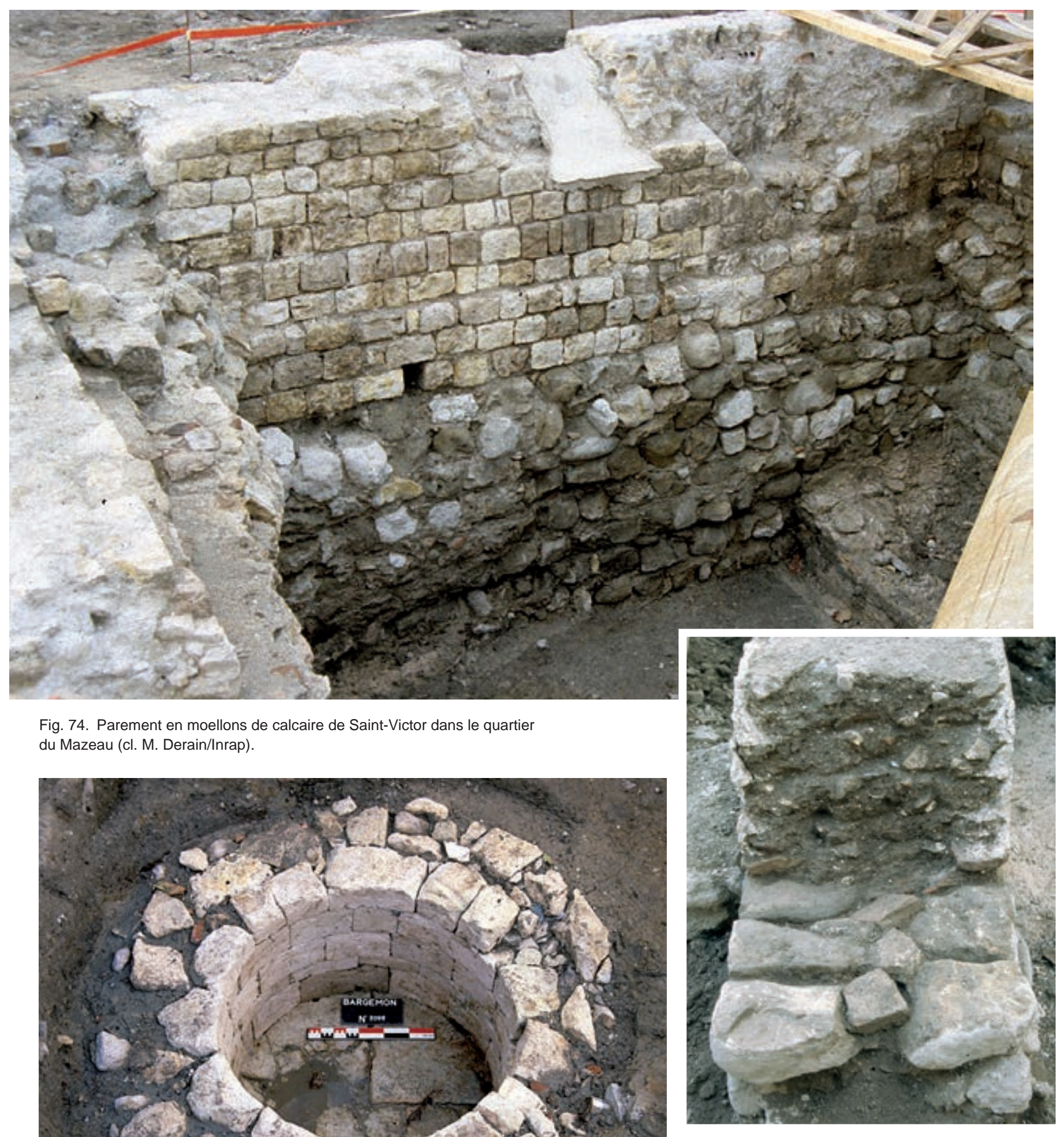

Fig. 76. Vue d'un mur en terre banchée en cours de démontage (cl. M. Derain/Inrap).

Fig. 75. Un puits du quartier du Mazeau (T. Maziers/Inrap). 
part et d'autre de la base maçonnée par des potelets et des clés. Au contact du pisé et de la fondation, plusieurs alignements de pierres transversaux, distants entre eux de $1,50 \mathrm{~m}$, sont visibles. Ces dispositifs résultent de l'obturation des orifices résultants de l'enlèvement des clés horizontales qui assurent le maintien des banches et des potelets, lors de la mise en place du pisé.

Les murs dotés d'un solin protégeant l'élévation en terre correspondent à des murs extérieurs, à la différence des murs de refend dépourvus de ce dispositif. Parmi les quatre murs de la maison E, seul le mur de fond de parcelle a conservé un lambeau d'élévation en pisé, mais les deux murs latéraux sont dotés d'assises de moellons arasées au même niveau que le solin de la façade arrière et pour certains d'entre eux, d'orifices qui pourraient correspondre à des trous de clés de banches. Ainsi trois des murs de la maison E, à l'exception peut-être de la façade sur rue, entièrement refaite, ont-ils dû être construits en terre damée sur solins de pierres.

La qualité de la mise en œuvre observée révèle une bonne maîtrise des procédés de construction en terre, qui laisse penser que ces témoignages s'inscrivent dans une tradition de savoir-faire locale bien établie. La présence de murets en adobe élargit l'éventail des techniques de construction en terre crue à l'époque médiévale.

Les murs en terre massive repérés au bourg des Olliers (Marchesi et al. 1997) et dans le quartier du Panier (Reynaud 1998), témoignent de la permanence de la technique jusqu'au bas Moyen Âge. Dans la plupart des exemples relevés, les murs en terre sont liés à des murs en pierres dans la même construction. Au Panier, c'est même un mur composite associant les deux techniques qui est décrit. La terre crue est également mentionnée pour l'enceinte de la ville comtale du XII ${ }^{\mathrm{e}} \mathrm{s}$. (Bouiron 2001c, p. 80).

\subsubsection{Les revêtements}

La rareté des exemples conservés ne permet pas d'imaginer un large éventail de techniques de revêtement de sols et de murs à l'époque concernée. Hormis la terre battue pour les sols, bien attestée, les autres modes de revêtement ne sont représentés que par un sol dallé dans la maison canoniale.

Sur certaines élévations, un enduit au mortier est appliqué. Le mortier utilisé est posé en couche mince et confectionné avec un sable fin ou peut-être tamisé, à la différence du mortier à hourder, plus grossier. L'intégration de tuileau dans le mortier de chaux permet dans quelques rares cas de tapisser l'intérieur des ouvrages hydrauliques -caniveaux et cuves, observés près de la cathédrale, mais les caniveaux sont le plus souvent réalisés en pierre.

\subsubsection{Les éléments architectoniques : piédroits, seuils et piliers}

L'état de conservation des élévations ne permet pas d'aborder de façon synthétique les modes de construction des éléments architectoniques dans le bâti médiéval. Seuls quelques rares exemples sont à signaler et se distinguent par l'utilisation de la pierre de taille, en particulier de La Couronne. La maison canoniale est dotée d'une

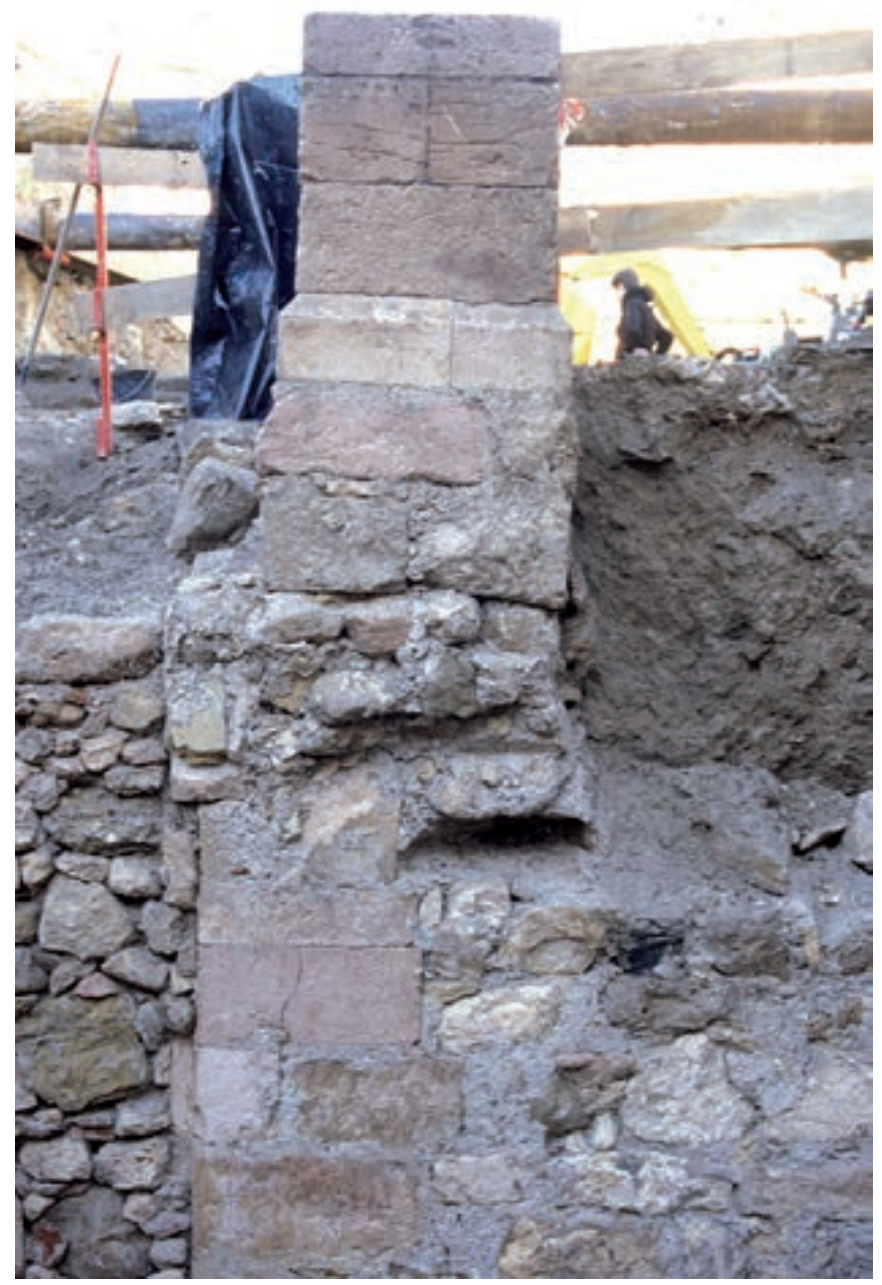

Fig. 77. Pilier de la maison canoniale près de la cathédrale (cl. T. Maziers/Inrap).

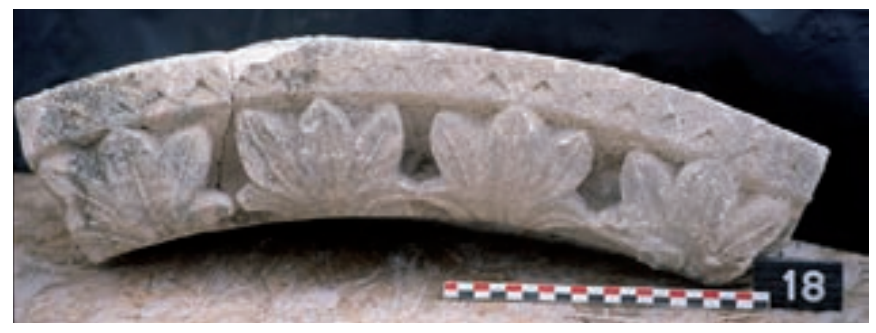

Fig. 78. Fragment d'arc décoré en calcaire de La Couronne (cl. T. Maziers/Inrap). 
série de piliers parementés en molasse de La Couronne (fig. 77). Dans le quartier du Mazeau, un piédroit et des seuils à feuillure sont également réalisés en blocs de molasse, de calcaire de Saint-Victor et de tuf. Sur la plupart de ces éléments, des indices de remploi ont été relevés, montrant que la pierre de taille neuve semble au Moyen Âge réservée à des usages exceptionnels.

Trouvé en remploi dans le quartier du Mazeau, un fragment d'archivolte d'arc plein-cintre portant un décor de feuillage, en calcaire de La Couronne, constitue l'un des rares témoignages de l'aspect des façades médiévales (fig. 78).

\section{Les matériaux et techniques à l'Époque moderne}

Les textes sont bien plus détaillés pour l'Époque moderne. Ceci permet d'appréhender plus finement la question des matériaux et des techniques employés pour la construction.

\subsection{Les matériaux recensés à l'Époque moderne d'après les données de fouille et les documents d'archive (A. Mezzoud, R. Thernot d'après M. Vacca-Goutouli)}

Les informations sur les matériaux et les techniques mises en œuvre dans la construction de l'habitat moderne sont de nature différente suivant qu'elles proviennent des données de fouille ou des documents écrits relatifs aux bâtiments.

Les opérations archéologiques ont toujours abordé le bâti après arasement. L'étude des élévations n'a donc pas été possible, mais en contrepartie, le démontage des structures conservées a livré des informations nombreuses et précises sur les matériaux employés et sur les techniques, comme la taille de la pierre, les techniques de fondation et de reprise en sous-œuvre, dont les textes ne font pas état de façon détaillée. Des blocs en remploi appartenant à des élévations ont été également retrouvés et livrent des indications sur des façades en grand appareil disparues anciennement.

Les textes collectés, prix-faits et rapports de future cautelle, évoquent essentiellement les élévations, avec des indications sur les ouvrages en maçonnerie, la charpenterie, la menuiserie et la couverture. Ces actes utilisent une terminologie technique conventionnelle marquée par les provençalismes. Dans quelques cas, il a été possible de mettre en relation les structures décrites dans un document et les vestiges archéologiques, permettant de mesurer l'adéquation ou à l'inverse les distorsions entre les travaux prévus et leur exécution effective.

D'un point de vue chronologique, les données archéologiques sont inégalement réparties. Rares pour la période allant du $\mathrm{XV}^{\mathrm{e}} \mathrm{s}$. au milieu du XVII ${ }^{\mathrm{e}}$ s., elles deviennent ensuite plus abondantes. Les textes retrouvés couvrent la période s'étendant de la fin du $\mathrm{XVI}^{\mathrm{e}} \mathrm{s}$. au milieu du XVIII ${ }^{\mathrm{e}} \mathrm{s}$.

\subsubsection{Les roches (A. Mezzoud, $R$. Thernot, d'après M. Vacca-Goutoulli)}

Plusieurs types de blocs sont employés suivant leur emplacement dans la construction.

\section{Les blocs}

La pierre de taille issue des diverses carrières de la Couronne est largement utilisée dans les structures de l'Époque moderne. Les lieux d'extraction cités dans les textes sont Carreau, la Baume, Mussou ${ }^{142}$. Les pierres, acheminées par bateau jusqu'à Marseille, sont débitées en modules normalisés : bards, quairon, bujets, quairades, grazes, croizilhons, montants ${ }^{143}$. Les différences de modules et de qualité, et donc de coût, des blocs correspondent à des utilisations architectoniques spécifiques et révèlent une forme de normalisation de ceux-ci. Généralement, la pierre à grain fin, bien cimentée, de bonne tenue d'arête, de couleur rose provenant de Carro, est destinée à des ouvrages nécessitant un ajustement précis comme les arcs ou recevant un décor sculpté tels que les encadrements de baies. Les bancs donnant des pierres plus coquillières, plus tendres, fournissent les blocs utilisés en fondation ou dans les parements. L'acheminement par voie de mer fait l'objet de contrats détaillés entre les protagonistes, carrier, tailleur, maçon ${ }^{144}$.

Bien que les carrières de La Couronne prédominent dans l'approvisionnement des chantiers, d'autres roches sont représentées ponctuellement dans les structures en grand appareil moderne. La base de la façade de la maison située à l'angle des rues de la Guirlande et de la Taulisse est en partie parementée en blocs de grès à joints sciés et en tuf. La pierre de Rognes est signalée pour la construction d'un immeuble dans la «Ville Nouvelle ${ }^{145}$.

Les traces d'outils relevées sur les blocs témoignent des étapes de l'élaboration des blocs depuis la carrière jusqu'à la mise en œuvre. L'équarrissement des blocs

\footnotetext{
142 ACM HH 414.

143 AD13 373 E 270, fol. 1036.

144 AD13 392 E 103, fol. 75v.

145 AD13 380 E 170, fol. 938.
} 


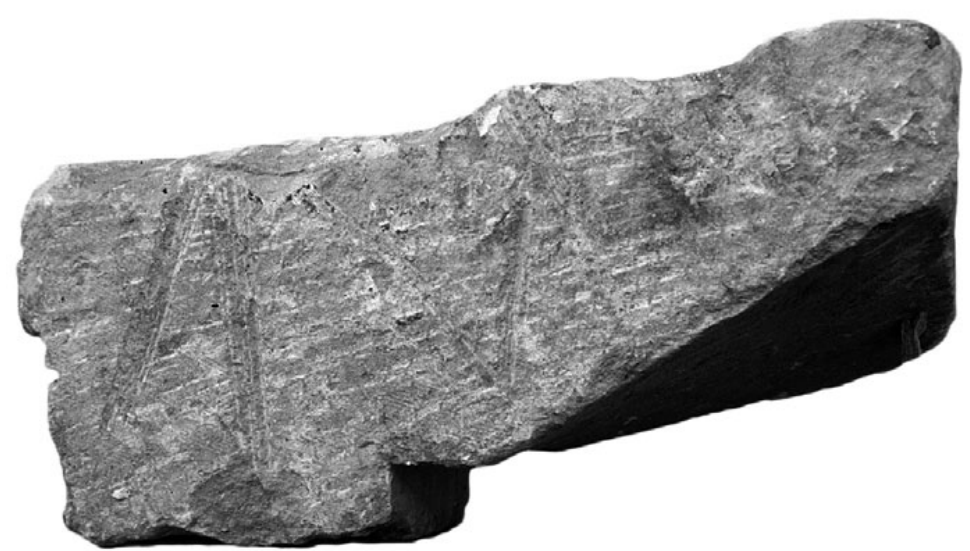

Fig. 79. Traces de taillant brettelé sur l'une des faces d'un claveau d'arc avec arrière-voussure (cl. M. Vacca-Goutoulli).

est révélé par les impacts de marteau taillant brettelé, outil également utilisé pour la finition des lits de pose et d'attente (fig. 79). Les tracés préparatoires à la taille des moulures sont marqués à la pointe sur l'une des faces. Les faces vues ont perdu en général tout indice d'outil hormis les discrètes rainures de la ripe. Sur les lits d'attente des blocs de parement ou les claveaux, des abreuvoirs sont creusés afin de favoriser la répartition du mortier et l'élimination des excès qui permettent de ménager des joints très fins. Lors de la mise en place des blocs dans l'ouvrage, des ajustements sont pratiqués par enlèvement de matière à l'aide d'un ciseau plat.

\section{Les moellons et les cailloux}

Les pierres utilisées dans le blocage des murs sont de nature très variée et s'ouvrent au répertoire disponible localement : grès, poudingue, calcaires lacustre, urgonien, etc. Les remplois sont souvent représentés, y compris par des blocs de grand appareil provenant de façades démantelées. Les galets et autres petits modules de cailloux de toutes origines constituent le matériau des sols pavés fréquents au rez-de-chaussée et dans les caves, les calades.

Durant la fin du XVII ${ }^{\mathrm{e}}$ s., dans le quartier de l'Hôtel de Ville, le schiste ardoisier a été utilisé pour réaliser des parements de caniveau, des arases dans les murs et même un dallage de sol de cave sous forme de plaques hexagonales. Matériau d'importation lointaine destiné à conférer aux toitures des bâtiments du pouvoir un aspect similaire à celui du nord de la France, le schiste ardoisier est utilisé à cette période dans les grands chantiers voisins que sont l'Hôtel de Ville et les arsenaux. Les utilisations recensées semblent résulter de la récupération des rebuts de ces chantiers.

\section{Le sable}

Les sables utilisés dans la confection des mortiers proviennent de diverses sources. Dans certains mortiers, on reconnaît les agrégats du poudingue stampien exploité pour le sable noyé dans le ciment dont ce conglomérat est constitué. Le «bon sable de la mer» est plusieurs fois préconisé dans les prix-faits, parfois associé au « sable de terre » ${ }^{\mathbf{1 4 6}}$ et des fosses à mortier contenant du sable marin ont été retrouvées dans l'Agrandissement. D'autres textes recommandent le sable d'Arenc, quartier périphérique de la ville dont le toponyme est éloquent quant à la nature de son sol, ou encore de «Portugalle », c'est-à-dire provenant de l'anse de Portegalle, au nord de La Major.

\subsubsection{La terre cuite (R. Thernot)}

L'usage des céramiques architecturales (mallons/ malons d'après maloun, Mistral 1878, p. 258) est évoqué dans les textes du XVI ${ }^{\mathrm{e}} \mathrm{s}$. (Amouric et al. 1997), en particulier pour la réalisation de voûtes : «...lad. crotte y entra plus de huict mille mallons... ${ }^{\mathbf{1 4 7}}$. L'exemple le plus précoce recensé en fouille se situe dans le bourg de Morier, représenté par l'empreinte de carreaux de $20 \mathrm{~cm}$ sur $15,5 \mathrm{~cm}$ dans la chape de pose. À la fin du XVII ${ }^{\mathrm{e}} \mathrm{s}$., les exemples conservés de terres cuites architecturales sont fréquents, ce à quoi font écho les mentions dans les textes. Les textes signalent les malons de crotte, destinés à l'origine à la confection des voûtes (crotto), les malons de couvert, destinés à recevoir une chappe de plâtre ou de mortier, les malons d'un pan carré (pancarra Mistral 1878, p. 468) de 24 à $25 \mathrm{~cm}$ de côté, ou

146 AD13 364 E 299, fol. 615.

147 AD13 360 E 35, fol. 413, daté de 1599. 
de terceneau/tiercenal. Le prix-fait que signe en 1696 Pierre Mesnier pour faire construire sa maison précise que les terres cuites doivent venir du quartier de Séon ${ }^{\mathbf{1 4 8}}$, site qui sera celui des tuileries de Marseille au XIX ${ }^{\mathrm{e}} \mathrm{s}$. (Leroy 1847). En 1663, un autre prix-fait stipule que «tous les mallons que employera dans toutte la susd. ouvre seront de la fabrique d'Ensues $\gg{ }^{\mathbf{1 4 9}}$. Dans un prixfait de 1715, les origines et/ou les qualités des divers types de carreaux et de briques sont précisées : tomettes de Séon, mallons de Tersenal, briques des cloisons en mallons de Chautel ${ }^{150}$. Ces mentions ouvrent aux questions de terminologie, laquelle semble encore mouvante à cette période, de même qu'à celle, corollaire, de la normalisation des produits, et enfin à celle des sites de production dont le recensement reste à mener.

Les informations disponibles sur les terres cuites architecturales trouvées en fouille concernent essentiellement les modules (longueurs, largeurs, parfois épaisseurs). Les données techniques - pâte, traitement des surfaces, traitement des bords - sont rarement mentionnées. La mise en correspondance entre la terminologie utilisée dans les textes et les éléments trouvés en fouille, permettant l'établissement d'une typologie, reste difficile à établir.

\section{Les modules carrés}

Les carreaux de module carré mesurent de 23 à $24 \mathrm{~cm}$ de côté et 1,8 à $3,5 \mathrm{~cm}$ d'épaisseur. Couvrant une surface de $0,05 \mathrm{~m}^{2}$ chacun, ils sont utilisés comme revêtements des sols de cave, de locaux de plain-pied et même dans le chevet de la chapelle des Pénitents à côté de la cathédrale. Ils sont prépondérants dans l'Agrandissement avec au moins sept occurrences sur les neuf sols documentés recensés dans ce quartier. Ils sont attestés de la fin du XVII ${ }^{\mathrm{e}}$ s. (cave du quartier du Mazeau) jusqu'au plein XVIII ${ }^{\mathrm{e}} \mathrm{s}$. (réfection du pavement de la chapelle des Pénitents daté de 1731). Ils sont assimilables au «pan carré » produit au $\mathrm{XIX}^{\mathrm{e}}$ s. par les fabriques de SéonSaint-Henri, de $23 \mathrm{~cm}$ de côté, et épais de $2 \mathrm{~cm}$ pour ceux de simple épaisseur et 3,5 à $4 \mathrm{~cm}$ pour les carreaux de double épaisseur (Leroy 1847, p. 39).

\section{Les modules rectangulaires de rapport $1 / 2$}

Les carreaux rectangulaires de format allongé mesurent de 26 à 27,5 cm de long, de 12 à 13,5 cm de large et 3 à 4,5 cm d'épaisseur. Couvrant chacun une surface de $0,03 \mathrm{~m}^{2}$, ils sont présents dans les sols de cave et de

148 AD13 364 E 299, fol. 615.

149 AD13 364 E 274, fol. 653v.

150 AD13 363 E 250, fol. 393 ; année 1715. rez-de-chaussée du quartier du Mazeau et de la cathédrale. Les parois de l'une des cuves trouvées dans les caves de l'Hôtel Surian derrière le pavillon Bargemon sont doublées de briques de ce module disposées en panneresses. Dans le rapport d'estime daté de $1734^{151}$ et concernant la parcelle 399 du quartier du Mazeau, une cave est décrite comme étant pavée en partie de «moilon de crotte ». Ce sol carrelé retrouvé en fouille est constitué de carreaux de $26 \mathrm{~cm}$ sur $12,5 \mathrm{~cm}$ et $3,2 \mathrm{~cm}$ d'épaisseur. Ce module de terre cuite est attesté de la fin du XVII ${ }^{\mathrm{e}}$ s. (sol du Logis de la Taulisse) au milieu du XVIII ${ }^{\mathrm{e}}$ s. (sol du Logis du Rozier). Au XIX ${ }^{\mathrm{e}}$ s., il a disparu du répertoire dressé par Victor Leroy (ibidem). Peut-être s'agit-il aussi des tierceneaux des textes, qui au $X^{\mathrm{e}} \mathrm{s}$. d'après Leroy ne mesurent que $23 \mathrm{~cm}$ de long, $12 \mathrm{~cm}$ de large et de 2 à $4 \mathrm{~cm}$ d'épaisseur (ibidem). Cette appellation semble renvoyer au terme provençal et français méridional (tiersenal/tercenal) ${ }^{\mathbf{1 5 2}}$ désignant les arsenaux ou plus précisément les formes de radoub où étaient remisées les galères, sans qu'on puisse dire si cela fait référence au lieu de fabrication ou au lieu où on les a utilisés en grand nombre.

\section{Les modules rectangulaires de rapport 1/1,6}

Les éléments mesurant de 24 à $25 \mathrm{~cm}$ de long, de 15 à $16 \mathrm{~cm}$ de large et de 3 à $4 \mathrm{~cm}$ d'épaisseur sont présents dans un tiers des sols étudiés. Les briques mises en œuvre dans les élévations et les voûtes des caves se conforment à ce module, comme les voûtes de la cave du Logis du Rozier sur le Mazeau. La surface des éléments n'est pas parfaitement lissée, favorisant l'accroche du mortier. Leur aspect est d'autant plus notable quand ils sont utilisés comme carreaux au sol, comme dans l'Agrandissement.

$\mathrm{Au}$ sol, chaque élément couvre une surface de près de $0,04 \mathrm{~m}^{2}$. Ce module est attesté en fouille de la fin du XVII ${ }^{\mathrm{e}}$ s. au courant du XVIII ${ }^{\mathrm{e}}$ s. L'utilisation de ces

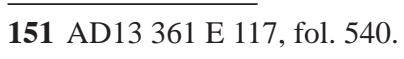

152 Arsenal (nom masculin) correspond à une forme tardive, succédant à deux séries de mots bien distincts : tarsenal, tercenal, tersenal (employés jusqu' au XVI ${ }^{\mathrm{e}} \mathrm{s}$.) et archenal, arsenail (XV ${ }^{\mathrm{e}} \mathrm{s}$. ), arsenac aboutissant à la forme arsenal qui a éliminé les autres. Ces formes viennent d'un emprunt à l'arabe dār ('aş-) şan'a «maison de construction, de fabrication », peut-être emprunt direct par les dialectes italiens qui ont assourdi le $« \mathrm{~d} »$ arabe en $« \mathrm{t} »$; les formes sans « $\mathrm{t}$ » venant du vénitien ancien arzana. On suppose que la fausse coupe di arzana en a résulté. Le suffixe -al est savant, utilisé au XVII ${ }^{\mathrm{e}}$ s. Dès le XVII ${ }^{\mathrm{e}}$ s., arsenal est utilisé pour l'expression « dépôt d'armes ». D'après : Jana Řehořová : Emprunts Arabes en Français, Masarykova Univerzita, Pedagogická Fakulta, Katedra francouzského jazyka a literatury. Brno 2007. URL: is.muni.cz/ th/80324/pedf_m/DP-emprunts_arabes_en_francais-.txt - 201k, consulté le 8 septembre 2008. 
éléments pour la réalisation de voûtes semblerait le désigner comme le «malon de crotte ». Au XIX ${ }^{\mathrm{e}}$ s., Victor Leroy désigne en effet comme «crottes » les briques de $23 \mathrm{~cm}$ de long, $15 \mathrm{~cm}$ de large et de 2,2 à $4 \mathrm{~cm}$ d'épaisseur.

\section{Les autres modules rectangulaires}

Plusieurs formats de briques rectangulaires plus rares ne se rapprochent pas des trois précédemment identifiés. Il est probable que la proximité des sites de production, favorable à l'expérimentation, la multiplicité des ateliers, la diversité de la commande, l'empirisme des pratiques constructives aient conduit à la fabrication de séries du Mazeau, un lambeau de sol était revêtu de carreaux de $25 \mathrm{~cm}$ sur $13 \mathrm{~cm}$ épais de $3 \mathrm{~cm}$, portant sur leur face supérieure un décor estampé composé d'un motif cordiforme entourant le mot «bien». Il ne s'agit pas d'une pose à l'envers laissant apparaître la marque de fabrique car l'envers du carreau, non lissé est bien identifiable comme tel.

\section{Les modules hexagonaux}

Réputées caractéristiques des sols provençaux traditionnels, les tomettes sont relativement rares dans les secteurs fouillés, si ce n'est dans les niveaux de démoli-

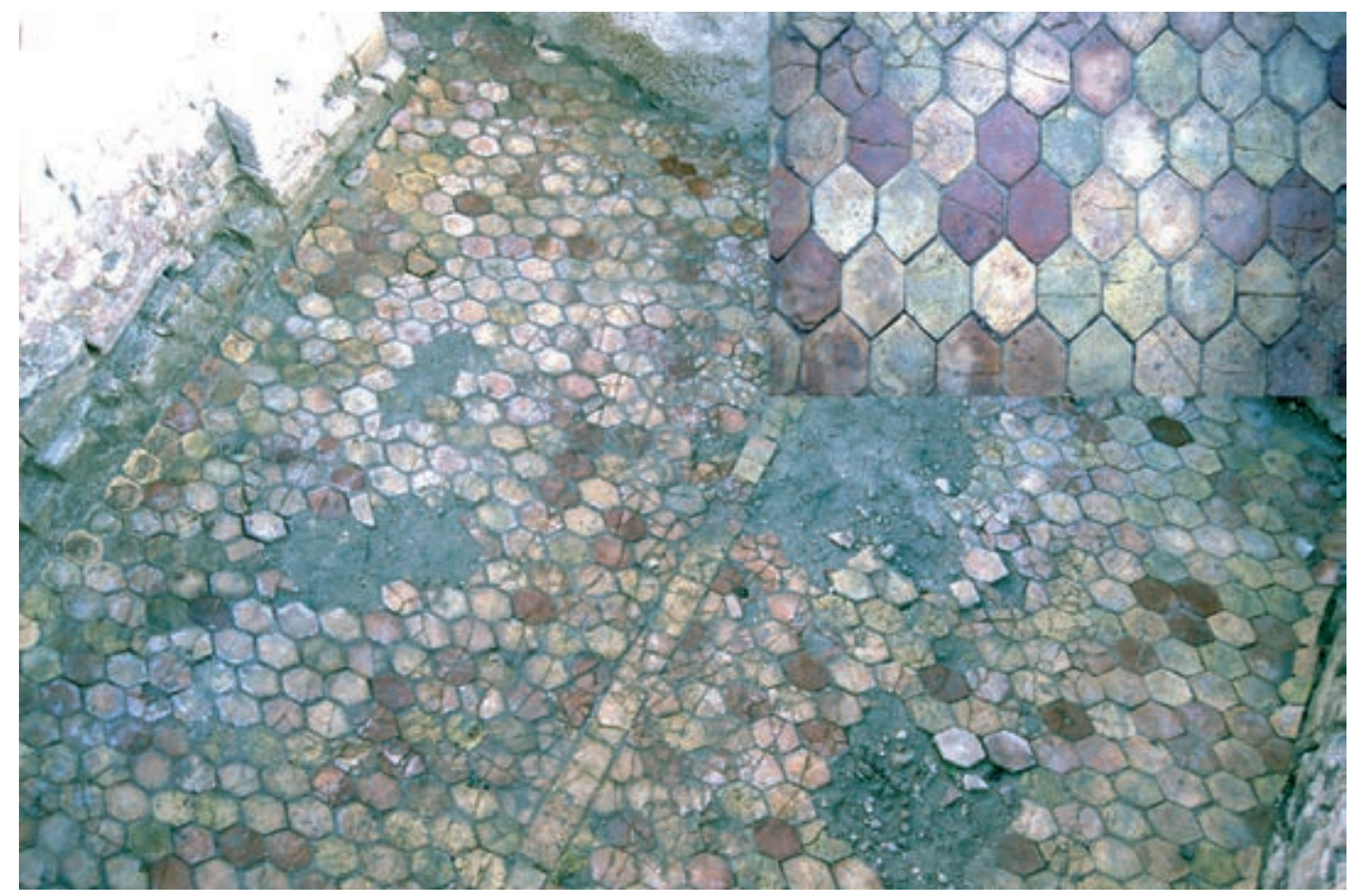

Fig. 80. Un sol carrelé de «navettes» dans le quartier de la Loge (cl. T. Maziers/Inrap).

limitées ou à l'utilisation inhabituelle d'éléments dans des ouvrages pour lesquels ils n'étaient pas destinés.

Ainsi près de l'Hôtel de Ville on trouve un sol de cave du début du XVIII ${ }^{\mathrm{e}}$ s., revêtu de carreaux de $22 \mathrm{~cm}$ de long, $8 \mathrm{~cm}$ de large et $3 \mathrm{~cm}$ d'épaisseur, dont le module est à rapprocher des «briques murettes» du XIX ${ }^{\mathrm{e}} \mathrm{s}$. (ibidem). Les modules $25 \mathrm{~cm}$ sur $12,5 \mathrm{~cm}$, ou $12 \mathrm{~cm}$ sur $6 \mathrm{~cm}$, égaux à $1 / 2$ mais plus petits que le type courant, ou encore des séries d'éléments de $26 \mathrm{~cm}$ sur $14 \mathrm{~cm}$ ont été vus une fois chacun pour la réalisation de sols près du Mazeau ou dans l'Agrandissement. Près de la cathédrale, un sol de la maison 7F, mal daté mais postérieur au $\mathrm{XVI}^{\mathrm{e}} \mathrm{s}$., est habillé de modules de $17 \mathrm{~cm}$ sur $13 \mathrm{~cm}$. Près tion contemporains. Ces observations laissent penser que ces éléments sont affectés préférentiellement aux sols des étages. Quelques exemples ont toutefois été relevés, témoignant, par leur caractère atypique, des évolutions de cette fabrication dont la standardisation ne semble intervenir qu'au XIX' s. Dans le quartier de l'Hôtel de Ville, un sol de cave daté du XVIII ${ }^{\mathrm{e}}$ s. est revêtu de tomettes de $9 \mathrm{~cm}$ de diamètre et de $2,5 \mathrm{~cm}$ d'épaisseur, et une autre cave est pavée de navettes avec un fil d'eau en malons rectangulaires. Au même endroit, ont été recueillis en remblai deux modules hexagonaux affectant la forme de navettes de $22 \mathrm{~cm}$ de long, et de 11 à $13 \mathrm{~cm}$ de large (fig. 80). Ces éléments ont été datés par le mobilier qui 
leur était associé de la fin du XVII ${ }^{\mathrm{e}}$ s. (Abel 1997, p. 38). Dans les textes, les «malons à six coins » ${ }^{153}$ ou « mallons de thomette du cartier de Séon ${ }^{154}$ sont mentionnés au sol des étages.

\section{Les carreaux vernissés et décorés}

Dans le quartier de l'Hôtel de Ville, des carreaux revêtus d'engobe et de vernis, vert et parfois incolore, de format carré de $12,5 \mathrm{~cm}$ de côté ont été trouvés dans des niveaux de démolition datés de la fin du XVII s. sassociés aux navettes décrites ci-dessus (Abel 1997, p. 38). Dans le même quartier (parcelle 387), un lambeau de carrelage de la fin du XVII ${ }^{\mathrm{e}}$ s. est composé de carreaux revêtus de vernis jaune de module $25 \mathrm{~cm}$ sur $15 \mathrm{~cm}$, qui semblent en situation de remploi car parfois posés à l'envers.

Quasi-absents des vestiges archéologiques du Moyen Âge les carreaux décorés restent extrêmement peu représentés à l'Époque moderne. Dans l'Agrandissement ont été découverts des fragments de carreaux de Delft datés du XVIII' s. (Abel 2001). Dans la chapelle des Pénitents blancs de la rue Trigance, des fragments de carreaux décorés catalans du XVII ${ }^{\mathrm{e}} \mathrm{s}$. ont été recueillis (Barra 2002). Ces éléments témoignent du raffinement du décor de certains espaces, mais s'éloignent du domaine des matériaux de construction stricto sensu.

\section{Les tuyaux}

Les prix-faits évoquent la fourniture de borneaux ou bourneaux pour conduire les eaux hors de la maison depuis les eyguiers. Il s'agit de tronçons de tuyaux en terre cuite vernissés à l'intérieur, de $7 / 8 \mathrm{~cm}$ de diamètre. Dans la rue des Treize-Coins, des canalisations modernes faites de borneaux de $45 \mathrm{~cm}$ de long chacun ont été observées.

\subsubsection{Les liants et les enduits (R. Thernot)}

Les liants sont facilement observable en fouille. Il est en revanche toujours plus difficile de leur faire correspondre des descriptions issues des textes d'archives.

\section{Le mortier}

Les mortiers sont souvent confectionnés avec un sable moins grossier qu'au Moyen Âge. Au XVIII ${ }^{\mathrm{e}}$ s., ils sont parfois moins durs et laissent transparaître la couleur jaune ou grise du sable. Lorsqu'il s'agit de créer

153 AD13 390 E 236, fol. 240v.

154 AD13 363 E 250, fol. 393, année 1715. une chape préparatoire à la pose d'un sol carrelé, le mortier est peu dosé en chaux afin d'absorber les déformations du sol et des murs. Dans les voûtes en briques des caves, on observe parfois, comme dans la cave de la parcelle $357 \mathrm{du}$ Mazeau, l'incorporation de particules minérales dures et noires dont l'origine est inconnue.

Les prix-faits précisent que le mortier doit être «bon » et fait de « chaux et sable ». Il est utilisé pour hourder les moellons, enduire les murs, dont les façades («Engranera le carrage à bon mortier, chaux et sable ...» ${ }^{155}$ ) et sceller les tuiles (tuilles amourteiras). La qualité du sable à utiliser est parfois précisée et plusieurs prix-faits stipulent que le sable doit être de mer ${ }^{\mathbf{1 5 6}}$. Il arrive que le commanditaire exige que la chaux soit «de tuillière de cette ville » ${ }^{157}$.

\section{Le plâtre}

Le plâtre est utilisé pour ses qualités de plasticité et d'adhérence. Le plâtre (gip) «blanc » ou « noir » apparaît dans les textes avec le mortier de chaux pour la confection des enduits («... comme aussy la murailhe du ciel ouvert dault en hault de platre ou de mortier au chois dudit Sieur Médicis... » ${ }^{\mathbf{1 5 8}}$ ). On le trouve signalé comme matériau au sol «... ladite salle est pavée de platre en mauvais état ${ }^{\mathbf{1 5 9}}$, ou encore comme bourrage entre les chevrons des planchers pour faire un «solier negat» ou liant des malons de couvert de la toiture «Les couverts seront de briques bien jointes de platre et les tuillères par dessus (...) bien jointes de mortier ${ }^{\mathbf{1 6 0}}$. Il intervient dans les enduits de giparie qui habillent les intérieurs, les cloisons (bugets), les plafonds, les cheminées et les escaliers à ossature de bois. Le plâtre est dans certains cas préconisé associé à la chaux et au sable pour la confection des enduits intérieurs ${ }^{\mathbf{1 6 1}}$.

Le plâtre blanc et le plâtre noir sont souvent cités conjointement dans les prix-faits montrant que leurs usages diffèrent sur le chantier, mais ces derniers ne sont pas explicités. Il est vraisemblable que le plâtre blanc soit utilisé pour la finition et le noir pour le scellement et le bourrage des ouvrages.

Le plâtre provient «de Corporières » lorsqu'une mention d'origine est préconisée, mais on ne connaît pas pour l'heure la localisation précise correspondante. Sur

155 AD13 362 E 125, fol. 919v, le 4 mai 1672.

156 AD13 363 E 250, fol. 393, année 1715.

157 AD13 364 E 299, fol. 615.

158 AD13 360 E 35, fol. 719v.

159 AD13 361 E 117, fol. 540, 1734.

160 AD13 364 E 299, fol. 615.

161 AD13 391 E 406, fol. 199. 
la carte de Cassini, un lieu-dit « quartier de Carpoulier» apparaît au nord-est du village des Camoins.

Victor Leroy signale la distinction de couleur entre le plâtre blanc de Roquevaire et les plâtres gris des Olives, des Caillols, d'Allauch, ou des Camoins. Hormis Roquevaire plus éloigné, les autres lieux d'extraction de gypse sont donc concentrés dans un rayon de 3 kilomètres à l'est du territoire communal de la ville.

\section{Le mortier hydraulique}

Le mortier hydraulique est obtenu par adjonction de tuileau ou de pouzzolane, conférant au mélange une fois sec des propriétés de résistance et d'étanchéité. Ces propriétés résultent des réactions dites «pouzzolaniques » intervenues entre la chaux, les silicates et les aluminates contenues dans l'argile cuite ou la pouzzolane. Ce mortier apparaît sous la dénomination de «batun ou batum » dans les textes. D'après F. Mistral, le batun est un « corroi de mortier battu» (Mistral 1878, p. 247). Parfois la poudre de tuileau ou de pouzzolane semble être désignée sous ce nom puisqu'il est cité dans l'énumération des matériaux à fournir. Le mélange est utilisé pour le revêtement interne des cuves et l'isolation des ouvrages exposés à l'humidité. Ainsi dans le prix-fait conclu entre un certain Antelme et le maçon pour des travaux dans le logis de la Taulisse, il est stipulé que la cour sera recouverte de ce type de mortier («... réparé le pavé dud. ciel ouvert avec du battum pour empecher que les eaux pluviales ny croupissent ... » ${ }^{\mathbf{1 6 2}}$ ). La chapelle des Pénitents à côté de la cathédrale voit ses fondations revêtues d'une couche de mortier de pouzzolane pour lutter contre l'humidité. Les cuves à huile sont enduites de batum $^{\mathbf{1 6 3}}$, à l'instar de celles revêtues d'enduit de mortier de tuileau, retrouvées dans l'une des caves des maisons de la rue de Olives.

\subsubsection{Le bois (R. Thernot)}

Les informations concernant l'usage du bois dans la construction moderne sont d'ordre différent suivant qu'elles proviennent de la fouille ou de l'étude des textes. Sur les sites, c'est essentiellement la présence de pieux sous les fondations et de dispositifs d'étaiement des murs de soutènement qui est relevée. Les fondations sur radier de blocs de pierre reposent dans certains cas sur des semis de pieux destinés à stabiliser les sols, particulièrement sur les terrains instables proches du port. Le creusement des caves en sous-œuvre impose la mise en place de systèmes d'étaiement provisoire mais dans

162 AD13 360 E 75, fol. 561. 163 AD13 364 E 274, fol. 653v. certains cas, la construction des murs de soutènement intègre des bois noyés dans le blocage.

Dans les documents d'archives, c'est l'origine et l'usage des bois qui sont décrits pour les ouvrages de charpenterie et de menuiserie. Les dénominations du bois de charpente dans les prix-faits concernent l'essence avec le bois de sap, mentionné fréquemment pour les poutres, et le bois du Rauve ou bois de Rones, transporté par flottage. Les travettes (traveto) posées sur les poutres sont en pin. Le noyer est cité pour la menuiserie des portes et des fenêtres, plus fréquemment réalisée en «bois blanc», dans un rapport de proportion de un à six. Le chêne et le mesle (mélèze), très rarement cités, sont aussi employés dans la menuiserie. À noter aussi l'utilisation de pieux importés de pitch pin ${ }^{\mathbf{1 6 4}}$ sous une fondation de façade de la rue Sainte-Claire, au nord de la ville.

\subsection{Les techniques de constructions modernes (R. Thernot)}

Les techniques employées dans la constructions sont variable suivant la nature des espaces et, bien sûr, des matériaux employés.

\subsubsection{La maçonnerie}

On distinguera ici les techniques employées dans les fondations des immeubles et le travail en élévation qui nécessite un soin plus important dans la mise en œuvre.

\section{Les fondations}

Les fondations modernes sont construites soit en blocage, soit en grand appareil. La préexistence de fondations plus anciennes dont la solidité ou la largeur ne sont pas compatibles avec la nouvelle construction, et l'instabilité du sol, sont les deux principales contraintes techniques que les constructeurs ont à affronter. Dans le premier cas, deux solutions se présentent : la reconstruction complète après démolition, ou la mise en place d'un radier de grand appareil de largeur adaptée posé sur l'ancienne fondation, éventuellement soutenu par des pieux de bois. Dans le second cas, c'est également la solution du radier de blocs posé sur un semis de pieux enfoncés dans le sol qui est adoptée.

Les fondations en blocage font appel à des éléments très hétéroclites, en particulier des remplois de pierres récupérées lors de démolitions. Le mortier est souvent de faible dureté. La construction en tranchée se traduit

164 Pin d'Amérique du nord, côte est (détermination F. Guibal, IMEP), Sillano et al. 2007a, p. 111. 


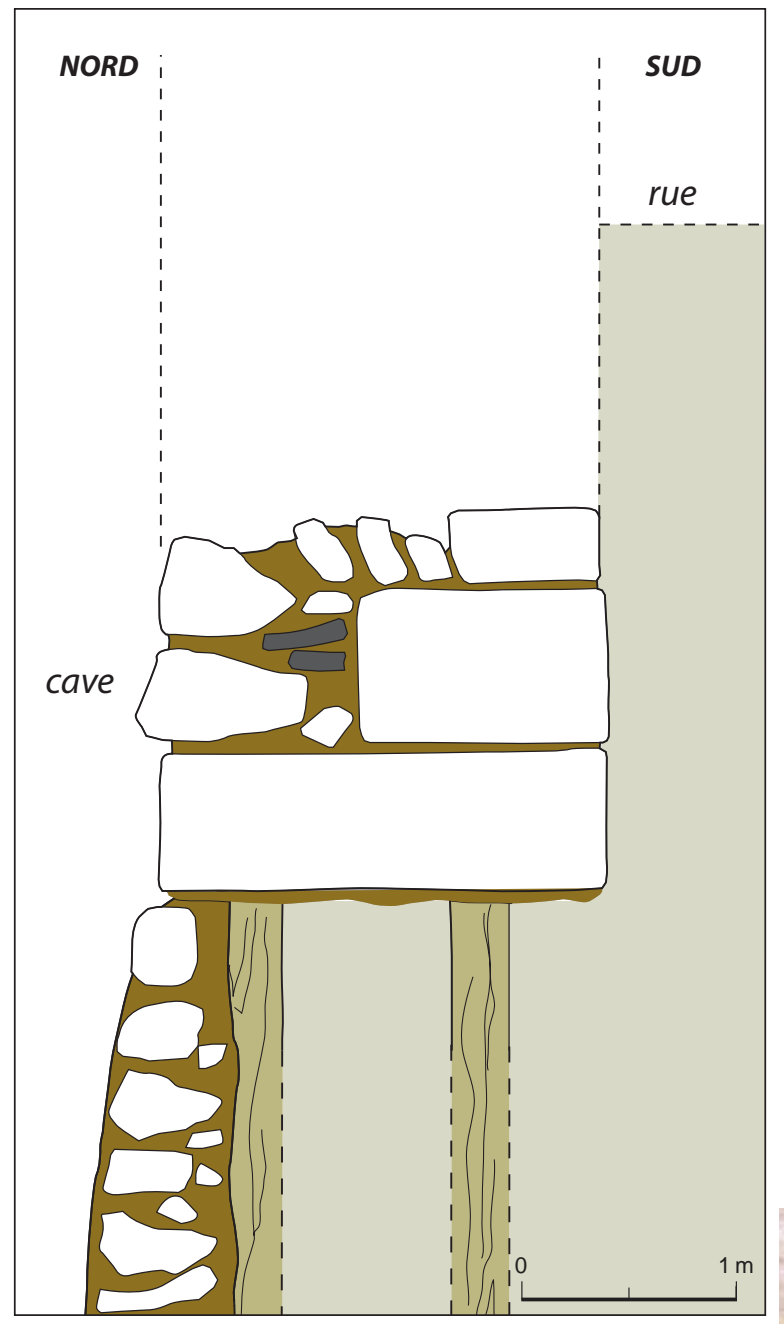

souvent par une alternance d'assises de moellons bruts et de lits de mortier débordants. La reconstruction de la maison de Catherine Vias en 1668 près du Mazeau implique d'après le prix-fait la mise en place de fondations nouvelles après démontage des anciennes, mais cette reconstruction totale n'a semble-t-il pas été effective (cf. infra $\S \mathrm{II}, 2,3.4 .8$.). Dans l'Agrandissement, des fondations de la fin du XVII ${ }^{e}$ s. sont construites en blocage parementé de façon irrégulière, à l'exception d'un mur dont la fondation est assisée. Dans le cours du siècle suivant, les fondations sont toujours fréquemment en blocage enduit.

Les radiers de blocs sont formés par une file d'éléments en pierre de La Couronne, jaune ou rose taillés, larges de 50 à $60 \mathrm{~cm}$ et épais de $25 \mathrm{~cm}$ en moyenne, posés en panneresses-parpaings. Ils reposent sur des fondations médiévales, comme sur la parcelle $401 \mathrm{du}$ quartier du Mazeau, ou sur une file de pieux de bois, comme cela a été pratiqué sur la parcelle 373 du même secteur (fig. 81). Sur ces arases sont construites des maçonneries comportant le plus souvent un parement en grand appareil et un blocage lié au mortier, enduit à l'intérieur.

Dans l'Agrandissement, les fondations de l'auberge du Petit Saint-Jean, mise en place dans le cours du XVIII ${ }^{\text {s. }}$., se distinguent par la qualité de leur construction. Un puissant radier de blocs de calcaire de

Fig. 81. Coupe sur une fondation moderne en blocs taillés reposant sur des pieux en bois (DAO B. Sillano/ Inrap).

Fig. 82. Arc de décharge sur un puits de l'Alcazar (cl. T. Maziers/Inrap)

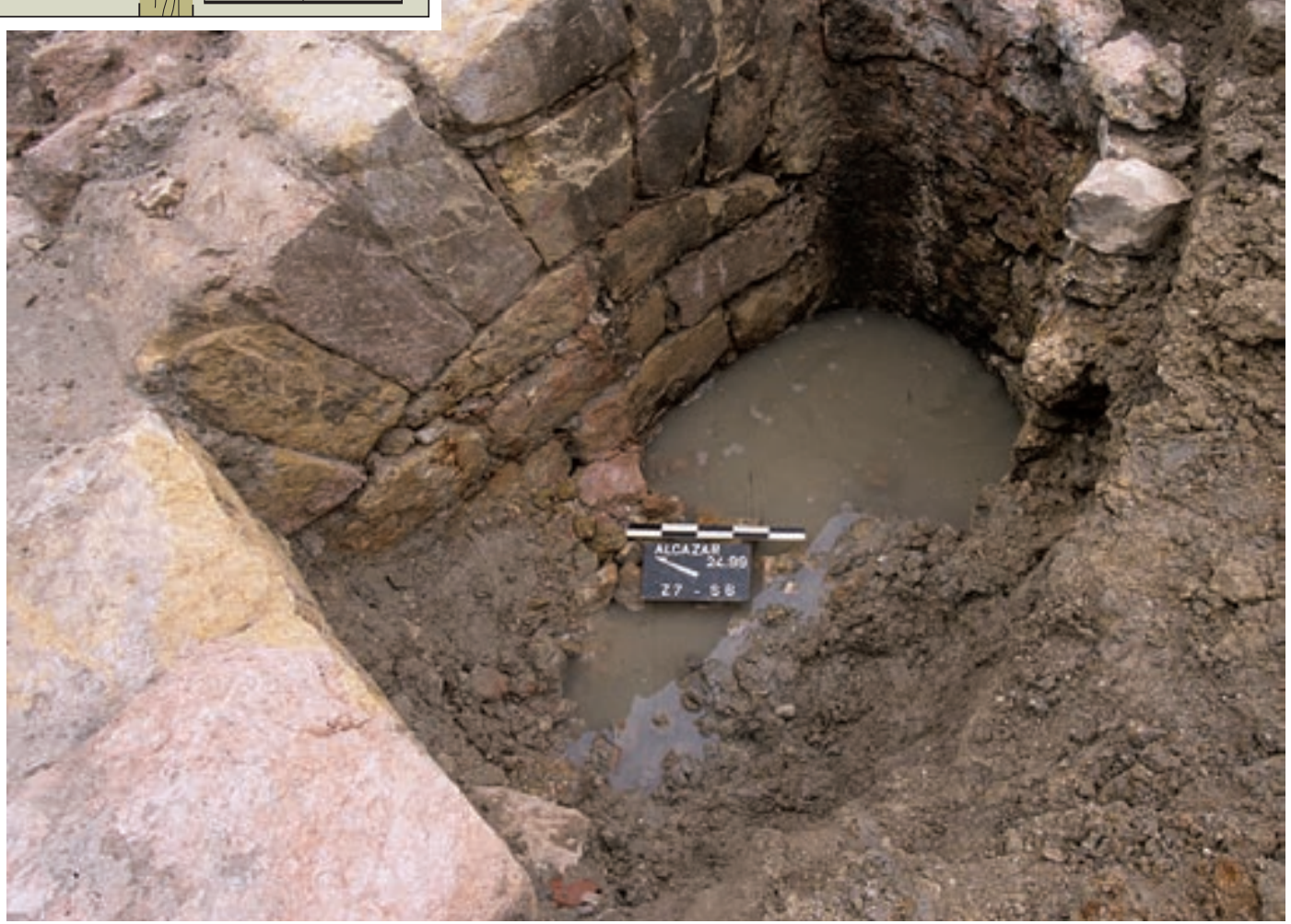


La Couronne est installé en fond de tranchée et reçoit une fondation maçonnée large de $1 \mathrm{~m}$, liée avec un mortier dur. Un puits antérieur est enjambé par un arc de décharge en grand appareil relié au radier (fig. 82).

Dans les textes, les précisions sur les fondations sont laconiques et se limitent à la recommandation du principe de «fonder sur le ferme » et à mentionner une épaisseur de mur ou la profondeur totale. Ainsi on peut lire que le maçon doit «... bastir de pierre de tailhe le caraige de lad. maison depuis le fondement jusques a la seconde codière et plus hault sy bon semblera audict Reynaudet comme aussy le coing dicelle dhault en haut jusques au thoect sive couvert de la ditte maison de la dite pierre de tailhe. Lequel fondemens la prendra jusques au ferme mesmement sur le coing ... ${ }^{\mathbf{1 6 5}}$. Au XVII ${ }^{\mathrm{e}} \mathrm{s}$., les notations ne sont pas plus précises : «se fera une autre murette au maguesin de la guirlande pour la séparation de la montée, laquelle murette seslevera jusques au couvert qui sera fondue sur le ferme et despesseur suffisante... ${ }^{\mathbf{1 6 6}}$. En 1675, un maçon doit ancrer les fondations d'une maison de l'Agrandissement à 10 pans $(2,5 \mathrm{~m})$ de profondeur ${ }^{\mathbf{1 6 7}}$. Les fondations retrouvées sur la parcelle concernée ne semblent pas correspondre à la prescription du prix-fait.

\section{Les élévations}

Les élévations sont construites en maçonnerie parementée en grand appareil ou en blocage enduit de mortier. Le blocage interne fait appel à des moellons et des cailloux non retouchés nommés (pierre) pastouire (pastouiro $=$ moellons/blocage de moellons, Mistral 1878, p. 496), utilisables uniquement noyés dans le mortier. C'est dans le blocage que sont recyclés les matériaux extraits des ouvrages démolis.

Dans la maison de Catherine Vias, rue de la Guirlande, le maçon doit monter en façade des murs parementés d'un pan de pierre de taille et d'un pan de maçonnerie ${ }^{\mathbf{1 6 8}}$ et c'est effectivement un parement de blocs taillés de tuf, de grès et calcaire de La Couronne, qui a été mis en place à l'extérieur et un blocage à l'intérieur, pour une largeur totale de $50 \mathrm{~cm}$.

Le prix-fait précise parfois l'épaisseur et la diminution de celle-ci en fonction de la hauteur. Ainsi en 1696, Pierre Mesnier exige que les murailles aient « deux pans despesseur montées en diminuant de ung dousième de pan par canne de bonne pierre de roche de la garde aux fondements, avec de bon mortier dont le sable sera de

165 AD13 360 E 33, fol. 296, 1597.

166 AD13 393 E 82, fol. 715.

167 AD13 390 E 236, fol. 191.

168 AD13 393 E 87, fol. 580. la mer enduitte dedans et dehors et la chaux des enduis sera de tuillière de cette ville ... ${ }^{\mathbf{1 6 9}}$.

Les façades en blocage sont enduites de mortier et le terme « engrana » exprime cette action. Pour l'intérieur, les contractants utilisent le mot «aplaner» (aplana: lisser/Mistral 1878, p. 112) pour désigner l'action de lisser au plâtre ou au mortier les murs : «Engranera le carage à bon mortier, chaux et sable tout le dedans de lad. maison aplané à point de blanchir» ${ }^{\mathbf{1 7 0}}$; «toutes les murailles seront aplanées par dedans et le carage engrané par dehors ${ }^{\mathbf{1 7 1}}$.

Les façades ou parties de façade en pierres de taille sont construites avec parcimonie. Ainsi, le maçon Jean Bonnet doit-il construire sur le Cours une maison pour François Chaurousset en $1675^{172}$ dont « tout le carage du cousté du cours sera de pierre de tailh conforme a lad. maison des pères missionaires et le carage du couste de lad. rue Saint Jean sera de pierre de tailh jusques au premier courdon de coudière ensemble tous les fenestrages et contours de coudières de chaque estage dud. cousté de la rue seront aussi de pierre de tailh et le reste dud. carage sera de pierre chaux et sable ... ». La façade la plus en vue est entièrement en pierres de taille, tandis que la façade sur la rue adjacente en pierres de taille au rez-de-chaussée est enduite au niveau des étages. Seuls les encadrements de baies doivent être tous en pierre. Sur des artères de moindre importance, la même hiérarchie est retrouvée comme dans la maison faisant le coin de la rue de la Guirlande et de la rue de la Taulisse que fait reconstruire Catherine Vias en 1668.

Dans d'autres situa9tions plus modestes, seules les «coudières »-les appuis- sont en pierre mais les «fenestres faictes d'une croizière et demi de masonnerie et giperie $\gg{ }^{173}$. Enfin, les coudières aussi peuvent être réalisées en plâtre additionné de tuileau «à façon de tailhe, et ce de bon gip avec du battum s'entend toute la largeur de lad. maison ${ }^{174}$. La pierre de taille utilisée doit être neuve.

\subsubsection{Les sols}

Deux grandes catégories de sols « construits » ont été observés : les sols à galets ( « calades ») et ceux avec des carreaux de pavement.

169 AD13 364 E 299, fol. 615.

170 AD13 362 E 125, fol. 919v.

171 AD13 390 E 236, fol. 240v : prix-fait pour Alexandre Evesque contre Jean Bonnet.

172 AD13 361 E 62, fol. 100v.

173 AD13 351 E 962, fol. 719.

174 AD13 391 E 383, fol. 214. 


\section{Sols caladés}

Certains sols de caves et de rez-de-chaussée sont revêtus d'un pavage de cailloux et de galets nommé «calade » (fig. 83). Ce mode de revêtement d'origine médiévale perdure jusqu'à $\mathrm{XIX}^{\mathrm{e}} \mathrm{s}$. comme en témoignent deux exemples de sols de rue retrouvés dans la rue Four-du-Chapitre. Toutefois, les calades des caves et des rez-de-chaussée tendent à être remplacées à la fin du XVII ${ }^{\mathrm{s}}$ s. par les sols carrelés.

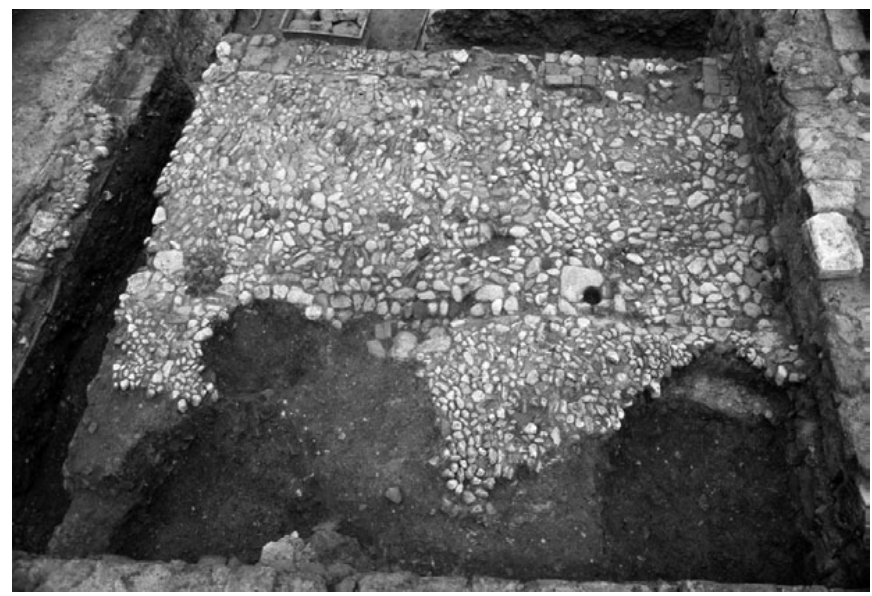

Fig. 83. Exemple de sol caladé dans le quartier de la Loge (parcelle 386) (cl. M. Derain/Inrap).

\section{Sols carrelés}

Un des exemples les plus précoces de sol en terre cuite recensés à l'Époque moderne semblerait être dans le bourg de Morier, un sol postérieur au $\mathrm{XVI}^{\mathrm{e}}$ s. et antérieur au milieu du XVII ${ }^{\mathrm{e}}$ s., dont il ne reste que les empreintes affichant un module de $20 \mathrm{~cm}$ sur $15,5 \mathrm{~cm}$ (parcelle 20, cf. infra § II, 3, 3.1.3.). La récupération des éléments ne permet pas d'assurer qu'ils étaient en terre cuite, cependant les dimensions sont compatibles avec ce matériau, plus qu'avec des dalles de pierre. Un autre se trouve sur la place du Petit-Mazeau, des carreaux de $26 \mathrm{~cm}$ par $12,5 \mathrm{~cm}$ et $3 \mathrm{~cm}$ d'épaisseur, d'une datation peu assurée mais ancienne (espace 6, cf. infra $\S$ II, 2, 3.1.). Les autres sols carrelés retrouvés se mettent en place entre la fin du XVII ${ }^{e}$ s. et le XVIII ${ }^{e}$ s. dans les rez-de-chaussée et les caves, remplaçant les calades et les sols en terre battue.

Le sol d'une tarasse au dernier étage de la maison construite en 1637 près du Mazeau est logiquement recouvert de malons ${ }^{175}$.

175 AD13 360 E 72, fol. 360.

\subsubsection{Les escaliers}

Les visettes (visèto: escalier en limaçon, Mistral 1878, p. 1133) désignent des escaliers dans les prix-faits. Il s'agit en principe d'escaliers en vis de tradition médiévale, mais vraisemblablement parfois d'escaliers rampes sur rampe comme l'indiquent les mentions de balustres, de longueurs et largeurs. Les deux solutions sont économes en espace et en matériaux. Ils sont construits en bois et en maçonnerie le plus souvent de plâtre mais

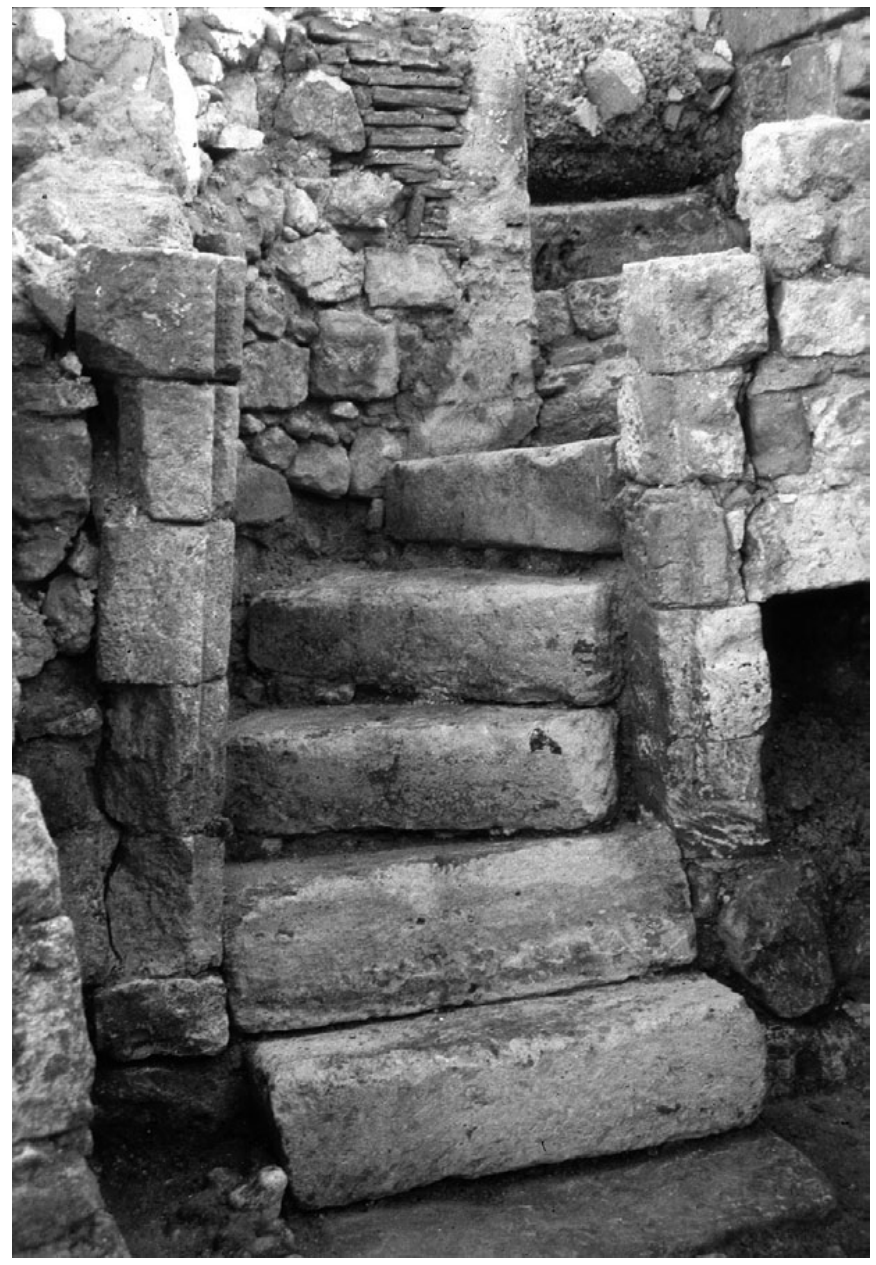

Fig. 84. Départ d'escalier en pierre de taille dans une cave du quartier de la Loge (cl. M. Derain/Inrap)

parfois en pierre de taille. La main courante et les balustres sont également en pierre ou en giparie. Les contremarches des parties maçonnées sont revêtues de bois. La volée de marches qui descend à la cave est en pierres de taille afin de résister à l'humidité (fig. 84), de même que la partie d'escalier naissant au rez-dechaussée car étant «a veue de la porte sera en pierre de tailhe. ». Sur la parcelle 360 du quartier du Mazeau, on monte à l'étage par quatorze marches dont sept en pierre 
et sept en giperie et on descend à la cave par des marches en pierre ${ }^{176}$. Le nombre de marches entre les étages est en moyenne de quatorze à seize pour les étages inférieurs, y compris la cave, le dernier étage étant plus bas, onze ou douze degrés sont parfois suffisants.

Rares sont les mentions d'escaliers comptant plus de vingt degrés entre les étages. Les parcelles 394 ou 399 de la rue de la Guirlande où s'établissent de vastes et riches demeures comportent respectivement vingt et vingtquatre marches pour rallier le premier étage, signalant l'opulence des commanditaires qui peuvent -et doiventtenter de rapprocher leur résidence du modèle de l'hôtel aristocratique avec sa cage d'escalier monumentale.

Les fouilles ont livré des escaliers de cave, généralement en pierre de taille de La Couronne, ainsi que, dans des remblais de démolition, quelques marches en pierre portant noyau. Les hauteurs relevées sont de l'ordre de 0,20 m, ce qui semble correspondre aux hauteurs d'étage de douze pans $(3 \mathrm{~m})$ à quatorze pans $(3,5 \mathrm{~m})$ des maisons courantes indiquées dans certains textes.

\subsubsection{La charpenterie et la couverture}

Point d'ouvrages de charpenterie complexes à Marseille, mais des planchers et une toiture construits suivant la même technique : poutres ancrées dans les murs mitoyens soutenant les travettes (bois d'enfûtage) qui reçoivent la chape de mortier ou de plâtre sur laquelle sont éventuellement posés les carreaux ou les tomettes. En toiture, les travettes sont recouvertes de malons de couvert plâtrés ou de planches (tables dans le rapport de future cautelle $\left.{ }^{177}\right)$ et de tuiles scellées au mortier. Les calamands $($ calaman $=$ poutre, Mistral 1878, p. 423) ou sommiers, les pannes de toiture et les solives de plancher, sont « ronds d'une main ouvert» (soit un pan ou $25 \mathrm{~cm}$ ), ou «carrés dung pan et quart dhauteur et une main ouvert d'épaisseur » (soit $32 \mathrm{~cm}$ de haut et $25 \mathrm{~cm}$ de large environ). Les poutres sont distantes de 1,5 m entre elles. Le dénombrement de deux à six poutres par niveaux correspond aux longueurs des bâtiments variant entre 4,5 m et $10 \mathrm{~m}$ de profondeur. La cherté du bois conduit à utiliser aussi les dosses, pièces sujettes aux déformations, nommées escoudens dans les textes du XVII et du XVIII' s., comme bois d'enfûtage.

\subsubsection{Les caves}

La construction des caves se généralise à l'Époque moderne. Les maisons nouvellement construites en possèdent presque toute une et les maisons anciennes

176 AD13 353 E 95, fol. 76.

177 AD13 391 E 406, fol. 162v.

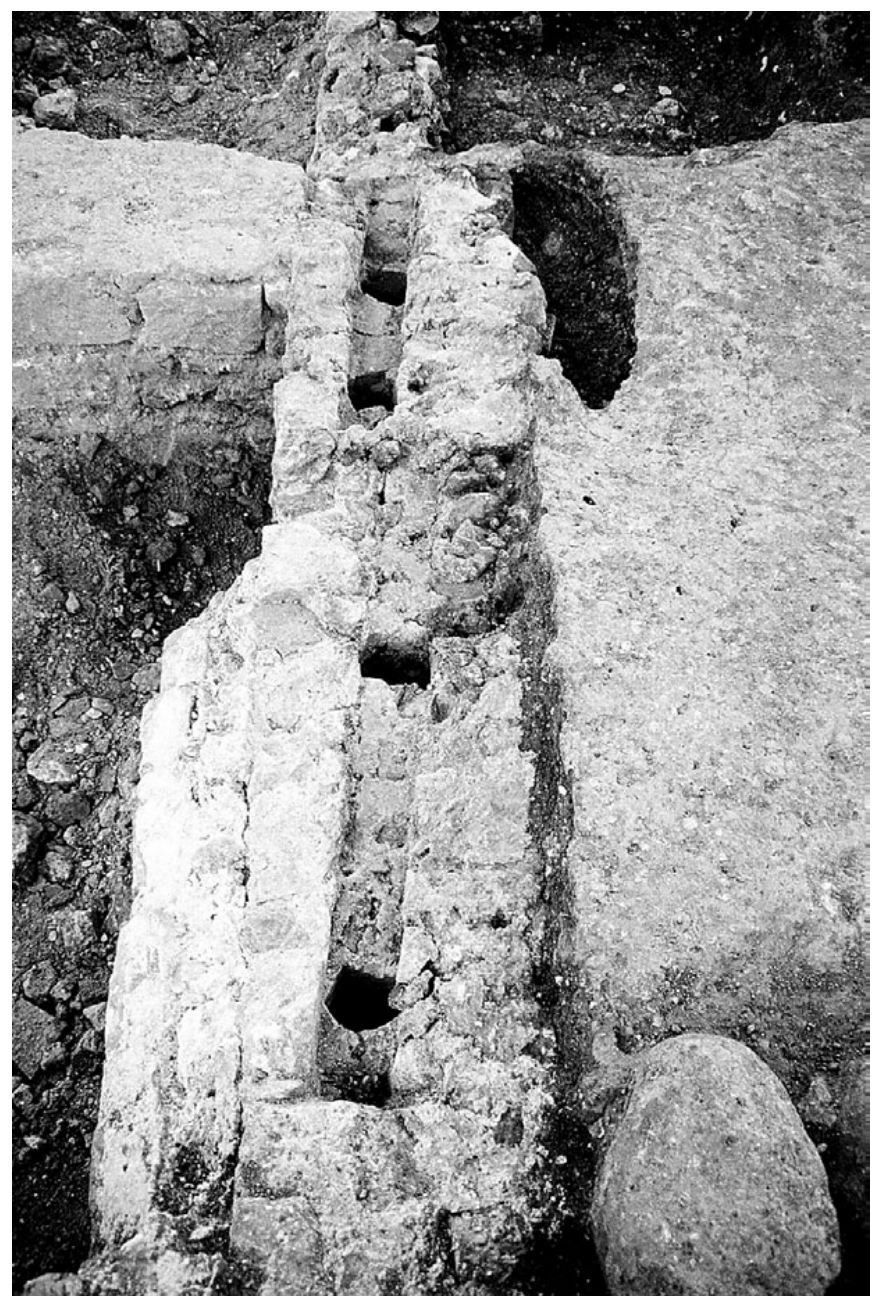

Fig. 85. Série de pieux en bois noyés dans le blocage d'un mur de cave témoignant des dispositifs d'étaiement lors de la construction en sous-œuvre des caves (cl. M. Derain/Inrap).

s'en dotent grâce à des techniques de construction en sous-œuvre.

Dans les constructions nouvelles, le creusement d'une cave nécessite la mise en place d'étaiement des terrains riverains de l'excavation. Ainsi dans le prix-fait signé par Mathieu de Madières avec Toussaint Simian en 1662 pour la reconstruction de sa maison, il est précisé que le maçon « apontellera et soubstiendra lesdits bastiments et ceux des voisins sy besoing et affin qu'il ne puissent souffrir ni arriver perils ni dommages et respondra du tout de son propre, ... ${ }^{178}$ (apountela $=$ étayer, Mistral 1878, p. 114). On relève plusieurs exemples de murs de soutènement en maçonnerie ennoyant des pieux parfois reliés par des pièces horizontales (fig. 85). Les murs sont construits par bandes parallèles verticales de 0,50 à 1,30 $\mathrm{m}$ de large. Les pièces d'étaiement dont le négatif

178 AD13 393 E 82, fol. 715. 


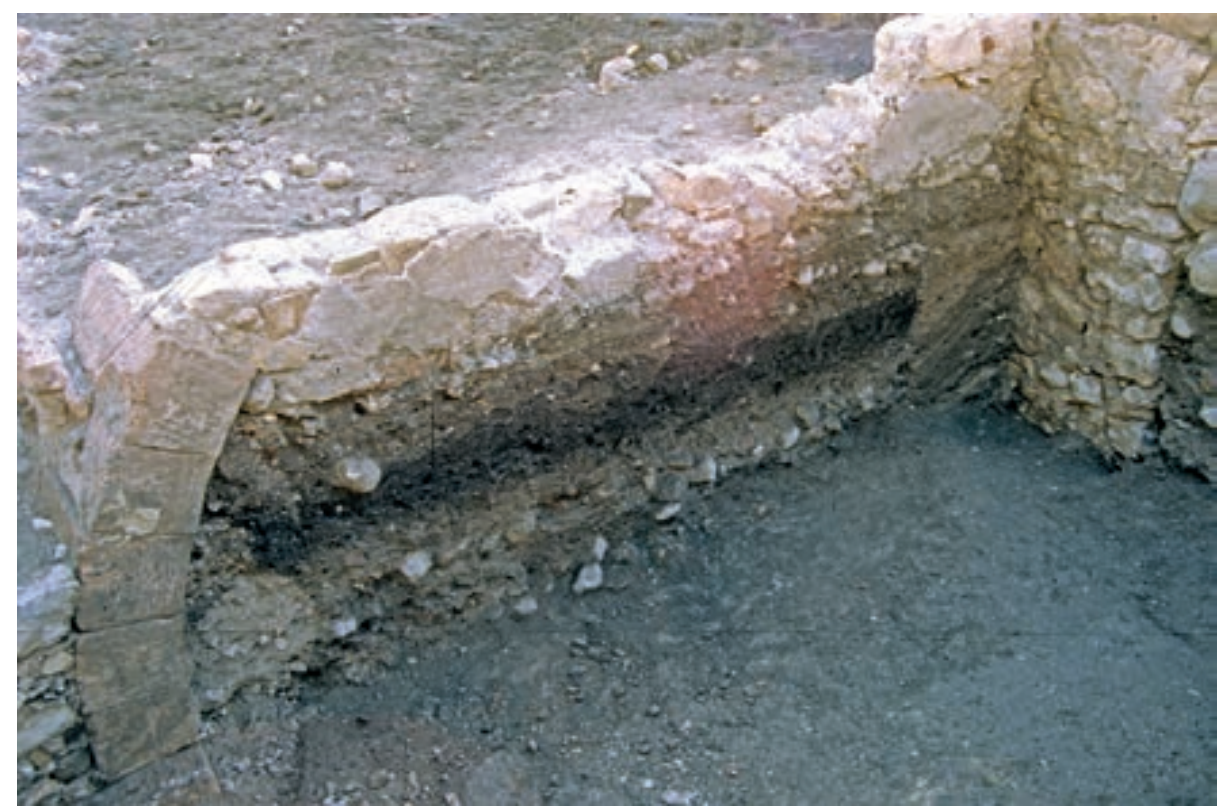

Fig. 86. Arc de décharge construit en prévision du creusement d'une cave inachevée sur la fouille de la place Bargemon (cl. M. Derain/Inrap).

apparaît dans le mortier sont des bois de section rectangulaire ou carrée de 10 à $15 \mathrm{~cm}$ de côté.

L'exemple de creusement de cave en sous-œuvre le plus révélateur de la procédure est fourni par une cave inachevée située dans le quartier de l'Hôtel de Ville, à l'angle de la rue de la Guirlande et de la rue de la Taulisse ( $c f$. infra $\S$ II, 2, 3.3.6.). Dans un premier temps, des puits permettant la construction de piliers en grand appareil ont été creusés à la périphérie et au centre de la parcelle. Ensuite, des arcs de décharge en grand appareil ont été lancés entre les piliers sous les murs de refend (fig. 86). Après la construction de tous les éléments assurant la reprise des descentes de charges, le volume de la cave peut être excavé et les bermes sont stabilisées avec des murs de soutènement en blocage. Dans le cas présent seul un tiers de la surface de la cave a été creusé, laissant inachevés les travaux des autres secteurs.

Les extensions de caves sous la rue sont également l'occasion pour les maîtres maçons de faire preuve de leurs compétences. Ces travaux qui empiètent sur l'espace public sont vraisemblablement encadrés par des réglementations qui limitent à la moitié de la largeur de la rue la longueur de l'extension, comme le laisse entendre en 1637 un prix-fait qui précise que pour la construction d'une cave "l'entrepreneur prendra de toute parts et jusques a demy rue comme il est permis ${ }^{179}$.

Ces travaux impliquent la mise en place d'un arc de décharge en grand appareil à l'aplomb de la façade sur

179 AD13 360 E 72, fol. 360.

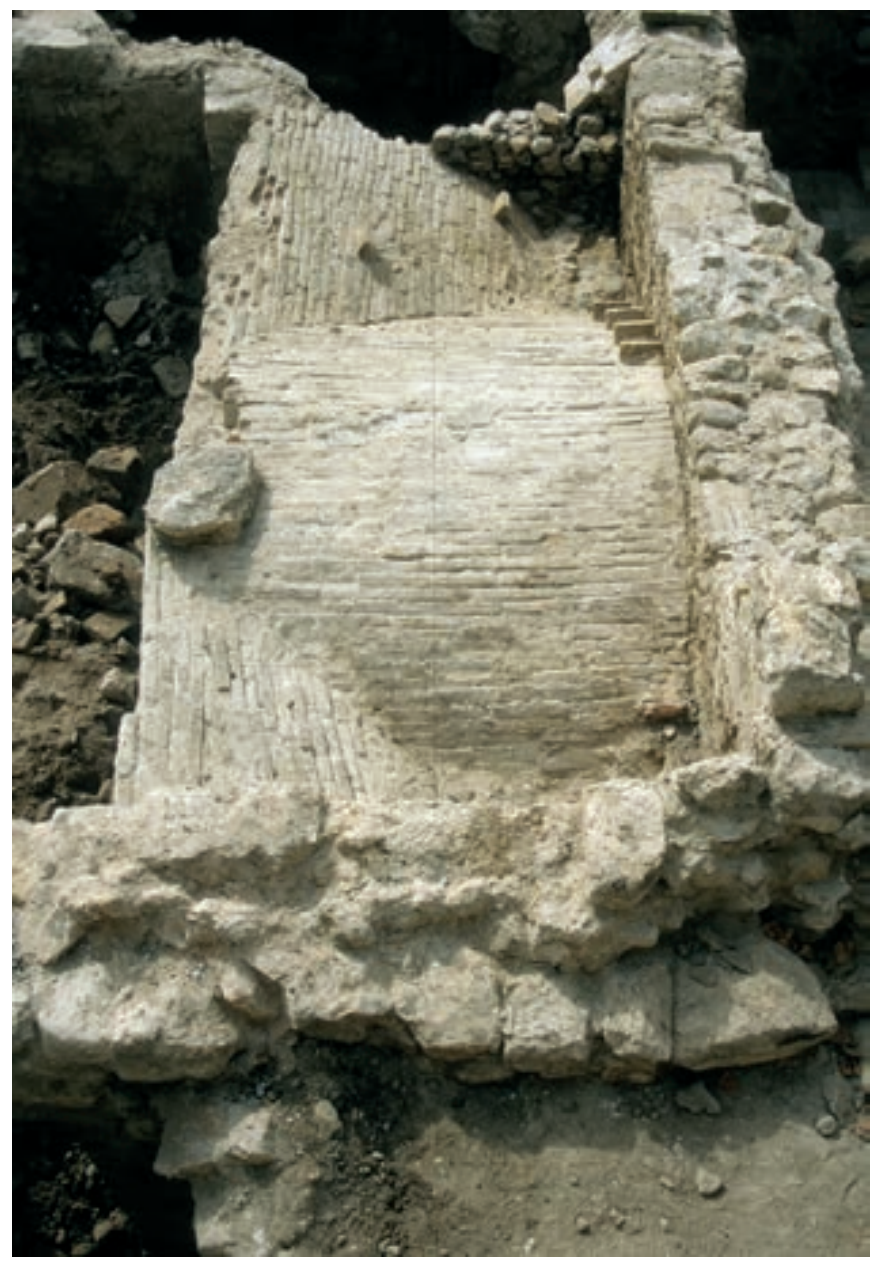

Fig. 87. Extrados d'une voûte d'arêtes en briques sur une cave (cl. M. Derain/Inrap) 


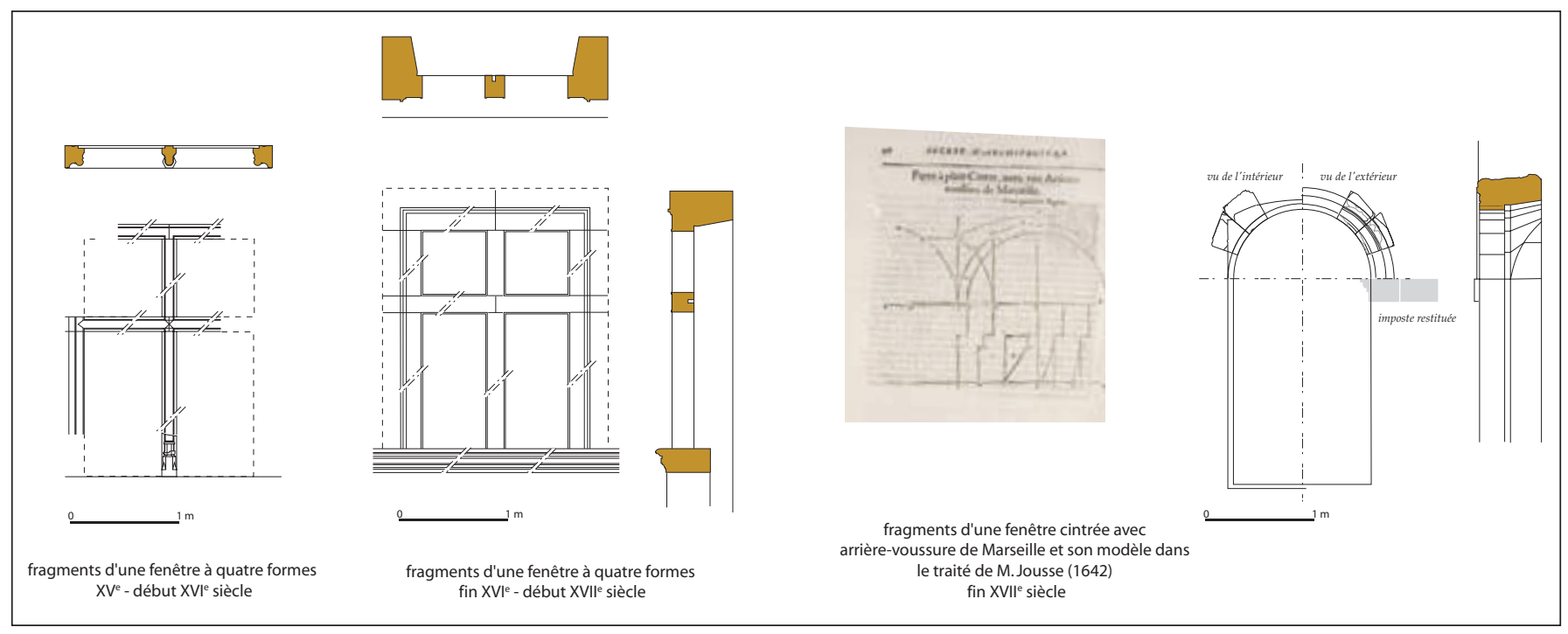

Fig. 88. Trois baies provenant de façades démolies (DAO R. Thernot/Inrap).

rue. Ensuite est effectué le creusement de l'extension avec confortement des terres, la mise en place d'une voûte et d'une trémie affleurant au niveau de circulation. Ces extensions sont motivées par la possibilité d'ouvrir le volume de la cave directement sur la rue, et de transférer des charges sans passer par le rez-de-chaussée et l'escalier. Modification d'activité, difficulté d'entretien des structures exposées aux infiltrations et à la circulation, ou nouvelle réglementation, quel que soit le motif, elles sont toutes remblayées dans le cours du XVIII ${ }^{\mathrm{e}} \mathrm{s}$.

Les caves retrouvées sont toutes voûtées même si des indices laissent penser que des planchers ont pu en couvrir certaines, en raison du niveau de leur sol primitif plus élevé. Les voûtes en berceau ou à pénétration sont en briques et reposent sur des impostes et des culots ancrés dans les murs ou sur des piliers axiaux et les murs d'échiffre des escaliers d'accès (fig. 87).

Dans les caves, les sols - caladés ou carrelés - sont dotés de deux contrepentes convergeant vers un fil d'eau central lui-même en pente, conduisant les eaux de ruissellement - infiltrations ou épandages accidentels - vers une auge monolithique placée contre l'un des murs. Ce dispositif est signalé à Aix-en-Provence dès le $\mathrm{XV}^{\mathrm{e}} \mathrm{s}$. où il est cité dans les prix-faits comme d'origine piémontaise (Bernardi 1995, p. 366-367).

\subsection{La baie et son évolution ( $R$. Thernot avec la coll. de M. Vacca Goutoulli et L. Duval)}

Les principaux chantiers de fouille marseillais ont abordé le bâti médiéval et moderne après une phase de dérasement des élévations, chacune d'origine différente : restructuration urbaine du second empire autour de la cathédrale, destructions au cours de la seconde guerre mondiale pour le quartier du Mazeau, et démolition récente pour l'îlot de l'Alcazar. Ces dérasements ont bien évidemment fait disparaître les façades des bâtiments étudiés. Cependant des blocs provenant d'anciennes façades démontées avaient déjà fait l'objet de remplois dans de nouvelles structures épargnées et livrent indirectement des informations sur des bâtiments effacés du paysage urbain depuis longtemps (fig. 88). Les maisons du quartier du Mazeau fournissent ainsi trois exemples de baies caractéristiques de l'évolution des formes du décor et des techniques de stéréotomie entre la fin du Moyen Âge et l'Époque moderne. La situation en remploi des blocs, offrant la possibilité de démonter les structures et d'observer les blocs sur toutes leurs faces, ouvre à une approche associant l'étude des techniques et celle des formes.

\subsubsection{La baie dans les documents d'archives}

Dans les documents d'archives, les mentions concernant les fenêtres se résument à une typologie déclinant les fenêtres à crozières/croisières correspondant aux fenêtres à quatre formes, avec meneau et croisillon, éléments de remplage désignés sous le nom de crousillon, et les bastardes plus petites, sans doute sans remplage. Le remplage de pierre peut être remplacé par une armature de menuiserie avec quatre volets intérieurs qui constituent « une fermure de bois blanc à quatre jours ». Les dimensions des fenêtres à quatre formes, souvent carrées, sont de l'ordre de six à sept pans soit 1,50 m à $1,75 \mathrm{~m}$. Les baies de moindre dimension mesurent de deux et demi à quatre pans $(0,62$ à $1 \mathrm{~m})$ de large et de quatre à six pans de haut (1 à 1,5 m). Parfois, des fenêtres 
larges de six pans et hautes de quatre sont citées et sont dotées de fermures à deux jours.

Les fenêtres sont plus rarement dites « à la romaine » ou «à l'italienne ». Dans la maison que fait construire Catherine Vias à l'angle de la rue de la Guirlande et de la Taulisse en 1668, les fenêtres sont «à la romaine» et au dernier niveau «en fasson de luquerne » sous la corniche de pierre «avec ses architectures ${ }^{\mathbf{1 8 0}}$, révélant une influence de l'architecture baroque avec ce dernier étage en attique que l'on retrouvera sur l'Hôtel de Ville (1666/1673) et les maisons du cours, édifices conçus sous l'impulsion des frères Puget.

\subsubsection{La baie à meneau et croisillon de la fin du Moyen Âge}

Dans les murs de la cave de la parcelle 373 ( $c f$. infra $\S$ II, 2, 3.4.1.), ont été recueillis plusieurs fragments en remploi appartenant à une série cohérente de baies à quatre formes : meneau, croisillon, piédroit, linteau (fig. 89). Le meneau central, large de $8 \mathrm{~cm}$ et profond de $13 \mathrm{~cm}$, comporte à l'instar du croisillon une feuillure à l'intérieur, et une moulure en tore formant une colonnette à l'extérieur. Sur un socle rectangulaire, la base de la colonnette est de section hexagonale. Le fût cylindrique de celle-ci d'un diamètre de $5 \mathrm{~cm}$ se détache du meneau par l'intermédiaire d'une gorge à profil en cavet. Le piédroit est composé d'un corps de moulures complexe dont la partie principale en tore répond à la colonnette du meneau. Le décor de cette fenêtre semble pouvoir être rattaché au $\mathrm{XV}^{\mathrm{e}}$ s. ou au début du $\mathrm{XVI}^{\mathrm{e}} \mathrm{s}$. car la présence de tore est peu fréquente dans le cours du $\mathrm{XVI}^{\mathrm{e}} \mathrm{s}$. où les moulures deviennent plus anguleuses. Les éléments en calcaire rose à grain fin sont taillés soigneusement et sont revêtus d'un badigeon blanc sur les parties exposées.

\subsubsection{La baie à meneau et croisillon moderne}

Dans une cave située à l'angle de la rue des Olives et de la rue de la Prison, un dépôt de plus de cent blocs architecturaux en attente de remploi a été partiellement dégagé ( $c f$. infra $\S$ II, 2, 3.4.2.). Parmi les blocs conservés, se trouvent plusieurs éléments provenant d'un même type de baie. Il s'agit également d'une baie à quatre formes, avec un remplage composé d'un meneau et d'un croisillon. L'appartenance à une même série d'ouverture est déterminée par l'identité du matériau utilisé et du décor porté par les piédroits et les meneaux. Le matériau est un calcaire burdigalien de couleur rose soutenu, dépourvu de coquilles de grandes dimensions, fin

180 AD13 393 E 87, fol. 580. et bien cimenté, apparenté à la production des carrières de Carro ou du Baou Tailla, près de La Couronne. Les blocs dans lesquels ont été taillés les piédroits ont pour module $58 \mathrm{~cm}$ de long, $37 \mathrm{~cm}$ de profondeur et $22 \mathrm{~cm}$ de large. Le meneau subsistant mesure $68 \mathrm{~cm}$ de haut, $20 \mathrm{~cm}$ de profondeur et $18 \mathrm{~cm}$ de large. Les faces sont soigneusement taillées et les traces d'impact d'outils discrètes, même sur les lits d'attente et de pose où seules des marques de taillant brettelé apparaissent. Des tracés à la pointe sont visibles à l'arrière du meneau, en lien avec la taille de celui-ci ou peut-être avec la pose des menuiseries. La mouluration est sobre, composée d'un

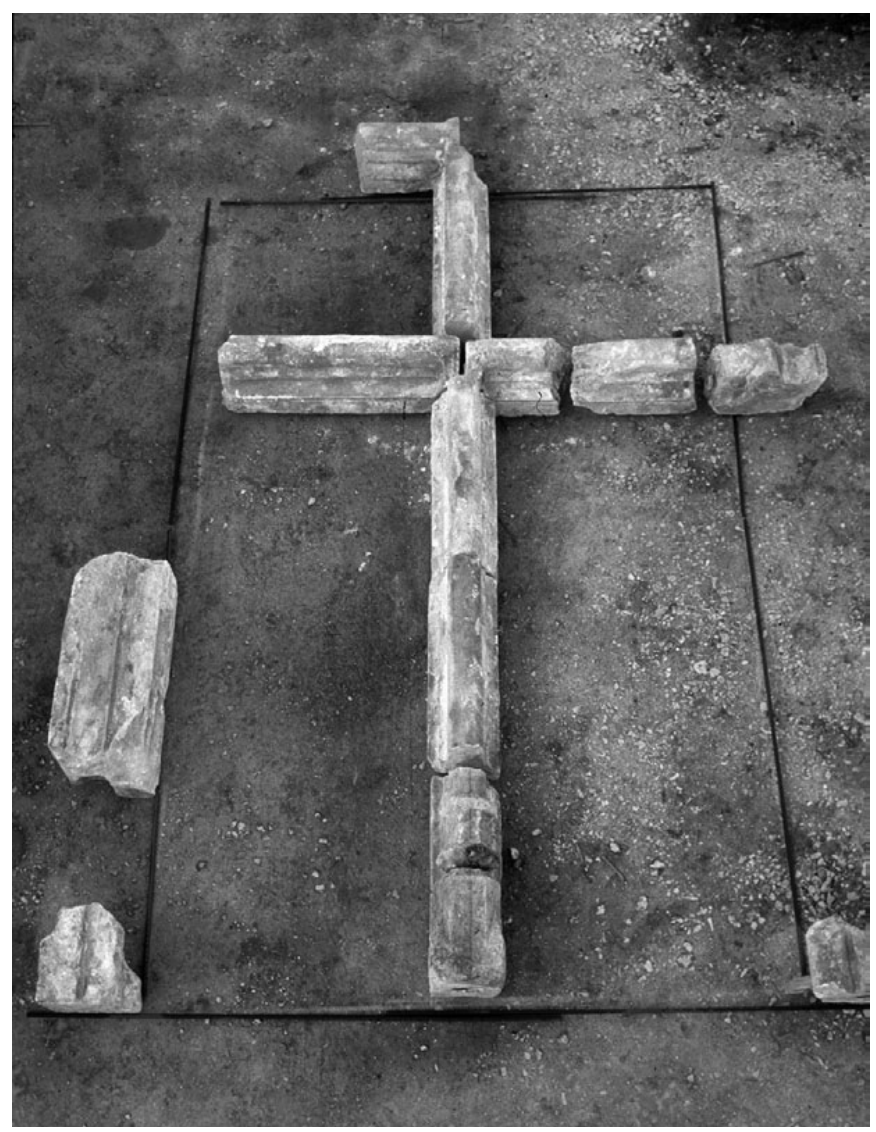

Fig. 89. Reconstitution de la fenêtre de l'Hôtel de Remezan d'après les blocs en remploi (cl. R. Thernot/Inrap).

bandeau plat encadré par deux réglets saillants sur les meneaux. Sur le piédroit, la moulure est formée par un réglet et un cavet. Les piédroits sont dotés d'une feuillure et forment un ébrasement vers l'intérieur. Les meneaux sont dépourvus de feuillure, mais portent des mortaises qui pourraient traduire le scellement d'une menuiserie plaquée sur leur face interne. Un appui de fenêtre portant une moulure composée d'un larmier à profil en doucine surplombant un bandeau saillant et un cavet, pourrait correspondre à une baie identique. 
Ce type de baie au décor simple renvoie à des exemples courants dans l'architecture locale de la fin du $\mathrm{XVI}^{\mathrm{e}}$ et du XVII ${ }^{\mathrm{e}}$ s., avant que les remplages de pierre ne soient remplacés par des ouvrages de menuiserie (Massot 1992, p. 65). Un tableau représentant une vue du quai de l'Hôtel de Ville pendant la peste de 1720 montre que les bâtiments entourant la mairie se conforment à ce modèle, désigné sous le nom de crozières dans les prix-faits (fig. 90).

\subsubsection{La baie en arc plein cintre avec arrière-voussure}

La diffusion dans l'architecture civile d'ouvrages où les techniques complexes de taille de la pierre et de clavage sont développées afin de dégager de vastes volumes ou de larges ouvertures, ou plus simplement pour manifester le prestige des propriétaires, génère de nouvelles modes architecturales. Les chef-d'œuvres de stéréotomie comme la voûte plate de l'Hôtel de Ville d'Arles restent l'exception, néanmoins ils suscitent un engouement pour la prouesse technique, relayé par la diffusion de manuels qui popularisent des modèles d'ouvrages de stéréotomie, comme celui de Mathurin Jousse en 1642, Le secret d'architecture découvrant fidèlement les traits géométriques, couppes et dérobemens nécessaires dans les bastimens. Issue des savoir-faire développés par les tailleurs de pierres au Moyen Âge dans le sudest, avec en particulier la célèbre vis de Saint-Gilles, l'art de la stéréotomie gagne Paris à la fin $\mathrm{XV}^{\mathrm{e}} \mathrm{s}$. La prépondérance culturelle de la capitale du royaume au cours des siècles suivants incite les provinces à adopter les modes parisiennes et en Provence à redécouvrir l'usage de la stéréotomie dans l'architecture (Pérouse de Monclos 1983).

Dans l'habitat privé, ces techniques sont exploitées dans la construction des escaliers à jour central et dans celle des baies. Les baies à couvrement clavé, rendant le meneau inutile, peuvent prendre des formes variées, signant l'adoption des modèles relevant de l'architecture classique ou baroque. Les arcs extérieurs des portes et des fenêtres se diversifient : plates-bandes appareillées, segments d'arcs ou arcs en plein cintre sont répartis dans les divers niveaux en lien avec la superposition des ordres. À l'intérieur des pièces, ces couvrements sont associés à des arcs plus ouverts couvrant l'embrasure. La présence des grands vantaux en menuiserie de ces fenêtres sans remplages, le souhait de laisser pénétrer la lumière, rendent nécessaire à la fois l'ébrasement des embrasures et la surélévation des soffites. Les deux arcs différents, intérieur et extérieur, sont reliés par une surface gauche formant une arrière-voussure. Ils ne sont plus juxtaposés comme auparavant. Une typologie des arrière-voussures est établie, déclinant les associations possibles des trois formes d'arc -arasé, segmentaire et plein cintre- sur les deux faces du mur : arrière-voussure de Saint-Antoine, de Marseille et de Montpellier. L' « arrière-voussure de Marseille », associe en façade un arc plein cintre à un arc segmentaire à l'intérieur. Les deux segments de cercle sont reliés par une surface hyperboloïdale. Ces volumes géométriques théoriques sont découpés en autant de voussoirs que nécessaire. Les joints convergents des voussoirs assurent le clavage de l'ouvrage.

Une série de claveaux en pierre de La Couronne, provenant d'une même façade, a été retrouvée dans les remblais de démolition de la place Villeneuve-Bargemon et en remploi dans certains murs de cave (parcelle 387). Les éléments sont tous taillés dans une pierre à grain fin, de teinte rose soutenu, présentant une fermeté autorisant la mouluration et la sculpture. Les éléments observés sur toutes leurs faces permettent de reconstituer le processus allant de la taille des blocs jusqu'à leur mise en œuvre. Les blocs ont à l'origine un module minimal de $60 \mathrm{~cm}$ de long, $32 \mathrm{~cm}$ de large et $30 \mathrm{~cm}$ de hauteur et un autre de 60 x 22 x $22 \mathrm{~cm}$. Les traces liées à l'extraction ont disparu en raison du travail de taille effectué. Les faces cachées portent des impacts de taillant brettelé et les faces visibles avec leurs moulures sont finies à la ripe. Des tracés préparatoires incisés à la pointe pour la taille des feuillures et l'épannelage du corps de moulures sont présents sur les lits de pose. Sur les lits de pose ou d'attente sont creusés des abreuvoirs permettant la bonne répartition du mortier et l'expulsion des excès de liant défavorables à la finesse recherchée des joints. Ces canaux sont creusés en forme de patte d'oie ou en réseau croisé à l'aide d'un marteau taillant brettelé, au ciseau ou à la broche. Le réseau d'abreuvoirs débouche à l'extrados.

Deux des claveaux proviennent d'un même type de baie, couverte d'un arc plein cintre en façade et d'un arc segmentaire à l'intérieur, formant sur l'embrasure une arrière-voussure de Marseille. Le décor est constitué par une archivolte composée de haut en bas d'un tore à profil asymétrique, puis d'un canal plat et enfin d'une gorge à profil également asymétrique. La restitution du cercle complet, d'un diamètre de $99 \mathrm{~cm}$, et le rythme des joints séparant les voussoirs offre l'image d'un ensemble cohérent. Cette restitution est très proche du modèle présenté par Mathurin Jousse (Jousse 1642, p. 208, fig. 104) dans son traité. On y retrouve les mêmes proportions et le même calepinage des claveaux.

Dans l'architecture marseillaise des XVII ${ }^{\mathrm{e}}$ et XVIII' ${ }^{\mathrm{s}}$ s., les fenêtres couvertes en plein-cintre ne sont pas rares à l'étage noble. La maison située au $n^{\circ} 17$ rue 


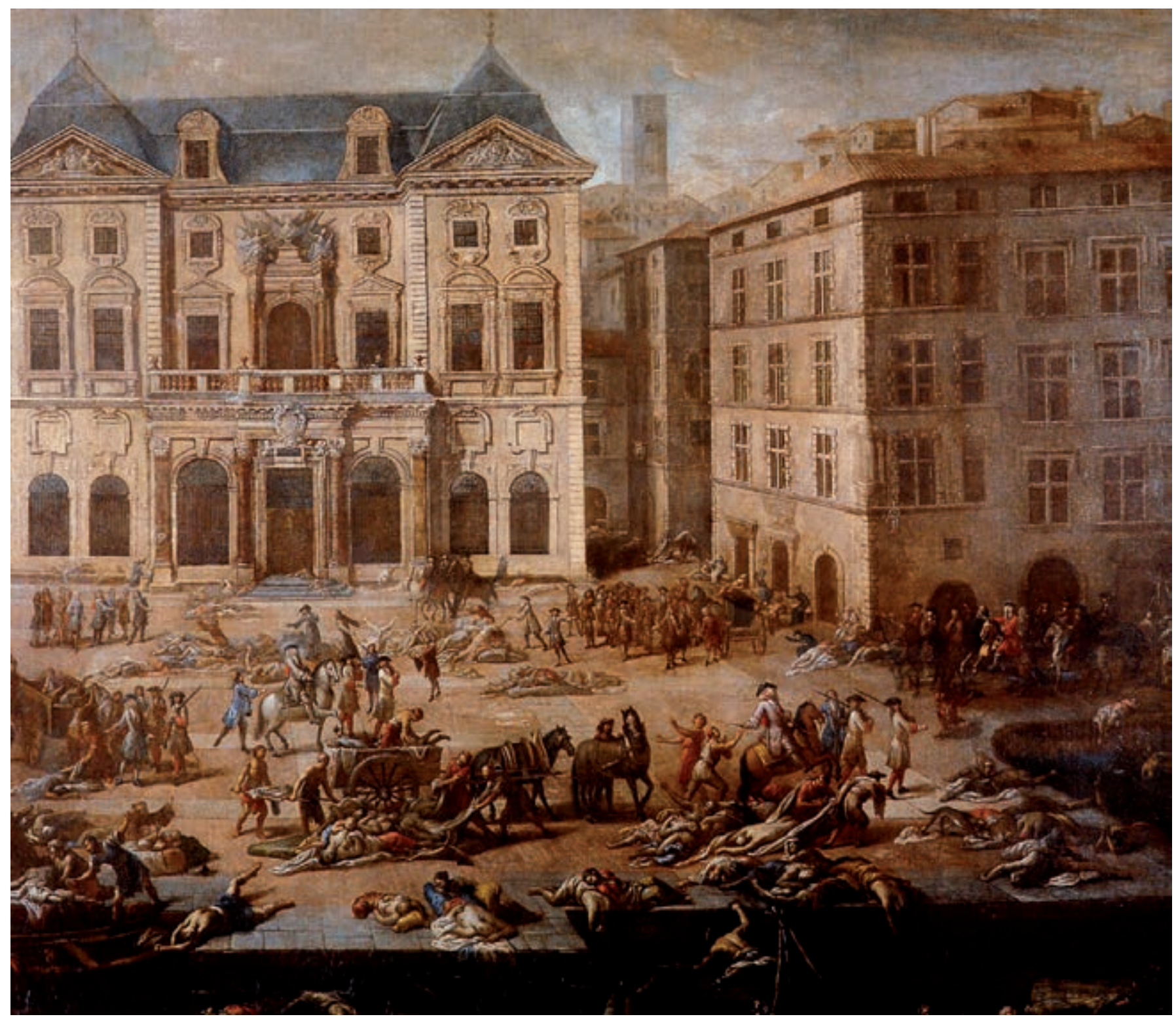

Fig. 90. L'Hôtel de Ville pendant la peste de 1720 (tableau de Michel Serre, Musée des Beaux-Arts, Marseille).

des Convalescents, avec ses quatre travées de baies en plein-cintre au premier étage, celle du $\mathrm{n}^{\circ} 32$ rue des Chapeliers (Durousseau 1990), ou l'hôtel du nº 56 rue Paradis (Gloton 1992), témoignent du goût marqué localement pour cette forme de baie quasiment absente dans d'autres villes de la province.

\section{Le projet de chantier de construction (C. Castrucci)}

Alors que les aspects techniques sont connus principalement par l'archéologie, le déroulement du chantier lui-même reste liée à des documents écrits que l'on connaît bien pour la période moderne.

\subsection{Rapports de future cautelle et prix-faits}

Deux types d'actes notariés ont soutenu nos recherches sur les chantiers de fouille marseillais: les rapports de future cautelle et les prix-faits. Ils nous ont apporté nombre d'informations sur les maisons découvertes en fouille et sur celles qui leur étaient immédiatement proches. C'est pourquoi il a paru nécessaire de présenter ces documents et leur contenu ainsi que leurs protagonistes et les circonstances de leur mise au point.

Dans le déroulement des événements, le rapport de future cautelle ou de future précaution est établi très fréquemment au profit du nouvel acquéreur à la suite d'une vente. Passé devant notaire, il permet au nouveau propriétaire de se prémunir contre une surévaluation. 
Ce document est un véritable rapport d'estime, dressé par deux experts, en présence du nouveau propriétaire -et de l'ancien s'il le désire- qui décrit l'ensemble de l'immeuble, étage par étage jusqu'au toit, tant dans son agencement que dans son mode de construction. La visite de la maison est alors faite pièce par pièce, dont on précise la plupart du temps l'orientation, les dimensions, les matériaux de construction utilisés, les éléments contenus dans chacune d'elles, la décoration le cas échéant et l'état dans lequel elle se trouve. Quelquefois la valeur est aussi précisée : lorsque c'est le cas, une comparaison entre le prix payé lors de l'achat et le prix de l'évaluation est possible pour l'historien. Ces documents sont les plus précieux pour la connaissance de l'habitat privé aux Temps Modernes car ce sont eux qui fournissent les éléments les plus nombreux. Ils situent le bien décrit ou renvoient à l' acte d'achat qui a suscité le rapport qui, lui, en donne la localisation et les confronts. Bien qu'il faille tenir compte des exagérations possibles des experts dans leurs descriptions concernant l'état dégradé des immeubles, ces états des lieux sont tout de même l'occasion d'avoir un panorama assez précis des habitations (cf. annexe 3 ).

Les prix-faits ou contrats de construction viennent en général à la suite de ces expertises. Et lorsqu'on a l'opportunité d'avoir les deux actes -rapport et prix-faitpassés chez le même notaire, on saisit alors un moment dans l'évolution d'un immeuble. Souvent le nouveau propriétaire a fait appel à un autre notaire pour recevoir le prix-fait, si bien que la recherche des uns comme des autres actes nécessite un dépouillement systématique de nombreux registres afin de tenter de retrouver le rapport qui correspond à tel prix-fait ou vice-versa.

Néanmoins la lecture des seuls prix-faits ne suffit pas à donner une idée précise d'une maison car ceux-ci ne mentionnent que les travaux à effectuer. Parfois établis pour la simple réfection d'un mur mitoyen, ou d'une partie quelconque de l'habitation, mais aussi pour des reconstructions totales, ils mettent en présence un commanditaire et un artisan chargé d'effectuer des travaux dont on précise les éléments, les délais à respecter et les prix fixés ${ }^{181}$. Cependant seul un corpus important de ces textes permet une étude approfondie, car le contenu des renseignements n'est pas homogène d'un prix-fait à un autre. Non seulement à cause de la variété des travaux à réaliser mais aussi par manque de normalisation dans la manière de les décrire. Pour exemple, on

181 À Paris, où la Chambre des Bâtiments contrôle et protège les métiers du bâtiment, le seul fait, pour un entrepreneur, de signer un marché à prix-fait ou un devis, le garantit du paiement de son travail (Carvais 1996). citera des expressions fréquemment rencontrées comme «à l'ordinaire », « de l'espesseur necessere » ou « selon la coutume » toutes allusions à des pratiques connues de l'époque mais qui ne sont pas décrites dans le texte en question et qui pourront l'être dans d'autres. Par ailleurs, de nombreux éléments font défaut et notamment le plan ou «dessaing » auquel il est parfois fait référence, qui accompagnait l'acte, mais qui a disparu ${ }^{182}$. Aucune superficie n'est spécifiée dans les textes qui ont fait l'objet de cette analyse. On ne connaît donc que très rarement la hauteur exacte d'une façade à élever, d'une « muraille maistresse » à rénover, d'une vizette à construire.

Au-delà donc de la nécessaire lecture critique et même si beaucoup d'éléments que nous aimerions connaître font défaut, les prix-faits sont un élément essentiel pour la connaissance de la construction car ils détiennent les éléments qui permettent de reconstituer les pratiques liées à la construction. ( $c f$. annexe 3 )

\subsection{Les parties en présence lors de l'établissement du contrat : le commanditaire et l'entrepreneur}

En présence du notaire et, généralement de deux témoins, deux parties sont essentiellement en cause : le commanditaire et le maçon.

Dans les cas étudiés, le commanditaire peut être un noble, un bourgeois, un marchand, ou un artisan, tous les corps de métiers et toutes les classes sociales sont représentées et font indifféremment appel à un ou plusieurs artisans, maîtres maçons ou gipiers, pour leur fournir un travail. En 1636, ce sont quatre maîtres maçons qui prennent à prix-fait la réunion des deux maisons qu'a acquises Pons Agnel et qu'il veut transformer en un immeuble de rapport ${ }^{183}$.

Le plus souvent un ou deux maitres seulement signent le contrat. Quelquefois l'un est maçon, l'autre gipier comme dans le contrat que passe Pierre Savignon en janvier 1635 pour sa maison de la rue de la Prison ${ }^{184}$. Ou bien les deux sont gipiers selon la nature des travaux. C'est le cas de Jean Tavernier et Michel Arnaud,

182 Nombre de ces prix-faits mentionnent une «besoigne » à faire «conformément est representé sur le plan et dessain sur ce fait» (AD13 391 E 376, fol. 926) ou «suivant l'ordre du plan qu'on a dressé » (AD13 393 E 82, fol. 715); l'un d'eux précise même que les deux parties étaient bien d'accord avec le plan qu'elles ont signé : «pour le département desditz membres seront comme il est marqué au plan qui a esté faict et signé par les parties » (AD13 380 E 169, fol. 380).

183 AD13 373 E 271, fol. 102.

184 AD13 360 E 70, fol. 71. Le prix-fait est passé avec Vincent Barnier, maitre maçon et Michel Arnaud, maître gipier. 
tous deux maistres gipiers qui sont engagés par Jean Mazerat pour faire des travaux de maçonnerie et de blanchiment $^{\mathbf{1 8 5}}$. Jean Boniffay, lui, est tailleur de pierre, et promet d'effectuer des transformations à la façade de la maison d'Henry David du côté de la place Vivaud ${ }^{\mathbf{1 8 6}}$.

En réalité, ces maçons étaient de véritables entrepreneurs capables de diriger l'ensemble des travaux; certains textes les désignent encore sous le terme de prefachiers, que Mistral fait dériver du terme pres- $f a$ qu'il traduit par «forfait, marché à la tâche » donnant pour définition pour pré-fachié celle de «tâcheron, ouvrier à la tâche, entrepreneur ». Le dictionnaire de S.-J. Honnorat, donne deux définitions du terme prefach : l'une traduisant l'entreprise à forfait, l'autre désignant une entente pour un travail à la tâche pour un prix toujours défini à l'avance (Bertrand à paraître).

Le terme d'entrepreneur apparaît une dizaine de fois ; c'est en qualité de propriétaires d'une maison qu'ils acquièrent ensemble que les architectes Jean Puget et Jean Meollan confient la reconstruction de la maison qu'ils viennent d'acheter en 1674 au maître maçon Guillaume Trienne.

Ces maîtres d'œuvre organisaient le travail et devaient recruter le nombre de personnes qui leur était indispensable. Aucune précision donnée dans les textes ne nous permet de quantifier le nombre de spécialistes et d'ouvriers ; mais ils font toujours l'objet d'une mention particulière dans les actes notariés. Ainsi, il est très fréquent que l'acte se termine en précisant que le maçon devra fournir « ses mains, celles de ses autres maitres et maneuvres (...)».

Les contrats ont également livré d'autres éléments sur la manière d'ordonner le travail. Lorsque Charles de Cazaux fait construire sa maison à côté de la maison de ville, les maçons Guillaume Ardent et Claude Collombaud sont «tenus (...) à commencer a travalher et faire travailher à lad. ceuvre le troysième du prochain mois de janvier et continuer jusques à la perfection dicelle avec tant de gens que seront nécessaire en nombre suffisant ${ }^{187} \gg$.

Les prefachiers avaient sous leurs ordres des manœuvres mais également les maîtres des autres corps de métier. Si l'entrepreneur était un gipier il pouvait s'entendre avec un maçon, capable de tailler la pierre et de la poser, lui-même se chargeant du reste de la «massonerie », ou avec un tailleur de pierre à qui il achetait la pierre une fois taillée. Les maçons semblent être, de ce point de vue plus polyvalents et savent tailler

185 AD13 391 E 342, fol. 180.

186 AD13 364 E 244, fol. 1328.

187 AD13 360 E 30, fol. 679. la pierre. Ceux qu'engagent Jean Boissely ont dû fournir «leurs mains» et payer «toutes les journées des autres maistres et maneuvres qu'ils employ(aient) ${ }^{\mathbf{1 8 8}}$ ». Tel autre contrat précise qu'à la «besougne » désignée «travailleront (...) trois hommes $m^{e s}$ maçons, scavoir Railhon et Roux et un autre $m^{e}$ maçon capable de son métier $\gg{ }^{\mathbf{1 8 9}}$.

Toutefois le commanditaire avait son mot à dire dans le choix des ouvriers ; c'est pourquoi Frédéric Bertin fait ajouter sur le contrat qu'il refuse de «faire travailler à lad. besogne aucun apprenti ${ }^{\mathbf{1 9 0}}{ }$. Il a même la possibilité de modifier la composition de l'équipe si quelqu'un ne lui convient pas, et si les maîtres maçons refusent d'en changer, «il sera permis aud. $s^{\mathrm{r}}$ Agnel d'en mettre telz. autres qu'il treuvera a propos aux despans desd. $m^{\text {es }} \mathbf{1 9 1}_{\gg \text {. }}$

Progressivement, au cours de la période étudiée, le besoin se fait sentir de fixer des règles pour les métiers du bâtiment; les textes réglementaires se saisissent des usages concernant l'embauche. Ceux-ci deviennent alors plus stricts. C'est ainsi qu'un règlement de la fin du XVIII ${ }^{\mathrm{e}}$ s. fixe l'ordre aux maîtres maçons de privilégier l'emploi des ouvriers français par rapport aux étrangers ; et ensuite de favoriser ceux qui seront capables de fournir un travail fini (cloison, cheminée, etc...) avant les simples ouvriers ${ }^{\mathbf{1 9 2}}$.

\subsection{Le déroulement des travaux : les tâches à accomplir par les maçons}

La description des travaux à effectuer est inégale et fait souvent référence à un plan, préalablement établi «suivant et conformément au dessaing et project que lesd. ouvriers en ont faict signés par les parties », qui n'est jamais joint au contrat : chaque cas est particulier et l'on trouve quelquefois plus de détails à propos d'un seul ouvrage à faire que dans un contrat prévu pour la réfection totale de la maison. Aussi, c'est à partir de l'ensemble des prix-faits recueillis qu'on obtient le plus

188 AD13 362 E 91, fol. 703

189 Un cas -isolé dans notre documentation-a retenu notre attention. Antoine Pontier avait signé un prix-fait pour effectuer des travaux dans sa maison, avec le maître maçon Antoine Eiguisier. Celui-ci décède probablement peu de temps après; et c'est vis-à-vis de sa veuve, avec l'accord du commanditaire, que Jean Ricard, maître gipier s'engage à effectuer l'ouvrage. La responsabilité du travail pouvait donc être prise aussi bien par l'un que par l'autre corps de métier. D'ailleurs le même jour, Jean Ricard passe un contrat avec Jean Lupin, maître maçon pour qu'il effectue les travaux de pierre de taille sur ce chantier (AD13 380 E 130, fol. 27, 203v et 204v).

190 AD13 362 E 127, fol. 1106.

191 AD13 373 E 271, fol. 102.

192 ACM DD 81. 
d'éléments possibles sur le montage d'un chantier, sur l'ensemble des tâches à effectuer, sur les droits et les obligations de l'entrepreneur.

La diversité des travaux à réaliser est ensuite inhérente au nombre de prix-faits étudiés. La centaine de contrats sur lesquels s'appuie notre étude, nous offre tout un panel d'ouvrages allant des simples travaux d'amélioration -blanchiement des murs, consolidation d'encadrements de portes ou de fenêtres, remplacement d'une porte-, à la démolition quasiment complète de l'immeuble pour tout reconstruire à neuf.

C'est le cas de la maison qu'acquiert Jean Griffet en 1637 pour laquelle il est prévu de monter quatre étages surmontés d'une lauvisse. Le rez-de-chaussée sera occupé par une boutique qui doit contenir un four pour la pâtisserie et sous laquelle on creusera une cave jusqu'à demie rue, ce qui nécessite la construction de deux arcades en pierre de taille ${ }^{193}$. Ou encore celui de Mathieu de Madières qui achète deux maisons pour les réunir en une seule ${ }^{194}$.

Dans ce cas, les maçons étaient chargés de démolir au préalable tout ou partie de l'immeuble existant. Parallèlement, ils devaient "apontel(er) suffisammant les maisons des voisins » afin d'éviter qu'elles ne s'effondrent. Ce qui entraînait un «droit d'appuyage» dû par l'entrepreneur. Parallèlement on montait les échafaudages, on posait gaches, gouffons, cordages.

Quelquefois, le propriétaire ne veut qu'ajouter des améliorations à son immeuble: Jean Descampz fait créer une fenêtre de pierre de taille à la cuisine au rez-dechaussée ${ }^{195}$, Jean-Baptiste Renaude fait refaire sa façade de pierre de taille ${ }^{196}$. Souvent il ne s'agit que de refaire un mur mitoyen tel celui que font rebâtir Jean-Baptiste Renaude et Melchion Medicis en $1597{ }^{197}$.

Pour tous ces travaux, à quelques exceptions près où l'on voit le commanditaire fournir les matériaux, l'entrepreneur est chargé de la fourniture des matériaux à l'exception, le plus souvent, des menuiseries et de la ferronnerie fournies par le propriétaire. En revanche, les matériaux de la démolition -la desfarde ou le debrisrevient dans la plupart des cas à l'entrepreneur qui a la possibilité de réutiliser les vieux matériaux à condition qu'ils soient «bons et receptables ».

Une fois les travaux effectués et après avoir utilisé les anciens matériaux valables, les maçons doivent débarrasser les décombres et faire "place nette ».

193 AD13 360 E 72, fol. 360.

194 AD13 393 E 82, fol. 715.

195 AD13 360 E 80, fol. 1112.

196 AD13 366 E 33, fol. 296.

197 AD13 360 E 33, fol. 376.

\subsection{Des travaux, à quel prix ?}

Le prix des travaux est, pour la majorité des cas, fixé forfaitairement comprenant l'ensemble de l'ouvrage à réaliser, la fourniture des matériaux et de la main d'œuvre. Dans quelques cas le prix est donné à la tâche, séparant par exemple la démolition du reste du travail : ainsi Barthélemy Gorge paiera 261 livres pour la démolition, le prix du reste étant fixé au toisé ${ }^{198}$.

Le prix-fait que passe Phrédéric Bertin prévoit que c'est lui, le commanditaire, qui paiera la main d'œuvre ${ }^{199}$. D'autres, comme celui de Louis Boutassi, fixent un prix au toisé pour la construction de la façade et un prix global pour le reste de l'ouvrage ${ }^{200}$. Le maçon qu'engage Isabeau de Bocquin pour sa maison, fixe un prix au toisé pour chaque tâche à exécuter, la fourniture des matériaux étant comprise ${ }^{201}$. Le prix-fait pour les ouvrages réalisés par Vincent Meollan à la demeure de Louys Felix ne concerne que la main d'œuvre puisque c'est le propriétaire qui fournit tous les matériaux. Il est indiqué à la tâche et au toisé ${ }^{202}$.

Dans tous les cas, il est impossible de savoir le prix effectif des travaux : facturés à la tâche, il manque la superficie construite ou restaurée; au forfait, on ne connaît aucun détail sur le coût de la main d'œuvre et sur la hiérarchie des prix des tâches à accomplir. De même la valeur des ouvrages est difficile à évaluer: aucun élément ne permet d'attester qu'un mur, monté de taille jusqu'à une certaine hauteur puis de maçonnerie avec des décors de taille, coûtait moins cher qu'une façade de taille du rez-de-chaussée jusqu'au toit sans autre ornement de taille. Il est donc difficile d'établir des comparaisons d'une construction à une autre.

Jamais on ne peut faire la part du prix des matériaux dans les sommes fixées, l'approvisionnement se faisant de différentes façons. Des textes issus des sources notariées, illustreront la difficulté de saisir des prix unitaires fixes : les contrats de vente de pierre de taille serviront d'exemple à ce propos. En effet, ces textes nous présentent divers cas : soit, le pereiron vend une quantité plus ou moins détaillée de pierre à un tailleur de pierre; soit il traite avec un maçon qui faisait tailler la pierre ; soit encore il vend directement ses pierres à un propriétaire qui charge ensuite un entrepreneur de travaux dans un de ses immeubles. Même en considérant que les coûts sont obligatoirement différents selon que la pierre était brute ou déjà taillée, la difficulté est là. Car chaque

198 AD13 390 E 383, fol. 1125.

199 AD13 362 E 127, fol. 1106.

200 AD13 390 E 163, fol. 196.

201 AD13 362 E 91, fol. 1444v.

202 AD13 360 E 51, fol. 765v. 
cas est différent de l'autre. Comment connaître le prix unitaire de la pierre vendue par Jean Remondon, pereiron de Martigues lorsqu'il cède à un tailleur de pierre de Marseille «toute la pierre qu'il trouvera à propos» pour la somme de trente sept livres dix sols ${ }^{203}$ ? Comment comparer le coût de la pierre de taille que le maçon Cezard Portal acquiert pour un prix calculé au toisé, taillée et posée ${ }^{204}$, avec celui que paient Anthoine Roux et Jacques Mourenas, respectivement hoste et marchand de Martigues qui achètent leur pierre de La Couronne au prix unitaire des cent queirons ${ }^{205}$ ? D'autres contrats de la fin du XVI ${ }^{\mathrm{e}}$ s., fixent des tarifs en fonction des dimensions des pierres : c'est le cas de Louis Félix qui se procure des « cairons (...) de trois pans pour huict escus dix sols le cent et les grases de quatre pans et demy (...) vingt sous chasque piece ${ }^{206}$.

Quoiqu'il en soit, le montant dû n'est jamais payé en une seule fois. Une partie de la somme -souvent la moitié- est versée au moment de la signature du contrat; le reste est soit versé à la fin des travaux dont la durée varie selon le type de travail à effectuer entre un mois et demi et un an ; soit réglé par moitié à mi-travail et le reste à la fin de celui-ci. Soit encore au fur et à mesure de l'achèvement de chaque étage.

Le contrat se conclut quelquefois par quelques mentions particulières: par exemple, on précise que les travaux réalisés pour la maison de Jean Le Sonneur devront être estimés par deux amis communs ${ }^{207}$. L'entrepreneur des travaux de la maison de Jean Griffet est prié " d'avoir faicte (ladicte maison) bien et deuement la clef à la main du proprietaire dans la feste de Pasques prochaine ${ }^{208}$.

En résumé, le contrat à prix-fait est un contrat passé entre deux personnes dont l'une accepte, sous certaines conditions -délai, prix, fourniture de tout ou partie des matériaux- d'exécuter un travail ordonné par l'autre en prenant à sa charge d'engager tous les corps de métier qu'il juge nécessaire pour mener à bien cette opération qu'ils soient maitres ou manœuvres. Dans la plupart des cas il doit également fournir tout ou partie des matériaux, ceux-ci étant compris dans la somme fixée. À l'entrepreneur, alors, de «reque(rir) aux pereirons » la pierre de taille nécessaire à la construction, comme le précise les termes du contrat que passe Pons Agnel avec quatre maçons.

203 AD13 380 E 204, fol. 476.

204 AD13 373 E 303, fol. 344v.

205 AD13 363 E 175, fol. 557.

206 AD13 360 E 30, fol. 684v.

207 AD13 360 E 110, fol. 25v.

208 AD13 360 E 72, fol. 360.

\section{La pierre de taille : un élément de l'économie marseillaise (C. Castrucci)}

Les prix-faits nous ont montré comment s'organisait un chantier en amont des travaux, précisant quelques aspects des droits et des obligations des acteurs de la construction. La flambée immobilière suscitée par la décision de l'agrandissement de la ville dans le dernier tiers du XVII ${ }^{\mathrm{e}}$ s., ainsi que les travaux de construction qu'elle a générés, ont entraîné des façons de procéder dont on peut entrevoir les prémices à la lecture plus approfondie de ces mêmes textes.

Les matériaux de construction ont, dans ce contexte, joué un rôle économique important. L'utilisation de la pierre, et en particulier la pierre de taille, a retenu notre attention et sera l'objet de la présente analyse. Les questions posées seront les suivantes : quels signes dévoilent l'importance grandissante que prend l'utilisation de la pierre de taille dans les constructions? De quelle façon cette dernière est-elle utilisée ? Quelle place pour la pierre « récupérée » ? Comment l'emploi plus systématique de la pierre de taille définit-il de nouvelles pratiques économiques?

\subsection{L'utilisation de la pierre de taille : entre nécessité technique et volonté d'ostentation}

Au XVII s., l'emploi de la pierre de taille dans les constructions privées qui ne sont pas obligatoirement des demeures de prestige devient de plus en plus fréquent. Dans nombre de prix-faits, les propriétaires du quartier du Corps-de-Ville ou de celui de Blanquerie décident de faire construire ou réédifier telle ou telle partie de la maison en pierre de taille en remplacement de l'ancienne maçonnerie délabrée. Quelles sont les parties du bâtiment auxquelles la pierre de taille est plus particulièrement destinée ? Son emploi avait-il pour seul but d'apporter une meilleure solidité ou un plus bel aspect ? Utilisait-on seulement de la pierre neuve ?Y avait-il des manières communes d'utiliser ce matériau?

\subsection{De la pierre de taille dans toute la maison?}

Les divers textes dont nous disposons et les exemples trouvés en fouille montrent que la pierre de taille n'était pas utilisée dans tout le bâtiment et qu'on ne faisait poser de la neuve qu'exceptionnellement. Son emploi pour des nécessités techniques semble logiquement prévaloir dans tous les cas. 
Son utilisation pour une meilleure solidité du bâtiment semble évidente. Mais elle n'était pas systématique. La plupart des fondations trouvées en fouilles sont faites de gros moellons mêlés de pierres de récupération liées à un mortier. Quelques cas évoquent le choix de la pierre de taille, neuve de surcroît, à des endroits stratégiques du bâtiment. C'est celui de la maison de Jacques de Forbin, rue de la Loge, où les fondations sont faites sur pieux et « de bonne pierre de taille neufve et dure de la Coronne d'espesseur de trois pans jusqu'à ras de terre ${ }^{209}$.

Les caves découvertes en fouille, voutées en berceau, étaient également le plus souvent construites en moellons grossiers (Sillano 2005, p. 486). Pourtant, dès la fin du $\mathrm{XVI}^{\mathrm{e}}$ s., certaines étaient construites en pierre de taille. Ainsi Melchior Medicis fait-il construire « une crotte (au) dessoulz de ladite maison de la longueur et largeur d'icelle (...) acrossiver avec un pillier ou deux sy est de besoing (...) de bonne pierre de tailhe ». Les arcs de décharge : "trois arcs doubleaux pour porter les murettes d'hault en hault pour fere separation des chambres et salle» devaient également être de taille de même que les escaliers d'accès «jusques a ras de terre ${ }^{\mathbf{2 1 0}}$. Une autre que construit le gipier Reynaud Beroty pour Jean Griffet contient des arcades de pierre de taille ${ }^{211}$.

Au cours du XVII ${ }^{\mathrm{e}}$ s., la pierre de taille est de plus en plus souvent présente dans les caves dont la création tend à se généraliser dans le secteur du Corps-de-Ville. Les nombreux textes signalant qu' on crée une cave en sous-œuvre dans un immeuble qui n'en possédait pas, ou qu'on en refait entièrement certaines déjà existantes, témoignent du soin dont leur édification était l'objet.

L'évolution de la fonction de la cave, résultat de l'évolution de la maison elle-même, explique l'attention nouvelle portée à leur édification. Au XVII ${ }^{\mathrm{e}}$ s., l'espace manque dans la vieille ville pour construire des maisons nouvelles. Force est donc de rehausser d'un ou deux étages celles qui existent, ou bien de les élargir en cœur d'îlot; les boutiques deviennent également systématiques dans chaque immeuble avec la cave qui y est liée. Celle-ci joue alors un double rôle de fondation et de lieu de stockage nécessaire. Elle se doit d'être saine et les matériaux qui la constituent plus résistants. Rue Coutellerie, le prix-fait passé pour la reconstruction de la maison d'Anthoine Pontier stipule clairement, que, d'une part les fondations seront en pierre de taille de trois pans d'épaisseur, et d'autre part, que l'entrepreneur «fera la crotte (...) a crosier, (...) y posera les marches de tailhe que seront necessere pour y dessendre et fera

209 AD13 380 E 163, fol. 742.

210 AD13 360 E 35, fol. 413.

211 AD13 360 E 72, fol. 360. un arc doubleau de bonne pierre de tailhe (...) pour y appuyer les deux meyneaux de la vizette quy prandra sa naissance sur lade crotte ${ }^{\mathbf{2 1 2}}$. On construit en pierre de taille les arcs doubleaux qui soutiennent la voûte de la cave, de même que les escaliers qui y descendent. Celle de la maison de Cosme de Monteoulx, près de la Loge en est un bel exemple. Les piliers placés dans la crotte qu'on élargit, chargés de soutenir les étages, ainsi que les arcades, devront être de pierre de taille que le commanditaire s'engage à fournir ${ }^{213}$. Chez Mathieu de Madières la descente de la cave sera de pierre de taille d'une quinzaine de marches ${ }^{\mathbf{2 1 4}}$.

La pierre de taille est aussi un gage d'une meilleure étanchéité par rapport aux moellons ordinaires, surtout lorsqu' on la revêt de batum, mortier à base de sable et de poudre de tuileau ${ }^{215}$; c'est pourquoi on l'utilise dans les canalisations qui amènent l'eau à la rue, soit à partir des puits comme celui de Jean Descamps pour lequel il demande d' « y mettre un canal de taille de trois pans de long allant à la rue pour donner cours aux eaux $\gg^{216}$ soit à partir de la «pille » ou «eyguier» de la cuisine. Un exemple de ces canalisations a été trouvé rue de la Guirlande (Sillano 2005, p. 491).

D'autres parties des habitations sont de plus en plus souvent construites en pierre de taille : les armoires intérieures, les portes intérieures, les cheminées avec des «bards de taille $\mathbf{2 1 7} »$, un pour le foyer et un autre pour le devant. Les puits dont «le rond» se fait en pierre de taille sont toujours accompagnés d'une «pille » ou d'un «bassinet » et de «bourneaux » ou d'une « gorgue pour conduire l'eau à la rue». L'ensemble de ces ouvrages, mis à part les borneaux qui sont en terre cuite, est en pierre de taille, comme on le voit dans la maison de Jean Griffet ou chez Melchion Medicis.

Un autre exemple est fourni par la fouille de l'Espace Bargemon où des structures en forme de bassins situées au même niveau ont été découvertes. Il s'agissait de constructions bâties au niveau des caves d'une habitation, sur un sol caladé et recouvertes d'un enduit rougeâtre

212 AD13 380 E 130, fol. 27.

213 AD13 352 E 155, fol. 142v.

214 AD13 393 E 82, fol. 715.

215 Pour la composition du batum, $c f$. infra $\$$ 2.1.3. ; la définition donnée dans le dictionnaire d'Honnorat est celle d'un ciment fait avec de la brique pilée, rendu imperméable par corroyage, Honnorat 1846-1847. Voir également : Leroy 1847, p. 34 et 68. Un arrêt du parlement en date du 25 mai 1748 concernant les matériaux propres pour la maçonnerie exige que «les tuilleaux ou briques dont on fait la poudre ou batun pour le ciment seront bien cuits sans aucun mélange de terre, plâtre et mortier ny daucune poterie qui ait receu du vernis ou qui ai contenu de liqueurs grasses et huilleuses », ACM FF 187, fol. 292.

216 AD13 360 E 80, fol. 1112.

217 Gros bloc de pierre. 
très épais. Ces ensembles ressemblent fort aux citernes à huile qu'a fait construire Jean Abeille dans la rue de la Prison (Sillano 2005, p. 490). En 1663 ce dernier prévoit de placer l'une des trois citernes qu'il souhaite faire édifier, appelées « pille a tenir huylle » au niveau des caves. Ayant environ 2,5 m de profondeur, l'une devait être placée sur un sol caladé d'environ $50 \mathrm{~cm}$ d'épaisseur «faite de massonnerie la moytié par dessoubz et l'autre moytié par dessus avec le battum » et comporter au-dessus une voûte de brique ; l'ensemble devait être entouré de pierre de taille recouverte du fameux batum, enduit utilisé pour ses qualités étanches. Les deux autres pilles que fait construire Jean Abeille furent placées dans le couloir du rez-de-chaussée, de même facture, de même profondeur que la précédente et séparées par un mur ${ }^{\mathbf{2 1 8}}$.

Les fours pour la pâtisserie ou pour la rôtisserie, nombreux au marché du Mazeau, sont également reconstruits entièrement de taille. Pour éviter les risques d'incendie, on prend la précaution de paver le four avec des «bards de feu » et de poser «trois bards de pierre de taille contre la muraille ${ }^{\mathbf{2 1 9}}$.

Le rôle technique de la pierre de taille dans le bâtiment, s'il n'est pas à démontrer, n'est pas la seule cause de son utilisation. Ainsi, il est clair que son emploi dans les façades poursuit un double but : technique et décoratif. Elles sont rarement construites en grand appareil, comme cela semble être le cas en Provence en général : la pierre de taille est généralement placée en parement du mur, l'intérieur de celui-ci étant construit en moellons ; Jean-Baptiste Meollan qui s'engage à refaire la façade de la maison de Jean Bissar ${ }^{220}$ est tenu de «faire de pierre de taille neufve (...) le carage de lad. maison» qui « par dedans (sera) de bonne pierre, chaux et sable». La façade de la maison de Catherine de Vias «aura un pan de taille d'espaisseur et un autre pan de massonerie par dedans » 221. Bernabel Treman édifiera pour Honoré Béraud «le caraige du coste du port de pierre de taille avec sa massonnerie par dernier ${ }^{222}$.

Le rôle décoratif de la pierre de taille est ainsi perceptible dans la composition des façades. Il est clair, par exemple, que la décision de poser de la pierre de taille à l'angle d'une maison faisant l'angle d'une rue -comme le fait faire François Coudonneau, dont la demeure fait l'angle de la rue Négrel et de la traverse de la Fontainede-l'Aumône et qui prévoit que le coin de l'immeuble soit de pierre de taille « en forme de pillastre (...) jusques

218 AD13 364 E 274, fol. 653v.

219 Par exemple dans le prix-fait de Jean Griffet AD13 360 E 72, fol. 360 .

220 AD13 360 E 89, fol. 1176.

221 AD13 393 E 87, fol. 580.

222 AD13 362 E 101, fol. 534v. au couvert »- poursuit le but de mettre le bâtiment en valeur autant que celui de le fortifier ${ }^{223}$.

Les façades donnant sur une rue importante sont privilégiées par rapport aux autres visant sur des traverses ou sur des cours intérieures. Cependant rares sont celles qui seront en pierre de taille du niveau de la rue jusqu' au toit. Le plus souvent, la pierre de taille occupe un ou deux niveaux, c'est-à-dire le rez-de-chaussée et le premier, le reste est construit en maçonnerie avec les fenêtres de taille ou seulement leurs accoudoirs. Jean-Estienne Ribouillon fait refaire la façade de sa maison donnant sur la place Neuve de pierre de taille «jusques au premier cordon», et "de chasque cotté et a chasqun des trois estages sera fait une fenestre faite de brique avec sa coudiere de taille ${ }^{224}$. Barthellemy Couzinery ${ }^{225}$ fait poser la pierre de taille sur trois des quatre étages de façade. On souligne les étages avec des courdons qui courent sur toute la largeur de la maison, on ajoute un entablement au-dessus de la porte d'entrée. François Coudonneau fait ajouter également «quatre courdons de taille qui regneront sur les deux rues » et prend modèle sur une maison voisine en faisant faire « de pierre de taille les deux croisieres du troiziesme cours, les quatre demyes croisieres et petite fenestre du cabinet $»$. Alexandre Evesque, dont la maison est reconstruite sur le Cours, prend soin de faire faire «la premiere rampe et main courante a la veue de la porte » de pierre de taille ${ }^{226}$.

Le plus souvent, la pierre de taille est présente sur une hauteur qui va du niveau de la rue jusqu'à la première ou deuxième coudière. Les portes d'entrée ne sont pas toutes aussi luxueuses que celle de la maison de Jean Louys Allemand, proche de la Poissonnerie «avec ses deux chapiteaux, deux pillastres, cornisses, platfons ou cadre au milieu ${ }^{227}$ entièrement en pierre de taille. De même, si Mathieu de Madières et Louis Boutassi ont la possibilité de faire "autant de fenestres de taille que besoin sera avec leurs caudières ${ }^{228}$, d'autres choisissent de ne l'employer qu'avec parcimonie : uniquement pour les seuls accoudoirs; ou bien, pour les fenêtres entières mais sur un seul niveau. La maison d'Isabeau Chastannier, rue Torte, avait «les croisieres de trois estages aussi de taille» celles du quatrième étaient en brique avec seulement les accoudoirs de taille ${ }^{229}$. Toutefois, toutes les façades ne sont pas aussi remarquables; nombre d'entre elles sont simplement en

223 AD13 360 E 80, fol. 446.

224 AD13 355 E 454, fol. 265.

225 AD13 362 E 115, fol. 51.

226 AD13 390 E 236, fol. 240v.

227 AD13 360 E 50, fol. 853v.

228 AD13 390 E 163, fol. 196.

229 AD13 364 E 293, fol. 626v. 
maçonnerie enduites et blanchies à la chaux, comportant uniquement en pierre de taille une porte d'entrée de la maison et une autre pour la boutique.

\subsection{Pierre de taille neuve ou pierre récupérée ?}

Économie oblige, tous les propriétaires ne peuvent s'offrir du matériau neuf. Si plusieurs contrats prévoient de placer de la pierre de taille neuve, nombre d'entre eux, on l'a dit, préconisent surtout la réutilisation de la pierre de taille récupérée de la démolition par l'entrepreneur. Les témoignages archéologiques sont venus confirmer cette pratique. Ainsi, dans les caves de deux parcelles situées rue de la Guirlande, deux états de construction ont été observés. La partie la plus ancienne contenait des pierres de remploi alors que la plus récente était édifiée avec du matériau neuf (Sillano 2005, p. 479).

Si les contrats stipulent clairement la réutilisation des matériaux dans les constructions neuves et les reconstructions, le choix en faveur de la pierre de taille neuve n'est pas aussi clair. Encore une fois le vocabulaire employé, souvent très allusif, n'autorise des certitudes que dans très peu de cas. S'il est bien souvent suggéré que le maître maçon doit se servir d'une pierre d'une qualité supérieure, on ne précise pas exactement à laquelle on fait référence. Ainsi, des expressions telles que «bonne pierre», «de la qualité la meilleure», «non du plus riche ny du moindre », ne nous disent pas grand-chose sur la pierre dont il s'agit ni sur ses qualités. Faut-il entendre que l'on choisit de la pierre neuve lorsqu'on parle de «bonne pierre »? Dans plusieurs cas, cette option est clairement énoncée, notamment lorsqu'il s'agit d'ouvrages pour conforter le bâtiment, comme on l'a vu pour les fondations de la maison de Jacques Forbin, rue de la Loge ou pour la façade de celle de Jean Bissar. Pour les autres cas la question se pose.

Un élément de réponse est amené dans un des prix-faits dont nous disposons. Le début de contrat engage les maçons chargés des travaux de la maison de Louis Boutassi à refaire la muraille « de bonne pierre de taille » recommandant plus loin «sans y employer aucune des vieilles »; l'acte se termine en leur demandant de fournir «toute la taille neuve ${ }^{230}$ : on peut supposer que dans ce cas précis il s'agit de pierre de taille neuve. Mais on ne peut pas le généraliser à tous les autres.

Car, par ailleurs, les fouilles ont livré des murs de caves bâtis avec des matériaux hétérogènes mêlant moellons de calcaire, galets, cailloux et fragments de tuiles.

230 AD13 390 E 163, fol. 196.
La prescription d'utiliser de la «bonne pierre » pourrait également signifier de ne mettre que des moellons joints par un mortier et pas d'autres matériaux.

Presque tous les contrats stipulent que les maçons pouvaient utiliser la pierre de la démolition, une solution n'excluant pas l'autre pour autant : on pouvait tout aussi bien choisir de mettre de la pierre de taille neuve dans un mur de façade ou des appuis de fenêtres et garder la vieille pierre pour des murs de cloisons ou de mitoyenneté. On peut donc supposer qu'en l'absence d'autre précision, c'est bien de la pierre récupérée que l'on utilisait à condition qu'elle soit «bonne et receptable », ce réemploi permettant de réaliser une économie sur le prix des travaux.

Les propriétaires eux-mêmes conservaient des matériaux des constructions antérieures. Jean Bissar, propriétaire d'un immeuble dans la rue Torte, désire garder les matériaux restants de la démolition ${ }^{231}$. Dans une cave d'immeuble de la fouille Bargemon, un témoignage de cet usage a été remarqué. Situé en bordure de la rue de la Prison et faisant l'angle de la rue des Olives, une série de pierres de taille était soigneusement rangée dans la cave, probablement en attente d'une future utilisation ${ }^{\mathbf{2 3 2}}$.

Ce stockage tend à montrer que la pierre de taille était un matériau couteux, et que tout un marché des matériaux d'occasion devait être organisé.

\subsection{Une pierre de taille de quelle provenance et de quelle qualité ?}

Les contrats de construction évoquent peu la provenance des pierres, pas plus d'ailleurs que celle de la plupart des matériaux de construction. Seules quelquesuns d'entre eux précisent que le maçon devra utiliser des pierres de La Couronne ou de la Garde ${ }^{233}$. En revanche la fourniture de pierre donne lieu à des contrats passés

\section{AD13 360 E 69, fol. 1176.}

232 Sur la manière dont les pierres étaient disposées, $c f$. Duval 2005. Une anecdote qui se passe dans la rue de la Prison où est situé l'immeuble pourrait illustrer et justifier ce dépôt. En 1713, Honoré de Rome d'Ardenne, Capitaine de la Maison du Roi dont il a hérité par testament de Gaspard de Romme (un des gentilshommes de la maison du Roi située à l'ouest de la rue de la Prison) demande aux échevins de la ville que la rue soit agrandie devant la maison qu'il vient de faire reconstruire afin qu'elle soit mise en valeur. L'affaire est très compliquée. Mais il obtient gain de cause, la rue est élargie. Il est probable que les façades des maisons qui lui faisaient face ont dû être détruites et qu'à cette occasion, on a voulu conserver des éléments de la construction pour une réutilisation postérieure (ACM DD 107).

233 «la taille tant dedans que dehors à croches et lances d'un pan espesseur enduitte de bonne pierre de la Coronne» (AD13 $391 \mathrm{E}$ 424 , fol. $514 \mathrm{v}) » ;$ " que les pierres de taille seront de celles apellées de Notre Dame » (AD13 360 E 80, fol. 446). 
entre pereirons et maçons ou tailleurs de pierre qui permettent d'éclairer cette question ${ }^{234}$.

Ainsi, les contrats passés entre des carriers de Martigues, de La Couronne et des maçons ou des marchands semblent prouver que ces deux variétés étaient les plus recherchées. Certains d'entre eux indiquent même le nom du terroir précis : la carrière de Simeon Gay, carrier de La Couronne, qui vend à des marchands de Martigues «quatre cens queirons pierre de la Couronne bonne et receptable » était située «dans le cartier des Gardis au terroir dud. La Couronne » et celle de Jean Remondon au « cartier de Lamoreus $» \mathbf{2 3 5}$.

L'accord liant les maçons chargés des travaux des Arsenaux à leurs fournisseurs stipule que les pierres de taille de La Couronne à fournir seront de trois types différents : rouge et blanche, jaune et commune, chaque qualité ayant son prix.

Quelle importance réelle prenait la part des matériaux dans le prix global ? Là encore, les sources nous présentent des cas très divers et l'on a du mal à identifier des prix bien réguliers. L'acquéreur des pierres pouvait tout aussi bien être le commanditaire qui se chargeait de faire tailler et poser la pierre, que le tailleur de pierre qui cherchait ensuite un client ; ou encore le maçon, chargé d'une construction et de la fourniture des matériaux. Tout dépendait à qui on achetait la pierre : au pereiron, possesseur de la terre et vendeur de ses pierres, ou au tailleur de pierre qui avait déjà effectué un travail dessus après les avoir acquises.

L'intervention de transporteurs était-elle systématique ? En 1615 Cézard Cauvin, chargé du chantier de l'église des Pères Augustins Réformés, passe contrat pour «luy fournir et porter la quantite de cinquante cannes de muraille de pierre pastouire bonne marchande, receptable de l'espesseur de deux pans moingz cart» qu'il paie 2 livres 9 sous pour chaque canne carrée ${ }^{236}$.

Y avait-il un prix fixe pour la pierre brute ? En 1718 , le tailleur de pierre Jean Bernard acquiert «toute la pierre qu'il trouvera à propos » à un carrier de La Couronne pour 37 sols 10 sous; or, la même année, le carrier Joseph Vachier autorise Antoine Nicolas à prendre «toute les pierres de taille [qu'il] pourra faire enlever dans [sa] periere » mais pour 55 livres cette

234 Dans les actes notariés marseillais que nous avons découvert, les pereirons sont de simples vendeurs, propriétaires d'une terre riche en pierre. Ils n'apparaissent jamais comme étant également tailleurs, contrairement à ceux de la région aixoise cités par $\mathrm{P}$. Bernardi.

235 AD13 392 E 103, fol. 75v ; 380 E 204, fol. 476.

236 AD13 383 E 76, fol. 984v. fois ? La qualité de la pierre était-elle supérieure dans le second cas au point qu'elle coûte 18 livres de plus ou bien est-ce la quantité qui a fait la différence?

\subsection{De la prise en charge des enjeux économiques par les autorités communales}

L'intérêt d'employer de la pierre de taille dans les constructions à Marseille n'est pas nouveau. Mais les nombreuses destructions et transformations qu'a subies la vieille ville entre le $\mathrm{XIX}^{\mathrm{e}}$ et le $\mathrm{XX}^{\mathrm{e}}$ s. -percement de la rue Impériale, destruction de $1943, \ldots$ - nous privent de témoins architecturaux des époques médiévale et moderne. Seuls « rescapés » de ces disparitions, la Maison Diamantée et l'Hôtel de Cabre étaient-ils pour autant réellement représentatifs de leur époque (Bertrand à paraître) ? Les études d'archives menées à l'occasion des chantiers de fouille autour de l'Hôtel de Ville, en révélant un grand nombre de constructions privées de l'Époque moderne nous autorisent à replacer ces « exceptions » dans un contexte plus juste. Et ainsi de constater qu'elles figuraient parmi les habitations les plus caractéristiques du quartier. La richesse de leur construction qui les distingue des autres, réservée aux familles nobles en général, n'était pas courante dans le quartier jusqu'au début du XVII ${ }^{\mathrm{e}} \mathrm{s}$.

C'est sous l'influence de deux facteurs que, dans le courant du XVII' ${ }^{\mathrm{e}}$ s., l'emploi de la pierre de taille devient plus courant : tout d'abord, l'enrichissement du groupe des marchands et de celui des artisans, ce qui leur a permis d'accéder à un matériau plus coûteux ; ensuite la volonté du pouvoir royal d'embellir la ville en l'agrandissant. Ce qui a eu pour effet d'abord l'accès d'un plus grand nombre à un matériau coûteux et a parallèlement entraîné une flambée immobilière accompagnée de la construction de nouvelles maisons ; et, de façon concomitante, celle de mettre en place un certain nombre de mesures propres à faire respecter un certain ordre : la création du Cours, lieu symbolique de cet agrandissement, a été accompagnée de l'édification d'un modèle auquel toute nouvelle construction sur cette artère devait se conformer.

L'Agrandissement est l'occasion de mettre la ville en valeur et de la placer sur le même rang que d'autres villes européennes. L'ouverture du Cours est aussi le théâtre de modifications en terme de construction, modifications qui contiennent en elles-mêmes des facteurs de changement économique et vont entraîner des réactions de la part des autorités.

La fouille de l'Alcazar a permis de retrouver des prixfaits d'immeubles situés sur le Cours qui ont été évalués par des experts avant d'être frappés d'alignement et 
reconstruits selon certaines normes. Ils reçoivent d'ailleurs un dédommagement pour cela.

Une délibération municipale accorde à un certain Pontis la possibilité de construire une maison sur un terrain que la communauté lui a cédé, attenant à un immeuble qu'il possédait. Le Conseil décide que la façade de sa maison servira «de règle et modelle aux autres qui seront construites au Cours ». Cette façade comprendra un bossage d'angle, des pilastres, les fenêtres auront des corniches, des triglyphes et des architraves ${ }^{237}$. Ce texte date de 1670 , c'est-à-dire 5 ans avant la «reconstruction » des maisons de l'îlot de l'Alcazar dont les prix-faits exposent d'autres détails sur les volontés municipales : la façade doit être de pierre de taille, le nombre d'étages et de fenêtres est normalisé ; on prévoit une boutique en rez-de-chaussée et une lauvisse au-dessus du dernier étage. La présence de la pierre de taille y est forte, essentiellement en extérieur et toujours placée du côté du Cours.

À partir de ce moment là, la pierre de taille ne va plus être réservée aux seuls hôtels particuliers et édifices religieux ; elle va pénétrer dans les habitations particulières où elle sera de plus en plus présente. Les nombreux prix-faits que nous avons rencontrés en sont la preuve. La pierre de taille est montrée comme un élément indispensable d'une demeure qui se voulait «moderne ». Si bien que cela a entraîné un changement dans les mentalités. Même si on n'était pas d'un rang social très élevé, on aspirait à pouvoir construire dans la nouvelle partie de la ville, mais également dans la ville ancienne, une maison où la pierre de taille était présente. Celle-ci est devenue en quelque sorte, à ce moment là, plus qu'auparavant un signe de reconnaissance d'un certain rang social. Ces nouveaux comportements vont entraîner une augmentation de la consommation et amplifier un marché déjà existant.

\subsection{Les signes de l'évolution}

Parmi les signes avant-coureurs que 1'on peut remarquer, la généralisation du vocabulaire utilisé pour désigner la pierre en est un. Dans son analyse des termes ayant désigné les différents blocs commercialisés en Provence à la fin du Moyen Âge, P. Bernardi montre la richesse des vocables désignant la pierre (Bernardi 2004). Plusieurs achats de pierre du $\mathrm{XVI}^{\mathrm{e}} \mathrm{s}$. à Marseille l'illustrent également. Ainsi, dans l'accord qu'ils passent avec Louis Félix, les carriers Louis Peynier et Esprit Collomb promettent de lui vendre « tous les cairons, bugetz de trois pans et bugez

237 ACM BB 104, fol. 58-60, cité par B. Henin (1986). de moison et autre tailhe que seront necesseres » pour la construction de sa maison devant le Palais ; les prix sont détaillés selon qu'il s'agisse de grases, croisilhons de fenestres, de fugairons, de cairades de moison ou encore de marches bujadées ${ }^{238}$. Chacun d'entre eux désignait des blocs de dimensions différentes selon leur destination.

Or, à Marseille au XVII ${ }^{\mathrm{e}}$ s., ces termes n'apparaissent pratiquement plus dans les actes de la construction au profit de celui de cayron, qui, de plus en plus fréquemment désigne toute forme de pierre ${ }^{239}$. Ainsi, les pierres de taille que se font livrer les pères du Saint-Sacrement lors de la construction de l'église de la congrégation seront «reduite(s) a la forme et manière accoutumée »; mais elles ont été livrées et payées en queirons ${ }^{240}$. Comme si ce terme, évoquant une pratique ancienne, devenait à la fois une unité de mesure et un « objet idéal », une sorte d'étalon (Bernardi 2004). Ainsi, lorsque les architectes chargés de la construction de l'Arsenal passent contrat pour qu'on leur livre des pierres de La Couronne nécessaires, les prix unitaires sont calculés avec le queiron comme seule référence ${ }^{241}$. Par ailleurs, dans le premier tiers du XVIII ${ }^{\mathrm{e}}$ s., plusieurs affiches viennent fixer le taux de la maçonnerie, le prix des matériaux et la taille des pierres.

Cette évolution arrive dans un contexte où depuis plusieurs décennies, les règles en matière de construction paraissent avoir laissé la place à la coutume. Les divers points évoqués dans cette étude ont montré à quel point les manières de procéder font souvent référence à des habitudes connues, mais aussi à l'initiative personnelle du commanditaire.

Confrontés à une question économique qu'ils se voient obligés de gérer, les échevins de Marseille prennent alors un certain nombre de mesures qui visent à normaliser un marché qu'il devient nécessaire d'encadrer. Si dans la pratique le vocabulaire employé pour désigner les pierres est un signe annonciateur de changements amorcés, ce n'est qu'au début du XVIII' $\mathrm{s}$. que les textes règlementaires vont commencer à émerger. Plusieurs ordonnances de police et affiches concernant le taux de la maçonnerie viennent fixer un règlement qui n'avait pas été modifié depuis le début du $\mathrm{XIV}^{\mathrm{e}} \mathrm{s}$. Il semble, à lire le préambule de l'ordonnance de police publiée en 1730, que l'absence de « regle fixe et uniforme » a entraîné beaucoup d'abus tant du point de vue des constructions défectueuses,

\section{AD13 360 E 684v.}

$239 \mathrm{P}$. Bernardi précise que le cayron succède à la dénomination d'ursonus, son ancêtre médiéval, tout en conservant les mêmes dimensions de 2 pans $1 / 2$ en longueur pour 1 pan de hauteur et autant de largeur fixées par les Statuts marseillais de 1315.

240 AD13 380 E 155, fol. 768v.

241 AD13 363 E 175, fol. 557. 
que des prix pratiqués. Les experts eux-mêmes chargés d'intervenir dans les conflits, faute de règles, ont agi différemment les uns des autres. Ce «règlement pour la construction des édifices et bâtimens publics et particuliers et pour la maniere de les toiser ou canner, pour en faire l'évaluation et prisée » a donc pour rôle de fixer des règles en matière de construction, afin d'éviter les malfaçons et les fluctuations de prix injustifiées. L'interdiction $\mathrm{du}$ « regrat de pierres de taille » du 8 juillet 1757 et celle «den faire venir d'autres que de la mesure prescrite par les reglemens » vient confirmer les premières mesures de 1730 et 1745 .
Ainsi face à un marché de la construction grandissant, la nécessité d'apporter un cadre aux professionnels du bâtiment à Marseille s'est imposée. Marseille n'est pas la seule ville concernée par ces mesures. Mais Louis XIV veut la transformer en une grande ville moderne et il s'agit donc de modifier ses habitudes. Pour cela les métiers du bâtiment ne peuvent pas être laissés à la seule initiative des échevins. Il veut leur imposer des règles d'uniformité dans les manières de construire et dans celles de contrôler déjà en place à Paris. Ces premières décisions sont une première étape vers cette normalisation. 


\section{Chapitre 4}

\section{Habiter, entre utilitas et amenitas}

$\mathrm{L}$ es fouilles archéologiques marseillaises ont principalement porté sur des quartiers d'habitat, qu'ils soient à l'intérieur de la ville ou dans ses abords immédiats. Si les vestiges en étaient souvent mal conservés, la multiplication des points d'observation permet une première approche de l'habitat marseillais au Moyen Âge et à l'Époque moderne.

\section{L'organisation spatiale des maisons médiévales (N. Scherrer, R. Thernot)}

Notre analyse de l'habitat urbain marseillais au Moyen Âge s'appuie essentiellement sur les vestiges retrouvés sur les chantiers de grandes fouilles d'archéologie préventive (notamment les fouilles de la place Général-de-Gaulle, de l'Alcazar, de l'Espace Bargemon et du Tunnel de la Major ${ }^{242}$ ). Les recherches d'archives, effectuées dans le cadre des études consécutives à la fouille, sont venues enrichir les données de terrain.

\subsection{Les formes du bâti domestique dans trois quartiers}

Les textes parlent rarement de la structure même de la maison; sont généralement indiqués les confronts et les propriétaires. Dans les textes retrouvés pour la période du XII ${ }^{e}$ au $\mathrm{XV}^{\mathrm{e}}$ s., les maisons sont désignées de façon équivalente sous les termes d'hospitium, domus, ou hostal, tant dans la ville intra muros que dans le bourg de Morier ${ }^{243}$. Dans le faubourg, la typologie se diversifie et apparaissent également les bastita, cabanna, domuncula et moreriis, faisant référence vraisemblablement à des constructions plus modestes, à caractère rural, comme l'indiquent les mentions parallèles de viridarium (verger) et d'ortus (jardin). D'après les Statuts de la ville, en plus des bastida, émergent aussi dans la campagne environnante les turres, dans lesquelles certains propriétaires

242 Voir respectivement Bouiron 2001a ; Bouiron 2001b, Mellinand 2005, Barra et al. 2004.

243 Rigaud, Bouiron 2001 ; Rigaud, Bouiron In : Mellinand 2005. élèvent des colombes. En ville, avec certaines maisons près du Mazeau au $\mathrm{XV}^{\mathrm{e}}$ s., sont mentionnées des dépendances, stabulo et crota. Ces deux types d'espaces témoignent d'une part de la présence des animaux dans la ville et d'autre part du fait que les caves qui apparaissent à Marseille à la fin du Moyen Âge sont considérées comme des espaces annexes ( $c f$. infra § 3.2.).

Dans les fouilles, les vestiges de maisons médiévales relevés, altérés par les constructions suivantes, sont souvent incomplets. Toutefois des tendances s'esquissent à partir des trois sites explorés, correspondant chacun à des quartiers très différents. Près de la cathédrale, les maisons se développent sur des bandes de terrain et jouxtent des espaces ouverts intercalés entre les bâtiments, voire riverains des rues. L'évolution la plus notable à la fin du XIII ${ }^{e}$ s., liée à la proximité de la cathédrale, se traduit par la construction de la maison canoniale. Près du Mazeau, le quartier présente un plan plus structuré, avec des alignements sur rue, où des unités construites différenciées coexistent. Si certaines ont livré peu d'informations et semblent se rattacher au modèle de la maison en lanière, avec des largeurs de l'ordre de 4,50 m, d'autres plus vastes sont subdivisées en plusieurs espaces internes et comportent des espaces ouverts enclos de murs. Dans le bourg de Morier, l'habitat apparaît d'abord évidemment plus lâche avec une seule bâtisse carrée au XII ${ }^{e}$ s. de 9,40 m de côté (serait-ce une de ces tours au sommet desquelles est aménagé un colombier?). Ensuite il se densifie, mais reste plus modeste à première vue, desservi par des voies irrégulières et composé de maisons à deux espaces, souvent traversantes, larges de 4 à $6 \mathrm{~m}$. En revanche, les maisons d'angle, de plan complexe, attestent de programmes plus riches mis en œuvre dans ce faubourg et corrigent l'image modeste de ce quartier extra-urbain qui accueille par ailleurs des édifices religieux importants.

\subsection{Dimensions et organisation du bâti}

Les fouilles permettent de mieux comprendre l'organisation de l'habitat: le plan et les circulations horizontales (et dans de rares cas verticales) sont les 
mieux documentés. Certains sols sont toutefois conservés et des aménagements particuliers ont pu être dégagés.

\subsubsection{Le plan}

Dans la ville épiscopale, près de la cathédrale, les constructions qui s'établissent entre le $\mathrm{X}^{\mathrm{e}}$ et le $\mathrm{XII}^{\mathrm{e}} \mathrm{s}$. se présentent sous la forme de lanières de 4 à $6 \mathrm{~m}$ de large et vraisemblablement de 9 à $15 \mathrm{~m}$ de long, à l'intérieur desquelles des partitions légères ont pu exister. Le découpage foncier suggéré par ces premières constructions conservées, lui-même en grande partie hérité de l'Antiquité, sous-tend le développement de l'habitat au cours des siècles suivants. La maison canoniale construite vers la fin du XIII ${ }^{\mathrm{e}}$ s. se distingue par son emprise de plus de $15 \mathrm{~m}$ de large, et le recours à des formes architecturales savantes comme les piliers porteurs dégageant l'espace du rez-de-chaussée et les voûtes nervurées lancées entre eux pour couvrir ce volume. Par ses caractéristiques, elle n'est pas représentative du bâti domestique médiéval marseillais courant où ces éléments architectoniques, pourtant reconnus dans d'autres villes comme Montpellier, n'ont pas été retrouvés.

Dans la ville vicomtale, dans le quartier du Mazeau, le découpage foncier préexistant, mais affranchi pour l'essentiel des morphogènes antiques, régit l'implantation des nouvelles constructions qui se mettent en place à partir du XII ${ }^{\mathrm{e}} \mathrm{s}$. Ici, les plans des maisons offrent une relative diversité de largeur et d'organisation. Ici encore un bâtiment se distingue ; sa fonction n'est pas assurée, mais il pourrait correspondre à des Bains. Ce grand bâtiment qui borde la rive orientale de la future rue de la Guirlande occupe $23 \mathrm{~m}$ de long et plus de $10 \mathrm{~m}$ en profondeur ( $c f$. infra $\S$ II, 2, 2.3.2.). Ses refends découpent quatre espaces de superficie variable, de 4 à $7 \mathrm{~m}$ de large. Les rares aménagements de ce bâtiment rescapés des restructurations ultérieures laissent envisager qu'il abritait des fonctions non domestiques. Hormis cet édifice, la construction la plus ancienne subsistante est de taille modeste (moins de $4 \mathrm{~m}$ de large) et occupe une position non riveraine des rues (Ilot III, unité G). Les constructions qui se greffent au tournant des $\mathrm{XII}^{\mathrm{e}}$ et $\mathrm{XIII}^{\mathrm{e}} \mathrm{s}$. sur ces premiers bâtiments composent de grands rectangles de $7,50 \mathrm{~m}$ à $8 \mathrm{~m}$ de large et de 15 à $16 \mathrm{~m}$ de long, particulièrement lisibles dans l'îlot II (maisons A, B, D et E, $c f$. fig. 39). Les portées sont comprises entre 4 et $6 \mathrm{~m}$ quand les refends sont conservés. Des espaces de 12 à $45 \mathrm{~m}^{2}$ sont déterminés, $28 \mathrm{~m}^{2}$ étant la mesure la plus fréquente. Les petits côtés de l'emprise sont orientés vers la rue. Pour les parcelles d'angle, la rue principale est indiquée par le choix d'orientation de ce petit côté. La hiérarchie des rues au moment de la création du bâti peut être modifiée par la suite comme sur la rue de la
Prison par des retournements de parcelle; les parcelles situées à l'ouest de la rue de la Taulisse orientent leurs petits côtés vers la rue du Coq-d'Inde dans le courant du Moyen Âge. Il est à noter que les murs de façade sur rue peuvent être construits de façon homogène devant plusieurs entités mitoyennes (îlots II et III du Mazeau). Cette disposition, associée à l'homogénéité générale des modes de construction et des modules, laisse penser que l'habitat a été planifié et mis en place de façon concertée. De telles campagnes de construction caractérisées par des murs reliant plusieurs parcelles mitoyennes ont été observées dans le bourg Sainte-Catherine pour la fin $\mathrm{du} \mathrm{XIII}{ }^{\mathrm{e}}$ s. et semblent correspondre à des ensembles bâtis détenus par un seul propriétaire (Bouiron 2001a, p. 89-115 et p. 319-320).

Dans le quartier suburbain de Morier, le développement du bâti se caractérise par la présence de maisons à deux pièces équivalentes dans l'îlot en bande le plus à l'ouest, et de constructions plus complexes, composées d'espaces de dimensions très variables, dans les îlots situés à l'est de format plus massif ( $c f$. fig. 40). Toutefois, dans les deux cas, les murs porteurs dégagent des espaces de 4,50 $\mathrm{m}$ de large dans les îlots orientaux et de 4 à $5 \mathrm{~m}$ dans l'îlot occidental. Les distances plus grandes pourraient n'avoir pas été couvertes. Les surfaces déterminées par les murs porteurs varient de 14 à $42 \mathrm{~m}^{2}$ dans l'îlot occidental (moyenne : $28 \mathrm{~m}^{2}$ ) et de 28 à $62 \mathrm{~m}^{2}$ dans les îlots orientaux. Tout à fait à l'est et au sud de la zone explorée, des parcelles partiellement encloses de murs et dotées de puits semblent correspondre à des jardins. Les pièces sont en enfilade sans couloirs ni vestibules, qui ne deviennent fréquents qu'au $\mathrm{XV}^{\mathrm{e}}$ s. (Garrigou Grandchamp 1992, p. 82). Des greniers pouvaient également exister. Un exemple de cave médiévale a été retrouvé dans le quartier du Mazeau (îlot II unité D), mais l'usage ne semble s'en développer qu'à l'Époque moderne.

\subsubsection{Les circulations et ouvertures}

Les relations entre la maison et l'espace public ne sont pas toujours faciles à déchiffrer sur le terrain. Les murs sont souvent arasés jusqu'aux fondations, de nombreux aménagements sont donc perdus (portes, fenêtres, escaliers...). Les circulations horizontales restent cependant plus perceptibles que les circulations verticales. Les ouvertures se font très majoritairement sur la rue et, dans les faubourgs, des accès sont parfois ménagés à l'arrière de la maison vers des espaces ouverts (cours ou jardins) comme cela a été observé sur le site de la place Général-de-Gaulle (Scherrer, Bouiron 2001). Dans le bourg de Morier, les ouvertures ne sont pas conservées, mais les maisons ont au moins une façade sur rue et pour 
certaines donnent à l'arrière sur des lopins de terrain clôturés, interprétés comme des espaces ouverts. Les maisons situées à l'est de la rue de Morier sont peutêtre celles qui sont mentionnées dans un texte de 1322 , quatre maisons entourées d'un pati fermé de mur ${ }^{\mathbf{2 4 4}}$. Dans la ville, les espaces ouverts sont beaucoup plus rares : ils sont quasi inexistants dans la ville basse, mais des jardins et espaces ouverts (places, esplanades) subsistent dans le quartier de la cathédrale, ce qui nous est confirmé par les mentions de jardins ou vergers dans les textes d'archives (Rigaud 2004). Le port joue comme un pôle attractif, ce qui explique la densité du bâti dans la ville basse.

Les liaisons intérieures se font par des portes qui sont parfois repérées en fouille par une dalle de seuil, elles sont très rarement conservées en élévation. Il ne semble pas y avoir de largeur type pour les portes ; néanmoins, les ouvertures sur rues sont généralement plus grandes que les ouvertures intérieures ou celles qui donnent sur des espaces ouverts à l'arrière de la maison. Les séparations des pièces peuvent se faire au moyen de portes ou d'arcades retombant sur des piliers. Un module de 0,80 à $0,95 \mathrm{~m}$ de largeur semble se répéter pour les portes intérieures ou secondaires autour de la cathédrale. La maison canoniale fait exception avec deux ouvertures internes de 2,10 m et 1,40 m. Dans le bourg de Morier, les ouvertures ne sont généralement pas retrouvées, à l'exception d'une porte de $1,50 \mathrm{~m}$ dans le bâtiment $4 \mathrm{C}$, considéré comme maison double (cf. infra $\S$ II, 3, 2.3.2.).

Dans l'unité C du quartier du Mazeau, les portes sont situées contre un angle de la maison et non au centre du mur de façade ; aucune d'elles n'est suffisamment conservée pour en déterminer la largeur ( $c f$. infra $\S$ II, 2, 2.3.3.). De manière générale, le creusement des caves modernes a largement contrarié la compréhension de l'organisation spatiale dans ce secteur.

Les portes dont une partie de l'élévation a été retrouvée se composent de blocs taillés soigneusement agencés : ceci explique aussi qu'elles aient fait l'objet de récupérations quasi systématiques. Les seuils retrouvés en fouille sont constitués de dalles taillées (avec ou sans emmarchement) ou d'une maçonnerie de moellons, parfois d'un agencement de fragments de terre cuite. Il est loisible de penser que certains seuils étaient formés de simples planches de bois qui ont bien sûr disparu. Quand elles ont été conservées, les feuillures des seuils montrent que les portes s'ouvrent vers l'intérieur (unité C dans le quartier du Mazeau (Mellinand 2005) et dans le bourg Sainte-Catherine (Scherrer, Bouiron 2001, p. 111).

244 Sur la fouille, les maisons ne sont pas «entourées » mais adossées à des espaces supposés ouverts et fermés par des murs (Rigaud, Bouiron 2001, p. 17, AD13 4 HD B 42 pièce 5).
Dans certaines vues de Marseille (gravures ou peintures), les rez-de-chaussée présentent des ouvertures doubles. Les représentations figurées qui nous sont parvenues datent de la période moderne, la plus ancienne étant le tableau représentant le prêche de la Madeleine, daté du début du XVI ${ }^{\text {e }}$ s. Ce sont peut-être des représentations «arrangées » d'une réalité plus ordinaire. Ces ouvertures ont-elles vraiment existé ? L'arasement des murs ne permet pas de répondre. Des alignements de trous de poteaux retrouvés dans la rue de la Taulisse (Thernot 1997) peuvent signifier la présence de fenêtres à ouvroir dans la façade des bâtiments.

Des fenêtres, rien ne nous est parvenu; là encore, l'archéologue se tourne prudemment vers les représentations anciennes. Les fenêtres semblent être de pierre et sont parfois géminées. L'absence de fragments de verre de vitre dans les couches de démolition laisse penser que l'obturation des fenêtres se faisait avec des étamines ou du papier, ciré ou huilé ou que ces vitres ne nous sont pas parvenues. Les volets de bois n'ont pas laissé de traces pour les archéologues.

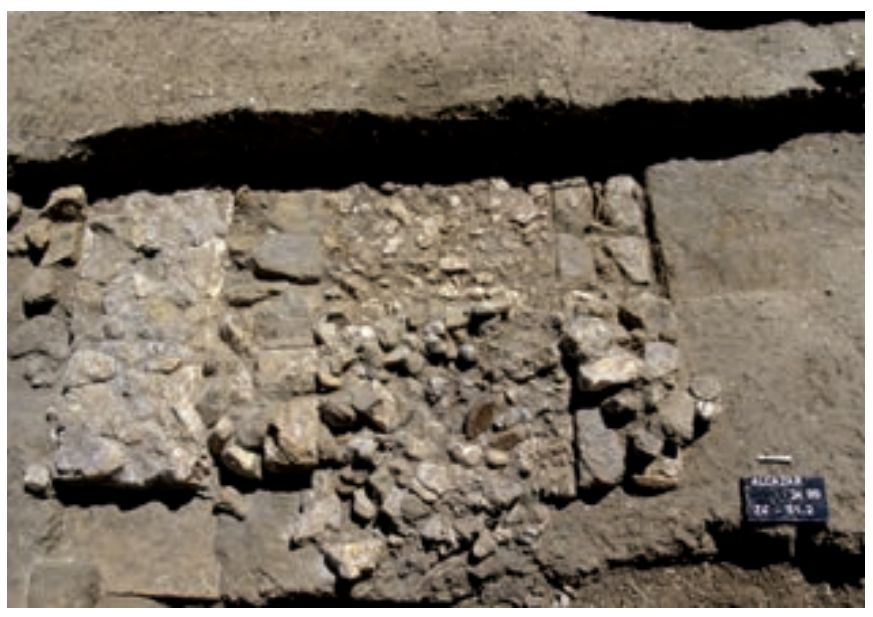

Fig. 91. Vestige d'escalier ? (pièce 4C2) (cl. F. Parent/Inrap).

Il n'existe pas de vestiges d'escaliers, ni dans les maisons, ni dans les rues. Seul un empierrement rectangulaire de $2 \mathrm{~m}$ de profondeur sur $1 \mathrm{~m}$ de largeur dans l'espace 4C du bourg de Morier peut correspondre aux vestiges d'une base d'escalier (fig. 91). La circulation avec le ou les étages pouvait se faire au moyen de simples échelles ou escaliers de bois. Sur les illustrations anciennes, des maisons avec un ou plusieurs étages sont représentées, et les textes d'archives en mentionnent ${ }^{245}$, mais rien dans les fouilles ne permet de confirmer leur existence.

245 Pour exemple, un texte de 1322 mentionne quatre maisons de deux étages dans la carriera del Morier (AD13 4 HD B 42 pièce 5). 
La circulation autour des puits est très diversifiée ; ils sont parfois dans les rues, parfois dans des espaces ouverts clôturés par des murs, parfois dans les maisons, parfois à cheval sur deux maisons ( $c f$. supra $\S \mathrm{II}, 2,3.1 .1$.). Les accès aux puits sont donc fonction de leur statut.

\subsubsection{Aménagements spécifiques : latrines, fosses}

Des fosses sont retrouvées en fouille aussi bien dans les espaces de vie qu'à l'extérieur. Leur fonction reste souvent énigmatique, leur forme et le contenu de leur comblement ne permettant pas d'en définir l'usage. Elles peuvent être le reflet du calage d'une structure ou d'un meuble disparu (coffres, vases de stockage) ou d'une activité qui n'a pas laissé de trace caractéristique. De même le système de fosse visant à recevoir les eaux usées (Napoléone 2002, p. 255-256, fig. 27) n'est pas forcément identifiable.

Le comblement de certaines fosses est parfois plus explicite. Dans un bâtiment du bourg de Morier (bâtiment 4C) ont été retrouvés des fragments de corail puis des recharges contenant des éléments métalliques dont des rebuts de fabrication de fer; faut-il y voir un artisanat lié à la bijouterie ou la succession d'une forge à celle d'un travail sur le corail (tri après pêche ou bijouterie) ? La présence d'un fer d'équidé avec le corail peut aussi laisser penser à un dépôt apotropaïque, le corail étant réputé pour éloigner la foudre des maisons (Alexandre-Bidon, Lorcin 2006, p. 194) et le fer à cheval un porte-bonheur.

Dans le cœur de l'îlot III du quartier du Mazeau, deux fosses associées sont sans conteste le résultat du travail du corail ; l'une contient des déchets de taille de corail, l'autre du sable pur qui est utilisé dans le travail de ce matériau.

Les Statuts de la ville de Marseille réglementent de façon précise le dépôt des immondices au XIII ${ }^{\mathrm{e}} \mathrm{s}$. (Pernoud 1949, L. IV, § 4). Extra muros, des secteurs bien délimités sont affectés à ce dépôt et dans d'autres il est prohibé. Les déchets sont rejetés à l'extérieur de l'enceinte. Les textes réglementaires dont se dote la ville se montrent aussi très soucieux d'éviter tout déversement de matériaux ou d'immondices dans le port afin de limiter son envasement. Les rues devaient être entretenues car les pluies entraînent les ordures déposées vers la mer (chapitre 40 du livre IV). De fait, on ne trouve pas de fosses dépotoirs dans les espaces privés.

Les latrines existent dans le sud de la France dès le $\mathrm{XII}^{\mathrm{e}} \mathrm{s}$. mais ne se généralisent qu'à partir du $\mathrm{XIV}^{\mathrm{e}} \mathrm{s}$. (Garrigou-Grandchamp 1992, p. 90). Quelques-unes, maçonnées, ont été reconnues dans les chantiers marseillais, mais un certain nombre d'entre elles pouvaient être en bois (dans la maison ou la cour), installées en hauteur et avoir disparu (Napoléone 2002, p. 239-263). Dans le quartier du Mazeau, une cuve de latrines voûtée de $2,5 \mathrm{~m}$ sur $3 \mathrm{~m}$, datée de la seconde moitié du XII ${ }^{\mathrm{e}} \mathrm{s}$. a été fouillée dans la maison B. Lors du remembrement parcellaire qui affecte cet îlot, de nouvelles cuves plus petites $(1,03 \times 0,80 \mathrm{~m}$ et $1,82 \times 0,75 \mathrm{~m})$ sont aménagées à l'ouest de celui-ci.

Deux latrines ont été exhumées dans l'habitat situé près de la cathédrale, l'une pour le XIII ${ }^{\mathrm{e}} \mathrm{s}$., large de 2,5 m (maison 7H), l'autre datée du XIV e s. occupant un rectangle de 1,3 m sur $0,95 \mathrm{~m}$ (maison 7J) (fig. 92). Ce sont des structures rectangulaires enterrées et accolées à la maison. Elles se composent de murets de moellons et cailloux liés à la terre installés contre le creusement.

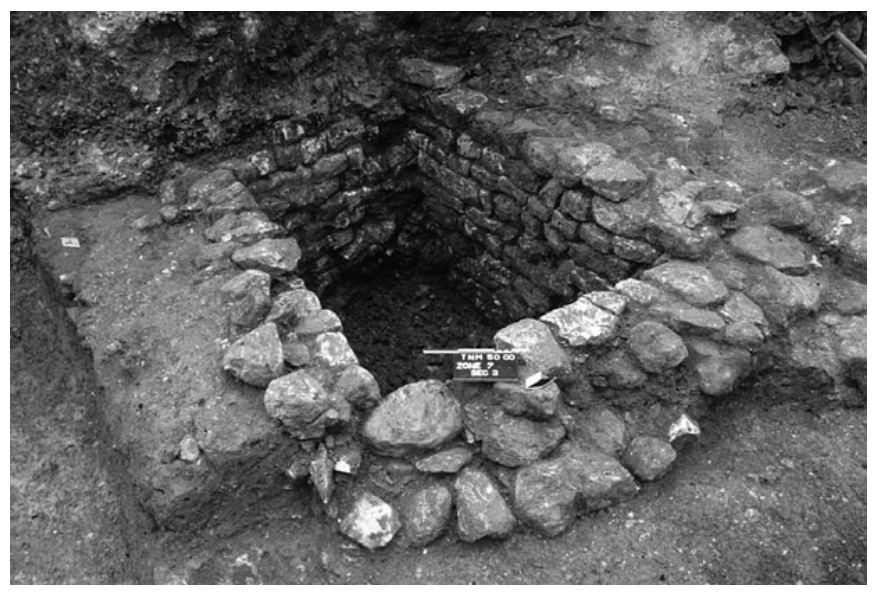

Fig. 92. Latrine du XIVe s. (cl. F. Parent/Inrap).

\subsubsection{Sols et structures de combustion}

Les sols sont majoritairement constitués de terre battue. Leur base est formée d'une couche généralement argileuse surmontée parfois d'une fine recharge de chaux ou sableuse. Souvent de fines couches de sédimentation les recouvrent, bien qu'ils soient manifestement entretenus. Par ailleurs, ils ont pu être couverts de tapis. Les restes carbonisés d'un morceau de natte en fibres végétales tressées mis au jour sur le sol d'une des maisons du bourg de Morier sont peut-être le témoin d'une couverture sur le sol de terre battue (fig. 93).

Quelques rares vestiges de sols construits nous sont parvenus. Pour exemple, le sol du deuxième état de la pièce sud-ouest de la maison canoniale se compose d'un pavement de pierres et de béton de tuile au retaillé (XIII'-XIVes.).

Les ateliers de potiers découverts au quartier SainteBarbe produisaient des carreaux de terre cuite bruts ou décorés (Marchesi et al. 1997). Ils sont certainement destinés au revêtement des sols d'édifices civils ou religieux importants (couvents, églises, châteaux...), puisqu'on ne les retrouve pas dans l'habitat courant marseillais, ni dans les destructions de ces maisons. 


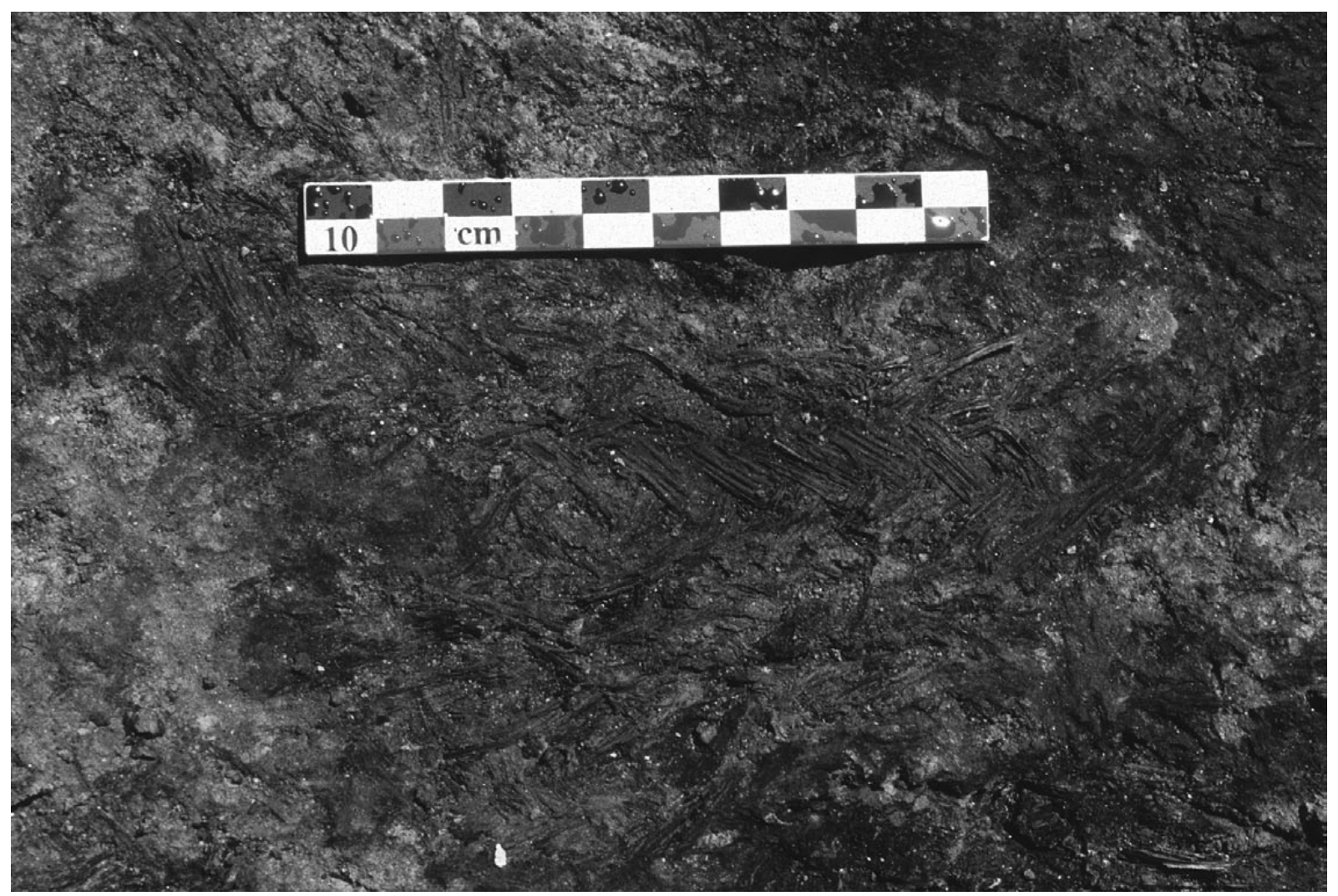

Fig. 93. Sol revêtu d'une natte, carbonisée lors de la destruction du bourg de Morier (cl. F. Parent/Inrap).

Les foyers connus par l'archéologie se situent au rezde-chaussée. Leur fonction est peut-être multiple, ils servent à la cuisine et au chauffage ou au travail. Ce sont généralement de simples cuvettes creusées dans le sol, avec échappement libre de la fumée (fig. 94). Aucune hotte d'évacuation n'est attestée, mais des structures constituées de planches recouvertes d'argile ou des structures maçonnées incluses dans l'élévation du mur ont pu exister (Chapelot, Fossier 1980, p. 224). C'est peut-être le cas du foyer de la maison dite « du Panier » (Reynaud 1998, p. 432). Il se compose d'un agencement de pierres plates associé à une banquette, qui peut former la base d'une substructure disparue, hotte ou cheminée. Des braseros peuvent également être utilisés et ne pas laisser de traces au sol. Le foyer est parfois aménagé de quelques éléments, pierres ou d'éléments de terre cuite formant contour ou base. Les foyers semi-circulaires sont appuyés contre un mur, sinon les foyers circulaires, carrés, rectangulaires ou lenticulaires sont indifféremment dans un endroit ou un autre de la pièce.

La fondation d'une cheminée de 3,30 m de largeur pour 1,30 $\mathrm{m}$ de profondeur, a été observée dans la maison canoniale près de la cathédrale de La Major ; elle date du $\mathrm{XIV}^{\mathrm{e}} \mathrm{s}$. C'est le seul exemple connu à ce jour (fig. 95). Il est cependant possible que des cheminées soient installées à l'étage dans la salle d'habitation ou qu'elles soient intégrées dans l'élévation du mur (Napoléone 2002, p. 239-263) et qu'elles nous échappent de ce fait. Dans ce cas, les foyers retrouvés dans les rez-de-chaussée devaient servir à l'activité effectuée à ce niveau, voire à l'éclairement et au chauffage durant le travail quotidien. La gravure d'Ercole Negro datée autour de 1590 représente systématiquement les maisons avec des cheminées d'où s'échappent de la fumée : s'agit-il d'une stylisation ou d'un reflet de l'existant? Sur le tableau du Prêche de la Madeleine, des cheminées sont représentées sur quelques maisons seulement.

\subsubsection{Les objets de la maison}

Le mobilier de la maison (lit, armoire, coffres...) n'est pas retrouvé en fouille ; il est sûrement déménagé avant les destructions ou, majoritairement en bois, il s'est décomposé. Il est documenté par l'iconographie et par les textes, les inventaires particulièrement (AlexandreBidon 2006, p. 40). Le lit est presque toujours mentionné dans les textes; châlit bordé ou cordé, couvert de couvertures et coussins, il semble que cet élément mobilier occupe une place importante dans la maison (Contamine 1985, p. 421-501).

La vaisselle de céramique ne nous parvient que sous forme de rares tessons ; il est probable que ces ustensiles 


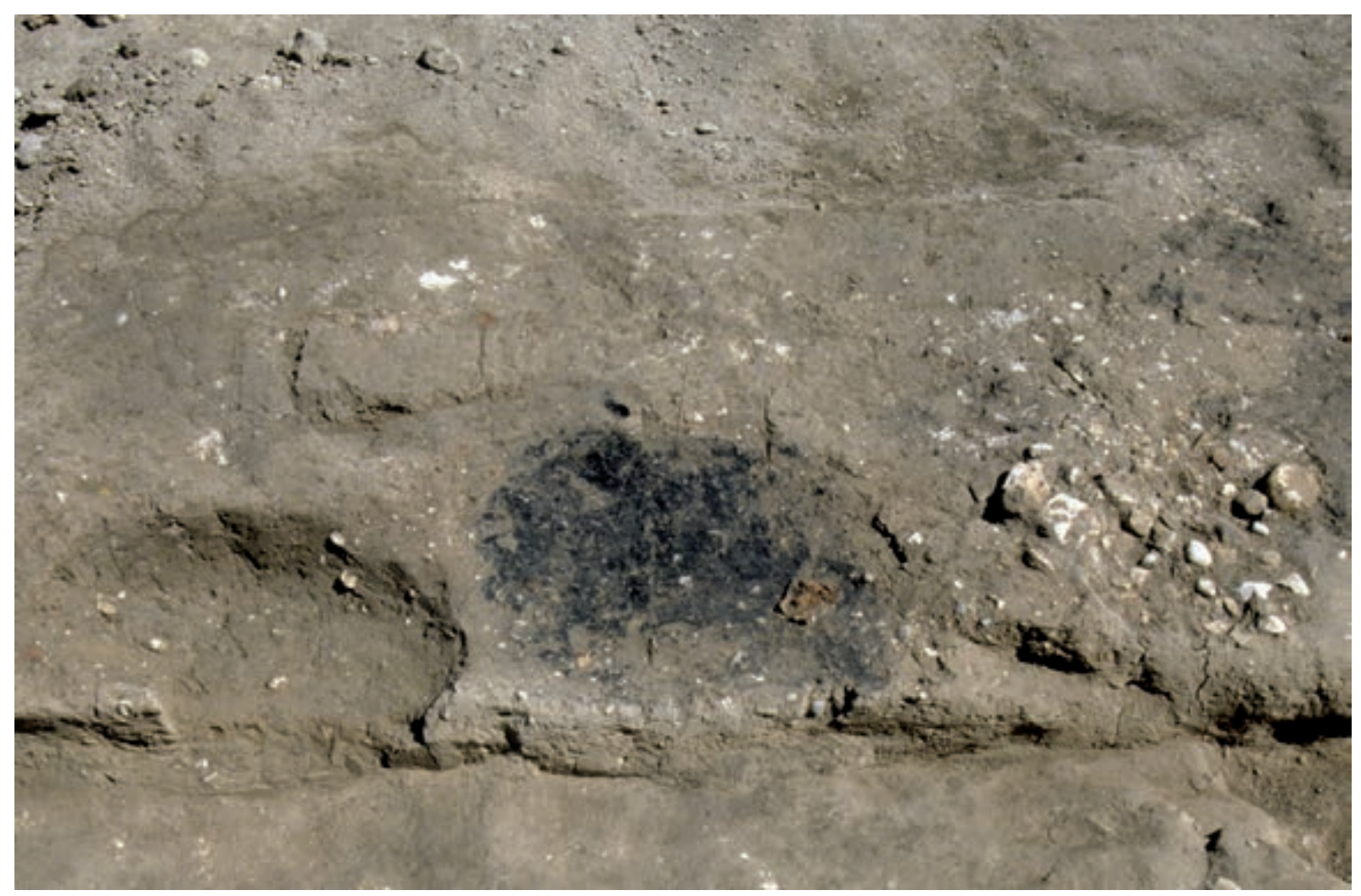

Fig. 94. Foyer dans un des espaces d'habitation du bourg de Morier (cl. T. Maziers/Inrap).

sont conservés lors des déménagements et évacués dans les zones de rejet une fois cassés. Des plats en bois ont existé, mais ne sont pas conservés ; seule une structure hydraulique dans la ville basse a livré des ustensiles de table en bois préservés par l'humidité du milieu ${ }^{246}$. Les objets de céramique sont essentiellement de la vaisselle à usage culinaire et de service (Parent 2005 ; Parent 2001), produite localement et importée du pourtour de la Méditerranée.

Le verre médiéval se conserve très mal ${ }^{247}$, aussi est-il possible que son usage ait été plus répandu que les vestiges peuvent le laisser penser. Les quelques fragments retrouvés en fouille proviennent essentiellement des gobelets, des verres et des bouteilles (Michel 2001 ; Michel 2004).

Peu d'objets métalliques sont conservés, soit qu'ils aient été récupérés, soit refondus. Ceux qui nous sont parvenus restent à étudier de manière plus précise.

Les éléments organiques sont perdus, sauf s'ils ont brûlé, comme le fragment de natte évoqué plus haut (cf. fig. 93).

246 Information orale de P. Mellinand concernant des vestiges du site de la place Jules-Verne.

247 La préparation de la pâte est de qualité moyenne dès l'Antiquité tardive et durant le Moyen Âge ; les objets en verre de ces périodes ne sont que rarement conservés.

\subsection{Les fonctions de la maison}

Les relations entre les hommes se transforment au fur et à mesure de l'essor de la ville ; la relation avec la terre change, de nouvelles professions apparaissent (notamment liées à la gestion de l'espace public), la relation à la ville et à l'habitat se modifie. Ceci génèrera un certain nombre d'améliorations techniques (perfectionnement des systèmes de chauffage et hydrauliques par exemple) mais aussi un changement dans la gestion de l'habitat avec la création de faubourgs, la modification de la gestion de l'espace public, de la relation entre le privé et le public, entre le privé et le travail. Le port forme un «pôle d'attraction » qui suscite des échanges avec les campagnes mais aussi avec l'étranger; ainsi de nouvelles technologies sont importées avec les populations (par exemple le four à barre d'enfournement du quartier des Olliers), les savoir-faire s'échangent et favorisent les évolutions techniques. Ces changements ne sont pas perceptibles au niveau de la structure générale de l'habitat, mais il est possible qu'ils l'étaient au niveau des aménagements sans que l'archéologie puisse en rendre compte du fait des destructions postérieures.

La notion d'aise au Moyen Âge passe essentiellement par les questions de chauffage, d'accès à l'eau, d'évacuation des déchets et eaux sales et de protection contre 


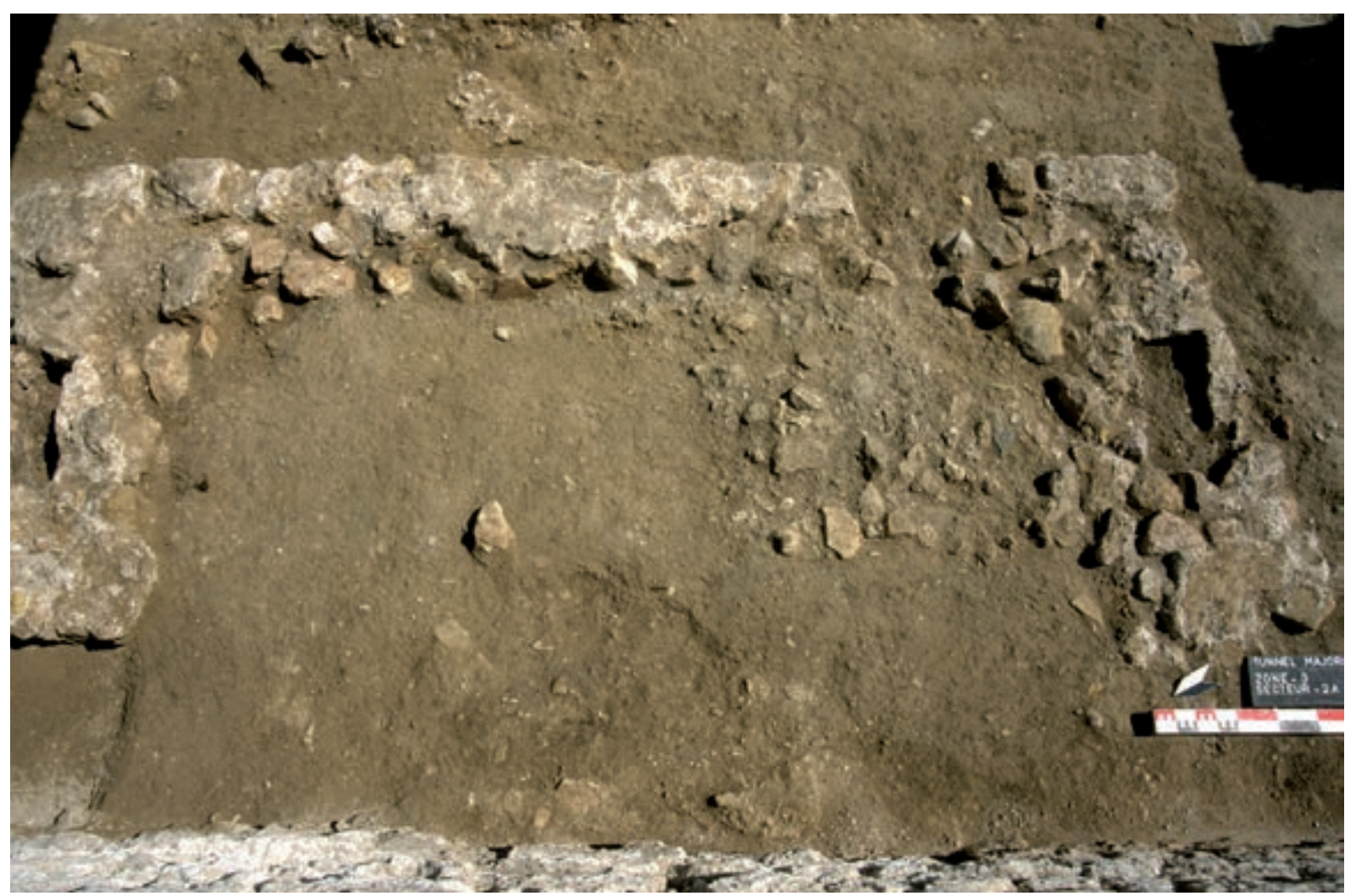

Fig. 95. Fondation de cheminée du XIVe s. (cl. F. Parent/Inrap).

les intempéries et les voleurs. C'est à ces préoccupations ainsi qu'à la question du travail que la disposition de la maison doit répondre au mieux. Les pièces de dimensions restreintes sont faciles à chauffer; il semble que la question de la fumée du foyer ait été un souci essentiel (Alexandre-Bidon 2006, p. 129-130).

À une époque où «le travail vaut baronnie» (Dell'Umbria 2006, p. 29), le rôle des métiers est fondamental dans l'organisation de la ville et par conséquent sur l'organisation domestique. L'essentiel des activités relevait du négoce et des productions artisanales. Les professions, dans leur grande majorité, s'exerçaient dans la maison ; la création de lieux de travail séparés de l'habitat se développe néanmoins dans le courant du Moyen Âge.

La maison accueillait au rez-de-chaussée une boutique, des animaux et des activités professionnelles dont des traces sont parfois perceptibles sur les sols observés en fouille, par exemple le tri du corail dans une maison du quartier de la cathédrale ou le travail du métal dans une maison du bourg Sainte-Catherine. De nombreuses activités professionnelles recensées dans la ville basse ne laissent pas de traces spécifiques, notamment celles qui sont liées au commerce, la confection de vêtements ou de chaussures (Smail 2001). L'artisanat qui est largement familial au début du Moyen Âge, devient une proto-industrie au fil du temps (Dell’Umbria 2006, p. 94-95 ; Bernardi 2006, p. 122). Il semble que, même dans le cas de grandes unités artisanales constituées, une partie de l'espace soit dévolu à l'habitat. Ainsi dans la tannerie du bourg de Morier qui est en activité de la fin du XII ${ }^{e}$ s au milieu du XIII ${ }^{e}$ s., le bâtiment 2 pourrait être dévolu au logement des tanneurs, bien que cette industrie dégage des odeurs importunes ( $c f$. infra $\S$ II, 3, 2.2.3.).

D'après les textes, les pièces ne semblent pas spécialisées comme de nos jours ; il est, par exemple, probable que le lit côtoyait la table (Alexandre-Bidon 2006, p. 133). L'étage (voire les étages) est généralement considéré comme strictement domestique. Les textes, notamment les inventaires, font état de la répartition différenciée du lieu de travail et du logement ainsi que les représentations dans les livres enluminés. Néanmoins, il n'est pas exclu que toute la maison puisse être considérée «comme un atelier potentiel» (Bernardi 2006, p. 119) et que des activités s'exercent dans n'importe quelle pièce. Parfois des apprentis ou salariés peuvent loger aussi dans la maison, soit qu'ils en louent un étage (Garrigou-Grandchamp 1992), soit qu'ils soient hébergés avec la famille. Il est également possible que plusieurs familles partagent un immeuble.

Jusqu'à la fin du Moyen Âge, la notion du bien commun prévaut sur celle de l'individualité, «l'utilitas pour tous » prime sur «la commoditas des particuliers» 
(Braunstein 1999, p. 529). Les valeurs chrétiennes et de chevalerie sont prégnantes dans le mode de vie, au service du collectif, et ce au moins jusqu'à la fin du XIII' $\mathrm{s}$. (Dell'Umbria 2006, p. 65-69). La maison ne correspond pas exactement à l'espace privé tel qu'il est envisagé de nos jours ; si l'espace intérieur relève du domaine privé, l'aspect extérieur est soumis au regard collectif.

La façade de la maison et la qualité de ses aménagements sont des indicateurs du niveau social de celui qui en est le propriétaire ou qui l'habite. Il a été remarqué que les éléments ostentatoires des maisons médiévales se développaient surtout sur les élévations, fenêtres, baies, décors sculptés... (Esquieu 2006, p. 229 ; Garrigou-Grandchamp 1992, p. 63). Ces éléments nous échappent pour l'habitat marseillais très dégradé par les occupations ultérieures. Il est probable que le souci de paraître ne devait pas se limiter à l'espace de la demeure mais s'étendre à l'image globale de la ville. Les toitures marseillaises étaient majoritairement couvertes de tuiles, les couches de destructions en contiennent, les représentations figurées les montrent et les textes en parlent (Rigaud, Bouiron 2001, p. 21). Ce matériau est utile car étanche et ininflammable, mais il répond aussi à un souci esthétique d'homogénéïté de l'urbanisme (Jaritz 2006, p. 250). Les seuls éléments de décor qui nous soient parvenus sont des traces d'enduit mural, généralement blanchâtre ; est-ce un souci de décor ou plutôt une simple protection des murs ? Là encore l'utile est peut-être lié à l'agréable.

Un travail sur les textes d'archives, particulièrement sur les inventaires permettrait de mieux cerner nombre d'aspects de la vie domestique et laborieuse dans la ville et la relation entre la vie privée et le monde du travail.

\section{Manières d'habiter à Marseille : les formes de l'habitat entre la fin du XVI ${ }^{\text {e }}$ et le début du XVIII' s. (C. Castrucci)}

«L'habitat marseillais a mauvaise réputation » : c'est en ces termes qu'André Zysberg, soucieux de réhabiliter l'habitat marseillais du XVII' s., entame le chapitre qu'il lui consacre, dans son ouvrage sur Marseille au XVII ${ }^{\mathrm{e}} \mathrm{s}$. (Zysberg 2007). La thèse de B. Hénin sur l'habitat privé marseillais au dernier tiers du XVII ${ }^{\mathrm{e}}$ s., a certes largement contribué à une meilleure connaissance des manières d'habiter des Marseillais à compter de cette époque. L'analyse socio-politique qu'elle formule (Hénin 1986), et qui se dégage des mutations opérées au moment de l'agrandissement de la ville, ne fait que conforter l'idée que l'habitat marseillais ne se transforme pas seulement de par la volonté royale et selon les goûts urbanistiques en vogue, mais aussi sous la pression de la nouvelle élite locale. Les métamorphoses de l'architecture baroque ont modifié l'enveloppe de nombreuses demeures marseillaises. Mais dans la grande majorité des cas, même après l'Agrandissement, on continue à voir s'imbriquer -ou du moins se côtoyer- sous le même toit, lieux de vie et activités professionnelles : activités artisanales et commerçantes sont toujours présentes en rez-de-chaussée de l'ensemble des immeubles en particulier au nord de la ville, en bordure des anciennes murailles. C'est pourquoi l'image du fameux «deux fenêtres » exigu, mal bâti et inséré dans un tissu urbain aux rues insalubres, reste effectivement très présent dans les esprits. Mais n'est-ce pas le cas pour toutes les grandes villes ? Daniel Roche ne nous décrit-il pas Paris, même encore au milieu du XVIII ${ }^{\mathrm{e}}$ s., comme une ville aux maisons « exiguës avec souvent deux fenêtres en façades, peu de profondeur et quatre à cinq étages » dans des quartiers aux « rues étroites, malpropres, obscures » (Roche 1981, p. 103).

Nous ne reviendrons pas sur la qualité des constructions utilisant la pierre, ce qui, comme le souligne A. Zysberg, est une avancée par rapport à une ville comme Paris ou Rouen dont les maisons sont encore, à la même époque construites en bois (Carbonnier 2006). Ni sur l'état de dégradation dans laquelle sont décrits les immeubles dans la majorité des rapports de future cautelle durant tout le XVII ${ }^{\mathrm{e}}$ s. Il faudrait aborder, pour expliquer cet état de fait, la question du statut foncier de ces maisons, ce qui nécessiterait la consultation d'autres sources d'archives que celles qui ont été sollicitées dans le cadre de cette étude. Toutefois il semble assez facile de croire, comme le démontre D. Roche, que les propriétaires n'ont pas grand intérêt à maintenir leurs immeubles en bon état de conservation à cause du coût que cela représente ${ }^{248}$.

Notre propos est donc ici de déterminer, à partir d'unités d'habitation en apparence semblables, différentes manières d'habiter. C'est grâce à une centaine de rapports de future cautelle, dont l'intérêt a déjà été signalé supra que cela a pu se faire. Ces contrats nous éclairent sur l'agencement des maisons, sur la géométrie des pièces, sur leurs dimensions, leurs ouvertures, sur l'existence ou l'absence d'une cour, des escaliers. Toutefois bien que très riches, ces actes, ne disent pas tout: ils sont muets sur les rapports qui s'établissent à l'intérieur du logement, sur les «façons d'utiliser l'espace pour réaliser les besoins biologiques élémentaires » (Roche 1981). En bref, ils ne nous disent rien des occupants des

248 «Le patrimoine immobilier ancien est moins bien entretenu parce que les réparations coûtent plus, l'investissement rapporte moins et l'on peut conserver un profit locatif à moindre frais » (Roche 1981, p. 102). 
habitations : s'ils sont propriétaires, locataires ou même sous-locataires, si la maison est occupée par une même famille, si elle n'en occupe qu'une partie, ou s'il y a des domestiques qui vivent sous le même toit. Pour connaître ces éléments, il nous faudrait consulter les contrats d'arrentements, les quittances qui nous donneraient le statut et le coût de l'habitation. Nous ne pourrons apporter, de ce point de vue-là, que des hypothèses.

Toutefois, ils permettent d'approcher au plus près l'intérieur des maisons et ainsi de les aborder selon un angle de vue totalement différent. Des manières de vivre diverses se dégagent de la façon dont les différentes pièces sont agencées.

Nous avons ainsi observé l'emplacement de certaines pièces comme la cuisine, l'étendue de la salle basse par rapport à la surface au sol, et celle de la communication entre les différentes pièces. Les rapports ont été interrogés également sur les points suivants : l'entrée de la maison se fait-elle directement dans la boutique ou dans la salle basse ? Y a-t-il une entrée séparée pour la maison et pour la ou les boutiques ? L'escalier existe-t-il de manière indépendante par rapport à l'ensemble de l'immeuble ? Ou bien commence-t-il dans la salle basse ou dans la boutique ? Distribue-t-il des pièces le long de sa montée ou bien y a-t-il de vrais étages ? La cuisine est-elle au rez-de-chaussée ? en entresol ? au premier étage ? La boutique est-elle en relation avec une cave ? De quoi sont composés les étages ?

Ainsi, modifiant notre façon de les appréhender, le regard porté sur les habitations change. Nous ne voyons plus seulement des maisons étroites et exigües avec leurs « deux fenêtres » en façade, haute de quatre voire cinq étages, sombres parce qu'imbriquées dans un tissu urbain trop resséré, aux îlots séparés les uns des autres par des rues étroites et insalubres.

De l'ensemble des réponses apportées à ces questions à partir de l'observation d'unités à la superficie quasiment semblable, nous essaierons de définir différentes manières d'habiter. Au fil des années, les réponses à ces mêmes questions changent, non pas de façon homogène ni progressive, ni dans tous les secteurs en même temps, mais une évolution est visible. Dans un contexte de densification de la population, les immeubles se sont agrandis, on les a rehaussés, étendus en cœur d'îlot. C'est également sur cette évolution que nous nous interrogerons.

Plusieurs types d'habitation existent à Marseille tout au long de la période considérée. Le «deux fenêtres » revêt plusieurs réalités que nous allons tenter d'approcher par la description de maisons qui ont fait l'objet d'une fouille et par la comparaison avec d'autres maisons de secteurs voisins. En effet, nous avons perçu, de l'étude de ces différents textes une évolution qui se fait progressivement mais qui n'arrive pas partout à la fois. C'est de cette évolution «chaotique » que nous parlerons également.

\subsection{La maison « basique »}

Le type le plus simple de maison -doit-on dire la maison la plus petite ?- se rencontre encore au début du XVIII s. Ainsi la maison la plus simple que les sources nous ont livrée appartient à Françoise Tastone qui l'achète le 20 septembre 1732 rue de l'Abadie ${ }^{249}$. C'est une maison de trois étages, mesurant environ $3 \mathrm{~m}$ de large sur $11 \mathrm{~m}$ de long et pour $13 \mathrm{~m}$ de hauteur; elle ne comporte qu'une seule fenêtre par étage. On entre dans une salle basse suivie d'un cellier. Chacun des étages est composé d'une salle dans laquelle la présence d'une cheminée, d'une pille (évier), d'un escudelier pour ranger la vaisselle et d'une armoire atteste qu'elle sert de cuisine. La pièce est éclairée par une seule fenêtre qui donne sur la rue. Les chambres s'ouvrent sur un ciel ouvert, petite cour intérieure.

Le rapport d'estime qui fait état de la maison qu'achète Antoine Dou, rue du Prat, proche de l'Hôtel-Dieu, date de 1661. Élevée de deux étages -seuls le rez-de-chaussée et le premier étage appartiennent à Antoine Dou-elle est composée d'une boutique servant d'étable, d'environ $2,5 \mathrm{~m}$ de large pour $10,5 \mathrm{~m}$ de profondeur et $3,75 \mathrm{~m}$ de hauteur. Au-dessus se trouve une salle de 5,5 m de long sur 2,5 $\mathrm{m}$ de large et $3 \mathrm{~m}$ de hauteur éclairée par deux fenêtres; il y a également une cheminée. On ne précise pas si celle-ci est accompagnée d'un eyguier, d'un escudelier et d'une armoire qui auraient pu prouver que cette pièce servait de cuisine. En revanche, on nous signale que la chambre dont elle n'est séparée que par une cloison, est traversée par les escaliers qui montent à l'étage supérieur dépendant d'un autre propriétaire. Ses dimensions sont quasiment les mêmes que celles de la pièce voisine $(5,25 \times 2,5 \times 2 \mathrm{~m})^{250}$.

Deux autres maisons de même sorte, bien qu'un peu plus élevées, peuvent être comparées à cette dernière : ce sont celles que Jean-Pierre Savignon acquiert de Marc Antoine de Vento en 1657, proche de l'Hôtel de Ville ${ }^{251}$ (cf. infra § II, 2, 3.4.10). Il s'agit de deux bâtisses se faisant face de part et d'autre d'un même îlot, reliées entre elles par une basse-cour intérieure. L'une a deux étages donnant sur un ciel ouvert; seul le premier étage comporte deux fenêtres croisées. Les autres niveaux

249 AD13 390 E 243, fol. 499.

250 AD13 390 E 222, fol. 894.

251 AD13 391 E 386, fol. 642v. 
n'en ont qu'une donnant soit sur le ciel ouvert, soit sur la basse-cour. Elle est composée d'une salle basse de 40 pans de long pour 22 de large (soit 10 x $5,5 \mathrm{~m}$ ) et occupe tout le rez-de-chaussée ; ce qui fait une surface habitable de $55 \mathrm{~m}^{2}$. Une porte au fond de la salle donne accès à une basse-cour. Au-dessus de la salle et aux mêmes dimensions, se trouve la cuisine. Celle-ci occupe donc tout l'étage. Le deuxième étage comprend une chambre, une arrière chambre et un petit cabinet qui donnent sur une cour. Au troisième étage se trouve un galatas, sorte de grenier ${ }^{252}$, mesurant $6 \times 5,50 \mathrm{~m}$ et qui contient une cheminée. Au-dessus, l'espace sous le toit est occupé par une charbonnière en demi-étage. L'autre maison, côté rue Bernard-de-Conques et au fond de la basse-cour, est plus petite puisque la salle basse n'est que de $20 \mathrm{~m}^{2}$ : elle a trois étages dont seul le premier a deux croisières comme l'autre. La salle-basse est suivie d'un petit secret qui ouvre sur un ciel ouvert. Une cave, plus grande que la salle basse, occupe une superficie de 7 x 5,5 m. De la cuisine située en contrebas, on monte à une chambre, située sur la cave, de 5,5 x $4 \mathrm{~m}$. Deux autres chambres sont au même niveau : l'une contient une cheminée et prend jour par une croisière sur une cour. Au-dessus une grande chambre de 5,5 x 5,5 m s'ouvre sur la basse-cour ; à côté d'elle se trouve un petit cabinet ou depance de 1,25 x 2,5 m. Au troisième étage une chambre de 5,5 x 4,25 m côtoie un pigeonnier à côté duquel se trouve un galatas. Les éléments nous manquent pour savoir comment ces acquisitions sont transformées par les deux propriétaires. Jean-Pierre Savignon réunit-il ses deux maisons comme le projettent d'autres propriétaires du même secteur ${ }^{253}$ ?

On rencontre d'autres maisons de ce type dans le même secteur de l'Hôtel de Ville pour la même époque -de petite superficie, élevées de trois étages et d'une lauvisse servant quelquefois de terrasse- : celle de Gabriel Lebois $^{\mathbf{2 5 4}}$ à l'angle de la rue Saint-Christophe et de celle de la Guirlande en deux corps de bâtiments ; celle de Pons Agnel rue Négrel, celles qu' achètent Louis et Pierre Mallet $^{255}$ rue de la Taulisse ou celle de Pierre Ricard ${ }^{256}$ voisine de celle de Jean-Pierre Savignon.

252 F. Mistral traduit le terme de galatas par galetas, chambre haute (Mistral 1878) ; Le Robert (Dictionnaire alphabétique et analytique de la langue française 1983), évoque un logement pratiqué sous les combles, un grenier par extension un logement misérable.

253 Nous avons plusieurs exemples de réunions de maisons. Citons seulement : Mathieu de Madières à la rue de la Guirlande en 1662 (AD13 393 E 82, fol. 715) ; Jean Boisselli rue des Ventos en 1642 (AD13 357 E 133, fol. 462) ; Barthellemy Callamand à l'angle de la rue des Ventos et de la Guirlande (AD13 391 E 376, fol. 926).

254 AD13 391 E 385, fol. 604

255 AD13 353 E 95, fol. 76.

256 AD13 391 E 386, fol. 817.

\subsection{Des maisons à double affectation}

La plupart des rapports de visite étudiés pour le quartier du Corps-de-Ville signalent la présence d'une cuisine au premier étage ; cet état de fait n'est pas toujours en rapport avec la taille de la maison mais plutôt avec l'activité qui se déroule au rez-de-chaussée. Dans les exemples cités, qui, rappelons le, concernent des maisons de petite taille, plusieurs cuisines sont au premier étage, le rez-de-chaussée étant occupé par une seule boutique ou par une salle-basse dans laquelle se concentre l'activité du propriétaire ou de l'occupant de la maison. Ainsi François Courdonneau, chirurgien rue Négrel, a l'intention d'exercer son activité dans la maison qu'il fait reconstruire et demande au maçon de commencer les travaux par la boutique ; celui-ci «sera tenu l'avoir faite et preparée dans trois mois prochains en fasson que led. Courdonneau y puisse entrer et s'en servir à la fonction de sa vacation $\gg{ }^{257}$. La salle basse de la maison que Barthelemy Couzinery possède à côté de la Maison du roi, rue de la Prison, d'environ $40 \mathrm{~m}^{2}$ sert également à l'activité professionnelle de l'occupant; peut-être est-ce une taverne car on y trouve un puits avec une niche pour y mettre des fiolles et des verres, ainsi qu'une despance, placée dans un coin du mur, pour «paistrir le pain » ${ }^{\mathbf{2 5 8}}$.

Les frères Mallet achètent deux maisons, à l'angle de la rue de la Prison et de celle du Coq-d'Inde, dont deux des trois boutiques sont pourvues d'un four de pâtissier ${ }^{259}$. L'entrée de l'une des maisons est indépendante de celle de la boutique. Celle-ci conduit, à l'aide d'un escalier, à un étage qui communique avec l'autre maison acquise. On accède ensuite par une échelle, à un poulailler situé au-dessus. Le premier étage de l'une des maisons est donc composé d'une cuisine à l'arrière du bâtiment d'environ $15 \mathrm{~m}^{2}$; la salle de réception, d'une superficie de $30 \mathrm{~m}^{2}$ fait l'angle des deux rues et est éclairée par trois fenêtres : deux sur la façade nord, une à l'ouest. La chambre est située au second où se trouve encore une autre salle de mêmes dimensions que celle du dessous.

Il y a trois entrées à la maison acquise par Pierre Chainé à la rue du Petit-Mazeau ( $c f$. infra $\S$ II, 2, 3.1.) : deux correspondent aux boutiques respectivement de boucherie et de rôtisserie placées au rez-de-chaussée, la troisième est l'entrée de la maison, dont la surface au sol est d'environ $34 \mathrm{~m}^{2}$.

257 AD13 360 E 80, fol. 446

258 AD13 362 E 115, fol. 51.

259 AD13 353 E 95, fol. 76. 
Ailleurs, la cuisine peut également être placée en entresol : c'est ce qu'on trouve à la maison qu'acquiert Jean Roustan le 5 janvier $1646^{260}$. En gravissant cinq marches au-dessus d'une salle basse on accède à la cuisine d'environ $12 \mathrm{~m}^{2}$, qui se trouve donc placée entre le rez-de-chaussée et le premier étage.

La présence de plusieurs boutiques rend l'organisation de la maison plus complexe ; J.-F. Cabestan évoque l'effet «perturbateur», de celles-ci sur l'ensemble de l'immeuble (Cabestan 1997, p. 167). En effet, le fait que le propriétaire exerce ou pas une activité dans l'une de ces boutiques aura des conséquences sur l'ensemble de la maison. Cette activité nécessite-t-elle la présence d'employés au domicile, comme on l'a vu dans la maison de B. Callamand qui emploie un garçon de comptoir? Il faudra prévoir un endroit pour les loger. Si un ou plusieurs membres de la famille participent à cette activité, une communication entre la maison et la boutique sera indispensable. La présence de la cuisine, en entresol, comme on l'a vu, participe de cette préoccupation et présente également l'avantage d'un gain de place; le reste de l'organisation est défini en fonction de cet élément.

La présence de la cuisine au rez-de-chaussée est également la preuve de la double affectation lieu de travail/ habitation. Le rez-de-chaussée de la maison de François Ganteaume située dans une traverse proche de la rue de Negreoux est, de ce point de vue, intéressant. La cuisine, distincte d'une salle basse d'une grandeur de $30 \mathrm{~m}^{2}$, communique avec cette dernière. Sur le même plan se situent un cellier d'une superficie égale à celle de la salle basse, et une toute petite étable -environ $5 \mathrm{~m}^{2}$. De la salle basse part la montée d'escaliers allant vers les pièces d'habitation : une salle et une chambre au premier étage ; une seconde chambre sous le toit ${ }^{261}$.

La maison du boulanger Julien Meyer, à la rue de la Fontaine-de-l'Aumône, est très surprenante : l'affectation de la boutique est clairement définie puisqu'elle contient un four de boulanger; mais c'est au second étage qu'on a placé un «moullin pour batteler la farine », alors qu'une chambre occupe le premier étage au-dessus du four. Une autre chambre est ensuite située au troisième et un petit débarras au-dessus, à côté du galinier et du pigeonnier. On a ainsi un exemple type d'une famille dont la vie quotidienne s'imbrique totalement avec l'activité artisanale du chef de famille ${ }^{262}$.

La montée d'escaliers de la maison de Barthellemy Callamand ${ }^{263}$, à quatre meyneaux, est également située

260 AD13 373 E 286, fol. 40v.

261 AD13 381 E 243, fol. 572.

262 AD13 381 E 243, fol. 387v.

263 AD13 391 E 376, fol. 901v. au fond de la salle basse, sans séparation avec celle-ci, prouvant que l'occupant des lieux y exerce une activité (parcelle 383, cf. infra § II, 2, 3.5.1.). La maison est ici plus grande puisque sa superficie au sol est de $64 \mathrm{~m}^{2}$ : la cuisine en occupe la moitié, le reste étant pour la salle basse. Les deux étages au-dessus sont composés chacun d'une salle et d'une chambre; dans la montée d'escaliers, entre le premier et le second étage, on trouve une pièce appelée dépence dont la taille est aussi importante - environ $40 \mathrm{~m}^{2}$ - que la salle du premier.

L'organisation de ces immeubles découle donc de ce qui se déroule au rez-de-chaussée : les pièces d'habitation, salles et chambres sont réparties dans les étages. En général, chaque niveau est composé d'une salle, située du côté le plus lumineux, et d'une chambre -quelquefois suivie d'une arrière-chambre- dont la fenêtre s'ouvre sur un ciel ouvert ou arrière cour.

Plusieurs éléments les caractérisent : leur exiguité bien sûr, mais aussi leur double affectation qui impliquent de prime abord, même lorsque la maison n'est occupée que par une seule famille, une grande promiscuité entre les différents occupants. Mais de la présence de domestiques ou de personnes aidant à l' activité professionnelle du maître de maison, ainsi que de celle de locataires dans les étages supérieurs dépourvus de commodités, découle une dépendance de ces occupants les uns vis-à-vis des autres bien plus grande : l'existence d'une seule cuisine pour plusieurs étages, les lieux d'aisance ou lieux communs placés au sommet de l'immeuble ne devaient pas faciliter la vie quotidienne. Aussi, J.-F. Cabestan voit-il dans ce style de maisons, une certaine manière de vivre dans laquelle « un propriétaire principal «chapeautait » [une] maisonnée où chacun des habitants était assujetti à son autorité » (Cabestan 1997, p. 175).

L'évolution que l'on perçoit, à partir du milieu du $\mathrm{XVII}^{\mathrm{e}} \mathrm{s}$. dans l'organisation spatiale des immeubles va dans le sens de la rationalisation de l'habitat: présence d'une seconde cuisine, voire une cuisine par étage, entrée de l'immeuble indépendante de celle de la boutique, avec une montée d'escaliers indépendante, distribution à chaque étage de pièces autonomes, séparées par un petit repos, correspond à la disparition progressive de cette ancienne façon de vivre. Ces transformations ne vont pas se réaliser de manière uniforme. Un des éléments majeurs déclencheur de ces modifications est l'absence à l'intérieur de ces maisons du propriétaire ou du locataire principal (Cabestan 1997).

Mais avant d'aborder cette évolution, il nous faut observer l'état des constructions dans le faubourg des Roubaud, situé par définition hors les murs de la ville, dans la première moitié du XVII $\mathrm{s}$. 


\subsection{Les maisons du faubourg des Roubaud au début du XVII' ${ }^{\text {e }}{ }^{264}$}

Le faubourg des Roubaud n'est encore, à la même époque, qu'un secteur très agricole. Les bâtiments, peu nombreux, consistent essentiellement en écuries ou greniers à foin dispersés sur de grands terrains arborés. En témoigne l'immense terrain que cède, en 1636, Clère de Guérin aux pères de la Mission de Provence pour leur installation ( $c f$. annexe 3.3.). Il s'agit de jardins, sur lesquels les deux seuls bâtiments présents sont la maison que la propriétaire se réserve, à propos de laquelle l'acte de cession ne donne aucune précision, et une étable placée sur une des parcelles destinées à la Congrégation.

De même, le bâtiment que les frères Boisson acquièrent de la discussion des biens d'Antoine Evesque en 1672 ne consiste qu'en une écurie et un grenier à foin au-dessus. On trouve encore, en 1662, un petit bâtiment se trouvant sur l'une des «places à bâtir maison » que cède Jean-Baptiste de Félix à Antoine Evesque ${ }^{265}$ : il n'est élevé que de 5,25 m.

C'est grâce à deux rapports d'expertise décidés par le Bureau de l'Agrandissement que les maisons de ce quartier nous sont connues. Le premier est dressé en 1668, en préalable aux transformations dont le secteur va être le théâtre. Le second est fait en 1682 alors que celui-ci a subi de nombreuses modifications justifiant, dans la plupart des cas, une plus-value assez conséquente. Pour chaque propriété, les experts donnent le nom du propriétaire, les confronts, la date de l'acquisition, et souvent les dimensions. C'est la mise en parallèle de ces deux documents qui permet de saisir l'évolution qui s'est produite. De plus, certaines descriptions fournissent des informations permettant de retrouver l'acte d'achat d'un bien chez le notaire ; lequel acte est souvent suivi d'un rapport de future cautelle ${ }^{266}$. On a alors une idée précise de l'organisation de ces constructions. C'est ainsi qu'on peut remarquer qu'en début de période nombre de petits bâtiments de l'îlot fouillé sont des écuries avec un grenier à foin au-dessus ${ }^{267}$.

Plusieurs petites auberges composent également l'îlot où s'installent les pères de la Mission de Provence en 1636. La proximité d'une des portes de la ville -la porte

264 Rappelons que les maisons dont il est question sont placées sur le seul îlot concerné par la fouille -îlot compris entre les rues du Petit-Saint-Jean, du Baignoir, rue Dauphine, le Cours- elles ne représentent donc qu'un petit échantillon des bâtiments existants à la même époque dans ce secteur relativement étendu.

265 AD13 360 E 158, fol. 262v.

266 Voir l'analyse de cet acte notarié au chapitre intitulé « Du projet au chantier », supra $\S 3.4$.

267 ACM DD 157, fol. 123 à 143 ; DD 164. Voir également infra $\S$ II, 3, 1.2. : « Du faubourg des Roubaud au quartier de Blanquerie ». du Marché- et la présence du Relais des chevaux dans l'îlot voisin ont naturellement suscité l'établissement de ces petits hôtels. L'un d'entre eux est déjà présent à cette date : c'est celui qui a pour enseigne Le Canard, acquis par Henry Geoffroy en 1634. Il est en limite de l'ancien rempart. L'acte de vente décrit une vieille maison de $8 \mathrm{~m}$ sur $20 \mathrm{~m}$ avec des arbres plantés le long du fossé. À proximité du Canard, est installé un autre établissement identique. Il est cédé à George Vesque en 1638, dont le fils Henry entreprend d'y faire réaliser des transformations en 1668 lorsque les travaux de l'Agrandissement sont déjà en cours. Placé sur le Cours à l'angle de la rue du Petit-Saint-Jean, il porte alors le nom du Cheval Rouge.

L'évolution du quartier au moment de l'Agrandissement va se faire à la faveur de ces petits bâtiments qui vont être agrandis et transformés en immeubles d'habitation, et également des auberges dont le nombre va croître. Ainsi, le rapport d'estime établi en 1668, alors que les travaux de l'Agrandissement ne sont qu'entamés, fait état de quatre auberges : Le Canard, Les Trois Mulets, Le Cheval Rouge et Le Petit Saint-Jean; une quinzaine d'années après, la nouvelle évaluation en dénombre trois de plus pour ce seul secteur: Le Petit Paris, L'Écu d'Or et Le Mouton Couronné ${ }^{268}$. Ce qui monte à sept le nombre d'auberges dans le même îlot.

D'autres éléments amenés par l'étude que Jean-Marc Chancel a effectuée pour l'ensemble des maisons du faubourg diversifient la vision du secteur. Certains îlots sont composés de maisons implantées sur des parcelles de 4 à $7 \mathrm{~m}$ de large pour 8 à 14 de long, occupant presque l'ensemble de la parcelle avec seulement une petite courette en fond. Elles sont élevées de deux à trois étages sur boutique et arrière-boutique donnant sur une courette. La montée d'escaliers, appuyée sur le mur mitoyen, conduit aux étages composés d'une salle sur la rue éclairée par deux fenêtres et une chambre sur l'arrière cour ${ }^{269}$.

D'autres établissements religieux viennent s'installer sur d'importantes propriétés à peu près à la même époque que les pères de la congrégation Saint-Hommebon, en arrière de ce qui deviendra le Cours. Les grands propriétaires des lieux leur cèdent leurs terrains : c'est le cas des prêtres de la Mission de France qui établissent leur église, maison jardin et pré sur «deux jardins (...) par eux acquis de $m^{\mathrm{r}}$ des Penes » en 1651. Les trois propriétés sur lesquelles les religieuses Récolettes installent leur monastère dans les années 1646 et 1647, entre la

268 Nous possédons plusieurs contrats de construction de ces auberges.

269 Observations exprimées par J.-M. Chancel (1980, p. 105-115). 
rue Saint-Louis et la rue Thubaneau ${ }^{270}$, paraissent faire exception à cette règle puisqu'elles appartiennent à des artisans ; il s'agit peut-être de lots dont le propriétaire s'est dessaisi antérieurement ${ }^{271}$.

Ces propriétés contiennent des petits bâtiments tel celui situé sur un des jardins que vend en 1672 Jean Pol de Foresta, conseiller du roi et juge du palais. Dénommé le pavillon, sa superficie au sol est d'environ $73 \mathrm{~m}^{2}$; composé de deux étages, sa hauteur est de $10 \mathrm{~m}$. Dans le jardin se trouve un réservoir d'eau avec un lavoir, une fontaine et une treille ${ }^{272}$. Le jardin où s'installent les pères de la Mission de France côtoie une fabrique de cire existant avant l'Agrandissement ${ }^{273}$.

L'affectation très spécifique des constructions de l'îlot fouillé dans le faubourg des Roubaud -établissement religieux très étendu dans l'îlot, auberges- rend difficile une réelle comparaison avec les maisons du quartier du Corps-de-Ville -sauf pour les auberges. Cependant le modèle de maisons décrit par J.-M. Chancel présente de fortes ressemblances avec ces dernières.

La mutation de l'habitat marseillais est concomitante de l'opération d'Agrandissement, conduite à partir de 1666. L'ouverture du Cours impose l'alignement des bâtiments qui s'y trouvent, obligeant les propriétaires à reconstruire leurs maisons. Les premières mesures prises par les directeurs du Bureau de l'Agrandissement concernent essentiellement un aspect décoratif : nombre d'étages, uniformisation des façades, type de décor agrémenté de pilastres, de corniches et d'architraves, qualité des matériaux à utiliser (cf. supra $\S \mathrm{I}, 2,1.3$.). Cette opération marque une étape dans l'histoire de la construction à Marseille. Les normalisations dont elle va être accompagnée signent le début des modifications des manières d'habiter que J.-M. Chancel souligne. Le climat de changement dans lequel se trouve la ville et la mutation d'ordre social dans la direction de celle-ci, entraînent une série de nouveaux comportements visà-vis de l'urbanisme, de la construction, et donc des manières d'habiter qui dépassent les seules volontés royales. Les décisions qui sont prises répondent à la fois à une nécessité d'extension de la ville, à la fois à un désir de l'embellir. De tous ces éléments découleront, progressivement, de nouvelles manières de s'emparer de l'espace d'habitation. Ainsi, le système de distribution des étages par une cage d'escalier indépendante, qui va

270 À cette époque cette rue n'est qu'une courte traverse (cf. supra § I, 2, 1.3.)

271 Voir les actes d'acquisitions des Récolettes : AD13 357 E 137, fol. 280, 13 mars 1646; AD13 363 E 177, fol. 907v, 15 mars 1646; AD13 357 E 138, fol. 1127v, $1^{\text {er }}$ octobre 1647.

272 AD13 363 E 169, fol. 209v.

273 ACM DD 164, fol. 210. contribuer à autonomiser ceux-ci, va entraîner un mode d'occupation des immeubles plus varié : chaque étage devenant indépendant, des familles de statut social différent pourront se côtoyer (Chancel 1978).

Dans la première moitié du XVII ${ }^{\mathrm{e}}$ s., la morphologie de la ville n'a pas encore été affectée par les modifications urbanistiques qui vont accompagner, une trentaine d'années plus tard, une amorce d'évolution de la forme de l'habitat. Celui-ci, établi entre ville et «terroir», tente d'apporter des réponses aux demandes de ceux qui le fréquentent : petits bâtiments agricoles, auberges, petites habitations liées à l'artisanat ou à la petite industrie pratiqué par leur occupant, s'y sont installés que la flambée immobilière va progressivement transformer en immeubles de rapport.

\subsection{L'évolution de l'habitat vers l'immeuble d'appartement}

Les travaux de l'Agrandissement sont venus également résoudre le problème du surpeuplement de la vieille ville causé par l'importante poussée démographique. Ils entrainent la flambée de nouvelles constructions dans les nouveaux quartiers mais aussi les transformations à l'intérieur de la cité qui en découlent sont une évidence. De plus, on assiste, dans la seconde moitié du XVII ${ }^{\mathrm{s}}$ s. à l'arrivée, à la tête de la municipalité, d'une nouvelle classe dirigeante. Celle-ci, porteuse de nouvelles aspirations et d'une autre culture, va encourager les changements dans l'habitat marseillais.

La famille de Vento n'est pas la seule famille noble à céder ses demeures familiales ( $c f$. infra § II, 2, 1.2.3.). D'autres comme les Remezan ou les Village, les imiteront. Ces habitations sont acquises par des marchands ayant obtenu des responsabilités au Conseil municipal et dont le statut social est alors amélioré. Soucieux d'asseoir leur pouvoir et ayant à cœur de l'afficher, ils voient dans le fait de posséder une maison au Corps-deVille, un élément indispensable de leur ascension sociale (Kaiser 1992). Or ces personnes, bien qu'animées par le même goût du pouvoir que leurs prédécesseurs, n'en ont pas moins d'autres préoccupations. En particulier celle de réaliser des affaires, de rentabiliser leurs acquisitions. De plus, la demande accrue de logements due à la poussée démographique, requiert des logements pour les employés des nouveaux propriétaires, pour les domestiques aussi. Mais également pour les artisans ou petits employés qui, attirés par les marchés de la boucherie, de la poissonnerie ou par l'activité du port voient dans le fait d'habiter à proximité de ces lieux d'activité, une nécessité. Tout cela va de pair avec le fait que la «nouvelle clientèle» arrivée au pouvoir est porteuse 
d'exigences nouvelles : désir d'espaces plus vastes, de lieux de vie plus aérés, de plus de confort. Influencée par les discours des médecins qui mettent en valeur des « oppositions essentielles où se nouent les rapports entre bâtiment, rue, cité, société » (Roche 1981), cette nouvelle élite va devoir composer avec plusieurs éléments : celui de devoir augmenter le nombre d'habitations, de faire en sorte que celles-ci soient plus « salubres » (Roche 1981, p. 103), et de tirer parti le plus possible du bâti déjà existant. Il s'agit de faire face à la réalité économique qui pousse les propriétaires à tirer profit de l'entassement d'une population en pleine augmentation.

Dans un premier temps on rehausse les immeubles qui passent systématiquement de deux ou trois étages à quatre surmontés d'une lauvisse ${ }^{274}$ : c'est le cas de la maison d'Anne Audier, rue du Colombier, qui passe à trois étages sur le devant et cinq sur l'arrière ${ }^{275}$; celle de Jean Blanc, rue de Saint-Victoret, est augmentée d'un étage ${ }^{276}$; on rehausse encore celle de Jean Griffet près du Petit Mazeau «pour fere divers estaiges soetables a sa famille » ${ }^{277}$. Pour gagner de la place, on réunit aussi deux petites maisons : le marchand Boissely fait regrouper en une seule les deux maisons à deux étages qu'il acquiert rue de la Guirlande ${ }^{278}$; c'est aussi le cas de Barthelemy Callamand et de Mathieu de Madières dans la même rue ${ }^{279}$.

En même temps, les demeures bourgeoises de la fin du XVI ${ }^{\mathrm{e}}$ s. - Hôtel Vivaud, la demeure de la famille de Vento rue Ventomagy- constituent un modèle dont la nouvelle bourgeoisie aspire à imiter le luxe, l'espace ou le décor; c'est pourquoi certains commanditaires demandent à leur maçon de reproduire tel ou tel décor de façade qu' on imagine « riche », appartenant à un notable de la ville. C'est le cas de François Courdonneau, rue Fontaine-de-l'Aumône, qui demande à son maçon de lui faire «le coing jusques au couvert de pierre de taille en forme de pillastre et à bosse de la mesme fasson de celuy du sr Gueydon rue Coutellerie » ${ }^{280}$; ou celui de Philippe Silvestre, rue de la Croix-d'Or, qui veut que les fenêtres du premier étage soient décorées de moulures «comme celles de la maison de Demantellery ${ }^{281}$. Au-delà des modifications architecturales, il s'agit de transformations plus profondes puisque ce sont les manières d'habiter

274 Ce en quoi Marseille est d'une certaine façon « en retard » par rapport à Lyon dont les maisons sont à 4,5 et même 6 étages dès le début du XVII' s. (Cabestan 1997).

275 AD13 358 E 134, fol. 151.

276 AD13 361 E 73, fol. $15 \mathrm{v}$.

277 AD13 360 E 72, fol. 360.

278 AD13 362 E 91, fol. 703.

279 AD13 391 E 376, fol. 926 et 393 E 82, fol. 715.

280 AD13 360 E 80, fol. 446.

281 AD13 352 E 155, fol. 223. qui vont changer. Celles-ci ne vont pourtant pas se faire uniformément, ni dans le temps ni dans l'espace.

Doit-on voir l'origine des changements opérés dans les maisons à la seule décision royale ? Il est plus exact de dire que celle-ci arrive dans un contexte où la pensée sur le «désir» d'habiter est en train d'évoluer. Même si ça n'est qu'une ébauche. Car les décisions administratives portent plus sur l'« enveloppe architecturale » prescrivant depuis le XVII ${ }^{\mathrm{e}} \mathrm{s}$. des alignements, empêchant l'emprise trop importante des immeubles sur la rue, mais s'inquiétant peu de la spatialité ou de la fonctionnalité de l'habitat. Quoiqu'il en soit, l'alignement du Cours qui va entraîner la réfection d'un certain nombre d'habitations déjà en place, va être l'occasion d'édicter des «modèles » dont l'influence dépasse la seule ville de Marseille. L'agrandissement de la ville n'est en effet pas un mouvement isolé. Il reflète la volonté royale de «prendre en main [le] fait urbain » (Hénin 1986). L'urbanisme baroque touche plusieurs villes françaises mais aussi européennes. De nouvelles villes naissent, dont la morphologie puise son inspiration chez les architectes italiens.

À Marseille, les premières transformations ont lieu dans le faubourg des Roubaud, premier secteur de la ville à être concerné par les travaux de l'Agrandissement. Outre les innovations mises en application sur le Cours par les directeurs de l'Agrandissement, les constructions dans cette nouvelle partie de la ville vont prendre une tout autre allure. De nouvelles formes de bâtiments voient le jour : le fameux immeuble à trois fenêtres dont Béatrice Hénin souligne la naissance à cette époque, ainsi que les hôtels particuliers comprenant ou non un jardin et composé d'un ou plusieurs corps de bâtiments.

Le cœur de la vieille ville offre moins de possibilités d'extension. La mutation urbanistique sera moins visible du fait qu'une vision globale de la ville est seulement en train de naître. Dans ce secteur, les modifications vont continuer à se faire « au coup par coup ». Telle ou telle maison est rénovée, agrandie, ou rehaussée au gré de mutations d'immeubles ou d'une décision municipale d'aligner une rue. De la même façon que l'urbanisme n'est que très progressivement modifié, l'ensemble des habitations du Corps-de-Ville ne va pas évoluer simultanément.

Parmi les éléments relevés dans les rapports de future cautelle et dans les prix-faits, plusieurs sont annonciateurs de l'évolution de l'organisation spatiale des immeubles, en particulier l'entrée de l'immeuble séparée de celle de la boutique, rendant la montée d'escaliers indépendante et chargée de distribuer des étages autonomes. La présence d'une seconde cuisine en étage dans l'immeuble préfigure de ces changements : en 1683, à la maison 


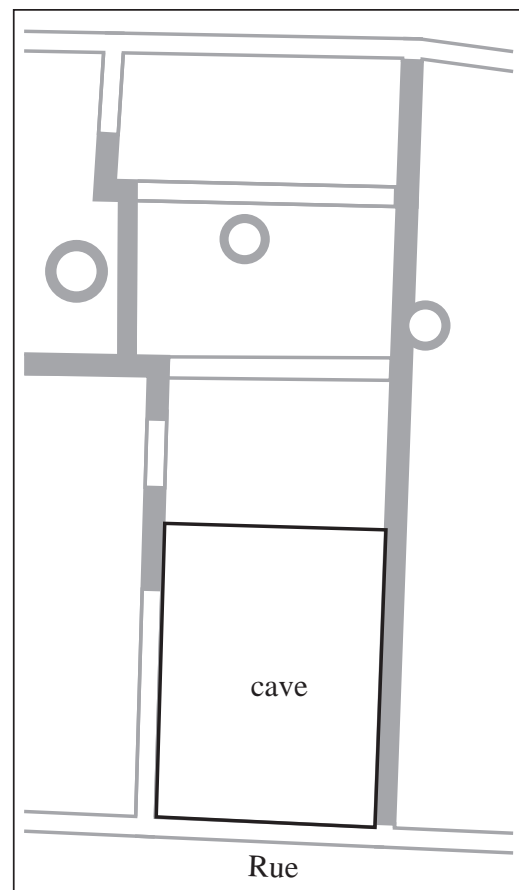

Sous-sol

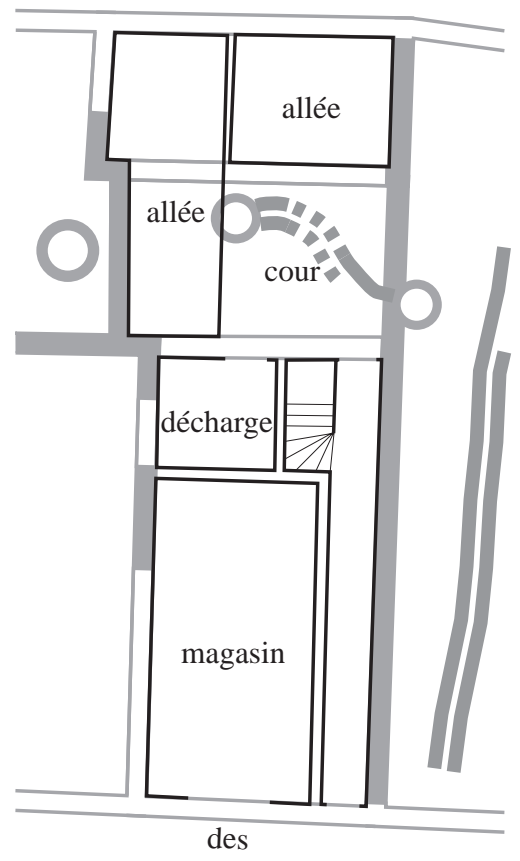

Rez-de-chaussée

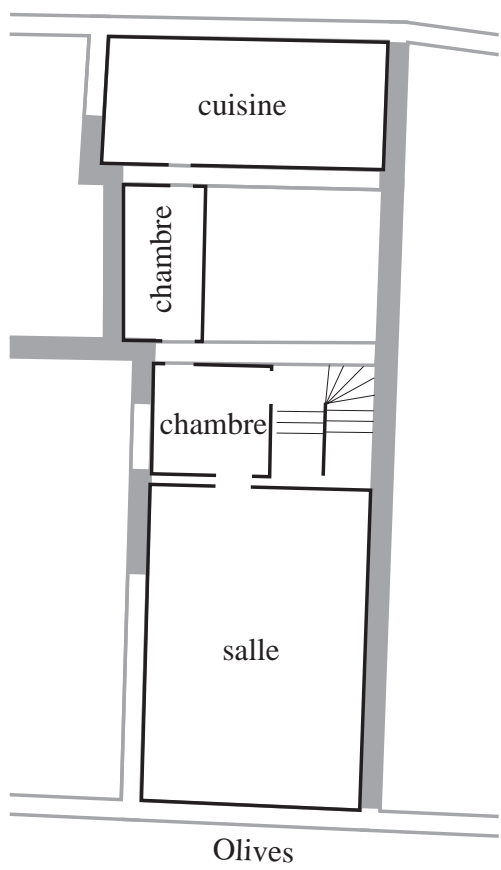

Premier étage

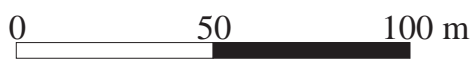

Fig. 96. Reconstitution de l'aménagement interne de la parcelle 372 en 1707 (DAO B. Sillano/Inrap).

qu'Anne Audier fait reconstruire rue du Colombier on installe un pille (évier) à chaque étage. Cette nouveauté est accompagnée de l'installation d'un réseau d'écoulement des eaux usées qui fait également partie de cette évolution. C'est pourquoi on installe désormais les éviers « avec leurs bourneaux pour conduire l'eau à la rue et les gorgues de taille au plan de la rue ». Outre la recherche des décors déjà évoqué, les changements vont en général dans le sens de plus de confort, plus d'espace et d'une meilleure hygiène (installation des lieux communs dans les derniers étages, système d'évacuation des eaux).

Au Corps-de-Ville, ce n'est qu'au début du XVIII ${ }^{\mathrm{e}} \mathrm{s}$. que ces mutations sont visibles dans certains immeubles : la maison de Louise Blanche n'est pas la seule à adopter une superficie importante des pièces principales (fig. 96), entre 40 et $50 \mathrm{~m}^{2}$ de superficie ${ }^{282}$; celles de la maison de Jean Olivier sont également très vastes, y compris la cuisine dont la superficie est de $20 \mathrm{~m}^{2283}$. Dans l'Agrandissement, dès 1673, Antoine Amalric fait construire deux maisons, rue de la Poissonnerie, caractéristiques des nouvelles transformations. Elles sont composées chacune de quatre étages, dotés de douze

282 ACM FF 1192, fol. 57.

283 AD13 361 E 117, fol. 540. cheminées -c'est-à-dire trois par étage- accompagnées chacune d'un escudelier, d'une pille et de leurs borneaux pour conduire l'eau à la rue ${ }^{284}$. Ce qui est le comble de la modernité puisque ceci atteste de la présence de l'eau dans plusieurs pièces de l'étage. Enfin, la cuisine ne se contente pas de gagner les étages, mais commence, de plus, à être indépendante des autres pièces de celui-ci ; en général, sa porte d'entrée est située de l'autre côté d'un palier dont la présence est aussi une nouveauté. Si chaque étage de la maison de Jean Fesquet, rue de la Guirlande, comporte trois portes par palier, le premier étage de la maison de Jean Olivier n'en comporte que deux. L'une qui conduit aux pièces de réception et au reste de l'appartement; l'autre qui a un accès direct dans la cuisine. Ainsi, les occupants des autres étages peuvent accéder à la cuisine sans pénétrer dans l'intimité de ceux du premier.

Parallèlement à la transformation de l'agencement de l'immeuble, les façades vont être traitées de façon particulière par les architectes : elles deviennent le lieu d'une écriture savante, où les références à la "grande architecture » auparavant réservée aux demeures nobles,

284 AD13 380 E 169, fol. 380. 
viennent confirmer le progrès social de la bourgeoisie. Celles de la maison d'Antoine Amalric sont non seulement construites entièrement de pierre de taille, mais ont un « cordon » qui souligne chaque étage. Les angles de l'immeuble sont également traités en pierre de taille « en forme de pillastre », et chaque entrée est dotée de sa porte de pierre de taille avec sa fenêtre à bossage.

\subsection{Un lieu de vie plus luxueux ou plus autonome?}

En ouvrant les intérieurs des maisons de deux secteurs de la ville, cette courte recherche poursuivait un double but : celui de définir la manière dont vivaient les Marseillais au XVII ${ }^{\mathrm{e}}$ s. Il s'agissait également de montrer les transformations dans les manières d'habiter en ville et de tenter de découvrir sous l'effet de quels facteurs ces mutations s'opéraient.

Les secteurs sur lesquels elle s'appuie étant limités aux deux quartiers du Corps-de-Ville et des Roubaud (ou Blanquerie), les récits sont sélectifs et l'étude n'est donc pas exhaustive. Cependant quelques étapes significatives de l'évolution de l'habitat marseillais et de l'élaboration de l'immeuble d'appartement ont pu être saisies. La mise en relation de plusieurs faits parfois contradictoires a conduit à un résultat unique si ce n'est à l'image d'un habitat homogène.

D'une façon générale, on peut dire qu'à partir du milieu du XVII ${ }^{\mathrm{e}}$ s. les étages s'acheminent vers une autonomie progressive : les pièces éparpillées sur plusieurs niveaux disparaissent ; « les cellules d'habitation... tendent à rassembler leurs différents organes constitutifs à l'intérieur d'une enceinte » (Cabestan 1997) transformant chaque étage en unité indépendante. Les portes palières, dont on a signalé l'apparition, et qui permettent d'isoler la cuisine au-delà d'un palier commun, vont voir leur nombre progressivement se réduire, et ainsi la porte unique va symboliser cette autonomie. Le vocabulaire évolue également et de nouveaux termes apparaissent : l'appartement dans lequel Jean Fesquet en 1714 a installé un comptoir au deuxième étage de son immeuble, alors que le salon est situé au-dessous.

C'est ainsi que progressivement les maisons deviennent des immeubles. Sous la poussée de faits complexes : d'abord le refus de dépendre du chef de famille, le désir de plus de confort, de disposer de plus d'espace. Les constructeurs ne se contentent plus de répondre aux exigences des commanditaires; ils cherchent à répondre aux besoins d'une clientèle de « locataires potentiels ». D' autant que, comme l'observe J.-F. Cabestan, le rapport du logement au sol se modifie. D'une part, l'élévation des pièces de la vie intime abandonne au rez-de-chaussée les seuls éléments qui ne peuvent pas gravir les étages : écuries, remises, puits, caves. D'autre part, elle entraîne la cohabitation sous le même toit, de personnes étrangères les unes aux autres ; celles-ci vont avoir d'autant plus à cour d'occuper des appartements indépendants.

\section{L'habitat au sein du parcellaire : l'exemple des parcelles fouillées}

Dernière étape de l'approche de l'occupation du territoire urbain, nous abordons, à l'échelle de la parcelle, la répartition et l'évolution des zones bâties. Il est entendu que la parcelle n'est pas une entité figée puisqu'elle n'est que la traduction d'une propriété foncière qui évolue avec le temps; néanmoins, en dehors des cas particuliers où elles résultent d'un regroupement d'unités antérieures, les parcelles dessinées sur le cadastre napoléonien s'avèrent être la traduction d'un découpage foncier relativement pérenne. Nous essaierons également de cerner les traits caractéristiques de cet habitat, au niveau de son étendue, son élévation, sa distribution, ou encore son aspect extérieur, autant de matières qui peuvent être abordées grâce aux données de fouille et aux textes, devis et expertises.

\subsection{La maison (B. Sillano)}

Afin de traduire la diversité des habitations urbaines sans anticiper sur la classe sociale des occupants, nous avons pris le parti de les diviser en trois catégories basées sur la structure de l'habitation. La première concerne les bâtiments à travée unique, pour la plupart des habitations modestes, aux contours hérités du Moyen Âge, et associées aux classes populaires. La seconde concerne les bâtiments d'angle, souvent très différents des premiers ; et la dernière concerne les bâtiments à plusieurs travées, parfois en angle, et que nous appelons de manière un peu abusive les hôtels particuliers.

\subsubsection{La maison à travée unique}

On peut retrouver une évolution de ce type d'habitat à travers les siècles et en fonction de la place disponible pour la construction : ainsi le quartier de l'Agrandissement présente des caractéristiques différentes du cœur de ville.

\section{La maison à travée unique au XVI ${ }^{e} s$.}

En raison des remaniements dont font l'objet les habitations au cours de la période moderne, du peu de mobilier céramique datant, et de l'absence de textes 
$\mathrm{du} \mathrm{XVI}^{\mathrm{e}}$ s. suffisamment explicites pour reconstituer l'habitat, nous n'avons aucune certitude concernant le bâti du début de l'Époque moderne. Pourtant, l'Histoire nous l'apprend, la population, toujours confinée entre les vieux remparts, connaît alors un essor considérable qui suppose implicitement une augmentation de la surface habitable.

Quelques rares exemples de niveaux archéologiques, incontestablement datés du XVI ${ }^{\mathrm{e}} \mathrm{s}$. par le mobilier, attestent que le bâti est alors en pleine mutation. Près du Palais royal, les parcelles 365 et 366 voient leurs constructions médiévales entièrement dérasées, et remplacées par des bâtiments où toutes les formes de l'habitat moderne sont présentes. Dans l'îlot suivant, un mur de refend massif reprend l'axe de la parcelle 386, attestant de l'unification précoce de cet immeuble. Mais, en dehors de ces rares exemples ( $c f$. infra, les parcelles d'angle), force est d'admettre que nous ne savons pas reconnaitre l'habitat du XVI $\mathrm{s}$. Tout au plus constatons nous qu'il existe un intermédiaire entre l'habitat médiéval, étriqué, et l'habitat dense et envahissant du XVII ${ }^{\mathrm{e}} \mathrm{s}$. En effet, si l'habitat se cantonne initialement à de petites unités très étroites réparties sur le pourtour des îlots, il gagne progressivement le cœur d'îlot pour aboutir à un habitat aux contours complexes. Par déduction, nous pouvons supposer que ces unités « génératrices » correspondent aux logis du début de l'Époque moderne.

Dans la plupart des cas, de manière plus flagrante dans les quartiers du Panier et de Saint-Jean qu'autour du port, les travées sont étroites, directement héritées de l'époque médiévale. Citons par exemple les bâtiments établis le long de la rue de la Guirlande, face au marché du Petit Mazeau (parcelles 400, 401 et $402-c f$. infra $\S$ II, 2, 3.1.). Larges de $4 \mathrm{~m}$, ils ont une profondeur d'environ $8 \mathrm{~m}$ qui pourrait n'avoir été fixée qu'au début de l'Époque moderne, comme tend à l'indiquer la nature différente des murs de devant et de derrière. Par là-même, nous reconnaissons dans la distribution des caractères novateurs. L'espace est divisé en deux avec, sur la rue, une pièce qui occupe toute la largeur pour une profondeur de $6 \mathrm{~m}$, et en retrait un espace profond de $2 \mathrm{~m}$ où sont regroupés l'escalier, le puits, un éventuel puits de lumière et des débarras (cabinets, souillardes). C'est la configuration la plus courante pour les habitations sises dans le quartier du Panier. Pour exemple, les îlots détruits pour réaliser la place des Pistoles se présentent sous la forme d'un chapelet de parcelles relativement similaires disposées de part et d'autre d'un axe médian; elles ont une largeur qui oscille autour de $4 \mathrm{~m}$ et une longueur qui varie de 6 à $10 \mathrm{~m}$ (fig. 97). Lorsque la parcelle est courte, l'escalier à vis est disposé dans un angle opposé à la rue. Lorsqu'elle est longue, audelà de 7,50 m, l'escalier est placé au fond de la pièce principale, ou immédiatement après, et une arrière-boutique, probablement aveugle, est alors créée en fond de parcelle. Dans quelques cas, une cloison ménage un couloir le long de la boutique, réduisant d'autant sa largeur, parfois jusqu'à seulement 2,50 m, mais nous ne savons pas si celui-ci était prévu initialement dans la distribution ou s'il s'agit d'une adaptation récente.

Dans aucun cas, nous n'avons trouvé trace d'un escalier à vis circulaire, courant à l'époque renaissance lorsque le bâtiment dépasse deux étages et remplacé ensuite par l'escalier rampe sur rampe. Dans quelques cas, nous pouvons restituer une cage de forme carrée, d'environ 2 à $2,50 \mathrm{~m}$ de côté, qui pourrait très bien remplacer un prédécesseur de forme circulaire (fig. 98). Lorsque c'est possible, ces circulations sont repoussées à l'extérieur, en cœur d'îlot, ce qui libère plus de place. Ainsi, la boutique que possédait Claude Garcin sur le Petit Mazeau en $1655^{285}$, occupe tout «le plan de ladid. maison », soit 4,50 m par 7,50 m et «la visette faicte a deux mainaux (...) prend son entrée dans lad. boutique tout contre la cheminée de lad. rostisserie ». Tout contre se trouve «un petit ciel ouvert de deux pan et demi de large tout contre la muraille » du voisin. De la même manière, l'îlot situé à l'est de la zone est suffisamment large pour permettre la création d'un espace ouvert central avec les circulations. La parcelle 394, décrite en $1656^{286}$, est large de $4,80 \mathrm{~m}$ et traverse l'îlot dans sa largeur (fig. 99 et 100). Aux extrémités se trouvent des bâtiments, certainement indépendants à l'origine, d'environ $8 \mathrm{~m}$ de longueur. $\mathrm{Au}$ centre, une vaste cour accueille un escalier qui remplace les anciennes visettes antérieures au regroupement. Enfin, sur le Petit Mazeau encore, en 1680, la maison de Pierre Chainé est de dimensions similaires, mais, comme elle est entourée par des rues sur trois côtés, elle est contrainte d'intégrer l'escalier dans la boutique ${ }^{287}$.

Près de la Loge, les bâtiments sont plus longs. Ainsi, la maison de Louise Blanche (parcelle $372^{288}$ ) comprenait, en 1707, un corps de logis frontal de $4 \mathrm{~m}$ de largeur pour $11,50 \mathrm{~m}$ de profondeur hors murs. Ce bâtiment, dont nous n'avons reconnu qu'une partie de ses substructions reprises par des caves, était bordé à l'ouest par une rue, absorbée à l'Époque moderne et au nord par une placette, devenue cour intérieure. La maison voisine (parcelle 371) est plus large, mais la présence, jusqu'au $\mathrm{XVII}{ }^{\mathrm{e}}$ s., de canalisations en son sein indique qu'elle a été bâtie tardivement.

285 AD13 351 E 962, fol. 719v.

286 AD13 391 E 385, fol. 604.

287 «Le plan de lad. boutique ou rosticerie quelle se treuve séparée par un buguet que sert de séparation de lad. boutique et vizette» (AD13 391 E 406, fol. 162v).

288 ACM FF 1192, fol. 57. 


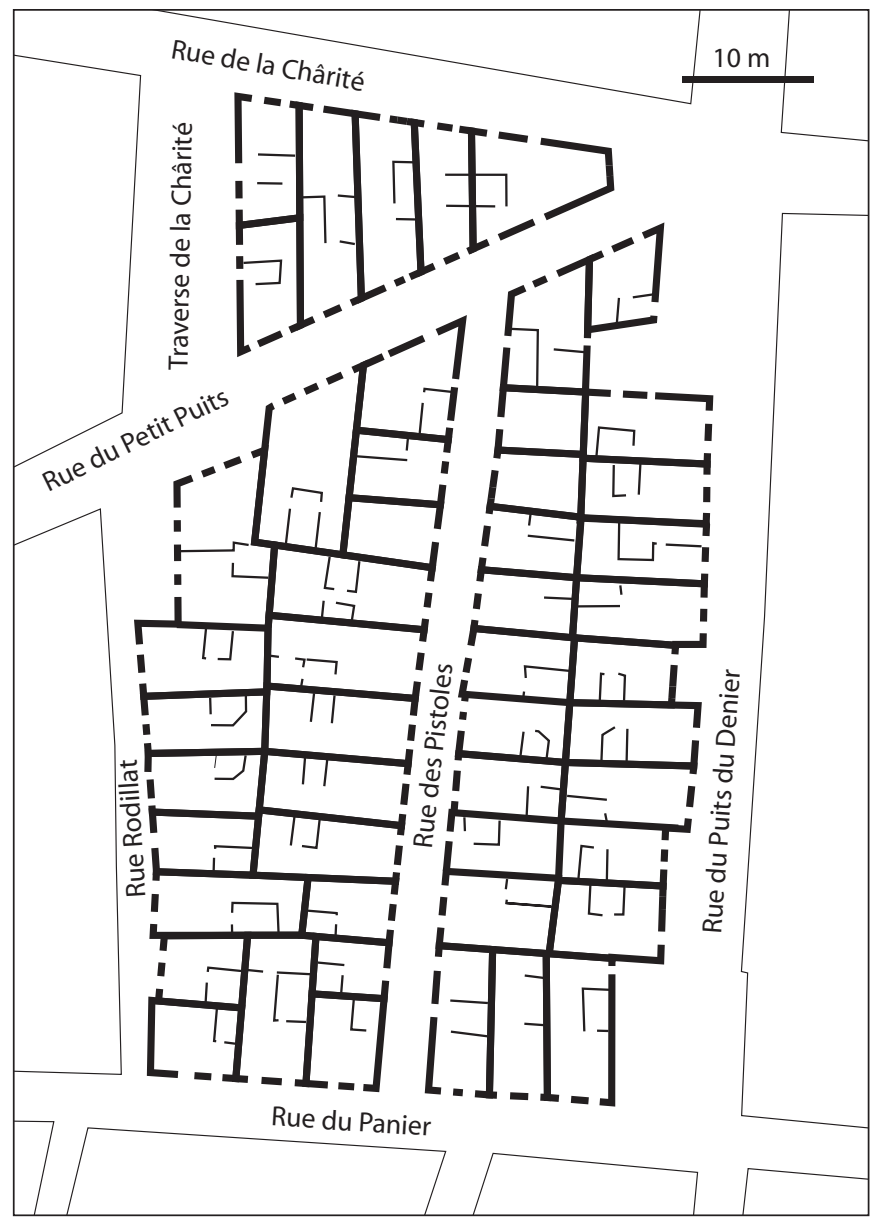

Fig. 97. Reconstitution du parcellaire de l'îlot des Pistoles à partir d'un relevé antérieur à la création de la place (DAO B. Sillano/Inrap).

À travers ces quelques exemples glanés dans le quartier de la Loge, nous retrouvons un module de maison à travée unique relativement récurent, d'environ 4 à 4,50 $\mathrm{m}$ de largeur pour $8 \mathrm{~m}$ de profondeur. Il est cependant clair que ces dimensions sont imposées pour partie par un parcellaire étriqué hérité du Moyen Âge et qu'elles ne sont pas entièrement révélatrices de l'évolution du bâti à la Renaissance. Par exemple, la faible largeur des parcelles, qui correspond à un maximum en matière de couvrement par un plancher bois, est difficilement compatible avec la création d'un couloir permettant d'accéder aux circulations placées en cœur d'îlot. Ce qui, aux époques antérieures, ne posait pas de problème dans la mesure où les immeubles étaient peu élevés et en général occupés par une seule famille, va devenir une contrainte du moment que l'extension des surfaces habitables entraîne une multiplication des occupants. En conséquence, l'augmentation de la largeur des parcelles deviendra une nécessité et la réalisation de couloirs latéraux sur des parcelles étroites n'est qu'un pis-aller afin d'adapter une forme archaïque.

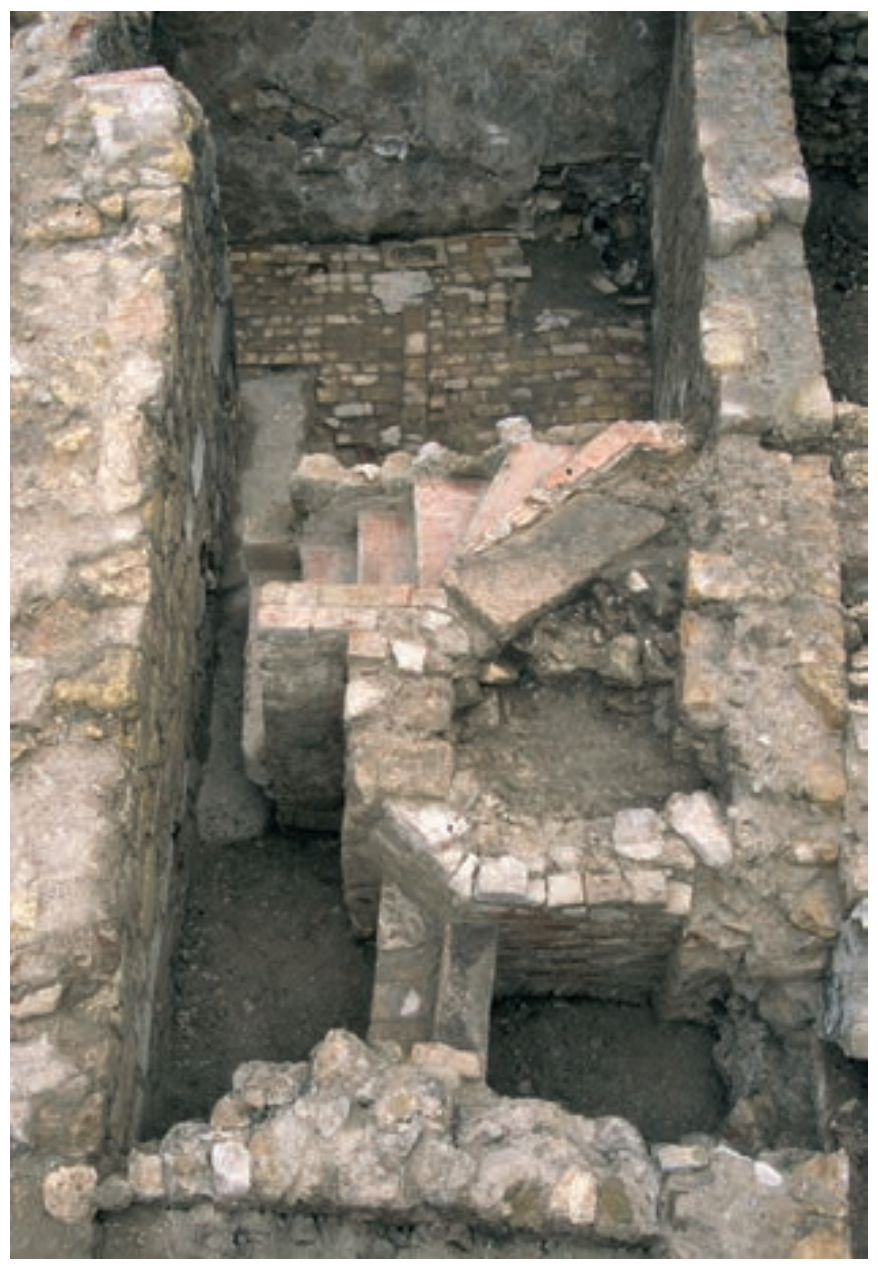

Fig. 98. L'escalier de la parcelle 361 (cl. M. Derain/Inrap).

Pour l'instant, l'accès aux escaliers se fait depuis la boutique du rez-de-chaussée, même dans les maisons édifiées au début de l'Époque moderne sur le Petit Mazeau, perpendiculairement aux parcelles médiévales ( $c f$. infra $\S \mathrm{II}, 2,3.1$.). L'habitat au XVI ${ }^{\mathrm{e}} \mathrm{s}$. est bien résumé par un rapport de $1642^{289}$ qui concerne la parcelle 384 ; il comprend des « corps séparés ayant chascun son entree, ung ciel ouvert, sa visete ", et seulement deux étages. Mais ce ne sont là que des lieux communs et l'apport de l'archéologie est, dans ce contexte, plutôt décevant.

\section{La transformation du bâti au XVII ${ }^{e}$ s. dans la « vieille ville»}

L'évolution du bâti à partir du XVII ${ }^{\mathrm{e}} \mathrm{s}$. est mieux illustrée, par les extensions du bâti en cœur d'îlot mais aussi et surtout par les caves, qui forment la majeure partie des structures modernes observées en fouille;

289 AD13 357 E 133, fol. 462, 357 E 193 fol. 462. 


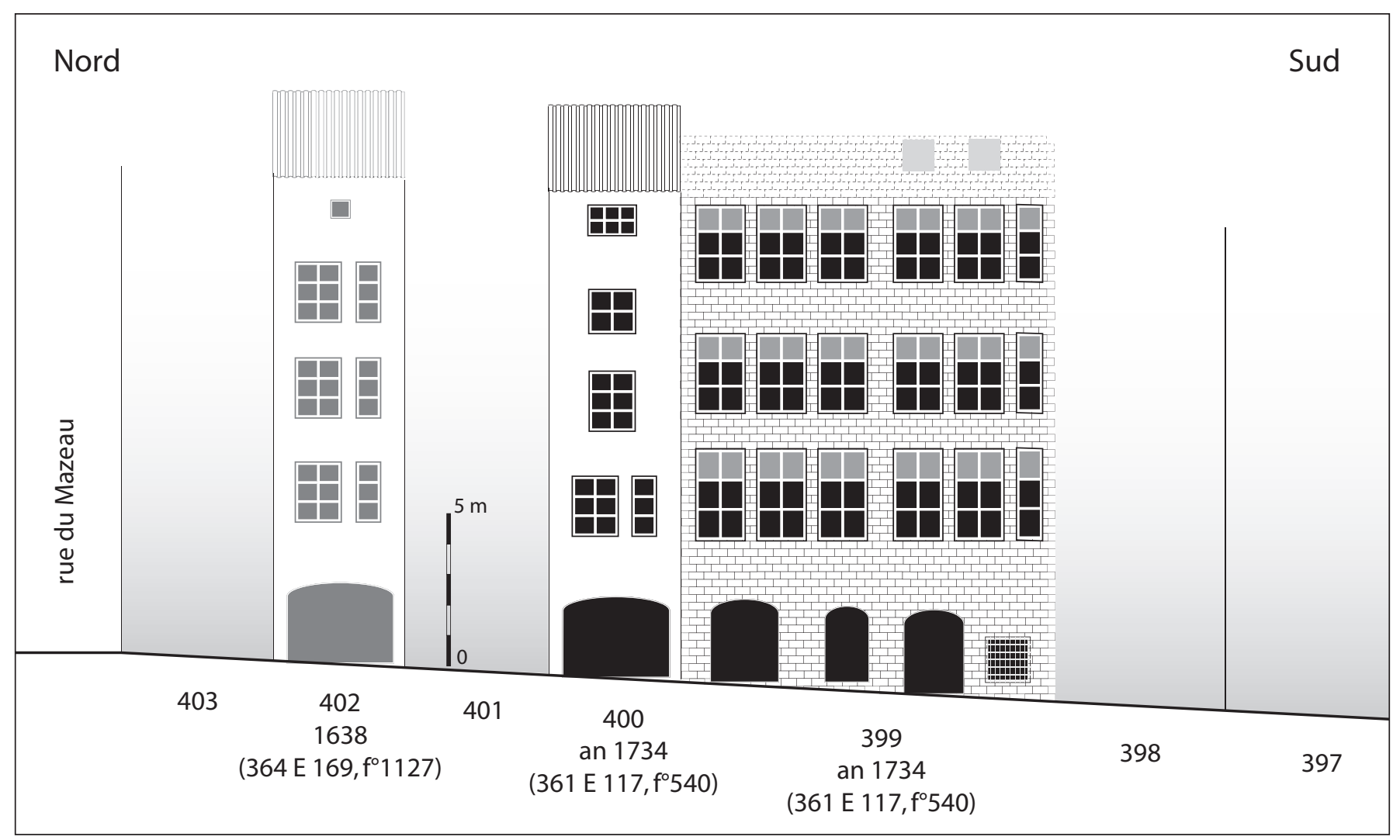

Fig. 99. Reconstitution des façades de la rue de la Guirlande (côté est) d'après les actes notariés (DAO B. Sillano/Inrap).

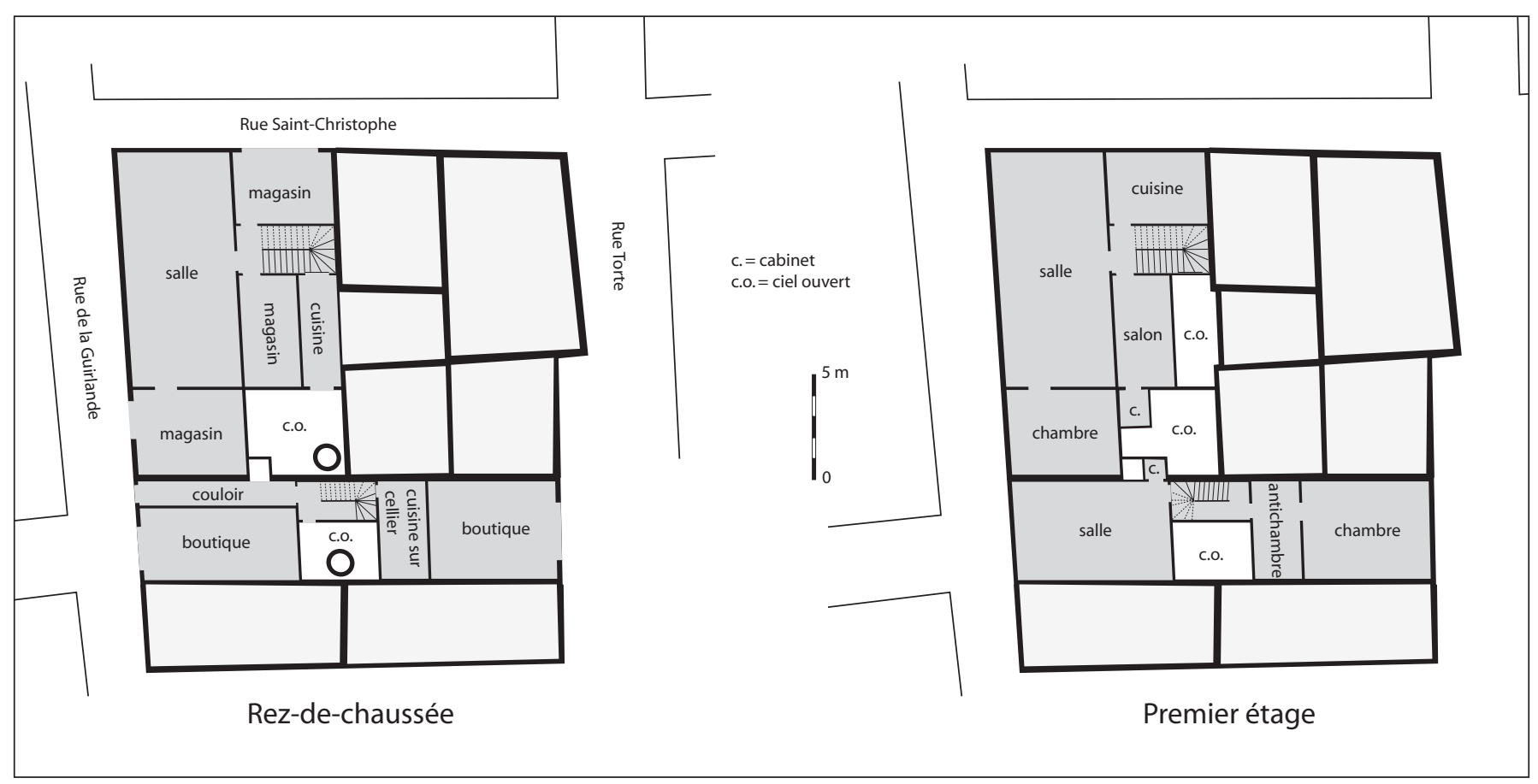

Fig. 100. Plan restitué des parcelles 394 et 395 d'après les actes notariés (DAO B. Sillano/Inrap). 
elles sont traitées dans un chapitre séparé ( $c f$. infra). Les textes abondants, devis (priffaits) et expertises (rapports de future cautelle), complètent nos connaissances avec des descriptions très précises d'immeubles et des modes de construction.

La volonté d'agrandir l'habitat, par extension horizontale et verticale, initiée à la fin du siècle précédent, est particulièrement prégnante au XVII ${ }^{\mathrm{e}} \mathrm{s}$. Lorsque les îlots sont trop étroits, dans le quartier du Panier par exemple ou pour certains îlots de la ville basse, à l'est de la mairie, l'extension en cœur d'îlot n'est pas possible et la seule alternative est l'agrégation de parcelles attenantes. Cette méthode, qui allonge la façade sur la rue, aboutit à des bâtiments à plusieurs travées, de même qu'elle est fréquemment mise en œuvre pour les immeubles d'angle (cf. infra). En dehors de ces cas, comme le montre le cadastre napoléonien où abondent les parcelles étroites, ces regroupements sont assez rares. Citons Antoine Chaurousset qui, en 1724, déclare posséder les parcelles 401 et $402^{290}$. Ce regroupement, confirmé par l'existence d'une communication entre les caves, n'est cependant pas antérieur au $\mathrm{XVIII}^{\mathrm{e}} \mathrm{s}$. et ne semble pas être pérenne puisque les parcelles sont à nouveau dissociées sur le cadastre napoléonien. Un autre moyen d'agrandir la surface est d'acquérir la maison en vis-à-vis sur l'îlot. Ainsi, la parcelle traversante 394 , mentionnée en $1656^{291}$, a tout juste la longueur suffisante pour accueillir au centre un petit ciel ouvert et un escalier, qui confèrent à l'ensemble une parfaite symétrie ( $c f$. fig. 100). La boutique ouverte sur la rue Torte (appelée "rue traverse » dans le texte) n'est pas reliée au reste de la maison à laquelle on accède uniquement depuis la rue de la Guirlande. Dans l'îlot au sud du Petit Mazeau, l'existence d'un escalier unique pour les parcelles 359 et 364, également en vis-à-vis de l'îlot, suppose qu'elles appartiennent au même propriétaire. Ici, les deux lots sont si peu profonds qu'il n'est plus nécessaire d'avoir de ciel ouvert pour l'éclairage. Les exemples de telles parcelles traversantes abondent sur le cadastre napoléonien, mais, sur les îlots étroits, la seule extension possible reste souvent vers le haut. Les étages sont souvent rajoutés au bâti antérieur et rares sont, dans les textes, les mentions de reconstructions totales nécessitées par le rehaussement. La faible hauteur des étages permet leur multiplication sans altérer la solidité de l'édifice.

Lorsque les îlots sont plus larges, libérant un espace intérieur longtemps occupé par des cours ou jardins, l'extension du bâti est plus aisée. Les rajouts sont cependant rarement en harmonie avec le bâtiment principal mais plutôt le résultat d'un partage de l'espace libre

290 ACM CC $1, n^{\circ} 113$ et 114.

291 AD13 391 E 385, fol. 604.

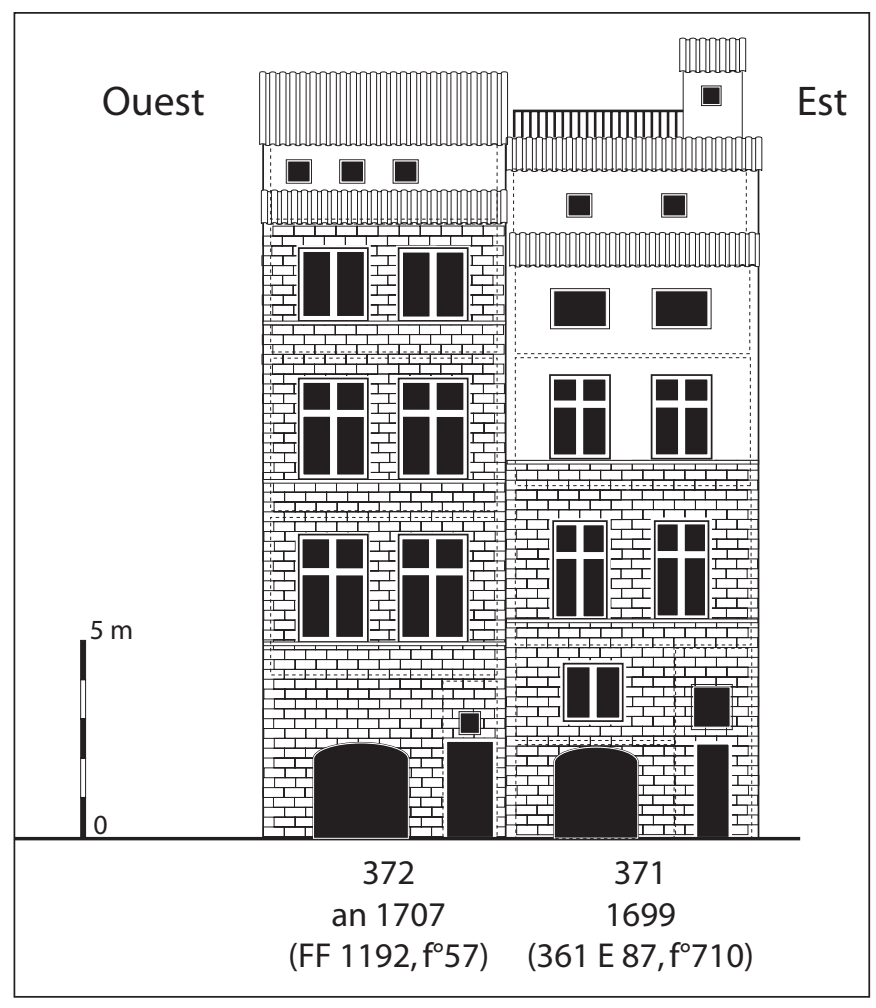

Fig. 101. Reconstitution de deux façades de la rue des Olives d'après les actes notariés (DAO B. Sillano/Inrap).

entre riverains. Par exemple, la parcelle 401 associe au bâtiment frontal un espace en retrait de plan carré, complètement décalé par rapport à l'axe, obtenu par division en quatre du cœur d'îlot ( $c f$. fig. 46). Cet espace, dont le rez-de-chaussée appartient au voisin, possède quatre étages desservis depuis l'escalier du bâtiment principal par l'intermédiaire de repos de $0,50 \mathrm{~m}$ de large pour $2,50 \mathrm{~m}$ de long greffés sur la vizette. La maison de Louise Blanche (parcelle 372, déjà évoquée), décrite en $1707^{292}$, voit le ciel ouvert considérablement réduit au profit de constructions disposées sur son pourtour, en débordement sur la parcelle voisine, établies sur plusieurs étages et supportées par deux «allées », vraisemblablement des préaux voûtés ( $c f$. fig. 96). Un long couloir à côté de la boutique permet l'accès à l'escalier, placé au centre, à partir duquel les pièces sont desservies par de multiples repos, demi repos et tambour. Les bâtiments en retrait accueillent la cuisine et les chambres alors que nous trouvons en façade de vastes salles, aux deux premiers étages. La hauteur des pièces, autour de $4 \mathrm{~m}$, la grande taille des fenêtres (des croisières de 1,75 m de large pour 2,75 $\mathrm{m}$ de haut) et la façade entièrement en pierres de taille montrent par ailleurs le caractère luxueux de cette 


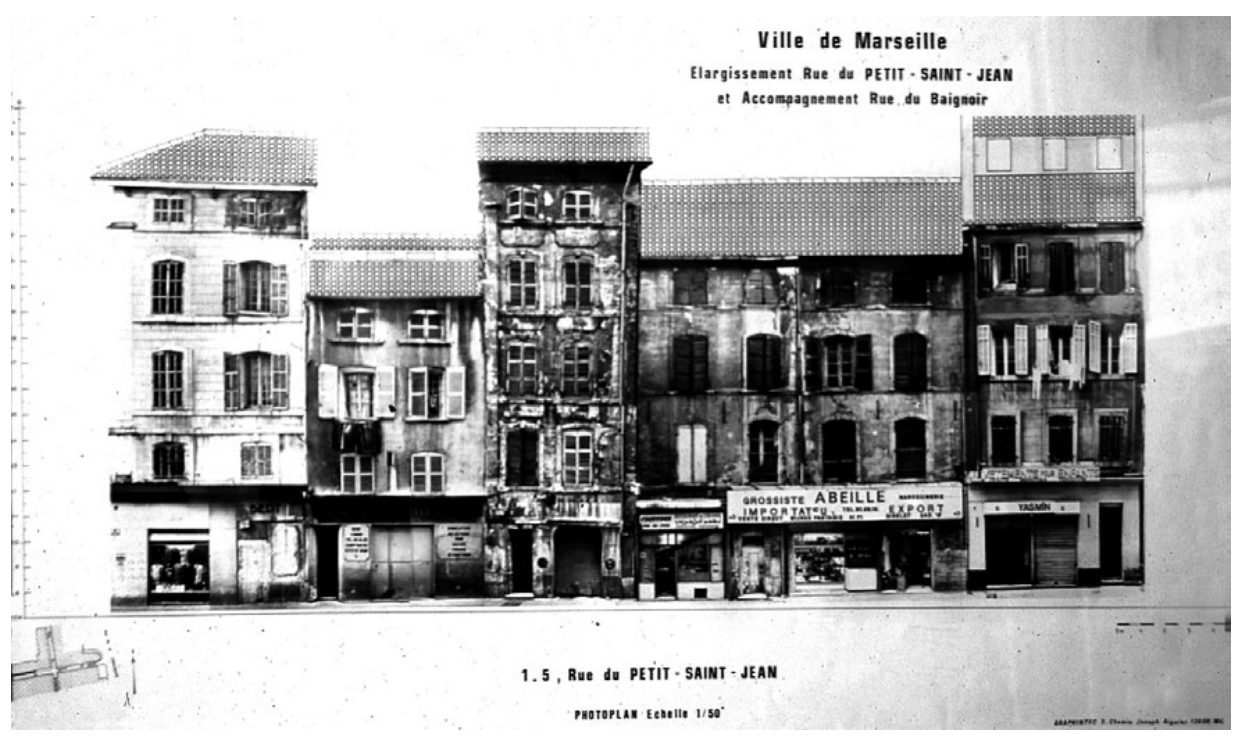

Fig. 102. Photo-relevé de la façade nord de la rue du Petit-Saint-Jean antérieure à la démolition des îlots (Atelier du Patrimoine/Ville de Marseille)

demeure, symptomatique de l'habitat à proximité de la Loge (fig. 101). La parcelle voisine 371 présente une façade et des dimensions relativement similaires, mais elle est traversante, en liaison avec la parcelle 362. Ici, la multiplication des escaliers, dont le nombre de marches (degrés) varie de cinq à vingt, dénote une conception au coup par coup, sans prise en compte globale de l'espace vital. Ces deux parcelles, ainsi que la voisine 361, sont l'aboutissement de multiples transactions où nous les trouvons parfois associées, d'autres fois indépendantes. Ainsi, Marc-Antoine de Vento les possédait toutes lorsqu'il les vend en 1656, la parcelle 361 d'une part ${ }^{293}$, les deux autres, groupées, d'autre part ${ }^{294}$. Puis ces dernières sont séparées en $1699^{295}$. Ces transactions entraînent une modification des circulations, que révèle leur complexité, mais aussi une imbrication des espaces, sensible au niveau des caves puisque la parcelle 371 est en liaison avec une cave sous chacune des deux autres parcelles. Cet exemple nous montre par ailleurs que la tendance à l'agrandissement des surfaces habitables n'est pas une généralité, puisque le phénomène inverse se produit également.

\section{La maison à travée unique dans la Ville Nouvelle au XVII ${ }^{e}$.}

Nous avons peu d'exemple de maison à travée unique dans les faubourgs antérieurement à l'Agrandissement de Louis XIV. Citons, sur le Grand-Caire, la maison de

293 AD13 391 E 386, fol. 817.

294 AD13 391 E 386, fol. 642v.

295 AD13 361 E 87, fol. 710.
M. Chaurousset, qui a probablement été édifiée au début du XVII ${ }^{\mathrm{e}} \mathrm{s}$. et qui, avec une longueur de $8 \mathrm{~m}$ pour une largeur de $7 \mathrm{~m}$, montre qu'en l'absence de contraintes spatiales, la maison à travée unique se développe sur une grande superficie. À la même époque, à l'écart des rues, nous trouvons la maison du $\mathrm{S}^{\mathrm{r}}$ de la Reynarde, de $4 \mathrm{~m}$ par $7 \mathrm{~m}$ ou encore la «petite maison et grand patti se joignant » mentionnée en $1636^{296}$ à l'angle du «chemin vieux».

La densification de l'habitat dans les faubourgs n'est effective que lorsqu'ils sont intégrés dans la Ville Nouvelle de Louis XIV. Le lotissement de l'ex-jardin Barnier, le long du tout nouveau prolongement de la rue du Petit-Saint-Jean, est sans conteste le plus révélateur de ce qui se pratique à cette époque. Les parcelles, créées en $1675^{297}$, ont des dimensions proches, entre $5,50 \mathrm{~m}$ et $6 \mathrm{~m}$ de large pour $14 \mathrm{~m}$ de profondeur; à une exception près, les bâtiments se développent sur toute la largeur pour une profondeur de $11 \mathrm{~m}$, le fond étant occupé par une cour. La division du sous-sol, étudiée sur les trois parcelles dans l'emprise de fouille de l'Alcazar, met en évidence une partition transversale et non pas longitudinale. Il semble que chaque étage ne possède qu'une seule pièce ouverte sur la rue, alors que la partie en retrait comprend un escalier adossé à un mur mitoyen et une pièce ouverte sur la cour. Un photo-relevé immédiatement antérieur aux démolitions montre la diversité du traitement des façades de ces parcelles pourtant similaires (fig. 102). Certaines n' ont que deux larges fenêtres par étage, une autre trois, probable

296 AD13 364 E 267, fol. 1578v.

297 Ventes de Thomas de Riquetti, AD13 380 E 171, fol. 49 et 380 E 170, fol. 1395 . 
réfection récente du bâtiment afin d'adopter le type marseillais du «trois fenêtres »; la largeur des parcelles n'est pas suffisante pour créer les deux pièces ouvertes sur la rue caractéristiques de ce style.

\section{Rentabilisation de l'espace au XVIII ${ }^{e}$ s.}

Au XVIII ${ }^{e}$ s., l'espace est rentabilisé au mieux afin d'avoir le plus possible de surfaces habitables. Par exemple, le bâti de la parcelle 402 s'étend à tout l'espace disponible, dans l'axe de la façade mais également sur le revers de la parcelle voisine.

Le seul frein à ce développement est l'éclairage des pièces en retraits qui nécessite des ciels ouverts, de plus en plus réduits à des puits de lumière et la plupart du temps vitrés ${ }^{298}$. Les textes regorgent d'exemples de mise en commun des espaces ouverts. Ainsi, dans une seule expertise de $1734^{299}$ (parcelle 399, cf. infra), nous trouvons des pièces qui ouvrent sur le ciel ouvert de la propriété, d'autres qui prennent jour «a un ciel ouvert commun avec ladite maison et celle du sieur Boisson» (au sud), d'autres au « ciel ouvert de la maison voisine » (parcelle 400, au nord), laquelle possède également des pièces « visant au ciel ouvert de la maison du Sr Sallart » (à l'est). Le problème de l'éclairage est souvent pris dans sa globalité et suppose une entente préalable entre les riverains. Autre exemple, en 1744, date inscrite sur une pierre de fondation d'un mur de refend, M. Fiquet fait entreprendre des travaux de grande envergure sur la parcelle 372. Nous en avons retrouvé la cave, qui occupe tout l'arrière de la parcelle où se trouvait un ciel ouvert. La pièce du rez-de-chaussée, visible sur un plan de $1948^{300}$, est munie d'un pilier central qui permet le recouvrement de sa grande surface. Dans ce cas, la disparition du ciel ouvert est autorisée par l'acquisition par Fiquet de la parcelle voisine 354, dont la cour intérieure est mise en commun.

Dans la Ville Nouvelle, les parcelles loties à partir de 1720 par la congrégation Saint-Hommebon le long de la rue du Baignoir sont caractéristiques de la maison à travée unique au XVIII ${ }^{\mathrm{e}} \mathrm{s}$. Les parcelles, larges de $7 \mathrm{~m}$, pour une longueur de $13 \mathrm{~m}$, sont entièrement occupées par le bâti, les pièces du fond prenant jour sur le revers. La partition des caves présente un découpage longitudinal que

298 Cette indication nous est donnée « en creux » par une expertise de 1713 où il est dit que le ciel ouvert n'est point vitré et est entièrement découvert (AD13 391 E 424, fol. 115), ce qui parait suffisamment anormal pour être spécifié.

299 AD13 361 E 117, fol. 540.

300 Les parcelles situées au nord de la rue des Olives ont échappé au dynamitage de 1943 et ont été réutilisées comme bureaux par la mairie. reprennent les étages. Côté rue, deux pièces se partagent l'espace, l'une de 2,50 $\mathrm{m}$ de large, l'autre de 3,50 $\mathrm{m}$; le « trois fenêtres » a fait son apparition.

\subsubsection{La maison d'angle}

Les parcelles d'angle profitent d'une part de plusieurs façades pour l'éclairage mais aussi d'une situation privilégiée qui les met en valeur. À ce titre, elles sont très recherchées et généralement occupées par de vastes demeures, résultat d'un regroupement de plusieurs unités. Quelques rares exemples n'ont cependant pas été remaniés, comme la parcelle 356, à l'angle de la rue de la Prison et de celle de la Taulisse, qui conserve les mêmes caractéristiques que les maisons à une travée, mis à part un éclairage supplémentaire.

Les exemples les plus intéressants sont aux angles de l'îlot situé au sud du marché du Petit Mazeau; les parcelles, 359 (le Logis du Rozier), 366 et 387, présentent une distribution caractéristique de cette position privilégiée. L'emprise, de $10 \mathrm{~m}$ par 7,5 m pour les deux premières, est divisée en quatre parties égales. Le quart interne à l'îlot reçoit la cour, le puits et les circulations. Les deux quarts frontaux sont, suivant les étages, soit regroupés pour former une seule pièce, de $5 \mathrm{~m}$ par 7,5 $\mathrm{m}$, soit individualisés. Dans le premier cas, un arc devait nécessairement scinder la pièce en deux afin de supporter les refends des étages supérieurs et recevoir les poutres, dont la portée se réduit alors à moins de $4 \mathrm{~m}$. Le dernier quart reçoit les communs, vestibule ou chambre. Lorsque l'entrée est en bout de parcelle, un couloir permet l'accès aux escaliers ; lorsqu'elle est sur le côté, une petite pièce fait office de vestibule. Les façades peuvent recevoir un traitement différent ; la façade est de la parcelle 387, sur la rue de la Guirlande, est en pierre de taille «jusques a lendroit des appuys des fenestres du second corp » et la façade sud, sur la rue de la Taulisse, « entièrement de taille jusques au couvert » ${ }^{301}$, ce qui est surprenant puisque la première rue est plus importante.

La même division de l'espace est reproduite sur la parcelle 384, mais elle ne s'applique que lorsque les proportions le permettent. Les exemples cités ont un rapport longueur sur largeur qui oscille autour de 1,30 m ; au-delà, il n'est plus possible d'obtenir quatre parts « harmoniques ». La parcelle 387, trop longue, isole un espace en bout, affecté aux écuries au rez-de-chaussée, afin de rétablir des proportions faciles à subdiviser. La parcelle 360 est exceptionnellement allongée et parallèle à la rue. Elle est divisée en trois, l'espace central accueillant l'escalier. De même, dans la Ville Nouvelle,

$\overline{301}$ AD13 358 E 140, fol. 736v. 
la parcelle 40, à l'angle de la rue du Petit-Saint-Jean et de la rue du Baignoir, est divisée en trois dans le sens de la largeur ; deux parties de taille identiques et une troisième plus étroite qui reçoit l'escalier. Il ne semble pas y avoir de volonté de privilégier une pièce plus vaste à l'angle qui bénéficierait d'un double éclairage.

\subsubsection{La maison à plusieurs travées et les hôtels particuliers}

La différenciation entre l'hôtel particulier et l'habitation bourgeoise est beaucoup plus difficile à faire à Marseille qu'à Aix-en-Provence, où s'établit la grande noblesse, et s'il est possible de voir la nuance dans la Ville Nouvelle, en rive sud du port, la distinction est impossible dans le quartier du Corps-de-Ville, occupé très tôt par la noblesse puis par de riches négociants. Cependant, l'étude du domaine bâti met en exergue de vastes demeures, d'une largeur supérieure ou égale à deux travées, pour lesquelles nous pourrions adopter le qualificatif d'hôtels particuliers, même si cette notion n'est apparue que tardivement et qu'elle est abusive pour des édifices du début de la période moderne.

Un simple regard sur le cadastre napoléonien suffit à comprendre que les parcelles les plus vastes sont pour la plupart groupées autour de la Loge. Certaines sont dans l'emprise des fouilles, telle les parcelles 370, 386 ou encore 399 ; d'autres, à proximité, comme les parcelles 369 ou 395, nous sont partiellement restituées par les textes. Enfin, des édifices majeurs subdivisés par la suite, comme l'Hôtel de Remezan, nous sont apparus en fouille.

D'une manière générale, l'emprise de ces demeures est le résultat d'un regroupement de parcelles accolées. Ainsi, nous avons pu constater que la parcelle 386 regroupe plusieurs parcelles «en lanière » disposées entre deux rues médiévales. La parcelle 399 occupe deux travées de l'ancien bâtiment médiéval des entrepôts auxquelles s'ajoutent un espace en retrait. L'Hôtel de Remezan, et probablement aussi l'Hôtel de SaintVictoret (le tiers méridional du pavillon Daviel) ouvrent sur trois rues et ont des emprises relativement similaires qui regroupent plusieurs parcelles médiévales localisées en bout d'îlot. Nous ne pouvons cependant pas assimiler les parcelles initiales aux travées qui composent l'hôtel. $\mathrm{Si}$, parfois, les premières se retrouvent dans les secondes, un remembrement est toujours possible et même parfois nécessaire. Ainsi, l'Hôtel de Gérente (parcelle 370) est constitué de trois travées dont la disposition « en éventail » permet de rattraper la différence d'orientation des murs extrêmes tout en conférant à l'ensemble une parfaite symétrie. Cette répartition ne peut être réalisée qu'au sein d'une seule et même propriété.
Les modifications opérées lors de la réunification de deux lots est bien illustrée par un devis de $1646^{302}$ qui concerne ce qui deviendra la parcelle 383, à l'angle de la rue des Olives et de celle de la Guirlande. Afin que «lesd. maisons soyent réduittes en une, les vizettes» seront détruites "dhault en bas et de bas en hault» et remplacées par une «vizette a quatre meinaux» d'une emprise de $4 \mathrm{~m}$ par $3 \mathrm{~m}$ ainsi qu'un ciel ouvert de même dimension. De nouvelles pièces sont créées en partie sur l'ancienne cour qui est partiellement obturée par «une murette du ciel ouvert jusques au plus hault estage pour séparation dudit ciel ouvert avec les chambres ». La terrasse de la maison d'angle sera abandonnée au profit d'un toit et la toiture de l'autre maison sera mise « a lesgal et a niveau de celluy de laditte maison du coing ». Les maçons creuseront un puits «de la mesme proffondeur que sont ceux des présents ». L'essentiel des modifications porte donc sur les circulations et l'uniformisation des couvertures, mais la structure même de l'édifice ne semble pas trop modifiée. Il s'agit d'avantage d'adapter le bâti ancien que de le refaire entièrement.

Dans certains cas, la réunion de deux lots se traduit par une reconstruction importante. La parcelle 399, par exemple, voit sa limite méridionale déborder légèrement sur la parcelle suivante afin d'obtenir des espaces plus larges. L'examen de la façade, restituée d'après les textes ${ }^{303}$, montre en outre que la dénivellation entre les sols, liée à la pente de la rue, est absorbée par le rez-de-chaussée et inopérante sur les étages suivants. Cependant, s'il y a un réajustement des niveaux d'étage, les murs antérieurs, en dehors du mur sud, ont été conservés et quelquefois doublés. De même pour la parcelle $395^{304}$, deux bâtiments plus anciens sont perceptibles dans le plan restitué alors que les pièces d'un même étage sont à la même hauteur. Ici, la dénivellation de la rue est compensée par la salle disposée à l'angle dont le sol est surcreusé de manière à être de plain-pied avec l'entrée, comme l'indique le «reposoir relevé par un petit degré de pierre de taille ». La façade confirme l'uniformité de l'ensemble, tout en laissant transparaître la distribution irrégulière des pièces par celle, similaire, des fenêtres (fig. 103).

La disposition des espaces est très différente de celle qui est adoptée plus tard dans les hôtels de la Ville Nouvelle ou à Aix-en-Provence. Ici, aucune cour placée au-devant ne met en valeur la façade et la cour intérieure est réduite à sa plus simple expression afin d'éclairer les pièces. Dans les immeubles d'angle, celle-ci est systématiquement placée dans le quart le plus éloigné

302 AD13 391 E 376, fol. 926

303 AD13 361 E 117, fol. 540.

304 AD13 391 E 424, fol. 115. 


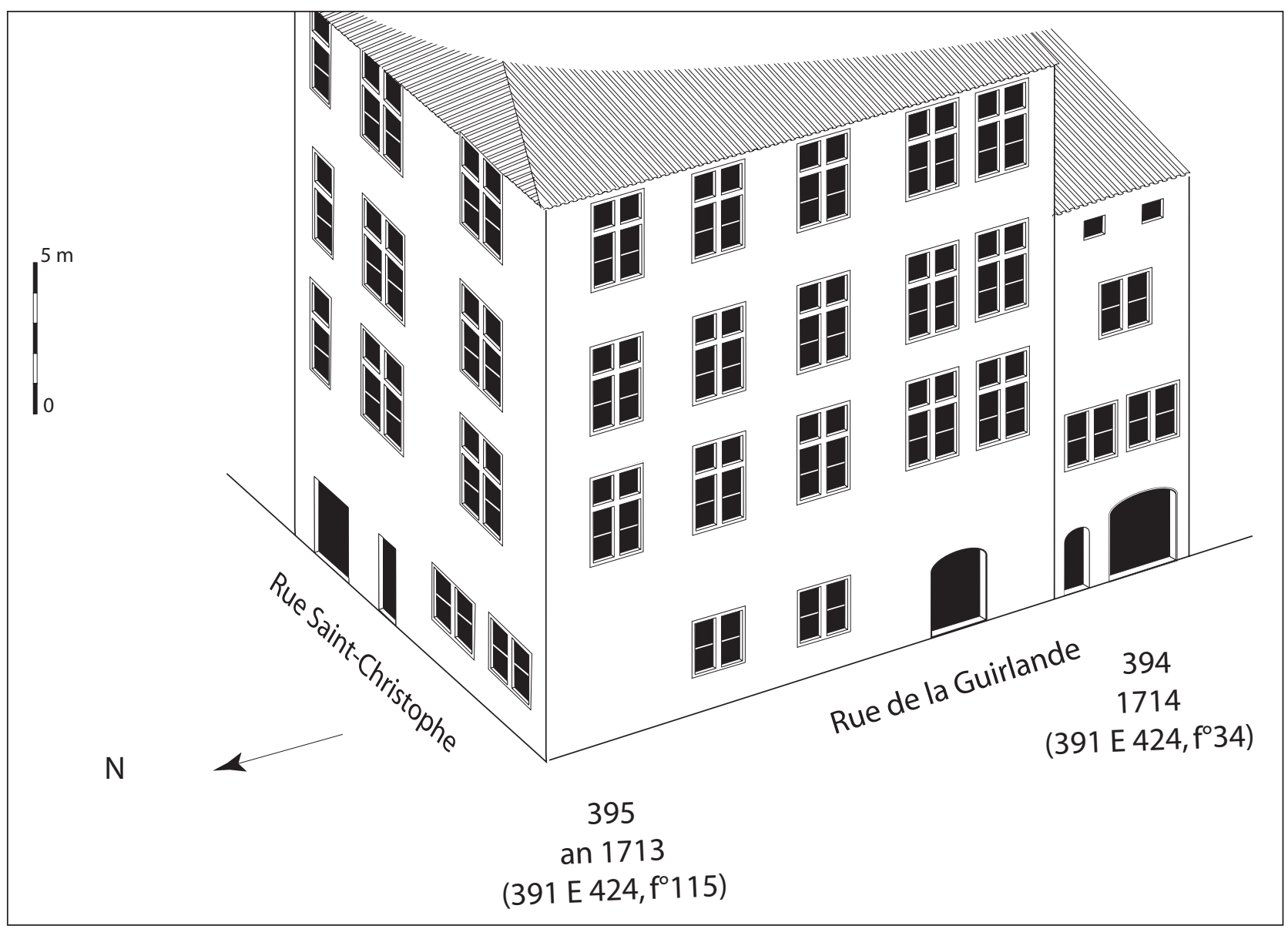

Fig. 103. Reconstitution des bâtiments sur les parcelles 394 et 395 d'après les actes notariés (DAO B. Sillano/Inrap).

des façades. Seul l'Hôtel de Gérente (parcelle 370) fait exception avec sa disposition tripartite. Trois ailes de bâti encadrent une cour intérieure allongée de forme trapézoïdale orientée au nord, vers le cœur d'îlot. Le parti pris de tourner le dos aux espaces publics, quitte à se priver de l'exposition au soleil, est probablement symptomatique de l'esprit de la classe aisée marseillaise d'alors.

La distribution des pièces ne semble obéir à aucune volonté de symétrie, mais résulte d'une adaptation de la structure héritée du passé. La parcelle 399 s'ouvre, par une porte assez étroite, sur un «vestibulle pavé de pierre de taille » de $43 \mathrm{~m}^{2}$ duquel on accède aux escaliers. Sur la parcelle 395, l'accès à l'escalier se fait soit par la boutique sur la rue de la Guirlande, après avoir traversé une grande salle, soit par la boutique de la rue Saint-Christophe. Dans tous les cas, l'absence de couloir permettant l'accès direct aux circulations est notoire, par opposition aux habitats dits « populaires ». Pour la même demeure, les dimensions des pièces sont très variables ; celles, superposées, de la parcelle 395 mesurent $5 \mathrm{~m}$ par $11,50 \mathrm{~m}$, alors que d'autres, surtout les chambres, sont très exigus. L'opposition entre les pièces de réception et les communs semble relativement bien marquée, cependant nous ne la retrouvons pas dans la hauteur des pièces qui, bien qu'elle soit décroissante au fur et à mesure qu'on monte, reste relativement élevée dans tous les cas. De même, il n'y a pas de discrimination dans l'éclairage, toujours important, même lorsque la fenêtre ouvre sur la cour. La relative petitesse des pièces communes semble d'avantage le fait d'une nécessité que d'une négligence des lieux non ouverts aux visiteurs.

Les façades, sur les exemplaires que nous possédons, sont sobres; peu de sculptures ou de décors particuliers sont spécifiés dans les textes. Citons la maison que fait édifier Charles de Cazaulx en $1593^{305}$ avec des «piedz droictz que seront canellés, un carage (façade) des mesmes façons faicts et ordonnance de celluy de la maison de Lazarin nineau » et des portes que les maçons seront «tenus enrichir de telle façon que plaira aud. Sieur consul». En dehors de ce cas particulier, il semble que seul l'usage de la pierre de taille sur toute la hauteur de la façade différencie les hôtels particuliers ; lors de la construction de la parcelle 399, un placage de pierres de

305 AD13 360 E 30, fol. 679. 
taille a été apposé sur toute la façade unifiée, gommant ainsi les états antérieurs. Mais ce n'est pas une généralité puisque la maison que fait construire Catherine Vias (parcelle 386) est « de tailhe despuis le plan de la rue jusques au premier cordon (...) et le dessus (...) de massonerie » ${ }^{\mathbf{3 0 6}}$. Les portes sont pour la plupart « entourée de pierre de taille ». Le nombre d'ouverture et leur grande dimension est, en revanche, exceptionnel. Si on fait le rapport entre les vides et les pleins sur les façades des parcelles 395 et 399, on obtient des taux respectifs, pour l'ensemble de la façade, de $29 \%$ et $38 \%$, et pour les trois étages uniquement, de $37 \%$ et $44 \%$. L'écart est grand face à des édifices considérés comme étant bien éclairés, tel l'Hôtel d'Agut, à Aix-en-Provence, où le taux est de $26 \%$ (Massot 1992, p. 66). Cette prééminence des ouvertures est probablement une réponse à l'étroitesse des rues qui, du fait de la forte élévation des immeubles, sont très sombres.

Les quelques exemples d'hôtels particuliers concernés par le chantier de Villeneuve Bargemon, ou à proximité, permettent d'illustrer ce qu'étaient les maisons bourgeoises édifiées dans un quartier densément urbanisé. Largement inspiré de l'existant, dont ils reprennent la structure tout en associant plusieurs unités, il ont une distribution peu organisée, peu d'espaces ouverts, peu d'embellissement des façades, ce qui dénote une absence de volonté de mise en valeur du patrimoine. A contrario, le grand nombre d'ouvertures et le confort des pièces montrent l'importance accordée au bien-être des occupants. Le caractère ostentatoire est moins marqué ici, au XVII ${ }^{\text {e }}$ s., qu'il ne le sera au siècle suivant dans la Ville Nouvelle. L'Hôtel de Gérente (parcelle 370), dont nous ne possédons malheureusement que le plan, fait cependant exception. La disposition des bâtiments, l'importance de la cour, dénote une recherche architecturale qu'il eut été souhaitable d'affiner grâce à des expertises. Nul doute que, compte tenu de sa situation, juste derrière la Loge, et de sa grande taille, cet hôtel soit un élément majeur du cadre urbain.

Les faubourgs, tout au moins ceux qui ont été arasés

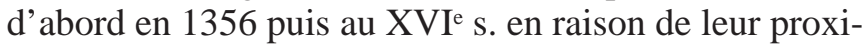
mité avec les remparts, présentent l'avantage d'offrir aux constructions modernes la place suffisante pour pouvoir s'étendre à souhait. Ainsi, les premières maisons que l'on voit s'édifier le long du Grand-Caire (précurseur du cours Belsunce) sont de grande dimension. L'auberge du Canard, au centre de la façade de l'îlot de l'Alcazar, mesure $12 \mathrm{~m}$ de long pour 8,25 m de large alors que sa voisine, le Logis des Trois Mulets, $17 \mathrm{~m}$ de long pour $9 \mathrm{~m}$ de large. Mais ces deux exemples, avec seulement deux étages, sont des auberges et à ce titre ils ne sont pas significatifs de l'habitat.

\subsection{Les caves ( $R$. Thernot)}

La présence quasi-systématique de caves dans le sous-sol des quartiers explorés procure à l'archéologie un champ d'étude abondant en informations pour les formes et les techniques de constructions de l'Époque moderne. La multiplicité des exemples nous renseigne aussi sur les usages de ces lieux particuliers dans l'habitat et sur leur articulation fonctionnelle avec les autres espaces privés et l'espace public. La généralisation des caves dans presque toutes les parcelles traduit la densification de l'habitat dans la ville intra muros avant l'Agrandissement. Toutefois l'existence de caves dans le nouveau quartier créé en 1666, dans lequel rares sont les maisons qui en sont dépourvues, montre qu'elles font partie intégrante du programme de l'habitation urbaine à l'Époque moderne, à la différence de la période médiévale.

Les datations liées au matériel céramique ou déduites des rapports d'expertise montrent que la période allant du milieu du XVI ${ }^{\mathrm{e}}$ s. au milieu du XVII ${ }^{\mathrm{e}}$ s. est celle pendant laquelle sont creusées la plupart des caves dans la vieille ville. Dans les textes, les mentions les plus anciennes retrouvées concernent le quartier du Mazeau et sont datées de la fin du XVe s. ${ }^{307}$, ce qui semble correspondre à la chronologie relevée à Aix-en-Provence où la crota apparaît dans les textes de la seconde moitié du XVe $\mathrm{S}$. (Bernardi 1995, p. 367). Il est à noter que les maisons de Marseille sont dépourvues de caves au Moyen Âge, comme dans un grand nombre de villes importantes du Sud-est à la même époque : Aix-en-Provence, Nîmes, Montpellier, ... (Joly à paraître).

\subsubsection{Des annexes rajoutées à la maison}

Dans la vieille ville, les cas de reconstruction totale de maison sont rares et les caves sont fréquemment construites en sous-œuvre sous les maisons déjà existantes et remaniées tout au long des siècles antérieurs. Cette technique est connue au moins dès la fin du Moyen Âge dans la région (Bernardi 1995, p. 274). Dans les textes, la cave est souvent mentionnée sous le nom régional de «crotte », désignant tout autant la voûte proprement dite que l'espace voûté. Cette appellation trahit le caractère largement dominant de la technique de la voûte sur le plancher de bois pour le couvrement des caves. L'évocation de ces creusements en sous-œuvre 
apparaît dans les prix-faits. Celui conclu entre Melchior Medicis et le maçon Vincent Meollan en 1599 stipule que le maçon promet « ... de faire besougne suivante... ascavoir une crotte du dessoulz de la ladite maison de la longueur et largeur dicelle et de hauteur de deux cannées acrossiver avec un un pillon ou deux sy est de besoing pour soustenir ladite crotte... ${ }^{308}$, donc de construire sous la maison une cave couverte de voûtes d'arêtes reposant sur un ou deux piliers; celui passé entre Jacques Gautier, boulanger, et Jean Cotta, maître maçon, pour une maison du Mazeau rappelle qu'il faudra « rompre le sollier quest à présent aud. logis et au lieu et place d'icelui y faire une cave ou crotte de longueur de trente pans ou environ et de largeur de dix huit pans aussi ou environ ${ }^{309}$. Là, le commanditaire juge utile de préciser que la démolition du sol du rez-de-chaussée doit précéder le creusement de la cave. La généralisation des caves confère un niveau supplémentaire au tissu bâti. Ce niveau souterrain s'affranchit en partie des contraintes foncières du rez-de-chaussée. Certaines caves outrepassent l'aplomb de la façade pour se prolonger sous la rue, faisant se superposer espace public et privé. Ailleurs, des communications s'établissent d'une cave à l'autre, imbriquant les propriétés de façon parfois complexe. La cave est une annexe de la maison et peut faire l'objet de transactions séparées. Ainsi, le marchand Jean Surian achète-t-il en 1704 une maison sans les boutiques et les caves qui se trouvent à son pied, puis il fait l'acquisition d'une partie des caves provenant de la même succession $^{310}$. À l'angle des rues de la Guirlande et des Olives, la parcelle 384 est dotée de trois caves en 1642 et l'une d'entre elles appartient au propriétaire de la parcelle voisine ${ }^{311}$. Les fouilles pratiquées ont montré l'existence de portes de communication entre les caves, parfois rebouchées en fonction des changements de propriétaires. Dans le Logis de la Taulisse, la porte qui relie les deux caves permet de traverser l'îlot par les sous-sols, de la place du Mazeau à la rue de la Taulisse.

\subsubsection{L'emprise des caves}

Les caves occupent le plus souvent toute l'emprise du bâti de surface, à l'exception des éventuelles cours situées à l'arrière des maisons. Elles ne comptent qu'un seul niveau, sans doute en raison de la relative planéité des quartiers étudiés, les pentes fortes suscitant souvent l'aménagement de plusieurs niveaux de caves. Il arrive que le volume final résulte de plusieurs campagnes de

308 AD13 360 E 35, fol. 413.

309 AD13 391 E 383, fol. 214.

310 AD13 361 E 92, fol. 145v et 361 E 92, fol. 296v.

311 AD13 357 E 133, fol. 462. creusement, comme sur la parcelle 402 sur la rue de la Guirlande dont la cave progresse vers le cœur de l'îlot entre le XVII et la fin du XVIII ${ }^{\mathrm{e}}$ s. en deux étapes successives, parallèlement à l'abandon de l'extension sous la rue, au bouchage d'une porte donnant sur la cave voisine et au déplacement de l'escalier d'accès.

Dans le quartier du Petit Mazeau, certaines caves s'étendent en partie sous la rue. Cet empiètement varie : il peut n'être que «de 4 pans dans la rue » ${ }^{\mathbf{3 1 2}}$ soit $1 \mathrm{~m}$, de 5 pans $^{313}$, voire de 8 pans $^{314}$. Ces extensions sous l'espace public retrouvées en fouille sont de dimensions compatibles avec des mentions dans les rapports d'expertise. On observe qu'elles sont condamnées dans le cours du XVIII' s.

\subsubsection{Les accès, les communications}

La communication avec le rez-de-chaussée s'effectue par un escalier droit ou à quartiers tournants (fig. 104). Cet accès est en fond de parcelle ou dans l'un des angles arrière comme sur les parcelles donnant sur la rue de la Guirlande près de l'Hôtel de Ville. Afin de préserver le volume utile de la cave, l'escalier naît souvent dans l'arrière-cour lorsqu'elle existe, comme dans la maison du $\mathrm{n}^{\circ} 9$ de la rue des Treize-Coins ou la maison du Chapitre, près de la Cathédrale. L'accès à la cave se fait donc depuis un espace éloigné de la rue et parfois extérieur à l'habitation. Les caves peuvent communiquer entre elles et au XVIII' s., il n'est pas rare que les rapports d'expertise rendent compte de deux ou trois caves communicantes dans le tréfonds des maisons, comme sur la parcelle 395 à l'angle de la rue de la Guirlande et de la rue Saint-Christophe ${ }^{315}$. Dans quelques cas, le niveau de conservation des murs a permis de constater la présence de soupiraux donnant sur la rue.

Dans le quartier du Petit Mazeau, les caves s'étendant sous l'espace public comportent au niveau du sol de la rue une trémie fermée par une trappe, au sommet de la voûte (fig. 105). Cette disposition permet de transférer des chargements directement de la rue à la cave sans passer par le rez-de-chaussée et l'escalier.

\subsubsection{Les aménagements, les usages}

Les sols sont constitués de deux contre-pentes convergeant vers un fil d'eau axial aboutissant à un petit réservoir monolithique ancré à fleur de sol. Ce dispositif permet à la fois de recueillir les eaux de ruissellement

312 AD13 351 E 962, fol. 719v.

313 ACM FF 1203, n² 21, 18 février 1718.

314 AD13 391 E 406, fol. 162v.

315 AD13 391 E 424, fol. 115, 27 mars 1713. 


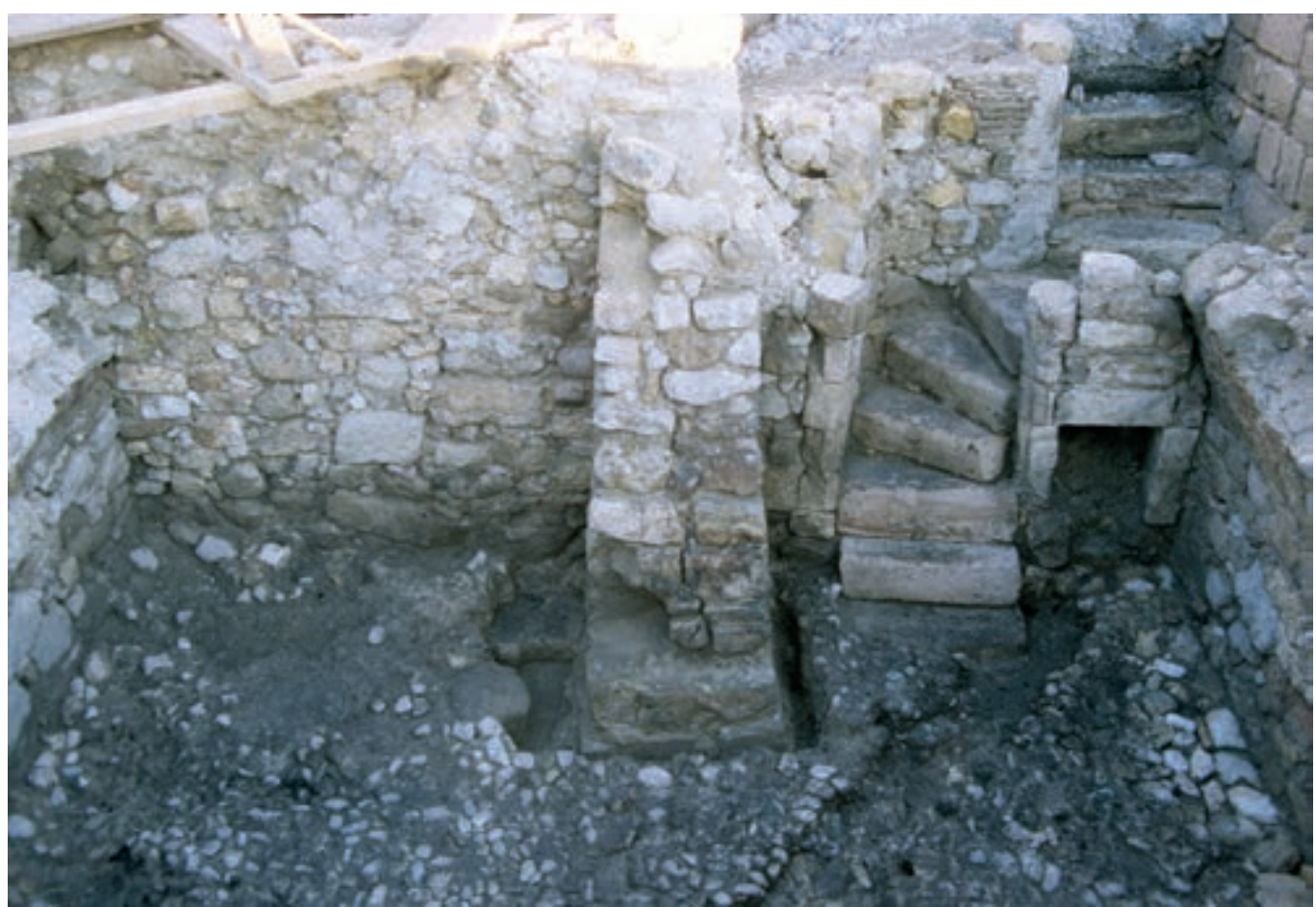

Fig. 104.

Circulations

dans la cave

de la parcelle 398

(cl. M. Derain/Inrap).

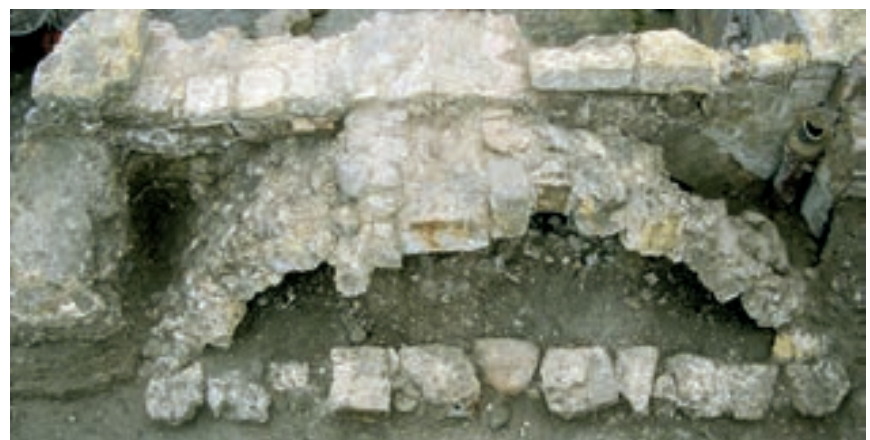

Fig. 105. L'extension sous la rue de la cave de la parcelle 364 (cl. M. Derain/Inrap).

inhérentes à la situation enterrée de l'espace et les fluides résultant du transvasement des liquides alimentaires conservés tels que le vin ou l'huile, ou simplement puisés comme l'eau. À la fin du XV $\mathrm{XV}^{\mathrm{e}} \mathrm{s}$. à Aix-en-Provence, la technique visant à doter la cave d'un sol à double pente est décrite dans les prix-faits comme d'origine piémontaise (Bernardi 1995, p. 366). À l'angle de la rue de la Guirlande et de la rue des Olives, les structures en grand appareil de la cave portent sur $50 \mathrm{~cm}$ de haut la trace de remontées d'eau, qui ont affecté l'espace et sans doute compromis son usage.

Les caves comportent souvent un puits accessible par une baie ouverte dans le chemisage permettant de puiser de l'eau. Ce puits, généralement plus ancien que la cave, atteint le rez-de-chaussée et son enveloppe externe a été reprise et dotée d'un parement maçonné à l'occasion du creusement de la cave (fig. 106).

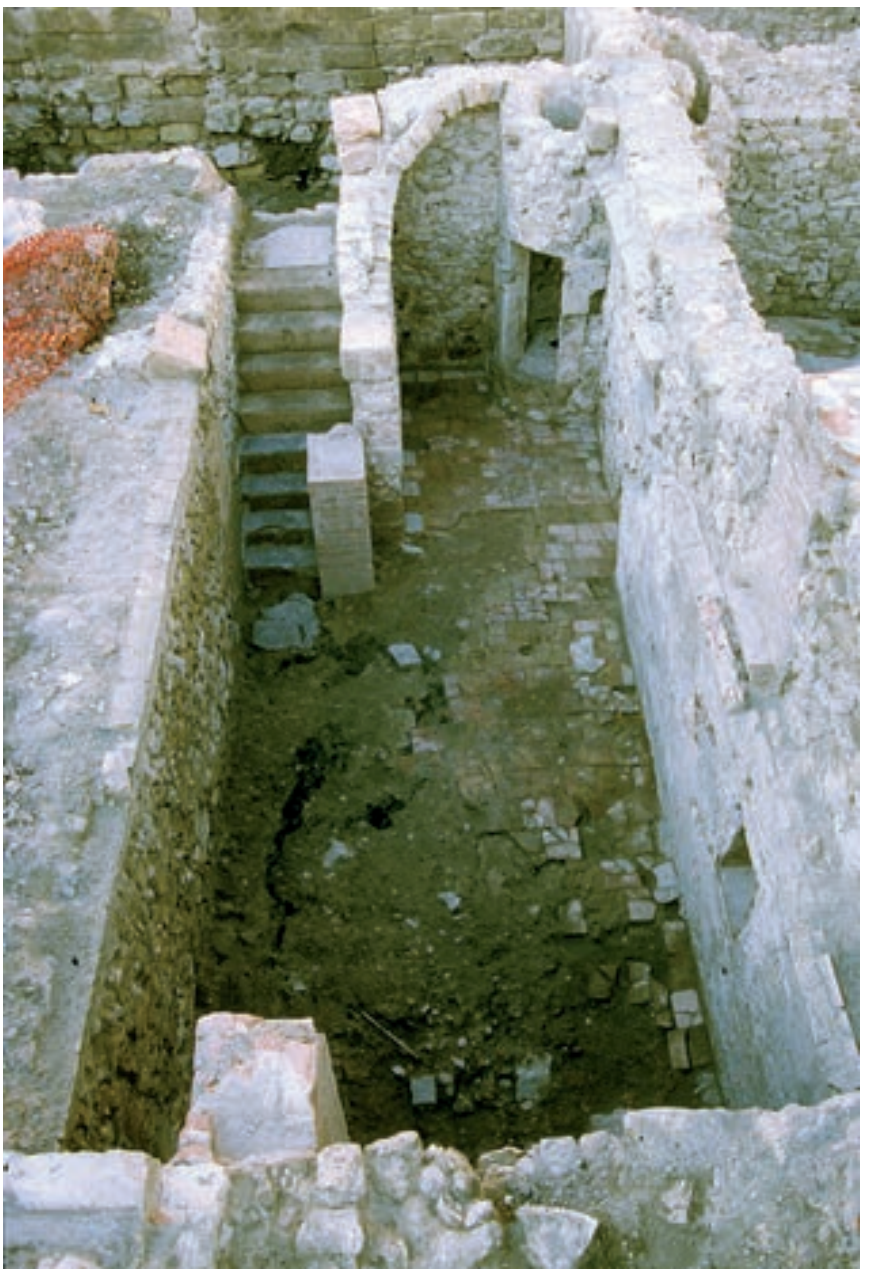

Fig. 106. Vue d'ensemble de la cave de la parcelle 397 (cl M. Derain/Inrap). 
PREMIÈRE PARTIE : ÉTUDE TOPOGRAPHIQUE ET MORPHOLOGIQUE D'UNE VILLE MULTIPOLAIRE

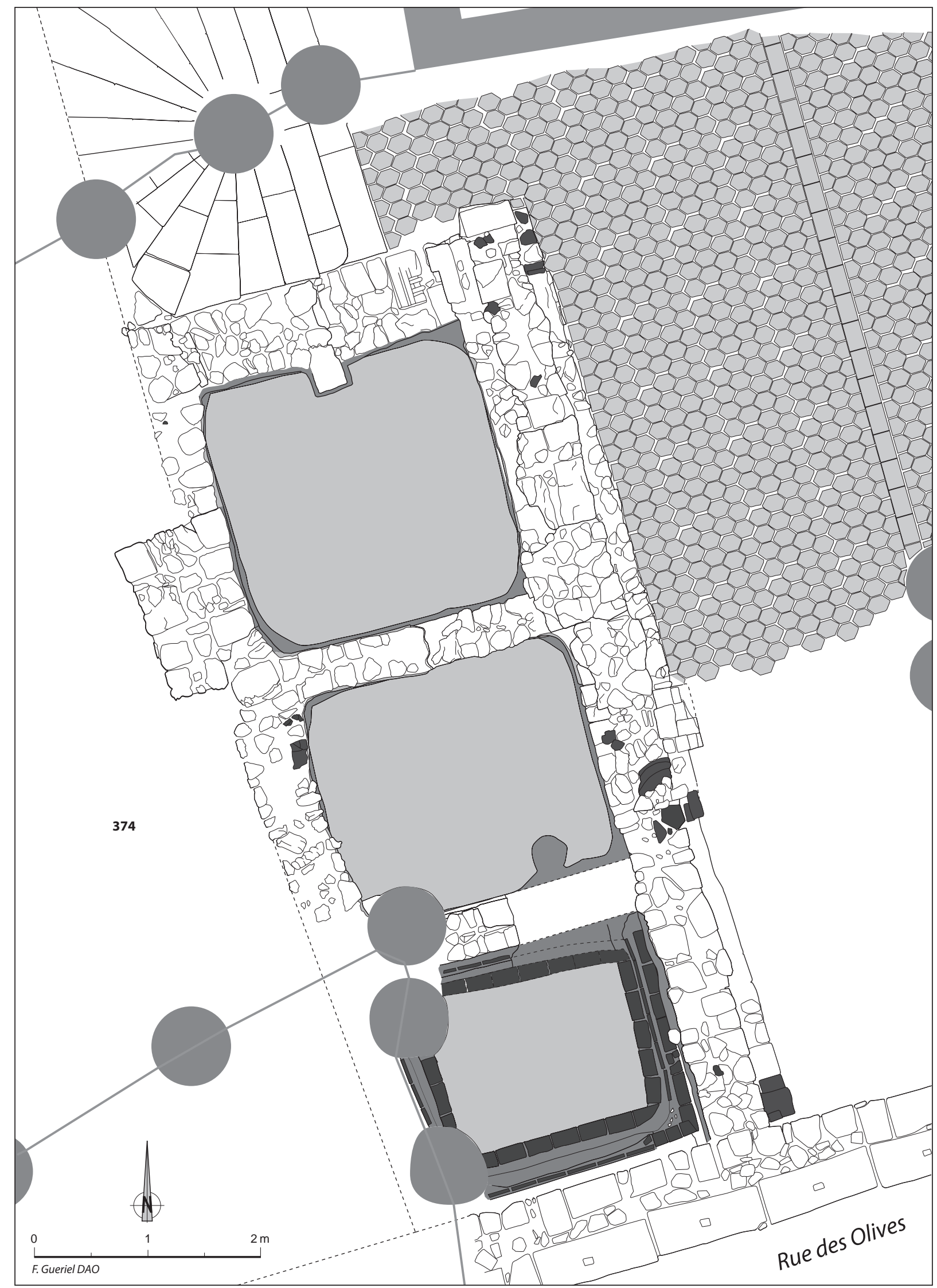

Fig. 107. Plan des cuves de la parcelle 373 (DAO N. Bourgarel/Inrap). 


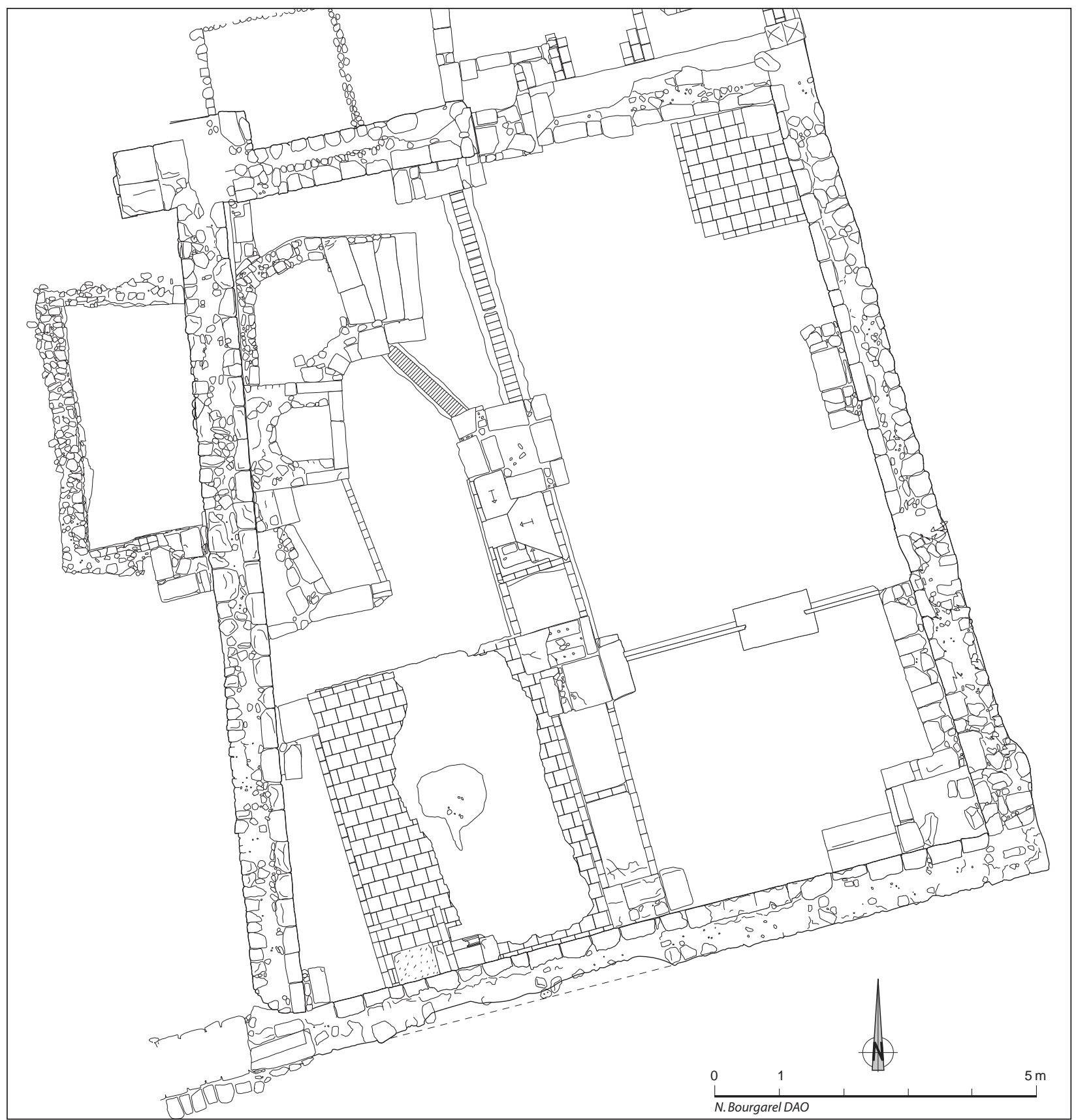

Fig. 108. Plan de la cave de la parcelle 384 (DAO N. Bourgarel/Inrap)

Les caves peuvent accueillir aussi des cuves pour divers usages notamment des cuves à huiles. Dans une cave de la rue des Olives, les dispositifs caractéristiques de celles-ci ont été dégagés. Il s'agit de trois cuves juxtaposées, revêtues d'une épaisse couche d'enduit étanche (fig. 107). La cuve jouxtant la façade sur rue présente quelques particularités par rapport aux deux autres. Elle est de taille plus réduite, son étanchéité est renforcée par l'intercalation de parements de briques entre les couches de mortier de tuileau, et son fond est plus haut que celui des deux suivantes. Ce dispositif fait écho à la description relevée dans un prix-fait de $1663^{316}$ dans laquelle est mentionnée la construction d'une cave avec trois cuves «a tenir huylle», dont «une dessoutz le trapadour (couloir) aboutissant au premier degré de la maison ». L'étanchéité de ces cuves sera obtenue par l'application de couches de batum sur la maçonnerie et devra être vérifiée par un test de remplissage.

316 AD13 364 E 274, fol. 653v. 


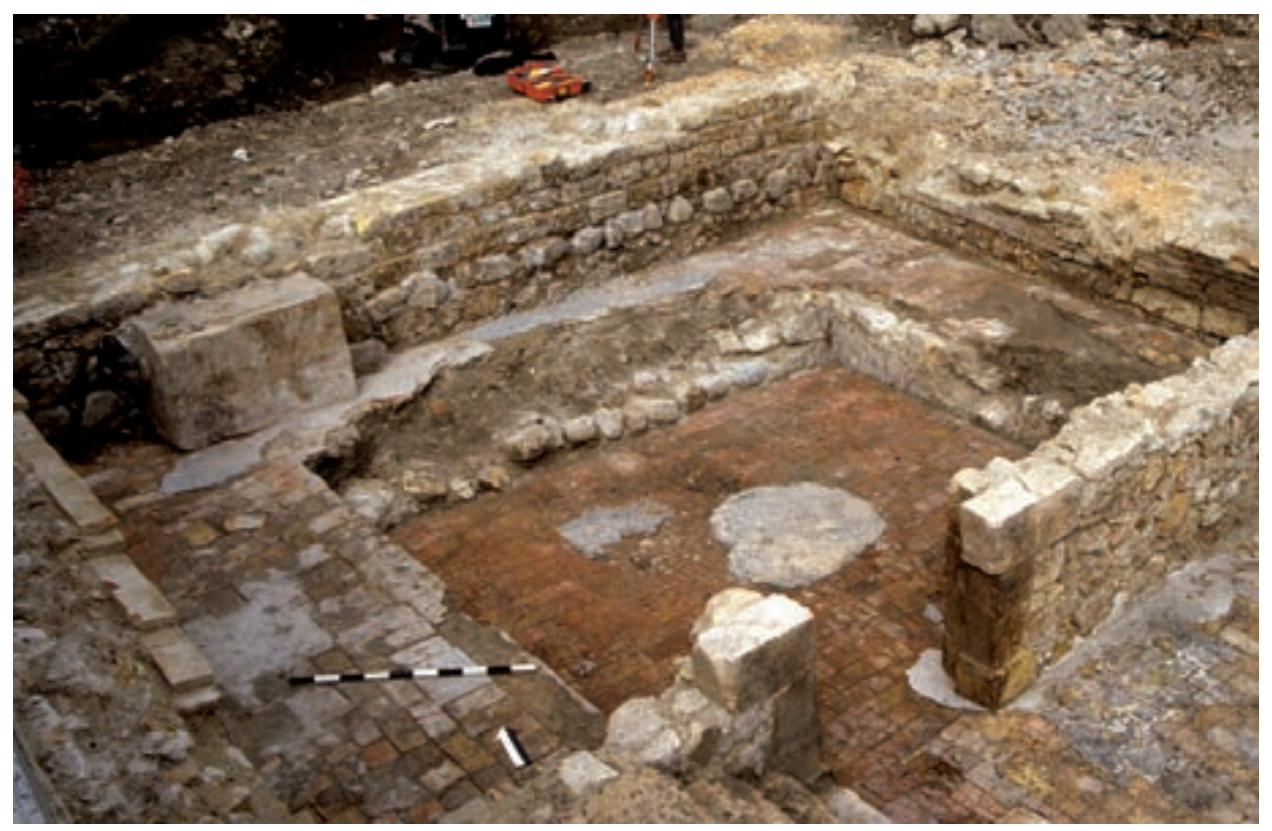

Fig. 109. Les vestiges des caves de la parcelle 362 (cl. M. Derain/Inrap).

Les cuves recevant les effluents des latrines sont rares. Dans le quartier du Mazeau, un exemplaire complet a été relevé ( $c f$. infra $\S$ II, 2, 3.4.10.). La cuve a été creusée dans le sol de la cave daté de la première moitié du $\mathrm{XVII}^{\mathrm{e}} \mathrm{s}$. Elle est couverte d'une voûte en berceau dotée d'une trappe de visite et est dépourvue de fond maçonné. Elle est abandonnée à la fin du XVII ${ }^{\mathrm{e}} \mathrm{s}$. d'après le matériel céramique recueilli dans son colmatage. Sa situation encaissée a dû rendre son curage difficile et a motivé peut-être son rapide abandon. Des cuves à fonction indéterminées prennent place souvent dans les caves. Dans la cave située à l'angle des rues de la Guirlande et des Olives, des cuves juxtaposées se caractérisent pour la plupart par des remplissages constitués de fragments de bois et d'écorces (fig. 108).

Les caves sont avant tout des lieux de stockage qui prennent le relai des «maguezins » des rez-de-chaussée lorsque les locaux de plain-pied sont affectés à d'autres usages. L'espace y est exploité au mieux comme le montrent les niches aménagées sous les escaliers ( $c f$. fig. 104). Dans une cave au sud de la rue de la Taulisse, une banquette de $40 \mathrm{~cm}$ de haut, et large de $130 \mathrm{~cm}$ au plus a été construite contre trois des murs de la cave, à l'exception de celui percé par une porte ( $c f$. infra § II, 2, 3.4.10.). Cette banquette carrelée est peut-être destinée à isoler des produits de l'humidité du sol, ou peut être pour mettre des fûts en hauteur (fig. 109).

La nature des produits et denrées conservées n'est pas décelable par les indices archéologiques et les textes restent peu loquaces sur le sujet hormis pour les cuves à huile. À proximité du pavillon Bargemon, une cave a servi de dépôt de blocs récupérés sur une façade démolie (cf. infra § II, 2, 3.4.2.). Ce stockage, déposé à la fin du $\mathrm{XVIII}^{\mathrm{e}} \mathrm{s}$. était à l'évidence provisoire mais a finalement perduré jusqu'à la destruction de l'immeuble en 1943, ayant été scellé par le recul de la façade. Cette utilisation particulière et sans doute peu adaptée montre le caractère plurifonctionnel des caves.

\subsubsection{Les extensions sous la rue}

Sous certaines maisons du quartier du Mazeau, l'emprise des caves s'étend sous la rue pour permettre l'installation d'une trappe au ras du sol ménageant un accès direct à la cave et de rendre autonome la cave par rapport à la maison (fig. 110). Il n'est pas toujours assuré qu'un autre accès ait existé dès l'origine en raison des nombreux remaniements ultérieurs. Lorsqu'un autre escalier est conservé (rue de la Guirlande, parcelle 399), il n'est pas forcément contemporain du premier état de la cave. Il est à noter dans ce quartier que deux des caves dotées d'une extension sous la rue sont précisément des caves également munies de portes communiquant avec d'autres caves dès leur état primitif : caves du logis de la Taulisse sur la parcelle 358 ( $c f$. infra § II, 2, 3.3.5.) et cave de la parcelle 402 ( $c f$. infra § II, 2, 3.2.4.). Cette extension sous la voie respecte vraisemblablement une proportion encadrée par des règles, comme le suggère la mention : "jusques a demie rue comme il est permis » ${ }^{317}$.

317 AD13 360 E 72 , fol. 360 . 


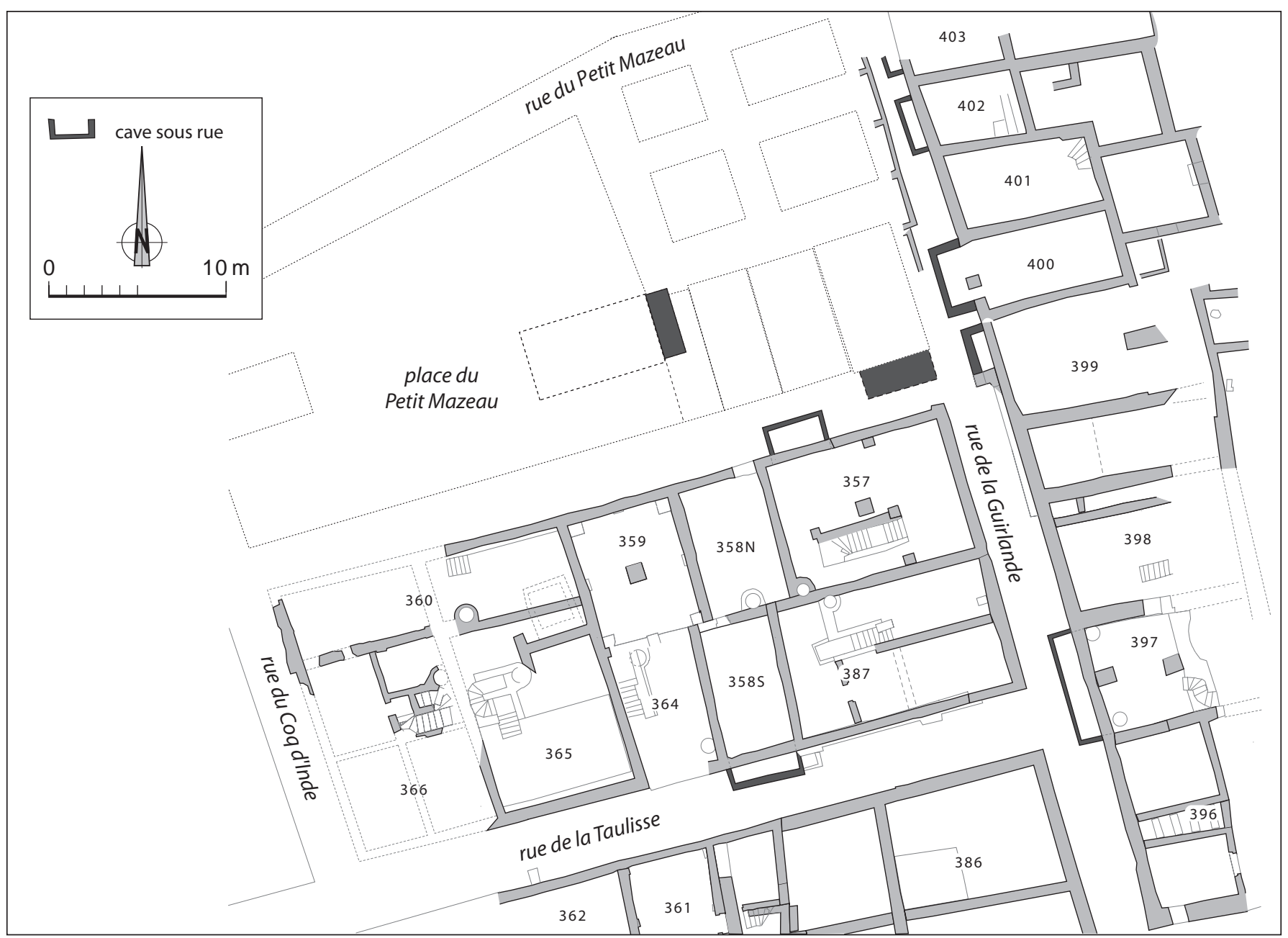

Fig. 110. Plan des caves prolongées sous la rue dans le quartier du Mazeau (DAO F. Guériel/Inrap).

Dans ce quartier où prend place le marché de la boucherie, les actes notariés évoquent souvent la coexistence d'une boutique ou d'un banc pour débiter la viande et d'une cave, ces deux pièces faisant parfois seules l'objet de la vente indépendamment de la maison qui les surmonte. Ces locaux, réserve et boutique parfois munie d'un four, semblent bien répondre aux besoins de ces commerces réservés à la clientèle aisée que sont la boucherie, la pâtisserie (fabricant de pâtés de viande à l'origine), et la rôtisserie. Ces empiètements sous la rue traduisent la fluctuation au cours du temps des notions d'espace privé et d'espace public. L'espace de la rue géré pour le bien commun par les consuls fait l'objet d'une appropriation partielle de la part de ces professions dont l'activité dépend directement de celui-ci pour leur approvisionnement et pour l'écoulement de leurs produits. Les trappes au ras du sol créent à l'évidence des obstacles à la circulation et constituent un danger lorsqu'elles sont ouvertes. Les extensions sous la rue génèrent donc des problèmes d'entretien, de stabilité et de praticabilité de la voie publique. Elles rendent difficile l'installation de réseaux d'eaux usées et imposent leur entretien rigoureux lorsqu'ils existent. Dans la rue de la Guirlande, un égout maçonné du XVI ${ }^{\mathrm{e}}$ s., scellant lui-même d'anciennes extensions de cave en rive ouest, est coupé par des caves mises en place au début du XVII ${ }^{\mathrm{e}}$ s. Au cours du XVIII ${ }^{\mathrm{e}}$ s., on observe l'abandon progressif des extensions sous l'espace public. Sous l'arc diaphragme qui perce les fondations de la façade, est alors inséré un mur de soutènement et l'espace gagné sous la rue est comblé. S'agit-il d'un changement d'activités dans le secteur ou d'une mesure d'interdiction communale ? On sait qu'à Riom, des mesures municipales d'interdiction ont été réitérées du $\mathrm{XVI}^{\mathrm{e}}$ au XIX ${ }^{\mathrm{e}} \mathrm{s}$. afin de faire disparaître ces ouvrages : «...et les entrées des caves respondant sur les rues seront closes et basties pour obvier à plusieurs inconvéniens qui pourroient advenir » (Renaud 2007, p. 61-63). Les recherches locales à Marseille n' ont pas encore levé le voile sur cet aspect de l'évolution urbaine de la ville. 


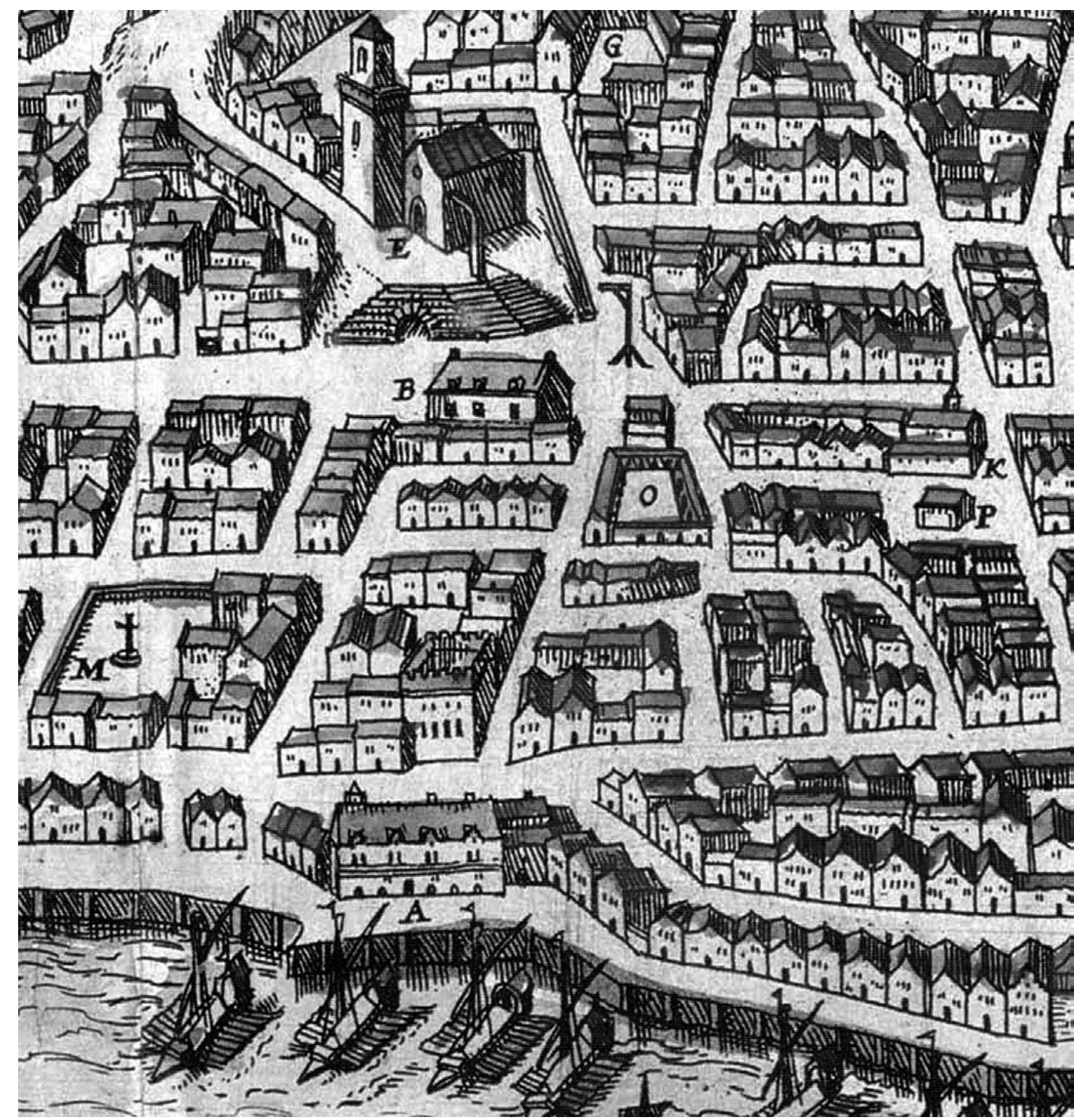

Fig. 111. Le petit Mazeau (lettre "O") sur le plan de G. Braun (1582) (cl. MHM). 


\section{Chapitre 5}

\section{Échanger, travailler, petites et grandes « industries » à Marseille}

Q uelques découvertes archéologiques particulières, au sein des quartiers d'habitation, nous renseignent sur des bâtiments liés au commerce et aux industries. C'est le cas en particulier d'un marché particulier, la boucherie, à proximité immédiate de l'axe principal que constitue la Grand-Rue.

\section{Les marchés}

Deux marchés alimentaires importants ont pu être approchés par l'archéologie, plus exactement frôlés par des fouilles. Le premier, le marché du Petit Mazeau, marché à la viande, est au cœur de la cité, à la frontière entre villes basse et haute, et à l'extrémité de la Grand-Rue, la seule voie carrossable intra muros, pour ainsi dire l'épine dorsale du réseau viaire. Cette rue permet d'atteindre la place aux Herbes devant l'église Notre-Dame des Accoules, où se tient un marché et dessert également le Grand Mazeau, plus proche des remparts. Une halle aux poissons est située rue de la Poissonnerie-Vieille. Le second, le marché aux fruits et légumes, est hors la ville, au carrefour de la Grand-Rue et des chemins d'Aix et d'Aubagne, et il profite des lices orientales, tout au moins à l'époque moderne.

Mieux renseignés par les fouilles, l'environnement de ces marchés, artisanat et auberges, n'entre pas dans ce chapitre, même si les textes en montrent l'imbrication.

\subsection{Un emplacement marchand : le macellum de Acuis (P. Rigaud)}

Non documenté par les fouilles, le parvum masellum apparaît dans les textes en 1220 dans un document donnant le tracé des limites entre la ville haute sous contrôle de l'évêque et la ville basse sous celui du vicomte de Marseille. Il est question d'un chemin conduisant à une porte au macellum novi marquant la distinction entre possession épiscopale et vicomtale (Bourrilly 1925, p. j. XXII, 316). Remarquable dans le paysage urbain, on le distingue du macellum vetus situé au Tholonée. Il est spécifié dans un premier document fiscal dans lequel on y fait mention qu'il avait appartenu au moins pour l'obtention des cens attachés à son existence à Ancelme Fer et son fils et successeur Ancelme Briton dont les biens avaient été confisqués au profit du comte au milieu du $\mathrm{XIII}{ }^{\mathrm{e}} \mathrm{s}$. suite à la révolte dont il avait été l'un de conjurés (Bourrilly 1925, p. 223).

En 1301, les cens sont dus par un certain Étienne Baudoyn. Le trézain sur les ventes quant à lui est perçu par le clavaire royal ${ }^{318}$. Par la suite une autre mention de cens perçu par la Cour est attestée en 1317-18 pour deux tables (tabula) appartenant à Durand Bermond dans ce qu'on appelle dorénavant le macellum de Acuis en raison de sa proximité avec l'église des Accoules.

Il est difficile d'obtenir d'après les textes une description du site. La dimension topographique du masel peut relativement s'évaluer d'après une iconographie tardive. La vue figurée donnée par G. Braun (1582) laisse indiquer un espace ouvert clos par des constructions déterminant un quadrilatère bâti muni d'ouvertures visibles dans le sud (fig. 111) alors que celle dressée par Maretz (milieu XVII ${ }^{e}$ s.) est moins précise et laisse une certaine ambiguïté sur la position du Petit Mazeau. Les plans de 1632 et 1700 donnent une disposition peu utilisable en raison d'une possible confusion entre ilots bâtis et non bâtis. Le plan cadastral de 1820 indique une situation semblable à celui de 1700 en montrant un quadrilatère coupé en son milieu par une voie transversale.

Sa disposition est peu explicite dans les registres de cens car les confronts ne sont pas définis dans une perspective globale mais d'après les maisons et éventuellement les îlots qui sont en situation de proximité. Les dénominations de rues ne sont qu'assez peu indicatrices en raison de l'ambiguité et la correspondance des noms avec les lieux (nous mettons à part les carerrias publicas dont l'appellation générique n'apporte que peu d'éléments). En règle générales elles ne sont pas nommées hormis dans quelques rares cas. En 1377 il est question d'une carreria recta dicti macelli, dénommée en 1405 carreria dicto macello de Acuis ${ }^{319}$.

318 AD13 B 1936 fol. 66v, 1301. 319 AD13 B 1177 fol. 1v et 3, 1405. 
Au moins une entrée permet l'accès de la rue au masel : «...passagio sive introytu dictum macelli cum carreria publica... ${ }^{320}$. Il est possible que cette entrée se ferme par une grille ou herse (tribulis macelli) puisque une maison confronte avec l'une d'elle ${ }^{321}$. Des indications permettent de savoir que la couverture de tuiles du masel (« cappam dicti macelli sive teguliciam ») ou «cappam sive tabuliciam » est soutenue par des piliers (pilare) dont un parmi d'autres est plus gros, au milieu, semble -t-il, du masel : «...duas tabulas macellis... subtus cappam dicti macelli sive teguliciam confrontatas ab una parte cum tabulis macelli Antoni Fayssati macellarii et ab alia parte cum tabulis macelli Rostagni Raymundi etiam macellarii...; et cum magno pilari ipsius macelli... »; « ...tabulam sive excortegatorium ante magnum pillari... »; «tabulam... confrontante cum magno pilari sistentis in medio dicti macellum...»; «...luegam tabule... confrontante cum magnum pillori substinenti capam dici macelli... ${ }^{322}$ puisqu'il en existe de plus petits : parvo pilari ${ }^{323}$. La plupart des étals paraissent se trouver à l'abri de cette partie couverte (subtus cappam).

Les cens donnent généralement des indications sur les noms des vendeurs, les proximités et juxtapositions des tables ou bien encore la vacuité de certaines places (tabula vacat). On peut également distinguer des nuances vraisemblablement sur les dimensions des étals et dans les dénominations: tabulam et taulono comme dans l'état de ceux de Johannes Maleti en $1377^{324}$. Certains étals paraissent se situer en bordure de la rue : «Item tenet Johannis Maleti ibidem quandam tabulam cum uno taulono juxta Johannis Relhe et juxta quantonum hospitii Bertholomeo de Montilis et juxta carreria rectam dicti macelli $\gg \mathbf{3 2 5}$ et dans des boutiques placées hors (?) de la couverture du masel : «Jacobus Bontosii alias de Brusa macellarius... duas tabulas macelli cum quadam butigia scitas in dicto macello subtus non cappam sive tabuliciam dicti macelli... \ ${ }^{\mathbf{3 2 6}}$. Ces étals, du moins dans des attestations tardives $(1537,1547)$ sont disposés selon des alignements peut-être continus puisqu'il est question dans un premier texte d'une première ligne de tables : «...tabulam facientum cantonum que est in prima lignea tabularum... » ${ }^{327}$. En 1547 l'existence d'au moins deux lignes d'étals est confirmée : «...une table qui solloyt

320 AD13 B 1177 fol. 2v et 5, 1405 ; AD13 B 836 n $^{\circ} 351,1446$. 321 AD13 B 1177 fol. 2v, 1405.

322 AD13 B 831 fol. 28, 1377 ; AD13 B 1177 fol. 1, 1405 ; AD13 B $836 \mathrm{n}^{\circ} 348, \mathrm{n}^{\circ} 361,1446$; AD13 B $836 \mathrm{n}^{\circ} 353,1449$.

323 AD13 B 1177 fol. 4v, 1405 ; AD13 B 836 n 370, 1447.

324 AD13 B 831 fol. 28.

325 AD13 B 831 fol. 29, 1377.

326 AD13 B 1177 fol. 2, 1405.

327 AD13 B 871 fol. 38, 1537. estre de Jacques Descallis la quelle est en la premiere ligne des tables du Petit Masel des Accolles... » ; «Item une autre taulle... laquelle estoye de Honorat de Bosc qu'est la seconde ligne des tables qu'on mentient devers le septentrion... ${ }^{328}$. Pour circuler en interne entre les étals on trouve des passages : «...duobus exitibus sive passagiis tabularum... » ${ }^{329}$. Ces dispositions peuvent laisser entendre une éventuelle hiérarchie, peu perceptible toutefois.

Des espaces libérés existent sous forme d'emplacements vides d'étals, ces lieux sont dits vacat tabula, locus, luegas voire patuo, en 1377 : «...quidam locus in quo solebat predicte Bermundi tabulam habere qui locus vacat» ${ }^{\mathbf{3 3 0}}$; en 1405 : «...quamdam locam sive luega tabule macelli...» ${ }^{331}$; en 1446 : «...tabulono sibi contiguo confrontante cum quodam patuo in quo solebat esse tabula... nunc vacante et cum alia luega dicti macelli... »; «patuo sive tabula Guilhelmi Relhoni... ${ }^{332}$. Au XVI ${ }^{\mathrm{e}}$ s. d'après la documentation étudiée il n'y a pas de mentions de ces lieux vides.

Les indications quant la spécialisation des tables sont assez rares, en fait il semble qu'elles servent pour l'essentiel à la vente des viandes. Quelques-unes, de plus petites, sont mentionnées pour l'usage plus particulier de l'écorchage et de la découpe, en 1405: «...quamdam tabulam macelli cum uno tabulono ad scortitandum...» ${ }^{333}$; en 1446 : «...tabulam sive excortegatorium... » ${ }^{334}$, de même en 1537 : « ...tabula masselli ad sindendum carnes... ${ }^{335}$. Quelques indications précisent les fonctions de certains lieux mais il s'agit d'une période révolue en 1547 : «...un devant de bas sive maison... appellé la Triparie ou se soulloyt par temps passé couper les testes de motons... » ${ }^{336}$. Il est vraisemblable qu'en ce lieu l'on traitait les abats (tripe, têtes...). L'endroit où l'on tue les bœufs est mentionné en 1547 : «Item, une place la ou soulloit avoyr une table et une place d'ung cambal et ung anel de fer ou l'on atachoyt les beuf pour les tuer... ». Le cambal est une sorte d'échelle verticale où la carcasse du bœuf est accrochée en vue de son découpage ${ }^{337}$.

Des fours à pâtisserie (pâtés de viande sans doute) sont installés dans certaines maisons dans le Petit Masel

328 AD13 B 871 fol. 68, 1547.

329 AD13 B 1177 fol. 4, 1405.

330 AD13 B 831 fol. 28v, 1377.

331 AD13 B 1177 fol. 4, 1405.

332 AD13 B $836 n^{\circ} 352, n^{\circ} 374,1446$.

333 AD13 B 1177 fol. 2, 1405.

334 AD13 B $836 n^{\circ} 348,1446$.

335 AD13 B 863 fol. 2 et 19, 1537.

336 AD13 B 871 fol. 66, 1547.

337 AD13 B 871 fol. $73 v$ et $362 v, 1547$. 
ou à proximité, les premières mentions apparaissent à partir de 1446 à propos d'un confront mais il n'est pas précisé s'il s'agit d'un four à pâtisserie ou destiné à un autre usage (furni Jaumete Burlone ${ }^{338}$ ). Ce n'est qu'environ un siècle plus tard que l'on retrouve mention d'une maison à pâtisserie ayant appartenu à Mathelin Girard qui est déclaré décédé, une autre déclaration précisant qu'il était pâtissier ${ }^{339}$. Cette maison se trouve sur la place du Mazel et confronte la maison de la Triperie. Leur proximité laisse entendre l'existence de lieux spécialisés.

Des boutiques (appotheca) sont mentionnées dans une reconnaissance de 1405. Il semble qu'il faille entendre par butigia, appotheca un synonyme de tabulas macelli; peut être s'agit-il de cabanes de planches situées hors de la couverture de tuiles du masel mais dans son périmètre puisque l'on précise dans le premier document : "...duas tabulas macelli cum quadam butigia scitas in dicto macello subtus non cappam sive tabuliciam dicti macelli... ${ }^{\mathbf{3 4 0}}$.

En 1405, on trouve mention de la boquaria qui est dite dans le masel, un certain Guillaume Frances la possède entièrement ( tenere et possedere totam boquariam ») et on la situe à l'entrée du bordel, certainement la rue de ce nom au bout de l'îlot du Saint-Esprit. En 1449, la boucherie est au même endroit mais c'est une femme Jaumone Borrele qui la reconnait, par héritage de son père, macellarius ${ }^{\mathbf{3 4 1}}$. Il apparaît que les occurrences de boquaria restent faibles par rapport à la mention plus générale de masellum, l'étymologie le rappelle : la boquaria, est le lieu ou l'on abat les bêtes, où l'on tue les boucs, le masellum étant le site où l'on procède à la vente.

Les appelations de métiers restent dans le convenu, d'une manière générale les intervenants et possesseurs de tables du Petit Masel sont dits macellarius; il ne s'agit que d'hommes. L'un d'eux, en 1547 un certain Pierre Santone dit le Petit, est dit $M^{e}$ bouchier pour la viande ${ }^{\mathbf{3 4 2}}$. Un juriste néanmoins possède en 1405 un étal ; Antoine Arnaud est qualifié de «vir, nobilis et circumspectus dominus » ${ }^{343}$. De même un «genovoys de Marceile», Jacques Bricard, est qualifié de noble en $1547^{344}$.

Les femmes, lorsqu'elles possèdent des étals sont dites filles, femmes, épouses ou veuves d'un homme qui généralement est un macellarius. En 1547, l'une d'elles

338 AD13 B $836 \mathrm{n}^{\circ} 347,1446$.

339 AD13 B 871 fol. 66 et $68 \mathrm{v}, 1547$.

340 AD13 B 1177 fol. 2, 1405 ; AD13 B 836 370, 379, 1447 ; AD13 B 863 fol. 2, 1537.

341 AD13 B 1777 fol. 4, 1405 ; AD13 B 836 n 382, 1449.

342 AD13 B 871 fol. 73, 1547.

343 AD13 B 1777 fol. 4v, 1405.

344 AD13 B 871 fol. 66.
Angelina Aymoneta possède « avec autorité et licence de son mari » une table à découper la chair au Petit Mazel des Acolles ${ }^{345}$. Dans de rares cas, le métier du mari est autre que macellarius ; ainsi, on trouve en 1405 un marin mais celui-ci est décédé ${ }^{346}$. Dans un autre cas, l'honesta mulier Laurete Bernucie est la femme d'un marchand ${ }^{347}$.

\subsection{Le Petit Mazeau à l'Époque moderne (C. Castrucci)}

La désignation de «Petit Mazel» apparaît dans les textes à partir du $\mathrm{XVI}^{\mathrm{e}} \mathrm{s}$. Au siècle suivant, certains immeubles ou boutiques sont situés «dans l'enclos du petit Mazeau», ou bien «sous la halle du Petit Mazeau » ${ }^{348}$. Ce qui permet de penser qu' on a voulu soit le séparer de celui des Accoules, soit le déplacer mais de toute façon le délimiter, construire un espace bâti symbolisant le lieu, rassembler les boutiques en un endroit clos, circonscrit par des immeubles et des rues.

Ceci vient illustrer le raisonnement de Jacques Heers pour l'Italie centrale au Moyen Âge. Pour lui, la construction des bâtiments utilitaires liés au ravitaillement, paraît lié à une politique concertée. Il démontre que l'aménagement de lieux de boucheries, et de marchés par la commune ne résultait pas d'une intention de construire un paysage mais d'une volonté politique visant d'une part à provoquer le rassemblement de nombreuses personnes en certains lieux, d'autre part à contrôler les prix et les abus de toutes sortes (Heers 1989) Les mesures qui sont prises par les autorités marseillaises pour limiter la taille des étals ressortent de ce type de démarche. Et il semble bien que c'est ce que les autorités marseillaises visaient.

Il est alors délimité par des immeubles qui bordaient au nord la Grand-Rue, et trois rues sans véritable nom : à l'ouest, celle qui longeait le Palais, dénommé quelquefois « la rue du Coq-d'Inde », au sud la rue appelée «du Petit-Mazeau » ${ }^{349}$, à l'ouest, la rue de la Guirlande. Toutefois plusieurs actes situent des maisons ou des boutiques au Petit Mazeau lorsqu'ils sont placés à l'est de

345 AD13 B 871 fol. 70v, 1547.

346 AD13 B 1777 fol. 4v et 5, 1405.

347 AD13 B 836 n $^{\circ} 347,1446$.

348 AD13 360 E 75, fol. 747 ; 366 E 237, fol. 248 ; ACM CC1, $\mathrm{n}^{\circ} 649$.

349 Cette dénomination était donnée également à une autre rue, orientée est/ouest également mais située à l'est de la rue de la Guirlande, ainsi qu'à la rue de la Guirlande, ce qui crée des difficultés dans la localisation de certains immeubles. Ce fut le cas pour Mathieu de Madières qui avait passé un prix-fait pour deux maisons simplement signalées dans cet acte comme étant «au Petit Mazeau ». Ce n'est qu'en découvrant les confronts sur l'acte d'achat trouvé dans un deuxième temps, que ses maisons ont pu être placées à l'est de la rue de la Guirlande. 
la rue de la Guirlande en droite ligne de la place dont il est question, ce qui rend difficile certaines localisations. Parallèlement à sa délimitation topographique, le Petit Masel se spécialise pour la boucherie, la rôtisserie, la pâtisserie et la boulangerie.

La présence d'une triperie est également caractéristique de ce lieu: on trouve plusieurs évocations de ce bâtiment: Marie-Thérèse Cauvet déclare en 1729 posséder un "banc à couper chair avec sa cave" situé « sous la halle du petit Mazeau» au nord de «la rue traverse allant à la Triperie » ${ }^{\mathbf{3 5 0}}$. La boutique de Balthazar Silvestre fait coin à la rue de la Triperie, celle qu' achète François Gaultier en 1642 confronte «les bancs et bâtiments de la Triperie ${ }^{351 \gg .}$. Les boutiques avec cave que vend Marquise Tripoulette voisinent « de couchant avec les bans et bastimentz appelés de la Triparie $\gg{ }^{352}$.

La particularité du Petit Mazeau réside dans le fait de ne pas être occupé uniquement par des étals et des boutiques: des habitations quelquefois assez importantes se mêlent au dédale des petites ruelles séparant les différents îlots qui le composent. Dès le XVI ${ }^{\mathrm{e}}$ s., une liste de reconnaissances de cens dû au roi vient confirmer cette coexistence entre immeubles et boutiques. La déclaration de Jean Ralhon disant posséder sur le Petit Mazeau une maison qui en confronte deux autres, puis trois tables dont une avec une crotte au-dessous en offre un bel exemple ${ }^{353}$. Les textes du XVII ${ }^{\mathrm{e}}$ s. apportent plus de précisions sur la dimension de ce mélange (fig. 112). Ainsi l'acte d'achat de la maison qu'acquiert Claude Garcin en 1655 permet de connaître l'existence par confronts de trois autres maisons ${ }^{354}$. La plupart de ces maisons ont une boutique en rez-de-chaussée : c'est le cas de celle qu'achète Pierre Chayné qui a une boutique de pâtisserie et 30 pans de façade, soit environ 7,50 m. La boutique qu'achète P. Sabatier ne paraît pas être surmontée d'une maison, pas plus que celle de Jean Sauzède qu'elle confronte ; en revanche, elle est attenante à une maison, celle de Jean Audhemar. Quant aux «bancs à couper cher avec boutegons et cave » acquis par François Gaultier, ils sont situés en bordure de la rue de la Guirlande et ne sont séparés des maisons voisines que par trois petites ruelles ${ }^{355}$.

Les maisons, hautes de quatre étages avec une terrasse au-dessus, sont assez modestes. Boucheries, fours de rôtisserie ou de pâtisserie occupent les rez-de-chaussée.

350 ACM CC $1, \mathrm{n}^{\circ} 147$

351 AD13 362 E 111, fol. 173v ; AD13 373 E 282, fol. 392.

352 AD13 373 E 282, fol. 392.

353 AD13 B 871, fol. 72, 1547.

354 Respectivement les maisons de Joseph Chambon, Jacques Gautier et Jean Griffet AD13 351 E 962, fol. 695v.

355 AD13 373 E 282, fol. 392.
Des escaliers en pierre de taille donnent accès aux caves situées au-dessous, qui prennent la largeur de l'immeuble et débordent en partie sous la rue.

La rue qui borde, au sud, le Petit Mazeau est occupée par des auberges. D'est en ouest, on trouve le Logis du Rozier, le Logis de la Taulisse et celui du Coq d'Inde. Trois autres auberges sont également présentes sur le marché. Deux d'entre elles appartiennent à Jacques Gaultier : La Couppe et La Licorne. Les Trois Maures n'est connue que par confronts et nous n'avons pas de renseignements sur son propriétaire. Pourquoi ces auberges si près du marché ? Est-ce la proximité du marché qui a suscité leur présence ou celle de la Maison commune? Accueillaient-elles de simples travailleurs journaliers ou au contraire des marchands étrangers venus faire des affaires en ville ? Les rapports qui en sont faits et les prix-faits établis montrent des bâtiments peu élevés, de deux à trois étages, et que l'on trouve en assez mauvais état au milieu du XVII ${ }^{\mathrm{e}} \mathrm{s}$. C'est entre les années 1637 et 1655 que les propriétaires des auberges que nous avons pu repérer dans les textes et en fouille décident de faire réparer leur immeuble. Plusieurs des réparations entreprises visent à une amélioration de l'habitat : meilleure étanchéité en ajoutant du batum soit aux rebords des fenêtres, soit aux conduits des eaux usées, mise en place d'arcades en pierre de taille pour soutenir les étages. Jacques Gaultier, lui, décide de refaire entièrement la façade du côté sud du Logis de la Licorne, et d'y faire percer trois portes de pierre de taille ${ }^{356}$.

L'attraction pour ce petit secteur, de la largeur d'un îlot était donc importante. Les artisans, les livreurs, les chalands devaient déambuler sur cette place au même titre que les notables de la ville qui avaient leurs affaires dans les îlots proches. Y compris les maçons, et autres gens des chantiers de construction.

\subsection{Approche archéologique des lieux de marché à l'Époque moderne (B. Sillano)}

Le masel du $\mathrm{XV}^{\mathrm{e}}$ s., jusqu'à la moitié du siècle suivant, semble disposer d'un espace couvert soutenu par des piliers, dans lequel s'alignent les tables des bouchers, peut être à l'image de la représentation extraite de Braun (cf. fig. 111). Mais ce pourrait n'être qu'une partie du marché, la triperie par exemple se situant à l'extérieur, probablement vers le Saint-Esprit, tout comme la bocquaria, l'endroit où l'on tue les bêtes. Il n'est pas possible de localiser précisément cette halle, située en gros entre la rue de la Guirlande et le palais comtal. Doit-on en reconnaître

356 AD13 390 E 216, fol. 1210. 


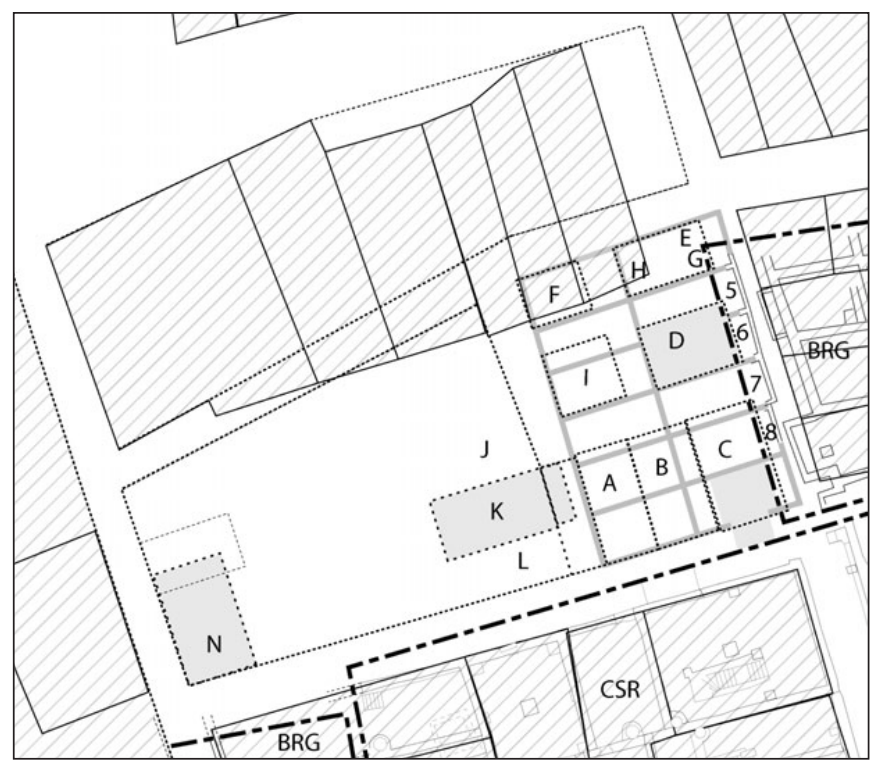

Fig. 112. Restitution de la place du Petit-Mazeau d'après le plan de 1784 (DAO B. Sillano/Inrap).

une partie dans les parcelles étroites observées en limite de fouille en bordure de cette rue? Rien n'indique que ces lots soient médiévaux, car tout vestige a disparu, mais le fait est que des caves s'y insèrent dans le courant du $\mathrm{XVI}^{\mathrm{e}}$ s. et que celles-ci sont construites en sous œuvre, ce qui suppose des bâtiments antérieurs ( $c f$. infra $\S$ II, 2, 3.1.). Nous n'irons pas plus loin dans l'interprétation.

Le marché du Petit Mazel, dénomination apparue au $\mathrm{XVI}^{\mathrm{e}}$ s., semble se différentier du macellum de Acuis; il y est toujours question de «halle du Petit Mazeau ». Le premier plan précis du marché moderne date de 1784, il a été établi afin de créer la place du Petit Mazeau, lorsque les bancs des bouchers n'étaient plus en usage. Il met en évidence quatre petits bâtiments séparés par des ruelles dont l'un est clairement subdivisé en quatre ( $c f$. fig. 112). Les textes nous apprennent qu'ils accueillent les bancs des bouchers. Le fait est que ce plan, où alternent le long de la rue de la Guirlande bâtiments et ruelles, ne peut s' accorder avec les vestiges mis au jour, une succession de parcelles jointives. Force est d'admettre que le lieu a été profondément remanié, parallèlement à l'élargissement de la partie nord de la rue de la Guirlande et donc abandon des caves situées sur sa rive occidentale. Insuffisamment renseignée, elle ne permet pas d'en proposer une datation précise mais, compte tenu de la nature des espaces abandonnés, des caves pavées de briques, nous pouvons admettre qu'elle remonte au moins à la seconde moitié du $\mathrm{XVI}^{\mathrm{e}}$ s. Le Petit Mazeau accueille la triperie disparue du Saint-Esprit, alors que la tuerie est centralisée près de la porte de la Joliette dès le milieu du XVI ${ }^{\mathrm{e}} \mathrm{s}$.

Autre lieu, le grand marché, sur les lices orientales. Mentionné au XVII ${ }^{e}$ s., nous ne connaissons pas l'importance qu'il pouvait avoir auparavant. Il est clair que sa situation extra muros ne lui garantit pas un caractère pérenne; néanmoins l'espace libéré des constructions médiévales au $\mathrm{XVI}^{\mathrm{e}}$ s. et sa situation stratégique au débouché du chemin d'Aix et de la GrandRue en fait une plaque tournante des échanges entre la ville et son territoire. La superposition des parcellaires médiévaux et modernes mis au jour sur le chantier de l'Alcazar, met en évidence une transformation profonde de la place qui suppose nécessairement une décision communale ( $c f$. $\S$ supra I, 2, 1.3.2.). Les textes, appuyés par les vestiges de l'arrière des maisons riveraines, permettent de restituer une façade d'îlot rectiligne, parallèle au rempart et séparé de la place du marché par un fossé. On l'appelle le Grand-Caire (le grand côté), sur le plan Maretz on y voit une rangée d'arbre, probablement le long du fossé, ainsi que deux fontaines monumentales. Tout comme la création du Petit Mazel, il s'agissait là, vers la fin du XVI' ${ }^{\mathrm{e}}$ s., d'améliorer les lieux de commerce afin d'inciter au rassemblement, probablement pour mieux en contrôler les prix.

\section{Lieux d'échanges médiévaux (F. Paone)}

Bien que peu abordés lors des fouilles archéologiques marseillaise, les lieux d'échanges (de commerces, de services) forment pourtant l'une des composantes de la ville. Bien peu d'indices nous sont offerts pour les identifier.

\subsection{Boutiques et entrepôts}

La connaissance des lieux de commerce et stockage de Marseille durant le Moyen Âge se fait d'avantage sur la base des sources écrites que matérielles. Les indices d'échanges sont matérialisés par les céramiques découvertes en fouille qui témoignent de la diversité des importations, mais les espaces boutiquiers qui peuvent être à la fois des lieux de vente et de production sont rarement mis au jour. Les rez-de-chaussée des maisons traditionnellement dévolus aux activités professionnelles livrent bien peu d'aménagements significatifs permettant d'identifier les métiers exercés. Seuls sont présents quelques fosses ou des rebuts de travail pour le métal ou le corail notamment; parfois, une lentille rubéfiée atteste de la présence d'un foyer sans qu'il soit possible de préciser s'il servait à un usage professionnel ou domestique. Les sources écrites apportent d'autres précisions. La topographie socioprofessionnelle a été appréhendée par D.-L. Smail pour le XIVe s. à partir de registres de tailles, et ce dernier a montré un double phénomène : le regroupement de membres d'un même corps 

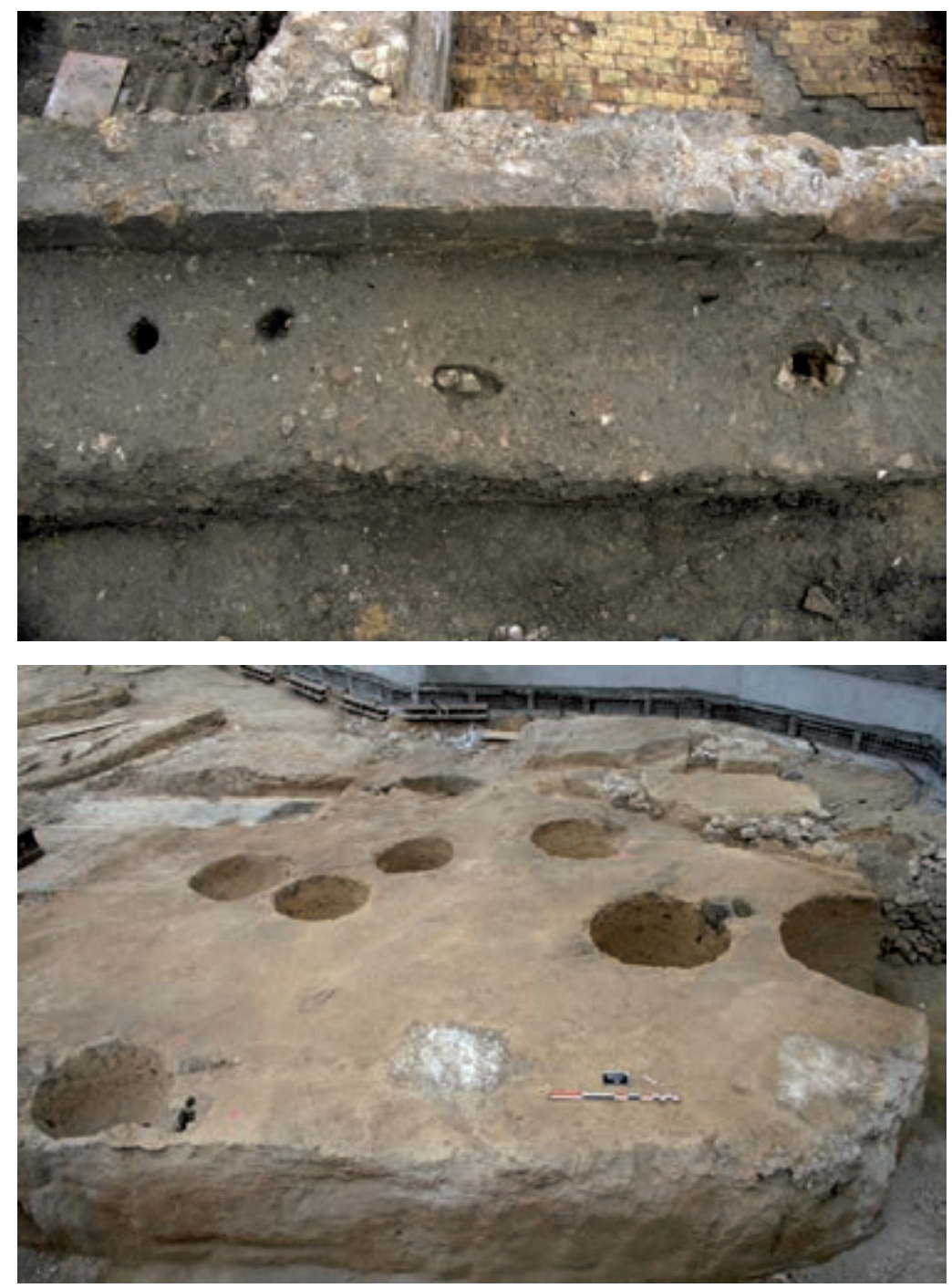

Fig. 113. Alignement de trous de poteaux le long d'une façade (cl. M. Derain/Inrap).
Fig. 114. Vue de l'aire d'ensilage du chantier de la rue Trinquet (cl. S. Mathie/Inrap). de métier dans un voisinage proche et également l'hétérogénéité socioprofessionnelle des rues (Smail 2001, p. 307-316). Enfin, les lieux de stockage sont peu connus et sont répartis naturellement à proximité du port mais également dans la ville haute.

Dans la ville basse, où sont concentrés artisans et commerçants, le quartier du Mazeau occupe une place essentielle et sa vocation marchande est clairement établie avec, notamment, le regroupement des métiers de bouches. Y sont concentrés la place aux Herbes située au sud de Notre-Dame des Accoules et le Petit Mazeau, établi à l'est du palais comtal, qui, au XIVe s. est également appelé « le Mazel de las Acolas ». Il formait, avec le Grand Mazeau, les seuls lieux dévolus à la boucherie à Marseille. Les fouilles César et Bargemon ont permis de dégager plusieurs îlots attenants au Petit Mazeau et il était concevable d'y retrouver des espaces boutiquiers, fréquemment évoqués dans ce type de contexte. Mais les découvertes n’ont pas été à la mesure de ces espérances, et les vestiges ténus des maisons médiévales surcreusées par des caves modernes sont, pour la plupart des cas, amputés de leurs sols d'utilisation; les façades étant en grande partie dérasées, aucun indice de porte boutiquière ou d'ouvroir n'a été observé. Les rares aménagements pouvant être liés à une activité marchande ont été découverts dans la rue de la Taulisse où le long d'une façade est disposé un ensemble de trois trous et bases de poteaux. Non alignés, ces poteaux sont espacés de 1,50 m et à moins de 0,30 m du mur; deux d'entre eux sont calés sur des socles en calcaire, le troisième d'une vingtaine de centimètres de diamètre est fixé dans la terre et maintenu par trois pierres. L'ensemble devait supporter une structure légère, un étal peut-être. Devant cette maison, mais également le long de la pièce mitoyenne, le sol ne s'appuie pas contre toute la façade mais contre une banquette dont ne demeure qu'une empreinte de 3,6 m sur $0,40 \mathrm{~m}$ de large (fig. 113). Ces dimensions sont en deçà des réglementations municipales, mais ces exemples ne semblent pas être représentatifs puisque les Statuts 
municipaux limitent l'emprise des étals des marchands à un maximum de quatre pans de large et trois dans les traverses ${ }^{357}$. La présence d'auvents, dont d'autres supports sont attribuables à l'Époque moderne, semble avoir caractérisé cette rue jusqu'à en déterminer la nouvelle toponymie utilisée à partir du XVII ${ }^{\mathrm{e}} \mathrm{s}$. « Taulisse », de l'occitan teulissa désignant la toiture.

Composants essentiels de villes portuaires à forte vocation commerçante, les lieux de stockages (magasins ou entrepôts) sont bien peu documentés par les archives et ne semblent pas être des marqueurs toponymiques contrairement au regroupement par rues des corps de métiers. Des espaces rudimentaires sont rattachés à des phases anciennes, entre le $\mathrm{IX}^{\mathrm{e}}$ s. et le $\mathrm{XII}^{\mathrm{e}}$ s., et sont destinés à la conservation des céréales. Sur la butte des Carmes, plusieurs aires d'ensilage sont apparues ainsi que dans le secteur de la Bourse, entre l'ancien rempart antique et l'extension de 1040 (Bonifay et al. 1984). Les premières découvertes, réalisées lors du chantier des Équipements Publics, livrent une quinzaine de silos de forme ovoïde, tous creusés dans le stampien (Willaume et al. 1983). En 2007, lors de l'opération de la Rue Trinquet, est apparu un nouvel ensemble de fosses dont les comblements contiennent des résidus de blé, d'orge pour l'essentiel mais également de riz en très faible quantité (Verdin 2008, p. 258-260) (fig. 114). En grande partie dérasés, ces silos, pourvus d'un fond plat ou en cuvette, ont des parois légèrement évasées et leur diamètre observé est compris entre 1,10 et $2,20 \mathrm{~m}$. La présence dans les remplissages de moellons et de dalles peut laisser penser que certains d'entre eux avaient une partie des parois et une couverture en pierre. Aucune organisation précise ne transparaît dans leur emplacement, les silos étant répartis de façon irrégulière ; le recoupement de certains d'entre eux atteste cependant d'une mise en place échelonnée entre le $\mathrm{X}^{\mathrm{e}}$ et le XII ${ }^{\mathrm{e}} \mathrm{s}$. La présence d'un bâtiment attenant ou d'une clôture est également notée mais il semble que cet ensemble s'étende bien au delà de l'emprise du site. Ces zones de stockage dégagées sur des surfaces trop partielles, ne nous livrent donc pas d'information sur l'organisation, la circulation intérieure ni sur la gestion de ces fosses. À la fin du XII ${ }^{\mathrm{e}}$ s., près de l'église des Carmes, une annonerie est répertoriée en remplacement probablement de l'aire d'ensilage découverte en fouille (Scherrer 2008, p. 131-138). Mais l'annonerie principale est, semblet-il, celle localisée vers le port non loin de la porte de Lauret. Elle faisait office d'entrepôt et de lieu de commerce, et comportait à la fin du XIII ${ }^{\mathrm{e}} \mathrm{s}$. dix-huit lieux de stockage et était non loin de l'office municipal des poids

357 Statuts municipaux L.VI. c. 12. et mesures. Le blé importé pouvait également être vendu directement à la place du Temple dès son déchargement, mais pas au delà de quinze jours après le débarquement. On sait que la réglementation concernant le blé et la farine était sévère, qu'en cas de disette la réquisition de ces marchandises sur les navires était de mise.

\subsection{L’édifice de la rue de la Guirlande}

À l'est du Petit Mazeau, est conservé un puissant bâtiment de près de $300 \mathrm{~m}^{2}$ au sol dont le rez-de-chaussée et les étages ont disparu mais qui est doté de plusieurs espaces souterrains ( $c f$. infra § II, 2, 2.3.2.). Établi durant la seconde moitié du XII ${ }^{\mathrm{e}}$ s., cet édifice, que les recherches les plus récentes identifient comme un établissement de Bains, est placé au débouché de plusieurs rues dans un souci d'accessibilité, et probablement de visibilité au sein du quartier marchand. Il est établi le long de la rue de la Guirlande. Ses espaces nord et sud sont dans l'axe des rues est-ouest, rues dites du Mazeau et de la Taulisse ; une desserte devait le longer au nord. Ce bâtiment ${ }^{358}$ mesure $24 \mathrm{~m}$ de long et sa largeur est comprise entre $14 \mathrm{~m}$ au nord et $10 \mathrm{~m}$ au sud hors œuvre. Cette forme trapézoïdale est induite par une adaptation de son plan à deux orientations dont l'une est héritée de l'Antiquité. Il se dégage de l'ensemble de cet édifice une homogénéité de construction, dans le choix des matériaux comme dans leur mise en œuvre. La présence d'une façade aveugle sur au moins $13 \mathrm{~m}$ de long en partie centrale de l'édifice sous-tend que les accès s'effectuaient à partir des pièces nord et sud (espaces 1 et 6), placées respectivement dans l'axe des rues du Petit-Mazeau et de la Taulisse ${ }^{359}$. Dès l'origine, les sols à l'intérieur de l'édifice sont en contrebas de la rue, un plancher pouvant être restitué un mètre plus bas à partir du ressaut de fondation, ce qui implique la présence d'emmarchements.

Nous ne disposons pas d'une vision exhaustive du plan, qui est amputé en partie orientale. Nous savons cependant que ce bâtiment se compose au rez-de-chaussée d'au moins quatre espaces principaux, dont le plus étroit est dès l'origine compartimenté en deux petites pièces séparées par un couloir central. Au nord, la première salle, d'une superficie de $47,5 \mathrm{~m}^{2}$, communique avec un espace de $61,75 \mathrm{~m}^{2}$ par l'intermédiaire d'un couloir central qui devait vraisemblablement aussi desservir

358 L'essentiel des descriptions provient de l'analyse de V. Rinalducci réalisée lors du chantier « César 1 ».

359 On note d'ailleurs que ce sont uniquement dans ces espaces que les extensions de cave moderne dans la rue sont réalisées, la présence de percements (porche ou porte) dans les maçonneries médiévales ayant probablement facilité leur mise en œuvre. 


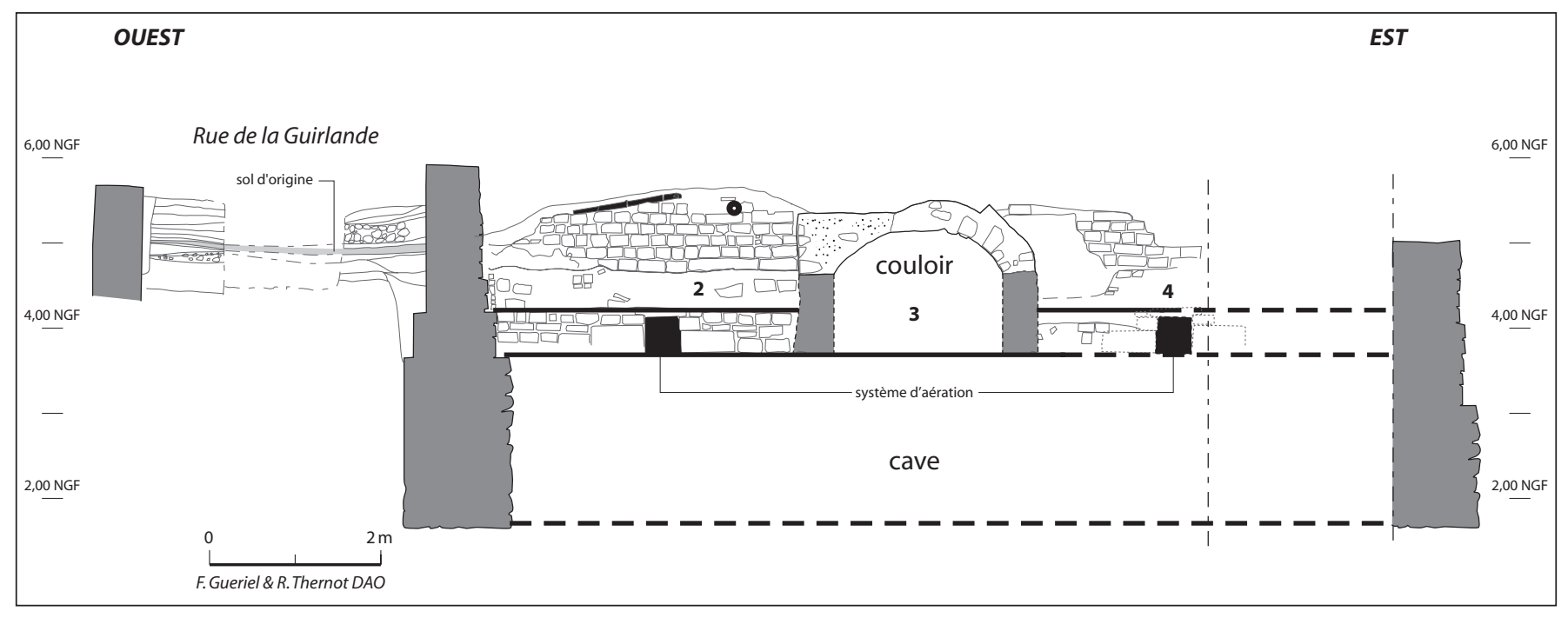

Fig. 115. Section ouest-est de la rue de la Guirlande et du bâtiment des Bains (DAO F. Gueriel, R. Thernot/Inrap).

les petites pièces latérales d'une douzaine de mètres carrés. Ce passage, large de $2 \mathrm{~m}$, a une hauteur sous l'intrados peu élevée, avoisinant $1,8 \mathrm{~m}$, soit nettement moindre que celle des pièces attenantes. Enfin l'espace méridional, accessible uniquement depuis l'extérieur, mesure $9 \mathrm{~m}$ de longueur pour une largeur de $6 \mathrm{~m}$, soit $54 \mathrm{~m}^{2}$, très proche du type des entrepôts (fig. 115).

Les élévations sont construites en petit appareil réglé de moellons de Saint-Victor. D'une épaisseur de 0,6 m, elles s'élargissent à la base sur trois assises formant ressauts. C'est à l'emplacement de ces ressauts que plusieurs ouvertures sont établies dans les murs de refend. Trois baies sont disposées selon un même alignement d'un mur à l'autre offrant ainsi une symétrie entre les pièces $1,2,5$ et 6 . Un percement comparable est réalisé dans le mur mitoyen des espaces 5 et 6 , il se situe dans l'axe du couloir C. Il est envisageable que, par symétrie, d'autres ouvertures aient été aménagées dans la partie orientale de l'édifice, mais cela n'a pu être vérifié. Compte tenu de leur emplacement à la base des élévations, ces baies, dont les dimensions sont comprises entre $0,5 \mathrm{~m}$ et $0,6 \mathrm{~m}$ de largeur et $0,75 \mathrm{~m}$ de hauteur, ne sont pas destinées à l'éclairage, mais plus vraisemblablement à garantir une circulation d'air entre chaque espace.

Ce système d'aération est complété par des réseaux de tuyaux de terre cuite intégrés dans les maçonneries et dont les conduits latéraux formant parfois un coude, aboutissent à l'aplomb du parement intérieur ( $c f$. fig. 73). Ces canalisations constituent un réseau d'assainissement et probablement d'aération de cette construction dont le rez-de-chaussée est en partie souterrain et la façade dépourvue d'ouverture. La mise en place de tuyaux « aériques » est préconisée dans divers traités d'architecture afin d'assainir les établissements fermés tels les prisons, les hôpitaux, les entrepôts. Dans l'Encyclopédie, est mentionné l'emploi de conduits de terre assurant le renouvellement de l'air dans des lieux fréquentés du public notamment une chambre des communes ou un lieu de spectacles. Ces canalisations sont cependant disposées verticalement, dans les voûtes et plafonds, ce qui n'est pas le cas de l'exemple présenté. À l'exception des aménagements en lien avec la construction, un puits forme le seul élément utilitaire encore en place.

Cet important édifice semble avoir été pourvu de caves si l'on en juge par la présence de puissants soubassements épais de $1 \mathrm{~m}$, dont l'organisation spatiale est identique au niveau supérieur. Interprétées initialement comme des fondations, ces maçonneries de $2 \mathrm{~m}$ de haut sont formées d'assises très irrégulières de blocs simplement retouchés de grès et de poudingue pour l'essentiel, contrastant en cela avec le petit appareil régulier du rez-de-chaussée ; elles ont pu constituer les parois de caves. En effet, une hauteur des murs de plus de $2 \mathrm{~m}$ rend concevable l'existence d'un sous-sol, existence que pourrait confirmer la présence d'enduit sur la face interne des maçonneries. Ce revêtement, permettant d'atténuer l'irrégularité des parois, est très ponctuellement conservé (murs nord et sud de l'espace E) et le peu de soin accordé à l'appareil irrégulier des murs complique son application. L'existence de ces caves (donc d'espace vide) justifierait alors le montage d'un échafaudage dont demeurent les ancrages (trou de boulin) au niveau du changement d'appareil.

A proximité immédiate de cet édifice, a été retrouvé un petit complexe hydraulique composé d'un puits à noria et d'une cuve placés dans une cour ; il est difficile d'établir avec certitude qu'il a pu servir à alimenter le bâtiment en eau mais c'est vraisemblable. 


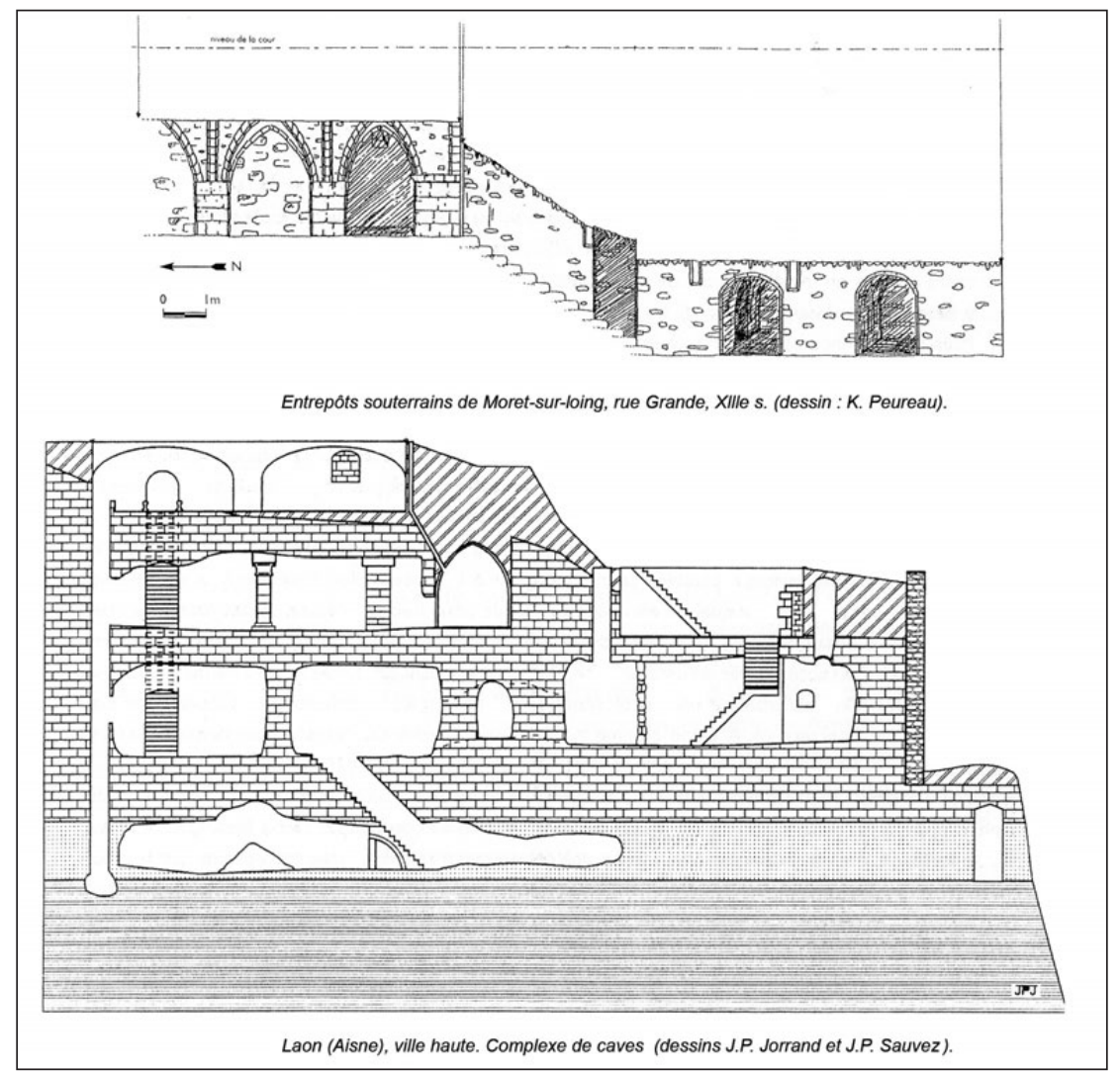

Fig. 116. Exemples d'entrepôts souterrains (extrait de Alexandre-Bidon, Lorcin 2003).

La proximité du Mazeau nous a laissé envisager que ce bâtiment ait pu avoir un lien direct avec l'activité des bouchers. À Paris, le quartier du Châtelet regroupait la rue de la Triperie, l'Ecorcherie et la Grande Boucherie vaste construction comprenant trois niveaux dont des caves. La construction de caves monumentales au cours du Moyen Âge est signalée dans plusieurs villes marchandes, ces lieux sont souvent placés sous les halles ou les places de marchés; ils peuvent également être réunis dans un seul édifice et occupent plusieurs étages (Alexandre-Bidon, Lorcin 2003, p. 216-218). (fig. 116).

Cependant, une seconde interprétation nous est apporté grâce aux données nouvelles provenant du dépouillement par M. Bouiron ${ }^{360}$ de registres concernant les propriétés de l'abbaye Saint-Sauveur. Il apparaît que plusieurs maisons de ce quartier relevant du monastère sont situées à proximité de bains. L'éventualité que cet ensemble vaste corresponde à des étuves doit donc être envisagée, même si l'ampleur de la construction comme son organisation spatiale peuvent surprendre. Dans un article consacré aux bains à Naples entre le $\mathrm{X}^{\mathrm{e}}$ et le $\mathrm{XIII}^{\mathrm{e}}$ s., A. Feniello et D. Boisseuil ${ }^{361}$ ont montré le rôle

$360 \mathrm{M}$. Bouiron à paraître.

361 Feniello, Boisseuil 2002, p. 71-81. prépondérant joué par les monastères dans la mise en place et la gestion d'étuves publiques conçues comme des ressources financières importantes mais également des éléments marquants du paysage urbain. Doit-on imaginer qu'une semblable démarche ait animé les moniales de Saint-Sauveur?

\subsection{En conclusion}

Comme nous pouvons le voir de nouveau, Marseille souffre de l'éradication de ses constructions médiévales dont ne demeurent parfois que quelques assises. Il est donc bien difficile de mesurer l'activité marchande et d'évaluer comment elle s'insère dans les unités d'habitations. De semblables difficultés concernent les espaces de stockage dont la connaissance est tout aussi tributaire de leur mauvais état de conservation et du dégagement trop limité des plans des bâtiments. D'autre part, la généralisation de la conservation en sacs ou en tonneau peut être envisagée. Enfin, les probables étuves découvertes dans le quartier du Mazeau souffrent à bien des égards de l'amputation de ses sols mais aussi de la méconnaissance archéologique de ces établissements. Peu attestés en fouille, les bains publics sont pourtant des marqueurs essentiels de la ville médiévale. 


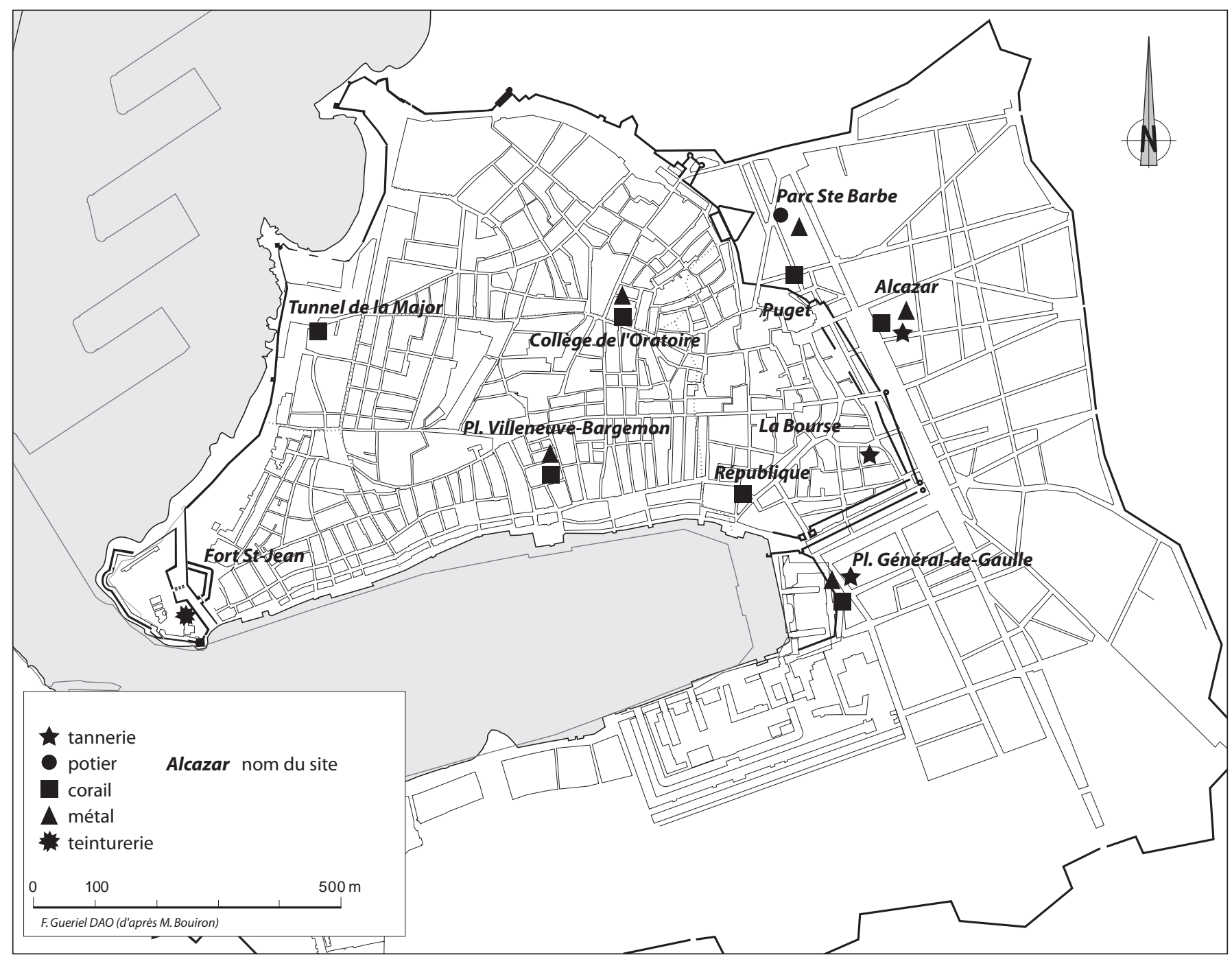

Fig. 117. Localisation des découvertes relatives à l'artisanat au Moyen Âge (DAO F. Gueriel, B. Sillano/Inrap sur fond de plan M. Bouiron).

\section{L'artisanat à Marseille au Moyen Âge (É. Leal)}

L'artisanat à Marseille, centre économique majeur du comté de Provence et place seconde du grand négoce international, joue un rôle majeur dans la vitalité économique de la cité. À côté des ateliers destinés à pourvoir aux besoins des habitants de la cité, se développent dès la fin du XII ${ }^{\mathrm{e}}$ s. des activités artisanales d'ampleur, au fort pouvoir spéculatif et apte à constituer une marchandise destinée à l'exportation, régionale vers l'intérieur des terres ou tournée vers les circuits d'échanges internationaux par voies maritimes. C'est plus particulièrement le cas des ateliers de tannerie et du travail du corail (fig. 117)

La richesse de la documentation archivistique relative à l'activité artisanale de la ville a retenu l'attention de plusieurs chercheurs depuis longtemps. La publication du VI ${ }^{\mathrm{e}}$ livre des Statuts au début du XX ${ }^{\mathrm{e}} \mathrm{s}$.
(Crémieux 1917) et les recherches effectuées sur le commerce (Pernoud 1948; Baratier, Reynaud 1951) ont été récemment amendées de travaux portant sur la topographie socioprofessionnelle de la ville au XIV ${ }^{\mathrm{e}} \mathrm{s}$. (Smail 2001).

L'activité artisanale d'une population appréhendée à travers les vestiges archéologiques reste tout aussi aléatoire que peuvent l'être les données archivistiques, l'ampleur ou l'impact économique d'une production n'étant absolument pas en rapport avec les vestiges identifiants. L'exemple le plus flagrant est sans doute celui du travail du corail qui participe largement à la richesse de la ville mais ne laisse que des traces ténues et souvent peu explicites. À cela, il convient d'ajouter le degré très variable d'informations livrées par les vestiges. En effet, le petit artisanat ne nécessite pas d'installation lourde spécialisée, donc moins d'espaces de travail. Dans ce cas, ce ne sont donc plus les équipements qui 
renseignent sur l'activité, mais les déchets produits ou les stocks de matière première entreposés dans l'attente de leur traitement. Au contraire, des activités demandant des infrastructures plus élaborées et pérennes sont surtout renseignées dans leur aspect fonctionnel et beaucoup moins par leur type de production. C'est le cas des teintureries et des tanneries dont le produit fini périssable ne bénéficie que rarement des conditions permettant sa conservation au sein même du site.

\subsection{Les traces du petit artisanat}

Dans cette catégorie d'activité, c'est la transformation du corail et le travail des métaux qui livrent les vestiges les plus explicites en raison des déchets qu'ils génèrent. Si la présence de ces activités est en général aisément discernable à partir des seuls vestiges archéologiques, leur nature et leur ampleur est en revanche toujours difficile à estimer.

\subsubsection{Le travail du corail}

$\mathrm{Au}$ Moyen Âge, tous les peuples riverains de l'ouest de la Méditerranée (Arabes, Génois, Catalans, Marseillais...) se lancent dans l'exploitation et la commercialisation de l' «or rouge ». Marseille se présente alors comme une importante place du commerce du corail grâce aux importants fonds coralligènes que compte la côte provençale. Si l'on se réfère aux écrits de Pline, les fonds corallifères de la côte marseillaise sont exploités dès l'Antiquité, mais aucune découverte archéologique n'a malheureusement permis de préciser cette activité pour la période antique. À Marseille, la commercialisation du corail est attestée par les archives dès le $\mathrm{XI}^{\mathrm{e}} \mathrm{s}$. Dès cette période, les pêcheurs marseillais ne peuvent plus se limiter au rivage provençal où les fonds coralligènes se raréfient mais cherchent au contraire de nouveaux sites de pêche. Ils se fixent notamment en Sardaigne grâce à la protection de l'abbaye Saint-Victor qui y fonde des prieurés. La concurrence avec les Catalans, les Arabes et les Génois, également très actifs dans se secteur de pêche, est rude. Il semble que la dynastie angevine favorise l'implantation des marseillais dans les eaux de Naples alors que la couronne d'Aragon autorise les Catalans à développer leur activité en Sicile et autour de la Sardaigne (Bresc 1984 ; Laroche 1999).

L'effervescence et les enjeux politico-financiers qui se développent autour de l'exploitation du corail résulte de la préciosité de ce matériau -qui ira bientôt de pair avec sa rareté puisqu'à la fin du Moyen Âge, le marseillais Jean de Forbin est amené à négocier l'exclusité du corail de l'Algarve portugais afin de palier la baisse de production méditerranéenne (Bresc 2000, p. 42)- et de son intégration dans le grand commerce méditerranéen. En effet, si une certaine quantité est traitée puis utilisée sur place pour un artisanat de luxe (bijouterie, orfèvrerie, chapelets), une grande partie de la production occidentale (brute ou sous forme de boutons ou de perles) est exportée vers l'Orient (Alexandrie, Damas Beyrouth, Rhodes) et constitue un moyen de paiement très prisé en raison de la haute valeur commerciale du produit. Pour Marseille, il constitue une excellente monnaie d'échange pour payer les produits acheminés depuis Alexandrie, où la cité possède un consulat depuis le milieu du XIII' s. (Bresc 2000, p. 14).

Le commerce et le travail du corail à Marseille sont suffisamment importants dans l'économie de la ville pour susciter des décisions politiques au plus haut niveau. Les archives de Marseille recèlent deux documents officiels en rapport avec cette activité. L'un, daté du 28 juin 1258, est un acte de reconnaissance du roi d'Aragon et de Sardaigne accordant aux corailleurs l'exemption des droits pour le transport de leurs marchandises par les frontières de son royaume. L'autre, daté du 6 octobre 1355, émane de la reine Jeanne qui confirme les franchises accordées par Charles II aux Marseillais et à tous les provençaux demeurant en Sicile ou en Sardaigne (zone d'activité privilégiée des Catalans à partir $\mathrm{du} \mathrm{XIV}^{\mathrm{e}} \mathrm{s}$.) ainsi que tous les privilèges qui leurs sont concédés pour la pêche du corail et des poissons (Laroche 1999, p. 169).

Loin de se limiter à la période médiévale, l'activité du corail à Marseille se prolonge de manière prospère au moins jusqu'à la fin du XVII ${ }^{\mathrm{e}}$ s., ceci alors même que le monopole de l'exploitation sur les côtes provençale est accordé en 1467 à une compagnie italienne et vénitienne et que le roi René cède à un de ses familiers tous ses droits sur la pêche du corail entre l'embouchure du Rhône et celle du Var. En 1552, Tomasino Lenche, sujet originaire de Morsiglia (en Corse) établi à Marseille depuis 1533, fonde la Grande Compagnie du Corail grâce à laquelle il va vite s'enrichir. Il établit des comptoirs sur les côtes d'Afrique du nord (Bône, La Calle, Massacarès). Il devient alors un des principaux notables de Marseille et s'allie aux Forbin, autres grands brasseurs d'affaires, par le mariage de sa fille unique avec Jean-Baptiste de Forbin-Gardane (Vergé-Franceschi 2004, p. 74).

Aux XVI $-\mathrm{XVII}^{\mathrm{e}}$ s., Marseille abrite de riches corailleurs et reste un centre de travail du corail important. À la fin du XVI ${ }^{\mathrm{e}}$ s., on compte 130 ouvrières employées à gratter le corail et en 1695 , le propriétaire d'une manufacture de corail indique employer pas moins de 400 ouvriers répartis sur Marseille et Cassis (Laroche 1990, p. 172). 
Les traces archéologiques du travail du corail apparaissent bien tenues au regard des enjeux et des richesses dont les archives font état. Cette activité a été identifiée en six points de la ville, pour une période allant du XIII au XVI ${ }^{\mathrm{e}}$ s.

Les fouilles du Tunnel de la Major, localisées dans la ville de la prévôté, ont été l'occasion de découvrir des débris de corail rouge dans les niveaux d'occupation d'un habitat du XIII' ${ }^{\mathrm{e}}$ s., situé sur le flanc ouest de la butte Saint-Laurent (Barra et al. 2004, p. 298-299). Ils se trouvaient stockés en des espaces bien précis, à l'intérieur même du bâtiment et sur le sol de la cour qui le borde au sud. Ces débris de corail correspondent à des espèces locales ${ }^{\mathbf{3 6 2}}$ et ont la particularité de provenir d'amas côtiers d'animaux morts et non pas d'une récolte d'animaux vivants. Dans ce cas, il s'agit donc d'un matériau de second choix mais qui n'en garde pas moins une valeur marchande sous l'appellation de terrail. Aucun des fragments ne présentant de traces d'outils, il n'est pas impossible que ces débris résultent plutôt d'un tri de matériaux destinés à la vente que de déchets d'atelier.

Le siècle suivant est documenté par le bourg des Olliers au nord-est de la ville et le bourg Sainte-Catherine, au sud-est. Au milieu du XIV e s., une population de forgerons occupe le quartier autrefois dévolu aux potiers. Au sein de l'artisanat de forge clairement attesté, se trouvent des déchets de corail en abondance (Marchesi et al. 1997, p. 51). Alors que l'on a pour habitude d'appréhender les activités artisanales de manière très sectorielle, se trouvent ici corrélées deux activités artisanales, non complémentaires d'un point de vue technique mais menées au sein de mêmes espaces. Le bourg SainteCatherine a également livré pour la même période une fosse creusée dans la calade de la rue principale remplie de fragments de branches de corail associés à des scories métalliques mais sans qu'il soit possible de localiser plus précisément cette activité au sein de l'îlot (Bouiron 2001a, p. 114). La couche de démolition qui scelle les maisons de l'îlot sud a par ailleurs livré des déchets bruts de corail (Bouiron 2001a, p. 120). Signalons enfin pour cette période la découverte de quelques fragments de corail et d'un dépôt de sables gris sur un sol de l'espace 4C du bourg de Morier (Bouiron 2001b, p. 368).

Sur le site de la place Villeneuve-Bargemon, dans la ville basse, une fosse dépotoir recelant des déchets de taille associée à une seconde fosse contenant du sable pur témoignent d'une activité de corailleurs dans ce quartier (Paone 1997, p. 2). Ces structures sont localisées en cœur d'îlot, dans l'angle d'un espace ouvert. Leur datation est

362 Précisions fournies par Mme Sylvie Pichard du Museum d'Histoire Naturelle de Marseille. malheureusement très aléatoire, située entre le XIII ${ }^{\mathrm{e}}$ et le XVII ${ }^{\mathrm{e}} \mathrm{s}$.

Enfin, la présence d'un artisan corailleur œuvrant au tout début du $\mathrm{XVI}^{\mathrm{e}}$ s. a été identifiée dans le cadre de l'opération de diagnostic République - surverse VieuxPort, située au bas de la rue de la République. Son activité est perceptible grâce à une couche dépotoir, constituée de sables marins gris très riches en débris de corail rouge (deux kilogrammes après lavage et tri) découverte à l'angle de deux murs, dans une cour de l'îlot (Sillano 2004, p. 46-47). Les fragments sont de petite taille (de 3 à $30 \mathrm{~mm}$ ) et très vacuolaires en raison du prélèvement de matière effectué sur les branches.

\subsubsection{Le travail des métaux}

Le travail des métaux est indispensable à bien des secteurs d'activité et intervient souvent en annexe d'une activité principale pour laquelle on répare ou prépare ses outils sur place. Nous avons décidé de traiter le travail du métal dans le petit artisanat bien qu'il n'en fasse pas toujours partie. La principale raison de ce choix résulte dans le fait qu'aucun élément n'ayant permis de définir de véritable complexe métallurgiste (à l'exception peut-être de la forge du bourg des Olliers), il se range davantage parmi les petits ateliers. Par ailleurs, sa répercussion sur son environnement urbain apparaît mineure face à des activités comme le tannage ou la poterie, par ailleurs grandes consommatrices d'eau, puisqu'il s'insère dans une trame parcellaire dense, ceci en dépit des risques d'incendies que les foyers génèrent, et de la pollution engendrée. Enfin, l'association quasi-systématique entre le travail du corail et celui des métaux a conduit à privilégier le cadre du petit artisanat.

Dans la ville basse, sur le site de l'Espace Bargemon, un artisanat des métaux, daté de la seconde moitié du $\mathrm{XII}^{\mathrm{e}}$ s., est attesté dans les environs immédiats du site (cf. infra $\S \mathrm{II}, 2,2.2$.). En l'absence de structures permettant de localiser avec précision l'atelier, c'est la présence de déchets issus de curage de four qui témoigne de cette activité. Ils sont essentiellement rejetés sur les voies sous la forme de recharges riches en cendres, charbons de bois, scories métalliques et nodules de bronze ou dans des fosses (Mellinand 2005, p. 312). Ainsi l'ensemble de la rue de la Guirlande reçoit des épandages de cendres et charbons de bois mêlés à des passées oxydées riches en scories de fer et de bronze. Les mêmes niveaux se retrouvent au carrefour des rues de la Taulisse et du Petit-Mazeau.

Ces niveaux, marqués de manière évidente par cette l'activité métallurgiste, constituent les plus anciennes traces de l'occupation médiévale de ce quartier, alors caractérisée par une trame parcellaire peu dense, sans 
qu'il s'agisse pour autant d'une activité nouvellement installée dans ce secteur. En effet, au regard de la quantité de scories, de débris métalliques (cuivre et bronze), de zones rubéfiées et des amas de cendres et charbons qui marquent les niveaux antérieurs, cet artisanat y est sans doute présent dès l'Antiquité. La proximité du port et des multiples besoins que son activité génère a très certainement largement contribué au maintien d'un travail du métal dans ce secteur de la ville.

À proximité de la Grand-Rue, sur le chantier République - surverse Vieux-Port, les traces d'une activité métallurgique ont été repérées dans un contexte de la seconde moitié du XIII ${ }^{\mathrm{e}}$ s., se poursuivant peut-être jusque dans la première moitié du XIV e s. (Sillano 2004, p. 45). Les vestiges consistent en des sols fortement rubéfiés, riche en débris métalliques et scories. L'étroitesse des sondages ne permet pas de définir avec précision dans quel cadre se développe cette activité. Elle semble prendre place au sein d'un parcellaire déjà bien organisé mais dont la densité ne peut être déterminée.

En bordure de ville, dans le bourg des Olliers situé au nord-est des remparts, une zone de forge succède à des ateliers de potiers perpétuant de la sorte des métiers des arts du feu entre les années 1320 et 1350 (Marchesi et al. 1997, p. 48-55). On y retrouve l'association caractéristique des déchets de forge et de corail. Plusieurs bâtiments ont livré les traces tangibles de cette activité (amas de scories, débris métalliques, fosses à déchets) mais c'est la maison XI qui reste la plus significative. Les aménagements sont regroupés en un ensemble cohérent composé de nombreuses fosses, de zones d'épandage de déchets et de stockage de combustible. Une fosse particulièrement rubéfiée est interprétée comme la base du foyer de forge. Des structures plus rarement perceptibles, comme l'emplacement du billot supportant l'enclume, les calages plats destinés à recevoir le baquet de trempe ou la fosse à réserve de combustible, ont pu être mis en évidence. Les fosses de rejets ont livré une importante quantité de scories, dont certaines en plaque, et des culots de fond de fours, des pierres à aiguiser, des nodules de cuivre, du charbon de bois. L'analyse des scories et du fond de culot de four les classe dans la catégorie des déchets de forge.

Les sols brûlés découverts sur le site Puget III, localisé au sud du quartier Saint-Barbe, (Moliner et al. 1993, p. 46-47), à la surface desquels ont été récoltées des scories, permettent d'étendre la zone de forge jusque dans cette zone. L'analyse d'une de ces scories a permis de confirmer qu'il s'agissait également d'un résidu de travail de forgeage (Marchesi et al. 1997, p. 53).

Dans le bourg Sainte-Catherine, plusieurs espaces attestent du travail du métal dans la première moitié du XIV' s. (Bouiron 2001a, p. 98-99). C'est plus particulièrement le cas d'une maison de l'îlot nord (pièce B9), située à l'angle de la rue principale (rue droite Sainte-Catherine) et d'une ruelle perpendiculaire (rue Raymond-Rascas) (Bouiron 2001a, p. 332-333). Des amas de scories et de débris métalliques, les nombreuses fosses à déchets comblées de scories et de débris métalliques, de charbons de bois, découvertes au sein de cet espace, la découverte de pierres à aiguiser et la rubéfaction des niveaux d'occupation, témoignent d'un travail du métal développé au sein d'un atelier de forge.

Au milieu du XIV ${ }^{\mathrm{e}}$ s., le rez-de-chaussée de la maison C6, située dans l'îlot sud en rive de rue, est marquée par la présence de deux grandes plaques foyère et d'une petite fosse oblongue remplie d'un sable blanc que l'on retrouve également en épandage un peu plus loin, associé à des scories. Les auteurs parlent d'une «activité artisanale légère du fer, associée à une autre activité dont nous n'avons plus la trace » (Bouiron 2001a, p. 105). Au regard de la présence du sable et de la découverte de fragment de corail dans une fosse de la rue principale, il est possible que l'autre activité soit liée au travail de corail.

Par ailleurs, le puits-citerne plus au nord (cour B3), autrefois dévolu à la tannerie mais servant désormais de dépotoir, a livré six creusets et une cucurbite. L'ensemble de ces pièces est réalisé en argile kaolinitique ferrugineuse. Ces objets doivent leur teinte grise actuelle aux fortes températures qu'elles ont subies. Les creusets, à profil tronconique et fond plat, possèdent un bec verseur pincé. Leur paroi intérieure porte des traces de vitrification et des résidus métalliques. La cucurbite ou « boîte à cémenter » est un objet du travail du métal bien connu de l'iconographie et des traités alchimiques médiévaux mais plus rarement découvert en fouille. Il s'agit de la partie inférieure de la chaudière d'un alambic qui, remplie de cendres et fermée hermétiquement avec de la laine et de l'argile, permettait de rendre fusible certains métaux.

La particularité de ces instruments de métallurgistes, qui n'appartiennent pas aux grands travaux de forge, corrélée aux résultats des analyses du contenu des creusets indiquant le traitement du cuivre, de l'argent et de l'or évoquent la présence de bronziers ou orfèvres dans l'îlot central.

Enfin, au bourg de Morier, une pièce de l'îlot IVC (la pièce IVC1) présente des niveaux d'occupation, datés de la fin du XIII ${ }^{\mathrm{e}}$ s. ou du début du XIV ${ }^{\mathrm{e}}$ s., pouvant être mis en relation avec une activité de métallurgie (Bouiron 2001b, p. 368). Il s'agit d'une part d'un niveau de sable gris contenant des objets en fer et en alliage cuivreux et d'autre part d'un niveau rubéfié riche en charbons et cendres, incluant par ailleurs des clous, une lame de couteau avec soie, un élément en alliage cuivreux ainsi que des rebuts de fabrication métallique (fer ?). Sur le même 
sol ont également été récoltés quelques fragments de corail. Cet artisanat se déroule au rez-de-chaussée d'une maison située à l'angle de deux rues, dans un contexte parcellaire fort dense puisque le bourg est alors entièrement loti.

Plusieurs sites ont montré l'association du travail du métal avec celui du corail. Et malgré le peu d'éléments que l'on possède sur la raison de cette association, il convient de revenir sur cette particularité. Il est évidemment possible d'imaginer, dans le cas où les déchets sont individualisés au sein d'espaces différents, à une simple proximité des deux artisanats. En revanche, dans les cas où les déchets se trouvent associés au sein des mêmes zones de rejets et parfois même des mêmes structures (bourg des Olliers, bourg Sainte-Catherine, bourg de Morier), il convient d'envisager la place du corail dans le cadre de la métallurgie.

Parmi les multiples utilisations du corail, son usage comme matière précieuse en orfèvrerie est très développé au Moyen Âge, son caractère prophylactique en faisant un matériau de choix. Il est par conséquent possible que le corail présent dans les ateliers de métallurgie intervienne dans l'ornementation des objets produits où il est serti. Dans la majorité des cas, c'est le travail de métallurgie qui semble prépondérant par rapport à celui du corail. C'est certainement le cas lorsque de véritables ateliers de forge ont pu être identifiés (bourg des Olliers). En revanche, des exemples comme celui du bourg de Morier et l'atelier C6 du bourg Sainte-Catherine amènent à davantage de réserve sur l'identification du matériau travaillé. Si le travail du métal y est bien attesté, il ne constitue pas obligatoirement l'objet premier de cet atelier mais résulte peut-être de la réparation d'outils pour le travail du corail.

\subsubsection{Traces d'un savetier}

Nous conclurons cet inventaire des petits ateliers par le site Puget III, au sud du quartier Sainte-Barbe. Des niveaux alluvionnaires antérieurs au rempart, piégés au pied de la butte des Carmes et de la colline Saint-Charles, $\mathrm{y}$ ont livré des pièces de chaussures, de lanières et des déchets de cuir, ainsi qu'un morceau de tissu (Moliner et al. 1993, p. 26-27). Les pièces de chaussures se composent pour l'essentiel de semelles de cuir, fragmentaires ou presque complètes, portant des traces de couture. La composition du fragment de tissu, de couleur pourpre, n'a pas été déterminée. La datation de ces dépôts se situe après le $\mathrm{X}^{\mathrm{e}} \mathrm{s}$. et avant le XIII ${ }^{\mathrm{e}} \mathrm{s}$. Ces éléments évoquent la présence d'un atelier de savetier mais le fait qu'il ne s'agit pas de mobilier en place ne permet pas de localiser ici un atelier de travail du cuir.

\subsection{Les grands ateliers}

Dès la fin du XII ${ }^{e}$ s., les espaces suburbains les plus proches de la cité sont dévolus à de vastes complexes artisanaux.

\subsubsection{Les potiers}

A la fin du XII e s., une communauté de potiers s'implante dans le quartier Sainte-Barbe, au nord-est de la cité (Marchesi et al. 1997). Elle y développe une production inédite de vaisselle glaçurée et de faïence décorée de tradition arabe.

L'urbanisation de cette zone située en bordure de rempart, sur le flanc sud de la colline Saint-Charles, se développe en plusieurs phases mais toujours selon un maillage régulier. Les bâtiments sont installés avec régularité sur chaque parcelle perpendiculaire à la rue et les fours se répartissent dans les différents espaces de travail. Outre les structures liées à la cuisson de la céramique, les équipements sont constitués de bassins, d'aire de séchage, de fosses de tournage. Particulièrement dynamique dans la seconde moitié du siècle, la production est progressivement abandonnée à partir de l'extrême fin du XIII ${ }^{\mathrm{e}}$ s., les derniers fours ayant pu fonctionner jusque vers les années 1340. L'approvisionnement en eau est assuré par un puits et le ruisseau de la Frache. L'évacuation des eaux usées, réglementée par les Statuts municipaux (Pernoud 1949), est assurée par un réseau de tuyaux en terre cuite desservant certains bâtiments.

La particularité de ces ateliers est leur installation dans un lotissement parfaitement adapté à l'activité qui s'y déroule. La découverte d'une élévation en terre crue sur solin de pierre atteste très clairement de l'utilisation de cette technique lors de la structuration de ce quartier.

Cette activité ayant déjà fait l'objet de nombreuses publications, nous ne nous y attarderons pas.

\subsubsection{Les tanneurs}

L'un des artisanat les plus prospères à Marseille semble avoir été celui de la tannerie et de ses métiers annexes (Casal 1991, p. 160 ; Pernoud 1949, XLII). Cette corporation a retenu l'attention des chercheurs depuis longtemps (Dupanloup 1966) d'autant plus que les Statuts municipaux de la ville (Crémieux 1917), rédigés entre 1268 et 1480 par le Conseil de la Ville, permettent de suivre l'évolution de la corporation tout au long du $\mathrm{XIV}^{\mathrm{e}}$ s. et atteste de l'ampleur de son activité suscitant une réglementation précise quant à son exercice, à la marque des peaux et cuirs, aux procédés de fabrication, aux obligations de voiries. Si ce n'est qu'au début du $\mathrm{XIV}^{\mathrm{e}} \mathrm{s}$. que le groupement des cuiratiers atteint un degré 
d'organisation appréciable, ils sont présents de longue date à Marseille ainsi qu'en témoignent certaines prescriptions du Livre Rouge des Statuts municipaux établis entre 1225 et 1257 . La toponymie de la ville indique deux points d'activité. Le premier est situé extra muros et est localisé, à partir des actes du notaire Raymond Rougiers, dans la rue des Ateliers (carriera operatorum curatarie), localisée le « long d'une déviation du cours du Jarret et des sources de Saint-Bauzille, derrière le couvent des Frères Mineurs » (Dupanloup 1969, p. 152). Le second, le quartier de la Blanquerie, se développe intra muros, près de la place du Tholonée et du quartier des bouchers (Smail 2001, p. 368), et semble davantage correspondre à l'emplacement des logements des familles de tanneurs et de leurs ouvriers. L'approvisionnement en peaux s'effectue à partir de différents points de la Méditerranée (Sardaigne, Roumanie, Espagne, Algerie, Syrie), mais également à partir de l'arrière-pays provençal qui fournit largement bovins, ovins et caprins. Il apparaît dans les différentes tractations commerciales connues que l'artisanat de la tannerie est à Marseille une source de revenu confortable pour les divers bailleurs de fonds et que la ville est réputée pour la qualité de sa production largement exportée outre-mer. Cette qualité est soigneusement contrôlée par quatre prud'hommes chargés de vérifier la totalité des opérations, ainsi que les matériaux utilisés, avant d'apposer la marque garantissant la qualité des peaux à la fin du traitement (Dupanloup 1966).

Aucun des deux établissements découverts, l'un au bourg de Morier et l' autre au bourg Sainte-Catherine, n'a pu être appréhendé dans sa totalité. Ils fournissent néanmoins un ensemble de données satisfaisant permettant une première approche raisonnée des grands complexes artisanaux de ce type.

\section{La tannerie du bourg de Morier}

Le complexe de tannerie découvert au bourg de Morier est constitué de deux vastes bâtiments associés à un imposant réseau hydraulique. L'ensemble de ces constructions, en usage entre la fin du XII ${ }^{\mathrm{e}}$ s. et le milieu du XIII ${ }^{\mathrm{e}} \mathrm{s}$., couvre une superficie de plus de $640 \mathrm{~m}^{2}$ et s'étend au nord jusqu'à la rue Crotte-Vieille.

$\mathrm{Au}$ regard des seuls vestiges archéologiques, le complexe artisanal se présente comme un ensemble particulièrement homogène tant en ce qui concerne le découpage interne des différents espaces, que les techniques mises en œuvre dans les sols et les supports, seuls éléments architecturaux tangibles qui nous soient parvenus.

La régularité des dimensions des pièces révèle l'utilisation d'un module de construction rectangulaire de 6,5 x 5,5 m de côté ( $c f . \S$ II, 3, 2.2.). Ainsi, l'espace 1C et la cour $1 \mathrm{D}$ correspondent à quatre modules accolés à l'intersection desquels le puits citerne est établi. Au nord, les pièces $1 \mathrm{~A}$ et $1 \mathrm{~B}$, prolongées jusqu'au tracé hypothétique de la rue Crota vielha, reproduisent les mêmes proportions. À l'est, la pièce $2 \mathrm{C}$ adopte encore la même largeur de module.

La réalisation de cet ensemble modularisé s'est néanmoins conformé à certaines contraintes préexistantes, comme la présence d'une voie de circulation ancienne nord-sud sur laquelle se sont installées les pièces $2 \mathrm{~A}$ et 2B. La largeur de ces deux pièces ne se conforme alors plus à celle du module mais à celle de la voie soit 7,5 m. Le relief naturel a conditionné l'altitude les surfaces d'occupation extérieures et intérieures des deux édifices au double pendage du terrain, de l'est vers l'ouest et du nord vers le sud, induisant ainsi un dénivelé de 1,82\% entre le niveau de sol des pièces est du bâtiment 2 et les pièces ouest du bâtiment 1 . Ce pendage s'applique évidemment de la même manière à la rue Crotte-Vieille.

La majorité des sols mis au jour sont de simples surfaces de terre battue très rudimentaires. De tels sols paraissent mal adaptés à une activité aussi salissante et polluante que le tannage. Il est notamment peu probable que les surfaces de terre battue du bâtiment 1 , où se fait l'essentiel des opérations, aient été laissées à nu. En conséquence, ce sont plutôt des planchers en bois, facilement lessivable, qu'il convient de restituer pour ce bâtiment, tout du moins dans les espaces couverts.

Les murs sont pour l'essentiel liés à la terre avec des fondations solides, d'une largeur moyenne de $0,80 \mathrm{~m}$, et souvent débordantes le long du parement intérieur du mur. Quelques variantes peuvent intervenir ponctuellement. C'est le cas de deux murs porteurs du bâtiment $1^{363}$ liés au mortier avec des joints très épais, peut-être dans une volonté d'étanchéifier un espace particulièrement exposé aux risques d'infiltration (présence des deux grandes cuves quadrangulaires adossées à chacun de ces murs); d'un mur porteur du bâtiment 2 dont la fondation possède une ampleur unique avec une largeur de $1 \mathrm{~m}$ et une profondeur de $0,80 \mathrm{~m}$ ou encore du mur de clôture dont le parement interne a reçu un enduit de chaux ${ }^{364}$. L'homogénéité pétrographique des matériaux, essentiellement du calcaire stampien dit « calcaire de Saint-Victor », sous-tend un approvisionnement en carrière et une proportion moindre de pierres réutilisées.

Bien qu'aucun élément ne permette de rendre compte de l'élévation du complexe artisanal, il est probable que les deux bâtiments ont possédé plusieurs niveaux ou étages, maçonnés ou en matériaux plus légers. Les caractéristiques générales des murs porteurs (dimensions et

363 Les murs MR7374 et MR7412.

364 Les murs MR7030 et MR7715 respectivement. 
techniques) et la nature des niveaux de destruction du bâtiment 2, dont la forte proportion d'argile pourrait correspondre à l'effondrement de murs en pisé, corroborent cette hypothèse et ceci malgré l'absence archéologique de dispositif d'accès à un étage dans le plan du rez-de-chaussée.

À l'ouest, le bâtiment 1, équipé d'installations particulières et pourvu d'annexes, apparaît clairement comme une unité entièrement dévolue au traitement des peaux, l'atelier proprement dit. Il comporte des cuves quadrangulaires et plusieurs batteries de cuves circulaires, un point d'approvisionnement en eau, une zone de dépotoir à l'arrière $(1 \mathrm{H})$ et des espaces de combustion $(1 \mathrm{~F}$ et $1 \mathrm{G})$.

L'ensemble du bâtiment 2, s'il n'apparaît pas marqué par les différentes activités de tannage, est pourtant bien intégré dans le complexe. Il est probable que l'ensemble de cet édifice a été dévolu au logement, peut-être au maître de l'atelier. Son intégration ultérieure dans le faubourg tendrait par ailleurs à attester cette fonction dès la période de la tannerie et ceci en contraste avec le bâtiment de l'atelier qui a été entièrement arasé, la campagne de destruction et d'assainissement dont il a fait l'objet étant justifiée par les pollutions engendrées par le traitement des peaux. Ainsi, s'il ne faut pas écarter le bâtiment 2 des activités de la tannerie, notamment au sein de la cour fermée ayant pu faire office d'herboire et de lieu de stockage des produits finis, c'est davantage à des fonctions domestiques qu'il convient de le réserver.

Si l'ensemble du complexe est assez bien compris dans ses structures et dans sa fonctionnalité, il reste des lacunes (fig. 118). En effet, sur l'ensemble des vestiges appartenant au complexe artisanal, peu sont liés à l'évacuation des différents bains qui est pourtant indispensable pour les cuves du travail de rivière. Une petite tranchée d'une quarantaine de centimètres remplie de dépôts cendreux traverse le terrain au sud du bâtiment 2 pour se déverser dans le grand fossé nord-sud ${ }^{365}$, mais n'offre pas de solution satisfaisante au problème d'écoulement des eaux souillées. La proximité du fossé défensif le rend apte à recevoir les vidanges de la tannerie. Il est par conséquent possible que l'évacuation se faisait dans la partie occidentale de l'atelier, hors emprise de la fouille.

D'autres questions sont en suspens quant aux lieux et dispositifs de séchage des peaux. Elles étaient probablement suspendues pour faciliter leur égouttement, et on peut envisager l'existence d'éléments aériens (poutraisons encastrées dans les maçonneries par exemple) sur lesquels les cuirs étaient empilés. De tels aménagements ne laissent pas de trace dans des vestiges particulièrement arasés. Il est également possible que le séchage

365 Le fossé FO11258. des peaux s'effectuait tout au sud du complexe artisanal, dans la zone dépourvue de construction. Si c'est le cas, le système de support des peaux reste encore à déterminer.

\section{La tannerie du bourg Sainte-Catherine}

Le complexe artisanal découvert dans le bourg Sainte-Catherine, à l'angle de la rue principale et d'une ruelle perpendiculaire, est un ensemble assez vaste, reconnu sur une superficie de plus de $310 \mathrm{~m}^{2}$ (Bouiron 2001a, p. 64-67). La portion mise au jour se compose de deux pièces rectangulaires juxtaposées, perpendiculaires à la rue, à l'arrière desquelles se développe une cour équipée d'un vaste puits-citerne, et d'un vaste espace ouvert au sud.

Le complexe artisanal s'inscrit dans une trame parcellaire lâche ménageant de vastes espaces mais déjà modularisée. En effet, la largeur de 3,60 m des deux pièces en rive de rue annonce la largeur des parcelles laniérées définies lors de la phase ultérieure de densification de l'îlot. La largeur de la cour latérale correspond à quatre de ces modules.

La découverte d'une cuve en bois très concrétionnée a conduit à identifier cet ensemble comme une tannerie. Des dispositifs de tannage à proprement parler ne subsiste que cette cuve circulaire en bois découverte dans un angle de l'arrière-cour. Elle est ancrée dans le sol sur une profondeur de $0,20 \mathrm{~m}$ et possède un tracé circulaire de 1,34 à $1,42 \mathrm{~m}$ de diamètre. L'approvisionnement en eau s'effectue grâce à un puits-citerne tronconique, creusé au sein de la même cour arrière. Il possède un diamètre d'ouverture relativement restreint, de seulement $0,80 \mathrm{~m}$, mais s'élargit très vite jusqu'à atteindre un diamètre de 2,10 m. Cet imposant diamètre se double d'une largeur de parement conséquente de l'ordre $0,80 \mathrm{~m}$. Les auteurs évoquent la présence d'un fond dallé à une profondeur de $7 \mathrm{~m}$, mais qui n'a pu être observé avec précision. Le raccordement du puits-citerne à une canalisation couverte en dalle de calcaire permet la récupération des eaux de pluie et des écoulements venant du nord à l'intérieur de cette structure. Le dispositif d'évacuation des eaux usées issues de la tannerie n'a pas été identifié lors de la fouille de cet ensemble. C'est le ruisseau des cuiratiers en bordure ouest de la voie principale, plus tard connue sous le nom de rue droite Sainte-Catherine, qui semble principalement assumer cette fonction (Bouiron 2001a, p. 234). Il aurait en effet pour principale fonction de détourner du Vieux-Port les eaux usées, plus particulièrement celles issues des ateliers de tannage (Duprat, Rambert 1935, p. 94-95). La question d'éventuelle pollution du port par les eaux usées se trouve posée à plusieurs reprise dans les Statuts municipaux de la ville, notamment dans les articles I-59 (Pernoud 1949, p. 67) 
et I-63 (Pernoud 1949, p. 68-69). Le rejet des eaux usées de la tannerie du bourg Sainte-Catherine dans le ruisseau de la Cuiraterie, que l'on trouve mentionné dans un texte du cartulaire de Saint-Victor (Bouiron 2001e, p. 327), se conforme à cette réglementation.

Le complexe artisanal se complète par un vaste espace libre, qui se développe au sud sur une largeur totale de $16 \mathrm{~m}$ en rive de la rue principale et une longueur reconnue de $10 \mathrm{~m}$.

La surface explorée, qui ne concerne que la partie ouest de cet atelier, n'offre pas les mêmes possibilités interprétatives que l'établissement du bourg de Morier. Il est néanmoins possible de reconnaître la répartition fonctionnelle des différentes pièces. Ainsi les pièces $\mathrm{B} 1$ et $\mathrm{B} 2$, située en rive de la rue principale, peuvent comporter un corps de logis à l'étage, mais le rez-dechaussée est en général dévolu aux magasins et doit receler un passage vers la cour où se déroule l'essentiel de l'activité. La cour arrière B3 recèle le point de puisage de l'eau, d'un usage continuel dans cette activité, ainsi qu'une cuve en bois circulaire permettant de penser que s'effectue là le travail de tannage proprement-dit. La vaste cour latérale, également en rive de la rue principale, permet un accès direct pour le passage des charrois et une vaste zone pour le séchage des peaux. La zone de rejet des déchets osseux sans doute située plus à l'est, à l'arrière des bâtiments, n'a malheureusement pas été localisée.

Les documents d'archives complètent cet inventaire des établissement extra muros. Un texte de 1214 mentionne la présence d'une tannerie devant la porte du Lauret (Bouiron 2001e, p. 327). Il n'est pas possible au regard de cette seule mention de préciser à quel bourg appartient l'atelier. La porte du Lauret indique néanmoins une implantation réalisée dans les espaces périurbains proches de la cité, à mi-chemin des deux autres ateliers. Enfin, le testament d'un grand personnage marseillais signale l'existence d'un autre atelier mais sans en préciser l'emplacement (Bouiron 2001e, p. 327).

\subsubsection{Les teinturiers}

La teinturerie tient également une grande place dans l'activité de la ville. Les artisans marseillais sont réputés pour la qualité de leur couleur grâce aux matières tinctoriales importées d'Orient mais également d'Espagne, de Catalogne et du Languedoc qui viennent compléter la garance locale (Casal 1991, p. 73). Des règlements sévères, contrôlés par les prud'hommes, assure la qualité et la bonne utilisation des différents produits (Pernoud 1949, XLIII et p. 223).

On connaît également un texte, daté du 31 octobre 1264, qui mentionne une teinturerie dans le bourg du
Saint-Sépulcre (Bouiron 2009c, p. 75-76) ${ }^{366}$, dénomination ancienne du bourg Sainte-Catherine.

À la pointe ouest de la ville basse, la fouille du monte-charge du fort Saint-Jean a révélé la présence d'un ensemble artisanal matérialisé par une série de cuves rupestres et d'un bassin (Paone et al. 2007, p. 44-45). Les cuves sont de dimensions variables, de 0,6 x $0,5 \times 0,26 \mathrm{~m}$ pour les plus petites à $1,1 \times 1,1 \times 0,9 \mathrm{~m}$. Le bassin est bordé par un mur et revêtu de béton de tuileau. Un système de rigole assure l'écoulement du bassin vers l'une des cuves. La datation de cet ensemble est problématique en l'absence de stratigraphie précise mais peut globalement être attribué au bas Moyen Âge. L'absence de dépôts significatifs dans les cuves rend l'identification de cet ensemble artisanal hypothétique. Il semblerait néanmoins qu'il puisse être mis en relation avec un atelier de teinture des filets de pêche mentionné dans un document d'archive de 1490 et localisé sur le plateau de la Tourette.

\subsection{Artisanat, industrie et développement urbain}

Les grandes installations artisanales, qui nécessitent des équipements spécialisés et parfois complexes, ne peuvent se développer dans n'importe quel bâtiment et en n'importe quel lieu de la ville. Si les nuisances et les dangers générés par de telles activités ont sans doute influé sur le choix du site d'implantation, il est peu probable que ce soit le seul ni le principal élément décisif. En effet, le poncif voulant reléguer les activités polluantes à l'extérieur de la ville ne peut s'appliquer en ces seuls termes, le processus d'installation de ces grands ateliers participant d'un schéma beaucoup plus complexe et bien moins dépréciateur.

Le contexte d'installation des ateliers de tannerie aux faubourgs de Morier et Sainte-Catherine et de potiers dans le quartier Sainte-Barbe montre bien qu'ils s'implantent dans des zones pas ou peu touchées par des phénomènes d'urbanisation extra muros. Ils mettent à profit une trame urbaine lâche autorisant de grands espaces. Le fait de s'installer dans un cadre urbanistique peu prégnant n'est cependant en aucun cas l'occasion de développer un parcellaire aléatoire ou d'échapper aux règlements sanitaires ou de construction en vigueur. Au contraire, la conquête de ces zones périurbaines est le moyen d'élaborer des complexes parfaitement adaptés à l'artisanat concerné, tant en ce qui concerne

366 Vente par Gui de Reco à Jean Boisson d'un atelier de teinturerie, d'un jardin et de son terrain, situés dans le bourg du Saint-Sépulcre : AD13, 3 B 801, fol. 29-29v. Texte publié dans Bouiron 2001, p. 259260 et traduit dans Bouiron 2009c, p. 76-77. 


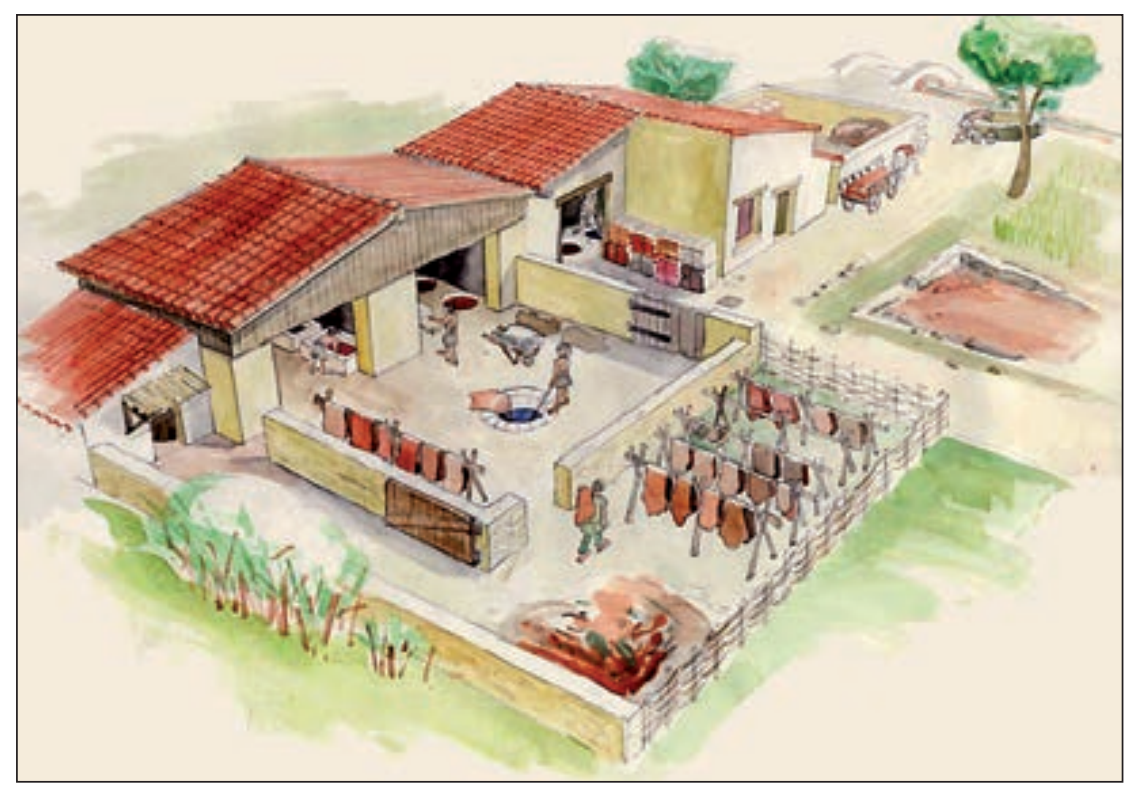

Fig. 118. Proposition de restitution de la tannerie du bourg de Morier vers 1200

(dessin G. Frommherz/Inrap).

la fonctionnalité des plans et des équipements mis en place, que de la question de l'approvisionnement-évacuation des eaux et de l'acheminement des matériaux.

La découverte d'élévation en terre crue au bourg des Olliers (Marchesi et al. 1997, p. 114-115) ainsi que les indices très probants de cette technique dans la tannerie de Morier et au bourg Sainte-Catherine (Bouiron 2001a, p. 118-119) témoignent d'un mode de construction adapté à une mise en œuvre rapide. Il est identifié également dans des bâtiments civils intra muros à partir de la fin du XII e s. jusqu'au XIV'e s. (Thernot, Vecchione 2001).

La terre crue est une technique particulièrement intéressante par sa mise en œuvre rapide et économe quant à l'approvisionnement du matériau qui s'effectue sur place ou à proximité. Dans les différents exemples marseillais intra et extra muros, le choix de ce mode de construction ne correspond pas à une carence de matériau ou de moyens financiers mais s'inscrit au contraire dans un contexte économique favorable, où le bâtiment perd sa fonction de signe extérieur de pouvoir ou de richesse. La fouille d'un faubourg de Narbonne a montré l'importance de cette technique dans l'essor des quartiers extra muros prospères grâce à leur fort dynamisme économique (De Chazelles, Leal 2003). Dans ce contexte, c'est la rapidité de construction et la fonctionnalité du bâtiment qui prime sur l'aspect formel et la symbolique architecturale. L'identification de la terre crue dans les complexes artisanaux des quartiers Sainte-Barbe, Sainte-Catherine et Morier se révèle par conséquent particulièrement significative de leur statut et de leur contexte de développement.

Ainsi, ces grands ateliers constituent un élément structurant des faubourgs du XIII ${ }^{e}$ s. Ils participent activement à leur essor et ont un fort impact sur la physionomie de l'îlot par la taille de leur installation et les différentes infrastructures d'approvisionnement qu'ils nécessitent. L'eau naturelle ou canalisée est un élément essentiel de ces complexes qui sont prioritairement tournés vers la production et où la composante domestique est négligeable peut-être même absente.

Les facteurs politiques, fiscaux et fonciers qui conditionnent l'apparition de tels établissements en périphérie immédiate de la ville ne sont pas connus. Il est en revanche certain que leur installation correspond à un contexte économique très précis caractérisé par une grande vitalité et une forte concentration de capitaux. L'essor rapide de ces différents ateliers mobilisant une quantité importante de main d'œuvre amène à s'interroger sur sa provenance. Si la main d'œuvre non qualifiée peut être recrutée sur place, on ignore ce qu'il en est des ouvriers spécialisés. On a vu pour le cas des ateliers de potier de Sainte-Barbe l'utilisation d'un savoir faire étranger. Est-ce le cas pour les ateliers de tannerie ?

Les auteurs soulignent souvent la durée de fonctionnement limitée dans le temps de ce type d'installations qui paraît sans rapport avec les efforts financiers et techniques consacrés à leur mise en place: une cinquantaine d'année pour les tanneries de SainteCatherine et de Morier, à peine un siècle pour les potiers de Sainte-Barbe.

La même brièveté de fonctionnement s'observe pour la tannerie découverte à Rouen, sur le site de la rue Martainville (Calderoni 2000). Construite extra muros dans le courant du XIII ${ }^{\mathrm{e}}$ s., elle n'est en usage que jusqu'à la fin de ce siècle. L'arrêt de l'activité des tanneurs correspond à un développement de l'habitat qui se densifie vite dès le début du $\mathrm{XIV}^{\mathrm{e}} \mathrm{s}$. 
Malgré les désagréments qu'elle génère, la tannerie n'est pas toujours reléguée à l'extérieur de la ville, telle la tannerie découverte sur le site du Moulinet à Troyes (Deborde et al. 2002). Elle est construite dès la fin du $\mathrm{XI}^{\mathrm{e}}$ s. dans la partie sud de la ville, dans une zone de marais, et perdure jusqu'à la fin du $\mathrm{XV}^{\mathrm{e}} \mathrm{s}$. Dans ce cas, on assiste à une fondation antérieure et une activité prolongée. Ce type d'atelier participe d'un contexte de développement différent, moins réactif économiquement mais également moins sensible, davantage intégré dans une tradition que ne le sont les activités extra muros.

À l'abandon des tanneries marseillaises dans la seconde moitié du XIII ${ }^{\mathrm{e}}$ s., succède une trame laniérée dense, identique à la configuration des îlots intra muros. Bien qu'il ne soit pas possible de déterminer si le statut de ces terres ou le bénéficiaire changent, il semble à l'évidence que la pression foncière ne s'exerce plus de la même manière, le lotissement dense de la zone apparaissant alors plus rentable que la conservation de la tannerie. L'extinction des grands ateliers de SainteBarbe, de Sainte-Catherine et de Morier ne signifie pas pour autant l'abandon de toute activité artisanale. À Sainte-Barbe, les nouveaux artisans, toujours spécialisés dans les arts du feu, travaillent alors en priorité le métal mais les archives font par ailleurs état, entre les années 1328 et 1361, d'une population comprenant notamment un arbalétrier, un trompettier, un bâtier, un peyrier, un lapicide, des laboureurs, un charretier, un boucher, un avocat et un maréchal-ferrant (Marchesi et al. 1997, p. 106). Au bourg Sainte-Catherine, un atelier de forge est crée à l'extrême fin du XIII' ${ }^{\mathrm{s}}$. ou au début du $\mathrm{XIV}^{\mathrm{e}} \mathrm{s}$. à l'angle des rues Raymond-Rascas et droite SainteCatherine et la découverte de plusieurs creusets dans un dépotoir du $\mathrm{XIV}^{\mathrm{e}} \mathrm{s}$. permet de penser qu'un orfèvre/ bronzier est également en activité. Au bourg de Morier, le même phénomène s'observe avec la présence d'un artisan du métal au sein de l'îlot du XIVe s. En même temps qu'ils se diversifient dans leur activité et se densifient, ces quartiers industrieux sont donc désormais aussi des lieux d'habitation comme en témoigne le mobilier de la vie quotidienne issu de ces niveaux.

Dans un contexte intra muros, les ateliers sont davantage durables et apparaissent plus tôt. À mesure que le tissu économique de la ville s'organise, ils laissent leur trace dans la toponymie des rues et des quartiers (Smail 2001). Les installations extra muros ne participent pas du même phénomène économique. Les productions qui se développent en couronne autour de la ville dans une période comprise entre la fin du XII ${ }^{e}$ s. et le milieu du XIII ${ }^{e}$ s., alors même que certaines d'entre elles existent au sein même des remparts, s'apparentent à des mises de fonds rapides dans des secteurs d'activités très rémunérateurs et demandant une main-d'œuvre qualifiée. La présence de tels complexes artisanaux ne s'étend pas au-delà du début du XIV ${ }^{\mathrm{e}} \mathrm{s}$. C'est alors que la configuration artisanale périurbaine se modifie avec la disparition des grands complexes au profit d'ateliers de moindre ampleur et plus diversifiés, plus étroitement fondus dans le découpage laniéré des îlots.

\section{Témoignages archéologiques sur le commerce, l'industrie et l'artisanat à l'Époque moderne (B. Sillano)}

Les textes, nombreux à partir du XVII e s., mentionnent dans le quartier du Mazeau la présence systématique d'une boutique (où l'on vend) ou d'un magasin (où l'on stocke) sur la rue. Les caves, majoritaires, ont fait disparaître les sols du rez de chaussée avec leur destruction en 1943. Les rares maisons qui n'en aient pas, comme la parcelle d'angle 386 (cf. infra § II, 2, 3.4.6.), ne présentent pas d'aménagement qui soit spécifique à un commerce. Il en va de même des caves, évidement dépourvues de la marchandise qu'elles contenaient, à une seule exception près, le dépôt lapidaire dans la parcelle 374 ( $c f$. infra § II, 2, 3.4.2.). Le contenant a été conservé parce que propice à recevoir la nouvelle façade sur la rue de la Prison, reculée au XVIII s. Cet exemple unique témoigne de l'extrême diversité des matières stockées dans les magasins, majoritaires, de la ville basse. Deux caves, qui ont conservé des aménagements spécifiques, complètent le tableau.

La première est une cave à vin; elle est dotée sur trois côtés de banquettes, remblayées de terre, hautes de $40 \mathrm{~cm}$ pour une largeur de $1,30 \mathrm{~m}$ (parcelle 362 , cf. infra $\S$ II, 2, 3.4.10.). Elle a probablement été construite au XVIII ${ }^{\mathrm{e}}$ s., par réduction de la cave initiale et reste fonctionnelle en 1934. La seconde possède trois cuves d'un volume minimum de 6500 et 4500 litres (parcelle 373, cf. infra § II, 2, 3.4.3.). Leur installation a nécessité la reconstruction d'un mur mitoyen ainsi que le déplacement d'un refend. Fondées sur un semi de pieux, elles sont étanchéifiées au batum, un enduit de tuileau. La plus petite, à l'extrémité, se distingue par encollage de briques de chant entre deux couches de batum. La fonction de ces cuves resterait un mystère sans un prix fait de 1663 pour un proche voisin, Jean Abeille demeurant rue de la Prison (Sillano 2005, p. 490) qui concerne la construction de cuves à huiles. Tout coïncide dans les données techniques : nombre, dimensions, singularité de l'une des trois. L'augmentation des unités de stockage d'huile correspond à une demande croissante, en particulier par l'industrie avec les savonneries (Boulanger 1996). 
Ces magasins, probablement disséminés parmi les artisans dont témoignent les noms de rues à l'est de la zone étudiée, sont près de la Loge mêlés aux maisons du patriciat. Autour du marché du Petit Mazeau, les artisans rôtisseurs se partagent l'espace avec les auberges. Seule la rôtisserie de M. Gautier était dans l'emprise des fouilles (parcelle 402, cf. infra § II, 2, 3.2.4.). Des reconstructions du XVIII' ${ }^{\mathrm{s}}$ s. ont aboli toute trace de cette activité, en particulier le four, néanmoins un rapport de future cautelle, appuyé par le relevé des structures, permet de restituer la boutique ( $c f$. fig. 46). Une salle largement ouverte sur la rue, profonde de $5 \mathrm{~m}$ et large de $4 \mathrm{~m}$ et une salle arrière plus petite, accédant à la cour intérieure et au four, placé à l'extérieur du bâtiment. La cave est dotée d'une extension sous la rue ( $c f$. supra $\S \mathrm{I}, 4,3.2$.), comme beaucoup d'autres dans le secteur. Cette spécificité, très contraignante pour la circulation dans les rues, devait répondre à un besoin impérieux. Il est probable qu'elle serve à faire transiter ailleurs que par boutique la matière première essentielle aux rôtisseurs, à savoir le bois. Apparues au début du XVII es., elles sont abandonnées au suivant, pour des raisons de sécurité, mais aussi parce que les artisans rôtisseurs disparaissent du Mazeau, en même temps que le marché qui est à l'abandon lors de la création de la place en 1784.

L'industrie, en pleine croissance dès le $\mathrm{XVI}^{\mathrm{e}} \mathrm{s}$., est exclue de la ville basse. Elle partage avec les institutions religieuses les terrains au nord de la ville, sur l'autre versant des buttes. Elle occupe également les terrains hors les murs, avant que la création de la ville nouvelle ne les repousse. Aucune d'entre elle n'a été fouillée à une exception de taille, la manufacture royale de poudre et salpêtre (Castrucci et al. 2007), dans l'angle nord-est de la ville nouvelle.

Le moins que l'on puisse dire est que, pour l'instant, l'archéologie des Temps Modernes, trop longtemps oubliée des opérations de sauvetage, n'apporte pas grand-chose à la connaissance des lieux de commerce et d'artisanal. Certes, elle bénéficie de l'abondance des textes, mais elle ne profite pas de l'information inédite que renferment les fosses dépotoirs si courantes au Moyen Âge (au moins hors de Marseille). Elle se prive enfin et surtout de l'étude de bâti, insuffisamment prescrite, qui apporterait bien plus d'informations.

\section{Les auberges à l'Époque moderne}

Autre grande catégorie de bâtiments attestée par les archives et rencontrée sur les fouilles: les auberges. Si celles-ci sont déjà présentes à Marseille au Moyen Âge, ce sont surtout les édifices modernes qui sont documentés.

\subsection{Le monde des auberges à Marseille aux $\mathrm{XVI}^{\mathrm{e}}$-XVII ${ }^{\mathrm{e}} \mathbf{\text { s. }}{ }^{367}$ (C. Rigouleau)}

Les auberges et autres logis ont pour origine l'hospitalité privée offerte aux voyageurs par les monastères durant le Moyen Âge. À partir du XI s. le développement des axes de communication entraîne un afflux plus important de voyageurs. Commencent alors à apparaître des débits de boissons qui se transforment progressivement en auberges. Ces dernières prennent pleinement leur essor à la fin du XIII ${ }^{\mathrm{e}} \mathrm{s}$. et au $\mathrm{XIV}^{\mathrm{e}} \mathrm{s}$. Elles deviennent les indispensables « auxiliaires de la route ${ }^{368}$. La cité phocéenne, grâce à la présence de son port, est au cœur d'une activité commerciale intense. Les voyageurs sont nombreux à transiter par la ville venant ainsi grossir la clientèle des aubergistes.

Définir l'auberge n'est pas chose facile comme en témoigne la réflexion de Jeanne Coron: "Si l'on tente de les distinguer grâce aux services qu'ils proposent cela se complique davantage. Ils ont tous comme point commun d'accueillir des personnes pour se restaurer, boire un verre, ou pour loger (...). De plus, dans nos sources, les termes ne sont pas clairs et la police emploie souvent plusieurs de ces noms pour désigner un même établissement» (Coron 2002, p. 20). L'auberge ${ }^{369}$, par son fonctionnement, apparaît comme un lieu complexe. L'aubergiste lui-même est un personnage ambivalent. Dans les actes, on va le retrouver sous des identités différentes.

Les actes notariés ont constitué la principale source pour l'appréhension de l'auberge et de son tenancier. Pour la période envisagée, cette dernière constitue l'unique moyen de découvrir le monde des auberges marseillais. Parallèlement les notes de l'érudit Pierre Bertas ont été un guide précieux permettant d'identifier certains de ces lieux dans la masse des archives notariées ${ }^{370}$. Un corpus de 192 actes notariés a été ainsi constitué. Cet ensemble se compose d'actes différents (mariage, testament, inventaire après-décès, reconnaissance de dette...) ayant pour point commun une auberge ou un aubergiste. Cependant tous les actes n'offrent pas la même richesse de renseignements.

Ce type de bâtiment n'a laissé que peu de traces pour cette période. Les hôtes sont visibles dans les actes car ils en sont les acteurs, l'auberge y apparaît seulement comme un élément secondaire. Seront ici

367 Cet article a été réalisé d'après le DEA de Céline Rigouleau soutenu en 2004 (Rigouleau 2004).

368 Cette expression est empruntée à Philippe Wolff (1978, p. 93).

369 Trois termes servent à désigner l'auberge dans les actes pour la période envisagée : auberge, logis et hôtellerie.

370 ACM fonds Pierre Bertas 20 ii. 
Fig. 119. Carte de la répartition des auberges étudiées par C. Rigouleau XVIe-XVII $\mathrm{s}$.

(DAO F. Guériel/Inrap d'après le fond de plan de M. Bouiron).

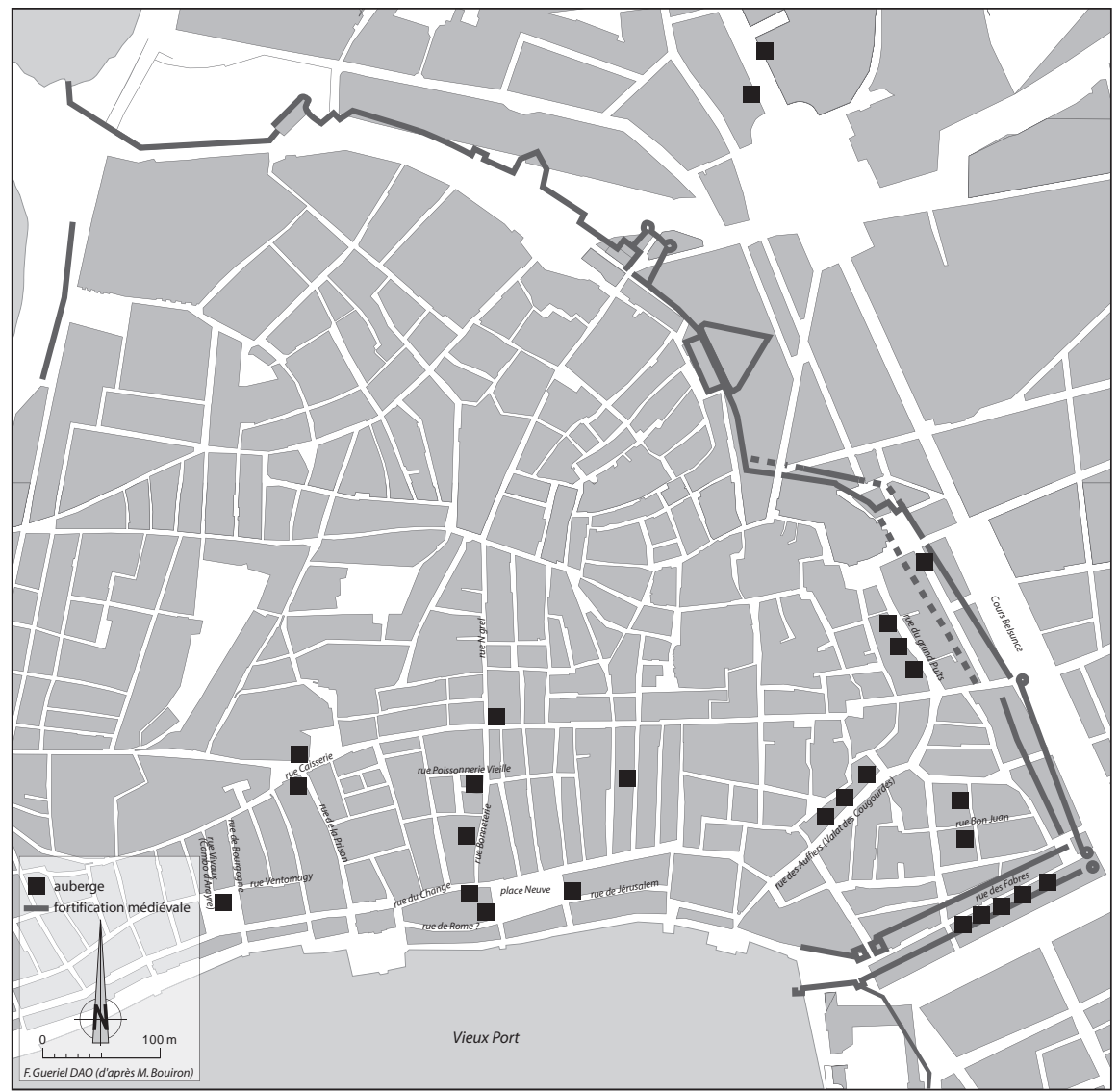

successivement envisagés les critères de choix puis l'auberge comme structure d'accueil et une esquisse de la vie des aubergistes.

\subsubsection{Quelle auberge choisir?}

Un large éventail de choix est offert à la personne à la recherche d'une auberge. La situation de l'établissement dans la ville et les services qu'elle propose peuvent être des facteurs de sélection. L'influence de l'enseigne reste un peu mystérieuse. Certaines d'entre elles, comme Le Cheval Blanc, se retrouvent dans presque toutes les villes de France. Véhiculaient-elles ainsi un symbolisme puissant qui inciterait le client à choisir l'auberge à laquelle elle est accrochée ? La situation de l'établissement dans la ville peut être un élément déterminant dans le choix (fig. 119). Pour Marseille, si l'on regarde leur répartition, elles se regroupent majoritairement dans le quartier de la Blanquerie autour de la porte Réale et de celle du Marché ainsi que dans le quartier du Corps-deVille. Les auberges constituant le premier regroupement se sont placées sur les axes de circulation dans la ville. De plus, le fait qu'elles s'amassent autour des portes indique qu'elles se destinaient à accueillir les voyageurs entrant dans la cité. Un autre élément incite les aubergistes à s'installer dans ces lieux : «De nombreuses considérations concourent à cette prédilection : le désir de happer le client dès son arrivée en ville, mais aussi le besoin d'espace et la nécessité d'un accès rapide aux pâturages du terroir» (Coulet 1988, p. 324). En effet, plusieurs hôtes louent des vignes ou des prés, comme Bertin Duroure, tenant le Logis des Trois Rois qui, en 1555 , loue trois prés au terroir de la ville ${ }^{371}$.

Par ailleurs on peut s'interroger : est-ce volontairement que les auberges se situent majoritairement autour de l'église Saint-Martin ? Curieusement, pour Paris, aux $\mathrm{XVII}^{\mathrm{e}}$ et XVIII ${ }^{\mathrm{e}}$ s., Annick Pardailhé-Galabrun a remarqué que « la rue Saint-Martin prolongée par le faubourg de même nom et ses rues avoisinantes (...) constituent un axe privilégié d'implantation hôtelière » (PardailhéGalabrun 1988, p. 106-107). Un dépouillement plus massif fournirait peut-être des éléments de réponse. Par ailleurs, les établissements suivant leur situation géographique semblent être destinés à différents types de personnes. En effet, le Corps-de-Ville est le quartier riche : c'est le lieu où se traitent les affaires. Il est habité principalement par de riches marchands et la noblesse. Aussi les clients séjournant dans les auberges de ce

371 AD13 373 E 199, fol. 524-525, 16 décembre 1555. 
quartier étaient peut-être en relation avec ce milieu. De même, ceux logeant à la Blanquerie pouvaient être de simples marchands ou muletiers qui faisaient leur commerce avec des habitants du quartier ainsi qu'avec les marchés avoisinants. Aucune auberge n'est signalée dans le quartier Cavaillon et seulement une dans celui de Saint-Jean. Cette absence est peut-être due au hasard de la constitution de l'échantillon d'actes présentés ; cela nécessiterait d'être approfondi. On peut penser cependant que l'intérêt de développer une hôtellerie dans le quartier le plus pauvre (Cavaillon) était limité.

Les services proposés par l'établissement jouaient sans doute un rôle au moment du choix. Pouvoir loger sa monture est un argument important. Toutes les auberges ne disposent pas de la place nécessaire pour une telle installation car, comme le montre Philippe Wolff, c'est un réel investissement : « il fallait encore y tenir des écuries pour les chevaux et mulets des clients, et ce jusqu'en plein centre de la ville ; la totalité ou presque du rez-dechaussée y était consacré » (Wolff 1978, p. 98). Aussi ne pas posséder de telles structures est un handicap. Jean Bernard et Claude Husson, hôtes du Logis de la Croix d'Or décident donc de louer en plus de l'auberge, une étable ${ }^{372}$. L'aspect matériel de ce lieu et l'accueil proposé au client peuvent être ainsi bien différent d'un établissement à l' autre.

\subsubsection{L'auberge : une structure d'accueil particulière}

Le bâtiment de l'auberge ne répond pas à des normes fixes ${ }^{373}$. Sa taille varie selon la fortune de son aubergiste. Deux des auberges présentées semblent comporter l'une un étage et l'autre trois. Une des pièces du Logis du Dauphin est décrite comme étant «deux degrés sous ladite cuisine », on peut penser qu'il y a donc trois étages. Les deux autres logis comportent des pièces situées audessus d'une autre. Les inventaires étant des actes peu précis sur ce genre d'information, il n'est pas possible de connaître davantage de détails sur la disposition verticale de ces lieux. Par exemple, on ne peut pas savoir où se situent les escaliers et ni quelles étaient leurs formes. L'échelle retrouvée dans la chambre haute du Logis de la Rose peut signifier l'existence d'une mezzanine ou celle d'un étage supplémentaire. Cependant il est possible, bien que peu probable, que certains de ces lieux ne possèdent

372 AD13 373 E 189, fol. 540, 2 septembre 1545.

373 L'organisation interne d'une auberge reste mal connue pour cette période. En effet, l'auberge en tant que bâtiment n'apparaît pas dans les actes. Seuls les inventaires après-décès nous livrent quelques informations qui sont ici détaillées (trois inventaires après décès ont été utilisés pour cette étude). pas d'étages. En effet, d'après des recherches effectuées sur un grand nombre d'inventaires, Noël Coulet arrive à la conclusion suivante : "l'existence d'un étage apparaît, en tout cas, comme la règle commune » (Coulet 1988, p. 327). Le nombre de pièces et de dépendances varie d'une auberge à l'autre. Plus elle est importante, plus le nombre de pièces s'accroît. Le Logis du Dauphin comporte, par exemple, quinze pièces et dépendances, celui de La Rose huit et seulement cinq pièces figurent dans l'inventaire de l'auberge de Sainte-Barbe ${ }^{374}$. De plus, contrairement aux habitations traditionnelles de l'époque, les pièces de l'auberge se spécialisent. Ainsi, plus le nombre de pièces est élevé plus leur spécialisation est visible. La salle, présente dans chaque auberge, est une pièce commune qui est par excellence réservée aux repas. L'existence d'une cuisine permet à Antoine Crotte dit Coste de préparer les repas dans celle-ci plutôt que dans la salle. En effet, les ustensiles de cuisine ont été majoritairement retrouvés dans cette pièce et aucun ne figure dans la salle. De plus, les mentions de cheminée dans le cellier indiquent que la préparation et cuisson des aliments ne se fait pas directement dans la salle, ce qui permet aux clients d'éviter d'être incommodés par la fumée et le bruit. On compte en général au moins une cheminée par auberge. La restauration occupe une place importante dans le fonctionnement de ce lieu. Au moins une cinquantaine de personnes peuvent venir boire ou se restaurer dans les trois logis inventoriés. La restauration devait être un moyen pour l'aubergiste de réaliser des marges bénéficiaires importantes.

Le nombre de chambres est sensiblement le même dans les trois auberges : quatre pour le Logis du Dauphin et de Sainte-Barbe et cinq pour celui de La Rose. Cet élément permet de classer ces auberges comme relativement grandes. En effet, Noël Coulet a rencontré cinq à sept chambres dans les auberges les plus importantes (Coulet 1976, p. 110). Ce type de pièces peut s'individualiser. Dans certaines auberges, en effet, les chambres portent des noms. Pierre Bertas en a rencontré dans l'inventaire du Logis de l'Écu de Bourgogne ${ }^{375}$. De même, Noël Coulet en a rencontré plusieurs. Elles peuvent porter des noms de saints, de couleur, de lieux ou des qualificatifs divers (par exemple la chambre du lit neuf) (Coulet 1988, p. 327). Parmi ces chambres se trouve celle de l'aubergiste. Généralement, cette pièce

374 Il semble que pour cette dernière l'ensemble des pièces ne figure pas sur l'inventaire. Il est indiqué qu'une chambre est située au-dessus de la salle «regardant vers le second cellier». Or aucun cellier n'a été visité durant l'inventaire.

375 ACM Fonds Pierre Bertas, 20 ii 107 : inventaire de L'Ecu de Bourgogne, notaire Jean Gille, fol. 431v, 4 janvier 1519. 
est celle où l'aubergiste a entreposé le plus de fatras et où ne figure qu'un seul lit. Comme le fait remarquer Dominique Villate: «le mobilier de la chambre des patrons est souvent excédentaire car elle semble faire office de débarras, du moins dans les établissements peu à l'aise côté espace » (Villate 1992, p. 143). Un châlit et cinq caisses se trouvent dans la petite chambre de l'auberge du Dauphin. Le contenu d'une de ces caisses est intéressant : elle est « remplies des acoustrements de la maison et de quelques escriptures vielhes concernant les instruments, tiltres, documens et procès vieulx de ladite maison ». On est tenté de croire que, vu ce contenu, Antoine Crotte dit Coste, l'hôte, garde cette caisse près de lui. Par ailleurs, cette pièce est située deux degrés sous la cuisine. Or Antoine Crotte teste dans son lit «à la chambre basse regardant vers la grande rue » ${ }^{376}$. Ainsi le croisement de ces deux types de données permet d'affirmer que cette pièce est celle de l'aubergiste.

Pour une des auberges (celle du Dauphin), un puits est mentionné. Ce type d'élément n'étant pas toujours jugé digne de figurer dans les inventaires, il est possible que d'autres auberges en soient équipées. Il permettait d'être rapidement approvisionné en eau en particulier pour la cuisine et pour abreuver les bêtes. Aucun lieu ni aucun objet (comme par exemple les pots de chambre) ne sont destinés à la satisfaction des besoins naturels. Au $\mathrm{XVIII}^{\mathrm{e}}$ s. seulement commencent à apparaître des pièces appelées « commodités».

L'auberge n'est pas une maison comme les autres. On voit nettement se dessiner, grâce à la prépondérance des objets liés aux repas (tables, vaisselle, ustensiles de cuisine) et l'importance de la literie, ses deux fonctions principales : servir à manger et à boire ainsi qu'offrir le gîte. Après avoir vu l'aspect matériel de ce lieu, intéressons-nous aux tenanciers à travers les principaux traits de leur vie quotidienne dont ils ont laissé trace.

\subsubsection{Tenir une auberge}

Combien de temps un aubergiste exerce t-il ? À quel moment de la vie devient-on aubergiste ? Ces questions nous interrogent sur l'identité des personnes qui ont exercé ce métier. En effet, il ne semble pas exister de formation spécifique pour devenir aubergiste. Aussi ce métier intervient-il peut-être au milieu ou à la fin d'une vie, comme un achèvement de carrière. Doit-on se constituer un pécule avant de devenir hôte ? Le cas d'Antoine Crotte dit Coste vient appuyer cette hypothèse. Celui-ci est marchand à partir de 1553 et au moins jusqu' en 1569 . Puis il apparaît comme hôte dans les actes à partir de

376 Testament d'Antoine Crotte dit Coste, AD13 353 E 30, fol. $684 \mathrm{v}-687 \mathrm{v}, 15$ août 1585 .
1571. On peut même penser qu'il a continué à exercer son métier de marchand. Parallèlement, comme l'a remarqué Wolfgang Kaiser, la profession d'aubergiste peut servir de propulseur de carrière (Kaiser 1992, p. 78). En effet, deux personnages témoignent de cette pratique : Nicolas de Cucurne et Joseph Cabre. Ce dernier est le tenancier d'une auberge en 1566 et devient premier consul de la ville en $1570^{377}$. De même, Nicolas de Cucurne apparaît en 1569 comme hôte de La Fleur de Lys, il est qualifié de noble en 1573 et d'écuyer en $1574^{378}$. Ainsi, « il appartenait à ce groupe de notables qui, comme exploitants agricoles, étaient parvenus à la richesse et à la renommée » (Kaiser 1992, p. 78). En revanche, pour certains hôtes, cette profession est une véritable vocation. Par exemple, Charles Denis tient le Logis de la Coupe pendant près de 32 ans ${ }^{379}$ ! Pour la majorité, en revanche le métier d'aubergiste s'exerce sur une durée relativement courte : 31 d'entre eux tiennent un établissement sur une période de 2 à 4 ans. Plusieurs d'entre eux ont eu une autre profession avant de devenir aubergiste. Un acte de 1569 témoigne de ces pratiques : Antoine Bouchet y apparaît comme «jadis bastier à présent hoste » ${ }^{\mathbf{3 8 0}}$. De même, certains indices laissent penser que la personne a dû exercer un autre métier auparavant. Antoine Huillet, par exemple, est qualifié de tailleur de toile en 1553 et devient hôte en 1575 (ou même avant) ${ }^{381}$. La condition sociale des aubergistes est donc variable.

La famille joue un rôle primordial dans l'aide qui lui est apportée. Les femmes apparaissent comme indispensables au bon fonctionnement de l'auberge. C'est une véritable collaboration entre le mari et la femme qui permet à celui-ci de pouvoir exercer un second métier. De la même façon, les enfants, dès leur plus jeune âge, sont mis à contribution. On peut également observer, dans ce milieu, une autre forme de collaboration : celle des parents proches ou des amis. Enfin, la majorité des hôtes ne sont que locataires de leur auberge. Comme le dit bien Dominique Villate: «s'il désire devenir propriétaire,

377 ACM Fonds Pierre Bertas, 20 ii 107, logis de Cabre.

378 ACM Fonds Pierre Bertas, 20 ii 109, logis de la Fleur de Lys (2 janvier 1569) ; AD13 351 E 899, fol. 329v, 18 octobre 1573 et 351 E 901, fol. 1341-1341v, 16 septembre 1574.

379 Il s'agit bien de la même personne car pour les deux actes retrouvés les plus extrêmes (1510-1541) son épouse, Antoinette Cannebière, est mentionnée. ACM Fonds Pierre Bertas, 20 ii 108, auberge de La Coupe (15 actes concernent Charles Denis).

380 AD13 351 E 891, fol. 632, 17 décembre 1569, reconnaissance de dettes pour Dominique Duroure contre Antoine Bouchet. Dans un obligé en date du 23 novembre 1587, il est à nouveau qualifié de bastier, AD13 363 E 68, fol. 462.

381 AD13 380 E 51, fol. 278, 9 novembre 1553, obligé pour Antoine Huillet, tailleur de toile de Marseille et AD13 351 E 904, fol. 11141114v, 22 juillet 1575, quittance pour Antoine Huillet, hôte dudit Marseille. 
sa bourse doit être bien garnie. En fait, le plus souvent, à moins de recueillir la succession de parents hôteliers ou d'épouser quelqu'un de la profession, il faut se contenter longtemps d'être un simple locataire et de s'acharner au travail »(Villatte 1992, p. 290). Le nombre important d'actes d'arrentement retrouvés vient corroborer ce propos : 20 sur 192 soit $10 \%$ du corpus. Généralement les auberges appartiennent à des personnes aisées voire nobles qui se dotent de revenus supplémentaires en les louant ${ }^{382}$. On observe ainsi une échelle qui va du partage de location d'un même établissement par deux personnes jusqu'à l'aubergiste notoire possédant sa propre auberge.

Etre aubergiste, c'est avant tout être polyvalent. Bien souvent, les revenus issus de l'auberge ne sont pas suffisants pour faire vivre une famille ou tout du moins pour s'enrichir. Plusieurs combines élaborées par l'aubergiste viennent pallier le manque à gagner. Tout d'abord, ce dernier peut gérer plusieurs établissements. C'est le cas semble-t-il de Claude Husson qui tient l'auberge de La Croix d'Or de 1547 à 1556 et qui, dans un acte, est qualifié d'hôte du Logis du Mulet en $1552^{383}$. De plus, il est précisé que ce dernier établissement est situé tout près du Logis de la Croix d'Or. Rien ne nous empêche de penser que cet hôte a géré les deux auberges pendant un certain temps. Par ailleurs, d'autres moyens sont utilisés pour accroître les ressources : les ventes de denrées (vin et céréales) et de mulets en sont les deux principaux. En plus de la gestion de son auberge, l'hôte peut cultiver des vignes. Une partie du vin qu'il en produit est réservé à la consommation dans son établissement et une autre est destinée à la vente. Six milleroles ${ }^{384} \mathrm{de}$ vin sont ainsi stockées dans la cave du Logis de la Croix d'Or ${ }^{385}$. De même, l'avoine est une céréale cultivée par l'hôte pour ses équidés. Il vend vraisemblablement le surplus. Le commerce de mulets, chevaux et ânes est une activité secondaire importante pour les hôtes. Les transactions qui lui sont liées s'étalent sur une palette riche : vente, échange, location et prêt, transport. Sur les 56 actes retenus comme témoins du commerce des aubergistes, 25 concernent ce type de transactions, soit environ $47 \%$ ! Il s'agit d'un véritable commerce parallèle qui ne demande pas beaucoup d'investissement : le foin, l'avoine et l'étable étant nécessaires pour loger les

382 Noël Coulet montre, qu'au $X^{\mathrm{e}}$ s., les auberges sont détenues par les trois groupes sociaux «les entreprenants de la capitale»: les grands officiers et les gradés en loi, les marchands, les notaires (Coulet 1988, p. 333).

383 ACM Fonds Pierre Bertas, 20 ii 108, Logis de la Croix d'Or et 20 ii 110, Logis du Mulet.

384 Mesure de l'huile ou du vin en Basse-Provence. Une millerole vaut environ 64, 384 litres (Kaiser 1992, p. 355).

385 AD13 380 E 86, fol. 598v-599v, 26 novembre 1593, acte d'arrentement pour Philippe Granier. chevaux ou autres équidés des clients. Ce type d'activité est relativement lucrative : un mulet se vend en moyenne 33 écus, un cheval 11 et un âne 10. De plus, c'est un investissement à long terme, ces animaux étant les principaux moyens de transport des hommes et marchandises de l'époque. Il peut aussi prendre en pension ces animaux. Cette activité semble être fréquente comme l'a remarqué Richard Gascon : « la plupart des hôteliers étaient en même temps loueurs de chevaux » (Gascon 1971, p. 173). À Marseille, les hôtes font de même, comme en témoigne la réaction de Joachim Bellue qui veut reprendre son cheval atteint d'une maladie appelée le «mal cadic » ${ }^{\mathbf{3 8 6}}$. Par ailleurs, les hôtes cultivent fréquemment des prés en plus de la gestion de l'auberge. Bertin Duroure, tenant le Logis des Trois Rois, loue les trois prés de la bastide du noble Amat Somati ${ }^{387}$. Ces terrains sont cultivés principalement pour le foin, principal aliment donné aux équidés ${ }^{\mathbf{3 8 8}}$. Or, produire son propre fourrage permet à l'aubergiste d'éviter d'être dépendant des laboureurs. En effet, à la suite de mauvaises récoltes, les prix pouvaient monter très rapidement et devenir ainsi un manque à gagner pour l'hôte. Antoine Crotte dit Coste possède ainsi deux fenières pleines (granges à foins) ${ }^{389}$. Certains d'entre eux, faute d'argent et de temps peut-être, ne peuvent faire autrement, comme Gaspard Guiran, qui achète à Mathieu Bertrand, ménager, 150 quintaux de foin pour 9 sous/quintal. Cultiver son champ, évite ainsi à l'hôte de faire des dépenses inutiles et de dépendre de quelqu'un.

Ce second métier peut être celui qu'il exerçait avant de devenir hôte ou qui l'a poussé à le devenir. Le métier d'aubergiste équivaut, de manière visible ou invisible, à exercer une autre profession en parallèle. En effet, comme il a été démontré précédemment, de par ses activités secondaires, l'aubergiste est aussi laboureur et muletier.

\subsubsection{Conclusion}

Définir le monde de l'auberge est difficile car on est confronté à un prisme. L'établissement sert à la fois à recevoir des clients mais aussi des chevaux ou des mulets et à stocker des denrées. De même, on peut y venir simplement pour manger, boire ou s'installer pour un séjour plus durable. L'aubergiste n'exerce pas seulement ce métier mais aussi celui de laboureur

386 AD13 360 E 20, fol. 1017v-1018v, 16 octobre 1584.

387 AD13 373 E 199, fol. 524-525, 16 décembre 1555, acte d'arrentement pour noble Amat Somati, écuyer de Marseille.

388 Il en est même la base car l'avoine est une céréale très énergétique mais peu nourrissante et de surcroît coûteuse.

389 AD13 353 E 30, fol. 849-851v, 23 septembre 1585, inventaire après décès d'Antoine Crotte dit Coste. 
et de loueur d'équidés. Si l'on observe le tenancier au sein de sa famille, on s'aperçoit que «c'est dans ce secteur d'activités que la superposition des gestes, liés au vécu familial et au métier est la plus frappante et la plus habituelle » (Pardailhé-Galabrun 1988, p. 329). Si la structure du bâtiment de l'auberge reste très mal connue pour la période de l'Ancien Régime à Marseille, un document trouvé au hasard des archives éclaire ce point. Laurent Parlier, seigneur de la soie cévenole au XVIII ${ }^{\mathrm{e}}$ s. possédait une auberge dans un petit village, Le Pompidou (Chabrol 1994). Dans le but de réaliser des travaux, celui-ci a dressé un plan méticuleux de son établissement. On y retrouve ainsi la polyvalence de ce lieu d'accueil (que nous avions pu établir non pas grâce à des plans mais à des actes notariés) ${ }^{\mathbf{3 9 0}}$ (fig. 120).

Durant tout l'Ancien Régime, l'auberge joue un rôle majeur : elle accueille les voyageurs. Cette vocation s'est progressivement transformée. L'essor du développement des moyens de transports au XIX ${ }^{\mathrm{e}} \mathrm{s}$. permet de raccourcir considérablement les distances temporelles. Ce phénomène va avoir des répercussions sur les auberges qui vont se traduire de deux manières. D'une part, l'hôtel vient petit à petit supplanter, dès le XVIII ${ }^{\mathrm{e}}$ s., l'auberge par son nombre de clients. Cette dernière apparaît donc dépassée au siècle suivant. D'autre part, l'affaiblissement de son activité entraîne également un changement dans le langage courant : le terme « auberge » disparaît au profit de celui d' « hôtel ». Les progrès dans les transports provoquent la mort de ces lieux comme structures de d'accueil de masse et leur naissance comme arguments touristiques.

\subsection{Les auberges observées en fouille (C. Castrucci, B. Sillano)}

La présence de plusieurs auberges à proximité les de l'Hôtel de Ville et proche du faubourg des Roubaud, deux secteurs concernés par des fouilles archéologiques n'a rien de surprenant. L'un est proche du port et de la Loge et l'autre d'une des portes de la ville, lieux privilégiés pour l'installation d'établissements où accueillir des hôtes de passage, venant pour traiter des affaires ou employés dans un grand chantier, « étranger de passage recherch[ant] un logis où l'on parle sa langue (...) où l'hôte puisse lui servir d'interprète » (Coulet 1993). La différence est que les auberges situées près des portes de la ville ont, si ce n'est dans leurs murs au moins à proximité, une écurie. La circulation à cheval dans la

390 On peut noter son côté rarissime. Il est conservé aux AD48, fonds Parlier-Chabrol $39 \mathrm{~J}$ (ce fonds étant en cours de classement, il n'est, à ce jour, pas encore communicable). vieille ville étant limitée ${ }^{391}$, le voyageur préfèrera laisser sa monture à l' auberge. Il est probable que les clients des auberges situées dans le quartier de la Loge sont soit des piétons, soit arrivés par la mer.

Rien en apparence ne distingue une auberge d'un immeuble ordinaire. Seule son enseigne, suspendue par une chaîne de fer à un cadre de bois ou à une poutre, la signale par un nom évoquant le bestiaire, l'héraldique, la flore, le sacré : La Licorne, Le Cheval Rouge, L'Écu de France, Le Rosier, le Petit-Saint-Jean. Leurs tenanciers sont locataires d'après un bail de trois à cinq ans, conclu par des propriétaires artisans, bourgeois ou nobles. Ils sont responsables du bon entretien de l'immeuble ; c'est ainsi que les experts faisant la visite du Logis du Rozier demande à Jacques Faure, son exploitant, de rendre des comptes sur les réparations qu'il a fait faire.

Parmi la dizaine d'auberges repérées dans la documentation, aucune n'est décrite avec suffisamment de détails pour que l'on puisse avoir une idée précise de son organisation intérieure. Un rapport d'estime nous apprend seulement que le Logis du Rosier contient deux «appartements» placés au-dessous du niveau de la rue $^{392}$. Les quatre autres logis situés dans le même secteur du Corps-de-Ville-Le Coq d'Inde, La Taulisse, La Licorne, La Coupe- ne sont évoqués qu'en confronts ou à propos de répartions qui ne permettent pas d'appréhender la hauteur du bâtiment, des étages, la superficie ni la disposition ou la spécialisation des pièces. En revanche, les deux expertises réalisées sur les propriétés touchées par l'Agrandissement nous apportent des éléments concernant les sept auberges situées sur l'îlot de l'Alcazar. Les estimations ayant été faites à une quinzaine d'années d'intervalle, elles mettent en évidence les transformations réalisées (fig. 121).

Deux d'entre elles ont été observées partiellement en fouille, ce sont les logis des Trois Mulets et celui du Canard, mitoyens et disposés le long du Grand-Caire. Elles ont, avant l'Agrandissement, des dimensions similaires et très importantes $(8 \mathrm{~m}$ de façade, $12 \mathrm{~m}$ de profondeur). Elles sont dotées d'une écurie, soit au rezde-chaussée sur rue, soit dans un bâtiment annexe en fond de cour, de celliers, de greniers à foin, ainsi que de chambres, cuisines et autres pièces disposées sur deux étages. Lors de la création du Cours, sous Louis XIV, les propriétaires sont forcés d'amputer leur bâtiment, pour certains de la moitié de leur superficie. Ils compensent cette perte en empiétant sur la cour. Elevé ensuite de quatre étages, comme le requiert le Bureau

391 La circulation des charrettes à l'intérieur de la vieille ville était interdite depuis le Moyen Âge pour régler le problème d'entretien des rues.

392 ACM FF $1182, n^{\circ} 104$. 


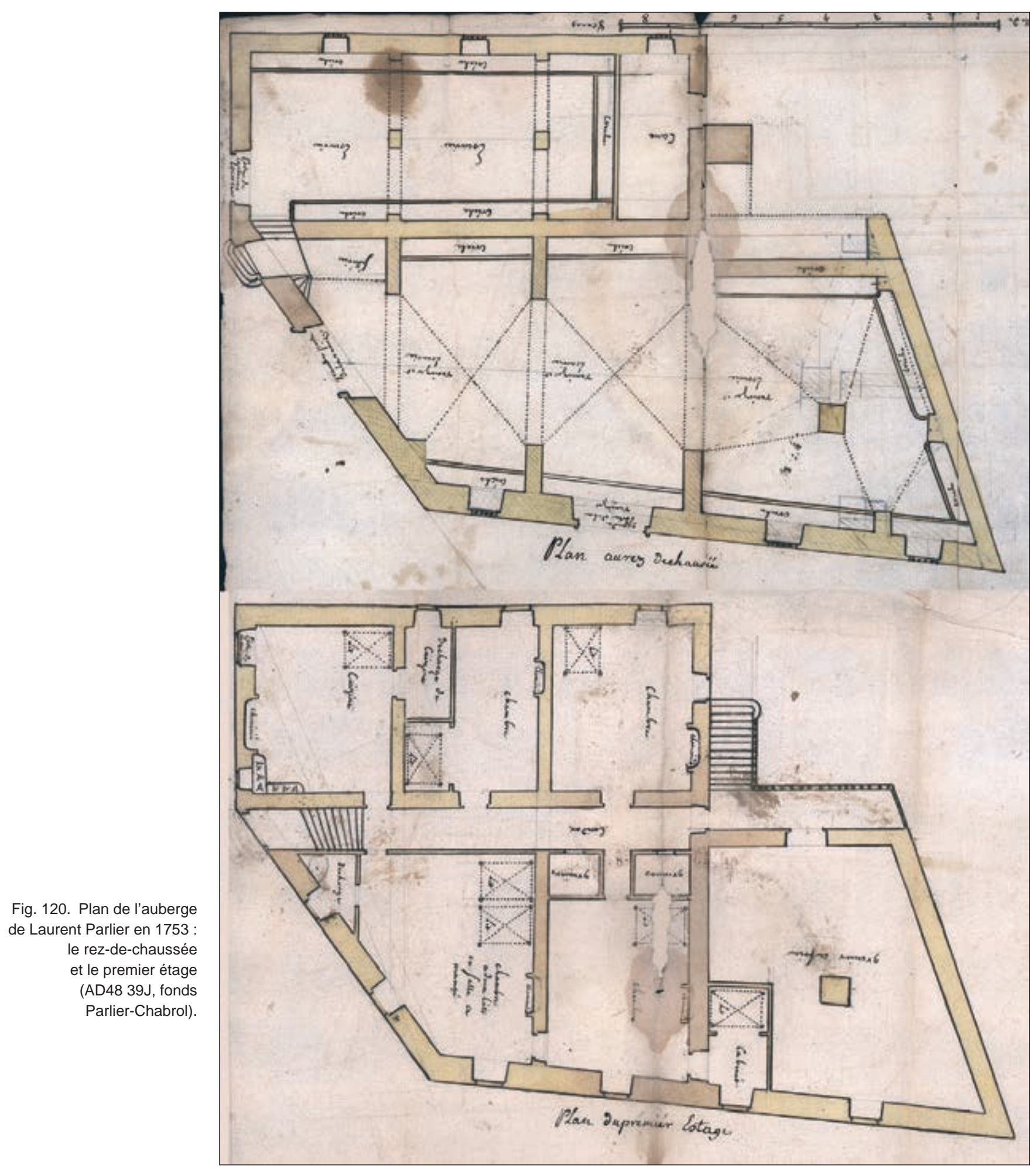

de l'Agrandissement, le Logis du Canard perd sa vocation alors que celui des Trois Mulets perd son écurie. Parallèlement apparaît à proximité le Logis du Mouton Couronné, un petit immeuble placé dans l'axe de l'îlot sous lequel se trouve la porte cochère permettant l'accès au cœur d'îlot où se trouvent de nombreuses écuries, propriétés de la congrégation Saint-Hommebon. Juste à côté s'édifie l'auberge du Cheval Rouge, reliée à une écurie ouverte sur la rue transverse.

L'auberge du Petit Saint-Jean, qui a donné son nom à la traverse qui permettait d'y accéder depuis le GrandCaire, a été édifiée peu avant l'Agrandissement et n'a 


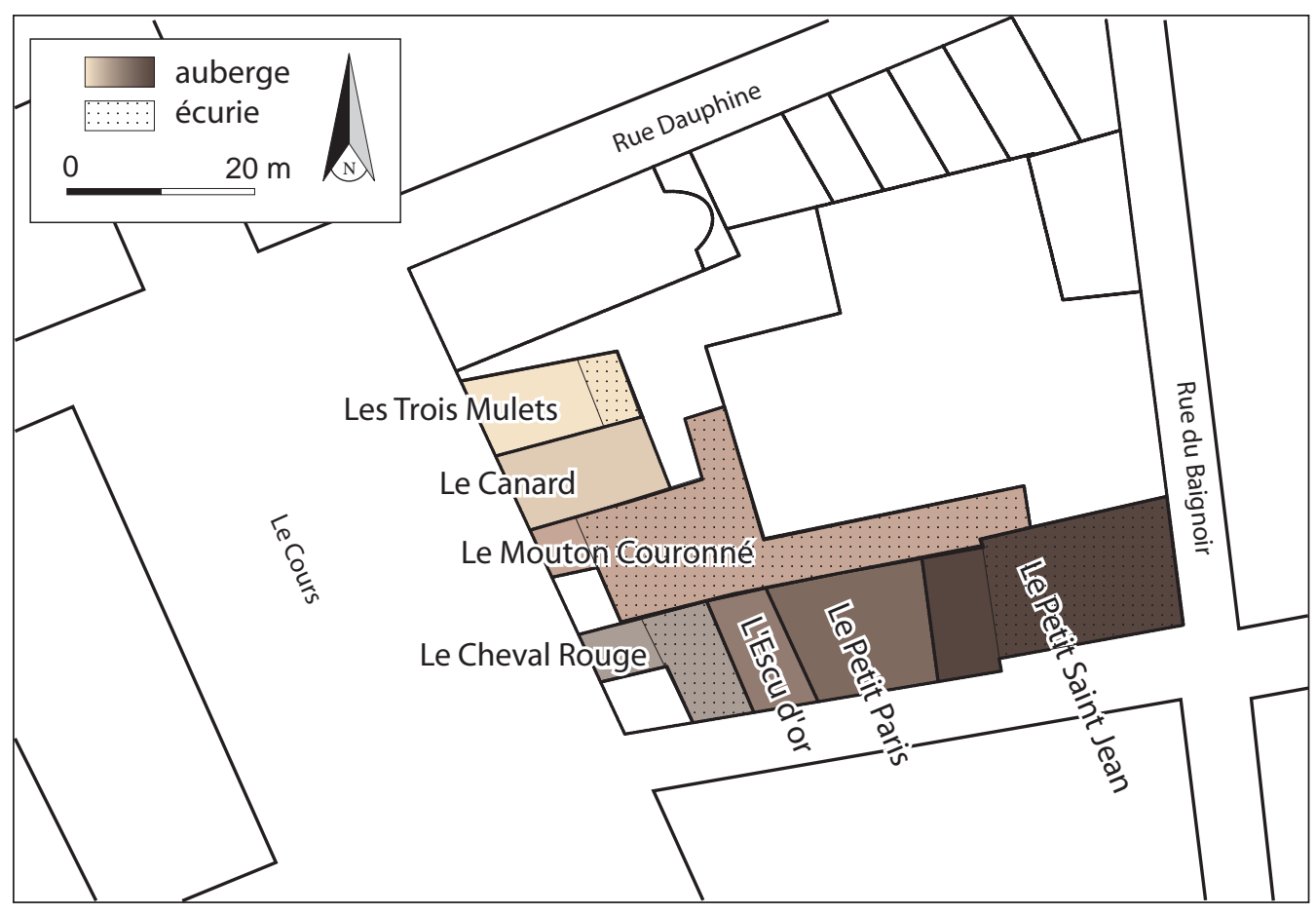

Fig. 121. Localisation des auberges présentes sur l'îlot de l'Alcazar (DAO Sillano/Inrap).

pas subi de modification dans la «Ville Nouvelle». Elle est composée de deux bâtiments légèrement en retrait par rapport à la rue. Le plus vaste, $20 \mathrm{~m}$ par $12 \mathrm{~m}$, situé à l'angle des rues, est une écurie surmontée d'un fenil, l'autre étant un bâtiment de deux étages. Les trois autres parcelles disposées le long de cette rue étaient, avant l'Agrandissement, de simples écuries surmontées d'un grenier. Dans le rapport d'estime de 1683, l'une d'elles est devenue le logis de l' «Escu de France », sans modification du bâti mais transformation de l'écurie en boutique, les deux autres ont été regroupées et reconstruites, sous l'enseigne du logis du « Petit Paris ». Celui-ci est doté de deux étages et d'une écurie ; il figure parmi les plus grands du quartier (11 $\mathrm{m}$ de large pour $13 \mathrm{~m}$ de profondeur).

La fonction de ces auberges est évoquée dans l'article précédent, nous n'y reviendrons pas. La présence systématique des écuries en rez-de-chaussée et des greniers à foin au premier étage -pour celles qui n'ont pas plus de deux étages- vient confirmer le rôle d'hébergement des bêtes et du stockage du fourrage, activités pratiquées par les aubergistes depuis le Moyen Âge et dont N. Coulet précise qu'elles sont les plus rentables. Il faut noter que la congrégation Saint-Hommebon rentabilise le cœur d'îlot dont elle est propriétaire en y établissant des écuries derrière l'auberge du Mouton Couronné mais aussi sur tout le pourtour de leur jardin. Une seule auberge possède une cave. La disposition des lieux de logement réservés aux hôtes ainsi que leur nombre, varient en fonction de la hauteur et de la grandeur de l'édifice. Au premier étage est située la cuisine où l'on prépare les repas et la salle qui lui est attenante. Celle-ci est le lieu de convivialité : on y prend les repas, on y joue, on apprend les nouvelles. Au même niveau peut se trouver une chambre. Les plus petites peuvent ne proposer qu'une ou deux chambres situées au dessus, au même niveau que le grenier à foin. Les plus importantes, comme celle du Petit Saint-Jean, offrent 6 chambres placées au même étage que le grenier à foin. Elles sont situées au dessus de l' « appartement» du premier niveau du logis : celui-ci est composé d'une cuisine, d'une chambre et d'une salle. L'auberge du Cheval Rouge contient « six lits ayant chacun sa paillasse et matelas, traversins, couverts, trois desquels sont garnis dung courtinage chacung toille de levant à oeil de bouf et cinq qui ont leur surail » ${ }^{393}$ lorsque Jacques Ribouton l'acquiert d'Henri Vesque en 1671. Peut-être a-t-elle pris encore plus d'ampleur après les travaux réalisés en 1674 et 1675 .

Si comme le souligne Daniel Roche la présence de dépendances, de jardins ou de caves « est un indice de la place occupée dans la hiérarchie des établissements » (Roche 2000), on peut considérer que les auberges de ce secteur de la ville, grâce à l'ampleur de leur superficie, la présence d'écuries, de caves, sont assez bien cotées.

393 AD13 390 E 232, fol. 432. 
Deuxième Partie

\author{
PRÉSENTATION \\ DE QUELQUES QUARTIERS \\ À LA LUMIÈRE \\ DES FOUILLES ARCHÉOLOGIQUES
}

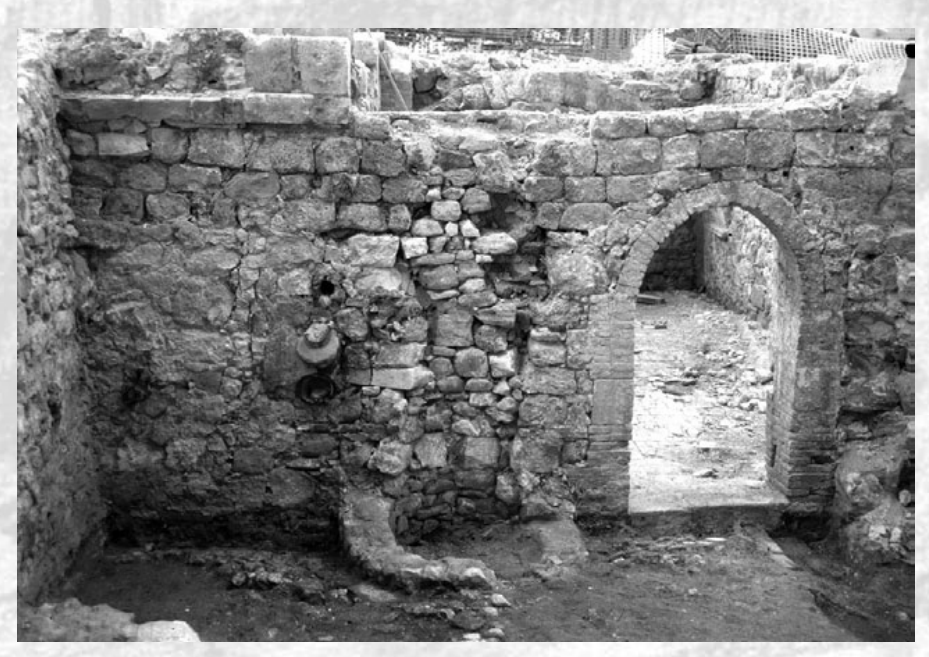




\section{Chapitre 1}

\section{La ville supérieure : le quartier de la Major}

$\mathrm{L}$ e tracé du Tunnel de la Major se situe dans la ville prévôtale; il traverse le quartier de la cathédrale, de la limite de la ville au nord à l'est du chevet de la vieille Major, et se poursuit vers le flanc nord de la butte Saint-Laurent. La ville est protégée au nord par un rempart et ce n'est qu'au XIV ${ }^{\mathrm{e}}$ s. que la présence d'un mur défensif est attestée le long de la falaise occidentale ${ }^{394}$. Les axes de circulation hérités des périodes précédentes convergent vers le groupe cathédral. Celui-ci est remanié au milieu du $\mathrm{XI}^{\mathrm{e}} \mathrm{s}$. puis dans le courant du XII s. (Paone, Bouiron 1999). La présence de l'église a certainement eu un impact important sur le tracé des voies et l'implantation de constructions destinées au clergé mais aussi aux civils. Sur le site, les occupations les plus anciennes ( $\mathrm{IX}^{\mathrm{e}}-\mathrm{XI}^{\mathrm{e}} \mathrm{s}$.) ont été arasées par celles des siècles suivants, particulièrement des XIII et $\mathrm{XIV}^{\mathrm{e}} \mathrm{s}$., elles-mêmes largement ruinées par des creusements modernes. Le groupe canonial qui fera l'objet d'une autre publication n'est pas traité dans le présent volume.

\section{Le quartier de la Major à l'époque médiévale et la fortification (P. Rigaud, M. Bouiron, N. Scherrer)}

Le quartier de la Major, qui tient son nom de la présence de la cathédrale (Sainte-Marie-Majeure), se situe à l'ouest de la ville médiévale. Il est limité dans la partie occidentale par la mer, au nord par l'anse de l'Ourse, le cap de Titol et la porte Gallica; à l'est, les limites du quartier sont plus floues mais il semble à la lumière de nombreux textes -pas toujours très explicites- que celleci est située à l'est de l'important axe de circulation qu'est la rue Francigena dite plus tard « de l'Evêché », entre la porte Gallica et la place de Lenche. Enfin au sud, la zone s'étend jusqu'à l'esplanade de la Tourette et la colline surmontée par le château Babon, surplombant à son extrémité le Vieux Port. Ces éléments de topographie urbaine médiévale et moderne marquent approximativement à la fois la limite du quartier et la zone d'influence directe

394 L'enceinte du bord de mer a été retrouvée en fouille (Bouiron, De Luca 1994). (juridique, religieuse, économique) de ce qu'il est habituel d'appeler la ville prévôtale (Mabilly 1905, p. 55-65).

L'étude des fonds disponibles tant aux Archives Communales qu'aux Archives Départementales, malgré les inévitables lacunes documentaires, permet d'appréhender globalement le quartier de la Major dans son évolution urbaine et tout particulièrement la zone située à proximité immédiate de la cathédrale. Nous ne traiterons pas cependant des édifices en lien direct avec l'ensemble cathédral. Nous sortirons en revanche de la période concernée pour l'analyse de la fortification du front de mer car son évolution est continue jusqu'au début du XVIII ${ }^{e}$ s. Nous donnons en annexe $\left(n^{\circ} 1\right)$ la transcription de l'état de cens du Chapitre en 1310.

\subsection{Le réseau viaire ${ }^{395}$}

Le réseau des rues de l'Antiquité reste très présent dans le parcellaire. Les axes des voies antiques en particulier, même s'ils ont été parfois légèrement décalés, déterminent l'implantation des bâtiments du Moyen Âge. Une évolution de la trame est cependant perceptible avec, notamment, la création de la rue des Treize-Coins qui s'inscrit suivant une orientation biaise.

\subsubsection{Les rues nord-sud}

Nous dénombrons quatre rues nord-sud, qui reprennent pour la plupart les axes anciens de l'Antiquité (la numérotation se fera par rapport aux rues définies lors de la fouille du Tunnel de la Major). Nous les indiquons d'ouest en est et donnons les résultats stratigraphiques lorsque les voies ont fait l'objet d'une fouille.

\section{Le chemin public occidental qui va à Saint-Laurent (voie $V$ )}

Cette voie de $4 \mathrm{~m}$ de largeur existe déjà dans l'Antiquité. Elle est mentionnée dans un acte notarié en 1466

395 D'après O. Maufras, P. Rigaud et E. Yebdri. In : Barra et al. 2004. 
comme «chemin public qui va à Saint-Laurent» et la situe à l'ouest de la Maison de l'enfirmarie ${ }^{396}$, ellemême installée en 1453 sous la prévôté ${ }^{397}$. La fouille a montré qu'elle est décalée vers l'est au Moyen Âge ; elle recouvre un bassin hellénistique démonté au XII ${ }^{\mathrm{e}} \mathrm{s}$.

Un niveau de circulation de cailloutis et mortier très lacunaire a été retrouvé à 11,27 m NGF. Un autre lambeau de sol, constitué d'une couche de sable et de charbons compactée, recouverte par une couche très compacte de fragments de céramique roulés ou non pris dans une matrice fine d'argile, est conservé sur une très petite surface plus au nord. C'est la chronologie relative basée sur les liens stratigraphiques qui permet de les dater du Moyen Âge.

\section{La voie orientale qui va à Saint-Laurent (voie VI)}

La voie orientale entre la maison du Chapitre et l'église Saint-Laurent est mentionnée dans des textes de 1220 et de $1286^{398}$. Un espace ouvert de 3,80 m de large a été mis au jour entre deux bâtiments sur le site (4 et 3A). Celui-ci pourrait correspondre à l'extrémité nord de cette rue, au débouché de la rue Four-du-Chapitre.

L'actuelle rue Miradou, dont l'installation n'est pas datée, est légèrement décalée à l'ouest de cette voie. Au XVII ${ }^{e}$ s., une rue de l'Amiradou ou Amiradour apparaît dans les textes ${ }^{399}$; est-elle identique à l'actuelle rue Miradou ? Il est peu probable qu'un décalage vers l'ouest ait été effectué à une époque récente. Quoiqu'il en soit, l'orientation de la trame du bâti retrouvé en fouille au pied de la butte Saint-Laurent laisse penser que cette rue existe bel et bien dès le Moyen Âge et qu'elle se confond probablement avec le chemin oriental du texte de 1286.

\section{La rue de l'Aumône (= rue de la Cathédrale)}

La rue de l'Aumône (actuelle rue de la Cathédrale, nommée rue de la Foire pendant la période révolutionnaire), située à l'est de la voie orientale qui mène à Saint-Laurent, relie la place de Lenche à la rue Fourdu-Chapitre. Elle n'a pas fait l'objet de fouille. Cette rue débouche actuellement sur la rue Four-du-Chapitre. Or auparavant, elle se prolongeait vers le nord par une impasse (traversia que non transit, androna que non transit), mentionnée dans les textes des $\mathrm{XIV}^{\mathrm{e}}$ et $\mathrm{XV}^{\mathrm{e}} \mathrm{s} .{ }^{400}$.

396 AD13 351 E 441, fol. 128; 351 E 1046, fol. 2v (copie du $\mathrm{XVI}{ }^{\mathrm{e}} \mathrm{s}$.).

397 AD13 6 G 342, n 2290.

$398 \mathrm{AD} 136 \mathrm{G} 27 \mathrm{n}^{\circ} 158$.

399 ACM DD 142, $\mathrm{n}^{\circ} 74$ (v. 1680), $\mathrm{n}^{\circ} 75$ (28 avril 1698); DD 32 (doc. n. fol.) not. $\mathrm{M}^{\mathrm{e}}$ Amoureux.

400 AD13 6 G 379, nº 2492.
Elle apparaît dans les textes médiévaux et de la période moderne sous le nom de rue de l'Aumône ou de l'Aumône-du-Chapitre (carreria helemosine, carreria domus helemosine, rue dicte de l'Amorne du chapitre), probablement en raison de la distribution de pain aux pauvres (la rue longe la façade ouest de la maison des chanoines et conduit à proximité du four du Chapitre) ${ }^{401}$.

Elle est attestée tardivement dans les textes : en 1327 vente d'une maison "in carreria Elemosine ${ }^{\mathbf{4 0 2}}$, puis en $13421363,1386^{403}$. En 1480, «la carreria domus helemosine » est dite «régale », donc un espace public ${ }^{404}$. Elle remonte néanmoins à 1'Antiquité ou à l'Antiquité tardive (Bouiron 2001d, p. 154).

\section{La traverse}

Nous trouvons dans les textes médiévaux la mention d'une petite rue sans nom («traversia») située entre deux îlots, dans le prolongement méridional de la rue Rouge du cadastre napoléonien. Elle existe encore dans sa partie nord au début du $\mathrm{XIX}^{\mathrm{e}} \mathrm{s}$. et a servi d'axe pour le tracé de la rue Rouge ${ }^{405}$. Elle constitue la survivance de l'axe antique aboutissant à la place de Lenche, dont on suit la trace très nette dans le parcellaire. À l'Époque moderne, elle se trouve derrière le nouvel Évêché ; elle est fermée en $1686^{406}$. Nous n'avons pas réussi cependant à savoir si cette rue existe encore au Moyen Âge au sud de la rue Four-du-Chapitre ${ }^{407}$.

\section{La rue Francigène}

Le cardo suivant vers l'est a pris, au XIII' ${ }^{\text {e }}$. au plus tard (date des premières mentions), les noms de rue Francigène ou rue Gallique ; c'est donc la rue « de France ». Elle porte également par endroit le nom de rue «droite qui va au couvent de la Sainte-Trinité » (dans sa partie nord) et rue «droite de la Pierre-de-l'Image » (à proximité de cet emplacement) ${ }^{408}$. C'est un axe médiéval

401 AD13 6 G 57, n 380. Au XVII ${ }^{\mathrm{e}}$ s., elle prend ponctuellement le nom de rue Françoise et au XVIII ${ }^{e}$ s. elle devient la rue de la Foire. 402 AD13 6 G $57, n^{\circ} 380$.

403 AD13 6 G 96, n 644 ; 6 G 151, n 10401 ; 6 G 201, nº 1380.

404 AD13 366 E 10, fol. 122-122v.

405 Celle-ci fut percée vers 1745 lorsque l'on délimita le couvent des religieuses du Saint-Sacrement. Elle fut d'abord réservé à un usage restreint.

406 AD13 6 G 437 (15 novembre 1686).

407 Notre impression d'après la lecture du parcellaire, non argumentée à l'heure actuelle par les textes anciens, est que cette rue se prolonge au sud jusqu'à l' ancien decumanus situé entre la place de Lenche et la rue Four-du-Chapitre.

408 Carreria Francigena, Franceza, Gallica, recta qua itur ad Sanctam Trinitatem, carreria recta Petri Imagini ; rue de l'Évêché depuis le XVII' $\mathrm{s}$. 
important qui traverse la ville dans sa moitié nord, depuis la porte Gallique au nord jusqu'à la place de Lenche et de là l'église Saint-Laurent au sud. On peut suivre en particulier le cheminement du pape Urbain V lors de son entrée à Marseille ${ }^{409}$ : il entre en effet par la porta Gallica et emprunte cet axe majeur.

La rue dessert plusieurs places, édifices et établissements religieux. L'habitat s'est aggloméré le long de cette voie très souvent citée dans les actes notariés et les membres du clergé de la cathédrale sont nombreux à y avoir une maison. Ils habitent en effet principalement cette rue, la place devant La Major et la rue Four-du-Chapitre.

\section{La rue Tennerii}

Il s'agit d'une rue rarement mentionnée ; sa situation est difficile à cerner. Tout au moins dans un cas elle semble proche de la cathédrale et de la maison du four : en 1446 un boucher achète une maison dans cette rue «...in carreria Tennerii confrontante cum domo furni ecclesie sedis... ${ }^{410}$. En 1461, une nouvelle mention d'une rue de même nom mais probablement pas située dans le quartier de la Major; cependant, l'absence d'indications précises ne permet pas de positionner les lieux ${ }^{411}$. La même année, le même toponyme apparaît près de la grande boucherie (du Tolonée) $)^{\mathbf{4 1 2}}$.

\subsubsection{Les voies est-ouest}

Des rues est-ouest sont mentionnées à plusieurs reprises dans les textes du $\mathrm{XIV}^{\mathrm{e}}$ et du $\mathrm{XV}^{\mathrm{e}}$ s. Les traces qui en ont été identifiées sur la fouille, montrent la continuité avec les axes antiques.

\section{La traverse du cimetière (voie I)}

$\mathrm{Au}$ nord, tout porte à croire que la voie I, attestée archéologiquement jusqu'à l'Antiquité tardive, existe toujours au Moyen Âge. Elle est également repérable à l'Époque contemporaine par une canalisation qui la longe ; elle est par ailleurs représentée sur le cadastre napoléonien. Aucun niveau de circulation n'a été observé pour le Moyen Âge, mais des constructions semblent en suivre le tracé. Entre l'Antiquité et l'Époque moderne, la voie s'est décalée vers le nord. Son bord septentrional antique est devenu sa limite méridionale moderne, sans

409 ACM BB 24, fol. 223-224v ; Albanès 1865.

410 AD13 391 E 50, fol. 318v.

411 AD13 391 E 62, fol. 231.

412 AD13 391 E 62, fol. 310v. Dans une note, E. Duprat indique qu'une rue des Tanneurs (fin XVIII ${ }^{e}$ s.) correspond à celle appelée par la suite rue des Phocéens (Duprat 1940, p. 31 n. 2). que l'on sache précisément quand est intervenue cette modification.

A l'ouest, l'église Saint-Jean, telle que nous la localisons, ouvre au sud sur la voie I. De même est-ce à l'extrémité orientale de cette rue ${ }^{413}$ (appelée alors «traverse du cimetière »), au débouché sur la rue Francigena, que l'on situe des maisons de prêtres au $\mathrm{XV}^{\mathrm{e}}$ s. En 1606, la chapelle des Pénitents Blancs est accolée à son bord sud. L'on considère que c'est à dessein que ces édifices ont été rapprochés de l'axe de circulation toujours actif et non par le hasard de la conservation de murs procédant d'un même alignement qui aurait permis la renaissance moderne de la rue après sa disparition pendant plusieurs siècles.

\section{La rue des Treize-Coins}

Un nouvel axe est créé, probablement dans les premiers siècles du Moyen Âge, sur l'emprise méridionale du cimetière, au sud-est de la cathédrale. Il s'agit de la rue des Treize-Coins, également appelée carreria Peyra de l'Imaja ${ }^{\mathbf{4 1 4}}$, carreria recta Peyra de l'Imaja ou encore rue des Treize-Cantons ${ }^{415}$, et mentionnée sous ce nom au

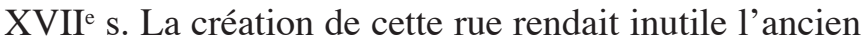
decumanus (voie II).

Cette rue ne suit pas la trame antique. De direction nord-est/sud-ouest, elle relie en ligne droite la cathédrale au nouveau Palais épiscopal édifié sur la butte des Carmes avant 1152 (Bouiron 2001d, p. 154 ; Bouiron 2001f, p. 260) ${ }^{416}$. La fouille n'a pas permis de dater la création de la rue, le niveau de circulation le plus ancien conservé étant un pavage de galets du XVIII ${ }^{\mathrm{e}} \mathrm{s} .{ }^{417}$. Les maisons qui la bordent au sud sont édifiées, l'une dans le courant du $\mathrm{XIV}^{\mathrm{e}}$ s. (2B), l'autre au début de ce siècle. (2C).

Sur le cadastre napoléonien, son tracé forme un élargissement au sud-est du chevet de la cathédrale romane, permettant de contourner celle-ci vers son entrée méridionale. Ce tracé est attesté par les façades du XVIII ${ }^{\mathrm{e}} \mathrm{s}$. contre lesquelles s'appuient les niveaux de rue, mais

413 Nous ne pensons pas en effet qu'elle ait existé au Moyen Âge à l'est de la rue Francigena.

414 Le nom « Pierre-de-l'Image » fait référence à la chapelle de la pierre de l'Image, dédiée à sainte Marie-Madeleine autrefois située à l'angle de la rue Francigène et de la rue des Treize-Coins. La chapelle a donné son nom aux deux rues, la rue Francigène se distinguant dans les textes anciens par le qualificatif « droite ».

415 En provençal, cantoun signifie « coin ». Il s'agit en fait d'une référence aux cantons suisses.

416 Plus à l'est, la rue porte les noms de rue du Petit-Puits et rue de Lorette.

417 La chape d'installation du pavage est à cet endroit sur une tombe datée au plus tôt du début du $\mathrm{XIV}^{\mathrm{e}} \mathrm{s}$. La rue a probablement été agrandie au XVIII ${ }^{\mathrm{e}} \mathrm{s}$. 
l'emplacement de la façade médiévale dans l'axe du mur moderne, suggère que le tracé est fixé dès le XIV $\mathrm{S}$.

\section{La rue Four-du-Chapitre}

La rue Four-du-Chapitre (traversia que est juxtas furnum de canonica) et parfois « rue publique » (carreria publica $)^{418}$, a livré des niveaux médiévaux.

Trois niveaux de circulation gravillonneux datés du $\mathrm{XII}^{\mathrm{e}}$ s., se superposent à un dépôt formé par le ruissellement des eaux, qui couvre lui-même un chemin de terre $\mathrm{du} \mathrm{VI}^{\mathrm{e}} \mathrm{s}$. Trois autres apports de limons sableux enrichis de graviers ou de déchets de taille de calcaire rehaussent la rue d'une vingtaine de centimètres au XIII' $\mathrm{s}$. Ces circulations sont surmontées d'un pavage de petits galets, puis, d'un nouvel apport de terre battue et de cailloutis daté de la première moitié du XIV ${ }^{\mathrm{e}} \mathrm{s}$.

$\mathrm{Au} \mathrm{XVI}{ }^{\mathrm{e}}$ s., la circulation est entretenue par d'autres remblaiements; deux d'entre eux sont conservés sous les niveaux de voie du XIX ${ }^{\mathrm{e}}$ s.

\subsection{Le rempart du front de mer}

Les premières attestations précisant l'existence du rempart dans la zone occidentale de la ville apparaissent en 1323 avec plus ou moins de détails. Les textes sont généralement peu précis sur les emplacements où se réalisent les travaux d'entretien qui restent tout au long du temps une préoccupation constante, récurrente pour le pouvoir municipal.

Pendant la période médiévale et moderne, quelques documents fournissent parfois des indications techniques sur la construction. Ces données peuvent parfois être mises en relation avec certaines observations réalisées sur les vestiges retrouvés.

\subsubsection{Le rempart médiéval}

En 1323, la ville se préoccupe de faire construire des bretèches (vestrescae) sur la portion des murs regardant la mer, de 1'hôpital Saint-Jean-de-Jérusalem à la Porta Gallica, mais sans donner de précisions quant à leurs emplacements ou dispositions ${ }^{419}$.

418 Les premières mentions de la rue remontent à 1220 et 1267 (AD13 6 G 480, fol. 13).

419 ACM BB 13, fol. 46. Les bretèches (occitan bertrescas, vertrescas) sont des constructions en surplomb saillant à l'extérieur du rempart, des sortes de balcons fermés et couverts permettant l'observation et éventuellement le jet de projectiles sur l'ennemi approché au pied de la muraille. Ces bretèches ont pu être transformées en bastions et ces derniers peuvent être repérés grâce aux plans de ville successifs, notamment à partir de la vue figurée d'Ercole Negro
Il est certain que le mur se poursuit jusqu'à l'anse de l'Ourse puisqu'en 1357 on procède à des réparations dans cette zone, réparations fortement motivées par la situation de crise que subit la ville à cette période ${ }^{\mathbf{4 2 0}}$. En 1374, un document précise le rôle des sixains devant défendre une portion de rempart (Bernardi 2001). On attribue au quartier de la Draperie la défense de la tour des murailles de la mer (celle dite d'en Baral, probablement une tour entre celle de Saint-Jean et La Major) jusqu'aux murs de la prévôté ; les quartiers de Saint-Jacques et Saint-Martin ont en charge la maison du prévôt et le cimetière ${ }^{\mathbf{4 2 1}}$. Une précision est apportée à la caractéristique du mur de défense vers l'Ourse lors de travaux à réaliser : il est muni de merlons ${ }^{\mathbf{4 2 2}}$, ce qui trouve une confirmation tardive sur la vue figurée d'Ercole Negro.

En 1407, les conseillers nomment deux maçons, père et fils, pour construire à neuf ( «facere et construere de novo ») un mur de 60 cannes $(120 \mathrm{~m})$ de long depuis le jardin de l'archidiacre (se trouvant au nord de la prévôté) tirant vers la maison de la prévôté en allant vers l'arche (arcam) d'un certain Jacques Bayssan située du coté de la Tourette ${ }^{423}$. Le prix-fait indique que le barri doit être réalisé tant en hauteur qu'en largeur comme celui placé du coté de la mer (du Titol ?) et comme celui des Trinitaires.

En 1424, une année après l'attaque aragonaise, la ville entreprend de faire des travaux de réfection sur les murailles et de les pourvoir en armement défensif. Il semble que l'on procède à un terrassement du coté de La Major jusqu'à la Tourette, probablement pour aménager un espace propice à la disposition d'artillerie à poudre (un grand trabuc et d'autres petits). Il est assez vraisemblable que la plate-forme aménagée soit celle qui perdura pendant toute la période moderne -pour la mise en place d'une batterie d'artillerie- au moins jusque vers la fin du XVIII' ${ }^{\mathrm{s}}{ }^{\mathbf{4 2 4}}$.

qui était ingénieur militaire et donc tout particulièrement intéressé par la question des fortifications. Il se pose la question du vocabulaire technique employé selon les époques, quelle signification peut avoir le terme vertresca dans un contexte donné -celui de 1323et l'absence du mot et/ou son remplacement par un autre (scubia) dans les documents relatifs aux réparations mais plus tardifs voire modernes?

420 Arnaud de Cervole conduisant la guerre des routiers menace à un moment (1358) d'assiéger Marseille. ACM BB 22 fol. 151. B. Roberty (AD13 22 F 14) pensait que le rempart ne couvrait pas cette zone en 1390, en réalité les textes confirment son existence.

421 ACM EE 4 fol. 7 ; Duprat 1922, p. 94.

422 ACM EE 4 fol. $18 \mathrm{v}$.

423 AD13 355 E 62 fol. 48v.

424 Cette position d'artillerie avec ses pièces est représentée de manière récurrente sur de nombreux plans et vues de Marseille. Les canons en position élevée pouvaient battre les navires ennemis qui 
Des murs neufs furent faits sur le cimetière mais aussi vers l'Ourse et on construisit une verdesca sur la tour du cimetière que Ruffi nomme la Tour du Cabiscolat ${ }^{\mathbf{4 2 5}}$. L'année suivante (1425) divers travaux sont faits sur le mur vers le cimetière («versus simentery corritoria aptentur»), un escalier est bâti pour accéder depuis le jardin du prévôt à ce couroir et on dispose des machines de guerre (trepas) entre la tour de Imbert (?) jusqu'à l'Ourse ${ }^{426}$.

En 1481, une délibération du conseil demande une fois encore de faire un couroir sur les remparts («faciendum corratoria circumcirca meniam...») et de réparer la porte de l'Ourse ${ }^{427}$.

\subsubsection{Le rempart à l'Époque moderne $\left(X V I^{e}\right.$-début $\left.\mathrm{XVIII}{ }^{e} \mathrm{~s}.\right)$}

Les négociations entre la ville et la Prévôté prennent d'autres aspects, notamment touchant à la sécurité et la circulation des gens lorsqu'en 1549 le prévôt prétend faire un jardin derrière sa maison et un mur qui joindrait au rempart. Cette affaire de porte d'accès au jardin et par conséquence de clef afin d'éviter que le peuple n'entre dans le jardin est soumise à la sagacité du conseil qui doit estimer s'il est préjudiciable ou non à la ville d'autoriser pareille latitude ${ }^{\mathbf{4 2 8}}$.

Un peu plus tard, en 1575, lors d'une nouvelle situation de crise (la guerre civile) d'autres informations touchant aux murailles de la ville sont données à l'occasion d'une enquête réalisée par des commissaires préposés aux remparts qui vérifient le bon état des lieux et font des propositions de réfections. Il semble qu'il soit proposé de démolir le mur du jardin du prévôt mentionné en 1549: «Au quartier de l'église Majeur trouvons qu'il faut démolir une muraille du jardin de la prévôté joignant aux meurs du coté du cimetiere et y faire passage en telle sorte que aisément on puisse aller et repasser le long des murailles jusques a l'edifice de ladite prévôté... ». On précise également que du côté du grand jardin «il y a [...] quelques petite crottes vers

auraient pu tenter d'approcher ou mettre des troupes en terre. Un prix fait daté de 1625 indique que l'on utilise des planches de chêne et des pierres taillées de 3 pans de large pour l'usage de la batterie (ACM BB 67, fol. 145 ; BB 251 D, fol. 51.

425 AD13 352 E 159 fol. 10v, 15, 24, 41v, 44. Ce document est cité d'après les notes de B. Roberty (AD13 $22 \mathrm{~F} 14$ et $22 \mathrm{~F} 86, \mathrm{n}^{\circ} 251$ ). Nous n'avons pu vérifier sur le texte original celui-ci étant porté manquant au 19 octobre 2000. Ruffi I, 293 cité par Roberty.

426 AD13 355 E 126 fol. 156. La tour d'Imbert pourrait être celle que Grosson appelle la tour de la prévôté Imbert, peut être un prévôt ayant fait construire ladite tour (Grosson 1773, p. 13).

427 АCM BB 32, fol. 193.

428 ACM BB 37, fol. 22v. lesdites murailles les faudra combler et remplir ycelles de terre ». Ces petites crottes sont peut être des affouillements causes des effondrements passés et à venir. On signale également la présence d'une vizette qui est sans doute un bastion voire une de ces verdescas ou scubias attenantes au mur d'enceinte et regardant vers la mer ${ }^{429}$.

La tendance à l'empiètement sur le terrain de la Prévôté sous prétexte d'accès aux murailles est l'objet d'un conflit récurrent vis-à-vis des autorités municipales. Il est manifeste une fois de plus lorsque le prévôt, dans un texte non daté mais rédigé sans doute après l'alerte de 1707 (invasion de la Provence orientale par le duc de Savoie), demande la démolition d'un magasin construit dans le jardin de la prévôté ${ }^{\mathbf{3 0}}$.

Il faut attendre 1621 pour trouver un texte donnant des précisions techniques quant à la construction ou plutôt la reconstruction d'une partie du rempart «proche l'esglise Majeur » ${ }^{\mathbf{3 1}}$. Ce document semble assez intéressant pour connaître et éventuellement interpréter les techniques employées dans l'édification de la muraille de la cité. Le prix-fait apporte des éléments relatifs aux nombreux détails entrant dans une telle reconstruction. La destruction des parties du mur ne présentant plus de fondement (probablement par effondrement) emmène à la préparation du terrain : «caver jusqu'au ferme » et piloter si nécessaire. Suivent ensuite les indications nécessaires au travail de maçonnerie et les dimensions requises pour une bonne stabilité de l'ouvrage : 8 pans ${ }^{\mathbf{4 3 2}}$ à la base de la fondation, 6 pans au ras de terre, on placera ensuite une première fillade de carthier, des pierres de taille insérées dans l'épaisseur des murs et cela sur le devant (donc visibles), l'arrière sera rempli de mortier. On laissera sur le devant du mur, à la base, un pare pied de 3 pans d'épaisseur dont la hauteur voulue sera estimée par les syndics. La mise en place de contreforts se fait de 12 pans en 12 pans pour une épaisseur de 3 pans. La position de ces éléments est ambiguë : sont-ils en avant de la muraille ou au contraire en arrière (du coté ville), en soutien, ce qui est plus vraisemblable ${ }^{\mathbf{4 3 3}}$ ?

La suite du texte donne encore quelques indications notamment pour l'évacuation des eaux (on utilise pour

429 ACM DD 132. Copie dans Roberty AD13 22 F 14.

430 AD13 6 G 459.

431 АCM BB 65A, fol. 20.

432 Le pan de Marseille vaut $0,2516 \mathrm{~m}$.

433 Le texte dit: "Plus fault faire de contrefortz de douze pans en douze pans de l'espesseur de trois pans et ce prandront despuis le fondemant de lad. muraille et de la longueur necessaire les montant jusqu'a plan de tere estant pour soubstenir la terre a l'avant que la muraille ne ce corrompe». La difficulté d'interprétation vient du sens «...pour soubstenir la terre a l'avant que la muraille ne ce corrompe ». Les contreforts en avant [du mur] ou avant que le mur ne se corrompe? 
cela une gorgue de tuille), la nécessité de fournir le matériel nécessaires et les délais à respecter-le prix-fait étant passé le 15 décembre les maçons sont tenus d'avoir monté deux cannes hors de terre pour le 15 janvier et d'avoir achevé le tout à la fin de février. La longueur totale de l'ouvrage à réaliser n'est malheureusement pas indiquée.

Un autre prix-fait plus tardif (après 1707) concerne une fois de plus le rempart, à la fois mur de défense et de soutien à la terrasse de la prévôté. Là également il est précisé que les réparations se font par nécessité : «...une muraille qu'il faut faire au coste de la mer pour soutenir la muraille de la maison ou regale de monsieur le Prevost de l'eglise cathedralle de cette ville parce que le fondement luy ont manqué et le rocher quy s'est brisé par sa cheute et pour éviter une plus grande chute a besoin d'estre au plutot reparé ${ }^{434}$.

L'attendu des travaux se fait de la même manière que le devis précédent: on aménage un escarpement de 4 pans de large sur 6 cannes de longueur ${ }^{435}$ (ce qui représente probablement la longueur de la réparation à effectuer) afin de préparer un lit de pierres de taille (éloigné de 4 pans du mur de la maison de la prévôté). Les pierres seront de 4 pans de long pour 3 de large et posées en pointe sur 8 pans de hauteur sur les 6 cannes de la longueur; la hauteur du mur devant atteindre 28 pans. Le mortier utilisé est composé de chaux et «sable de la mer $\gg$ et de $«$ porcelaine $»{ }^{\mathbf{4 3 6}}$.

\subsubsection{La faiblesse du rempart de l'anse de l'Ourse}

Les textes d'archives indiquent que les murs édifiés en bordure de mer ont tendance à l'effondrement, en raison de la trop grande proximité des constructions avec la falaise bordant le littoral. Le ressac de la mer provoqué par le mistral (le vent dominant) battant le pied qui finit par causer la chute du mur, les pluies minant la base d'un mur trop peu assis en retrait, semblent être les causes probables des destructions aboutissant à des plaintes et réclamations. Des plaintes sont déposées soit par des particuliers, dans un cas, soit par le prévôt à qui l'on impose de faire des travaux.

\footnotetext{
434 AD13 6 G 459.

435 La canne de Marseille vaut 2,012 m.

436 L'usage de sable de mer peut paraître surprenant, cependant celui-ci fut utilisé dans la construction jusque dans une période récente. Il était effectivement pratique de se procurer ce matériaux que l'on avait sur place ou à une faible distance dans le cas d'une ville côtière comme Marseille. Le sable une fois récolté était étalé de manière à être lavé et dessalé pendant la saison des pluies (automne, printemps) ; il était ensuite utilisé normalement. La «porcelaine » est un gravier ou sable composé de coquillages broyés (d'après le dictionnaire de La Furetière).
}

En 1368, Antoine Engran teinturier, un particulier possédant un operatorum blancarie du coté du Titol, réclame (avec humilité) à la ville la valeur de son atelier parce que le rempart s'était écroulé ${ }^{437}$. De même, les travaux d'entretien des murs de la prévôté semblent incomber à la ville mais non sans réticence quant à la prise en charge des frais, le problème étant même dans un cas transmis au pape pour arbitrage entre les chanoines et l'autorité municipale ${ }^{\mathbf{4 3 8}}$.

Les matériaux qui chutent à la mer peuvent être précieux et nécessaires pour la reconstruction, notamment s'il s'agit -à priori- de pierres taillées. En 1409, des dépenses sont engagées pour fabriquer une tenaille en fer (tenalhis fereis, tenaciarum ferri) afin d'extraire des pierres se trouvant au fond de l'eau pro "extrahendo lapides a fundo maris ». Justement, celles-ci sont à proximité de La Major "prope ecclesiam Beate Maria sedis »; s'agit-il de pierres tombées du rempart de la prévôté, effondré et mentionné comme tel en 1403 ou encore provenant d'une destruction plus ancienne? Le texte n'est pas plus explicite ni plus précis quant au lieu de dépôt. On sait seulement qu'elles serviront aux travaux du rempart vers l'hôpital Saint-Jean «pro constructione murorum Sancti Johannis... » ${ }^{\mathbf{4 3 9}}$.

À la fin du XVII e comme au début du XIX ${ }^{\mathrm{e}}$ s., le problème de la solidité des murs reste posé à peu près dans les mêmes termes du coté de la prévôté ou vers la Tourette : «...les murailles de la ville sur lesquelles la maison de la prévosté s'apuie menassent ruine pour avoir esté minées par l'eau de la mer qui bat contre icelle et la cheutte de cette muraille pourroit entresner celle de la maison... \ ${ }^{440}$. Grosson raconte que jusqu'en 1747 il a vu «...des pans de murs considérables, faisant partie des anciens remparts sur l'anse de l'Ourse. Ils avoient été abandonnés pour en construire d'autres à quelques toises de distance : ces derniers sont tombés à leur tour depuis le cimetière de la Charité jusque à l'angle du monastère des Carmélites et en reconstruisant cette partie, on a été obligé d'ouvrir une porte pour faire jetter les décombres de la ville en cet endroit afin de garantir les remparts d'une nouvelle chûte » (Grosson 1773, p. 13) ${ }^{441}$. Dans ces cas, les échevins renvoient à

437 ACM BB, 26 fol. 51 (1368).

438 ACM BB 23, fol. 40, 67, 170-172 (1361) ; BB 25, fol. 61 (1365) ; BB 32, fol. 85v-86, 114 (1403).

439 ACM CC 464, fol. $28 n^{\circ} 2$, fol. $32 n^{\circ} 2$.

440 ACM BB 116 fol. 41 (2e foliotation) (1680).

441 En 1809 encore, «...L'inspecteur soussigné a l'honneur de rendre compte à Mr le Maire de Marseille baron de St Joseph... que s'étant trouvé par hazard à la Tourette ou il s'est apperçu que le rampart qui soutient la partie de cette place en descendant à la Major près le corps de garde de la douane impériale du coté du Midi en tirant vers le fort St Jean est tellement dégradé par le pied sur une 
l'autorité supérieure pour obtenir l'autorisation du gouverneur royal ou du ministre de la Guerre.

\subsection{Les édifices et lieux particuliers}

Les édifices remarquables sont rares à proximité immédiate de la cathédrale. Ils sont liés en particulier à l'eau, avec l'arrivée de l'aqueduc dans la ville haute à la fin du XIII's.

\subsubsection{La Pierre-de-l'Image}

Au niveau de l'intersection entre la rue Francigena et la rue des Treize-Coins, on note la présence d'une chapelle dédiée à Marie-Madeleine, dans laquelle était conservée une effigie en relief de la sainte environnée de personnages qui l'écoutaient ${ }^{442}$. Cette chapelle attestée à la fin du XIII ${ }^{\mathrm{e}}$ s., fut démolie et reconstruite en 1615 et définitivement détruite au début du XIX ${ }^{\mathrm{e}}$ s. ${ }^{443}$.

Bory notait en 1861: «Sur tous les anciens plans topographiques de Marseille soit gravés soit manuscrits on voit figurer à environ $180 \mathrm{~m}$ de la Major un oratoire ou petite chapelle... ce modeste monument de forme quadrangulaire occupait la partie ouest du carrefour appelé des 13 Coins et y embrassait une superficie de 15 pans de longueur sur 18 de profondeur. La porte d'entrée s'ouvrait sur la rue Droite [rue de l'Evêché] » (Bory 1861, p. 33) ${ }^{444}$.

La chapelle apparaît peut être isolée sur la vue figurée de Negro, sur le plan Maretz et sous forme d'une croix sur le plan Demarest ainsi que sur un projet d'alignement des rues du secteur en $1819^{445}$.

longueur d'environ quinze mètres ou il se trouve totalement en l'air sur une hauteur moyenne de trois mètres environ, ce rempart dans cette partie qui se trouvait établie sur de l'argile que les pluies ont fait dissoudre a occasionné cette détérioration et continue toujours à s'augmenter de plus en plus ce qui fait craindre l'écroulement total de cette partie de rampart qui peut non seulement occasionner quelques accidents facheux mais encore des fraix conséquents à la commune pour son rétablissement... » (ACM 27 M 1).

442 Roberty AD13 22 F 76, $\mathrm{n}^{\circ} 26$ (d'après Ruffi II, 91). Il est intéressant de rapprocher cette lapis ymaginis de la scène du tableau montrant la Madeleine adossée à un mur antiquisant et prêchant à un parterre de personnages attentifs. Ce tableau est conservé au Musée du Vieux-Marseille, Boyer 1989. 1292 : ACM DD 270, $n^{\circ} 55 ; 5$ des calendes de septembre 1296 : AD13 6 G 31, $n^{\circ} 187$ et 6 G 480, fol. 32 (Mabilly 1905, p. 146).

443 Un réquisitoire du 5 juillet 1780 décrit la chapelle et propose de supprimer la messe en raison de l'incommodité du lieu et du bruit environnant (AD13 6 G 471 fol. 287v).

444 L'auteur a dû avoir connaissance du réquisitoire de 1780. 445 ACM 40 Fi 185.

\subsubsection{Des bains publics}

Le premier document concernant la question de l'eau dans le quartier prévôtal est relatif à des bains (balnea) qui sont donnés en location à deux frères. Cet établissement fait l'objet d'une concession emphytéotique par le prévôt R. de Peyrola en 1214. L'acte de 1251 qui nous en a conservé le texte, est un vidimus plus tardif ${ }^{\mathbf{4 4 6}}$. Ces bains sont situés sur la rue Francigena et ouvrent également sur la rue parallèle, à l'est. Ils sont probablement situés à mi-chemin entre la Pierre-de-l'Image et l'inflexion conduisant à la porte Gallique.

En 1310, le détail des biens relevant de la directe de l'CEuvre de la Major permet de retrouver les possesseurs de ces biens: Hugues Martin en tient un quart, Pierre Colombier en tient la moitié ${ }^{447}$. En 1352 on situe cet établissement dans la rue Francigena avec plusieurs confronts de maisons et on précise que sert à son usage un chaudron (cacabo) d'une contenance de 6 milleroles, malheureusement cassé (fracto) ${ }^{448}$.

En 1378, ces bains sont loués par un laborator Jacques Arnulf et une femme Jacmeta Guigues à une noble dame Auriole, femme de Pons de Jerusalem. D'après le contrat, des travaux de remise en état sont nécessaires : il faut réparer la porte, mettre un seau et une corde au puits, refaire la toiture, arranger le chaudron et mettre à disposition 15 seaux de bois («pohateriis fusteis bonis et sufficientis ») ${ }^{449}$. En 1455, Isabelle la Faisa, loue au noble Jacques Boniface l'établissement de bains ${ }^{\mathbf{4 5 0}}$. En 1472 l'héritier de Jacques, le chanoine Noffri Boniface, vend pour 190 florins les maisons dans lesquelles sont les étuves (stuphe) et un puits ${ }^{\mathbf{4 5 1}}$.

Les bains n'existent plus en 1493: la maison et un pati attenant où ils se trouvaient («domus et patui appellati olim estuba ») sont achetés par un prêtre de la Major $^{452}$.

446 AD13 6 G 438, fol. 33 ; Mabilly 1905, 63 n. 3.

447 Un huitième provient de l'achat de Guillaume de Caussio, un quart d'un autre achat à Jacques de Caussio et un huitième vient de l'achat fait à Guillelma, fille de Pierre Bouquier.

448 AD13 6 G 125, n 844. La millerole de Marseille (milharola) a une valeur de 64,3841 .

449 AD13 351 E 46, fol. 103v.

450 AD13 391 E 52 fol. 143. Il semblerait d'après le patronyme qu'il s'agisse d'une prostituée (?). On sait qu'à l'époque médiévale que les bains ou étuves ont la réputation de servir de lieux de débauche ce qui, par ailleurs, est parfaitement accepté malgré le discours moral de rigueur.

451 AD13 6 G 369, n 2450.

452 AD13 391 E 142 fol. 131. 


\subsubsection{La fontaine de la Major et les adductions d'eau}

Du fait de la situation topographique (et politique) de la ville haute, la question de l'alimentation en eau était d'importance. Des puits dans les parties basses sur le piémont ouest pouvaient sans doute recueillir les eaux du ruissellement souterrain, mais peut être en quantité insuffisante. Ce problème trouva une solution bien après la séparation des juridictions, avec l'intervention du comte de Provence en 1285 qui demanda aux conseillers de la ville basse d'accorder l'adduction d'eau aux habitants de la ville supérieure. La ville s'engage à construire l'aqueduc permettant l'apport de l'indispensable fluide. Un acte daté de 1292 décida enfin que l'eau serait amenée à « la Peira de l'Ymage in illa parte que pertinet ad prepositum » où fut construit une fontaine et un réceptacle. En 1296 on parle d'une «fons lapideus edificari ad recipiendum aquam ibidem venetam proximo vocatam de l'oyde... » ${ }^{453}$.

Cette fontaine en pierre appelée Fons Majoris, Fons de la Mayor, Fons Ymaginis Beate Marie Magdalene, Fons de la Mage ou Fons Magdalenes est située dans une maison sur la place de la Pierre-de-l'Image à proximité de la chapelle, mais elle est parfois dite dans une rue ou une traverse. Elle doit jouer par son emplacement un rôle important dans la vie du quartier ${ }^{454}$. Des conduites dites «canones ecclesie Maioris" ou "cannones Ymaginis Beate Marie Magdalene » sont le cas échéant des indicateurs dans le positionnement des confronts de maisons, prolongées vers l'ouest ; elles doivent alimenter La Major et ses dépendances ${ }^{455}$.

De fait, les textes sont peu prolixes sur la présence de puits dans la zone proche de La Major. On en signale en 1480 et 1497 dans un pati et dans un verger de la rue Francigena ${ }^{456}$. En 1552, un litige oppose un marinier du quartier à la ville à propos d'un puits creusé indûment (?) ${ }^{457}$. La maison du Chapitre possède également un puits qui est seulement mentionné à partir de $1734{ }^{458}$.

453 Amargier 1987, 285-286. $1296: 6$ G 31, $n^{\circ} 187$; 6 G 480, fol. 32, Mabilly 1905, p. 146. Les bains qui sont attestés avant mention de la fontaine étaient alimentés par un puits en 1378 ils n'étaient peut être pas reliés à adduction à celle-ci, $351 \mathrm{E} 46$ fol. 103v.

454 La rue est dite carreria Fontis en 1349, AD13 6 G 116, n 779. P. Amargier note la relation entre la sacralisation du lieu et la mise en place du réseau hydraulique (Amargier 1987, p. 284).

4551373 : AD13 6 G 173, n 1196 ; 1390 : 6 G 216, n 1476 ; 1439 :

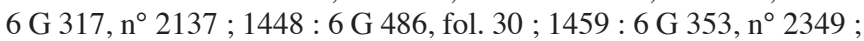
1461 : 6 G 490, fol. 33 ; 1472 : 6 G 369, n $2450 ; 1486$ : 6 G 493,

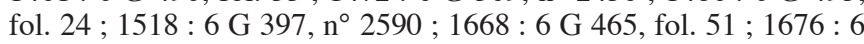
G 466, fol. 35v. Il est probable qu'il n'y pas de véritable distinction sémantique entre ces dénominations.

456 AD13 366 E 10, fol. 122v ; 355 E 178, fol. 29v.

457 ADM BB 37 fol. $115 \mathrm{v}-116$, le texte est confus, peu clair.

458 AD13 6 G 444, fol. 73v.
Un peu plus tardivement (1769), un document confirme que l'eau qui alimente La Major, la sacristie et le jardin (un liard) provient de la fontaine de la Madeleine. Un acte notarié du 4 août 1580 aurait entériné ce fait ${ }^{459}$.

\subsection{Espaces cultivés, espaces habités autour de la cathédrale}

Les textes nous donnent une idée de l'occupation des espaces autour de la cathédrale. Si les terrains libres étaient probablement en grand nombre autour de la cathédrale au début du Moyen Âge, ils subsistent encore largement aux $\mathrm{XIV}^{\mathrm{e}}$ et $\mathrm{XV}^{\mathrm{e}} \mathrm{s}$. La mention quasi systématique du métier exercé par les emphytéotes permet d'approcher la composition sociale du quartier de la Major.

\subsubsection{Les espaces libres}

Il doit rester des espaces libres c'est-à-dire non urbanisés à la fin du XIII ${ }^{\mathrm{e}}$ s. (1298) dans une zone située au sud de la cathédrale appelée Ferragine furni, vraisemblablement en raison de la proximité du four du Chapitre. Ce ferrage semble s'étendre jusque vers la mer à l'ouest, au nord jusqu'aux maisons d'habitation d'Audemar del Casal et d'Arnaud Safabrega qui confronte la maison et le jardin du prêtre Arnaud Andrieu. Ph. Mabilly dit, d'après un registre de notaire, qu'à proximité de la maison de Safabrega se trouve la chapelle Saint-Jean ${ }^{460}$.

En 1388 le Chapitre donne en accapte à un laborator un verger et un casal de maison détruit ainsi qu'un pati franc de servitudes près de l'église et derrière (retro) la prévôté (« ...viridarium et casalia hospitiorum diruptorum et patua simul contigua...»). Cette zone confronte avec le pati de la prévôté, la maison du Chapitre, la rue qui conduit à Saint-Laurent, le rempart (barrio), avec une rue traversant au milieu du pati en allant vers la mer et une autre terre ou pasquier appartenant à un certain Aicard Roquevaire et pour finir un sentier également au milieu ${ }^{461}$. Dans ce quartier, la densité urbaine est certainement élevée mais certaines maisons placées le long des rues et traverses semblent alterner avec des jardins et des vergers, une dénomination non contrôlable et qui peut avoir les mêmes significations. Fâcheusement, presque aucun texte ne donne de détails sur le contenu

\section{ACM DD 280.}

460 Mabilly 1905, 55-56 n. 1. Ces registres de notaires n'ont pu être consultés lors de l'étude d'archives, étant incommunicables et non microfilmés.

461 AD13 351 E 88, fol. 45. 
de ces espaces cultivés et/ou plantés ${ }^{\mathbf{4 6 2}}$. On peut imaginer qu'il y ait eu des arbres fruitiers (et/ou d'agrément) avec au sol des herbes cultivées et autres ortolailles.

Sur ces zones non bâties on édifie des maisons; celles-ci disparaissant, on voit sur ces lieux de maison (locus hospitiorum ou pati ou casal) réapparaître des jardins/vergers.

Ces espaces « vides » quelquefois entourés de murs assurent une protection au binôme maison/jardin-verger. Ces maisons disposent parfois d'une cour que l'on suppose entourée de murs et peut-être ouverte par une porte donnant sur la rue ${ }^{463}$.

Il reste difficile de situer ces modifications du paysage urbain bien que l'iconographie -les vues figurées de la ville aux $\mathrm{XVI}^{\mathrm{e}}-\mathrm{XVII}{ }^{\mathrm{e}}$ s. notamment- montre ou plutôt laisse percevoir une idée de cette occupation de l'espace.

\subsubsection{La composition sociale du quartier}

La composition sociale du quartier est fortement marquée par la présence des chanoines et des prêtres attachés au service de la cathédrale. Ils tiennent pour une bonne part sans doute la rue Francigena et les rues adjacentes. Toutefois certaines professions notamment artisanales occupent également le terrain autour de cette rue Francigena, un des axes majeurs de la Marseille médiévale.

A la fin du XIII ${ }^{\mathrm{e}}$ s. on peut rencontrer des laborators qui probablement cultivent des terrains hors les murs, des maystres d'ayssa -c'est-à-dire des charpentiers de marine-, des avitailleurs de navires (cargator navium). Certains autres métiers sont effectivement liés à la pratique de la mer, tel un canabasserio qui habite près de l'église en $1287^{464}$.

Un registre de cens pour l'année 1310 qui malencontreusement ne donne que peu d'indications sur les métiers et les lieux d'habitations indique que de nombreuses femmes (veuves ?) possèdent des maisons et les patronymes semblent provenir d'origines diverses mais d'une majorité des régions occitanes voisines (mais à quel niveau de génération ?) : Maussac (?), Albi, Sommières, La Voulte, Rodez, Lunel, Narbonne, Valence...

On trouve parmi ces gens un médecin, maître Victor, qui est dit phisicus ; il fait preuve de générosité en 1296 lorsqu'il teste en faveur de l'Aumône de la Major avec la donation de sa maison. On s'en souvient encore (on consulte le registre) lorsque le Chapitre en 1453 y

462 Une mention de 1391 fait état d'un pasquier dans la rue Francigena planté en consegalha, c'est-à-dire du méteil (mélange de blé et de seigle), AD13 6 G 219, n 1498.

463 En 1363, AD13 6 G 151, n 1041.

464 AD13 6 G 27, n 163. installera une infirmerie, les revenus censuels ne suffisant plus à entretenir la chapellenie qu'il avait fondée ${ }^{465}$. Au début du siècle suivant on mentionne un tailleur de pierre dans la rue Gallica ; sa maison confronte avec celle d'un pelissier ${ }^{466}$. En 1360 un drapier, Symon d'Apt, reconnaît un atelier de blanchisserie (operatorium blancarie) au nord de La Major vers lo Titol et au bord de la mer ${ }^{467}$.

Un document de 1357 précise que la ville veut favoriser l'installation d'artisans dans la rue Francigena. Ces artisans sont des forgerons (fabris), des maréchaux (manescallis), des bastiers (basteriis) -fabricants de bâts pour les animaux-, des ciriers (candelariis), des cordiers (corderiis), des fabricants de boucliers (factoribus bloqueriis), des serruriers (seraleriis), des blanchisseurs (blanqueriis) et des cuiratiers (coreatoribus). Une catégorie reste difficilement identifiable sous le nom de cepi ; il pourrait s'agir de spécialistes du travail du bois (un сер ou sep est un support d'artillerie, un jas d'ancre ou un joug) ${ }^{468}$.

Cette décision favorable aux «gens mécaniques» témoigne de l'importance de cette rue dans l'économie marseillaise. Cette délibération n'est peut être pas seulement le fait de la bonne disposition de la rue, il se pourrait que les circonstances politico-militaires (la guerre des routiers par Arnaud de Cervole, la menace d'un siège) conduisent les autorités à prendre ces dispositions afin de rassembler des spécialistes ayant une certaine valeur stratégique pour la ville en un même lieu.

\subsubsection{Les îlots}

L'étude d'archives conduite lors de la fouille par Philippe Rigaud a rassemblé de nombreux documents qui permettent de mieux cerner la réalité de l'occupation des îlots à l'époque médiévale. Un écueil toutefois important consiste dans la nature des occupants des maisons, vergers et autres étables : il s'agit pour la plupart de clercs, non mariés par nature, et qui ne transmettent généralement pas le bien dont ils sont les emphytéotes. Il est donc très difficile de suivre des généalogies de propriétés comme nous le faisons dans les autres quartiers de Marseille.

Il faut dès lors avoir des indications topographiques précises (orientations cardinales, noms de rue...) que l'on trouve rarement avant le $\mathrm{XV}^{\mathrm{e}} \mathrm{s}$. La vision des îlots, en particulier ceux à l'est de la cathédrale, est donc presque exclusivement celle de ce siècle (fig. 122).

465 AD13 6 G 31, nº $193 ; 6$ G 342, n 2290.

$466 \mathrm{AD} 136 \mathrm{G} 444, \mathrm{n}^{\circ} 285$.

467 AD13 6 G 143, n 979 .

468 ACM BB 22, fol. 160-160v. 
Malgré la richesse des archives depuis le XIII' s., il reste un travail important à accomplir pour faire le lien avec les siècles précédents.

\section{L'îlot 1 et 7}

Les premiers îlots que nous avons pu repérer confrontent le cimetière de La Major. Les maisons et vergers qui les composent ouvrent sur la voie principale Francigena à l'est. Une traverse (dite «du cimetière ») sépare les deux îlots qui sont dans le prolongement l'un de l'autre. $\mathrm{Au}$ sud, la maison et verger de Jean Bourguignon forme vers le milieu du XVe s. l'angle sur la rue des TreizeCoins («versus cantonum dictum Ymaginem Beate Marie Magdalenes ») ${ }^{469}$. Trois autres propriétés non bâties au XVe $\mathrm{X}$. constituent le reste de l'îlot $1^{\mathbf{4 7 0}}$.

L'îlot 7, beaucoup plus long, comprend également des maisons et vergers ; les actes étant de période différente, nous n'avons pas pu les organiser au sein de l'îlot ${ }^{471}$. C'est dans cet îlot que s'installent au XVIII ${ }^{\mathrm{e}} \mathrm{s}$. les religieuses du Saint-Sacrement. La partie nord de l'îlot, comme on le voit sur les plans de l'Époque moderne, arrive au contact de l'anse de l'Ourse. On localise dans cette partie un verger qui confronte avec le littoral à la fin du XIV $\mathrm{X}^{\mathrm{e}} \mathrm{s}$. (probablement à la suite de la disparition du rempart au niveau de l'anse) ${ }^{472}$. Un atelier de travail des peaux est localisé en arrière de l'îlot ${ }^{473}$; il jouxte une traverse, appelée « de Vivaude Chabasse » au début du $\mathrm{XIV}^{\mathrm{e}} \mathrm{S}$., qui correspond à un chemin conduisant à la mer, partant probablement de la rue Francigena et créant la pointe nord de l'îlot.

\section{L'îlot 2}

L'îlot 2 est situé au sud de l'îlot 1, de l'autre côté de la rue des Treize-Coins. Les actes conservés permettent de restituer l'ensemble des constituants de cet îlot au $\mathrm{XV}^{\mathrm{e}} \mathrm{s}$. Les maisons ouvrent toutes sur la rue Francigena. À l'arrière de l'îlot (à l'ouest), deux jardins longent les maisons et confrontent la traverse sans nom qui les

469 AD13 6 G 347, n 2318 (16 janvier 1455); 366 E 10, fol. 69 (5 décembre 1478) ; 391 E 85, fol. 315v (20 mars 1498).

470 Du sud vers le nord : verger de Guillaume Auriol (AD13 391 E 74, fol. 32v, 29 mai 1471) ; verger de Jean Bourguignon (6 G 357, $\mathrm{n}^{\circ} 2372,16$ décembre 1460) et verger de Nicolas Girard (391 E 125, fol. 5, 30 mars 1478).

471 Maison de Pierre de Denis (AD13 351 E 670, fol. 50, 29 juillet 1387) ; verger de Pierre Mossi (6 G 489, fol. 18, 30 avril 1392) ; deux maisons détruites de Pierre Ruffi (351 E 114, fol. 117, 2 octobre 1422).

472 Verger de Laurencet Martini (AD13 351 E 98, fol. 126, 26 février 1398).

473 AD13 381 E 13, 1307 (Mabilly 1905, p. 23) ; 355 E 11, fol. 2 (31 décembre 1360 ; Teissier 1891, p. 143 incomplet et fautif). sépare de l'îlot 4 ; ils sont rattachés dans la seconde moitié du $\mathrm{XV}^{\mathrm{e}} \mathrm{s}$. aux maisons principales ${ }^{474}$. Toute la moitié sud de l'îlot est constituée au $\mathrm{XV}^{\mathrm{e}} \mathrm{s}$. d'un grand jardin de la famille Boniface ${ }^{475}$. Cette propriété correspond au terrain acquis pour la construction de l'Évêché au XVII' $\mathrm{s}$.

\section{L'îlot 3}

Cet îlot est localisé à l'est du précédent, de l'autre côté de la rue Francigena. Nous avons pu localiser quelques confronts dans la partie nord de l'îlot, proche de la Pierre-de-l'Image. La rue qui en constitue la limite orientale ne porte pas de nom au $\mathrm{XV}^{\mathrm{e}} \mathrm{s}$. L'occupation de l'îlot semble assez dense, avec de nombreuses maisons, certaines avec étables, mais pas de vergers ${ }^{476}$. On est là dans un îlot étroit dont les maisons occupent toute la largeur. L'une des maisons appartient au Luminaire du Bienheureux Saint-Lazare de Marseille.

\section{L'îlot 4}

L'îlot 4 est un ancien îlot double ; il comprend en effet, dans le prolongement de la rue de l'Aumône, une impasse (androna que non transit) signalée comme confront. À l'ouest se trouve la maison des chanoines. $\mathrm{Au}$ nord, on signale au XVe s. l'école des enfants qui constitue vraisemblablement l'angle formant décroché sur la rue des Treize-Coins ${ }^{477}$. Plusieurs maisons, parfois

$474 \mathrm{Du}$ nord au sud : maison et verger de Jen Bourguignon (AD13

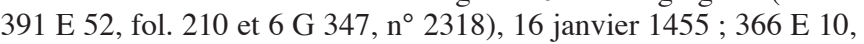
fol. 69, 5 décembre 1478); maison d'Honorat de Ysia (pas d'acte retrouvé); maison puis maison et verger de Jean Dominonis (6 G $287, \mathrm{n}^{\circ} 1961$ et 1962,$1424 ; 6 \mathrm{G} 369, \mathrm{n}^{\circ} 1443,22$ juin $1471 ; 351 \mathrm{E}$ 452, fol. 17v, 31 mars 1478 ; 366 E 10, fol. 77, 21 mai 1479) ; étable de Pierre de Roquefort (pas d'acte retrouvé) ; maison puis maison

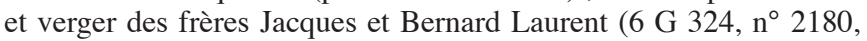

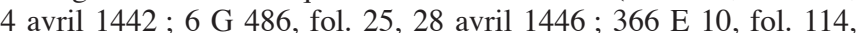
14 octobre 1479); maison de Batrone Chautard (6 G 240, n 1689, $1^{\text {er }}$ octobre $1401 ; 351 \mathrm{E} 161 \mathrm{E}$, fol. 142,17 décembre $1408 ; 355 \mathrm{E}$ 123 , fol. 208v, 7 octobre 1433).

475 Guillaume Boniface en 1401, Vivaud Boniface en 1408, Jacques Boniface en 1433 et 1442, Vivaud Boniface en 1472 et 1479; AD13 6 G $370, n^{\circ} 2448$ (28 septembre 1472).

476 Maison au nord: AD13 391 E 64, fol. 302v (6 novembre 1462) : maison et étable de Jean Bourguignon (355 E 129, fol. 59v, 5 décembre 1430 ; 6 G 490, fol. 33, 7 mars 1461) ; maison d'Honorat Angeli (AD13 6 G 486, fol. 30) ; maison de Pierre Boniface (355 E 129, fol. 214, 25 novembre $1432 ; 6$ G $365, n^{\circ} 2418,6$ juin 1468); maison de Jean de Cuers (6 G 380, $\mathrm{n}^{\circ} 2499,7$ décembre 1480) ; deux maisons d'Aicard Jourdan (355 E 94, fol. 97v et 6 G 306, n 2070,

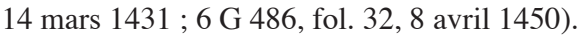

477 AD13 391 E 142, fol. 141 : «(...) confrontante (...) cum domo capituli cantonum facere in qua sunt escole puerorum dicte ecclesiem sedis (...)»(22 novembre 1493). 


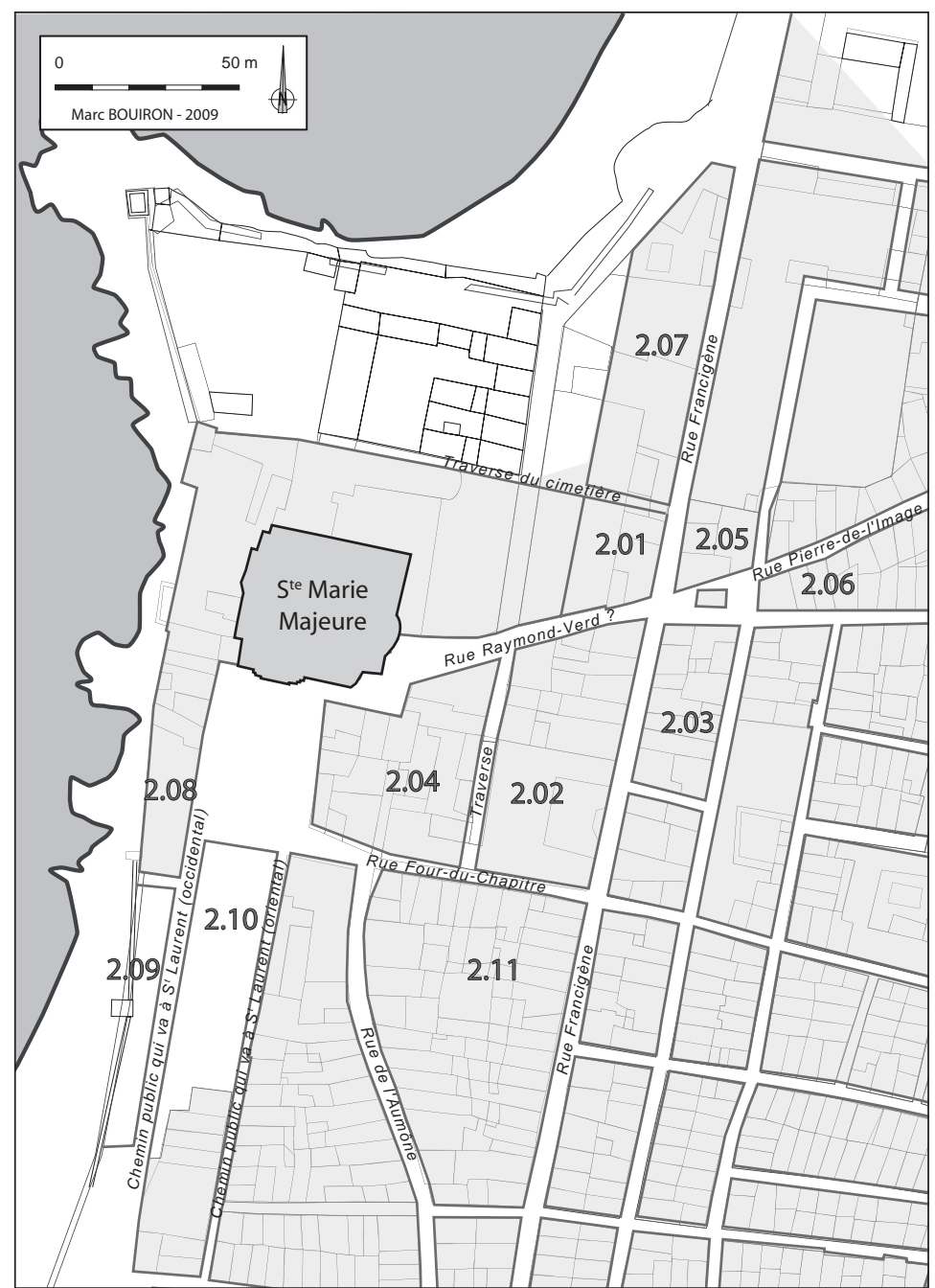

Fig. 122. Plan d'ensemble des îlots autour de la Major (DAO M. Bouiron/Ville de Nice).

avec verger sont attestées, sans que l'on puisse résoudre de manière définitive l'organisation des confronts ${ }^{478}$.

Il semble très probable que le nord de l'îlot ait accueilli la grande maison de l'archidiacre Raymond Verd, signalée par les textes ${ }^{479}$ : les différentes maisons contigues qu'il a achetées ont ensuite été probablement fusionnées pour constituer une seule grande maison donnant sur la rue. Nous pensons qu'elle était donc située au nord de cet îlot et ouvrit sur la rue des Treize-Coins, dont le tronçon proche de La Major porte le nom de « rue de Raymond-Verd».

478 Maison de Mathieu Triqueloti (AD13 351 E 114, fol. 54v, 20 octobre 1421) ; maison de Barthélémy Garnier (351 E 291, fol. 268, 14 janvier 1428) ; maison de Pierre Julien au nord de l'îlot (391 E 142, fol. 141, 22 novembre 1493); maison et verger de Nicolas Girard, au sud-est de l'îlot (2 G 379, n 2492, 2 octobre 1479 ; id., $\mathrm{n}^{\circ} 2493$ bis, 16 octobre 1479).

479 Voir en particulier le texte de 1310 en annexe $\mathrm{n}^{\circ} 1$. Testament de Raymond Verd : AD 136 G 63 (27 octobre 1330).
Si cette localisation est exacte, cela permet de proposer une organisation de l'îlot pour la fin du $\mathrm{XIII}^{\mathrm{e}}$ s. et le $\mathrm{XIV}^{\mathrm{e}} \mathrm{s}$. On aurait en effet une maison au nord qui appartient à Rainier de Reims, puis Jean Lodenes et Martin Auriol avant d'être acquise par Raimond Verd ${ }^{\mathbf{4 8 0}}$. Au sud (?), elle confronte deux maisons, l'une achetée à Marie Cabestan ${ }^{481}$ et l'autre à Martin Auriol ${ }^{482}$. Une dernière maison également contiguë aux précédentes est acquise de Jean Lodenes ${ }^{\mathbf{4 8 3}}$. La conservation dans les archives de la Major des actes concernant ces maisons s'explique probablement par le legs de l'ensemble bâti, avec les actes de propriétés antérieurs. Il est possible qu'à cette époque, la traverse dans le prolongement de la rue de l'Aumône n'ait pas encore été transformée en impasse. Il reste donc une incertitude sur le localisation de cet ensemble dans la partie occidentale ou orientale du large îlot $4{ }^{\mathbf{4 8 4}}$.

\section{Les îlots 5 et 6}

Nous avons rassemblé peu de documentation sur les îlots qui bordent la Pierre-de-l'Image au nord (îlot 5) et à l'est (îlot 6). L'îlot nord est compris entre deux rues nord-sud parallèles : la rue Francigena et une rue sans nom. Un ou deux vergers occupent la pointe sud de l'îlot; il s'agit d'anciennes places de maisons signalées détruites en $1398{ }^{485}$. Ces vergers confrontent une grande propriété cultivée (terra) appartenant à la famille Boniface.

L'îlot à l'est, donc au-dessus (topographiquement) de la Pierre-de-l'Image, n'est mentionné que dans un acte signalé par B. Roberty, qui indique deux rues latérales, l'une qui va à Saint-Jacquesdes-Épées et la seconde à Saint-Antoine ${ }^{486}$.

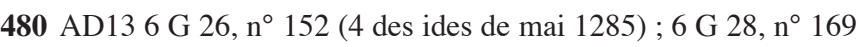
(août 1289) ; 6 G 502, maison de Martin Auriol (1310) ; 6 G 45, $\mathrm{n}^{\circ} 292$ (15 des calendes de mars 1316); 6 G 155, n 1066 (19 octobre 1365) ; $6 \mathrm{G} 188, \mathrm{n}^{\circ} 1298$ (26 avril 1380).

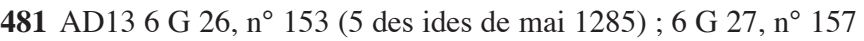
(avril 1286) ; 6 G 502, maison de R. Verd achetée à Marie Cabestan (1310).

482 AD13 6 G 27, $\mathrm{n}^{\circ} 157$ (avril 1286) ; 6 G 502, maison de M. Auriol achetée à Marie Cabestan (1310).

483 AD13 6 G 27, n 161 (juin 1287); id. n 163 (15 des calendes d'août 1287) ; 6 G 502, maison de R. Verd achetée à Jean Lodenes (1310).

484 Il faut espérer pouvoir un jour reprendre dans le détail les actes pour affiner la localisation de la maison de R. Verd.

485 AD 13351 E 94, fol. 15 (9 avril 1395) ; 351 E 98, fol. 186 (30 mai 1398) ; 6 G 353, $\mathrm{n}^{\circ} 2349$ (1er juillet 1459); 6 G 493, fol. 24 (15 mars 1486). Second verger : 351 E 94, fol. 68v (8 mai 1395).

48613 janvier 1481, mais la côte indiquée est mauvaise et n'a pas permis de retrouver l'acte. 


\section{Les îlots 8 et 9}

Au sud-ouest de la zone étudiée, deux îlots sont localisés le long du front de mer. Le premier, au nord (îlot 8) semble renfermer la maison du précenteur. On signale en 1388 un pré et un verger, avec des places de maisons détruites ${ }^{487}$. Au sud, l'îlot 9 correspond à une partie du ferrage du château Babon; une maison avec verger est connue dans cet îlot ${ }^{488}$. Là encore il faudrait poursuivre l'étude de façon plus précise pour comprendre l'évolution de cette zone.

\section{L'îlot 10}

L'îlot 10 est situé à l'est de l'îlot 9, entre la voie qui mène à Saint-Laurent et celle qui va au château Babon. Nous positionnons dans cet îlot un possible ensemble de maisons ${ }^{489}$. Il s'agit de maisons proches du four du Chapitre dans la seconde moitié du XIII' ${ }^{\mathrm{e}}$ s. Cette localisation permet de proposer un emplacement pour le four lui-même. Il est donc dans le prolongement de l'actuelle rue Four-du-Chapitre, dont le nom remonte très certainement au Moyen Âge.

Il est possible que le four n'existe plus dans cet îlot à la fin du Moyen Âge ; une aire semble occuper la partie nord de l'îlot en $1398^{490}$.

\section{L'îlot 11}

Le dernier îlot étudié correspond à celui qui est situé entre la rue de l'Aumône (actuelle rue de la Cathédrale) et la rue Francigena. Nous n'avons pas pu là encore retrouver suffisamment d'actes pour bien comprendre l'organisation de l'îlot. Les deux rues sont bordées de maisons ; l'importante largeur de l'îlot au nord permet d'avoir en cœur d'îlot des vergers et autres terrains découverts ${ }^{491}$.

Les autres îlots, situés de l'autre côté de la rue Francigena n'ont pas réellement été repérés dans les textes collationnés.

487 AD13 351 E 88 fol. 45 (14 août 1388).

488 AD 13381 E 11 (3 des ides d'avril 1298 ; Mabilly 1905, p. 56 n. 1).

489 Maison de maître Victor, physicus (6 G 20, n 116 et 6 G 480, fol. $9 \mathrm{v}, 17$ février $1268 ; 6 \mathrm{G} \mathrm{31}, \mathrm{n}^{\circ} 193$, 15 février 1296) ; maison de

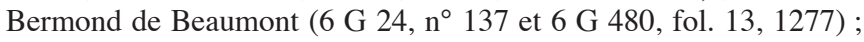
maison de Bertrand de Beaumont (6 G 27, $\mathrm{n}^{\circ}$ 158, 14 des calendes d'octobre 1286). Les confronts indiquent quatre autres maisons (Nicolas de Narbonne et Marie Assaudi en 1296 ; Garssies Caisserie et Béatrice Guigues en 1277).

490 AD13 351 E 98, fol. 177.

491 AD13 366 E 10, fol. 122 (24 janvier 1480), 122v (10 mars 1480) et 124 (21 février 1480) ; 391 E 58bis, fol. 312 ( $1^{\mathrm{er}}$ août 1493$)$; 391 E 142, fol. 227 (23 janvier 1494) ; 391 E 84, fol. 13 (17 avril 1497).

\section{2. Évolution du quartier autour du groupe épiscopal (N. Scherrer, N. Valour)}

La fouille du Tunnel de la Major a permis d'étudier de façon plus précise l'évolution de l'occupation du quartier autour de la cathédrale. Nous ne traiterons ici que de l'habitat civil, en suivant un ordre chronologique et topographique.

\subsection{L'habitat aux $\mathrm{X}^{\mathrm{e}}-\mathrm{XIII}{ }^{\mathrm{e}} \mathrm{S}^{492}$}

La rue Four-du-Chapitre reprend le tracé du chemin du $\mathrm{V}^{\mathrm{e}} \mathrm{s}$. Elle dessert au nord un bâtiment (2A) d'au moins deux pièces et au sud une série de fosses. Les vestiges de l'habitat sont répartis au nord de la rue Four-du-Chapitre et sur le flanc nord de la butte Saint-Laurent (fig. 123).

\subsubsection{L'occupation au sud de la rue Four-du-Chapitre}

L'îlot sud de la rue Four-du-Chapitre se caractérise surtout par une série de fosses (fig. 124). Aucun indice ne permet de leur attribuer de fonction précise.

Une tranchée longue de $4 \mathrm{~m}$ et large de $0,50 \mathrm{~m}$, orientée est-ouest, est le seul vestige qui évoque la présence possible d'un bâtiment au sud de la rue. Son orientation n'est d'ailleurs pas exactement parallèle au mur de façade du bâtiment $2 \mathrm{~A}$ et à la rue Four-du-Chapitre. Au fond de la tranchée, un lit d'éclats de taille de calcaire est daté du début du XII' ${ }^{\mathrm{s}}$ s. ; s'agit-il d'une tranchée d'épierrement de mur (comblement argileux avec inclusions de charbons de bois, d'éclats de taille) ? Rien ne permet de la définir comme mur de limite entre l'îlot et la rue ou comme mur de façade d'un bâtiment. Une fosse coupe le comblement de la tranchée et un sol couvre le comblement de la fosse. Ce sol extérieur charbonneux peu épais contient de nombreux coquillages et de la faune. Un trou de poteau et trois fosses sont creusés à partir du sol. Proches les uns des autres, ovales ou circulaires à l'ouverture, ils varient en taille de 0,42 à $1,60 \mathrm{~m}$ et en profondeur de 0,30 à $0,75 \mathrm{~m}$. Leurs profils et leurs comblements diffèrent. La céramique, retrouvée dans ces fosses, datée des $\mathrm{V}-\mathrm{VI}^{\mathrm{e}} \mathrm{s}$. est résiduelle. Ces aménagements en creux et le sol sont recouverts par des remblais limoneux argileux sableux. La fondation d'un mur du $\mathrm{V}^{\mathrm{e}} \mathrm{s}$. est épierrée, et après récupération des matériaux,

492 D'après les textes de L. Argueyrolles, L. Ben Chaba, S. Fournier, O. Maufras, K. Monteil, S. Puech, C. Richarté, N. Scherrer, N. Valour. In : Barra et al. 2004. 
CHAPITRE 1 - LA VILLE SUPÉRIEURE : LE QUARTIER DE LA MAJOR

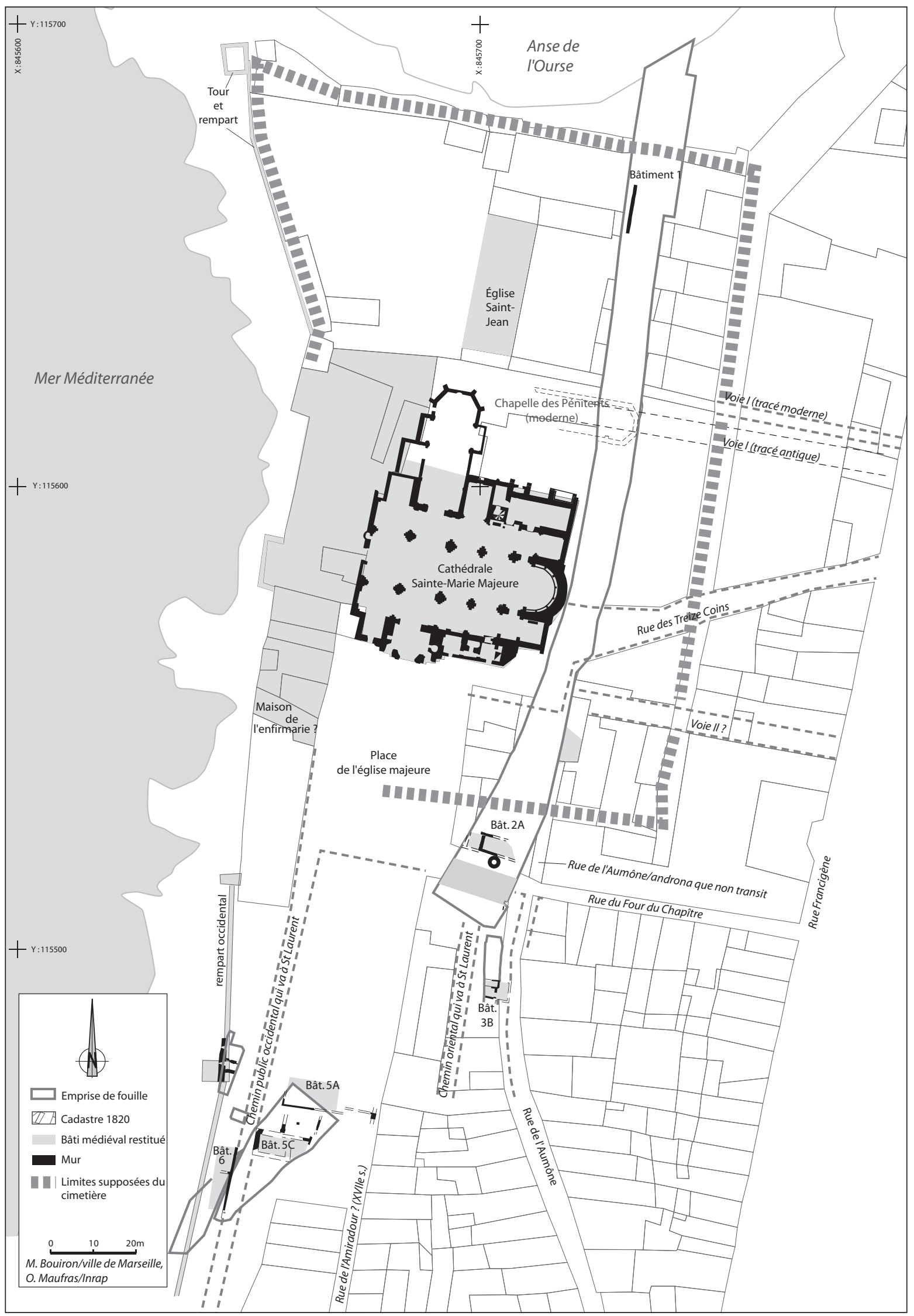

Fig. 123. Plan général des vestiges et des rues médiévales (DAO M. Bouiron/Ville de Nice, O. Maufras/Inrap). 


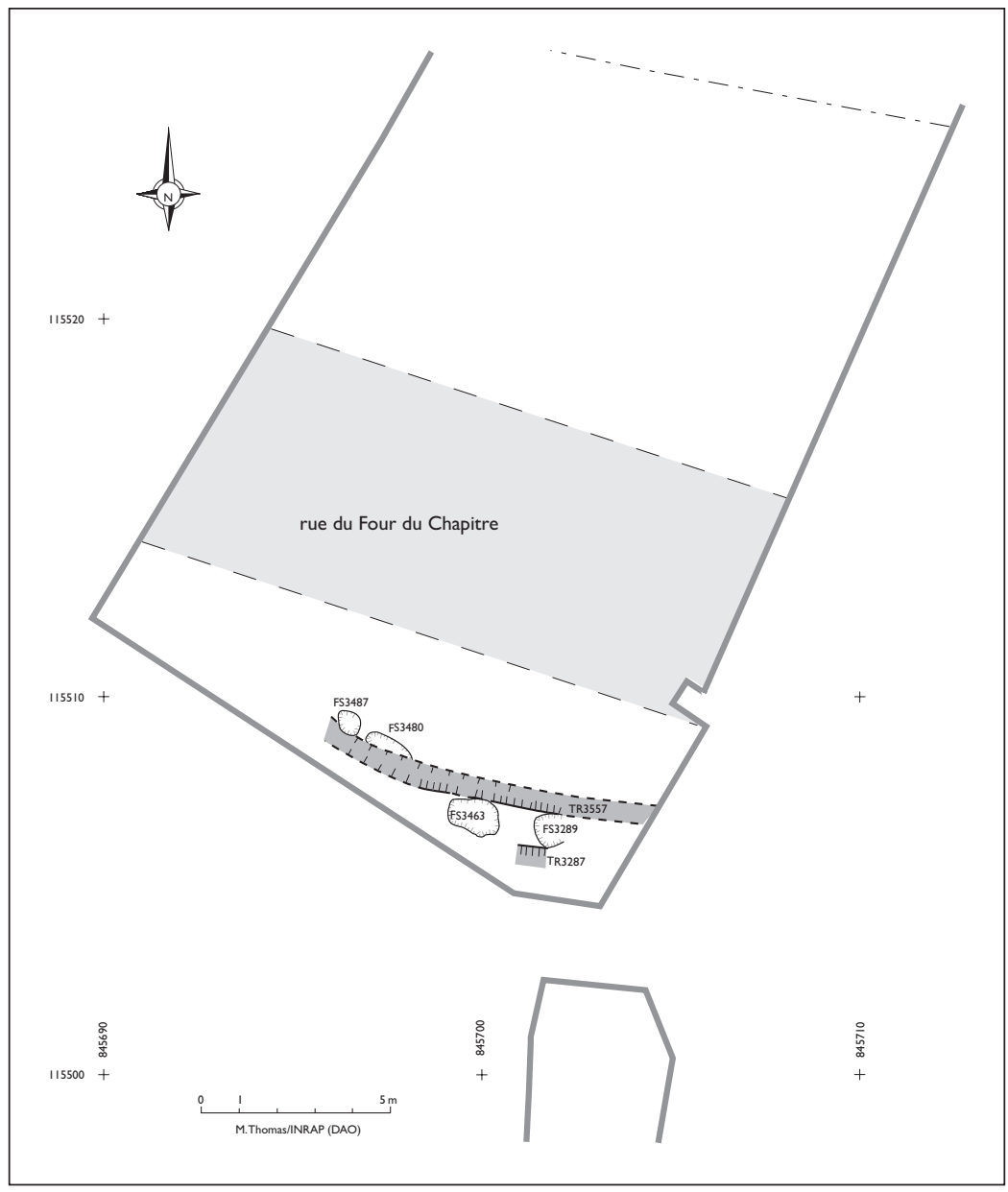

Fig. 124. L'occupation de part et d'autre

de la rue Four-du-Chapitre aux X-XIIe s. (DAO M. Thomas/Inrap).

une couche de chaux contenant de nombreux tessons (datés des X-XII ${ }^{\mathrm{e}}$ s.) et des tuiles scelle le comblement de la tranchée d'épierrement. L'ensemble est recouvert par les derniers remblais d'exhaussement du secteur. La surface au sud de la rue Four-du-Chapitre est essentiellement une occupation en aire ouverte, dépourvue de bâtiments, surtout marquée par des creusements dont la fonction n'est pas déterminée.

\subsubsection{L'habitat sur le flanc nord de la butte Saint-Laurent}

La partie sud du chantier se situe au pied du flanc nord de la butte Saint-Laurent. Depuis l'Antiquité, la zone est aménagée en terrasses. Au Moyen Âge, elles sont disposées suivant une double pente, à la fois vers la mer et vers la cathédrale de La Major. Des bâtiments ont été mis au jour de part et d'autre du chemin public occidental qui va à Saint-Laurent, dont la pente, bien que peu accentuée, a permis de canaliser les eaux de ruissellement dans cette zone (fig. 125).
Le bâtiment 6, dont la façade orientale existe déjà antérieurement, est situé à l'ouest du chemin occidental qui va à Saint-Laurent. Il n'est que partiellement présent dans l'emprise de la fouille. Sa longueur est d'au moins $14 \mathrm{~m}$ et il est subdivisé par un refend intérieur. Nous sommes donc en présence d'un bâtiment relativement long comprenant au moins deux pièces en rez-de-chaussée ou d'une façade commune à plusieurs maisons. Les deux murs présentent une élévation très soignée de grands blocs taillés de matériaux disparates, poudingue, travertin et calcaire urgonien dans la façade ; s'y ajoute du grès dans le refend (fig. 126). Un pan de la construction qui contient des blocs en remploi correspond à une reprise du mur datée du XII ${ }^{\mathrm{e}}$ s., sûrement le bouchage d'une porte. L'occupation intérieure est sur deux paliers, au nord, en contrebas de la rue ${ }^{493}$, au sud, au niveau de la voie. Ce bâtiment présente une qualité architecturale qui laisse supposer qu'il s'agit d'un bâtiment un peu

$493 \mathrm{La}$ base de l'élévation intérieure est $0,40 \mathrm{~m}$ plus bas que les niveaux de voirie. 


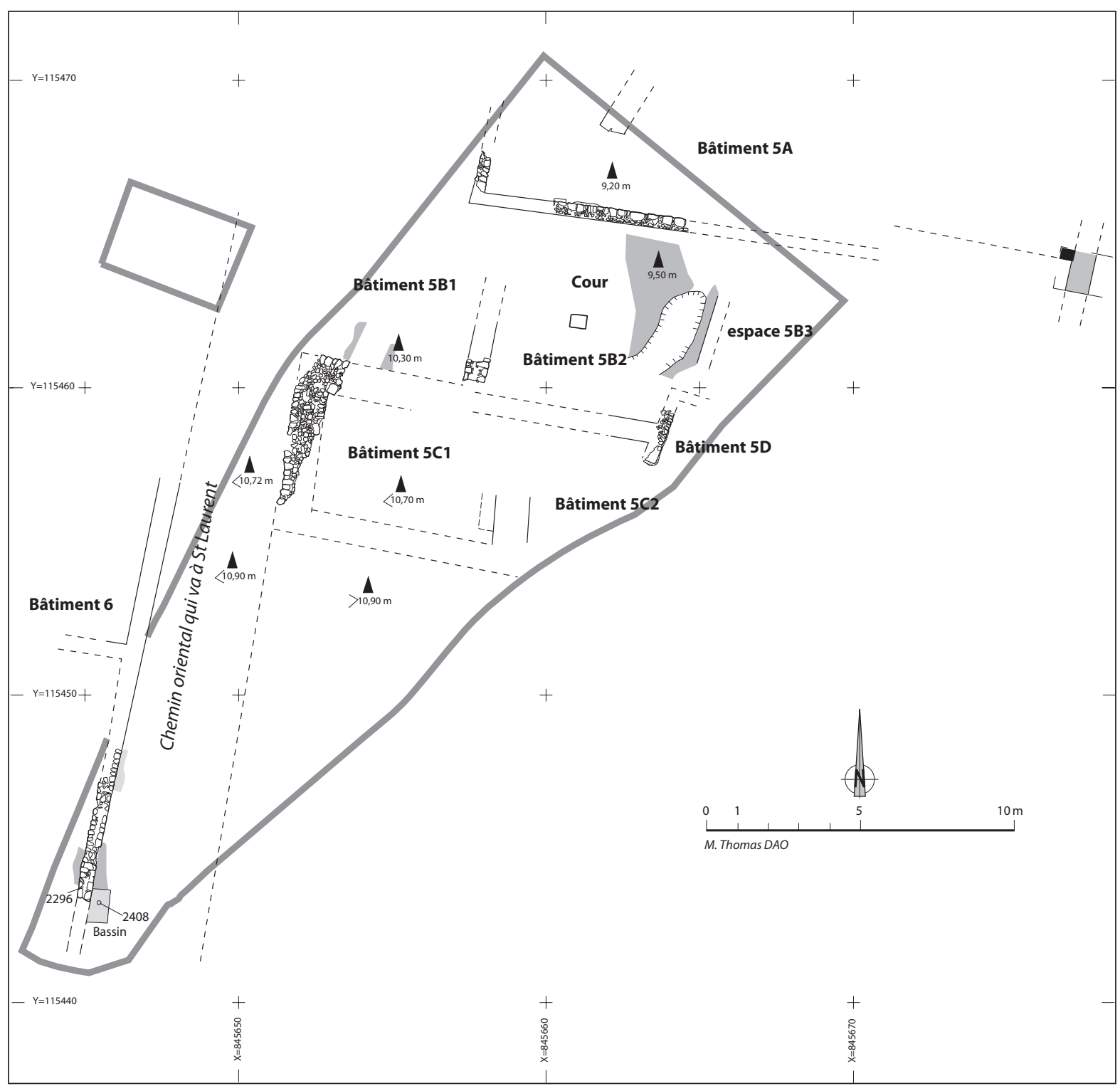

Fig. 125. L'habitat sur le flanc nord de la butte Saint-Laurent au XIIe s. (DAO M. Thomas/Inrap).

exceptionnel dont la destination nous échappe faute d'informations complémentaires dans les textes d'archives.

Le bâtiment $\mathbf{5 A}$ est situé au nord-est du chemin occidental qui va à Saint-Laurent. Il est implanté sur la terrasse la plus basse de la fouille ${ }^{494}$. La façade méridionale a été dégagée sur près de $10 \mathrm{~m}$ de long, mais se prolonge au-delà. Les murs, largement épierrés et arasés jusqu'en fondation, sont composés d'éléments pétrographiques divers (calcaires, grès poudingue et travertins) liés à la terre ; ce type de construction est courant durant la période médiévale à Marseille ( $c f$. supra $\S \mathrm{I}, 3,1.1$.). Un mur de direction nord-est/sud-ouest, hérité de la

494 L'altitude de la première assise d'élévation des murs, à l'intérieur du bâtiment, se situe entre 9,10 et 9,20 m NGF.

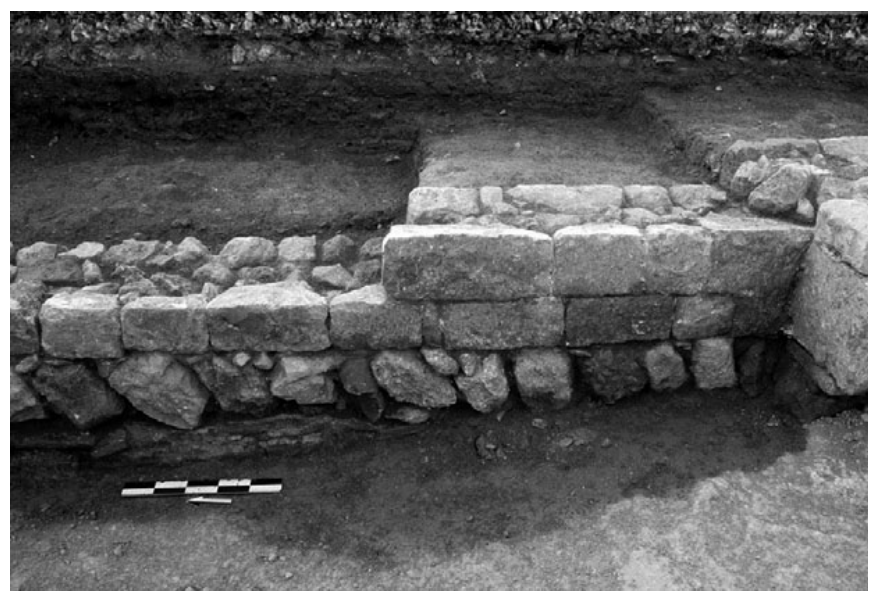

Fig. 126. La façade orientale du bâtiment 6 (cl. F. Parent/Inrap). 
phase antérieure, semble servir de mur de refend dans le bâtiment médiéval. Il ne se développe pas jusqu'à la façade méridionale, ménageant ainsi un passage d'environ $2,50 \mathrm{~m}$ entre une pièce orientale et une pièce occidentale. Le sol n'est pas conservé.

La parcelle à l'arrière du bâtiment $5 \mathrm{~A}$ est une longue lanière de terrain délimitée au nord et au sud par les façades des bâtiments 5A et 5C. Elle est scindée par deux murs nord-sud en trois espaces difficiles à caractériser. À l'ouest, un mur de moellons calcaires liés au mortier, sépare le bâtiment 5B1 de l'espace 5B2; à l'est, un mur étroit ${ }^{495}$ constitué de briques de terre crue et daté du XII ${ }^{e}$ s. isole l'espace 5B2 d'un espace ouvert (espace 5B3). Cette technique de construction est exceptionnelle au Moyen Âge à Marseille dont c'est le seul exemple connu à ce jour. Ce mur semble présenter une orientation légèrement divergente par rapport aux autres murs ; il est difficile cependant de l'affirmer car il n'a été que très partiellement observé.

La limite ouest du bâtiment 5B1 est hors emprise. Deux lambeaux de sols de terre battue ont été observés ${ }^{496}$. L'espace 5B2 ${ }^{497}$ présente des sols successifs de terre battue dont les surfaces sont irrégulières et sont $1 \mathrm{~m}$ plus bas que le sol du bâtiment 5B1. Ces niveaux sont datés des $\mathrm{XII}^{\mathrm{e}}-\mathrm{XIII}{ }^{\mathrm{e}} \mathrm{s}$. Cet espace est donc en contrebas du bâtiment 5B1, ce qui est contraire à la pente générale du terrain; en revanche, il est à la même altitude que l'espace oriental 5B3 qui est certainement un espace ouvert. Le mur de terre crue est vraisemblablement un muret non porteur qui ne constitue qu'une limite de propriété. L'espace 5B2 est limité sur trois côtés par des murs maçonnés. Un support se situe au centre de l'espace; il a pu servir de fondation à un pilier de pierre ou de bois lui-même support d'auvent, ou bien constituer le soubassement à une installation artisanale. L'espace 5B3, quant à lui, pourrait déboucher soit sur un autre bâtiment, soit sur une place, soit sur une voie (qui se situerait à peu près sous l'actuelle rue Miradou).

Le bâtiment 5C, situé au sud de la cour, est parallèle au bâtiment $5 \mathrm{~A}$. L'édifice mesure $12 \mathrm{~m}$ sur $6 \mathrm{~m}$ au minimum. Au nord et à l'ouest, deux larges murs liés à la terre ${ }^{498}$ chaînés entre eux sont partiellement conservés en fondation. L'axe de la façade méridionale était certainement à l'emplacement du mur médiéval de la phase suivante. À l'est, la limite semble être formée par un autre édifice, le bâtiment 5D. Un cloisonnement à l'intérieur du bâtiment $5 \mathrm{C}$ n'est conservé que par la tranchée d'épierrement et la semelle de fondation en mortier avec

495 Sa largeur est de $0,45 \mathrm{~m}$.

496 Ils se situent à 10,30 m NGF.

$497 \mathrm{Il}$ mesure $24 \mathrm{~m}^{2}$.

498 Ils mesurent 1,10 et $1,20 \mathrm{~m}$ de large. l'empreinte des gros blocs de la première assise ${ }^{499}$. Lui est liée une structure bâtie de 0,50 sur $0,80 \mathrm{~m}$, également repérée par la semelle de fondation de mortier ; il s'agit d'un support, peut-être d'un contrefort, ou simplement de la base d'un emmarchement. Il est possible que ces structures soient héritées d'une phase précédente. La largeur des murs de cette construction, supérieure à $1 \mathrm{~m}$, laisse imaginer une solide construction à étages. Le bâtiment 5C n'a pas livré de sol du fait des dérasements ultérieurs, mais ils sont au moins $0,40 \mathrm{~m}$ plus hauts que celui du bâtiment 5B1.

Le bâtiment 5D n'est perçu que par un mur nordnord-est/sud-sud-ouest et un retour supposé : le niveau intérieur de ce bâti est $1 \mathrm{~m}$ plus haut que celui de l'espace $5 \mathrm{~B} 2$ qui le borde au nord. Son orientation est légèrement divergente par rapport à la trame des autres constructions. Ce n'est pas un phénomène isolé car le mur de terre crue est également divergent. Ces pièces sont peut-être orientées vers un autre axe de circulation à l'est, éventuellement la rue Miradou qui est hors emprise de la fouille. Cependant cette rue n'est pas attestée par les archives pour cette époque.

Les quelques datations recueillies pour les deux bâtiments situent les structures dans l'Antiquité tardive ou plus vraisemblablement aux $\mathrm{X}^{\mathrm{e}}-\mathrm{XI}^{\mathrm{e}}$ s. Elles sont recoupées par les vestiges du XIII' $s$.

$\mathrm{Au}$ sud, les dérasements modernes ont tout détruit, les murs y compris, jusqu'aux niveaux de l'Antiquité tardive ; les niveaux médiévaux étaient donc plus hauts, soit au-dessus de 10,90 m NGF.

\subsection{L'habitat au XIII' ${ }^{\mathrm{e}}$.}

Au XIII ${ }^{e}$ s., le paysage est toujours marqué par le cimetière. Au sud de la rue Four-du-Chapitre, l'habitat se développe avec la construction de deux bâtiments en façade (bâtiments 4 et $3 \mathrm{~A}$ ) et un bâtiment à l'arrière de l'îlot (3B). Au pied de la butte Saint-Laurent, les constructions ne sont que partiellement modifiées.

\subsubsection{La densification du bâti au sud de la rue Four-du-Chapitre}

Si au nord de la rue Four-du-Chapitre l'espace devient ouvert et libre de constructions, au sud de la rue, les terrains sont progressivement bâtis au XIII' s. (fig. 127). Deux bâtiments, sans doute des habitations, sont édifiés le long de la rue et une maison est construite en retrait dans l'îlot au cours de la seconde moitié du XIII ${ }^{\mathrm{e}} \mathrm{s}$. Les bâtiments 4 et $3 \mathrm{~A}$ sont construits sur des remblais datés

499 Il mesure $1,05 \mathrm{~m}$ de large. 


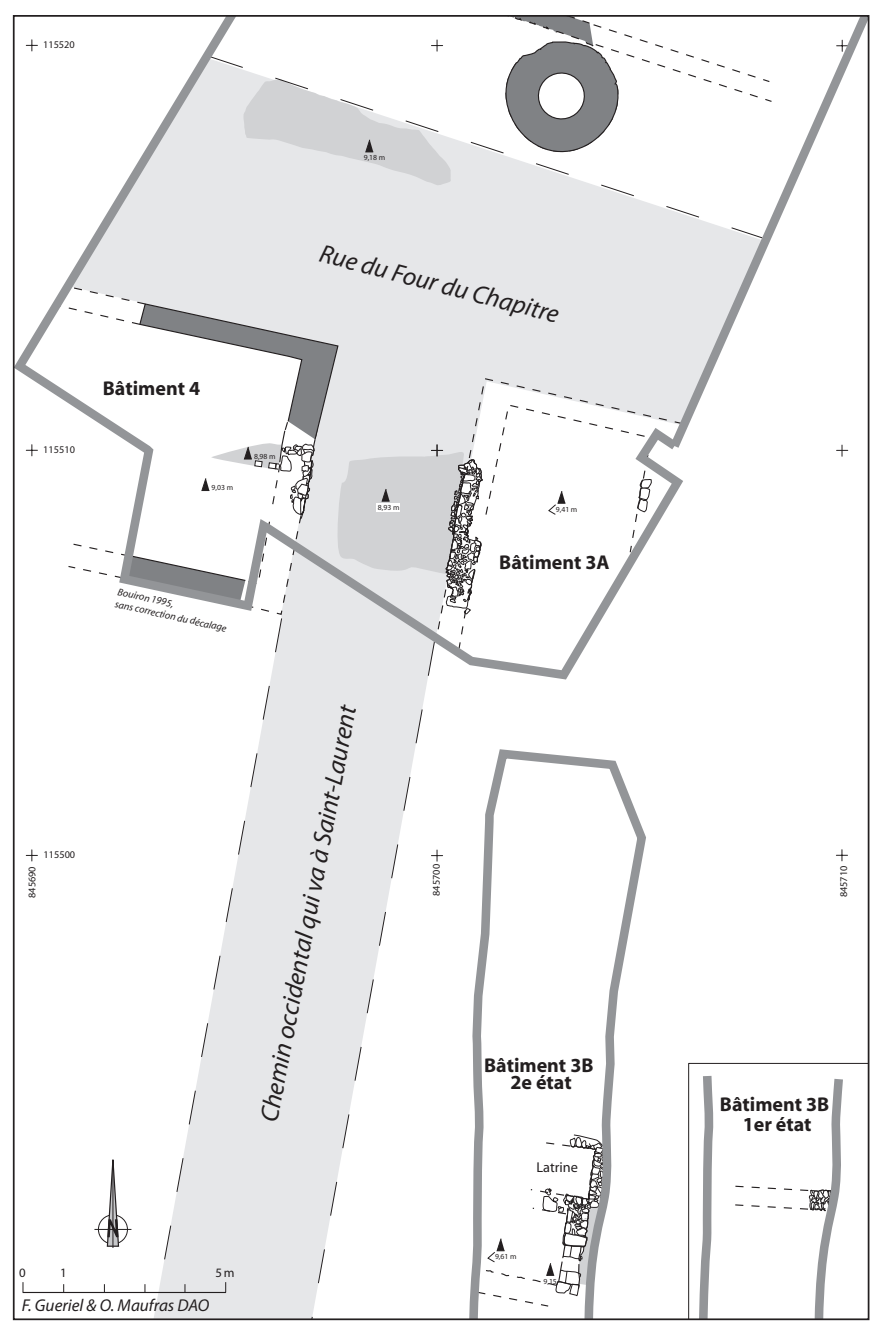

Fig. 127. L'habitat de part et d'autre de la rue Four-du-Chapitre au XIII' s. (DAO F. Guériel, O. Maufras/Inrap).

des X-XII ${ }^{\mathrm{e}}$ s. de part et d'autre d'un espace ouvert qui peut correspondre à l'extrémité d'une rue perpendiculaire à la rue Four-du-Chapitre : le chemin oriental qui va à Saint-Laurent (voie VI).

Le bâtiment 4 est à l'angle sud-ouest des rues et le bâtiment 3A à l'angle sud-est. L'angle nord-est du bâtiment 4, dégagé partiellement dans le cadre de diagnostics (Bouiron et al. 1995), présente une façade sur rue au nord, une façade à l'est et un mur au sud. La construction a été observée sur 4,50 m d'est en ouest sur 6,80 m. Son extension complète déborde l'emprise du tracé du tunnel. Son mode de construction est hétérogène. La façade nord et celle du mur oriental ont été traitées différemment de celle du sud. Les premiers ont deux assises de fondation de blocs équarris liés à la terre (respectivement larges de 0,55 et 0,45 m), et une assise d'élévation de moellons de calcaire à peine plus étroite soigneusement parementée, également liée à la terre. Le mur méridional, fondé plus profondément $(1,10 \mathrm{~m}$, large de $0,60 \mathrm{~m})$ est lié au mortier (Bouiron et al. 1995, p. 36). À l'intérieur du bâtiment, plusieurs niveaux fins d'occupation se situent à l'ouest du mur oriental. Une couche de cendre de $5 \mathrm{~cm}$ d'épaisseur maximale, datée du XIII ${ }^{\mathrm{e}}$ s., sert de lit de pose et de niveau d'assainissement au sol. Ce sol épais de $2 \mathrm{~cm}$ est composé d'une chape de chaux sur $1 \mathrm{~cm}$ et de terre battue sur l'autre centimètre. Il est surmonté de deux recharges compactes limoneuses sableuses avec quelques tuiles et cailloutis, daté du XIII' $\mathrm{s}$.

Le bâtiment 3A fait face au précédent, de l'autre côté du chemin oriental qui va à Saint-Laurent (voie VI). Seuls deux murs parallèles orientés nord-sud et de construction soignée subsistent : celui de la façade donnant sur la voie, et celui d'un mur de refend ou d'une façade orientale. La construction observée sur 5,50 m de long (d'est en ouest) et $4 \mathrm{~m}$ de large (soit une superficie de $22 \mathrm{~m}^{2}$ ) n'a conservé aucun sol. Le mur de façade, massif, atteint $0,85 \mathrm{~m}$ de large en fondation (mais celleci se limite à une assise de pierres sur un hérisson de fragments de tuiles) et $0,70 \mathrm{~m}$ en élévation. Des moellons de calcaire de taille variable, bruts ou équarris, liés avec du limon forment un double parement régulier. Le mur à l'est conserve $0,50 \mathrm{~m}$ de largeur, mais son parement oriental a disparu; il emploie dans la fondation conservée des matériaux disparates: galets et pierres calcaires taillées.

Le bâtiment, installé sur une terrasse, surplombait le bâtiment 4 d'au moins 0,43 m. Les aménagements modernes ont arasé la construction. L'espace, entre les bâtiments, large d'environ 3,10 m est considéré comme le chemin oriental qui va à Saint-Laurent (voie VI). C'est un niveau horizontal (l'altitude supérieure est à 8,93 m $\mathrm{NGF}$ ), épais de $10 \mathrm{~cm}$, qui recouvre la tranchée de fondation et remonte légèrement contre la première assise d'élévation de la façade occidentale du bâtiment oriental (3A). Ce niveau limoneux sableux gris avec quelques fragments de mortier de chaux est daté par la céramique des XII ${ }^{\mathrm{e}}$-XIII' $\mathrm{e}$.

La maison 3B, en retrait dans l'îlot, est construite au XIII $^{\mathrm{e}} \mathrm{s}$. à une vingtaine de mètres au sud des bâtiments 4 et $3 \mathrm{~A}$, entre le chemin oriental qui va à Saint-Laurent (voie VI) et la rue de l'Aumône auxquelles elle semble être perpendiculaire. Comme les précédentes, elle est largement hors emprise et en partie détruite par les constructions modernes. Les deux pièces, partiellement dégagées, ne permettent pas de saisir le plan d'ensemble de la bâtisse, ni de restituer le tracé exact de la rue de l'Aumône.

Deux états sont perceptibles. Le premier est représenté par un mur est-ouest qui recoupe une fosse antérieure $\left(\mathrm{X}^{\mathrm{e}}-\mathrm{XII}{ }^{\mathrm{e}} \mathrm{s}\right.$.). Ce mur imposant, large de $0,70 \mathrm{~m}$, peut-être un mur de façade, conserve quatre assises de fondation et cinq assises d'élévation. La maçonnerie est faite de moellons et de blocs retouchés de matériaux disparates 
(calcaire rose de La Couronne, tuf, grès, calcaire tendre, poudingue) disposés en deux parements avec un blocage interne d'éclat de pierre et de tuiles, le tout lié à la terre. La présence de mortier sur certains blocs montre qu'ils sont en remploi.

Le second état marque l'abandon du mur et la construction d'une latrine par dessus. Chaque mur de la latrine n'est formé que d'un seul parement orienté vers l'intérieur de la structure ; l'espace entre le parement et le creusement est comblé de pierres de tailles diverses. Le comblement de la structure est composé de limons sableux brun foncé contenant de la cendre, de nombreux charbons de bois, de rares cailloutis et des traces de plâtre rose. Les apports organiques du sédiment permettent d'identifier une latrine. Au sud de celle-ci, des éléments de maçonnerie conservés permettent de restituer deux pièces, l'une à l'ouest de l'autre, limitées au sud par un mur de façade ou de refend.

La pièce occidentale, particulièrement étroite, est dégagée sur $10 \mathrm{~m}^{2}$ : le mur méridional a été largement épierré et le mur occidental est hors emprise. Le mur oriental, mieux conservé, est percé d'une porte avec un seuil aménagé $(0,93$ x 0,40-0,50 m) pour accéder à la pièce voisine. Le sol a disparu, du fait d'un décaissement moderne. Le substrat présente dans ce secteur une remontée prononcée vers l'est où il culmine à 9,61 m NGF. Ceci indique une altitude supérieure du sol médiéval. La pièce est donc surélevée par rapport au seuil, situé à 9,15 m NGF. Il ne reste rien de l'emmarchement nécessaire pour rattraper la différence de niveau. Une feuillure à l'ouest des piédroits constitue la trace d'un vantail de porte ouvrant à l'est.

La pièce orientale n'a été observée que sur une petite superficie. Le substrat, retaillé horizontalement, est couvert par une fine couche d'argile damée qui forme le sol. La présence de petits charbons et de cendres qui noircissent la surface donnent l'impression d'une occupation domestique. La pièce est en contrebas de sa voisine à l'ouest, d'une cinquantaine de centimètres au moins puisque son sol est à 9,06 m NGF. Ainsi, la construction est étagée suivant le sens du pendage naturel.

La maison 3B est homogène : ses murs sont chaînés les uns aux autres et pareillement bâtis de matériaux disparates liés à la terre. Elle est datée de la seconde moitié du XIII ${ }^{\mathrm{e}} \mathrm{s}$. par la céramique et une monnaie retrouvées dans le sol de la pièce orientale.

\subsubsection{L'évolution du bâti sur la butte Saint-Laurent au $X I I I^{e} s$.}

Le bâtiment 6 ne conserve pas trace de son évolution au XIII ${ }^{\mathrm{e}}$ s., mais pas de témoin non plus de son abandon : il semble bien perdurer tel quel (fig. 128).
En revanche, l'espace interne du bâtiment $5 \mathbf{A}$ est détruit jusqu'aux couches de l'Antiquité tardive et c'est à cette occasion que le mur antique qui subsistait dans la pièce est arasé ainsi que probablement les premiers sols médiévaux. Deux remblais d'une dizaine de centimètres d'épaisseur chacun sont rapportés, puis recoupés par l'installation d'une nouvelle cloison nord-sud, conservée sur une assise de fondation et constituée de moellons retouchés de calcaire liés à la terre. Le mur ${ }^{500}$ est interrompu au sud avant le mur de façade pour ménager un espace de 0,80 m de large qui correspond à une ouverture. Au nord, la cloison s'appuie sur la fondation de l'ancien mur arasé et couverte par le sol de chantier, formant ainsi un autre passage. Ces remaniements sont datés de la seconde moitié du XIII' ${ }^{\mathrm{e}}$ s. De part et d'autre de la cloison, deux lambeaux de sols de mortier fin et blanc ont été mis au jour ; ce sont certainement les surfaces de chantier. Elles sont surmontées d'une seconde couche de mortier, partiellement conservée. Ces sols ont une surface relativement plane. Dans la pièce orientale, un foyer de 0,50 sur $0,40 \mathrm{~m}$ a été observé à proximité de la cloison ; il est formé d'une surface rubéfiée et constellée de cendres et de charbons, sans aménagements. Quelques fragments de corail ont été découverts dans le sol de cette pièce.

Le bâtiment 5B1 perdure peut-être tel qu'il était au XII ${ }^{\mathrm{e}}$ s. Sa limite avec l'espace 5B2 est arasée à une date mal définie, et aucun vestige ne peut être attribué à cette période.

Entre les espaces 5B2 et $\mathbf{5 B 3}$ est construit un mur de direction nord-est/sud-ouest de 0,65 m de large, soit également divergent vers l'est par rapport aux autres constructions. Son contact avec les bâtiments $5 \mathrm{~A}$ et $5 \mathrm{C}$ n'est pas conservé. Le parement ouest est couvert d'un enduit de mortier de chaux lissé qui s'interrompt horizontalement à hauteur de la première assise d'élévation. Il est vraisemblable que cet espace ouvert ou semiouvert est alors fermé en un bâtiment. Un sol de terre s'appuie aux deux murs au niveau de la base des enduits. Il est surmonté d'un niveau de cailloutis et d'une lentille de charbon de bois et de cendres indiquant un feu occasionnel. Le sol présente un pendage vers le nord. Ces couches témoignent d'une occupation continue entre la fin du XII ${ }^{e}$ et tout le $\mathrm{XIII}^{\mathrm{e}}$ s., sans que celle-ci puisse être caractérisée. Ces couches contiennent des déchets de corail.

L'espace 5B3 est vierge de construction à la fin du XII et au tout début du XIII ${ }^{\mathrm{e}}$ s. : l'occupation est simplement marquée par le creusement de quelques fosses dont la fonction n'est pas définissable et par des

$\mathbf{5 0 0}$ Il mesure $0,55 \mathrm{~m}$ de large. 


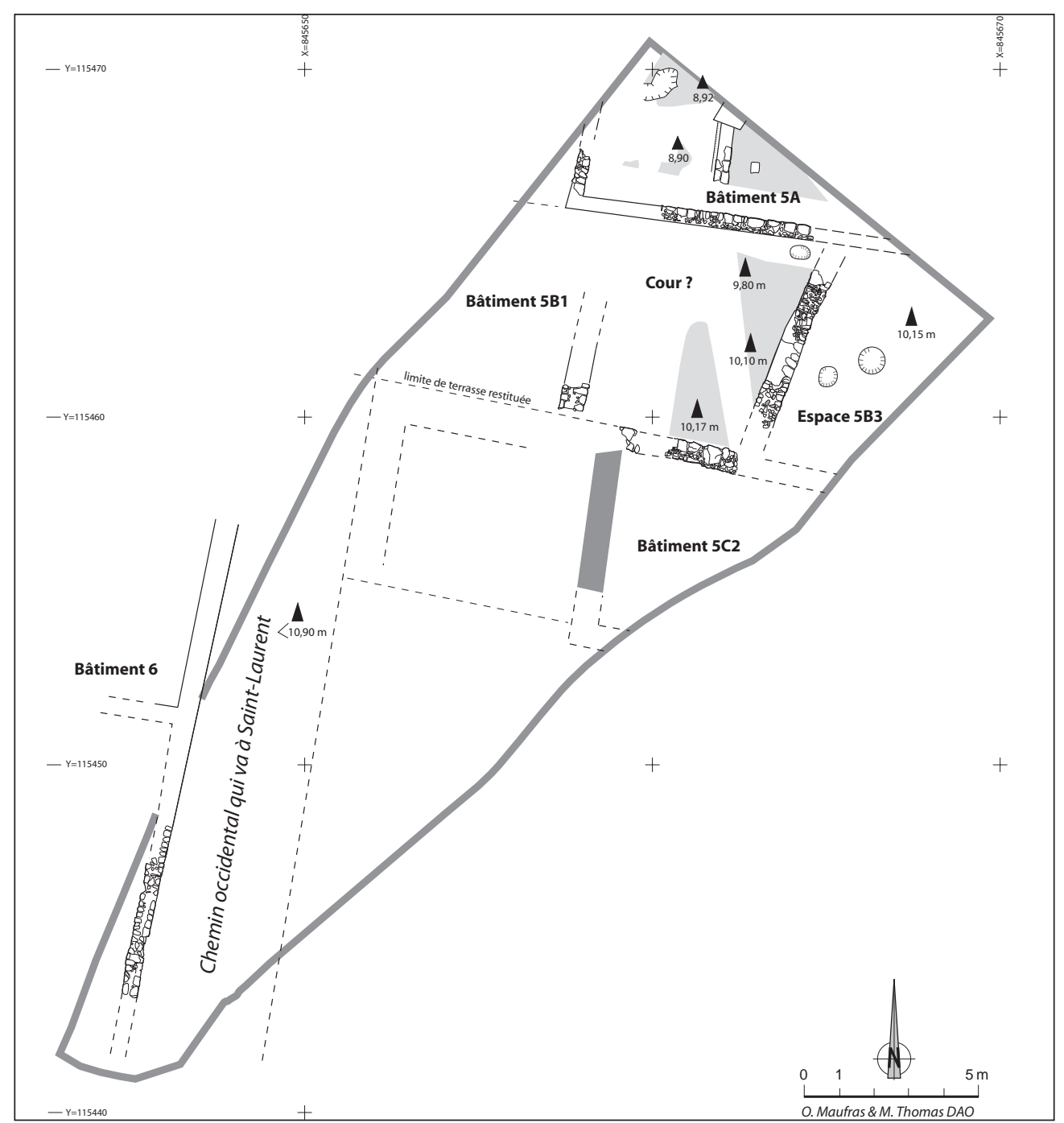

Fig. 128. L'habitat sur le flanc nord de la butte Saint-Laurent dans la première moitié du XIIIle S. (DAO O. Maufras, M. Thomas/Inrap).

remblais successifs peu épais et diversement étendus. L'espace semble toujours fonctionner comme une zone ouverte vers l'est.

Dans le courant de la seconde moitié du XIII ${ }^{\mathrm{e}} \mathrm{s}$. (fig. 129), l'espace entre les bâtiments $5 \mathrm{~A}$ et $5 \mathrm{C}$ reste à peu près identique. Néanmoins, le mur séparant les espaces 5B2 et 5B3 est détruit puis le terrain est remblayé par des couches datées du milieu et de la seconde moitié du XIII' s. qui contiennent également des déchets de corail. Un nouveau mur, d'une direction plus conforme à l'orientation du bâti de l'îlot, est ensuite installé dans une tranchée de fondation qui perce ces remblais. Il est constitué de blocs et moellons régulièrement assisés et enduit de mortier blanc sur son parement ouest. En revanche aucune trace d'un mur de façade occidental ne subsiste ; l'espace est peut-être ouvert, ou sa limite est en bordure de rue à l'ouest, hors emprise du chantier. L'espace 5B2 reçoit alors un remblai puis un sol qui remonte à l'est et au sud sur les murs et présente toujours une pente vers le nord-ouest. Il est assez régulier et se compose d'une surface de mortier de chaux parfois en gros nodules. Cet espace est par la suite abandonné ; une couche de sables, limons et de mortier de chaux qui provient certainement de la dégradation de l'enduit des murs, est surmontée de deux remblais contenant des éléments de construction (blocs, fragments de tuiles, cailloutis et enduit). Ces deux couches coïncident certainement avec la récupération des matériaux des élévations des murs avant épierrement des parties enfouies.

La plupart des couches du bâtiment 5A et de l'espace $5 \mathrm{~B} 2$ ont livré des déchets de corail. Ce ne sont pas les rejets d'un travail artisanal, mais des débris qui proviennent certainement d'un tri avant vente du corail à des 


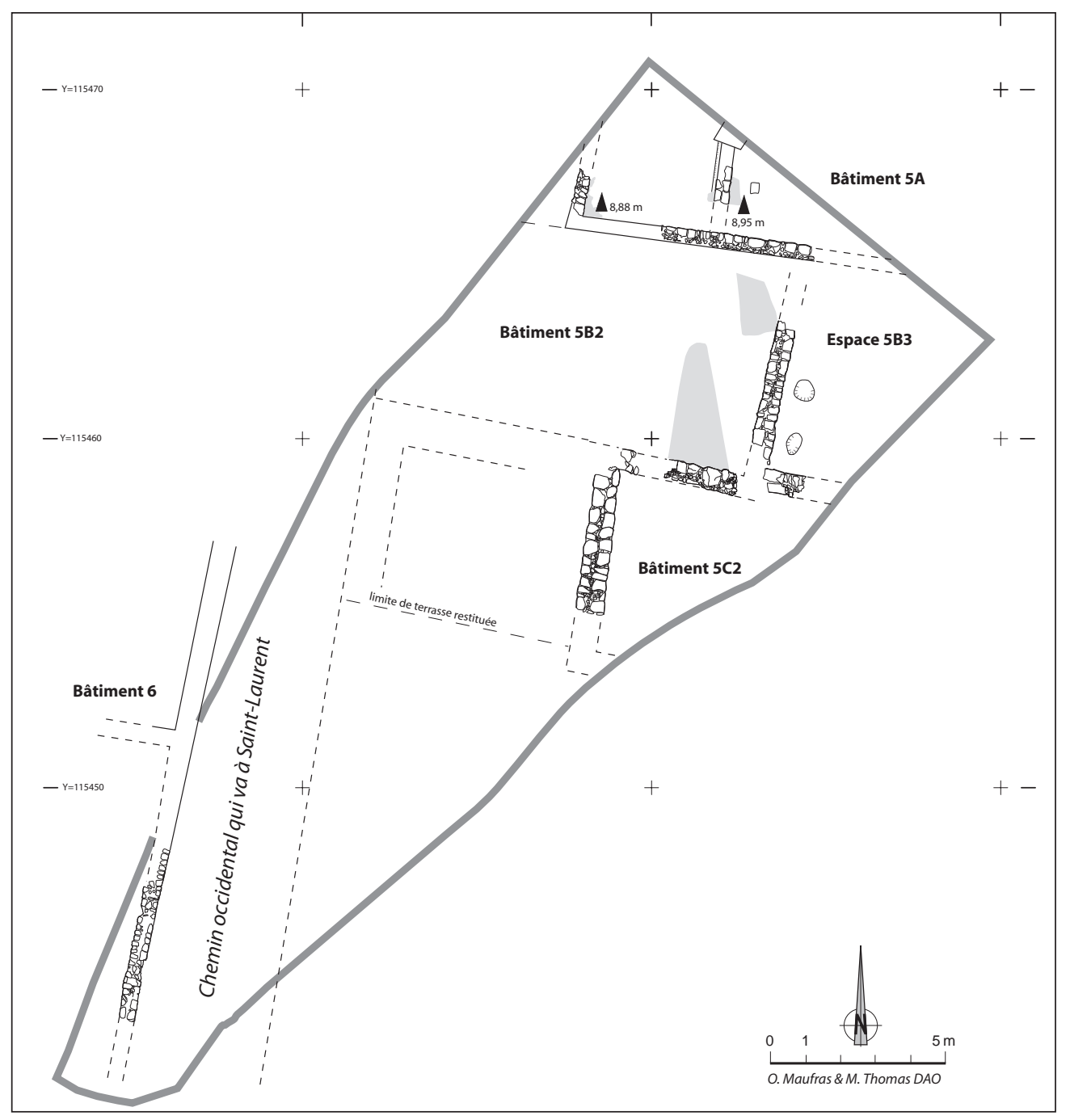

Fig. 129. L'habitat sur le flanc nord de la butte Saint-Laurent dans la seconde moitié du XIII $\mathrm{S}$.

(DAO O. Maufras, M. Thomas/Inrap).

ateliers de joaillerie ( $c f$. supra $\S \mathrm{I}, 3,1.1$.$) . Quelques-$ unes de ces couches ont livré du mobilier du XIII ${ }^{\mathrm{e}} \mathrm{s}$.

Le bâtiment 5D est rasé au XIII' ${ }^{\mathrm{s}}$ s. et le bâtiment $5 \mathrm{C}$ est reconstruit. Le dérasement moderne du terrain jusqu'aux niveaux du $\mathrm{XII}^{\mathrm{e}} \mathrm{s}$. ne permet pas de comprendre à quel moment sont détruits les deux gros murs nord et ouest du bâtiment $5 \mathrm{C}$; il n'est donc pas possible de conclure si la pièce $5 \mathrm{C} 1$ existe encore. Trois nouveaux murs redessinent la pièce $5 \mathrm{C} 2$ qui mesure au moins $6 \mathrm{~m}$ sur 4,80 m. La façade septentrionale est alors constituée de deux murs de part et d'autre de l'axe du mur qui forme la limite entre l'espace 5B2 et l'espace oriental 5B3. Les murs ne sont, ni exactement alignés l'un avec l'autre, ni de même facture. Le tronçon ouest, bâti comme un mur de terrasse, est constitué de blocs de calcaire, grès et travertin liés à la terre, et est recouvert d'un enduit sur son parement nord. Le second tronçon ne se compose que de calcaire. La liaison entre ces deux pans de mur et le mur de l'espace 5B2 n'est pas conservée de sorte que la chronologie relative de leurs installations n'a pas pu être établie. Un mur de direction nord-sud est bâti en retour vers le sud formant la limite ouest de la pièce $5 \mathrm{C} 2$. Il est construit en blocs bruts ou retouchés de calcaire, de grès, de travertin et de poudingue, liés à la terre. Il est rapidement remplacé par un autre mur qui surmonte son arasement, bâti avec des matériaux similaires. Aucun sol ni aucun remblai de cette phase n'est conservé.

\subsection{L'habitat de la fin du XIII' ${ }^{\mathrm{e}}$ s. et du $\mathrm{XIV}^{\mathrm{e}} \mathrm{s}$.}

Dans la partie nord, l'occupation à la fin du XIII ${ }^{\mathrm{e}}$ et $\mathrm{au} \mathrm{XIV}^{\mathrm{e}}$ s. est similaire à celle de la phase antérieure, sauf au sud-est de la cathédrale où elle se développe avec la construction de maisons réduisant l'emprise du cimetière (fig. 130). L'habitat mis en place est celui du 


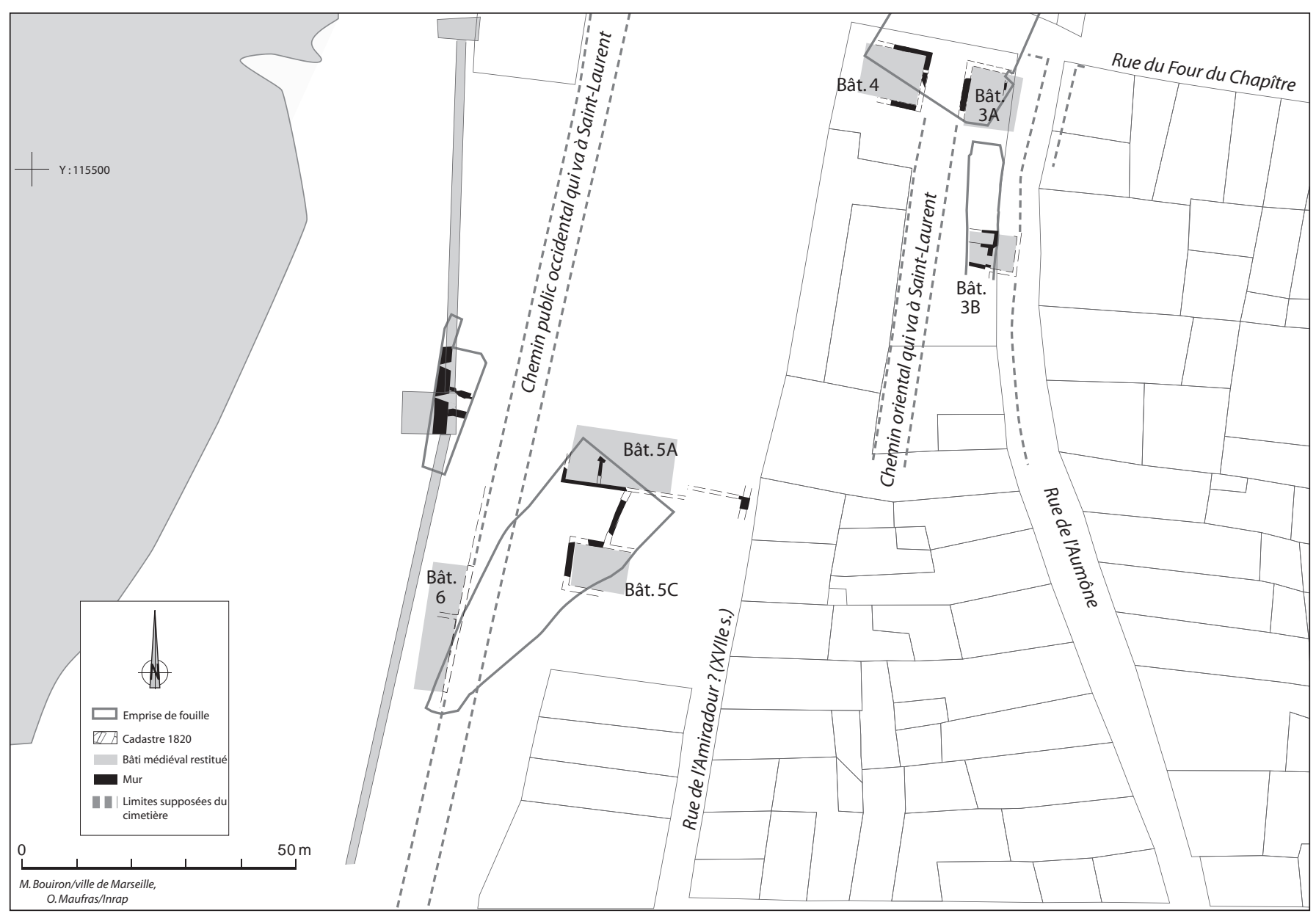

Fig. 130. L'habitat au XIVe s. (DAO M. Bouiron/Ville de Nice, O. Maufras/Inrap).

clergé. Une maison, identifiée comme la maison canoniale, est également construite à cette période ${ }^{501}$. Au sud, le bâti devient plus clairsemé puis une place est créée.

\subsubsection{Au sud de la rue Four-du-Chapitre}

Au sud de la rue Four-du-Chapitre, les bâtiments 4, $3 \mathrm{~A}, 3 \mathrm{~B}$ perdurent jusqu'à l'Époque moderne, au cours de laquelle ils feront l'objet de transformations. Aucune modification n'est perceptible pour le XIV ${ }^{\mathrm{e}} \mathrm{s}$.

\subsubsection{Le recul du bâti sur la butte Saint-Laurent}

Le bâti du pied de la butte Saint-Laurent est progressivement démonté à partir de la fin du XIII" s. (fig. 131). C'est entre 1320 et 1330 qu'est construit le rempart occidental qui longe la mer; il ne sera détruit qu'au XIX ${ }^{\mathrm{e}} \mathrm{s}$. (Bouiron, De Luca 1994).

501 Celle-ci fera l'objet d'une publication ultérieure dans le cadre du volume sur le groupe cathédral.
Le long bâtiment 6, dont les niveaux du $\mathrm{XII}^{\mathrm{e}} \mathrm{s}$. sont directement surmontés par des décaissements du $\mathrm{XIX}^{\mathrm{e}}$ s., n'est pas documenté, mais on peut se poser la question de savoir si la construction du rempart n'a pas été l'occasion de sa destruction. La distance entre la façade orientale du bâtiment et le tracé supposé du rempart (Bouiron 2001c) est seulement de $5 \mathrm{~m}$, mais cela est peut-être suffisant pour que le bâtiment reste intact.

Les murs du bâtiment 5A sont épierrés, des matériaux récupérés, d'autres laissés sur place sur les sols d'occupation du XIII' s. Cette couche d'abandon, datée également du XIII ${ }^{\mathrm{e}}$ s., est directement recouverte par un remblai contenant des mobiliers du milieu du XIX ${ }^{\mathrm{e}} \mathrm{s}$. Au sud, certains murs existent encore au moins partiellement en élévation puisque le mur de direction nord-sud qui séparait l'espace 5B2 de l'espace 5B3 retient de part et d'autre une couche de démolition et le mur formant un retour oriental est arasé à une cote supérieure à celle de cette couche. Ici encore, les niveaux de démolition sont directement surmontés par des couches d'époques moderne et contemporaine. 


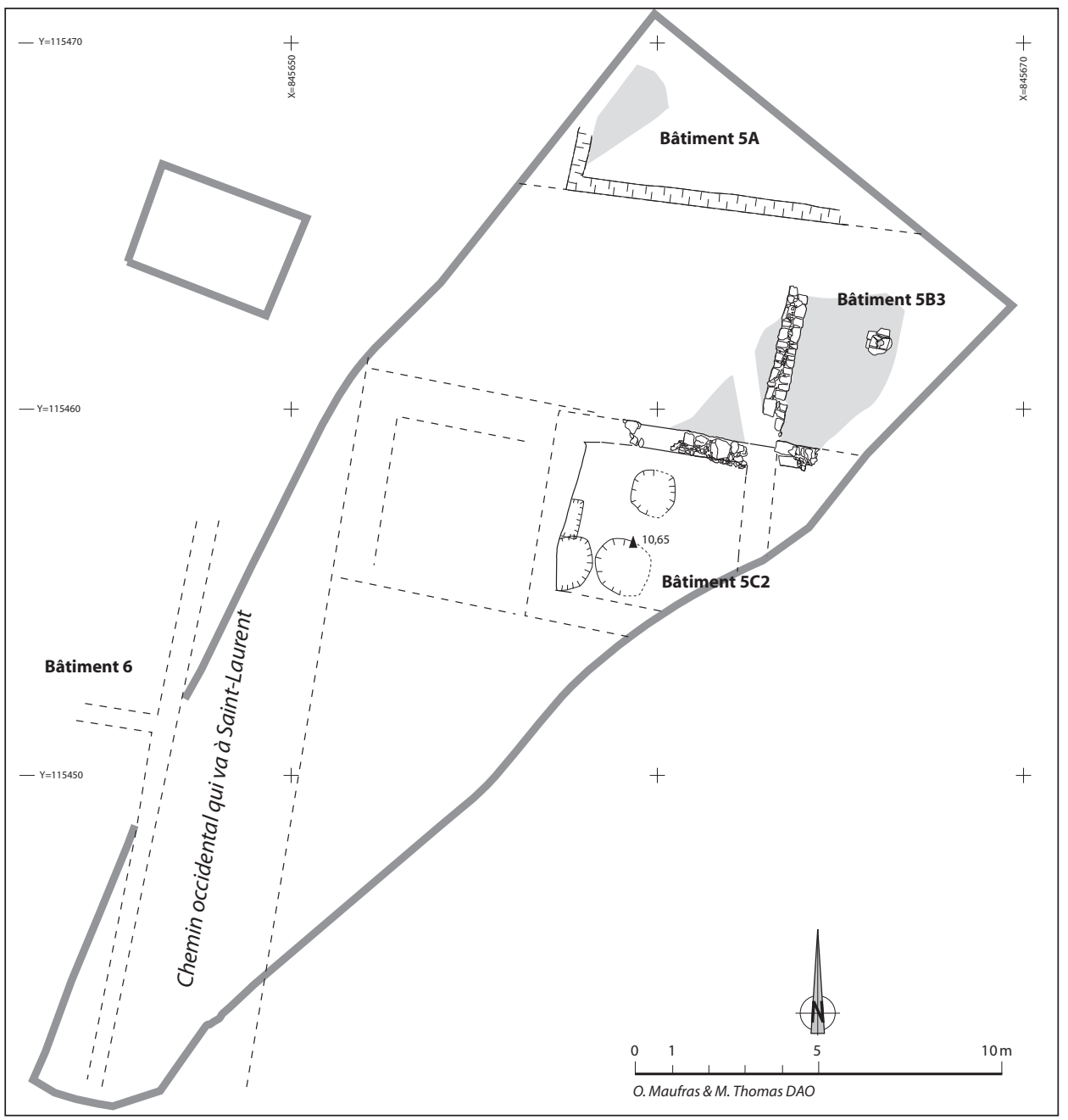

Fig. 131. Le recul progressif de I'habitat sur le flanc nord de la butte Saint-Laurent à la fin du XIIIe s. (DAO O. Maufras, M. Thomas/Inrap).

À la fin du XIII ${ }^{\mathrm{e}} \mathrm{s}$. ou au début du XIV $\mathrm{XI}^{\mathrm{e}}$ s., la façade occidentale de la pièce $5 \mathrm{C} 2$ fait l'objet d'une nouvelle transformation. Elle est abattue et son arase est recouverte par un remblai largement constitué des débris de la destruction de ses murs et de sa toiture (blocs, mortiers, enduit, tuiles). La nouvelle façade est érigée à l'ouest de la première (peut-être d'ailleurs antérieurement à son démontage pour limiter le temps où le bâtiment est resté découvert), agrandissant le bâtiment de $0,60 \mathrm{~m}$ vers l'ouest. Le mur nord existant est allongé vers l'ouest et un mur de façade méridionale est construit. À l'est, un mur ferme l'espace, qui a la forme d'une salle quadrangulaire, presque carrée de 2,30 sur 2,10 m. Les murs ont été largement épierrés ou détruits par les canalisations récentes ; on ne connaît donc pas la nature de leur maçonnerie. Le sol interne n'est pas conservé non plus, mais le remblai de démolition qui le supportait est percé de plusieurs fosses. Les trois fosses les plus anciennes sont circulaires; leur diamètre se situe entre 1,20 et $1,45 \mathrm{~m}$. Elles ne présentent aucun aménagement particulier et n'ont qu'une faible profondeur conservée, de 0,10 à 1,25 m. Même si les couches ont été tronquées sur plusieurs décimètres de profondeur, elles restent peu profondes. Elles ne correspondent donc pas à des silos mais au calage de structures, probablement des tonneaux ou des cuves en bois. Une quatrième fosse contemporaine est installée contre la façade occidentale ; elle est rectangulaire $(1,10$ sur $0,40 \mathrm{~m})$ et est aussi peu profonde $(0,10 \mathrm{~m})$. Elle a pu servir également à l'installation d'une structure. Les comblements d'abandon des fosses contiennent des matériaux de construction sans doute issus d'une démolition dont de nombreux morceaux d'argile rubéfiée ${ }^{502}$, des rejets de cuisine et de petit artisanat, métal, corail (peut-être issus des couches antérieures avoisinantes). Cette petite

502 Aucune trace de foyer ou de four n'a été retrouvée. 
pièce appartient certainement à un ensemble plus vaste, peut-être à vocation artisanale.

\subsubsection{La création de l'esplanade de la Tourette}

Par la suite, le bâti est entièrement détruit et une place est créée. Seule une structure maçonnée qui semble correspondre à un support a été retrouvée. Elle est constituée de blocs et dalles de calcaire liées au mortier et forme une base de 0,65 sur $0,75 \mathrm{~m}$ et $0,18 \mathrm{~m}$ de profondeur conservée. Cet aménagement est percé en son centre d'une ouverture de $16 \mathrm{~cm}$ de diamètre dont la paroi interne est cannelée d'entailles verticales. Ce trou central a pu servir au calage d'un poteau étroit ou d'une hampe. La date de la transformation de l'îlot en place intervient au plus tôt à la fin du XIII ${ }^{\mathrm{e}}$ s., date du rare mobilier retrouvé dans la structure elle-même, mais sûrement plus tardivement. La création d'un espace libre à l'arrière du rempart a pu sembler indispensable à la défense de la ville, peut-être pour rendre plus ardu le franchissement de la muraille. Par ailleurs, un texte de 1424 fait état du remboursement des avances faites « pour avoir fait terrasser la rive de la mer de l'est du siège à la Tourette ${ }^{\mathbf{5 0 3}}$. Donc la place semble bien avoir été créée avant cette date, soit à la fin du $\mathrm{XIV}^{\mathrm{e}}$ s. ou au tout début du XV $\mathrm{XV}^{\mathrm{e}}$ s., détruisant certainement les traces de l'habitat du XIV ${ }^{\text {e }}$ s. dont il ne nous est presque rien parvenu.

\subsection{Conclusion}

Les lacunes importantes, dues à la faible largeur du tracé du tunnel et aux perturbations modernes et contemporaines, ne permettent pas une vraie vision de la densité de l'habitat du Moyen Âge sur ce secteur de la ville. Cependant, aux $\mathrm{X}^{\mathrm{e}}-\mathrm{XII}^{\mathrm{e}}$ s. et au $\mathrm{XIII}^{\mathrm{e}}$ s., les espaces construits et espaces libres maillent le territoire vers le nord tandis que le bâti est assez dense au sud. À partir de la fin du XIII' ${ }^{\mathrm{e}} \mathrm{s}$ et début du XIV ${ }^{\mathrm{e}}$ s., l'habitat s'intensifie vers le nord, alors qu'il tend à reculer vers le sud. Est-ce la volonté de conserver des espaces libres à l'arrière des murs du rempart construit en 1320-1330 ou le désir de ménager un accès monumental à l'entrée sud de La Major, qui constitue l'entrée principale de la cathédrale, qui a incité à détruire le bâti dans la zone sud ? Les voies aussi bien celles héritées de l'Antiquité que celles nouvellement créées, convergent vers la cathédrale de La Major.

Les parcelles ne sont jamais complètes dans l'emprise du chantier; néanmoins quelques remarques peuvent être faites. Les largeurs lorsqu'elles sont perçues dans

503 Notaires, AD13 392 E 159 d'après B. Roberty (manquant au 19 octobre 2000) fol. 10v. leur intégralité sont comprises entre 4,50 et $6 \mathrm{~m}$, ce qui est conforme à la réception d'une poutraison. Ces dimensions sont supérieures à celles observées dans le bourg Sainte-Catherine (Bouiron 2001a), plus proches de $4 \mathrm{~m}$. Différents modules apparaissent, entre 4 et $7 \mathrm{~m}$ dans le bourg de Morier, entre 4 et $5 \mathrm{~m}$ et parfois même $8 \mathrm{~m}$ sous la place Villeneuve-Bargemon. Les maisons d'angle 4 et $3 \mathrm{~A}$ sont incomplètes. Les longueurs sont systématiquement incomplètes, mais supérieures à $10 \mathrm{~m}$, ce qui correspond à la longueur des parcelles médiévales retrouvées dans les chantiers cités ci-dessus (entre 10 et $16 \mathrm{~m}$, Paone 2005).

Le point commun avec les maisons des quartiers de faubourg est qu'elles ouvrent par le petit côté sur les voies de circulation. Ici, les ouvertures sur l'extérieur ne sont majoritairement pas conservées, mais la maison 3B ouvre sur la rue de l'Aumône par le petit côté et il doit en être de même pour les bâtiments 5A, 5B1 et $5 \mathrm{C}$ qui sont perpendiculaires au chemin occidental qui va à Saint-Laurent. Inversement la maison $2 \mathrm{~B}$, liée aux chanoines, ouvre sur la rue des Treize-Coins sur sa longueur et le bâtiment 6 sur la voie occidentale qui mène à Saint-Laurent. Cette disposition est plus rare mais peut s'expliquer par la position des constructions. Le bâtiment 6 est peut-être axé parallèlement à la voie car l'emplacement en bord de la falaise ne permettait pas da faire autrement ; le bâtiment $2 \mathrm{~B}$ est proche de la cathédrale et c'est peut-être volontairement que sa longue façade se développe sur la rue vers le chevet de l'église.

Les éléments structurants de l'architecture sont en pierre, à l'exception d'un mur en briques de terre crue dans l'îlot de la butte Saint-Laurent. Dans la partie sud du chantier, les murs sont tellement arasés et épierrés qu'il est difficile de définir de façon plus précise les matériaux de construction. Dans la partie nord du site, le matériau le plus utilisé est le calcaire blanc de SaintVictor, sous forme de blocs pour les fondations et de moellons équarris pour les élévations. Le liant varie suivant la nature de la construction et sa date : pour les fondations des $\mathrm{X}-\mathrm{XII}{ }^{\mathrm{e}}$ et $\mathrm{XIII}{ }^{\mathrm{e}}$ s., on utilise du mortier ou de la terre. Les élévations sont en revanche essentiellement liées à de la terre. À la fin du XIII' ${ }^{\mathrm{e}}$ s. ou au début du XIVe s., elles sont liées avec du mortier et les fondations avec de la terre ou du mortier. Les murs de façades ou de refend ont des largeurs remarquables, souvent supérieures à $0,80 \mathrm{~m}$. On peut penser qu'il s'agit de bâtiments à plusieurs étages même si aucun élément archéologique ne permet de le confirmer.

De manière générale, l'implantation du bâti autour de la cathédrale de La Major et au pied de la butte SaintLaurent est conforme à ce qu'était l'usage à Marseille au Moyen Âge. 
DEUXIÈME PARTIE : PRÉSENTATION DE QUELQUES QUARTIERS À LA LUMIÈRE DES FOUILLES ARCHÉOLOGIQUES

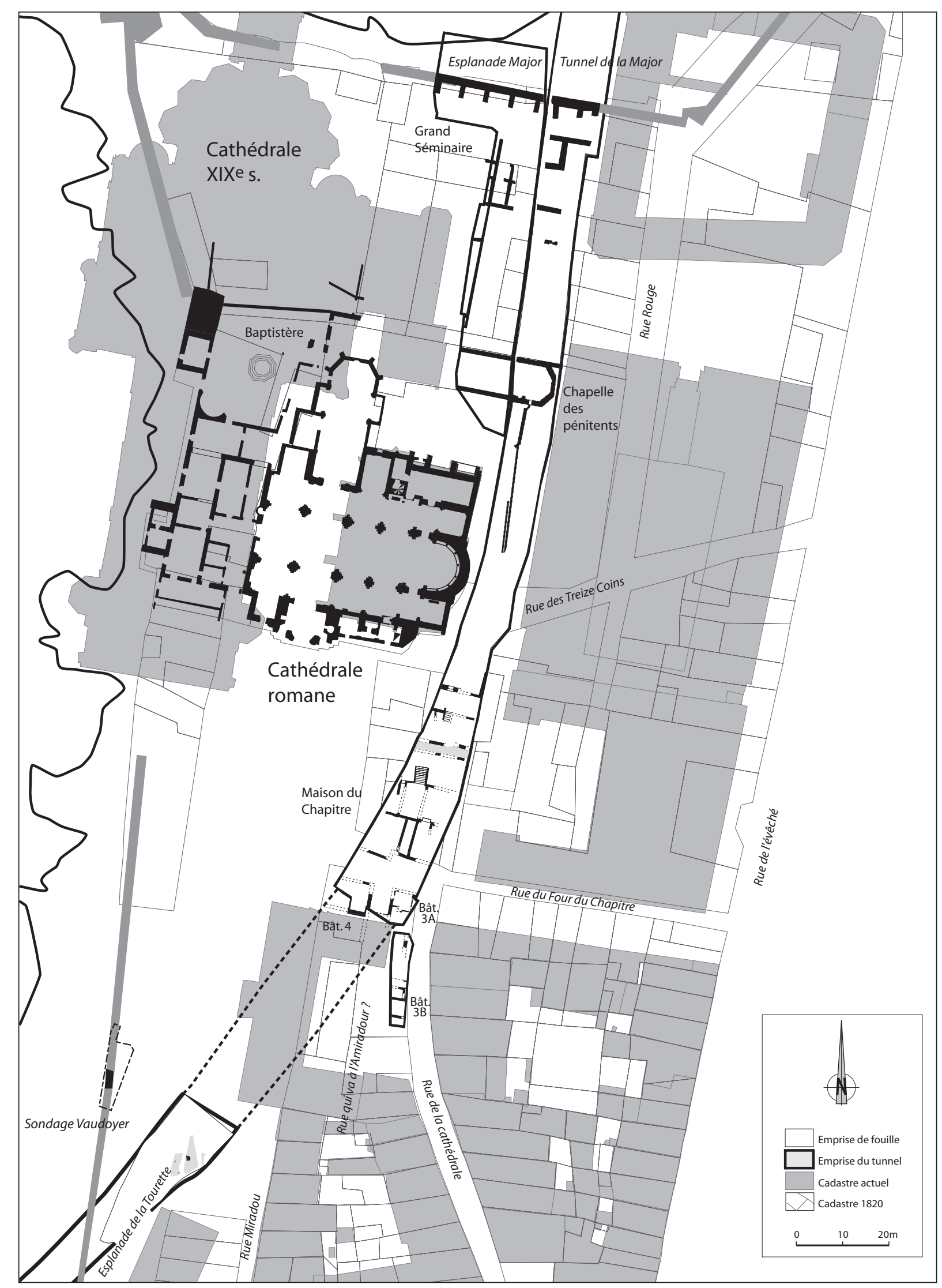

Fig. 132. Plan général des vestiges modernes et contemporains (jusqu'au milieu du XIXe $\mathrm{s}$.) (DAO M. Bouiron/Ville de Nice, O. Maufras/Inrap). 


\section{Les transformations durant la période moderne (N. Scherrer, N. Valour) ${ }^{504}$}

Jusqu'au XIX ${ }^{e}$ s., le quartier de la Major est fermé au nord et à l'ouest par le mur d'enceinte de la ville (fig. 132). Avec le temps, ces ouvrages se détériorent et la documentation écrite rend compte des problèmes posés par la dégradation progressive des murs et des besoins récurrents de travaux de consolidation. Un mur de soutènement de la falaise a été mis au jour à l'extrémité nord du chantier. Le maillage des rues subit quelques modifications de tracé et de nouvelles rues sont créées.

Le quartier de la Major reste religieux au début du $\mathrm{XVII}^{\mathrm{e}} \mathrm{s}$. La chapelle de la confrérie des Pénitents blancs de Saint-Lazare est édifiée dans le cimetière (elle ne sera pas traitée dans ce volume mais dans celui du groupe cathédral). Les textes attestent l'implantation religieuse jusqu'au sud de la rue Four-du-Chapitre. À la fin du XVIII ${ }^{\mathrm{e}}$ s., la maison commune devient la maison du bas clergé et n'abrite plus que des curés et prêtres du bas chœur. Ils y resteront jusqu'à la vente de l'îlot comme bien national en $1792^{505}$. Les constructions de l'îlot sud du vallon, réservées à l'habitat, sont regroupées au $\mathrm{XIX}^{\mathrm{e}} \mathrm{s}$. au sein d'une fabrique de colle.

$\mathrm{Au}$ sud de notre emprise sont conservés quelques niveaux de l'aménagement de l'esplanade de la Tourette. Les vestiges modernes, mieux conservés que les constructions antérieures, ont été cependant perturbés par le dérasement préalable à l'installation de la rue Robert-Schuman (seconde moitié du XIX ${ }^{\mathrm{e}} \mathrm{s}$.).

\subsection{L'évolution du réseau viaire}

À l'Époque moderne, le réseau des rues reste globalement inchangé. La grande nouveauté est la création de la rue Rouge à l'est de notre emprise en 1745. Le chemin public occidental qui va de la cathédrale à l'église SaintLaurent est plus large à l'Époque moderne qu'au Moyen Âge; il a été agrandi par la création de l'esplanade de la Tourette au $\mathrm{XV}^{\mathrm{e}} \mathrm{s}$. Les niveaux de sol de cet élargissement ont été retrouvés sur une surface très réduite. Le devenir du chemin oriental qui mène à Saint-Laurent est moins évident ; elle n'est peut-être plus passante au nord. L'accès à la rue Four-du-Chapitre semble en partie barré par un muret (si celui-ci n'est pas le vestige d'une marche dans la rue).

504 D'après les textes de S. Barbier, C. Barra, L. Ben Chaba, S. Fournier, O. Maufras, N. Scherrer, S. Vondra, E. Yebdri in Barra et al. 2004.

505 AD13 1 Q 660.

\subsubsection{La rue des Treize-Coins}

Les vestiges modernes de la rue des Treize-Coins se composent de deux niveaux de circulation successifs et de trois canalisations enterrées, préservées sur environ $4 \mathrm{~m}^{2}$ dans le renfoncement à l'angle des bâtiments $2 \mathrm{~B}$ et $2 \mathrm{C}$. Le niveau moderne le plus ancien est un remblai de limons bruns qui couvre directement le cimetière médiéval, sans doute parce que son épandage succède au dérasement des niveaux médiévaux. La couche devait s'appuyer contre la façade médiévale du bâtiment $2 \mathrm{~B}$; elle est recoupée par la façade moderne de cette maison. Par ailleurs, elle est percée par quatre canalisations qui sont des évacuations aménagées dans la rue, observées sur environ $1,50 \mathrm{~m}$ à $7 \mathrm{~m}$ de long. Les unes sont appareillées, les autres faites de borneaux de terre cuite d'environ $0,45 \mathrm{~m}$ chacun. Le niveau de circulation correspondant à cet état de la rue n'est pas conservé. Le deuxième état moderne de la rue correspond à un nouvel apport de composé de chaux et de brésié et à une couche fine de sédimentation. Sur une très petite surface, le revêtement de cette rue est conservé : il s'agit d'un pavage de galets posés sur chant qui couvre la tranchée

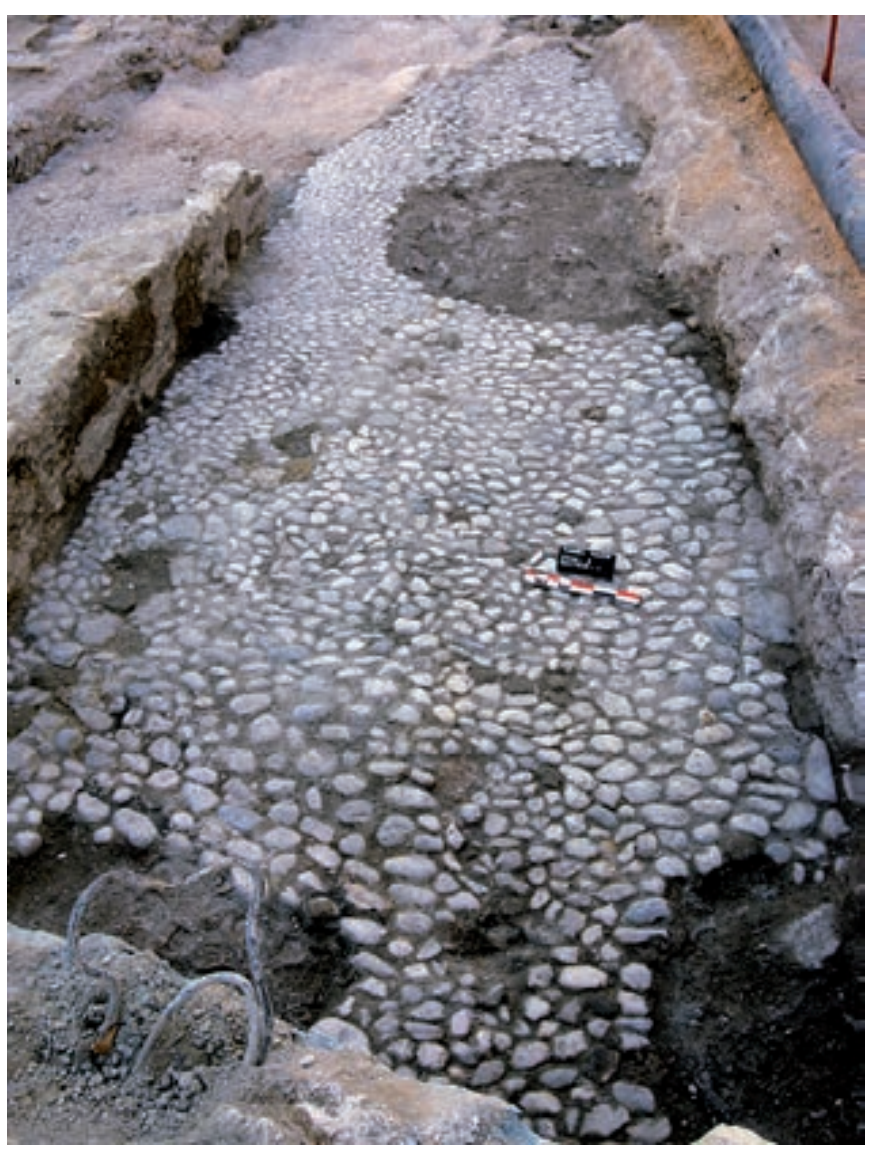

Fig. 133. La calade de galets de la rue Four-du-Chapitre, fin du XVIIe s. (cl. F. Parent/Inrap) 
de fondation de la nouvelle façade du bâtiment $2 \mathrm{~B}$. Le troisième état associe de nouveau des remblais d'exhaussement à un sol pavé. Les apports de limons et de sables couvrent l'état précédent et sont percés par l'installation d'un collecteur, plus profond mais de même capacité que les précédents. La chaussée se compose d'un pavage de galets posés sur chant ou à plat, abîmés par une ornière dans l'axe de la rue. Ces niveaux de circulation sont tous datés autour de la seconde moitié du XVIII' $\mathrm{s}$.

\subsubsection{La rue Four-du-Chapitre}

La rue Four-du-Chapitre a légèrement changé d'emprise à l'Époque moderne du fait du déplacement de la façade méridionale de la maison du Chapitre. À l'endroit où la rue débouche sur la place de la Major son emprise est réduite de $0,50 \mathrm{~m}$. Au sud, l'alignement du bâti reste stable et la bordure de la rue garde sa configuration jusqu'au $\mathrm{XIX}^{\mathrm{e}} \mathrm{s}$. La construction d'une usine de colle occasionne de nouveau une réduction de la voie : sa façade est construite $2 \mathrm{~m}$ en avant des façades médiévales ce qui réduit la largeur de la rue à $4 \mathrm{~m}$. Le niveau de la rue est rehaussé à l'Époque moderne, par l'apport de remblais; cinq conduites sont alors installées. Ces aménagements sont couverts par une calade de galets posés sur chant conservée sur $9 \mathrm{~m}^{2}$ et datée par la céramique du dernier quart du XVII ${ }^{\mathrm{e}}$ s. (fig. 133).

\subsubsection{Une ruelle est-ouest au sud de la rue des Treize-Coins}

Entre la rue des Treize-Coins et la rue Four-duChapitre, une ruelle est partiellement conservée dans sa partie orientale. Elle est pavée de galets et suit la pente naturelle du terrain (d'est en ouest vers la mer). L'écoulement est facilité par un fil d'eau constitué d'un alignement de galets inférieurs au reste du pavement. Les galets sont disposés sur chant et liés à des sables limoneux jaune (fin XVII ${ }^{\mathrm{e}}$-fin XVIII' ${ }^{\mathrm{e}}$ s.). La surface de circulation est recouverte par endroits d'une mince couche de terre charbonneuse qui contient des particules de fer. La ruelle sera détruite par un grand collecteur du XIX ${ }^{\mathrm{e}} \mathrm{s}$.

Elle peut ouvrir à l'ouest sur la place de la Major, mais son débouché oriental reste plus énigmatique (rue androna que non transit?).

\subsection{Le mur de confortement de la falaise}

Le rempart à l'ouest de l'esplanade de la Tourette est hors emprise du chantier du tunnel, mais a été observé sur environ $11 \mathrm{~m}$ de longueur avenue Vaudoyer (Bouiron,

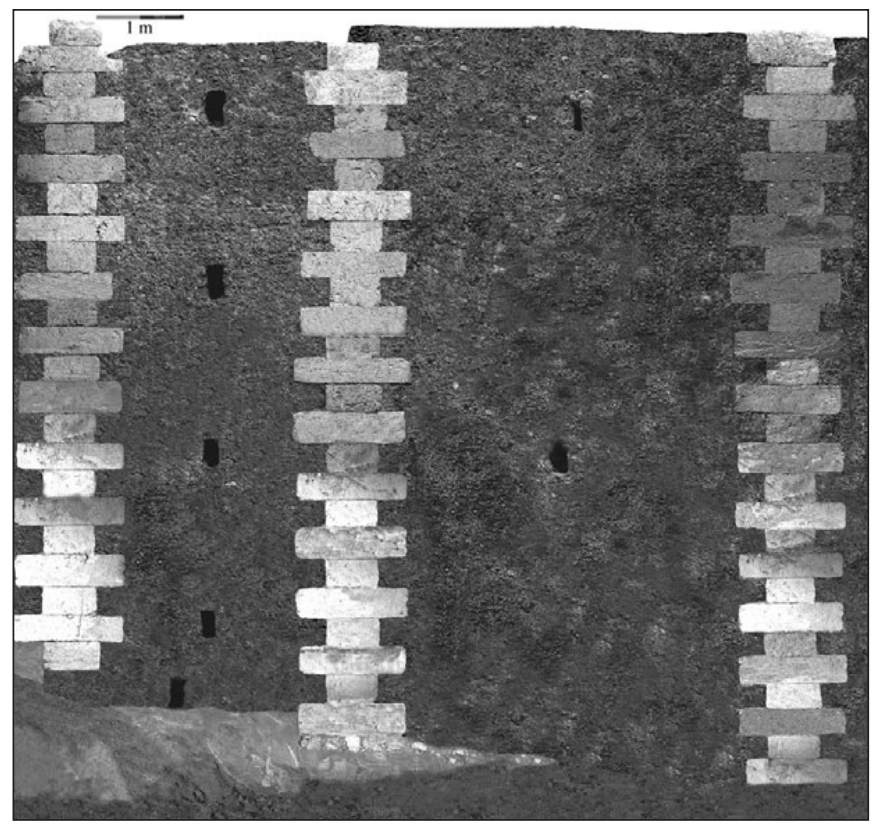

Fig. 134. Le mur de soutènement de la falaise vu du nord (reconstitution d'après photomontage T. Maziers/Inrap).

De Luca 1994). Construit entre 1320 et 1330, il n'est détruit qu'au XIX ${ }^{\mathrm{e}} \mathrm{s}$.

$\mathrm{Au}$ nord, un grand mur a été observé sur 10,30 m de long. Il n'est conservé qu'en fondation, sur une profondeur de 8,80 m. Celle-ci est bâtie directement sur le substrat entaillé par une grande tranchée. Le mur présente un parement vertical, côté ville, au sud, et un parement avec un fruit d'environ $6 \%$ côté mer, au nord. La base de la fondation mesure 2,30 $\mathrm{m}$ de large puis $1,80 \mathrm{~m}$ à la hauteur de son arasement qui correspond approximativement au niveau du sol contemporain intra muros. Le parement nord présente des assises régulières de blocs de poudingue et de calcaire urgonien. Le parement sud est fait de moellons de calcaire urgonien, disposés en assises moins régulières. Le blocage est constitué surtout de pierres de poudingue de tous calibres auxquelles sont associés des fragments de tuile et de céramique. L'ensemble est lié à un mortier gris abondant sur lequel on a distingué par endroits les traces des coffrages de mise en œuvre. Le mur est renforcé à l'arrière par des contreforts : trois ont été mis au jour, distants d'environ 2,5 et $4,5 \mathrm{~m}$. Ils sont construits en même temps que l'ouvrage principal auquel deux d'entre eux sont châ̂nés sur le parement méridional. Constitués de murs de longueur et de largeur irrégulière, ils sont ancrés dans la tranchée qui forme des paliers en escalier pour leur servir d'appui. L'ouvrage est daté entre le deuxième quart et la fin du XVIII ${ }^{\mathrm{e}}$ s. Le parement septentrional du mur est régulièrement aménagé de raidisseurs sur le parement septentrional en pendant aux contreforts. Ils 
sont constitués de blocs en grand appareil taillés dans le calcaire rosé de La Couronne ${ }^{\mathbf{5 0 6}}$, disposés alternativement en boutisse et en panneresse pour former trois jambes harpées. Celles-ci apportent non seulement de la rigidité au mur, mais fournissent aussi une certaine esthétique à l'ensemble (fig. 134). La maçonnerie est percée, sur le tronçon qui en a été dégagé, d'au moins sept chantepleures qui facilitent l'écoulement des eaux d'infiltrations retenues à l'arrière du mur.

\subsection{Les îlots au sud de la rue Four-du-Chapitre : de l'habitat à l'industrie}

Le bâti de l'îlot reste à l'Époque moderne tel qu'il était au Moyen Âge. Les maisons 4, 3A et 3B conservent leurs limites antérieures, mais subissent des réfections internes. À la fin du XVIII' ${ }^{\mathrm{e}}$ s. ou au début du XIX ${ }^{\mathrm{e}} \mathrm{s}$., l'implantation de la fabrique de colle d'Auguste Signoret transforme les bâtiments jusque-là utilisés comme dépendances de l'archidiaconat.

\subsubsection{La maison 4}

Les murs de la maison 4 (fig. 135) sont reconstruits et le sol réaménagé. Le terrain est d'abord nivelé sur le sol médiéval avec des limons bruns. Des carreaux rectangulaires (27 x $13 \mathrm{~cm})$, installés sur une fine chape de mortier grisâtre et de chaux, sont disposés en rangée dans la partie nord de la pièce et forment un tapis carré dans la partie sud, devant une cheminée. Celle-ci est bâtie contre le mur de façade oriental. Elle mesure $2 \mathrm{~m}$ sur 1,10 m. Une dalle de pierre bloquée par des briques posée sur chant supporte la sole. Une fosse perce le niveau de sol carrelé. De la céramique de Monteluppo, datée de la première moitié du $\mathrm{XVI}^{\mathrm{e}} \mathrm{s}$. a été retrouvée dans son comblement (Bouiron et al. 1995, p. 39). Le sol de l'état précédent est remplacé ; seule la chape en mortier de chaux est conservée sur une faible superficie.

\subsubsection{L'évolution du bâtiment 3A}

Le bâtiment oriental 3A ( $c f$. fig. 135) conserve lui aussi ses limites antérieures. La façade occidentale de la maison est partiellement refaite. À l'intérieur, une cave (ou une pièce semi-enterrée) est creusée jusqu'au sol antique en béton de tuileau qui sert de sol à la cave, par le rajout de carreaux pour les parties manquantes (terre cuite jaune de 26,5 x $13 \mathrm{~cm}$ de côté). Le niveau de circulation est à $8,40 \mathrm{~m}$ NGF.

506 Un certain nombre de ces blocs sont des remplois.

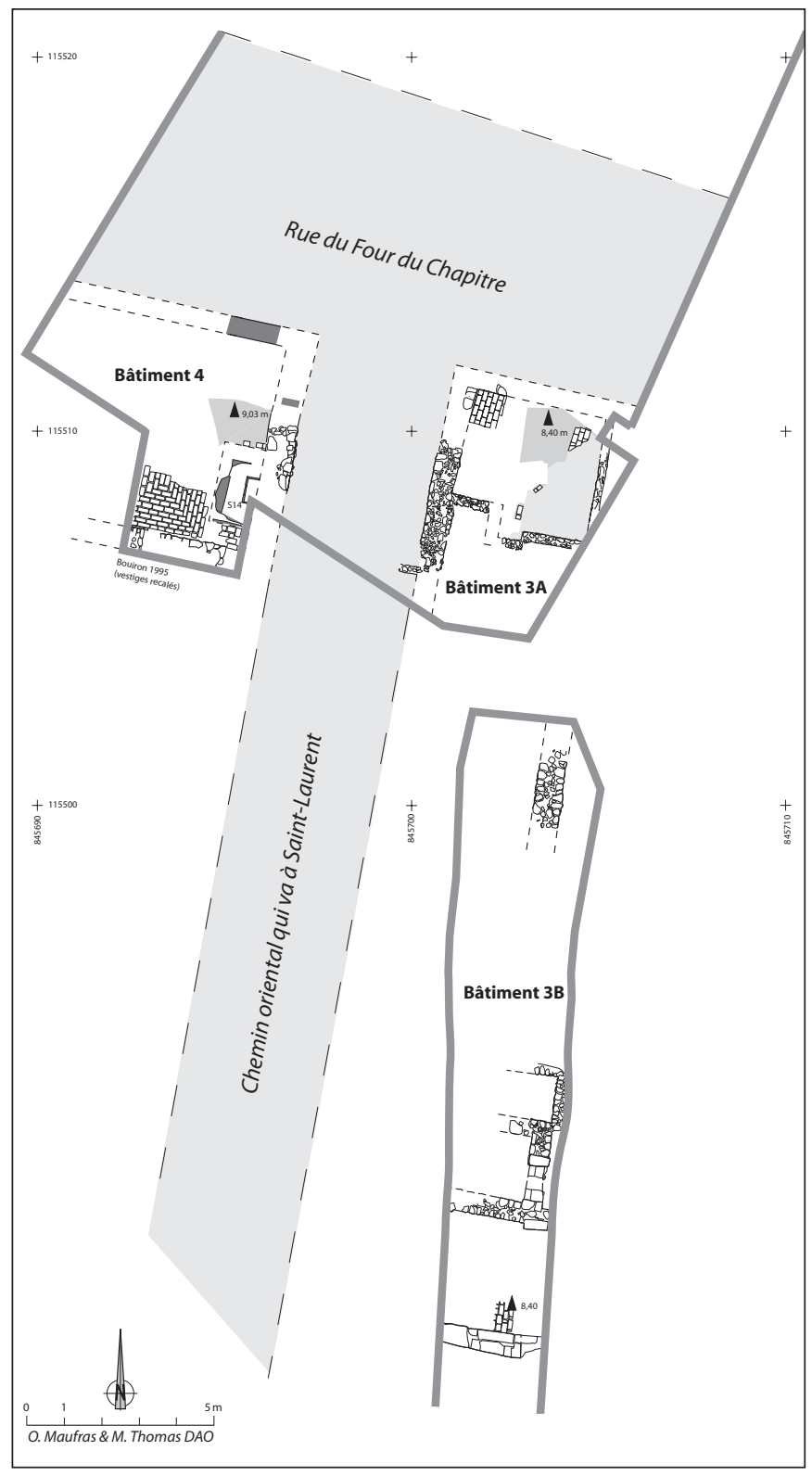

Fig. 135. Plan des immeubles modernes au sud de la rue Four-du-Chapitre (DAO O. Maufras, M. Thomas/Inrap).

Cette pièce, localisée dans la partie nord de la maison $3 \mathrm{~A}$, est limitée aux sud et à l'est par des cloisons. La cloison méridionale n'est pas rectiligne, elle forme un petit recoin (une armoire ?). Elle est chaînée au nouveau parement de la façade occidentale. La cloison orientale surmonte celle du Moyen Âge. Toutes les maçonneries conservées en fondation sur une ou deux assises sont des moellons bruts ou retouchés de calcaire liés à un mortier gris et maigre. Un enduit gris de chaux recouvre les murs. Aucun mobilier n'est associé à ces aménagements datés du XVII ${ }^{\mathrm{e}}$ s. par les travaux de 1995 (Bouiron et al. 1995, p. 39). 


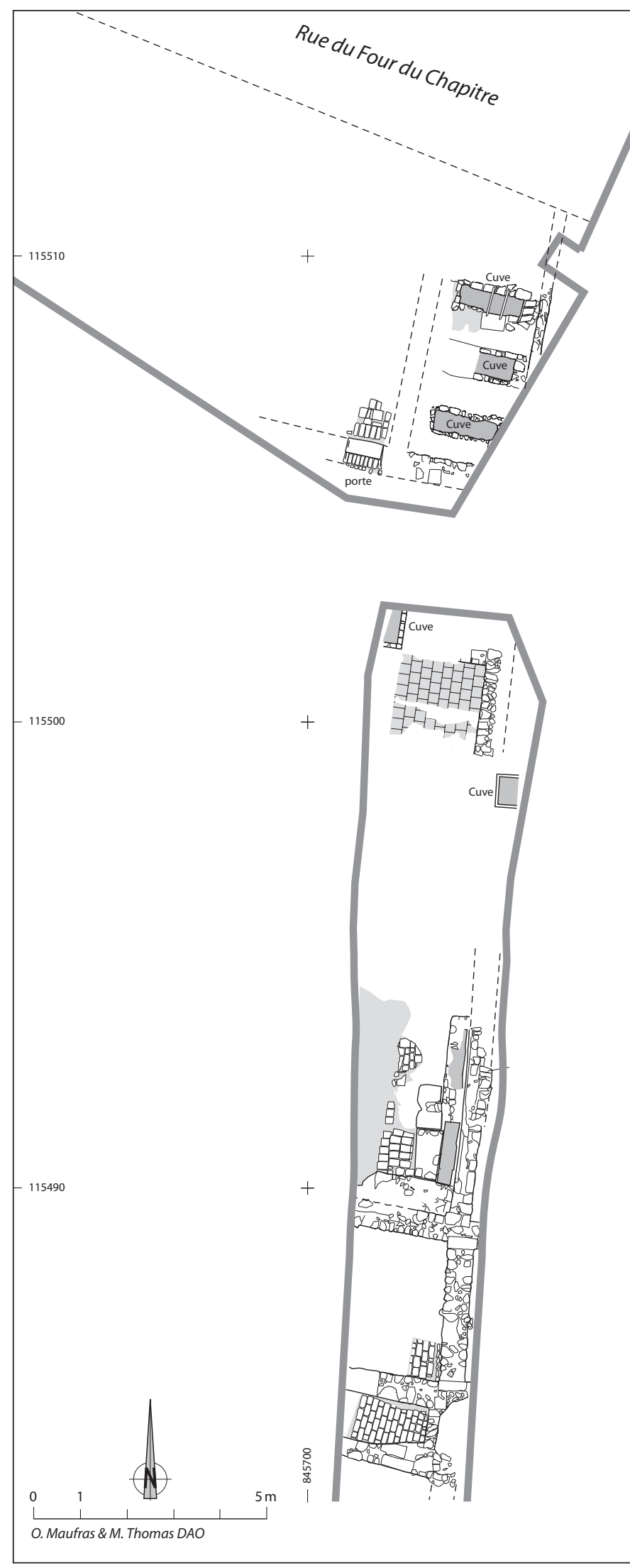

Fig. 136. Les vestiges de la fabrique de colle d'Auguste Signoret (DAO O. Maufras, M. Thomas/Inrap).

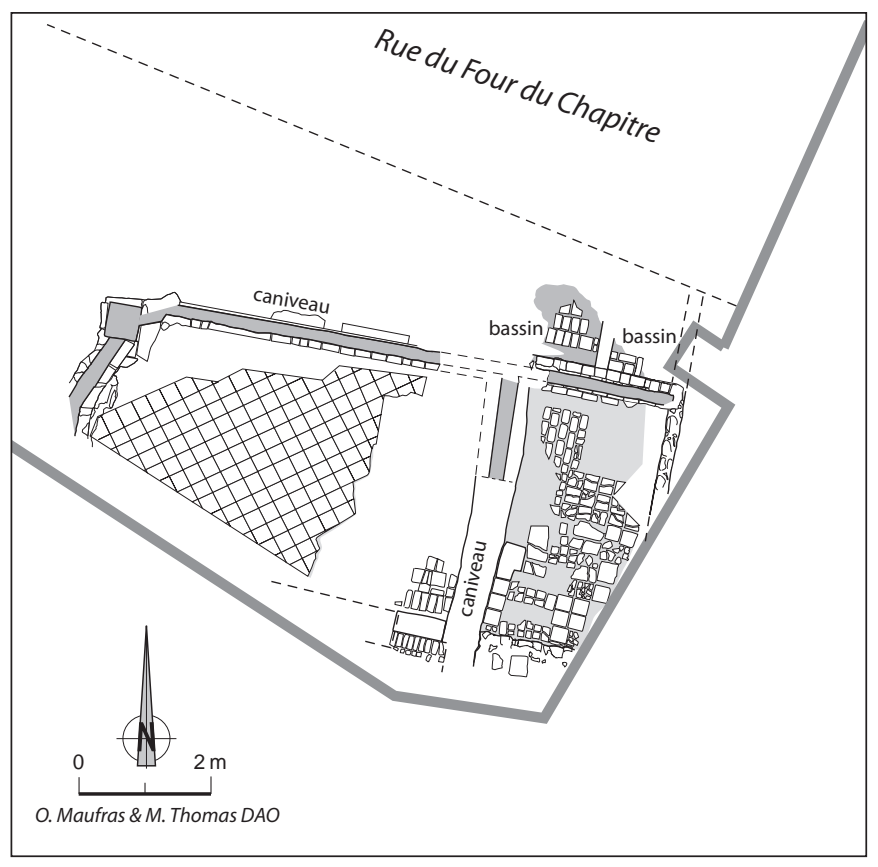

Fig. 137. Deuxième état des espaces nord de la fabrique de colle (DAO O. Maufras, M. Thomas/Inrap).

\subsubsection{La transformation du chemin oriental qui va à Saint-Laurent et des bâtiments 4 et $3 A$}

Entre les bâtiments 3B et 3A, un muret est construit d'est en ouest sur l'emprise du chemin oriental qui va à Saint-Laurent ( $c f$. fig. 135). Ce mur est similaire aux murs de la maison $3 \mathrm{~A}$ à laquelle il s'adosse : maçonnerie constituée d'un blocage de pierres brutes ou équarries liées par un mortier gris et maigre de chaux. Le muret est-il un aménagement de la chaussée (une marche qui réduit le degré de la pente) ou s'agit-il d'une construction empiétant sur l'emprise de la rue ? Dans ce dernier cas, son extrémité nord au moins serait abandonnée et son espace privatisé. Les dénombrements cadastraux de 1629 à 1698 ne fournissent pas de localisation précise des îlots. En revanche, au XVIII ${ }^{\mathrm{e}}$ s., ce secteur appartient à l'isle 283 et une seule maison (la vingtième qui appartient à l'archidiaconat dont elle constitue une dépendance) occupe l'espace entre la rue Four-duChapitre au nord (rue Chaufoir en 1796), la place de la Major à l'ouest et la rue de la Cathédrale à l'est (rue de la Foire). Le chemin oriental qui mène à Saint-Laurent n'est alors plus passant. Il est possible cependant que son extrémité nord reste un espace ouvert (une cour) puisque la propriété qui l'occupe est composée à la fin du XVIII s. d'un immeuble de deux étages, remise, écurie et fenière. Les bâtiments 4 et $3 \mathrm{~A}$ ont donc été regroupés en une même propriété avant la Révolution, maison disposant au rez-de-chaussée de cinq pièces en 


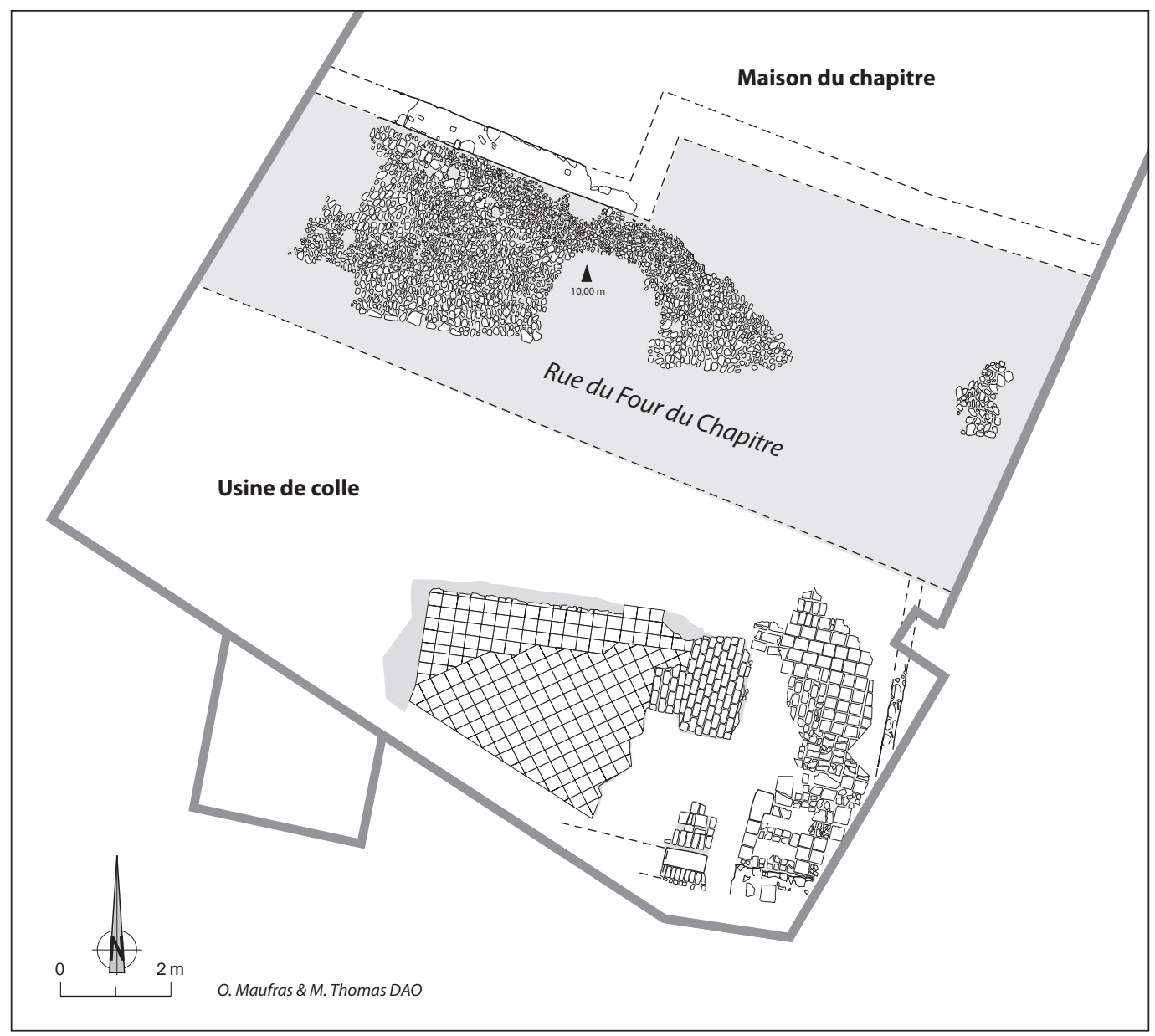

Fig. 138. Troisième état des espaces nord de la fabrique de colle (DAO O. Maufras, M. Thomas/Inrap).

1796 dont un salon avec cheminée de marbre et une cuisine avec sa cheminée ${ }^{\mathbf{5 0 7}}$.

\subsubsection{Le bâtiment $3 B$}

La maison 3B ( $c f$. fig. 135) s'étend vers le sud. Une cave est installée dans la pièce méridionale de la maison. Rien ne précise si le mur méridional est une cloison ou une façade de la maison. Une porte d'accès ouvre sur un espace indéterminé au sud : deux marches dans l'embrasure de la porte prouve un niveau de sol supérieur. La cave est une pièce de 2,85 à $3 \mathrm{~m}$ de large, observée sur $2,75 \mathrm{~m}$ de long. Ses murs sont construits en moellons et cailloux bruts ou retouchés de calcaire, de grès et de poudingue liés au mortier. Les assises sont plus régulières à l'extrémité orientale du mur et autour de la porte, dont le seuil et un piédroit sont conservés : ces deux parties sont en pierres taillées de calcaire rose de La Couronne. La cave reçoit un enduit conservé

$\mathbf{5 0 7}$ AD13 1 Q 217. inégalement sur le mur nord et le piédroit de l'entrée. Les carreaux de terre cuite, disposés en rangs nord-sud et à joints alternés formant le sol (à 8,40 m NGF), sont installés sur une chape de mortier gris posée sur le substrat régularisé. Ces carreaux, de 26,5 sur $13 \mathrm{~cm}$, sont identiques à ceux du sol du bâtiment $3 \mathrm{~A}$.

\subsubsection{Un quatrième bâtiment?}

Plus au nord, un mur est le seul vestige d'une construction entre les maisons 3A et 3B ( $c f$. fig. 135). Aucun lien archéologique ne permet de le rattacher aux maisons $3 \mathrm{~A}$ ou $3 \mathrm{~B}$ ou à un autre bâtiment. Orienté nord-sud, il est large de 0,70 m. Des moellons et cailloux de calcaire de La Couronne, de Saint-Victor forment les parements, et des tomettes, des fragments d'enduit et de béton de tuileau sont utilisés pour le blocage. La maçonnerie est de qualité, les assises sont régulières. Le mur est en appui direct sur les constructions et remblais antiques; on le suppose moderne par son mortier similaire à celui des autres constructions du secteur, il est ensuite directement recouvert par les murs de la fabrique de colle. 


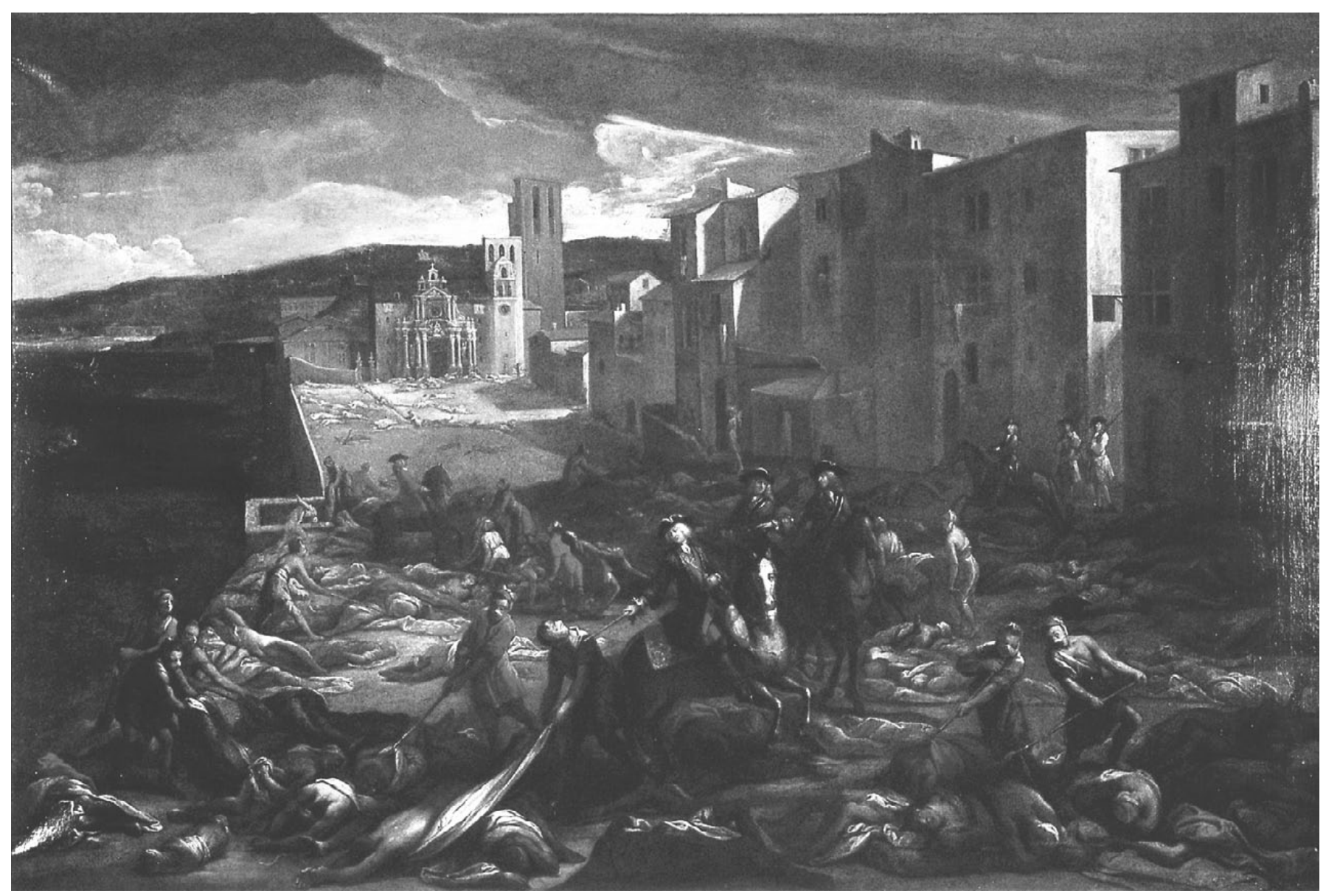

Fig. 139. Scène de la peste de 1720 à la Tourette, tableau de Michel Serre (Musée Fabre, Montpellier)

\subsubsection{La fabrique de colle}

La fabrique de colle (1790-1881) s'établit dans les maisons 3B et 3A (fig. 136 à 138). En 1790, Auguste Signoret achète, pour installer une fabrique de colle, l'immeuble et les parties attenantes constituant la maison 20 de l'île $283^{508}$. Il devient propriétaire, à la suite du Chapitre, des bâtiments 3B et 3A, mais aussi des maisons voisines à l'ouest, et notamment de la maison 4 . A. Signoret est indiqué comme propriétaire des parcelles 809 à 814 dans le cadastre de 1820 ; il occupe toute la pointe nord de l'îlot. Ces parcelles correspondent alors à une fabrique, un hangar, deux cours, un jardin d'agrément et un bassin ${ }^{509}$. La fabrique de colle est active jusqu'en 1870 malgré une expropriation en 1855 en vue du dérasement général du secteur pour le projet de construction de la nouvelle cathédrale ${ }^{510}$. La fabrique ne disparaît qu'en 1881 au profit de la construction du bâti-

508 La vente est citée dans un acte de 1791, ACM 21 G 19 fol. 36v. 509 AD13 P4/1832, p. 68.

510 ACM 52 M 30. ment d'une école devenue aujourd'hui mairie de quartier. Les vestiges découverts sont les pièces orientales de la fabrique. Trois états sont conservés au nord sans pouvoir être liés chronologiquement aux aménagements sud. L'installation de la fabrique dans les bâtiments du XVIII ${ }^{\mathrm{e}} \mathrm{s}$. n'occasionne que quelques réfections de murs. Ainsi la façade sur la rue Four-du-Chapitre est remplacée par un mur installé en avant du mur antérieur, agrandissant l'espace disponible. Ce mur ne conservait qu'un bloc de travertin taillé (qui n'a pas été relevé). Le cloisonnement interne réutilise les anciens murs au nord et de nouvelles cloisons délimitent au moins six pièces. Un seuil permet de passer de la pièce nord à la pièce sud. Cette dernière n'est pas conservée, mais, les traces d'arrachement de marches dans l'embrasure de la porte montrent un sol plus élevé. Les murs sont construits en cailloux et en pierres brutes retouchées ou équarries, disposés en assises horizontales mais de manière irrégulière et liées au mortier, à l'exception d'un mur lié à la terre. Certains matériaux sont des remplois (pierres de taille et pierres sculptées). Les sols bâtis sont pour la plupart carrelés. Les pièces comportent cuves et canalisations. 
Trois états successifs ont été perçus. Dans un premier temps, l'espace donnant sur la rue Four-duChapitre est divisé en deux salles au moins par une cloison entièrement récupérée au cours de l'état suivant. Rien n'est conservé de la pièce occidentale, sinon une petite surface du sol. Trois cuves rectangulaires occupent le réduit formant la pièce orientale, laissant peu de place à la circulation. Ces bassins sont installés dans des fosses, construits principalement en briques et enduits. Les réfections de l'enduit ont été faites au ciment, indiquant une utilisation jusque dans la seconde moitié du $\mathrm{XIX}^{\mathrm{e}}$ s. Le sol conservé entre deux cuves est constitué d'une chape de mortier recouverte d'enduit servant à l'étanchéité des cuves. Les cuves des pièces méridionales sont d'un autre type : en briques et pierres liées au mortier et de plan carré ou très étroites et en béton de chaux et de sable. Installées sur des banquettes maçonnées appuyées au mur, elles sont confortées par des structures bâties quadrangulaires dont la fonction exacte n'a pas été déterminée. Dans un deuxième temps, l'espace septentrional est unifié par le démontage de la cloison et l'abandon des cuves. Des canalisations sont installées : l'une d'elles utilise la tranchée de fondation du mur démonté. Elle communique avec une autre disposée en angle, percée d'un regard et alimentent deux bassins. Les sols sont alors carrelés à plusieurs reprises vu l'hétérogénéité des matériaux retrouvés. Au cours du troisième état, les canalisations sont abandonnées et le sol refait. L'ensemble du bâtiment est recouvert par un remblai de démolition au nord issu sans doute de la destruction de 1881. La rue n'est pas touchée au moment de ces travaux.

\subsection{L'esplanade de la Tourette}

Au sud de l'emprise, les bâtiments d'époque médiévale sont détruits pour former une esplanade au début du XVe s. ${ }^{511}$ (fig. 139, $c f$. supra $§ 2.3 .3$.). La destination originelle de cette plateforme nous échappe, les niveaux correspondants ayant été dérasés. Une autre mention nous est parvenue au travers d'un texte de 1625 issu des archives municipales qui parle de la création d'une «platte forme pour les canons qui sont tout proches de l'église majeure » ${ }^{\mathbf{5 1 2}}$. Rien n'est conservé de cette plateforme maçonnée. Le premier niveau de circulation observé est daté du XVIII ${ }^{\mathrm{e}}$ s. et se compose d'un

511 Elle semble bien exister en 1424, un texte notarial en faisant mention : AD13 392 E 159, fol. 10v d'après B. Roberty (manquant au 19 octobre 2000).

512 Prix-fait pour la construction de la batterie de la Major : ACM BB 67 fol. 145. radier de cailloux et de fragments de tuiles dans un liant de terre et de chaux; il est surmonté d'une couche de finition constituée de fragments de tuiles et de briques concassées liées au mortier de chaux. Le sommet se situe aux alentours de $11 \mathrm{~m} \mathrm{NGF}$ avec un léger pendage vers le nord-nord-ouest. Quatre aménagements ont été découverts dans ces sols, une dalle calcaire, un moellon calcaire fiché en terre sur chant, et deux fosses dont on peut penser qu'elles sont les témoins de deux autres supports. Leur fonction reste cependant obscure et aucune de ces structures n'a livré de mobilier.

\subsection{Conclusion}

Le tracé de l'enceinte est bien connu pour l'Époque moderne car elle n'a été détruite qu'au $\mathrm{XIX}^{\mathrm{e}} \mathrm{s}$., lors de la création des ports modernes. L'esplanade de la Tourette est également bien documentée par l'iconographie, car cette zone est restée vierge de construction du début du $\mathrm{XV}^{\mathrm{e}} \mathrm{s}$. à nos jours, formant sûrement une esplanade d'arrivée monumentale à l'entrée méridionale de l'église. Le réseau viaire change peu et les îlots ne sont pas profondément modifiés durant cette période. Les maisons subissent en revanche des réfections internes; des caves sont construites dans les bâtiments $2 \mathrm{~B}, 2 \mathrm{C}$ et $3 \mathrm{~B}$. À la fin du XVIII ${ }^{\mathrm{e}}$ s., une fabrique de colle s'installe autour de la rue Four-du-Chapitre, dans une zone qui était plutôt vouée au clergé auparavant. 


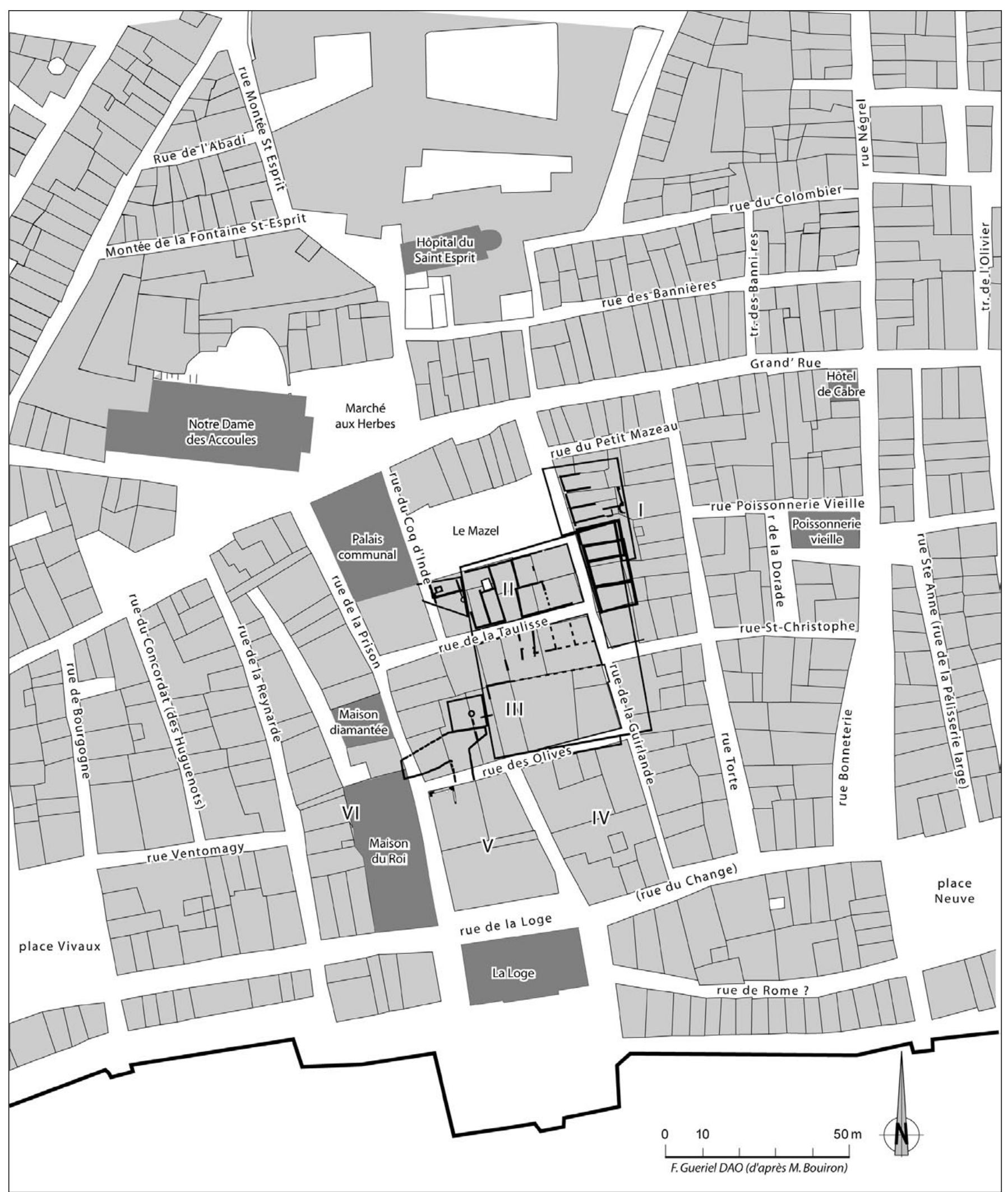

Fig. 140. Plan d'ensemble du quartier derrière la Mairie sur fond cadastral de 1820 (DAO F. Guériel/Inrap, M. Bouiron/Ville de Nice) 


\section{Chapitre 2}

\section{La ville basse : \\ le quartier du Mazeau et de la Loge}

\section{L} es fouilles autour de la Mairie (et particulièrement au nord, sur l'emprise de la place Villeneuve-Bargemon) ont jeté un éclairage nouveau sur le quartier du port compris la Loge et l'église des Accoules.

\section{La ville basse à la lumière des sources écrites}

Avant d'entrer dans le détail des résultats archéologiques, le cadre topographique et historique du développement et de l'occupation du quartier peut être appréhendé au moyen des textes d'archives, particulièrement nombreux pour cette zone de la ville.

\subsection{Les édifices et lieux majeurs du quartier (F. Paone)}

Cette étude s'appuie sur des informations éparses et inégales, car les couches archéologiques sont essentiellement conservées dans les rues et plus rarement à l'intérieur des constructions. La compréhension de l'organisation spatiale et fonctionnelle des maisons du quartier du Mazeau (fig. 140) est contrariée par le creusement des caves modernes, les données sont donc ténues et les séquences stratigraphiques rares. De plus, l'emprise des fouilles n'aborde pas l'environnement monumental pourtant particulièrement présent sur la rive nord du port.

En effet, ce secteur de la ville basse polarise l'implantation d'établissements religieux majeurs et de lieux de pouvoirs politiques et commerçants. Sont établis entre le $\mathrm{XI}^{\mathrm{e}} \mathrm{s}$. et le $\mathrm{XV}^{\mathrm{e}}$ s., le palais communal, l'hôpital Saint-Esprit, la Loge, la Maison du roi, ainsi que des établissements religieux de référence, le monastère Saint-Sauveur (dans un premier temps) et la paroisse Notre-Dame des Accoules. Ces édifices s'intègrent donc dans ce quartier à forte vocation marchande et artisanale, où les possibilités de remodelage de la topographie restent malgré tout limitées. Il nous est d'autant plus difficile de mesurer le retentissement de telles constructions sur l'évolution morphologique du quartier, qu'à l'exception de Notre-Dame des Accoules en partie amputée de nos jours, tous ces édifices ont disparu. Plusieurs emplacements dévolus au commerce de denrées étaient également présents dans le secteur, il s'agit de la place aux Herbes et du Petit-Mazeau.

Établi durant une période où les contraintes spatiales sont encore mineures vers 1030, le monastère féminin -placé plus tard sous la titulature de Saint-Sauveur- est construit au sud de la butte des Moulins; la première

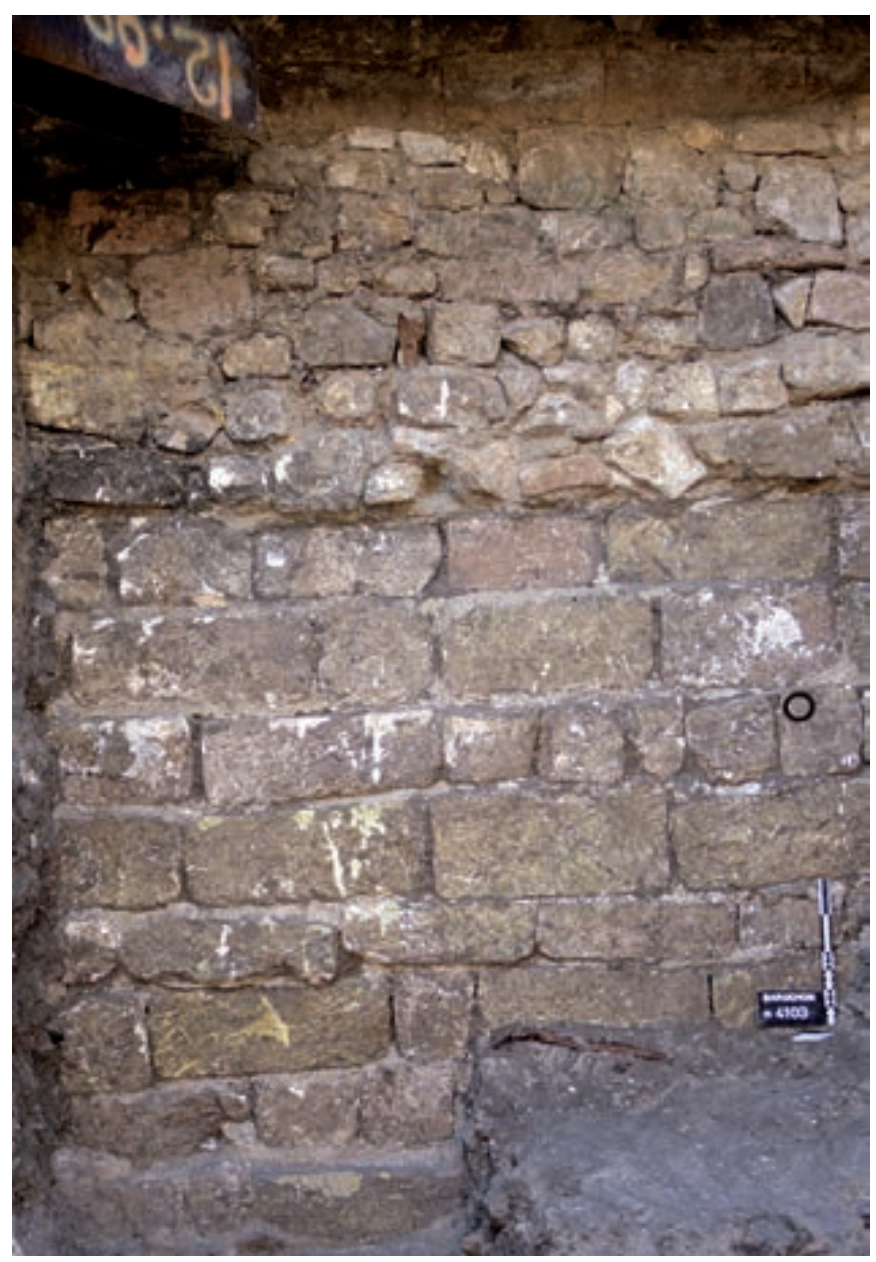

Fig. 141. Vue de la maçonnerie en moyen appareil de calcaire rose, sous le palais Daviel (cl. T. Maziers/Inrap). 
mention de son église d'origine, Notre-Dame des Accoules, n'apparaît qu'en $1060^{\mathbf{5 1 3}}$. Richement doté par les vicomtes de Marseille à partir de 1031, le monastère possède des terrains destinés à être lotis, comme l'indique son registre de cens daté du début du XIII ${ }^{\text {e }}$ s. ${ }^{\mathbf{5 1 4}}$. Y sont mentionnées «des maisons s'étendant au nord de l'hôpital Saint-Esprit à la limite méridionale de la place de Lenche et, au sud, probablement jusqu'aux îles de maisons relevant des vicomtes au bord du port » (Bouiron 2001d, p. 155). Après le transfert du couvent dès 1178 non loin du château Babon (sur l'actuelle place de Lenche), cette zone relève de la paroisse de NotreDame des Accoules. L'église, reconstruite au début du XIII $^{\text {e }}$ s. et probablement autour de 1300 (HartmannVirnich 2001 p. 286-287), est établie au débouché de la Grand-Rue, s’intégrant en cela dans le réseau viaire antique ; son cimetière s'étendait au sud de la butte des Moulins. Son emplacement dominant en partie la ville basse en fait l'un des éléments majeurs de la topographie du quartier. Cette mise en espace est intéressante car bien qu'étant en position excentrée, elle est placée au débouché d'un axe antique important, la rue Caisserie.

Fondé en 1188 par les Frères du Saint-Esprit de Montpellier, l'hôpital Saint-Esprit relève quelques années plus tard du monastère Saint-Sauveur. Placé au pied de la butte des Moulins, non loin de Notre-Dame des Accoules, il sera détruit lors de la construction de l'Hôtel-Dieu au XVIII' s., aussi son impact sur l'évolution morphologique du quartier ne peut être mesuré. Cet établissement a, pour un tout autre domaine, une importance considérable dans l'histoire marseillaise puisqu'il accueille dans ses murs les réunions de la Confrérie du Saint-Esprit (qu'il ne faut pas confondre avec l'hôpital du même nom) dont les membres constituent les fondements de l'émancipation communale.

Dès 1225, la commune de Marseille se dote d'un Palais communal, lieu de réunion et de représentation du nouveau pouvoir, à l'instar des cités italiennes dont sont originaires les podestats (Bouiron 2001f, p. 258). D'abord communal, le Palais passe sous le contrôle du comte Charles I'r d'Anjou en 1257. La localisation ellemême ne pose pas de problème, il est à l'emplacement actuel du Palais Daviel, ouvre au nord sur la Grand-Rue et la place des Accoules et occupe tout l'espace entre les deux rues latérales (rues de la Prison et du Coq$\mathrm{d}^{\prime}$ Inde). Il renferme, aux $\mathrm{XIV}^{\mathrm{e}}$ et $\mathrm{XV}^{\mathrm{e}}$ s., la claverie et la prison, celle-ci se trouvant à l'ouest, du côté de la rue de la Prison. Quelques mentions de paiement s'y

513 Sur tout ceci, nous suivons les hypothèses de $\mathrm{M}$. Bouiron (2009c, p. 46-47) ; voir également Bouiron à paraître.

$514 \mathrm{Ce}$ document est intégralement retranscrit par $\mathrm{M}$. Bouiron (2009c, p. 56-74) rapportent dans les cahiers tenus par les clavaires ; elles indiquent des travaux en particulier à la prison ${ }^{\mathbf{5 1 5}}$, tandis que quelques inventaires rédigés par le clavaire donnent une idée de sa structure interne ${ }^{516}$. À partir du milieu du $\mathrm{XV}^{\mathrm{e}}$ s. (mais peut-être après la reconstruction qui suit le sac des Catalans de 1423 ?), il est mentionné comme Palatium curie regis ${ }^{\mathbf{5 1 7}}$ qu'il ne faut pas confondre avec la Maison du roi (Castrucci 2001). C'est sur l'emplacement de la claverie qu'est construit au XVI ${ }^{\mathrm{e}}$ s. le Palais de justice, rebâti deux siècles plus tard et connu sous la dénomination de palais Daviel. Lors de la fouille de l'Espace Bargemon, a été mis au jour sous les fondations de l'actuel monument, un imposant mur en pierre de taille. Observée sur une hauteur de $2 \mathrm{~m}$, cette maçonnerie en calcaire de La Couronne offre un appareil régulier posé sur deux ressauts de fondation. L'étude stratigraphique permet de dater de façon certaine cette construction de la fin $\mathrm{XII}^{\mathrm{e}}$ s. ou du début du XIII' ${ }^{\mathrm{e}}$ s. ; sa mise en œuvre (appareil régulier en blocs taillés) et le choix du matériau (calcaire de La Couronne) la rapprochent d'édifices monumentaux contemporains encore présents dans le paysage marseillais tels que la cathédrale de La Major ou l'église Saint-Laurent. Ces éléments indiquent que ce mur pourrait correspondre à un bâtiment majeur, situé au sud du palais communal puisque les textes indiquent que le palais originel était limité à la partie nord du pavillon Daviel (fig. 141).

Située au sud de Notre-Dame des Accoules la place aux Herbes est installée au débouché de la Grand-Rue. Elle est accolée au Petit Mazeau, établi à l'est du palais comtal, qui, au XIV ${ }^{\mathrm{e}} \mathrm{s}$. est également appelé «le mazel de las Acolas ». Il formait, avec le Grand Mazeau, les seuls lieux dévolus à la boucherie à Marseille. Nous ne savons à quand remonte son établissement ni sous quelle forme il s'organise. Nous renvoyons à la première partie $(\S \mathrm{I}, 5,1.2$.) pour ce lieu de commerce.

\subsection{Le quartier du Mazeau au Moyen Âge (M. Bouiron avec la coll. de $P$. Rigaud)}

Pour la période médiévale, l'étude d'archives a été conduite durant la dernière phase de fouille (Espace Bargemon) par Philippe Rigaud. Ses transcriptions, très nombreuses, ont fait l'objet d'un premier rapport.

515 Marches refaites à l'escalier menant aux cellules et serrures en 1330 (AD06 B 1940, fol. 202-202v); travaux dans la claverie en 1483 et 1505 et construction de salles supplémentaires en 1508-1512 (AD06 22 F 69).

516 AD 06 B 1941, fol. 7v (1352) ; B 1942, fol. 6v (1358).

517 Voir en particulier les confronts de l'îlot 6.03 ci-après. 


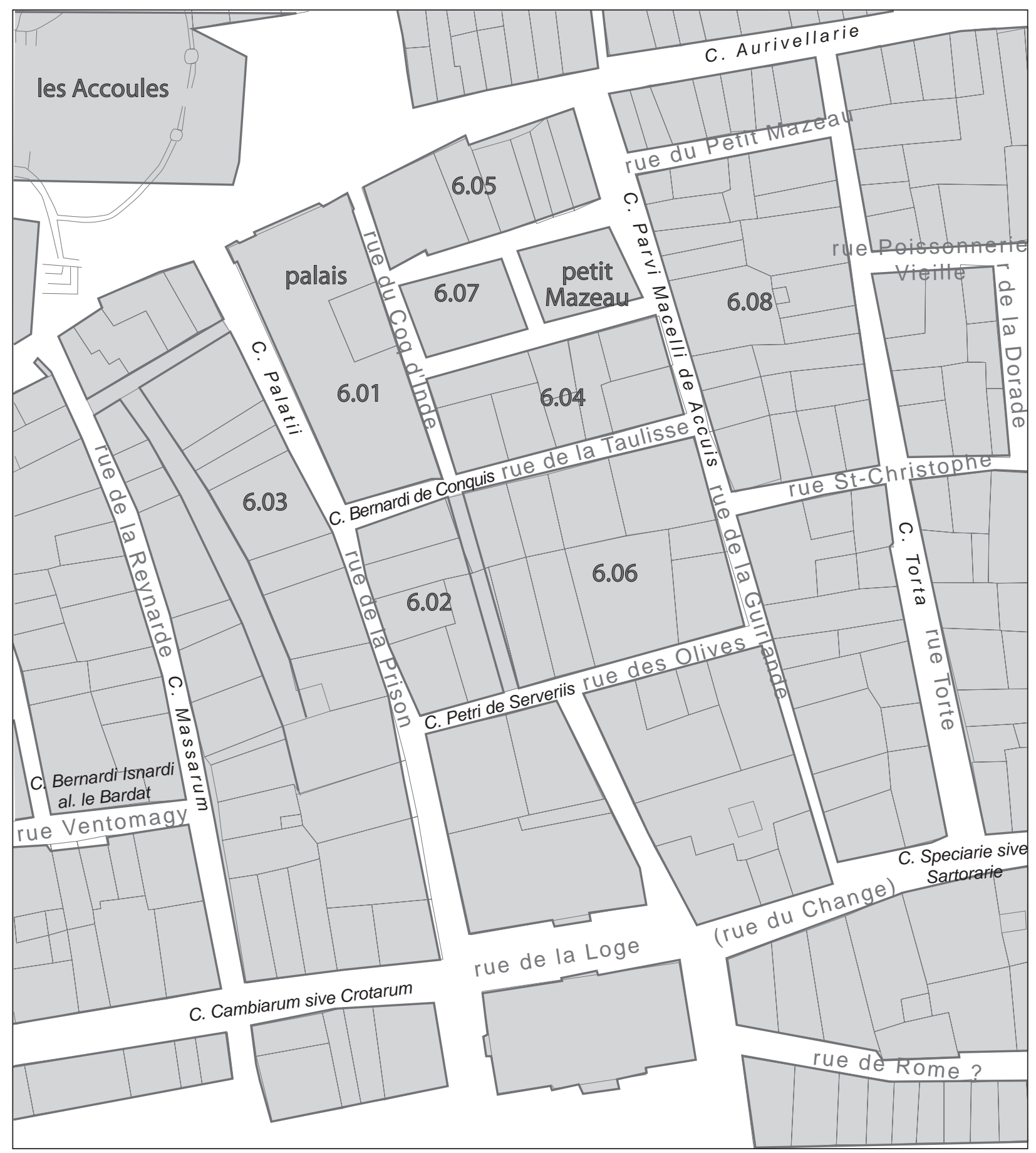

Fig. 142. Plan des îlots autour de la place Bargemon (DAO M. Bouiron/Ville de Nice).

Par la suite, il a fallu reprendre ses données, de manière longue et fastidieuse mais néanmoins indispensable, afin de préciser les localisations par îlot. Ceci a permis de suivre des transmissions de propriété, parfois depuis la seconde moitié du XIII ${ }^{\mathrm{e}}$ s., malgré les dénominations changeantes des rues ou des îlots.

Dans l'étude qui suit, nous examinerons d'abord le cadre topographique que constituent les rues et les édifices remarquables, avant d'étudier en détail, îlot par îlot, les évolutions de l'occupation du sol (fig. 142).

\subsubsection{Le réseau des rues}

La fouille de la place Bargemon a permis, au travers de l'étude d'archives conduite par P. Rigaud pour la période médiévale et Colette Castrucci pour la période 
moderne, de mieux comprendre l'évolution de la toponymie viaire. Nous utiliserons ici le nom des rues avant la destruction du quartier en 1943.

Quatre rues nord-sud (rue de la Reynarde, rue de la Prison, rue du Coq-d'Inde et rue de la Guirlande) et trois rues est-ouest (Grand-Rue au nord, rue de la Taulisse et rue des Olives au sud) concernent la zone qui a fait l'objet de l'étude d'archives. Toutes remontent au Moyen Âge.

\section{Les rues nord-sud}

A l'ouest, la rue de la Reynarde garde une toponymie constante depuis le Moyen Âge jusqu'en plein $\mathrm{XVII}^{\mathrm{e}}$ s. : carreria de las Massas (1380), carreria Massarum (1502), rue des Masses (1666). Une ruelle sans nom sous forme d'impasse apparaît à l'est de cette rue ; elle permet de desservir des propriétés morcelées principalement après 1423 . Cette ruelle apparaît toutefois, pour la détermination des confronts des maisons qui la bordent à l'ouest et à l'est, bien moins importante que la rue de la Reynarde ou celle de la Prison.

L'actuelle rue de la Prison est dénommée tantôt par rapport au Palais qu'elle borde, aux prisons ou à sa direction vers le port. Elle est la rue près du Palais en 1298 (carreria prope Palacium), la traverse devant la Prison (traversa davant la carcer) au début du $\mathrm{XV}^{\mathrm{e}} \mathrm{s}$., la rue qui va au port (carreria qua itur versus portum) en 1449, mais surtout la rue du Palais du XIV e au XVI ${ }^{\mathrm{e}}$ s. (carreria Palacii en 1346, 1452, 1454, rue du Pallais du Roy en 1547/49, rue du Palais en 1547/49 et 1571) et enfin la rue de la Prison au XVII ${ }^{\mathrm{e}} \mathrm{s}$. (rue desservant des Acoulles au port dite de la Prison en 1683).

La rue du Coq-d'Inde est à l'origine la rue droite du Palais (carriera drecha del Palays en 1395) puis la rue du Mazeau (carreria publica Macelli en 1449), peut-être après la disparition du tronçon entre la rue de la Taulisse et la rue des Olives (après 1423 ?). Elle devient ensuite la rue allant des Accoules à la Loge en 1571 puis la rue de traverse appelée du Palais en 1683.

La dernière rue nord-sud, la rue de la Guirlande, porte des noms différents au Moyen Âge mais qui se rapportent tous au Mazeau : rue du (Petit) Mazeau (des Accoules) (carreria macelli de Acuis en 1377 et 1405, carreria del Masel de las Acolas vers 1430, carreria recta macelli de Accuis en 1432, rue du Petit Mazel des Accolles en 1560 et 1569) ; rue sous le (Petit) Mazeau (des Accoules) (carriera sos lo Mazel de las Acoas en 1396, carreria subtus macellum de Acuis en 1447); rue allant au Mazeau (grande rue allant vers le Mazel des Accoles ou rue qui va au Mazeau en 1547/48); rue allant du Petit Mazeau aux Changes/à la Loge (grande rue tirant à la Loge en 1643, rue descendant du Petit
Mazeau à la Loge en 1715) ; enfin rue de la Guirlande en 1608,1644 et 1743 .

\section{Les rues est-ouest}

Au nord, la Grand-Rue porte plusieurs noms suivant les tronçons successifs. À l'est du Palais communal, c'est la rue Aurivellarie. Ainsi en 1450: carreria publica nuncupata Aurivellarie tendente versus ecclesiem Nostre-Domine de Accuis. Cette dénomination est la seule utilisée au Moyen Âge.

La rue de la Taulisse s'appelle initialement rue Bernard-de-Conques (carreria de Bernat de Concas en 1383-1387), nom que l'on retrouve encore de manière anecdotique au XVII' ${ }^{\mathrm{e}}$ s. (rue appelée Conquis en 1683). Elle devient cependant ensuite une simple traverse allant au Mazeau des Accoules (transversia prothendo ad macellum de Acuis en 1405) pour perdre tout nom au XVI ${ }^{\mathrm{e}}$ s. (traverse en $1547 / 49$ et 1560 , traverse tirant vers les prisons en 1560 et 1569, petite ruete en 1571).

La rue des Olives est au Moyen Âge la rue Pierrede-Servières (traverssa de mossen Peyre Servieras en 1395, carriera que va a l'ostal de mossen Peire de Servieras en 1396, carreria domini Petri de Serveriis en 1432). Elle devient au XVII ${ }^{\mathrm{e}}$ s. la rue des Ventos (1608, 1699), du nom d'une famille de propriétaire de maisons dans cette rue.

\subsubsection{Les îlots}

Nous avons déterminé 8 îlots ( $c f$. fig. 142) autour de la zone de la fouille Bargemon, que nous étudierons en détail, depuis la rue de la Reynarde à l'ouest jusqu'à la partie de l'îlot bordant à l'est rue de la Guirlande, et du nord au sud entre la Grand-Rue et la rue des Olives au sud ${ }^{518}$.

\section{L'îlot 6.01}

Le premier îlot étudié correspond à l'ensemble bâti contenant le Palais. Celui-ci semble occuper les deuxtiers nord de l'îlot, tandis que la partie sud est bâtie de maisons. Le registre de cens du comte de Provence, daté de 1302, signale que la possession des maisons de cet îlot (au moins deux sur les trois) provient de Briton Anselme, l'un des principaux artisans de l'opposition à Charles I ${ }^{\text {er }} \mathrm{d}$ 'Anjou et dont les biens ont été confisqués en 1257. Le Palais a été bâti dans les années 1220 par les représentants de la commune marseillaise, au premier rang desquels se trouvaient les membres de la famille

518 Nous avons utilisé une numérotation spécifique des îlots, plus large que celle utilisée par les fouilleurs. 
Anselme ; il est possible que le terrain ait été donné par l'un d'entre eux. La partie sud serait restée entre leurs mains et transmise ensuite à Briton Anselme.

Il nous semble possible de rattacher à cet îlot au premier registre de cens, daté de 1265 , trois maisons qui sont signalées dans l'île de maison de Guitelme de Caranson ${ }^{519}$. Ce sont en effet les seules maisons « héritées » de Briton Anselme, au nombre de trois dans un îlot, et qui paient deux sous de cens chacune comme en 1302. Elles sont par ailleurs signalées les premières de la liste des anciens cens de Briton Anselme. Par la suite, on l'a dit, seules deux sont serviles au comte et tenues par diverses personnes en 1298 et $1302^{\mathbf{5 2 0}}$ (héritiers du juriste Gilles de Revolta puis le notaire Gilles Noé dans l'angle sud-est; héritiers de Pierre Garini à l'ouest du précédent) puis en 1377 par Bernard de Conques en indivision avec Batrona (de Conques ?), veuve de Jacques de Montmirat, d'où le nom d' ' île de Bernard-de-Conques » donné alors à l'îlot ${ }^{521}$. La maison à l'angle semble avoir brûlé (elle est dite combustam domum en 1377) ce qui explique peut-être pourquoi aucun cens n'était perçu en 1405. Même situation en 1449, tandis que les deux maisons sont passées aux mains de Silone Jeanne ${ }^{522}$.

La troisième maison, à l'ouest, où habite Audibert en 1298, le juriste Jean Joli en 1377 puis son fils Jacques, est servile à l'hôpital Saint-Esprit à la fin du XIV ${ }^{\mathrm{e}} \mathrm{s} .{ }^{523}$.

$\mathrm{Au}$ début du XVI ${ }^{\mathrm{e}}$ s., les trois maisons sont regroupées en une seule, servile au comte pour la part de la maison centrale seulement. Elle appartient à Jean Huc, puis à son fils François Huc; elle est transmise ensuite à sa femme Claude Cépède en 1530 puis à Pierre Huc, sieur de la Reynarde en $15711^{524}$.

Ces maisons confrontent au sud la rue de la Taulisse, qui porte le nom de Bernard-de-Conques dans la seconde moitié du XIV e s. Compte-tenu de la configuration de

519 AD06 B 812, fol. 16: «Isla de Guitelmin de Caranson. Guitelmin de Caranson ser per.I. maison.II.s. Johan Boisson per.I. maison ser.II.s. Alazais de la Sieutat ser per.I. maison.II.s».

520 AD06 B 1019, fol. 13v (1298); AD06 B 1937, fol. 125v-126 (1302).

521 AD06 B 831, fol. 52 : insula Bernardi de Conquis. En 1405, l'îlot est dit sous le mazeau des Accoules et derrière le Palais du roi : «Insula Bernardi de Conquis suptus macellum de Acuis et retro Palatium Regium » (AD06 B 1177, fol. 60v).

522 Reconnaissance effectuée par son neveu et procurateur Mathieu Vivaud: AD06 B 836, $\mathrm{n}^{\circ} 366$.

523 AD06 1 HD B 33, fol. 20v (1380); B 34, fol. 21v et B 36, fol. $27 \mathrm{v}(1383)$ : «Item, serv Jaume Joli que esta en la carreria de Bernat de Concas, filh que fon de maystre Johan Joli (...) »; B 35, fol. 28 (1384) ; B 104, fol. 29v (1386) ; B 37, fol. 22v (1387).

524 AD13 B 859, fol. 61v (1530); B 871, fol. 121 (1547/1549); B 881, fol. 271 (1560) ; B 886, fol. 335v (1571). l'îlot, il s'agit probablement de maisons en parcelles étroites, dont le petit côté ouvre sur la rue. Une étude plus fine du Palais communal permettrait peut-être de retrouver ses dimensions exactes et de localiser ainsi la limite des maisons au sud.

\section{L'îlot 6.02 (= îlot III partie ouest)}

Cet îlot, situé au sud du précédent, disparaît à la fin du Moyen Âge et est englobé ensuite avec l'îlot 6.06.

Dans l'état actuel de nos connaissances, nous n'avons d'indications que pour la (grande ?) maison située au sud-est de l'îlot, qui est donnée aux hôpitaux Saint-Esprit et Saint-Jacques de Galice en 1395 par Bonvineta Reynaud, femme de Jean Reynaud et probable fille d'un membre de la famille Bonvin. Cette maison passe ensuite à Jacques de Remezan vers 1460 , qui l'affranchit comme le signale une mention dans un registre de l'hôpital Saint-Esprit. Cette maison confronte une seconde maison appartenant aux mêmes en 1395 et une autre maison du notaire Guillaume Bayle. Il faudrait poursuivre les recherches d'archives pour appréhender la partie nord de l'îlot.

\section{L'îlot 6.03}

À l'ouest de l'îlot du Palais, se trouve un îlot très allongé, délimité par la rue de la Prison d'une part et la rue des Masses (carriera Massarum ou carreria de las Massas) et subdivisé dans le sens de la longueur par une impasse nord-sud. Au nord, il est séparé de la Grand-Rue par un petit îlot dont nous ne traiterons pas ici.

Au nord de l'îlot se trouve une maison, servile à l'hôpital Saint-Esprit, qui fait face à la prison du Palais royal. Ses propriétaires sont connus par les registres de reconnaissance de cet hôpital : il s'agit du notaire Jacques Aycart entre 1376 et 1394, son fils Laurent Aycart également notaire de 1396 à $1408^{525}$, puis Martin Blanc, Jean Chautart, vicaire des Accoules, Antoine Ruffi (ou Roux) en 1452 et 1471, enfin Bernard Ruffi en $1523^{526}$. À la fin du XVI ${ }^{\mathrm{e}}$ s., cette maison appartient à Louis de Félix, sieur de la Reynarde ; ce sont ses descendants qui donneront leur nom à l'ancienne rue des Masses. La valeur du cens

525 C'est un des rédacteurs du Thesaur del hospital de Sant Sperit publié par Martin-Dietrich Glessgen (1989).

526 AD13 1 HD B 31, fol. 5 (1361-1376); B 32, fol. 12 (1379) ; B 33, fol. 16v (1380), B 34, fol. 17 et B 36, fol. 19 (1383) ; B 35, fol. 20 (1384) ; B 104, fol. 21v (1386) ; B 37, fol. 16 (1387) ; B 38, fol. 22 (1389); B 39, fol. 21 (1390); B 105, fol. 22 (1393); B 106, fol. 16v (1394) ; B 107, fol. 31 (1396) ; B 109, fol. 31v (1402-1410) ; B 110, fol. 15v (1408); B 42, fol. 38v (1465 ?); B 10, fol. 73 et B 20, fol. 81v et fol. 93-94 (1471) ; B 8, fol. 179 (1502) ; B 29, fol. 260-261v et B 24 fol. $112(1452,1471,1523,1583,1666,1675)$. 
est relativement importante jusqu'en 1408 (40 sous). Par la suite, la maison, probablement détruite lors du sac des Catalans en 1423, semble avoir été divisée en plusieurs emplacements, ce qui explique que dans les successions des reconnaissances le cens apparaisse ensuite réduit à seulement 2 sous à partir de 1452 .

Immédiatement au sud se trouvent deux maisons, l'une tenue par Jean Sansonet en 1452 puis Jacques Tripillion, l'autre par Louis Manaud en 1454 ; le tout est réuni par Honorat Forbin puis divisé entre ses deux filles Catherine Forbin (vendue ensuite à Antoine Tourrel) et Marguerite Forbin femme de Charles de Monteaux (Montilis) à la fin du XVe s. ${ }^{\mathbf{5 2 7}}$.

Plus au sud, nous connaissons plusieurs maisons, serviles au monastère Saint-Sauveur. L'une fait l'objet d'une vente en 1346 au prix de 38 livres, avec un cens de 30 sous ${ }^{528}$. D'autres maisons dépendant du même monastère ne sont pas localisées avec certitude dans la rue.

\section{L'îlot 6.04 (= îlot II)}

Cet îlot est situé immédiatement au sud du Mazeau et au nord de la rue de la Taulisse. Il semble que l'îlot soit composé de deux ensembles fonciers (au moins au $\mathrm{XV}^{\mathrm{e}} \mathrm{s}$.). Nous manquons singulièrement d'information pour la période médiévale, la plupart des actes retrouvés se rapportant aux XVI ${ }^{\mathrm{e}}$ et XVII ${ }^{\mathrm{e}} \mathrm{s}$.

La partie occidentale (parcelles 360, 365 et 366) est soumise au cens du roi au $\mathrm{XVI}^{\mathrm{e}}$ s., mais avec des adjonctions successives. À la fin du XIV ${ }^{\text {e }}$ s., l'ensemble de la partie occidentale appartient à la famille de Monteaux (latin Montilis) ${ }^{529}$. Pour une raison que l'on ignore, on voit apparaître un cens au comte en 1405 pour la seule partie nord où se trouve une chambre et un petit four (fornellum) contre la maison principale. La valeur du cens, de 2 sous, se trouve réduite à partir de 1547 à 6 patacs (soit 1 sou) à la suite d'une probable division : Benoit Rocher déclare alors le tiers d'une maison et un casal (ce qui devait en effet revenir à la demi-valeur de la propriété d'origine). Cet ensemble deviendra le Logis du Coq d'Inde au XVII ${ }^{\mathrm{e}}$ s. La partie sud appartient à

527 AD13 1 HD B 8, fol. 121, 128-129 et fol. 140 (1452, 1454, 1457); B 18, fol. 130 et 173 et B 19 , fol. 85 et $104(1518,1520)$; B 14, fol. 154 et B 15, fol. 90 (1560); B 21, fol. 39 et 192 (1568, $1583)$; B 13, fol. 92 (1595) ; B 29, fol. $252-256$ v et B 24 , fol. $110-$ 111 (1452, 1454, 1457, 1487, 1504, 1518, 1528, 1560, 1568, 1595, 1609).

528 AD13 $61 \mathrm{H} 8, \mathrm{n}^{\circ} 3$ (12 mars 1346).

529 AD13 B 831, fol. 29 (confront avec la maison de Barthélémy de Monteaux en 1377) ; B 1177, fol. 60v (1405) ; B 836, n 372 (1446); B 863, fol. 163 (1537) ; B 871, fol. 71v et 363 (1547-1549); B 859, fol. $16 \mathrm{v},, 51 \mathrm{v}$ et $309 \mathrm{v}(1560-1571)$; B 881, fol. $262 \mathrm{v}(1560) ; 351 \mathrm{E}$ 94, fol. 1186 (1654) ; 353 E 95, fol. 76 (1655) ; 364 E 256, fol. 1140 (1670) ; 372 E 97, fol. 316 (1695) ; 361 E 93, fol. 226v (1705).
Antoine Huc à la même époque et paie 4 s. 4 d. de cens : on peut penser qu'il s'agit de l'adjonction de deux cens plus anciens de 2 s. 2 d. chacun. La séparation entre propriétaires a dû intervenir dans la première moitié du XVI ${ }^{\mathrm{e}}$ s. puisque l'on garde encore la mémoire d'une appartenance de la partie nord à Jean Huc en 1569. On ne sait pas en revanche comment ce bien est entré dans la directe du roi.

La partie orientale (parcelles 357 à 359, 364 et 387) pourrait être sous la directe partielle ou totale de l'hôpital Saint-Jacques de Galice ; un complément de recherche que nous n'avons pas pu entreprendre dans ces fonds serait nécessaire pour préciser l'évolution médiévale des propriétés. En 1417, Jean Ledoscii, boucher, reconnaît à cet hôpital une maison qui est dite dans le Mazeau (in massello de Acuis) ce qui montre bien l'ouverture directe à cette époque sur le Mazeau situé immédiatement au nord. À l'est et au sud, se trouvent deux maisons appartenant à Nicolas d'Aix ${ }^{\mathbf{5 3 0}}$. Nous n'avons pas plus d'indication sur cet îlot pour l'époque médiévale.

\section{L'îlot 6.05}

L'îlot 6.05 est situé au nord du Mazeau et longe la rue principale Aurivellarie (ou Grand-Rue). Une partie des maisons est servile à Saint-Sauveur : en 1450, Guillaume Rehon vend à Honorat de Bourg-Neuf une maison avec four et deux places où se trouvaient autrefois des maisons probablement détruites en $1423{ }^{531}$. À l'ouest de cet ensemble, à cette date, se trouve la maison du notaire Palamède Vinateri et à l'est la maison de la veuve du boucher Peyronet d'Aix. L'ensemble des maisons confronte les deux rues au nord et au sud. Plus à l'est, à l'angle de l'îlot, une maison est servile à l'hôpital Saint-Esprit ; elle comprend également deux étals de boucher et appartient au boucher Jacques Bermon à la fin du XIV e s., à Antoine Bernus puis Jean Bernus au début du siècle suivant ${ }^{532}$. L'ensemble est alors détruit par les Catalans en 1423 ; le cens passe de 5 sous à 16 deniers. Elle sera par la suite habitée par le notaire Robert Ruffi par regroupement de deux maisons ouvrant l'une au nord et l'autre au sud.

\section{L'îlot 6.06 (= îlot III partie est)}

Cet îlot est situé entre la rue de la Taulisse et la rue des Olives ; il porte le nom de Jacques Jaucenne en 1377.

530 AD13 4 HD B 5, fol. 184.

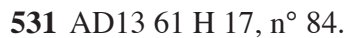

532 AD13 1 HD B 106, fol. 1 (1394); B 107, fol. 1 (1396) ; B 109, fol. 138v (1402-1410); B 108, fol. 58 (1410); B 12, fol. 83 (1423); B 24, fol. 101 (1423, 1446, 1485, 1515, 1586, 1633). 
Il s'agit d'un des îlots dégagés dans la première fouille de la place Bargemon, ce qui permet de confronter les textes avec la réalité archéologique et d'affiner ainsi les localisations.

Dans l'angle nord-est de l'îlot, on trouve trois maisons contiguës en 1298, ainsi regroupées dans la reconnaissance de Geoffroy de Gênes auprès du comte, le tout pour un cens total de 2 sous (soit 8 deniers par maison). En 1377 et 1405, Jacques Jaucenne reconnaît une maison située à l'angle de l'îlot pour 18 deniers. S'agit-il des anciennes maisons? Cela semble vraisemblable, d'autant plus qu'une note marginale dans l'enquête de 1298 signale que la possession en est passée à Jacques Jaucenne. Ainsi est constituée une grande maison d'angle, dont la valeur est probablement moins importante que les trois maisons isolées, ce qui explique la baisse du cens. C'est ensuite son petit-fils Jacques Gassin qui la tient en 1446 et 1447. Un siècle plus tard, la maison est en possession des trois frères Barthélémy, Baptiste et Christofol Cassin «aultrement dict Cepede $\gg 533$.

A l'ouest de ces maisons, on suit la filiation d'une autre maison, également servile au comte et au roi pour 18 deniers de cens, depuis Daniel Bonaventure en 1298 et 1303, noble Guigues de Montolieu en 1377 et 1405 (provenant de la dot de sa première femme Sauseta), puis sa veuve Batrona de Soliers en 1424. Elle devient ensuite la propriété de Guillaume Coste dit Pavie en 1447 puis Albertini Cachoti quelques années plus tard. Elle passe ensuite entre les mains de la famille Vento qui semble l'avoir affranchie car on ne la retrouve plus ensuite parmi les biens du roi ${ }^{534}$.

On trouve à l'ouest de cette maison une maison tenue par Pierre de Saint-Jacques pour 18 deniers en 1303 puis deux autres maisons, toujours reconnues au comte en 1298 et 1303 par Léonard Pisan puis par Jean Cayrellerii ${ }^{535}$. Le cens de ces deux dernières est de deux sous, ce qui devrait, pour ces deux maisons correspondre à la surface des trois maisons de Geoffroy de Gênes. La première de ces deux maisons faisait coin avec le prolongement disparu de la rue du Coq-d'Inde. Enfin il faut ajouter une dernière petite maison, tenue par Giraud Delbatut pour seulement 3 oboles (c'est-à-dire $1 \frac{1}{2}$ denier). Ces quatre maisons sont ensuite absentes des registres de reconnaissance du comte. Nous savons qu'en 1377 et 1405,

533 AD13 B 1019, fol. 13v (1298); B 1937, fol. 126 (1303) ; B 831, fol. 52v (1377) ; B 1177, fol. 4v (1405); B 836, n 341 et 416 (1446, 1447) ; B 871, fol. 71-71v, 362v-363 (1547-1548) ; B 881, fol. 258v (1560) ; B 859, fol. 10, 50v, 306 (1569).

534 AD13 B 1019, fol. 13v (1298) ; B 1937, fol. 126 (1303) ; B 831, fol. 52v (1377) ; B 1177, fol. 4v (1405); B 836, n 365 (1447); B $836, n^{\circ} 387$ (1449?).

535 AD13 B 1019, fol. 13v (1298) ; B 1937, fol. 126 (1303). l'ancienne maison de Pierre de Saint-Jacques est possédée par noble Bérenger Martin. Or un acte conservé dans les archives de l'hôpital Saint-Esprit, indique que cet ensemble, probablement affranchi par Bérenger Martin, a été donné à l'hôpital par celui-ci le 27 janvier $1396^{536}$. Ainsi est constitué une nouvelle maison d'angle, équivalente en dimensions à celle de Jacques Jaucenne. Cette maison est détruite en 1423 ( «fon reducha la dita censa a XVI s. car lo dit hostal es tot fondut en l'invasion per los Catalans facha ») ; le cens passe alors de 20 livres à 60 deniers en 1424. Par la suite, on trouve un laboureur, Foulques Isnard puis Perceval Vento à partir de 1465. La maison sera affranchie en 1607.

On remarquera que l'ensemble des maisons signalées ci-dessus, qui correspond approximativement à la moitié nord de l'îlot, relève du comte de Provence. Si l'on observe ce que la fouille a mis au jour, il s'agit de toute la partie nord de l'îlot qui remonte à la fin du XII ${ }^{e} \mathrm{~s}$. Au sud de ces maisons, un espace longiligne traversant l'îlot correspond probablement à une ancienne voie (dans l'axe de la rue Saint-Christophe) qui a été très tôt englobée dans un îlot plus grand. Ainsi s'explique la petite maison de Giraud Delbatut ${ }^{537}$ : elle a été construite sur l'emprise de cet axe, à l'ouest, tandis que les maisons qui la bordaient au nord s'appropriaient chacune un tronçon.

Ces maisons proviennent des confiscations opérées sur les biens de Briton Anselme, dont on retrouve la trace dans le registre le plus ancien des reconnaissances des biens du comte, daté de 1265. À cette date, l'îlot porte le nom de Bernard Bonafos et ne constitue que la partie nord de l'îlot 6.06 ; la disparition de la rue intermédiaire n'a pas encore eu lieu. Ainsi trouve-t-on trace d'une possession homogène, probablement bâtie par les ancêtres de Briton Anselme. Par ailleurs, on notera également que dans cette proposition, les îlots que les fouilleurs ont numéroté II et III ont à l'origine des dimensions semblables, situés l'un au nord l'autre au sud de cet îlot étroit. L'ensemble relève-t-il d'un même lotissement ?

Au sud de l'îlot, nous n'avons à notre disposition que les mentions de confronts pour connaître les

536 «Item, una carta presa, sos escricha e senhada per maistre Laurens Aycart, notari, l'an mil.CCCXCV., di XXVII de jenoyer, contenent que lo noble Berengon Martin vendet per via de mal afranquiment al hospital.XX. libras censals am la maior senhoria [per.I. hostal] pausat en la carriera sos lo masel de las Acoas; confronta am l'ostal de mossen Peire de Servieras que fom de sen Jacme de Galbert, am l'altre hostal de dit mossen Peire, e am la carriera que va a l'ostal del dit mossen Peire, e am l'ostal dotal de donna Sauseta, molher de sen Guigo de Montolieu, e am la carriera publica; e apres es la reconoycensa facha per lo dit Berenguier e la ratiffication facha per dona Borgonhona, molheur sieua, lo dit an, di.XII. de febrier ; senhada per : K. XIIII. »(Glessgen 1989, p. 156). 537 Dans le registre de 1298, une note marginale postérieure indique «on dit qu'elle fût à Jacques de Gaubert ». 
propriétaires des maisons. En partant de l'ouest, on a tout d'abord deux maisons qui appartiennent en 1377 à Pierre de Servières. La première provient de Jacques de Gaubert et la seconde semble lui appartenir en propre (ou au moins depuis plus longtemps). Il s'agit probablement d'une maison avec un espace libre autour puisqu'elle est donnée comme confront de quasiment toutes les maisons de la partie nord. Après la destruction de 1423, la maison est possédée par des bouchers.

Seule semble rester à l'écart une petite maison située le long de la rue de la Guirlande, au contact de la maison de Jacques Jaucenne et possédée par les héritiers de Raymond de Narbonne en 1298 et 1303, Sancia fille de P. Carbonel en 1377, Pierre Gaudili en 1446-1447, puis Pierre Vento et ses héritiers au milieu du XVI ${ }^{\mathrm{e}}$ s. ${ }^{\mathbf{5 3 8}}$. La maison à l'angle sud-est de l'îlot, probablement assez grande, appartient en 1377 à Antoine Bonvin. L'ensemble de la moitié sud est donc restée aux mains de seigneurs et n'a pas été donnée à un établissement religieux ou hospitalier.

\section{Ilot 6.07}

Il s'agit de l'îlot du Mazeau. À l'époque médiévale, aucune maison n'est construite à cette emplacement. Les premières traces de bâtiments sont signalées dans les registres de reconnaissances du comte de 1537 et suivantes. Ces maisons peuvent remonter au début de ce siècle ; il faudrait vérifier s'il ne s'agit pas à cette époque de compenser une éventuelle disparition de la bocaria, c'est à dire l'endroit où l'on va découper les animaux, qui est située au Moyen Âge au nord de la Grand-Rue, dans l'îlot de l'hôpital Saint-Esprit.

\section{Ilot 6.08 (îlot I)}

Le dernier îlot de notre étude est situé à l'est de la rue de la Guirlande. Pour ne pas trop déborder la zone analysée, la recherche en archives ne s'est pas portée sur la rue Torte, qui délimite l'îlot à l'est. Nous n'avons donc à notre disposition que les maisons qui constituent la moitié occidentale de l'îlot, celui-ci étant orienté nord-sud avec des maisons adossées ouvrant à l'est et à l'ouest.

Les quatre maisons situées au nord-ouest de l'îlot relèvent du comte de Provence. Elles ne sont repérées qu'en 1377 ; là encore la recherche devra être approfondie dans le cadre de l'étude des possessions comtales marseillaises. La maison à l'angle comprend également trois étals de boucher; elle appartient à Roland

538 Etrangement, la maison n'apparaît qu'une fois dans les biens relevant du comte : B 831, fol. 52v (1377). Le reste des indications de possesseur est donné par les confronts.
Borillon en 1377, à son fils Antoine en 1405, puis à Jaumette Borillonne, femme d'Antoine Massatelli qui la transmettent à leur fils Jean avant $1459^{539}$. Un four est signalé dans cette maison à partir de 1459, peut-être lié à une reconstruction après 1423. La maison suivante, au sud, comprend également deux étals de boucher; elle est reconnue par Alexis Rebuffat en 1377, son fils Jacques en 1405 et Guillaume Rellon en $1446^{540}$. La troisième maison, avec ses deux étals de boucher, appartient en 1377 à Bernarde, fille de Christiane de Amfloris, à Huguette André, femme du boucher Louis, en 1405 et à Guillaume Rellon en $1446^{541}$. La dernière maison servile au comte appartient à Jeanne Alaman, femme de Raymond Borgondionis en 1377, à Rostaing Raimond en 1405 et à Huguette Cristofol en 1450 ; on précise à cette date qu'il existe une place pour faire deux étals de boucher ${ }^{542}$. Toutes ces maisons paient 70 sous de cens avant 1423 (et 32 sous après), sauf la maison d'angle qui paie 20 sous de plus; elles sont situées face au Mazeau et lui sont donc directement liées, ce qui explique les étals de bouchers associés aux maisons.

$\mathrm{Au}$ sud se trouve un ensemble de maisons qui relève de l'hôpital Saint-Jacques-de-Galice. Les deux premières apparaissent dans les possessions de cet hôpital dans le dernier quart du XIV ${ }^{\mathrm{e}}$ s. Celle qui confronte les maisons du comte paie un cens de 4 sous et appartient à Jean Textoris en 1485 puis Jérôme Pinet en 1490 et $1512^{543}$. La suivante, au cens de 16 sous, appartient à la famille de Forbin : Jacques de 1477 à 1490, Charles en 1508, puis Claude Forbin et ses héritiers au milieu du $\mathrm{XVI}^{\mathrm{e}} \mathrm{s} .{ }^{544}$

Les trois maisons qui suivent sont particulièrement intéressantes car nous arrivons à suivre la façon dont elles sont rentrées en possession des deux hôpitaux SaintJacques-de-Galice et Saint-Esprit, grâce aux notices rédigées dans le Thesaur del hospital de Sant Sperit ${ }^{545}$.

539 AD13 B 831, fol. 26v (1377); B 1177, fol. 2v (1405); B 836, $\mathrm{n}^{\circ} 346(1459)$.

540 AD13 B 831, fol. 26v et 27 (1377); B 1177, fol. 1v (1405); B $836, \mathrm{n}^{\circ} 357$ (1446).

541 AD13 B 831, fol. 26v et 27 (1377) ; B 1177, fol. 1v (1405) ; B $836, \mathrm{n}^{\circ} 358(1446)$.

542 AD13 B 831, fol. 26v et 27 (1377); B 1177, fol. 3 (1405); B $836, n^{\circ} 340(1450)$.

543 AD13 4 HD B 8, fol. 261 (1485); B 15, fol. 77 (1490); B 18, fol. 71v (1512).

544 AD13 4 HD B 6, fol. 51 (1477) ; B 15, fol. 80 (1529).

545 Glessgen 1989, p. 157 (1385) (Thesaur fol. 65) : «Item, una carta presa, escricha e senhada per maistre Laurens Aycart, notari, l'an MCCCLXXXV, di VIIII de mas, contenent que mossen Peire Alaman, cavalier, vendet a sen Jolian de Casals, mercant de Masselha, las censas sos escrichas per pres de CCCIII florins e VI sols, lo quals confesset aver agut; senhada per : K. XVIII. 
Le 9 mars 1385, le chevalier Pierre Alaman vend au marchand Julien de Casaux de nombreux cens qu'il possède sur des maisons. Parmi celles-ci, une grande maison, dans laquelle habite Aicard Catalan, lequel verse un cens très important de $81.10 \mathrm{~s} .8 \mathrm{~d}$. ; au sud de la précédente, une maison du pêcheur Pierre Viguier qui paie un cens de $41.5 \mathrm{~s}$. et $4 \mathrm{~d}$. (c'est-à-dire exactement la moitié du cens précédent). En 1394, Julien de Casaux, dans son testament, institue comme héritiers les deux hôpitaux Saint-Jacques-de-Galice et Saint-Esprit. La division des biens qui intervient à ce moment là donne à l'hôpital Saint-Jacques la première maison et à l'hôpital SaintEsprit la seconde. Nous suivons ainsi dans les registres de ces deux hôpitaux le devenir de ces possessions. On notera en particulier que le cens de la première maison est considérablement réduit après 1423 puisqu'il passe à 21 . Nous n'avons pas d'indication sur les maisons de la partie sud de l'îlot.

Cet ensemble mérite que l'on s'y arrête un instant, en confrontation avec les données archéologiques. Nous sommes en effet ici dans l'îlot numéroté I par les fouilleurs, et dont seule la partie occidentale était dans l'emprise de la fouille. Si nous reprenons le compte des maisons par rapport aux découvertes archéologiques, les quatre maisons comtales correspondent aux maisons $\mathrm{A}$ à $\mathrm{C}$ (plus la maison d'angle hors d'emprise de la fouille). La petite maison suivante est entre les maisons $\mathrm{C}$ et $\mathrm{D}$ (celle qui ne verse que 4 sous à l'hôpital Saint-Jacques de Galice). La suivante, qui paie un cens important pour la fin du $\mathrm{XV}^{\mathrm{e}}$ s. de 16 s., appartient à Jacques Forbin, seigneur de Gardanne ; un confront plus ancien avec l' " hospitio penoris » (c'est-à-dire la maison du cellier) irait dans le sens d'une interprétation comme entrepôt : le grand bâtiment (puisque nous sommes ici sur la salle 1 du grand bâtiment D) aurait eu, à la fin du Moyen-Âge, une vocation de cellier. Peut-être faut-il associer à cette maison les pièces 2 à 4 de la fouille, et voir ensuite dans la salle 5 l'emplacement de la grande

Primo las VIII libras X sols VIII dr que serv Aycart Catalan per I hostal e-patil tenens pausas en la carriera [rue A] desos lo Masel Antic; e del dit hostal si son fachas II pars, de-las quals l'un es de Laurens Bernat, mercant, e serv a-l'espital de Sant Jacme per la devesion de-las censas del dit sen Jolian ; e l'altre [7] ten Antoneta Atanossa, filha del dit Aicart, com apar en libre A.

Item, las IIII ll. V s. IIII dr. que serv Peire Beguier, pescador, per I hostal pausat en la dita carriera, lo qual es devesit en II pars; e-l'una ten Bernat Beguier, son filh, e l'altra sos neps, fils de Victor, son frayre, com apar en $A$, folio $C X X I$ ».

Glessgen 1989, p. 51-52 (1394) (Thesaur fol. 5v) : «Item, una carta presa, sos escricha per la man de maistre Laurens Aycart, notari, l'an mil CCCXCIIII, di redier de jenoyer, contenent lo testament e-los codecils del honorable home sen Jolian de Casals, mercant, lo qual fes heres l'espital de Sant Sperit e l'espital de Sant Jacme, dotat per sen Bernat Garnier; senhat per : A. XXXV». maison d'Aicard Catalan, divisée ensuite en deux parties : l'une à sa fille Antoinette Atanulf au nord (servile à l'hôpital Saint-Esprit) et la seconde à Laurent Bernard (servile à l'hôpital Saint-Jacques de Galice). La pièce 6 correspond ensuite à la maison de Pierre Viguier, ellemême divisée par la suite en deux parties entre ses deux fils Victor et Bernard Viguier, relevant toutes deux de l'hôpital Saint-Esprit.

Nous pouvons ici remonter au milieu du $\mathrm{XIV}^{\mathrm{e}} \mathrm{s}$. avec une possession du chevalier Pierre Alaman, grand personnage marseillais, fils de Giraud Alaman et possessionné largement à Marseille et dans ses faubourgs ${ }^{546}$. Nous possédons un compromis passé avec Jean Boniface, évêque de Glandèves et ancien sacriste du chapitre de la Major, à propos de l'héritage de Douce Alaman, grand-mère paternelle de Pierre Alaman junior, et arrière grand-mère de Jean Boniface ${ }^{547}$. Pierre Alaman senior, celui qui nous intéresse ici, était donc le fils de Giraud et Douce Alaman et marié avec Françoise ${ }^{548}$; il meurt en $1406^{549}$ et est enterré dans la chapelle des Alaman fondée dans l'église des Dominicains sous le titre de Saint-Jacques ${ }^{550}$. On notera par ailleurs que Hugues Alaman, frère de Giraud, fut l'héritier universel du chevalier Philippe Anselme en 1301 (Bouiron 2001a, p. 259-270). Ce ne sont ici que quelques pistes de transmission qui devront être confrontées à de nouvelles découvertes dans les archives. Mais d'ores et déjà, la relecture toute récente d'un acte daté de 1214 permet de proposer une interprétation à ce grand bâtiment et donne une vision des îlots au début du XIII ${ }^{\mathrm{e}} .{ }^{551}$.

\subsubsection{Analyse comparée de l'étude d'archives et de l'archéologie}

Un des points importants de cette étude est de pouvoir, pour la première fois, obtenir une correspondance entre bâtiments médiévaux et textes d'archives en particulier grâce à l'étude de l'îlot 6.06. Sans entrer trop dans

546 Son fils du même nom était le représentant des intérêts de Montpellier à Marseille, et à ce titre prieur de la chapelle suburbaine de Sainte-Catherine en 1428-1431 (Bouiron 2001a, p. 259-270).

547 AD13 355 E 66, acte inséré entre fol. 12 et 13 (25 avril 1410).

548 Testament de Nicolave Alaman, fille de noble Pierre Alaman et Françoise, et femme de Guillaume de Favas. AD13 23 H 12, charte $\mathrm{n}^{\circ} 81$ (26 avril 1411).

549 Partage des biens de feu noble Pierre Alaman entre Sansone, femme de Guigues de Montolieu et Béatrice de Vaquières, sœurs. AD13 H, $23 \mathrm{H} 10$ charte $\mathrm{n}^{\circ} 73$ (26 ? 1406).

550 Testament de Nicolave Alaman ( $c f$. supra note 548).

551 Voir l'article Bouiron à paraître qui reprend dans le détail la localisation des différents bâtiments du début du XIII ${ }^{e}$ s. grâce à l'interprétation d'un texte provenant des archives de l'abbaye Saint-Sauveur (AD13 61 H 2, pièce 12 du 21 juillet 1214), dont la transcription est donnée en annexe de l'article. 
l'interprétation historique qui est ici prématurée, il faut noter quelques aspects novateurs.

Nous pouvons en particulier réfléchir pour la première fois sur la valeur du cens à Marseille. Il est entendu que le cens est établi à l'origine en fonction de la surface des terrains. L'angle nord-est de l'îlot 6.06, dans lequel on restitue trois maisons relativement petites, correspond aux trois maisons de Geoffroy de Gênes en 1298 qui ont une valeur, pour elles trois, de 2 sous de cens, soit 24 deniers. Les dimensions relevées en fouille de cette parcelle un peu irrégulière sont d'environ 15 à $16 \mathrm{~m}$ d'est en ouest (soit $71 / 2$ à 8 cannes) et 7 à $8 \mathrm{~m}$ (soit $31 / 2$ à 4 cannes) du nord au sud (en excluant la zone de l'ancienne ruelle). La surface est donc comprise entre $261 / 4$ et 32 cannes carrées. On est donc proche du denier par canne carrée, avec une valeur comprise entre 1 1/5 et 1 1/3 denier. Si l'on prend l'espace intérieur, on est à $14 \mathrm{~m}$ (soit 7 cannes) d'est en ouest et $6 \mathrm{~m}$ (soit 3 cannes) du nord au sud soit 21 cannes carrées. Nous retiendrons donc, pour donner un ordre de grandeur, la valeur d'un denier par canne carrée qui pouvait, par sa relative simplicité, être calculée facilement. Il est probable que cette valeur a subi ensuite des fluctuations, en particulier suivant la présence ou non d'un bâtiment sur la parcelle. Ainsi s'expliquent des valeurs de cens plus élevées par la suite. Ce n'est probablement pas le cas au XIII' $\mathrm{s}$.

Autre élément important, c'est la réalité foncière seigneuriale que l'on devine autour du Palais communal. Il est très vraisemblable que l'ensemble de la zone s'étendant entre le Palais et le Mazeau à l'est et jusqu'au milieu de l'îlot 6.06 a appartenu à la famille Anselme/Fer. La compréhension exacte de cette possession implique d'abord de pouvoir localiser précisément tous les terrains ayant été confisqués par le comte en $1257^{552}$.

Si l'on étudie l'emprise entre la rue du Coq-d'Inde et son prolongement sud (la «rue droite du Palais ») et la rue de la Guirlande, on observe un ensemble d'îlots primitifs allongés dans le sens est-ouest, ce qui va à l'inverse de ce que l'on trouve habituellement dans la zone de la rive nord du Vieux-Port. Or nous avons là un découpage très régulier : un îlot, probablement existant au nord avec maisons au nord et au sud (sous la directe en particulier de l'abbaye Saint-Sauveur), puis l'îlot du Mazeau, à nouveau un îlot avec deux rangs de maisons adossées, un îlot étroit puis un nouvel îlot à

552 Ceci sera réalisé dans le cadre de la vaste publication de l'Enquête de 1333, sous la direction de T. Pécout ; en l'absence d'une telle enquête à Marseille, nous publierons avec J. Sibon les deux registres du XIII ${ }^{\text {s }}$ s. (1265 et 1298) en axant l'étude sur les aspects topographiques. maisons adossées. Ceci ressemble fortement à un lotissement dans lequel il faudrait peut-être comprendre l'îlot du Palais et celui qui lui est voisin au sud. Si l'on songe à la possession d'une partie de ces îlots par Briton Anselme en 1257, la datation archéologique de mise en place de ces îlots, dans la seconde moitié du XII ${ }^{\mathrm{e}} \mathrm{s}$. est tout à fait compatible avec la création d'un lotissement par le plus illustre des représentants de la famille Hugues Fer, viguier des vicomtes de Marseille dans le dernier tiers du XII ${ }^{\mathrm{e}}$ s. La construction du Palais communal et du Mazeau sur cette zone peut avoir renforcé encore le prestige de cette famille seigneuriale marseillaise.

Cette interprétation est confirmée par le texte de 1214 que nous avons signalé supra. Il s'agit d'une sentence arbitrale entre l'abbaye Saint-Sauveur et Anselme Fer, le père de Briton Anselme, et lui-même fils d'Hugues Fer, viguier des vicomtes et premier artisan de l'indépendance communale. Ici, deux îlots sont signalés, avec des maisons, qui confrontent à l'est un établissement de bains. L'étude des confronts indique que les îlots correspondent à la partie nord de l'îlot III (6.06) (qui est donc bien séparé en deux parties distinctes à l'origine) et à l'îlot II (6.04). L'établissement de bains est donc dans l'îlot I (6.08) et peut être assimilé au grand bâtiment retrouvé en fouille.

La localisation des terrains dont le trézain est revendiqué par Anselme Fer montre la progressive récupération du foncier appartenant au monastère, tel que nous la décrivions plus haut. Elle témoigne également d'un temps où le monastère contrôlait toutes les maisons, probablement construites rapidement sous forme de lotissement monastique, premier évènement de ce type signalé à Marseille que l'on doit faire remonter à la seconde moitié du XII ${ }^{\mathrm{e}} \mathrm{s}$.

Pour les périodes plus récentes, et en particulier de la seconde moitié du XIV ${ }^{\mathrm{e}}$ s., il faut noter l'ampleur des possessions qui sont données aux deux hôpitaux principaux (Saint-Esprit et Saint-Jacques de Galice). Là encore la recherche devra être poursuivie pour connaître les possessions initiales, en particulier celles qui sont données par le riche fondateur de l'hôpital Saint-Jacques, Bernard Garnier.

Enfin, ces textes permettent d'aborder la question de la population du quartier. Bien évidemment, la présence du Palais communal d'un côté et du port de l'autre en fait le quartier privilégié des grandes familles marseillaises. Progressivement se constituent de grandes maisons, en particulier aux angles des îlots comme le montre bien l'exemple de l'îlot 6.06. À cet égard, le sac de la ville par les Catalans marque une véritable rupture dans l'occupation du quartier. La quasi totalité des habitations, lorsqu'elles ne sont pas détruites, passent ensuite 
aux mains d'une population moins prestigieuse, parmi laquelle on compte beaucoup de bouchers. La proximité du Mazeau a ici largement influencé la transformation de la population. Il faut attendre la seconde moitié du $\mathrm{XVI}^{\mathrm{e}}$ s. pour qu'apparaissent de nouveau des habitants d'un rang important. Les mêmes transformations du bâti se produisent ensuite, avec le regroupement des parcelles pour la construction de demeures prestigieuses.

\subsection{Le quartier du Corps-de-Ville à la lumière des sources écrites (C. Castrucci)}

Dans son ouvrage sur Lyon au XVIII ${ }^{e}$ s., Maurice Garden évoque la difficulté à approcher une ville par l'intermédiaire du quartier tant ce qui se trame au sein de celui-ci est complexe. Et s'il assure que le quartier « présente l'avantage de mieux appréhender les liens ténus du quotidien » et « redonne vie aux signes d'une solidarité de l'instant », il met en garde sur la nécessité de chercher le sens de ce qu'y vivent ses habitants en empruntant également d'autres pistes (Garden 1969, p. 488).

C'est donc consciente des difficultés que nous allions rencontrer que nous avons tenté d'approcher ce quartier du Corps-de-Ville dans lequel se situaient les chantiers de fouille faisant l'objet de la présente étude. Ce n'est qu'au début du $\mathrm{XVI}^{\mathrm{e}}$ s. que ce quartier prend son existence. Auparavant, l'étendue de ce secteur de la ville était incluse dans les trois sixains -qui découpaient la ville depuis le XIII' s.- qu'elle regroupe désormais : les Accoules, la Draperie et Saint-Jacques, les Accoules devenant de ce fait la paroisse du Corps-de-Ville.

Les trois autres quartiers se partagent le reste de la ville : Saint-Jean, qui existait déjà, Blanquerie et Cavaillon. Pourquoi donne-t-on le nom de Corps-deVille à ce quartier ? Cette dénomination ne se retrouve dans aucune autre ville à la même époque (Coste 1970) ${ }^{553}$. Quelles étaient les limites géographiques de ce quartier, qu'est-ce qui le définissait ? Pourquoi ce nom de Corps-de-Ville ? Venait-il des édifices qui y étaient en place ? De la qualité des personnes qui y possédaient des demeures ? Des activités qui s'y déroulaient?

Maurice Garden dit encore qu'un quartier peut être défini par la stabilité de sa population, par des «lieux, des institutions, des signes symboliques qui concourent à unifier la pratique [d'un] territoire »; mais cela peut être aussi « une rue, un pâté de maison un seul côté d'une rue » (Garden 1984). Au travers des vestiges découverts

553 J.-P. Coste l'emploie dans son étude sur Aix. Il procède à un redécoupage des 6 quartiers d'Aix qu'il réorganise en 10 secteurs pour les besoins de son analyse. L'un d'eux porte le nom de Corpsde-Ville, terme emprunté à un rôle d'auberges de la fin du XVII' $\mathrm{s}$. en fouille et des textes d'archives le concernant, nous allons tenter de décrire un quartier qui n'était peut-être pas uniforme mais composé de petites unités dont la somme avait probablement formé un tout homogène ou très complexe.

\subsubsection{Limites topographiques à l'Époque moderne}

Situé au pied de la butte des moulins, le quartier de Corps-de-Ville avait une limite commune avec chacun des trois autres quartiers : à l'ouest Saint-Jean, à l'est Blanquerie, au nord Cavaillon.

Le quartier était donc inclus entre, à l'ouest la place Vivaud, à l'est la place Neuve, au nord l'église des Accoules et l'hôpital Saint-Esprit, enfin au sud, le port vers où convergeait l'essentiel de l'activité. Une rangée d'immeubles le séparait de la Maison commune, ancienne Loge des marchands.

Toutefois, les limites exactes en étaient assez floues. Selon les sources, on trouve telle parcelle comme appartenant à un quartier ou à un autre. C'est le cas par exemple pour la limite avec le quartier de Cavaillon. Plusieurs maisons, acquises au milieu du XVIII ${ }^{\mathrm{e}}$ s. par les recteurs de l'Hôtel-Dieu en vue de son agrandissement, sont placées dans la rue de l'Abadie ou des Cartiers. Les actes notariés mentionnent celle-ci tantôt au Corps-de-Ville tantôt à Cavaillon ${ }^{554}$. C'est également le cas de la rue du Prat, située en limite du Corps-de-Ville et de Cavaillon. Un registre de cens dus au roi, dressé entre 1686 et 1689 , la signale tantôt dans l'un, tantôt dans l'autre quartier ${ }^{555}$. Ce qui est étonnant c'est qu'on ne rencontre pas ce problème pour la rue Négrel (ou de Négreaux) qui lui est pourtant parallèle et que toutes les sources placent au Corps-de-Ville. S'agissait-il d'un côté entier de la rue qui était dévolu à l'un ou à l'autre quartier ? Peut-être avait-on divisé la rue en deux secteurs, la partie la plus au nord appartenant à Cavaillon l'autre au Corps-de-Ville ? Le problème est exactement le même pour la limite entre le Corps-de-Ville et le quartier Saint-Jean. On sait que la rue de la Reynarde était incluse dans le Corps-deVille, et que la place Vivaud se trouvait à Saint-Jean. En revanche, l'île de maisons entre ces deux points comportait des bâtiments faisant partie de l'un comme de l'autre

554 Pour la rue située au Corps-de-Ville : AD13 361 E 123, fol. 466 ;

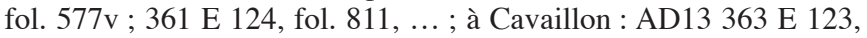

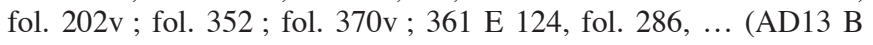
929, $8^{\text {e }}$ cayer, fol. 23 et fol. 30). Ce qui est étonnant c'est qu'on ne rencontre pas ce problème pour la rue Négrel ou de Négreaux qui lui est pourtant parallèle.

555 AD13 B 929, 8e cayer, fol. 23 et fol. 30. 
quartier ${ }^{556}$. L'appartenance évoluait aussi avec le temps. Ainsi la même habitation à l'angle de la rue des Ventos et de la place Vivaud est-elle signalée dans une reconnaissance de cens de 1686 à Saint-Jean, alors qu'en 1729, elle est placée dans le Corps-de-Ville ${ }^{557}$. Le découpage administratif a une logique qui lui est propre. Peut-être certains immeubles échappaient-ils à certains recensements laissant alors le greffier libre de ses appréciations.

Une autre explication peut également entrer en ligne de compte: lorsqu'une maison est servile au roi, elle l'est, dans la plupart des cas dans son intégralité ; alors que très souvent les établissements religieux partagent avec tel ou tel autre, des parts d'immeubles. Ainsi dans la rue de Rome en 1715, Julien Rimbaud reconnaît une maison par indivis à la chapellenie Saint-Elzéar et à l'hôpital Saint-Esprit ${ }^{558}$. En 1742, Antoine Roland reconnaît au même chapitre une maison rue du Petit-Jérusalem, «dans laquelle une maison servile à la Major avait été incorporée » ${ }^{559}$. Dans le même registre de cens de Saint-Victor, Joseph Durand reconnaît, en 1741 «pour un tiers par indivis avec le Chapitre de la Major, pour les autres deux tiers la moitié du couchant sur la rue de la Bonneterie d'une maison ${ }^{\mathbf{5 6 0}}$. Or les registres de cens des établissements religieux ou hospitaliers ne tiennent pas compte de ce découpage «politico-militaire »; les listes des censitaires sont dressées par nom de rues ${ }^{\mathbf{5 6 1}}$. Ce qui nous permet d'aborder la question du sens donné à cette dénomination de Corps-de-Ville. On ne la repère que dans les documents officiels dépendants du pouvoir civil - registres de cens dus au roi, textes règlementaires, actes notariés.

Doit-on dire que le pouvoir religieux « résiste » au pouvoir civil en n'adoptant pas cette dénomination? Bien sûr, les registres de cens regroupent les rues selon un ordre logique de localisation : il est très rare qu'au milieu d'une liste de rues d'un certain secteur on en trouve une faisant partie d'un tout autre quartier. Mais la coexistence de ces deux manières de procéder montre l'imbrication entre le politique et le religieux. L'emprise des établissements religieux était une réalité constante pour chaque marseillais de cette époque : il faut voir qu'autour de la paroisse se déroulait plusieurs moments

556 Ceux situés le plus à l'ouest et donnant à l'est de la place Vivaud, semblent avoir été inclus dans le quartier Saint-Jean (AD13 364 E 224, fol. 881).

557 AD13 B 929, fol. 53v en 1683 ; ACM CC1, fol. 34, n 107.

558 AD13 1 H 973, fol. 214.

559 AD13 1 H 973, fol. 232.

560 AD13 1 H 973, fol. 28.

561 Tout au plus, trouve-t-on, dans un registre de cens de SaintVictor, une liste de censitaires dépendant de la Ville basse jusqu'à Saint-Laurent, témoignage d'un vestige de l'ancien découpage de Marseille entre Ville haute et Ville basse. importants de la vie des gens ${ }^{\mathbf{5 6 2}}$. D'autant que l'habitation que l'on occupait ou que l'on possédait, pouvait « être servile » à un établissement religieux différent de celui de la paroisse dont dépendait l'habitation, ou au roi. Chacun était alors dépendant des deux pouvoirs.

\subsubsection{Configuration du quartier}

Plusieurs éléments permettent d'aborder le quartier de Corps-de-Ville et d'en donner une première image.

La concentration des lieux de pouvoirs, civil et religieux -la Maison de ville, le Change, la Maison du roi, le Palais, l'église des Accoules- est une réalité depuis le Moyen Âge. De cette concentration a découlé la nécessité pour les élites de s'y trouver, leur volonté aussi. W. Kaiser montre comment le seul fait de posséder une maison au Corps-de-Ville était un signe d'ascension sociale. Certains n'hésitèrent pas à déclarer leur patrimoine immobilier au Corps-de-Ville alors qu'ils représentaient un autre quartier au Conseil (Kaiser 1992, p. 86). La classe sociale au pouvoir changera au cours du XVII' $\mathrm{s}$. avec l'enrichissement des marchands, mais le désir d'être présent dans ce quartier restera intact. La proximité du port, par où arrivent toutes les marchandises, est un élément important participant de la «mixité sociale» de cet endroit. Cette proximité est aussi bien un atout pour faciliter l'arrivage des fournitures de toutes sortes, qu'un élément à l'origine de la mise en place de lieux spécifiques où ces produits vont être écoulés comme le Mazeau ou la Poissonnerie.

Le quartier était une unité politico-militaire, constituée d'une milice et dirigée par un capitaine. Chacun d'entre eux était représenté par plusieurs membres au Conseil. R. Busquet souligne que le règlement permettait à un groupe de s'installer à l'Hôtel de Ville et de s'y maintenir indéfiniment (Busquet 1945). Effectivement, les membres sortants du Conseil élisaient leurs successeurs avant de partir ; cette cooptation confirmait à l'infini le pouvoir d'une élite dirigeante et interdisait l'entrée au Conseil à tout autre parti. W. Kaiser cite une plainte rapporté par A. de Ruffi sur le fait que seuls étaient perpétuellement élus ceux qui avaient le plus de relations dans le collège d'électeurs (Kaiser 1992, p. 138). Il s'agit donc de voir maintenant comment les choses se sont articulées.

\section{Les rues}

Le réseau de voirie ne semble pas avoir connu de modifications notables jusqu'au début du XVIII' s. Trois

562 À propos de l'implication des établissements religieux séculiers et réguliers dans l'administration de la cité, voir Dolan 1981. 


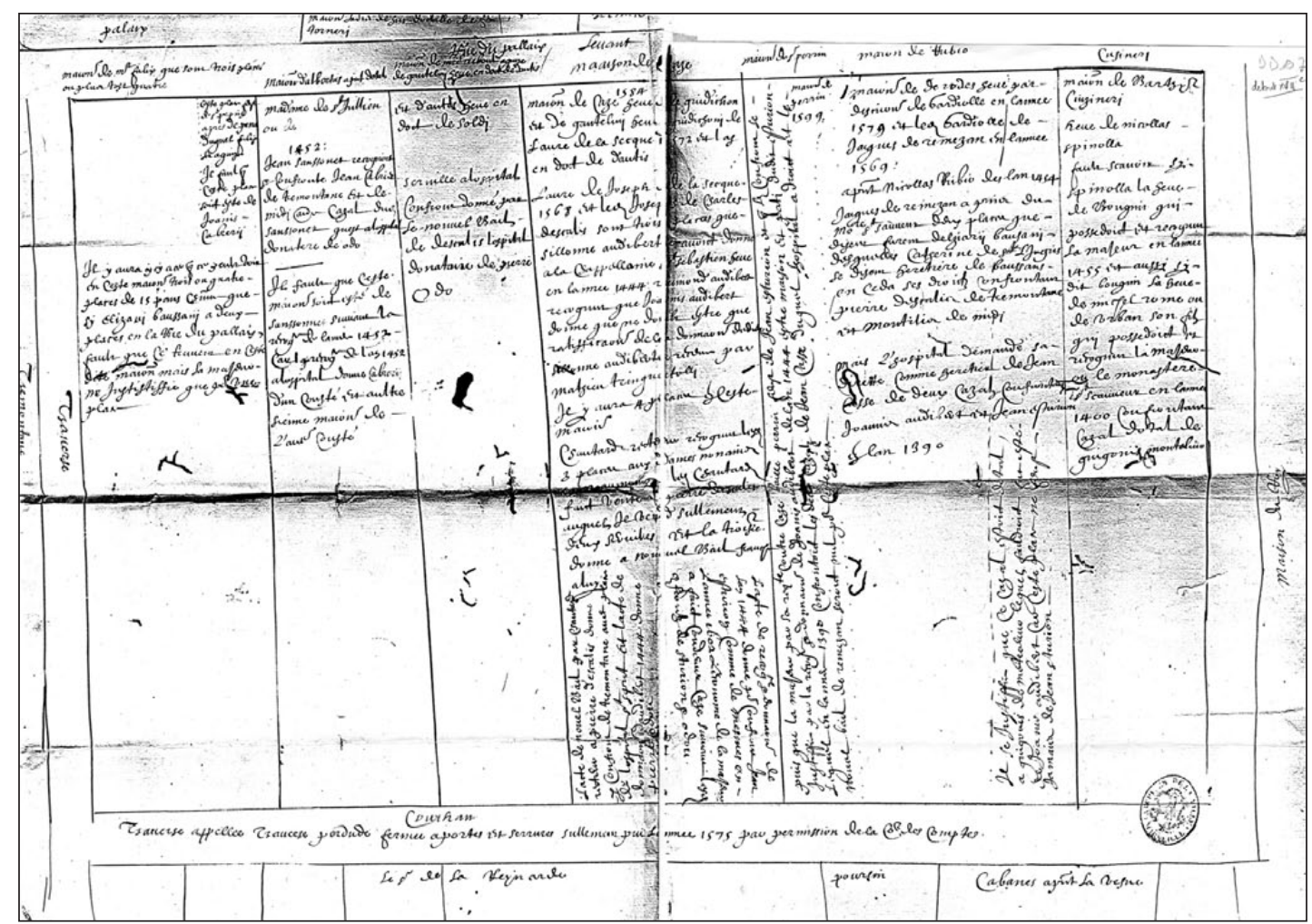

Fig. 143. Plan-terrier (début XVII $\mathrm{s}$.) où sont indiqués les différents propriétaires des maisons proches de la Maison du roi à partir du XVe s. (ACM DD 107).

rues principales traversent le quartier : d'est en ouest, la rue de la Loge ou du Change, bordant la Maison commune, et conduisant vers l'ouest, à la place Vivaud, vers l'est à la place Neuve; du nord au sud : la rue de la Guirlande, souvent confondue dans les textes avec la rue du Petit-Mazeau parce qu'elle «descend du Petit Mazeau à la Loge » ou, qu'elle «monte du la Loge au Petit Mazeau » ${ }^{\mathbf{5 6 3}}$; la rue de la Prison ou, pour mieux la définir «rue publique venant de l'église des Acoulles et pallaix royal à la Loge et rive du port » ${ }^{\mathbf{5 6 4}} \mathrm{ou}$ 《rue montant de la Loge au Palais » ${ }^{565}$ ou encore «rue descendant du palais au port $\gg \mathbf{5 6 6}$

D'autres rues permettaient la circulation entre les îlots. Pour n'en citer que quelques unes : la rue de la Reynarde, d'orientation nord-sud, parallèle à la rue de la Prison, allant de la Grand Rue au port ; d'est en ouest et les plus proches de l'Hôtel de Ville, allant de la rue de la Guirlande à la rue de la Prison : la rue des Olives dite aussi des Vento ${ }^{\mathbf{5 6 7}}$; et la rue de la Taulisse ou Pierre de

563 AD13 364 E 347, fol. 285v ; 372 E 89, fol. 586.

564 AD13 360 E 29, fol. 732.

565 AD13 357 E 146, fol. 254.

566 AD13 362 E 165, fol. 4.

567 1686, 1718, 1730, 1740 : AD13 372 E 89, fol. 586 ; 364 E 449, fol. $78 \mathrm{v}$; 363 E 273 ; 360 E 146, fol. 178v ; 360 E 156, fol. 1054v.
Servian ${ }^{568}$. Enfin la rue Ventomagy allant de la Prison à la place Vivaud.

On remarque également la présence d'un certain nombre de passages desservant les îlots. Au XVI ${ }^{\mathrm{e}}$ s., une petite ruelle en L permettait de traverser l'îlot à l'ouest de la rue de la Prison où se trouvait la Maison du roi. Cette «traverse perdude » fut fermée en 1575 par autorisation de la Cour des Comptes. Sa trace est encore visible sur le plan napoléonien mais seule la parcelle donnant sur la rue de la Prison d'orientation est-ouest, a été lotie ou plus exactement a été élargie de ce passage (parcelle 347, fig. 143 et 144) ${ }^{\mathbf{5 6 9}}$. Un passage nord-sud, dans le prolongement de la rue du Concordat, entre la rue Ventomagy et celle de la Loge, entre les propriétés de Jean Guiramand (parcelle 1020) et celle des héritiers

568 1662 : AD13 391 E 391, fol. 978 ; 1668 : AD13 393 E 87, fol. $457 ; 1720$ : AD13 362 E $162: 1743$ : AD13 360 E 159.

569 C'est grâce à un croquis dressé en 1609, trouvé aux Archives communales que ce fait a pu être découvert. Le plan a été dressé probablement dans l'optique d'établir un plan cadastral, une sorte de plan terrier. Le passage a dû être inclus dans la parcelle 347 assez tardivement, puisqu'il ne l'est pas au moment où le croquis de 1609 est dressé ni en 1716 lorsque le toisage des maisons voisines pour évaluer la contribution des habitants de la rue aux dépenses provoquées par l'élargissement de celle-ci est préparé (AD13 391 E 424$, fol. $71 \mathrm{v})$. 
de Georges Fournier (parcelle 1023), a également été loti entre 1655 et 1730.

Dans les années 1715, la rue de la Guirlande est alignée, la rue de la Prison élargie. En projet depuis 1680, l'élargissement de la rue de la Prison semble avoir été effectif aux alentours de 1715 puisque Honoré de Rome d'Ardenne, voulant reconstruire plusieurs bâtiments de son logis de la Maison du roi, réclame cet élargissement afin que sa demeure soit mieux en vue du port. Les maisons de la rue Ventomagy sont aussi frappées d'alignement à la même époque. Mais en 1782, celui-ci ne semble pas encore terminé puisqu'une maison est désignée comme «sujete à l'alignement d'après le plan de $1725 »{ }^{570}$.

Le quartier de Corps-de-Ville peut donc être ainsi dessiné malgré le flou de ses contours.

\subsubsection{Population et architecture}

Nous disposons de peu d'éléments pour le XVI e s., mais la présence de demeures de familles éminentes dans le secteur comme celles des Vento, celle du $\mathrm{S}^{\mathrm{r}}$ de Remezan, de Françoise Vivaud à proximité sur la place du même nom, de l'écuyer Cosme de Monteulx, la Maison Diamantée construite par Pierre Gardiolle vers 1570 dans la rue du Palais (de la Prison), l'Hôtel Franciscou ou encore la Maison du roi, laisse supposer que le quartier était encore relativement riche à cette époque. Le regroupement compact des biens d'une même famille dans un même îlot caractérise ce début de période, formant de simples petites unités, évoquées par M. Garden, où l'espace est composé de « signes symboliques qui concourent à unifier la pratique quotidienne de ce territoire » (Garden 1984).

Certaines maisons découvertes en fouille et citées par les sources ne peuvent pas être documentées au-delà du XVII ${ }^{\mathrm{e}}$ s. Pourtant leur antériorité est prouvée par les matériaux en remploi utilisés dans les fondations. La présence des membres de la famille de certaines d'entre elles est également attestée par les sources. C'est le cas de la famille de Vento, au pouvoir municipal au XVI es., qui possédait plusieurs maisons de part et d'autre de l'Hôtel de Ville ( $c f$. fig. 144). Nous avons l'assurance que cette famille était déjà présente dans l'îlot entre la rue Pierre de Servian et celle des Olives avant 1608, puisque cette année-là Pierre Vento avait acquis de Jean et Marguerite de Vento, ses cousins, une maison faisant le coin de la rue éponyme (de Vento/des Olives) qui confrontait deux

570 ACM DD 121, 14 décembre 1782. autres maisons leur appartenant au nord et au sud ${ }^{571}$. Nous savons également que Marc-Antoine de Vento vend le même jour de 1656 les deux maisons qui lui appartiennent rue Pierre-de-Servian (de la Taulisse) respectivement à Pierre Savignon et à Pierre Ricard ${ }^{572}$. La famille de Vento possédait donc au moins la moitié est de cet îlot. On sait par ailleurs que la famille de Vento est également présente à l'ouest de l'Hôtel de Ville. Deux demeures se faisaient face de part et d'autre de la rue Ventomagy : l'une, décrite par L. Barthélémy, était située à l'angle des rues de Bourgogne et Ventomagy (Barthelemy 1885, p. 3-17); l'autre, à l'angle de la place Vivaud et de la rue Ventomagy, fut la maison dotale de Marquise de Vento, qu'elle cède à Jean Mouffic en $1620^{573}$.

D'autre part, le plan terrier, dressé au début du XVII ${ }^{\mathrm{e}}$ s. ( $c f$. fig. 143), s'il ne permet pas d'avoir des informations sur la qualité des maisons construites, a l'avantage de signaler la présence de familles puissantes dans le secteur à l'ouest de l'Hôtel de Ville : le $\mathrm{S}^{\mathrm{r}}$ de la Reynarde occupe deux parcelles (337-338 ?) dans la rue éponyme ; avant d'être possédée par Pierre Gardiolle en 1570, la Maison Diamantée, aurait appartenu à Jacques de Remezan. Quelques parcelles plus au nord, dans la rue du Palais, se trouvait la maison d'Albertas qui jouxtait la demeure d'Antoine de Félix, seigneur de la Reynarde.

Ces personnes étaient toutes, par le jeu de la cooptation et le truchement des alliances, au pouvoir municipal depuis le début du XVI $\mathrm{s}$. Une même famille peut s'être maintenue au pouvoir durant des décennies par cooptation. Après la chute de Cazaux, et jusqu'en 1643, les Valbelle et les Félix de la Reynarde, soutenus par le pouvoir royal, se sont partagés le pouvoir. Après la mort de Richelieu, les luttes de pouvoirs pour le Consulat entre les Vento, les Valbelle et les partisans de Niozelles ne cessent d'affaiblir le pouvoir royal. En 1660, Louis XIV fait supprimer le consulat. Il lui substitue un conseil d'échevins renouvelable par tiers chaque année, avec un premier échevin choisi parmi les gens de la Loge, tenant banque ou négociant, et le second parmi les bourgeois ou les marchands. Les nobles en sont totalement exclus.

Or, on s'aperçoit que c'est dans les années qui précèdent, entre 1654 et 1656, que plusieurs de ces familles vendent le patrimoine immobilier qu'elles possèdent au Corps-de-Ville. C'est à deux frères, Louis et Pierre

571 AD13 360 E 44, fol. 68. La maison acquise par Pierre Vento est en face de la maison de Cazaux. Elle confronte à l'est la rue de la Guirlande, au sud la rue des Vento, à l'ouest et au nord une maison qu'il possède déjà. $c f$. supra $§ 1.2$. pour la période médiévale.

572 AD13 391 E 385, fol. 884v.

573 AD13 360 E 56, fol. 206. 


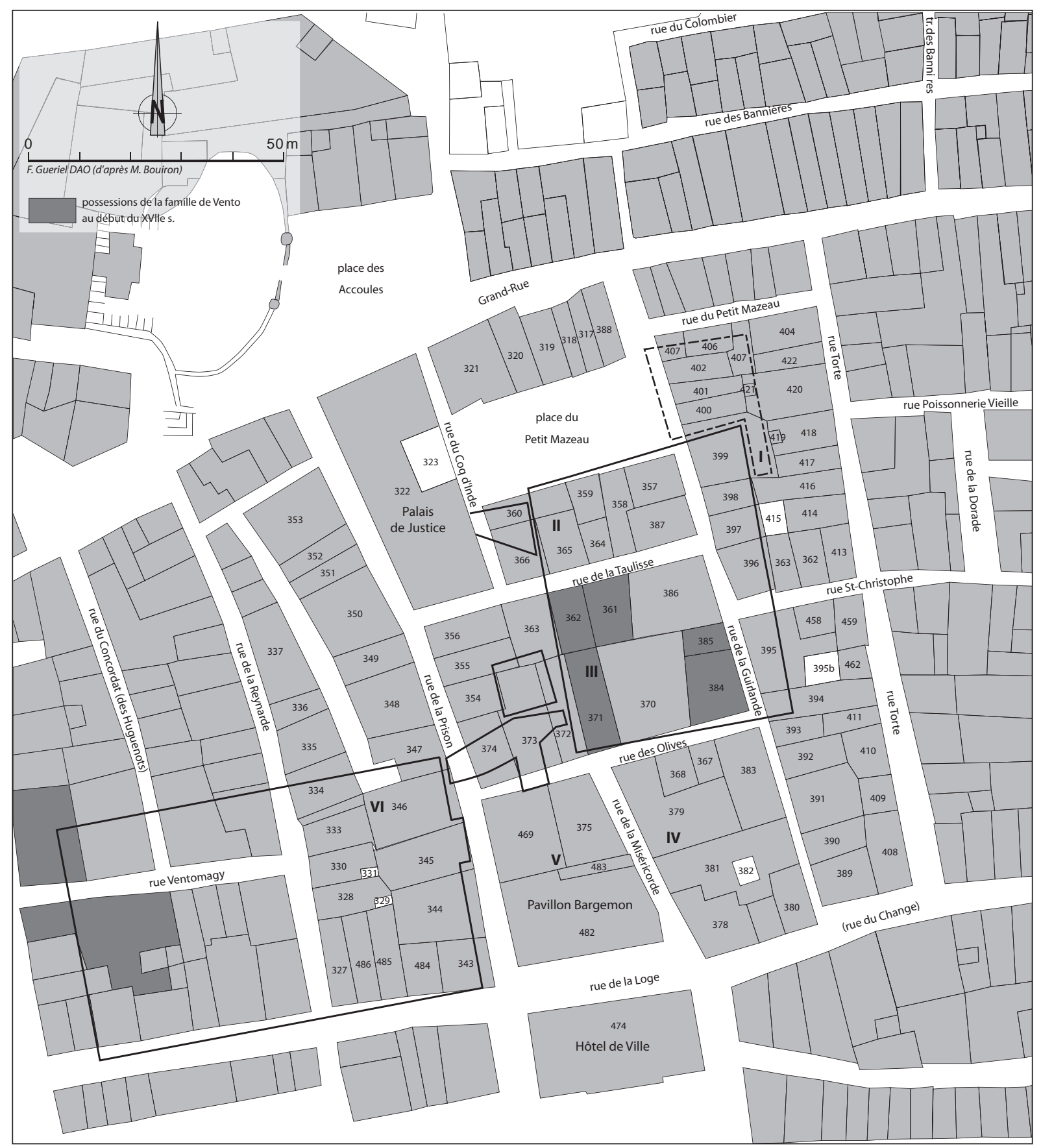

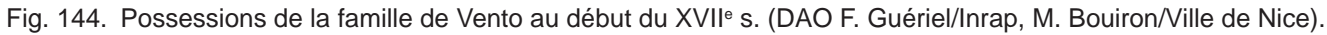

Mallet respectivement marchand et notaire, que le $S^{\mathrm{r}}$ de Valbelle vend, en 1654, deux maisons à l'angle de la rue du Mazeau et de celle du Coq-d'Inde. À un maître tonnelier que Marquise de Vento vend sa maison dotale de la rue Ventomagy. À Jean Martin, fils de marchand, et François Beillier, procureur, que Marguerite de Riquetti en cède deux également, à la rue de la Guirlande. Déjà en 1642, Marc-Antoine d'Agostine, fils et héritier de Françoise de Vento avait vendu deux immeubles contigus à l'angle de la rue de la Guirlande et de la rue des Vento (des Olives). Enfin, Jean-François et MarcAntoine de Crozet, père et fils, respectivement seigneur de Fos et écuyer de la ville de Marseille, vendent en 1656 une maison rue de la Guirlande, à l'angle de la rue Saint-Christophe.

Est-ce le pressentiment de leur déclin qui incite les élites locales à partir du Corps-de-Ville? Ou au contraire, la nouvelle classe dirigeante les a-t-elle poussées à s'en aller ? La volonté de ce nouveau groupe 


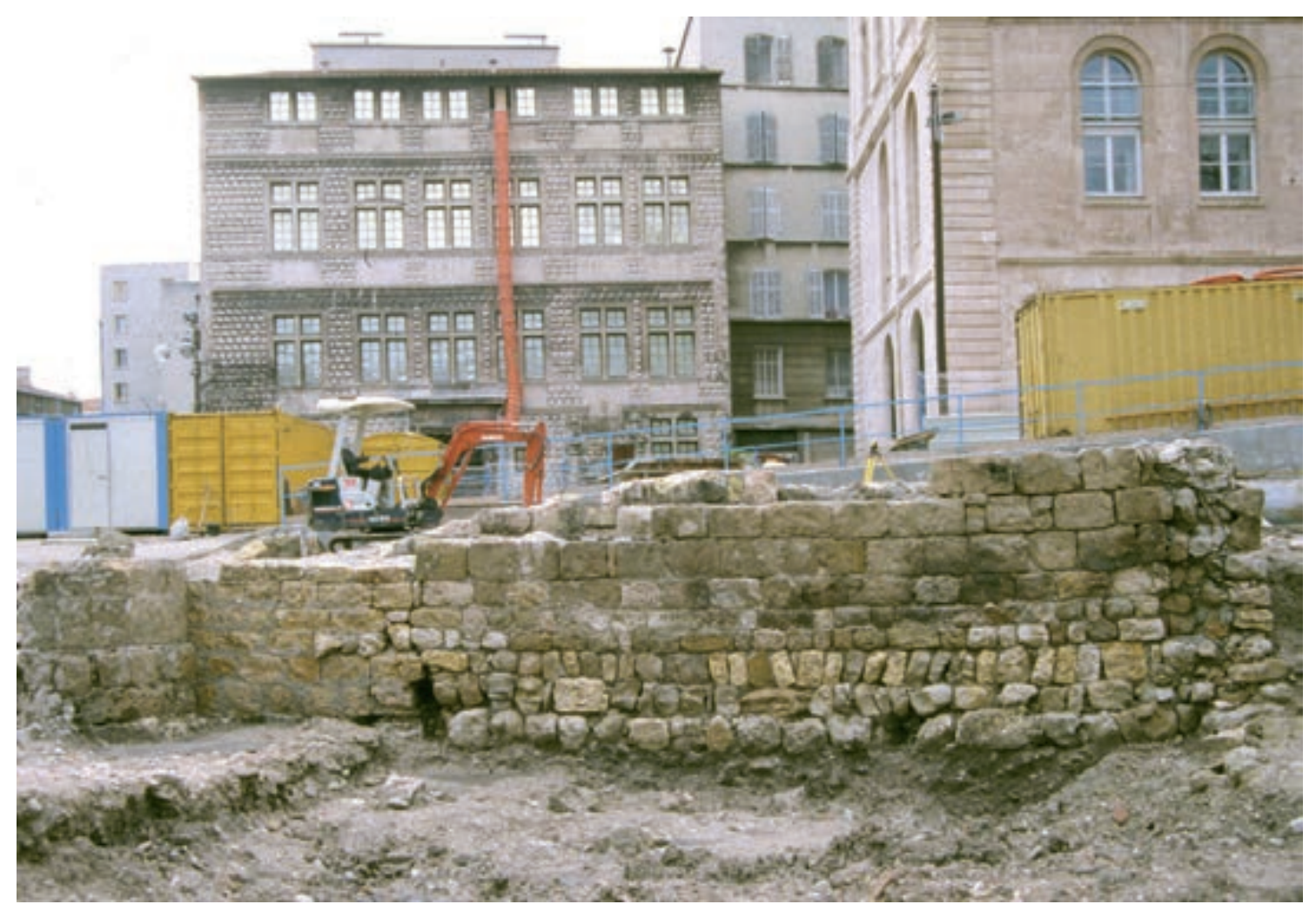

Fig. 145. Le mur 11020 et, en fond, la Maison Diamantée et une partie du pavillon Daviel (cl. M. Derain/Inrap).

social de prendre place dans ce secteur est nette car, dès 1654, les Échevins avaient acquis six maisons dans la rue de la Loge dont deux ont été converties en rue ${ }^{574}$.

Quoiqu'il en soit, en s'en allant, elles n'ont pas fait disparaître le désir de s'y établir, et la classe dirigeante nouvellement installée dans le gouvernement de la ville continue à considérer comme un symbole d'ascension sociale d'être présente dans ce secteur. Au vu du mauvais état dans lequel se trouvait la plupart des maisons vendues, cette mutation a dû se faire sans trop de difficultés : les immeubles ont dû être acquis à bon prix. L'état de délabrement, décrit dans les rapports de future cautelle, a dû inciter leurs propriétaires à diviser leur maison ou à en réunir deux, selon les cas, pour en faciliter la vente. Ce qui conforte l'hypothèse qu'on voulait vendre à tout prix en essayant d'en tirer le meilleur prix possible.

Ainsi, les deux cas évoqués plus haut de regroupement de parcelles ne reflètent pas des cas isolés : le marchand Mathieu de Madières obtient, en 1662, deux maisons de la discussion des biens de Jean-Baptiste de Varages. Melchion de Monteoux cède aussi deux maisons à Nicolas de Curet, dans la rue du Palais. David

574 ACM CC1, fol. 162.
Couzinery acquiert deux maisons de Marguerite Gaye, veuve de Claude Bouquet au cours de la même période.

La réunion ou la division de ces maisons va être un des facteurs de la modification de la physionomie du quartier. Les nombreuses reconstructions que ces récents achats et fusions occasionnent vont modifier également son aspect.

Trop peu de témoignages nous permettent de dresser un tableau réaliste du quartier au $\mathrm{XVI}^{\mathrm{e}} \mathrm{s}$. Bien que plusieurs demeures soient le lieu de divers travaux, les écrits dont nous disposons ne nous donnent que des informations fragmentaires sur ces maisons. Seuls les décors des plafonds de la maison de Vento à la rue Ventomagy nous sont connus (Barthelemy 1885, p. 353-358). J.-J. Gloton a montré que plusieurs détails de la façade de la Maison Diamantée (fig. 145), ne pouvaient être antérieurs à 1620. Le prix-fait que fait établir Charles de Cazaulx pour la grande maison qu'il fait construire en 1593 nous livre quelques informations très ténues; nous apprenons seulement que les maçons devront «faire les carrages de lad. maison (...) des mesmes façons, sortes et ordonnance de celluy de la maison de Lazarin Nineau, escuyer, sieur de Porcieux» située dans le quartier Saint-Jean. Le seul détail qui soit donné est que la façade en question est faite de pierre de taille, que «les piedz droictz (...) seront canelles » et que les «portes et entrées desd. 
maisons (...) seront tenus enrichir de telle façon que plaira aud. sieur consul ${ }^{575}$. De même, en 1584 Nicolas Albertas fait démolir pour la reconstruire la façade de sa maison rue du Change dont on nous dit qu'elle aura des frises et que les «codieres se feront de la mesme façon de celle de la maison $d u s^{r}$ Anthoine Lencho » ce qui, tout en nous communiquant très peu d'éléments, laisse tout de même supposer une décoration assez riche ${ }^{576}$.

Les rapports de future cautelle qui suivent les transactions faites dans les années 1655-1656 des maisons de Valbelle et de Vento sont peu bavards au sujet des façades, n'évoquant que leur état de vétusté. Si bien que seule la façade baroque avec sa superposition de colonnade de la demeure de Françoise Vivaud étudiée par J. Boyer nous est réellement connue pour cette période (Gloton 1980b, p. 163-174). La question de savoir si l'hôtel Vivaud était représentatif de l'ensemble des maisons du quartier au XVI ${ }^{\mathrm{e}}$ s. reste donc en suspens.

En revanche la volonté d'un décor chargé n'a pas faibli au début du XVII ${ }^{\mathrm{e}}$ s. et nombre de prix-faits, à l'exemple de ceux qui viennent d'être cités, évoquent un détail de la façade de la maison d'un grand personnage voisin qui devra être reproduit à la demande d'un commanditaire. La documentation concernant cette période, plus abondante, bien que peu explicite, permet plusieurs remarques concernant une certaine homogénéité dans la richesse des constructions.

Si les demeures telles que la Maison Diamantée et l'Hôtel Franciscou, rénovées ou construites dans cette période ne représentent pas la majorité des nouvelles habitations privées, elles jouent un rôle attractif et vont servir en quelque sorte de modèle. Un passage du prix-fait passé pour la maison de Louis Félix en 1615 résume bien l'état d'esprit qui va servir de fil conducteur aux constructions tout au long de ce siècle, même après l'agrandissement: après avoir précisé que le maître maçon devra mettre en œuvre toute la pierre de taille nécessaire à la construction, on précise que la porte d'entrée sera «façonnée non du plus riche ny du moindre, mais moyennant et comme pour les maisons de pareille quallité ». En résumé : il faut avoir une habitation digne de son rang. La plupart des prix-faits des maisons de notables les plus remarquables traduisent ce souhait: la demeure va continuer à refléter l'appartenance à un certain niveau social. L'hôtel de l'échevin Franciscou, construit en 1659, est un bel exemple de la maison baroque de cette nouvelle élite, désireuse d'afficher sa fortune.

La volonté d'ostentation va donc devenir systématique et va se traduire de différentes façons en fonction

575 AD13 360 E 30, fol. 679 .

576 AD13 360 E 20, fol. 980. des moyens dont on dispose. Toutes les façades ne seront pas aussi luxuriantes que celles de l'Hôtel Franciscou, mais, les textes sont clairs, dès que l'on est fortuné, on essaie de suivre un certain style, de s'inspirer voire de reproduire à l'identique tel détail de la maison d'un noble ou d'un notable.

La maison de Pons Agnel, située à l'angle de la rue de Negreoux et de la Grand-Rue est de ce point de vue exemplaire. En 1636, il engage quatre maîtres maçons pour la reconstruction et réunion de deux maisons qu'il vient d'acquérir. Ceux-ci ont pour consigne de faire «les hornemans des croizieres (...) de l'ordre de celles qui sont à la maison du $s^{r}$ Remondin, située a la place de Lenche (...) les hornemants des boutiques et enrechissemans de la porte (...) de l'ordre de celle de la maison de Sansson Napolon »; de plus «les coudières règneront tout autour de la maison, l'entablement et cornisse conformement a l'ordre de la maison de $m^{r}$ Darenne $\gg{ }^{577}$. Nombre de propriétaires invitent ainsi l'entrepreneur qu'ils engagent à reproduire tel ou tel détail d'une maison voisine : tel voudra reproduire la décoration de la porte d'entrée, tel autre la forme des fenêtres, ou même les volets de la demeure appartenant à une personne reconnue à qui il est important de ressembler.

Nombreuses sont les demeures dont les propriétaires ont voulu marquer leur appartenance à une classe sociale élevée. Les portes d'entrée d'immeubles sont en général le lieu privilégié pour cette démonstration : portes entourées de pilastres surmontées d'un chapiteau avec corniche et moulures de pierre de taille ${ }^{578}$. Le marchand Philippe Silvestre choisit de faire poser en tête de sa montée d'escalier un lion en pierre de taille, accompagné des armoiries du mâ̂tre de maison ${ }^{579}$.

Signe qu'il s'agit d'un matériau précieux, on imite aussi la pierre de taille. Il s'agit d'une technique qui permet d'imiter le dessin de la pierre taillée sur un mur en faux appareil, recouvert de plâtre (Bernardi 2004, p. 35) : plusieurs prix-faits évoquent cette pratique. Ainsi JeanBaptiste Meolan chargé de refaire la façade de la maison de Jean Bissar est chargé, pour toutes les parties qui ne seront pas en pierre de taille de La Couronne, de les blanchir «en sorte que regarde la taille ${ }^{\mathbf{5 8 0}}$. Les coudières ainsi que le courdon des premier et second étages de la maison de Pierre Donat seront également « a couleur de tailh ${ }^{\mathbf{5 8 1}}$. Le fait que les deux techniques aient pu coexister sur une même façade prouve que l'aspect

577 AD13 373 E 271, fol. 102.

578 AD13 360 E 50, fol. 853v ; 358 E 134, fol. 453 : 390 E 236, fol. $860 \mathrm{v}$.

579 AD13 355 E 411, fol. 223.

580 AD13 360 E 69, fol. 1176.

581 AD13 390 E 216, fol. 1125. 
économique d'une telle pratique n'était pas le seul but recherché, mais qu'il s'agissait probablement aussi d'une mode décorative.

L'aspect beaucoup plus simple des maisons que vendent de Valbelle en 1655 et de Vento en 1657 n'en est pas moins caractéristique des habitations anciennes: elles sont composées de deux étages, de pièces spacieuses, d'une basse cour, et sont pourvues d'écuries, d'un pigeonnier, quelquefois d'une charbonnière. La présence d'une boutique est également systématique. Les textes qui les décrivent ne nous donnent malheureusement aucun détail sur leur décor.

\subsubsection{Conclusion}

Cette étude qui avait pour objectif de présenter la physionomie contrastée du quartier de Corps-de-Ville entre la fin du XVI ${ }^{\mathrm{e}}$ s. et le début du XVIII ${ }^{\mathrm{e}}$ s. ne prétend pas être exhaustive.

D'autres aspects du quartier de Corps-de-Ville seraient encore à évoquer. Les textes permettent de mettre en évidence d'autres petites unités comme celle de la vieille poissonnerie, par exemple, à l'ouest du secteur fouillé, faisant face au Mazeau et dont plusieurs immeubles jouxtent le bâtiment lui-même ou les maisons placées à l'ouest de l'hôpital Saint-Esprit dont plusieurs actes prouvent qu'elles étaient possédées par un nombre de familles réduit. L'analyse plus détaillée des différents aspects les concernant ajouterait probablement de nouveaux éléments à l'image plurielle de l'ensemble du quartier.

\section{Mise en place et évolution du quartier au cours du Moyen Âge : l'apport de l'archéologie (F. Paone, R. Thernot)}

Le secteur étudié est situé dans la ville basse, il occupe une position centrale dans l'articulation des quartiers établis entre les promontoires rocheux des buttes des Moulins et de la Roquette et la rive nord du port. Cette zone stratégique dans la topographie de la ville est investie dès la fin du $\mathrm{V}^{\mathrm{e}} \mathrm{s}$. av. notre ère par un atelier des métaux et au sud une bande de terrain libre de construction semble correspondre à un premier axe de circulation longeant le port. Durand la période hellénistique se développe un chantier naval composé de neoria et de cales de halage. Au changement d'ère, la vocation du secteur évolue: un vaste établissement destiné au stockage et un complexe thermal sont implantés tandis que le réseau viaire se densifie. L'Antiquité tardive voit le maintien partiel des thermes qui accueillent alors un atelier de métallurgie jusqu'à $\mathrm{V}-\mathrm{VI}^{\mathrm{e}} \mathrm{s}$. Au siècle suivant, de nouveaux édifices apparaissent et s'organisent selon des orientations différentes ; cependant ces créations ne semblent pas survivre à la fin du VII ${ }^{\mathrm{e}}$ s. (Mellinand 2005, 499-p. 504). Le haut Moyen Âge se caractérise une fois encore à Marseille par des indices ténus témoignant d'avantage de campagnes d'épierrement que d'un investissement des lieux. Celui-ci a lieu 300 ans plus tard avec la renaissance d'un quartier à vocation portuaire et marchande. Cette zone constitue alors un secteur peuplé dont l'activité, favorisée par un négoce florissant avec le pourtour de la Méditerranée, va en se développant. C'est dans ce contexte d'expansion économique que nous devons replacer la création d'un nouveau quartier dans la paroisse des Accoules, au sud de l'église NotreDame, dans la seconde moitié du XII ${ }^{\mathrm{e}}$ - début du XIII ${ }^{\mathrm{e}} \mathrm{s}$. Parallèlement à l'enrichissement des marchands, l'émergence d'un pouvoir consulaire devra pour s'affirmer se frayer un chemin entre le pouvoir féodal des vicomtes et l'emprise du clergé ( $c f$. fig. 140).

\subsection{De la fin du VII ${ }^{\mathrm{e}}$ S. au $X I^{\mathrm{e}}$ s. (F. Paone)}

Bien d'avantage qu'une occupation structurée du secteur, les rares indices d'activités du haut Moyen Âge ont été observés uniquement en coupe sous ce qui deviendra l'îlot III. Ils correspondent à des campagnes de récupération de structures antiques, s'accompagnant de stockage temporaire de matériaux issus des surplus de démolitions.

L'espace est cependant organisé autour d'une maçonnerie est-ouest dont ne demeure toutefois que le négatif évasé, mesurant $2 \mathrm{~m}$ en partie haute pour se rétrécir à $0,95 \mathrm{~m}$ à la base sur une profondeur de $1,5 \mathrm{~m}$, ce qui témoigne de l'importance de la construction. Au nord de ce mur puissant se superpose un ensemble de fosses dont les profils en forme de cuvette pouvaient atteindre $8 \mathrm{~m}$ de longueur. Une caractéristique commune est le remplissage progressif de chacune avec des matériaux diversifiés déversés depuis les bords. Dans la fosse la plus ancienne, plusieurs comblements se distinguent, le comblement inférieur de limon argileux brun contient quelques éléments de terre cuite, de petites pierres calcaires et des nodules de mortier. Au-dessus se trouve un remblai de terre avec de nombreux éléments de destruction comparables à ceux du remplissage inférieur ainsi que des éclats de calcaire et du mortier. Se superpose une seconde fosse comblée d'alternance de remblais argilo-sableux brun, ocre gris inclus des fragments de calcaire, gravillons, mortier, béton de tuileau associés à des apports détritique de type terres cuites et charbons de bois. Mesurant $5 \mathrm{~m}$ de diamètre pour une profondeur 


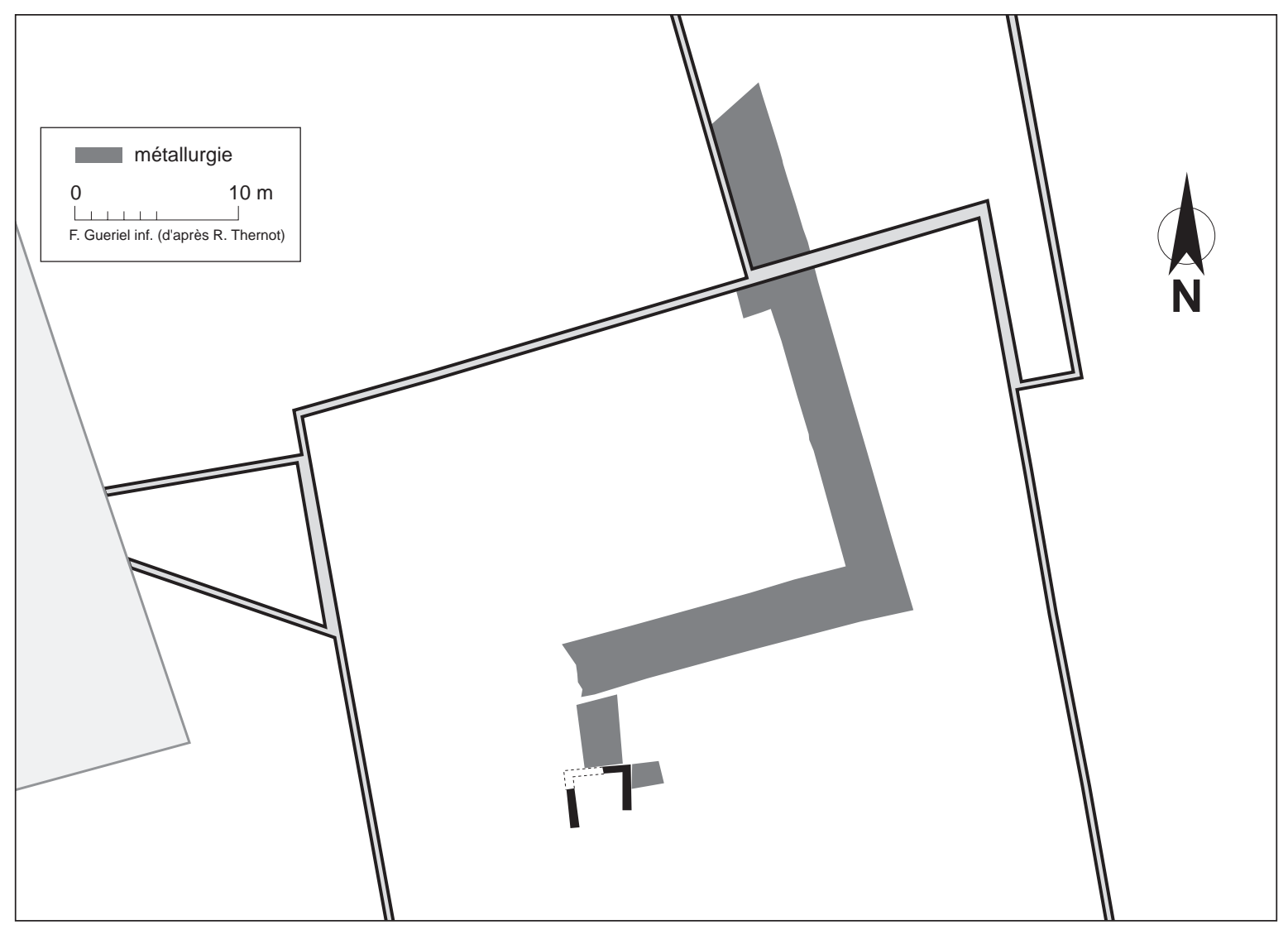

Fig. 146. Localisation des zones de métallurgie non détruites par les caves (DAO F. Guériel, R. Thernot//nrap).

conservée de $0,70 \mathrm{~m}$, une troisième fosse est remplie dans un premier temps d'une couche très argileuse en partie nord et hétérogène (cailloux calcaires, gravillons, nombreux éléments de terre cuite, gros nodules de mortier) scellée d'un niveau de terre sableuse et mortier pulvérulent avec des éclats de calcaire et terres cuites. La fréquence des rejets d'éléments de mortier et de pierres confirme que l'activité principale durant cette période consiste à détruire et épierrer les constructions préexistantes mais la répartition très limitée des informations au nord-est du site réduit la portée de ces observations.

Cette séquence est scellée par un remblai de plus d'un mètre d'épaisseur. L'aspect de ce remblai et le type de matériel céramique qu'il contient laissent penser qu'il a été constitué assez rapidement, comme pour répondre à la volonté de réaliser un terre-plein. C'est donc un terrain dépourvu de contraintes spatiales et propice au renouveau urbain que s'approprient progressivement les hommes du XII ${ }^{\mathrm{e}} \mathrm{s}$.

Un premier état, antérieur au travail des métaux du $\mathrm{XII}^{\mathrm{e}}$ s., est représenté par une assise large de $1 \mathrm{~m}$ et composée de gros moellons de calcaire froid, équarris et liés à la terre se développant sur une longueur de 5 à $6 \mathrm{~m}$ au moins. Cette structure adopte une orientation isocline aux murs antiques de l'ensemble thermal sous-jacent.
Elle est associée à une recharge argileuse qui surmonte les remblais massifs apportés antérieurement à la réurbanisation du quartier à cette époque. Le caractère isolé de l'observation, imputable à l'éradication des niveaux correspondant dans les autres secteurs ne permet pas de cerner la nature et l'importance de cette première construction médiévale qui va cependant imposer son orientation aux murs suivants.

\subsection{Première moitié du XII ${ }^{\mathrm{e}} \mathrm{s}$., des indices d'un travail des métaux ${ }^{582}$ (F. Paone)}

$\mathrm{Au}$ cours du XII ${ }^{\mathrm{e}}$ s., dans une zone laissée libre de construction s'installent des artisans de la métallurgie. La localisation de leurs ateliers demeure inconnue car les vestiges de l'occupation médiévale sont éradiqués en grande partie par le creusement de caves modernes (fig. 146). Cependant dans les espaces préservés tels que les rues et les zones dépourvues de caves, l'étendue des indices laissent penser que cette activité artisanale

582 D'après B. Sillano, zone 11, p. 1-5 in Paone, Sillano 1997 ; F. Paone, zone 7, p. 1-2 ; zone 9 p. 1-2 in Paone 1997c ; N. Nin, F. Paone vol. 1b p. 311-314 in Mellinand 2005. 


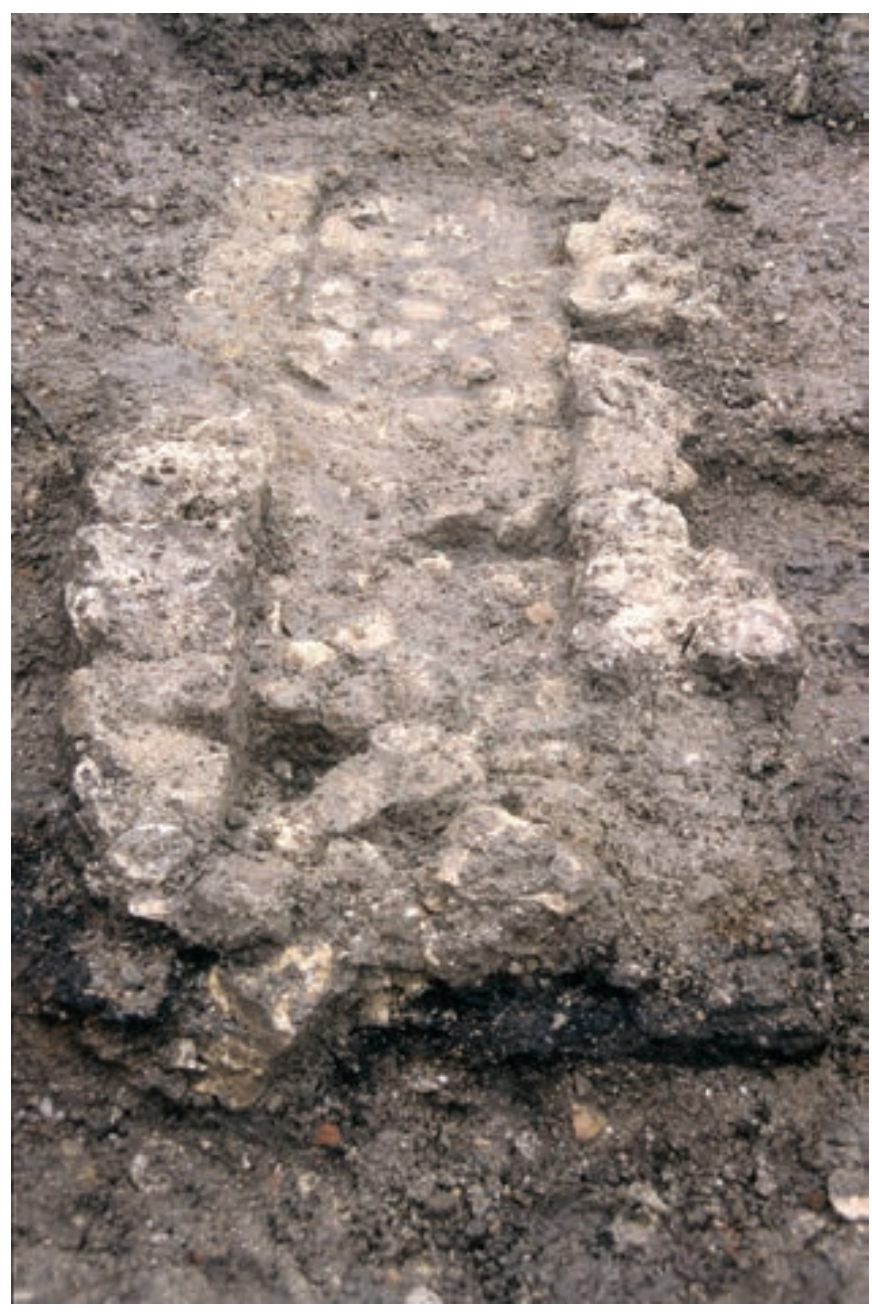

Fig. 147. Vue du caniveau ouest-est antérieur à l'îlot (cl. M. Derain/Inrap).

pouvait couvrir plus de $1000 \mathrm{~m}^{2}$. L'essentiel de ces traces est constitué de dépôts cendreux et charbonneux formant de véritables épandages, auxquels sont associées quelques structures de type foyer et fosse ainsi qu'en partie centrale du site un tronçon de caniveau et un petit espace bâti. Trois types de structures artisanales sont répartis sur le site mais leur espacement ne permet pas d'établir un lien fonctionnel entre eux.

Dans la partie centrale du site ${ }^{583}$ est localisé le seul espace construit conservé (espace A) pouvant être lié à cette phase d'activité. Son plan résulte d'une adaptation entre les orientations antiques sous-jacentes et du mur médiéval plus ancien, dont seul demeure une assise de fondation de direction nord-sud. Cette construction forme un espace réduit large de $3 \mathrm{~m}$ circonscrit par trois murs de 60 cm d'épaisseur. Ceux-ci se caractérisent par leurs parements régulièrement assisés et l'utilisation de

$\mathbf{5 8 3}$ Ces structures sont situées à l'emplacement du futur îlot médiéval III. moellons en calcaire lacustre dur liés au mortier ; les murs est et ouest ne sont pas parallèles ( $c f$. fig. 145) Le mur oriental s'installe sur le reliquat de fondation construite précédemment, en suivant la même orientation. Le mur occidental adopte une orientation intermédiaire entre celle qui est héritée de l'Antiquité romaine et celle qu'imposera le lotissement médiéval qui se met en place au cours du troisième état. À cette phase de construction, on peut associer un autre mur situé $4 \mathrm{~m}$ plus à l'ouest.

À l'intérieur de la pièce, les couches contemporaines ont disparu mais au vu des élévations, elles devaient être une dizaine de centimètres plus haut que celles de l'extérieur. La première, construite à base de chaux, forme une dépression dans laquelle s'est déposée une couche charbonneuse. Le second niveau, matérialisé par une couche d'argile jaune, est obtenu après nivellement du précédent et marque un pendage vers l'ouest. Plus au nord, il est possible d'associer à cet espace bâti un sol et, à l'est, une seconde couche qui est recoupée par une vaste dépression comblée par du brasier et surtout un niveau très reconnaissable de charbons et scories, qui se retrouve également en partie centrale. Sur ce niveau et sous le tracé de la future rue de la Taulisse, est bâtie une structure de forme rectangulaire et de profil en U conservée sur une longueur de 2,20 m et large de 0,80 m. Les piédroits nord et sud consistent en une assise de moellons préalablement installée entre lesquelles est établi sur une fine couche de limon de préparation un fond plat en pierres et galets (fig. 147). L'ensemble, qui s'apparente donc à un fond de caniveau, est comblé d'une épaisse couche de cendre homogène débordant parfois sur les rebords. Non loin apparaît le seul foyer construit conservé dont la sole, de $1 \mathrm{~m}$ de diamètre, est formée d'une chape d'adobes supportant une plaque d'argile rubéfiée.

Ces structures sont associées à une série d'épandages de couches de cendres et de charbons de bois, de niveaux oxydés verts contenant un grand nombre de scories de fer et de bronze. Sous l'emprise de la future rue de la Guirlande, ces rejets alternent avec des séquences de remblais et, plus au nord, une excavation ( $3 \times 1,10 \times 0,50 \mathrm{~m})$ qui, bien que partiellement conservée, entame une couche de sable très compacte. Cette fosse sert de réceptacle en premier lieu à un niveau de limon chargé en tuiles et moellons de calcaire de 10 à $15 \mathrm{~cm}$ auquel succèdent des épandages de charbons de bois, poches de cendres de $5 \mathrm{~cm}$ ainsi que de scories métalliques issues vraisemblablement de curage de four. L'ensemble est colmaté par un limon noir organique mêlé d'apports plus détritiques de faune, d'arêtes de poissons et de coquillages. L'espace environnant ne semble donc pas uniquement dévolu au travail mais accueille vraisemblablement des activités domestiques. 
Ces pratiques vont péricliter pour laisser place à l'établissement de véritables îlots d'habitation.

\subsection{Création et évolution du quartier de la seconde moitié du XII ${ }^{\mathrm{e}} \mathrm{s}$. jusqu'au XIV ${ }^{\mathrm{e}} \mathrm{s}$. (F. Paone, R. Thernot)}

L'élément essentiel pour la topographie des lieux est la mise en place, à partir de la seconde moitié du XII ${ }^{\mathrm{e}}$ s., d'un quartier d'habitation ouvert sur le commerce et le négoce. Cependant l'impact de l'urbanisme antique dans la structuration du nouveau quartier demeure important, et l'adaptation au tracé de la ligne de rivage, repoussée toujours plus au sud, est un autre facteur déterminant la nouvelle topographie des lieux. L'élément prégnant de la trame est le tracé de la Grand-Rue reprenant le decumanus antique qui, partant de la Porte d'Italie, constitue l'épine dorsale d'une trame orthonormée à laquelle se raccorde la rue Torte. Cette trame s'articule à l'ouest avec un autre système viaire dont l'orientation divergente est ordonnée, au nord, par la rue Caisserie, qui correspond au prolongement de la Grand-Rue et devait à l'origine mener au forum. La transition entre ces deux systèmes se matérialise au Moyen Âge par la rue de la Guirlande. La mise en place du quartier intègre partiellement le réseau viaire antique et est également conditionné par la configuration du trait de côte, pourtant non souligné par la présence de fortification.

Mais des différences notables entre la trame urbaine antique et médiévale sont perceptibles; elles s'expliquent en partie par un déclin de l'occupation de la zone portuaire durant l'extrême fin de l'Antiquité et au cours du haut Moyen Âge. Les fouilles ont montré la disparition de certains axes et des secteurs laissés en déshérence durant ces périodes caractérisées par des campagnes d'épierrements des constructions. De plus, l'envasement progressif du port entraîne un recul de la ligne de rivage qui pour l'époque qui nous préoccupe se situe à quelques mètres d'une voie majeure dans la topographie médiévale, la rue du Change. L'extension de la ville vers le plan d'eau s'accompagne de la mise en place d'un réseau viaire nouveau, exempté de toute contrainte spatiale héritée du passé.

\subsubsection{La trame viaire (F. Paone)}

L'étude de la voirie médiévale sur l'ensemble du site est étayée par la fouille de plusieurs rues, fouille partielle de l'axe majeur de la Guirlande et du Coqd'Inde, recherche plus exhaustive sur les rues dites du Petit-Mazeau et de la Taulisse (fig. 148). Les niveaux de circulation observés sont concomitants de la mise en place du quartier durant la seconde moitié du XII ${ }^{e} \mathrm{~s}$. et s'échelonnent jusqu'au XIII ${ }^{\mathrm{e}}$ s., les sols postérieurs ayant été éradiqués. Bien que la quantité et la qualité des informations soient inégales, il n'en demeure pas moins que les observations recueillies reflètent une intense vie urbaine générant une usure des sols et nécessitant de régulières remises en état.

\section{Les axes nord-sud}

Les rues disposées perpendiculairement au relief sont le réceptacle naturel d'écoulements naturels, l'exemple le plus représentatif étant illustré par la rue de la Reynarde dont le tracé reprend celui du talweg des Accoules ${ }^{584}$. Dans les rues de la Guirlande et du Coqd'Inde ces ruissellements se matérialisent par des dépôts alluviaux, mais ce phénomène est endigué par la densification de l'urbanisme et des mesures de captage des eaux de pluies.

\section{\ La rue de la Prison}

Anciennement dénommée la rue du Palais, la rue de la Prison est la plus occidentale des voies étudiées. Sa largeur est estimée à $3,50 \mathrm{~m}$. Une campagne de nivellement général, ainsi que l'installation d'un collecteur contemporain, ont entraîné la disparition des niveaux de circulation dans l'emprise des fouilles.

\section{La rue du Coq-d'Inde}

Délimitée dans le secteur documenté par l'ancien Palais communal à l'ouest et par la limite occidentale de l'îlot II, la rue du Coq-d'Inde mesure $3 \mathrm{~m}$ de large. Le niveau de circulation d'origine composé de chaux apparaît à 4,80 m NGF, et marque un pendage ouestest assez sensible, ponctuellement rattrapé par une recharge. Aucun pavage n'est conservé, et la fréquence des apports sédimentaires a généré un rehaussement rapide de la surface de circulation. Certains dépôts hydrauliques attestent d'écoulements d'eau réguliers, ils alternent avec des apports argileux ou gravillonneux. L'étude de l'îlot III ainsi que les textes ont montré que cette voie devait à l'origine se prolonger au sud jusqu'à la rue des Olives ( $c f$. infra §3.4.1.) et qu'elle était bordée d'un puits commun avec une parcelle de l'îlot (cf. infra §2.3.4.). Ce tronçon est intégré à l'îlot à l'Époque moderne.

584 Cette rue se situe dans l'emprise du chantier de la Place JulesVerne dirigée par A. Hesnard. Sous le tracé de la rue médiévale qui n'a pas été étudiée se trouvait un imposant collecteur canalisant les eaux du talweg au cours de l'Antiquité tardive. 

apparaissent vers le Mazeau à 5,75 $\mathrm{m}$ NGF et se poursuivent au bas de l'îlot II à 4,50 m NGF. Dans son prolongement méridional, les sols de rue sont pour l'essentiel éradiqués. À l'origine, la surface marque une inclinaison vers l'est créant ainsi une rigole le long de la façade orientale du grand entrepôt de l'îlot I qui est protégé par la légère remontée d'un sol chaulé. Palliant l'absence d'un système d'écoulement plus axial, un dispositif comparable est utilisé rue du Coq-d'Inde. Cependant, afin de faciliter la circulation, cette surface inclinée est colmatée par l'apport d'un remblai de nivellement qui ne parvient que partiellement à atténuer ce profil.

Si aucun sol pavé ne s'intègre dans la séquence stratigraphique de cette rue, en revanche un soin particulier est apporté à la composition de certains sols, stabilisés sur des couches préparatoires le long du Petit Mazeau. Un tri des matériaux est réalisé avec un calibrage des cailloux et galets, des nodules d'argile agglomérés font souvent office de matrice pour les lits de pose. Des remblais composés de cailloux et de sable servent également de radiers d'installation pour des sols homogènes de limons rapidement damés par la fréquentation des lieux. Les sols peuvent être stabilisés grâce à l'ajout de mortier dans leurs composantes. L'assainissement de la voie est parfois entrepris par l'étalement d'un lit de chaux, mais les derniers niveaux observés pour cette période montrent une détérioration de cet espace public dans lequel des apports détritiques (faune, céramique, métal, ...) sont régulièrement déversés, et ce malgré la réglementation municipale. À l'exception des quelques sols construits, les dépôts sont lenticulaires, résultant d'avantage de recharges ponctuelles répondant aux détériorations de la chaussée. La stratigraphie s'avère donc dense et cette accumulation entraîne un rehaussement significatif de la surface de circulation.

\section{Les axes est-ouest}

Par leur orientation, ces voies sont moins soumises aux ravinements provoqués par les pluies et autres intempéries, ce qui a permis la conservation d'une stratification dense et très litée formée de sols aux mises en œuvre variées. À l'exception de la rue des Olives récemment décaissée en totalité, ces axes sont fouillés sur la quasi totalité de leur emprise.

\section{$\square$ La rue bordant au sud le Petit Mazeau}

Bordant au nord l'îlot II et au sud le Petit Mazeau, cette rue forme la transition entre les rues du Coq-d'Inde et de la Guirlande. Son toponyme est inconnu, les ruelles qui encadrent la halle du Petit Mazeau n'ayant pas de dénomination particulière (fig. 149).
Longue d'une quarantaine de mètres, cette rue est fouillée sur plus de la moitié de son tracé qui est percé par des extensions de caves modernes ; elle est également amputée dans sa largeur par la paroi moulée ceinturant le chantier. Les strates sont repérées sur 1,60 m mais il semble que la largeur totale n'excède pas $2 \mathrm{~m}$ si l'on se base sur l'emplacement du fil d'eau axial d'un pavage. Les niveaux de sols sont parfaitement conservés et forment une accumulation sédimentaire sur plus de deux mètres de hauteur (de 4,90 m à 6,80 m NGF) pour une durée d'un peu plus d'un siècle. Ce rehaussement constant des surfaces de circulations est problématique, il ne peut être concevable qu'accompagné d'une transformation régulière des façades des maisons. L'évolution architecturale d'une partie des façades septentrionales de l'îlot II (les unités B et C) a ainsi été mise en lumière.

Les niveaux de circulation présents marquent une double inclinaison qui est assez significative du sud vers le nord et plus ténue de l'ouest vers l'est (vers la rue de la Guirlande) pour faciliter les écoulements. L'épaisseur de la sédimentation de rue est en partie justifiée par le manque de soin apporté à la réalisation de certains sols dont l'usure rapide est compensée par l'apport de recharges ponctuelles. Ces strates sont précisément circonscrites et leur mise en œuvre diffère selon la maison devant lesquelles elles sont situées. Les recharges de terre mêlées de matériaux de démolition ou de déchets domestiques s'intercalent ou s'accolent à des sols en terre battue, compactée par apport de matériaux triés et calibrés. On note également l'emploi de chaux pour augmenter la compacité des couches. Plusieurs exemples de maîtrise dans la mise en œuvre de ces niveaux sont apparus, tel ce pavage en dalles de calcaire jaune de La Couronne localisé devant l'unité $\mathrm{C}$ ou ce sol d'adobes formé d'une agglomération de boulettes et de briques d'argile ( $c f$. fig. 26). Un changement et une harmonisation des pratiques sont toutefois perceptibles : les sols de terre sont progressivement remplacés au cours du XIII ${ }^{\mathrm{e}} \mathrm{s}$. par la pose de calades de galets colmatés par de l'argile. Ces pavages sont présents sur l'ensemble de la rue.

L'observation des élévations a montré une reprise régulière des maçonneries voire, dans le cas de la maison $\mathrm{B}$, une reconstruction totale de la façade ; ces travaux ne sont naturellement pas sans incidence sur la rue et les traces d'activité de construction sont matérialisées par du brasier ou de la chaux. La communication entre la rue, où une intense circulation est avérée par les données archéologiques, et les espaces construits peu documentés, est problématique. On signale toutefois la présence d'ouvertures simplement attestées par des pierres de seuil ou par un piédroit de porte. Ainsi des portes juxtaposées desservent les ensembles $B$ et $C$ et un seuil avec un piédroit de porte ouvre sur l'ensemble B. Ces baies, 


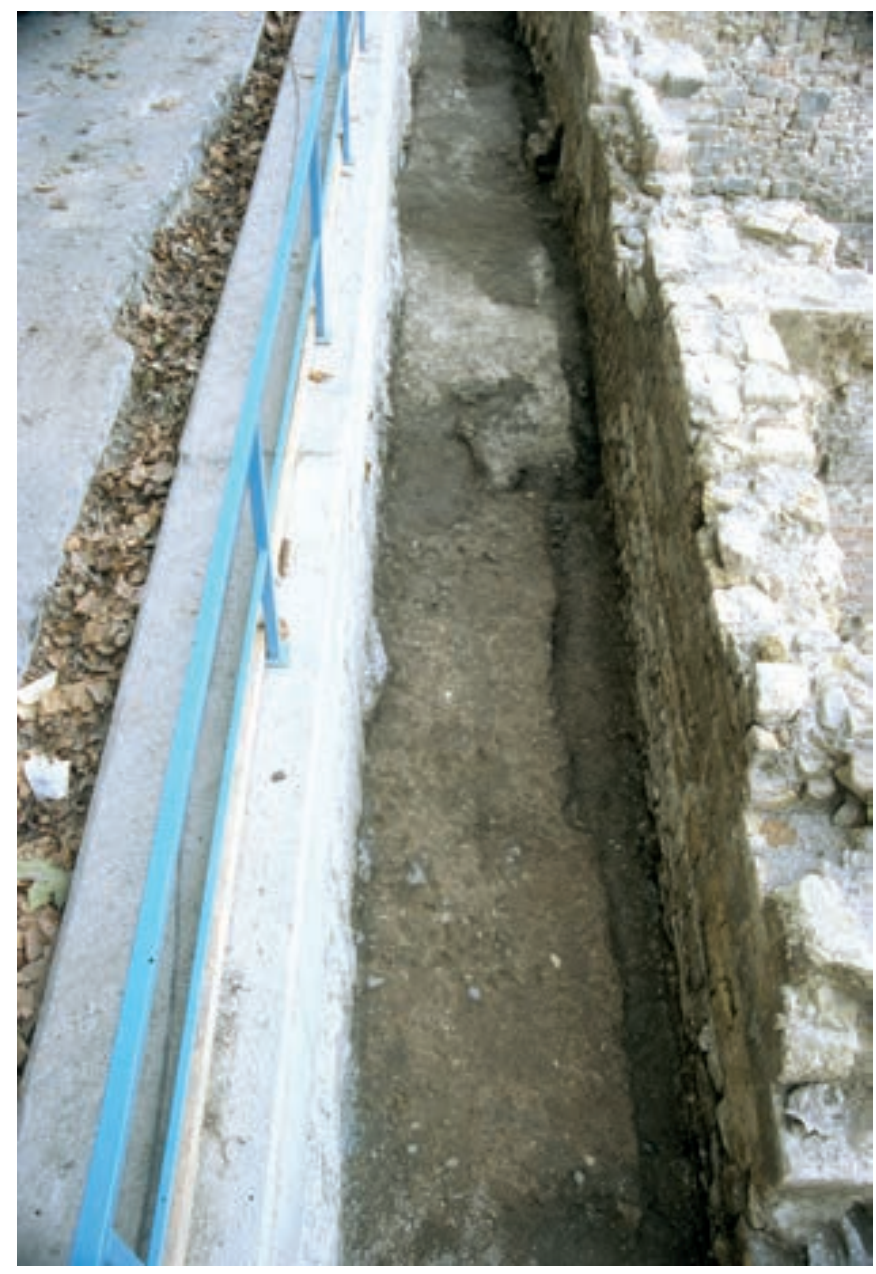

Fig. 149. La rue du Petit Mazeau vue de l'ouest (cl. M. Derain/Inrap).

dont l'encadrement n'est jamais complet, sont systématiquement obturées, et l'existence d'arcades boutiquières est très peu probable. Ces données sont pour le moins contradictoires avec l'emplacement de cette rue en bordure immédiate du Petit Mazeau, dans un secteur où l'activité marchande prédomine et où les échoppes sont donc sensées se trouver.

\section{- La rue Bernard-de-Conques (ou rue de la Taulisse)}

Cette voie forme la liaison entre la rue de la Prison à l'ouest et la Guirlande à l'est.

La fouille a porté sur plus de la moitié de sa longueur qui est de $58 \mathrm{~m}$ (fig. 150). Cet axe large de 3,60 m est bordé du nord au sud respectivement par les îlots II et III. Les données fournies par son étude sont exceptionnelles pour la compréhension de la chronologie de mise en place des maisons mais également pour la connaissance du lien structurel entre ces espaces bâtis et l'espace public qu'est la rue, rapport plus difficilement perceptible dans la rue du Petit-Mazeau. La stratigraphie est néanmoins moins dense que pour cette dernière, les niveaux archéologiques et les maçonneries ayant été dérasées beaucoup plus bas. Un important collecteur contemporain occupe l'axe de la rue, formant ainsi deux banquettes le long des façades, dont les équivalences stratigraphiques sont difficiles à établir.

L'établissement des maisons bordant la rue de la Taulisse est progressif, mais s'effectue dans un laps de temps assez court. Les façades intègrent dans leurs maçonneries des tuyaux de plomb ou de terre cuite faisant office de gouttière, qui se prolongent dans des caniveaux couverts et enterrés placés perpendiculairement aux murs pignons. Ces aménagements sont reliés à un égout couvert situé dans l'axe de la voie, égout qui a disparu lors de l'installation d'un collecteur moderne. Le raccordement au caniveau central se fait progressivement au fil des constructions des maisons (fig. 151).

Comme pour la rue du Petit-Mazeau, la mise en œuvre des sols diffère en fonction de la maison devant laquelle ils se trouvent, les reprises de maçonneries générant également un apport de matériaux et une utilisation systématique de chaux ou d'un lit de mortier. Les niveaux de terre battue incluent généralement des éléments calibrés et triés ; ils sont établis sur un niveau préparatoire. L'usage de nodules d'argile pure agglomérés est à signaler ; la mise en œuvre est comparable à celle rencontrée dans la rue du Petit-Mazeau. Malgré des similitudes avec les autres rues, la Taulisse peut être qualifiée de « rue propre », moins encombrée de détritus et rejets divers.

Cette rue se caractérise également par une série d'aménagements en lien avec les maisons riveraines. Si aucun seuil de porte n'est conservé dans les façades, en revanche la découverte de quelques emmarchements permet de positionner l'emplacement des accès et de documenter leur architecture. Mais l'essentiel du rapport entre les bâtiments et la rue nous est fourni par la présence en plusieurs endroits d'alignements de trous de poteaux et socles en pierre disposés parallèlement aux façades de l'îlot III ( $c f$. fig. 113). Ces structures porteuses, espacées l'une de l'autre de 1,50 m, étaient disposées à moins de 0,30 m des murs et devaient supporter des constructions légères de types étal ou auvent. Ces multiples aménagements extérieurs semblent avoir servi à caractériser cette rue tournée vers l'extérieur donc vers le commerce, le toponyme Taulisse ou Teulisso désignant une toiture de tuile, un auvent voir une halle.

\section{$\square$ Les dessertes}

À l'exception de l'îlot II dont les parcelles traversantes sont accessibles par les rues du Petit Mazeau et 


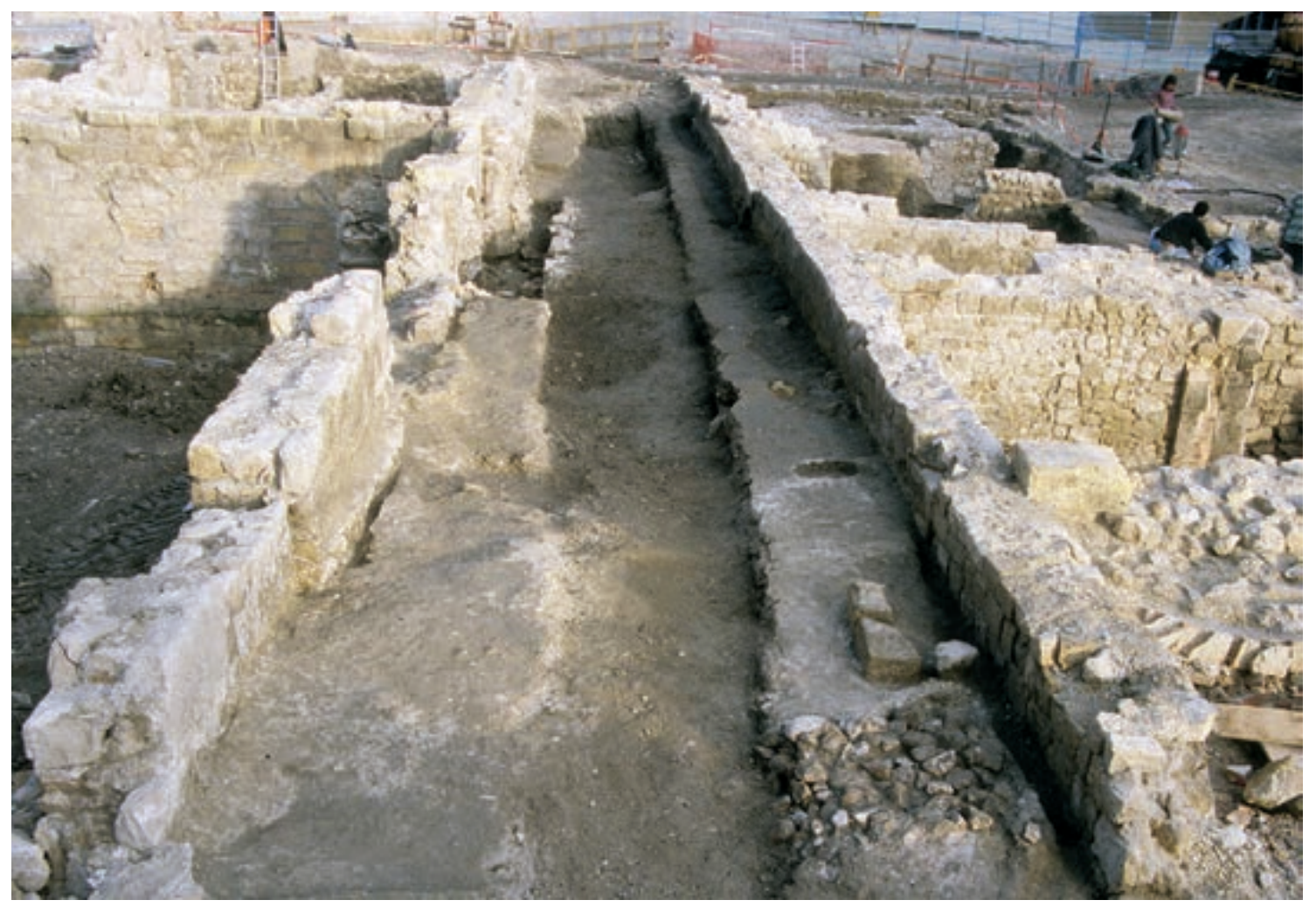

Fig. 150. Vue d'ensemble de la rue de la Taulisse en cours de fouille (cl. M. Derain/Inrap).

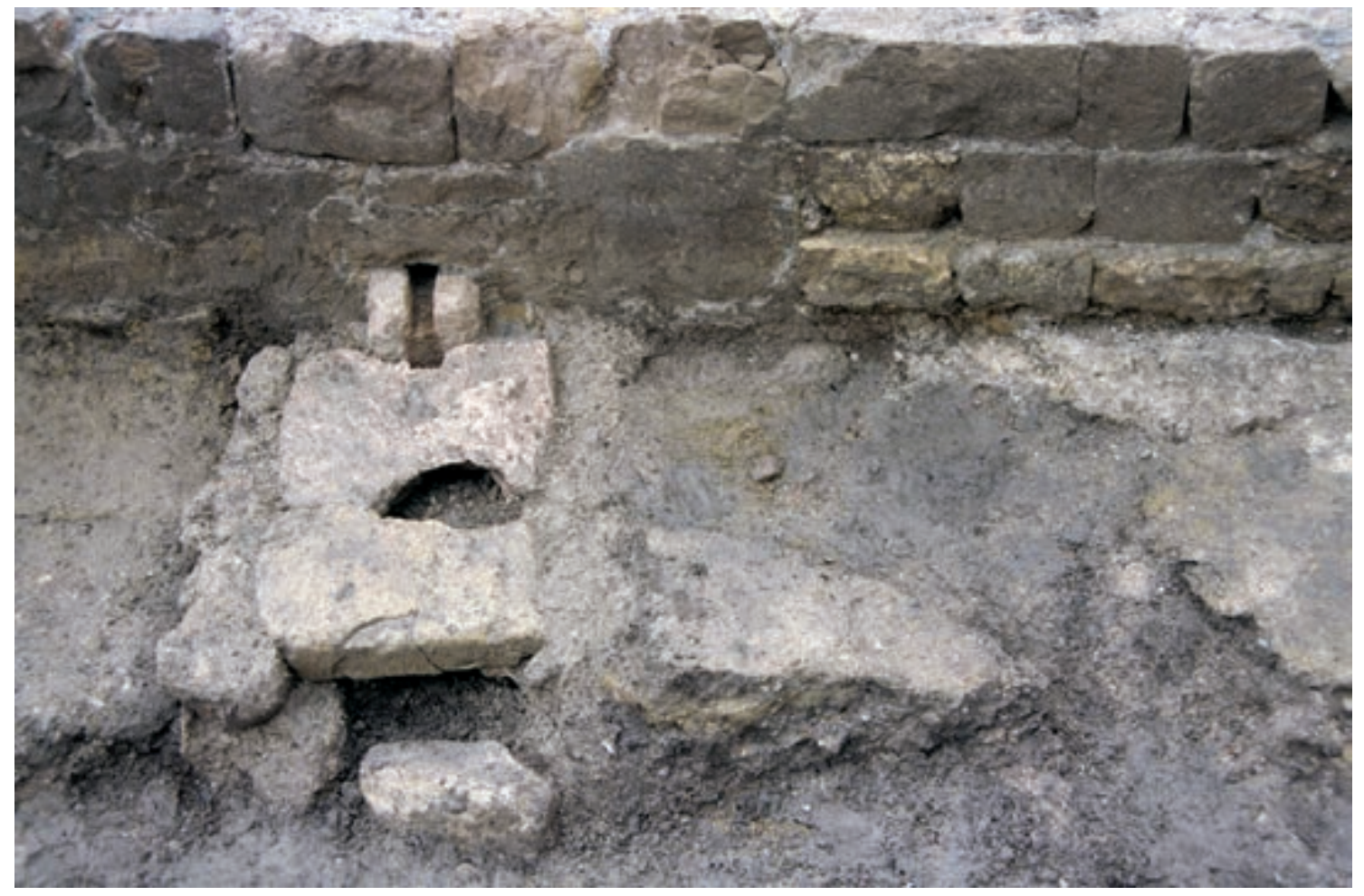

Fig. 151. Système d'égout raccordé à un collecteur central dans la rue de la Taulisse (cl. M. Derain/Inrap). 
de la Taulisse, les autres îlots possèdent, pour organiser l'accès des parcelles centrales, des petites dessertes. Dans l'îlot I, un passage étroit ouest-est de 1,5 m sépare l'entrepôt des maisons et permet d'accéder à une cour dotée d'un puits collectif ( $c f$. infra $\$ 2.3 .2$.). Un second passage d'axe nord-sud devait traverser tout l'îlot. Son tracé se devine encore sur les limites cadastrales napoléoniennes, mais au cours du XIVe $\mathrm{s}$. la densification des constructions conduit à l'annexion (partielle ?) de cette venelle au sein des propriétés. Dans l'îlot III, une restitution de ruelle est proposée dans le prolongement de la rue Saint-Christophe ( $c f$. infra $§$ 2.3.4.). Son emplacement s'explique peut-être par le nécessaire aménagement de pente par palier au sein de l'îlot.

\subsubsection{L'îlot I ${ }^{585}$ (F. Paone $)$}

Cet îlot de forme trapézoïdale mesure $32,5 \mathrm{~m}$ au nord et s'amenuise à $24 \mathrm{~m}$ au sud mais sa longueur est constante à $54 \mathrm{~m}$ (fig. 152). Il est bordé par les rues de la Guirlande à l'ouest, Saint-Christophe au sud, Torte à l'est et du Petit-Mazeau au nord. Son importante superficie nécessite l'existence en cœur d'îlot de plusieurs dessertes dont l'existence est validée par les découvertes archéologiques. Les fouilles ont porté sur la moitié occidentale de l'îlot.

Dans la moitié nord de l'îlot sont établies, entre la seconde moitié du XII ${ }^{\mathrm{e}}$ s. et le début du XIII ${ }^{\mathrm{e}}$ s., trois maisons dont ne demeurent que quelques tronçons de murs épars, déconnectés de toute stratigraphie et intégrés dans les maçonneries modernes. Ces vestiges témoignent cependant du maintien du découpage parcellaire jusqu'à l'Époque moderne. Au sud, un important bâtiment doté de plusieurs caves occupe la plus grande partie du secteur. Enfin, un puits et une cuve sont aménagés dans un espace ouvert desservi par un réseau de venelles. La deuxième phase datée du XIVe $\mathrm{s}$. s'illustre par une reprise des constructions en cœur d'îlot.

\section{Première phase : établissement des constructions de l'îlot I}

Cet îlot se compose au nord de plusieurs maisons qu'il est difficile de dater précisément, les liens avec les niveaux de rues ayant été détruits. L'essentiel des constructions concerne cependant un vaste bâtiment interprété comme un entrepôt. Enfin au sud, les espaces ne sont pas documentés par la fouille.

585 D'après V. Rinalducci, zone 8, p. 66-81 in Vecchione, Rinalducci 1997 ; F. Paone vol 1b, p. 315-324 et vol 2, p. 435-440 in Mellinand 2005 ; F. Paone, zone 3, in Paone 1997a.

\section{口Les maisons du nord de l'îlot}

Ces trois unités d'habitations (A, B, C), disposées en lanière le long de la rue de la Guirlande, présentent une largeur étroite comprise entre $3,60 \mathrm{~m}$ et $4 \mathrm{~m}$ pour une profondeur estimée à $8 \mathrm{~m}$, d'après des aménagements en cœur d'îlot, soit un rapport de 1/2. Elles ne sont attestées que par des tronçons de murs épars ; aucun sol n'est conservé.

Les façades sur rue, dont on soulignera le caractère lacunaire des vestiges ${ }^{\mathbf{5 8 6}}$, sont formées d'un double parement de petits moellons de Saint-Victor posés en boutisse-panneresse, assisés assez régulièrement et délimitant un blocage de cailloux bruts. Ceci s'accompagne de l'utilisation généralisée de limon comme liant avec ajout ponctuel de mortier maigre en faible quantité. Des différences apparaissent cependant dans leur largeur, comprise entre 56 et $63 \mathrm{~cm}$, de même que dans la nature de leurs fondations. Pour exemple, l'une des élévations repose sur une assise débordante en petits moellons bruts dont certains sont en grès. Placé $2,80 \mathrm{~m}$ plus au sud, un second mur est fondé sur une assise en épi non saillante sur un gros bloc de grès (fig. 153).

Les murs de refends sont simplement appuyés contre les murs de façades, aucun chaînage n'a été observé. Les élévations assisées sont en moellons équarris de calcaire tendre de Saint-Victor maintenus par de la terre et du mortier de chaux friable. Disposés en panneresse ou boutisse, ils peuvent reposer sur un ou deux lits de gros galets et moellons régulés par l'intermédiaire d'une arase de fragments de tuiles et de dallettes.

Ces constructions ne sont pas datées avec certitude car coupées de toute stratigraphie par les maçonneries modernes ; cependant les sols de circulation de la rue de la Guirlande indiquent une occupation des lieux à partir de la seconde moitié du XII ${ }^{\mathrm{e}} \mathrm{s}$.

\section{口 L'occupation en cour d'îlot}

Au cours du XII ${ }^{\mathrm{e}} \mathrm{s}$. est établi dans le secteur qui jusque là ne semble pas très loti, un complexe hydraulique composé d'un puits à noria, ainsi qu'une cuve rectangulaire dont l'usage est vraisemblablement en lien avec le puits. Cet ensemble se semble pas être associé à une parcelle particulière mais être établi sur un espace ouvert accessible par une desserte ouest/est comprise entre l'unité C et l'entrepôt méridional (fig. 154).

Le puits est de forme circulaire, pour la partie observée ; son extrémité orientale est cependant hors d'emprise

586 Ces murs sont conservés en moyenne sur une longueur de 0,60 m. 



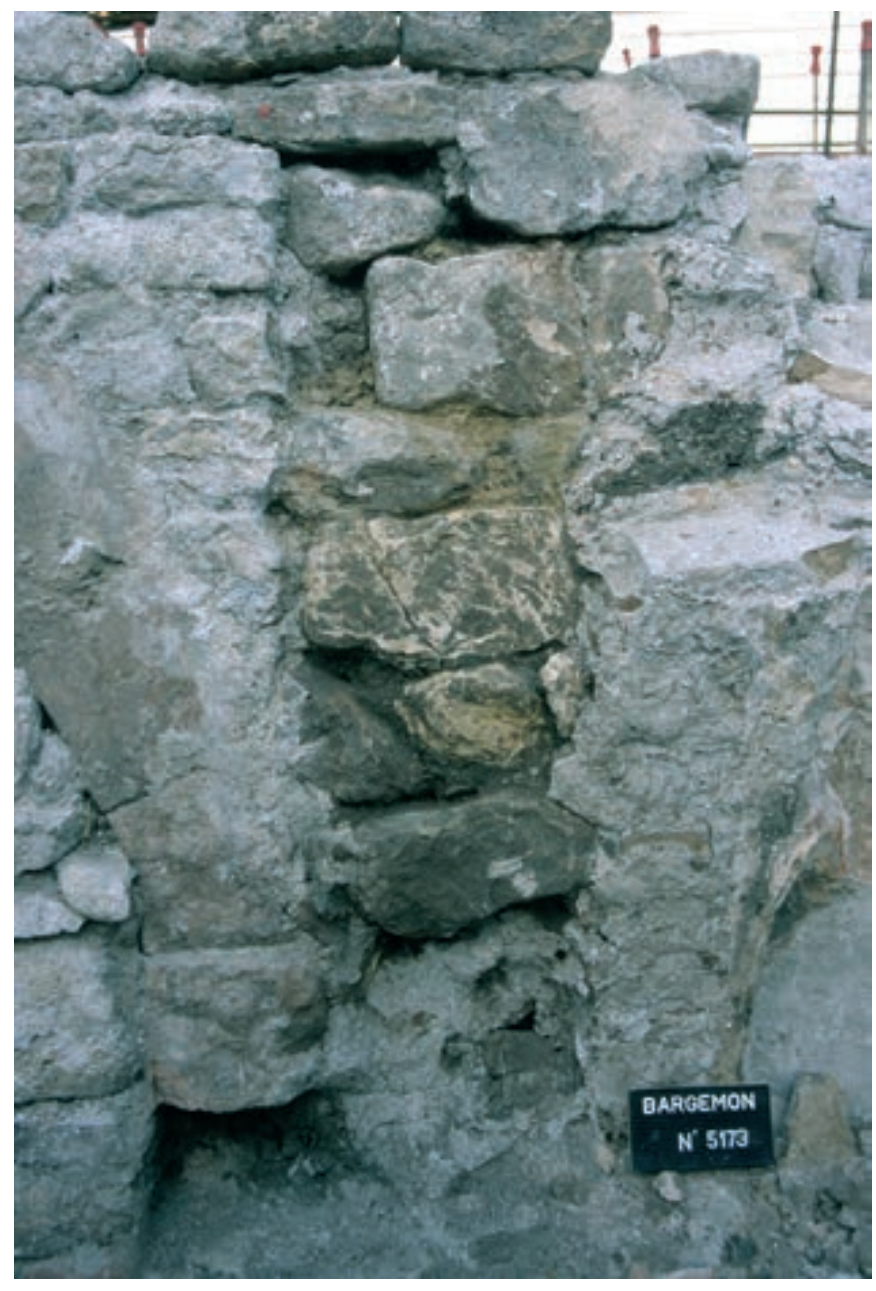

Fig. 153. Mur médiéval pris entre deux maçonneries modernes (cl. T. Maziers/Inrap).

puits de fragments de godets ${ }^{588}$ indique que cet aménagement correspond à une noria. Aussi est-il possible de restituer une forme ovale au puits, profil classiquement usité pour ce type d'aménagement. Cette interprétation justifie aussi le creusement d'installation rectangulaire conforme à l'emprise de la noria. Aucun aménagement particulier ou niveau de fonctionnement significatif n'a été observé, seuls sont présents un remblai et un massif d'argile ocre jaune intégrant des nodules d'argile rouge, ce matériau rappelle celui utilisé dans le remplissage de la fosse d'installation.

À $1,80 \mathrm{~m}$ à l'ouest de la noria, une cuve a été amputée par des constructions médiévales et modernes. Les parois est et sud ainsi que l'amorce du muret ouest sont préservés ce qui permet de déterminer un espace interne long d'au moins 1,95 m et large de 1,47 m, pour une

588 Des fragments de godets comparables ont été trouvés à Aixen-Provence au Palais Monclar. Associés à un puits à noria, ils sont datés du courant du XII ${ }^{\mathrm{e}} \mathrm{s}$. profondeur minimum de $1 \mathrm{~m}$. Les parois sont formées de moellons équarris, essentiellement en calcaire et plaqués en panneresse contre le sédiment; les pierres sont liées par un mortier blanc, dur avec des petits graviers et des galets. Le parement interne est très érodé, l'usure étant due à l'action de l'eau ou du vent. Aucune installation reliant le puits à la cuve n'est conservée, mais la contemporanéité de leur construction ainsi que leur fonction permettent d'envisager des rapprochements fonctionnels.

Dans le contexte général de mise en place du quartier, ces ouvrages hydrauliques semblent appartenir à une période transitoire d'urbanisation progressive du quartier où persistent des espaces libres encore dévolus au jardinage ou maraîchage.

\section{$\square$ Le grand bâtiment (unité D)}

Établi à la charnière du XII et du XIII' ${ }^{\mathrm{e}}$ s., cet édifice s'étend sur près de $300 \mathrm{~m}^{2}$; sa superficie s'explique par le regroupement d'au moins cinq parcelles ( $c f$. fig. 148). Son emplacement, au débouché de plusieurs axes de circulation, marque une volonté de visibilité du bâtiment à partir du réseau viaire. De même sa situation au sein du quartier marchand inscrit cette construction dans un secteur fréquenté et accessible. Il est établi le long de la rue de la Guirlande, ses espaces périmétraux sont dans l'axe des rues ouest-est, rues dites du Mazeau et de la Taulisse ; une desserte devait le longer au nord.

Ce bâtiment mesure $24 \mathrm{~m}$ de long et sa largeur est comprise entre $14 \mathrm{~m}$ au nord et $10 \mathrm{~m}$ au sud hors œuvre, d'où une forme trapézoïdale justifiée par une adaptation de son plan à deux orientations. La première, héritée de l'Antiquité, est déterminée par l'axe nord-sud de la rue Torte qui borde à l'est l'îlot et surtout par la superposition de deux murs de la piscine des thermes romains sous les murs transversaux de la salle méridionale. La seconde direction qui diverge vers l'ouest, est adoptée par la façade occidentale de l'édifice qui borde la rue médiévale de la Guirlande.

Cet édifice est partiellement conservé, l'absence de données pour la partie orientale compromettant la lisibilité du plan ; de même la destruction du mur septentrional par une cave moderne nous prive du rapport avec la desserte nord. Le bâti existant nous permet cependant de restituer un plan général de l'ensemble. Il se compose d'au moins quatre espaces principaux, dont le plus étroit est dès l'origine compartimenté en deux petites pièces séparées par un couloir central ${ }^{589}$.

589 La proposition de restitution du plan est basée sur une absence de cloisonnement en bordure orientale. 


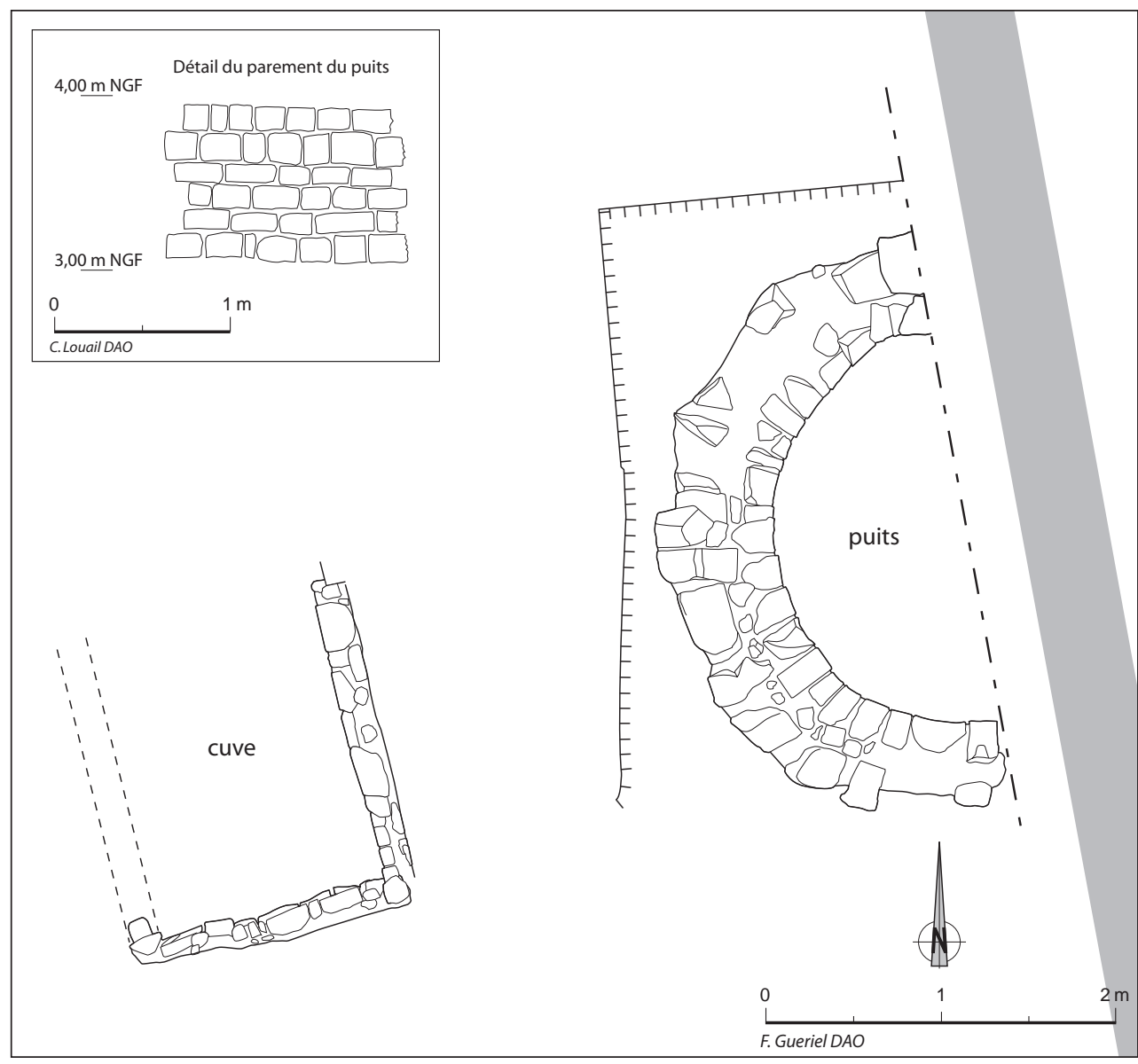

Fig. 154. Relevé des vestiges et élévation du puits de l'unité D (DAO F. Gueriel/Inrap).

La mise en œuvre de ce bâtiment est particulièrement soignée. Le mur de façade correspond à une maçonnerie relativement massive, d'une largeur de $0,60 \mathrm{~m}$, dont les parements observés sur 1,80 m de hauteur sont complètement aveugles. Construite en petit appareil réglé de moellons calcaires de Saint-Victor, elle est liée avec du mortier blanc compact contenant une grande quantité d'éléments siliceux, de sables grossiers ainsi que de nombreux gravillons roulés. La mise en œuvre très ordonnée présente des assises d'environ $15 \mathrm{~cm}$ d'épaisseur, à partir du sommet de la fondation, mais qui vont en s'amincissant légèrement en partie haute (environ $10 \mathrm{~cm}$ minimum). Le blocage interne intègre des moellons et des cailloux ainsi que de fragments de briques en terre cuite et de tegulae réutilisées. La régularité de certaines arases témoigne des étapes successives de montage des assises sur environ 65 à $70 \mathrm{~cm}$ de hauteur. La base de l'élévation ${ }^{590}$, composée de trois assises, comporte un ressaut d'une dizaine de centimètres qui constitue la transition entre l'élévation proprement dite et l'épais soubassement inférieur.

590 Deux trous de boulins de $10 \mathrm{~cm}$ de côté apparaissent à la base de l'élévation, ils sont espacés de $2,40 \mathrm{~m}$.

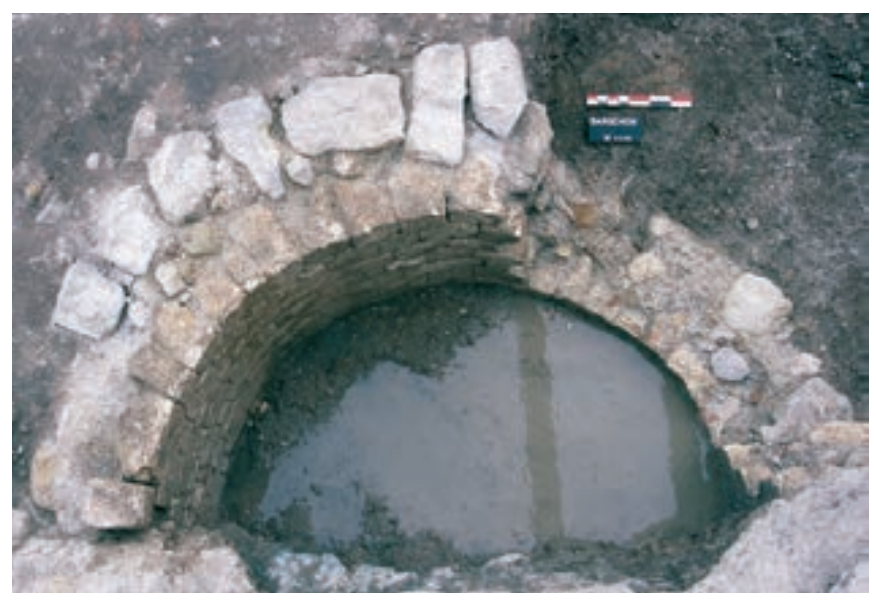

Celui-ci comportant un ressaut d'une vingtaine de centimètres de débordement interne, garantit l'assiette de ce mur. Mesurant $2 \mathrm{~m}$ de haut, les assises de fondations sont grossièrement horizontales et irrégulières en raison de leur hauteur (entre 25 et $30 \mathrm{~cm}$ ) conditionnées par la disparité des matériaux. Des blocs de grès et de poudingue à l'état brut ou très rarement équarris constituent la majorité des matériaux employés auxquels s'ajoutent ponctuellement de gros moellons de calcaire 
tendre et de tuf. Le mortier est passé à joints beurrés et forme par endroit un véritable enduit ( $c f$. fig. 74).

La limite orientale de cet édifice a également été observée sur sa face externe. De mise en œuvre comparable à la façade ouest, ce mur est conservé sur 4,2 m de hauteur dont 2,6 m d'élévation. Malgré les multiples perturbations qui l'affectent, le mur se prolonge encore sur 10,5 m. L'angle nord-est du bâtiment est repris au cours du XVI ${ }^{\text {e }}$ s. ; le chaînage est alors formé de deux blocs taillés contre lesquels s'appuie une assise de réglage en fragments de tegulce surmontée du petit appareil en moellons équarris de calcaire jaune. Le lien entre cette façade et les trois murs de refends est détruit par la paroi de limite de fouille en revanche ils sont parfaitement liés avec la façade occidentale. Les rangées d'assises correspondent entre elles perpendiculairement, leur mise en œuvre est identique ; il en va de même du choix des matériaux et de leurs modules. des éléments siliceux et du mica en proportion infime. Une gangue de mortier de chaux très adhérent enrobe ces tuyaux qui, au niveau des raccords perpendiculaires, sont calés par des briquettes de chant. Une série de trois canalisations parallèles est disposée dans l'axe des maçonneries. Les rangées ne se raccordent pas entre elles durant leur trajet dans le mur mais les tuyaux latéraux forment parfois un coude et aboutissent à l'aplomb du parement intérieur. Tous marquent un léger pendage du nord au sud pour les murs goutteraux ; les éléments pris dans les refends, convergent vers la façade sur rue. Le comblement des conduites a livré des indices d'un écoulement d'eau (fin dépôt de calcite sur les tuyaux) celui-ci ne semble cependant pas significatif de fréquentes et massives utilisations. L'articulation avec le puits situé dans l'angle sud-ouest du bâtiment reste problématique. Ce constat tend à indiquer que cet aménagement constitue un système aérique destiné à assainir les maçonneries.

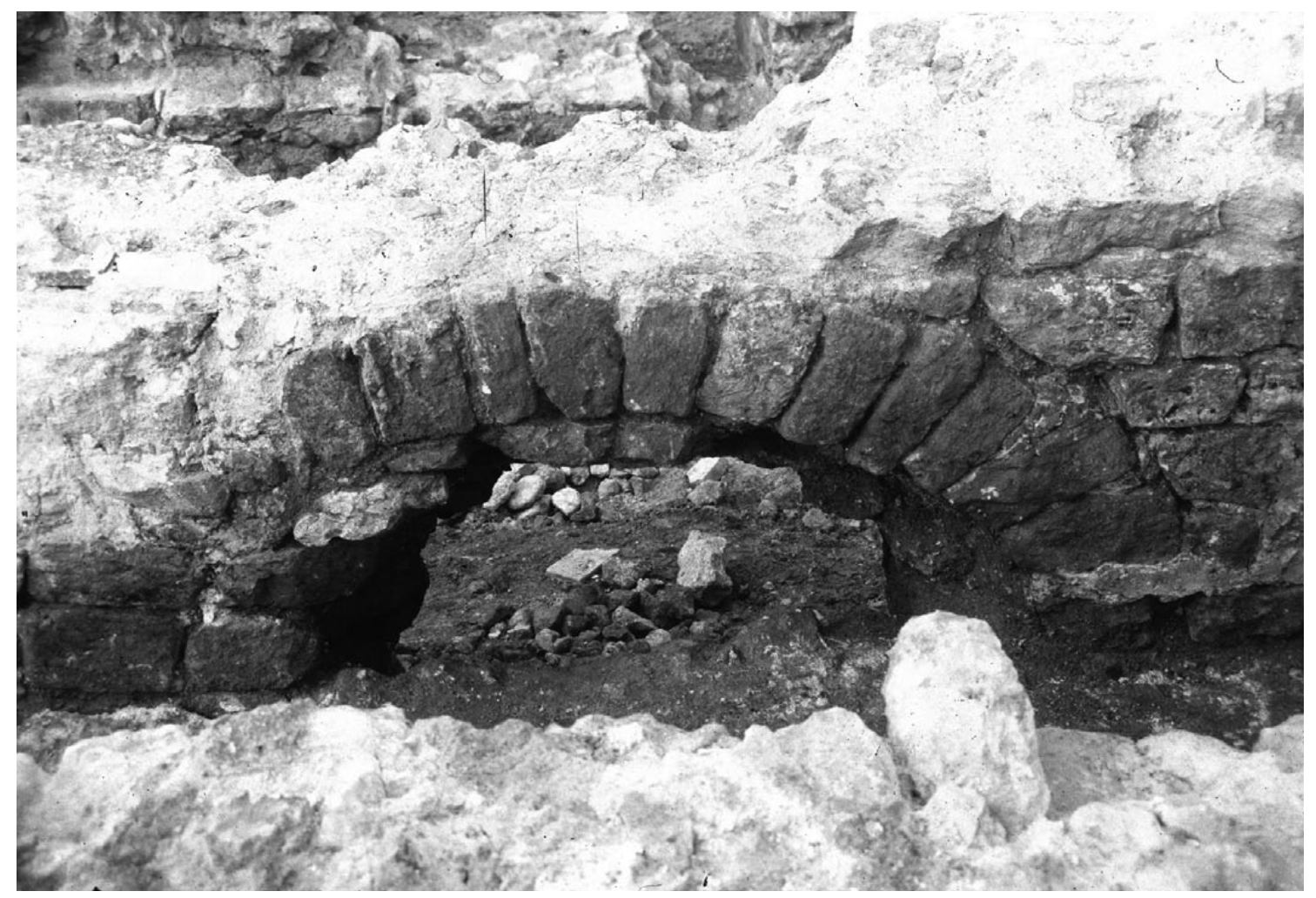

Fig. 156. Passage entre l'espace A et C (cl. M. Derain/Inrap).

Cet édifice est caractérisé par l'intégration dans l'ensemble des murs d'un réseau de tuyaux de terre cuite ( $c f$. fig. 73). Ces tubulures de forme tronconiques mesurent $0,34 \mathrm{~m}$ de long, pour des diamètres d'ouverture compris entre 5 et $9 \mathrm{~cm}$; l'emboîtement est matérialisé par une lèvre en bandeau. La pâte calcaire de couleur saumon présente de nombreux dégraissants parmi lesquels
L'étude de ce monument a montré l'existence d'au moins cinq espaces desservis, pour quatre d'entre eux, par un couloir central. Au nord, l'espace 1 a une longueur moyenne $10,5 \mathrm{~m}$ pour une largeur de 4,5 $\mathrm{m}$ soit une superficie de $47,5 \mathrm{~m}^{2}$. Le secteur intermédiaire est divisé en trois parties avec un couloir central ( $c f$. fig. 114, $\mathrm{n}^{\circ} 3$ ). Ce passage, d'une largeur de 1,5 m s'effectue par 
l'intermédiaire d'arcs plein cintre surbaissés, prolongés par une voûte vraisemblablement en berceau reposant sur deux murs parallèles dont ne demeurent que les traces d'arrachement (fig. 156). De part et d'autre de ce couloir avec lequel il devait communiquer se trouve deux pièces étroites ( $c f$. fig. 114, $\mathrm{n}^{\text {os }} 2$ et 4 ) sensiblement identiques de moins de 3,6 x 3,3 m soit moins de $12 \mathrm{~m}^{2}$ chacune. L'espace suivant ( $c f$. fig. 114, $\mathrm{n}^{\circ} 5$ ) mesure 9,5 m de long pour une largeur de $6,5 \mathrm{~m}$ soit $61,75 \mathrm{~m}^{2}$. Enfin l'espace méridional ( $c f$. fig. 114, $\mathrm{n}^{\circ} 6$ ) fait $9 \mathrm{~m}$ de longueur pour une largeur de $6 \mathrm{~m}$, soit $54 \mathrm{~m}^{2}$.

La fonction de ce vaste édifice est cependant difficilement déterminable. L'une des premières hypothèses retenue est que ce bâtiment imposant pouvait correspondre à un lieu de stockage, un entrepôt parfaitement intégré dans ce quartier de commerce et d'alimentation. Cependant l'étude des sources écrites a permis d'attester de l'existence d'un établissement balnéaire localisé dans cet îlot et placé sous la directe du monastère SaintSauveur (cf. supra $\S 1.2 .3$.).

\section{Deuxième phase : densification de l'habitat en coeur d'îlot}

La séquence suivante, placée chronologiquement au $\mathrm{XIV}^{\mathrm{e}}$ s., atteste d'une densification du réseau d'habitation au cœur de l'îlot, faisant table rase de l'ensemble hydraulique ; établis sur l'emplacement de la noria, un mur est-ouest et un pilier sont les seuls témoins d'un espace d'habitation qui devait se développer au nord et s'ouvrir vers l'est.

Conservé sur une longueur de $3 \mathrm{~m}$ et large de $0,60 \mathrm{~m}$, le mur fera office de fondation pour une construction moderne. Cette maçonnerie, caractérisée par un appareil de petits moellons de Saint-Victor présente des différences de mise en œuvre en partie centrale où les pierres sont plus irrégulièrement disposées avec des joints supérieurs à $5 \mathrm{~cm}^{591}$. Cependant, la semelle de fondation est composée de façon homogène de dalles de calcaires taillés de 65 x 48 x $13 \mathrm{~cm}$. À l'extrémité orientale de la maçonnerie est établi un pilier engagé en grand appareil saillant de $35 \mathrm{~cm}$ et reposant sur une profonde fondation en blocage de blocs, galets et moellons. Les blocs d'élévations, en calcaire de Saint-Victor (60 x 38 × $24 \mathrm{~cm})$, sont très finement taillés; ils portent deux chanfreins dans les angles et sont dotés d'un évidement central de 20 x $14 \mathrm{~cm}$. Ce pilier correspond au piédroit d'une ouverture située à l'angle sud-est de l'espace.

À l'intérieur de la pièce, un sol d'occupation est matérialisé par un lit de mortier de $4 \mathrm{~cm}$ d'épaisseur

591 On note également la présence en réemploi d'un tailloir d'une colonnette engagée, ornée d'un motif de croix de Saint-André. dans lequel est intégré, le long du mur, un mortier en marbre blanc à fond percé. Ce récipient, d'un diamètre externe de 0,66 m et de $20 \mathrm{~cm}$ de hauteur, est de forme circulaire et présente trois oreillettes finies et l'esquisse d'une quatrième.

Au sud du mur, est apporté un remblai de quarante centimètres d'épaisseur destiné à colmater le puits et niveler le terrain. Cette couche de limon compacte de couleur noire, intègre dans sa matrice de nombreux nodules d'argile plastique pure jaune et orange comparable à des fragments d'adobe. Du mobilier daté de la fin du $\mathrm{XIV}^{\mathrm{e}} \mathrm{s}$. provient de ce niveau qui marque la dernière trace d'occupation du secteur pour le bas Moyen Âge.

En résumé, cet îlot correspond à l'un des plus vastes du quartier, ce qui a rendu nécessaire la mise en place d'une desserte intermédiaire permettant l'accès au cœur d'îlot. Cependant la nécessité d'étendre et d'accroître le nombre des habitations dès le XIV ${ }^{\mathrm{e}} \mathrm{s}$. a conduit à l'annexion de cette ruelle et des espaces de cour pour la construction de nouvelles maisons. Cet îlot renferme le seul bâtiment monumental du site, correspondant peutêtre à des étuves.

\subsubsection{L'îlot II ${ }^{592}$ (R. Thernot)}

L'îlot II adopte une forme allongée et s'étire d'est en ouest sur $38 \mathrm{~m}$ de long tandis que sa largeur est de $16 \mathrm{~m}$. Il est bordé au nord par le Mazeau, au sud par la rue de la Taulisse, à l'ouest par la rue du Coq-d'Inde et à l'est par la rue de la Guirlande.

Lors de la première phase de construction, datée de la fin $\mathrm{XII}^{\mathrm{e}}$ - début XIII ${ }^{\mathrm{e}}$ s., les murs principaux divisent l'îlot en cinq unités différenciées, nommées d'ouest en est unités A, B, C, D et E. Les trois premières sont disposées transversalement, donnant sur les rues nord et sud. Les deux dernières, plus lacunaires, semblent orientées longitudinalement par rapport à l'îlot, et s'ouvrir sur la rue orientale, bien qu'elles bénéficient également de longs confronts avec les rues adjacentes. Les unités A et $\mathrm{B}$ à l'ouest mesurent $8 \mathrm{~m}$ de large et, occupant toute la largeur de l'îlot, $16 \mathrm{~m}$ de long; les unités D et E à l'est calquent les mêmes mesures, tandis que l'unité C, transversale et large de $6 \mathrm{~m}$ environ, assure le lien entre les deux paires précédentes.

Vers la fin de la période médiévale, les deux unités occidentales sont remembrées et, formant les entités F et $\mathrm{G}$, s'orientent longitudinalement.

592 D'après B. De Luca, M. Maurin, F. Moroldo vol 1a, p. 178-187 in Mellinand 2005 ; M. Vecchione, zones 2 et 4, et V. Rinalducci, zones 5 et 6, in Vecchione, Rinalducci 1997 ; F. Paone, zones 3, 7, 9 , in Paone 1997b. 


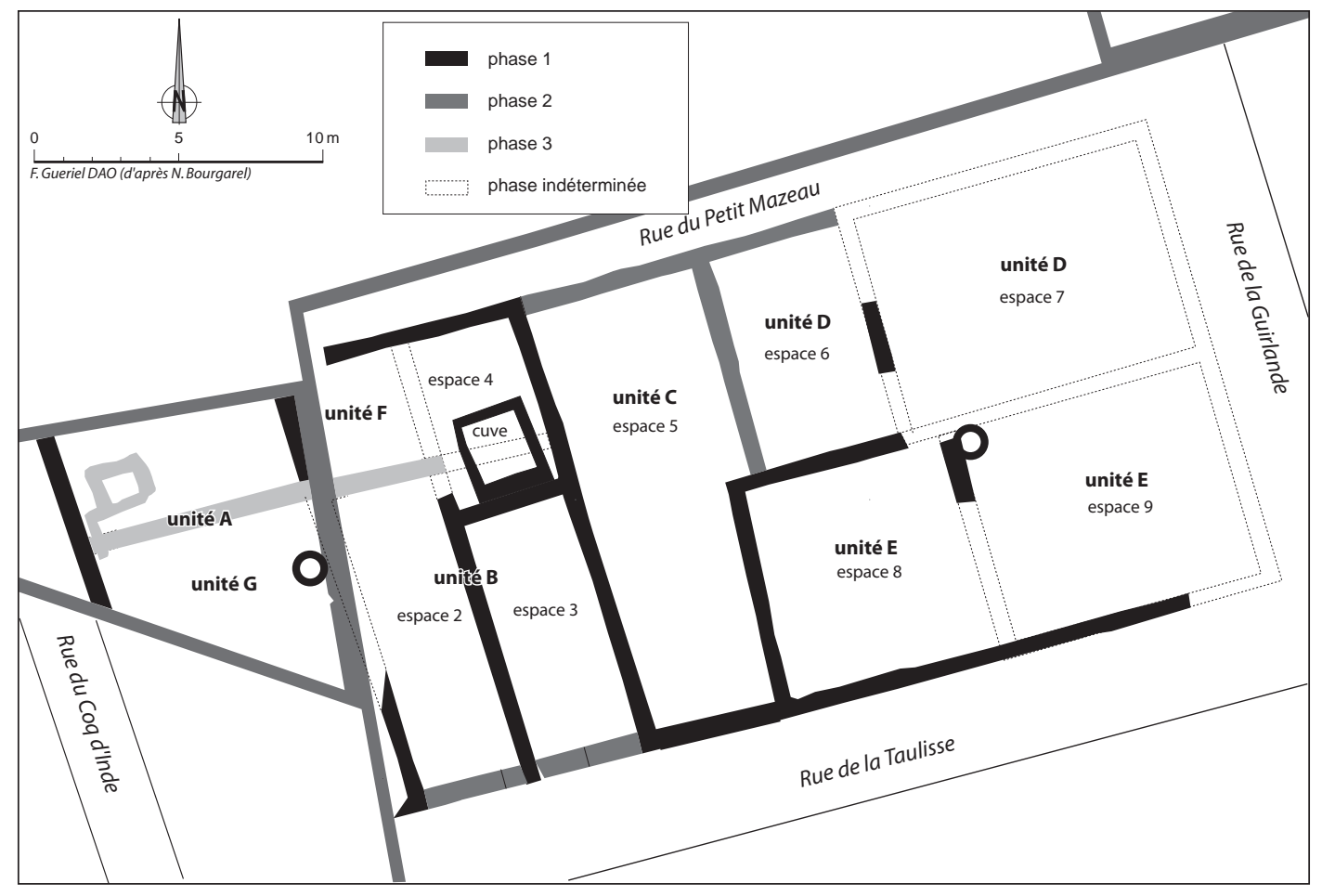

Fig. 157. Plan de l'îlot Il à l'époque médiévale (DAO F. Gueriel, B. Sillano/Inrap).

\section{L'unité A}

L'unité A (fig. 157) n'est matérialisée que par ses murs nord-sud et des niveaux de circulation. Les murs de direction est-ouest associés échappent au périmètre de la fouille. Ses limites nord et sud sont déduites de la projection vers l'ouest des murs de façade de l'îlot observés sur l'opération «César 1 », projection validée par l'analyse du cadastre moderne. Cette unité ne présente donc qu'un seul espace : l'espace 1.

Faisant suite à une phase de remblaiement et de récupération des matériaux sur les structures antiques sous-jacentes, datée par la céramique du début du XIII" $\mathrm{s}$. la construction de cette unité se traduit par la mise en place de deux murs parallèles d'axe nord-sud.

Le mur oriental, observé sur une longueur de $5 \mathrm{~m}$, est amputé de son parement oriental qui disparaît au sud sous la limite de fouille. La fondation du mur, installée dans une tranchée à profil en cuvette, est constituée de trois assises de fondation en ressaut, mettant en œuvre des moellons de calcaire brut et de quelques éléments en poudingue liés à la terre. L'assise d'élévation est composée de moellons équarris et de deux blocs en calcaire tendre. La fouille de cette construction a livré du matériel céramique de la fin du XII ${ }^{e}$ ou début du XIII ${ }^{e} s$.

Le mur occidental, observé sur une longueur de $6 \mathrm{~m}$, se compose d'une fondation de $1 \mathrm{~m}$ de haut, constituée de blocs et de moellons sommairement équarris, surmontée par une élévation parementée en petit appareil de calcaire, conservée sur une hauteur de $1,20 \mathrm{~m}$, soit 9 assises. L'ensemble est large de 0,70 m environ, sans ressaut de fondation. La fondation est installée dans une tranchée excédant de 15 à $20 \mathrm{~cm}$ la largeur de la maçonnerie de part et d'autre. Le comblement de cette tranchée est daté de la fin du XII ${ }^{\mathrm{e}}$ ou début du XIII ${ }^{\mathrm{e}} \mathrm{s}$.

Au sud du tronçon conservé du mur est et dans l'axe de ce dernier, est creusé un puits d'un diamètre interne de $0,84 \mathrm{~m}$, et conservé sur une hauteur de $4,50 \mathrm{~m}$ de haut (fig. 158). Associé à un réaménagement ponctuel du mur ouest, le cuvelage du puits est constitué de moellons en calcaire blanc soigneusement taillés, présentant une face concave. Deux modules différents sont mis en jeu alternativement dans le parement : $5 / 7 \mathrm{~cm}$ et $10 / 16 \mathrm{~cm}$ de longueur. Les assises, régulières, sont liées au mortier blanc gras avec inclusions de petits gravillons. Le mortier déborde largement à l'arrière dans le blocage qui comble la tranchée d'installation. Ce puits constitue le seul exemple relevé de puits mitoyen.

Entre les deux murs précités prennent place une série de niveaux de circulation. Le premier est un sol induré formé de cailloutis et de mortier, plan et horizontal, daté des $\mathrm{XII}^{\mathrm{e}}-\mathrm{XIII}{ }^{\mathrm{e}}$ s. C'est à partir de ce niveau que le mur occidental est construit. Parallèlement, au sud, se trouve un sol de chaux dont le contact avec le mur oriental est attesté et qui est daté du début du XIII ${ }^{e}$ s. Lui succède sans doute assez rapidement un sol constitué de mortier 


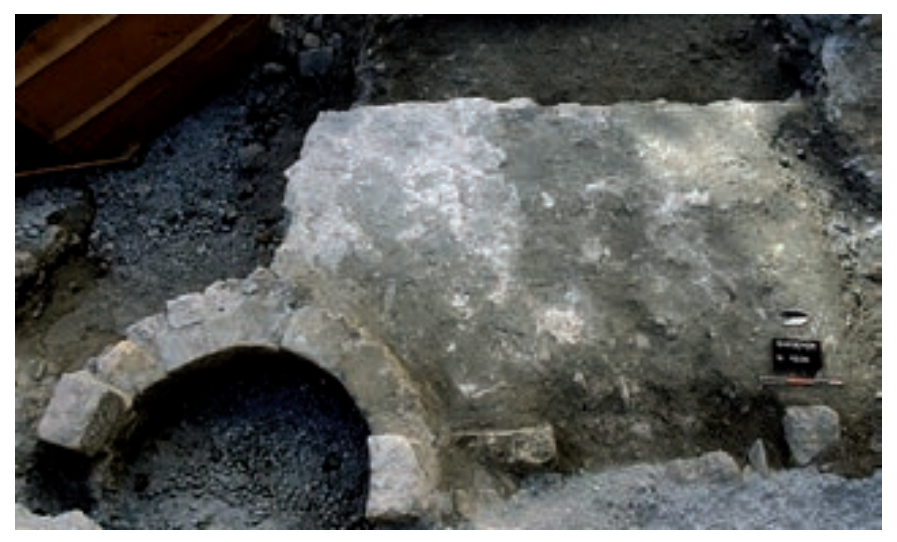

Fig. 158. Vue du puits et du sol de mortier dans l'unité A (îlot II) (cl. T. Maziers/Inrap).

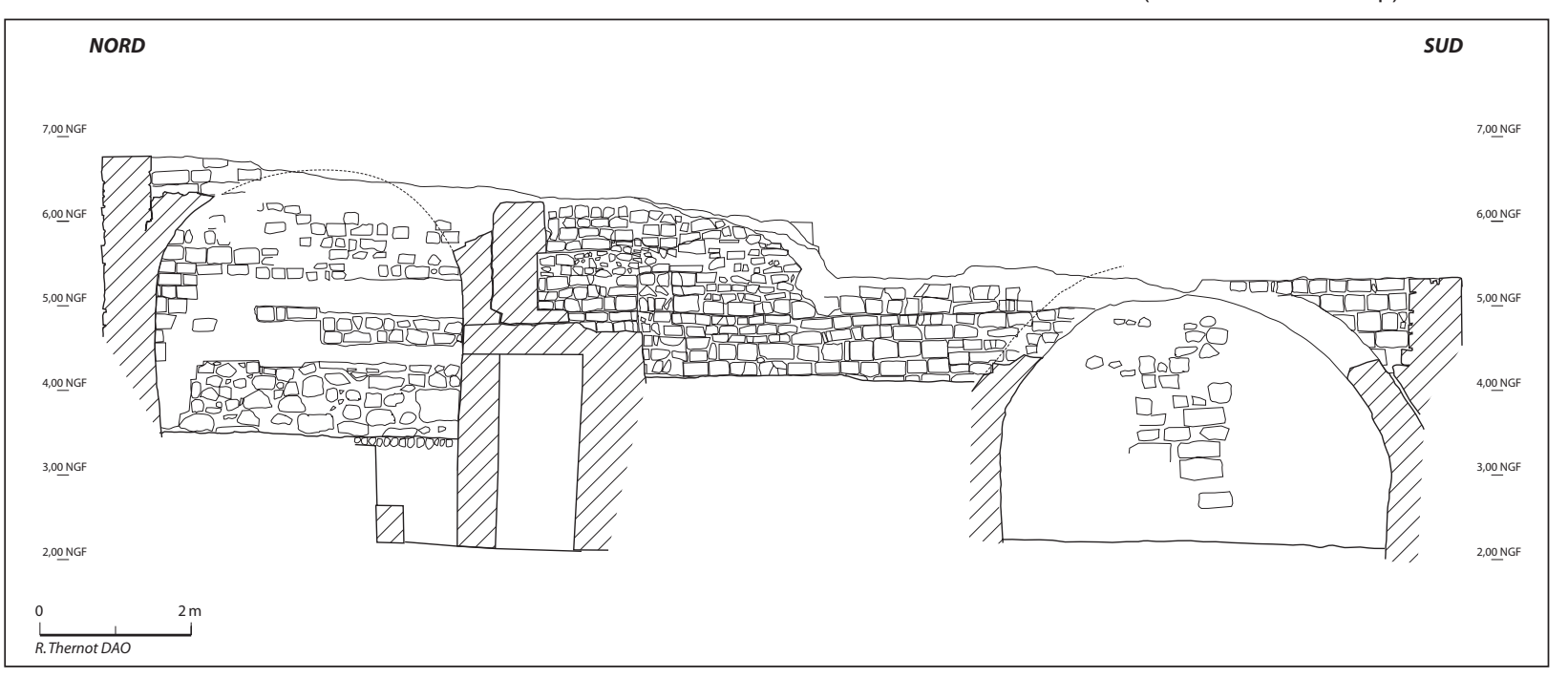

blanc et d'éclats de taille de calcaire blanc. Il est installé sur le comblement de la tranchée de fondation du mur riverain de la rue, peut-être pour combler une dépression le long de ce dernier, et semble avoir servi de niveau de travail en relation avec l'élévation du mur. Ces sols pourraient représenter des témoins du chantier de construction du bâtiment.

Un premier creusement peu profond apparaît ; il est de forme oblongue, orienté nord-sud, large de $0,32 \mathrm{~m}$ et long de $0,70 \mathrm{~m}$. Un second creusement linéaire possède un comblement essentiellement pierreux (galets, blocs et pierres) incluant de la faune -os et coquillages- des fragments de tuiles, certaines portant des traces de feu. Un limon sableux comble les interstices laissés entre les pierres.

Le sol de chaux est recouvert par une couche de limon sableux brun clair contenant de nombreuses inclusions de gravillons et de galets, quelques fragments de mortier fin, de charbons de bois, de la céramique résiduelle et des nodules d'argile. Le sol de mortier est quant à lui recouvert par un sédiment argilo-limoneux contenant des éclats de taille, des fragments de tuiles, de gros nodules de mortier, de la faune et peu de céramique néanmoins datable de la fin du XII ${ }^{e}$ ou du début du XIII" $\mathrm{s}$.
L'abandon, qui a livré du matériel céramique daté du début du XIII ${ }^{\mathrm{e}}$ s., est marqué successivement par deux couches de sédiment argileux peu compact brun, qui recouvrent les sols.

\section{L'unité B}

Cette unité observée sur l'opération «César 1 » forme une longue parcelle traversante, orientée nordouest/sud-est, qui relie la rue de la Taulisse au Mazeau. Longue de $16 \mathrm{~m}$ pour une largeur de $9 \mathrm{~m}$, elle est mitoyenne à l'ouest avec l'unité A dont ne subsiste qu'un court tronçon, la plus grande partie ayant disparu sous la paroi en béton formant la limite occidentale de la fouille. Avec ses deux murs de refend et la cuve voûtée qui est construite dans un second temps, elle représente l'une des unités médiévales les moins lacunaires; elle comporte 3 espaces numérotés 2,3 et 4 .

Les élévations des murs est et sud sont bâtis en petits moellons de calcaire tendre de couleur blanche, assisés et liés par un mortier maigre fait de chaux et de sable non tamisé comportant des petits galets (fig. 159). Le mur de façade nord est construit à partir d'une tranchée large de 30 à $40 \mathrm{~cm} \mathrm{La}$ fondation débordante est composée 
de moellons et blocs de grès et calcaire grossièrement équarris disposés en assises assez régulières. Les joints sont garnis de mortier blanc et dur comportant peu de graviers ; le mortier a flué contre les parois de la tranchée. L'élévation, accolée contre le mur de la façade voisine suivant un coup de sabre, est bâtie en moellons de Saint-Victor d'un module variant de $30 \times 15 \mathrm{~cm}$ à $14 \times 17 \mathrm{~cm}$. Le mortier est parfois beurré et les joints sont épais de 2 à $3 \mathrm{~cm}$. À une distance de $4,40 \mathrm{~m}$ de la jonction des deux murs de façade, un chambranle de porte en calcaire jaune a été ajouté mais toute relation stratigraphique avec les sols ayant disparu, ce dernier demeure indatable.

L'installation du mur de façade sur la rue de la Taulisse et les premiers niveaux d'utilisation de ce mur sont observés uniquement dans un sondage de 1,20 m sur $1,05 \mathrm{~m}$. Ce mur est constitué d'une fondation de cailloux et de moellons de grès avec quelques fragments de calcaire de La Couronne pour l'essentiel tout juste retouchés. L'élévation est parementée avec des blocs de grès taillés. Le blocage interne met en jeu des moellons équarris sommairement, de la terre et des éclats de tuf, dont des fragments d'angle de moellons. Le parement sud est enduit et des lits de joints tirés à la pointe sont conservés par endroits, sous une nouvelle couche d'enduit.

Contemporains de cette phase de construction, deux murs de refend construits en pisé banché, partagent l'unité en trois espaces ( $c f$. fig. 157). D'orientation nord-sud, le premier mur divise l'unité B en deux, isolant l'espace 2 à l'ouest des espaces 3 et 4 à l'est. Il est constitué d'une fondation débordante de blocs de grès bruts sans mortier, large de $0,75 \mathrm{~m}(c f$. fig. 76 et fig. 160), surmontée par un solin de deux assises de pierres équarries dont certaines sont posées en boutisses, et d'une assise de réglet en briques au-dessus de laquelle prennent place les élévations en pisé. Larges de $0,55 \mathrm{~m}$, celles-ci sont montées par lits de damage réguliers de $8 \mathrm{~cm}$ d'épaisseur, constitués d'un limon très homogène incluant quelques rares galets et cailloux de petite taille et de charbons de bois. Les lits occupent toute la largeur du mur et ont une longueur variant de 1,20 m à 1,50 m, qui semble correspondre au rythme de mise en place de la terre avant damage. Entre chaque lit est étalée une pellicule de mortier de $5 \mathrm{~mm}$ s'épaississant vers l'extérieur pour former un boudin prismatique qui s'étale verticalement contre la banche. Les parements de l'élévation sont protégés par un enduit de mortier compact, très riche en galets, assurant ainsi une parfaite cohésion entre l'enduit et le pisé (fig. 161). Pour finir, les parties visibles du mur, élévation en terre massive et soubassement en pierres, sont recouverts d'une pellicule de mortier blanc. Détruit au nord, ce refend est accroché au mur sud par un système de pénétration du mur de terre dans le blocage intérieur du mur de pierres.

Orienté est-ouest, le second mur relie le refend occidental, auquel il est appuyé, au mur oriental dans lequel il est ancré par pénétration dans le blocage. Les espaces 3 et 4 sont ainsi délimités. La fondation met en jeu des blocs bruts de poudingue identiques à la fondation de mur est, le soubassement est semblable à celui du mur nord-sud, de même que les lits de damage (fig. 162); mais en l'absence de boudins de mortier au contact des parements, l'élévation en terre reçoit directement l'application d'un enduit de mortier similaire à celui de l'autre mur. Le démontage de la structure a livré un lot relativement important de céramique, pour la plupart résiduelle, mais contenant 15 tessons de céramiques communes à pâte grise.

L'absence apparente de joints verticaux dans les élévations en terre massive, traduit l'utilisation de banches de toute longueur, maintenues en place par des pieux verticaux et des clés horizontales. C'est l'hypothèse à laquelle conduit l'observation d'une succession de files de pierres traversantes, distantes de 1,50 m, à la base de l'élévation en terre, pouvant représenter les obturations des trous de clé (Thernot, Vecchione 2003).

Les murs de refend en terre définissent ainsi trois espaces à l'intérieur de l'unité B. À l'ouest, l'espace 2, large de $4 \mathrm{~m}$ pour une longueur de $15 \mathrm{~m}$ n'a conservé qu'un seul sol de terre battue qui n'a pas livré de mobilier. Au sud-est, l'espace 3, long de 8,50 m pour une largeur de $3,50 \mathrm{~m}$, comporte un sol chaulé dont le contact avec la base des murs se traduit par une remontée du mortier. $\mathrm{Au}$ nord-est, dans le troisième et le plus petit module (espace 4 de $6 \mathrm{~m}$ sur 3,50 m), un lambeau de sol a livré, parmi un lot de céramiques antiques résiduelles, deux fragments de céramiques communes grises attribuables à la seconde moitié du XII ${ }^{\mathrm{e}} \mathrm{s}$. C'est dans cet espace 4 qu'est construite, dans une deuxième phase d'aménagement, une cuve enterrée de plan quadrangulaire $(2,50 \mathrm{~m} \times 3,00 \mathrm{~m})$ et couverte d'une voûte plein-cintre. Adossée au parement nord de la fondation de la limite sud, ses murs sont parementés à l'intérieur de moellons de calcaire blanc, parfaitement équarris et assisés, portant de très nettes traces d'usure hydraulique ( $c f$. fig. 57). L'absence de fond bâti et d'enduit hydraulique sur les murs incitent à proposer l'hypothèse d'une fonction de glacière ou encore de latrines. Afin de dépasser le sommet de la voûte de la cuve, le niveau de circulation dans l'espace 4 se situe $50 \mathrm{~cm}$ plus haut que ceux des espaces mitoyens.

Aucun indice quant à la fonction dévolue aux différents espaces de l'unité B n'a été décelé. En outre, la rareté du mobilier céramique non résiduel oblige à être prudent en ce qui concerne la période d'installation de la 
maison; toutefois les quelques tessons trouvés dans le démontage des murs en terre ne diffèrent guère de ceux livrés par les remblais d'installation et la construction semble réalisée dans la seconde moitié du XII ${ }^{\mathrm{e}} \mathrm{s}$.

Des travaux sont réalisés dans un second temps. La façade fermant l'espace 3 est rapidement reprise lors de la construction du mur méridional. Appuyé contre l'extrémité du refend en pisé nord-sud, ce mur ${ }^{593}$ est parementé en petit appareil de moellons de calcaire mêlant faciès dur et tendre de Saint-Victor, sans qu'une répartition spéciale de matériaux ne soit à signaler. Il est conservé en élévation sur une longueur de 1,25 m. Les fondations de moellons en poudingue et calcaire bruts reposent sur les fondations plus anciennes du mur initial. À l'est bien que formant un léger redan, d'autres blocs de poudingue témoignent de la poursuite du mur. Le nouveau tronçon de façade est recouvert d'un enduit peu épais blanc inégalement conservé, lui-même badigeonné d'un lit de mortier comme l'était la première façade partiellement conservée.

Un emmarchement est installé contre cette reprise de façade. Il est constitué de moellons et cailloux divers au-dessus desquels sont posées des pierres plates afin d'égaliser la surface de la marche. Le tout est lié à la terre et scellé en surface par un mortier jaune dur avec quelques petits galets. Le tout mesure 1,30 x 0,38 x 0,30 m.

La séquence médiévale observée sur l'emprise de l'unité B se solde par un arasement général des structures au-dessus duquel prennent place des niveaux datés du XVI $\mathrm{s}$.

\section{L'unité C}

L'étude des élévations et des traces d'usure météorique affectant les parements semblent indiquer que lors de la première phase d'installation du quartier (fin XII début XIII' ${ }^{\mathrm{s}}$ s.), l'unité C, d'une superficie de $80 \mathrm{~m}^{2}$, de même que l'espace 6 de l'unité D jouxtant l'unité $C$ au nord-est, sont des espaces ouverts.

Durant la deuxième moitié du XII ${ }^{\mathrm{e}} \mathrm{s}$. s'installe en rive nord de l'unité $\mathrm{C}$, sur un remblai de la rue, un mur conservé sur $7 \mathrm{~m}$ de long sur 2,20 $\mathrm{m}$ de hauteur pour une largeur de 0,55 m. Ce mur, construit de moellons de calcaire blanc de Saint-Victor (modules compris entre 20 et $30 \mathrm{~cm}$ de long pour une hauteur de 10 à $15 \mathrm{~cm}$ ), est lié au mortier gris et dur. Ses fondations intègrent également des blocs de grès. À l'ouest, la façade se termine par un coup de sabre au droit de la limite avec l'unité B. Sur la limite avec l'unité D, un muret perpendiculaire au mur de façade en saillie de $30 \mathrm{~cm}$, de $70 \mathrm{~cm}$ de long et $65 \mathrm{~cm}$

593 Dimensions conservées : 1,20 x 0,50 m. de large, lié aux fondations, fait office de contrefort à l'aplomb du jambage de deux portes. Ce dernier se place au droit d'un mur de refend qui marque la limite orientale de l'unité au cours de la deuxième phase de construction.

Le jambage est fait de pierres de taille en calcaire tendre disposé en carreaux et sur l'assise supérieure de deux blocs de tuf en boutisse. Intégrés de part et d'autre de ce dernier, deux seuils indiquent l'existence d'entrées mitoyennes desservant les unités C à l'ouest et D à l'est. Les feuillures impliquent que les portes s'ouvraient de l'intérieur. Ces seuils permettent de restituer approximativement le niveau de circulation. À l'est, le seuil est en calcaire de Saint-Victor, à l'ouest, le second seuil, plus haut d'une vingtaine de centimètres, est en calcaire jaune de La Couronne. La différence de niveau traduit la pente naturelle de la rue vers l'est (fig. 163).

Une cloison de brique de safre liées par de l'argile grise ${ }^{\mathbf{5 9 4}}$ forme une légère avancée par rapport aux autres bâtiments, seule construction en matériaux périssables il correspond peut être plus à une clôture basse qu'à un pignon. Les niveaux attenants à cette limite sont assez perturbés ${ }^{595}$, il est donc difficile de savoir quand rattacher cette construction.

Une nouvelle campagne de travaux affecte la façade nord de l'unité C. Elle concerne l'obturation de la porte située dans l'angle nord-est par un mur régulièrement parementé en moellons de Saint-Victor avec joints rentrants. Aucun indice de la nouvelle entrée ne subsiste.

L'unité $\mathrm{C}$ reste non bâtie au cours de la première phase de construction alors que les unités voisines sont déjà construites. Elle paraît représenter un espace tampon entre les deux paires de parcelles (A/B à l'ouest, et $\mathrm{D} / \mathrm{E}$ à l'est) disposées de part et d'autre. L'unité $\mathrm{C}$ pourrait ainsi avoir été un espace ouvert ou un passage annexé dans un deuxième temps par les constructions.

\section{L'unité D}

L'unité D occupant l'angle nord-est de l'îlot se divise en deux espaces inégaux 6 à l'ouest et 7 à l'est.

Les structures médiévales composant la partie orientale de l'unité D ont été pratiquement abolies lors de la réfection du bâtiment à l'Époque moderne, période où il apparaît sous le nom de Logis du Rozier. Néanmoins, des éléments attribuables au Moyen Âge subsistent sur le mur médian et sur le mur méridional, et permettent d'attester d'une construction sur ce terrain à cette époque.

594 Cette cloison a été amputée dans le sens de la largeur lors de l'installation d'un mur moderne.

595 La présence d'une rampe pour la pelle mécanique à cet endroit a contribué à la détérioration de la stratigraphie. 


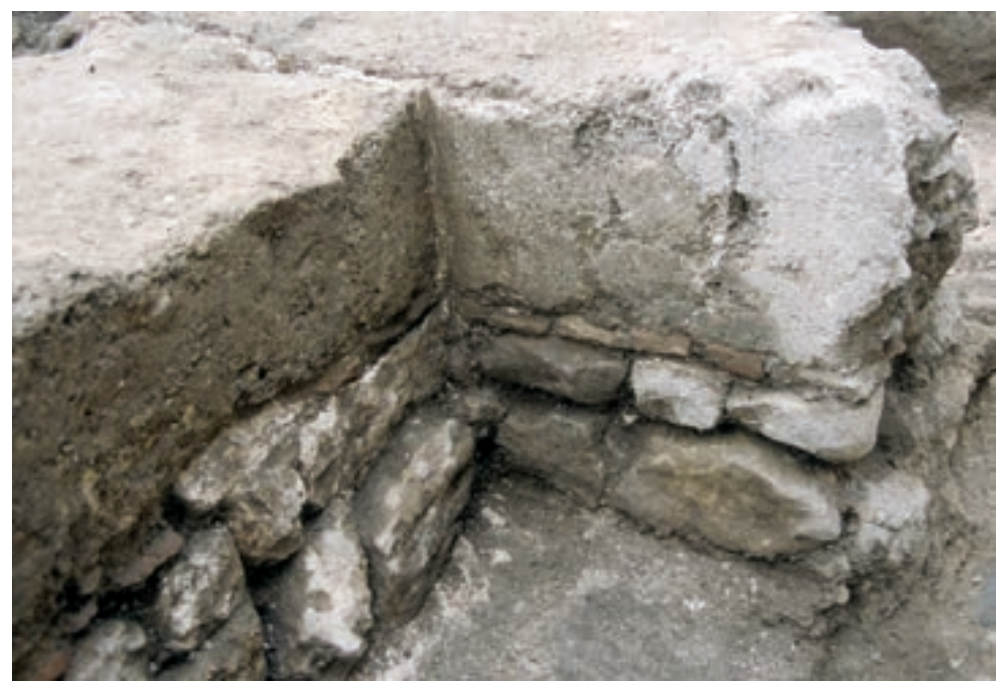

Fig. 160. Liaison des murs en pisé (cl. M. Derain/Inrap).

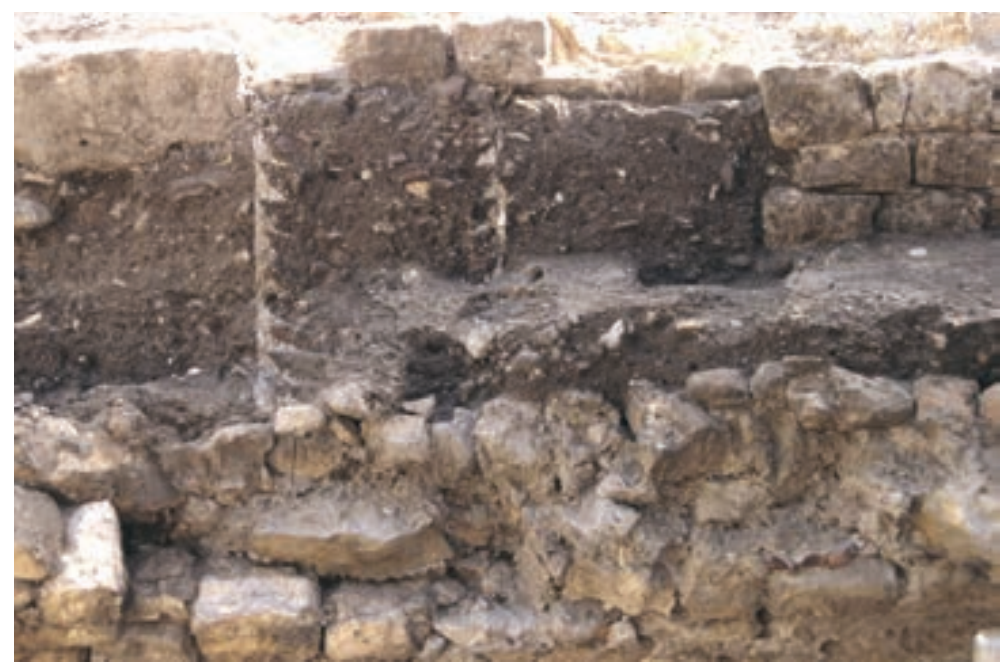

Fig. 161. Vue des banches successives (cl. M. Derain/Inrap).

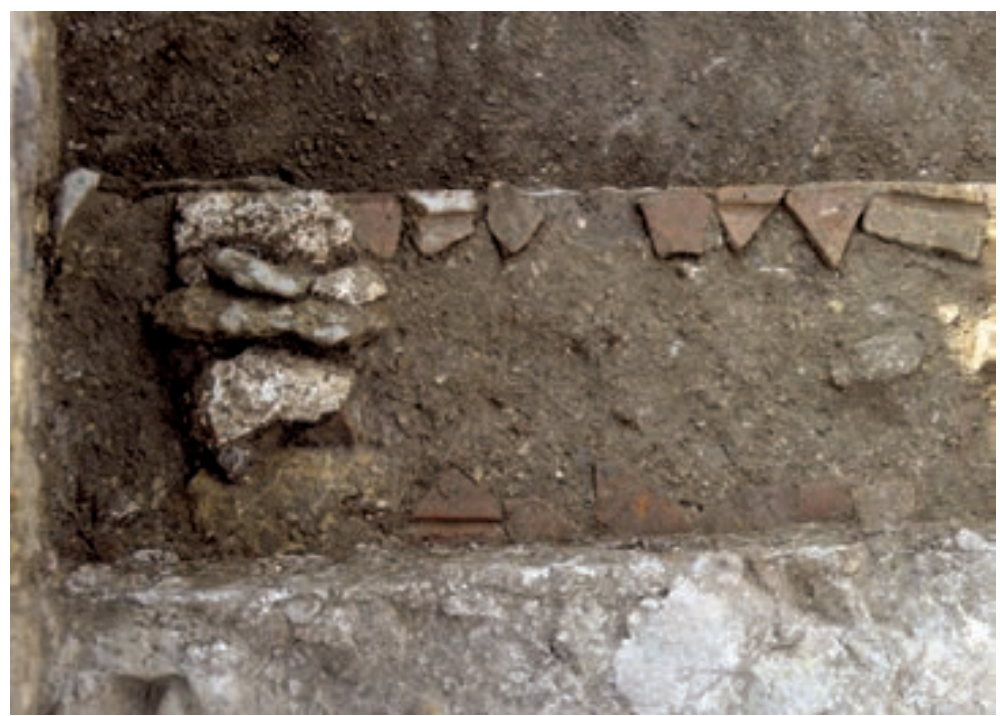

Fig. 162. Boutisses de pierre et réglet de tuiles (cl. M. Derain/Inrap).
À l'ouest de ce premier espace, les murs nord et ouest sont construits postérieurement.

Sur le parement ouest du mur médian, la présence de deux assises de moellons en calcaire de Saint-Victor situées au même niveau que celles du soubassement du mur nord de l'unité E, trahissent une phase de construction semblable. Sur le parement est, les indices sont plus nombreux (fig. 164). La mise en œuvre de ce parement dans sa moitié nord se caractérise par une absence de réutilisation de fragments de pierres taillées en calcaire de La Couronne et un emploi plus limité de fragments de carreaux de pavement en terre cuite. La construction en calcaire tendre est assisée, liée au mortier gris très clair à inclusions de chaux et réutilise des fragments de carreaux de terre cuite pour des calages ponctuels. La maçonnerie intègre dans l'angle inférieur nordouest un mur antique, dont le blocage a été bûché à l'aplomb du nu du mur médiéval et apparaît ainsi en coupe.

Une baie est liée au parement du mur dans son état initial. La baie, ouverte dans la moitié nord de l'élévation entre les espaces 6 et 7, ne subsiste plus que dans le parement oriental de ce mur, sous la forme d'un arc (de décharge ?) lacunaire, bloqué au mortier, constitué en majorité de claveaux de tuf auxquels se sont mêlés deux claveaux blancs de calcaire tendre. Les ruptures verticales situées dans l'axe des retombées de l'arc, juste en lieu et place des anciens jambages, entrent très profondément à l'intérieur du mur, dépassant le blocage interne. Il est donc probable que l'ouverture ait traversé le mur à l'origine, bien qu'un nouveau parement appliqué du côté occidental l'ait définitivement masquée. La hauteur de cette baie $(2,30 \mathrm{~m})$, bouchée depuis le sol jusqu'à l'intrados de l'arc ainsi que sa largeur $(1,20 \mathrm{~m})$ conduisent à y voir une porte de communication entre deux espaces situés à la cote de 2,30 m NGF environ. Ces espaces doivent donc correspondre à des caves couvertes de planchers car la présence du seuil ouvrant sur l'espace 6 situé à l'arrière du mur se place vers 6 m NGF. La porte est obturée en deux temps. Les deux obturations ayant des modes de constructions très différentes, cette baie a pu, soit continuer à fonctionner ultérieurement en temps que telle, après la réduction de sa hauteur due à la fermeture de son couvrement primitif en arc, soit servir de renfoncement ou de placard, bien que l'on n'aperçoive aucun revêtement habituellement nécessaire à cet aménagement. 

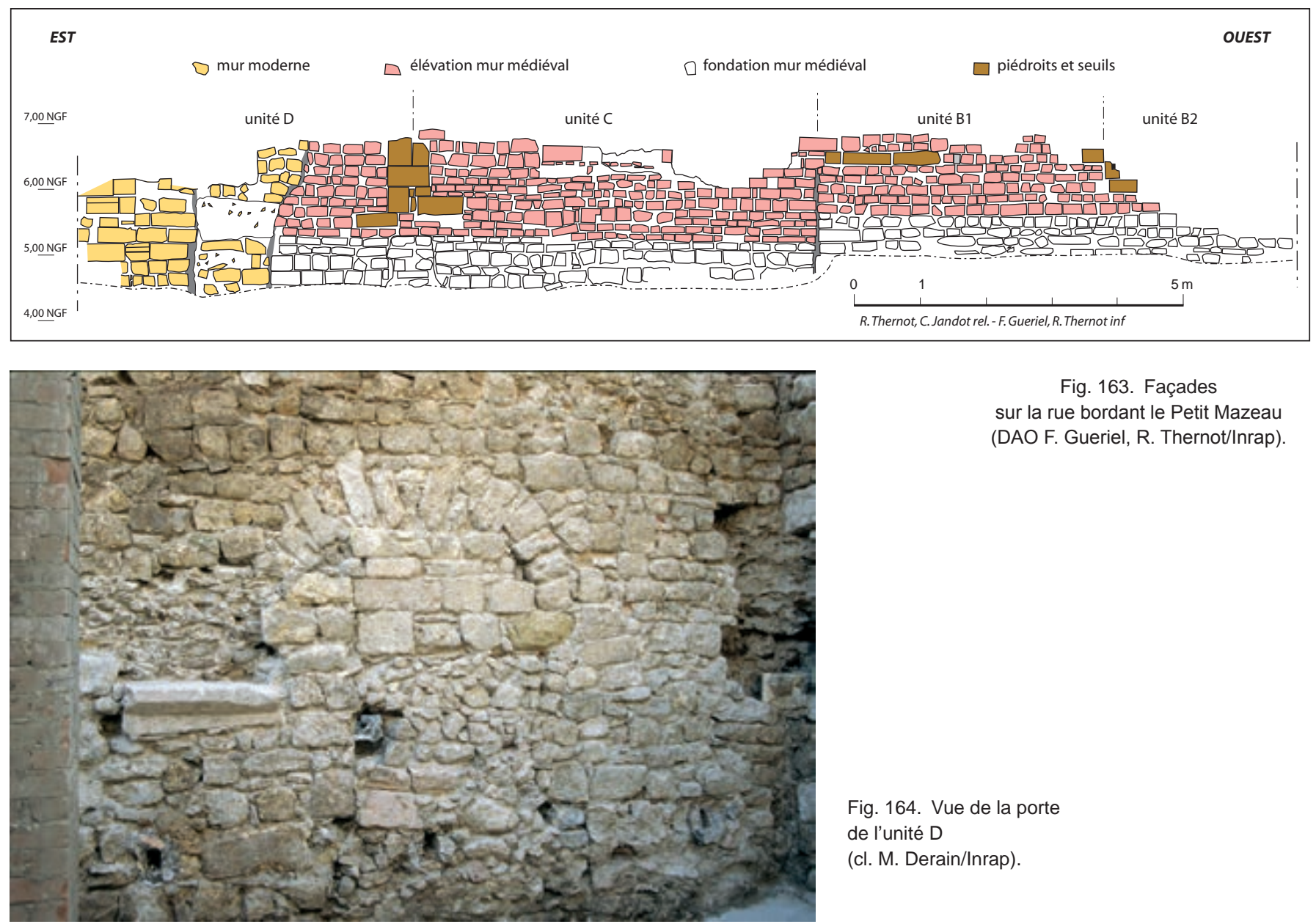

Fig. 163. Façades sur la rue bordant le Petit Mazeau (DAO F. Gueriel, R. Thernot//nrap)
La maçonnerie du mur sud de l'unité $\mathrm{D}$, perpendiculaire au mur médian, est liée à ce dernier et sa mise en œuvre en est très proche. Ce mur s'étend vers l'est, sur environ 3,70 m depuis l'angle sud-ouest de la cave, après quoi il est interrompu verticalement. L'angle formé par les deux murs est occupé par un puits intégré à la construction des parements.

$\mathrm{Au}$ début du XIII ${ }^{e}$ s., une nouvelle transformation intervient concernant l'accès à l'unité $\mathrm{D}$. La porte est murée par une construction de moellons de calcaire tendre ainsi que de quelques pierres de taille en réemploi. Dans la partie orientale, des fragments de tuiles servent de lit de réglage pour rattraper les différences de hauteur des pierres. Un nouvel accès est probablement installé plus à l'est mais une reprise moderne a totalement effacé toute trace et détruit la stratigraphie environnante. Du côté de la rue longeant le Mazeau, deux calades sont contemporaines de ce nouveau mur.

\section{L'unité $E$}

Occupant l'angle sud-est de l'îlot II, l'unité E se divise en deux espaces inégaux 8 à l'ouest et 9 à l'est.
Elle est déterminée au sud par sa façade sur rue, à l'ouest par un mur mitoyen avec l'unité C, au nord par le mur mitoyen avec l'unité D; elle a perdu toute trace de la façade orientale sur la rue de la Guirlande. Le mur de refend nord-sud détermine les deux espaces de l'unité : l'espace 8 à l'ouest et l'espace 9 à l'est.

L'unité $\mathrm{E}$ est construite sur le même remblai que l'unité B. L'extrémité ouest de la façade sud ne subsiste que sous forme de rares blocs de grès et moellons de calcaire conservés en partie haute du mur. Vers l'est, le mur comporte encore une partie médiévale conservée sur une longueur de $10 \mathrm{~m}$ et large de $0,60 \mathrm{~m}$. Le mur se compose de trois assises de fondation en appareil réglé de moellons de grès liés au mortier, conservées sur une hauteur totale de $0,70 \mathrm{~m}$. De bas en haut, la hauteur de chaque assise supérieure est moindre que celle qui la précède : elle varie de 0,30 à 0,25 et $0,18 \mathrm{~cm}$. L'élévation, plus affectée que la fondation par les multiples reprises des parements, n'est plus conservée que ponctuellement sur $3,70 \mathrm{~m}$ de longueur en tout, et trois assises superposées sur $0,70 \mathrm{~m}$ de hauteur. Un petit appareil régulier en moellons de calcaire de Saint-Victor et lié au mortier, habille encore le parement nord. 


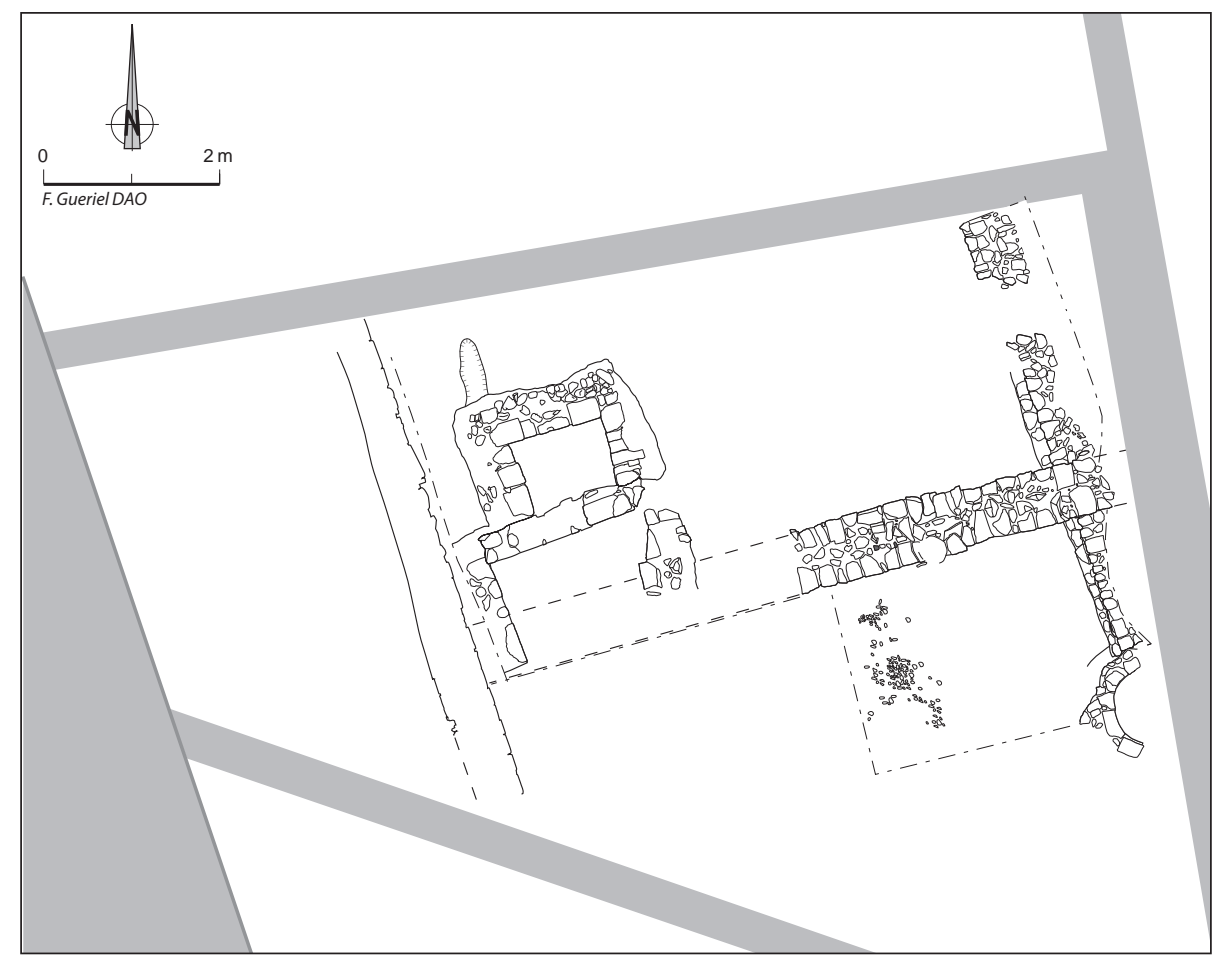

Fig. 165. Transformation du bâti au XIVe s. (DAO F. Gueriel/Inrap).

Les murs ouest et nord comportent des élévations en petits moellons assisés de calcaire tendre, quelques-uns de tuf, sur une fondation en gros galets de grès parfois posés de chant. Seul le mur nord a conservé un court tronçon d'élévation en pisé. La fondation ne comprend qu'une assise de gros galets, tandis que le solin est constitué de cinq assises de moellons calcaires liés par un mortier sableux de couleur jaune. Les lits de damage ont une épaisseur régulière de $8 \mathrm{~cm}$ et sont séparés par un fin lit de sable. Les parements sont enduits d'une pellicule de mortier de sable jaune incluant de petits galets.

Les murs parallèles ouest et est présentent, à des niveaux identiques à ceux du solin du mur nord, quelques assises de moellons calcaires qui laissent penser qu'eux aussi comportaient des élévations en pisé banché. Cette hypothèse est renforcée par l'observation, à la base du solin du mur oriental, d'orifices qui pourraient correspondre à des trous de clés de banches.

L'élévation du mur de refend est constituée de moellons grossièrement équarris et de cailloux retouchés. Parmi les matériaux composant cette élévation, on trouve du calcaire tendre de Saint-Victor, du calcaire tendre de la Couronne, du poudingue ainsi que des fragments de tuiles et de carreaux en terre cuite. L'ensemble présente un aspect perturbé trahissant des reprises fréquentes. Deux trous de boulins qui sont alignés horizontalement, espacés de $1,50 \mathrm{~m}$ et mesurant $18 \times 12 \times 22 \mathrm{~cm}$ se situent quasiment au sommet de cette élévation, mais ils ne traversent pas la largeur du mur qui mesure plus de $0,60 \mathrm{~m}$.

Un puits intégré à la construction du mur de refend et à celle du mur nord de l'unité prend place dans l'angle formé par ces deux murs. Le cuvelage du puits est lié au mortier grisâtre à inclusions de gravillons noirs. On note un emploi de fragments de moellons blancs de calcaire tendre de Saint-Victor. Ce cuvelage est contemporain à la construction du mur septentrional car certaines pierres sont communes aux deux constructions.

Une seule couche archéologique encore en place dans l'espace occidental peut correspondre approximativement au niveau de pose de la fondation médiévale, et contient trois tessons de céramique grise, dont deux fonds bombés, ainsi qu'une trentaine de fragments antiques. De plus, cette couche n'est plus en relation physique avec le mur car elle a été percée lors d'une reprise moderne du parement.

\section{Les unités $F$ et $G$ et refonte de l'unité $B\left(X I V^{e} s.\right)$}

Au cours du XIV ${ }^{\mathrm{e}} \mathrm{s}$. intervient un important remaniement. L'espace de plan carré de $16 \mathrm{~m}$ de côté couvert par les unités A et B est scindé en deux par la construction d'un mur orienté est-ouest et long de 15,50 m, qui divise l'espace en deux nouvelle unités : $\mathrm{F}$ et $\mathrm{G}$ ( $c f$. fig. 157). Plusieurs éléments y sont rattachés, malgré leur caractère 


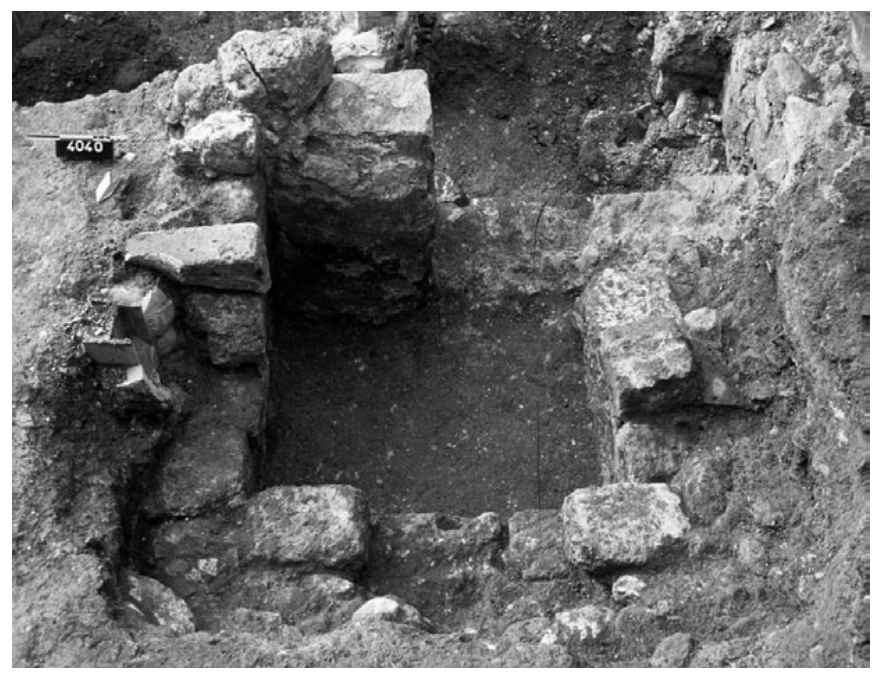

Fig. 166. Cuve (latrines ?) de l'unité F (cl. T. Maziers/Inrap).

parfois lacunaire, que compensent en partie les datations proposées par l'étude céramologique.

Dans l'emprise de l'unité A, le nouveau mur est constitué d'un double parement sur quatre assises irrégulières de cailloux et de moellons dont certains en remploi (en grès, calcaire de La Couronne, de Saint-Victor et de Cassis) maçonnés au mortier de chaux, les joints étant épais et creux. Ce mur a une largeur de 0,70 m et une longueur conservée de 3,65 m (fig. 165).

Au sud de ce mur, avec lequel le lien stratigraphique est hypothétique, est installé un sol, sous la forme d'une calade très lacunaire faite de galets reposant sur trois couches de remblais successifs. Il s'agit en premier lieu d'une faible épaisseur de sédiment charbonneux contenant des tuiles brûlées, également quelques cailloux et pouvant être attribuée au début du $\mathrm{XIV}^{\mathrm{e}} \mathrm{s}$. Il est recouvert par une couche hétérogène, meuble de couleur rose (mortier) à brun foncé, contenant de nombreuses pierres calcaires, fragments de mortier, de la faune et quelques tessons de céramiques; puis d'un sédiment argilo-sableux de couleur marron contenant des moellons, épais de 0,40 m environ, qui constitue le remblai de préparation du sol caladé.

Dans l'espace F, des citernes ou latrines de datation incertaine (le niveau de départ de leur creusement est inconnu) semblent pouvoir être rattachées à cette phase. Ce sont deux structures de plan quadrangulaire dont celle située au sud n'est que partiellement conservée : elle est recoupée par le creusement de la cave moderne (fig. 166). La cuve nord est de plan quadrangulaire ; les dimensions en sont 1,03 m d'est en ouest et $0,80 \mathrm{~m}$ du nord au sud. La profondeur maximale conservée est de $0,90 \mathrm{~m}$, et de $0,40 \mathrm{~m}$ en moyenne. Les faces internes de la structure sont enduites, mais pas le fond. Elle est flanquée d'une construction quadrangulaire appuyée également contre

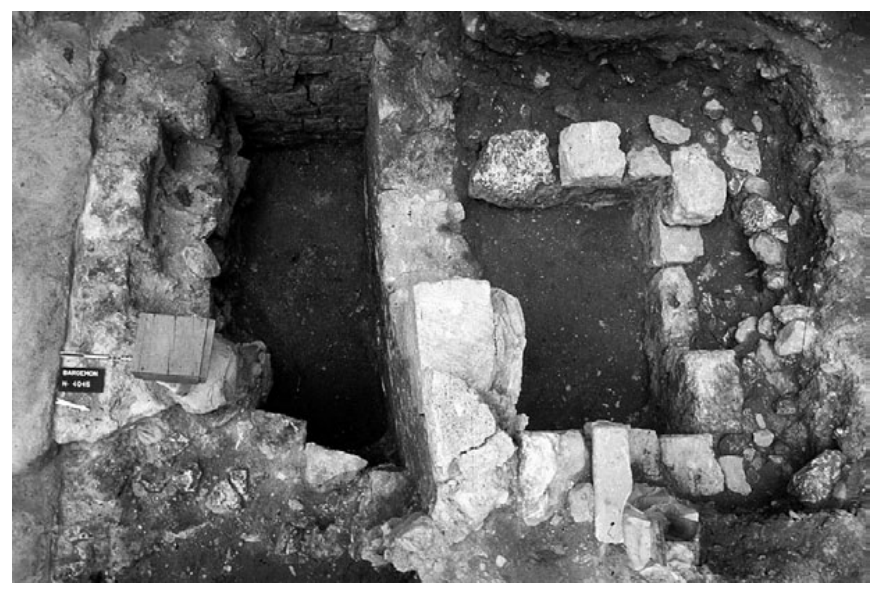

Fig. 167. Vue d'ensemble des cuves (latrines ?) (cl. T. Maziers/Inrap).

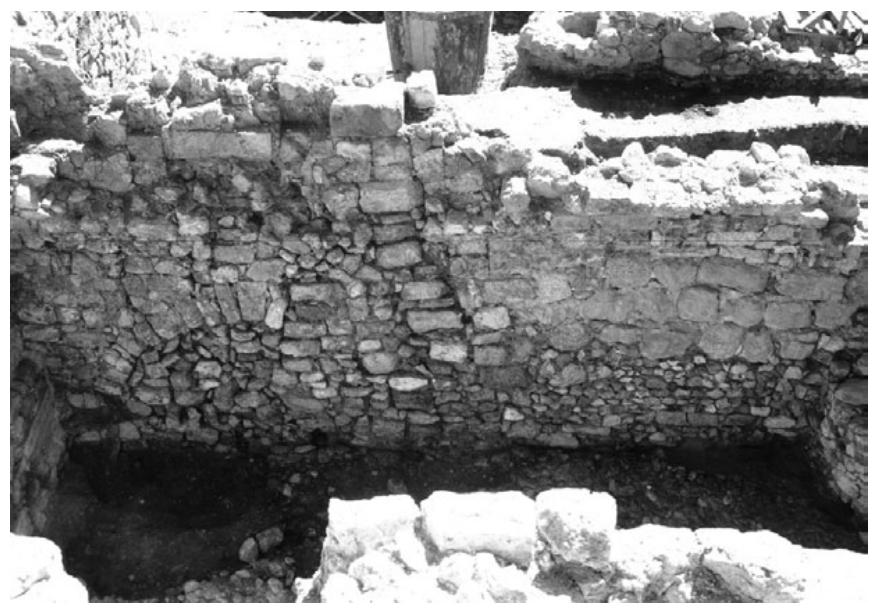

Fig. 168. Maçonneries divisant l'unité B (cl. M. Derain/Inrap).

le parement est de la façade sur la rue du Coq-d'Inde. Elle mesure 1,82 m d'est en ouest et est conservée sur $0,75 \mathrm{~m}$ du nord au sud. Des murets qui la composent, seul le muret occidental est bien conservé ; celui du sud a disparu et à l'est il ne subsiste qu'un maigre témoin. Ce sont des constructions soignées en petits moellons réguliers maçonnés au mortier mais non enduits, le fond n'étant pas aménagé. Il existe un passage parementé entre ces deux structures, à travers le mur mitoyen; il s'agit d'un piédroit, chaînage constitué de deux blocs, dont seul un côté est conservé sur une hauteur de $0,68 \mathrm{~m}$ (fig. 167). Ces deux pièces, de profondeur différente, sont partiellement épierrées et comblées d'une couche de gravats datée de la fin du XIII ${ }^{e}$ ou début du XIVe $s$.

Dans l'emprise de l'unité $\mathrm{B}$ et dans le prolongement du mur déterminant les unités $\mathrm{F}$ et $\mathrm{G}$, est également bâti un nouveau mur résultant de campagnes de construction successives qui suivent le même alignement. Ce mur laisse apparaître deux mises en œuvre différentes, trahissant une partition transversale intermédiaire disparue, témoignant aussi d'étapes de construction (fig. 168). 


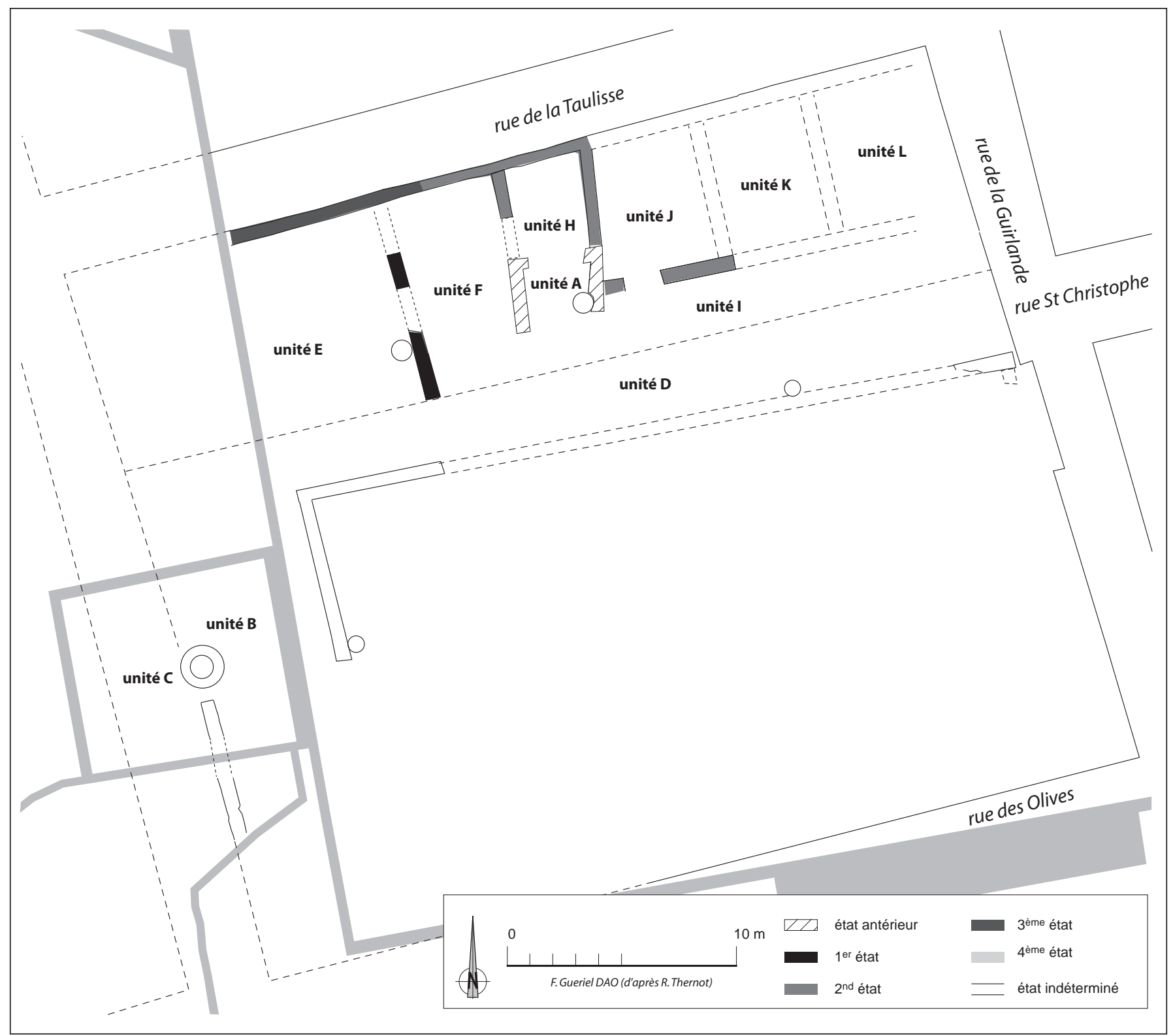

Fig. 169. Plan de l'îlot III à l'époque médiévale (DAO F. Gueriel/Inrap).

À l'est, appuyée sur une reprise du mur oriental, la construction est formée de moellons de calcaire blanc régulièrement assisés, posés sur une assise en ressaut. À l'ouest, le bâti est moins soigné ; on note la présence de nombreux remplois. L'élévation repose sur trois assises de fondation en gros blocs de grès traversants.

Cela pourrait signifier qu'approximativement à $3 \mathrm{~m}$ du mur oriental se trouvait un mur nord-sud scindant l'unité F en deux pièces d'inégales longueurs. Ce mur, dont aucune trace n'est relevée au revers du mur de la façade longeant le Mazeau, aurait disparu lors de la création de la cave moderne. Compte tenu de la profondeur du parement nord du nouveau mur divisant l'unité $\mathrm{B}$ par rapport à l'assise de fondation du parement sud, il est possible de situer à cette époque l'installation d'une première cave au nordest de l'unité F. Cette cave signerait l'abandon de la cuve orientale alors que se mettent en place à l'autre extrémité de l'unité les deux nouvelles cuves.

\section{Les niveaux de circulation}

L'étude de la mise en place des structures, pour lacunaires qu'elles soient, livre un certain nombre d'indication sur le niveau de circulation lors de la première phase de construction puis au cours de l'évolution du quartier.

La différence de niveau entre le Mazeau et la rue de la Taulisse, traduit l'étagement du quartier suivant la pente du terrain vers la mer. Les seuils donnant sur le 
premier espace se placent vers 5,80 m/6,00 m NGF, alors que sur la rue méridionale, le niveau de circulation se situe vers 4,30 m à l'ouest (sols de l'unité B) et 4,80 m à l'est (base de l'élévation de l'unité E). Cette différence de niveau est peut-être mise à profit pour installer des caves dans la partie nord de l'îlot. En effet, une cave dans l'unité $\mathrm{D}$ existe avec un sol à 2,30 m NGF et une autre cave semble être creusée au cours de la période au nord-est de l'unité G.

\section{En résumé}

L'îlot II est composé initialement de cinq parcelles à bâtir. Des unités A et B constituant la partie occidentale (cf. fig. 39), seul l'ensemble B fournit dès son origine des éléments de division de l'espace grâce à la conservation des murs de refends en pisé. Elle se compose donc d'au moins trois espaces répartis autour d'un refend longitudinal. À l'ouest, une pièce traversante de $14,80 \mathrm{~m}$ sur 3,50 m dans l'œuvre est accessible par les rues du Petit-Mazeau et de la Taulisse ; mais au vu de sa longueur, un cloisonnement intérieur de cet espace n'est pas à exclure. La moitié orientale de la maison est formée d'une pièce principale de $8,50 \times 3,50 \mathrm{~m}$ et d'une petite cour au nord mesurant $6 \mathrm{~m}$ sur 3,5 $\mathrm{m}$ dans laquelle une cuve voûtée était établie. La présence d'une base d'emmarchement le long du pignon méridional ainsi que d'un système de gouttière intégré dans cette façade permettent d'émettre l'hypothèse que la maison donnait sur la rue de la Taulisse. L'absence de niveaux stratigraphiques et de structures significatifs n'indique cependant pas que le rez-de-chaussée de ces maisons aient été à usage professionnel. Au nord-est de l'îlot, l'unité D placée perpendiculairement à la rue de la Guirlande se compose d'au moins deux caves qui communiquent ; cette partition reflète peut-être les divisions du rez-de-chaussée. La maison E, dépourvue de sous-sols, renferme aussi deux pièces, l'espace le plus petit mesurant déjà $8 \mathrm{~m}$ de coté. Enfin, la zone intermédiaire (unité $\mathrm{C}$ ) semble être restée dépourvue de constructions, ce qui explique que la maison $\mathrm{E}$ ait pu empiéter sur cette dernière. Au XIV ${ }^{\mathrm{e}} \mathrm{s}$., des modifications importantes entraînent le morcellement de certaines unités qui semblent alors disposées perpendiculairement à la rue du Coq-d'Inde.

\subsubsection{L'îlot III ${ }^{596}$ (R. Thernot)}

L'îlot III occupe au début de l'urbanisation du quartier une longueur de $38 \mathrm{~m}$ identique à celle de l'îlot II et une largeur de 32 m, soit le double de l'îlot II (fig. 169).

596 D'après B. Sillano, zones 11 et 12, et F. Paone MCR2 in Paone, Sillano 1997 ; B. Sillano vol 1a, p. 141-143 in Mellinand 2005.
Il est limité à l'ouest par une rue nord-sud placée dans le prolongement de la rue du Coq-d'Inde. Celle-ci sera abolie ultérieurement, portant la longueur totale de l'îlot à $56 \mathrm{~m}$, par la fusion entre l'îlot III primitif et l'îlot voisin à l'ouest, lui-même bordé à l'ouest par la rue de la Prison. Au nord, il est longé par la rue de la Taulisse, à l'est par la rue de la Guirlande, et au sud par la rue des Olives. Le découpage interne de l'époque médiévale n'est perceptible que dans la partie nord de l'îlot car le dérasement a affecté plus intensément sa partie sud. Ce découpage s'appuie sur un mur est-ouest, divisant l'îlot III en deux parties inégales, de 12,50 m et $20,50 \mathrm{~m}$ de large. Cette division se place dans l'alignement de la rive sud de la rue Saint-Christophe, laissant envisager l'existence d'un passage est-ouest (D) dans l'îlot. La présence à l'origine de chemins de desserte interne semble justifier les grandes dimensions de cet îlot, tel qu'il apparaît sur le cadastre moderne.

\section{Le phasage et les unités constructives}

Les structures bâties médiévales ont totalement disparu de la partie sud, à l'exception de deux murs nord-sud et de deux puits situés au sud-ouest. Dans la partie nord, subsiste une série de murs ou d'indices de murs, associée à des sols et à des puits, déterminant des espaces de 4 à $6 \mathrm{~m}$ de large. Dans cette partie, la stratigraphie des sols et des structures permet d'établir un phasage de l'occupation. Ce phasage ne peut pas être étendu objectivement à la partie sud, mais la nature des structures qui s'y trouvent incite à les associer à la première phase de construction. L'installation des premières structures ainsi que les modifications qui se greffent sur elles est datée de la période allant de la fin du XII ${ }^{\mathrm{s}} \mathrm{s}$. au XIII ${ }^{\mathrm{e}} \mathrm{s}$.

\section{口 État 1}

Au sud-ouest de l'îlot, un espace large de $6,50 \mathrm{~m}$ (espace B) dont les sols ont disparu est déterminé par deux murs parallèles.

Le mur ouest de l'espace B se place sur la rive orientale de la voie inférée d'après les textes (espace C). Il est conservé au niveau de sa fondation, sur une longueur de $6 \mathrm{~m}$ et une hauteur de $0,60 \mathrm{~m}$ environ. Dépourvue de ressaut, et irrégulièrement parementée, cette fondation est composée de moellons retouchés de natures diverses (calcaire dur pour moitié, travertin, grès, poudingue et micaschiste pour le reste), liés avec une terre brun foncé, chargée en tessons de céramique attribuables aux périodes romaine et tardo-antique. Le mur oriental, long de $7 \mathrm{~m}$, large de $0,60 \mathrm{~m}$, et conservé sur $0,40 \mathrm{~m}$ de haut, comporte deux parements assisés de moellons en calcaires dur et tendre, liés à la terre. 


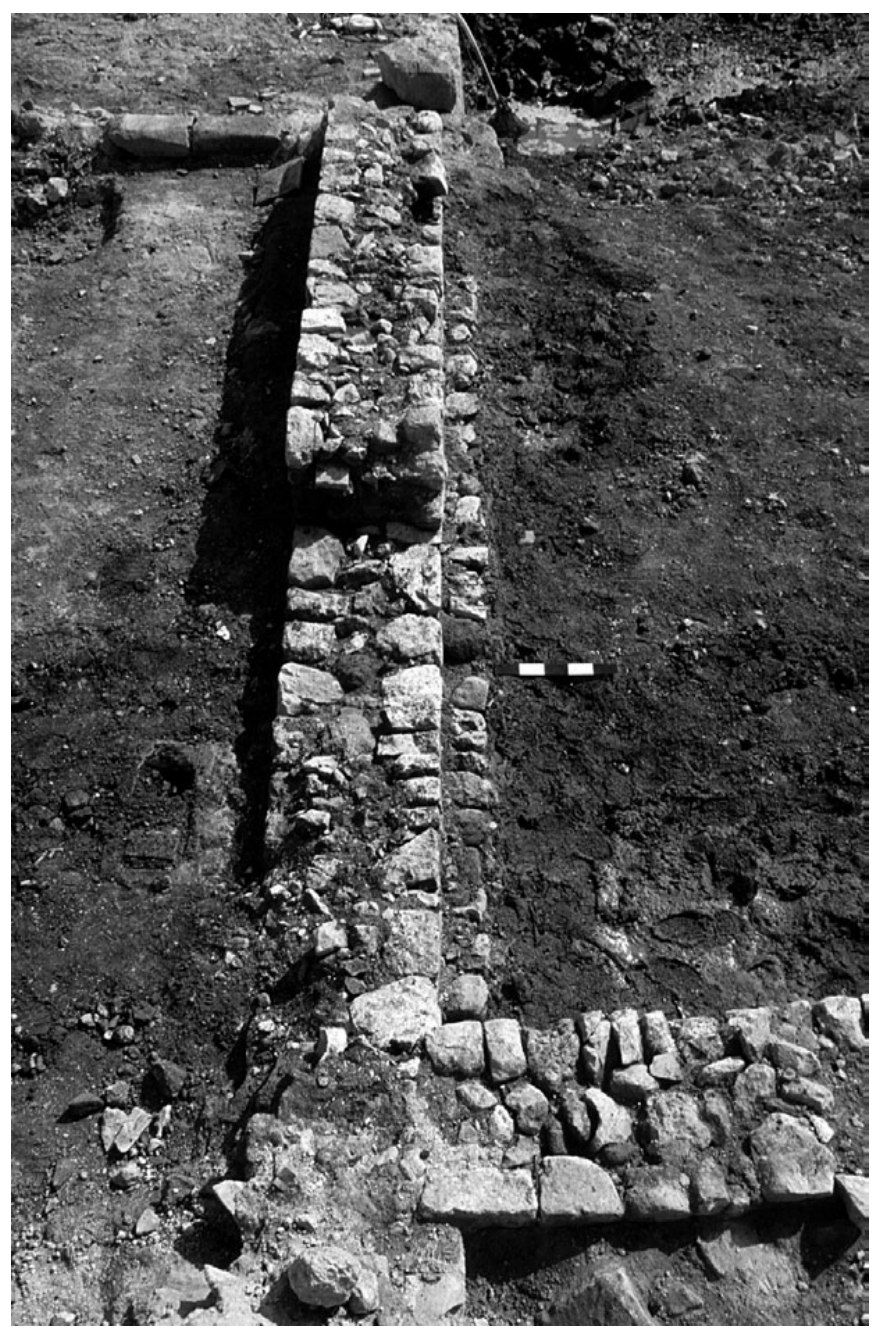

Fig. 170. Vue des murs chaînés au sud de l'espace D (cl. A. Arbion/Inrap).

Il se raccorde au nord avec le mur est-ouest de même facture, conservé sur une longueur de 6,50 m suivant une direction est-ouest (espace D, fig. 170). Celui-ci compte plusieurs assises de moellons liés à la terre, inégalement conservées. Une fondation débordante apparaît sous cette élévation. L'angle de l'espace D est occupé par une fosse riche en déchets de taille du corail, mais dont le niveau de creusement a disparu. Dans le même alignement, à l'extrémité orientale de l'îlot, un tronçon épargné long de 2,50 m témoigne du développement d'une limite construite rectiligne sur au moins $31 \mathrm{~m}$ à travers l'îlot. Ce segment de mur a conservé trois assises de fondation formées de moellons de grès et de poudingue disposés à plat ou en épi liés à la terre, et d'une élévation associant des moellons de calcaire lacustre, de grès et de tuf avec un bloc d'angle en calcaire rose de La Couronne, liés au mortier. L'extrémité de ce mur est caractérisée par la présence d'une amorce de retour vers le sud et celle d'un bloc taillé formant l'angle.
Dotés au moins de deux retours vers le sud, les murs qui forment la limite structurante est-ouest de l'îlot constituent également la probable rive d'un chemin de desserte. Le mode de construction des murs de la partie sud les différencie de ceux appartenant au premier état des structures associées à l'artisanat des métaux observées en partie nord et dans les autres îlots. Leur fonction structurante incite à les placer malgré tout dans une phase ancienne.

Un puits se place moins d'un mètre au nord dans l'alignement du mur occidental de l'espace B, qui s'interrompt dans ce secteur et on ignore s'il comportait à l'origine un retour perpendiculaire ( $c f$. fig. 75). Il n'est toutefois pas coupé par l'installation du puits, d'un diamètre interne de $1 \mathrm{~m}$. Le cuvelage et le fond sont composés d'un appareil régulier de moellons soigneusement taillés et ajustés, en calcaire de La Couronne, décolorés par les circulations d'eau. Deux petits orifices opposés diamétralement sont percés sur le fond au droit du cuvelage. À l'arrière du parement, un blocage de moellons et de cailloux bruts occupe la tranchée d'installation de la structure. Si le mur ouest forme la rive d'une voie nordsud située dans le prolongement de la rue du Coq-d'Inde, le puits se trouve à cheval sur la bordure de ce passage (espace C). Cette situation d'un puits en partie accessible depuis une voie n'a pas de parallèle dans d'autres secteurs. En revanche à proximité de la cathédrale, dans la rue Four-du-Chapitre, un puits est creusé également à l'extérieur d'un espace construit. L'éventuelle postériorité du puits sur le mur pourrait indiquer un changement de statut de l'espace.

\section{$\square$ État 2}

Le deuxième état est marqué par la mise en place d'espaces bâtis le long de la rue de la Taulisse (E, F, H, $\mathrm{J}$, K et L) dont l'existence est dès lors avérée. Cette étape chronologique peut être considérée ainsi comme la phase majeure de structuration du quartier en îlots. Les structures bâties de l'état antérieur (espace A) sont conservées et intégrées aux nouveaux espaces construits. Le long de la rue de la Taulisse, un mur de façade se développe devant plusieurs espaces (E, F et $\mathrm{H}$ ) et devait se prolonger vers l'est. Cette maçonnerie repose sur une fondation débordante constituée de galets bruts de provenance hétérogène, laissant penser qu'il s'agit de galets de lest de navire remployés dans la construction. L'élévation, liée au mortier, présente un appareil régulier constitué de moellons taillés en calcaire lacustre dur et tendre. À ce mur de façade se greffent deux murs de refend délimitant l'espace $\mathrm{H}$, qui prolongent les murs antérieurs de l'espace A. Le mur ouest est simplement accolé contre le parement interne, seul le mur oriental est lié au mur de 


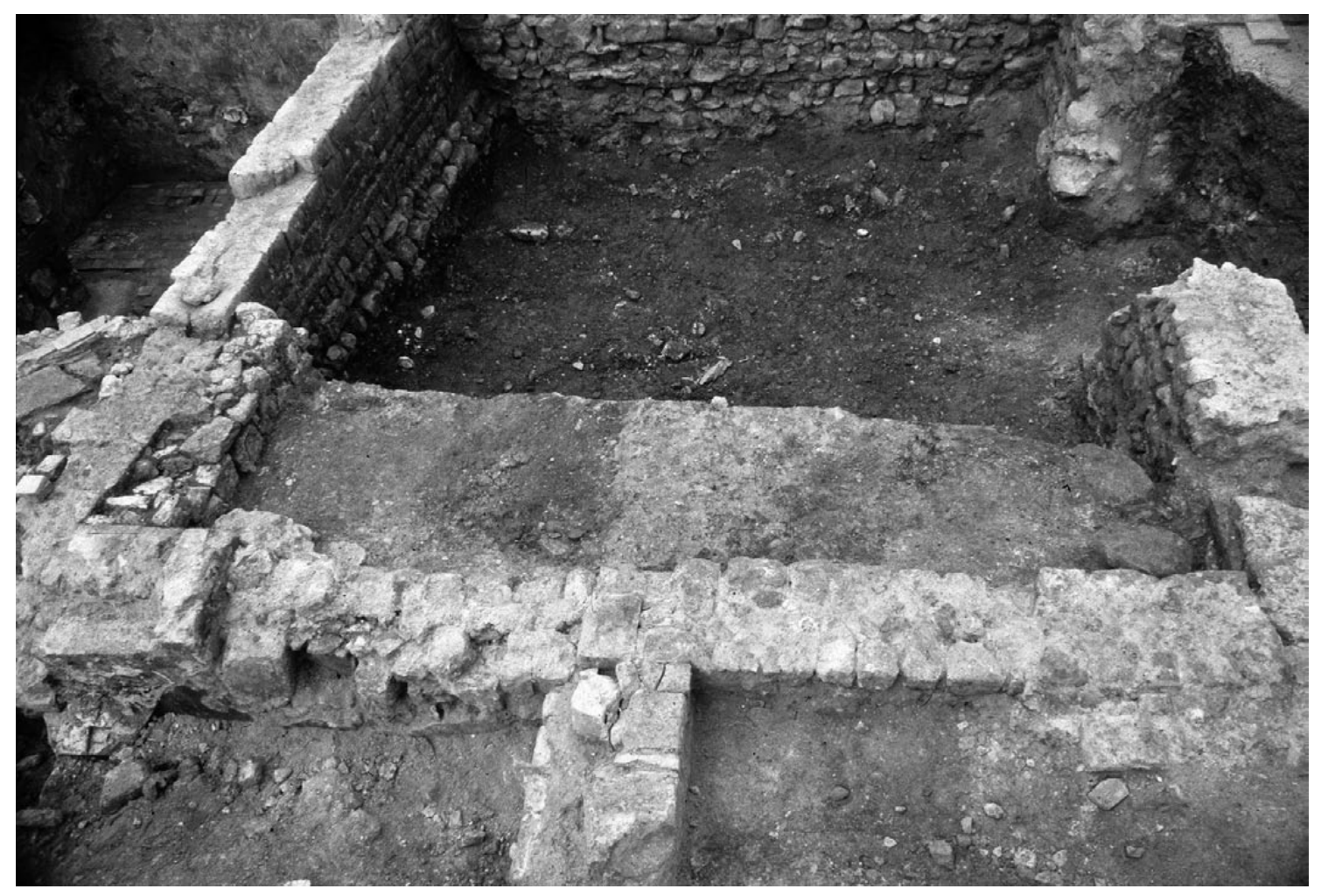

Fig. 171. Vue de l'espace K (cl. M. Derain/Inrap).

façade. Ce dernier présente une fondation composée de trois assises de blocs et de moellons bruts, formant des ressauts successifs. Les roches employées sont variées, associant pour l'essentiel des remplois de pierre froide et du tuf. La fondation porte une élévation qui a conservé deux assises de petits éléments taillés et quatre assises régulières de moellons de grès taillés ajustés avec soin.

La partition de l'espace se poursuit à l'est de ce petit ensemble, mais les murs, disparus pour la plupart, ne sont décelables que sous la forme d'indices (espaces $\mathrm{J}$, $\mathrm{K}$ et $\mathrm{L}$ ). En revanche, les sols associés à cet état ont été épargnés. Le mur de façade sur rue se poursuit devant ce secteur comme le révèle l'arrachement observé. Parallèle à ce mur et distant de $6,50 \mathrm{~m}$, un mur de direction est-ouest, doté d'une ouverture de $2 \mathrm{~m}$ de large, vient s'appuyer sur le mur est de l'espace A. Ce mur, large de $0,60 \mathrm{~m}$, se compose de deux parties distinctes dans leur mode de construction. À l'ouest, le piédroit de la porte est parementé sur les trois assises rescapées avec de petits blocs de tuf sciés, présentant au sommet un chanfrein horizontal sur les trois côtés. La partie orientale du mur est moins bien soignée. Elle est faite de moellons de grès et de calcaire tendre, équarris et liés avec un mortier abondant.

Deux refends se greffent entre ces deux murs parallèles ; ils sont représentés par un tronçon de fondation et une tranchée de récupération des matériaux. Le premier refend est distant de $5 \mathrm{~m}$ de l'alignement formé par les murs occidentaux et déterminent l'espace J. Les deux blocs de grès non retouchés qui subsistent sont implantés dans une tranchée nord-sud, large d'une quarantaine de centimètres, qui limite les sols de l'espace (fig. 171). À $5 \mathrm{~m}$ de ce vestige de mur, la tranchée de récupération parallèle, datée du XV ${ }^{\mathrm{e}} \mathrm{s}$., témoigne de l'existence d'un mur antérieur qu'il n'est pas interdit de rattacher à cet état du bâti. En effet, dans l'espace $\mathrm{K}$ délimité par ces deux derniers indices de murs, un niveau de recharge de sol témoigne de l'occupation des $\mathrm{XII}^{\mathrm{e}}-\mathrm{XIII}^{\mathrm{e}} \mathrm{s}$. Les niveaux de sol observés dans ces espaces sont ainsi constitués de recharges à base de terre et de limon sur lesquelles est installé un niveau de circulation en terre battue, incluant une forte proportion de cailloutis.

\section{En résumé}

Dans l'îlot III, les données sur l'organisation spatiale et fonctionnelle sont particulièrement pauvres ; cependant, la découverte dans la rue de la Taulisse (initialement Bernard-de-Conques) d'alignement de supports de bois laisse penser que les rez-de-chaussée des différentes maisons sont dotés de fenêtres à ouvroir ou étal confirmant ainsi la fonction boutiquière de ces pièces selon un schéma classiquement répandu dans la ville médiévale. 


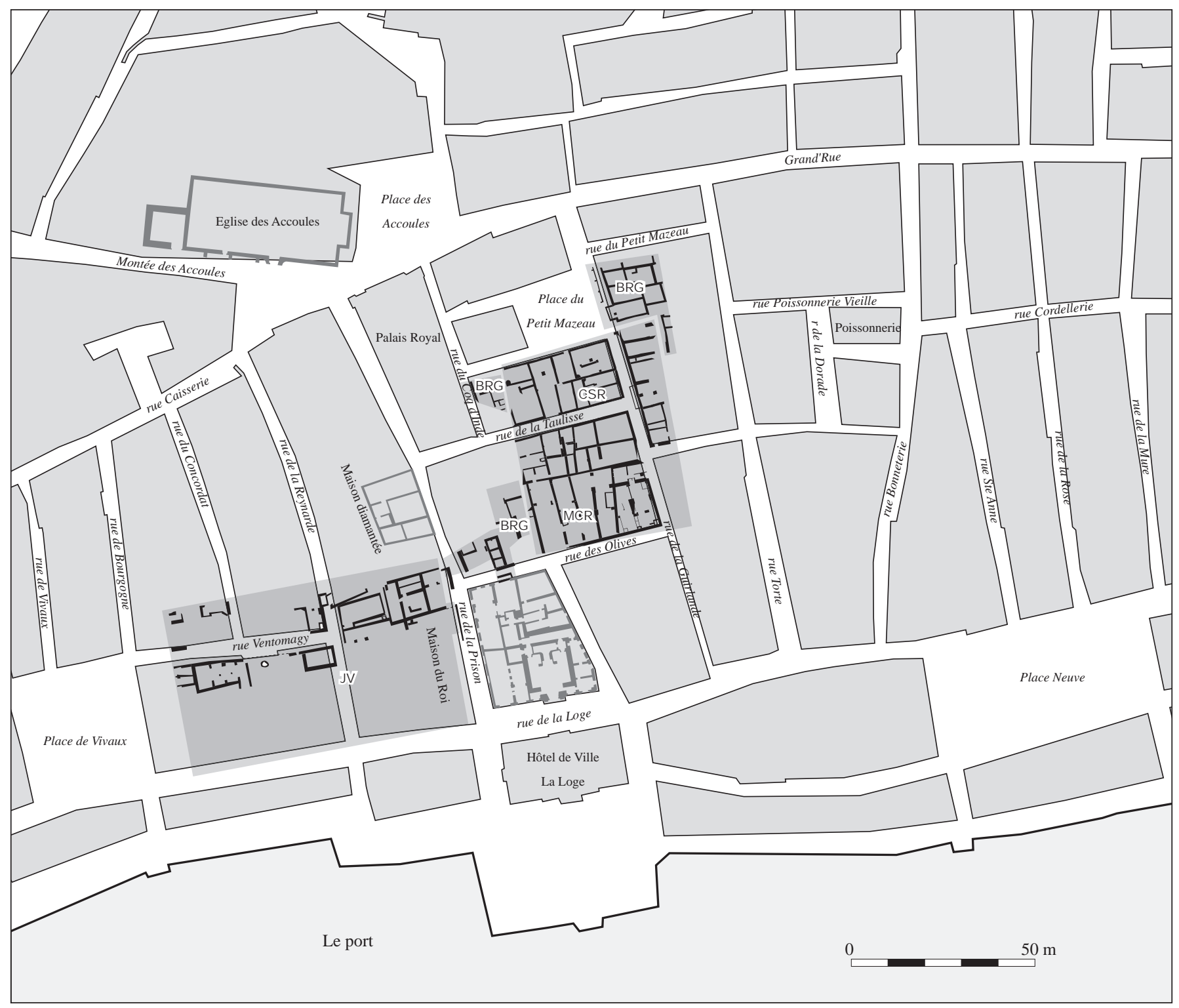

Fig. 172. Plan de situation des fouilles archéologiques autour de la Mairie. Les îlots dessinés sont ceux du plan Razaud (vers 1700) et les noms de rue ceux du cadastre napoléonien (1820). En foncé les vestiges retrouvés en fouille, en plus clair, les relevés des bâtiments encore en place (DAO B. Sillano/Inrap, M. Bouiron/Ville de Nice).

La présence d'auvent semble avoir perdurée jusqu'au $\mathrm{XVII}^{\mathrm{e}}$ s. puisqu'elle déterminera alors l'appellation de cette voie Taulisse (de l'occitan teulissa, toiture). De plus les maisons donnant sur la rue de la Taulisse sont toutes équipées d'un conduit d'évacuation des eaux de pluies intégré dans la maçonnerie des façades se déversant dans un égout central.

\subsubsection{En conclusion}

La fouille des séquences médiévales a fourni de précieuses informations sur la renaissance du quartier au cours du $\mathrm{XII}^{\mathrm{e}}$ s. mais des lacunes demeurent : la rareté des sols conservés nous prive d'information sur les aménagements domestiques ou professionnel ; les élévations en grande partie dérasées ne nous permettent plus de saisir le rapport entre l'habitat et la rue ainsi que l'organisation fonctionnelle des espaces au sein des constructions. Des lacunes chronologiques sont importantes : le XIVe s., bien peu documenté, laisse percevoir une densification de l'occupation; de même les dernières décennies du Moyen Âge sont difficilement perceptibles. Les causes de ces manques semblent multiples, le sac des Catalans qui a touché plus particulièrement la rive nord du port et les reconstructions modernes sont les explications le plus souvent avancées. 


\section{Pérennité et transformation du quartier du XVI ${ }^{\mathrm{e}}$ s. au XVIII ${ }^{\mathrm{e}}$ s. (B. Sillano, F. Paone)}

La rafle de 1943, organisée par la police française, suivie du dynamitage systématique des maisons par les Allemands a conduit à la disparition quasi-totale du quartier. Au sud de la Grand-Rue, seuls sont épargnés les bâtiments administratifs (Palais de justice, Mairie, pavillon Bargemon, ainsi que les parcelles 384 et 370 à 374) auxquels s'ajoutent quelques édifices prestigieux (Maison Diamantée, Hôtel de Cabre). Le reste n'est plus qu'un champ de ruines...

L'arasement des structures archéologiques est très variable d'un secteur à l'autre, tributaire du dynamitage mais aussi probablement des travaux de reconstruction qui ont suivi et dont nous n'avons pas le détail. Ainsi, sur l'emprise de l'ex-musée César, nous distinguons la moitié nord où les substructions sont conservées jusqu'au niveau du sol d'origine (rez-de-chaussée) alors que dans la moitié sud, le nivellement a outrepassé ce sol de près de $1 \mathrm{~m}$ de profondeur. La même différence entre le nord (zones 4 et 5) et le sud (zones 1, 2 et 3) a été observée pour l'opération Espace Bargemon.

Les caves, creusées quasi systématiquement à partir du XVII ${ }^{e}$ s., ont aussi considérablement dégradé le sous-sol et nous privent d'informations essentielles comme les tranchées d'installation des murs ainsi que les sols qui leur sont liés. Contrairement aux époques antérieures, les vestiges d'Époque moderne consistent essentiellement en des structures bâties, pour la plupart des murs. Le corollaire est la rareté du mobilier archéologique qui nous permettrait d'établir une chronologie absolue. Paradoxalement, ce sont les niveaux les plus proches de nous dans le temps qui sont les moins bien datés ; la date d'édification de nombreux murs modernes est établie avec une fourchette chronologique de deux siècles alors que la plupart des murs grecs sont datés à 25 ans près ! Les rues ont également été arasées profondément et ce d'autant plus qu'elles ont accueilli en leur axe des réseaux de canalisations successifs, les derniers effaçant les précédents.

La proximité du port et la nature peu accidentée des terrains ont favorisé le développement du quartier de Villeneuve-Bargemon à l'Époque moderne (fig. 172 et $c f$. fig. 47). Alors que les activités portuaires et commerciales prospèrent, le quartier devient le centre administratif de la ville. C'est également là que choisissent de s'installer la classe dirigeante, dans de beaux hôtels particuliers.

Au centre, la Loge, lieu de réunion des marchands et armateurs mais également maison de ville, devant laquelle se tenaient les bancs des changeurs, face au port. Installée en 1415 dans la maison d'un particulier, elle a été plusieurs fois réaménagée, puis détruite en 1653 avant de prendre place dans le nouvel Hôtel de Ville, dont la construction ne s'est terminée qu'en 1673. En 1650, le conseil municipal sépare l'administration du commerce de l'administration municipale, et crée la chambre du commerce. De fait, la Loge était placée au rez-de-chaussée du bâtiment alors que l'administration de la Ville était au premier étage, auquel on accédait par une passerelle depuis l'îlot voisin, le pavillon Bargemon. Ce dernier n'a jamais acquis l'unité prévue initialement car les travaux ont été interrompus. Seule une partie de la façade et l'escalier monumental ont été édifiés, conformément aux plans dressés par Esprit Brun. Au XIX ${ }^{\mathrm{e}} \mathrm{s}$., afin de mettre la mairie en valeur, un îlot complet est détruit et devient la place Villeneuve-Bargemon.

À l'opposé de la Loge, au nord, se trouve la GrandRue, véritable épine dorsale de la ville basse, quasiment le seul accès direct au cœur de la ville depuis les portes orientales et probablement un des plus praticable avec les charrettes ${ }^{597}$. Elle se termine sur l'église médiévale des Accoules, ou plus exactement sur une place du même nom où se tenait un marché essentiellement tourné vers les fruits et légumes. Elle dessert également le marché des bouchers et pâtissiers, le Petit Mazeau.

Le quartier de Villeneuve-Bargemon présente ainsi deux pôles d'activités très différentes. Le premier est lié au port, au commerce de gros et à l'administration communale ; il est fréquenté par une élite. Le second est lié au petit commerce alimentaire et s'adresse à toute la population. Entre ces deux pôles prennent place d'autres édifices prestigieux.

À l'ouest, le Palais, qui abrite jusqu'à la fin du Moyen Âge les services de l'administration du comte de Provence et ses officiers de justice. Une première fois reconstruit et agrandi vers 1545, il est jugé trop délabré en 1745 , et reconstruit ${ }^{598}$ en s'agrandissant à nouveau vers le sud d'une parcelle, rachetée en 1744 à un certain Ferrary. La longueur de cette parcelle, qui confronte trois rues, nous est donnée par un rapport dressé, en 1716, dans le but de faire contribuer aux dépenses d'alignement les propriétaires le long de la rue de la Prison. La maison des hoirs $d u s^{r}$. Frediany (= Ferrary ?), rachetée en 1634 à la «dame Louise de Félix, veuve de feu noble de Saint-Victoret », mesure $17 \mathrm{~m}$ de long, ce qui indique que l'ancien palais occupe seulement les deux-tiers de

597 Le marché des fruits et légumes principal se tenait hors les remparts, sur le Grand-Caire (qui deviendra le Cours Belsunce) parce que l'acheminement intra muros était difficile.

598 Après que les tribunaux ont été transportés provisoirement à l'Hôtel de Jarente (parcelle 370). 
la surface de l'actuel pavillon Daviel. Les fondations observées lors des fouilles de l'Espace Bargemon ne lui corrrespondraient donc pas.

Au sud-ouest se trouve la Maison du roi René, édifiée au $\mathrm{XV}^{\mathrm{e}}$ s. Cette vaste demeure, longue de $43 \mathrm{~m}$, marque le paysage jusqu'au XVIII ${ }^{\mathrm{e}} \mathrm{s}$. où elle tombe en ruine et sera démolie (Castrucci 2001). Citons également, à proximité, la Maison Diamantée, bâtie de la fin du XVI e s. au début du suivant (Conard 1977) ( $c f$. fig. 145).

\subsection{La place du Petit-Mazeau et le réseau viaire (B. Sillano)}

Tel qu'il apparaît sur le cadastre napoléonien, le quartier oriental du Vieux-Port se développe entre deux voies parallèles que sont la Grand-Rue au nord et la rue de la Loge au sud, approximativement parallèle aux quais mais séparée de ceux-ci par un alignement de maisons. Ces deux axes, distants de $120 \mathrm{~m}$, sont reliés par un nombre important de rues transverses, disposées selon un maillage très serré (l'écart entre elles est en moyenne de $25 \mathrm{~m}$ ) et quelquefois reliées entre elles par d'autres rues.

Situé vers l'extrémité de la Grand-Rue, le secteur concerné par les fouilles est encadré par les rues de la Guirlande et de la Prison, qui, par rapport à leurs homologues à l'est, ont un écartement double, de $60 \mathrm{~m}$. Au sud, elles sont reliées par les rues de la Taulisse et des Olives alors qu'au nord, le Palais de justice et la place du Petit Mazeau se partagent l'espace. Quelques ruelles complètent la trame, comme la rue du Coq-d'Inde, le long du palais, ou la rue de la Miséricorde, dont l'orientation ne s'explique ni par un héritage des périodes antérieures, ni par une nécessité liée à la présence d'un établissement particulier, et reste incompréhensible.

Nous évoquerons tout d'abord la place du Mazeau et en particulier les constructions qui s'y trouvaient avant que ne soit établie la place, ainsi que les textes qui s'y rapportent et permettent d'en dresser un tableau assez concret.

\section{Le Petit Mazeau}

Le marché des bouchers du Petit Mazeau est riverain des zones de fouilles archéologiques, mais leur échappe. Connu dès le Moyen Âge, il se tient sur ce qui est représenté comme une petite place sur la vue cavalière de Braun de 1572 ( $c f$. fig. 111), place agrandie à la fin du $\mathrm{XVIII}^{\mathrm{e}} \mathrm{s}$. La zone concernée par les fouilles est à priori en limite de cette dernière ; pourtant à l'extrémité orientale de petites caves nous sont apparues, témoignant d'une part de l'existence d'un bâti antérieur, d'autre part d'un réalignement de la rue de la Guirlande qu'aucun texte ne laissait pressentir (fig. 173). Ces espaces ont été largement endommagés par une canalisation en terre cuite, installée sous la rue à l'époque contemporaine, qui en a détruit l'essentiel et nous prive ainsi d'éléments de datation. Ils sont au nombre de cinq, de largeur identique $(2,70 \mathrm{~m})$ et n'ont pas été creusés simultanément. Leurs niveaux de sol varient entre 5,20 m et 5,70 m NGF; ils sont donc bien plus hauts que ceux des caves placées en vis-à-vis. Les murs mitoyens présentent un parement différent de chaque côté, témoin d'une installation en sous-œuvre. Les murs situés à l'extrémité ont un parement sur la seule face interne et sont adossés à la coupe du terrain. Nous présentons les espaces du nord au sud en adoptant la numérotation de la fouille, ceux-ci ayant disparu du parcellaire napoléonien.

L'espace 5a n'est conservé que dans son angle sud-est. Il est bordé par un mur de $25 \mathrm{~cm}$ d'épaisseur constitué de moellons de grès et travertin liés au mortier de chaux maigre. Sa paroi interne semble avoir subi l'action du feu et c'est probablement à la suite d'un incendie que le mur a été doublé par un second de nature similaire. L'espace 5b, qui lui est accolé au sud, est ceint de murs dont l'enduit nous a empêché de lire les élévations. L'appareillage semble être constitué de moellons de grès ou poudingue disposés en panneresse. L'espace 6 a été intégré dans un second temps entre ses voisins, ce qui explique une largeur moindre $(2,50 \mathrm{~m})$. Le mur oriental, épais de $40 \mathrm{~cm}$, possède des joints « beurrés » qui nuisent à sa lecture. Similaire aux autres murs de l'espace, il semble fait de moellons de travertin équarris, disposés en panneresse et liés par un mortier de chaux et sables marins. Le sol est pourvu d'un carrelage de terre cuite (carreaux de $26 \mathrm{~cm}$ par $12,5 \mathrm{~cm}$ pour $3 \mathrm{~cm}$ d'épaisseur). La pièce 7 se distingue par la mise en œuvre de ses murs (fig. 174) : ils possèdent un appareil réglé où alternent des assises en boutisse et des assises en panneresse de moellons équarris de calcaire tendre jaune, liés à la terre ; l'élévation repose sur une assise de blocs de poudingue et de moellons bruts disposés à plat ou en épis. Enfin, l'espace 8 est très mal conservé, mis à part un fragment de mur fait de moellons retouchés de nature pétrographique variée disposés selon un simple parement.

Ces espaces correspondent très certainement à des caves, mais, à la différence de celles qui sont situées sur la rive opposée de la rue, elles sont moins profondes et jointives, les parements des refends de nature différente trahissant un travail en sous-œuvre. Il est donc peu probable que ces caves soient en extension sous la rue, ce que confirme les textes, comme nous allons le voir.

Ces textes permettent de réaliser une esquisse topographique du Petit Mazeau immédiatement antérieure à l'élargissement de la fin de l'Époque moderne. Le document de base est un plan, daté de 1784, où sont dessinées 
les quelques parcelles qui doivent êtres rachetés pour créer la place, ainsi que les contours des îlots voisins (fig. 175). Nous constatons que le secteur était largement loti et qu'il s'étendait vers le nord. L'îlot septentrional, visible sur le cadastre de 1820, a été rallongé vers le sud consécutivement à la création de la place. Dans la partie nord-est, quatre bâtiments sont isolés et au sud, les deux parcelles d'angles sont individualisées alors que le reste semble former un îlot compact. Une série de rapports de visite et de devis nous renseigne en détail sur le secteur au XVII s., la difficulté provenant de la multiplicité des ruelles mentionnées par ces documents. En s'appuyant sur le plan de 1784 , sur les confronts et sur les descriptions, en particulier les dimensions, nous pouvons restituer la partie orientale de la place ( $c f$. fig. 112).

Commençons par la maison C. En 1645, Jean Caron, pâtissier, commande la construction d'un four dans sa boutique, louée à un certain Nicolas S(ere)n, « au devant du logis du Rozier ${ }^{599}$. Comme il ne s'agit pas des maisons situées à l'est de la rue de la Guirlande, que nous connaissons ( $c f$. infra), ce ne peut être que la maison B ou C. En 1680, Pierre Chainé achète à François Seren «la maison avec la petite boutique joignant par le dernier ${ }^{600}$. Il s'agit des deux bâtiments B et C. L'acte de vente précise que François Seren est le fils de Nicolas Seren et de Marguerite Sauzède. En 1704, les descendants de Chainé, Jeanne Marseille et sa petite fille Rose Mallet, revendent la maison à Honoré Surian ${ }^{601}$ et la boutique à Guillaume Arnaud. Le bâtiment $\mathrm{B}$ mesure $4 \mathrm{~m}$ par 7,25 m, hors murs, et le bâtiment C, 4,5 m par $7,5 \mathrm{~m}$ et possède en outre une cave de $3 \mathrm{~m}$ par $3,75 \mathrm{~m}$ avec une avancée sous la rue, au sud, de $2 \mathrm{~m}$ par 2,50 m. Parallèlement, en 1643, François Gautier fait établir un devis ${ }^{602}$ pour un ensemble de trois boutiques confrontant trois rues, dont la rue de la Guirlande à l'est, et, au sud, la maison de Jacques Sauzède (maison C) «petite ruelle que non passe entre deux ${ }^{603}$. Les dimensions de l'ensemble, 4,5 m par 5,5 m, confirment qu'il s'agit du bâtiment $\mathrm{D}$ dessiné sur le plan de 1784. Ainsi, nous pouvons restituer sur la rive occidentale de la rue de la Guirlande une maison, orientée nord-sud, également bordée par une rue au sud et une autre au nord. En cela, il n'existe aucune correspondance avec les données de terrain puisque les espaces fouillés sont jointifs (il n'y a pas de rue) et orientés d'est en ouest. Nous devons admettre

599 AD13 360 E 76, fol. 809v.

600 AD13 391 E 406, fol. 162v.

601 AD13 352 E 300, fol. 64, les deux transactions donnent lieu à l'établissement de deux rapports de future cautelle dans lesquels nous retrouvons le four, ainsi que les mêmes pièces et dimensions.

602 AD13 360 E 75, fol. 747v.

603 AD13 373 E 282, fol. 392. que, comme semblent l'attester les plans d'alignement, la rue de la Guirlande a été élargie avant la création de la place du Mazeau au XVIII e s., c'est-à-dire avant la mise en place des bancs mentionnés dès le $\mathrm{XVI}^{\mathrm{e}} \mathrm{s}$. Les caves, qui représentent probablement un des aménagements ultimes des habitations médiévales, seraient donc les plus anciennes que nous ayons eu le loisir d'observer en fouille. Les niveaux de sol, bien trop hauts par rapport à la chaussée moderne, témoignent d'un arasement important mais aussi probablement d'un rez-de-chaussée surélevé par rapport à la rue.

Reprenons la visite du Mazeau. Le bâtiment D est donc un ensemble de quatre boutiques, d'une dimension totale de $4,5 \mathrm{~m}$ par $5,5 \mathrm{~m}$, que fait réaménager $\mathrm{F}$. Gautier. Ces boutiques ont été acquises de Marquise Tripoulette laquelle les avait achetées à Jean Reilhon en $1549^{604}$. Elles sont bordées au nord par «la rue qui fait séparation des autres bancs sive tabliers quy sont dans led. petit Mazeau » et à l'ouest par «les bancs et batimants appelés de la triparie aussy petite ruelle entre deux». Le bâtiment I correspond donc à la triparie. L'acte de vente de Chainé (déja évoqué) précise que la maison et la boutique (bâtiment $\mathrm{C}$ ) « confrontent à l'est quest par dernier cave et boutique de rotisserie de Jacques Sabatier ». Il s'agit de la parcelle A. L'acte de vente de sa descendante, J. Marseille, nous apprend indirectement que cette boutique est ensuite vendue à Pierre Violle ; or, ce dernier est cité comme voisin, au sud d'une autre boutique achetée par Claude Aubran en 1723. Cette dernière se trouve à l'angle de la rue de la triparie, au nord, et de "la rue qui aboutit à l'ancien logis de la Tuilisse», à l'ouest. Outre le nom du propriétaire de la partie nord de la parcelle A, nous apprenons aussi l'existence d'une traverse dans l'axe du Logis de la Taulisse (parcelle 358). Cette rue est lisible sur le plan de 1784 à travers le décrochement du contour d'îlot, et elle transparait également au nord dans le cadastre napoléonien sous la forme d'une parcelle très étroite et longue.

Les précisions manquent pour établir un plan précis des parcelles à l'ouest de cette rue. Nous avons mention d'une maison achetée par Pierre Griffet en 1637 et qui confronte à l'est la rue «qui va aboutir au logis de la tuilisse ayant à son opposit le petit Mazeau » et au nord la rue du Petit-Mazeau ${ }^{605}$. Cette maison d'angle est ensuite vendue à Arène, charcutier, en 1673. En 1712, elle confronte au sud la maison de Joseph Garcin ${ }^{606}$, pâtissier, laquelle confronte, toujours au sud, le Logis du pavaillon royal ${ }^{607}$. Nous apprenons en outre que Garcin

604 AD13 352 E 132, fol. 186v

605 AD13 360 E 72, fol. 360.

606 AD13 361 E 99, fol. 2.

607 AD13 361 E 75, fol. 263. 


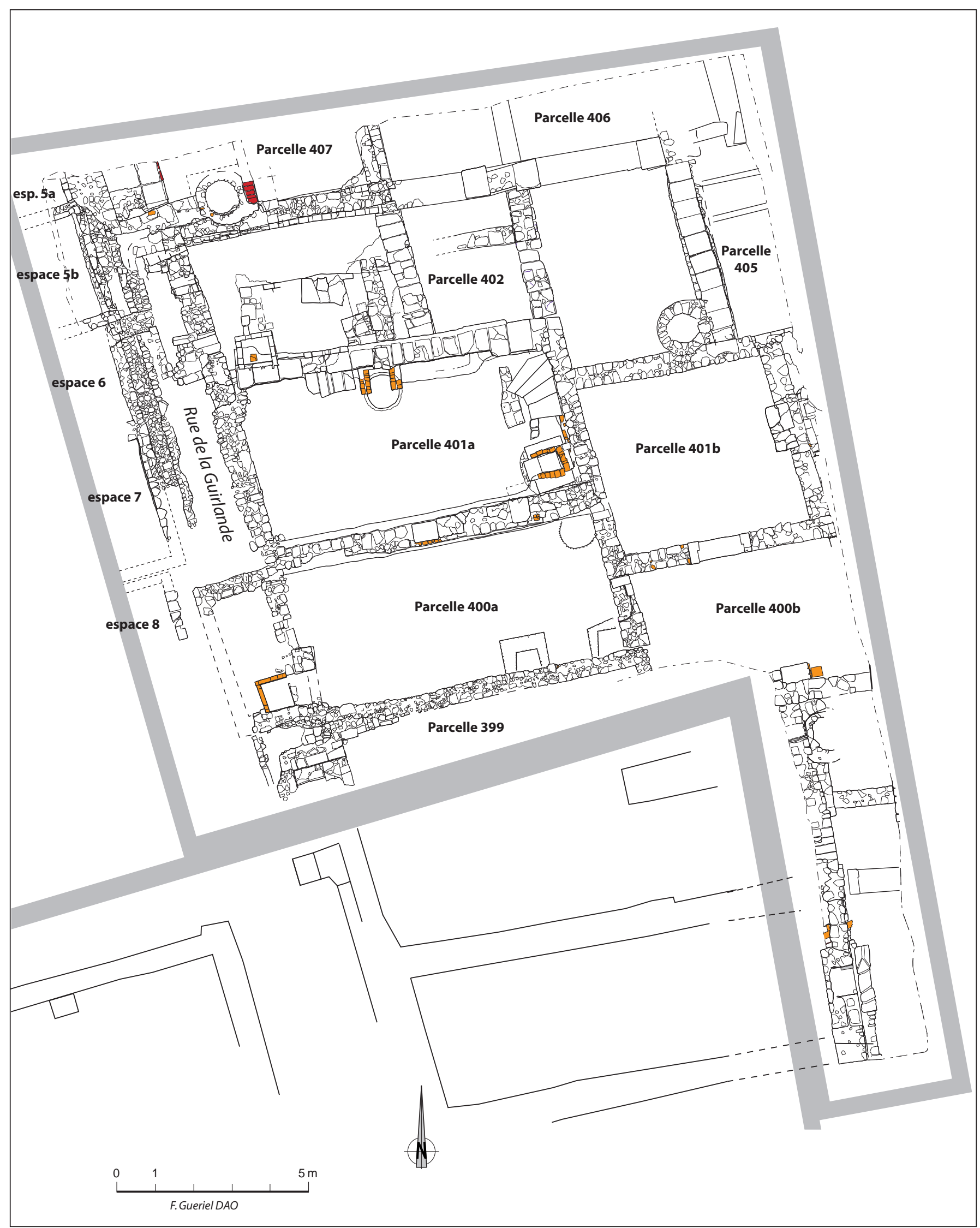

Fig. 173. Plan d'ensemble des vestiges modernes de la partie nord de l'îlot I (DAO F. Guériel/Inrap). 


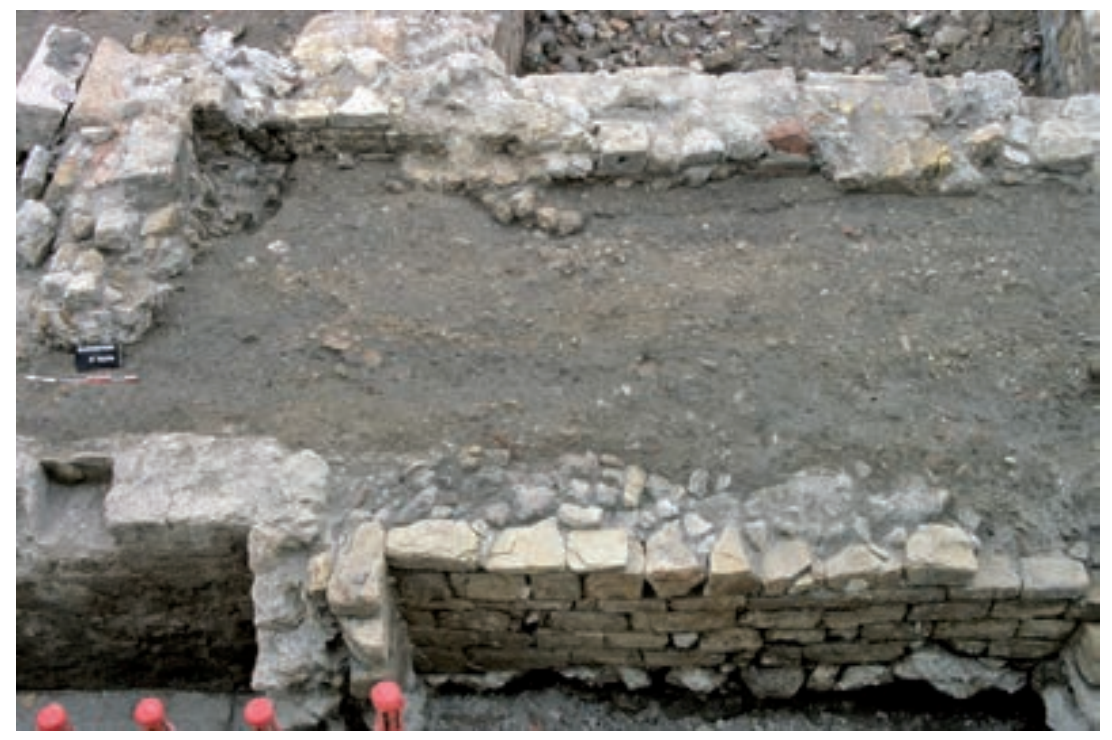

Fig. 174. Les espaces 6 et 7 du Petit Mazeau vus de l'ouest (cl. M. Maurin/Inrap).

Fig. 175. Plan du Petit-Mazeau en 1784 en prévision de la création de la place (le nord et en bas) (ACM A I91)

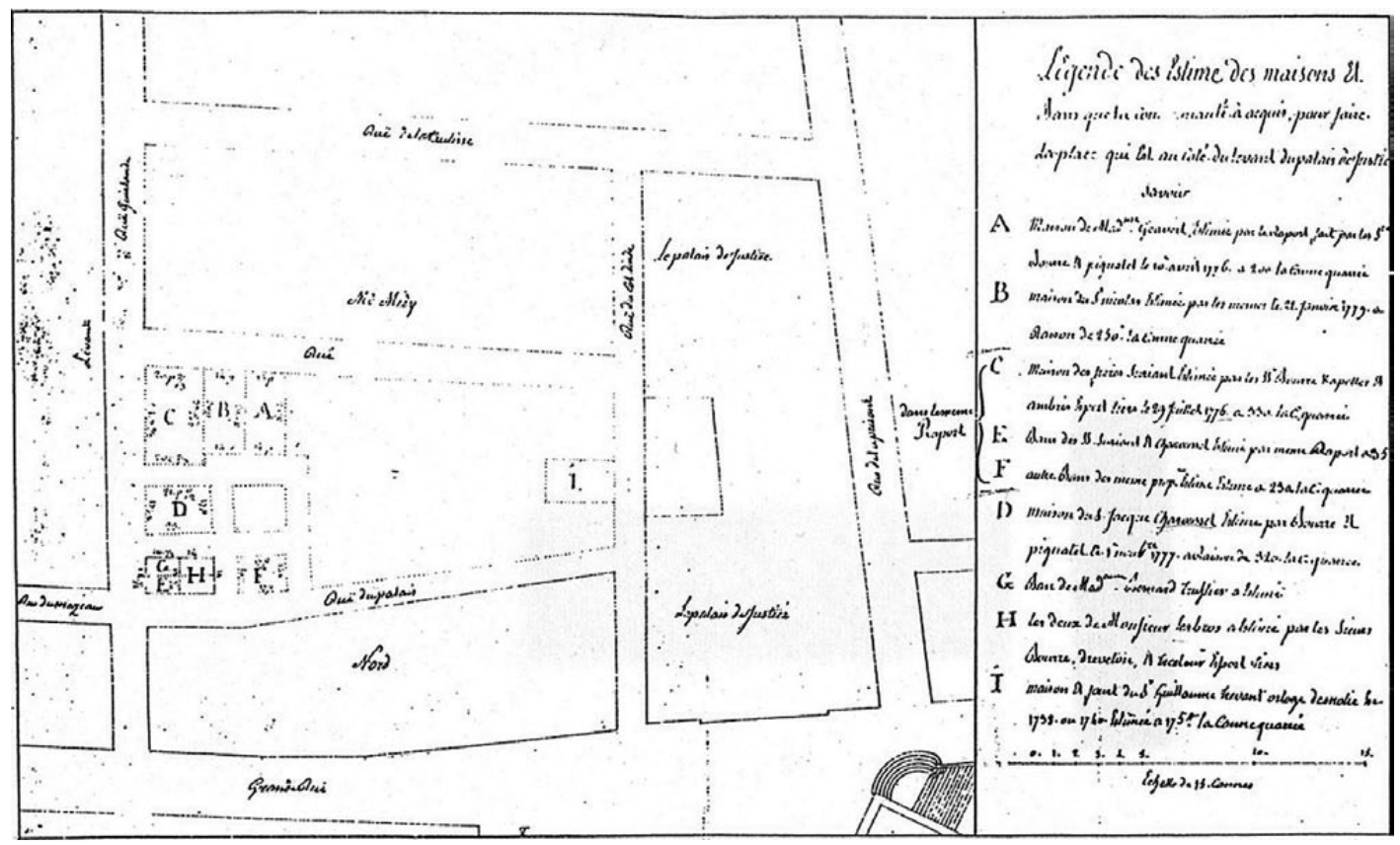

possède une cave de $4 \mathrm{~m}$ par 7,40 $\mathrm{m}$ avec une extension sous la rue de 3,75 m par 1,25 m. Le logis appartient à Jean Escuyer et donne sur une rue au sud «tirant vers le pallaix ». Nous possédons ainsi les trois parcelles à l'est de la rue allant au Logis de la Taulisse. Si on se réfère au plan de 1784, le nouveau logis mentionné serait face à la parcelle 359. Au nord de ces trois bâtiments se trouve une nouvelle rue d'axe est-ouest, qu'il est difficile de situer. À l'ouest de la propriété de Griffet est mentionné le Logis de la Licorne. Celui-ci appartient à Jacques Gautier, également possesseur de la maison suivante à l'ouest, le Logis de la Couppe ${ }^{608}$. Pour ce dernier, un

608 Deux devis, respectivement de 1655 et 1654 , nous renseignent (AD13 390 E 216, fol. 1210 et AD13 391 E 383, fol. 214). devis mentionne le creusement d'une cave, longue de 7,5 m et large de 4,5 m, et l'existence de trois façades au sud, nord et ouest, les deux premières étant plus soignées. Comme par ailleurs il est question de la maison «vizant à trois rue allant au palaix », nous en concluons qu'elle fait l'angle sud-ouest de l'îlot du Mazeau.

En conclusion, ces textes montrent clairement que ce qui n'est qu'une place après 1784 a été auparavant densément occupé. Les «bancs » des bouchers côtoient des boutiques installées au rez-de-chaussée de maisons assez vastes. L'ensemble est découpé par de multiples ruelles perpendiculaires qui n'ont probablement d'autre finalité que de permettre l'accès de la clientèle et dont l'origine remonte certainement au marché médiéval dont nous ne connaissons pas la configuration. 


\section{La rue de la Guirlande}

La fouille de l'ex-musée César nous a permis d'observer cette rue sur $50 \mathrm{~m}$ de long, mais la présence de la rampe d'accès au chantier nous prive de la moitié sud. La partie nord de la rue a été partiellement révélée par la fouille de l'espace Bargemon ; nous n'avons que sa rive orientale, car la rue est recoupée sur toute sa longueur par la paroi moulée et la grave de la murette-guide, n'épargnant qu'une bande régulière de $2,50 \mathrm{~m}$ de large. Les caves situées à l'ouest n'étaient pas dans l'emprise de la rue, compte tenu de leur faible profondeur, ce qui lui confère une largeur de 1,80 m. Les maisons mentionnées au XVII 's., à l'emplacement de la place du Mazeau, sont donc hors d'emprise du chantier archéologique, ce qui sous entend que la rue a subi un alignement, consécutif au remblaiement des caves. Sa largeur finale est très probablement équivalente à celle de son prolongement vers le sud qui est, dès le Moyen Âge, de 3,50 m. La plus ancienne mention du bâtiment $\mathrm{D}$ (les bancs de boucher) date de 1549 , si bien que nous pouvons situer cet acte d'urbanisme précoce au début du XVI ${ }^{\mathrm{e}} \mathrm{s}$. et peut-être au siècle précédent.

La partie sud de la rue recoupe le chantier César sur une longueur de $55 \mathrm{~m}$; cependant les aléas de fouille en font un des secteurs les moins bien étudiés ${ }^{609}$. Au nord de ce chantier, sa largeur est de 3,30 m; elle est bordée à l'est par un vaste édifice médiéval, sur une longueur de $22 \mathrm{~m}$, et au nord-ouest par un bâtiment (357) dont la façade est datée du XVI ${ }^{e}$ s. ${ }^{610}$. Aucune tranchée de récupération n'a été observée, les niveaux de circulation ayant pu être fouillés de part et d'autre d'une large tranchée de canalisation contemporaine. Lors de l'installation du bâtiment médiéval, la cote moyenne du sol de rue dans ce secteur est de $4,50 \mathrm{~m}$; au $\mathrm{XVI}^{\mathrm{e}}$ s., elle passe à 5,50 m. Dans l'intervalle, en l'absence de couches du bas Moyen Âge, un dérasement est probable.

\section{La rue de la Prison}

La rue de la Prison n'a été fouillée que sur une portion de quelques mètres ${ }^{611}$. La stratigraphie, très lacunaire, est enfouie sous un remblai de grave épais de $1 \mathrm{~m}$

609 F. Paone, «Les données de terrain: les rues», CSR zone 7 (Paone 1997a) et MCR zone 2 secteur 11. La partie nord, fouillée lors du chantier «César 1 », a servi de piste et n'a pu être fouillé que de manière ponctuelle; la partie sud, très dérasée, n'a été que très partiellement explorée lors de la fouille « César 2 ».

610 Deux tessons datants dans la tranchée de fondation pour 48 tessons résiduels.

611 Un gros collecteur est-ouest nous prive de toute la largeur au nord. Un regard bétonné, extrait avec difficulté par l'entreprise Bachy, a détruit toute la partie sud et un petit collecteur longe la façade est. à $1,50 \mathrm{~m}$ consécutif à un arasement subactuel d'origine indéterminée et aucun sol de rue n'est conservé. La fondation de l'Hôtel Rome d'Ardennes ( $c f$. infra) permet de restituer le niveau de la rue, au XVIII' ${ }^{\mathrm{s}}$., vers $2,50 \mathrm{~m}$ NGF, soit $1 \mathrm{~m}$ sous le niveau actuel ${ }^{612}$.

De nombreux textes mentionnent un alignement de la rue. Pour Giraud, dès 1680, il est question de récupérer $4 \mathrm{~m}$ sur toute la longueur de la façade de la Maison du roi ${ }^{613}$. Fabre pense que cet alignement n'a pas eu lieu et n'a touché que la partie du bâtiment située sur les quais ${ }^{614}$. En 1713, Honoré de Rome d'Ardennes, voulant reconstruire plusieurs bâtiments sur le corps septentrional de la Maison du roi, s'adresse aux autorités communales pour leur demander de combien il était tenu de reculer sa façade, attendu que la rue devait, d'après eux, être élargie de $2,50 \mathrm{~m}^{615}$. Il fut résolu de prendre environ $1,50 \mathrm{~m}$ sur le coté de la rue et pour se faire toutes les façades à l'ouest de la rue furent détruites et reconstruites sur leur nouvel alignement ${ }^{616}$. Bien que très perturbé, le terrain ne révèle pas de tranchée de récupération d'un mur de façade qui aurait été reculé d'une telle distance. Cependant, une tranchée, décalée de seulement $30 \mathrm{~cm}$ par rapport au mur du XVIII ${ }^{e}$ s., semble témoigner d'un réalignement modéré. Ce recul, insignifiant au niveau de la fouille, pourrait indiquer un redressement de la rue. En effet, nous constatons que les façades de la Maison Diamantée, au nord, et de l'Hôtel de Rome ne sont pas réellement alignées. Cette déclinaison trouve peut-être son origine dans un réalignement qui, débutant au niveau de la parcelle 346, s'amplifie vers le sud, le long de l'Hôtel de Rome d'Ardennes. Nous constatons en effet que sur le cadastre de 1820 la rue de la Prison s'élargit et devient rectiligne le long des parcelles 343 à 346 . La modeste tranchée de récupération repérée signifieraitelle que le réalignement a été effectif en 1715 ?

Sur l'autre rive, le plan des annexes de l'Hôtel de Ville de 1948 nous montre que la parcelle 374 est réduite par rapport à celle qui est dessinée sur le cadastre napoléonien. Ceci est confirmé par une photographie de la même époque (fig. 176) où nous voyons que sa façade est en retrait par rapport à la suivante (parcelle 354). Un contrefort contre le mur pignon, aveugle, de cette dernière correspond certainement à l'ancienne façade détruite. Nous n'avons pas de trace de cette construction

612 Son arase supérieure, plane et régulière, marque la séparation entre la fondation, dont le cœur est un blocage lié par un mortier très induré, et l'élévation, certainement récupérée parce qu'étant en pierre de taille.

613 Giraud 1962, p. 78.

614 ACM : BB 116, 28 avril 1680.

615 ACM BB 149, fol. 10.

616 ACM DD 107, 3 avril 1715. 


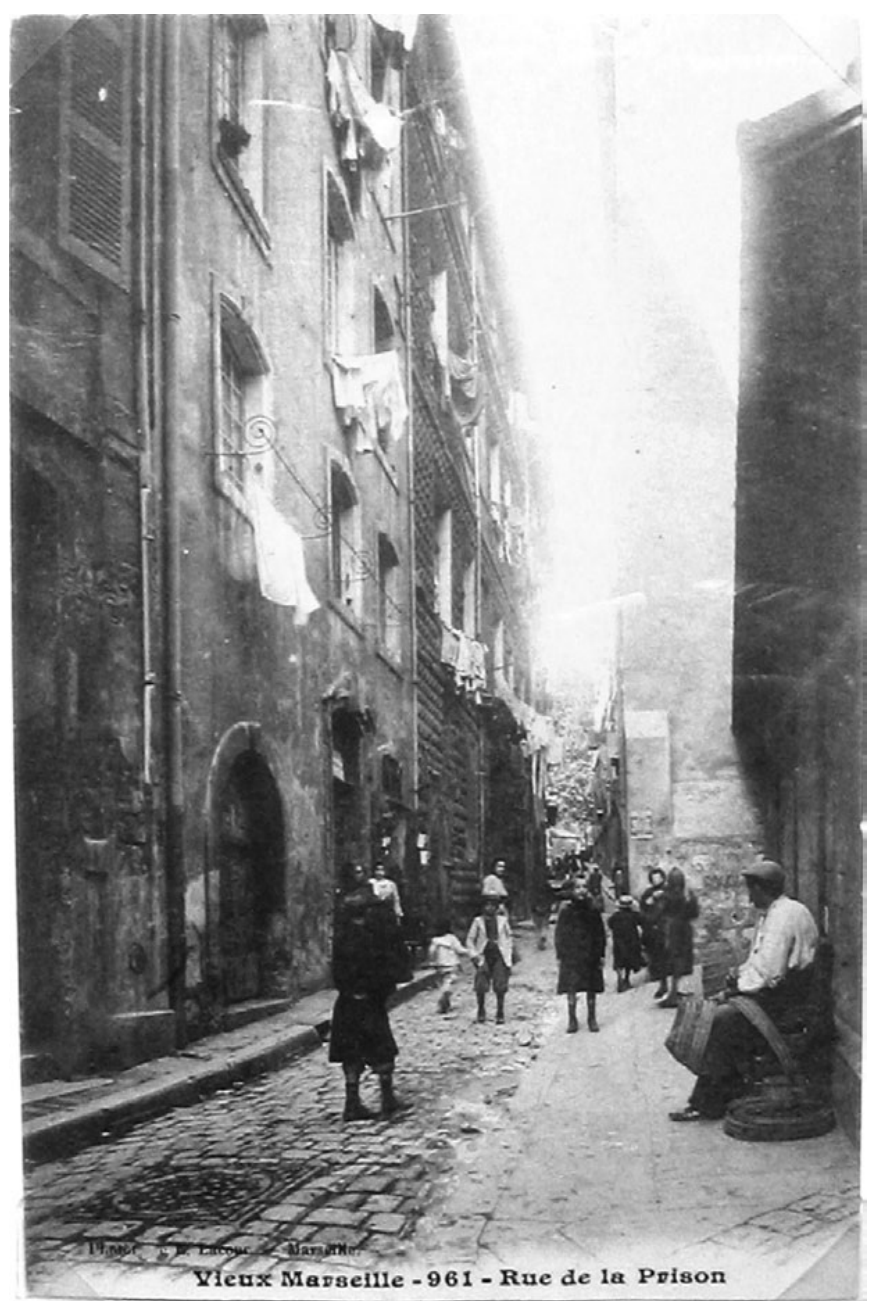

Fig. 176. La rue de la Prison au début du $X X^{e} \mathrm{~s}$ (Musée du Vieux-Marseille).

récente mais, comme elle ne possède pas d'étage, nous devons supposer que ses fondations sont peu profondes et n'affectent que la partie supérieure du terrain, arasé peu avant la fouille. La faible épaisseur des murs dessinés en 1948 confirme la légèreté de cette construction. Quoiqu'il en soit, le décalage suppose que la cave située contre l'ancienne façade n'est plus en usage, or nous avons daté son abandon de la seconde moitié du XIX ${ }^{\mathrm{e}} \mathrm{s}$. Un réalignement a donc été réalisé sur la rue de la Prison, mais il ne concerne qu'une parcelle. Il correspond à la démolition totale de l'ancien bâti et son remplacement par bâtiment sans étage qui semble très provisoire.

\section{La rue des Olives}

À l'instar de la rue de la Prison, la rue des Olives n'a été fouillée que sur un court tronçon et a subi un arasement subactuel profond $(1,10 \mathrm{~m})$. En outre, une cave en extension sous la rue nous prive de la moitié méridionale

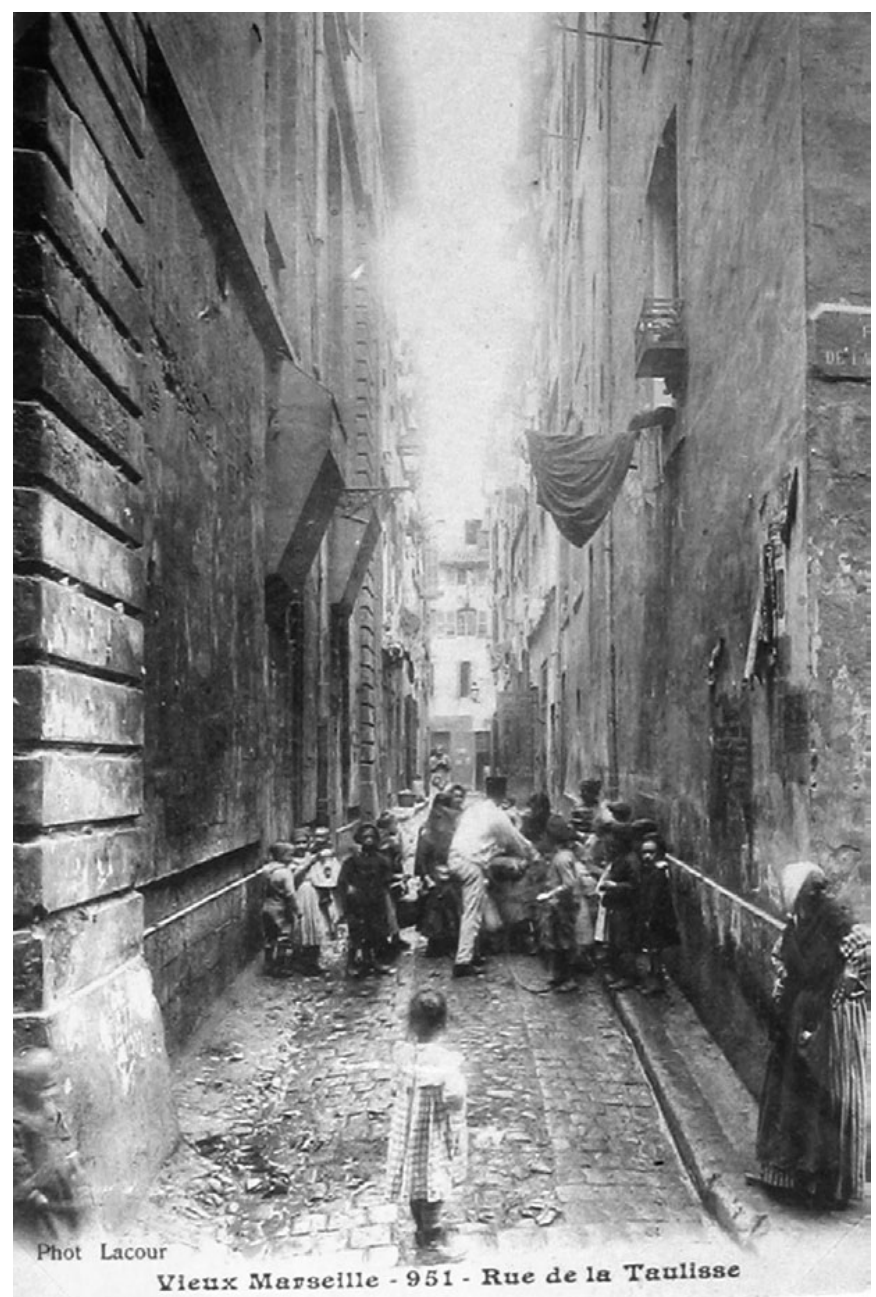

Fig. 177. La rue de la Taulisse au début du $X X^{\mathrm{e}} \mathrm{s}$. (Musée du Vieux-Marseille).

de la stratigraphie. Ceci explique peut-être qu'aucune construction ni sol médiéval n'aient été repérés. Elle est bordée au sud par l'actuel pavillon Bargemon, dont la façade, rhabillée, est large de 3,20 m. Compte tenu de la présence d'un bâtiment d'origine médiévale au nord, un éventuel alignement ne peut avoir été réalisé qu'au sud. La cave moderne en extension sous la rue nous prive de cette observation.

\section{La rue de la Taulisse}

Cette rue est, sur les deux-tiers de sa longueur, dans l'emprise du chantier César, ce qui en fait une des voies les mieux connues. Présente dès le Moyen Âge, elle a toujours conservé sa largeur, soit 3,60 m. Des aménagements datés du $\mathrm{XVI}^{\mathrm{e}} \mathrm{s}$. font suite à un arasement général des niveaux du bas Moyen Âge. Cette ruelle, qui relie deux axes importants (les rues de la Guirlande et de la Prison), semble secondaire. D'une part les parcelles à ses 


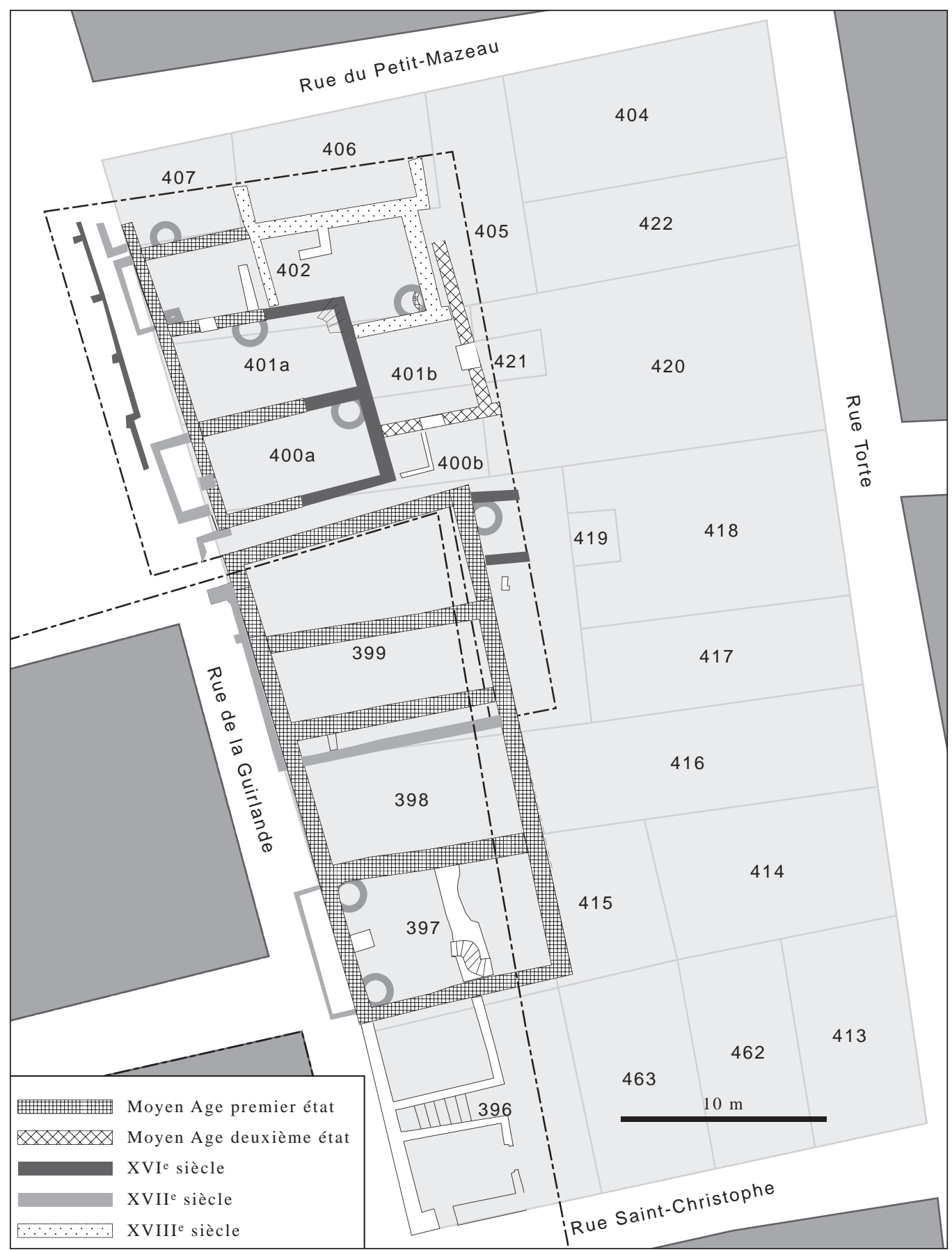

Fig. 178. Plan général de l'îlot I à l'époque moderne (DAO B. Sillano/Inrap).

extrémités ouvrent sur les autres rues, d'autre part aucune boutique ne semble y prendre place. Une photographie nous en donne l'image d'une rue très insalubre (fig. 177).

\section{La rue du Coq-d'Inde}

Le creusement d'une galerie a permis de recouper la rue du Coq-d'Inde sur une courte portion. Elle est bordée à l'ouest par le pavillon Daviel dont la fondation médiévale, en grand appareil de taille, a pu être observée, surmontée de la fondation puis de l'élévation moderne. De l'autre coté, les façades des parcelles 360 et 366 reposent sur un mur médiéval unique. La rue a donc toujours conservé sa largeur depuis cette époque, soit 1,90 m. Fait unique, elle a conservé un mince témoin des niveaux de circulation modernes, au sommet d'une épaisse succession de sols médiévaux. Le plus récent est une calade, abandonnée au milieu du XVIII ${ }^{\mathrm{s}}$ s., 
qui est en pente vers le sud mais aussi vers l'axe de la rue ${ }^{617}$. Au-dessous s'empilent, sur une trentaine de centimètres d'épaisseur, de fins niveaux très compacts, de nature diverses (cailloutis, argile, mélange hétérogène). L'étude de la parcelle 373 nous conduit à supposer que cette rue se prolongeait initialement vers le sud, au travers de l'îlot sud.

\section{2. Îlot I : à l'est du Petit Mazeau ${ }^{618}$ (F. Paone)}

L'îlot oriental est bordé respectivement au nord par la rue du Petit-Mazeau, au sud la rue Saint-Christophe, à l'ouest par la rue de la Guirlande et à l'est par la rue Torte (fig. 178). De cet îlot n'ont été reconnues en fouille que les parcelles ouvrant sur la rue de la Guirlande, à l'exception des vestiges de la parcelle 396 qui ont fait l'objet d'un simple relevé en plan. Ces parcelles forment des entités formelles distinctes, le plus souvent héritées du Moyen Âge, mais leur emprise évolue au cours de l'Époque moderne ; ainsi, la desserte nord-sud de cœur d'îlot attestée au Moyen Âge disparaît totalement au profit d'extension des constructions. Les habitations localisées dans le tiers septentrional (parcelles 400, 401 et 402) sont situées dans le périmètre du Petit Mazeau et reprennent la largeur modulaire de 7,5 m sur rue. En partie centrale, la prégnance d'un grand bâtiment médiéval semi-enterré conditionne le découpage parcellaire moderne (parcelles 397 à 399). Enfin la parcelle 396, située à l'angle de la rue de la Guirlande et de la rue Saint-Christophe, bien que dégagée lors de la fouille, n'a pas pu être étudiée. Pour les espaces situés en cœur d'îlot, le découpage parcellaire issu du cadastre napoléonien est arbitrairement utilisé car il diffère totalement des plans des vestiges modernes dont le découpage spatial est hérité de phases antérieures. Le maintien dans le paysage du bâtiment médiéval façonne totalement le parcellaire de la moitié sud de l'îlot.

Au cours du XVII ${ }^{\mathrm{e}}$ s., le creusement de caves sous l'emprise des immeubles se généralise. Contrairement aux autres îlots fouillés dont le découpage au sol est fidèle au cadastre de 1820, des différences notables apparaissent entre les subdivisions cadastrales et les vestiges archéologiques. Ainsi les espaces bordant la rue de la Guirlande sont moins profonds que les parcelles $n^{\circ} 402$, 401,400 et 399 auxquelles ils se rattachent. Ce constat

$\mathbf{6 1 7}$ La rue moderne, contrairement à la rue médiévale, présente un fil d'eau le long des façades et non dans l'axe de la rue. Cela ne s'applique certainement pas à une rue aussi étroite.

618 La présentation de l'îlot est une compilation des études de F. Paone 1997b, p. 4-7, V. Rinalducci 1997, p. 81-101, de C. Castrucci 1997, vol. 3, p. 555-563, F. Paone, R. Thernot vol. 1b, p. 324-367 et B. Sillano vol 2, p. 476-478 in Mellinand 2005. conduit à penser que les réalités foncières touchant le sous-sol peuvent être distinctes de celles qui sont inhérentes aux rez-de-chaussée des immeubles.

$\mathrm{Au}$ cours du XVIII ${ }^{\mathrm{e}}$ s., des modifications substantielles sont apportées, tant du point de vue spatial que fonctionnel. Ces bouleversements résultant vraisemblablement d'acquisitions foncières successives entraînent des modifications dans les circulations et accès aux espaces, qui voient également leurs aménagements internes évoluer. Les empiètements de cave sous rue sont systématiquement condamnés par l'ajout d'un mur obturant l'arc diaphragme. Ces mesures résultent peut-être d'arrêtés communaux visant à endiguer les troubles causés à la cohésion de la voirie, comme elles peuvent être le fruit d'une nécessité de confortement des immeubles déstabilisés par l'étendue des caves ou d'un changement de vocation de l'immeuble et, plus particulièrement, de la boutique qui occupe le rez-de-chaussée ( $c f$. fig. 173).

\subsubsection{La parcelle 407}

La parcelle 407 est à l'angle de la rue de la Guirlande et du Petit-Mazeau. L'étude d'archives n'a pas documenté cet espace, aussi ne sont présentées que les données archéologiques qui correspondent à la cave établie en sous-œuvre.

La cave mesure $6,60 \mathrm{~m}$ de long et possède une extension sous la rue de $0,90 \mathrm{~m}$ de longueur interne. Seule sa moitié méridionale a été fouillée. Elle est limitée, au sud, par un mur de soutènement qui double le mur de la cave voisine qu'elle réutilise dans sa moitié orientale. La construction de ce dernier est comparable à celle du mur occidental situé sous la rue, leur maçonnerie correspond à un blocage parementé de moellons et les blocs en calcaire rose de La Couronne. Leur largeur est de 0,66 cm pour le mur sud et inégale pour le mur ouest qui passe de $0,40 \mathrm{~m}$ à plus de $1 \mathrm{~m}$. Le mur est se différencie des deux autres par sa mise en œuvre en moellons de calcaire blanc de Saint-Victor liés avec un mortier gris clair et sa largeur de 0,40 m. La transition entre l'extension de la cave sous la rue et la façade est effectuée par un arc de décharge en blocs taillés de calcaire rose. L'espace est voûté d'un berceau en brique pleines ${ }^{619}$. Un puits d'un diamètre de $0,90 \mathrm{~m}$ prend place contre le mur méridional avec lequel il est lié. Son cuvelage est constitué d'une maçonnerie de moellons retouchés et de cailloux.

Dans une deuxième phase, la partie de la cave passant sous la rue est condamnée par un mur en grand appareil de blocs taillés placé sous l'arc de décharge, l'excroissance étant remblayée vers le début du $\mathrm{XIX}^{\mathrm{e}} \mathrm{s}$. Enfin au

619 Le module est de 24 x 17 x $3 \mathrm{~cm}$. 


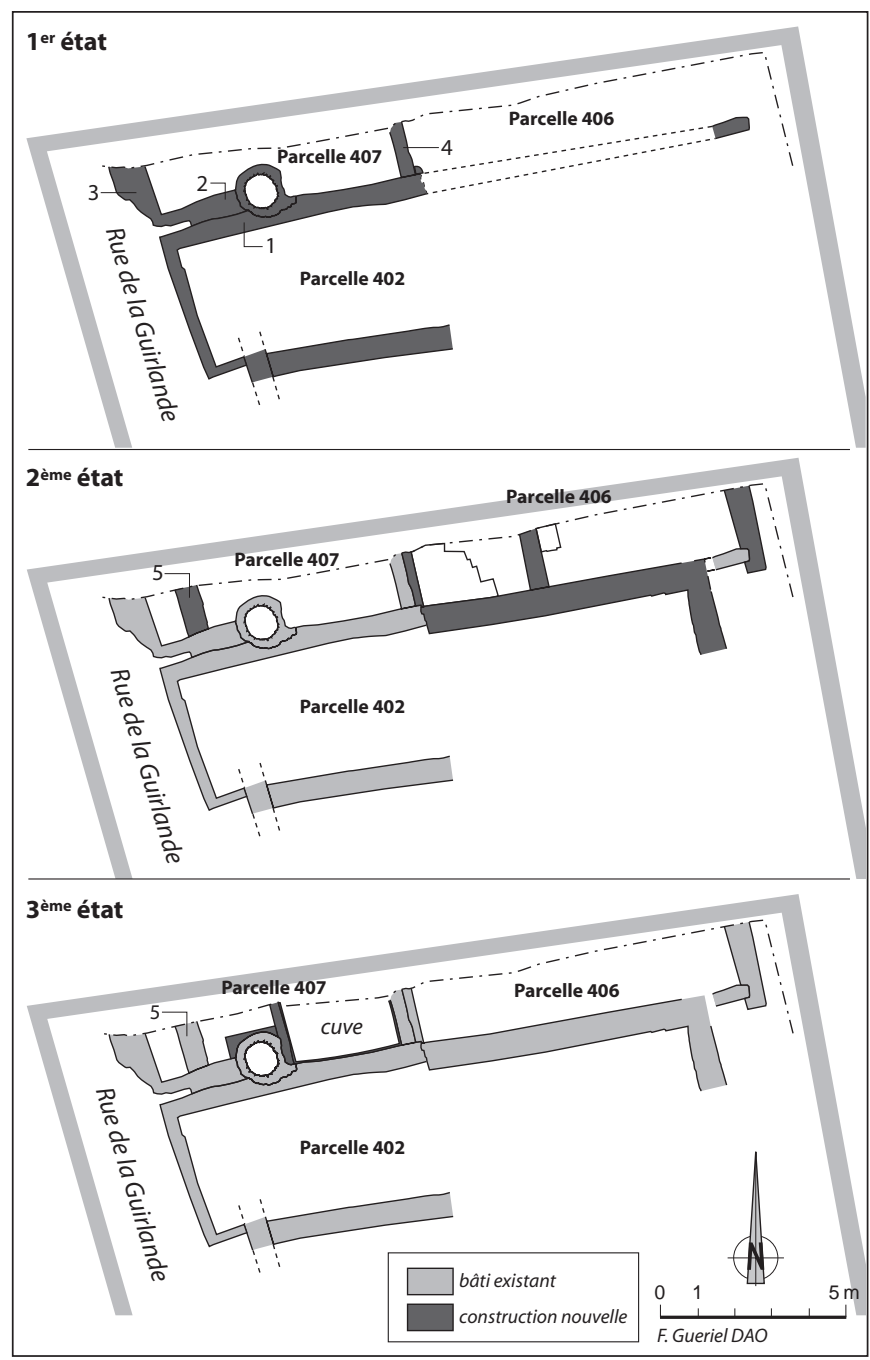

Fig. 179. Plan de l'état 1, 2 et 3 des parcelles 406 et 407 (DAO F. Gueriel/Inrap).

milieu du XVIII ${ }^{\mathrm{e}}$ s., une ultime phase de réaménagement est représentée par l'exhaussement de 1,20 m du sol constitué de carreaux de terre cuite ${ }^{\mathbf{6 2 0}}$. Cela entraîne la modification de la margelle du puits, alors rehaussé par un cuvelage en briques formant un plan carré de $0,60 \mathrm{~m}$ de côté. À l'est de ce dernier est aménagée une cuve à l'époque contemporaine (fig. 179).

\subsubsection{La parcelle 406}

Mitoyenne de la parcelle 407, la parcelle 406 s'ouvre au nord sur la rue du Petit-Mazeau. La cave localisée dans son emprise est longue de 8,60 m et empiète sur la parcelle 405 ; elle est divisée en deux parties au cours d'un réaménagement.

$\mathbf{6 2 0}$ Le module est de $23 \times 15 \times 1,5 \mathrm{~cm}$.
Large de $30 \mathrm{~cm}$, son mur méridional, dont ne demeure qu'un tronçon de maçonnerie de moellons de calcaire de Saint-Victor, est presque totalement reconstruit lors du creusement de la cave mitoyenne de la parcelle 402. Pour cette première phase d'aménagement, aucune limite orientale n'est conservée et ne demeure du premier couvrement qu'un culot dans l'angle sud-ouest. Le sol carrelé, disposé sur une préparation pavée sommairement, est composé d'éléments au module identique ${ }^{\mathbf{6 2 1}}$, mais d'aspects distincts ${ }^{\mathbf{6 2 2}}$.

L'extension à l'est de la cave de la parcelle 402 a un impact notable sur cet espace qui est alors divisé avec une limite orientale clairement définie. Cette dernière se compose d'assises de petits moellons équarris reposant sur un radier de gros blocs taillés posés à plat. Parallèlement le mur mitoyen avec la cave ouest est doublé par un plaquage d'une vingtaine de centimètres et la pièce est cloisonnée par un mur dont la mise en œuvre rappelle celle du mur oriental. Suite à l'apport d'un remblai à base de matériaux de démolition durant le troisième quart du XVIII ${ }^{\mathrm{e}} \mathrm{s}$., les nouveaux espaces sont recarrelés.

\subsubsection{La parcelle 405}

Cette parcelle, accessible par la rue du Petit-Mazeau, est de forme oblongue et forme un redan au contact de la parcelle 402. Nous pensons qu'elle reprend partiellement l'emplacement d'une ancienne venelle médiévale qui desservait le cœur d'îlot. Il est difficile d'établir quand ce secteur a été inféodé ou vraisemblablement à l'extrême fin du Moyen Âge ou au cours du XVI ${ }^{\mathrm{e}} \mathrm{s}$. L'étude d'archives n'a pas concerné cette partie, qui est, de plus, très partiellement documentée par la fouille.

Étroitement associé à la mise en place de la cave de la parcelle 406 qui le limite à l'ouest, ce secteur n'est visible que sur une bande restreinte de 1,50 $\mathrm{m}$ en limite du chantier. Sa situation en cœur d'îlot le soumet à de multiples changements ; ses limites sont façonnées par les maçonneries des parcelles mitoyennes, en particulier la parcelle 402. L'aménagement d'une cuve qui, dans un deuxième temps, forme le receptacle d'un dépotoir est à signaler.

\subsubsection{La parcelle 402}

La parcelle 402 est l'une des mieux documentées tant par les archives que par la fouille (fig. 180). Elle

621 Le module est de 25 x 13 × $3 \mathrm{~cm}$.

622 L'une des séries présente la particularité de porter un décor estampé en surface associant une figure cordiforme entourant l'inscription « BIEN ». 


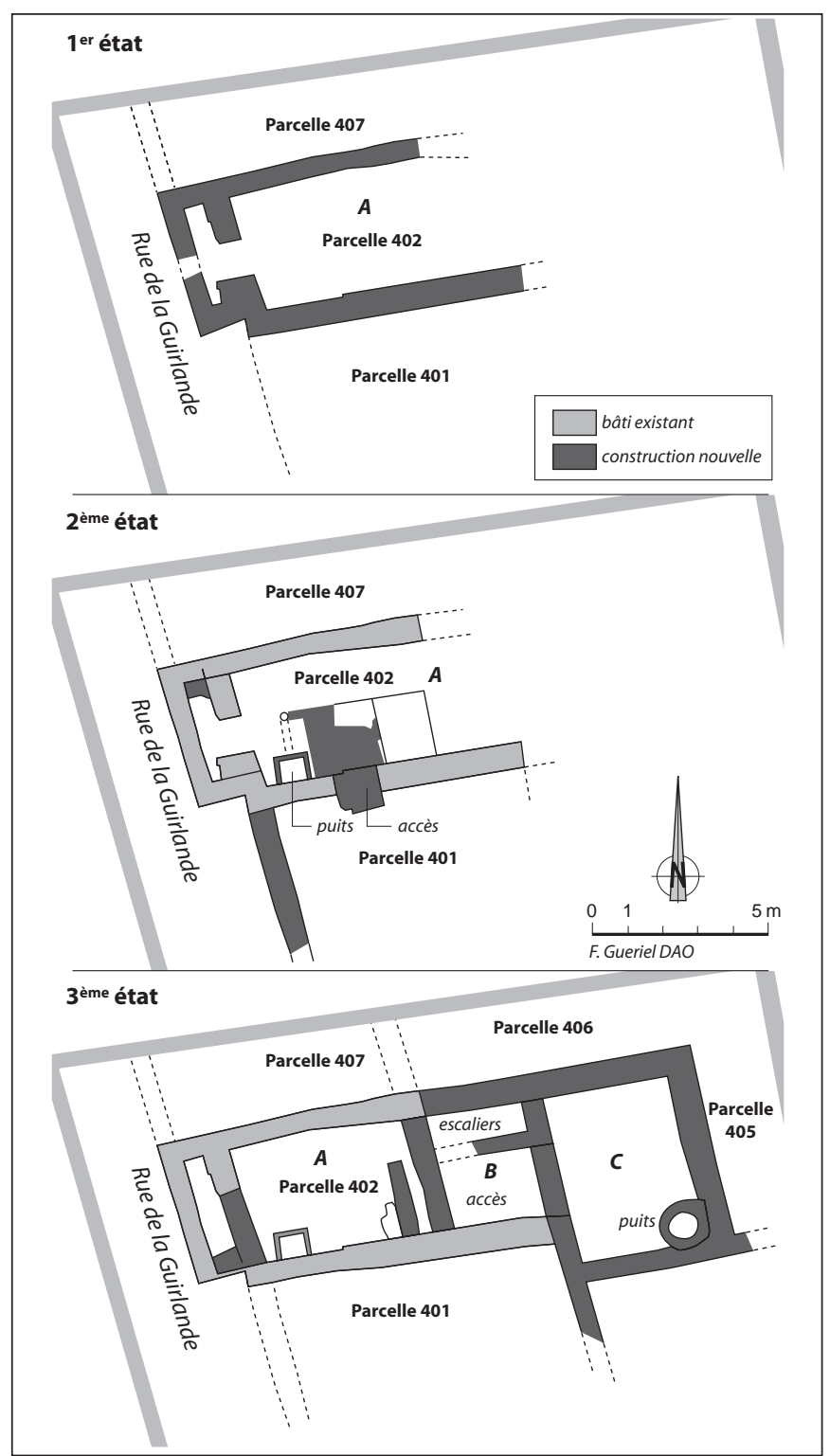

Fig. 180. Plan de l'état 1, 2 et 3 de la parcelle 402 (DAO F. Gueriel/Inrap).

pénètre profondément en cœur d'îlot lors d'une phase d'extension qui engendre une modification de ses limites périmétrales, qui à l'origine, devaient être de même dimension que les parcelles 400 et 401 , soit $8 \mathrm{~m} \mathrm{x} 4 \mathrm{~m}$. Cet ensemble intègre dans ses maçonneries des murs plus anciens, médiévaux pour certains, dont il reprend le tracé. Nous possédons un rapport de future cautelle ${ }^{\mathbf{6 2 3}}$ daté de 1638 qui se rapporte à cette parcelle. L'immeuble possède quatre étages du côté de la rue. Il possède une cave «avec un trellier de fer qui donne le jour », et au rez-de-chaussée une boutique qui ouvre sur la rue, «au fondz de laquelle y a ung four » à droite duquel

623 AD13 364 E 169, fol. 1127. on accède à un ciel ouvert équipé d'un puits. Les étages au-dessus de la boutique ne sont pas décrits mais «pardessus le four est une petite chambre appelée gloriette de la largeur de quatorze pans et dix pans de long ». Sont ensuite mentionnées deux autres chambres «au dessus de laditte gloriette et de la mesme grandeur». Ces informations permettent de restituer la répartition de pièces ( $c f$. fig. 46).

La fouille a montré que les fondations de l'immeuble, en pierre de taille, sont reprises en sous-œuvre par les caves dont l'installation s'est faite en trois étapes. La cave initiale, d'une superficie de $33 \mathrm{~m}^{2}$, est dotée d'une extension sous rue plus étroite que la longueur de la façade supportée par un arc de décharge en moellons taillés de calcaire rose. Le mur ouest, bâti pour l'essentiel avec des matériaux en réemploi, est enduit et percé dans un deuxième état d'une trémie accessible depuis la rue, le soupirail dont il est question dans l'acte de 1638. Les élévations des murs nord et sud associent des pierres de tailles diverses liées au mortier formant un parement irrégulier destiné à être enduit. La limite est de la cave a disparu et le couvrement de l'espace est formé d'une voûte en moellons en calcaire de La Couronne.

$\mathrm{Au}$ milieu du XVII ${ }^{\mathrm{e}}$ s., lors de la mise en place de la cave de la parcelle mitoyenne 401, une porte est établie entre les deux espaces souterrains. Cette communication est d'autant plus surprenante que si ces deux immeubles appartenaient à Simon Muret jusque là, celui relevant de la parcelle 402 est vendu en 1638 à François Gautier, maître boulanger. Elle pourrait s'expliquer par une propriété commune des lieux mais nous pensons qu'elle se justifie par l'usage collectif d'un puits réalisé dans la parcelle 402, à proximité précisément de la porte d'accès. De plus, un soin particulier est porté à la pose d'un carrelage de terre cuite ${ }^{624}$ disposé autour du seuil de la porte et du cuvelage quadrangulaire du puits ${ }^{625}$. Ce sol est clairement délimité par des cloisons et forme une surface aménagée de 2,5 x 2 m (fig. 181).

Au cours du XVIII ${ }^{\mathrm{e}} \mathrm{s}$. est entreprise l'extension de la cave en cœur d'îlot, sous l'emplacement du ciel ouvert mentionné dans l'acte de 1638. Ces travaux se traduisent par la reconstruction de l'ensemble des murs contigus qui déterminent alors un nouvel espace cloisonné ainsi que par une modification des accès et un exhaussement des niveaux de sols.

La configuration du secteur entraîne la condamnation de l'emprise de cave qui empiétait sous la rue. L'extension est alors obturée par un mur placé sous l'arc de décharge puis remblayé à partir de la trémie aménagée dans la voûte durant le troisième quart du XVIII' ${ }^{\mathrm{e}}$.

624 Ces carreaux mesurent $27 \times 13 \times 3 \mathrm{~cm}$ et sont orientés nord-sud. 625 Les dimensions internes du puits sont de $0,80 \times 0,75 \mathrm{~m}$. 


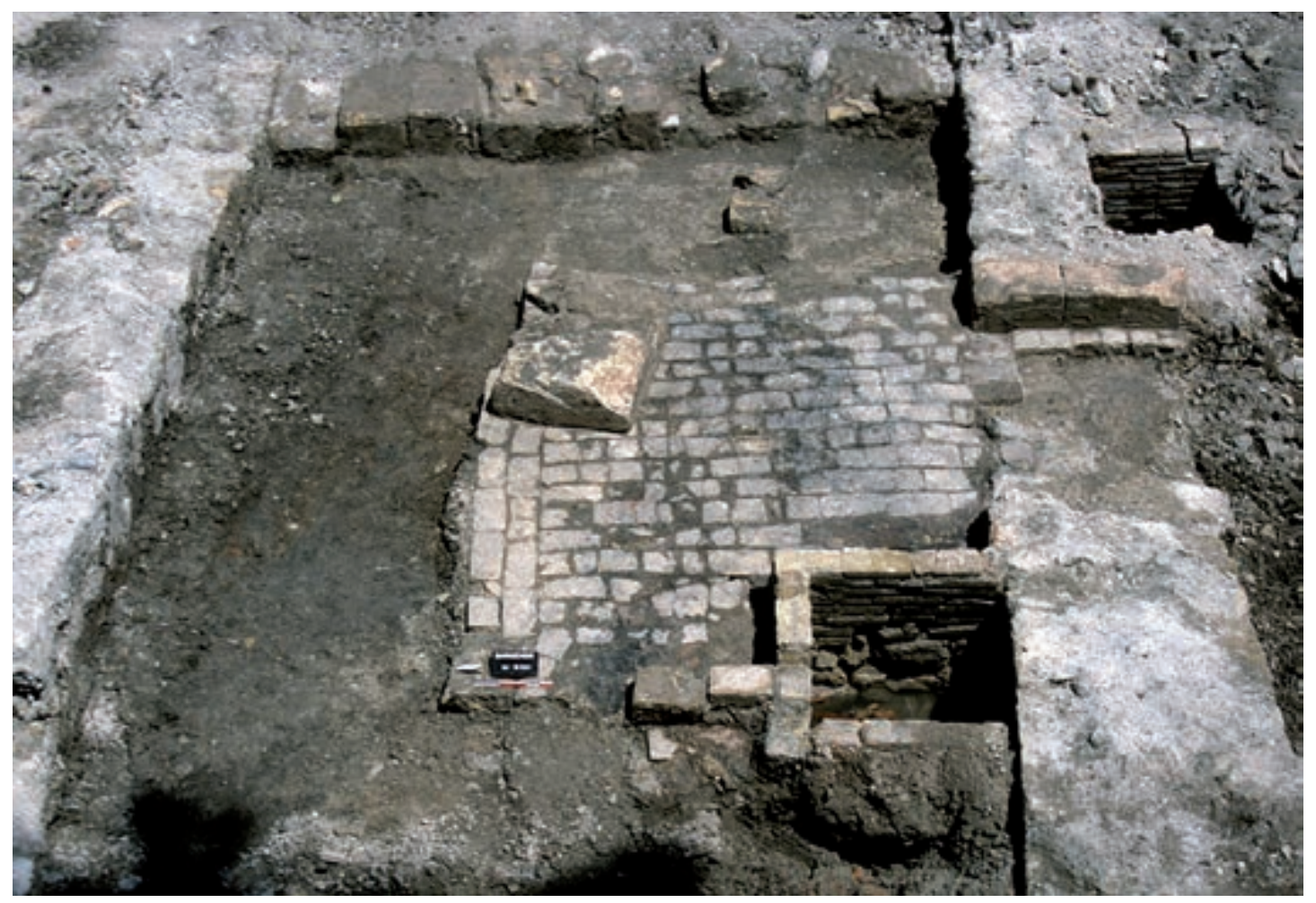

Fig. 181. Vue de l'aménagement de sol devant la porte et le puits (cl. T. Maziers/Inrap).

L'agrandissement de la cave s'accompagne d'une subdivision de la superficie acquise en trois pièces, dont les limites semblent correspondre aux partitions du rez-dechaussée décrites dans le rapport de future cautelle de 1638. La cave ouest (A), d'une emprise de $16,30 \mathrm{~m}^{2}$ est située sous la boutique et délimitée à l'est par un mur mesurant 2,86 x $0,58 \mathrm{~m}$, formé d'une fondation de gros blocs de calcaire disposés en parpaing-boutisse et supportant une élévation à appareil irrégulier. L'usage du puits est maintenu. Une ouverture de $82 \mathrm{~cm}$ de large est aménagée dans l'angle sud-est de la pièce ; elle est rapidement transformée en porte lorsque la communication avec la cave de la parcelle 401 est murée. L'accès au sous-sol s'effectue alors par un escalier situé dans une petite pièce médiane $(\mathrm{B})$ de $2,50 \mathrm{~m}$ par $3,50 \mathrm{~m}$. De l'escalier à volée droite ne reste que le mur d'échiffre, de $2,40 \times 0,55 \mathrm{~m}$, et son retour mesurant $0,55 \times 0,30 \mathrm{~m}$. Au milieu du XVIII ${ }^{\mathrm{e}}$ s., les sols de ces caves sont rehaussés par l'apport de remblais hétérogènes pouvant atteindre $1 \mathrm{~m}$ d'épaisseur dans la pièce centrale. Le module des carreaux ${ }^{626}$ utilisé diffère de celui employé jusque là. Ces multiples transformations s'accompagnent d'une reprise totale du voûtement qui est reconstruit en briques et adopte un profil en plein-cintre.

626 Ces carreaux mesurent $25 \times 16 \times 5 \mathrm{~cm}$.
Des travaux d'envergure sont également entrepris à l'est où la cave est prolongée sous l'emplacement du ciel ouvert et adopte une forme en L. Cette extension (C) s'effectue au détriment de la parcelle 401 qui relève à nouveau, en 1729 , d'un même propriétaire : Antoine Charousset. La mise en œuvre complexe de cet espace oriental de 4,80 x 3,50 m a entraîné un soin particulier dans la construction adaptée aux contraintes de stabilité sus-jacentes. Les murs sont pourvus systématiquement d'un radier de fondations en blocs taillés de La Couronne alignés en parpaing; leur élévation revêt un appareil irrégulier destiné à être enduit. L'angle sud-est de la pièce est particulièrement soigné puisqu'il intègre partiellement un puits plus ancien sur lequel se superpose le mur méridional par l'intermédiaire d'un arc de décharge. Les limites nord et est, plus larges que le mur sud $(0,75 \mathrm{~m}$ au lieu de $0,50 \mathrm{~m})$, conservent les traces des étapes de construction par tronçons successifs de maçonneries de 1,20 à 1,50 m. Dans l'angle sud-est de la salle est installé un puits dont la construction empiète sur le puits plus ancien. D'un diamètre interne de $0,85 \mathrm{~m}$, celui-ci fait appel majoritairement à des moellons bruts en poudingue et plus rarement des moellons en calcaire blanc. Dans un second état, le cuvelage réduit adopte une forme carrée de $50 \mathrm{~cm}$ de côté construit en brique ; il est en relation avec un rehaussement général du niveau de circulation et la pose d'un nouveau carrelage (fig. 182). 


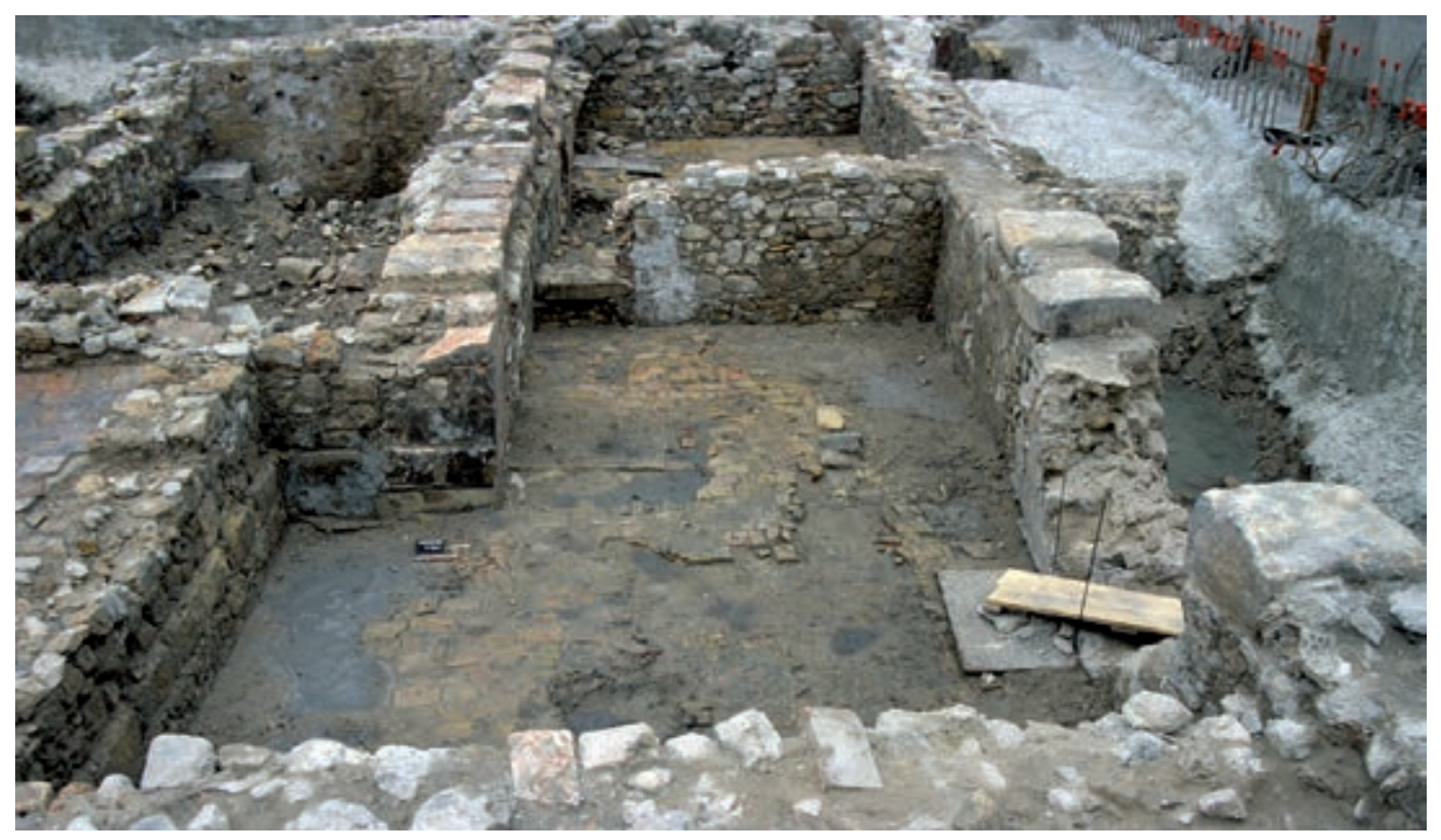

Fig. 182. Vue de la cave de la parcelle 402 (cl. F. Parent/Inrap).

Fig. 183. Vue générale de la cave de la parcelle 401 (cl. J. Collinet/Inrap).

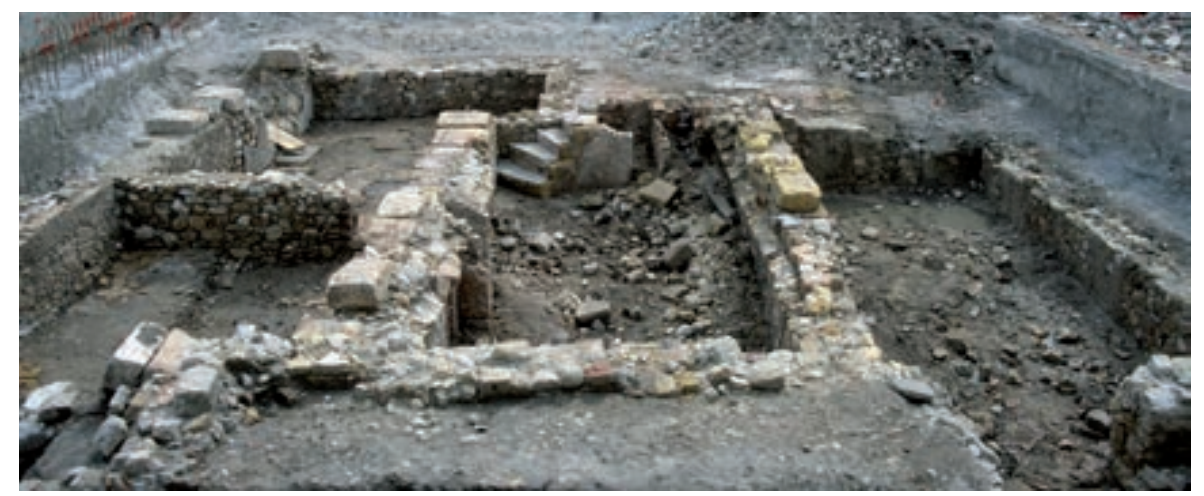

Ces espaces n'ont subi aucun autre remaniement et sont utilisés jusqu'à la destruction du quartier en 1943 comme l'attestent le comblement des puits et le remblaiement général de ces pièces. Au niveau du rezde-chaussée, ces travaux conduisent-il à la disparition du ciel ouvert ? A-t-il été englobé dans le bâti sous une forme plus restreinte ? L'absence de substructions qui puissent le matérialiser nous permet d'écarter cette hypothèse.

\subsubsection{La parcelle 401}

Peu d'informations nous sont fournies sur la parcelle 401 par les études d'archives. Nous savons seulement qu'elle relève du même propriétaire que celui de la parcelle voisine 402 (Simon Muret) jusqu'en 1638 puis de nouveau en 1729 (Antoine Charousset). Ces faits justifient vraisemblablement les évolutions conjointes de ces deux caves.

La fouille nous restitue deux espaces attribuables tardivement à la parcelle 401, à l'ouest une cave (A) et à l'est, une cour (B) dont l'emprise, désaxée au sud, trouve en partie son origine dans le plan d'une maison médiévale ( $c f$. supra § 2.3.2.).

La cave de la parcelle 401, postérieure à celle de l'unité 402, est la seule dont l'emprise n'empiète pas sur la rue. Elle conserve des systèmes de confortement de l'immeuble moderne sous lequel elle est bâtie en sous-œuvre; il demeure ponctuellement une assise de fondations reposant parfois sur un mur de refend du bas Moyen Âge. Certains blocs sont taillés dans du calcaire coquillier de La Couronne et sont disposés en parpaing boutisse ou panneresse ${ }^{627}$ en fonction des maçonneries sous-jacentes (fig. 183).

Cet espace mesure $8,20 \mathrm{~m}$ sur $4 \mathrm{~m}$ pour une hauteur estimée à $3 \mathrm{~m}$. Bien que l'ensemble des murs ne soit pas

627 Deux gabarits sont employés : les blocs de 0,60 et $0,66 \mathrm{~m}$ de long pour une largeur comprises entre 0,42 et $0,50 \mathrm{~m}$ de large, et les éléments plus petits de 0,50 à $0,55 \mathrm{~m}$ de long pour 0,26 à $0,40 \mathrm{~m}$ de large. 
contemporain, ils respectent le plan d'origine (fig. 184). Les murs nord, est et sud se caractérisent par un appareil assisé de moellons de calcaire de La Couronne associés à des galets et cailloux liés au mortier de chaux mêlés à du sable. Le mur ouest se distingue par l'hétérogénéité de sa construction, intégrant de nombreux remplois. Cet espace communique avec la cave nord par l'intermédiaire d'une porte de $1 \mathrm{~m}$ de large ; ses piédroits et l'arc plein cintre sont en pierre de taille de La Couronne. Du voûtement en berceau initial ne demeure que le départ en moellons et blocs posés en carreau et boutisse. L'accès à cet espace s'effectue par l'intermédiaire d'une volée d'escalier dont n'est conservée que la base du mur d'échiffre, disposé à 1,90 m du mur oriental.

Lors de l'extension de la cave de la parcelle 402 vers le sud-est, des reprises de maçonneries sont réalisées et la limite est modifiée. La nouvelle élévation, large de $50 \mathrm{~cm}$, présente une maçonnerie hétérogène tant par ses matériaux que par sa mise en œuvre ; un soin plus prononcé est apporté à la réalisation du nouveau chaînage d'angle en pierre de taille. Cette reprise des élévations s'accompagne de la destruction du voûtement en pierre au profit du couvrement plus léger en briques. Dans l'angle sud-est est établi un puits dont le cuvelage est en pierre et la margelle constituée de quatre blocs de calcaire coquiller jaune ${ }^{628}$. Ces réaménagements s'accompagnent de l'obturation de la porte reliant les caves des parcelles 402 et 401 .

Dans une troisième phase, le sol est fait de carreaux de terre cuite ${ }^{629}$ disposés sur une chape de mortier de $11 \mathrm{~cm}$ d'épaisseur reposant sur un remblai de démolition épais de $20 \mathrm{~cm}$. Un nouvel escalier d'accès, situé à l'angle nord-est de la cave reprend l'emplacement du précédent. Les blocs taillés, de 22 à $24 \mathrm{~cm}$ de long, forment les marches de la volée tournante, calés par des fragments de briques pleines. À l'est de l'ancien accès est établi un second puits d'un diamètre interne de $0,90 \mathrm{~m}$ et dont le cuvelage est formé de blocs de calcaire rose et de moellons bruts liés avec un mortier rose d'une grande dureté.

Seules des modifications mineures sont ensuite apportées; elles concernent l'ajout de réduits sous la cage d'escalier qui condamne le puits rendu obsolète par la présence du puits nord. Ce dernier est alors rehaussé d'un chemisage quadrangulaire $(0,65 \times 0,58 \mathrm{~m})$ en briquettes de terre cuite chamotée posées en panneresse. Ce conduit se prolongeait vraisemblablement jusqu'en rez-de-chaussée de l'immeuble, voire aux étages. L'ensemble de la cave, dans sa phase d'utilisation la plus récente, est badigeonné de chaux.

628 Dimensions des blocs : $1,22 \times 1,17 \times 0,27 \mathrm{~m}$.

629 Les carreaux mesurent de 26 x $14 \times 3 \mathrm{~cm}$.

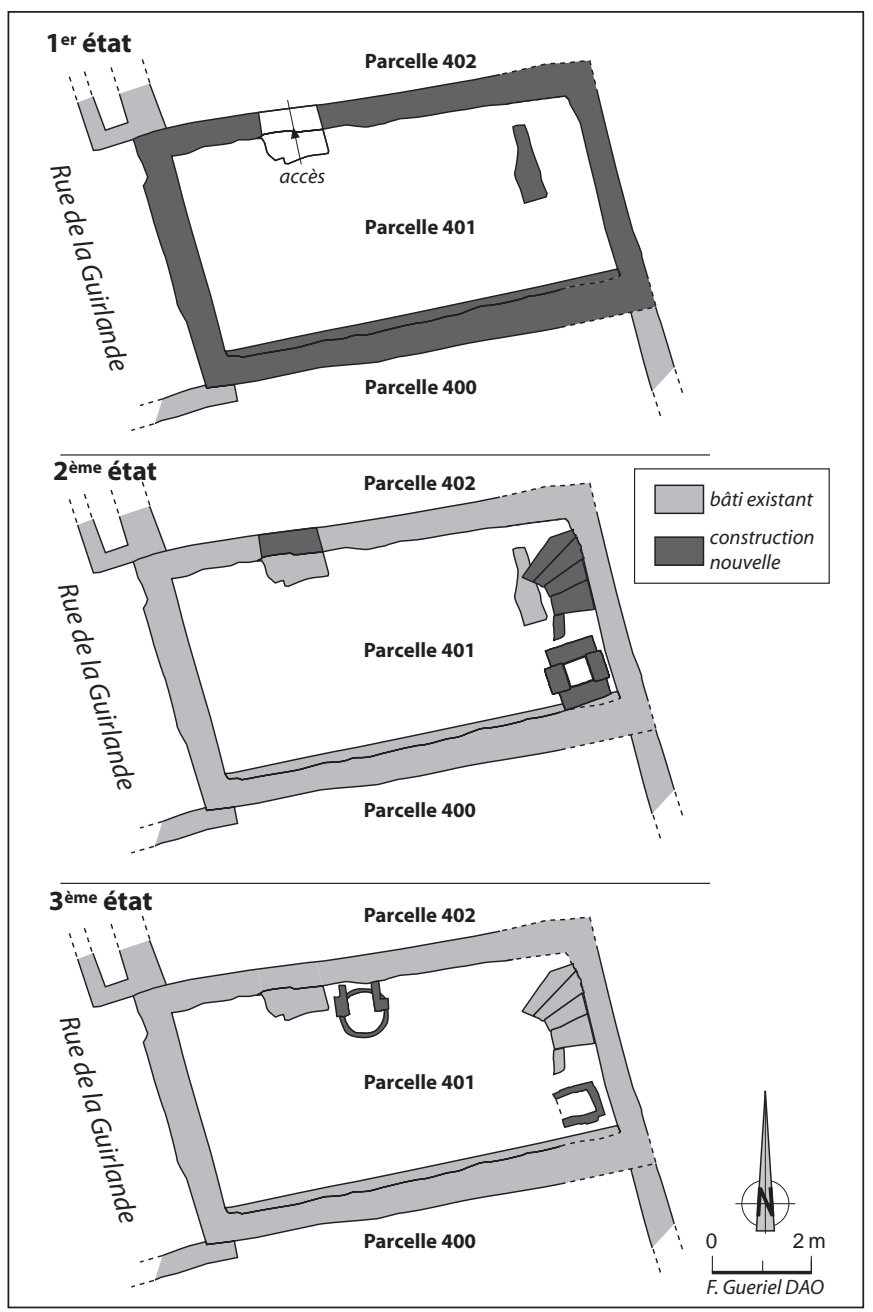

Fig. 184. Plan de l'état 1, 2 et 3 de la parcelle 401 (DAO F. Gueriel//nrap).

\subsubsection{La parcelle 400}

Les vestiges associés à cette parcelle proviennent d'une cave mise en œuvre dès le début du XVII ${ }^{e}$ s. dont l'aspect et les aménagements la différencient des autres exemples découverts.

Cet espace est creusé dans l'emprise d'un bâtiment riverain de la rue de la Guirlande en empiétant de $2 \mathrm{~m}$ sous celle-ci. Il mesure $10,24 \mathrm{~m}$ de long et $3,60 \mathrm{~m}$ de large et il est couvert d'une voûte en plein cintre, très peu conservée. Des fondations de la maison sous laquelle elle est implantée ne subsistent que deux reliquats de murs au nord de l'espace dont l'un est d'origine médiévale tandis que l'autre est un radier de blocs taillés correspondant à une fondation moderne (fig. 185).

Les murs de soutènement de l'espace sont réalisés en maçonnerie parementée irrégulièrement, liée avec un mortier friable mêlant réemplois, cailloux, galets, briques. Le départ de voûte, dont le liant est comparable, utilise essentiellement du calcaire blanc. Faisant 


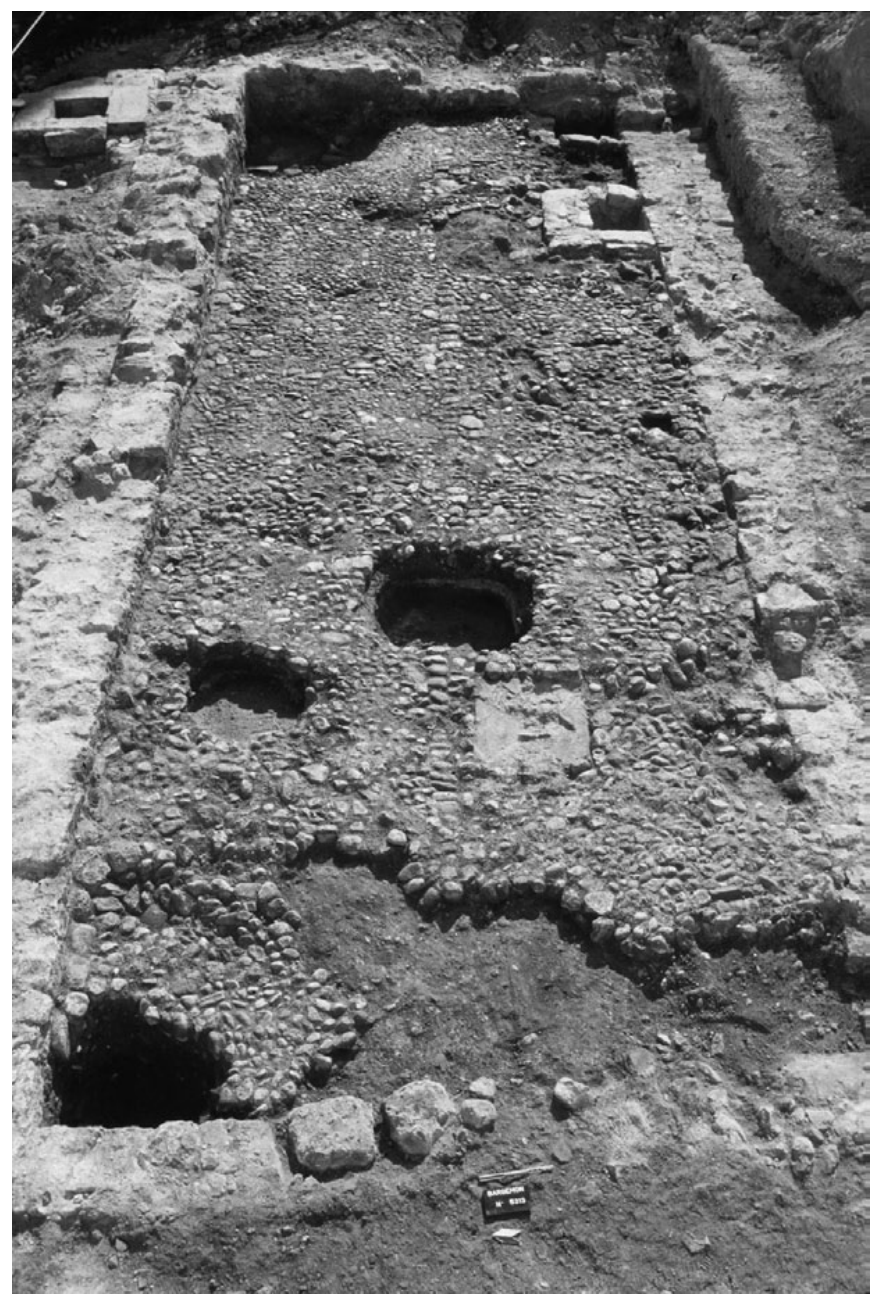

Fig. 185. Vue générale de la cave de la parcelle 400 (cl. N. Nin/Inrap).

office de support de façade, un pilier de section carrée de $0,56 \mathrm{~m}$ de côté est placé à $1 \mathrm{~m}$ du mur sud et à $1,80 \mathrm{~m}$ du mur nord. Le pilier est associé à un muret maçonné de $24 \mathrm{~cm}$ d'épaisseur qui vient s'accoler également au sud contre le mur de refend. Cette pièce est équipée, dans l'angle nord-est, d'un puits de $0,90 \mathrm{~m}$ de diamètre, sans margelle, et, dans le tiers oriental, d'une cuve de latrines enterrée. Cette dernière mesure $2,55 \mathrm{~m}$ sur 2,60 m et son voûtement en berceau segmentaire lui confère une hauteur maximale interne de $1,80 \mathrm{~m}$. Les parois de la cuve, larges de 28 à $35 \mathrm{~cm}$, ainsi que la voûte ${ }^{630}$, sont constituées de moellons calcaires de modules irréguliers, sommairement assisés, et liés avec un mortier relativement dur et abondant, recouvrant partiellement les pierres, pour former un enduit. Aucun revêtement de fond n'est à signaler. La cuve est dotée d'un regard d'accès saillant de 0,50 m à l'ouest, formé d'une dalle de couverture de calcaire tendre taillée

630 Les empreintes des planches du couchis du cintre, larges de 12 à $14 \mathrm{~cm}$ sont visibles sur le mortier.

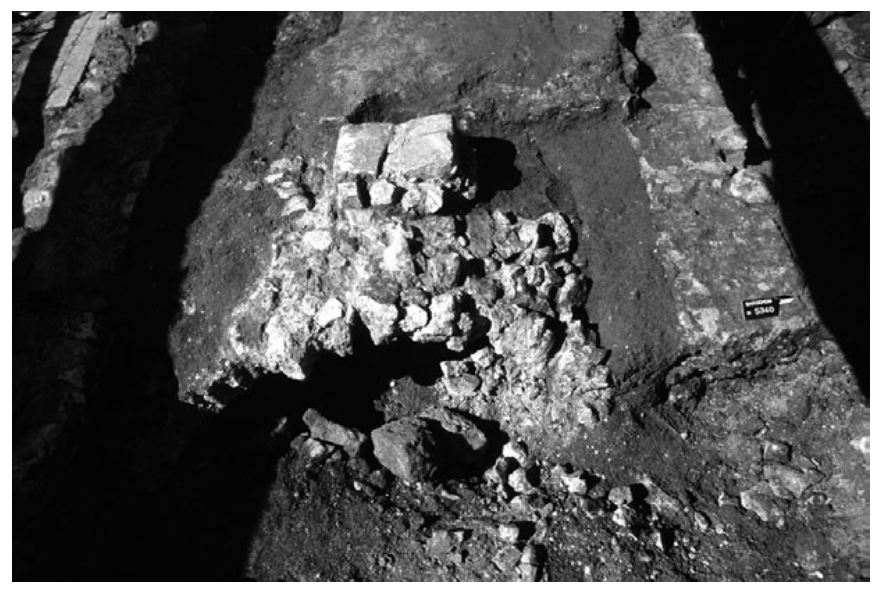

Fig. 186. Voûte de la cuve de la latrine avec dalle obturant l'accès (cl. N. Nin/Inrap).

posée sur deux murets. Le dépôt interne de la cuve, épais de $40 \mathrm{~cm}$, est un sédiment noirâtre très riche en charbons de bois de gros modules, et du mobilier de la fin du XVII' s. (fig. 186).

Reposant sur un remblai de nivellement, un sol caladé doté de deux contre-pentes convergeant vers un fil d'eau central constitue le sol de la cave. Contemporaines du sol caladé, deux cuves maçonnées, distantes de $2 \mathrm{~m}$, prennent place contre le mur méridional de la cave. Elles mesurent respectivement $0,80 \mathrm{~m}$ de côté et $1,20 \mathrm{~m}$ par $0,90 \mathrm{~m}$ et sont utilisés jusqu'au début du XVIII ${ }^{\mathrm{e}} \mathrm{s}$.

Entre le milieu du XVII ${ }^{e}$ s. et la fin du XVIII ${ }^{e}$ s., l'utilisation de la cave s'accompagne de plusieurs creusements de fosses entamant le sol caladé et les remblais d'installation. La plupart sont comblées de matériaux de démolition ; l'une d'elles pourrait correspondre à l'arrachement d'un pilier son fond étant tapissé de mortier (fig. 187).

Cette parcelle est documentée par un acte d'achat daté de $1734^{631}$, qui décrit les biens vendus par Ignace Darene de la Forbine à Jean Olivier, mais l'état des lieux diverge quelque peu des vestiges dégagés. Dans ce rapport, il est question d'une cave de «quatorse pans de large trente deux pans de long » et de «deux pilliers en pierres de taille pour soutenir la voutte». Le rez-de-chaussée est occupé par une boutique de $5,50 \mathrm{~m}$ de profondeur, et dans le fond de la parcelle par une suillarde prenant jour au ciel ouvert de la maison voisine. Les descriptifs des différents niveaux traduisent bien l'imbrication des propriétés dans les étages avec les espaces qui devraient relever de la parcelle 401. Au premier étage, auquel on accède depuis le fond de la boutique, sont mentionnées une salle, superposée à la boutique, et une chambre,

631 AD13 361 E 117, fol. 540. 


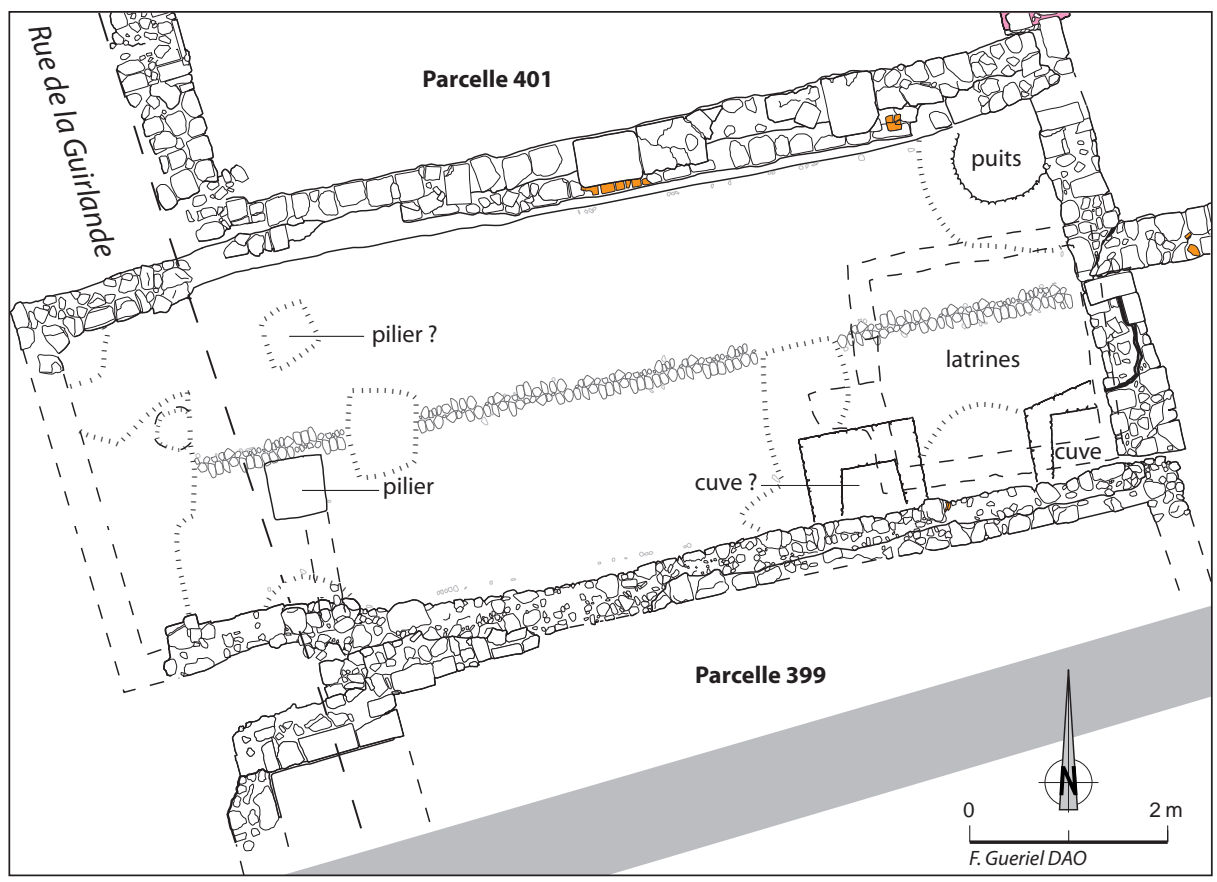

Fig. 187. Plan des structures modernes de la parcelle 400 (DAO F. Gueriel/Inrap).

éclairée par le puits de lumière du voisin. En raison de ses dimensions, $5 \mathrm{~m}$ par 4,75 m, cette dernière est nécessairement située dans un autre corps de bâtiment, comme semblent indiquer les rapporteurs qui sont «entrés sur le derrière de ladite maison » pour accéder à cette chambre. Or elle correspond exactement aux dimensions de la pièce orientale qui relève de la parcelle 401 (espace 401B, $c f$. infra $\$ 3.2 .10$.). Les trois étages suivants sont identiques, les pièces, sauf une au second, étant alors toutes des chambres. Les pièces ont une hauteur de $3 \mathrm{~m}$, sauf la boutique $(3,50 \mathrm{~m})$ et la chambre du premier (4,25 m). Il n'y a qu'une cheminée à chaque étage, soit dans la pièce de devant soit dans l'autre. Les fenêtres donnant sur la rue sont des «croisière et demy avec leur fermure à six jours bois blanc » de 1,50 $\mathrm{m}$ de large et de $2 \mathrm{~m}$ de hauteur, au premier et second étage, puis 1,40 m et $1 \mathrm{~m}$ de hauteur aux suivants. La façade est « tout de massonerie » (cf. fig. 46).

\subsubsection{La parcelle 399}

La parcelle 399 occupe, avec les parcelles 398 et 397 , l'emprise d'un grand bâtiment médiéval dont le plan des sous-sols conditionne en partie le découpage foncier moderne. L'unité 399 concerne plus particulièrement la moitié septentrionale du bâtiment médiéval auquel il faut ajouter l'annexion d'une venelle qui bordait cette construction au nord permettant l'accès aux espaces situés en cœur d'îlot, dont certains sont également intégrés à cette parcelle. La mise en place d'une vaste demeure, probablement au XVII ${ }^{\mathrm{e}}$ s. sur cette parcelle d'une superficie de $193 \mathrm{~m}^{2}$, s'est accompagnée d'une reprise totale de la façade sur rue. Cet ensemble, l'un des plus grands du quartier, est bien décrit dans un rapport d'estime de $1734^{632}$, concernant la vente d'Ignace Darene à Jean Olivier ${ }^{\mathbf{6 3 3}}$. Le rapport mentionne trois caves de grande dimension communiquant entre elles. Deux d'entre elles sont le long de la rue et occupent toute la largeur des pièces, soit $6 \mathrm{~m}$ pour l'une et 3,25 m pour l'autre. La troisième cave est disposée perpendiculairement aux autres, et sa longueur est de $11 \mathrm{~m}$ pour une largeur de $4 \mathrm{~m}$. La fouille a permis de retrouver ces trois ensembles.

La longueur de la première cave (A) est de $9 \mathrm{~m}$, délaissant en fond un espace de $2 \mathrm{~m}$ de large dévolu à l'escalier en pierres de taille. Le creusement de cette cave, qui réutilise en partie le bâtiment du Moyen Âge, a nécessité le décaissement de la ruelle ouest-est et l'éradication du puissant mur septentrional du bâtiment médiéval. Une excroissance située sous la rue de la Guirlande, plus étroite que l'espace principal, n'excède pas $2 \mathrm{~m}$ de large et 1,50 $\mathrm{m}$ de profondeur; elle est encadrée par un arc en anse de panier bâti en grand appareil de calcaire tendre particulièrement soigné. La base des murs est tapissée d'un enduit hydraulique (fig. 188). L'espace de la cave est voûté d'un berceau de blocs et moellons dont la naissance est marquée par un lit de blocs de poudingue. Le sol est carrelé de malons de terre cuite de 25 x 15 x $4 \mathrm{~cm}$. Au cours du XVIII' s., l'emprise sous la rue est condamnée par un mur caractérisé par un grand nombre de blocs taillés réutilisés dans sa maçonnerie.

$632 \mathrm{AD} 13361 \mathrm{E} 117$, fol. 540.

$\mathbf{6 3 3}$ AD13 364 E 256, fol. 1474. 
Fig. 188. Extension de la cave sous la rue de la Guirlande (cl. N. Nin/Inrap).

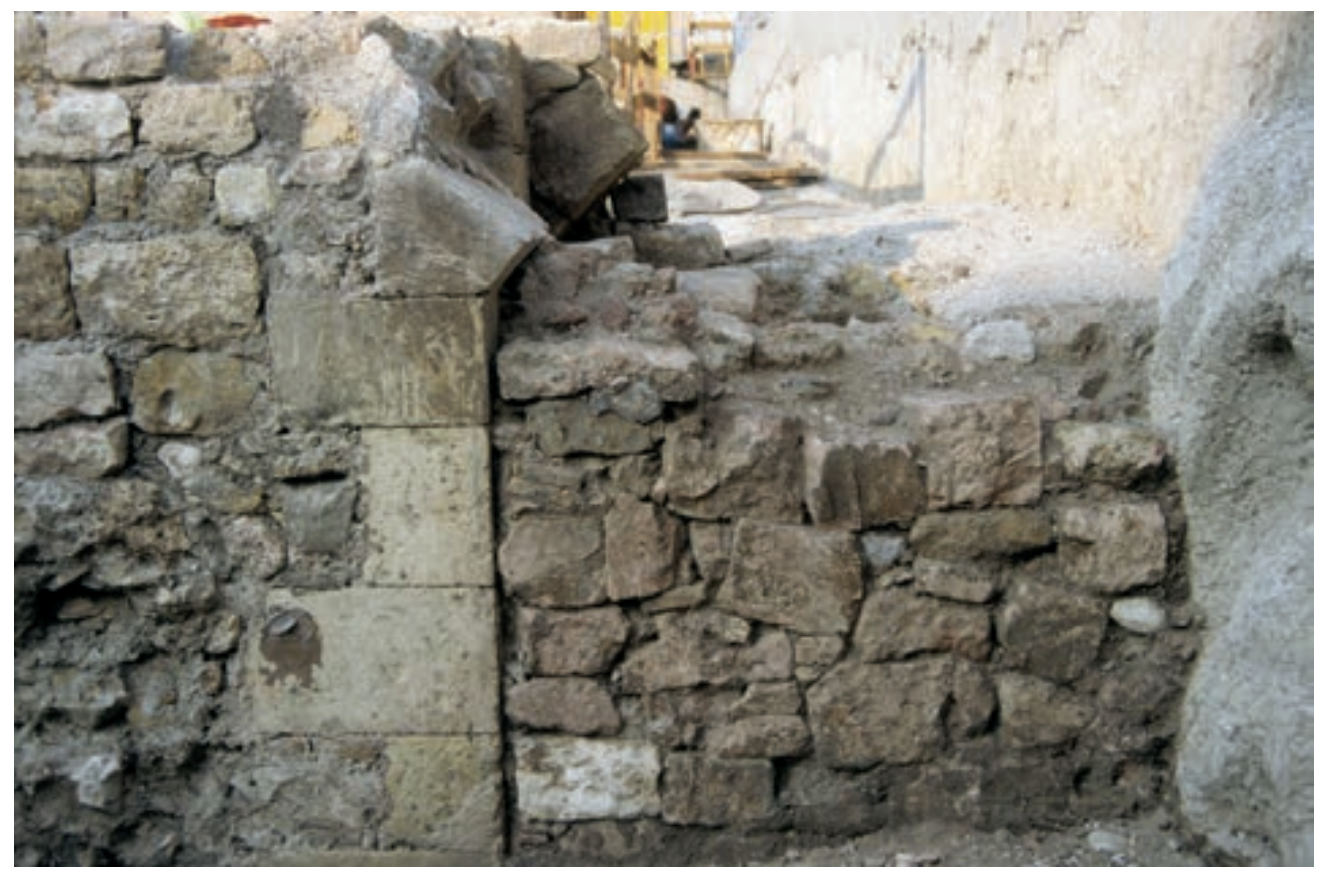

La seconde cave sur rue (B), longue de $10 \mathrm{~m}$, conserve pour limite les puissantes maçonneries médiévales. Aucune observation archéologique précise ne la concerne.

La troisième cave $(\mathrm{C})$, perpendiculaire aux deux autres, prend pour point d'ancrage le bâtiment médiéval à l'est duquel elle est aménagée. Des transformations successives caractérisent ce secteur en cœur d'îlot qui initialement n'est pas construit et devient l'enjeu de refontes foncières régulières. Dans un premier temps, l'espace est limité au nord par un mur placé dans le prolongement de la façade septentrionale. Il est pourvu d'un puits d'un diamètre interne de $90 \mathrm{~cm}$ qui entame partiellement l'épaisseur de la maçonnerie du Moyen Âge alors reprise. Dans la moitié sud de cette dernière est également percée une baie de $1,20 \mathrm{~m}$ de haut et $2 \mathrm{~m}$ de large destinée à éclairer la cave B depuis l'espace oriental toujours dénué de toute construction. De plus, une niche ou une cuve, de 1,50 x 0,40 m et tapissée d'un enduit hydraulique, est installée dans le parement du même mur. Le second état est marqué par le creusement de la cave qui ampute au sud le ciel ouvert sur plus de $2 / 3$ de sa longueur, ce dernier étant alors supporté par un mur de soutènement fait de moellons non assisés. Un petit vestibule pavé, de $1,50 \mathrm{~m}$ de côté, fait au nord la transition entre la cave ouest (B) dotée d'une porte en blocs appareillés et l'étroite cave carrelée ${ }^{634}$ au sud (fig. 189). S'ensuit une série de modifications fonctionnelles comme l'obturation de la baie et l'aménagement

634 Le module des carreaux est $26 \times 12,5 \times 3 \mathrm{~cm}$.

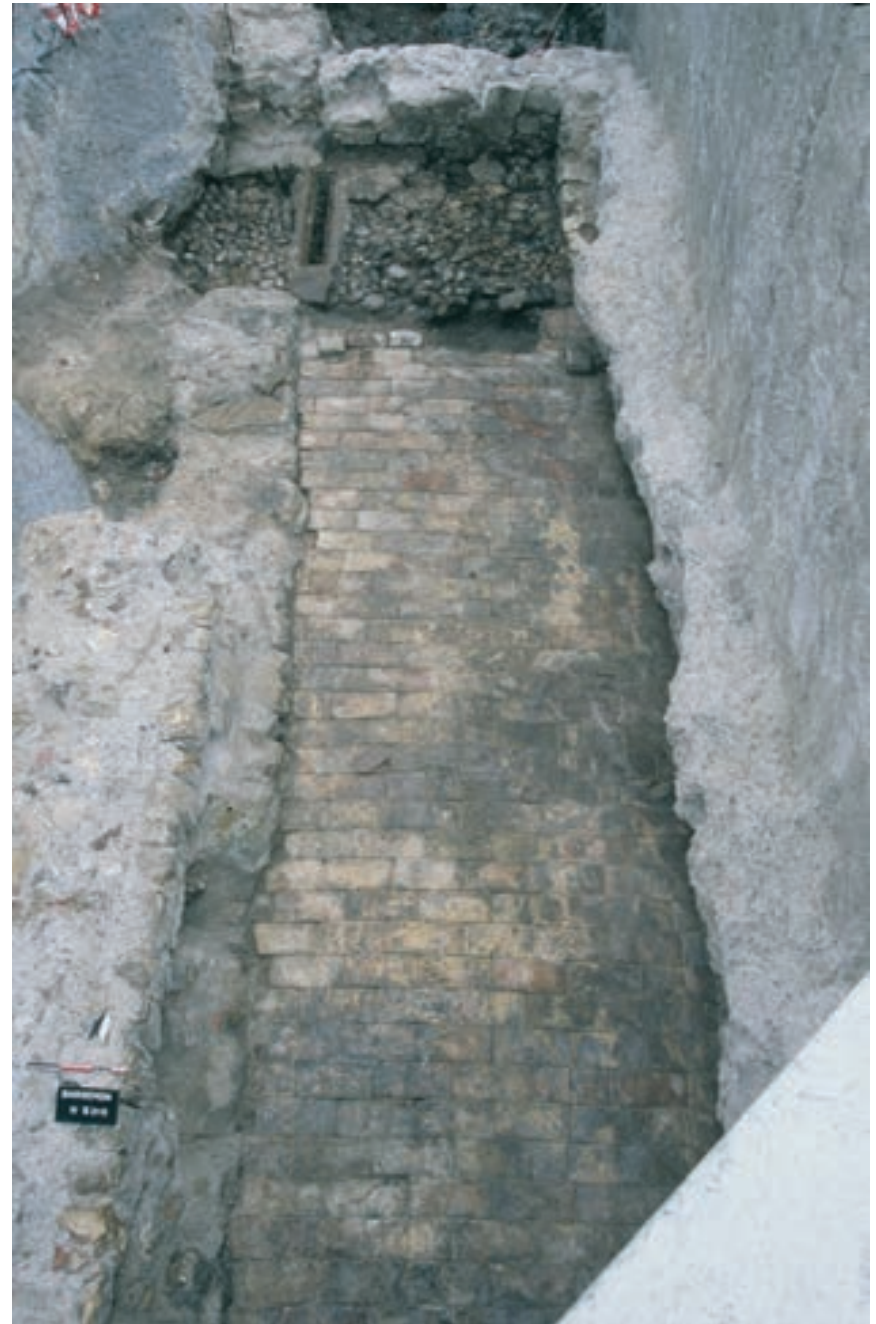

Fig. 189. Vue d'ensemble de la cave de la parcelle 399 (cl. N. Nin/Inrap) 


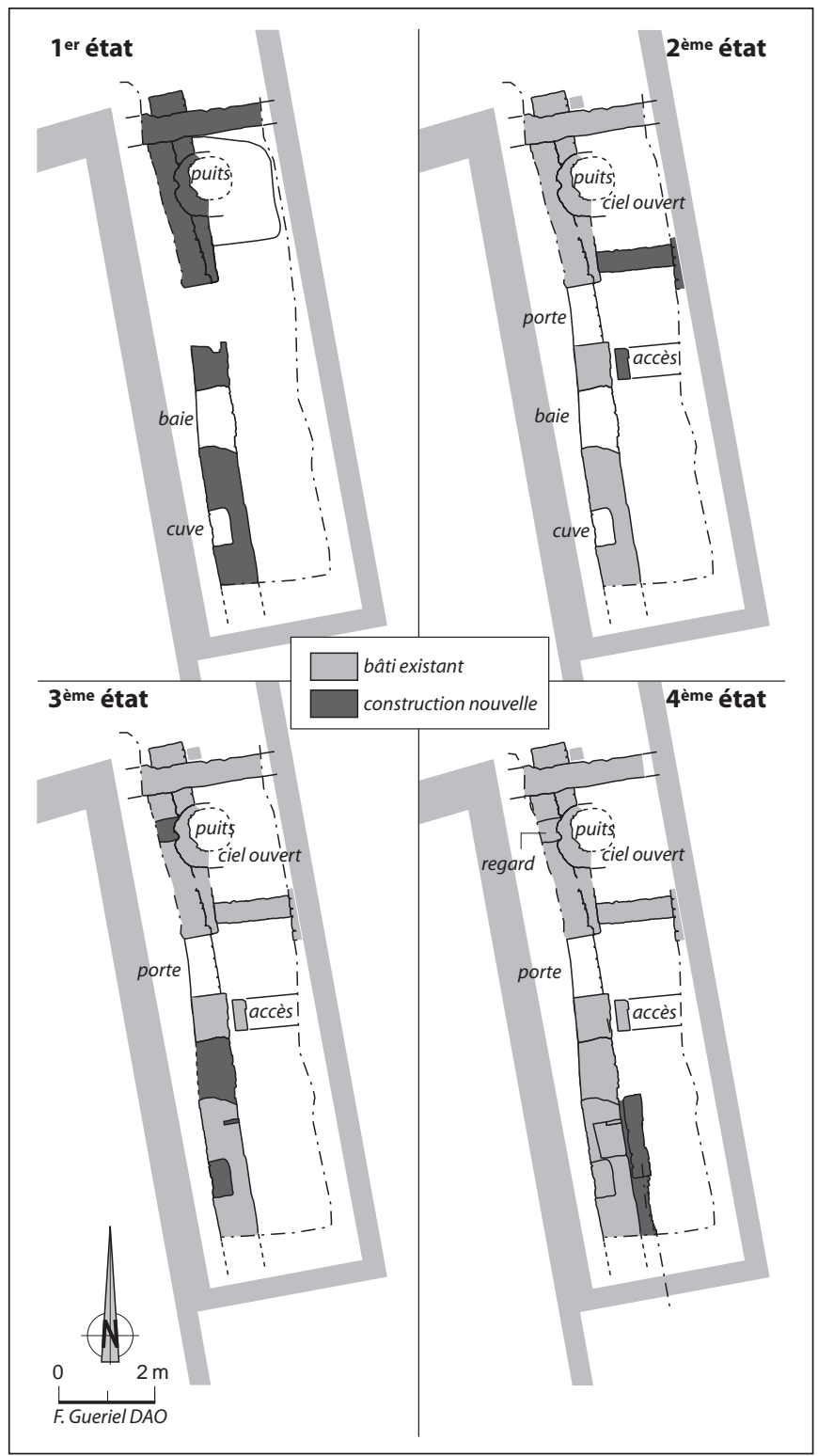

Fig. 190. Plan des états 1, 23 et 4 de la parcelle 400B (DAO F. Gueriel/Inrap).

dans le mur médiéval d'un petit regard de $20 \mathrm{~cm}$ de large à l'aplomb du puits. Les dimensions de cette cave, mentionnées dans le rapport de 1734, correspondent à une longueur de $11 \mathrm{~m}$ pour une largeur de $4 \mathrm{~m}$; ces mesures outrepassent ainsi la limite méridionale de la parcelle et traduisent la complexité dans l'imbrication de ces propriétés. Au XIX ${ }^{\mathrm{e}}$ s., cette cave est remblayée jusqu'à la naissance de la voûte, sur laquelle repose en partie les vestiges d'un bassin en grand appareil en calcaire de La Couronne (fig. 190).

L'acte de future cautelle de 1734 donne une visite précise des différents niveaux et montre une bipartition entre le corps de logis principal ayant quatre étages sur rue et les espaces arrières moins haut d'un niveau. Le rezde-chaussée garde une fonction commerçante puisque le grand vestibule (6 m par $7 \mathrm{~m}$ ) septentrional communique au sud avec une boutique également ouverte sur la rue, elle-même reliée à un magasin prenant jour dans la boutique. La largeur de ces deux dernières pièces, $5,25 \mathrm{~m}$, supérieure à celle de la cave au-dessous, s'explique par un processus original de partage de l'espace. En cœur d'îlot, la demeure comprend deux celliers ainsi qu'un ciel ouvert. Le premier étage, auquel on accède depuis le vestibule par un escalier droit comprend deux vastes salles et une cuisine, ainsi que deux chambres. Dans les trois étages suivants, nous dénombrons 11 chambres, une salle (au deuxième étage), deux cabinets et une bousquetière. L'ensemble est coiffé d'un pigeonnier et de deux décharges. Les pièces sont éclairées par des croisières placées sur la rue mesurant 2,50 m par 1,50 m, sauf au quatrième étage, sous les toits, où elles n'ont que $1 \mathrm{~m}$ de hauteur; il en est de même pour les pièces donnant sur la cour intérieure du voisin. Dans le corps de logis occidental, les hauteurs des pièces sont de $4,50 \mathrm{~m}$ au premier étage, 3,93 $\mathrm{m}$ au second, 3,62 $\mathrm{m}$ au troisième et 2,50 m au quatrième. Les pièces sur cour sont deux fois moins hautes et la présence de petits escaliers supplémentaires suppose l'existence de demi-étages.

La façade, entièrement en pierre de taille, englobe le parement de l'édifice préexistant ; ce rhabillage est fait en blocs de La Couronne parmi lesquels on compte de nombreux remplois; le tout repose en encorbellement sur un alignement de pieux. Celui-ci est continu jusqu'au droit de la limite méridionale de la parcelle qui, nous l'avons vu, a été déplacée. La construction de l'hôtel est très probablement contemporaine de l'élargissement de la parcelle qui se situerait durant le XVII ${ }^{\mathrm{e}}$ s. La fouille a montré que ce nouveau refend séparant les parcelles 399 et 398 ne repose pas sur le mur sud de la cave mais empiète sur les espaces méridionaux ( $c f$. infra $\$ 3.2 .8$.). Tout au plus pouvons-nous constater l'état de délabrement de cette construction en 1734 .

\subsubsection{La parcelle 398}

Cette parcelle borde au sud la demeure précédemment décrite et occupe, comme les deux ensembles mitoyens, une partie du grand bâtiment médiéval, dont elle ampute l'une des caves dans sa moitié nord d'une surface de presque $12 \mathrm{~m}^{2}$ ( $c f$. fig. 178). Le nouveau refend placé à moins de $1 \mathrm{~m}$ du mur nord antérieur n'est vraisemblablement pas justifié par une refonte particulière de la cave mais il sert à porter le nouveau mur de limite cadastrale présent au rez-de-chaussée. De la tranchée de fondation de cette maçonnerie provient du mobilier daté du $\mathrm{XV}^{\mathrm{e}} \mathrm{s}$., qui atteste peut être de l'ancienneté de la refonte 
parcellaire dans ce secteur et plus vraisemblablement de la fin de l'utilisation du bâtiment médiéval. Quoiqu'il en soit, l'espace au cours de XVIII' s. est carrelé par deux types de sols en terre cuite. Le plus ancien est formé de malons ${ }^{635}$ et d'un fil d'eau qui aboutit à l'ouest dans une pile monolithe de calcaire rose ${ }^{636}$; la reprise du sol, délimitée par la rigole, est réalisé à l'aide de tomettes hexagonales dépourvues d'estampille (fig. 191).

\subsubsection{La parcelle 397}

La parcelle 397 reprend l'emprise de l'espace méridional du grand bâtiment du Moyen Âge. Aucun document d'archive ne concerne cette unité qui de plus n'a été observée que dans sa moitié occidentale lors de la fouille. L'espace, semi enterré à l'origine, est repris par une cave moderne qui s'étend alors partiellement sous la rue en empiétant sur un tiers de sa largeur comme l'y autorisent les arrêtés municipaux. La cave, profonde de $6,50 \mathrm{~m}$ pour une largeur de $6 \mathrm{~m}$, n'occupe donc pas la superficie totale de la pièce médiévale qui est limitée à l'est par une maçonnerie hétérogène issus d'un cloisonnement ultérieur. Les puissantes maçonneries médiévales au nord et au sud sont en partie rechemisées par les retombées de la nouvelle voûte en berceau surbaissée faite en matériaux grossièrement dressés et d'origine pétrographiques diverses.

L'accès au sous-sol s'effectue par un escalier à volet tournant dont les marches monolithes sont en calcaire de La Couronne, et sous le repos duquel est aménagée une petite niche de $44 \times 50 \mathrm{~cm}$. La cave est équipée également d'un puits placé dans l'angle nord-ouest qui est construit au moyen de moellons et fragments de carreaux de terre cuite en réemploi noyés dans du mortier. Le cuvelage, d'un diamètre interne de $73 \mathrm{~cm}$, se poursuit au moins jusqu'au rez-de-chaussée : une ouverture d'accès est aménagée en blocs de moyen appareil bûchés et présentant une feuillure. La base du puits est enduite d'un béton hydraulique. Enfin, l'espace est pavé de deux sols de galets jointifs, disposés aléatoirement à l'exception d'une bordure d'éléments plus important placée le long des murs. On signalera une usure plus marquée sur le trajet allant de l'escalier au puits (fig. 192). À l'est de la cave a été aperçue sur une très petite surface une structure concave appuyée contre le mur oriental et qui pourrait s'apparenter à un four.

Pour répondre à des problèmes de stabilité de l'immeuble, sont entrepris au cours du XVIII' $\mathrm{s}$. des travaux de confortement en sous-œuvre dans la cave. La partie

635 Dimensions des malons : $22 \times 8 \times 3 \mathrm{~cm}$.

636 Cette dernière mesure $60 \times 49 \mathrm{~cm}$ les bords font 6 à $8 \mathrm{~cm}$ d'épaisseur et dans un angle une bonde de $6 \mathrm{~cm}$ est creusée. sous la rue est ainsi condamnée par un puissant mur composé de moellons et de blocs non assisés et par un contrefort central avec lequel il est chaîné. Un second contrefort formant le pendant du précédant vient étayer le mur oriental ( $c f$. fig. 104).

\subsubsection{Les espaces en cœur d'îlot, les pièces $401 B$ et $420 A$}

Ces espaces sont traités à part car ils constituent l'illustration parfaite de l'imbrication des propriétés au sein d'un même immeuble et témoignent de la difficile confrontation entre l'interprétation des vestiges et le découpage cadastral napoléonien. L'observation des circulations de ces constructions mises en place au XVI ${ }^{\mathrm{e}} \mathrm{s}$. semble indiquer que ces pièces sont rattachées aux maisons situées rue Torte (hors emprise) par lesquelles elles sont accessibles, et qu'elles relèvent donc initialement de la parcelle 420. Ces espaces fossilisent des constructions médiévales, dont elles reprennent le tracé ou sur lesquelles elles s'adossent. Leur emplacement en cœur d'îlot conduit à s'interroger sur l'usage de ces espaces car le niveau de leur sol d'utilisation ne correspond pas à celui d'une cave, mais s'apparente plutôt à celui d'un rez-de-chaussée voire d'entresol.

\section{L'espace $401 B$}

Décentré par rapport à l'axe de la parcelle 400, cet espace s'étend à l'origine sur toute la largeur de la parcelle 401 avec laquelle elle ne communique pas, soit une surface de 6,5 x $5 \mathrm{~m}$. En revanche, un accès montre qu'il existe un lien avec la pièce qui la borde immédiatement au sud (espace 420A). La difficulté à rattacher avec certitude cet espace à une parcelle ou une autre s'explique par le fait que son plan reprend en partie celui d'une salle du $\mathrm{XIV}^{\mathrm{e}} \mathrm{s}$. et n'obéit donc pas au redécoupage foncier moderne. Aussi ce secteur est l'un des espaces les plus soumis à l'évolution des parcelles mitoyennes.

Cette salle correspond à un rez-de-chaussée et seul demeure l'angle sud-est, matérialisé par des murs posés sur des maçonneries médiévales. Leurs élévations, d'une largeur de $0,58 \mathrm{~m}$, sont formées d'un double parement assisé de moellons et cailloux retouchés disposés en boutisse et liés au mortier sableux. Du refend occidental ne sont conservées que ses profondes fondations hautes de 0,90 m, composées d'une maçonnerie de cailloux et moellons bruts. Enfin on peut suggérer que cette pièce s'étendait au nord jusqu'à un puits appareillé qu'elle englobait. Au sud s'ouvre sur la pièce 420A une porte d'une largeur de 1,10 m dont les piédroits sont en blocs taillés et le seuil en carreaux en terre cuite disposés de chant, identiques à ceux utilisés par le sol construit. 


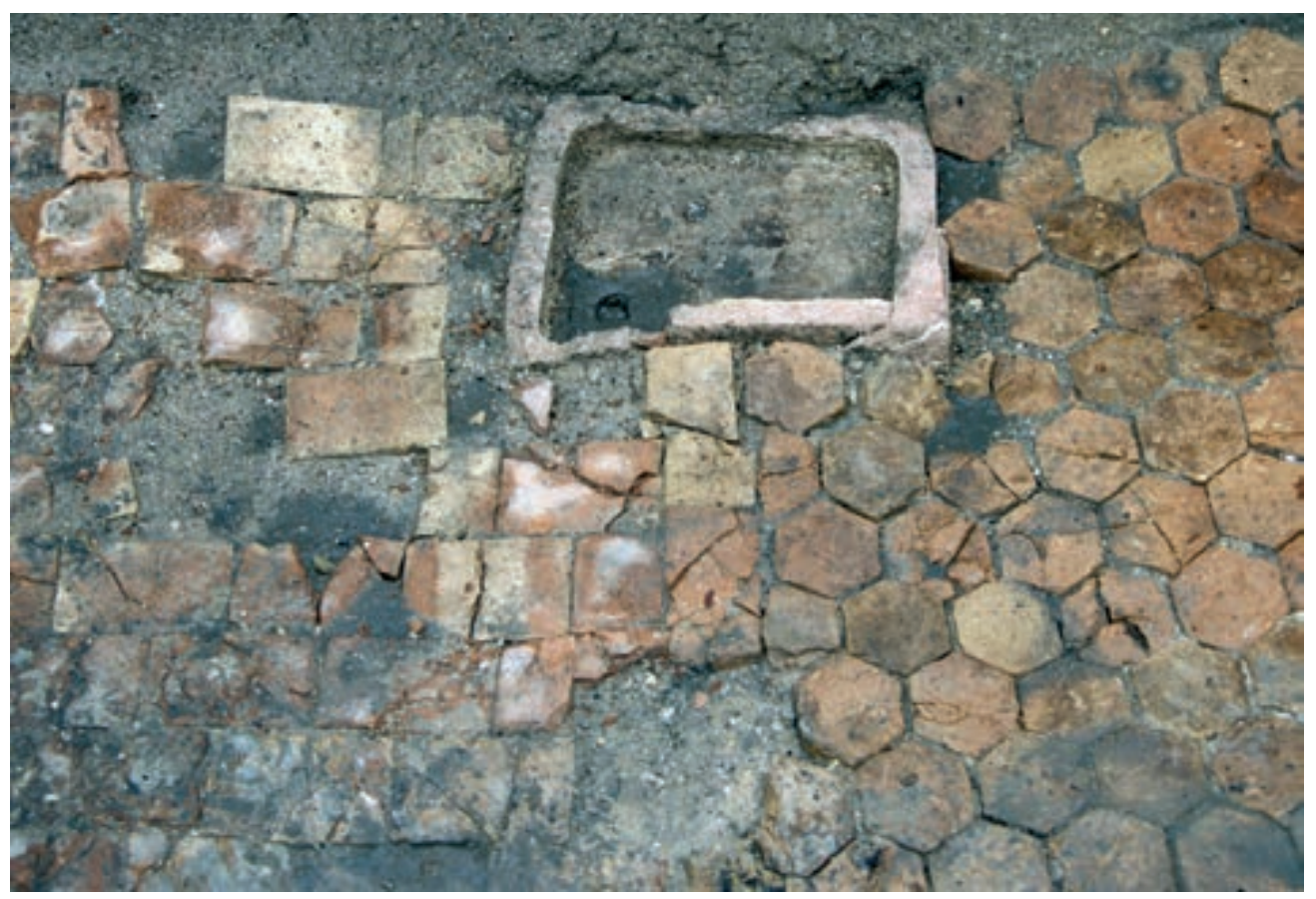

Fig. 191. Détail des sols et de la pile de la parcelle 398 (cl. F. Parent/Inrap).

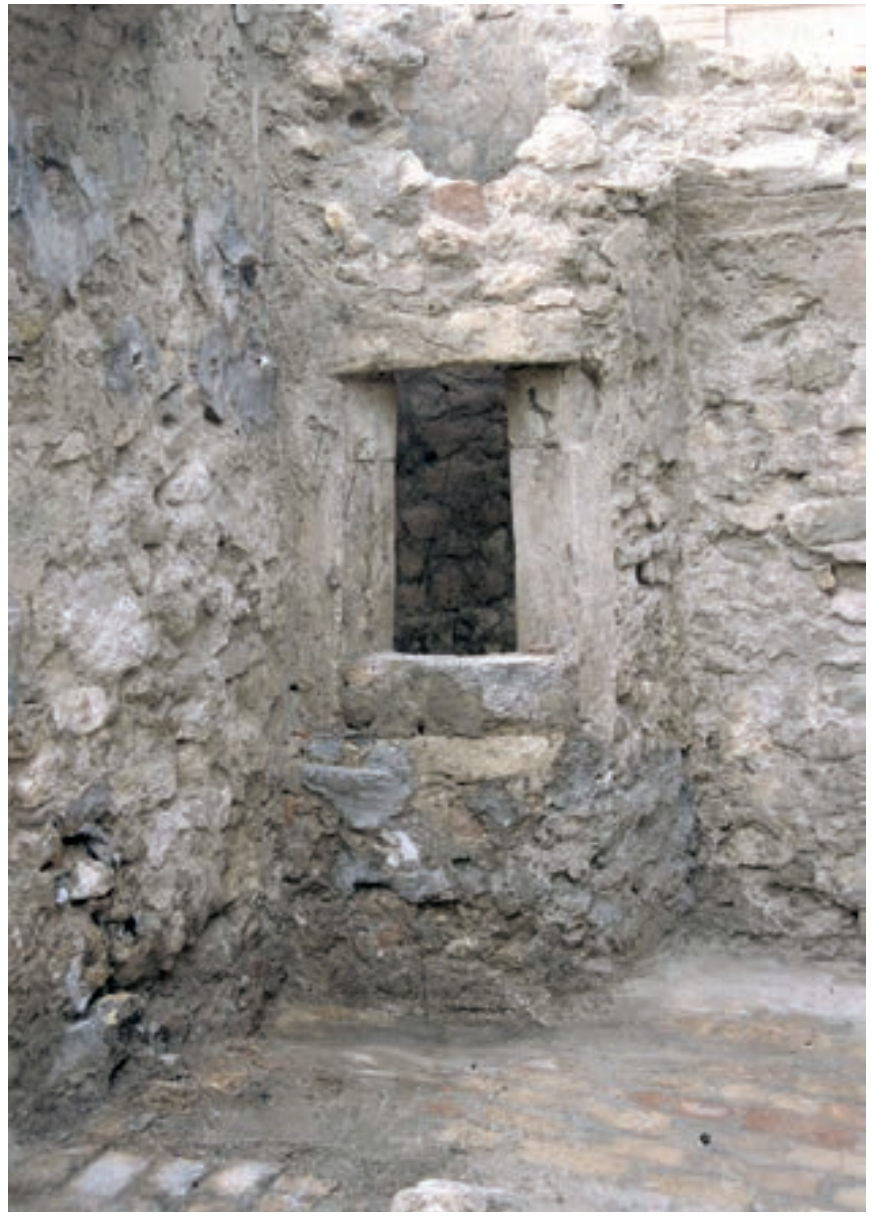

Fig. 192. Vue du puits de la parcelle 397 depuis le sud (cl. F. Parent/Inrap).
$\grave{A}$ une première transformation du mur occidental dû au creusement de la cave de la parcelle 400 , succède une série de changements provoqués par l'extension de la cave de la parcelle 402 au détriment de l'espace étudié. Une nouvelle limite septentrionale réduit la pièce qui ne mesure plus que $22 \mathrm{~m}^{2}$; le puits reconstruit relève alors de la cave 402C. La communication avec l'espace sud est condamnée ; l'accès s'effectue maintenant à l'est par l'intermédiaire d'un nouvel escalier établi durant la seconde moitié du XVIII ${ }^{\mathrm{e}}$ s. et dont ne demeure que deux dalles. Ces modifications entraînent des reprises ponctuelles du sol carrelé et une homogénéisation des parois est entreprise avec l'application d'un enduit sur le carrelage et les murs.

Durant le dernier quart du XVIII ${ }^{e}$ s., le sol est rehaussé d'une quarantaine de centimètres par l'apport d'un remblai composé de matériaux hétérogènes issus de démolition et d'un dépotoir qui supporte un nouveau carrelage (fig. 193 et fig. 194).

La fouille a montré la complexité d'attribuer ces vestiges à l'une ou l'autre des parcelles modernes. Le premier état de cet ensemble laisse penser qu'il est étroitement associé à la parcelle 420 avec laquelle il communique et qu'il relève probablement d'un même propriétaire. L'obturation de cet accès, mené conjointement à l'extension de la cave nord, indique alors qu'il peut être rattaché à la parcelle 401, mais un état des lieux de 1734 montre que les étages communiquent avec l'immeuble de la parcelle 400 . 


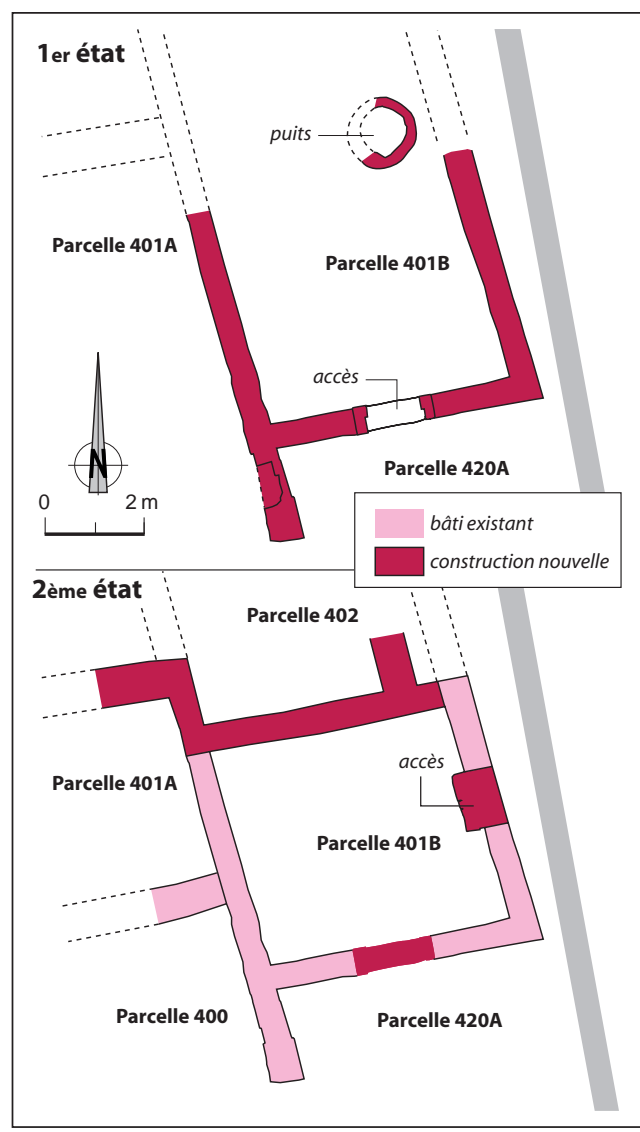

Fig. 193. Plan de l'état 1,2 de la parcelle 401B (DAO F. Gueriel/Inrap).
Fig. 195. Plan des états 1,2 et 3 des parcelles 401B et 420A (DAO F. Gueriel//nrap).

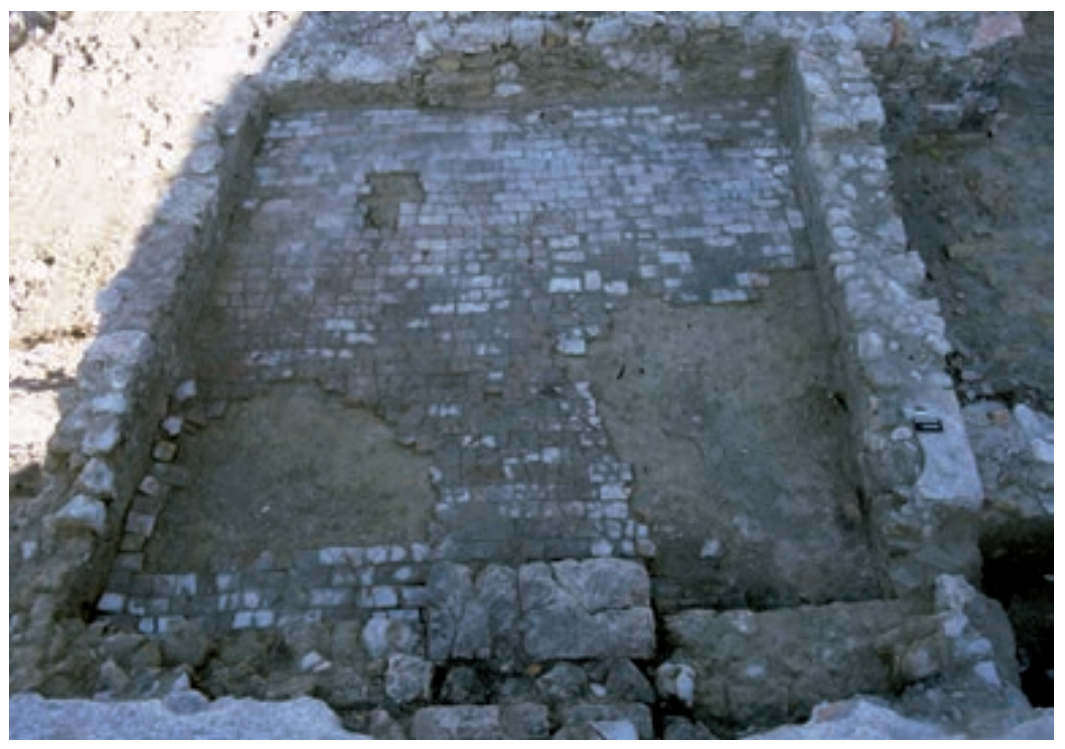

Fig. 194. Vue d'ensemble de la cave de la parcelle 401B (cl. F. Parent/Inrap).

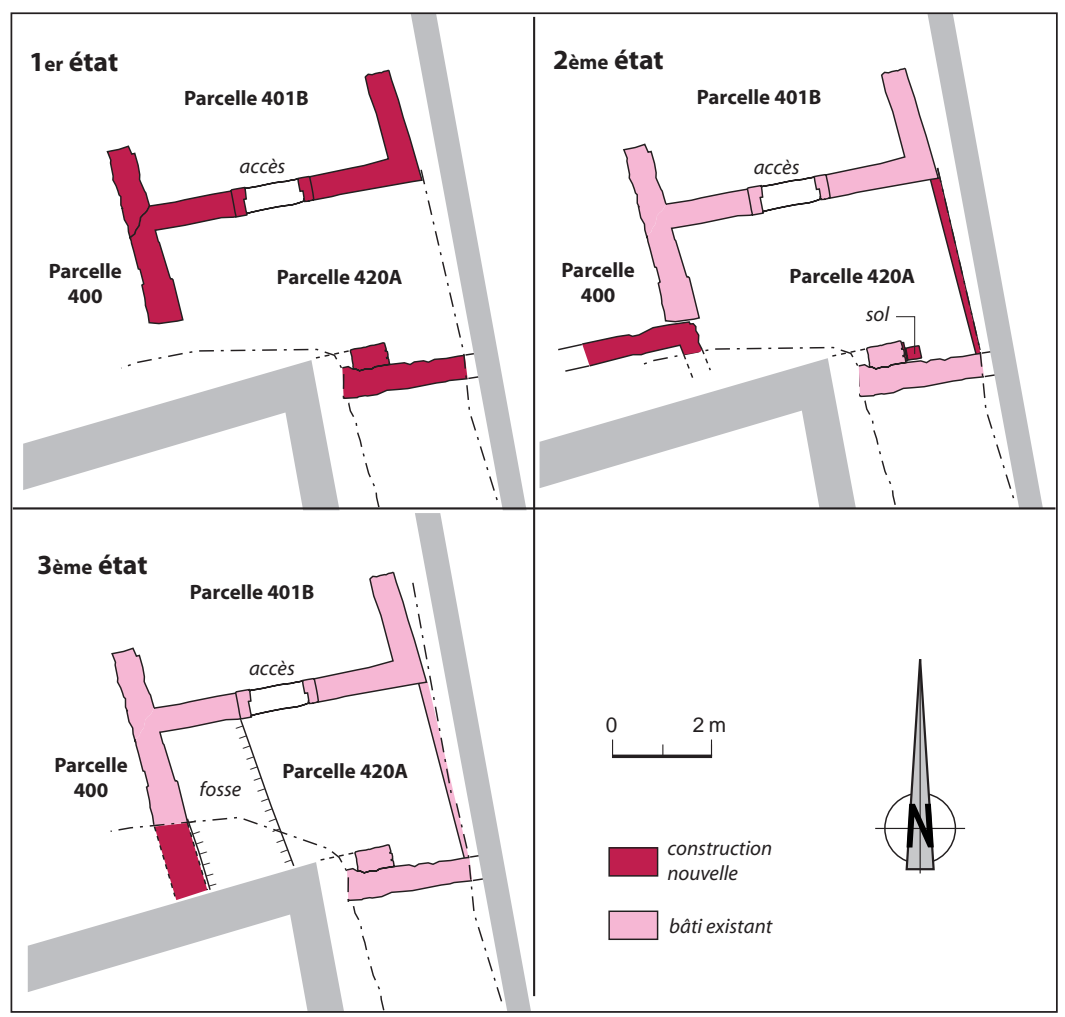

inconnu, mais il devait probablement s'appuyer contre le mur nord d'un grand bâtiment médiéval. Un pilier forme la transition de ce dernier avec la maçonnerie méridionale qui mesure $0,55 \mathrm{~m}$ de large et se compose d'un appareil régulier de moellons de calcaire en boutisse liés au mortier jaune. La limite orientale est inconnue pour cet état de même que le sol d'utilisation.

Dans une seconde phase est réalisée la fermeture de la communication avec le secteur 401B, en liaison avec un transfert probable de propriété de ce dernier. 

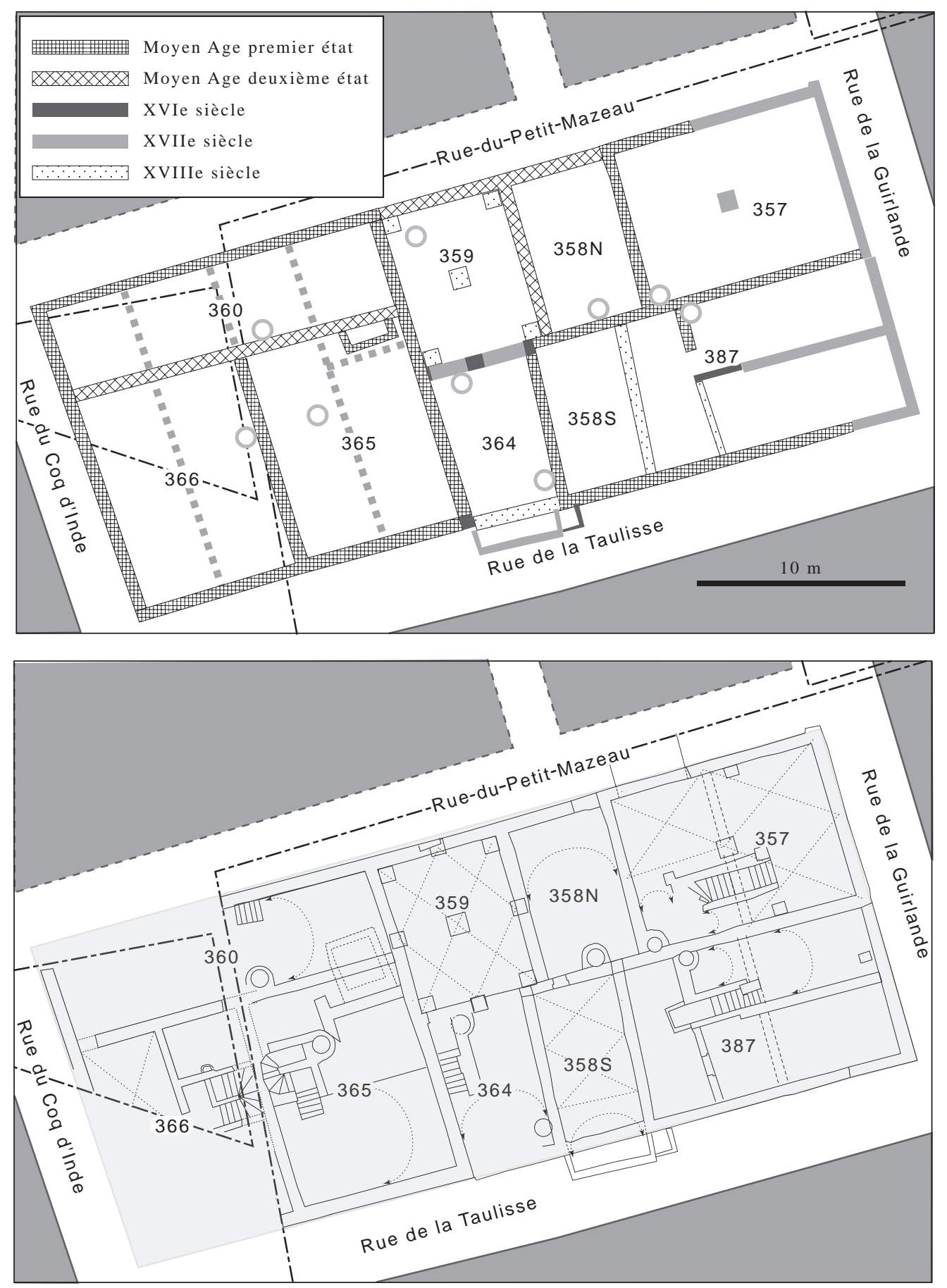

Fig. 196. Plan phasé et plan des vestiges de l'îlot II (DAO B. Sillano/Inrap)

Conjointement est construit un nouveau mur à l'est réduisant la largeur de l'espace à $5,20 \mathrm{~m}$. Son élévation ne conserve qu'une assise de moellons portée par un blocage profond de $1,40 \mathrm{~m}$. Un nouvel accès localisé dans l'angle nord-est est matérialisé par un emmarchement fait d'un bloc taillé de La Couronne bordé de deux moellons. La transition entre ces deux constructions est réalisée par l'intermédiaire d'une rigole matérialisée par une pierre surcreusée. Enfin est disposé un nouveau carrelage en terre cuite de module carré ${ }^{637}$.

Dans un état ultime d'occupation est établie, dans l'angle nord-ouest de la pièce, une importante fosse destinée au stockage de la chaux qui détruit en partie le sol de malons. Son creusement de plus de 2,90 m pour

$63723,5 \times 23 \times 2 \mathrm{~cm}$ 
$1,75 \mathrm{~m}$ et $1 \mathrm{~m}$ de profondeur percute une cuve médiévale qu'il réutilise pour le stockage de la chaux. Dans un second temps, cette fosse a servi de réceptacle à un dépotoir de céramiques, dont certaines sont complètes et datées de la seconde moitié du XVIII ${ }^{\mathrm{e}} \mathrm{s}$.

\section{3. Îlot II : au sud du Petit Mazeau (B. Sillano)}

Avec une largeur de $15 \mathrm{~m}$, l'îlot situé au sud de la place du Petit-Mazeau illustre parfaitement la trame médiévale (fig. 196). À son extrémité occidentale, les quatre parcelles mises en évidence par la fouille sont disposées transversalement, « en lanière », et déterminent le module qui, démultiplié, aboutit à un îlot tout en longueur. À la fin du Moyen Âge ou au début de l'Époque moderne, la forme de ces parcelles est modifiée afin de les adapter à un nouveau type d'habitat, alors que l'îlot conserve son emprise. Le long de la place du Petit-Mazeau, au nord, s'alignent les auberges tandis que sur la rue de la Taulisse, très secondaire, se trouvent les annexes, comme les écuries. Compte tenu des liens qui unissent souvent les immeubles entre ces deux côtés, nous étudierons cet îlot d'ouest en est, en passant en revue alternativement les parcelles du nord et du sud.

\subsubsection{Parcelle 366}

Obtenues par adjonction de deux parcelles «en lanière » médiévales diminuées du tiers septentrional de leur surface, les parcelles 365 et 366 sont de même module, 7,50 m par $10 \mathrm{~m}$. La seconde, située à l'angle de l'îlot, n'a pas été fouillée dans sa totalité (Mellinand 2005, p. 187-199) et aucun texte d'archive s'y référant n'a été trouvé. L'espace est subdivisé en trois parties. La plus importante, à l'angle des deux rues, occupe quasiment la moitié sud de la parcelle, mais elle est hors d'emprise de fouille. L'autre moitié est subdivisée en deux parties égales, de $5 \mathrm{~m}$ par 3,50 m, dont l'une, en cœur d'îlot, correspond à une cour et l'autre, contre la rue traverse, à une pièce (fig. 197).

La cour est elle-même subdivisée en deux, au droit du puits dont elle hérite de l'époque médiévale. Au nord, le sol, pavé de galets, est daté du XVIII ${ }^{\mathrm{e}}$ s. grâce au mobilier du remblai qui le supporte. Il est relié à la pièce à l'ouest par une ouverture large de 1,50 m dont il ne reste que l'empreinte et qui a été bouchée dans un second temps. $\mathrm{Au}$ sud est installé un escalier permettant l'accès à la cave occidentale (fig. 198). Large de $1 \mathrm{~m}$, il se compose de courtes volées droites de 5 marches en calcaire de La Couronne en remploi, de $35 \mathrm{~cm}$ de large, et de demitours aux extrémités. Nous avons là un très bel exemple des vizettes mentionnées dans les textes. Les murs qui

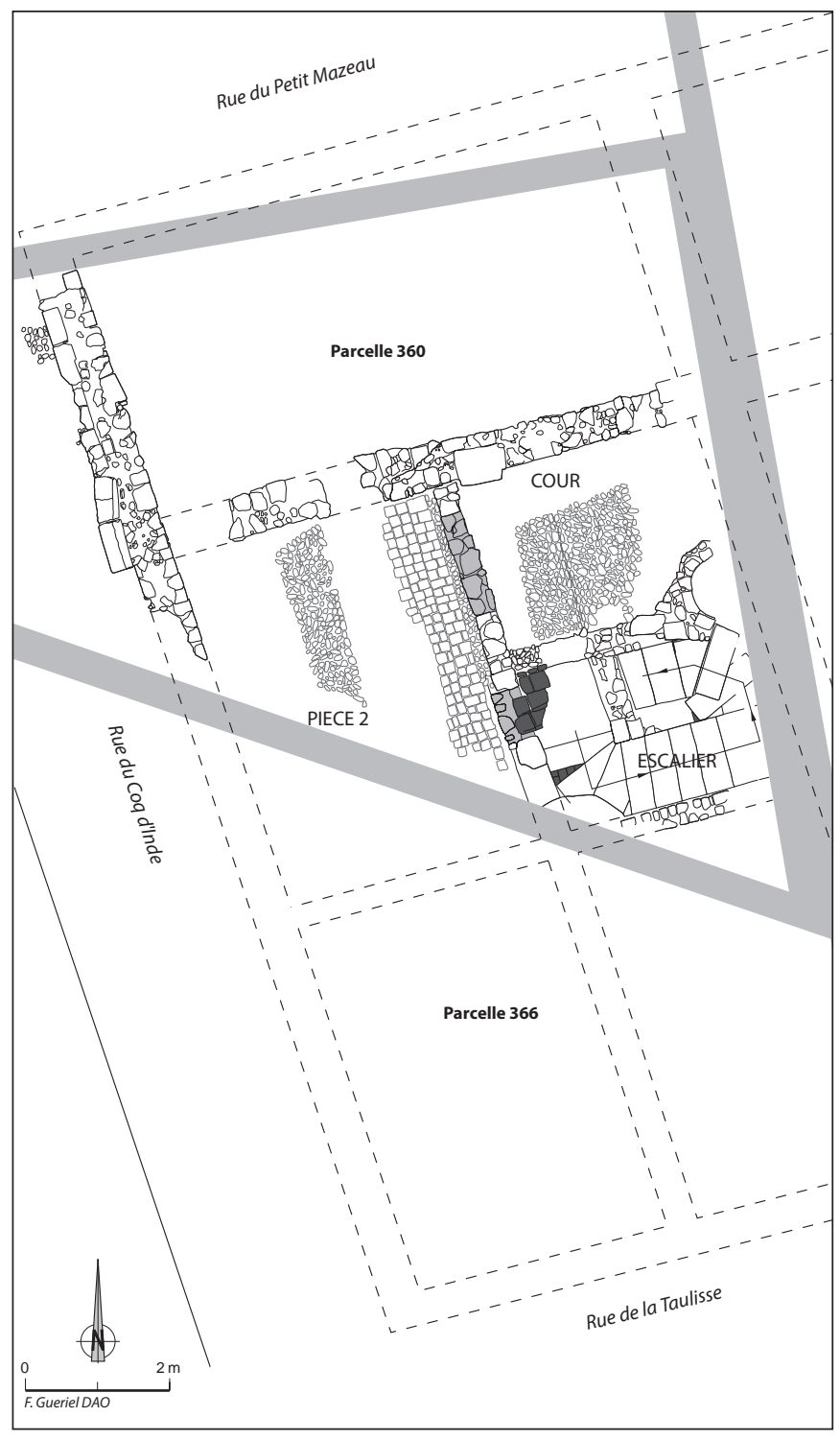

Fig. 197. Plan des vestiges des parcelles 360 et 366 (DAO F. Gueriel/Inrap).

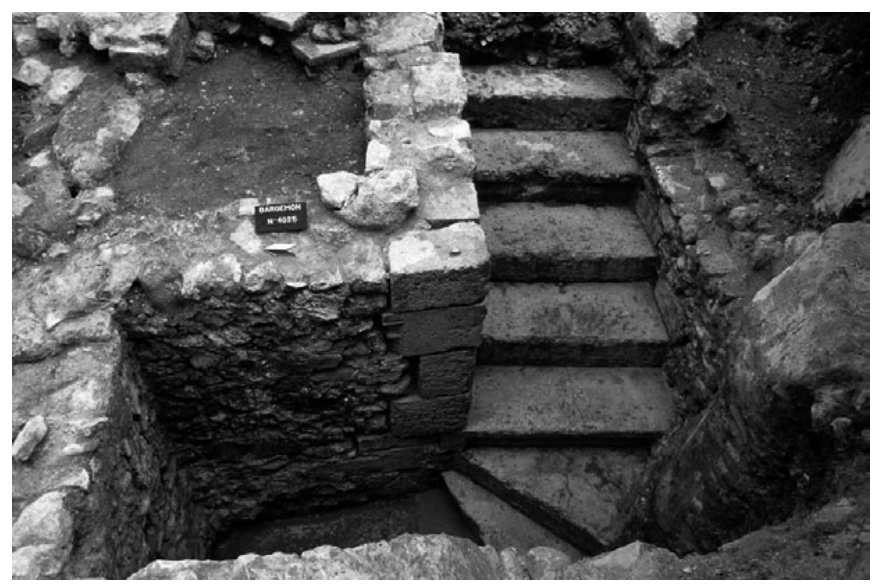

Fig. 198. L'escalier de la parcelle 366 (cl. T. Maziers/Inrap). 


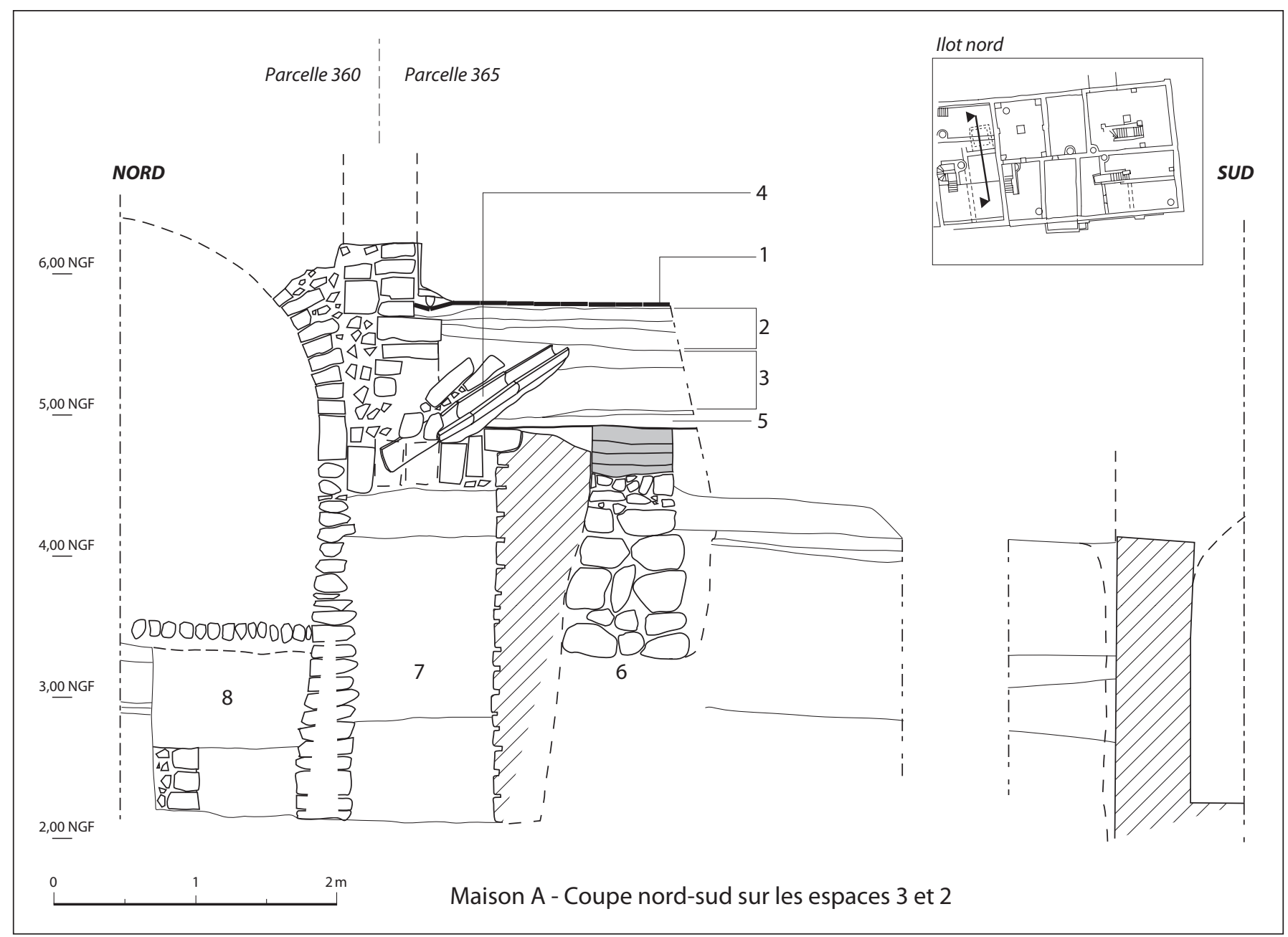

Fig. 199. Coupe nord-sud des structures des parcelles 360 et 365 (DAO R. Thernot/Inrap).

l'encadrent sont faits de matériaux divers, sauf le châ̂nage d'angle en pierre de taille en remploi. Une ouverture, au rez-de-chaussée, permet l'accès à la pièce occidentale. Elle n'a conservé que la base de ses piédroits, en calcaire coquillier taillé et mesure $0,80 \mathrm{~m}$ de large. Le palier est pavé de carreaux de 25 par $26 \mathrm{~cm}$, tout comme le seuil. Au sous-sol, une porte de $1 \mathrm{~m}$ de large accède à la cave. Intégralement conservée, elle mesure 1,80 m de haut et possède un arc en plein-cintre en calcaire coquillier, alors que les piédroits ne sont pas habillés. Face à cette porte, le couloir qui la relie à l'escalier possède encore une voûte plein cintre en briquettes dont le tas de charge a livré du mobilier du milieu du XVII ${ }^{\mathrm{e}} \mathrm{s}$.

Le sol de la pièce occidentale associe une calade, qui semblait couvrir originellement tout l'espace, et un pavement le long mur de refend oriental dont il n'est séparé que par une mince bande de galets. Il s'agit de pavés cubiques de dimensions variables (environ $15 \mathrm{~cm}$ de côté) disposés selon au moins deux bandes, larges de $30 \mathrm{~cm}$. Au-dessous, une cave est installée sur toute l'emprise de la pièce. Ses murs sont construits en sous-œuvre et deux niveaux de calade successifs occupent le sol. Le premier, qui s'étend également dans le petit couloir d'accès, remonte au XVII ${ }^{\mathrm{e}}$ ou XVIII ${ }^{\mathrm{e}}$ s., alors que le second est daté du $\mathrm{XIX}^{\mathrm{e}} \mathrm{s}$. La pièce est couverte d'une voûte d'arêtes en briques qui repose sur des murets d'ancrage à l'est et à l'ouest. Dans les angles, le tas de charge est fait de pierres liées au mortier et offre une surface plane.

\subsubsection{Parcelle 365}

À la différence de sa jumelle à l'ouest, la parcelle 365 n'est pas placée dans un angle d'îlot ce qui a une incidence sur son agencement. Elle a été fouillée intégralement (Vecchione 1997, p. 6-8), mais les observations sur la cave demeurent restreintes en raison des contingences de la fouille (stockage des déblais). Aucun texte d'archive y faisant référence n'a été trouvé.

Les constructions d'Époque moderne débutent avec une vaste campagne de travaux. Le préambule est le dérasement des structures médiévales, en particulier les murs de refend (fig. 199, $n^{\circ} 6$ ) des deux îlots accolés, 
puis un léger remblaiement (fig. $199, n^{\circ} 5$ ) qui a livré du mobilier du $\mathrm{XVI}^{\mathrm{e}} \mathrm{s}$. Puis les murs limitant la construction sont systématiquement repris. Au sud, les extrémités du mur antérieur sont refaites avec des moellons de pierre froide alors que la partie centrale est doublée, afin de supporter une élévation plus haute. À l'ouest, il semble en être de même alors qu'à l'est l'élévation réutilise des moellons de calcaire blanc. Au centre de l'espace est aménagé le soubassement de l'escalier en matériaux en remploi. Les sols associés à cette phase ont été éliminés lors du creusement de la cave.

À l'est de l'escalier, l'espace n'est pas excavé et il semble former une vaste cour intérieure, comme la présence de deux canalisations successives, qui se jettent dans l'ancienne «glacière » médiévale (fig. 199, $\left.n^{\circ} 7\right)$ réutilisée en puits perdu, le suggère. La première est faite avec deux parements de moellons et fond en schiste, l'autre (fig. 199, $\mathrm{n}^{\circ} 4$ ) avec des tuiles rondes disposées en fond comme en couverture puis enduites de bitume. Entre ces deux structures, une courte phase de remblaiement (fig. 199, $n^{\circ} 3$ ) est datée par le mobilier de la fin du XVII ${ }^{\mathrm{e}} \mathrm{s}$. L'ensemble est scellé par un remblai (fig. 199, $\mathrm{n}^{\circ}$ 2) puis par un sol de terre cuite (fig. 199, $\left.n^{\circ} 1\right)$ datés du début du XVIII ${ }^{\mathrm{e}} \mathrm{s}$. Un placard associé à ce niveau suggère que l'espace ouvert soit transformé en pièce d'habitation.

Au sud, la cave est probablement installée au XVII $\mathrm{s}$. Ses murs, construits en sous-œuvre, sont faits de moellons de calcaire, tuf et grès grossièrement assisés et à joints épais. Elle est couverte d'une voûte plein cintre de petits moellons et son dernier état de sol est un pavement de galets. L'escalier d'accès, tout d'abord droit, est modifié dans un second temps par installation d'une volée semi tournante alors que dans le même temps le puits est à nouveau cuvelé.

\subsubsection{Parcelle 360 : le Logis du Coq d'Inde, une parcelle toute en longueur}

Placée à l'angle de l'îlot, en vis-à-vis du Petit Mazeau, cette parcelle a la particularité d'être non seulement très longue (15 m par 4,5 m), mais aussi d'être disposée parallèlement à la rue principale. Elle a été fouillée sur deux opérations consécutives (Vecchione 1997, p. 6-8; Mellinand 2005, p. 187-189). Un texte d'archive y fait référence, sous l'appellation du Logis du Coq-d'Inde ${ }^{638}$. Pour la moitié ouest, la fouille se limite au mur de façade sur la rue du Coq-d'Inde. Un placage en calcaire de La Couronne disposé à l'extérieur du mur dénote un

$\mathbf{6 3 8}$ Lorsque l'on sait l'affection que portent les auberges aux animaux comestibles comme appellation, on peut supposer que c'est l'auberge qui a donné le nom à la rue traverse et non l'inverse. épaississement de la structure en prévision d'une élévation des murs. Il ne peut pas être daté. Un refend semble prendre la place d'une des limites de parcelle médiévale, dans l'alignement du mur mitoyen des parcelles 366 et 365 . Aucun sol du début de l'Époque moderne n'est conservé à cause de la cave qui occupe toute la moitié orientale de la parcelle. Ses murs, installés en sous-œuvre, sont faits de petits moellons, cailloux et galets ennoyés dans un mortier gras. Une voûte en berceau plein cintre, faite de moellons bien équarris, la recouvre entièrement (cf. fig. 199). Son sol est caladé, avec fil d'eau central, et repose sur un épais remblai qui a livré du mobilier attribuable au milieu du XVII ${ }^{e}$ s. L'accès se fait depuis la pièce à l'ouest par un escalier droit accolé à la façade alors qu'un puits est placé sur le mur opposé.

La vente que fait le sieur de Valbelle en $1654^{639}$ concerne deux maisons contiguës qui confrontent à l'est le Logis de la Taulisse, localisé sur la parcelle 358, au nord la «rue tirant au petit Mazeau », à l'ouest la «rue tirant à la place $d u$ palais royal ». Cet ensemble correspond donc aux parcelles 359 et 360 . L'année d'après est établi un rapport de future cautelle ${ }^{640}$. Au rez-de-chaussée, se trouve une boutique, ou magasin, à l'angle des rues, qui mesure de $4 \mathrm{~m}$ par $7 \mathrm{~m}$ et une autre de $5,25 \mathrm{~m}$ par $4 \mathrm{~m}$. L'accès à la grande salle se fait par trois portes, deux sur la rue du Mazeau, avec encadrement en pierre de taille, l'autre sur la rue du Coq-d'Inde, en mallons. L'autre boutique possède une porte en pierre de taille ainsi qu'un «petit fourneau servant pour les maistres pastissiers ». Aux étages, ces pièces sont surmontées d'autres de dimensions identiques, avec lesquelles elles n'ont pas de communication, auxquelles s'ajoutent une vizette placées entre elles et deux cabinets, d'environ $2 \mathrm{~m}$ par $2 \mathrm{~m}$, dont l'un est éclairé par une cour intérieure. Nous pouvons ainsi restituer l'agencement de la parcelle 360, avec des salles superposées sur la moitié occidentale et le reste occupé par les autres pièces et l'escalier (fig. 200). Les deux ailes de la parcelle sont donc indissociables ce qui prouve qu'elle est une et indivisible. La seule mention de l'autre maison est un étage « a plein pied du plus hault du corps de maison » précédent, situé " sous le toit et du costé de Levant joignant le logis de la Taulisse » et auquel on accède «par trois tours de vizette qui a son entrée et issue à la rue du costé de tresmontane ». En d'autres termes, les trois tours d'escalier correspondent aux trois étages et l'accès se fait par une entrée différente de la précédente. La deuxième maison se réduit donc à une pièce au dernier étage de l'immeuble voisin et non à la parcelle 359 en entier. Les dimensions de la cave correspondent par ailleurs à celle de la parcelle 360 et non à sa voisine.

639 AD13 353 E 94, fol. 1186. 640 AD13 353 E 95, fol. 96. 


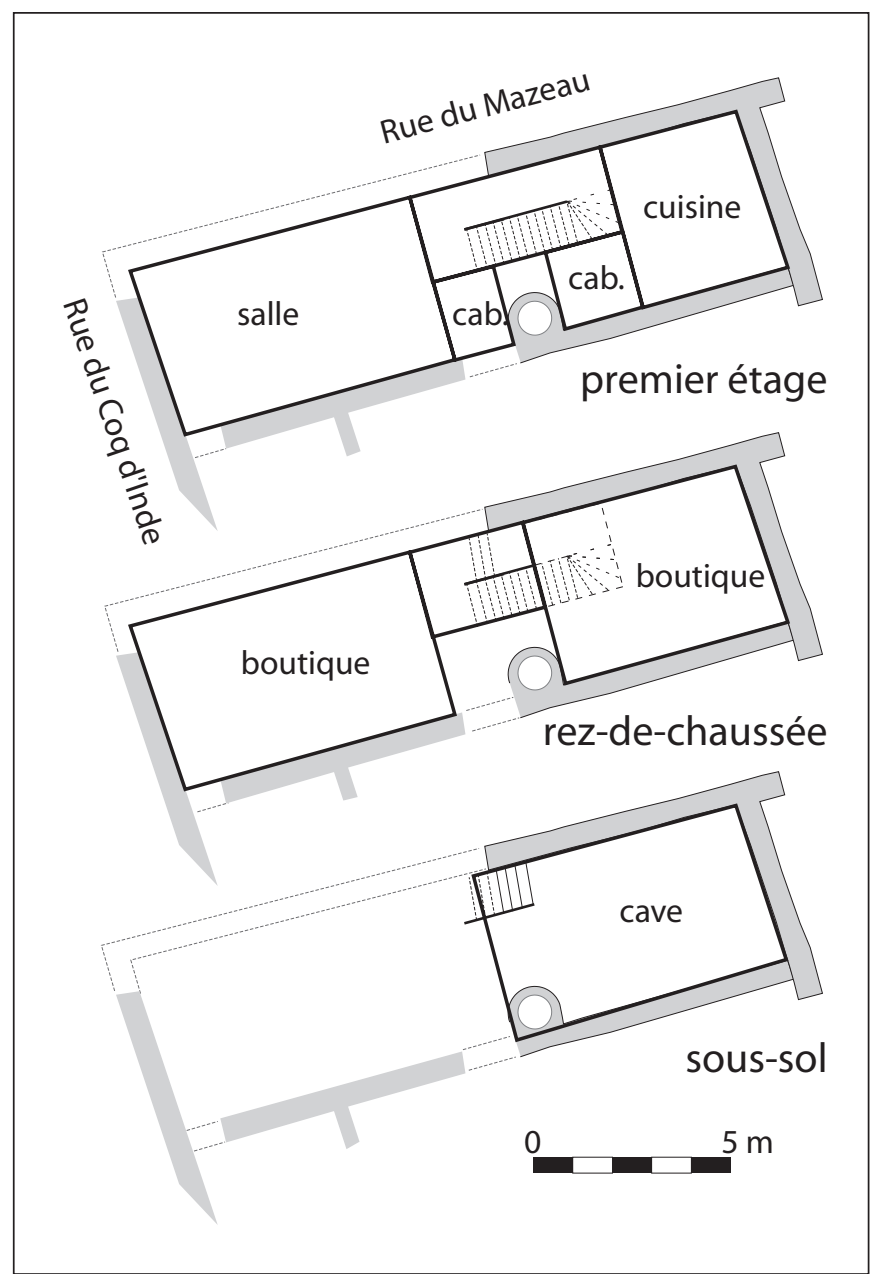

Fig. 200. Restitution de l'immeuble de la parcelle 360 d'après un rapport d'expertise (DAO B. Sillano/Inrap).

\subsubsection{Parcelle 359 et 364}

Au cours du Moyen Âge, les parcelles 359 et 364 n'étaient pas loties (Vecchione 1997, p. 10-12), et même si le passage d'un côté à l'autre de l'îlot a été, dans un second temps, obturé au nord par la construction d'un mur, les traces d'usure météoriques semblent indiquer que ces lots sont restés des espaces ouverts (fig. 201). Les premiers indices d'occupation, au $\mathrm{XVI}^{\mathrm{e}}$ s., sont des éléments architectoniques en blocs de calcaire de La Couronne. Ce sont deux chaînages d'angle, au sud-est de la parcelle 365 et au nord-ouest de la parcelle $358 \mathrm{~S}$, ainsi qu'un pilier associé à deux piliers adossés contre les murs voisins qui matérialisent pour la première fois le mur mitoyen entre les parcelles 359 et 364 . Aucun sol ne leur est associé et il est difficile de les interpréter.

La parcelle 359 est totalement enclose lorsque les ouvertures entre les piliers du mur méridional sont obturées. Les murs, hétérogènes, qui s'y insèrent ont livré de la céramique attribuable au XVII ${ }^{e} \mathrm{~s}$. Il semble toutefois qu'un passage soit conservé vers le sud. Parallèlement, la cave est creusée beaucoup moins profondément que ses voisines ce qui suppose un rez-de-chaussée surélevé. Elle est couverte par quatre voûtes d'arête en briques qui reposent sur un pilier central, des piliers adossés aux angles et des impostes monolithiques en pyramide tronquée au milieu des murs. Ces supports utilisent des blocs de calcaire de La Couronne, certains en remploi. Les piliers d'angles ont deux parements de blocs harpés complétés par un blocage de pierre en remploi et mortier, alors que le pilier central est entièrement parementé avec des blocs (fig. 202). Ils sont tous surmontés de chapiteaux en forme de pyramide tronquée. Dans la seconde moitié du XVIII ${ }^{\mathrm{e}}$ s., deux aménagements non interprétés sont réalisés dans l'angle nord-ouest. Il s'agit tout d'abord d'une petite pièce rectangulaire de $1,10 \mathrm{~m}$ par 1,50 m, ouverte par une porte avec seuil, qui est soit le soubassement d'un escalier soit, plus probablement, d'une échelle meunière. À proximité se trouve une sorte de conduit rectangulaire de $1,10 \mathrm{~m}$ par $0,50 \mathrm{~m}$ constitué d'éléments en remploi. Entre les deux se place un puits circulaire dont le cuvelage supérieur, de section carrée, a été rebâti. Par la suite, une cloison d'axe nordsud divise la cave en deux parties égales. Le seul sol conservé est un pavement de carreaux de terre cuite lié à cette cloison.

La parcelle 364 n'acquiert sa forme définitive que lorsque le mur de façade est édifié, à une époque indéterminée. De petite dimension, elle ne mesure que 7,50 m de long pour $4 \mathrm{~m}$ de large. L'installation de la cave, qui occupe toute la parcelle, n'est pas datée, néanmoins deux états ont pu être distingués. Le premier se manifeste par une reprise en sous-œuvre des murs latéraux avec une maçonnerie hétérogène. Aucun sol ne s'y rapporte, de même qu'il est impossible de savoir si le petit puits présent au sud-est de la pièce lui est contemporain ou antérieur. À l'origine, le couvrement de la pièce devait être un plafond plat puisque la création d'une voûte dans un second temps a nécessité l'abaissement du sol. À ce moment, les murs latéraux ont été doublés de briques afin de supporter une voûte en berceau d'axe nord-sud. L'accès se fait par un escalier droit, en pierre de taille, comme le piédroit du mur d'échiffre. En haut, le palier sert partiellement de couverture à un puits qui remplace l'autre, obturé par le placage de briques. D'après le mobilier, ce dernier est abandonné vers le milieu du $X V I^{e}$ s. ce qui nous permet de dater le second état de la cave. Le dernier sol de cave est constitué de carreaux de terre cuite avec fil d'eau aboutissant à une cuvette en pierre enterrée. Deux cercles de rouille témoignent du stockage de tonneaux. 


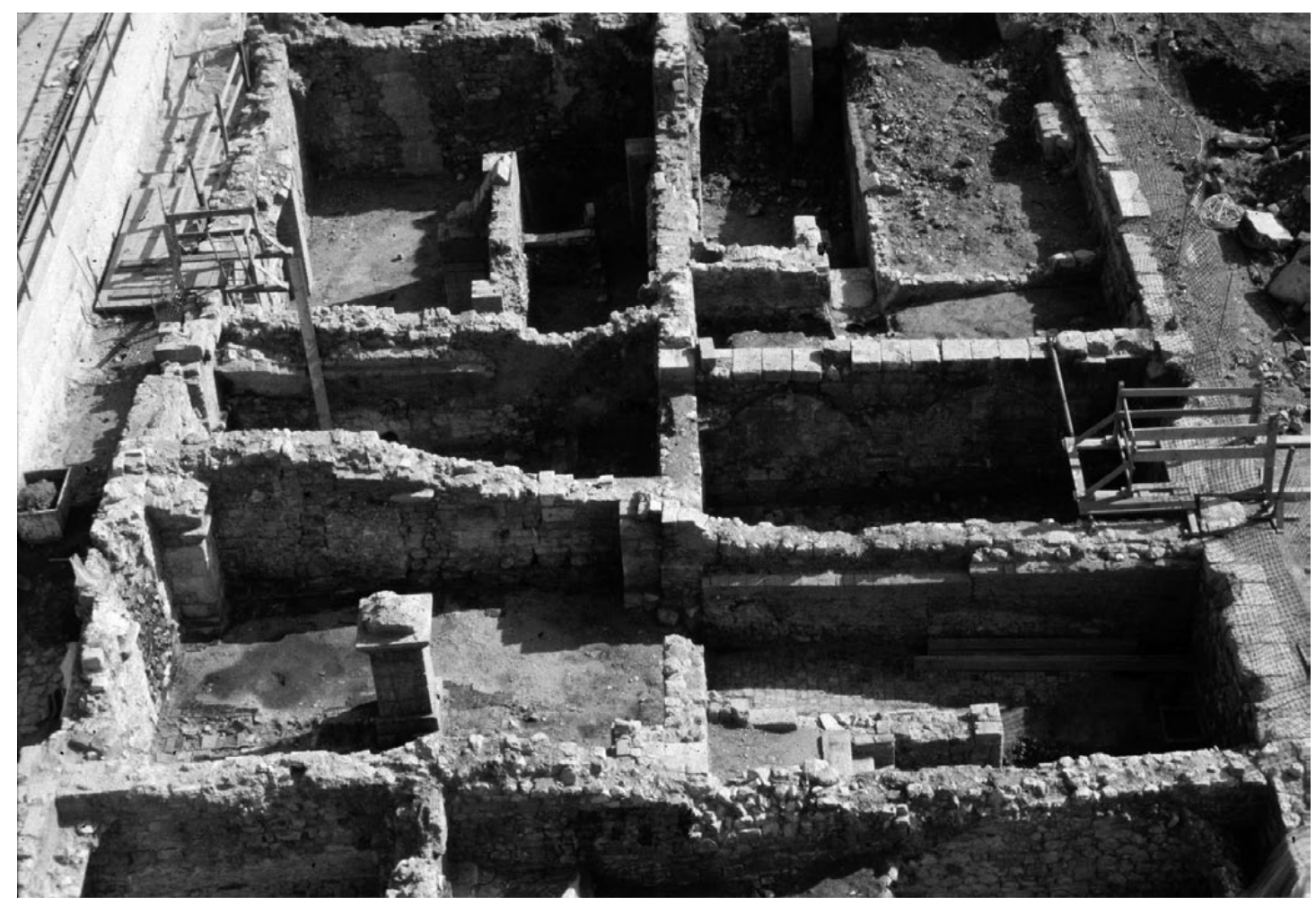

Fig. 201. La partie orientale de l'îlot II en cours de fouille, vu de l'ouest. Au premier plan, les parcelles 359 et 364 , au second, la parcelle 358, au dernier, les parcelles 357 et 387 (cl. M. Derain/Inrap).

\subsubsection{Parcelle 358 : le Logis de la Taulisse}

D'après les confronts des parcelles voisines, nous pouvons estimer que le Logis de la Taulisse se trouve sur la parcelle 358. Sa mention à la fois au nord, où est citée une rue «qui aboutit au logis de la Taulisse » comme au sud, où la rue porte son nom (ou inversement) indique clairement qu'il s'agit déjà d'une parcelle traversante comme elle est dessinée sur le cadastre napoléonien. Pour plus de commodité, nous numéroterons les deux espaces qui la composent $358 \mathrm{~N}$ (pour la partie qui est au nord) et $358 \mathrm{~S}$, car ils n'étaient pas liés à l'origine. Ils ont été créés tous deux au Moyen Âge, mais le second fait partie d'une maison plus ancienne et l'autre ne s'est individualisé que lors de la clôture d'un espace ouvert, parallèlement à la création des parcelles 359 et 364 (Vecchione 1997, p. 8-10).

Les caves ont éliminé toute trace d'occupation antérieure. Cependant, dans la rue de la Taulisse, recoupé par l'extension de la cave moderne, un vestige, abandonné (ou utilisé) au XVI ${ }^{\mathrm{e}}$ s., subsiste. Il s'agit de l'angle, presque droit, d'une fosse parementée par deux murets de $80 \mathrm{~cm}$ de haut, réalisés avec des moellons de calcaire de Saint-Victor. L'intérêt de cette structure réside dans sa datation, rarement mise en exergue sur le chantier, mais nous ne pouvons pas l'interpréter.

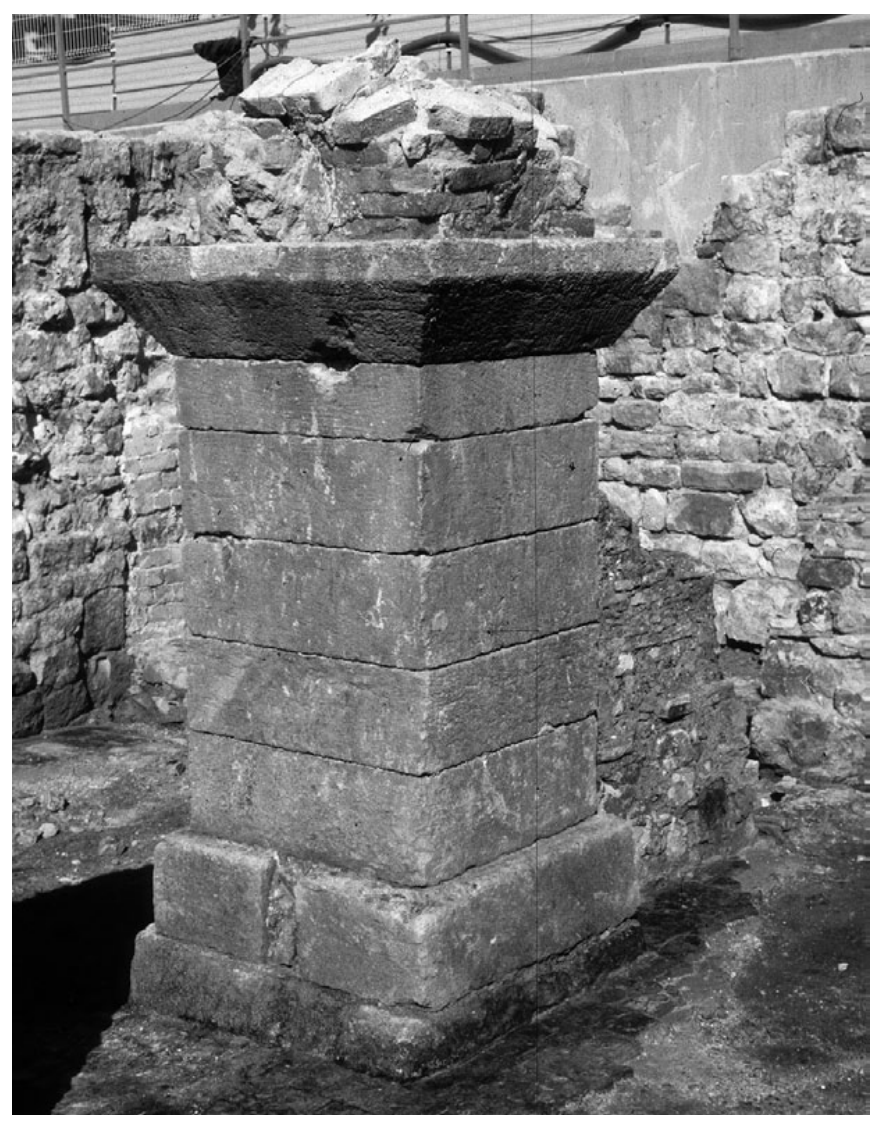

Fig. 202. Le pilier central de la cave de la parcelle 359 (cl. M. Derain/Inrap). 
La parcelle $358 \mathrm{~S}$ est la première à accueillir une cave. Les murs, bâtis en sous-œuvre, sont hétérogènes. Celui qui borde la rue est largement ouvert par un arc en pierre de taille permettant d'accéder à une portion de cave installée sous la rue. Cette extension profonde de $1 \mathrm{~m}$ occupe quasiment toute la largeur de la parcelle. Son voûtement est composé de claveaux de tailles et natures diverses. Le sommet est rehaussé pour l'ouverture d'une trémie ( $c f$. fig. 105). La cave elle-même, dans un premier état, est couverte de deux manières ; au sud une voûte de

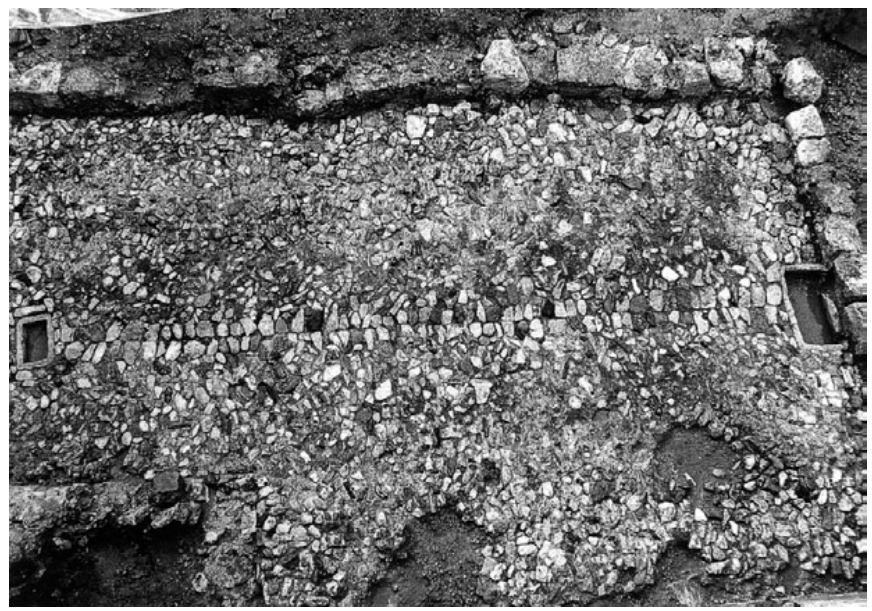

Fig. 203. Le sol de la cave au sud de la parcelle 358 (cl. M. Derain/Inrap). pierre en berceau et au nord une voûte d'arête supportée, aux angles, par de petits culots en forme d'ogive inversée. Conjointement est mise en place une calade avec fil d'eau axial et deux cuvettes enterrées (fig. 203) ainsi qu'un escalier, au sud-est de la cave, dont il ne reste que le soubassement. Le seul élément de datation est une monnaie datée de 1631 trouvée dans une réfection du sol. Dans un second temps, le mur oriental est détruit et remplacé par un mur massif fait de blocs de calcaire jaune (incluant de nombreux remplois), dont l'édification n'a pas porté atteinte à la voûte. Le sol est alors pavé de carreaux de terre cuite qui reposent sur une épaisse couche de destruction ayant livré du mobilier du début du XVIII ${ }^{\mathrm{e}} \mathrm{s}$.

La parcelle $358 \mathrm{~N}$ a conservé un lambeau de sol du rezde-chaussée, au-dessus d'une cave. Il s'agit de carreaux de terre cuite reposant sur le tas de charge des voûtes (qui a livré un tesson du $\mathrm{XVI}^{\mathrm{e}} \mathrm{s}$.), auxquel s'ajoute un remblai superficiel, daté de la première moitié du XVIII ${ }^{\mathrm{e}} \mathrm{s}$. La cave s'inscrit en sous-œuvre dans le bâti antérieur. Les murs, hétérogènes, utilisent des pierres en remploi et l'un d'eux s'appuie même sur une fondation antique. Au sud est installée une porte dont le chambranle est fait de briquettes (fig. 204). Bien intégrée dans la face nord du mur, elle est nettement insérée dans un percement du côté de la parcelle 358S, indiquant par là-même l'antériorité de sa cave. Conjointement est creusé un puits

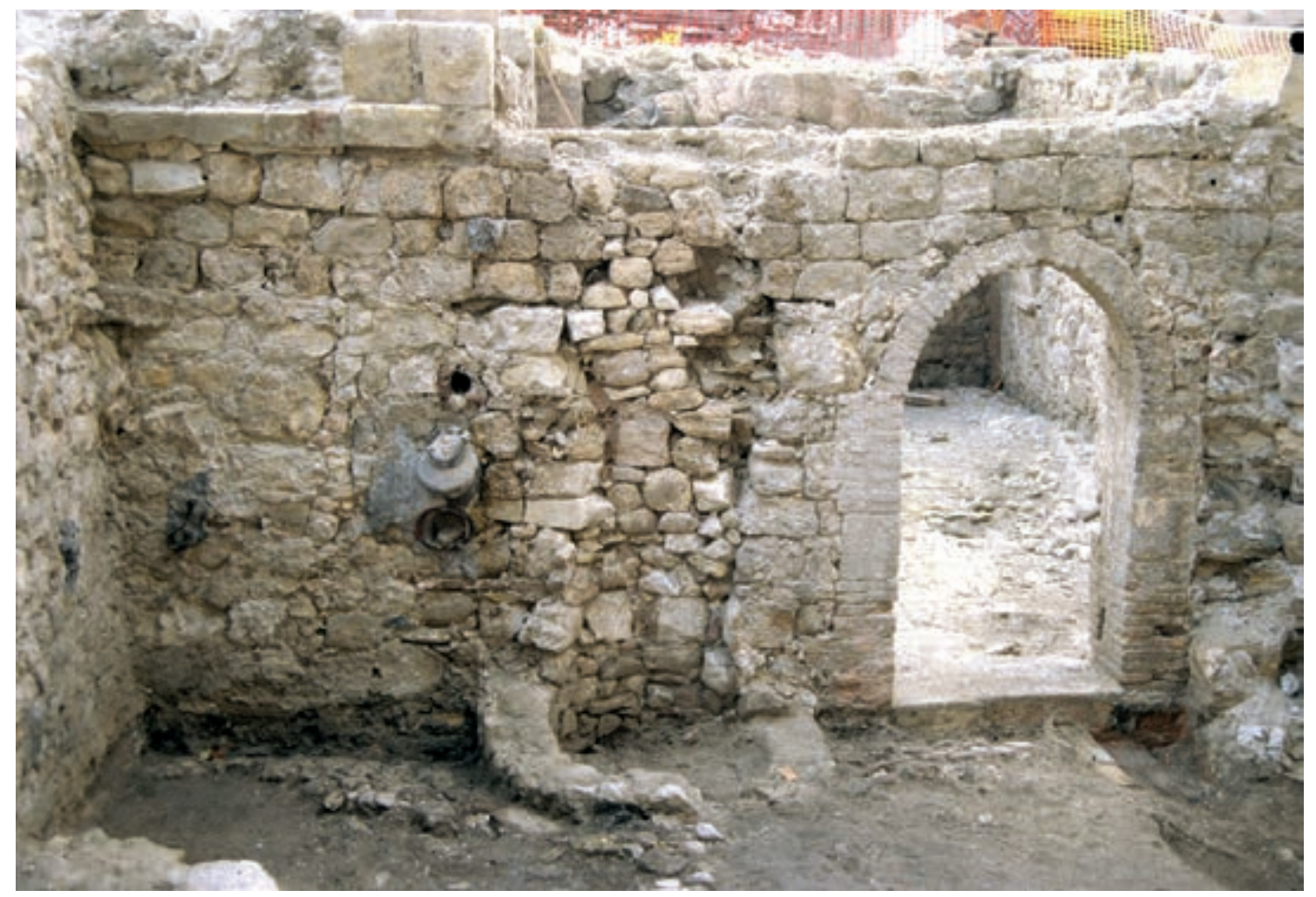

Fig. 204. Parfaite intégration de la porte dans le mur qui sépare les caves de la parcelle 358(cl. M. Derain/Inrap). 
adossé au même mur, à côté de la porte. Contre le mur oriental, au sud, est visible la trace d'un escalier arraché. Le mur nord présente à l'est une réfection en blocs de calcaire jaune, incluant un avaloir, qui pourrait correspondre à un effondrement de la façade. Le couvrement de la cave était assuré par une imposante voûte en berceau, d'axe nord-sud, faite de briques et ouverte par une trappe au nord. Le sol consiste d'abord en une calade, avec fil d'eau et pille en pierre, remplacé ensuite par un sol carrelé. Le remblai qui les sépare a livré du mobilier de la seconde moitié du XVII's.

\subsubsection{Parcelle 387 : une parcelle d'angle bien documentée}

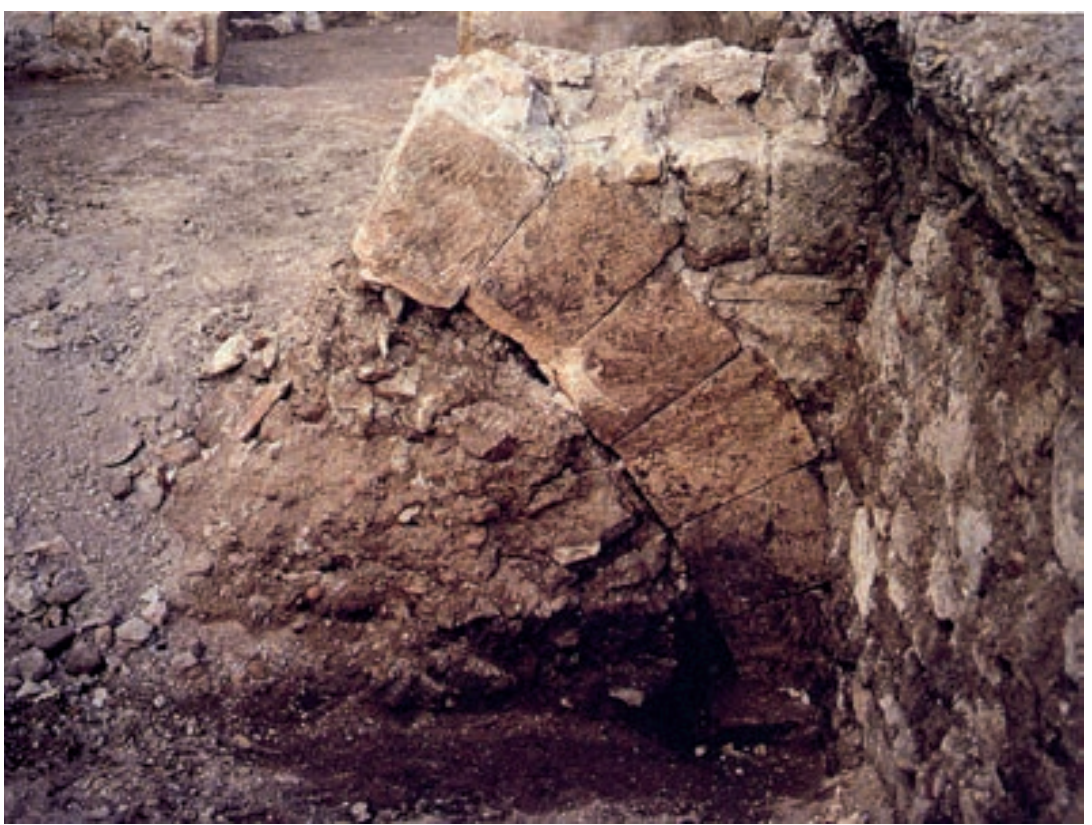

Fig. 205. Départ nord de l'arc doubleau-diaphragme de la cave non terminée de la parcelle 387 (cl. M. Derain/Inrap) parcelles 357 au nord et $358 \mathrm{~S}$ à l'ouest, ce qui a été identifié comme un îlot au Moyen Âge. Les textes nous apprennent par ailleurs que la première et la dernière connaissent une évolution de propriété commune qui explique certaines des transformations que nous allons voir.

Le bâtiment moderne qui prend place sur la parcelle 387 comprend deux espaces identiques disposés de front sur la rue de la Guirlande et un troisième au fond, perpendiculairement à la rue de la Taulisse (Rinalducci 1997, p. 36-66). Le mur de façade sur cette rue est continu le long des parcelles $358 \mathrm{~S}$ et 387 . Nous l'avons rattaché à la période médiévale d'après son architecture, mais sans en avoir de preuves matérielles, tout comme le mur nord. En revanche, la partie occidentale du mur de refend est clairement datée du $\mathrm{XVI}^{\mathrm{e}} \mathrm{s}$. par le mobilier contenu dans la tranchée de fondation. L'élévation conservée est faite d'un blocage désordonné de pierres de toutes natures, de carreaux de terre cuite et de tuiles. Vers l'ouest, il ne s'étend pas au-delà d'une limite marquée, au nord, par un retour massif du mur mitoyen, dans l'angle desquels vient s'insérer un puits. Nous supposons que ce mur, fait de matériaux divers disposés de manière désordonnée, matérialise l'arrière de la parcelle originelle. Sa datation n'est pas assurée, mais pourrait remonter au Moyen Âge.

Dans l'espace méridional, nous avons eu la chance d'étudier le processus de création d'une cave, car il n'a pas été mené à son terme. Contre le tronçon du mur de refend évoqué ci-dessus, ainsi que sous la fondation du mur de façade méridional, quatre éléments de soutènement constitués de piles et doubleaux ont été implantés en sous-œuvre, au sein de fosses, préalablement au

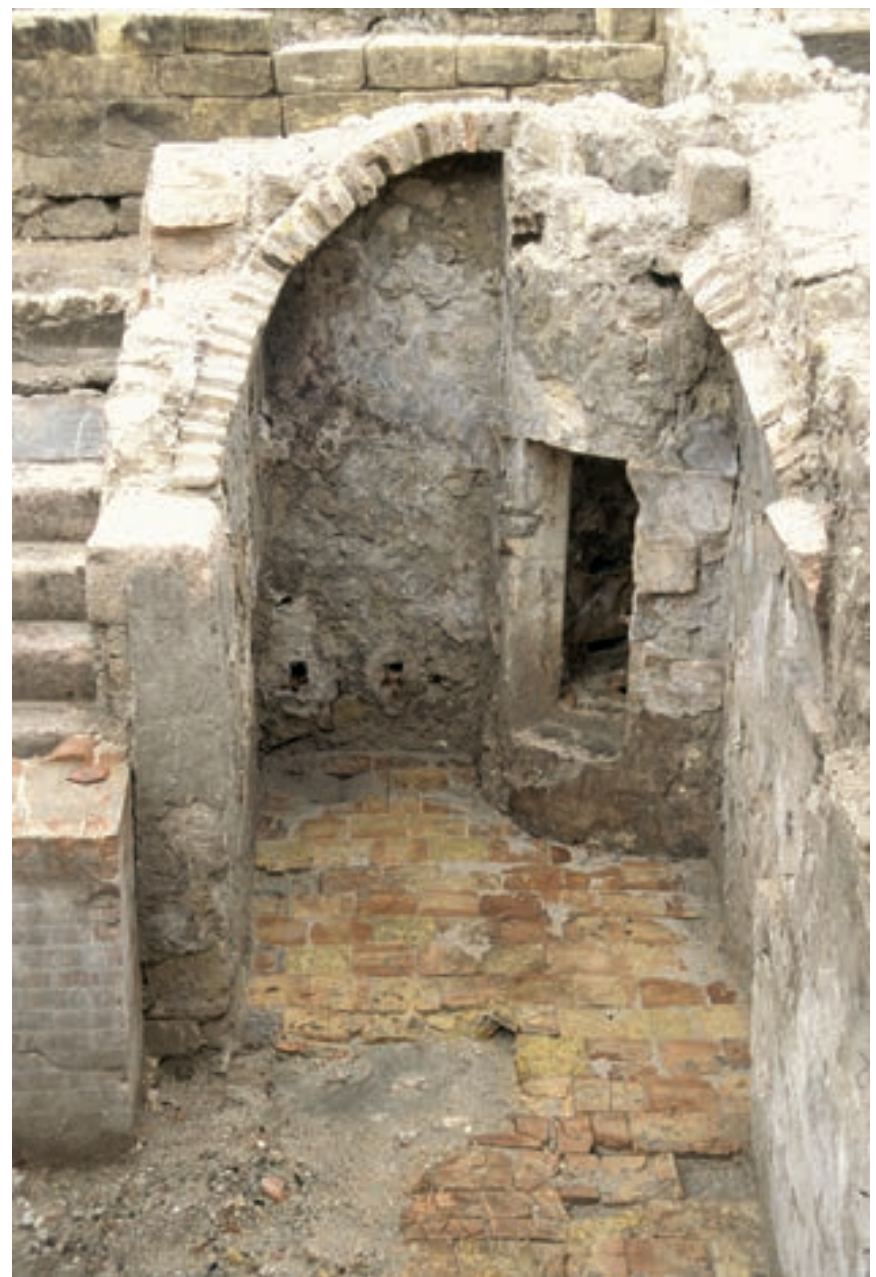

Fig. 206. Le puits de la cave de la parcelle 387 (cl. M. Derain/Inrap). 
creusement de la cave qui ne s'est jamais produit. Les piles, qui consistent en des murs assez haut (au moins $2,30 \mathrm{~m}$ ) et long de $1,10 \mathrm{~m}$ à $1,50 \mathrm{~m}$, visent à renforcer les points de réception de l'ossature du couvrement. Sur l'angle supérieur de la pile sud-est subsistait le départ d'un arc doubleau diaphragme en moyen appareil de pierre de taille soigneusement ajusté (fig. 205). L'imposte, de facture similaire, présente un simple chanfrein. Elle a été encastrée très profondément, dans un second temps, dans la pile mais aussi dans la fondation qui est reprise en sous-œuvre. Du côté opposé, un pilier carré, qui occupe toute l'épaisseur du mur et qui est réalisé également en pierre de taille, supporte l'imposte et l'arc. Au nord-ouest, l'arc est encastré dans le mur ; il a été nécessaire de réaliser un muret derrière afin de reporter l'effort sur l'extrémité du refend transverse. Il est intéressant de constater que le terrain a été creusé $a$ minima pour implanter l'ossature de la voûte, permettant ainsi de s'en servir pour soutenir les claveaux jusqu'à ce qu'ils aient leur propre cohésion. Le creusement de la cave se fait donc après la construction des arcs et peutêtre après celle de la voûte. Les tranchées d'installation ont livré du mobilier du début du XVII ${ }^{\mathrm{e}} \mathrm{s}$.

Si le pilier carré placé au sein du refend n'a jamais reçu d'arc au sud, il constitue en revanche un support pour celui de la cave septentrionale dont la construction n'a pas été abandonnée. Il atteste par là-même que cette dernière a été réalisée à la même période. La voûte, en berceau, est montée avec des briques. Elle est appuyée sur un mur de brique qui double le mur nord, et encastrée dans l'épaisseur du refend au sud. Vers l'ouest, elle se réduit pour couvrir le petit espace à côté de l'escalier (fig. 206). Ce dernier présente deux états successifs. Le premier n'a laissé que les extrémités bûchées de trois marches gironnées inscrites dans l'élévation des murs; le second conserve la partie droite alors qu' elle remplace l'escalier à vis. Dans l'angle nord-ouest, deux puits se superposent, le premier étant lié au mur septentrional, l'autre non. Leur diamètre interne est d'environ $80 \mathrm{~cm}$ et ils sont tous deux bâti avec des éclats de pierre de petit module. Le cuvelage, en élévation dans la cave, présente une ouverture de $50 \mathrm{~cm}$ de largeur, en moyenne, pour 1,27 m de hauteur. Faite en calcaire de La Couronne, elle possède un linteau et une margelle de forme arrondie qui épouse la forme du puits, et les piédroits, des blocs verticaux, sont ébrasés vers l'extérieur. Deux niveaux de sol successifs ont été mis au jour, mais la fouille a été interrompue avant de savoir s'il pouvait en exister un autre. Le premier, daté de la fin du XVII ${ }^{\mathrm{e}}$ s., est très hétérogène. Outre des carreaux de terre cuite rectangulaires, il remploie des fragments d'opus spicatum antique mais aussi des dalles de calcaire de La Couronne, pour la plupart en morceaux, de $0,82 \mathrm{~m}$ par $0,68 \mathrm{~m}$ pour une épaisseur de $0,12 \mathrm{~m}$.

À la fin du XVII ${ }^{\mathrm{e}}$ s. ou au début du siècle suivant, le mur de séparation avec la parcelle 358 est (re)édifié, traduisant peut-être l'annexion d'une partie de cette dernière. Conçu pour avoir un parement unique du côté occidental, il est construit avec des blocs de calcaire de La Couronne (longs de $62 \mathrm{~cm}$, larges de 30 à $60 \mathrm{~cm}$ et hauts de 22 à $24 \mathrm{~cm}$ ), assisés en parpaings et boutisses et complétés sur le revers par de la maçonnerie. L'espace qui le borde, aux confins de la parcelle, est doté d'un sol caladé au milieu du XVII ${ }^{\mathrm{e}}$ s. Il est ensuite rehaussé d'un sol de carreaux de terre cuite, conservé de manière très lacunaire autour de l'escalier. Au milieu du XVIII' s., les deux pièces voisines, à l'angle des deux rues, où le creusement de la cave a été abandonné, sont remblayées sur près de $1 \mathrm{~m}$ d'épaisseur ; puis deux cloisons sont bâties, à l'emplacement des arcs inutilisés. Le seul sol conservé, un carrelage, date du XIX ${ }^{\mathrm{e}} \mathrm{s}$.

Cette parcelle présente l'intérêt d'être bien documentée par les textes. Nous possédons deux rapports d'expertise dont l'un, daté de $1714^{641}$, permet de se représenter la répartition des pièces à chaque étage (fig. 207). Au rez-de-chaussée se trouvent une salle et une boutique ouvertes sur la rue de la Guirlande, une écurie ouverte sur la rue de la Taulisse et un ciel ouvert en cœur d'îlot. Au-dessous, la cave mentionnée semble de très petite dimension, antérieure à celle qui a été vue en fouille. Le sol de l'écurie est plus bas que celui des autres pièces, comme en témoignent les quatre marches descendantes qui permettent d'y accéder. Il semble que les deux pièces orientales, sur un même plan, adoptent un niveau moyen calé sur la pente de la rue de la Guirlande, alors que l'écurie est au même niveau que la rue de la Taulisse. De plus, les pièces ont une hauteur de 3,50 m alors que l'écurie est haute de 2,25 m. La différence de niveau et de hauteur permet de placer au-dessus de l'écurie une cuisine, de même hauteur, disposée en entresol. Dans les trois étages suivants sont disposées des chambres et salles, alors qu'au dernier étage se trouve un galetas. Celui-ci n'atteint pas la façade orientale car la pente du toit rejoint alors le plafond de l'étage inférieur. Dans l'espace restant, éclairés par des fenêtres dans le toit, se trouvent un poulailler et une charbonnière.

\subsubsection{Parcelle 357 : le Logis du Rozier}

Il ne reste aucun vestige des niveaux du rez-de-chaussée de la maison qui occupait la parcelle 357, mis à part un lambeau de sol carrelé (Rinalducci 1997, p. 8-35).

641 AD13 361 E 100, fol. 241. 


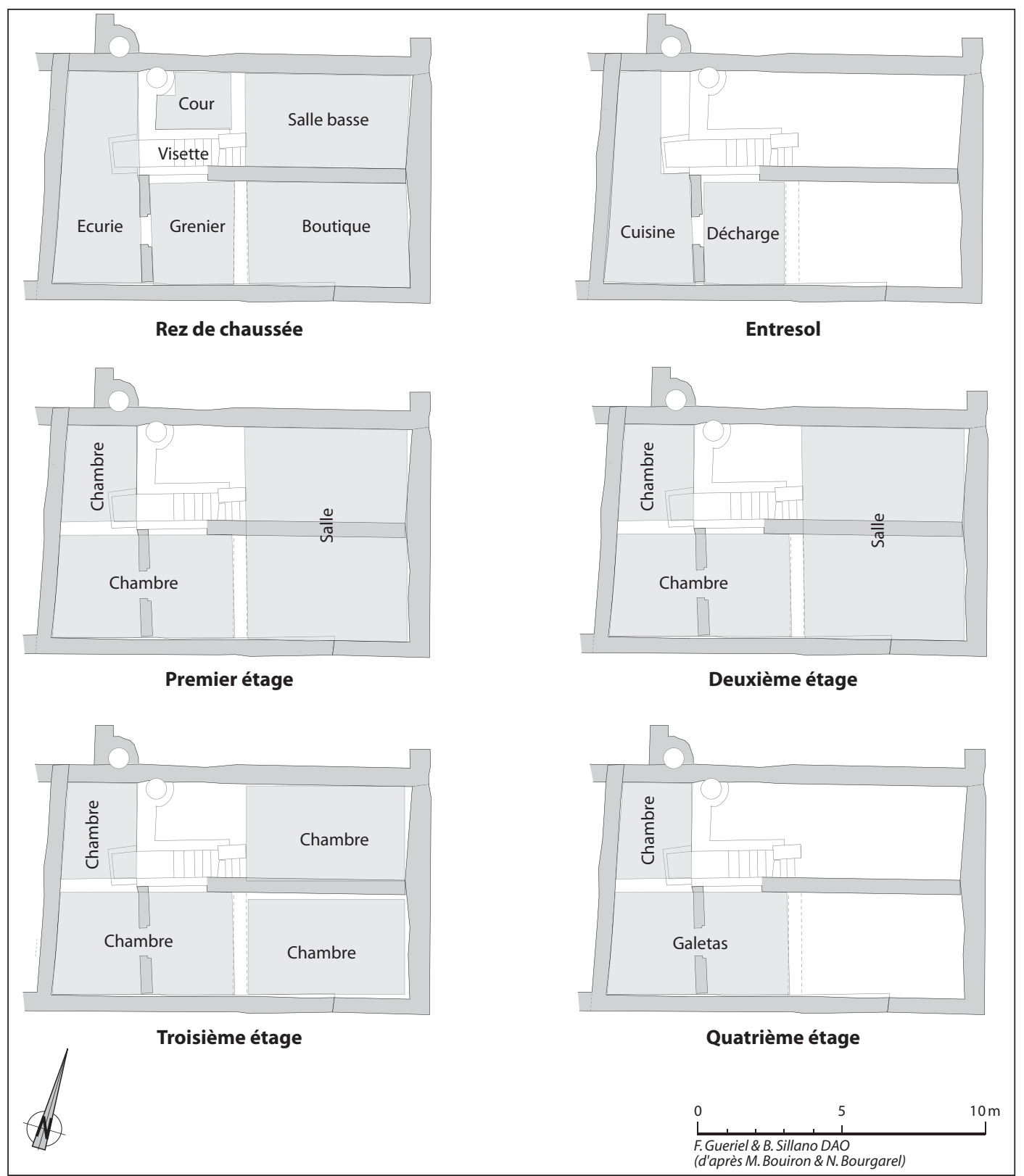

Fig. 207. Restitution de l'immeuble de la parcelle 387 d'après un rapport d'expertise (DAO F. Gueriel, B. Sillano/Inrap).

En revanche, les substructions du bâtiment, et en particulier les caves, ont été fouillées dans leur intégralité. Par ailleurs, des actes de vente mentionnent cet immeuble, vers la fin du XVII ${ }^{e}$ s., sous le vocable de Logis du Rozier, mais nous ne possédons aucun rapport d'estime.

Les murs de ceinture n'ont pas été édifiés à la même époque. Les plus anciens, liés entre eux, sont les murs mitoyens ouest et sud. Le premier est d'aspect très hétérogène sur toute la hauteur; il comporte dans son axe une ouverture, bouchée, dont l'arc est réalisé avec des moellons à peine équarris $(c f$. fig. 164). Le second est composé de deux entités accolées de part et d'autre d'un coup de sabre. Dans l'angle des deux est inséré un puits dont la construction est concomitante. À l'opposé, les deux murs de façade sur les rues du Petit-Mazeau et de la Guirlande sont également liés entre eux. Le premier est percé d'une large ouverture, surmontée d'un arc en pierre et prévue dès le départ, qui permet l'accès à une extension de la cave sous la rue. Le second fait une légère avancée par rapport à celui du voisin au sud. Sa tranchée de fondation extérieure a livré deux tessons de céramique datés du XVI ${ }^{e}$ s. Les deux murs sont de construction assez homogène, utilisant des moellons et blocs de calcaire, parfois en remploi, plus ou moins assisés. L'extension sous la rue n'occupe pas toute la largeur de parcelle comme on le rencontre habituellement mais 
seulement 3,20 m de large. En revanche, elle semble plus longue, mais la proximité de la paroi moulée du chantier et les risques d'effondrement n'ont pas permis une fouille exhaustive de cet espace. Les murs, comme la voûte, en berceau, sont montés avec des pierres de toute nature.

L'aménagement intérieur du sous-sol consiste en premier lieu en un escalier droit situé dans le quart interne de la parcelle. Il présente deux états : le premier, attesté par des traces de marches conservées en négatif dans un des murs de cage, était plus court de $1,50 \mathrm{~m}$ que l'autre en raison de l'étroitesse des marches et de leur hauteur $(20$ à $24 \mathrm{~cm})$. Le second, encore présent lors de la fouille, présente un repos qui divise en deux la volée droite et quelques marches gironnées à l'est qui amorcent un virage. Il est large de $1,40 \mathrm{~m}$; les marches sont en calcaire de La Couronne alors que le repos est carrelé. Il est daté de la fin du XVIII' s. par le mobilier issu du remblai d'installation. L'ensemble des sols de la cave est pavé de mallons et présente un fil d'eau dans la partie nord, orienté d'est en ouest où se trouve une conche en pierre monolithe. Ces sols fonctionnent avec le premier état de l'escalier et sont conservés lors de son agrandissement.

Au centre de la cave, postérieurement à la mise en place du premier escalier, et même de celle du carrelage, est implanté un pilier afin de refaire le couvrement (fig. 208). Il est de plan carré, de $80 \mathrm{~cm}$ de côté, haut de 1,40 m et monté avec des blocs de calcaire de La Couronne en remploi. Son imposte, de même nature mais légèrement débordante, supporte deux arcs lancés vers le nord et le sud. Ceux-ci sont larges d'environ $40 \mathrm{~cm}$ et montés avec des blocs de calcaire en remploi mais aussi des éléments en tuf, assez irréguliers. Ils s'appuient contre les murs latéraux sur des impostes intégrées à la construction. Des voûtes d'arête couvrent les trois quarts de la superficie, mis à part le quart interne où la présence concomitante de l'escalier et du puits d'angle nécessite la mise en place de deux petites voûtes en berceau. Des saignées dans les murs latéraux accueillent les voûtes, ainsi que des culots piriformes sculptés aux angles et des impostes en blocs de remploi, moulurées succinctement en un bandeau plat. Elles sont toutes réalisées en briquettes de $24 \mathrm{~cm}$ par $16 \mathrm{~cm}$ par 3 à $4 \mathrm{~cm}$ d'épaisseur (cf. fig. 87). Le blocage de ces voûtes a livré un tesson de céramique du XIX ${ }^{\mathrm{e}}$ s. parmi 19 autres résiduels.

Longue de $10 \mathrm{~m}$ pour une largeur de 7,5 m, la parcelle est très similaire, par ses dimensions, à celle qui se trouve dans l'angle opposé de l'îlot, la parcelle 366. La structure de l'immeuble qui y prend place est également très proche, comme en témoigne la division de l'espace en deux selon une transversale. Le mur tympan met en effet en exergue l'existence d'une pièce transversale de grande dimension ( $5 \mathrm{~m}$ par 7,50 m) ouverte sur deux rues à la fois, d'une petite pièce, de $5 \mathrm{~m}$ par $3,50 \mathrm{~m}$, ouverte sur l'autre rue et d'un espace en cœur d'îlot dévolu aux circulations et où se trouve probablement une cour intérieure attestée par le puits d'angle. Dans les deux parcelles, les caves sont couvertes en voûte d'arête mais, pour la parcelle 357, cette cave s'étend autour de l'escalier sous la forme d'un couloir voûté en berceau. On peut s'interroger sur la nécessité de cette extension, probablement facilitée par la forme de l'escalier, droit et non à vis comme dans les parcelles 365 et 366 . La nécessité d'avoir un accès au puits en sous-sol constitue peut-être un élément de réponse.

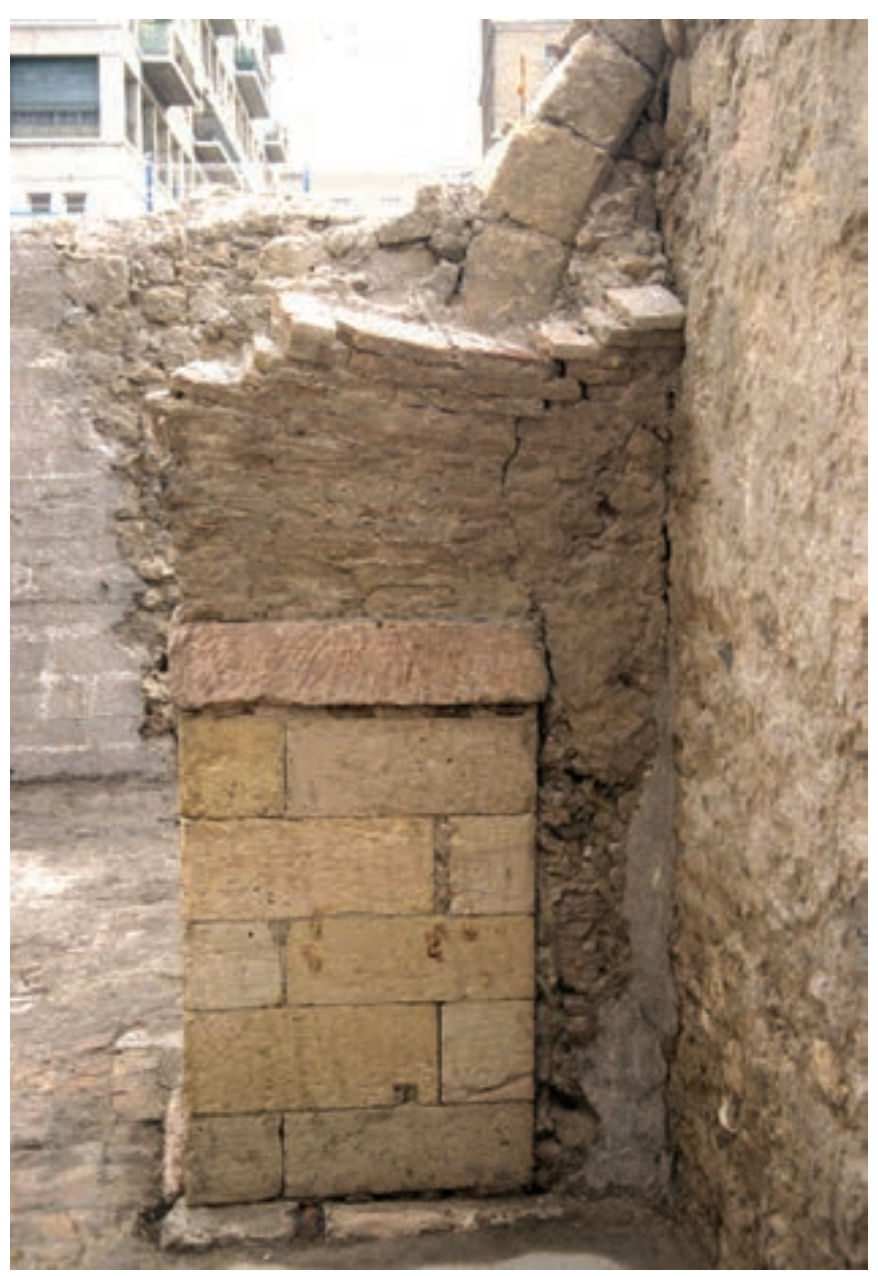

Fig. 208. Le pilier central de la cave de la parcelle 357 vu de l'ouest (cl. M. Derain/Inrap).

\section{4. Îlot III : au nord du pavillon Bargemon (B. Sillano)}

Avec une longueur de $55 \mathrm{~m}$ pour $33 \mathrm{~m}$ de large, l'îlot situé au nord du pavillon Bargemon est l'un des plus vastes, si ce n'est le plus vaste, de la ville ancienne (en dehors des îlots du nord de la ville, occupés par des manufactures) (fig. 209 et fig. 210). Il se singularise 

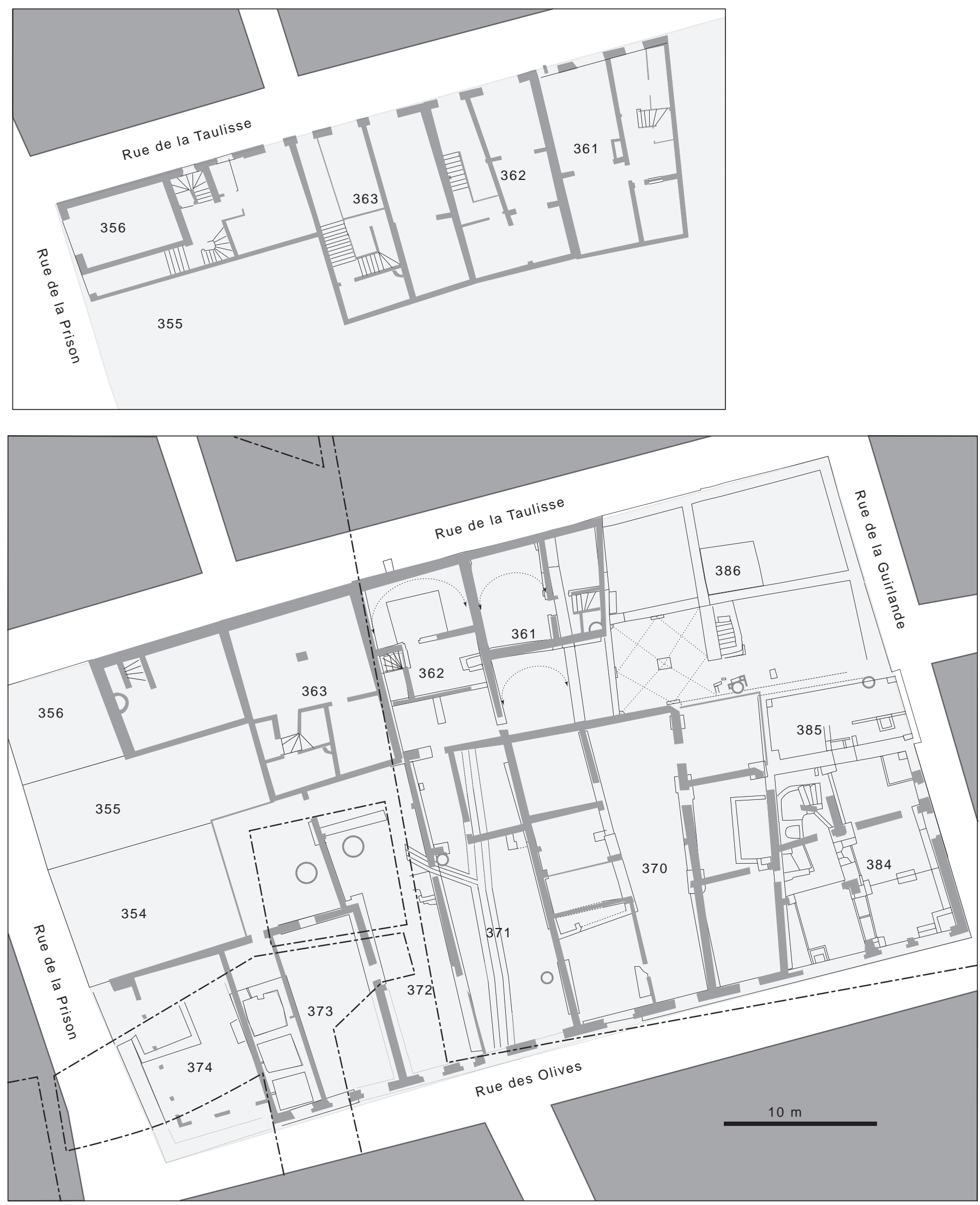

Fig. 209. Plan de l'îlot III d'après les relevés de 1948. En bas, rez-de-chaussée de la moitié sud, en correspondance avec les caves de la moitié nord. En haut, le rez-de-chaussée de la partie nord (DAO B. Sillano/Inrap). 


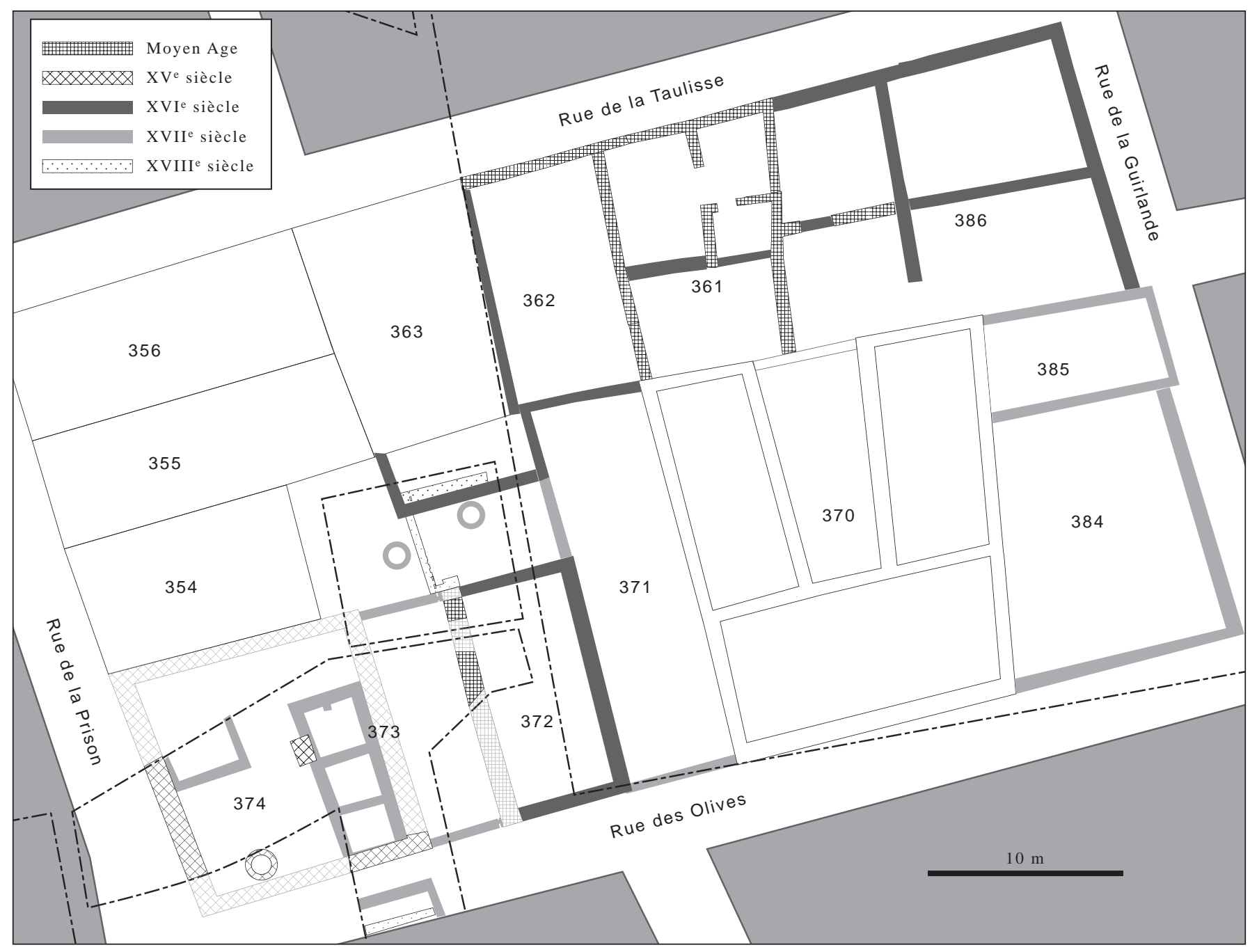

Fig. 210. Plan phasé de l'îlot III (DAO B. Sillano/Inrap).

également par son orientation. Alors que, à l'instar des rues, les îlots qui bordent la Grand-Rue et la rue Caisserie sont disposés perpendiculairement à celles-ci, l'îlot III, tout comme celui qui est juste au nord, leur est parallèle. Il se distingue enfin par la complexité de son découpage interne. Le parcellaire moderne est disposé de part et d'autre d'un axe transversal dont la position, décalée vers le nord par rapport à la médiane, suppose son antériorité. Il semble indiquer la préexistence d'une rue disparue. Au nord de cet axe, plusieurs constructions médiévales permettent d'imaginer un réseau complexe d'habitations aux contours compliqués. Dans la partie fouillée, les parcelles modernes sont le résultat d'agrégation d'unités plus anciennes, dont les orientations sont reprises par les refends. Au sud, par suite d'un nivellement, le bâti antérieur nous échappe. Néanmoins, à l'ouest de l'îlot, l'étude des fondations de la parcelle 373 a permis de mettre en évidence une rue disparue d'axe nord-sud, dans le prolongement de la rue du Coq-d'Inde.
Celle-ci, attestée également par les textes, isole un îlot orienté du nord au sud et qui est plus conforme à ceux que nous connaissons par ailleurs.

\subsection{1. À l'origine des parcelles 373 et 374 : l'Hôtel de Remezan}

Les parcelles 373 et 374 sont situées à l'angle des rues de la Prison, à l'ouest, et des Olives, au sud (fig. 211). Elles ont une origine commune, une vaste demeure d'époque gothique que nous avons appelé l'Hôtel de Remezan, bien qu'aucun texte retrouvé n'en fasse directement mention (Sillano 2005, p. 143-160 et 463-478). Cet édifice a été révélé par la fouille et, fait rarissime, daté par le décor architectural réutilisé en fondation qui, nous le verrons, provient du bâtiment supplanté.

Les parcelles 373 et 374 ont été fouillées de manière très partielle en raison de l'étroitesse de la zone ouverte (galerie Bargemon). Aucun lien physique n'a pu être 
établi entre les façades ouest et sud, l'emprise ayant un plan en forme de T. Pourtant, alors que leurs deux fondations n'appartiennent pas à la même parcelle du cadastre napoléonien, elles ont, pour partie, les mêmes caractéristiques. La rupture apparait le long de la façade de la parcelle 373. Alors que le sommet de la fondation est uniforme, en grand appareil, la base, à l'ouest, est similaire à celle de la parcelle 374 tandis qu'à l'est elle est d'un type différent (fig. 212). La partie similaire est conservée sur une hauteur de $0,60 \mathrm{~m}$ pour $1,10 \mathrm{~m}$ que nous pouvons restituer. Épaisse de $0,95 \mathrm{~m}$, elle est bâtie selon une technique particulière qui permet de rapprocher sans conteste les deux façades. Les quatre assises, qui sont faites de moellons et de blocs, bruts de taille, en grès ou poudingue, sont séparées par d'épais épandages de mortier (jusqu'à $8 \mathrm{~cm}$ d'épaisseur), réalisé avec un sable à gros gravier, blanc et très induré, qui ne s'insère pas toujours entre les blocs, ménageant ainsi des espaces vides entre eux. Entre les parements, le blocage est réalisés avec des cailloux de toute nature. Vers le milieu de la parcelle 373 , cette fondation amorce un retour, détruit par les aménagements postérieurs, marqué par un gros bloc de grès qui déborde largement à l'intérieur de la cave aménagée dans un second temps. Une seule structure peut être associée aux façades primitives : il s'agit d'un pilier situé au milieu de la limite entre les parcelles 373 et 374 . Mesurant environ $1 \mathrm{~m}$ par $1,40 \mathrm{~m}$, sa fondation est installée dans une large fosse et présente de petits ressauts successifs. Elle a une hauteur conservée de $0,90 \mathrm{~m}$, qui devait avoisiner les $2 \mathrm{~m}$ à l'origine. Le mode de construction est similaire à celui du mur de façade, mais les matériaux, des blocs de calcaire de La Couronne taillés en remploi, diffèrent.

Ces corrélations nous amènent ainsi à reconnaître un vaste bâtiment qui occupe la parcelle 374 et la moitié de la parcelle 373, à l'angle des deux rues. Son extension vers le nord n'est pas connue. Elle correspond probablement à la limite avec la parcelle 354, compte tenu du caractère central du pilier, mais l'hypothèse d'un bâtiment plus étendu vers le nord n'est pas à exclure. Il n'en reste pas moins que l'édifice mesure au moins $11 \mathrm{~m}$ par $12 \mathrm{~m}$. À l'est, il est séparé de la parcelle 372, bordée par un mur médiéval, par un espace de $3 \mathrm{~m}$, à l'origine ouvert sur la rue ou tout au moins limité par un mur dont les fondations auraient été remplacées par un mur en grand appareil, trop frêle pour supporter un grand immeuble. Si l'on considère son alignement, au nord, avec la rue du Coq-d'Inde et certaines limites de parcelle qui l'en séparent, il est possible d'y reconnaître une rue qui délimite un îlot similaire à celui du Palais de justice, qu'il prolonge. La parcelle 373 aurait ainsi été créée en agrégeant une portion de rue et une partie d'un vaste bâtiment.
Aucun mobilier céramique ne permet de dater les murs, les piliers ainsi que les transformations postérieures. Cependant, si pendant un temps l'ancienne façade du bâtiment sur le rue disparue faisait office de mur de refend dans la parcelle 373, lorsqu'il s'est agit de le remplacer par un autre plus adapté, les matériaux utilisés ont été ceux de l'ancienne façade. Or ces constructions utilisent un lot important de blocs en calcaire de La Couronne de dimension moyenne mais surtout de nombreux éléments moulurés correspondant à des fenêtres au décor gothique, ainsi qu'un fragment d'arcature de porte décorée par un feuillage sculpté en bas relief ( $c f$. fig. 78, fig. 88, et fig. 89, $c f$. supra § I, 3, 3.2.). L'homogénéité du lot confirme la provenance unique de ces éléments qui correspond à l'ancienne façade du bâtiment. Ce type de décor survit encore à Marseille en 1535 (Hôtel de Cabre, encore en élévation à proximité du chantier), mais se rapporte plus généralement au siècle précédent. Nous remarquons que les piédroits sont moins travaillés que ceux de l'Hôtel de Cabre, ce qui dénote soit un caractère ostentatoire moindre, soit, plus probablement, une construction antérieure. Vers 1650, la propriété appartient à la famille de Remezan, tout comme l'a été le cazal vendu à Pierre Gardiolle en 1569 où a pris place la Maison Diamantée. Cette famille, dans la généalogie de laquelle nous trouvons Julien de Remezan, conseiller du roi René et intendant de ses finances et, plus tard, Jacques de Remezan, négociant marseillais ayant amassé une grande fortune et dont il fait distribution en 1491, possédait une maison place Vivaud (Bouyala d'Arnaud 1959, p. 171). Il semble que cette dernière soit louée et ne soit pas leur résidence principale. Sa localisation sur la parcelle 374 reste donc dans le domaine du possible. Par défaut, et dans l'attente d'une recherche plus approfondie, nous appellerons cet édifice l'Hôtel de Remezan.

\subsubsection{Parcelle 374 : un dépôt lapidaire dans une cave}

L'Hôtel de Remezan se départit du tiers oriental de sa surface et devient la parcelle 374 du cadastre napoléonien. La fouille ne met pas en évidence de modifications notoire des murs maîtres (Sillano 2005, p. 143-160, et 463-478). La cave qu'elle renferme, que nous allons évoquer, est abandonnée au $\mathrm{XIX}^{\mathrm{e}} \mathrm{s}$. Or elle se situe à l'aplomb d'une nouvelle façade, en retrait, visible sur des plans du $\mathrm{XX}^{\mathrm{e}} \mathrm{s}$. La fouille n'en a pas trouvé trace car, comme le montre le plan, elle est très fine et donc certainement très peu fondée. Il est probable que, à l'instar de la Maison du roi, située en vis-à-vis, l'Hôtel de Remezan ait été conservé jusqu'au XVIII ${ }^{\mathrm{e}} \mathrm{s}$. où, à l'état de ruine, il fut détruit pour être remplacé par un simple hangar. La seule modification notoire durant tout ce 


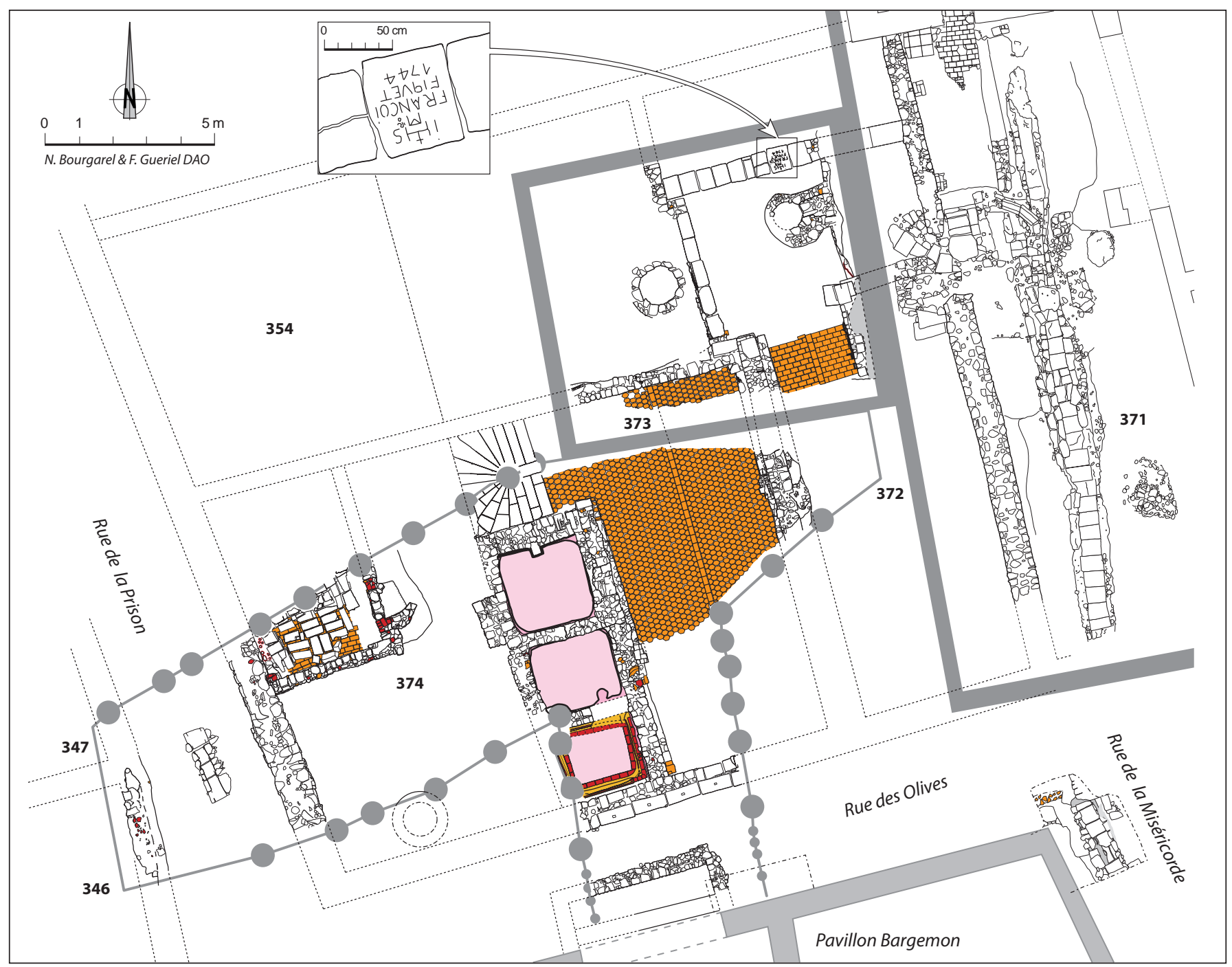

Fig. 211. Plan des vestiges modernes de la partie sud-ouest de l'îlot III (DAO N. Bourgarel, F. Gueriel/Inrap).

temps est le creusement d'une cave dans l'angle nordouest du bâtiment. Large de 3,50 m pour une longueur estimée de 5 à $6 \mathrm{~m}$, elle est limitée par des murs installés en sous-œuvre. Au sud, la présence de coups de sabre dans l'élévation est caractéristique d'un sous-œuvre par panneaux, comme nous l'avons vu par ailleurs. Cela confirme l'existence d'un refend orienté d'est en ouest dont il ne reste pas de trace. Un pilier d'angle indique que la cave était couverte par une voûte d'arête. Le sol est pavé de carreaux $(26 \times 13 \times 3 \mathrm{~cm})$ dans lequel un fil d'eau médian est matérialisé par des carreaux alignés. L'originalité de cette cave réside dans son comblement ; un lot important de blocs de récupération soigneusement rangés (fig. 213, cf. supra § I, 3, 3.3.). Ils sont disposés selon cinq alignements, sur une hauteur maximale observée de 6 assises. Des espaces latéraux sont ménagés afin de permettre la circulation. La dernière recharge de sol de cette cave remonte à la seconde moitié du XVIII ${ }^{\mathrm{e}} \mathrm{s}$.
Son abandon date, d'après le mobilier, de la seconde moitié du XIX ${ }^{\mathrm{e}} \mathrm{s}$.

\subsubsection{Parcelle 373 : des cuves}

Nous l'avons vu, la création de la parcelle 373 s'est constituée par agrégation d'une portion de rue et d'un bâtiment plus ancien. Au-delà du piédroit de ce bâtiment, la fondation est prolongée pour fermer la rue (Sillano 2005, p. 143-160 et 463-478). Elle est réalisée avec une assise de blocs de pierres de taille reposant sur des têtes de pieux et lié par un fin mortier maigre. La partie supérieure de la fondation, continue sur toute la longueur, atteste de la réunification de la façade, c'est-à-dire de l'individualisation de la parcelle 373 telle qu'elle nous est restituée sur le cadastre napoléonien. Elle est faite, côté rue, d'un alignement de gros blocs taillés identiques $(1,00 \times 0,40 \times 0,26 \mathrm{~m})$ en calcaire de La Couronne et 

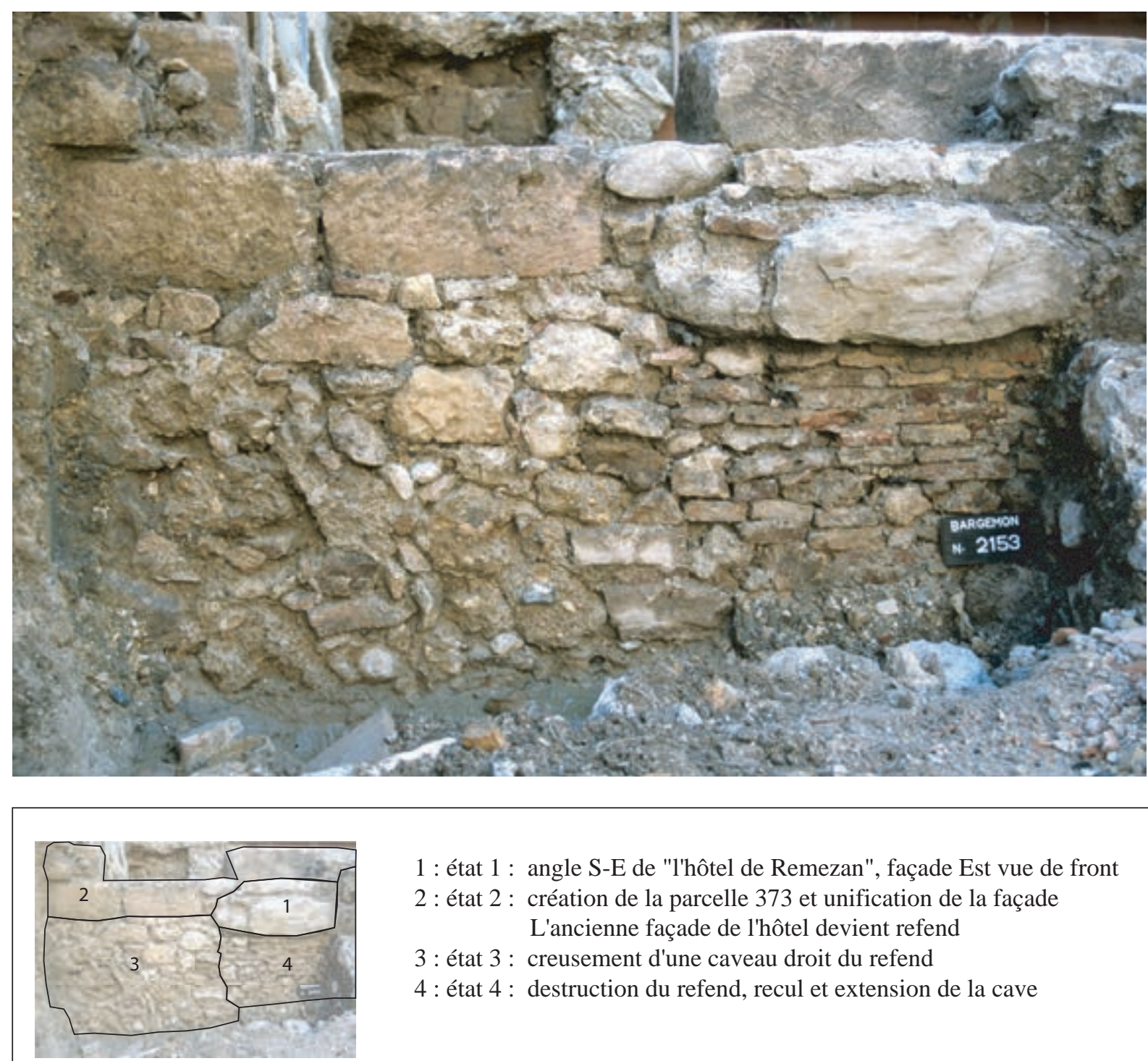

1 : état 1 : angle S-E de "l'hôtel de Remezan", façade Est vue de front

2 : état 2 : création de la parcelle 373 et unification de la façade L'ancienne façade de l'hôtel devient refend

3 : état 3 : creusement d'une caveau droit du refend

4 : état 4 : destruction du refend, recul et extension de la cave

Fig. 212. Le mur sud de la cave de la parcelle 373 et ses différents états (cl. F. Parent/Inrap).

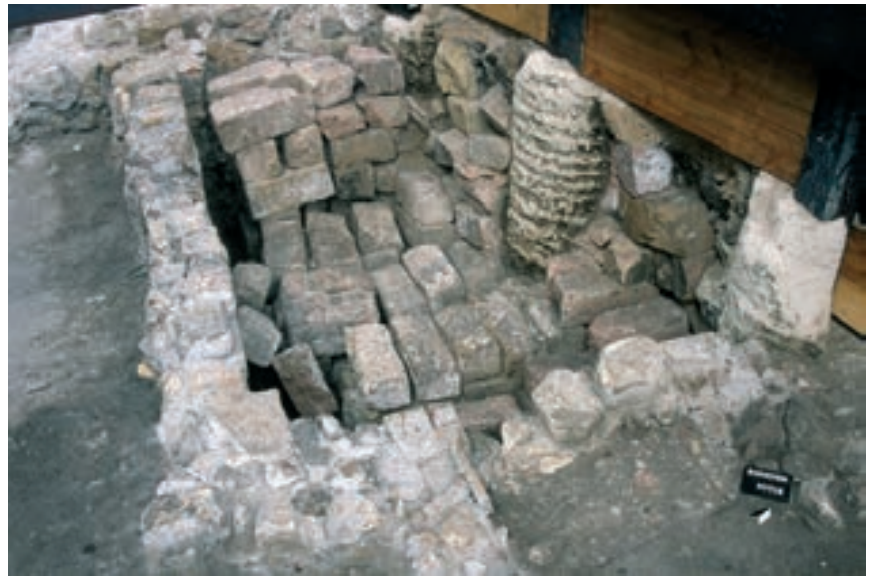

Fig. 213. Le dépôt lapidaire dans le cave de la parcelle 374 (cl. T. Maziers/Inrap).

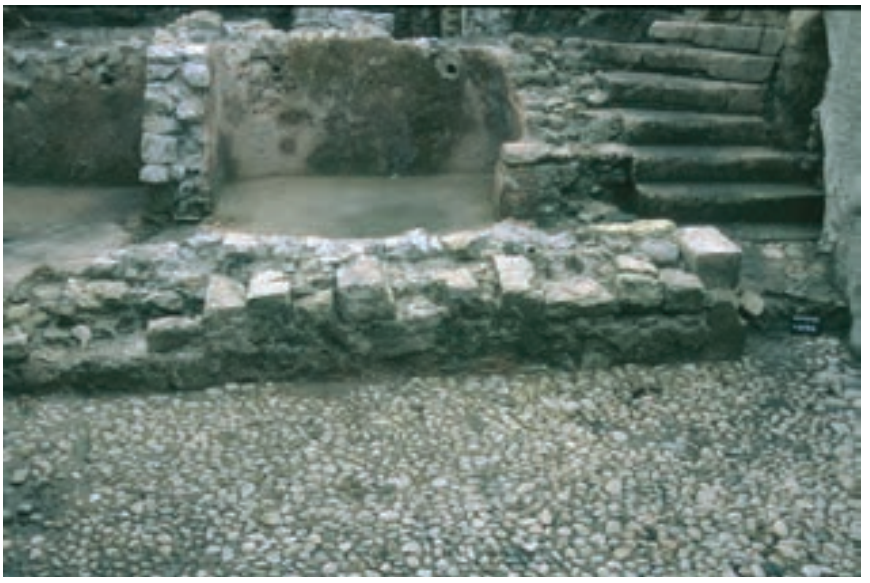

Fig. 214. Le sol de la cave de la parcelle 373 avec les cuves nord et l'escalier (cl. T. Maziers/Inrap). 
possédant en leur centre un trou de louve. Sur l'autre face, un parement irrégulier aussi bien dans la nature des éléments que dans leurs dispositions, porte l'épaisseur totale du mur à $0,75 \mathrm{~m}$. Le mur en grand appareil qui obture cette voie est fondée sur pieux ( $c f$. fig. 81). Dans un second temps, une cave est creusée à l'est du refend, qui est encore l'ancienne façade de l'Hôtel de Remezan. Le mur en sous-œuvre est très peu épais et ne sert qu'à masquer la coupe de terre. Nous ne connaissons pas son extension totale car elle a été étendue dans un second temps. Trois bassins ont été réalisés consécutivement à la démolition du refend et son remplacement par un autre, parallèle et contre le précédent (fig. 214). La construction de cet ensemble est très hétérogène et complexe ; nous ne l'évoquerons pas en détail, la dominante étant, nous l'avons vu, la réutilisation des éléments architecturaux qui constituent l'ancienne façade.

Les trois cuves s'alignent du nord au sud le long de la bordure occidentale de la parcelle. Deux d'entre elles, au nord, sont de dimensions et de conceptions similaires, la troisième, contre la façade, est à la fois plus petite, plus massive et aménagée différemment. La première, carrée, mesure à l'intérieur 2,30 m de côté, la seconde 2,10 m par $2,40 \mathrm{~m}$ et la dernière $1,60 \mathrm{~m}$ par $1,95 \mathrm{~m}$, avec une forme légèrement évasée. Aucune d'entre elles n'est conservée intégralement et nous pouvons simplement affirmer que leur hauteur est supérieure à $1,35 \mathrm{~m}$, ce qui leur confère des volumes respectifs supérieurs à $6,6 \mathrm{~m}^{3}, 6,25 \mathrm{~m}^{3}$ et $4,4 \mathrm{~m}^{3}$. Le mortier de tuileau qui les enduit est apposé directement sur les murs, mais dans la dernière cuve, il est doublé par un chemisage de briquettes (13 x 26 x 3,8 cm) disposées en panneresse, lui-même doublé par un placage des briques de chant $(15,5 \times 24,5 \times 3 \mathrm{~cm})$ recouvert par une dernière couche de mortier hydraulique. Les fonds des deux premières cuves sont à la même cote et faits d'un béton de tuileau extrêmement induré de $10 \mathrm{~cm}$ d'épaisseur reposant sur un radier de cailloutis de $15 \mathrm{~cm}$ d'épaisseur. Le fond de la dernière cuve est $20 \mathrm{~cm}$ plus haut et composé, comme les flancs, d'un dallage de briquettes recouvertes d'un enduit, qui repose sur une chape identique à celle des autres cuves, le tout superposé à un radier de $25 \mathrm{~cm}$ d'épaisseur, lui-même fondé sur pieux. Ceux-ci, d'un diamètre moyen de $10 \mathrm{~cm}$, sont disposés tous les 20 à $30 \mathrm{~cm}$.

La cave à l'est chevauche les deux zones de fouille, séparées par une paroi moulée (en béton). Elle mesure 11,30 $\mathrm{m}$ de long pour $5 \mathrm{~m}$ de large. Des supports en briquettes sont intégrés dans un chemisage qui couvre les murs latéraux et délimitent des compartiments de 3,50 m de long. Certains s'évasent latéralement et longitudinalement, ce qui indique qu'ils supportent une voûte d'arête. D'autres, comme celui qui se situe dans l'angle nordest, amorcent une forme d'arc de cercle dans le sens de la largeur de la parcelle, mais pas longitudinalement, ce qui suppose une voûte en berceau ; enfin d'autres sont hybrides. Ces observations font supposer que les deux compartiments sud ont une voûte d'arête alors que le compartiment nord, contre lequel s'appuie le couloir menant à l'escalier, a une voûte en berceau. L'escalier d'accès est situé dans l'espace voisin, au nord des cuves et seule une moitié est dans l'emprise de la fouille. Elle comprend une courte volée droite et un quart de tour. Les marches, en calcaire de La Couronne, ne sont pas monolithes (le module le plus fréquent est de $1 \mathrm{~m}$ ) et il ne possède curieusement pas de mur d'échiffre occidental. Deux niveaux de sols successifs, séparés par un remblai d'une vingtaine de centimètres, daté de la première moitié du XVIII ${ }^{\mathrm{e}}$ s., sont liés à ces murs. À la base, il s'agit d'un sol caladé que des traces de mortier rouge permettent de lier aux bassins voisins. Le second est un pavement de navettes avec un fil d'eau d'axe nord-sud en briquettes ( $c f$. fig. 80). À l'époque contemporaine, les bassins sont abandonnés et réutilisés en cuve à charbon.

Au nord de cet espace bâti, une vaste cour de forme carrée est agrégée à la parcelle 374 . En raison d'un nivellement important, il ne reste aucun vestige des niveaux de sol qui l'occupaient. Seul un puits nous est parvenu. Il a un diamètre interne de 1,10 m et son cuvelage est fait de moellons de calcaire liés à la terre et non assisés. Le statut foncier de cette cour reste à élucider car le cadastre napoléonien masque les états antérieurs. Il est clair en effet que, compte tenu de son emplacement central, cet espace ouvert profite à toutes les parcelles environnantes. À l'est, la parcelle 372 empiète légèrement dessus, aux dépends de ce qui était une ancienne rue. À l'ouest, en revanche, la parcelle 354, selon le cadastre, est en retrait. Or ces deux parcelles appartiennent au même propriétaire au XVIII ${ }^{\mathrm{e}}$ s., M. Fiquet ( $c f$. infra $\S 3.4 .4$.) ; en est-il de même pour la cour qui les sépare ?

La fondation sur pieux et radier de blocs de taille utilisée pour obturer la rue, et donc contemporaine de l'individualisation de la parcelle 373 , renvoie à une technique qui ne semble pas pratiquée avant le XVIII ${ }^{\mathrm{e}} \mathrm{s}$. Pourtant, la fouille montre que cet état est bien antérieur au carrelage de «navettes », daté, lui, du début de ce même siècle. Un acte de vente de la parcelle voisine atteste de l'existence de la parcelle dès $1592^{\mathbf{6 4 2}}$. Nous possédons également un prix-fait de 1655 pour la reconstruction du mur mitoyen entre les parcelles 373 et $374^{643}$. Nous pouvons raisonnablement supposer que ces travaux entrent dans une campagne plus large qui, comme elle ne concerne pas la parcelle du commanditaire, affecte probablement la parcelle 373 . De plus, les

642 AD13 360 E 29, fol. 732.

643 AD13 391 E 384, fol. 392. 
cuves situées en bordure du mur mitoyen n'étant pas installées en sous-œuvre, il est probable qu'elles aient été construites en même temps que ce mur, c'est-à-dire vers 1655. Rétrospectivement, il n'est pas impossible que les fondations sur pieux datent effectivement de la création de la parcelle 373, avant 1592.

\subsubsection{Parcelle 372 : de la maison isolée à l'auberge des Trois Amis}

Cette parcelle est située sur trois chantiers de fouille différents et recoupée par deux parois moulées (Sillano 2005, p. 143-160 et 463-478; Paone 1997b, secteur 1). Le mur le plus ancien qui la délimite est à l'ouest. La céramique qu'il contient, assez abondante, est résiduelle et aucune datation ne peut être proposée ; mais par sa nature et son liant, le mur a été attribué à la période médiévale. Il ne se prolonge pas jusqu'au fond de la parcelle moderne où un puits se trouve juste sur son axe. La massivité de la construction suggère qu'il s'agit d'un mur porteur lié à un bâtiment qui, en raison de la présence de la rue à l'ouest, se trouve nécessairement sur la parcelle 372. À l'est, les canalisations qui courent dans la parcelle 371 supposent qu'il s'agit également d'un espace ouvert. La limite entre ces deux parcelles suit approximativement un mur antique qui séparait le grand domaine des thermes de celui des entrepôts romains. En fond de parcelle, une portion de mur avec une amorce de retour adossés à un creusement attestent de la présence d'une cave et donc d'un autre bâtiment. Ces derniers sont très homogènes, faits de pierres de calcaire lacustre liés à la terre, soigneusement taillés et agencés. Une expertise de 1707 met effectivement en évidence la bipartition de la parcelle, avec un bâtiment sur la rue et un autre en fond, séparés par un ciel ouvert. Elle nous renseigne aussi sur la longueur du bâtiment principal, $12 \mathrm{~m}$, pour une largeur de $6 \mathrm{~m}$. Au fond, la deuxième maison est plus petite $(7 \mathrm{~m}$ par $4 \mathrm{~m})$ (il s'agit probablement d'une annexe) ; entre les deux bâtiments se trouve une cour.

Dans un second temps, une cave est creusée sous le bâtiment principal. Localement, ce creusement a eu pour effet de rectifier l'orientation du mur antique. Là, il est limité en profondeur, où un ressaut est conservé à une altitude supérieure à celle du sol carrelé le plus récent ce qui indique que le premier sol de la cave était plus haut et a donc disparu. En face, le mur de la cave est construit en sous-œuvre du mur médiéval dont il fallut enlever le parement oriental afin d'augmenter son épaisseur en le recouvrant d'un mur en moellons de nature diverse, équarris. Il présente un ressaut de fondation à la même altitude que celui qui a été évoqué précédemment. Au nord, la présence d'une canalisation dans l'angle (cf. infra § 3.4.10.) nous indique que la cave n'était pas encore creusée et qu'il existait certainement une cour intérieure.

Le rapport de 1707 montre que la parcelle possède déjà une extension vers l'ouest. Il mentionne la cour centrale, avec un puits, bordée par deux allées voûtées. Il est également question d'une cave de 4,25 $\mathrm{m}$ de large pour $8 \mathrm{~m}$ de long, plus étroite que celle qui a été fouillée et que nous devons situer dans la partie sud de la parcelle, en dehors de la zone fouillée. Depuis la cour, un escalier, visiblement intégré au bâtiment et probablement tournant car il est question d'un tambour et de demy repos, mène aux trois étages. Chacun d'eux comprend une pièce de grande dimension du côté de la rue, appelée salle aux deux premiers étages, une autre, transverse, de taille similaire en fond de parcelle, dont une cuisine au premier étage, et des petites pièces entre les deux, des décharges ou des chambres. La cuisine et la salle au premier étage possèdent une cheminée mais aussi « une pille avec son bassinet de taille et son conduit jusques à la rüe». La première a en outre un potager de taille qui lui vaut probablement son qualificatif. La hauteur des pièces est en moyenne de $4 \mathrm{~m}$. L'édifice possède un quatrième étage en retrait, occupé par une lauvisse. La façade, longue de $6 \mathrm{~m}$, est en pierre de taille et percée de deux fenêtres à chaque étage. Aux deux premiers, ce sont des « croisières de sept pans de large et dix auteur fermant de bois de noyer en six voletz dont deux sont vitréz à chaque croisière alors qu'au dernier ce sont des croisières batardes fermant en deux voletz bois blanc à placage ».

Dans un troisième temps, les murs de la partie nord de la parcelle sont entièrement refaits en grand appareil de taille. L'extrémité nord du mur médiéval est tronquée par l'installation d'un piédroit en gros blocs taillés de calcaire de La Couronne. Un retour d'un mètre le prolonge vers l'extérieur du bâtiment, où il est lié avec un mur fait de blocs de parpaing alignés. Trop étroit $(35 \mathrm{~cm})$ pour être porteur, il s'apparente à un mur en sous-œuvre ou à une extension de la cave, le piédroit en pierre de taille étant alors un support d'arcature qui permet de soutenir le mur maître. Il s'aligne sur le bâtiment situé en fond de parcelle, où il est lié à un retour qui reprend celui de ce bâtiment. Celui-ci est fait de blocs de même nature mais beaucoup plus imposant (son épaisseur est de $60 \mathrm{~cm}$ ). Un de ces blocs présente sur sa face supérieure une inscription qui indique un nom, François Fiquet, et une date, 1744 (fig. 215). Un autre pilier en pierre de taille est apposé contre le mur oriental, légèrement décalé par rapport au premier. Il marque une rupture dans le mur, plus épais au sud où il correspond au bâtiment principal, et étroit au nord. Il s'agit certainement d'un bouchage plus tardif de ce qui était un espace ouvert. À l'intérieur de ce dernier se trouve un puits dont le cuvelage est fait de matériaux très divers, et en particulier des fragments 


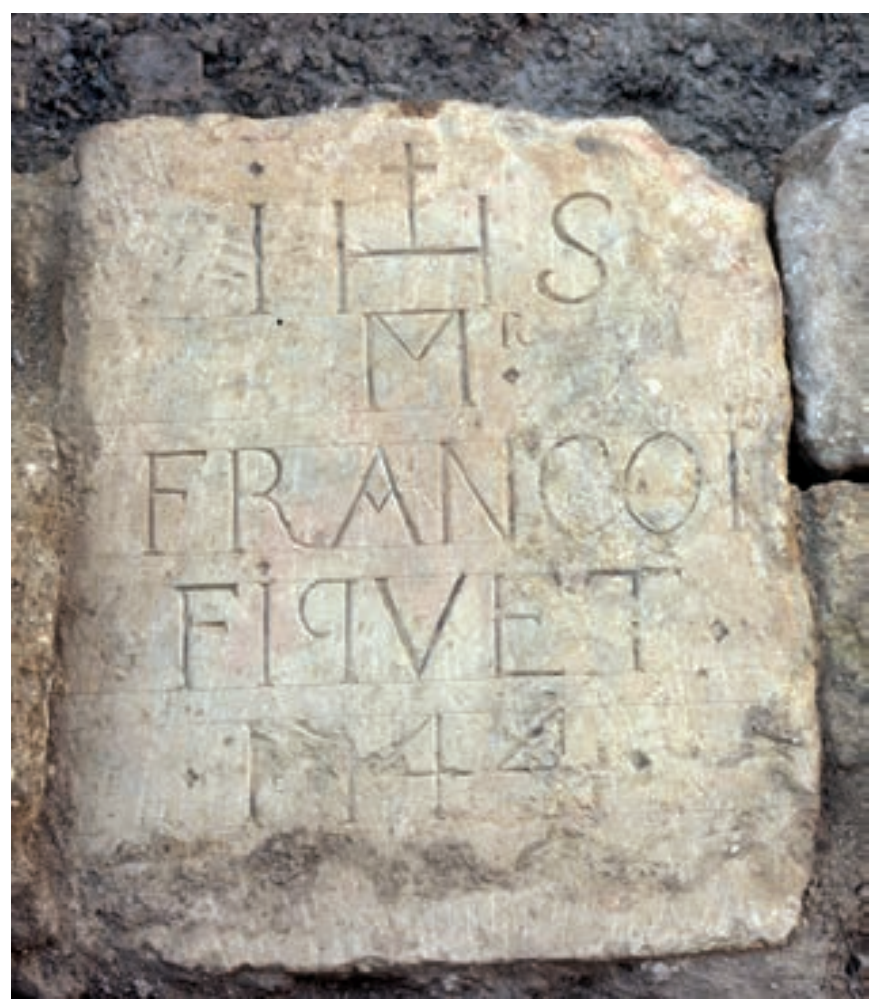

Fig. 215. Le bloc de fondation avec inscription (cl. T. Maziers/Inrap).

de jarres datés du XVIII ${ }^{\mathrm{e}} \mathrm{s}$. Ce puits présente un exutoire à l'est qui le relie à une canalisation, ou plutôt un drain, en pierres sans liant, qui traverse le mur pour se diriger vers la partie de la parcelle 371.

La question d'un remploi pour la pierre qui porte l'inscription pourrait se poser en l'absence du « $\mathrm{s}$ » de François, par manque de place. La singularité du bloc, par son module unique dans l'assise basse du mur (des parpaings réguliers en pierre de La Couronne), mais aussi sa position centrale dans le mur, semble exclure le remploi. La datation, 1744, également, car la technique de la fondation en pierre de La Couronne est typiquement du XVIII ${ }^{\mathrm{e}}$ s. Enfin, si aucun texte, pour l'instant, ne confirme cette acquisition, la famille Fiquet est néanmoins propriétaire de la parcelle 354 voisine. Force est d'admettre que l'inscription nous livre bien le nom du propriétaire, M. Fiquet, et la date des travaux. Si le graveur n'a pu finir le mot « François », c'est probablement par erreur.

Ces travaux ont étendu largement le sous-sol, indiquant une réduction, voire une disparition de la cour. Aucun texte ne nous renseigne et seul un plan du rez-dechaussée nous est parvenu car ce bâtiment, qui a échappé à la destruction de 1943, a été topographié en 1948. Le ciel ouvert n'existe plus; une grande salle occupe son emplacement ainsi que les deux anciennes allées, également détruites. Un pilier, à l'aplomb du nouveau refend, soutient son plafond et probablement les refends des étages supérieurs. Au sous-sol, la cave s'étend vers le nord et semble, à terme, occuper tout l'espace de la parcelle. La façade semble refaite car les deux ouvertures dessinées en 1948 sont disposées de manière symétrique ce qui n'est pas compatible avec la coexistence d'un magasin et d'un couloir latéral. Le plan de 1948 montre une ouverture sur la cour intérieure du voisin à l'ouest dont l'origine remonte probablement à l'acquisition de la parcelle 354 par le même Fiquet. C'est la possibilité de prendre la lumière dans cette cour qui lui a permis d'éliminer l'ancien ciel ouvert. L'agrandissement de l'espace habitable est tributaire de cette acquisition.

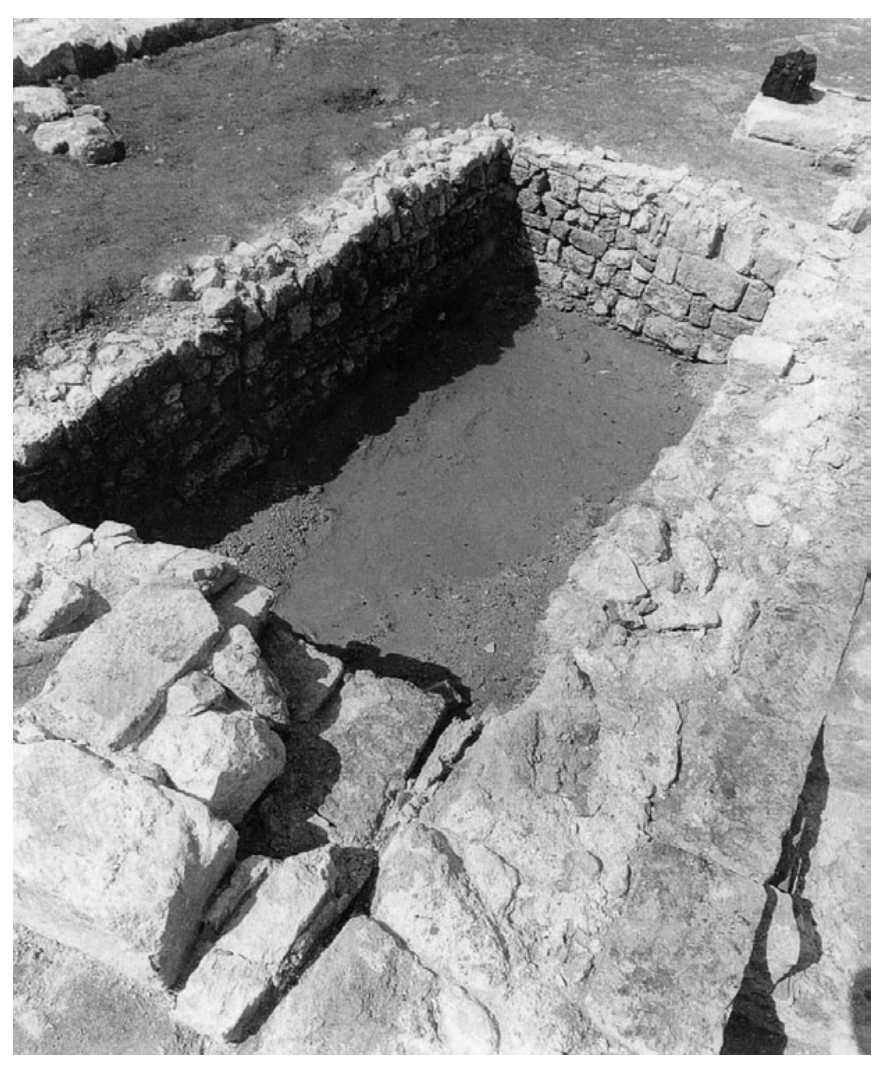

Fig. 216. La cuve de la parcelle 370 (cl. M. Derain/Inrap).

\subsubsection{Parcelle 370 : l'Hôtel de Gérente}

La parcelle 370, d'une superficie d'environ $260 \mathrm{~m}^{2}$, est de loin la plus grande du quartier. Utilisée pour le stockage des déblais lors du chantier archéologique de 1996, la parcelle n'a été étudiée que dans sa partie orientale (Paone 1997b, secteurs 3,4 5 et 10 et Sillano 2005. p. 463-478). Là, de puissants piliers en calcaire de La Couronne intégrés aux murs dessinent un bâtiment parallèle à la bordure orientale, large de $5 \mathrm{~m}$ et long de $12 \mathrm{~m}$. Cette bordure doit son orientation oblique à un héritage antique : le mur occidental des thermes romains. Les fondations, qui sont faites d'un grand nombre de remploi 
et de pierres de toutes natures, reposent sur des pieux. Contre cette bordure, une cuve ou latrine est installée (fig. 216). Elle est profonde de $90 \mathrm{~cm}$, large de $2,9 \mathrm{~m}$ et longue de 4,50 m, parementée par un petit appareil assisé de calcaire lacustre et son fond est réalisé avec de l'argile stampienne compactée. De l'autre côté de la parcelle, les murs n'ont pas été étudiés, mais leur plan dessine un bâtiment de même dimension, parallèle à l'autre bord. La déclinaison entre les deux limites est absorbée par une cour de forme trapézoïdale d'une largeur moyenne de $3,50 \mathrm{~m}$, percée d'un puits en son centre et pourvue d'un sol caladé. Ces structures ne sont pas datées, même si les murs en grand appareil fondés sur pieux renvoient plutôt au XVIII' ${ }^{\mathrm{s}}$ s. Cependant, la symétrie des deux bâtiments, l'exiguïté de la partie centrale et l'absence de limites antérieures suggèrent que le découpage observé est mis en place dès l'origine. Nous aurions là un des plus vastes hôtels particuliers du début de l'Époque moderne.

En 1643, la parcelle appartient au noble André de Gérente, sieur de Carry et de Venelles ${ }^{644}$, premier consul en 1640 , puis député du commerce de 1654 à 1656 . En 1742, il s'agit de l'ancien hôtel du marquis Jarente La Bruyère où les tribunaux du palais de Justice, très délabré, furent transférés (Fabre 1867-1869, t. II ; Tavernier 1976, p. 103). En 1833, c'est une «maison à deux ailes de bâtisse, prenant jour sur la cour intérieure qui en dépend $\gg{ }^{645}$.

\subsubsection{Parcelles 384 : naissance d'une parcelle d'angle}

Le soin apporté à la construction des caves de la parcelle 384, leur caractère ostentatoire et la forme trapézoïdale de l'ensemble font la singularité de la parcelle 387 ( $c f$. fig. 108) (Paone 1997b, secteur 17; Sillano 2005, p. 463-478). Ces vestiges, datés au plus tôt de la deuxième moitié du XVII ${ }^{\mathrm{e}} \mathrm{s}$., masquent entièrement un état antérieur dont aucun vestige ne nous est parvenu. Un document d'archive, une expertise réalisée en $1642^{\mathbf{6 4 6}}$, nous permet cependant de l'aborder. La parcelle, dont les dimensions correspondent exactement à celle du cadastre napoléonien, contient «deux corps séparés ayant chascune maison son entree, ung ciel ouvert, sa visete et monee a deux meyneaux de plastre ». Le plan et les dimensions des caves nous permettent de reconnaître le long de la rue de la Guirlande la «maison faisant le canton », large de $7 \mathrm{~m}$, accolée à une autre large de $4 \mathrm{~m}$ seulement. La première a été achetée par Pierre de Vento à sa cousine en

644 AD13 353 E 87ter, fol. 352.

645 Archives Chambre de Commerce ME 2-0.

646 AD 357 E 133, fol. 462.
$1606^{647}$. Comme il était alors propriétaire de la seconde, ainsi que de la maison au nord (parcelle 385 ?), c'est à lui que la parcelle 384 doit son emprise finale. En 1642, les façades sont tellement vieilles qu'elles s'affaissent «les carages et fassades soubzplombant tant dung coste que daultre denviron ung pan ». L'interprétation du texte pose problème car il semble que chaque maison possède son escalier et ciel ouvert, or l'une d'entre elles est disposée le long de la rue et ne nécessite donc pas de cour intérieure. Il s'agit donc probablement d'un ciel ouvert commun et il doit donc en être de même pour l'escalier. Trois caves occupent le sous-sol : deux disposées sous l'emprise des maisons, la troisième perpendiculaire, au nord. Elles ont probablement une origine très ancienne puisqu'elles sont mentionnées dès $1432^{648}$. Au-dessus de cette dernière et au rez-de-chaussée de la maison d'angle se trouvent deux boutiques. Les maisons ont deux étages plus une lauvisse au fond (au nord). La façade le long de la rue de la Guirlande est en maçonnerie et crépie. L'autre, «ensamble la fassade », c'est-à-dire identique pour les deux maisons, est en pierre de taille jusqu'à la «première coudière », puis en maçonnerie. L'angle est en pierre de taille sur toute la hauteur.

La parcelle est reconstruite en 1642 et nous en possédons le devis ${ }^{649}$. Il y est dit que les maçons sont tenus «d'abatre et desmollir entièrement lesd. deux maisons dhault en bas et de bas en hault, comme encore les deux caves quy sont en icelles maisons sy bon semble au commanditaire ». Les façades devront être rebâties « conformemant à celle de la maison du sr Dominique Truc dudit Marseille sans y comprendre aucune sorte de moulleures cornisses ny sortie, et par dedans lesd. carages et sur le dernier de la taille y feront la massonnerie que sera necessaire despesseur competante ». Ce sont ces constructions qui nous sont parvenues.

La parcelle est occupée par une unique cave, de construction homogène qui est l'objet de nombreux aménagements, et de tentative d'assainissement. De forme trapézoïdale, elle mesure $12,60 \mathrm{~m}$ pour les cotés ouest et sud, $12 \mathrm{~m}$ pour l'est et $10 \mathrm{~m}$ au nord. La pièce s'illustre par la qualité de sa construction caractérisée par un parement interne de blocs taillés de calcaire tendre jaune disposés en panneresse et un parement externe de moellons et cailloux d'origines diverses (calcaire dur tendre, blocs de grès) entre lesquels le blocage est fait de mortier blanc dur avec galets de 0,5 à $2 \mathrm{~cm}$ mêlés à des déchets de taille. La pièce se divise en plusieurs travées marquées par deux piliers massifs situés dans l'axe et associés à des supports adossés, tous en pierre

647 AD13 360 E 44, fol. 68.

648 AD13 1 HD B 12, fol. 165v.

649 AD13 362 E 91, fol. 703. 
de taille. Le premier sol observé est fait de dalles de calcaires posées sur un niveau de brasier. Dans un second temps, au XIX ${ }^{\mathrm{e}}$ s., les sols sont exhaussés, certainement à cause d'un problème d'humidité. Une communication est alors créée avec la parcelle au nord (385), un escalier est installé et les sols sont pavés. Ces aménagements ont certainement masqué ceux qui nous font défaut pour la période moderne, en particulier l'accès à la cave.

\subsubsection{Parcelle 385 : un petit immeuble}

Cette parcelle, placée le long de la rue de la Guirlande, est de petite dimension $(9 \mathrm{~m}$ de long pour $4 \mathrm{~m}$ de large). Elle est peu renseignée par les textes, si ce n'est qu'elle semble plus ou moins liée à la parcelle 384, au sud, puisqu'elle a appartenu un temps au même propriétaire et que les caves ont été reliées à l'époque contemporaine ( $c f$. supra $\S 3.4 .6$.). D'un point de vue archéologique, nous avons distingué deux états (Paone 1997b, secteur 15). Le premier concerne le creusement de la cave dont le sol, pavé de galet, a livré une pièce datée de 1591. Les murs, installés en sous-œuvre, atteignent, ou non, le sous-œuvre des caves voisines. Au sud, en particulier, les hypocaustes des thermes romains ont été conservés entre les deux placages. Ils sont faits de matériaux divers et hétérogènes et présentent parfois les traces d'étaiement caractéristiques (usage de $\mathrm{T}$ en bois afin de soutenir la fondation lors du creusement de la cave). Un puits est intégré dans la maçonnerie du mur septentrional. Son cuvelage est fait de moellons de calcaire rose vers le haut, de calcaire blanc vers le bas. On ne sait s'il s'agit d'un puits médiéval réutilisé, mais il est abandonné dès le XVIII' $\mathrm{s}$. Il débouchait à la surface par une ouverture pratiquée dans la voûte en berceau qui coiffe la cave. Celle-ci est appuyée sur trois arcs doubleaux dont deux, répartis à l'intérieur de la pièce, sont faits de blocs de calcaire jaune tendre et le dernier, contre la façade, est en calcaire rose. Il pourrait correspondre à un projet avorté d'extension de la cave sous la rue, comme nous en avons observé par ailleurs. Enfin, une ouverture est pratiquée vers la cave de la parcelle 384. Une cloison divise la cave en deux, chaque espace étant pavé de galets. Le sol occidental possède une rigole en croix, l'autre deux rigoles parallèles. Dans la moitié sud de ce dernier sont installés dans un second temps des espaces cloisonnés et revêtus avec des briques. Ils intègrent un autre puits, peut-être antérieur, qui est rhabillé par un cuvelage carré de blocs et briques.

\subsubsection{Parcelle 386 : autre parcelle d'angle}

La parcelle d'angle 386 est intéressante à plus d'un titre. Il s'agit d'une parcelle d'angle de grande dimension, dont nous connaissons bien la mise en place grâce a une stratigraphie intégralement conservée, certains espaces n'étant pas percés de cave (Sillano 1997), et assez bien documentée du point de vue des archives. Elle est également la seule à avoir livré un niveau de sol suffisamment riche en mobilier pour pouvoir être daté du XVI ${ }^{\mathrm{e}}$ s. Cependant, malgré tout cela, des incertitudes subsistent comme nous allons le voir.

Longue de $15 \mathrm{~m}$ sur la rue de la Taulisse pour une largeur de $14 \mathrm{~m}$ sur la rue de la Guirlande, la parcelle 386 est subdivisée en plusieurs espaces fouillés à différents moments. Un refend axial, orienté d'est en ouest la divise en deux parties égales; au nord, trois secteurs non excavés, au sud trois autres occupés par des caves. Il est clair que cette parcelle doit son origine à l'agglomération de plusieurs parcelles médiévales. Nous en avons clairement identifié trois, disposées en lanières, d'orientation nord-sud, et dont le contour est à l'origine du secteur nord-est. Des murs médiévaux sont réutilisés à l'Époque moderne, comme la limite ouest de la parcelle ou la partie occidentale du refend axial. Mais avant d'essayer de restituer l'historique de cet immeuble d'angle par le biais des archives, voyons ce que nous livre l'archéologie.

Le comblement de la tranchée de récupération d'un des murs médiévaux est daté du XVe $\mathrm{s}$. S'y superpose un remblai et un sol de terre battue attribué, grâce au mobilier, au XVI ${ }^{\mathrm{e}}$ s. Ce dernier scelle la tranchée de fondation du mur de refend qui traverse toute la parcelle du nord au sud et dont la conception est parfaitement similaire à celle des murs de façade contre lequel il s'appuie. La fondation est épaisse de $80 \mathrm{~cm}$, plus large à la base, profonde de $2 \mathrm{~m}$ pour les façades et 1,20 m pour le refend. Sa mise en œuvre est particulière voire discriminante pour cette période (fig. 217) : il s'agit d'une alternance de lits épais de mortier débordants et d'assises de moellons et blocs non liés entre eux. La nature des éléments est variée, essentiellement du poudingue, des grès mais également de nombreux galets de lest. L'élévation, dont seule une assise est conservée, est large de $76 \mathrm{~cm}$ et diffère selon les secteurs. Pour la façade nord, du côté externe, elle est très uniforme, constituée d'un moyen appareil de taille, en tuf ou en grès, jointoyé à la scie ; du côté interne, elle est moins bien soignée, en appareil de tuf ou grès équarris, à joints épais, ce qui se justifie par un enduit appliqué immédiatement après la construction. Pour la façade est, la nature des blocs diffère puisqu'il s'agit de calcaire rose. La seule structure associée, outre le sol, est un caniveau en pierre qui court le long du refend est-ouest ( $c f$. fig. 60). Le reste des maçonneries ne nous est pas parvenu, en particulier dans la moitié sud de la parcelle où seuls les sous-œuvres des murs de façade et de refend, postérieurs, ont été observés. 


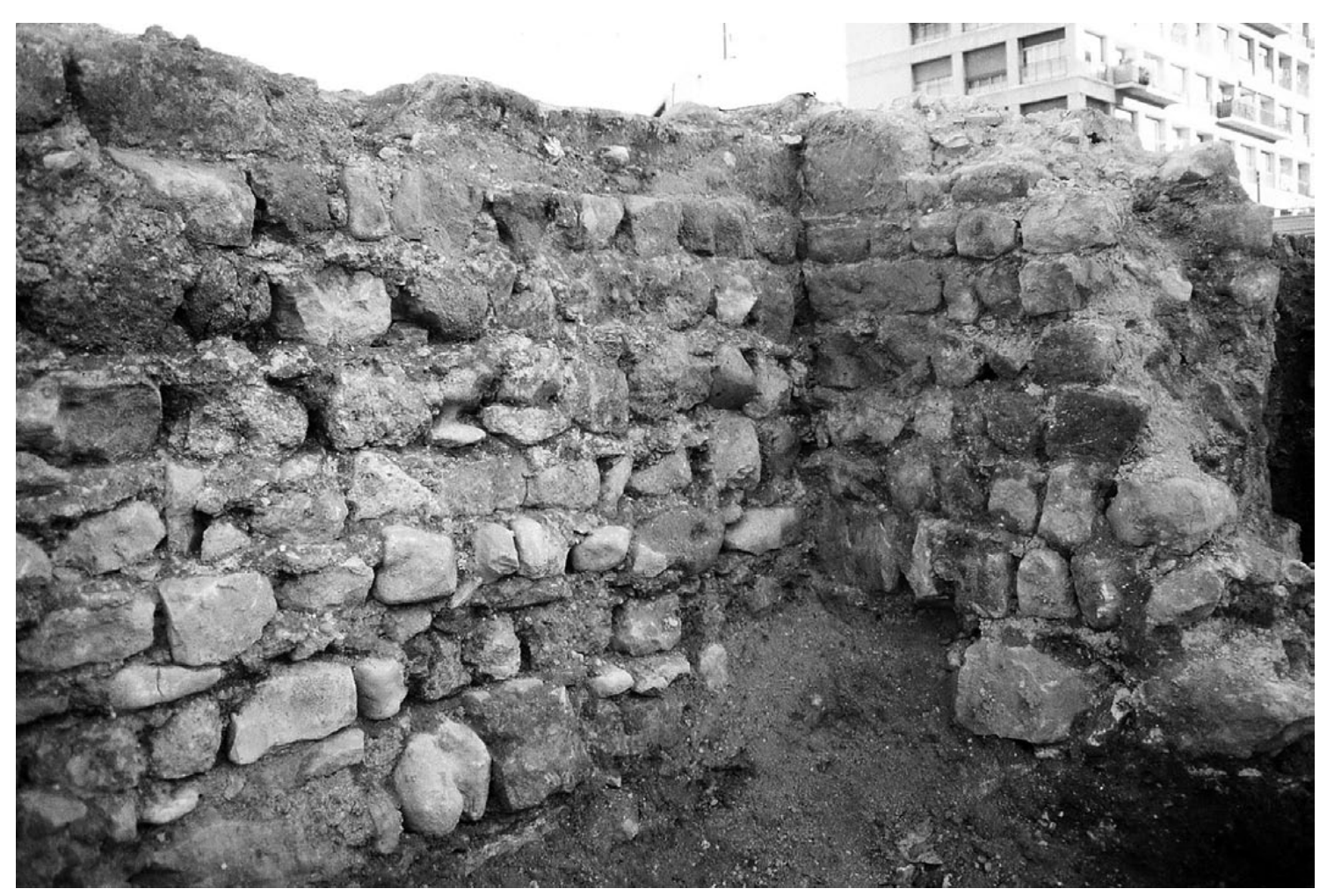

Fig. 217. Le mur de façade nord (à gauche) et le refend de la parcelle 386 (cl. M. Derain/Inrap).

D'importants travaux de réfection sont attestés par une vaste fosse à chaux, située dans un angle, large de $3,20 \mathrm{~m}$ pour $4 \mathrm{~m}$ de longueur et $1,60 \mathrm{~m}$ de profondeur. Un de ses flancs est renforcé par un mur constitué uniquement de blocs en remploi, fragments d'arc et de moulure, disposés en parpaing. Elle est ensuite comblée partiellement pour être transformée en latrines grâce à un coffrage en bois, qui permet d'en conserver le tiers oriental. Les remblais apposés contre ce gabarit ont une grande cohésion assurée par de la chaux infiltrée à l'état liquide dans les gravats meubles. Tous les niveaux de sol environnant lui étant postérieurs, nous devons admettre que cette latrine a été rapidement abandonnée, dans le courant du XVII ${ }^{\mathrm{e}}$ s. Il est possible qu'elle n'ait été utilisée que lors du chantier. Celui-ci consiste, pour ce que nous avons pu voir, à refaire les façades, établir de nouveaux sols et creuser des caves. L'élévation nord montre que, sur l'assise en tuf, une seconde en pierre de taille de La Couronne, légèrement débordante, pourrait ne pas avoir été construite dans la foulée de la première. Une calade occupe une moitié de l'espace nord-est, à l'angle des deux rues, alors qu'un sol en terre battue, peut-être le soubassement d'un sol bâti récupéré, couvre l'autre moitié ( $c f$. fig. 83). Entre les deux, des petits piliers de briquettes pourraient correspondre à une cloison légère. L'agencement des galets de la calade (cf. supra $§$ 2.2.2.) suggère des aménagements en matériaux légers qui auraient disparu : pieux en bois, cloison, cuve. L'espace le plus à l'ouest est également pavé de galets. Au sud, les murs des caves présentent un découpage par panneaux de $70 \mathrm{~cm}$ à $1,30 \mathrm{~m}$, caractéristique des sous-œuvres, attestés par les négatifs de boisages en forme de $\mathrm{T}$, retrouvés à l'intérieur de la maçonnerie et destinés à soutenir la fondation. La première cave, au sud-ouest, est approximativement carrée, de $6 \mathrm{~m}$ de côté. Elle est couverte de quatre voûtes d'arête en briquettes reposant sur un pilier central fait de blocs de calcaire rose avec un chapiteau chanfreiné. Les retombées se font sur des culots également en calcaire de La Couronne. Le sol est caladé et marqué par des rigoles, matérialisées par des galets alignés et convergentes vers le centre. L'autre cave mesure $9,50 \mathrm{~m}$ de long pour $5 \mathrm{~m}$ de large. Elle est voûtée en berceau comme l'attestent deux assises de blocs de grès taillés. Elle possède un escalier d'accès, fait de marches en calcaire rose, adossé contre le mur mitoyen avec l'autre cave avec laquelle elle est reliée par une porte de $1,20 \mathrm{~m}$ de large. Un puits lui fait face, dont le diamètre est réduit au sommet par une arcature de briquettes avec chaînage d'angle en pierre dans lequel est pratiquée une ouverture. Il est probable que dans un premier temps, l'escalier ne desservait que le puits et la cave située à l'ouest, avant que toute la cave orientale ne soit creusée. Le sol est pavé de briquettes de $26 \mathrm{~cm}$ par $13 \mathrm{~cm}$, avec fil d'eau central. Les espaces au nord subissent également 
des modifications au XVIII ${ }^{e}$ s., qui consistent essentiellement à rehausser les sols pour les remplacer par des pavements de carreau de terre cuite.

Jusqu'à la fin du XVI ${ }^{\mathrm{e}} \mathrm{s}$, il est trop difficile, et risqué, d'établir des correspondances entre les textes d'archives et les données de terrain. À l'Époque moderne, des habitations à l'angle de la rue de la Taulisse (ex Pierre-de-Servian) et de la Guirlande sont mentionnées dans de nombreuses transactions, trop nombreuses même puisqu'il subsiste des espaces non localisés. Il s'agit pour la plupart de «parties de maison », qui sont cédées, parfois simplement des étages. Ces lots sont tellement imbriqués qu'il est impossible d'en cerner la topographie complète. De plus, si la généalogie parcellaire peut être établie autour de 1560, il subsiste un grand hiatus jusqu'en 1640 ; les noms changent et plus aucun lien n'existe. Après de nombreux essais infructueux, nous avons décidé de ne prendre en compte que les textes du XVII $\mathrm{s}$.

Il reste que la multiplicité des propriétaires est incompatible avec une parcelle unie par des façades uniformes. Nous devons admettre que, dès le $\mathrm{XVI}^{\mathrm{e}} \mathrm{s}$., c'est un immeuble unique qui a été divisé en lots acquis par de multiples «copropriétaires » que de Gérente rachète dans la totalité à partie de $1643^{650}$. La totalité de la parcelle est ensuite rachetée progressivement par J. Fouquier entre 1662 et $1665^{651}$, qui la revend complète à Catherine de Vias en $1668^{652}$. Celle-ci la fait rebâtir ${ }^{653}$ et la revend à J. Tisseur en 1672 dont le père la revend à son tour au même Fouquier en $1679^{654}$. De telles transactions sont davantage l'apanage d'investisseurs que de propriétaires habitant sur place. Le fait de n'avoir trouvé en fouille que les fondations des murs nous prive d'éventuelles ouvertures dans les murs qui auraient pu nous éclairer sur le lien éventuel entre les espaces et donc sur leur appartenance à une seule famille ou non.

En fin de compte, les textes, pourtant nombreux, amènent plus de questions qu'ils ne nous aident. En particulier le devis de 1668 , où le maçon est tenu de «desmollir toute lad. maison et de rebastir de neuf (...) faisant le fondement de massonerie jusques au ferme », alors que nous supposons que les fondations remontent au XVI ${ }^{\mathrm{e}} \mathrm{s}$. Force est d'admettre que leur massivité explique pourquoi l'entrepreneur les a jugées suffisantes et a repris uniquement les élévations. Les travaux de

650 AD13 353 E 87ter, fol. 352 ; AD13 353 E 88, fol. 451 ; AD13 353 E 88 fol. 988.

651 AD13 391 E 391, fol. 978 ; AD13 394, fol. 845

652 AD13 393 E 87, fol. 457.

653 Devis AD13 393 E 87, fol. 580.

654 AD13 394 E 29, fol. 694v. l'entrepreneur Bouisson correspondent donc plutôt à la reconstruction de la façade en calcaire rose. C'est le même maçon qui "fera les crottes de la cave ». Il est peu probable que l'édifice ait été rasé par la suite, car si le prix-fait de 1668 a été suivi d'effet, le bâtiment est suffisamment robuste pour traverser les siècles. Les travaux de réfection des caves comme des sols n'ont certainement pas affecté les superstructures.

\subsubsection{Parcelle 361 : intégration d'un bâti médiéval}

Le bâti installé sur la parcelle 361 est en grande partie fondé sur des constructions d'époque médiévale, ce qui explique l'aspect irrégulier et étriqué des différents espaces qui le composent (Sillano 1997). Seuls le refend est-ouest et la limite méridionale sont attribués à l'Époque moderne. Mais, là encore, il est difficile de savoir quand et comment cette parcelle s'est constituée, en particulier à cause des caves qui ont éliminé toute la séquence stratigraphique. L'étude de cette parcelle semble indissociable de celle des parcelles voisines 362 et 371. En effet, compte tenu de la pente du nord vers le sud, les parcelles situées au sud de l'îlot ne pouvaient se permettre d'avoir des caves profondes, en raison de la proximité de la nappe phréatique, ce qui n'était pas le cas des parcelles situées au nord de l'îlot. Il s'ensuit que les caves, toutes placées au nord, font l'objet d'un partage entre l'ensemble des propriétaires.

Les pièces s'organisent autour d'un petit espace central, adossé au mur oriental, dans lequel un puits et un escalier nous font reconnaître un espace ouvert (un mur massif traverse la parcelle de part en part, il correspond à un contrefort pour les immeubles au sud, établi après la démolition du bâti en 1943). Au sud, la cave mesure 7,50 m par $5 \mathrm{~m}$. Ses murs sont bâtis en sous-œuvre, mis à part le mur méridional, trop arasé, pour lequel nous ne pouvons rien dire. Le seul aménagement interne est un carrelage de terre cuite, avec fil d'eau orienté vers une auge, qui a fait l'objet de multiples réfections. Au nord de l'escalier, une petite cave a également été installée en sous-œuvre. Les parements ont été réalisés en portions de 1 à $2 \mathrm{~m}$ de large, ils sont de conception très hétérogène et leur sommet s'adapte à la base de la fondation au moyen de briquettes. Le sol est pavé de carreaux de terre cuite à double pente convergeant vers un fil d'eau axial orienté vers une auge enterrée au nord. L'escalier est tournant et ses marches sont couvertes de carreaux de terre cuite. La cave ouest est de taille moyenne, ses murs sont bâtis en sous-œuvre, sauf peut être le mur occidental qui semble traité d'une seule pièce (fig. 218). Il est structuré par trois piliers engagés faits de blocs de calcaire de La Couronne qui soutiennent une voûte d'arête en briquettes, partiellement conservée. Côté est, les mêmes piliers existent ; 


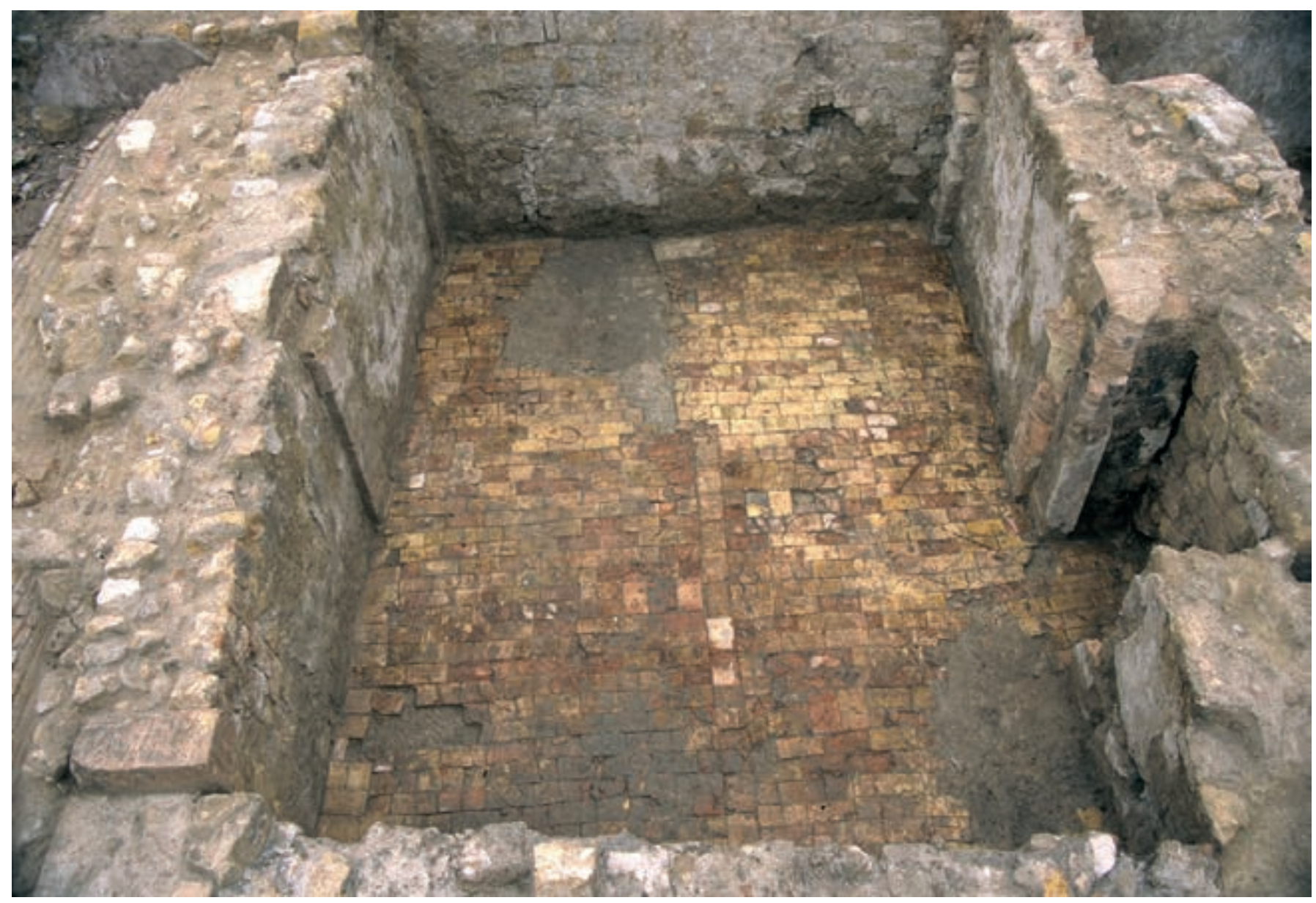

Fig. 218. Le sol de la cave de la parcelle 361 (cl. M. Derain/Inrap).

celui qui est au centre sert également de piédroit à l'ouverture qui donne accès à l'escalier. Celle-ci est couverte d'un arc en plein cintre de même nature. Le sol est également pavé de carreaux de terre cuite avec fil d'eau et auge contre le mur septentrional.

Le rapport de future cautelle de Ricard contre Vento, établi en $1657^{655}$, est une aide précieuse pour saisir l'organisation du bâtiment, bien qu'il soit difficile à comprendre. Les nombreuses mentions de la «maison du sieur Savignon » qui y sont faites indiquent d'emblée son lien avec la voisine (parcelle 362). Ainsi, il est question d'une boutique prenant son entrée et le jour dans la cour de l'autre maison. Plus loin est mentionné un couloir qui aboutit à une chambre de l'autre maison. La servitude de passage est donc réciproque ce qui indique clairement que non seulement les deux maisons appartenaient à la même personne, Marc-Antoine de Vento, mais aussi qu'elles étaient indivisibles. Au soussol, la seule pièce mentionnée est un cellier auquel on

655 AD13 391 E 386, fol. 817. accède par 13 marches, ce qui sous-entend qu'il s'agit d'une cave (le terme cellier peut être employé car on lit que son plafond n'est pas voûté mais en planches). Les dimensions, $3 \mathrm{~m}$ par $5 \mathrm{~m}$, ne correspondent pas à la cave occidentale; elle a dû être étendue par la suite. L'autre cave, à l'est, n'est pas encore creusée et la cave méridionale est déjà en liaison avec la parcelle 371 (cf. infra $\S$ 3.4.10.). Au rez-de-chaussée, en entrant dans le couloir, se trouve une boutique à gauche, qui est nécessairement la pièce orientale (bien que les dimensions ne correspondent pas exactement ; la pièce fouillée est plus courte d'un mètre). De l'autre côté, une autre boutique prend jour à la rue alors qu'elle s'ouvre vers la parcelle voisine. Au fond, une arrière-boutique, puis le ciel ouvert et la vizette. Il est difficile de faire rentrer toutes ces pièces dans l'espace de l'escalier et celui qui lui est attenant au nord, mais en admettant que le couloir est dans l'axe de la parcelle, on peut supposer que le magasin est très étroit et s'étend jusqu'au-dessus de l'escalier. Au premier étage, nous trouvons une salle et une cuisine ouvertes sur la rue, une chambre ouverte sur le ciel ouvert du voisin et une autre ouverte sur le ciel 
ouvert de la maison. S'ajoute un couloir qui aboutit à la cuisine du voisin. Au second étage, se trouve une vaste salle avec cheminée, une chambre au-dessus et de même dimension que la cuisine, et derrière, également une chambre et arrière-chambre comme au premier étage. $\mathrm{Au}$ troisième et dernier étage, sont mentionnés une salle et un galetas.

\subsubsection{Parcelles 362 et 371 : des parcelles traversantes}

La parcelle 371, ouverte sur la rue des Olives, a été, comme le démontrent les textes, reliée à la parcelle 362, ouverte sur la rue de la Taulisse, au nord, formant ainsi un ensemble qui traverse l'îlot de part en part. Ce n'est qu'au XVIII' s. que la scission, visible sur le cadastre napoléonien, est perceptible. La première parcelle accueille un bâtiment dont le rez-de-chaussée, de plainpied avec la rue, se trouve au même niveau que les caves de la seconde. La différence d'altitude entre les deux rues explique ce décalage. Nous verrons que dans les faits, ces parcelles accueillent des habitations différentes et très imbriquées puisque les possessions s'étendent même sous les parcelles voisines.

La parcelle 362 acquiert ses contours au Moyen Âge; les murs médiévaux, soigneusement appareillés, sont encore présents dans le bâti détruit en 1943 (Paone 1997b, secteurs 2, 7 et 9). Les premières constructions d'Époque moderne sont deux caves, installées en sousœuvre ( $c f$. fig. 109). La première, au nord, mesure $6 \mathrm{~m}$ par $4 \mathrm{~m}$ et elle est voûtée de briques disposées en berceau qui reposent sur un ressaut de pierre tendre. La seconde est également voûtée en berceau, le ressaut n'étant présent qu'à l'est. Elle renferme un escalier tournant, aux marches en calcaire de La Couronne, dont le remblai sous-jacent contient du mobilier daté du milieu du XVII ${ }^{\mathrm{e}}$ s. Le premier sol conservé est fait de briques et possède une auge enterrée. Un puits est présent à l'est, également ouvert de l'autre côté sur la cave de la parcelle 361. La margelle est faite de blocs de calcaire rose en remploi ; le puits est abandonné dans le courant du XVIII' s. Cette pièce est subdivisée en deux dans un second temps, la partie sud, désormais isolée de l'escalier, n'étant plus accessible que depuis la parcelle 371. L'autre est dotée d'une banquette de $80 \mathrm{~cm}$ de large qui court le long de la nouvelle cloison. La cave septentrionale reçoit le même aménagement. La banquette, large de $1,30 \mathrm{~m}$ pour $40 \mathrm{~cm}$ de hauteur, fait tout le pourtour de l'espace, en dehors du côté sud où existe l'ouverture. Elle est réalisée avec des murets de blocs et moellons de calcaire tendre contre lesquels sont apposés des remblais qui soutiennent un carrelage de terre cuite.
A l'occasion de ces travaux, les pavements des deux caves sont refaits. La nouvelle cave au sud communique avec le rez-de-chaussée du bâtiment voisin par une porte faite de briquettes d'un côté, de moellons de l'autre, avec un léger emmarchement en pierre de taille. Elle communique également vers l'est avec la cave située sous la parcelle 361 par une porte aux piédroits et seuil en calcaire de La Couronne.

La caractéristique principale de la parcelle 371 est la présence d'un réseau de canalisations d'eaux usées. Celui-ci, probablement installé dans un espace ouvert, une cour ou jardin dépendant de la parcelle 362, a subi de multiples réaménagements. Le détail en est décrit plus haut (cf. supra $§ 3.2 .2$.) ; nous n'évoquerons ici que leur organisation. Le premier ne traverse pas toute la parcelle du nord au sud, car il fait un coude vers l'ouest afin de contourner le bâtiment voisin de la parcelle 372 (cf. supra § 3.4.4.). Ensuite, il est prolongé vers le nord pour recueillir les eaux de la parcelle 362 . Ultérieurement, un puits obture la ramification occidentale, avant que celle-ci ne soit recréée un peu plus au nord. Le mobilier recueilli dans les niveaux d'abandon de ces structures date de la fin du XVII ${ }^{\mathrm{e}} \mathrm{s}$.

Nous possédons deux expertises de ces parcelles réalisées à la suite de transaction. La première date de 1657 et mentionne les deux parcelles ${ }^{\mathbf{6 5 6}}$. Pour la parcelle 362 , il est question d'une cave de $6 \mathrm{~m}$ par $7 \mathrm{~m}$, ce qui pourrait correspondre à la cave nord augmentée de la cave centrale hors banquette. La mise en place de l'escalier vers le milieu du XVII ${ }^{\mathrm{e}}$ s., compatible avec ces dates, indique que la cave a été creusée peu avant. Une autre expertise est faite en $1699^{657}$, suite à la scission de la parcelle en deux. Il apparaît que des travaux ont été réalisés entre les deux dates: en particulier la cave a été étendue à toute la parcelle 362 et la cave sud à été cédée à la parcelle 361 voisine. La banquette caractéristique du stockage de fûts de vin, semble être tardive puisque ce n'est qu'en 1937 qu'est mentionné un «bar-restaurant, vins et liqueurs ». Une mise en place dès le XVIII' ${ }^{\mathrm{s}}$., où nous avons un hiatus textuel, n'est cependant pas exclue. Pour le reste, le texte est difficile à interpréter, la seule certitude est qu'il s'agit d'un immeuble de trois étages avec une salle, une cuisine, neuf chambres, un cabinet, un galetas et un pigeonnier.

Pour la parcelle 371 , le puits a été installé entre les deux transactions puisqu'il est mentionné dans la seconde et pas la première. Les canalisations ne sont en revanche jamais mentionnées, mais étant en sous-sol, cela n'implique pas leur absence. L'hypothèse d'un espace ouvert n'est plus valable en 1657 car alors la parcelle 371 est

656 AD13 391 E 385, fol. 642v 657 AD13 361 E 87, fol. 710. 
bâtie et possède au moins un bâtiment, côté rue, de $10 \mathrm{~m}$ de long, avec cour et escalier en retrait. En 1699, ce bâtiment possède, par calcul du nombre de marches mentionnées, quatre ou cinq étages. Lui est adjoint un second immeuble en fond de parcelle, de l'autre côté d'une cour où se trouve un escalier. Les étages ne se correspondent pas, quelques balcons en assurent la liaison. Une seule des deux caves du fond porte cette dénomination, l'autre est qualifiée de cellier. On dénombre au total deux magasins, un cellier, une cave, une cuisine, deux salles, cinq chambres, un pigeonnier, un lieu commun et une terrasse. Rétrospectivement, la bipartition de l'espace en 1699 nous éclaire sur le texte de 1657. Le magasin bordé d'un couloir n'était alors qu'une unique salle à travers laquelle il fallait passer pour accéder au fond. Il n'est surmonté que de deux étages plus une charbonnière sous le toit. Le bâtiment en fond de cour se réduit à un petit magasin, il n'y a pas encore de caves.

\subsubsection{Parcelles hors emprise de fouille : 354,355 , 356 et 363}

Les quatre parcelles situées à l'angle nord-ouest de l'îlot sont hors d'emprise de fouille. En revanche, nous possédons le plan de certaines d'entre elles, dressé en 1931, ainsi qu'une description de la parcelle 356 en $1937^{658}$.

La parcelle 363 est de forme pratiquement quadrangulaire et relativement grande $(8,50 \mathrm{~m}$ par $12 \mathrm{~m})$. Au rez-de-chaussée, elle est subdivisée en deux parties, selon une transversale d'axe nord-sud, dont le module n'est pas sans évoquer deux parcelles médiévales. L'existence d'une rue dans le prolongement de la rue du Coq-d'Inde contredit cependant cette hypothèse. Au sous-sol, elle est aménagée par une grande cave de $6,50 \mathrm{~m}$ par 8,50 m avec pilier central.

La parcelle 356 est large de 6,50 m et longue de $15 \mathrm{~m}$, tout comme sa voisine, la parcelle 355 , peut-être un peu moins large. Sachant qu'elles sont bordées aux deux extrémités par des rues, dont une disparue, il est aisé d'y reconnaître des parcelles médiévales subsistant à l'Époque moderne. La parcelle d'angle possède deux parties distinctes, ouvrant chacune sur une rue différente, séparées par les escaliers et circulations. Le descriptif de 1937 cite, pour le troisième étage, une «pièce sur courette ». Cet espace ouvert n'étant pas mentionné audessous, il ne peut se situer que dans la parcelle 355. À l'instar de la parcelle 372, le bâti a été contraint de ménager une cour afin d'éclairer les pièces en cœur d'îlot.

658 ACM 8 O 20.

\subsection{Autres îlots en bordure des fouilles (B. Sillano)}

Bien que la fouille ait surtout concerné la place Villeneuve-Bargemon, l'étude d'archives a permis de mieux connaître l'ensemble des îlots situés alentour.

\subsubsection{Illot IV : à l'est du pavillon Bargemon}

Cet îlot, disparu en 1833 pour créer la place Villeneuve, est hors d'emprise de fouille. Le cadastre napoléonien indique l'existence de vastes parcelles. Quelques textes nous renseignent sur les deux parcelles d'angle 379 et 383. L'un d'entre eux est un devis qui concerne la maison que fait édifier C. Cazaulx en 1593 (parcelle 379). Il s'agit d'un édifice de prestige dont les carages (façades), en pierre de taille garnies «par derrière de toute pierre ${ }^{\mathbf{6 5 9}}$ ", seront « des mesmes façons faicts et ordonnance de celluy de la maison de Lazarin Nineau escuyer ${ }^{\mathbf{6 0 0}}$ (...) qui est faite de tailhe ormis les niches qu'ils n'y feront diversifiant touteffois lesd. piedz. droitz que seront canellés ». La construction de cette maison est interrompue par l'assassinat de Casaulx, puis, après un temps d'abandon, reprise par Mazerat en 1611. Le rapport de visite ${ }^{661}$ précise alors que la maison s'est beaucoup dégradée en l'absence de toit ${ }^{\mathbf{6 6 2}}$; nous pouvons supposer que l'élévation, haute de $9 \mathrm{~m}$, n'est pas finie. Un rapport de visite établi en $1674^{663}$, nous décrit la maison terminée. Elle est somptueuse, avec des plafond hauts de $5 \mathrm{~m}$, des fenêtres immenses $(2 \mathrm{~m}$ de large pour $3 \mathrm{~m}$ de haut) et une décoration abondante («frise de peinture de quelque mistère » dans une salle, «chérubins et décor darchitecture » autour de la porte de cette même salle). Les façades ont $15 \mathrm{~m}$ de haut (un rez-de-chaussée de $3,50 \mathrm{~m}$ de haut, et trois étages respectivement de $5 \mathrm{~m}, 4,25 \mathrm{~m}$ et $4 \mathrm{~m}$ de haut) et « jusques a la dernière coudière du plus hault est de pierre de taille et le restant jusques au touet de six pans dautheur de massonnerie et à chacune croisière y a un pilastre et cornisse par dessus fronton et chapiteau et une niche sur le coing sans aucune figure ». De plus, «la grande porte de la rue a onze pans et demy d'haulteur (environ $3 \mathrm{~m}$ ) et sept et demy de long (environ $2 \mathrm{~m}$ ) avec son pillastre de chasque costé de la cornisse par-dessus le tout en pierre de taille ». La parcelle 383, dans le même îlot, acquise par B. Callamand en 1646, présente des similitudes.

659 AD13 360 E 30, fol. 679.

660 «Faisant coing en la rue de la croix blanche venant de leglise des accoule à la loge... à la grand rue de la Loge ».

661 AD13 360 E 47, fol. 746.

662 «Estant ruyneux et crevassé en plusieurs endroictz par la longueur de temps quont souffert les eaux pluviales ».

663 AD13 391 E 403, fol. 500v. 
Les experts la visitant ont trouvé la façade, sur la rue de la Guirlande, «bastie de pierre de tailhe despuis le plan de la rue jusques a la coudière des fenestres du plus hault et dernier estage et pour le restant dud. carage quest de l'hauteur de cinq pans (1,25 m) jusques au toed est bastie de massonerie ${ }^{\mathbf{6 6 4}} \gg$. Ces constructions, avec frontons, chapiteaux et piédroits cannelés sur la façade de Casaulx, sont empreintes de l'esprit classique.

\subsection{2. Îlot $V$ : le pavillon Bargemon}

En 1715, période de reconstructions en bas de la rue de la Prison, J. de Curet fait entièrement rebâtir sa maison ${ }^{665}$ (probablement la partie nord de la parcelle 482). En 1719, c'est «la maison où était le bureau de Poste » qui est reconstruite ${ }^{\mathbf{6 6 6}}$. Elle est située dans la partie méridionale de la parcelle 482 et mesure, dans le rapport de 1716, $9 \mathrm{~m}$ de long sur la rue de la Prison. C'est l'une des premières acquisitions de la Ville destinée à agrandir l'Hôtel de Ville, nouvellement construit, vers ce qui deviendra le pavillon Bargemon.

L'idée de ce pavillon prend corps en 1740 avec la destruction d'immeubles vétustes dans la partie orientale (parcelle 482 est) alors que la partie occidentale est simplement étançonnée (parcelle 482 ouest). La reconstruction a fait l'objet de multiples projets et c'est celui d'Esprit Brun qui a été retenu. Les travaux ont eu lieu entre 1782 et 1786 , mais ne furent pas terminés. La partie ouest (l'ancien bureau de poste) ne sera démolie et rebâtie qu'en 1791. La place Villeneuve-Bargemon est créée en 1826 par suppression de huit immeubles. Les maisons situées au nord du pavillon Bargemon, le long de la rue des Olives, ne sont rachetées qu'en 1848.

\subsubsection{Illot VI : la maison du Roi}

Une série de textes nous apprennent que le bâti le long de la rue de la Prison, dans sa partie méridionale, subit de grosses modifications au XVII ${ }^{\mathrm{s}}$ s. Ces travaux sont à mettre en relation avec un projet d'alignement de la rue évoqué dans de nombreux actes. Ils font suite à la démolition de l'ancienne Maison du roi ${ }^{667}$, dont les travaux ont également ébranlés les maisons en vis-à-vis, soutenues par des contreforts en bois transversaux.

664 AD13 391 E 376, fol. 901v.

665 AD13 363 E 250, fol. 393.

666 Devis estimatif du 8 mars 1719, texte dont la source est inconnue. 667 Bouyala d'Arnaud nous apprend qu'à l'occasion de la visite du Duc de Mercœur, qui logeait à la Maison du roi, en 1659, il fût tiré tant de coups de canons que la maison s'en trouva ébranlée. Elle fût condamnée à la démolition (Bouyala d'Arnaud 1959, p. 169).
Le terrain est alors morcelé puis partiellement revendu. En 1713, H. de Rome d'Ardenne passe un prixfait pour la reconstruction de sa maison, qui correspond probablement aux parcelles 343,344 et $345^{\mathbf{6 6 8}}$. La même année, la parcelle 346, qu'achète Crozet, n'est qu'une place à bâtir maison ${ }^{\mathbf{6} 9}$. Les vestiges mis en évidence par les fouilles de l'Espace Bargemon et de la place JulesVerne correspondent à l'édifice qu'il fait probablement édifier peu après.

Seules les fondations ont été conservées. Elles présentent la particularité de reposer, outre sur un alignement de gros blocs taillés, sur une poutre sablière (fig. 219). Le reste, en poudingue, est irrégulier et lié par un mortier jaune très induré. Nous pouvons faire une analogie avec un devis, daté de 1719 , établi pour la maison au sud de la parcelle $482^{670}$. Il y est dit «premièrement on creusera les fondements de ladite maison lesquels a les estrémités de l'eau de deux pans et demi d'épaisseur que l'on pilotera avec des pilotins de bois de pin d'environ une main ouverte d'épaisseur de trois rangs dans l'épaisseur de la muraille et par-dessus desdits pilotins y sera mis le bordage de chêne vieux d'environ un tiers de pan d'épaisseur cloué sur les pilotins à neuf livres la canne. De plus on mettra deux rangs de pierre de taille brute au fondements sur le bordage de chêne qui fera épaisseur de murailles posé avec du bon mortier faict de chaux et de sable de mer. De plus toute la pierre de taille sera de la Corone et réceptable et bien taillée esquarrie avec son architecture nécessaire posée et regrillée à seize livre la canne ». La suite nous indique que les façades, «bâties avec de bonnes pierres poutrières », seront enduites. La mention de l'eau, bien que difficile à saisir, renvoie à une condition sine qua non de l'utilisation de telles fondations : la présence de la nappe, qui garantie la conservation des pieux. Nous voyons ici que la pierre de La Couronne n'est utilisée qu'en fondation et a été taillée pour cette construction.

Ce type de fondation est ensuite utilisé, mais de manière amplifiée, lors de la construction de la façade et de l'escalier d'Esprit Brun en 1780. Les pieux ont un diamètre moyen de $0,40 \mathrm{~m}$, sont espacés tous les $20 \mathrm{~cm}$ et supportent un bordage de chêne.

668 AD13 391 E 242, fol. 514v. Nous apprenons dans un acte établi 4 ans plus tard qu'il possède deux maisons, correspondant pour la première aux parcelles 343 et 344 et pour l'autre à la parcelle 345 . 669 AD13 391 E 424, fol. 71v.

670 Nous ne connaissons les sources de ce texte. Il concerne une maison où était le bureau de poste tout proche de l'Hôtel de Ville appartenant à la communauté faisant coin de la rue qui va aux Accoules. La similitude entre les dates de construction et dans la localisation pourrait laisser envisager qu'il s'agit du même type de construction appliqué en deux endroits proches. 


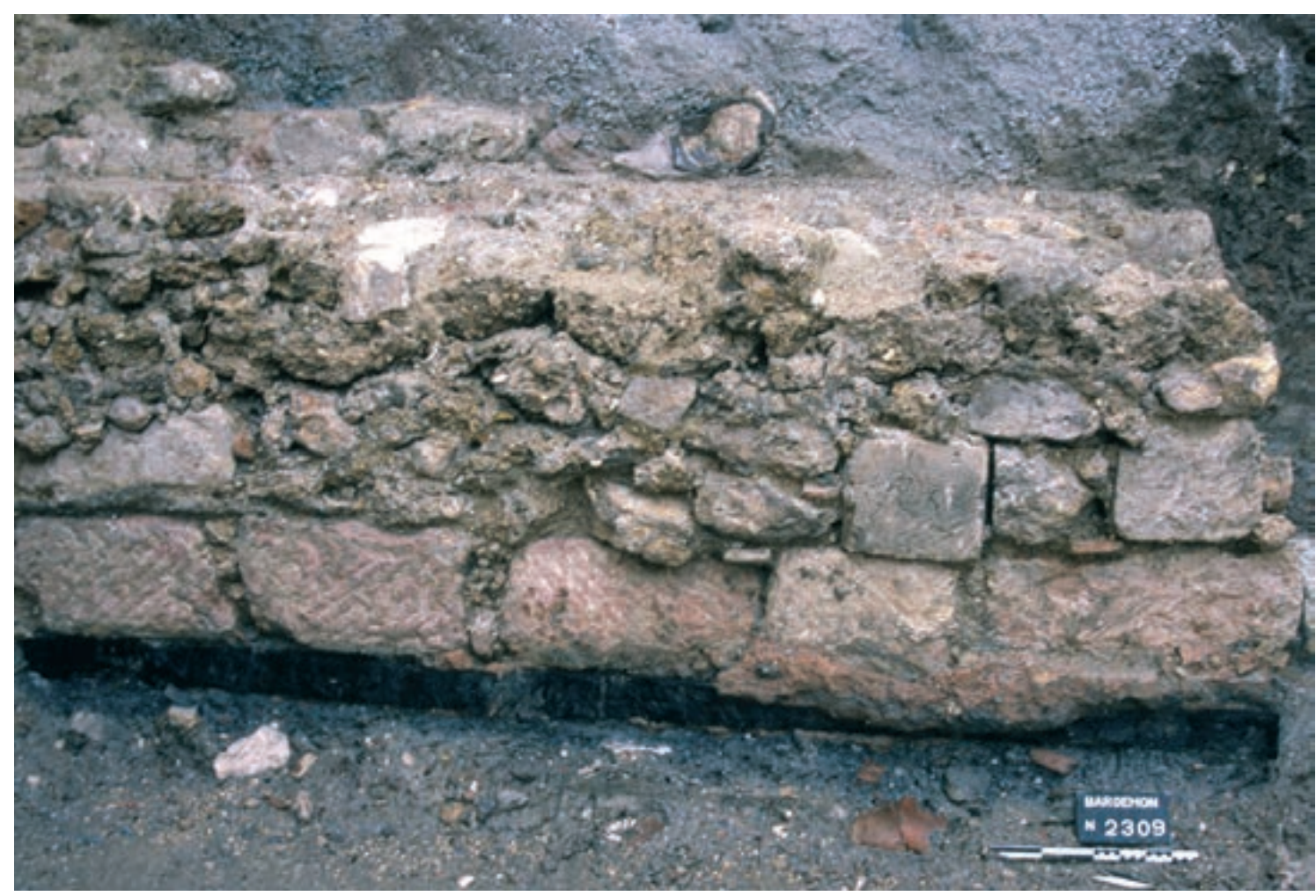

Fig. 219. La fondation de la façade de l'Hôtel de Rome d'Ardennes (cl. T. Maziers/Inrap).

\subsection{Conclusion}

Les trois îlots concernés par les fouilles, auxquels s'ajoute le secteur du Petit Mazeau, illustrent donc autant de manières différentes de traiter le parcellaire médiéval pour l'adapter au module architectural généré au $\mathrm{XVI}^{\mathrm{e}} \mathrm{s}$. Ces transformations obéissent également aux spécificités de chaque secteur qui se dessinent alors (fig. 220).

\subsubsection{Un quartier bipolaire}

Au nord, le quartier des bouchers se constitue autour d'un noyau formé par les bancs et se voit percé de multiples ruelles facilitant le large drainage de la population. Les parcelles périphériques, comme celles à l'est de la rue de la Guirlande, sont occupées par des boutiques et des rôtisseries ${ }^{671}$. En cela, le bâti médiéval étriqué convient parfaitement, ce qui pourrait expliquer sa conservation.

$\mathrm{Au}$ sud, la proximité du port et de la Loge confère d'emblée au secteur un caractère fastueux. La Maison du roi et l'Hôtel de Remezan en sont deux exemples précoces. Au XVI ${ }^{\mathrm{e}}$ s. s'installent l'Hôtel de Jarente et la parcelle 386, futur Hôtel de Vias. Dans l'îlot plus au sud, Casaulx entreprend, en 1593, la construction d'une

$\mathbf{6 7 1}$ Ce terme regroupe également les pâtissiers et boulanger car à cette époque un même four pouvait avoir de multiples usages. vaste demeure (parcelle 379) qui, abandonnée pendant un temps après de son assassinat, sera terminée par Mazerat. La maison Curet (parcelle 369), en vis-à-vis avec la maison du roi, mesure, en 1716, 27,50 $\mathrm{m}$ le long de la rue de la Prison «y compris l'ancienne maison». Dans le même rapport nous apprenons que la maison qui sera englobée dans la construction du nouveau Palais de justice mesure $17 \mathrm{~m}$ de long. Nous savons également, par un acte de vente antérieur ${ }^{672}$, qu'elle a appartenu à la famille de Saint-Victoret et qu'elle était bordée par trois rues, c'est-à-dire qu'elle occupait toute la largeur de l'îlot. Les parcelles 399, 383 et 384, également très vastes, se sont constituées au XVII ${ }^{e}$ s. par agrégation de parcelles plus petites.

Entre ces deux pôles, l'îlot central, en liaison avec le Petit Mazeau qu'il borde, accueille des auberges. À l'ouest, le Logis du Coq d'Inde ${ }^{673}$ disposé, fait rarissime, parallèlement à la rue ; à l'est, le Logis du Rozier, vaste maison rectangulaire. Le Logis de la Taulisse ${ }^{674}$, coincé entre les deux, est tout en longueur et traverse l'îlot. Il s'est constitué tardivement par regroupement de deux parcelles. Sur la même rue, à l'ouest du Petit Mazeau,

672 AD13 360 E 70, fol. 71, daté de 1634.

673 Il appartient à Jean des Oliviers en 1593 (ACM fonds Bertas 20 ii 108).

674 Mentionné en 1591 (ACM fonds Bertas 20 ii 112). 


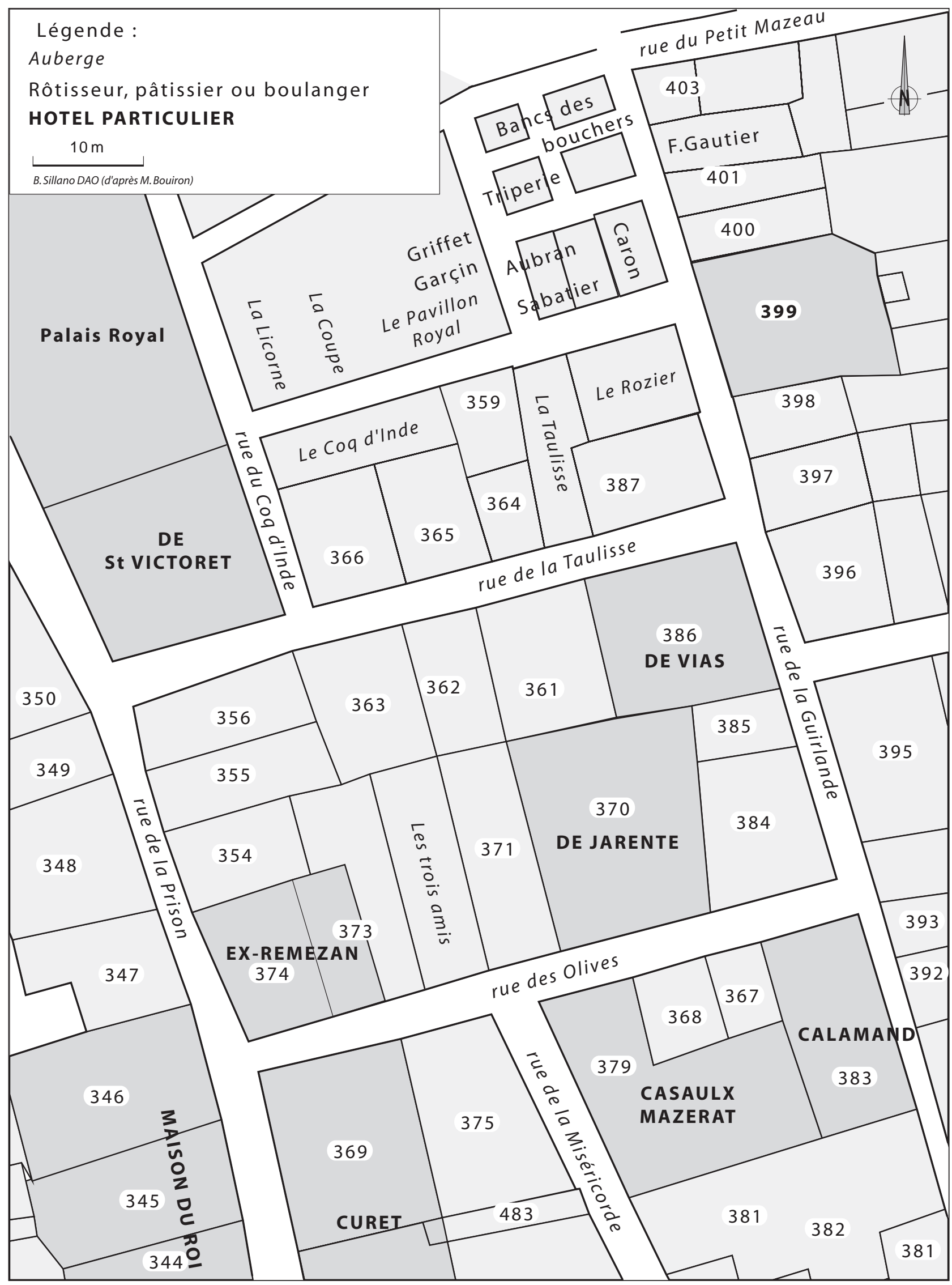

Fig. 220. Hôtels particuliers, boutiques et auberges aux XVIle et XVIII $\mathrm{s}$. dans le quartier de la Loge (DAO B. Sillano/Inrap). 
s'alignent les auberges de La Licorne et de La Coupe, appartenant toutes deux à Jacques Gautier, ainsi que celle du Pavillon Royal, appartenant à Jean Escuyer.

\subsubsection{Les premières habitations modernes}

Deux édifices témoignent d'une activité constructive au XVe s., ce sont la maison du Roi René, qui occupe les parcelles 343 à 346, et, en vis-à-vis, l'Hôtel de Remezan (parcelles 374 et 373 ouest), dont l'existence a été révélée par la fouille. Mais il semble que ce soit au $\mathrm{XVI}^{\mathrm{e}} \mathrm{s}$. que la plupart des habitations adoptent une configuration qu'elles conserveront jusqu'à leur démolition en 1943, à quelques modifications près. Du point de vue archéologique, ceci reste bien sûr une hypothèse dans la mesure où, nous ne le répèterons jamais assez, peu d'unités stratigraphiques susceptibles d'apporter des datations nous sont parvenues. Les textes d'archive recueillis, qui couvrent essentiellement le XVII ${ }^{e}$ s., nous apportent cependant la preuve de l'existence d'un bâti bien antérieur et nous éclairent indirectement sur l'occupation au $\mathrm{XVI}^{\mathrm{e}} \mathrm{s}$.

Dans l'îlot sud, nous voyons coexister de vastes hôtels particuliers, comme l'Hôtel de Jarente ou de Vias (parcelles 370 et 386), avec de petits immeubles à deux étages (parcelle 384 est et 384 ouest) ou des maisons isolées (parcelle 372 sud). Cette dernière, organisée autour d'une cour intérieure nantie d'un puits, comprend un bâtiment en façade et un bâtiment en fond de parcelle. Cette disposition est relativement courante à cette époque, comme cela a été observé à Lyon lors des fouilles de la presqu'île (Arlaud 2000, p. 232-250). Nous constatons qu'à l'origine le cœur de l'îlot III est largement occupé par des jardins, comme on les apperçoit nettement sur le plan Maretz (vers 1630, $c f$. fig. 10), bien que la topographie des rues soit inexacte.

Dans l'îlot I, si les limites médiévales sont conservées, le rattachement des lots en cœur d'îlot à des parcelles en bordure de rue permet d'agrandir l'espace disponible. L'exemple de la parcelle 402 nous montre cependant qu'à la fin du XVI ${ }^{\mathrm{e}}$ s., cet espace n'est toujours pas traité dans sa globalité puisque le bâti originel, le long de la rue, est toujours dissocié d'un bâti plus léger en cœur d'îlot. De même, la parcelle 400 ne semble s'approprier l'espace mitoyen en cœur d'îlot que tardivement et en commençant par les étages (cet espace appartenait tout d'abord à la parcelle à l'est). Enfin, la parcelle 401 n'est reliée à sa voisine au nord qu'à partir du XVII ${ }^{\mathrm{e}} \mathrm{s}$. Si l'on ajoute la pérennité du bâtiment médiéval, qui n'est remodelé que plus tard, nous pouvons considérer que le bâti, tout au moins dans ses limites extérieures, est, au début du XVIe s., le même que celui du XIVe s.

En raison des réaménagements postérieurs et surtout des caves, nous ne possédons pas de traces tangibles des aménagements internes des maisons du XVI ${ }^{\mathrm{e}} \mathrm{s}$. Dans certains cas, la forme de la parcelle est tellement liée à la distribution intérieure que nous pouvons supposer qu'elle ne subit pas de modification. Il en va ainsi des parcelles 357, 387, 386 et 365, d'un module d'environ $12 \mathrm{~m}$ par $8 \mathrm{~m}$. Divisées en deux transversalement, un coté est occupé par une pièce (donc de $6 \mathrm{~m}$ par $8 \mathrm{~m}$ ) pendant que l'autre est encore subdivisé pour réaliser une petite pièce et, en cœur d'îlot, un ciel ouvert où se trouve l'escalier. Nous ne possédons aucun texte suffisamment ancien pour connaître le nombre d'étage à l'origine. À la fin du XVII ${ }^{e}$ s., les parcelles 357,387 et 360 n'en possèdent que trois, plus éventuellement un quatrième derrière, sous le toit. Il s'agit très probablement de leur état initial.

Dans quelques cas, les textes nous éclairent sur les premières habitations. Ainsi, les deux maisons accolées dans la parcelle 384 ont un corps de bâtiment, une visette, une cour et sont élevées de deux étages devant plus une lauvisse derrière. C'est l'un des rares exemples d'escalier extérieur au bâti, configuration pourtant courante au $\mathrm{XVI}^{\mathrm{e}}$ s. Au contraire, les parcelles 402,400 et 372 possèdent toute un escalier intérieur situé au fond du bâtiment principal, contre le ciel ouvert placé en cœur d'îlot. $\mathrm{Au}$ début du XVII ${ }^{\mathrm{e}}$ s., la parcelle 402 est déjà élevée de quatre étages. La parcelle 372 n'en a toujours que trois au début du XVIII ${ }^{\mathrm{e}}$ s., alors que la parcelle 400 en a quatre.

Des caves sont également mentionnées dès le milieu du XVI ${ }^{e}$ s., particulièrement sur le secteur du Petit Mazeau, en liaison avec des bancs de boucher. La fouille et les textes permettent d'en reconnaître quelques-unes, de très petite dimension par rapport aux parcelles.

Enfin, nous ne connaissons rien de la distribution des pièces dans les hôtels particuliers, mais la puissance de certaines fondations, comme la parcelle 386 , suggère des édifices assez élevés.

\subsubsection{L'extension de la surface habitable au XVII ${ }^{e}$.}

D'un point de vue archéologique, le XVII ${ }^{\mathrm{e}}$ s. est celui qui nous a laissé le plus de vestiges car il affecte notre propre terrain d'étude, le sous-sol. En effet, à partir de l'extrême fin du XVI ${ }^{\mathrm{e}} \mathrm{s}$., les caves se généralisent et occupent toute l'emprise du bâti, parfois plus, en extension sous la rue. Cette entreprise semble répondre à un besoin accru de place, peut-être en liaison avec un commerce de plus en plus spéculatif et qui nécessite donc des stocks. Mais l'installation d'une cave au moment même où la municipalité autorise une extension sous la rue suggère également que celles-ci ont une justification pratique.

Au point de vue technique, les différences que l'on peut faire d'après le type de recouvrement des caves et les matériaux utilisés ne semblent pas significatives 
d'une évolution chronologique. La voûte en berceau montée avec des pierres est bien sûr la technique la plus ancienne. Certains rapports d'estime la citent d'ailleurs comme une preuve d'ancienneté de la maison. Mais elle est toujours utilisée au milieu du XVII ${ }^{\mathrm{e}}$ s. À l'inverse, les caves voûtées d'arête, en brique, sous les parcelles 357 et 387 ne semblent apparaître qu'au XVIII' ${ }^{\mathrm{e}}$ s., mais des textes mentionnent de telles constructions dès l'extrême fin du XVI ${ }^{\mathrm{e}}$ s. Enfin, la cave sous plancher en bois, à la mise en œuvre rapide et peu onéreuse, (mais nous laissant peu de traces) peut avoir eu de belles heures, mais elle est toujours remplacée tôt ou tard par une construction en dur.

En dehors du creusement des caves, pour la plupart installées en sous-œuvre, le XVII ${ }^{\mathrm{e}}$ s. ne témoigne pas, à travers les textes comme les données de fouille, d'une activité de construction importante. Tout au plus pouvons-nous citer quelques reconstructions complètes comme la maison que J. Griffet fait «construire et édifier de neuf dans ses longueurs et largeur » en 1637, ou même la parcelle 384, créée en remplacement de deux maisons modestes en ruine. Les devis concernent essentiellement des réfections de façade ou de murs mitoyens, mais peu de reconstructions complètes. Cette faible activité ne doit cependant pas masquer un trait important: l'extension de l'espace habitable. En profondeur tout d'abord, puisqu'il semble que les parties en cœur d'îlot, anciennes cours, voient l'installation de bâtiments annexes de petite dimension et plus ou moins élevés. En hauteur probablement, car la reconstruction d'un mur maître n'a souvent d'autre objectif que d'ajouter des étages, comme le demande J. Blanc en 1691 lorsqu'il fait établir un devis pour un «haussement d'un estage». Cette élévation est probablement moins courante qu'on ne le suppose car les rapports d'estime mentionnent souvent un nombre d'étage élevé dès le début du XVII ${ }^{\mathrm{e}} \mathrm{s}$. Pour preuve, la mise en place en parallèle d'une cave et d'étages supplémentaires suppose une reconstruction complète car il ne paraît pas raisonnable de rehausser un mur alors qu'on le sape en sous-œuvre. Or la plupart des caves sont creusées ainsi. La reconstruction d'une façade a plus généralement pour objet l'union de plusieurs lots, comme cela s'est vu lors de la création de la parcelle 373. C'est ainsi qu'est conçue la parcelle 399, individualisée par un doublage de la façade en pierre de taille, et agrégeant d'une part plusieurs espaces des « étuves » médiévales, mais également un ancien passage au nord de ces dernières. Ce lot confirme la nouvelle répartition de l'espace qui prévaut au XVII' ${ }^{\text {s }}$. puisque il est limité au sud par un refend décalé par rapport à l'ancienne partition des « étuves ». Citons également l'acquisition par Gautier, en 1655, d'une maison voisine d'une de ses propriétés et qu'il fait rehausser et dont il fait reconstruire la façade « de mesme ordre et quallité de celluy de la susd. autre maison dud. Gautier ». Également les deux maisons nouvellement acquises par B. Callamand et qu'il fait réaménager en 1646 pour aboutir à la parcelle 383 . 


\section{Chapitre 3}

\section{Le faubourg et la Ville Nouvelle : du bourg de Morier au quartier de Roubaud}

$\mathrm{S}$ i l'étude de l'occupation bâtie intra muros est particulièrement riche d'enseignement, les fouilles conduites dans un des faubourgs de la ville, sur le site de l'actuelle Bibliothèque Municipale de l'Alcazar, ont révélé une occupation régulière des abords de la ville. Cet espace de pulsation urbaine est particulièrement révélateur des modes d'habitation pour les époques médiévale et moderne.

\section{Présentation du bourg à la lumière des archives}

Une étude d'archives complète a été menée sur les possessions et les constructions situées sur le site de l'Alcazar et ses abords. Si les données sont nombreuses pour le Moyen Âge, on notera l'éclairage particulier que nous livrent les documents d'archives pour le moment de l'Agrandissement voulu par Louis XIV.

\subsection{Le bourg de Morier au Moyen Âge (Ph. Rigaud, M. Bouiron)}

Situé en périphérie immédiate de la ville, le quartier exploré dans la documentation d'archive, comprenant la zone de fouille de l'Alcazar, est placé à proximité et à l'extérieur des remparts de la troisième enceinte médiévale (celle du milieu du XIII ${ }^{\text {e }}$ s.) et des portes correspondantes ouvrant vers l'est ${ }^{675}$. Il se place selon des axes de sortie et de pénétration de la ville à partir de deux principales portes, celles du Marché et celle de Saint-Martin. Le segment d'enceinte compris entre ces deux portes, avec le fossé correspondant ${ }^{676}$, constitue donc la limite occidentale de notre étude (fig. 221).

675 Sur l'évolution de l'enceinte, on renverra à Bouiron 2001c et à Bouiron 2009c, p. 49 sq.

676 Des indications tardives (1405 et 1406) précisent l'emplacement du quartier de Morier par rapport à l'enceinte de la ville : « ...burgo Morerii... retro vallato meniorum Mercati...», AD13 B 1177, fol. $63 \mathrm{v} \mathrm{n}^{\circ} 589 ;$ « ...burgo dictum del Morier extra portale Fori... », AD13 351 E 225, fol. 100.
Les confronts les plus sûrs se positionnent en fonction des axes est-ouest de fait, l'extension du quartier est difficilement discernable vers l'est, au nord et au sud. L'étude a permis de préciser les limites de quartier avec certains chemins nord-sud ou des rues issues des portes de l'enceinte urbaine.

\subsubsection{Les faubourgs est de Marseille}

La question des diverses appellations de ces quartiers périphériques se pose d'emblée. Il semble que la dénomination du bourg de Morier soit la plus ancienne. Elle est suivie ensuite de bourg de Roubaud, après l'établissement des Béguines dans la zone concernée. Durant la même période, on trouve le bourg Sainte-Claire au nord, du nom du couvent des Clarisses, et le bourg Saint-Louis (du nom du couvent des Frères mineurs détenteurs des reliques de Saint-Louis de Toulouse) au sud de la zone étudiée. Les diverses appellations successives ou concomitantes de ces divers quartiers ont parfois « fusionné » du fait de leur proximité.

\section{Le bourg de Morier}

Un diplôme de l'empereur Frédéric I ${ }^{\text {er }}$ en 1164, donnant les limites de la ville épiscopale, ses droits et possessions hors de l'enceinte, énumère deux « vallées » du territoire marseillais déterminant deux quartiers ruraux : la vallée Saint-Bauzille et la vallée de Morier ${ }^{67}$. Il apparait cependant que ces deux possessions voisines appartenaient auparavant aux vicomtes de Marseille. Qualifié d'honneur, le val de Morier provient de l'archevêque d'Arles Aicard, mort vers 1113 et membre de la famille vicomtale ${ }^{678}$. En 1230, dans un recueil de document établissant des cens payées par divers propriétaires (probablement des emphytéotes) auprès du chapitre cathédral de la Major, un verger (viridarium de

677 GCNN, Marseille, $\mathrm{n}^{\circ}$ 164, 82. Traduit par T. Pécout (2009, p. 172). Sur ces vallées, voir Bouiron Gantès 2001, p. 31-32.

678 GCNN, Marseille, $\mathrm{n}^{\circ}$ 163, 80 ; Poly 1976, p. 222 n. 71. Voir Mazel 2009, p. 151 sq. (texte et traduction). L'honor est une dotation de terre, un bénéfice du temporel de l'église épiscopale. 
DEUXIÈME PARTIE : PRÉSENTATION DE QUELQUES QUARTIERS À LA LUMIÈRE DES FOUILLES ARCHÉOLOGIQUES

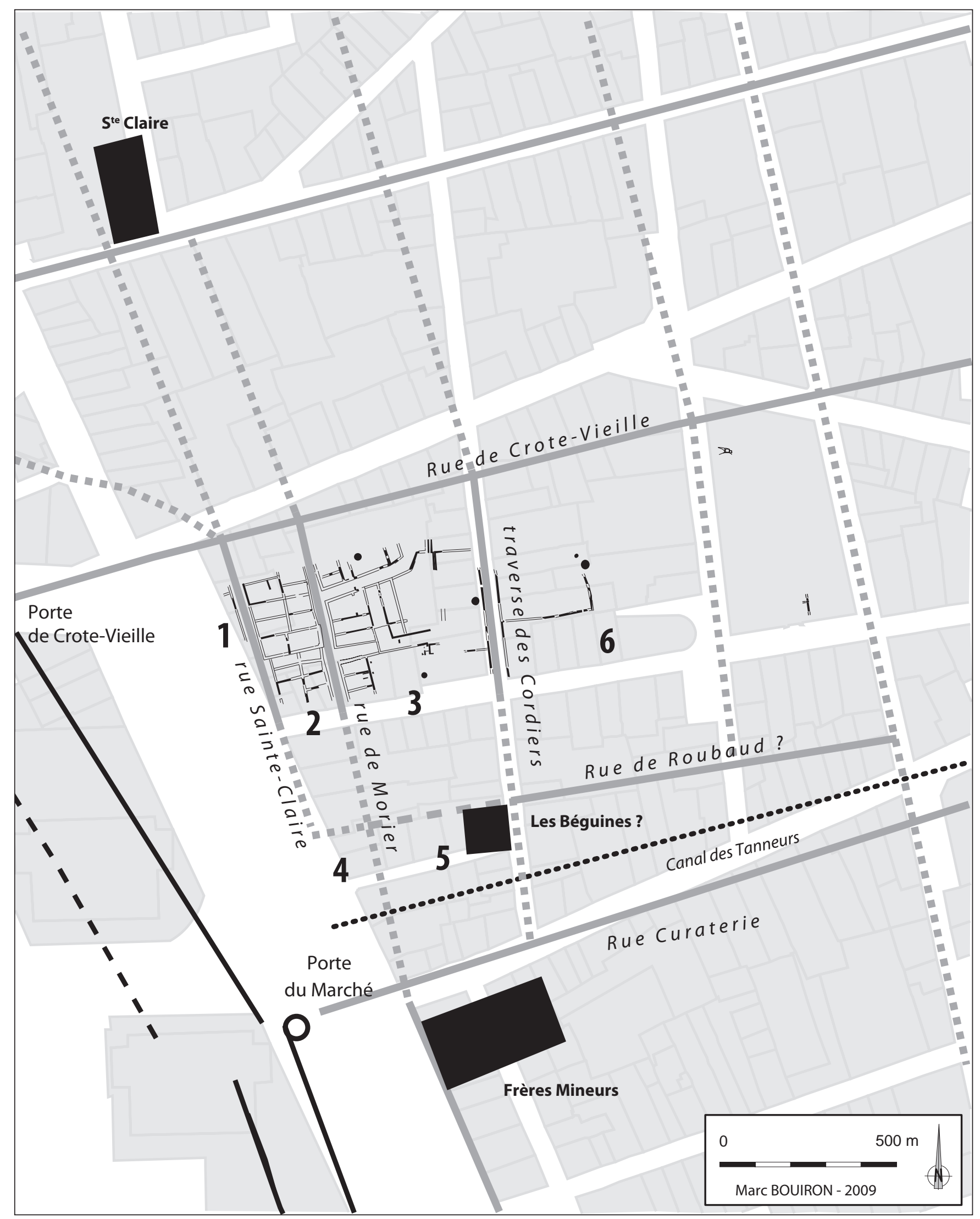

Fig. 221. Fond de plan des îlots autour de l'Alcazar (DAO M. Bouiron/Ville de Nice).

338 
Moreriis) est taxé de 60 sous payables à la Saint-Michel (29 septembre) sans que soit donné le nom du possesseur. D'autres terres (jardins, vignes) sises à Saint-Bauzille sont également taxées ${ }^{679}$. La valeur du cens du jardin de Morier est peut-être l'indication d'une surface relativement importante par comparaison avec celle pratiquée dans la zone voisine de Saint-Bauzille (de 5 s. pour un petit jardin, ortus minus, à 30 s. pour une vigne de 2 carterées). En 1255 un chanoine de la Prévôté, Guillaume Ricavi, achète à Gentiane Abelia une terre dans le quartier de Morier en confront avec l'honor de la Prévôté, une voie publique, une autre voie, l'eau du Jarret, une vigne et au dessus une troisième voie publique ${ }^{\mathbf{6 8 0}}$.

Il faut attendre 1265 pour découvrir parmi les cens payés auprès du comte de Provence une mention du bourg de Morier. Cette appellation est importante puisque pour la première fois est attestée la présence de maisons, ce qui détermine l'existence d'un faubourg sis hors les murs. Ce borguet est formé de plusieurs maisons mais sans que l'on en connaisse le nombre total. Dans cette brève liste, quatre propriétaires possèdent au moins une maison : un certain Pierre Gautier et une femme, Bertomieuna, en détiennent chacun une ; les deux autres possédants en ont plusieurs (Bertrand de l'Aumône et Bernard de Pise) ${ }^{\mathbf{6 8 1}}$.

En 1297, une transaction entre les dames de Roubaud et un prêtre (cappellarius) nommé Jacques Bonacros fait état de constructions (edifficio) établies illégalement et empiétant sur le béal du Jarret, depuis une tour ayant appartenu à Bertrand de Trets (Bertrandi Terici) jusqu'à un abreuvoir rond (abeuratorium rotundum) et à la maison de J. Bonacros ${ }^{\mathbf{6 8 2}}$. Ces terres sont sous la juridiction des dames de Roubaud ${ }^{683}$. La question de ces constructions se reposera lors du conseil de ville du 25 octobre

679 AD13 6 G 438, fol. 29.

$680 \mathrm{AD} 136 \mathrm{G} 16 \mathrm{n}^{\circ} 88$.

681 AD13 B 812, fol. 24. En raison de la mention concomitante des isllas de Sçant Laurentz et du Morier, E. Duprat (1935, p. 85-86) a supposé qu'il existait un bourg Saint-Laurent voisin de celui du Morier. Il est plus vraisemblable qu'il s'agisse de deux quartiers éloignés l'un de l'autre dont certains cens sont placés sous la tutelle du comte.

682 E. Duprat (Duprat, Rambert 1935, p. 85) précise que «la tour de Bertrand de Trets [vicomte de Marseille] avait appartenu précédemment à Raymond-Geoffroy [un vicomte de Marseille père du précédent]», mais ne cite pas sa source. Lors de la vente de ses biens aux recteurs de Saint-Esprit en 1216, Raimond-Geoffroy déclare garder une tour : «...de predicta autem venditione excipimus et nobis retinemus turrem nostram et plateam cum suis pertinentiis... confrontatur ab oriente via publica et a meridie Toloneo et ab occidente domibus quondam Bertrandi Fabri et a septentrione domibus Judeorum...». Il s'agit d'une tour intra muros ou faisant partie de l'enceinte. Un Bertrand de Trets chevalier est cité comme témoin de l'acte (Gérin Ricard-Isnard 1926, p. 119, n 391). Il est probable qu'Eugène Duprat a mal interprété ce texte.

$683 \mathrm{AD} 1364 \mathrm{H} 1, \mathrm{n}^{\circ} 7$.
1329 : ce même Jacques Bonacros déclare que l'on avait à nouveau construit des maisons («domos aliquas de novo facere ») et qu'il fallait que le conseil examine la situation qui pourrait être en contradiction avec les Statuts de la ville ${ }^{\mathbf{6 8 4}}$. Nous voyons ainsi se densifier les faubourgs.

En 1298, le bourg de Morier est une réalité tangible avec la présence de plusieurs maisons placées vraisemblablement le long d'une rue (carreria de Morerio). Ces maisons sont en confronts les unes par rapport aux autres; on compte dix habitations (domibus), un casal et un four, pour lesquels les propriétaires paient le cens au comte ${ }^{\mathbf{6 8 5}}$.

Le testament de Jacques Martin, établi en 1302 avec codicile en 1304, montre que celui-ci possédait des maisons dans le quartier (« in suburbio Morerii »). Certaines habitations situées devant la maison des dames de Roubaud ( « ante domum honestarum dominarum dictarum de Robaudo »), étaient placées sous la directe du Chapitre de la Major. De nombreuses autres (18) à proximité, dans une rue devant la porte de la nouvelle église des Frères mineurs (ou la nouvelle porte de l'église) ${ }^{\mathbf{6 8 6}}$.

Assez curieusement, l'appellation bourg de Morier tend à s'amenuiser dès le début du XIV ${ }^{\mathrm{e}} \mathrm{s}$. sans toutefois disparaître, au profit d'appellations plus spécialisées selon la proximité des possessions de tel ou tel établissement religieux ${ }^{687}$.

\section{Le bourg de Roubaud}

Il est vraisemblable de penser que l'installation d'un établissement de béguines de Roubaud à Marseille, au milieu du XIII ${ }^{\mathrm{e}} \mathrm{s}$. (la date n'est pas précise), a été rendu possible par l'existence préalable des prémices d'un faubourg, en l'occurrence le bourg de Morier ${ }^{688}$.

Comme l'a fait remarquer J.-H. Albanès, l'appellation de bourg de Roubaud ne prend le dessus qu'assez tardivement et, paradoxalement, alors que l'établissement hors les murs a disparu victime des destructions volontaires du milieu du XIVe s. (Albanès 1879, LXV).

\section{ACM BB 16, fol. $91 r^{\circ}$ v.}

685 Voir le texte dans Paone 2009, p. 89.

686 AD 136 G 18 et ACM 1 ii 45, fol. 12.

687 Albanès (Albanès 1879, LXV) fait remarquer ce changement de noms : « au XIV ${ }^{\mathrm{e}}$ s. on employa plutôt des dénominations tirées des églises et des monastères ». 1424: « in burgo Sancte Clare alias del Morier », AD13 4 HD B 32, fol. $247 ; 1430$ : « in burgo Morierii prope Sanctam Claram », AD13 351 E 276, fol. 28 ; 1602, : « lieu dict le bourc Saint-Loys ou des Robaudz. », AD13 4 HD B 30, fol. $248,249 \mathrm{v}$.

688 Ruffi (Ruffi 1696, II, p. 109) donne la date de 1272, suivi en cela par les historiens anciens de la ville, Bouche, Belsunce ; B. Roberty reprend cette date, $\mathrm{AD} 1322 \mathrm{~F} 81 \mathrm{n}^{\circ} 16$. Albanès (Albanès 1879, LIII) et Villard (Villard, Villard 1970, p. 191) proposent l'année 1250. Sur l'établissement des Béguines de Roubaud à Marseille, Albanès 1879. 
Si l'on mentionne dès 1325/1326 l'existence du faubourg et d'une rue de Roubaud (burgo de Robaut et carreria de Robaudo) ${ }^{689}$, l'appellation générique du quartier -depuis seulement la fin du XIVe s. (1391) ${ }^{690}$ connaît une assez longue fortune jusqu'au XVI et même le début du XVII ${ }^{\mathrm{e}}$ s. ${ }^{\mathbf{6 9 1}}$.

\section{Le bourg Sainte-Claire}

Le bourg Sainte-Claire, au nord de celui de Roubaud, doit son appellation à la mise en place du couvent des Clarisses en $1254^{\mathbf{6 9 2}}$. L'espace bâti défini comme bourg Sainte-Claire s'établit en premier lieu sur l'alignement de la rue conduisant au monastère et/ou à l'église (carreria Santa-Clara, carreria ecclesie Santa-Clara ${ }^{693}$ ). En 1298, les propriétaires de ces maisons doivent payer des cens au comte de Provence: on en compte quatre, un four et son casal ${ }^{694}$.

Comme pour celui de Roubaud et de Morier, la mention de ce quartier comme entité propre liée à l'établissement des Clarisses n'apparaît paradoxalement que tardivement et notamment après l'anéantissement du couvent suite à l'arasement des bourgs extérieurs et de la plupart des édifices religieux en $1357-58^{695}$. De fait, le quartier composé de jardins, de vignes et de vergers après cet épisode destructeur est connu sous le nom de «Sainte-Claire-la-Vieille » suite au transfert du couvent à l'intérieur de la ville en $1357^{\mathbf{6 9 6}}$.

\section{Le bourg Saint-Louis}

Le bourg Saint-Louis ou bourg des Frères mineurs tire son nom à la présence des Franciscains au sud du

689 AD13 6 G 54, n ${ }^{\circ} 359$ et 6 G 56, n 370 .

$690 \mathrm{AD} 13355$ E 75, fol. 95 : « borgus Massilie monasterium de Robaudo ».

691 1602: « lieu dict le bourc Saint-Loys ou des Robaudz », AD13 4 HD B 30 , fol. $248,249 \mathrm{v}$.

692 Espeut 1953, p. 1 ; Roberty, AD13 8 F 48.

693 1388: «...in burgo seu carreria monasterio veteris Sancte Clare...», AD13 351 E 58, fol. 31v. 1392: « ...carreria recta procendente a dicto monasterio antiquo usque portale de Crota vielha... », AD13 351 E 62, fol. 145v. D'après P. Espeut (1953, p. 4) la rue Longue des Capucins, Espeut, d'après B. Roberty la rue des Dominicaines (AD13 22 F 81, n 15), d'après E. Duprat (1935, p. 85) la rue des Petites Maries.

694 "In carreria ecclesie Sancte Clare», AD13 B 1019, fol. 9. Texte dans Paone 2009, p. 89.

6951424 : «...burgo Sancte Clare alias del Morier... », AD13 4 HD B 32, fol. 247 ; 1534 : «...Sancte Clare la vielhe deven las yeras de la Fracha... », AD13 390 E 12, fol. 193. La confusion des appellations de ce quartier imbriqué est courante.

696 Dans un premier temps dans la maison du Temple puis dans la rue de l'Escarlate près de l'église Saint-Cannat, ACM BB 22, fol. 83 ; Espeut 1953, p. 10. bourg de Morier dans le milieu du XIII' ${ }^{\mathrm{e}} \mathrm{s}$. D'après la tradition, ils se seraient installés dans le quartier vers $1215^{697}$. Le bourg se situe face à la porte du Marché, audelà du fossé, et semble se construire à partir de l'église et des bâtiments conventuels et en particulier d'une rue à vocation artisanale, celle des Cuiratiers (Curataria, dels Obradors, Operatorium).

Le bourg Saint-Louis entretient la confusion avec les autres dénominations (Roubaud, Morier, Sainte-Claire) notamment après les destructions du milieu du XIV ${ }^{\mathrm{e}} \mathrm{s}$. sans qu'il soit possible de définir son emprise avec certitude.

Ayant échappé à la première destruction des années 1357-58, le couvent et son église semblent structurer à nouveau un espace suburbain dont la dénomination prend le pas sur les autres. En 1423, lors du sac de Marseille par les Aragonais, la zone artisanale est en partie détruite sans que le couvent ou l'église ne soit touchés (hormis le vol des reliques de Saint-Louis de Toulouse ${ }^{698}$ ). Plus tard les destructions volontaires préalables au siège de la ville par les troupes impériales (en 1524) seront fatales à l'établissement des Mineurs.

\section{Un épisode fondateur : la destruction des faubourgs (1357/1358)}

La documentation donnée par les textes (à partir du milieu du XIII' ${ }^{\mathrm{s}}$ s.) confirme une urbanisation assez dense du terroir immédiatement proche de la ceinture de rempart dans l'est de la ville, à proximité des portes de la Frache, du Marché et du Lauret (Bouiron 2001e, p. 331332). Pour des raisons militaires, cette urbanisation en marche va brusquement se trouver anéantie dans le milieu du XIV ${ }^{\mathrm{e}} \mathrm{s}$. Les tensions politiques dues en partie aux conséquences du conflit franco-anglais vont transporter sur les terres provençales le conflit latent puis ouvert opposant les divers protagonistes se disputant la succession du comté de Provence ${ }^{699}$.

À partir de la mort du comte de Provence Robert d'Anjou (1343) s'ouvre une ère de troubles, liée en particulier à la succession de Jeanne, petite-fille de Robert. Marseille soutenait la comtesse contre les ambitions de Robert de Duras, de la même famille angevine mais prétendant au comté. Plus tard, l'étendard

697 Roberty, AD13 22 F 81 § VII, n 19 ; Duprat, Rambert 1935, p. 85. Les Frères mineurs de Marseille ne semblent pas avoir fait l'objet d'étude particulière (sauf le diplôme de J. Billioud (1949) qui n'a jamais été publié).

698 Saint-Louis de Toulouse, fils de Charles II d'Anjou et de Marie de Hongrie (1274-1297), canonisé en 1317 (Laurent 1954 ; Bonnot 1988, p. 132-138).

699 Sur la destruction du faubourg de Roubaud, nous renvoyons à Rigaud 2001 
de la révolte contre Jeanne fut relevé par la famille des Baux d'Avellino. Cette dernière reçut le soutien militaire actif d'Arnaud de Cervole dit l'Archiprêtre, chef de Routiers (Grandes Compagnies) qui venant de Languedoc passèrent le Rhône en juillet 1357 avec la bénédiction du dauphin Charles (fils de Jean II roi de France) (Cherest 1879).

L'arrivée des Routiers plongea la Basse Provence dans une situation d'insécurité généralisée. Marseille, fortement engagée dans le conflit aux cotés de Jeanne, prit alors des dispositions en vue de résister à un possible siège (Léonard 1936, p. 298-320). Elles furent lourdes de conséquences pour les faubourgs extérieurs de la ville.

Le $1^{\text {er }}$ novembre 1357 , le conseil de ville décida de faire creuser des tranchées rejoignant les fossés placés au devant les remparts devant chaque porte afin que l'ennemi ne puisse miner la base des murs ( ne muris possit minadi $»)$; de détruire les ponts et d'abaisser les maisons placées devant le rempart jusqu'à un certain niveau («signa facta») ${ }^{700}$. Les 7 et 17 novembre le conseil enjoignit que les maisons des bourgs extérieurs soient également abaissées jusqu'à un niveau estimé par des maîtres maçons désignés et réquisitionnés par le viguier ${ }^{701}$.

Le conseil du 28 novembre -et de nombreux autres jusqu'à fin février-, devant les difficultés rencontrées pour faire accomplir les ordres, demanda à ce que les maisons soient abaissées ou détruites jusqu'aux fondations si nécessaire et qu'il n'y ait pas d'abus dans les estimations de cens à venir. Il fut également décidé que les places des maisons détruites soient exemptées de cens et qu'il n'en soit plus construit d'autres ${ }^{702}$.

Afin que l'ennemi ne puisse trouver de subsistance (victualia, pasture animalium) on décida de rapatrier en ville ce qui pourrait lui être utile ${ }^{703}$. La situation politicomilitaire s'étant redressée, le siège de la ville craint et

700 ACM BB 22, fol. 58, 141v. L'ordre de faire détruire les maisons et les ponts franchissant les douves du fossé est répété plusieurs fois, ce qui semble prouver une probable mauvaise volonté de la population habitant les faubourgs.

701 ACM BB 22, fol. 62v, 68 .

702 ACM BB 22, fol. 74v, 81, 84, 90. En 1364 des maisons sont dites crematis, ce qui laisse supposer quelles furent détruites dans l'urgence avant que les gens aient pu récupérer les bois de charpente, matériaux éminemment combustibles, ACM BB 25, fol. 79 .

703 ACM BB 22, fol. 83v, 141v. Une lettre d'Arnaud de Cervole interceptée par les Marseillais et adressée à Antoine des Baux, prévôt du chapitre de Marseille, demande si les maisons des bourgs avaient été ou non épargnées par les défenseurs auquel cas en vue du siège il augmenterait ses moyens militaires avant de s'y porter : « car qui ten la borgada non pert a ren... », ACM BB 22, fol. $155 \mathrm{v}$. Ce document écrit à Pélissanne début mars 1358 (n. s.) a été publié par Léonard (1936, p. 628, P. J. LXXXV). attendu n'eut finalement pas lieu alors que les destructions avaient été accomplies.

Lors des destructions volontaires des faubourgs on récupéra les matériaux de construction (tuile, pierres et bois) de ce qui singulièrement est appelé casalia ou «loca hospitiorum diruptorum », c'est dire les emplacements des anciennes maisons établies le long des rues ${ }^{704}$.

Ces matériaux, pour certains d'entre eux, furent probablement utilisés par les emphytéotes, leurs successeurs ou de nouveaux acheteurs -une délibération de la ville en 1364 précisa que les seigneurs directs des maisons ou possessions incendiées ne pouvaient exiger les cens que les emphytéotes leur payaient à partir du jour de leur destruction ${ }^{705}$ - pour édifier des murs fermant les jardins et vergers qui occupèrent les sites retournés à une fonction rurale et agricole ${ }^{706}$.

\subsubsection{Les édifices religieux}

Plusieurs édifices religieux (couvents ou congrégations) ont occupé les faubourgs de la ville. Pour la partie orientale qui nous concerne ici, le site de l'Alcazar est compris entre le couvent de Sainte-Claire au nord et des Franciscains au sud, et à proximité immédiate du Béguinage de Roubaud qui finit par donner son nom au quartier.

\section{Les Béguines de Roubaud}

En raison de la destruction des faubourgs en 135758, l'emplacement matériel de la maison des Béguines est assez difficilement discernable dans la topographie suburbaine de Marseille.

Les Béguines de Marseille ne formaient pas à proprement parler une congrégation religieuse comme institution régulièrement formée et acceptée en tant que telle par l'Église ${ }^{707}$. Lorsque la fondatrice de cette institution, Douceline de Digne $(† 1274)$, établit une fondation (estament) à Marseille, il est probable qu'elle trouva un appui auprès des Frères mineurs déjà installé dans le quartier de Morier au milieu du XIII ${ }^{\mathrm{e}} \mathrm{s}$. dont le couvent était tenu par son frère Hugues de Digne. L'appellation -tardive- de bourg de Roubaud tient de toute évidence à l'implantation d'origine à Hyères près du ruisseau du

7041366 : AD13 351 E 28, fol. 143.

705 Délibération du 25 février 1364, ACM BB, 25 fol. 79.

706 En 1405 un laboureur (laborator) reconnait un cens à la cour comtale pour une terre dans une locam hospitii située dans la carreria Morerii, AD13 B 1177, fol. 64v n 597.

707 Sur l'institution du Béguinage dans les pays d'Oc en général (avec ses difficultés d'insertion dans l'église), Mollat 1964, p. 108182 ; Manselli 1989 ; à Marseille, Albanès 1879, LX-LXIII. 
même nom. Le site éponyme se transposa alors à leur maison marseillaise ${ }^{708}$.

Le chanoine Albanès suppose qu'elles s'installèrent dans le quartier de Crote-Vieille du nom du chemin près duquel elles établirent leur maison. Il ne nous semble pas, contrairement à cette hypothèse, que ce nom soit attesté à l'époque de leur implantation. À notre connaissance, le nom de Crote-Vieille n'apparaît pas avant $1332^{709}$ bien que le chemin ait pu exister auparavant en correspondance avec l'entrée d'une porte de la ville près de l'église Saint-Martin. La Porte Crote-Vieille n'est mentionnée avec certitude qu'en $1350^{710}$ puis 1392 : « carreria recta qua tendit ad ipsum Portale de Crota vielha... ${ }^{711}$.

D'après Albanès, il faut situer l'emplacement de la maison des Béguines («in carreria de Robaut») dans la rue Dauphine/Nationale continuée par la rue des Convalescents, Saint-Bazile et Consolat ${ }^{712}$. Albanès note, lors d'achat de cens par Philippa Porcelet, prieure de Roubaud en 1297, que les propriétés étaient établies sur une «carreria sive transversia Corderiorum confrontato ab una parte cum orto Guillelmi Ysnardi et ab alia parte cum edificio dominarum de Robaut et ab alia parte cum bedali seu vallato et ab alia parte cum dicta transversia... ${ }^{713}$. L'étude d'archives indique que l'actuelle rue du Baignoir correspond à la traverse des Cordiers, recoupant la rue Crote-Vieille et la rue de Roubaud. Nous situons donc cet établissement à l'angle nord-ouest des actuelles rues du Relais et du Baignoir.

Albanès, citant un texte du 11 janvier 1297 (a. s.) indique l'existence d'un nouveau bâtiment que firent construire les Béguines et placé sous la directe de Philippa Porcelet. Celui-ci est probablement à proximité des édifices occupés par la congrégation (il ne s'agit pas forcément d'un bâtiment principal), « in quo loco dicte domine Beguine edificium novum fecerunt» (Albanès 1879 , p. 269, doc. XI). Il se pourrait qu'il s'agisse d'une nouvelle construction dans le cadre d'une extension de la communauté. Certains actes sont passés par les Béguines, en 1280 et 1292, «in domo de Robaudo, in porticu domus de Robaudo »; en 1288 et 1297 (n. s ?), « in oratorio domus de Robaudo»; en 1341 et 1359,

708 Albanès 1879, LXIV ; Carozzi 1973. Dans les années 1280, quelques documents commerciaux sont passés par les Béguines devant notaire in domo de Robaudo, Blancard 1884-1885, p. 372-380. 709 AD13 3 B 27, fol. 266.

710 ACM BB 21, fol. 82 cit. par Duprat 1922, p. 96.

711 AD13 351 E 65, fol. 107

712 Albanès 1879, LXV-LXVIII.

713 Albanès 1879, LXVIII-LXIX, p. 266-267. Sur Philippa Porcelet, Aurell i Cardona 1986, p. 165-169.
« in domo de Robaut in parlatorio » ${ }^{714}$. Le récit de la Vida de sainte Douceline fournit ici et là quelques indications sur les bâtiments leur appartenant. Il est question d'une capella protégée par des grilles (cledas) afin de contenir l'enthousiasme des fidèles attachés à la personnalité de la sainte (Albanès 1879, p. 84). Il est aussi fait mention d'un dormidor, peut-être le bâtiment neuf de 1297 : «E adoncs si bastia e si edificava en Marsella li maizon de Robaut et le dormidors eran adonc fach de nou... » ${ }^{715}$.

Après la destruction du quartier, les Béguines s'installèrent intra muros, " in carreria Francigena » ${ }^{716}$ au plus tard en 1366. En 1414, lors de la liquidation des biens des Béguines, il semble qu'il subsiste une maison leur appartenant entourée de casalia et de maisons détruites. Cette maison -avec une grande salle (aula magna)- se trouvait à l'entrée de l'église et à l'arrière de l'autel où se trouvait une fontaine «fons aque cum canonno » ${ }^{717}$.

\section{Le couvent Sainte-Claire}

Le chanoine Espeut place le couvent Sainte-Claire à proximité de l'emplacement de l'actuelle église des Récollets (église Saint-Théodore) mais dans la rue Longue-des-Capucins (Espeut 1953, p. 2, 4). E. Duprat (1935, p. 86) propose le haut de la rue des Petites-Maries.

Cette situation reste approximative, toutefois un texte de 1392 positionnant un verger dans le bourg Sainte-Claire donne comme confront une rue droite allant de l'ancien monastère à la Porte Crote-Vieille ${ }^{718}$. Le plan anonyme de la fin du XVII ${ }^{\mathrm{e}}$ s. ${ }^{719}$ semble confirmer l'existence de cette rue qui pourrait correspondre à l'actuelle rue des Petites-Maries prolongée vers le sudouest. À la fin du XIVe s., l'emplacement du couvent avec des vestiges de la clôture subsistaient au moins dans les appellations et la topographie vécue ${ }^{720}$. Il en est de même au début du $\mathrm{XV}^{\mathrm{e}} \mathrm{s}$. : on distingue encore parmi les vergers et des maisons non détruites (?) la cuisine du monastère (focanea $)^{721}$.

714 Albanès 1879, doc. IV, V,VIII, IX, XI, XVI, XVII ; Blancard 1884-1885, p. 372, 373, 375, 377, 379.

715 Albanès 1879, p. 114-116.

716 Albanès 1879 : LXXI ; vers 1360 d'après Villard (1970, p. 191). Dans le $1^{\text {er }}$ quart du XIV ${ }^{\mathrm{e}} \mathrm{s}$. les Béguins et Béguines eurent quelques difficultés avec l'Inquisition notamment à Marseille (Mollat 1964, I, p. $116-117$ n. 1).

717 AD13 28 H 34, n 213.

718 1392: «...carriera recta procendente a dicto monasterio antiquo usque portale de Crota vielha... », AD13 351 E 62, fol. 145v. 719 Plan anonyme conservé au Service Historique de la Marine à Vincennes, publié par Zysberg 1983, p. 67.

720 1392: «...quandam area dictam de Sancta Clara et cum rieja (grille) monasteri antiqui Sancte Clare... », AD13 355 E 47, fol. 63, idem fol. $65 \mathrm{v}$.

7211405 : AD13 4 HD B 31, fol. 119. 


\section{Le couvent Saint-Louis}

À la faveur du grand mouvement des ordres mendiants, les Franciscains installent leur monastère, église, cloître et cimetière dans le quartier de Morier dans la première moitié du XIII ${ }^{e} s .{ }^{722}$. Le couvent des Frères mineurs jouissait auprès de la population marseillaise d'un grand prestige en raison de la présence des reliques de Saint-Louis de Toulouse ${ }^{723}$.

E. Duprat (1935, p. 85) situe le couvent à l'emplacement de la rue Poids-de-la-Farine, ouverte selon lui sur les ruines occasionnées par sa destruction en 1523. Albanès (1879, LXVIII) préfère situer le couvent rue Tapis-Vert. Il est suivi en cela par B. Roberty avec plus de précisions : «le couvent était entre les rues du TapisVert et de l'Arbre, l'église était bâtie en face de la porte du Marché les bâtiments séparés des remparts par les lices extérieures et le Prat Auquier [appelé] plus tard le Grand Caire puis le cours Saint-Louis puis le cours Belsunce ${ }^{724}$.

Pas plus que pour les autres établissements conventuels il n'existe de descriptions contemporaines concernant le couvent Saint-Louis. En 1395, on reconstruit le dortoir avec des bois venant d'Avignon probablement par flottage ${ }^{725}$. En 1433 est signalée la reconstruction d'un mur de 7 cannes ( $14 \mathrm{~m}$ ) de long pour 18 pans $(2,25 \mathrm{~m})$ de haut autour du jardin de l'infirmerie, qui confronte à celui du réfectoire ${ }^{726}$.

Tout au plus le chroniqueur marseillais Honorat de Valbelle indique que sa destruction intervient à partir de 1523 : l'église autour du 29 juin 1524 -non sans dommages pour les démolisseurs- et le presbytère à partir du 12 juillet «fon ung ediffici sumptuoux et lo plus bel presbiteri de gleysso que fosso en lo rialme de Franso...» (Valbelle 1985, p. 117, 124, 128).

À la fin du XIX' ${ }^{\mathrm{e}}$ s., J. A. B. Mortreuil, sans citer ses sources, proposait une courte description générale du

722 Avant 1248, Villard, Villard 1970, p. 129. Mentions du cimetière en 1398: «...terram... confrontatam ab una parte cum camino publico portal de Crota vielha et ab alia parte cum camino quo itur in carnassium... » AD13 1 HD B 7, fol. $120 ; 1427$ : «...ortum... confrontantes... cum symenterio ecclesie Fratrum minoris...», AD13 351 E 187, fol. 217 et 221v. Valbelle (1985, p. 124) note que les habitants « déménagèrent » les morts du cimetière avec ou sans permission.

723 Les Mineurs de Marseille eurent, tout comme les Béguines, de graves difficultés avec l'Église et la papauté. À Marseille en 1318, quatre Mineurs accusés d'hérésie furent brûlés par l'Inquisition (Manselli 1989, p. 129).

724 Roberty AD13 22 F 81 § VII n ${ }^{\circ} 19$.

725 AD13 351 E 123, fol. 234-238. En 1492 Jacques de Forbin, seigneur de Gardanne, contribua à la construction du quatrième pilier de droite de l'église Saint-Louis, GCNN Marseille, n 1359, p. 169. 726 AD13 351 E 220 en date du 2 juillet 1433. monastère des Mineurs : «Le monastère aux murs crénelés s'élevait au centre comme une forteresse munie de tous les ouvrages nécessaires à repousser une attaque et dominait de toute sa hauteur les habitations qui l'environnait et étaient venues sous son égide un abri tutélaire » (Mortreuil 1872). Ce descriptif s'appuie peut-être sur une réalité ; il expliquerait le fait que le couvent n'ait pas été détruit lors des menaces de siège des années 1357-58.

\subsubsection{Les voies de circulation}

«Tous les anciens faubourgs de Marseille s'étendaient le long des chemins qui partaient des portes de la ville et s'en allaient vers la campagne. Trouver un chemin, c'est trouver le faubourg qui lui correspond ». «En avançant vers le rempart les rues se groupent au lieu de se diviser de manière à canaliser la circulation vers les portes »; ces citations de J. H. Albanès et de G. Rambert résument bien l'organisation du viaire principal partant des portes du rempart oriental de la ville ${ }^{727}$.

\section{La rue Crote-Vieille}

Reprenant ici l'argumentation du chanoine Albanès et de Mabilly (Albanès 1879, LXVII ; Mabilly 1905, p. 53), E. Duprat (Duprat, Rambert 1935, p. 86) place assez justement la Porte Crote-Vieille contre le chevet de l'église Saint-Martin, au niveau de l'enceinte établie à partir du milieu du XIII ${ }^{\mathrm{e}} \mathrm{s} .{ }^{728}$.

Comme nous l'avons vu plus haut, la mention de la porte n'est qu'assez tardive (1350) alors que le chemin du même nom est attesté en $1332^{729}$. En réalité les mentions topographiques directes de la porte manquent, peut-être par son peu d'importance en raison d'une fermeture quasi permanente ${ }^{730}$. La seule mention -indirecte- est tardive (1481); la porte n'est pas nommée mais le positionnement topographique semble suffisant pour l'identifier : «In portale clauso super cimeterium Sancti Martini : primo una bombarda cum tribus masculis et uno conheto ${ }^{731}$.

727 Albanès 1879, LXVI ; Rambert 1934, p. 225. Dans ses Statuts de 1253, la ville se préoccupe de l'élargissement des chemins des faubourgs ( $«$ stratas publicas que sunt extra Massiliam in territorio Massilie...»), Pernoud 1949, L. I c. 42, 55.

728 En 1590 une vigne à Crote-Vieille est placée «du coste de la ville la ou est la tour, confronte avec le chemin public allant a la porte du Marché... », AD13 353 E 35, fol. 853.

729 ACM BB 21, fol. 82 ; AD13 3 B 27, fol. 266.

730 A l'inverse, le 30 novembre 1350 une délibération du conseil préconise de fermer toutes les portes de la ville sauf celle de CroteVieille et celle des Oliers, ACM BB 21, fol. 82.

731 ACM BB 32, fol. 199v. La position d'artillerie comprend une bombarde munie de 3 mascles (culasses mobiles chargées de poudre) et d'un coin de bois ou de métal pour bloquer la culasse. 
Il est possible que le nom de Crote-Vieille soit en rapport avec un aqueduc ( crota) conduisant les eaux du Jarret et ses dérivés vers la ville ${ }^{732}$. On peut également imaginer qu'il désigne l'ouverture de la porte dans la muraille, sous forme de voûte.

La rue Crote-Vieille se dirigeait vers Saint-Bauzille en recoupant la rue qui va du Plan Saint-Michel jusqu'au-dessus de Sainte-Claire ${ }^{733}$ et des traverses dont l'une conduit au cimetière (carnassium) des Frères mineurs vers le sud ${ }^{734}$. Elle est dite carreria recta en $1392^{735}$, camino publico en $1396^{736}$. Au cours de ce siècle, le quartier de Crote-Vieille est parfois associé avec Saint-Bauzille (« loco dicto a Crota vielha sive Sant Bauzili...») ${ }^{737}$. Comme il est proche de vignes et de la rue Curatarie, on peut supposer que ce lieu-dit et donc son appellation trouve des extensions vers l'est mais également au nord, vers 1'emplacement de SainteClaire (« loco dicto a Crota vielha sive a Sancta Clara la vielha ») ${ }^{738}$. D'autres noms de lieux, la Safraneyra ( a Crota vielha alias la Safraneyra ») ${ }^{739}$, le camp de Ricau, (« vinea sita prope Crota vielha alias lo camp de Ricaut ») ${ }^{\mathbf{7 4 0}}$ confirment la diffusion du toponyme vers des marges incertaines et peu lisibles.

\section{La rue Sainte-Claire}

La rue la plus proche du rempart, retrouvée à l'extrémité occidentale de la fouille de l'Alcazar, portait le nom de Sainte-Claire. Sa prolongation vers le nord amenait en effet au contact de cette église. Elle est mentionnée dès 1298. Après la destruction du faubourg, le toponyme

$7321474:$ :...aqueductum sive crotam ad construendum ayguerum...» ACM BB 33, fol. 86 ; Alibert 1966, Cròta : crypte, grotte, cave, voûte, souterrain voûté.

7331396 : « ...terre sitis ad portale de Crota vielha... confrontatis cum camino publico de Crota vielha quo itur ad Sanctum Bausilum et cum camino publico quo itur de supra monasterium antiqum Sancte Clare ad planum Sancti Michaelis et cum quodam adayguerio sive transversia modica per quam ducitur seu derivatur quedam aqua... », document aux Archives Communales de Marseille (non retrouvé) cité par Albanès 1879, LXIX.

734 1398: «...terram... confrontatam ab una parte cum camino publico portal de Crota vielha et ab alia parte cum camino quo itur in carnassium ... transversia et acquerio ortolonarum in medio... », AD13 1 HD B 7, fol. 120.

735 AD13 351 E 62, fol. 145v.

736 Document aux Archives Communales de Marseille (non retrouvé) cité par Albanès 1879, LXIX.

737 1514 : AD13 4 HD B 9, fol. 223 ; 1560 : AD13 4 HD B 22, fol. 43 .

738 1526 : AD13 351 E 853, fol. 246.

7391526 : AD13 351 E 853, fol. 307.

740 On connait le toponyme camp de Ricau en 1417 que l'on situe «retro monasterium Sancte Clare », AD13 351 E 170, fol. 26v et en 1526, AD13 351 E 853, fol. 307. subsiste plutôt vers le nord, du côté de l'ancien couvent des Clarisses.

\section{La rue de Morier}

Comme pour la rue de Roubaud, la rue de Morier se confond avec l'appellation générique désignant le quartier du même nom ( $c f$. supra $\$ 1.1 .1$.). Le nom de la rue apparaît en 1298 (carreria de Morerio) dans une liste : 11 propriétaires de maisons (plus un four et un casal) en confronts paient un cens aux autorités comtales.

Cette voie traverse le site de l'Alcazar : parallèle à la rue Sainte-Claire, elle est bordée de maisons des deux côtés. Il s'agit bien d'un axe principal, ancien, qui sert d'articulation pour la structuration des faubourgs. Après 1405, il semble que la rue fusionne avec l'appellation générique de Morier au sens de bourg.

\section{La rue/traverse des Cordiers}

La première mention est donnée dans un texte de 1290 , il y est question d'un verger situé dans le bourg de Roquefort (ou de Sion) in carreria ou transversia Cordierorum $^{741}$. Il s'agit de l'actuelle rue du Baignoir qui a également fait l'objet d'une fouille.

En 1297, Philippa Porcelet, béguine de Roubaud, procéda à des achats de cens auprès de deux propriétaires, le vicomte Bertrand de Marseille et le damoiseau Raimond de Soliers (et de sa femme Hugueta) dans la rue ou traverse des Cordiers ; celle-ci relève de la ville vicomtale. Ces achats de cens dans la transversia dicta Cordierorum dont certaines propriétés (maisons, vergers, jardins) étaient contiguës à la maison de Roubaud mais aussi, indication topographique, avec un «bedali seu vallato », une dérivation du Jarret. On notera également la présence de Raimond Turel, un cordier qui dispose d'une maison et d'un jardin dans cette traverse (Albanès 1879, p. 266). C'est dans cette zone que les Béguines édifièrent l'année suivante une nouvelle construction.

Plus tard, en 1341 et au-delà, la transversia est appelée carreria (Albanès 1879, p. 269) mais conserve parfois son «statut» de traverse (en 1390 et 1441 : « in transversia ab antiquo appellata traversia Cordierorum... »; « carreria sive traversia dictam dels Cordiers ») ${ }^{742}$. Il n'apparaît plus de constructions dans cette traverse après les destructions du milieu du XIV ${ }^{\mathrm{e}} \mathrm{s}$. et elle disparaît de la documentation après le milieu du $\mathrm{XV}^{\mathrm{e}} \mathrm{s}$.

741 Cité par Albanès 1879, LXX. Le mot carreria ou transversia ayant disparu du texte original il est difficile de se prononcer sur le terme utilisé.

7421390 : Albanès 1879, p. 291 (AD13 64 H 6) ; 1441 : AD13 351 E 711, fol. 105, 109. 


\section{La rue de Roubaud}

Cette rue, de direction est-ouest, est située au sud de la rue Crotte-Vieille. Elle est peut-être documentée pour la première fois dans la $2^{\mathrm{e}}$ moitié du XIII ${ }^{\mathrm{e}} \mathrm{s}$. dans la Vida de Santa Doucelina mais sans qu'elle soit nommée explicitement du nom de Roubaud: "aquellas...[que] s'eran embeguinadas en la carriera pres de Robaut en Massella...». Les maisons d'après la Vida seraient occupées par des malades venus trouver de l'aide auprès des Béguines : «E dels paures malautes implian los hostals de la carriera... » (Albanès 1879, p. 48, 66). Il peut s'agir également de la traverse des Cordiers.

Ce n'est qu'en 1323 et/ou 1332 qu'elle est clairement dite de Roubaud («carreria dictam dominam de Robaudo »); on la situe in burgo Morerio. La rue est bordée de maisons, de vergers ces derniers peut-être en alternance ${ }^{743}$.

Après les destructions du milieu du XIV ${ }^{\mathrm{e}} \mathrm{s}$. et jusqu'à la fin du XVI ${ }^{\mathrm{e}}$ s., le paysage est constitué de vergers, fayssas cultivées. De rares mentions témoignent de la survivance d'un habitat très dispersé : une vente de maison dans un verger ( hospitium infra dictam viridario ») en $1419^{744}$, une domuncula en $1461^{745}$. La rue de Roubaud est parfois confondue avec celle de Morier dans une appellation générique désignant le quartier ${ }^{746}$.

\section{La rue de la Cuiraterie}

Cette rue est dénommée ainsi à de nombreuses reprises en raison de la présence d'ateliers dont l'activité est basée sur le traitement des peaux.

Tout comme les autres rues, la Curataria n'est pas aisée à cerner; il semble toutefois qu'en raison de l'existence d'un chemin au droit de la porte du Marché, celle-ci se situe au sud de l'actuelle rue du Tapis-Vert en se dirigeant vers le Plan Saint-Michel.

Dans la $1^{\text {re }}$ moitié du XIV ${ }^{\text {e }}$ s., la rue de la Curatarial Obradors/Operatorium est bordée d'ateliers, de maisons, de jardins et de vergers elle est comparable pour les

743 AD13 3 B 27, fol. 266v, 281 ; AD13 4 HD B 1bis, fol. 39: «...Rainaut Barnaut ostallier que esta en la carreria de Robaut», cette intéressante indication de cens payé à l'hôpital Saint-Esprit (présence d'une auberge dans le quartier) pourrait dater de 1323, (la transcription de l'acte est du XVII ${ }^{-}-X{ }^{2} I^{e}$ s., de ce fait cette date n'est pas bien précisée, entre 1323 et 1370). Dans la Vida de Santa Doucelina il est peut-être fait mention d'une auberge dans la rue : « $E$ mezeron lo [un paure malaut] en.I. alberc justa Robaut... » (Albanès 1879, p. 66). Le mot alberc, sémantiquement un abri, peut aussi bien signifier auberge ou maison.

744 AD13 391 E 55, fol. 40.

745 AD13 4 HD B 3, fol. 84 ; AD13 391 E 55, fol. 40 ; 4 HD B 14, fol. 320 ; 6 G 490, fol. 1, 3, 4, 11 .

746 «In carreria dels Robaus alias lo Morier », AD13 6 G 490, fol. 1. trois derniers points aux autres rues étudiées plus haut. Plus tardivement, elle est appelée chemin Saint-Louis.

\section{Les traverses anonymes}

D'après les indications portées sur les plans anonymes de la fin du XVII ${ }^{\mathrm{e}}$ s. lors des projets d'agrandissement, il existe un réseau de traverses reliant les voies principales entre elles ${ }^{747}$. Ces traverses constituent un viaire secondaire et de là participent à la constitution de la trame des faubourgs (ou de ce qu'il en reste après le milieu $\mathrm{du} \mathrm{XIV}^{\mathrm{e}} \mathrm{s}$.) pendant la période médiévale et moderne antérieure à la nouvelle urbanisation de la fin du XVII e $\mathrm{s}$.

Ces couloirs de circulation (traversia, transversia) se trouvent dans tous les bourgs nommés dans les textes et sont généralement anonymes et de fait difficilement localisables par des indications topographiques précises ${ }^{748}$. Tout au plus quelques adjectifs qualifient certaines d'entre elles : une transversia modica dite aussi adayguerio est mentionnée en 1396 vers Crote-Vieille ; il y circule une eau dérivée (Albanès 1879, LXIX). Parfois une indication est donnée par la direction de la traverse : «traversia qua tendit versus los arcs...», "traversia protendente versus Sanctam Claram ${ }^{749}$. Souvent les traverses sont mentionnées comme confronts entre un jardin, un verger : « [viridarium] in traversia »; «parva traversia introitus dicte viridarii ${ }^{750}$; certaines sont dénommées par le lieu ou par le propriétaire : traversia Curatarie ; traversia Ludovici Suavis ${ }^{751}$. Il semble donc que ce viaire secondaire détermine des zones d'habitation à l'époque des faubourgs habités, puis des propriétés agricoles plus tardivement.

Certaines d'entre elles sont dévolues à un rôle de décharge sauvage au grand dam des propriétaires riverains. En 1446 le noble Bertrand de Bardonechia se plaint de ce que l'on jette des cadavres d'animaux dans les traverses proches de sa propriété : «...quod cadavera animalium plurima mortuorum fecentur prohidentur in transversiis sub burgiorum presentis civitatis pocissive prope ejus viridarium... ${ }^{752}$. Jean Forbin à son tour, en 1466, lors d'un conseil de ville se plaint de dépôts sauvages dans une traverse près de son verger : « ...ex sertis viridarium suum est

747 Voir les plans du Service Historique de la Marine, Vincennes, publiés par Zysberg 1983, p. 32 et 67.

748 La seule traverse nommée est celle des Cordiers, supra.

749 1415: AD13 4 HD B 32, fol. 166 ; 1419, 391 E 55, fol. 40 ; 1461, 6 G 490, fol. 11 .

7501424 : AD13 4 HD B 32, fol. 247 ; 1424, 4 HD B 5, fol. 223 ; 1492, ACM 2 ii 566.

7511424 : AD13 4 HD B 13, fol. 187 ; 1459, 4 HD B 2, fol. 234.

752 ACM BB 33A, fol. 15. Voir également, en 1552, l'occupation illicite d'une petite ruelle (non nommée) entre la porte du Marché et le couvent Sainte-Claire, AD13 Aix B 1275 fol. 268. 
quedam transversia ubi ripanter multum res infecte... »; il propose de fermer à clef ce passage ${ }^{753}$.

Le paysage des anciens faubourgs à partir de la $2^{\mathrm{e}}$ moitié du XIVe s. donne l'impression d'une zone marginalisée, retournée à la ruralité. Une série d'espaces que l'on reconnaît par les anciennes dénominations, familières, faits de vergers, de jardins fermés de murs arrosés par des béals et des puits, peut-être parsemés de ruines aux emplacements des anciennes maisons et ateliers (surtout concentrés aux abords d'une rue spécialisée). Une zone parcourue de rues/chemins principaux établissant la liaison de la ville avec son terroir et de passages (les traverses) parfois privatisés et rognés sur l'usage collectif par des utilisations abusives et répréhensibles.

Au centre de ce retour à une périphérie rurale suburbaine devait s'élever le riche couvent des Frères mineurs avec son église et ses annexes, jusqu'en 1524, date fatidique ramenant pour de nombreuses décennies le quartier au rang de terroir hors les murs.

\subsubsection{Les vallées et les circulations d'eau}

Plusieurs vallées s'étendent à l'est de la ville ; la plupart canalisent les eaux de pluie et ont donc fait l'objet d'aménagements hydrauliques aux abords de la ville.

\section{La vallée Saint-Bauzille}

La vallée Saint-Bauzille prenait place vers Longchamp et était traversée par le chemin de la Madeleine. D’après B. Roberty, ce lieu-dit était représenté par une dépression entre la Plaine et la colline Saint-Charles; les actuelles rue Consolat et de l'Arbre en formaient le thalweg. Le nom de val Saint-Bauzille s'appliquait en fait au territoire parcouru par le Canal des Jardiniers (et ses ramifications) qui traversait en conduite souterraine le quartier de la Cavalerie inférieure entre le boulevard de la Madeleine, le haut de la rue Consolat et le Jarret ${ }^{754}$.

D’après Meynier, « le bras du Jarret commençait au point voisin de l'ancien jardin des Chartreux parcourait la vallée Saint-Bauzille, une partie du Cours [Belsunce] aboutissait au port par la place dite de la Fusterie. Il est probable que [cette] dérivation fut pratiquée au moyen d'une digue sans toucher au lit du petit ruisseau et que sur cet ancien lit fut établi le canal des arrosants de la Magdelaine construit au XIII ${ }^{\mathrm{e}} \mathrm{s}$. connu sous le nom de Valat dei Coucourgodos... » (Meynier 1866, p. 46).

De fait, la vallée Saint-Bauzille semble avoir accueilli un bras du Jarret dérivé vers l'ouest de la ville avec des

753 ACM BB 33C, fol. 10v.

754 Roberty 1937, p. 20-25 ; Roberty AD13 22 F 82, fol. 20. ramifications d'arrosage et d'alimentation des ateliers de cuiratiers. Il est appelé en 1392 la ribiera de Sant Bauzili $^{755}$. Cette zone est occupée par des vergers, des vignes et des jardins.

\section{La vallée de Morier}

Le val de Morier -le site est mentionné en $1164^{756}$ a donné son nom au bourg homonyme ${ }^{757}$ et peut-être à une dérivation (?) du Jarret qu'il faut certainement considérer comme un terme générique, un cours d'eau, qui arrose la zone (en 1355 on parle du «Jarretum del Morier... in territorio Massilie » $\left.{ }^{758}\right)$. Cette dérivation semble être parallèle à l'ancienne rue de Morier et pourrait s'apparenter au vallon Saint-Charles ou au vallon Saint-Martin conduisant vers la Porte Crote-Vieille. En 1395, une terre située près de cette porte est confrontée avec la «mater aqua Jareti in medio » ${ }^{759}$. En 1519, on évoque encore le «loco dicto al valon de Morrier » ${ }^{\mathbf{7 6 0}}$. En réalité les documents restent peu explicites sur les positionnements de ces vallons.

\section{Les dérivés du Jarret et les aménagements hydrauliques}

Les premières mentions relatives aux aménagements des cours d'eaux conduisant vers la partie est de la ville apparaissent dans les chapitres des Statuts de la ville rédigés en 1253 : « nous ordonnons que deux ou trois probes hommes soient choisis pour qu'ils soient tenus d'amener les eaux du Jarret dans les jardins et les blanqueries par les lieux les plus aptes (...); ayant soin d'empêcher que cette eau ne soit conduite de manière à couler dans le port de Marseille (...) que l'eau du Jarret ne viennent dans le port de Marseille et que les jardiniers reçoivent l'eau de telle sorte qu'elle n'arrive pas jusqu'au port » (Pernoud 1949, p. 59, 68 - L. I, c. 59, 63). Ruffi précise que le financement de ces travaux fut assuré par les Chapitres de Paix qui accordèrent aux Marseillais les matériaux provenant de la démolition des forteresses des confins du territoire afin de payer leurs dettes et pour la construction de leurs aqueducs (Ruffi 1696, I, p. 148).

Dans la transaction passée en 1297 entre les dames de Roubaud et Jacques Bonacros, il est question d'un espace entre le béal du Jarret (bedale aque Jarreti, bedale

755 AD13 351 E 65, fol. 107.

756 Valle de Moreriis en 1164, GCNN, Marseille $\mathrm{n}^{\circ} 164,82$.

757 GCNN, Marseille ${ }^{\circ} 164,82$.

758 ACM 2 ii 266.

759 AD13 355 E 48, fol. 41.

760 AD13 1 HD B 5, fol. 30. 
mayrem), d'une tour ayant appartenue à Bertrand de Trets et d'un abreuvoir rond (abeuratorium rotundum) qui pourrait être susceptible de recevoir et de redistribuer (?) les eaux canalisées par ce béal. Dans la zone ainsi définie on précise que des constructions avaient été édifiées en contradiction avec le règlement, empiétant sur les berges (« super predicti bedali et giet nullum fiat ediffictum ») du béal et du giet (deux mots synonymes ?) ceci dans la zone limite d'une canne ou 8 pans $(2 \mathrm{~m})^{\mathbf{7 6 1}}$. En 1329, J. Bonacros reposera le même problème de ces constructions illicites auprès du conseil de ville ${ }^{762}$.

Cependant les problèmes hydrauliques dans la zone vont nécessiter de nouveaux aménagements en 1319 , lorsque le conseil de ville discute de la nécessité de construire de nouveaux abreuvoirs et des adductions d'eau notamment à proximité de la maison de J. Bonacros. Une formulation précise peut-être la signification d'usage(s) de ces abeuratoria à construire : «...fiant abeuratorium novum quod competat cum aqua Jarreti devianda ibidem ${ }^{\mathbf{7 6 3}}$. Il apparaîtrait donc que ces constructions à travers le terme consacré abeuratorium soient à double usage, celui direct pour l'alimentation des animaux et celui de réceptacle de la dérivation des eaux du Jarret afin d'alimenter la ville ${ }^{764}$.

Le 31 mars 1319, un nouveau conseil de ville examine les coûts de réalisation de la couverture de pierre («crotono videlicet lausis copertis ») du vallat situé entre la maison de Guillaume Arnaud et le jardin d'en Boysson. La longueur de cet ouvrage depuis la maison de G. Arnaud jusqu'au carrefour de la Font Coberta serait de 150 cannes $(300 \mathrm{~m})$ et du carrefour jusqu'au jardin de Hugon Auriol 250 cannes (500 m). Les dimensions (longitudine, latitudine = largeur, hauteur ?) seraient de 5 pans $(0,63 \mathrm{~m})$ pour un coût de 4 livres royales les deux cannes ${ }^{765}$. Le conseil de ville décida les 21 septembre et 3 novembre 1319 de nommer 6 probes hommes afin de suivre l'œuvre des adductions d'eaux, des nouveaux abreuvoirs, des bassins (barquiles) et prélever une taxe sur les fours afin de financer les travaux dont la réparation de l'abeuratorium rotundum ${ }^{\mathbf{7 6 6}}$.

Ces travaux n'allaient pas sans difficulté ; ainsi les moniales de Sainte-Claire réclamèrent auprès du conseil des indemnités - payées sur le produit desdites eaux-en raison de la nécessaire destruction pour «l'ouvre de l'eau »d'un mur leur appartenant ${ }^{767}$. En 1331, le conseil

$761 \mathrm{AD} 1364 \mathrm{H} 1, \mathrm{n}^{\circ} 7$.

762 ACM BB 16, fol. 91r-v.

763 Conseil du 29 mars, ACM BB 12, fol. 75.

764 ACM BB 12, fol. 80.

765 АCM BB 12, fol. 79-81.

766 ACM BB 12, fol. 191, 266, 267.

767 ACM BB 12, fol. 59v, 60. chargea deux probes hommes de rechercher les meilleurs moyens possibles afin de procéder aux réparations des aque ductus du Jarret et de la vallée Saint-Bauzille alimentant les ateliers de la Blancarie, de la Cuiraterie et les jardins. Le financement devait en être assuré par une taxe appliquée aux usagers et riverains ${ }^{\mathbf{7 6 8}}$.

Les questions d'entretien et de réparations se posent de manière récurrente et nécessitent d'imposer des contributions financières : ainsi en 1401 pour le réservoir de la vallée Saint-Louis et les abreuvoirs à l'usage des bêtes (bestiarum) ${ }^{769}$. Lors de la venue du pape Urbain V à Marseille (1365), la ville se préoccupa de faire réparer, étancher, nettoyer et remplir d'eau les bassins (barquils), qui étaient devant le couvent Saint-Louis (sur le chemin d'entrée dans la cité) sans qu'il y ait de pollution due aux lessives de draps afin que les chevaux de la suite pontificale puissent s'y abreuver ${ }^{770}$. En 1366 et 1446 on se préoccupe de faire curer les conduites d'eau obstruées par les dépôts calcaires (tartare sive gresa) ${ }^{771}$.

Ces problèmes de réparations se situent généralement dans l'urgence faute probablement d'entretien suffisant. En 1469, en conseil, le jardinier Louis Borgonhon signale que le conduit d'alimentation de la ville «sistentum in ripparia Jarreti » menace ruine et à défaut d'une réfection rapide sera totalement détruit. Le conseil, devant cette impérieuse nécessité, prend la décision de le faire expertiser par un tailleur de pierre (lapicide expertus) et deux notables et, suite au rapport, de procéder aux travaux ${ }^{772}$. La délibération du 28 janvier 1474 constate que les racines des arbres poussant le long des conduits les détériorent et empêchent les eaux de couler librement; hors l'obligation de couper ces arbres, on interdit d'en planter à moins de quatre cannes des conduits sous peine de 100 livres d'amende ${ }^{773}$. Les vallons canalisant les eaux, encombrés de détritus divers, provoquent des inondations en décembre 1474 ; en conséquence, le conseil de ville du 28 novembre 1475 enjoignit aux propriétaires de nettoyer le cours des rivières ${ }^{774}$.

768 ACM BB 17, fol. 40-41.

769 ACM BB 32, fol. 51.

770 Albanès 1865, p. 31, XXV : «Item sian elegitz dos bons homes peyries que adobar fassan los barquils e curar que son davant Sant Lois e far inplir d'ayga per abeurar los cavals e sian ben estangs e negun non hi lavi draps ».

771 ACM BB 25, fol. 154v, la proposition de curage en 1446 correspond aux conduites de la Porte d'Aix allant à la fontaine proche de l'église des Carmes, ces dispositions peuvent également s'appliquer à tout ou partie du réseau... ACM BB 33A, fol. 20-20v.

772 ACM BB 33, fol. 21v (traduction en français dans ACM DD $308, \mathrm{n}^{\circ} 8$ ).

773 ACM BB 33, fol. 74v.

774 ACM DD 393 (traduction en français, $n^{\circ} 18$ ter). 


\subsubsection{L'occupation du sol}

Si le bâti est relativement dense dans les faubourgs au contact de la ville, on trouve très vite de grands jardins voire des terres mises en culture au fur et à mesure que l'on s'en éloigne. Après la destruction des faubourgs, ne restent que des jardins et des terres cultivées.

\section{Le bâti}

Les documents sont peu prolixes sur les caractéristiques physiques des maisons d'habitations ou de d'usage professionnel. Elles sont dénommées domus, hospitio, hostal, edificio, bastita, cabanna, domuncula, morerii.

Les trois premiers termes sont synonymes et désignent génériquement les maisons d'habitations des bourgs. Le mot edificio s'applique uniquement aux possessions immobilières des Béguines; il semble qu'il établit une distinction qualitative, architecturale peutêtre, se démarquant du reste des constructions. Bastita est proposé (en 1425, 1497, 1514, 1519, 1557) pour une maison de campagne plutôt modeste que l'on pourrait qualifier de cabanon, servant à l'exploitation des terrains cultivés succédant à la destruction des faubourgs. On le trouve effectivement associé à un jardin, un verger, une vigne ${ }^{775}$. Une «domus sucens appellatum cabanna » est implantée dans un verger en $1405^{776}$. Deux domuncula, terme synonyme de morerii, appartenant à deux propriétaires existent en 1430 et 1461, dans un jardin pour la première et dans la rue de Roubaud sur des fayssas plantées de vergers pour la seconde; ces petites maisons sont probablement à rapprocher des bastitas, pour un même usage agricole ${ }^{777}$.

Hors les bâtiments des établissements religieux ayant des fonctions propres (églises, chapelles, réfectoires, dortoirs, etc.), peu d'indications sont données sur les détails d'usage et de construction des maisons des faubourgs. On mentionne une butigia et un cellier (cellario) en 1350 élevé d'un demi-étage (medio solerio). Une auberge dans la rue de Roubaud est peut-être associée à l'estament des Béguines. En 1322, il existe dans la rue de Morier quatre maisons particulières de deux étages disposant d'un pati pour chacune d'elles.

Les maisons des faubourgs sont construites de pierres et de bois, couvertes de tuiles (lapidis, fustanibus, tegulis)

775 AD13 351 E 234, fol. ; 391 E 80 fol. 101 ; 4 HD B 9, fol. 223 ; 1 HD B 5, fol. 30 ; 1 HD B 14, fol. 14 ; 1 HD B 15, fol. 141. En 1433 on mentionne « una parva domus ruralis » dans un verger, AD13 355 E 123, fol. 19675.

776 AD13 B 1177, fol. 64v n 598 .

777 AD13 351 E 240, fol. 175v ; 6 G 490, fol. 3, 4. et leurs habitants récupèrent les matériaux jusqu'aux fondations des habitations détruites par fait de siège dans les années 1357-58 ${ }^{778}$. Certaines d'entre elles, ou plutôt les ruines subsistantes, ne sont mises en exploitation qu'un peu plus tard «per la perera » (pour la récupération des pierres) ${ }^{779}$. La destruction de certaines maisons par le feu devant les menaces des Routiers témoigne peut-être de l'urgence ${ }^{780}$. Dès lors, les emplacements des maisons fondudas sont appelés luegas, locus, boals.

En 1387 il est question de la mise en accapte d'un pati appartenant aux héritiers d'un boucher (macellario), qui confronte avec une scaudaria ${ }^{781}$. En 1391, on évoque une maison vendue à un autre boucher (" hospitum vocatam scaudaria cum virgulto »), il s'agit d'une construction légère où l'on prépare les animaux pour la boucherie, une chaudière $^{782}$. En 1422, on mentionne deux scaudarice dont l'une était attestée par la parentèle de propriété en $1387^{783}$. Cette présence de « chaudières » et de bouchers associés à ces établissements peuvent laisser supposer une relation avec les ateliers de cuiratiers, les macelliers procurant la matière première aux seconds.

\section{Les jardins et vergers}

Malgré l'urbanisation, la vocation du quartier semble se poursuivre autour de la pratique agricole du maraîchage et de l'arboriculture; en témoignent les nombreuses mentions de jardins (ortis) et de vergers (viridarii) disséminées dans toute la documentation. A fortiori après les destructions du milieu du XIV ${ }^{\mathrm{e}}$ s., jardins et vergers réoccupent les espaces anciennement bâtis.

Pratiquement aucune indication n'est donnée sur les espèces plantées pour la période médiévale, qu'il s'agisse de plantes horticoles, d'arbres fruitiers, de céréales ou de vignes ${ }^{784}$. Les documents restent toujours dans la plus

\section{ACM BB 22 fol. 84, 90.}

779 En 1364, AD13 4 HD B 1bis, fol. 43. H. de Valbelle indique qu'en 1523 les matériaux et le lieu de l'ancien couvent des Mineurs restèrent en la possession des Frères (Valbelle 1985, p. 117). En 1528 , par lettre patente du roi de France, les ruines et les matériaux furent donnés aux frères de l'Observance, $\mathrm{AD} 1328 \mathrm{H} 61, \mathrm{n}^{\circ} 382$ et $17 \mathrm{~F} 73, \mathrm{n}^{\circ} 13$ (copie XVII ${ }^{\mathrm{s}} \mathrm{s}$ ).

780 AD13 4 HD B 1bis, fol. 44v.

781 AD13 351 E 670, fol. 19.

782 AD13 355 E 75, fol. 95.

783 AD13 351 E 186, fol. 27v. Du Cange à l'entrée escaudeis évoque le travail d'échaudage des porcs.

784 Une seule mention de terrain planté de céréale (orge) au lieu-dit las Saffranieras derrière le monastère de Sainte-Claire est signalé en 1393, AD13 351 E 53, fol. 33v. On notera l'existence d'une pinède (pineta) et d'une olivette (oliveta) dans le val de Morier et dans le quartier de Robaud en 1458, 1498 et 1509, AD13 1 HD B 4, fol. 23 (et 1 HD B 11, fol. 28) ; 1 HD B 91, fol. 9v (et 1 HD B 4, fol. 17) ; 391 E 163, fol. 291 et 292. Sur la consommation des fruits à Marseille, Villard 1999, 511-522. 
grande généralité. Pour en savoir plus il est nécessaire de procéder (prudemment) par déduction et comparaison avec certains sites non identifiés mais probablement situés dans la proche périphérie marseillaise ( $\mathrm{au} \mathrm{XVI}{ }^{\mathrm{e}} \mathrm{s}$.).

Quelques brèves indications sur les jardins des quartiers de Roubaud et de Sion sont données par les chroniqueurs Honorat de Valbelle et Thierry de l'Estoile. Le premier mentionne simplement la présence d'arbres fruitiers et d'autres dans ces zones vouées à la destruction en 1523: «...coperon tos arbres fruchies et autres que eron dintre lodis jardins non n'exparmiant grans ni petis...» (Valbelle 1985, p. 128). Le second donne plus de détails : « ...ledict Miradel commissaire fit aussi briser et rompre toutes les maisons assises pres et hors la ville avecques les murailles des jardins de plaisance plantés de diverses et nobles especes d'arbres et autres gentillesses venues tant de Barbarie que de Surie et ne demeura bastiment ni maison de valeur autour de la ville de Marseille de la distance d'ung trait de harquebutte qui ne fut rasé... » ${ }^{785}$. Plus tardivement, en 1589 devant les menaces de siège pesant sur la ville, dans un quartier non nommé mais très probablement proche de la muraille de la ville, un jardin appartenant au sieur de Gémenos est saccagé avant d'être transformé en fossé pour la défense de la cité. Le 28 avril une expertise estima la valeur des arbres et légumes détruits : «Rapport d'estime des fruits, arbres et ortolailles, pasquiers, arraché de l'ordre de MM. les consuls dans la propriété estimée [du sieur de Gemenos] avant que d'être réduite en fossé. Jardin : ...certain treillard, arbres fruitiers consistant en prunières, figuières, poiriers, coudoniers, migranières, roziers et amarinières lesquels avons aussi estimés à ving ecus sols davantage avons trouvé audit jardin quantité d'ortolailles scavoir feves, epinards, oignons, aulx, artichaux et autres ortolailles menues avons aussi estimé a quatorze escus et finallement trouvé quelque pasquier semé audit jardin et la plus grande part d'iceluy le tout arraché depuis par lad. communauté pour faire les fossés pour la tuition et deffence de lad. ville de Marseille... » ${ }^{786}$. Une délibération du conseil de ville le 25 août 1589 confirma une fois de plus la subordination des activités agricoles à la défense de la ville : «...[Le conseil] a résolu et ordonné de démolir et abattre les batimens et murailles tant des jardins etant dehors et pres des murailles de la ville... ${ }^{787}$. Un autre verger en

785 D'après la copie de P. Bertas, ACM 20 ii 10, §4.

786 ACM DD 27.

787 ACM DD 27, n 10. L'occupation privée et illicite des espaces publics est évoquée par deux lettres du roi de France en septembre 1493 et août 1499, il demande la destruction des édifices et jardins établis dans les fossés de la ville, ACM DD 27. En 1494, une contestation opposa la ville et Gabriel de Vivaud à propos d'un fossé occupé par un jardin situé entre la Porte de la Frache et le pont de la
1590, non situé, contient des figuiers, des pruniers, des chichomeliers (jujubiers), résiniers (pins, lentisques ?) et autres fruitiers 788 .

Si l'occupation végétale des sols n'est pas particulièrement explicite, la mention de T. de l'Estoile indiquant l'existence de «jardins de plaisance plantés de diverses et nobles especes d'arbres et autres gentillesses venues tant de Barbarie que de Surie » semble démontrer que certains propriétaires, des marchands vraisemblablement comme la famille de Forbin ayant des liens commerciaux avec l'outre-mer, jugèrent opportun de planter des espèces exotiques à l'image des jardins royaux d'agrément ${ }^{789}$. Les jardins et vergers plus ordinaires mais certainement de rapports lucratifs (Villard 1999, p. 520) sont encadrés par des murs délimitant les espaces cultivés en confronts avec les rues et les traverses.

\section{L'occupation par îlot}

Sur la base des textes recueillis et présentés précédemment, nous avons tenté de regrouper les mentions des différentes propriétés dans la zone entre la rue de Crote-Vieille et le couvent des Franciscains. La quantité importante de documents d'archives autorise en effet des regroupements géographiques par îlots et à l'intérieur de ceux-ci par terrain ( $c f$. fig. 221). Cette étude tient compte également du réseau de voies découvert en fouille et des constructions qui ont été mises au jour.

Le premier îlot (1) est compris entre la rue SainteClaire et le fossé. Nous n'avons pas retrouvé de textes le concernant ; il est donc seulement documenté par la fouille de l'Alcazar. Il est vraisemblable d'imaginer un îlot très étroit car l'orientation convergente, au sud, de la rue et du fossé ne laisse pas beaucoup de place pour les maisons.

L'îlot 2 est délimité par deux rues (de Morier et de Sainte-Claire) comme en témoignent les maisons payant un cens au comte en 1298, qui sont sans doute jointives par leur mur arrière. Il comprend au moins quatre terrains juxtaposés.

Le premier terrain regroupe, en 1405 , des emplacements de maisons, sur une surface totale d'environ $285 \mathrm{~m}^{2}$. Il est compris entre la rue de Morier et celle de Sainte-Claire. Il est possible de situer à cet emplacement certaines maisons qui payent un cens au comte en 1298

porte du Marché, le jardin fut détruit et on donna l'ordre de curer le fossé, ACM DD $132, n^{\circ} 5$

788 AD 13393 E 275 en date du 28 septembre.

789 Le jardin du roi à Marseille se trouvait entre la rue Neuve SainteCatherine, la rue du Chantier et le quai de Rive Neuve, Bouiron et al. 2001c, p. 383. Sur les jardins royaux (à Aix), Coulet 1990, p. 275286 et Coulet 1991, p. 491-495. 
et qui semblent, d'après la mention du four de Nicholava de Montellis, se trouver au sein d'un même îlot donnant sur la rue de Morier (pour cinq d'entre elles) et sur celle de Sainte-Claire (pour cinq autres) ${ }^{790}$. Si l'on restitue une largeur d'environ $17 \mathrm{~m}$ entre les deux rues (telle que le donne la fouille), le terrain a en 1405, environ $16,50 \mathrm{~m}$ de long en partant de la rue de Crote-Vieille. Le montant du cens ( 8 sous) est proche de celui du troisième terrain (7 sous) correspondant à trois anciennes maisons (soit 2 s. 4 d. par place de maison). On peut imaginer ici, à l'origine, trois ou quatre maisons.

Un second terrain, situé au sud, ne fait pas l'objet d'une reconnaissance au comte en 1405, mais il semble bien qu'il lui soit redevable au moins en 1425. Les $45 \mathrm{~s}$. de cens correspondent certainement à un grand terrain. On proposera, à titre d'hypothèse, de placer ici les autres maisons payant un cens au comte en 1298 (description du sud vers le nord pour la rue de Morier et du nord vers le sud pour la rue Sainte-Claire ?) ${ }^{791}$.

Plus au sud, un autre terrain comprend à l'origine trois maisons qui proviennent de Bernard Garnier, regroupées avant 1370 en un seul terrain, servile à l'hôpital SaintJacques de Galice ${ }^{792}$. On propose de voir dans la partie sud de l'îlot, l'emplacement de maisons possédées également par l'hôpital Saint-Jacques de Galice à la suite de Bernard Garnier, et désemparées après leur destruction ${ }^{793}$. Une partie seulement correspondrait au terrain cédé aux frères Mineurs en $14288^{794}$.

L'îlot 3, au sud du précédent, est bordé directement par le fossé à l'ouest et par la rue de Morier à l'est. La rue qui sépare les îlots 2 et 3 pourrait correspondre à la rue de Roubaud. En 1316, onze maisons sont sous la directe de Bertrand de Fos, qu'il tient de sa sœur Mabile, ancienne béguine de Roubaud ${ }^{795}$. Leur père, Gui de Fos, était seigneur d'Hyères ; c'est probablement cette famille qui a fait venir les Béguines de Roubaud, installées par les Fos sur leurs possessions marseillaises.

790 AD13 B 1019, fol. 9 (1298); B 1177, fol. 63v n 589 (1405) ; B 1947, fol. 37 ( $2^{\mathrm{e}}$ cahier) (av. 1430).

791 AD13 B 812, fol. 24 (1265) ; B 1019, fol. 9 (1298) ; 351 E 709, fol. 145 (5 juin 1425).

792 Maison 1 : AD13 4 HD B 1, fol. 9v (1311) ; 4 HD B 1bis, fol. 44v (1358-1365). Maison 2: AD13 4 HD B 1, fol. 26 (1340) ; 4 HD B 1bis, fol. 44 (1359-1364). Maison 3 : 4 HD B 1, fol. 9 (1328), fol. 31v (1352) ; 4 HD B 1bis, fol. 124 et 440v (1343-1358). Le terrain réuni : AD13 4 HD B 5, fol. 46v (1431); 4 HD B 7, fol. 55 (1504).

793 AD13 4 HD B 1, fol. 2 (1315), fol. 4 (1349), fol. 8 (1319); fol. 9-10 (1311-1324), fol. 26 (1340), fol. 33 (1347) ; 4 HD B 1 bis, fol. 43-48 (1323-1335).

794 AD13 6 G 43, nº 287 (30 novembre 1428) ; 4 HD B 1, fol. 46 (1420).

795 Les mentions de maisons sont issues d'un inventaire des biens de Mabile de Fos, publié dans Bouiron, Rigaud 2009, p. 106-108 (document $\mathrm{n}^{\circ} 11$ ).
L'îlot 4 correspond à un petit îlot bordé par le grand chemin royal et par une petite traverse. Nous avons peu de mentions perceptibles de terrains dans cet îlot. $\mathrm{Au}$ sud, se trouve un terrain servile au comte ${ }^{796}$. Il est entouré de deux côtés par une vigne.

Deux îlots (5 et 6) sont situés au sud du précédent. Ils sont bordés à l'ouest par la rue de Morier et à l'est par la traverse des Cordiers ; la rue de Roubaud les coupe en deux parties inégales. Contrairement aux îlots situés immédiatement à l'ouest (2 et 3), il est encore difficile de répartir les terrains de part et d'autre de la rue de Roubaud. En particulier, les cens achetés par Philippa Porcelet en 1297 semblent témoigner, à cette époque, de l'absence de la rue de Roubaud qui aurait été percée un peu plus tard.

Le terrain situé au nord de l'îlot 5 confronte à l'ouest la rue de Morier et au nord une traverse ; il est servile au comte de Provence ${ }^{797}$. Il confronte un jardin et un verger (servile au comte ?) et des cens appartenant à Bernard Garnier transmis à l'hôpital Saint-Jacques de Galice ${ }^{798}$.

Un autre petit terrain relève du comte (cens de 8 d.) ${ }^{799}$; trois autres vergers sont jointifs de ce terrain, dont un servile aux Béguines de Roubaud (8 s.) puis aux Frères mineurs (2 s. 8 d. après 1423) ${ }^{800}$. Deux autres terrains sont serviles à la Major ; le premier est vendu en 1388 à Guillaume de Favas ${ }^{801}$. Le second passe avant 1514 à l'hôpital Saint-Jacques-de-Galice. Ce terrain est au sud de la rue du Petit-Saint-Jean ${ }^{802}$. Il est ensuite regroupé vers 1610 avec le terrain adjacent puis divisé pour construire des maisons au XVII ${ }^{\mathrm{e}}$ s. Il constitue alors les deux-tiers oriental de l'îlot actuellement compris entre la rue du Petit-Saint-Jean et la rue du Relais.

On proposera, par hypothèse, de placer dans cet îlot les cens acquis par Philippa Porcelet en 1297. Ils doivent prendre place à l'est, dans la partie méridionale. Sans pouvoir situer précisément ces possessions, il est vraisemblable de placer dans ces îlots des terrains serviles à la famille de Roquefort, au contact de la rue de Roubaud.

796 AD13 B 1177, fol. 64v nº 597 (1405); B 1949, fol. 37v (av. 1430).

797 AD13 B 1177, fol. $64 \mathrm{n}^{\circ} 591$ (1405); B 1949, fol. 37v (av. 1430) ; 351 E 276, fol. 28 (1430)

798 AD13 4 HD B 1, fol. 15v (?) ; 4 HD B 1bis, fol. 37 (1334), fol. 46v (1359), fol. 50v (1322) ; 4 HD B 5, fol. 233 (1424) ; 4 HD B 31, fol. 41 (7 octobre 1392) ; 4 HD B 42, pièce 5 (22 janvier 1322).

799 AD13 B 1177, fol. 64v n 598 (1405); 351 E 225, fol. 100 (1406) ; B 1949, fol. 37v (av. 1430) ; 351 E 276, fol. 28 (1430).

800 AD13 2 G $214 \mathrm{n}^{\circ} 1468$ (7 juin 1390) ; 351 E 175, fol. 7 (14 avril 1424) ; 28 H 39 (23 avril 1424).

801 AD13 351 E 58, fol. 31v (19 juin 1388).

802 AD13 391 E 58bis, fol. 14 (9 juin 1489); ACM 2 ii 566 (15 octobre 1492) ; AD13 4 HD B 9, fol. 221 (26 avril 1514) ; 4 HD B 19, n. fol. (1543) ; 4 HD B 21, fol. 4 (1555). 
A partir du début du XVI $\mathrm{X}^{\mathrm{e}}$ s., les îlots 2 et 5 sont assemblés en une même grand espace non bâti ${ }^{803}$.

L'îlot 7 est compris entre la traverse des Cordiers à l'ouest et la rue de la Providence à l'est. Il est limité au sud par la rue de Roubaud. Au nord de l'îlot, au contact de la rue Crote-Vieille, un terrain est servile dans la première moitié du $\mathrm{XV}^{\mathrm{e}} \mathrm{s}$. à Bérenger Vivaud ${ }^{804}$. Le confront donné avec la rue de Roubaud semble indiquer que l'ancienne traverse des Cordiers a pris ce nom.

A la même date, un autre terrain paie un cens à l'hôpital Saint-Esprit ${ }^{805}$. Dans les deux cas, les terrains sont dits derrière l'église des Franciscains ; les repères topographiques sont quasiment inexistants à cette époque dans les anciennes zones de faubourg, à l'est de la ville.

\subsection{Du faubourg des Roubaud au quartier de Blanquerie (C. Castrucci)}

Lorsqu'en 1666 arrivent les lettres patentes de Louis XIV, celles-ci ne concernent pas seulement les projets d'agrandissement de la ville de Marseille. Las de la volonté d'indépendance de Marseille vis-à-vis des autres provinces du royaume, le roi va utiliser la récente victoire de ses troupes sur la ville pour prendre un certain nombre de décisions visant à réinstaller l'autorité royale dans la cité phocéenne. Il supprime le consulat afin d'écarter la noblesse locale du pouvoir communal, il ordonne la construction des deux forts Saint-Nicolas et Saint-Jean, signe un édit d'affranchissement pour relancer le commerce. Mais le roi décide également de faire de Marseille une ville d'une aussi grande ampleur que d'autres villes européennes du XVII ${ }^{\mathrm{e}} \mathrm{s}$. Son projet «s'inscrit dans la droite ligne des opérations urbanistiques qui affecte l'ensemble des pays européens » (Henin 1986). Et en particulier Rome, que le pape, à la fin du XVI ${ }^{\mathrm{e}}$ s., décide de transformer en une ville dont la magnificence aura pour rôle de mettre en valeur la «victoire du dogme catholique ». Les principes de ce nouvel urbanisme allient l'ouverture de nouvelles rues, l'aménagement de places, au goût de la mise en scène visant à mettre en valeur de belles églises en faisant le choix de la géométrie et de l'uniformité des façades. Ce qui n'est pas sans rappeler une ancienne tradition italienne, puisqu'au Moyen Âge, l'une des grandes voies de la ville de Florence est conçue comme une rue de prestige : on y impose de belles pierres et on réglemente la hauteur et le dessin des arcades et des fenêtres ; la rue

803 AD13 B 1962 et B 1963 (1502 et 1503); 352 E 153, fol. 303 (21 avril 1558) ; B 859, fol. 46 (1560) ; B 881, fol. 158 (1560).

804 AD13 355 E 123, fol. 196 (6 octobre 1433).

805 AD13 355 E 123, fol. 204v (7 novembre 1433). prolonge la place en vue des rencontres sociales (Heers, 1989, p. 292). A Marseille, c'est exactement ce qui est voulu pour le Cours. On le voit bien sur la gravure de Jacques Rigaud inspirée du tableau de Michel Serre qui le représente. Au premier plan, des personnes de qualité se promènent tout en discutant ( $c f$. fig. 35).

Marseille est depuis trop longtemps resserrée dans ses murs; dans les vieilles rues étroites de la vieille ville, autour de l'Hôtel de Ville comme dans le quartier SaintJean, on a tenté de trouver des solutions au problème de logement : extension des immeubles en cœur d'îlots, rehaussement de plusieurs étages, réunion de deux maisons, comme on en trouve plusieurs cas au Corps-deVille. L'imbrication des maisons ainsi produite ajoutée au manque d'entretien des immeubles, ont créé une situation de promiscuité, d'insécurité et d'insalubrité devenue insupportable avec le temps. La maison qu'André de Gérente vend à Jean Fouquier en 1662 est de ce point de vue assez caractéristique : elle comprend une cave qui passe au-dessous de la maison du vendeur ainsi qu'un magasin au-dessus, dont l'entrée est séparée de celle de la maison d'habitation de Gérente par un couloir ${ }^{806}$.

L'état de délabrement des constructions décrit par les nombreux rapports de future cautelle rencontrés sont, en outre, une preuve de plus d'incommodité. Cette situation est aggravée aussi par le fait que de plus en plus le logement sert de lieu de travail : outre la famille, ces immeubles accueillent également un certain nombre de manouvriers qu'on loge quelquefois et qui viennent se rajouter à la population déjà trop nombreuse.

C'est alors par le côté est de la ville, près de la porte du marché, que le Bureau de l'Agrandissement décide de faire commencer les travaux d'extension. Le projet est d'inclure l'ancien faubourg médiéval, le faubourg des Roubaud ou faubourg Saint-Louis ou encore faubourg Saint-Bauzille dans la nouvelle enceinte de la ville. L'aspect de ce quartier va être complètement transformé en quelques années. Quel était-il avant la transformation? C'est à son évolution entre le début et la fin du XVII ${ }^{\mathrm{e}}$ s. que cette étude est consacrée.

\subsubsection{Situation du faubourg au début du XVII ${ }^{e}$ s.}

Lorsqu'en 1666 Louis XIV prend la décision d'agrandir Marseille, le secteur du «quartier des Roubaud»

$\mathbf{8 0 6}$ «Consistant la maison vandue en une cave qui contient le long de lad. maison et encore va au dessoubz, la maison d'habitation dud. $s^{r}$ de Gerente et jusque a la muraille maistresse d'icelle du coste de couchant (...) plus en un petit maguezin au dessus de lad. cave estant dud. coste du couchant sepparé du courroir et passage de la maison d'habitation dud. $s^{r}$ vandeur (...) sepparé d'avec l'escalier dud. sieur de Gerente par une muraille du coste de tresmontane (...) » : vente de Gérente à Jean Fouquier AD13 391 E 391, fol. 979. 
est un faubourg où s'est installée au fil du temps une population essentiellement composée d'artisans et d'aubergistes. Plusieurs dénominations le désignent : faubourg Saint-Louis, faubourg de la Porte du Marché, bourg Saint-Bauzille. Composé au début du siècle de grandes propriétés appartenant à des familles nobles telles celles de Beaulieu ou de Riquetty, occupées essentiellement de jardins et d'espaces arborés, ce secteur a déjà évolué lorsqu'arrivent les lettres patentes royales en 1666.

\section{Situation topographique}

L'îlot fouillé est situé en bordure du rempart médiéval, dont il est séparé par une quarantaine de mètres, face à une place appelée le Grand-Caire, dont l'appellation se perdra au fil du temps mais qui, durant tout le XVII ${ }^{\mathrm{e}}$ s., sert de point de repère pour le localiser. Il est bordé au nord, à l'est et au sud par trois chemins dont les noms évoquent, comme c'est souvent le cas à cette époque, l'endroit vers lequel ils conduisent. Ainsi au nord, se trouve un chemin défini par certains textes comme "le chemin tirant aux Pères Augustins Réformés » ${ }^{807}$. En 1671, les échevins décident, pour l'élargir, d'empiéter sur un terrain placé au nord, appartenant à André de Félix, sieur de Beaulieu, et lui réclament la «contenance de vingt quatre canes cinq pans et demy carré de son jardin ${ }^{808}$ pour élargir le chemin et le transformer en rue qui prendra le nom de Dauphine (il n'est pas élargi mais entièrement déplacé vers le nord); au sud, un autre chemin dont une partie est comprise dans la cession de la demoiselle de Guérin, sépare deux îlots. Les textes ne le désignent en général que comme traverse quelquefois en précisant «traverse derrière le Relais ». Prolongée en 1674 au moment de l'agrandissement de la ville, la «rue qui vient du cours et passe dans la rue du logis de St Jean », prendra à partir de ces années là le nom du logis éponyme, nom qui ne deviendra pourtant définitif qu'aux alentours de 1720 . Le chemin situé à l'est de l'îlot est défini essentiellement par rapport au Relais des chevaux qui se trouve dans l'îlot sud et est ainsi appelé «rue du Relais » ou encore «la rue du bureau des chevaux». Ce n'est qu'à partir de 1675, lorsque l'établissement des bains sera construit, qu'elle prendra le nom de rue du Baignoir.

Dans la prolongation du Grand-Caire, un chemin sera transformé après l'Agrandissement en rue en direction de la Porte royale ; il est occupé par la grande propriété de Beaulieu qu'il vendra dans les années précédant l'agrandissement, en grande partie à l'un des principaux échevins, Barthélémy Couzinery ${ }^{809}$. Les Pères Récollets

807 ACM BB 105, fol. 373.

808 ACM BB 105, fol. 373 et ACM BB 105bis, fol. 944. 809 ACM BB 105, fol. 262v. s'installent dans le secteur entre la Porte royale et le Grand-Caire $^{\mathbf{8 1 0}}$, au même moment où les pères de la congrégation du Saint-Sacrement prennent possession des terrains proches de la porte du Marché qu'ils acquièrent en 1636.

L'image d'un faubourg essentiellement occupé par des jardins au début du XVII' ${ }^{\mathrm{e}}$ s. est confortée par l'acte d'arrentement que passe Claire de Guérin en faveur des pères de la congrégation du Saint-Sacrement. Ce grand jardin d'environ $3000 \mathrm{~m}^{2}$ est en effet voisin de trois autres îlots dont les jardins ont une superficie analogue. Toutefois, quelques constructions sont disséminées sur ces propriétés, en particulier au bord des chemins, servant d'habitations, de bâtiments agricoles ou encore d'auberges.

\section{Des îlots peuplés d'auberges?}

Lorsqu'en 1636 Claire de Guérin passe en faveur des pères de la congrégation du Saint-Sacrement un arrentement perpétuel pour des terrains qu'elle possède près de la porte du Marché, seul un petit bâtiment contenant une pille et un second servant d'étable avec une basse-cour semblent installés sur l'ensemble transmis. Celui-ci est composé d'un grand jardin d'environ $3000 \mathrm{~m}^{2}$ attenant à un autre jardin de $100 \mathrm{~m}^{2}$ et de neuf places de maisons représentant approximativement $1000 \mathrm{~m}^{2811}$ (fig. 222).

Dans le même îlot, quelques maisons sont présentes sur les terrains voisins, et l'on peut imaginer la reconstitution suivante pour les années 1634-1640. À l'ouest, du côté de la place du Grand-Caire, quatre maisons dont trois sont des auberges : Les Trois Mulets appartenant à Jean-Claude Gauthier (parcelle 28), Le Canard acquise par Henry Geoffroy en 1634 (parcelle 27), et Le Cheval Rouge de George Evesque, qui fait l'angle avec la traverse (parcelles 22 à 24). Entre les deux dernières sont situées une place de maison cédée au Pères de la Mission en 1636 (parcelle 26) et la maison acquise en 1640 par Antoine Charousset, jouxtant celle de George Evesque (parcelle 25). Au nord, à l'angle du Grand-Caire et du chemin tirant aux Augustins, une place de maison contenant un petit bâtiment. Au nord-est, la maison de Claire de Guérin (parcelles 10-11); à l'est, sur la traverse, la maison de François Gaillard. Se succèdent ensuite trois places de maisons entourées de murailles d'une hauteur de 2,50 m à $3 \mathrm{~m}$, contenant étable et basse-cour ; elles sont en bordure sud du grand jardin cédé aux Pères de

810 Les pères Recollets de l'ordre de Saint-François acquièrent des terrains plantés de vignes au lieu dit le Bourg de Saincte Clere la Vielhe entre 1633 et 1634 d'une carteirade et demi chacun : AD13 393 E 57, fol. 784 ; AD13 393 E 58, fol. 351 ; AD13 380 E 125, fol. 1054. 811 AD13 380 E 172, fol. 1733. 


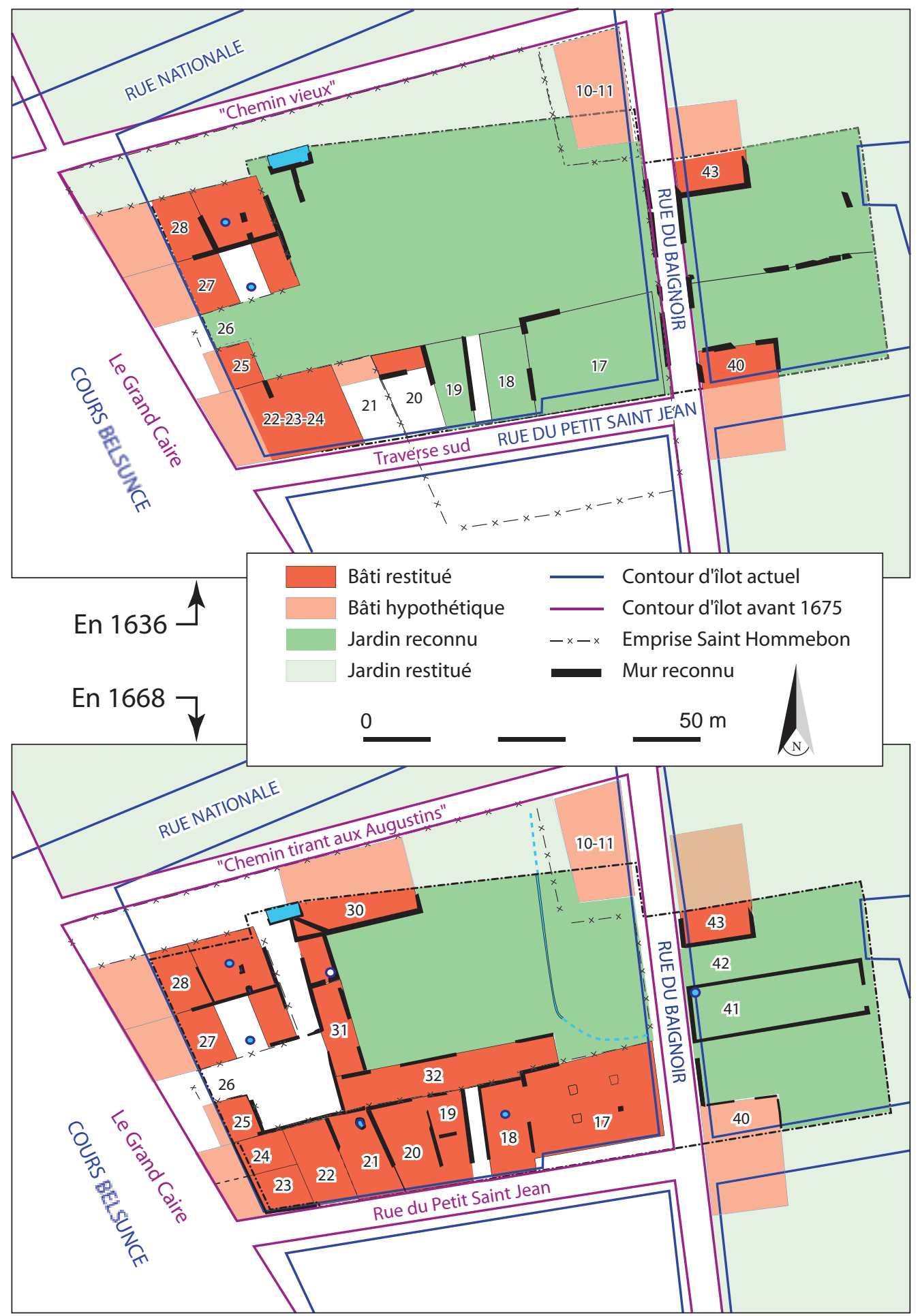

Fig. 222. Plan du secteur de l'Alcazar, partiellement restitué, en 1636 (en haut) et 1668 (en bas) (DAO B. Sillano/Inrap).

la Mission de Provence. Une autre place de maison, la plus à l'est et qui fait l'angle, se trouve en face de la propriété de Barnier, dont elle est séparée par une traverse. Ces cinq parcelles (parcelles 17 à 21) sont séparées d'un autre îlot placé au sud par une traverse. Celui-ci est occupé par le Relais des chevaux appartenant à François Pagi, entouré d'un grand jardin planté d'arbres fruitiers et de la maison de Pagi. Une autre auberge, le Logis de la Celle d'Or est attenante au Relais ainsi que de trois autres maisons. L'existence de deux autres auberges dénommées respectivement Logis des Deux-Indes et Logis des Trois Dauphins est attestée par des textes de 1675. Il est probable qu'elles étaient déjà là bien avant. Ce qui porte à trois le nombre des auberges présentes dans cet îlot. Et à six pour l'ensemble des deux îlots en bordure du Grand-Caire. 
On sait très peu de choses sur ces bâtiments que seule l'estime établie en 1668 détaille, alors que plusieurs d'entre eux ont déjà subi des transformations. Les bâtisses sont composées de deux étages dont les dimensions varient de 5,50 m à $11 \mathrm{~m}$ de large, et de 8 à $14 \mathrm{~m}$ de long. Plusieurs d'entre eux ont leurs rez-de-chaussée occupés par des boutiques et ils ont tous un cellier, une écurie, un grenier à foin au-dessus. Certains ont été restaurés dans les années 1655-1666. C'est le cas du Logis du Petit Saint-Jean transformé entre 1656 et 1662 par Antoine Voulaire, réunissant deux maisons que lui vend Nicolas de Felix. La partie côté est est rehaussée de six mètres environ doublant quasiment sa hauteur. On ajoute des chambres et des appartements. Quelques éléments en pierre de taille sont apportés à la construction : appuis des fenêtres, puits. On installe un système d'évacuation des eaux usées ( $c f$. supra $\S \mathrm{I}, 2,3.2 .2$.).

Ce n'est que dans les années 1674-1675 que l'îlot va être le lieu de profonds changements que l'on peut évaluer en comparant les deux rapports d'expertises dressés respectivement en 1667 et 1684 par les experts du Bureau de l'Agrandissement dans le but d'évaluer les propriétés concernées par l'agrandissement. C'est ce dont il va être question.

\subsubsection{Le faubourg des Roubaud: le début des travaux de l'Agrandissement}

À partir des années 1668-1670, les décisions vont se succéder. On projette la création d'un cours «symbole essentiel et le fait principal par quoi se caractérise la ville baroque » (Argan 1964). Le cours va devenir l'un des lieux symboles permettant le lien et l'articulation entre les anciens et nouveaux quartiers de la ville (Durousseau 1990, p. 25) ou au contraire en marquer la séparation (Chancel 1978). À Marseille en particulier, le Cours a pour rôle de faire contraste avec la vieille ville. Louis XIV veut que ce quartier de l'Agrandissement se distingue par rapport à la vieille ville peuplée de nombreux artisans. On espère surtout qu'il deviendra le quartier de la nouvelle élite dirigeante.

Nicolas Arnoul, l'Intendant des Galères, chargé par Colbert de diriger les travaux, nomme une commission qui, conseillée par les ingénieurs du roi, va mettre au point les premiers projets d'urbanisme. Mais la municipalité, se considérant flouée par les différentes mesures royales, est réticente à tous les projets de transformations. Elle obtient l'accord d'Arnoul puis de Colbert de diriger elle-même les travaux de l'Agrandissement. Le résultat est immédiat : les échevins décident d'annuler la commission d'Arnoul qu'ils remplacent par le « Bureau de l'Agrandissement », ayant à sa tête un Directeur et composé de commissaires choisis par eux-mêmes. Selon André Zysberg, Nicolas Arnoul se serait servi de son rôle de médiateur dans cette affaire pour en tirer d'immenses profits. Il semble en effet que Nicolas Arnoul se soit enrichi grâce à l'Agrandissement en pratiquant une spéculation foncière effrénée, et fait construire plusieurs immeubles sur la rive méridionale du port (Zysberg 2007). Ce qui peut expliquer qu'il ait soutenu les échevins dans leur volonté de gérer eux-mêmes la question de l'Agrandissement de la ville. Sa position de médiateur lui permettait en effet, tout en restant l'homme du roi, de pouvoir œuvrer pour ses propres intérêts. Aussi, il n'était pas très apprécié des Marseillais.

Quoiqu'il en soit, à partir de ce moment là, la municipalité, forte de cette reprise en main des opérations, va les diriger non sans favoriser les intérêts de ses membres et de ses alliés.

\section{La reprise en main municipale : les premières mesures}

On va utiliser les anciennes lices de la ville pour l'ouverture du Cours. Au vu des prescriptions établies, il apparaît que la municipalité a tenté de concilier la volonté royale désireuse de permettre à Marseille de trouver sa place dans le rang des grandes villes européennes modernes, et la conservation une certaine autonomie afin de pouvoir favoriser les intêrets locaux.

La décision royale suivie de la reprise en main des opérations et de l'instauration du Bureau de l'Agrandissement vont avoir plusieurs effets : tout d'abord la nomination d'experts, en l'occurrence les architectes Gaspard Puget et Mathieu Portal, chargés de dresser le plan d'alignement et d'évaluation des propriétés qui seront comprises dans l'Agrandissement.

En 1668, la visite de toutes les maisons qui doivent être insérées dans le nouveau quartier est effectuée. Le rapport détaille les dimensions et la composition de chacune d'elles et en fixe la plus-value ${ }^{812}$. Un autre rapport sera établi en 1682 suite aux «coupements » qu'avaient dû subir les maisons situées sur le Cours : chaque propriétaire reçoit un dédommagement financier pour les superficies soustraites ${ }^{813}$. Grâce à ces deux rapports nous pouvons nous faire une idée assez précise de l'évolution du quartier en moins de vingt ans. Ainsi l'auberge du Mouton Couronné, construite sur une place appartenant déjà aux pères de la Congrégation, placée entre celle de Laurent Geoffroy au nord et celle d'Étienne Chaurousset au sud n'était pas signalée lors du premier rapport. Elle devait être un passage pénétrant dans

812 ACM DD 157, fol. 123 à 143v.

813 ACM DD 155, fol. 229 ; DD 157, fol. 127 ; DD 159, fol. 47, 49, 61. 
l'îlot par où passaient les attelages. Le rapport précise qu'effectivement une maison y a été construite depuis l'agrandissement. De même, les deux maisons qui leur appartiennent donnant sur «la rue du Bureau des chevaux », ont été édifiées après $1668^{814}$.

La transformation du quartier va découler d'un certain nombre de mesures mises en place: d'abord une évaluation des propriétés comprises dans l'Agrandissement afin de fixer d'une part la superficie à ôter pour l'alignement des rues; d'autre part la plus-value dont elles seront l'objet.

Pour élaborer le plan d'alignement et créer un système viaire nouveau, la communauté fait l'acquisition de terrains privés qu'elle utilise pour ouvrir de nouvelles rues ; c'est le cas pour la rue Royale, ou pour la rue Dauphine dont la place nécessaire est prise sur des terrains acquis par Barthélemy Couzinery, un des principaux échevins de l'époque ${ }^{815}$. La mise en place de la rue du Petit-Saint-Jean, «qui va du cours, en passant par le Logis de Saint-Jean vers la porte nouvelle des pères Augustins refformés » se fera grâce à une portion de terrain prise dans le jardin du seigneur de Negreaux ${ }^{816}$, puis dans celui du $\mathrm{S}^{\mathrm{r}}$ de Ruffy ${ }^{\mathbf{8 1 7}}$. Dans le quartier de Bernard du Bois, la rue éponyme venant de la porte d'Aix à celle de Bernard-du-Bois est prolongée par une percée dans un terrain de Jean Garnier que la communauté lui achète en avril 1677 ; en contrepartie le propriétaire est dispensé du droit d'enceinte ${ }^{\mathbf{8 1 8}}$.

Cependant, la résistance des habitants est grande. Plusieurs cherchent à tirer profit de la situation. Nombre d'affaires signalent des cas de personnes ayant acquis des terrains dans l'Agrandissement. Ces événements démontrent aux autorités municipales, la nécessité d'ouvrir une rue qui valorisera leur propriété, au détriment de tout raisonnement urbanistique.

C'est le cas de Barthélémy Couzinery qui use de son influence d'échevin sur le conseil municipal pour faire ouvrir deux rues : la rue Dauphine et celle du Baignoir afin de mettre en valeur ses propriétés. Cette manière de procéder et de construire la ville en fonction de profits personnels continuera au XVIII ${ }^{\mathrm{e}} \mathrm{s}$. Ainsi, les quatre maîtres maçons qui achètent à Anne Dordis en 1715 des terrains, situés près de la porte Saint-Lazare «ditte du Bernard du Bois » sur lesquels ils sont «dans la resolution dy construire des maisons et de les vendre» demandent au conseil municipal d'ouvrir gratuitement

814 ACM DD 164.

815 ACM BB 105, fol. 262 v en 1671.

816 C'est la future rue du Petit-Saint-Jean, ACM DD 159, fol. 71 en 1674.

817 ACM DD 106, du 21 juin 1674.

818 ACM DD 101. deux rues dans leur terrain. Cela leur est accordé par délibération municipale le 20 décembre de la même année ${ }^{\mathbf{8 1 9}}$. La fille de Jean Garnier qui avait cédé un terrain pour l'ouverture de la rue Bernard-du-Bois en 1677, fait modifier une décision municipale pour la prolongation de la rue venant des Capucins. Cela lui est accordé. De même, la prolongation de la «rue tirant de midy a tremontane » qui doit passer dans la propriété de Jean Garnier au sud-est de la rue Bernard-du-Bois ${ }^{\mathbf{8 2 0}}$ est soumise, suite aux plaintes des propriétaires voisins, à des discussions qui durent des années.

Les sources nous éclairent nettement sur les manœuvres municipales, la communauté n'hésitant pas à modifier les plans d'urbanisme prévus initialement en fonction d'intérêts particuliers. La supplique que les prêtres du Saint-Sacrement envoient à l'Intendant de justice, Monseigneur Rouillé, comte de Meslay, est, sur ce point, révélatrice. Par cette demande, l'économe de la Congrégation révèle que les prêtres avaient construit leur église en fonction de l'établissement d'un premier plan d'alignement. Or, comme cela gênait le Juge du palais, les commissaires chargés de l'Agrandissement prétendent en avoir établi un autre, qui est cette fois préjudiciable aux pères. L'économe porte ce recours auprès de l'Intendant «pour faire remettre les choses dans l'estat quelles doivent estre » et argue également du fait qu'il n'a pas été consulté avant la décision de ces modifications alors que le couvent était le premier à en subir les inconvénients ${ }^{\mathbf{8 2 1}}$.

La mise en place d'une réglementation de la construction visant à normaliser et uniformiser les maisons sur le cours arrive de façon concomitante. La communauté vend des terrains à des particuliers qu'elle charge d'appliquer les normes de construction établies par le Bureau : c'est ainsi que la «place à bastir maison » joignant celle qu'il possède déjà sur le cours que reçoit le marchand de poudres Jean-Baptiste Pontis en 1670 , doit servir de modèle à toutes celles qui seront ensuite construites sur le cours. La décision prise en Conseil municipal notifie que «la maison que ledict Pontis fera construire tant dans ladite place, triangle, qu'en sa vieilhe maison doibt servir de regle et modelle aux autres que seront construites audict cours $\gg$. L'acte de vente décrit une partie de ces règles: la maison devra avoir sur le cours un arc de 6,50 m de hauteur pour 3,50 m de large, dans lequel la porte d'entrée sera comprise. Les fenêtres de l'entresol, également compris dans l'arceau, auront 1,50 m de largeur et autant de haut; alors que les fenêtres de la pièce principale auront

819 ACM DD 101.

820 ACM DD 101, 17 janvier 1728.

821 AD13 C 2181, doc. 13, vers 1670. 
2 m de hauteur et seront décorées d'une « plate bande » au-dessus ; celles de l'étage supérieur, placées à 4,50 m au-dessus, pourront se faire en ovale. La décoration sera composée de corniches, de triglyphes et d'architraves. Si le $\mathrm{S}^{\mathrm{r}}$ Pontis décide après l'établissement du contrat, d'ajouter d'autres étages, ceux-ci ne devront pas avoir plus de 3,50 m de haut. Le parvis de sa maison donnant du côté du Cours, devra être pavé « de brique a la fasson du quay du port» ( $c f$. fig. 20) alors que du côté de la rue on pavera avec de la pierre. L'angle de la maison devra être fait «de taille a grand bossage en talus d'un pour canne $\gg \mathbf{8 2 2}$.

Les prix-faits des maisons dont les vestiges ont été retrouvés en fouille en bordure du Cours, et qui sont reconstruites au moment de l'Agrandissement, donnent moins de détails sur la décoration mais prescrivent d'autres consignes. Les maisons, amputées d'environ 4,50 m pour l'alignement du Cours, doivent être pratiquement reconstruites en entier. Quatre des six contrats de construction des maisons concernées ont été retrouvés. Ils font référence à celui correspondant à la maison que font construire les Pères de la Mission ${ }^{823}$, et qui doit leur servir de modèle. Ils précisent que «le carage sera fait de pierre de tailhe de la mesme hauteur, architecture et façon de celluy de lad. maison desd. Pères missionnaires ».

En même temps, s'opère dès les années 1666-1670 une flambée spéculative qui va voir d'immenses propriétés vendues à des gens qui vont les lotir et les revendre plus cher ${ }^{824}$. Ainsi Barthelemy Couzinery achète en 1670 les terrains d'André de Félix, seigneur de Beaulieu situés entre la propriété des pères Récollets et celle des pères de la Mission de Provence, exceptés environ $1600 \mathrm{~m}^{2}$ que le vendeur se réserve. Dans les deux années qui suivent, il lotit l'intégralité et les vend une à une. Les pères de la Mission de Provence, qui n'avaient pas utilisé toute la partie située à l'est de leur jardin, la lotissent à des fins locatives. Ce qui justifie qu'en 1729, ils déclarent posséder, en plus de leur église, de la maison presbytérale et de leur jardin, « cinq maisons et demi des six qui sont sur

822 Cette référence est donnée par B. Hénin (1986).

823 La hauteur précise des constructions devait être indiquée dans ce prix-fait du logis appelé «le Mouton couronné », que les Pères font construire et qui a servi de modèle aux maisons voisines. Cet acte nous faisant défaut, il n'est pas possible d'avoir la hauteur des maisons reconstruites.

824 Il est curieux de constater que dès 1658, André de Felix, seigneur de Beaulieu, lotit la partie de son terrain située du côté « entre deux chemins des églizes des Pères de la Mission et Récollets », qui est le chemin qui ira ensuite vers la Porte d'Aix, alors que l'agrandissement n'est pas encore décidé. Sept de ces ventes nous sont connues. Les lots sont de 6 cannes de long et vingt pans de large - soit 5,50 m de façade pour $12 \mathrm{~m}$ de profondeur, alignés le long du chemin (Bouiron 2001 b, vol. 6 , p. 168-170 pour les références des actes). la dite rue du Relais » ainsi qu' « une maison ... servant de Logis où pend pour enseigne le Mouton Couronné, avec les écuries qui y sont dans le fonds $\gg \mathbf{8 2 5}$.

À partir de 1671, c'est Thomas de Riquety, sieur de Negreaux qui lotit sa propriété de part et d'autre de la rue du Petit-Saint-Jean. Celle-ci, comme cela a été évoqué, a été percée dans sa propriété. Les quatorze places vendues dont les textes nous ont fourni la trace, ont entre 5,50 et $6 \mathrm{~m}$ de largeur en façade pour $14 \mathrm{~m}$ de profondeur. Il les cède pour 36 livres la canne carrée ${ }^{826}$. C'est-à-dire un peu moins cher que celles que vend Barthélémy Couzinery qui, lui, vend 28 cannes carrées pour 1120 livres soit 40 livres la canne carrée ${ }^{\mathbf{8 2 7}}$. En revanche, à la même époque, Jean-Paul de Foresta propriétaire d'un grand domaine dans un des îlots situé à l'est de celui qui nous occupe, vend plusieurs lots de son bien au prix de 60 livres la canne carrée : à une ou deux années près, les prix des terrains proches du Cours ont flambé. En revanche près de la porte d'Aix et de la nouvelle enceinte, Anne Dordis, déjà citée, vend en 1716 un terrain au prix de 7 livres la canne carrée aux maçons Graille, Pecoul et Tian. C'est au même prix de 16 livres qu'elle vend encore, huit ans plus tard 201 cannes à la raffinerie de salpêtre pour 16 livres la canne carrée. Même si l'on prend en compte une dévaluation de la monnaie, la différence est trop importante pour ne pas mettre en évidence l'importance de la valeur qu'avaient pris les terrains aux abords immédiats du Cours dès le début des travaux, valeur qui ne s'étend aux autres quartiers que progressivement.

\section{La transformation de l'îlot face au Grand-Caire au moment de l'Agrandissement}

À partir des années 1666, l'îlot va subir d'importantes transformations qui verront leur aboutissement en 1675 au moment où toutes les maisons donnant sur le Cours auront été rénovées. Du côté de la rue du PetitSaint-Jean déjà, en 1656, Nicolas de Felix vend «deux places à bâtir maison se joignant » qui font l'angle de la rue du Petit-Saint-Jean et de celle du Relais des chevaux à Antoine Vollaire. Elles sont entourées de murs de clôture et ne contiennent qu'un petit bâtiment agricole. Le nouveau propriétaire fait reconstruire une maison de deux étages avec boutique au rez-de-chaussée ${ }^{\mathbf{8 2 8}}$.

\section{ACM CC1, fol. 88.}

826 Les références des textes sont dans le rapport de l'Alcazar, Bouiron 2001b, vol. 6, p. 174-179.

827 Vente de place à bâtir du Sr Couzinery à Jean-Baptiste Besson le 2 novembre 1671 : AD13 362 E 124, fol. 2364.

828 AD13 393 E 76, fol. 456v, 363 E 150, fol. 1434 et 363 E 157, fol. 393 . 
En 1662, Jean-Baptiste de Félix, neveu de Nicolas, vend à Antoine Evesque les deux places à bâtir contigüies. L'une des deux contient un petit bâtiment d'un étage de $8 \mathrm{~m}$ de large pour 3,50 $\mathrm{m}$ de haut environ ${ }^{829}$. En 1671 , Étienne et Jacques Boisson achètent une écurie et un grenier à foin faisant partie des biens acquis quelques années auparavant par Antoine Evesque et font immédiatement des travaux ${ }^{\mathbf{8 3 0}}$.

Henry Evesque revend le Logis du Cheval Rouge à Jacques Ribouton. Cette auberge est composée de deux corps de bâtiment. Ils communiquent par l'intérieur de l'îlot et forment un L; un bâtiment sur le Cours, l'autre sur la rue du Petit-Saint-Jean. La reconstruction des deux s'opère entre 1674 et 1675 . Elle met bien en évidence la volonté de privilégier et de normaliser l'aspect des immeubles situés sur le Cours. Ce qui n'était pas le cas dès que l'on pénétrait dans les rues adjacentes. En effet, la partie de l'immeuble placée sur la rue aura deux étages, une écurie, et une terrasse au-dessus, alors que, comme les autres maisons situées sur le Cours, l'autre corps de bâtiment de l'auberge aura quatre étages ${ }^{\mathbf{8 3 1}}$.

Les principales transformations de l'îlot concernent les bâtiments conventuels et les maisons situées sur le Cours. Les quatre prix-faits déjà signalés établis pour ces dernières en 1675, concernent les maisons de Jacques Ribouton, Anthoine Chaurousset, Alexandre Evesque et Laurens Geoffroy ${ }^{832}$. Diverses consignes sont communes pour les quatre constructions. Le nombre d'étages est fixé à quatre, et leur hauteur totale égalisée. De même, la hauteur des fondations devra être de 2,50 m sous terre et de $60 \mathrm{~cm}$ d'épaisseur. Les façades sont faites en pierre de taille du plan de la rue jusqu'au toit. À l'intérieur, plusieurs détails sont à respecter. Notamment l'édification d'un escalier en vis qui sera fait de quatre tours ; seules les quatre premières marches sont en pierre de taille, les autres sont construites avec du gip. On prévoit trois cheminées pour chaque maison dont le tuyau devra sortir au-dessus du toit de $1 \mathrm{~m}$. Leur foyer sera en pierre de taille avec un bard contre le mur. À côté on posera un évier muni d'un système pour l'écoulement de l'eau qui sera relié à une évacuation générale afin d'être dirigée vers un collecteur "leurs esguiers conduits par les bourneaux jusques à la rue pour y conduire les eaux». Les rez-de-chaussée sont occupés par une ou deux boutiques. Il y a une écurie à la maison de Jacques Ribouton où l'on précise qu'il faut poser des anneaux, des crèches et des rateliers pour les chevaux. Si plusieurs détails font

829 AD13 360 E 158, fol. 262v.

830 AD13 367 E 159, fol. 930v et 1182v.

831 AD13 390 E 235, fol. 332v.

832 AD13 390 E 236, fol. 191 ; 361 E 62, fol. 100v ; 390 E 236, fol. 240v ; 380 E 171, fol. 1411. défaut, comme la hauteur de chaque étage par exemple, ou le nombre de fenêtres ${ }^{833}$, d'autres ne sont pas laissés au hasard. Comme le type de plancher qui sont à édifier qui devront être «negats » et la qualité du bois dont on précise qu'il devra être neuf.

L'aspect scénographique est évidemment mis sur les bâtiments donnant sur le Cours. Il n'en est pas de même de ceux situés dans les rues adjacentes, même aux abords immédiats du Cours et notamment dans la rue du PetitSaint-Jean. On remarque la différence de construction entre les deux corps de bâtiment du Logis du Cheval Rouge, dont on se souvient que l'un est sur le Cours, l' autre dans la rue du Petit-Saint-Jean. Ils n'ont pas la même hauteur, puisque le bâtiment le moins en vue n'a que deux étages alors que l'autre en a quatre. De plus, l'utilisation de la pierre de taille pour sa façade n'est pas précisée, ce qui laisse supposer qu'on l'a construite en maçonnerie ; en revanche la brique est choisie pour faire les fenêtres. La partie du côté du Cours de la façade de la maison d'Antoine Evesque est en pierre de taille à l'identique de ses voisines ; pour celle du côté de la rue du Petit-Saint-Jean la pierre de taille n'est utilisée que «jusques au premier courdon de coudiere », puis autour des fenêtres.

D'une façon générale, outre la mise en valeur des maisons du Cours qui vient d'être évoquée, on remarque le soin apporté à la construction elle-même à partir de cette époque. Ce qui vient faire contraste avec la plupart des maisons construites antérieurement dans la vieille ville. En particulier, l'amélioration du système d'écoulement des eaux, relié à la rue par les bourneaux et les gorgues. L'utilisation de la pierre de taille dans le foyer des cheminées sert à protéger les murs mitoyens d'une usure précoce ; il devient nécessaire de faire sortir leurs tuyaux d'un mètre au-dessus du toit pour prévenir le refoulement des fumées et les risques d'incendie. On soigne également l'étanchéité des sols que l'on fait systématiquement carreler.

Valorisé aussi bien par le roi que par la communauté, l'ancien faubourg des Roubaud offrait l'occasion à nombre d'artisans, pour la première fois, de venir s'installer pour travailler dans un lieu où il y a de la place. On se souvient que les parcelles vendues par Thomas de Riquetty ont entre 5 et $6 \mathrm{~m}$ de large sur $14 \mathrm{~m}$ de profondeur. Celles cédées par André de Felix, seigneur de Beaulieu ont aussi $5 \mathrm{~m}$ de large pour $12 \mathrm{~m}$ de long. Quant à Barthélemy Couzinery les lots qu'il vend sont larges de $8 \mathrm{~m}$ et profonds de $14 \mathrm{~m}$. L'intérieur de l'îlot de l'Alcazar, occupé jusque là par des écuries ou des jardins, offre des possibilités d'extension aux auberges qui s'y trouvent.

833 Le nombre de fenêtres par étage n'est connu que pour la maison d'Antoine Evesque qui fait l'angle du Cours et de la rue. Le prix-fait précise qu'il doit y avoir quatre fenêtres par étage, deux de chaque côté. 
C'est pourquoi, dans un premier temps, ce ne sont pas des gens de la nouvelle classe dirigeante qui viennent s'installer dans ce quartier. Les actes de vente des terrains lotis par Barthelemy Couzinery et par Thomas de Riquetty viennent confirmer l'analyse de la répartition socio-professionnelle des commanditaires de ce quartier de l'agrandissement qu'a fait Béatrice Hénin : les places à bâtir sont acquises en majorité par des artisans, des marchands, des voituriers et des aubergistes (Henin 1986, p. 7). Aussi, les demeures prestigieuses du type de celle de l'Hôtel de Pesciolini, dénommé également Maison aux Cariatides, étudié par Georges Reynaud, ne sont pas nombreuses ${ }^{\mathbf{8 3 4}}$. Les auberges se sont agrandies et multipliées à partir de l'Agrandissement parce que la demande en était importante du fait de la nouvelle situation de ce quartier.

Une des destinations premières du Cours a été d'offrir un lieu de sociabilité à la bonne société marseillaise. En cela, il a répondu aux attentes de la royauté. Mais de plus il assurait un lieu de rencontres privilégié pour traiter des affaires. Il offrait un lieu agréable, où voyageurs et négociants venant faire leur commerce, pouvaient s'installer en arrivant dans la ville. La rue Royale, prolongeant le Cours jusqu'à la Porte d'Aix en facilitait l'accès. Être logé dans une auberge du Cours permettait d'avoir l'aisance de la proximité de la vieille ville et du port, où continuaient à se faire l'arrivée et l'expédition des marchandises, et de l'Hôtel de Ville, siège du pouvoir communal. C'était être dans la cité marseillaise, sans avoir les désagréments de la vieille ville.

\subsubsection{Conclusion}

L'avidité de certains spéculateurs, et le soutien que leur ont apporté les échevins ne sont pas les seules raisons qui ont contrecarré la volonté royale de faire de ce secteur un quartier résidentiel.

La poussée démographique du début du XVII ${ }^{\mathrm{e}} \mathrm{s}$. avait entraîné une demande croissante de logements que la vieille ville -à laquelle la seule réponse apportée pendant des années avait été de construire de nouveaux étages dans les immeubles anciens et d'empiéter sur les cours intérieures-n'arrivait pas à satisfaire. Les terrains de l'Agrandissement offrent des possibilités plus importantes de constructions de logements plus vastes dotés d'un jardin et d'une cour en arrière du bâtiment. C'est ce que souhaite Nicolas Arnoul et c'est une solution inespérée.

834 Le prix-fait de cet hôtel, daté du 18 juin 1672, confié à César Portal et Alexandre Casteau, est donné dans l'article de Georges Reynaud (Reynaud 1988, p. 377).
Premier secteur hors les murs à s'urbaniser au $\mathrm{XVII}^{\mathrm{e}}$ s. le faubourg des Roubaud n'est donc pas devenu un quartier résidentiel comme l'escomptait le pouvoir royal. Ce sont en majorité des artisans, des marchands, des aubergistes déjà présents en 1666, qui s'installent en nombre sur le Cours ; c'est ce qui différencie Marseille de sa rivale aixoise.

Comme le montre B. Hénin, l'évolution de ce secteur est donc un «compromis entre les aspirations monarchiques et les habitudes marseillaises » en vue de l'intégration de la ville au royaume français. Ainsi, le mouvement évolutif dont les prémisses sont antérieurs à 1666 va s'amplifier et le développement de la ville va se réaliser en fonction des besoins des classes sociales « en voie d'expansion économique » (Henin 1986).

\section{Le bourg de Morier médiéval}

Entre la fin du XII et le milieu du XIV e s., l'espace suburbain se densifie considérablement. Des phases d'occupation bien différenciées ont pu être mises en évidence grâce à la fouille.

\subsection{L'occupation au XII ${ }^{\mathrm{e}}$ s. (E. Leal, N. Scherrer)}

C'est probablement à partir du $\mathrm{XII}^{\mathrm{e}} \mathrm{s}$. que l'expansion urbaine se manifeste dans les zones hors les murs. Les constructions ultérieures et l'érosion ont laissé peu de vestiges des premières phases d'occupation.

\subsubsection{Une première occupation médiévale (début du XII ${ }^{e}$ s.) ${ }^{835}$}

Les premières traces tangibles d'une occupation médiévale apparaissent au-dessus d'une phase alluviale caractérisée par d'épais dépôts de limons jaunes qui viennent sceller l'arasement des structures de l'Antiquité tardive. La seule construction alors attestée sur le site est un bâtiment isolé, situé dans la partie centrale du terrain, à l'est du chemin de Morier (fig. 223). Autour de cet édifice, des zones de circulation ont été identifiées, le reste du terrain étant vierge de vestiges. Néanmoins, à l'extrémité orientale du site, des niveaux d'occupation sont ponctuellement perceptibles. La dissémination de ces témoins n'est justifiée qu'en partie par les multiples perturbations postérieures; elle est le marqueur d'un paysage clairsemé ouvert essentiellement sur la ruralité.

835 D'après É. Leal et P. Mellinand in Bouiron 2001b. 


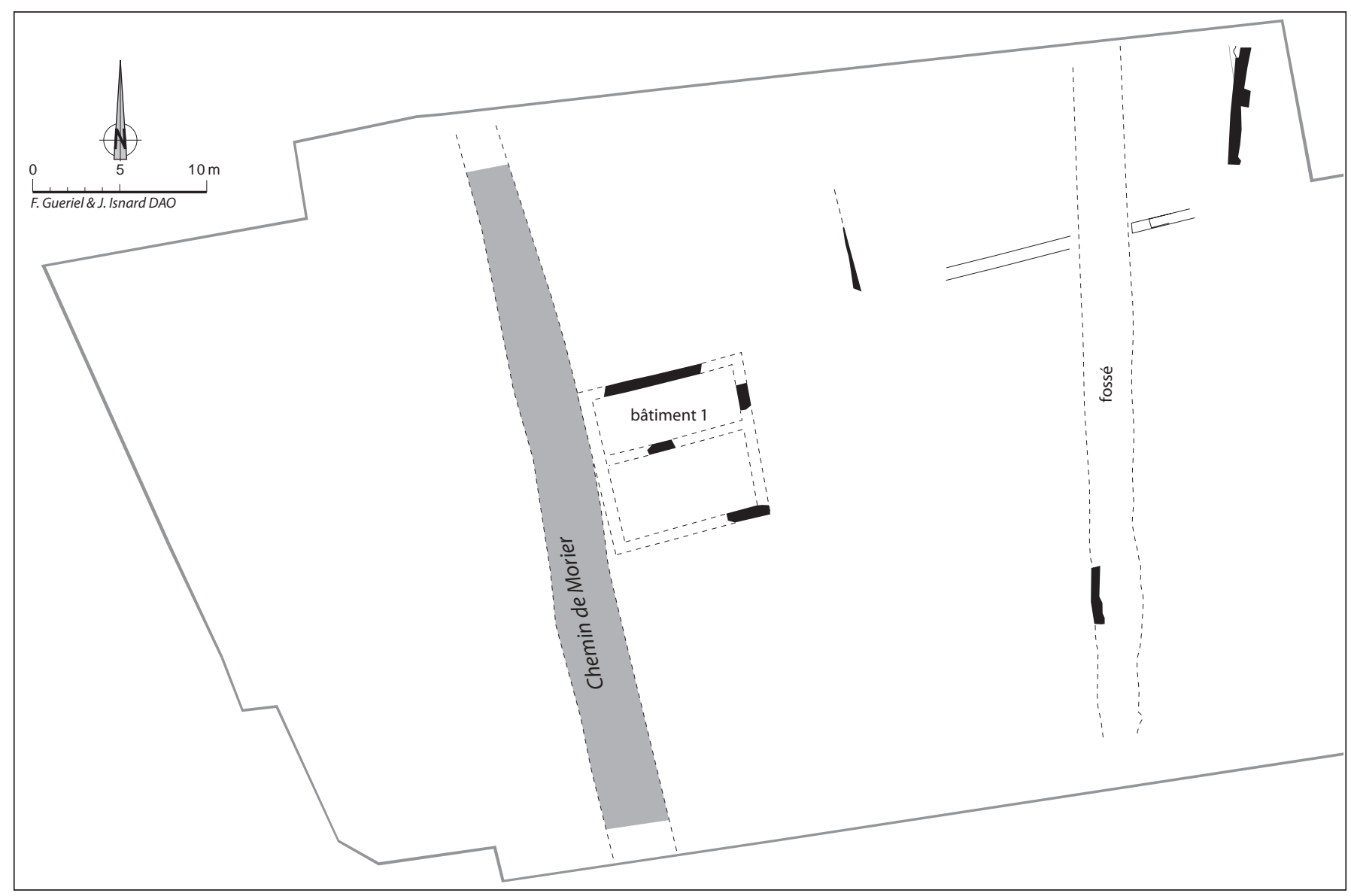

Fig. 223. Plan des vestiges au XIIe s. (DAO F. Gueriel, J. Isnard /Inrap).

\section{Le bâtiment 1}

Le bâtiment 1, de plan carré, mesure 9,40 m de côté et il est constitué de deux pièces, $1 \mathrm{~A}$ au nord et $1 \mathrm{~B}$ au sud (fig. 224). Son état de conservation est particulièrement médiocre en raison de la densité de l'occupation ultérieure et de la récupération presque systématique des matériaux de construction. Un épisode alluvial a également endommagé voire partiellement détruit ces installations déjà très frustres.

Le mur de façade occidental de ce bâtiment peut être restitué à l'emplacement d'un mur de façade d'un îlot établi lors de la mise en place du faubourg au XIII ${ }^{\mathrm{e}} \mathrm{s}$. La façade orientale est partiellement conservée sur ses deux assises de fondation. L'appareil assisé est constitué d'un double parement de moellons grossièrement équarris avec blocage interne composite (tuiles, briques, galets, cailloux de calcaire), lié à la terre. La première assise forme un ressaut et elle est essentiellement réalisée avec des galets; la seconde mêle galets et moellons de calcaires divers, de grès ou de poudingue. La largeur de ce mur est de $50 \mathrm{~cm}$ et atteint $65 \mathrm{~cm}$ avec le ressaut. Les murs nord et sud ont subi un épierrement systématique

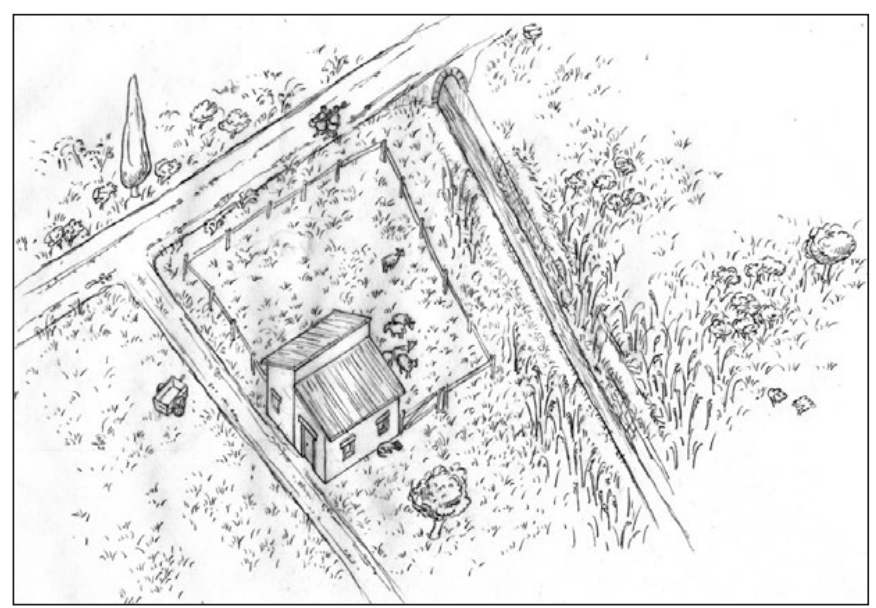

Fig. 224. Le site de l'Alcazar vers 1170 (dessin G. Frommherz/Inrap).

et il n'en subsiste plus que les tranchées de récupération ou un vestige de parement; leurs caractéristiques techniques nous sont par conséquent inconnues. Un mur transversal scinde le bâtiment en deux pièces. Il est conservé sur une longueur de $2 \mathrm{~m}$, avec une seule assise de fondation, soit $15 \mathrm{~cm}$ de haut. Celle-ci présente un appareil de moellons équarris disposés en boutisse 
et liés à la terre, formant un parement double sans blocage interne, d'une largeur totale de $60 \mathrm{~cm}$. Les moellons sont taillés dans divers calcaires, du grès ou du poudingue.

La pièce $1 \mathrm{~A}$, au nord, s'étend sur une surface de $25,5 \mathrm{~m}^{2}$. Son sol de terre battue présente une surface damée assez régulière, reposant sur une charge de limons sableux ou d'argiles jaunes selon les endroits. Il est en partie érodé puis recouvert par des dépôts de sables et graviers, diffus sur l'ensemble de la surface de l'espace ou ponctuellement concentrés dans des dépressions. La pièce $1 \mathrm{~B}$, au sud, s'étend sur une superficie de $36 \mathrm{~m}^{2}$. Elle est également pourvue d'un sol de terre battue, composé d'une couche de limons argilo-sableux jaunes d'environ $20 \mathrm{~cm}$ d'épaisseur. Comme le sol de la pièce précédente, la surface a été érodée par le passage d'alluvions, si bien qu'il n'est plus possible d'en observer la surface.

Aucun dispositif particulier ne permet de préciser l'utilisation, ni les accès de ce bâtiment. À l'est, zone que la séquence alluviale a particulièrement érodé, il ne subsiste aucun niveau de circulation aux abords du mur de façade orientale. En revanche, au nord et à l'ouest du bâtiment 1 a pu être fouillée une série de niveaux de circulation extérieure, révélant l'absence d'autres constructions contre la première. Un espace damé se développe vers le nord et l'ouest à partir de la façade septentrionale. Il est matérialisé par un sol de terre battue présentant une surface plane et assez régulière identifiée sur $44 \mathrm{~m}^{2}$. Ce niveau suit l'inclinaison naturelle du terrain vers le sud-ouest. Bien que son étendue n'ait été perçue que sur une bande de $4 \mathrm{~m}$ de large le long de la face nord du bâtiment, la séquence stratigraphique observée au-delà de cette surface damée révèle la continuité du remblai de nivellement sous-jacent. Identifié sur une largeur de $7 \mathrm{~m}$, cet épais remblai de limons argileux a été apporté afin de régulariser la série de sédiments de nature et d'origine diverses scellant la destruction des structures de l'Antiquité tardive. Contrairement aux sols des abords immédiats du bâtiment, les terrains plus au nord n'ont pas conservé leur surface de circulation. En effet, le sommet du remblai de nivellement est très nettement incisé par l'évènement torrentiel qui a érodé dans cette zone tous les niveaux de circulation. À l'ouest du bâtiment, des niveaux d'occupation sont identifiés tout le long de la façade occidentale, sur une largeur d'environ $3 \mathrm{~m}$. Les abords du bâtiment présentent soit de simples surfaces de sol damées installées sur un remblai de nivellement limoneux, soit, au contraire, des surfaces aménagées et chaulées sur une épaisseur d'environ $5 \mathrm{~cm}$, localisées devant la pièce $1 \mathrm{~B}$. Un niveau identique se retrouve au sud du terrain, ce qui confirme qu'il s'agit d'un chemin nord-sud le long du bâtiment et non d'une simple circulation autour du bâtiment. Par ailleurs, l'espace autour du bâtiment n'est pas strictement horizontal. Il est en effet marqué par un double pendage général de l'est vers l'ouest et du nord vers le sud, identique à la pente générale du site.

Au-delà des abords proches du bâtiment, les terrains qui s'étendent vers l'ouest ne présentent plus aucun aménagement particulier. Néanmoins, les remblais formant les terrains contemporains du bâtiment ont un sommet très régulier et damé attestant d'une occupation sans qu'il soit possible de préciser davantage le statut de ces terres; l'absence de sédiments propres à la culture ne permet sans doute pas d'envisager ici la présence d'une zone cultivée. Enfin plus au sud, les terrains situés de part et d'autre du chemin sont laissés dans l'état où ils étaient après l'épisode alluvial de la phase antérieure.

\section{Maintien de quelques murs hérités de l'Antiquité tardive}

Dans la partie centrale et plus particulièrement au nord, quelques murs, vestiges de l'occupation de l'Antiquité tardive, sont restés dans le paysage et ont peut-être en partie influencé l'orientation du bâtiment occidental. Il s'agit notamment d'un mur de terrasse orienté est-ouest qui est repris dans sa partie haute puisqu'une assise formée de blocs de calcaire mesurant entre 30 et $60 \mathrm{~cm}$ et liés à la terre sont disposés sur son arase.

\section{Des traces d'occupations ténues à l'est}

La zone orientale du chantier comporte une importante densité de caves modernes et la stratigraphie n'est épargnée qu'en quelques endroits. Au nord-est du site, deux niveaux superposés appartiennent vraisemblablement à la période médiévale, bien qu'aucun élément de datation n'ait été mis au jour. Le remblai inférieur se compose d'un sédiment sablo-limoneux, brun foncé, hétérogène par la nature des inclusions (nombreux cailloux et cailloutis) et des escargots. Un litage des éléments grossiers suggérant une esquisse de semelle de sol peut y être distinguée. Il est scellé par un second niveau limono-argileux brun contenant également des gravillons et des coquilles de gastéropodes.

Une seconde séquence stratigraphique partielle a été mise en évidence à l'extrême sud-est de l'espace, au contact de la limite de chantier. Le plus ancien niveau médiéval repéré, contenant de la céramique du XII ${ }^{\mathrm{e}} \mathrm{s}$, est composé de limons sableux mêlés d'éléments importants, de tuiles en particulier. On observe aussi une compaction et une coloration virant au gris, indication d'une plus grande concentration de matières organiques. Les vestiges présents sont ténus, mais attestent bien d'une occupation de cette zone dès le début du XII ${ }^{\mathrm{e}} \mathrm{s}$. 


\subsubsection{Une phase alluviale et la tentative d'assainissement du terrain (seconde moitié du XII ${ }^{e}$..$)^{836}$}

La séquence stratigraphique qui succède aux structures du premier état médiéval présente en certains points du site des dépôts de type alluvial, témoignant de manière tangible d'un ou de plusieurs épisodes d'inondation.

\section{Le recouvrement du bâtiment du $X I I^{e}$ s. et des terres adjacentes}

Cet épisode alluvial a été mis en évidence sur les sols à l'intérieur du bâtiment mais également sur les terres environnantes, et plus particulièrement au nord. D'un point de vue archéologique, il se caractérise par la présence de niveaux sableux et gravillonneux qui scellent des incisions dans les couches d'occupation du premier état médiéval. Il intervient sous forme de simple dépôt et recouvre les niveaux d'occupation en place lors de son activité. Son épaisseur peut être très faible, comme le dépôt sableux dans la rue, d'une épaisseur maximale de $10 \mathrm{~cm}$, ou au contraire très importante, comme la séquence au nord du bâtiment 1, alternant graviers et sables sur une épaisseur qui atteint $80 \mathrm{~cm}$. En certains points, son action a été davantage destructrice et érosive puisqu'il se présente sous forme de chenaux de profondeur et d'axe variables, entièrement comblés de dépôts alluviaux. C'est le cas au sud, dans la pièce $\mathrm{B}$ du bâtiment primitif, un chenal comblé de graviers, a entamé le sol et, au nord, un second chenal a creusé les surfaces extérieures.

Il semble qu'une partie des terres ait été laissée à l'abandon à la suite de cet épisode alluvial. C'est le cas de la zone correspondant à la surface précédemment occupée par le bâtiment du premier état et à ses terres environnantes. En effet, la séquence stratigraphique de ce secteur présente un hiatus chronologique se traduisant par des sédiments et des structures contemporaines du dernier état médiéval qui se superposent directement à la séquence alluviale scellant la première phase d'occupation. Ainsi l'état du début du XIII ${ }^{\mathrm{e}} \mathrm{s}$. se trouve absent de la séquence stratigraphique de cette zone, témoignant d'un abandon. La datation de cet apport alluvial est, comme pour la phase antérieure, particulièrement difficile. En effet, le mobilier recueilli dans ces niveaux est soit résiduel soit indatable car présent sous forme de fragments non exploitables. Ceci amène à établir une chronologie relative. Ainsi les éléments de datation, proposés avec toute la réserve qu'il convient, placent

836 D'après É. Leal, C. Aubourg et C. Voyez in Bouiron 2001b. l'épisode alluvial dans la seconde moitié du XII ${ }^{e}$ s. Il convient de préciser que si le terminus ante quem, fourni par la tannerie, dont l'occupation intervient chronologiquement à la fin du XII e et au tout début du XIII ${ }^{e}$ s. et postérieurement aux dépôts alluviaux, est relativement bien établie, en revanche le terminus post quem est largement tributaire du manque de mobilier datant pour la première occupation médiévale, située plutôt dans la première moitié du XII" $\mathrm{s}$.

\section{Le creusement d'un grand fossé}

Suite à cet épisode alluvial, une tentative de maitrise et de canalisation de l'eau est opérée par le creusement d'un important fossé de direction nord-sud, dont le tracé rectiligne a été repéré sur une longueur de 40 m environ. Il est vraisemblablement situé au débouché d'un cours d'eau descendant de la butte Saint-Charles, selon un axe nord-est/sud-ouest. Le départ du creusement n'est pas conservé, mais le négatif perce une épaisse couche sablo-limoneuse jaunâtre issue d'une phase de colluvionnement scellant les vestiges de l'Antiquité tardive. Le creusement initial du fossé possède un profil relativement régulier, en forme de U et aux bords évasés. D'une largeur moyenne de $3 \mathrm{~m}$ et d'une profondeur de $2 \mathrm{~m}$, il accuse un pendage général vers le sud suivant la déclivité naturelle du terrain. L'inclinaison de sa pente est faible mais suffisante pour l'évacuation des eaux.

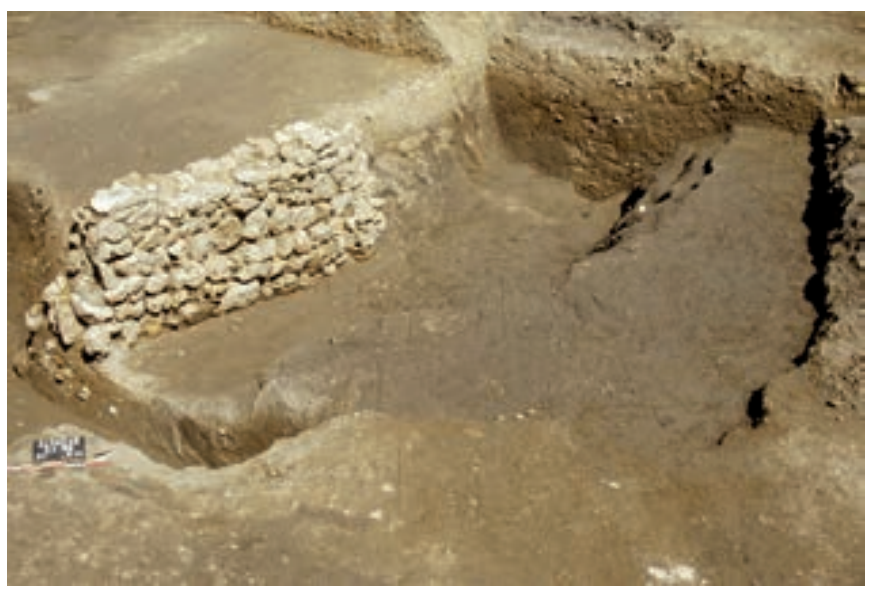

Fig. 225. Le mur de confortement dans le fossé (cl. C. Voyez/Inrap).

Au sud, un mur est aménagé à l'intérieur du fossé contre la paroi occidentale du creusement (fig. 225). Il est conservé sur $3 \mathrm{~m}$ de long, sur une hauteur totale de $1 \mathrm{~m}$ et constitué d'un ressaut de $50 \mathrm{~cm}$ de haut qui déborde de $20 \mathrm{~cm}$ vers l'intérieur. Composé d'un appareil irrégulier en pierres liées à la terre, il forme un confortement ponctuel puisqu'il ne se poursuit pas vers le nord. Il peut s'agir aussi d'un aménagement préalable à l'établissement d'une superstructure en bordure de fossé liée à 
l'activité de l'eau ; néanmoins, aucune trace à sa surface n'a été conservée. Le mobilier recueilli est résiduel et ne permet pas de proposer une datation pour l'édification du mur mais l'étude de la stratigraphie montre qu'il est réalisé lors de la création du fossé puisque toutes les couches de sédimentation qui se trouvent à l'intérieur s'appuient contre la structure bâtie.

Plusieurs comblements sensiblement identiques appartiennent à cet état : ces niveaux sont caractérisés par une sédimentation naturelle d'origine hydraulique liée au fonctionnement du fossé. Ces formations sont consécutives à une série d'épisodes alluviaux (crues et décrues), avec des dynamiques d'écoulements variables. Ces dépôts sont matérialisés par des alternances de lits de sables et de graviers entraînant parfois un matériel abondant se situant plutôt à la base, daté de la fin du $\mathrm{XII}^{\mathrm{e}}$ s. et du début du XIII' ${ }^{\mathrm{e}}$ s.

\subsubsection{Conclusion}

La première occupation du site au cours du XII ${ }^{\mathrm{e}} \mathrm{s}$. demeure encore mal précisée d'un point de vue fonctionnel. Le bâtiment 1 apparâ̂t comme un élément isolé en bordure de chemin, s'insérant dans un paysage très ouvert dont il est difficile de savoir s’il est dévolu à une activité agricole ou s'il correspond à un terrain en friche. La présence de sols chaulés témoigne d'une volonté d'assainissement et de stabilisation de la surface de circulation, particulièrement aux abords de la grande pièce méridionale. Il est possible que cet établissement ait abrité une activité professionnelle ou domestique en lien avec une exploitation agricole, où le petit artisanat lié aux outils est indispensable. La proximité du marché Saint-Martin localisé à côté de la porte du même nom, où se vendaient des cordages, ainsi que le maintien du toponyme des Cordiers qui sera attribué à la rue orientale, signifient peut-être que la culture du chanvre se situait sur ces terres riches en eau.

La réalisation du fossé dans cette zone inondable est un marqueur déterminant dans le paysage; son implantation semble constituer, dès l'origine une limite parcellaire. Il est par ailleurs, un élément préalable indispensable à l'implantation stable de nouvelles constructions à la fin du siècle.

\subsection{Un bourg essentiellement à vocation artisanale de la fin du $\mathrm{XII}^{\mathrm{e}} \mathrm{s}$. à la deuxième moitié du $\mathrm{XIII}^{\mathrm{e}} \mathrm{s}$. (E. Leal, F. Paone)}

À la fin du XII ${ }^{e}$ s., la réappropriation de zones jusqu'alors peu mises en valeur suscite une refonte totale de l'espace par la pérennisation de deux axes de circulation et la construction des divers dispositifs hydrauliques (fig. 226). La politique de maîtrise de l'eau, déjà amorcée avec le creusement d'un important fossé venant du nord, se concrétise par l'établissement d'un véritable complexe formé d'aqueducs et de puits citerne indispensables à l'implantation d'une zone artisanale d'envergure dévolue au travail de la peau, zone qui se developpe dans la partie nord du site. Le long du chemin de Morier, déjà attesté au début du XII ${ }^{\mathrm{e}}$ s., est construit un nouvel édifice au sud du bâtiment 1, partiellement détruit lors d'épisodes torrentiels. Enfin une occupation dispersée et peu structurée caractérise la lisière orientale du site.

\subsubsection{La stabilisation de la trame viaire ${ }^{837}$}

Le réseau viaire se définit à partir d'un axe principal ouest-est, localisé hors de l'emprise du site et dont la permanence d'utilisation est attestée depuis l'époque antique. À cette voie s'ajoute un axe nord-sud établi au cours du XII ${ }^{\mathrm{e}}$ s. Situé à quelques mètres de ce dernier, un nouvel espace de circulation borde, à l'ouest, un bâtiment de la tannerie dont l'implantation s'intègre entre ces voies et l'aqueduc oriental.

\section{Confirmation de l'existence d'un axe nord-sud, la rue de Morier}

Déjà attesté lors de la phase précédente sous la forme d'un simple chemin, cet axe semble davantage structuré au cours de cette période. Il assure un accès à un bâtiment méridional et constitue une desserte par le sud au complexe artisanal qui l'a alors partiellement annexé au nord, en supprimant toute communication avec la rue est-ouest ou de Crotte-Vieille.

Des différences de mises en œuvre le long de son tracé caractérisent les niveaux de circulation de cette rue. À proximité de la tannerie, est disposée une préparation de sol composée d'un cailloutis incluant des nodules de chaux. Plus au sud, une chape argileuse de $6 \mathrm{~cm}$ supporte une couche dense de petits galets pris dans une matrice sableuse de $4 \mathrm{~cm}$ d'épaisseur. Enfin le long du bâtiment 3, plusieurs sols en terre battue ou en argile se superposent et, ponctuellement, des niveaux de chaux servent directement de surface de circulation.

Plusieurs contextes de sédimentation liés à l'utilisation de la voie se retrouvent de manière discontinue sur les deux tiers du tracé. Ils sont constitués de dépôts de limon argileux recouvrant la totalité de la voie au sud, et d'un sédiment plus sableux au nord. Puis la rue

837 D'après L. Ben Chaba et É. Leal. in Bouiron 2001b, vol. 1-2, p. 319-321. 


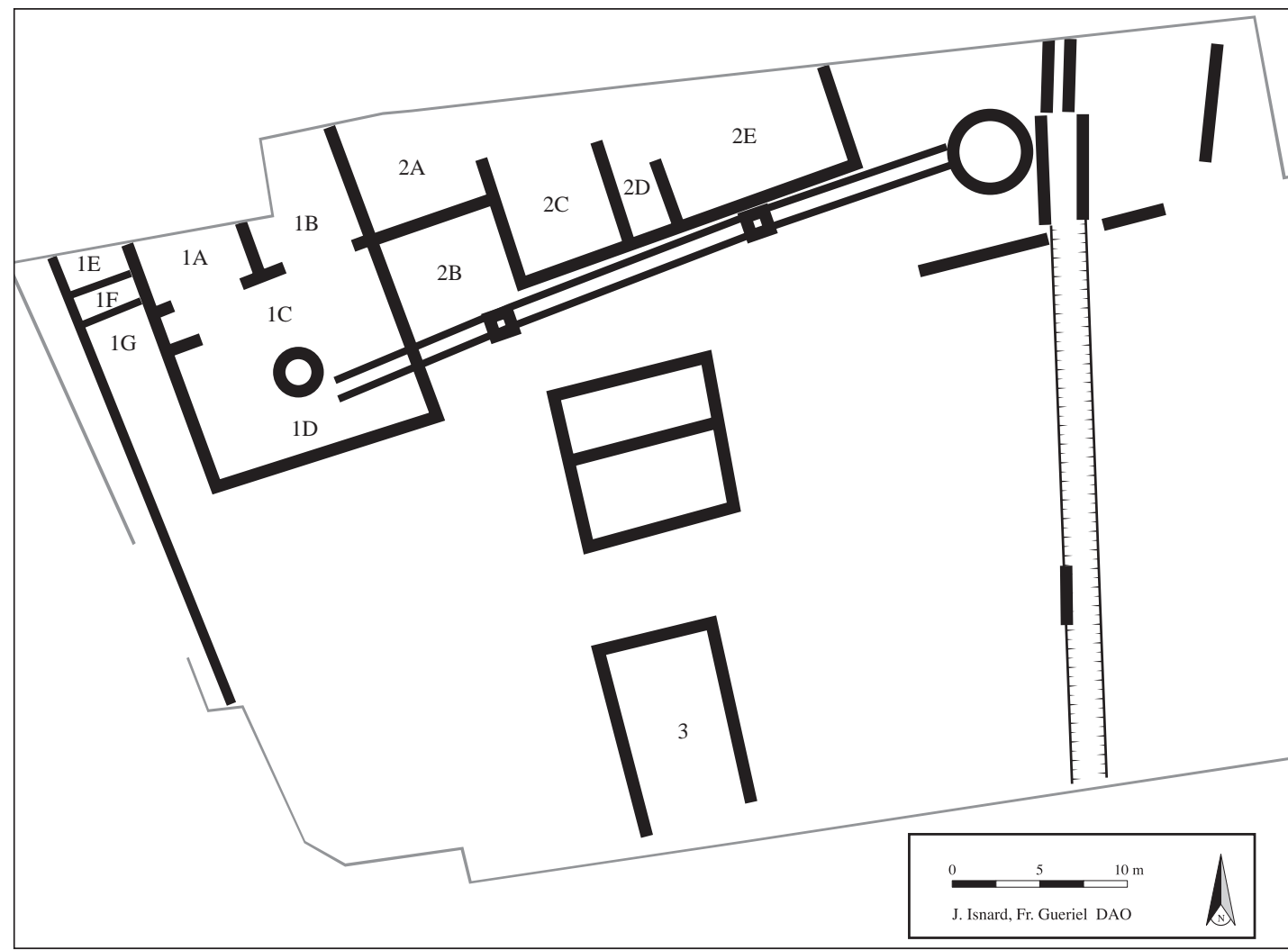

Fig. 226. Plan général

de la tannerie

(DAO J. Isnard,

F. Gueriel/Inrap).

est entièrement rénovée au sud par l'installation d'un nouveau sol constitué de déchets de taille, le long du bâtiment 3, l'apport de brasier de calcaire rose étant particulièrement soigné et compact. La surface de circulation de cette voie est par la suite régulièrement rechargée par de la chaux ou des éclats de taille.

Au début du XIII ${ }^{\mathrm{e}}$ s., suite à un épisode torrentiel qui ravine la surface de la rue et creuse une rigole, des travaux sont entrepris afin de niveler les irrégularités du terrain et le damer. En plus de la restauration du niveau de la rue, on procède à la mise en place d'un dispositif d'écoulement des eaux avec la construction d'un caniveau ( $c f$. fig. 28). Au nord, ce dernier longe la façade ouest du bâtiment primitif sur 3,50 m de long. Au sud, il traverse la rue sur un tracé oblique de 2,50 m de long. À l'extrémité méridionale de la rue, son tracé est dévié vers l'ouest en direction d'une construction disparue. La mise en œuvre du caniveau est identique sur les tronçons nord et sud. Le conduit de section rectangulaire $(12 \mathrm{~cm}$ de large sur $27 \mathrm{~cm}$ de profondeur) est formé par une couverture et deux parements en dalles équarries en calcaire crayeux oligocène ${ }^{838}$. Elles sont disposées de chant, sans liant, contre les parois de la tranchée d'installation dont le négatif matérialise le fond, non construit. Le pendage de ce caniveau, extrêmement faible, n'atteint que

838 Dimensions des dalles : 25 x 14 x $10 \mathrm{~cm}$.
$0,2 \%$ de déclivité contre $1 \%$ pour la pente des sols du deuxième état de rue. La poursuite de l'évacuation des eaux vers le sud se fait ensuite par l'intermédiaire d'une simple rigole bien marquée. Elle est profonde de $40 \mathrm{~cm}$, large de $30 \mathrm{~cm}$ et conservée sur 2,05 $\mathrm{m}$ de long et la transition avec la partie bâtie se fait par le biais d'une dalle en poudingue de $30 \mathrm{~cm}$ sur $22 \mathrm{~cm}$, pouvant faire office de regard. L'abandon de la rigole, daté de la première moitié du XIII ${ }^{\mathrm{e}}$ s., est caractérisé par des dépôts hydromorphes plus finement lités en partie inférieure.

Postérieurement à l'aménagement du caniveau, une ultime réfection de la rue est engagée au cours de la deuxième moitié du XIII ${ }^{\mathrm{e}} \mathrm{s}$. Les sols sont rechargés au sud par un cailloutis, venant sceller les dalles du caniveau, et un épandage de déchets de taille conférant un aspect soigné, solide et imperméable à la rue. Au nord, un remblai limoneux nivelle la surface avant la mise en place du niveau de circulation fait de limon sableux et charbonneux incluant de nombreux galets. L'apport d'un remblai composite de déchets de calcaire, de galets et de fragments de tuile procède de la dernière étape de réfection des sols avec un nouveau sol de rue, ponctuellement chaulé.

\section{Un espace de circulation à l'ouest de la tannerie}

Les niveaux observés à l'ouest de l'ensemble artisanal sont nettement différenciés de ceux identifiés dans les espaces intérieurs de cet ensemble puisqu'il s'agit 


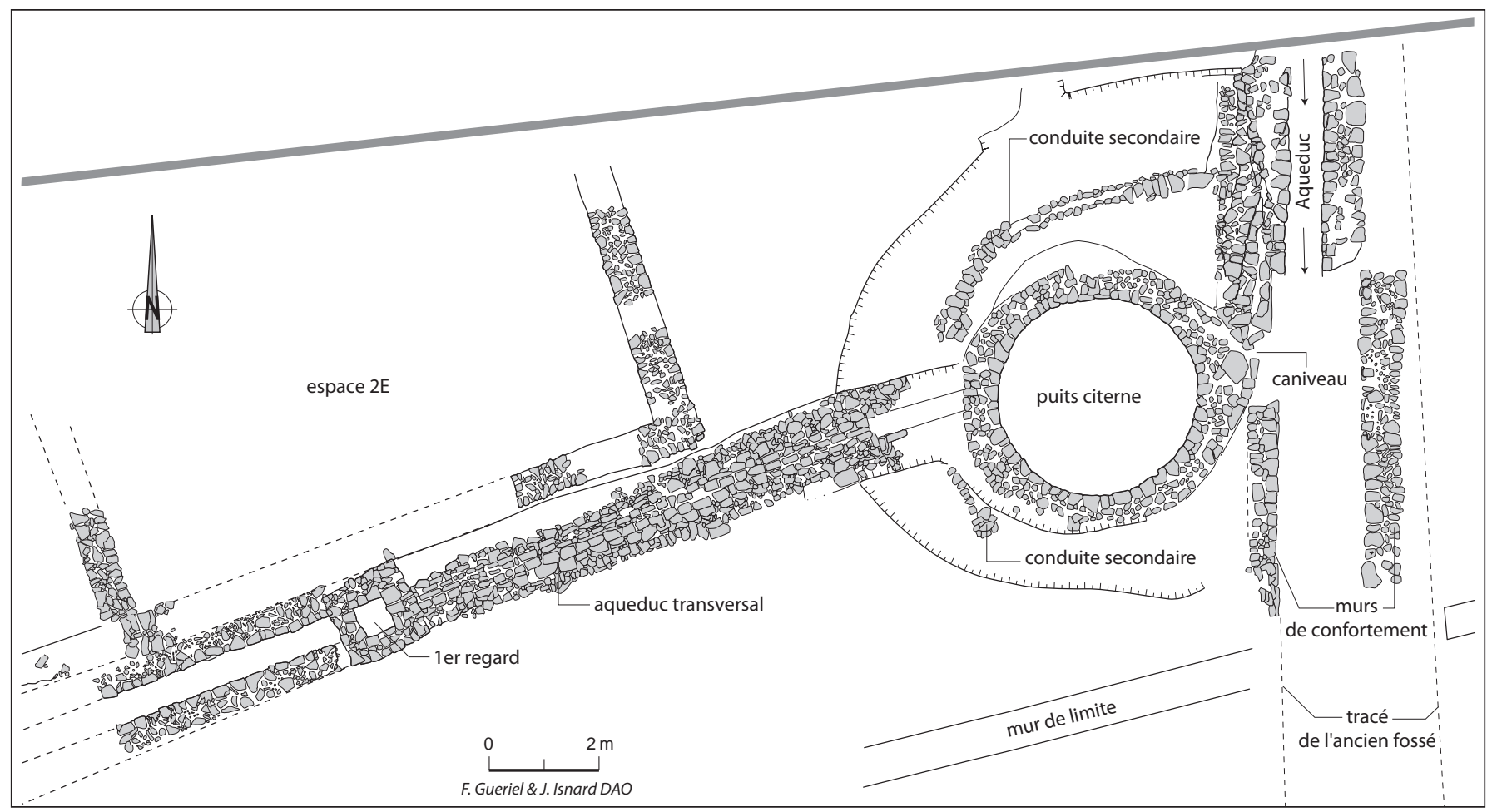

Fig. 227. Plan de détail du complexe hydraulique (DAO F. Gueriel, J. Isnard/Inrap).

essentiellement de niveaux de graviers posés sur un remblai de limon sableux de $25 \mathrm{~cm}$ d'épaisseur.

La nature de ces sols, leur homogénéité de structure et l'absence de mur de refend venant cloisonner l'espace évoquent plus particulièrement un espace ouvert et extérieur. Mais les données concernant l'extension de cet espace vers l'ouest sont très partielles et ne permettent pas de déterminer s'il s'agit d'une rue, d'une cour intérieure ou d'un terrain en arrière de parcelles.

\subsubsection{Le complexe hydraulique ${ }^{839}$}

À partir de la seconde moitié du XII ${ }^{\mathrm{e}}$ s., une série d'ouvrages hydrauliques structure le paysage et les constructions adjacentes. L'ensemble est relié à une dérivation du Jarret, petit ruisseau qui parcourait le val Saint-Bauzille, traverse le val de Morier et sert à alimenter principalement la zone artisanale et les jardins. Sur ce site, l'importance du complexe se justifie par l'installation de la tannerie dont les besoins en eau sont prépondérants. Ce réseau hydraulique se compose de deux aqueducs dont l'un, nord-sud reprend le tracé du fossé préexistant et l'autre, en diagonale, est pourvu de deux regards. Deux puits monumentaux complètent ce dispositif.

839 D'après Aubourg et al. in Bouiron 2001b, vol. 1-2, p. 322-329 et F. Paone in Bouiron 2001b, vol. 7, p. 100.

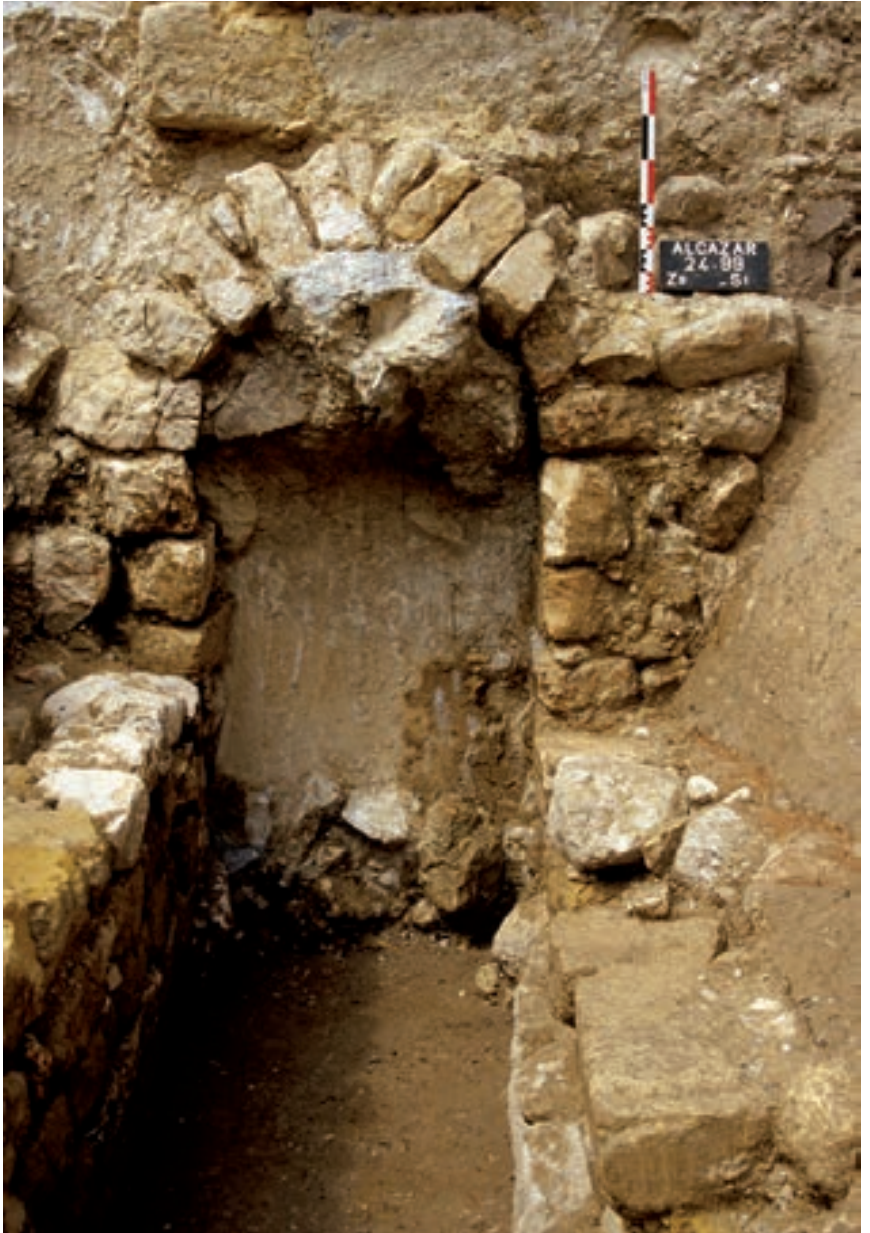

Fig. 228. Vue de l'aqueduc (cl. T. Maziers/Inrap). 


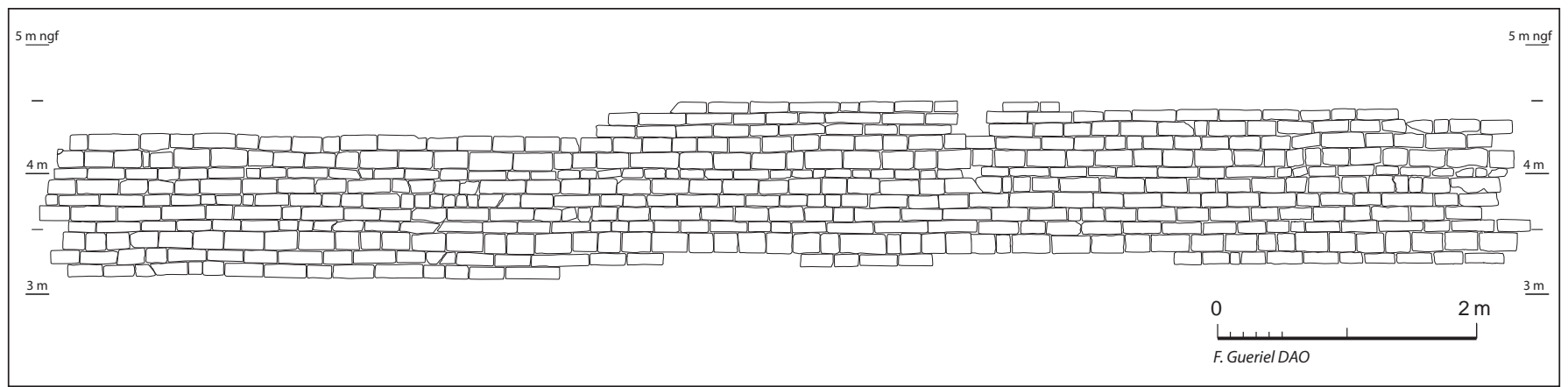

Fig. 229. Relevé en développé du parement du puits-citerne (DAO A.-C. Nalin, F. Gueriel/Inrap).

\section{L'aqueduc oriental et les systèmes d'alimentation du puits-citerne}

De direction nord-sud, cet aqueduc est construit dans l'emprise du fossé antérieur ( $c f$. supra $\$ 2.1 .2$.) qui, bien que partiellement comblé, est toujours en usage (fig. 227 et fig. 228). Le conduit est constitué d'une voûte en plein cintre de huit claveaux calcaires, de modules divers ${ }^{\mathbf{8 4 0}}$ et grossièrement appareillés, reposant sur des piédroits de 1,40 m de haut formés de huit assises de moellons équarris. L'ensemble délimite un canal de $80 \mathrm{~cm}$ de large pour une hauteur sous voûte de 1,70 m. L'extrémité des piédroits offre un aspect parementé signalant la fin de l'aménagement bâti qui se prolonge alors par le fossé à ciel ouvert.

Accolé à l'ouest de l'aqueduc, le puits-citerne monumental forme le principal pôle d'alimentation et de gestion en eau de l'établissement artisanal. Son installation s'accompagne de travaux de confortement de la paroi du fossé par deux murets dont les parements réguliers, fait de moellons de calcaire oligocène posés sur un lit de dalles, maintiennent un blocage de cailloux. Entre ces deux segments de murs ${ }^{841}$, distants de $1,30 \mathrm{~m}$ environ, s'insère un caniveau faisant la jonction entre le fossé et le puits. Ce petit aménagement, large de $15 \mathrm{~cm}$, est constitué de deux dalles de couverture en calcaire marneux ${ }^{842}$ posées sur deux parements de moellons équarris, posés de chant. Ce caniveau forme une alimentation secondaire et complémentaire d'un conduit plus important placé au-dessus. De ce canal ne demeure que l'un des piédroit composé d'un parement unique de cinq assises moellons de calcaire disposées en ressauts successifs et prolongé à l'ouest par une maçonnerie courbe de moellons grossièrement équarris.

840 Les dimensions des claveaux est comprise entre 20 et $30 \mathrm{~cm}$ de longueur et 7 à $15 \mathrm{~cm}$ de largeur.

841 La dalle de l'assise inférieure située à l'extrémité nord et sud des murs est taillée en biseau et de façon presque symétrique.

842 L. : 35 et $45 \mathrm{~cm}, 1$ : : 30 et $41 \mathrm{~cm}$, ép. : $12 \mathrm{~cm}$.

\section{Le bassin de décantation}

La réalisation du puits citerne attenant au fossé oriental a nécessité une campagne de travaux d'envergure. La fosse d'installation du cuvelage, dont les parois sont verticales, a un diamètre compris entre 7 et $9 \mathrm{~m}$; son comblement s'opère progressivement par l'apport d'argile plastique et imperméable en partie basse puis de limons gris associés à des nodules argileux, en fonction des étapes de montage du cuvelage. Ce dernier, épais de $70 \mathrm{~cm}$, détermine un diamètre interne de $3,60 \mathrm{~m}$ pour une hauteur conservé sur $5 \mathrm{~m}$. Le parement est constitué d'un petit appareil alterné de cinq assises de moellons en carreau puis un lit en boutisse, le tout agencé à joints vifs. Le blocage comprend des cailloux et des déchets de taille ainsi que quelques fragments de travertin. La base du cuvelage comporte un ressaut de $25 \mathrm{~cm}$ de haut. L'ensemble présente une homogénéité de construction due à l'emploi exclusif de calcaire à grain fin oligocène taillé ou scié. Des traces d'usure de cette roche tendre sont visibles sur le parement et trois dépôts de calcites indiquent les battements d'eau successifs (fig. 229).

Constituant en partie le réceptacle de l'aqueduc oriental, le puits-citerne a semble-t-il fait office de bassin de décantation afin de fournir en eau claire le puits établi dans la tannerie. Cet approvisionnement en eau maîtrisé est effectué par l'intermédiaire d'un aqueduc transversal.

\section{L'aqueduc transversal et son système de trop-plein}

L'aqueduc souterrain qui relie le puits-citerne au puits de la tannerie est long d'une quarantaine de mètres. Son orientation de direction nord-est/sud-ouest conditionne celle du complexe artisanal, devenant ainsi un élément majeur de l'organisation des différentes constructions environnantes. Parfaitement conservé à l'est, sur une longueur d'environ $30 \mathrm{~m}$, son tronçon ouest a fait l'objet d'une récupération intégrale lors de la mise en place du faubourg. L'ouvrage est installé dans une profonde tranchée de 2,50 $\mathrm{m}$ de haut qui entame largement les 
niveaux antiques. Son fond est plat, régulier et marqué par un faible pendage de $1 \%$, suffisant pour un écoulement régulier. Ses parois s'évasent selon une largeur variant entre 1,20 et $1,50 \mathrm{~m}$ pour atteindre $2,50 \mathrm{~m}$ en partie supérieure. Le conduit, dont le fond n'est pas aménagé, est formé de piédroits épais de 35 et $50 \mathrm{~cm}$ pour une hauteur moyenne de $85 \mathrm{~cm}$. Des assises régulières de moellons en calcaire oligocène, à alternance de rangs de moellons de section carrée et rectangulaire ${ }^{843}$, composent le parement interne. Les matériaux sont taillés sur la face formant parement, équarris sur les côtés et l'élévation soignée comporte cinq assises complétées, au niveau de la troisième, par un rang de réglage incluant des fragments de tuiles ou de briques de calage. Le canal possède une largeur de $60 \mathrm{~cm}$ pour une hauteur de 1,20 m sous voûte, soit un rapport de 1 sur 2 . Cette dernière repose directement au sommet des murets latéraux. Elle est constituée de claveaux taillés dans le même calcaire que les parements, formant un intrados en plein cintre renforcé par un blocage interne, identique à celui des murets, qui ne recouvre pas la totalité de l'extrados mais laisse à nu les trois claveaux sommitaux, derniers éléments mis en place.

L'aqueduc comprend deux regards d'accès au conduit, distants de $15 \mathrm{~m}$ et situés à équidistance de chaque puits de $12,50 \mathrm{~m}$. Le premier regard est formé d'un conduit de plan carré de $60 \mathrm{~cm}$ de côté interne et de $1 \mathrm{~m}$ de hauteur. Ses quatre murets sont bâtis en moyen appareil réglé, à double parement de $50 \mathrm{~cm}$ d'épaisseur, chaînés aux angles. Ils comprennent huit assises de moellons calcaires soigneusement équarris, assemblés à joints vifs. Les faces internes présentent trois séries de deux trous de boulin situés en vis-à-vis, au niveau de la première et huitième assise des parements nord et sud, et de la troisième assise des parois est et ouest. Ce dispositif permet de caler des traverses de bois pour descendre dans les regards lors des travaux d'entretien. Le second regard présente une technique de construction identique avec l'emploi des mêmes matériaux, auxquels se rajoutent quelques moellons en grès et en poudingue. Moins haut $(80 \mathrm{~cm})$, il est obturé par un fragment de dalle en poudingue épais de $8 \mathrm{~cm}$, parfaitement ajustée.

Ces dispositifs s'accompagnent d'un système de tropplein destiné à éviter tout engorgement de l'aqueduc établi en aval sur son extrémité orientale. Sur l'extrados de la voûte de l'aqueduc, est aménagée une canalisation de 1,45 m de longueur, 55 à $64 \mathrm{~cm}$ de large et une hauteur maximale de $40 \mathrm{~cm}$. Ses deux parois, faites d'une

843 Dimensions respectives des matériaux $20 \times 20 \mathrm{~cm}$ et 30 à $40 \times 20 \mathrm{~cm}$. assise de moellons ${ }^{844}$ et de petits blocs en calcaire et en grès, sont recouvertes de deux dalles en grès. Ce canal se déverse dans deux autres canalisations qui contournent le puits citerne pour aboutir dans le fossé réaménagé. Les deux conduites sont constituées de deux parements de cailloux et d'une couverture de cailloux, de moellons et de blocs calcaires, délimitant un conduit relativement étroit de $10 \mathrm{~cm}$ par $14 \mathrm{~cm}$.

\section{Le puits de la tannerie}

Un puits intégré dans l'enceinte de la tannerie, forme l'ultime ouvrage du complexe hydraulique. Cet ouvrage, qui sert à capter la nappe phréatique peut, lorsque l'activité de tannage le nécessite, recevoir une quantité d'eau plus importante par l'intermédiaire de cet aqueduc transversal. La jonction entre ces deux éléments n'est malheureusement pas conservée.

Le vaste et profond creusement servant à son installation est soigneusement étayé avec des planches en bois dont l'étude dendrochronologique ${ }^{845}$ permet de situer la date d'abattage des arbres au début de 1180 (fig. 230). Plaquées simplement contre la paroi de ce creusement d'environ 3,5 m de côté, les planches de sapin sont superposées à l'horizontale, à l'exception de l'angle sud-est où elles sont disposées verticalement en se chevauchant légèrement de manière à arrondir l'angle. Les planches ne possèdent aucun élément d'ancrage dans la paroi du creusement d'installation, le cuvelage de plan carré étant ensuite monté directement contre le coffrage. À l'intérieur de cet étaiement, justifié vraisemblablement par l'instabilité du terrain, le parement du puits en pierre monté à sec, épouse le plan du coffrage en bois et devait s'arrondir progressivement ${ }^{846}$. La partie supérieure du cuvelage du puits se réduit à $2,5 \mathrm{~m}$ de diamètre externe et est liée au mortier sur au moins $60 \mathrm{~cm}$ de haut. Sur sa face interne, de 1,5 $\mathrm{m}$ de diamètre, les moellons de calcaire placés en assises régulières sont sciés de manière à façonner la courbure du puits. À l'extérieur, au contraire, les moellons sont bruts et de nature variée (poudingue, grès, ...). Des blocs en calcaire sciés, de $50 \mathrm{~cm}$ de longueur, sont disposés de manière radiale au-dessus du cuvelage afin de former une margelle. Cette dernière porte des traces d'utilisation sous la forme de trois profondes entailles sur sa face interne, témoignant du frottement d'une corde.

844 L'emploi d'une pierre plate, disposée de chant, servant à la fois de claveaux de voûte et de parement nord de la canalisation confirme la contemporanéité de ces ouvrages.

845 Cette étude a été effectuée par F. Guibal, chargé de recherches IMEP (CNRS, UMR 6116).

846 L'articulation entre le cuvelage carré et circulaire n'a pas pu être observée. 

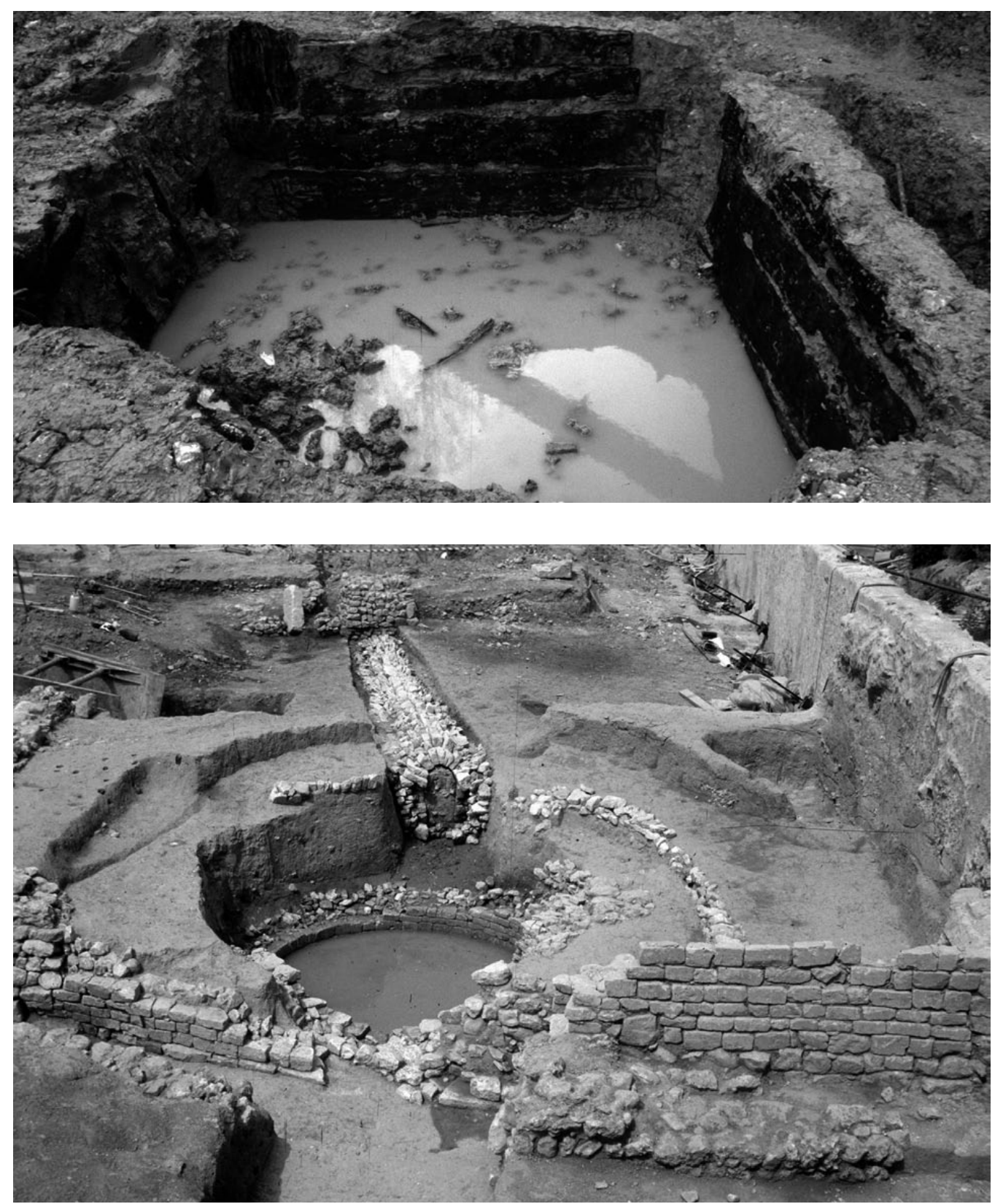

Fig. 230. Vue du coffrage en bois (cl. T. Maziers/Inrap).
Fig. 231. Le complexe hydraulique (cl. T. Maziers/Inrap).
Néanmoins la traction manuelle directe dont témoignent ces traces d'usure ne semble pas pouvoir constituer un mode de puisage adapté à la quantité d'eau nécessaire aux activités artisanales. Il faut donc envisager un dispositif de poulie permettant de remonter des quantités d'eau adaptées à ce type de travail (fig. 231).

\section{Ajout de structures complémentaires à l'aqueduc nord-sud et entretien du fossé}

Le complexe hydraulique d'origine est complété dans un deuxième temps par des confortements ponctuels et des travaux de plus d'envergure tel que le prolongement de l'aqueduc d'alimentation. Parallèlement, des dépôts apportés par l'eau rendent nécessaire un entretien régulier du fossé et un réaménagement comme l'illustre l'ajout d'une troisième portion d'aqueduc.

$\mathrm{Au}$ cours d'une nouvelle phase de réaménagement du fossé, l'extrémité méridionale de l'aqueduc est prolongée par l'adjonction d'un nouveau tronçon de $4 \mathrm{~m}$ de longueur. Les dimensions du canal sont de $60 \mathrm{~cm}$ à $80 \mathrm{~cm}$ de largeur pour 1,60 m de hauteur. L'ouvrage est constitué de deux piédroits en petit appareil à parement unique et blocage soutenant une couverture de dalles, et d'un fond non construit. Les deux piédroits se terminent par une face parementée correspondant à l'extrémité de l'aqueduc, alimentant à la fois le bassin de décantation et le fossé. Les piédroits ouest comprennent respectivement 
huit et douze assises régulières de moellons en calcaire oligocène, liés par un mortier jaune friable, supportant une réfection de trois assises de moellons en matériaux hétérogènes liés à un mortier blanc et s'incurvant vers l'intérieur. Les dalles calcaires de couverture contemporaines de la reprise de maçonnerie sont taillées selon un format rectangulaire de 68 × 50 x $16 \mathrm{~cm}$ et ajustées au mortier jaune.

Le confortement de la paroi orientale du fossé est entrepris au cours de la première moitié du XIII ${ }^{\mathrm{e}} \mathrm{s}$. avec la mise en place d'une maçonnerie qui fait le pendant du mur ouest. Observé sur 8,50 m de long, le nouveau mur comprend un double parement de moellons en calcaire blanc, complétés par quelques éléments en conglomérat et en grès jaune; son parement externe, conservé sur trois assises, affecte un profil bombé. L'ensemble mesure entre 60 et $90 \mathrm{~cm}$ de largeur. Il semble que cette structure ne se prolonge pas au delà d'un mur méridional faisant office de limite parcellaire.

Parallèlement, le mur de soutènement occidental du fossé fait l'objet d'une reprise par l'adjonction d'un petit massif quadrangulaire, s'appuyant à son extrémité sud et formant un retour vers l'ouest. Cette structure comprend un seul parement, grossièrement appareillé, construit en deux phases; la première est représentée par trois assises de moellons en calcaire et grès, liées à la terre, elle est surmontée par une maçonnerie de moellons de nature hétérogène (calcaire, grès, travertin, poudingue), liées à un mortier fin jaune.

$\mathrm{Au}$ début du $\mathrm{XIII}^{\mathrm{e}}$ s., après une période pendant laquelle le fossé se comble partiellement lors de crues importantes, un premier curage est réalisé sur l'ensemble de son tracé. L'ouverture du fossé d'une largeur de 1,60 m et d'une profondeur de $90 \mathrm{~cm}$ est sensiblement modifiée en raison de la présence du bassin. Le fossé, dans sa partie sud, conserve la même configuration que le précédent creusement effectué au XII ${ }^{\mathrm{e}} \mathrm{s}$. Le mur de soutènement qui le borde est toujours en usage. Les nombreux comblements d'origine fluviatile sont composés de limon argileux gris homogène incluant des lentilles de sables et de graviers intercalées. Ces dépôts très peu anthropisés indiquent des épisodes de stagnation d'eau qui alternent avec des dynamiques d'écoulements plutôt élevées.

Après ces travaux d'entretien du fossé s'ensuit, semble-t-il, une période d'étiage où le débit de l'eau, réduit, est canalisé entre le mur de soutènement à la hauteur de son ressaut, et un alignement sommaire de pierres posées de chant. Cet aménagement, présent uniquement dans la moitié sud du fossé, est disposé à $30 \mathrm{~cm}$ de distance du mur ouest et conservé sur une longueur de 1,20 m. Il est constitué de pierres calcaires équarries de dimensions diverses. Les écoulements, le long et à l'extérieur de ce petit canal, ont déposé des sédiments sableux et gravillonneux. Ces dépôts de nature hydraulique montrent que malgré la réduction de l'écoulement, la circulation de l'eau reste dynamique. L'installation du caniveau au même endroit que le mur de soutènement, pendant sa phase de fonctionnement, corrobore l'idée que ce dernier a une autre fonction que celui de retenir la paroi du fossé et laisse penser qu'il existait un aménagement construit en bordure du fossé, probablement en liaison avec une structure disparue.

\subsubsection{Un ensemble artisanal ${ }^{847}$}

La tannerie est constituée de deux vastes bâtiments associés à un imposant réseau hydraulique, dont la mise en œuvre et la gestion ont été abordées précédemment (cf. supra § I, 5, 2.2.2.). L'ensemble de ces constructions couvre une superficie de plus de $640 \mathrm{~m}^{2}$ et s'étend au nord jusqu'à la rue Crotte-Vieille. Cette tannerie se présente comme un ensemble particulièrement homogène dans le découpage interne des différents espaces, et les techniques mises en œuvre dans les sols et les supports. La régularité des dimensions des pièces révèle l'utilisation d'un ou plusieurs modules de construction de 6,5 x 5,5 m de coté inscrit dans un carroyage général (fig. 232). Ainsi, l'espace $1 \mathrm{C}$ et la cour 1D correspondent à quatre modules accolés, à l'intersection desquels le puits citerne est établi. Au nord, les pièces $1 \mathrm{~A}$ et $1 \mathrm{~B}$ reproduisent les mêmes proportions car elles se prolongent vraisemblablement jusqu'au tracé hypothétique de la rue Crotte-Vieille. À l'est, la pièce $2 \mathrm{C}$ du bâtiment 2 reproduit encore la même largeur de module. La réalisation de ce plan calibré intègre des contraintes préexistantes, comme par exemple la présence d'une voie de circulation ancienne qui conditionne la largeur de 7,5 $\mathrm{m}$ des pièces $2 \mathrm{~A}$ et $2 \mathrm{~B}$, établies sur cet axe.

La fouille a montré une répartition fonctionnelle des constructions. À l'ouest, le bâtiment 1, équipé d'installations particulières et pourvu d'annexes, apparaît clairement comme une unité entièrement dévolue au traitement des peaux, l'atelier proprement dit. Il comporte des cuves quadrangulaires et plusieurs séries (ou batteries) de cuves circulaires, un point d'approvisionnement en eau, une zone de dépotoir a l'arrière $(1 \mathrm{H})$ et des espaces de combustion (1F et 1G). À l'est de l'atelier, le complexe se poursuit dans le bâtiment 2 qui se présente comme une construction imposante pouvant être destinée au stockage des peaux tannées et vraisemblablement au logement des artisans. Enfin, la découverte de deux

847 D'après É. Leal in Bouiron 2001b, vol. 1-2, p. 330-339 et F. Paone in Bouiron 2001b, vol.7, p. 89-96. 


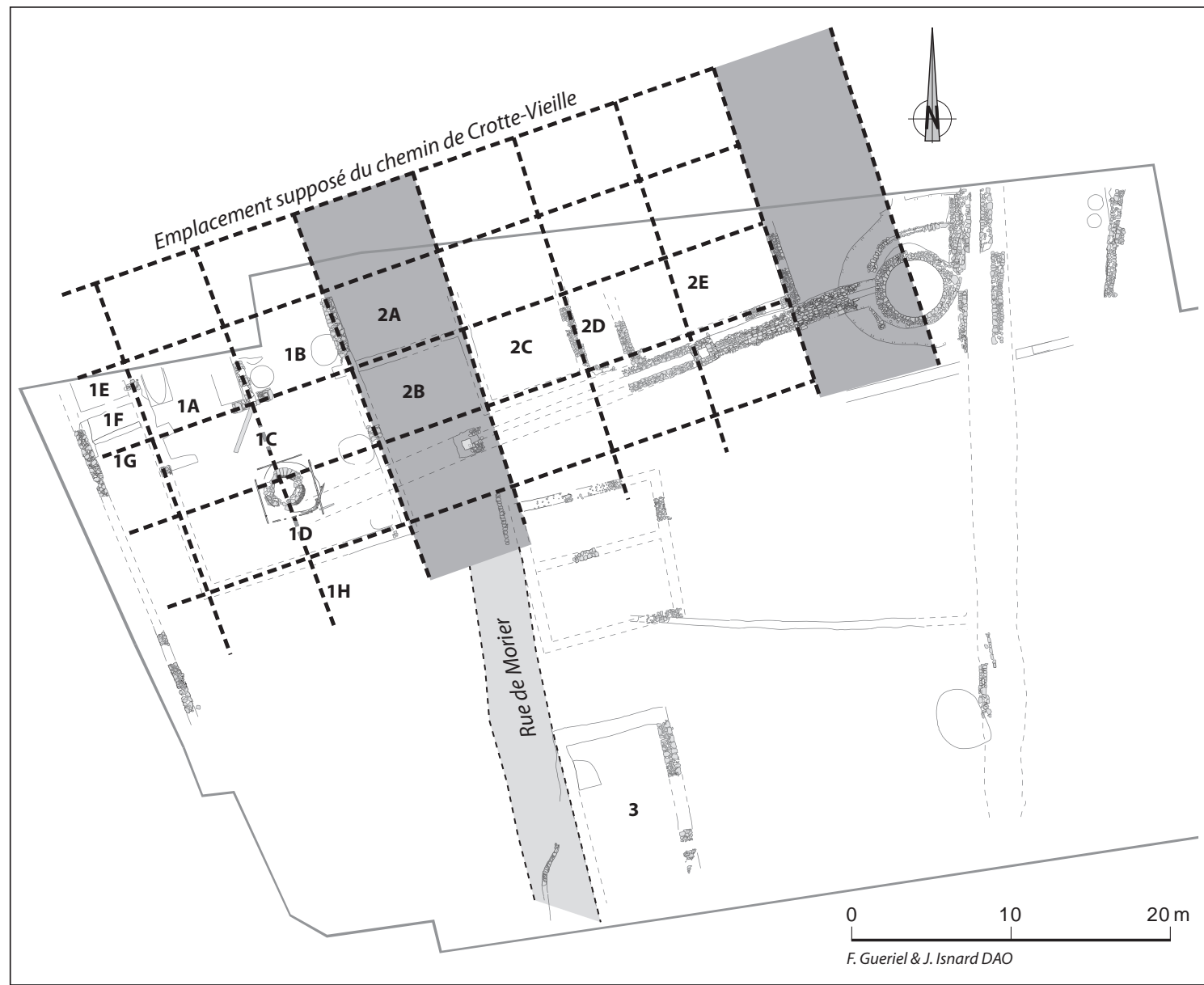

Fig. 232.

Plan modulaire de la tannerie de Morier (DAO F. Gueriel J.Isnard/Inrap) cuves en bois identiques laisse penser que cet atelier pouvait s'étendre à l'est de l'aqueduc et du puits citerne.

\section{Le bâtiment 1}

Le bâtiment 1 se compose d'une vaste unité principale, de plus de $200 \mathrm{~m}^{2}$, divisée en quatre pièces ou espaces ouverts communiquant les uns avec les autres (fig. 233). Les espaces 1A et 1B devaient ouvrir au nord sur un axe de circulation; à l'arrière de celles-ci se développent deux espaces successifs (1C, 1D) occupant chacun toute la largeur de la construction. À l'extérieur, les abords occidentaux du bâtiment sont marqués par des espaces couverts (1E, 1F), la présence d'un appentis $(1 \mathrm{G})$ contre le mur ouest et une zone de dépotoir au sud $(1 \mathrm{H})$. Enfin, l'ensemble est clôturé à l'ouest par le long mur de limite de parcelle, construit dans le prolongement du mur de façade ouest du bâtiment 1. La limite sud de cet ensemble n'a pu être déterminée.

\section{L'unité principale}

Des mises en œuvre distinctes caractérisent les murs porteurs. Le mur occidental est une maçonnerie dont la fondation, large de $80 \mathrm{~cm}$, présente quatre assises de moellons grossièrement équarris formant un parement double et blocage interne. Elle possède un ressaut de $20 \mathrm{~cm}$ sur son parement est. La seule assise d'élévation, large de $65 \mathrm{~cm}$, est à parement double et blocage interne de moellons plus soigneusement équarris et liés au même mortier. Le mur oriental est conservé sur une seule assise de fondation liée à la terre, haute de $25 \mathrm{~cm}$ et large de $80 \mathrm{~cm}$. Enfin, le mur sud complètement épierré n'est plus signalé que par sa tranchée de récupération, large de $78 \mathrm{~cm}$ pour une profondeur de $50 \mathrm{~cm}$. La façade nord se trouve hors d'emprise du chantier, mais devait border la rue Crotte-Vieille.

\section{$\square$ Les espaces $1 A$ et $1 B$}

Au nord, l'espace est cloisonné en deux pièces identiques, $1 \mathrm{~A}$ et $1 \mathrm{~B}$, largement ouvertes sur les espaces intérieurs grâce à des accès larges délimités par des piédroits. La construction du mur médian est comparable à celle du mur ouest : sa fondation de $68 \mathrm{~cm}$ de large comporte quatre assises régulières hautes de $65 \mathrm{~cm}$, supportant une élévation large de $52 \mathrm{~cm}$ et liée par un mortier épais et débordant. Les piédroits de chaque espace, de 


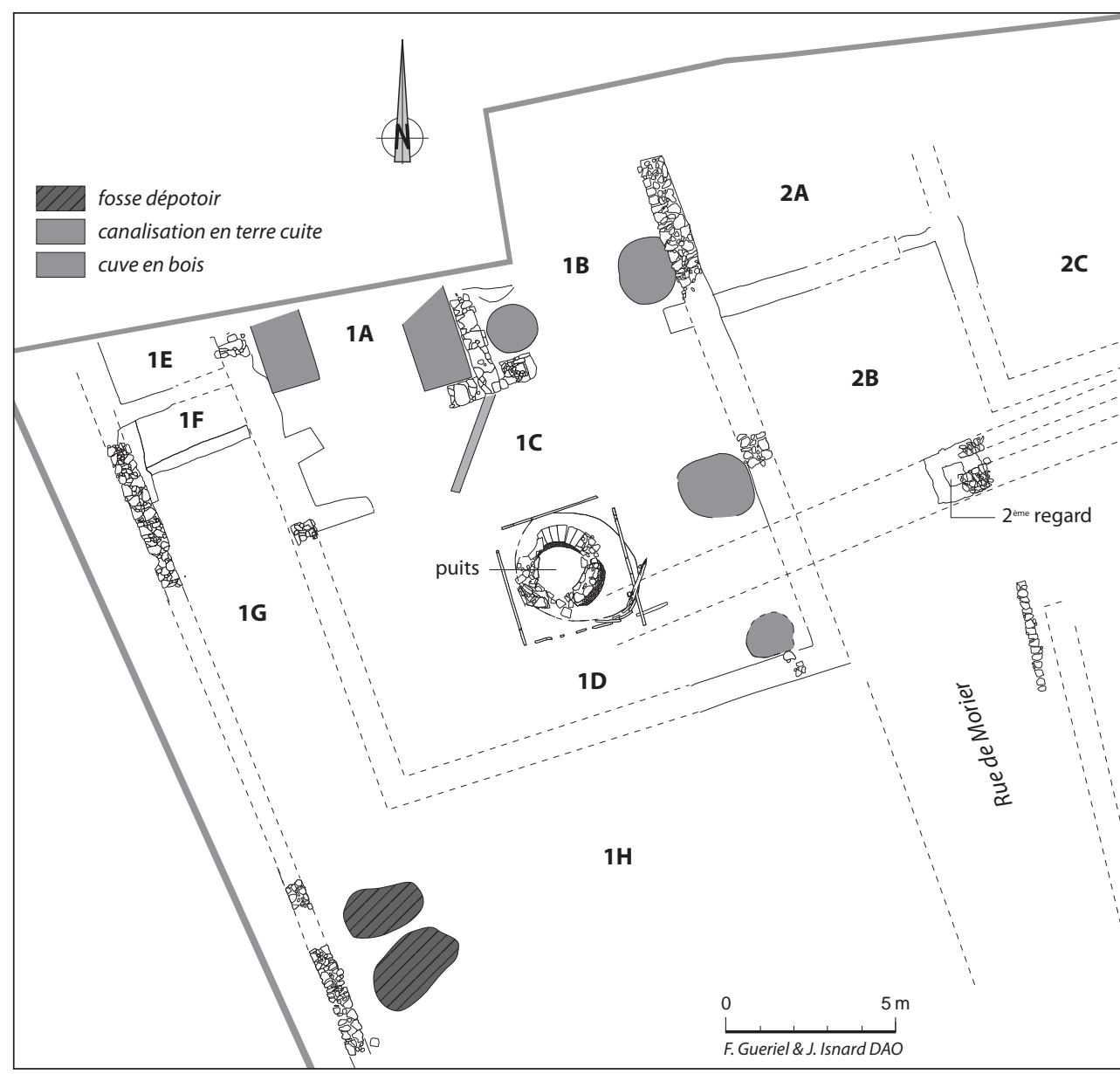

Fig. 233. Plan de détail de

l'ensemble 1

(DAO F. Gueriel, J. Isnard/Inrap).

mise en œuvre similaire, mesurent 90 x $70 \mathrm{~cm}$ et définissent des ouvertures de $6 \mathrm{~m}$ de large.

Ces deux pièces sont de configuration identique et présentent une largeur totale de $6,10 \mathrm{~m}$ pour une longueur minimale de $6 \mathrm{~m}$. Leurs sols en terre battue sont mis en place sur une épaisse charge limoneuse nivelant les dépôts alluviaux sous-jacents. Deux types d'aménagements de cuves caractérisent ces pièces. Dans la pièce 1A, deux cuves rectangulaires semi-enterrées sont installées le long de murs longitudinaux. Placée dans l'angle sud-est, une cuve est conservée sur une longueur de 2,70 m pour une largeur de 1,70 m ; arasée au niveau du sol, seule sa partie enterrée, profonde de $50 \mathrm{~cm}$, est conservée. Son profil révèle des parois droites et un fond plat mais présentant une inclinaison du nord au sud de l'ordre de $12 \mathrm{~cm}$. Le fond et les parois d'aspect ligneux témoignent d'un contenant initial en bois ; des concrétions issues de l'utilisation tapissent le fond. Le comblement d'abandon de la cuve est un sédiment gris clair très fin constitué essentiellement de cendres, mêlées à du sable ou en agrégats indurés. À l'ouest, une seconde cuve présente les mêmes caractéristiques de plan et de structure mais elle n'est conservée que sur une largeur de 1,60 m et une longueur de 1,20 m. Elle présente également des traces ligneuses et un comblement cendreux, conservés sur une hauteur de $20 \mathrm{~cm}$. Ses limites nord et sud sont perturbées par des installations postérieures, mais il est vraisemblable qu'elle occupait l'angle formé par le mur et le piédroit, à l'identique de la cuve orientale. Entre les deux cuves, un passage large d'environ 2,30 m permet de circuler entre les installations. La conservation du niveau de sol et du fond des cuves permet de restituer des installations semi-enterrées sur une profondeur de $50 \mathrm{~cm}$, le reste de la cuve étant en élévation au-dessus du sol sur une hauteur indéterminée.

La pièce $1 \mathbf{B}$ adjacente, comprend trois cuves circulaires, dont deux sont alignées le long du mur ouest et l'autre contre le mur est (fig. 234). La cuve installée dans l'angle sud-ouest a un diamètre de 1,50 m. Arasée dans sa quasi-totalité, elle n'est identifiable que sur une hauteur de $3 \mathrm{~cm}$. Son fond présente une surface bombée d'aspect ligneux avec des concrétions de calcite; sa paroi circulaire est épaisse de $3,5 \mathrm{~cm}$. À seulement $20 \mathrm{~cm}$ de cet aménagement, se trouve une autre cuve qui présente les mêmes traces ligneuses. Elle n'est que très partiellement conservée, sur un périmètre de seulement $1,16 \mathrm{~m}$ et son diamètre initial ne peut être restitué. 
Formant le pendant de la structure ouest, une troisième cuve extrêmement arasée n'est conservée que sur $1 \mathrm{~m}$ de diamètre. Son pourtour et son fond présentent une épaisseur de $10 \mathrm{~cm}$ de cendre indurée correspondant peut-être à un contenant de bois disparu. Toutes ces cuves sont comblées par du sédiment gris très cendreux.

\section{口 L'espace 1C}

Les deux pièces $1 \mathrm{~A}$ et $1 \mathrm{~B}$ ouvrent au sud sur le même espace $1 \mathrm{C}$ qui ne mesure que $2 \mathrm{~m}$ de profondeur, mais occupe toute la largeur du bâtiment, soit $12 \mathrm{~m}$. Au sud, il est séparé de l'espace 1D par un muret, perpendiculaire au mur porteur ouest, et dont ne demeure que sa tranchée d'épierrement, large de $50 \mathrm{~cm}$ pour une longueur de $1,50 \mathrm{~m}$. Si l'on restitue un pendant contre le mur porteur oriental, on obtient une ouverture de $9 \mathrm{~m}$ de large, amplitude rendant indispensable une structure porteuse intermédiaire qui n'a pas été découverte. L'espace 1C est pourvu d'un caniveau constitué d'un tuyau en terre cuite placé entre deux pierres plates posées de chant, le tout profondément enfoui (fig. 235). Ce caniveau, dont l'extrémité sud est détruite, débute à l'aplomb du mur médian puis traverse l'espace en biais sur une longueur d'environ 2,50 m. Il est ensuite scellé par un niveau de sol de terre battue mis en place sur une couche de préparation de $20 \mathrm{~cm}$ à $30 \mathrm{~cm}$ d'épaisseur.

\section{$\checkmark$ L'espace 1D}

L'espace 1D est une vaste cour intérieure de près de $105 \mathrm{~m}^{2}$ au centre de laquelle est établi le grand puits terminal alimenté par l'aqueduc ainsi que deux cuves circulaires disposées le long du mur est. Localisée dans l'angle sud-est de la cour, la première cuve n'est conservée que sur une moitié mais son diamètre interne restitué est de 1,20 m. Elle est cependant installée dans une fosse de $1,70 \mathrm{~m}$ de diamètre, dimension vraisemblablement justifiée par le profil de la cuve. Son fond est plat et ses parois, visibles sur une hauteur de $17 \mathrm{~cm}$, sont verticales. La seconde cuve possède un diamètre interne de $1,70 \mathrm{~m}$; pour un creusement d'installation d'un diamètre de 2,10 m (fig. 236). Son fond est plat et ses parois droites sont conservées sur une hauteur de $35 \mathrm{~cm}$. Toutes deux présentent des parois d'aspect ligneux, témoin d'un contenant de bois disparu, un comblement très fin gris cendreux et des traces d'un dépôt verdâtre à la base. Les sols de l'espace 1D sont conservés sur une infime portion et massivement érodés en raison de récupérations postérieures. L'aménagement de cet espace s'est effectué par un apport de remblais de limon hétérogènes, mis en place immédiatement au-dessus des dépôts de limon sous-jacents de manière à régulariser et damer la surface initiale.

\section{$\square$ Les espaces adjacents}

Le corps de bâtiment principal est bordé à l'ouest d'espaces attenants délimités par un mur de clôture restitué sur une longueur de $23 \mathrm{~m}$. Fondé sur trois assises de blocs de travertin montés à sec de manière à former un double parement sans blocage interne, ce mur conserve une élévation sur une hauteur de quatre assises (soit $60 \mathrm{~cm}$ ). L'appareil à double parement de moellons de travertin équarris et blocage interne (calcaire fin, travertin, grès) est assisé et lié à la terre. Sur son parement est, des plaques d'enduit de mortier de chaux très blanc témoignent d'un revêtement de cette façade du mur. Ce mur détermine deux petites pièces au nord $(1 \mathrm{E}$ et $1 \mathrm{~F})$ puis un espace oblong (1G) qui communique avec une vaste zone ouverte $(1 \mathrm{H})$ ( $c f$. fig. 233 et fig. 237).

\section{$\square$ Les espace $1 E$ et $1 F$}

La pièce $1 \mathbf{E}$ apparaît comme un espace étroit de 3,50 m. Elle n'est conservée que sur une longueur de $3 \mathrm{~m}$. Ses murs périmétraux sont massivement épierrés (à l'exception d'un tronçon) et son sol de terre battue est aménagé sur une charge limoneuse d'environ $10 \mathrm{~cm}$ d'épaisseur, venant régulariser les remblais sous-jacents issus de la construction de cette pièce ou du nivellement des séquences alluviales antérieures.

La pièce $1 F$ est un espace réduit ne mesurant que $5 \mathrm{~m}^{2}$ limité au sud par une cloison légère dont ne demeure que le négatif, de $20 \mathrm{~cm}$ de largeur. Un accès étroit d'une soixantaine de centimètres est aménagé au sud-est. Le sol de terre battue de cette pièce présente à sa surface des traces de cendres et de charbons de bois.

\section{$\square$ L'espace $1 G$}

L'espace $1 \mathrm{G}$, plus vaste, mesure environ $40 \mathrm{~m}^{2}$. Il possède un sol de terre battue caractérisé par un remblai de limon très compact et hétérogène avec des inclusions de graviers, éclats de calcaire et nodules de chaux, le tout d'une épaisseur de 10 à $15 \mathrm{~cm}$. Sa surface présente des dépôts charbonneux et plus ponctuellement des zones nettement rubéfiées attestant l'utilisation de feu dans cet espace. Bien qu'extérieur et ouvert sur la zone de dépotoir, il est probable que cet espace ait à l'origine été couvert par un auvent de manière à créer un appentis.

\section{口 L'espace $1 H$}

Enfin, au sud du bâtiment I, se développe une zone ouverte $(1 \mathrm{H})$ dont l'étendue n'est pas circonscrite. Ce vaste espace est marqué par un sol de terre battue mis en place sur un puissant remblai de 20 à $30 \mathrm{~cm}$ mêlant 
limons, fragments de tuiles et cailloux. La surface est très irrégulière et marquée par des dépôts cendreux et plusieurs dépressions.

Des niveaux de dépotoirs sont concentrés à l'intérieur des dépressions les plus profondes, mais débordent

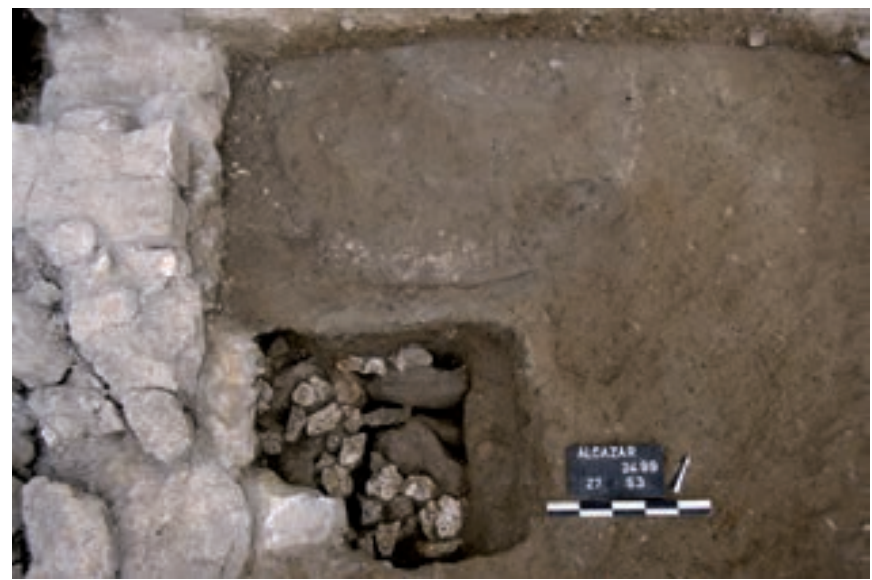

Fig. 234. La cuve dans l'angle de l'espace 1A (cl. F. Parent/Inrap).

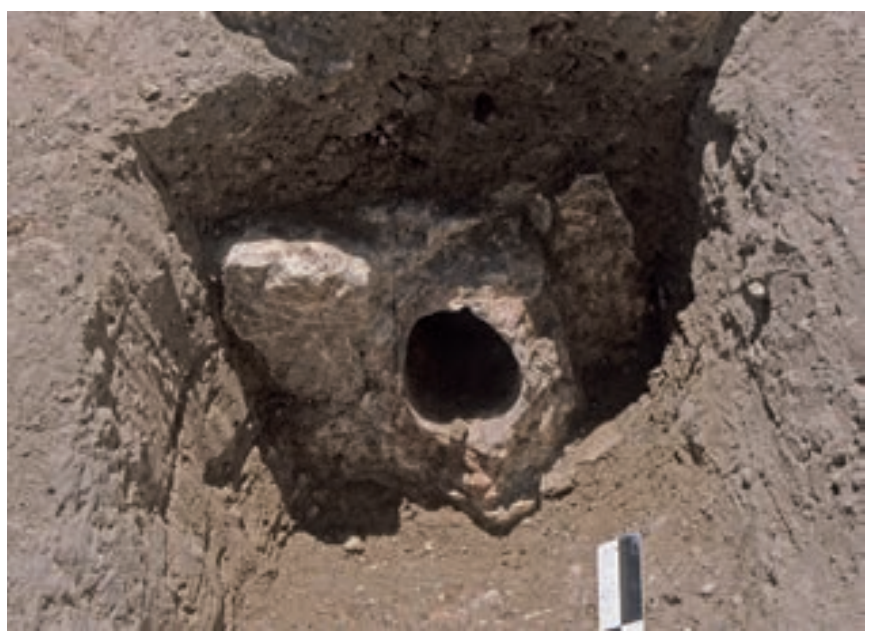

Fig. 235. Vue de la canalisation de l'espace 1C (cl. T. Maziers/Inrap).

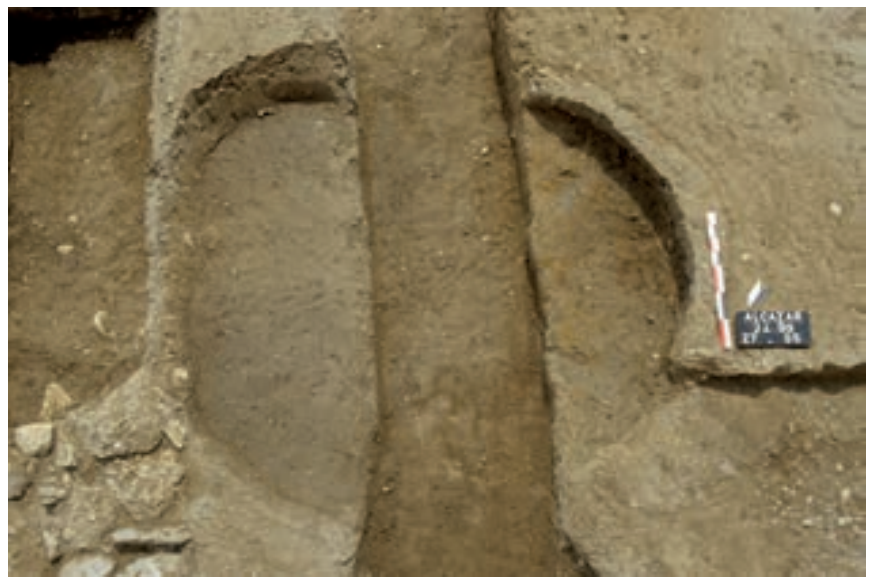

Fig. 236. La cuve de l'espace 1 D (cl. F. Parent/Inrap). également de celles-ci. Deux fosses-dépotoirs sont localisées dans l'angle nord-ouest de l'espace. Elles possèdent toutes deux un profil en cuvette et un tracé très irrégulier. La première a une profondeur de $50 \mathrm{~cm}$ et un diamètre d'environ $2 \mathrm{~m}$. Son comblement inférieur, épais de $30 \mathrm{~cm}$, est constitué d'un sédiment de limon caractérisé par une abondance de fragments de faune mêlés à des poches de cendres. Lui succède un comblement argileux brun daté de la fin du XII ${ }^{\mathrm{e}} \mathrm{s}$. qui intègre un mobilier osseux tout aussi abondant mais moins fragmenté. La fosse voisine présente les mêmes caractéristiques de comblement. Son profil est en cuvette à bords très évasés, d'une profondeur d'environ $30 \mathrm{~cm}$. Son contour, très irrégulier, s'étend sur une longueur de $3 \mathrm{~m}$. Son remplissage se compose d'apports multiples: aux argiles brunes riches en faune se superposent un épais dépôt de cendres d'environ $30 \mathrm{~cm}$ d'épaisseur puis un comblement où alternent, sur environ $25 \mathrm{~cm}$ d'épaisseur, des dépôts sableux très riches en ossements d'animaux et de fins dépôts cendreux.

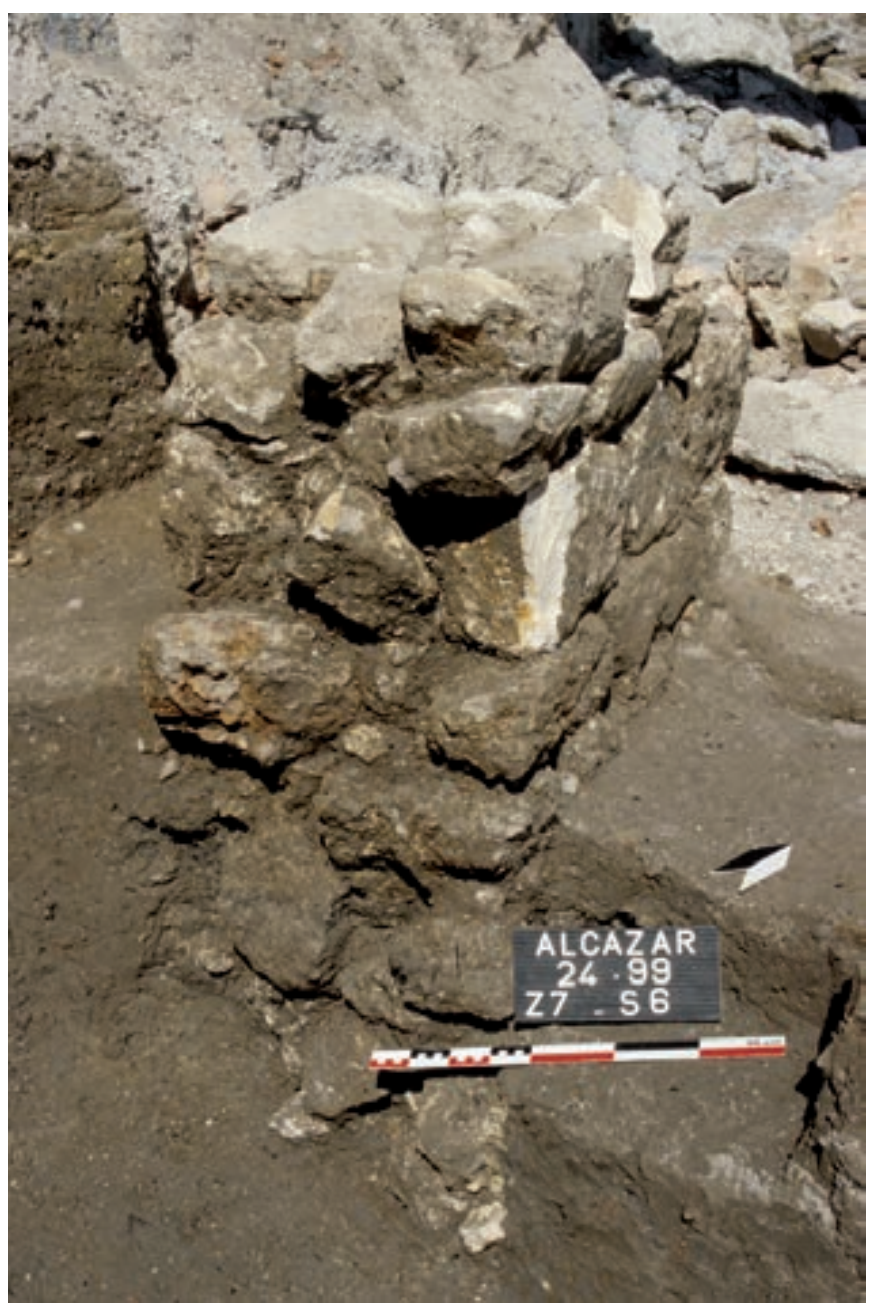

Fig. 237. Le mur de clôture de la tannerie (cl. T. Maziers/Inrap). 
Lors de son abandon, l'ensemble du dépotoir est scellé par des brasiers et éclats de calcaire. Circonscrits à la superficie des fosses, ils sont destinés à assainir une zone riche en matières organiques et à niveler les irrégularités provoquées par l'utilisation des fosses-dépotoirs. Le dernier niveau d'occupation est lui-même caractérisé par une surface très irrégulière et des traces cendreuses issues de l'activité artisanale qui se poursuit après le bouchage de ces fosses. La couleur brune et la texture évoque la putréfaction de la fourrure animale alors que l'étude des ossements révèle la présence exclusive des os des membres supérieurs et inférieurs. Il est probable qu'il s'agisse des restes d'équarissage des peaux.

\section{Organisation fonctionnelle de l'atelier}

La présence de cuves diverses au sein du bâtiment 1 indique que c'est là qu'il faut localiser l'atelier de tannage proprement dit. Dans la pièce 1A, deux cuves rectangulaires sont installées le long de chacun des murs. L'usage de ce type de bassin quadrangulaire est attesté pour le travail dit « de rivière ». Cette opération intervient en tout début de tannage et consiste à tremper et rincer les peaux avant l'application des produits tannants. À ce stade des opérations, le renouvellement fréquent de l'eau entraîne de nombreuses manipulations et, à l'intérieur du bâtiment, la nécessité de protéger les murs, d'où l'application sur les parements de mortier débordant pour en garantir l'étanchéité. C'est cette opération particulièrement astreignante de rinçage à l'eau claire des peaux qui a souvent justifié l'implantation des tanneries le long de cours d'eau. Cependant, on voit ici comment l'absence d'une véritable rivière en ce lieu est palliée par l'établissement de l'imposant réseau hydraulique garantissant un renouvellement en eau constant et suffisant pour le travail « de rivière ».

Dans l'espace mitoyen 1B, trois autres cuves circulaires sont conservées. Leur localisation le long des murs et la proximité de deux d'entre elles, distantes de seulement $0,20 \mathrm{~m}$, laissent préjuger que l'on se trouve ici en présence des vestiges de deux batteries de cuves circulaires. À l'identique des cuves quadrangulaires, elles présentent des parois et un fond ligneux concrétionnés, témoins d'un cuvelage de bois. Au regard de leur état de conservation, on a pu établir que leur diamètre moyen est de $1,50 \mathrm{~m}$, jamais inférieur à $1,20 \mathrm{~m}$. Le comblement de ces cuves circulaires est comme pour les autres aménagements composés d'un sédiment cendreux. Les cuves circulaires disposées en batterie sont attestées dans le travail de bassement c'est-à-dire l'opération véritable de tannage. Les peaux sont entassées dans ces cuves avec différents bains tannants, plus ou moins concentrés suivant le stade de la procédure.
L'espace 1C est conçu comme un espace intermédiaire entre les pièces de tannage $(1 \mathrm{~A}, 1 \mathrm{~B})$ et la cour arrière avec le puits (1D). Il n'est équipé d'aucun dispositif particulier à l'exception d'une canalisation en terre cuite qui part du cloisonnement central pour se déverser plus au sud. Les nombreuses perturbations modernes et contemporaines de cette zone ont malheureusement interrompu la canalisation, si bien qu'il n'est plus possible de déterminer son point de déversement. Le manque de données interprétatives ne permet pas d'identifier cette structure de manière satisfaisante et notamment de l'associer à l'évacuation des bains des cuves à proximité immédiate ou à une simple évacuation des eaux pluviales.

L'espace 1C s'ouvre largement sur la grande cour arrière 1D à partir de laquelle s'organise l'approvisionnement en eau. Le puits citerne placé au centre de l'espace est alimenté en eau propre par un aqueduc et sa margelle est à la même hauteur que le sol de travail afin de faciliter les manipulations courantes. Deux autres cuves destinées au tannage se tenaient dans cette cour, le long du mur oriental. Leur cuvelage en bois, d'un diamètre de $1,20 \mathrm{~m}$ et $1,70 \mathrm{~m}$, est disposé dans des fosses nettement plus larges, soit respectivement $1,70 \mathrm{~m}$ et $2,10 \mathrm{~m}$ de diamètre. Ces différences entre les dimensions des fosses et leur contenant s'expliquent sans doute par le profil bombé de ces cuves qui devaient alors davantage s'apparenter à des tonneaux. La présence de dépôts verdâtres ${ }^{848}$ clairement identifiés au fond de ces deux contenants semble correspondre à des résidus de tanin et c'est peut-être là qu'il était conservé avant d'être incorporé aux bains.

Malgré la variété et le nombre des dispositifs présents au sein de ce bâtiment, on constate que la disposition de chacun d'entre eux prend soin de ménager des aires de circulation convenables. Ainsi, les aménagements sont déportés le long des murs et les accès depuis la rue CrotteVieille jusqu'au fond de la cour arrière n'est pas gêné.

Le corps de bâtiment principal est pourvu de plusieurs pièces et espaces annexes. Au sud de la cour arrière se développe une zone non construite $(1 \mathrm{H})$ mais incluse dans l'enceinte de la tannerie. C'est là qu'ont été mises au jour plusieurs fosses comblées de cendres, provenant en partie des vidanges de cuves et de celles des foyers des espaces $1 \mathrm{E}$ et $1 \mathrm{~F}$, alternant avec des déchets de faune. Les rejets osseux sont constitués principalement de calotte crânienne, de corne et de bas de pattes. Ce type de mobilier osseux est encore une fois caractéristique d'un dépotoir de tannerie. En effet, il est attesté que, comme garantie de qualité, les tanneurs exigeaient

848 Ces dépôts n'ont pas pu faire l'objet d'une analyse physico-chimique. 
de recevoir les dépouilles avec la tête, les pieds et souvent la queue de l'animal. Une identification des restes osseux révèle par ailleurs que la majorité de ce mobilier est constituée d'os d'ovins et de caprins et en moindre quantité de bovins, ces différentes espèces correspondant donc aux types de peaux traitées.

Enfin, le long du mur ouest se tient une série de trois pièces ou espaces. Au nord, la pièce $1 \mathrm{E}$ n'a été observée que sur $10 \mathrm{~m}^{2}$ et ne présente pas d'aménagement particulier. Il semble en revanche qu'une certaine unité de fonctionnement prévaut entre $1 \mathrm{~F}$ et $1 \mathrm{G}$, comme le soustend la présence de cendre et charbons de bois sur le sol de ces deux espaces. La pièce $1 \mathrm{~F}$ forme un petit réduit de $5 \mathrm{~m}^{2}$ avec un sol en terre battue; il est séparé de $1 \mathrm{G}$ uniquement par une cloison. Ce dernier est un espace barlong probablement couvert par un auvent. Sur son sol très compact, plusieurs zones rubéfiées et des dépôts cendreux témoignent d'allumages réguliers de feux. Cet espace peut correspondre à une zone de séchage ou à une étuve consacrée à l'enfumage des peaux. Cette technique, bien que moins répandue, semble ici se substituer au chaulage pour le débourrage des peaux. Il faut cependant préciser que les vestiges archéologiques n'apportent pas de solutions définitives pour cette étape du traitement des peaux. En effet, l'absence de toute trace de chaux associée au peu de résidus que laisse une opération d'étuvage ne permet pas de trancher. En revanche, il est certain que la phase finale d'épilage se conclut par le frottement des peaux à l'aide de sable, ce qui explique peut-être la présence de poches sableuses dans plusieurs cuves et dans le dépotoir.

À l'est de l'atelier, le complexe se poursuit dans le bâtiment 2 . Il se présente comme une construction imposante, établie sur une ancienne zone de dépôts alluviaux ayant nécessitée un assainissement préalable, réalisé grâce à l'apport d'un remblai argileux étanche et stabilisateur. Malgré l'absence de toute installation technique tangible, l'organisation interne des espaces et les accès répondent au même souci de fonctionnalité. Au nord, la pièce $2 \mathrm{~A}$ s'ouvre sur la rue mais également vers l'arrière des bâtiments grâce à l'espace $2 \mathrm{~B}$ au sud. La fréquence d'utilisation de cette zone, dont la surface de circulation particulièrement sédimentée est marquée par des traces de piétinement, tient à la présence du regard occidental de l'aqueduc, mais peut-être aussi au fait que cette zone était réservée au déchargement ou même au stockage des matériaux en raison de son accès aisé grâce à la rue aménagée au-dessus de l'aqueduc est-ouest.

Parmi les différents espaces qui composent ce bâtiment, seule la pièce occidentale (2C) conserve les traces d'aménagements liés peut être à la présence d'un plancher ou d'une machinerie. Les supports verticaux découverts se composent de poteaux de bois dont les dimensions, comprises entre 20 et $26 \mathrm{~cm}$, et le nombre (l'espacement entre les poteaux est de $1 \mathrm{~m}$ ) indiquent qu'ils devaient supporter une charge lourde.

Une pièce étroite (2D) est accolée à l'est par une vaste cour (2E) de plus de $42 \mathrm{~m}^{2}$, dépourvue de vestiges déterminants.

\section{Le bâtiment 2}

Accolé à l'est du bâtiment 1, le bâtiment 2 est bordé au sud par l'aqueduc et devait s'étendre au nord jusqu'à la rue Crotte-Vieille (fig. 238). La majorité des murs étant encore une fois largement épierrée ou arasée, le plan comporte des lacunes. Il n'est conservé que sur une largeur de $6 \mathrm{~m}$, mais couvre une longueur totale de près de $20 \mathrm{~m}$. L'unité principale est divisée en trois espaces $(2 \mathrm{C}, 2 \mathrm{D}, 2 \mathrm{E})$; elle est unie au bâtiment 1 par les espaces $2 \mathrm{~A}$ et $2 \mathrm{~B}$ implantés sur une partie du tracé de la rue de Morier.

\section{$\square$ Les espaces $2 A$ et $2 B$}

Adossée à l'est du bâtiment 1 , la pièce $\mathbf{2 A}$ est conservée sur une longueur de $4 \mathrm{~m}$ pour une largeur totale de 7,50 m. Les murs, entièrement épierrés, ne sont plus signalés que par leur tranchée de récupération. Celle du mur sud est visible sur une longueur de 2,90 m et une largeur de $70 \mathrm{~cm}$, mais son prolongement oriental -plus étroit $(35 \mathrm{~cm})$ et court $(1 \mathrm{~m})$ - peut se justifier par la présence d'une cloison ou d'un seuil.

Mitoyen de la pièce 1A, l'espace 2B est ouvert au sud et permet l'accès au regard de l'aqueduc; il a une superficie de $45 \mathrm{~m}^{2}$. Le niveau de sol de cet espace est une simple surface damée au sommet des remblais de limons sous-jacents, située à une altitude légèrement supérieure à celle de la pièce $2 \mathrm{~A}$-la dalle de couverture du regard est quant à elle légèrement saillante.

\section{$\square$ Le bâtiment principal : les espaces $2 C, 2 D$ et $2 E$}

À l'est se trouve le corps de bâtiment principal divisé en trois pièces distinctes $2 \mathrm{C}, 2 \mathrm{D}$ et $2 \mathrm{E}$. Du mur occidental ne demeure que la tranchée d'épierrement, d'une largeur de $80 \mathrm{~cm}$ et d'une profondeur de $30 \mathrm{~cm}$. Les murs sud et est conservent uniquement des fondations de $80 \mathrm{~cm}$ de largeur et $35 \mathrm{~cm}$ de haut, formées de deux assises régulières déterminant un appareil à double parement de moellons équarris et calibrés et blocage interne de cailloux et galets, le tout lié à la terre. La mise en œuvre des fondations du refend médian, moins soignée, se justifie par l'emploi de matériaux grossièrement équarris et ses dimensions inférieures $(60 \times 30 \mathrm{~cm})$; en revanche, le refend ouest présente un soubassement plus puissant 


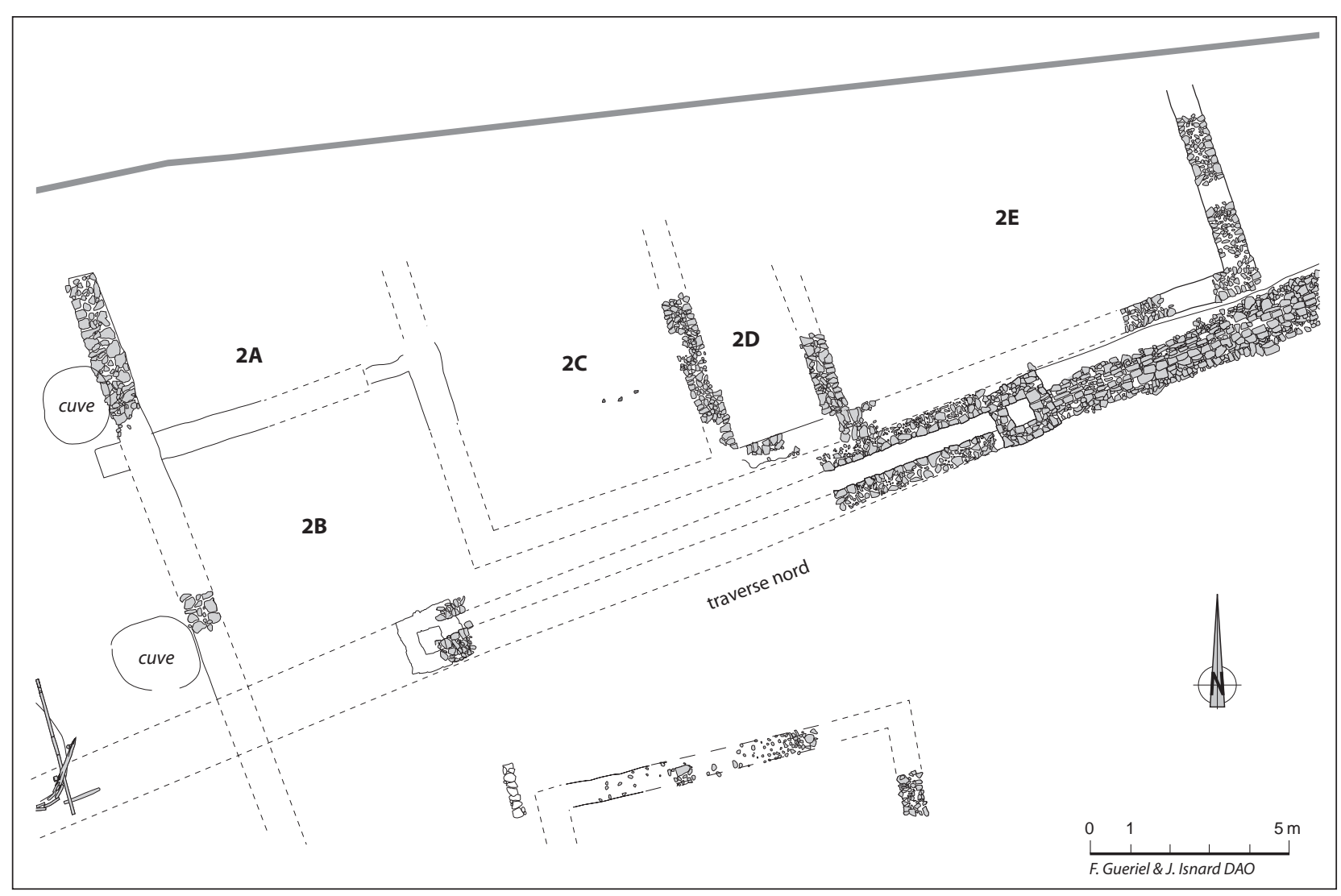

Fig. 238. Plan de détail du bâtiment 2 (DAO F. Gueriel, J. Isnard/Inrap).

(1 m) et débordant de $20 \mathrm{~cm}$ par rapport à l'élévation. La construction de ce bâtiment s'est accompagnée d'une campagne d'assainissement des terrains sous-jacents caractérisés par des dépôts alluviaux instables. Un important remblai de préparation de 10 à $20 \mathrm{~cm}$ d'épaisseur est constitué d'une chape d'argile très homogène et compacte, assurant l'étanchéité des sols de chaque pièce.

La pièce 2C est une pièce de 5,50 $\mathrm{m}$ de large, conservée sur une longueur de $5 \mathrm{~m}$. Son sol en terre battue est fortement damé, mais présente des irrégularités et un léger pendage vers l'ouest. Dans l'angle sud-est de la pièce, une structure légère est matérialisée par au moins trois trous de poteaux. Le premier $(24 \times 24$ x $26 \mathrm{~cm})$, possède un profil conique très régulier et comporte deux pierres de calage contre sa paroi ouest. Le deuxième mesure $20 \times 20 \times 15 \mathrm{~cm}$ et a un profil à parois droites et fond plat. Enfin, le dernier, beaucoup moins régulier, présente un plan ovale pour une profondeur de $20 \mathrm{~cm}$. Son profil comporte des parois droites irrégulières et un fond incliné. L'ancrage de ce poteau au sol est renforcé par un blocage de pierre et de galets contre le bord sud-ouest du négatif d'installation. Une perturbation postérieure a peut-être contribué à la disparition d'autres supports.

La pièce centrale $2 \mathrm{D}$, étroite, a une largeur totale de 2,20 m ; elle est conservée sur une longueur de $4 \mathrm{~m}$. Son niveau de sol, légèrement plus haut que celui de l'espace ouest, correspond à une surface de terre battue relativement régulière et dépourvue d'aménagement.

L'espace 2E, le plus vaste, a une largeur totale de $10,50 \mathrm{~m}$ pour une longueur minimale de $4 \mathrm{~m}$. Son niveau d'occupation est semblable aux précédents puisqu'il s'agit encore d'un sol de terre battue dont la surface en est relativement régulière. Ce sol, très partiellement conservé, n'a été observé que sur une superficie réduite $\left(4 \mathrm{~m}^{2}\right)$ en raison de la présence d'une grande cave moderne qui a éliminé d'éventuels aménagements internes.

Le bâtiment 2 ne comporte aucune installation particulière permettant de l'associer de manière définitive aux constructions voisines. En effet, la description des différentes pièces se rapporte très nettement à des espaces domestiques et non à un espace artisanal. Néanmoins, si l'on se reporte à l'agencement et à l'organisation générale des différents éléments, il apparaît qu'il participe du même ensemble. C'est au regard de cette cohésion que nous proposons d'associer ce deuxième bâtiment au même complexe artisanal que celui mis en évidence dans le bâtiment 1 , non comme zone de production mais comme annexe, destinée à entreposer les peaux et/ou à loger les tanneurs. 


\section{Une extension possible de la zone artisanale à l'est du puits-citerne et de l'aqueduc oriental ${ }^{849}$}

$\mathrm{Au}$ nord-est de l'aqueduc oriental, un secteur particulièrement perturbé par l'implantation d'une cave moderne a livré des fosses isolées ainsi que plusieurs murs grossièrement appareillés, mais l'état de conservation de ces vestiges ne permet pas d'établir avec certitude leur contemporanéité.

Ces fosses semblent alignées selon un axe nord-est/ sud-ouest matérialisé par le mur est. Elles ont une forme circulaire avec un diamètre sensiblement différent ${ }^{\mathbf{8 5 0}}$. Leur comblement identique est constitué de chaux indurée moulant des éléments de planches et renfermant quelques mottes de terre, débris de tuiles et ossements. Ces restes de planches correspondent à des empreintes de tonneaux ou de cuves, particulièrement nettes dans la fosse nord, dont un fond présente les traces de trois planches. Ces deux tonneaux, calés dans des fosses, apparaissent isolés; ils sont toutefois comparables aux découvertes liées au contexte de la tannerie.

\section{Conclusion}

L'ensemble artisanal, dont l'activité de tannerie est bien attestée par la présence de différentes cuves intégrées dans des espaces ouverts ou couverts et par le dépotoir comportant une quantité importante d'ossements d'animaux, occupe pour cet état une grande partie du site. En effet, si l'on considère l'établissement dans sa totalité, aménagements hydrauliques et bâtiments fonctionnels, on obtient une superficie minimale de près de $1425 \mathrm{~m}^{2}$.

L'étude céramologique comme dendrochronologique date le début du fonctionnement de cet ensemble de la fin du XII ${ }^{\mathrm{e}}$ s., et son activité est attestée jusque dans les premières décennies du XIII ${ }^{e} \mathrm{~s}$. La durée d'activité de ce complexe est par conséquent assez réduite si l'on se réfère aux données céramologiques. Il convient néanmoins de préciser que ce mobilier a été trouvé en petite quantité, excepté dans les fosses dépotoirs, et généralement sous forme de fragments peu exploitables. Ainsi, si le début de l'activité paraît bien fixée, la date de cessation de l'activité est en revanche plus aléatoire.

\subsubsection{Des occupations disséminées dans les environs de la tannerie}

$\mathrm{Au}$ sud et à l'ouest de l'établissement artisanal, les vestiges demeurent disséminés et peu structurés.

849 D'après M. Maurin, P. Reynaud, in Bouiron 2001b, vol. 1-2, p. 339-340.

850 Diamètre : $90 \mathrm{~cm}$ et $80 \mathrm{~cm}$, prof. conservée : $10 \mathrm{~cm}$.

\section{Le bâtiment $3^{851}$}

Le long de la rue de Morier, un nouvel édifice, le bâtiment 3 ( $c f$. fig. 232), est construit au sud de l'ancien bâtiment $1 \mathrm{du} \mathrm{XII}$ s. qui, bien que ruiné, reste néammois présent dans le paysage ( $c f$. fig. 238). Il est constitué d'une grande pièce, conservée sur $60 \mathrm{~m}^{2}$ et construite selon un plan rectangulaire orienté nord-sud. Cet espace, dont les dimensions extérieures sont de 10,50 m de long pour 7,50 m de large est amputé de sa façade sud tandis que ses murs nord et ouest ont été épierrés. La largeur des tranchées de récupération est de $70 \mathrm{~cm}$, comparable au négatif d'installation du mur oriental qui conserve une assise de fondation en pierres liées à la terre. L'appareil se présente avec deux parements de blocs ou de moellons de calcaire et de grès équarris avec un blocage interne.

À l'intérieur de cette maison, le sol de terre battue se compose d'un limon sableux compact brun, avec à l'ouest une zone de gravier et dans l'angle nord-est une zone brûlée. Le long du mur ouest, un foyer rudimentaire formant un demi-cercle de $70 \mathrm{~cm}$ est constitué d'une simple trace rubéfiée plus cendreuse en son centre. Le mauvais état de conservation général et l'absence d'aménagements caractéristiques rendent difficile la détermination d'une fonction de cet édifice qui s'apparente d'avantage à un habitat sans lien avec la tannerie.

\section{Les terres non loties ${ }^{852}$}

La concentration des vestiges sur la moitié occidentale du site contraste quelque peu avec les aménagements ponctuels répartis dans la partie orientale du site. Les données lacunaires restituent une vision très partielle de l'occupation dans plusieurs zones.

Au nord du bâtiment 3, un petit fossé transversal semble se déverser dans le fossé principal nord-sud. Large d'environ $40 \mathrm{~cm}$, il présente un faible pendage de l'ouest vers l'est de l'ordre de 1,1\%. Dans le comblement a été mis en évidence la présence d'un fin dépôt blanchâtre décrit lors de la fouille comme de la cendre. Son orientation isocline ne s'explique pas, ni son usage. Il aboutit non loin d'une importante fosse creusée en lisière du fossé nord-sud. D'un diamètre de 3,20 $\mathrm{m}$ pour une profondeur de 2,30 m, cette excavation aux parois verticales et au fond plat est comblée de limons sableux et de poches d'argiles stampiennes ainsi que de débris coquilliers. Son aspect semble indiquer qu'il pourrait s'agir d'un négatif de puits.

851 D'après N. Scherrer et E. Yebdri, in Bouiron 2001b, vol. 1-2, p. $340-341$

852 D'après L. Duval et P. Mellinand, in Bouiron 2001b, vol. 1-2, p. 341-343. 


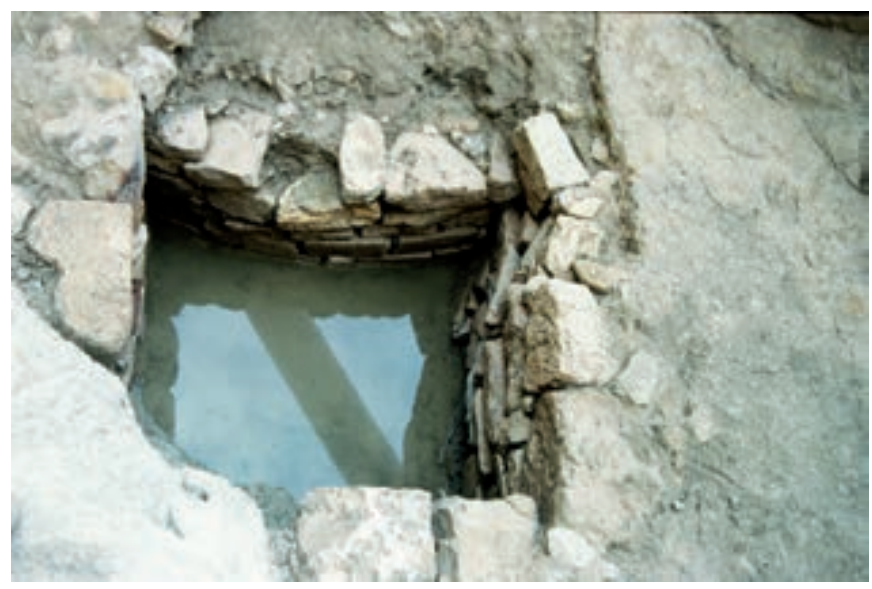

Fig. 239. Vue d'un puits d'angle (cl. T. Maziers/Inrap).

Les structures préservées dans l'extrémité orientale du site sont également éparses et aucune limite spatiale n'est conservée ; on note ainsi la présence d'un puits et de deux fosses aux remplissages particuliers.

Le puits est situé dans l'angle sud-est du chantier; son niveau de creusement n'a pas été retrouvé (fig. 239). Sa fosse d'installation, de plan circulaire et de profil conique, a un diamètre d'environ $3,20 \mathrm{~m}$; à l'intérieur celle-ci est installé un cuvelage de plan carré dont les parois internes mesurent $70 \mathrm{~cm}$ de côté. Ces parements, conservés sur deux assises, sont appareillés au moyen de moellons en calcaire lacustre soigneusement taillés. La longueur de ces moellons oscille entre $24 \mathrm{~cm}$ et $33 \mathrm{~cm}$, tandis que la hauteur des assises est identique $(13 \mathrm{~cm})$. Ces deux assises sont surmontées d'une reprise de l'élévation, conservée sur une hauteur maximale de cinq assises irrégulières $(75 \mathrm{~cm})$ et composée de matériaux hétéroclites, dont certains semblent provenir du chemisage initial du puits. Le calage du cuvelage est assuré par des cailloux et moellons de diverses natures pétrographiques, tandis que la large fosse d'installation est comblée au moyen d'une alternance de couches d'argile jaune d'origine stampienne et de couches de limon brunâtre. Cette structure semble plutôt destinée à une collecte des eaux contenues dans les terrains superficiels, plutôt qu'à la captation de la nappe phréatique. Cette différence n'est pas obligatoirement due à des exigences distinctes, mais peut-être simplement à une limitation des moyens à mettre en œuvre. Les niveaux de comblement du puits, attribuables au XIII ${ }^{\mathrm{e}}$ s., correspondent pour une part à une couche d'utilisation constituée d'argiles fines de décantation de couleur grise et pour une autre part à des couches d'abandon et de destruction de la structure, contenant de nombreux éléments provenant des parties supérieures du cuvelage.

Deux fosses sont également localisées en lisière orientale du site. La première est formée d'un vaste creusement profond de 3,28 m apparemment circulaire dont seul le bord nord est conservé. Ses parois sont relativement verticales et le profil du fond n'a pas fait l'objet d'observations détaillées. Cette fosse est comblée d'une succession de lits d'argile stampienne jaune alternant avec des strates de limon brun, composant ainsi un feuilletage similaire au comblement de la fosse d'installation du puits voisin. La vocation de cette fosse demeure problématique et la complexité et la régularité de son remplissage évoquent plus un comblement volontaire et réfléchi que le rebouchage d'un trou de spoliation. Étant donné que seule une petite moitié de cet ensemble était conservée, il est possible que la partie disparue ait recelé une structure pouvant s'apparenter à un puits. À un mètre à l'ouest de cette dernière, est située une seconde excavation de plan globalement quadrangulaire. Longue de $1,60 \mathrm{~m}$ et large de $1,30 \mathrm{~m}$, ses parois sont en pente douce, profondes d'une vingtaine de centimètres et son fond irrégulier. Son comblement homogène est constitué d'argile ocre jaune d'origine stampienne et contient du matériel de la première moitié du XIII ${ }^{\mathrm{e}} \mathrm{s}$. Il correspond vraisemblablement à une utilisation spécifique plutôt qu'à son abandon : fosse de décantation, aire de fabrication d'adobes, support ou base de pilier en terre évitant les remontées d'humidité.

\section{Disparition de la vocation artisanale du secteur et abandon du complexe hydraulique 853}

Au cours de la seconde moitié du XIII' s., l'activité artisanale du secteur périclite. Faute d'entretien, le réseau hydraulique s'envase et se colmate progressivement jusqu'à devenir inopérant, une partie de la tannerie est méthodiquement détruite et les matériaux récupérés. La disparition de cette infrastructure d'envergure dans la $2^{\mathrm{e}}$ moitié du XIII' ${ }^{\mathrm{e}}$ s. est peut-être consécutive à un déplacement de la corporation dans le quartier de SaintLouis, plus au sud. Il ne s'agit donc pas d'un abandon du secteur mais d'une volonté de changer la vocation du bourg destiné alors à accueillir quelques années plus tard un quartier d'habitation.

Si une partie du remplissage résulte d'apports successifs de sable issus de l'écoulement de l'eau et donc de l'utilisation de l'ensemble, l'abandon du complexe est constitué d'un colmatage d'épais dépôts limoneux. Le conduit de l'aqueduc nord-sud est comblé par des formations homogènes sablo-limoneuses issues d'écoulement lent, alternant avec des dépôts plus grossiers de type graviers et galets. À l'ouest, le puits citerne se remplit de limons de décantation gris compacts au cours

853 D’après É. Leal in Bouiron 2001b, vol. 1-2, p. 343. 


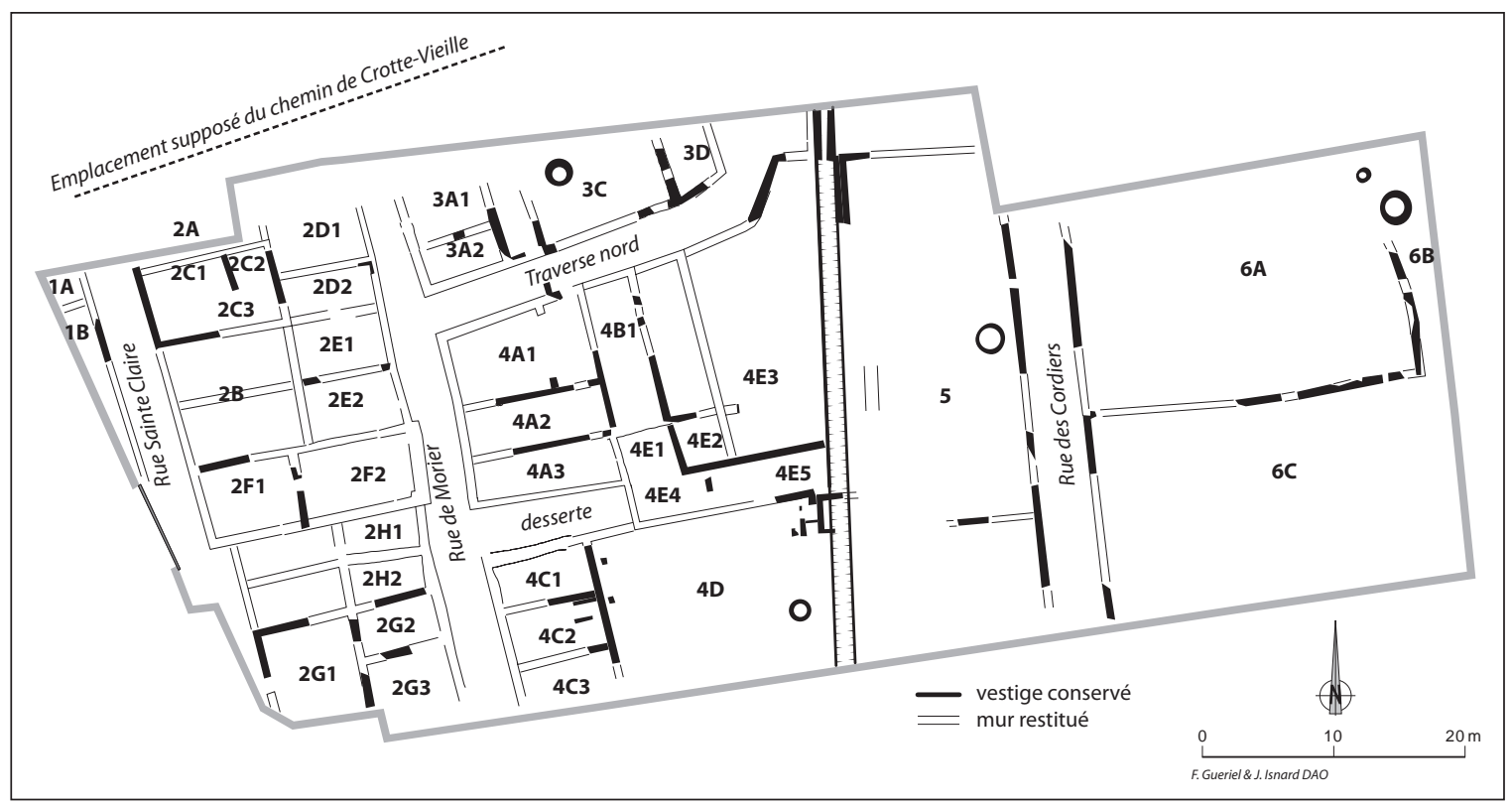

Fig. 240. Plan général du bourg de Morier dans la fouille de l'Alcazar (DAO F. Gueriel, J. Isnard/Inrap).

de la seconde moitié du XIII ${ }^{\mathrm{e}}$ s. ; cette accumulation sédimentaire est probablement liée à la récupération du système de vannes. L'aqueduc est-ouest est également comblé de dépôts lents puis d'apports plus torrentiels avant d'être partiellement récupéré sur toute la portion comprise entre le regard ouest et le puits terminal. À l'intérieur du bâtiment 1 de la tannerie, le puits inutilisé voit son cuvelage et sa margelle s'affaisser sur plus de $1 \mathrm{~m}$ de hauteur ce qui entraîne le comblement du conduit de l'aqueduc qui le jouxte.

L'abandon des bâtiments de la tannerie, à la suite duquel se mettra en place le faubourg, ne témoigne pas de démolition violente mais au contraire d'une récupération presque systématique des matériaux de construction. Le terrain destiné à accueillir des habitats est, soit préalablement remblayé sur près de $70 \mathrm{~cm}$ dans la zone de dépotoir, soit décaissé dans les espaces renfermant les cuves de tannage. Le bâtiment 2 mitoyen qui semblait dévolu au stockage des peaux et aux logements des artisans est réaménagé pour accueillir des maisons. La circulation sur la rue de Morier en direction de la rue Crotte-Vieille est rétablie suite à la destruction des espaces $2 \mathrm{~A}$ et $2 \mathrm{~B}$.

\subsection{Le faubourg médiéval (fin $X I I^{\mathrm{e}}$ - début $\mathrm{XIV}^{\mathrm{e}} \mathrm{s}$.) (E. Leal, F. Paone, N. Scherrer)}

On l'a dit, l'abandon de l'infrastructure de la tannerie dans la deuxième moitié du XIII ${ }^{\mathrm{e}} \mathrm{s}$. est peut-être consécutif à un déplacement de la corporation dans le quartier Saint-Louis, plus au sud. La transformation de la topographie des lieux s'opère par la mise en place d'un réseau d'axes de circulation nord-sud entre lesquels se développent différents îlots (fig. 240). Cette densification de l'occupation est, comme pour les états médiévaux précédents, plus particulièrement concentrée sur la moitié occidentale du site, soit sur les terres les plus proches de la ville et de son rempart.

\subsubsection{Le réseau viaire ${ }^{854}$ (F. Paone)}

Dès le $\mathrm{XII}^{\mathrm{e}} \mathrm{s}$. est attesté l'existence d'un premier chemin d'orientation nord-sud, la carreria del Morier, perpendiculaire à une voie remontant à l'Antiquité dénommée au Moyen Âge rue Crotte-Vieille. Mais la constitution progressive du quartier à la fin du XIII ${ }^{\mathrm{e}} \mathrm{s}$. rend nécessaire un maillage viaire plus dense, renforcé de deux nouvelles rues dont l'orientation est sensiblement la même que la première. L'espacement entre ces rues étant parfois important, une desserte des bâtiments a pu également être assurée par des traverses perpendiculaires. Le réseau viaire du secteur ne forme pas un tissu orthonormé du fait même de sa constitution progressive. Les contraintes topographiques engendrées par un tracé de voies anciennes et par la proximité du système défensif sont perceptibles dans la moitié occidentale du site. Ceci contraste avec la partie orientale où l'absence de sujétion permet la mise en place d'une voie large et rectiligne nord-sud dont l'usage a d'ailleurs

854 D'après L. Ben Chaba, L. Lefèvre-Gonzales, P. Mellinand, N. Scherrer, in Bouiron 2001b, vol. 1-2, p. 345-349, et F. Paone, in Bouiron 2001b, vol.7, p. 81-84. 
perduré jusqu'à nos jours. Le maillage des axes nordsud est irrégulier, $18 \mathrm{~m}$ entre la rue occidentale et la rue médiane, $44 \mathrm{~m}$ entre cette dernière et la voie orientale. Il semble toutefois beaucoup plus lâche que celui des traverses est-ouest, de $14 \mathrm{~m}$ en moyenne.

\section{Pérennisation de la rue de Morier}

La rue de Morier, attestée depuis le XII ${ }^{\mathrm{e}}$ s., forme un élément structurant pour la topographie des lieux. Son prolongement vers le nord n'a laissé aucune trace pour les phases antérieures à la création du faubourg, et sa jonction avec le rue Crotte-Vieille reste incertaine. Elle l'est d'autant plus qu'à la fin du XII ${ }^{\mathrm{e}}$ s., lors de la construction de la tannerie, deux pièces obturent au nord le tracé de cette voie. La jonction avec la rue Crotte-Vieille pouvait s'effectuer uniquement par une traverse bordant au sud l'un des bâtiments. À la fin du XIII' s. le faubourg se densifie, comme le montre en 1298 l'existence d'une liste de 11 propriétaires de maisons bordées par la carreria de Morier qui doivent un cens au comte ${ }^{855}$. Après le destruction d'une partie de la tannerie, les nouvelles maisons s'orientent perpendiculairement à cet axe.

À l'origine, la rue a une longueur d'environ $37 \mathrm{~m}$ et une largeur comprise entre 3 à 3,50 $\mathrm{m}$. Elle accuse un pendage général de $1 \%$ du nord au sud. L'ancienneté de cette voie se traduit par un tracé sinueux plus significatif que pour les autres axes pour lesquels, malgré une mise en place progressive des maisons du faubourg, les alignements de façades sont respectés.

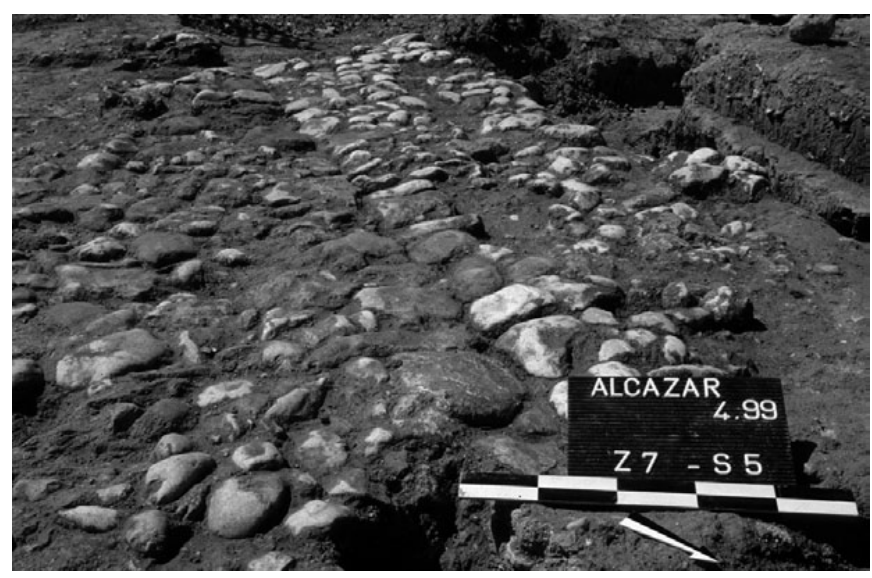

Fig. 241. Vue de la calade de la rue de Morier (cl. T. Maziers/Inrap)

À partir de la fin du XIII ${ }^{\mathrm{e}}$ ou du début du XIV ${ }^{\mathrm{e}} \mathrm{s}$. est réalisé un pavage dont ne subsistent que quelques tronçons répartis de manière lacunaire à l'extrême sud et au centre de la rue, sans que l'on puisse déterminer si cet

855 Il s'agit de la première mention de la rue de Morier. aménagement recouvrait, de façon logique, la totalité de la rue. Dans la partie centrale, cette calade, conservée sur une longueur de 4,50 m et une largeur de 2,35 m, est installée sur un lit de pose de limon incluant quelques fragments de tuiles et des charbons de bois (fig. 241). Le pavement est construit au moyen de galets et de quelques pierres brutes, d'une dizaine de centimètres, liés à la terre. Au centre, le passage d'un fil d'eau, d'orientation nord-sud, est matérialisé par l'alignement de pierres et de galets de plus gros module que celui utilisé pour élaborer le revêtement. Au sud, les vestiges de la calade sont ténus puisque conservés sur $70 \mathrm{~cm}$ de long et $40 \mathrm{~cm}$ de large. Elle est composée de galets de 4 à $5 \mathrm{~cm}$ de diamètre sans que l'on puisse savoir si, à l'instar de la portion découverte au nord, un fil d'eau y était aménagé. Le pavement est nivelé au moyen de recharges successives; il n'en reste par endroit que quelques galets alignés dans l'axe du fil d'eau.

\section{La rue Sainte-Claire}

Identifiée comme pouvant être la carreria Sancta Clara, la rue occidentale est établie lors de la mise en place du faubourg à la fin du XIII ${ }^{\mathrm{e}} \mathrm{s}$. Elle est légèrement décalée à l'est d'un espace de circulation perceptible le long du bâtiment 1 de la tannerie, qu'elle recouvre en partie. Ce réalignement est peut-être consécutif à la création des fossés avec murs de contrescarpe réalisé vers 1290. Mesurant 3,60 m de large, cette rue est la moins bien documentée. Elle est assez comparable à la rue médiane, tant par sa fonction de desserte d'habitations que par sa mise en œuvre. La mise en place progressive des façades sur rue ne semble pas s'inscrire dans un processus de respect d'un alignement ; son tracé oblique, amorcé par le décrochement formé par les bâtiments de l'ensemble 2G, retranscrit l'alignement du fossé défensif peu éloigné ${ }^{\mathbf{5 5 6}}$.

Le premier niveau attribuable de façon certaine à la voie est une couche damée de cailloutis pris dans une matrice argilo-limoneuse, épaisse de 2 à 5 centimètres contemporaine d'un sol de mortier compacté. Sur cette première surface de circulation détériorée sont déposées plusieurs recharges lenticulaires sableuses. Ce premier état de la voie est perturbé par l'implantation d'un caniveau transversal situé à l'extrême nord du chantier et orienté ouest-nord-ouest/est-sud-est. Cette canalisation, conservée sur un tronçon long de $2,18 \mathrm{~m}$ pour une largeur maximale atteignant $45 \mathrm{~cm}$, consiste en une simple rigole profonde de $15 \mathrm{~cm}$, creusée dans les niveaux sous-jacents. Elle est couverte de dalles et moellons de calcaire et poudingue disposés à plat. Au moment de

856 Le fossé se situerait au niveau du Cours Belsunce soit une trentaine de mètres à l'ouest. 


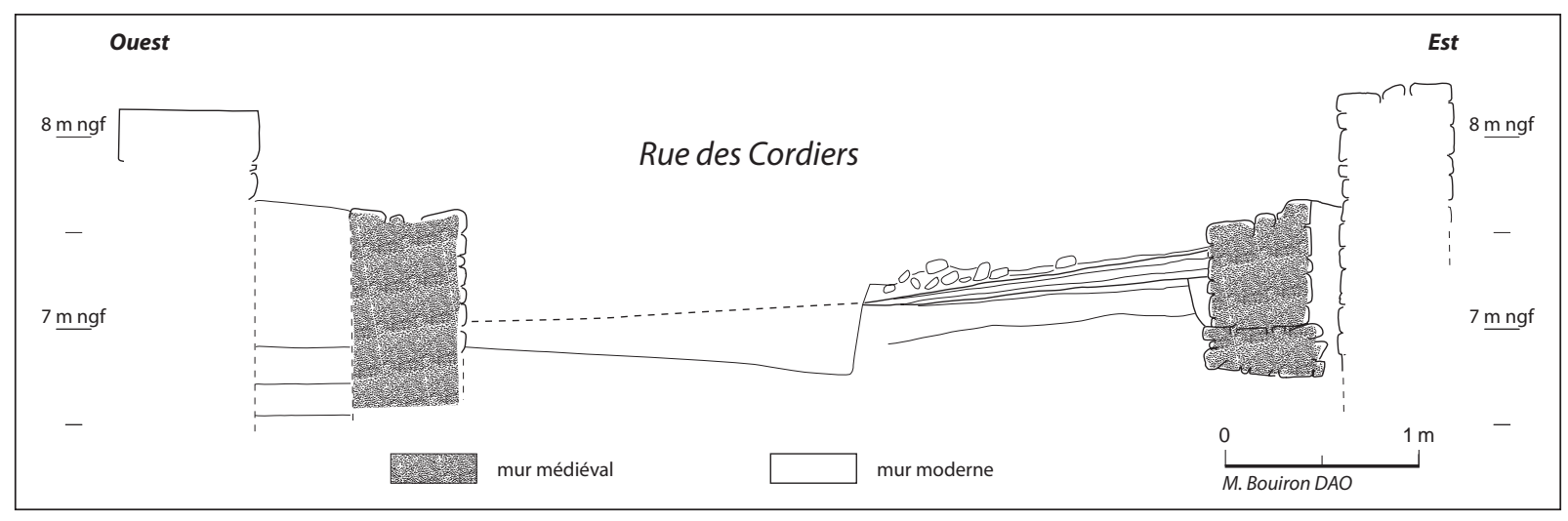

Fig. 242. Coupe de la rue des Cordiers (DAO M. Bouiron/Ville de Nice).

sa mise au jour, ce creusement était comblé d'un dépôt limono-sableux très homogène lié à son fonctionnement.

À cet état succède un rehaussement de la chaussée par l'apport de remblais destinés à supporter un sol caladé fouillé seulement dans la partie sud-ouest de la voie, tandis qu'au sud-est il laisse la place à un niveau de cailloutis équivalent. La calade associe des matériaux hétérogènes (galets, cailloux calcaires et fragments de terre cuite) dont il est difficile d'établir si certains relèvent d'apports liés à l'entretien de la voie. Ce sol, observé sur une superficie réduite de $3,5 \mathrm{~m}^{2}$, est bordé à l'ouest par un alignement de cailloux formant une rigole axiale à partir de laquelle se développe à l'est le sol de cailloutis damé mêlés à du mortier sur une épaisseur d'une dizaine de centimètre.

L'aménagement d'un caniveau collectif, mais surtout la mise en place de sols construits, témoignent du soin apporté à la réalisation des niveaux de circulation de cette rue, probablement nécessité par la forte fréquentation des lieux. Cependant ces sols sont observés sur une superficie extrêmement restreinte d'où l'impossibilité de juger de leur extension sur l'ensemble de la voie qui, de plus, est amputée à ses extrémités.

\section{La rue orientale ou rue des Cordiers}

La rue orientale est créée durant la deuxième moitié $\mathrm{du} \mathrm{XIII}^{\mathrm{e}}$ s. en reprenant un axe existant durant l'Antiquité. Elle est bordée de murs parfaitement rectilignes (fig. 242). Cette voie est la plus large puisqu'elle mesure 3,80 m d'est en ouest; son tracé s'implante sur un secteur vierge de construction donc dépourvu de contraintes lié à des constructions préexistantes. Son relatif éloignement du centre urbain, sa vocation à desservir des zones peu bâties, voire même agricoles, font de cette voie un axe de circulation mineur. Cependant, ce constat semble contredit par ses dimensions et par son maintien dans la trame urbaine contemporaine (rue du Baignoir).
Il semble donc qu'il faille chercher ailleurs, au nord ou au sud, la légitimité d'une telle voie. La lecture des archives nous apporte quelques éclaircissements : cette rue correspond probablement à la traverse des Cordiers recoupant la rue Crotte-Vieille au nord et celle des Roubaud au sud et mentionnée une première fois en 1290. En 1298, les Béguines de Roubaud édifient un nouveau bâtiment à proximité de leur couvent, sur des terres leur appartenant et situées le long de cette voie. Ainsi peut-on émettre l'hypothèse que la présence de propriétés et constructions relevant des Béguines a conditionné la topographie des alentours et notamment l'implantation de cette voie.

Cette rue est largement endommagée par la présence d'un collecteur central qui réduit la surface étudiée à $10 \mathrm{~m}^{2}$. Durant la phase la plus ancienne, la rue est bordée à l'est par une palissade en bois dont ne demeure qu'un alignement de sept poteaux. Six d'entre eux possèdent un diamètre compris entre de 8 et $12 \mathrm{~cm}$ et une profondeur moyenne de 8 à $12 \mathrm{~cm}$. Le septième, de plan rectangulaire et de gabarit supérieur $(21 \mathrm{x} 11 \mathrm{~cm})$, a un creusement en palier à l'est et des parois verticales sur trois côtés ; son fond est en pointe et sa profondeur de $10 \mathrm{~cm}$. La plupart des négatifs sont tapissés de chaux et de mortier ce qui peut être interprété probablement comme des pieux de fondation de maçonnerie. Les sols successifs sont caractérisés par des apports réguliers de gravillons ou de pierres mêlés à de l'argile ou des limons. Des nodules de mortier complètent parfois les éléments mis en œuvre. L'inclusion de matériaux plus hétérogènes est ponctuellement à signaler comme par exemple ce sol composé en partie de nodules de mortier, des fragments d'enduit et de nombreuses scories de métal ainsi que de mobilier céramique en abondance. À l'une des surfaces de circulation sont associés des fragments de tuiles et de céramiques disposés à plat. Les séquences sont damées et présentent un double pendage significatif d'est en ouest de 2,7 \%, moins marqué du nord au sud de 1,6\%. 
La présence d'un fil d'eau central sans aménagement particulier est également attestée. Cette traverse, qui s'implante au milieu du XIII ${ }^{\mathrm{e}}$ s., semble dépourvue de calade et aucune trace d'ornière n'a été repérée, mais l'étroitesse de sa partie conservée ne permet pas d'exclure leur existence.

\section{Les dessertes secondaires: une traverse nord et une impasse}

À ces rues principales s'ajoutent deux dessertes accessibles par la rue de Morier, l'une d'elle étant à usage privatif. Bordant au sud l'îlot III, la ruelle d'axe est-ouest, reprend l'emplacement de l'ancien aqueduc qui alimentait la tannerie. C'est par son intermédiaire que s'effectuait alors la communication entre la rue de Morier et la rue Crotte-Vieille. Avec l'établissement du faubourg, cet axe de 2,80 m de large permet l'accès au sud de l'îlot III et au nord de l'îlot IV. Un aménagement du dénivelé est-ouest est opéré par l'installation d'un emmarchement accolé aux façades. Conservé sur $1 \mathrm{~m}$ de long et sur une seule assise de $60 \mathrm{~cm}$, il est formé de gros blocs de calcaire retouchés, posés à plat, et de blocs plus petits à l'ouest et

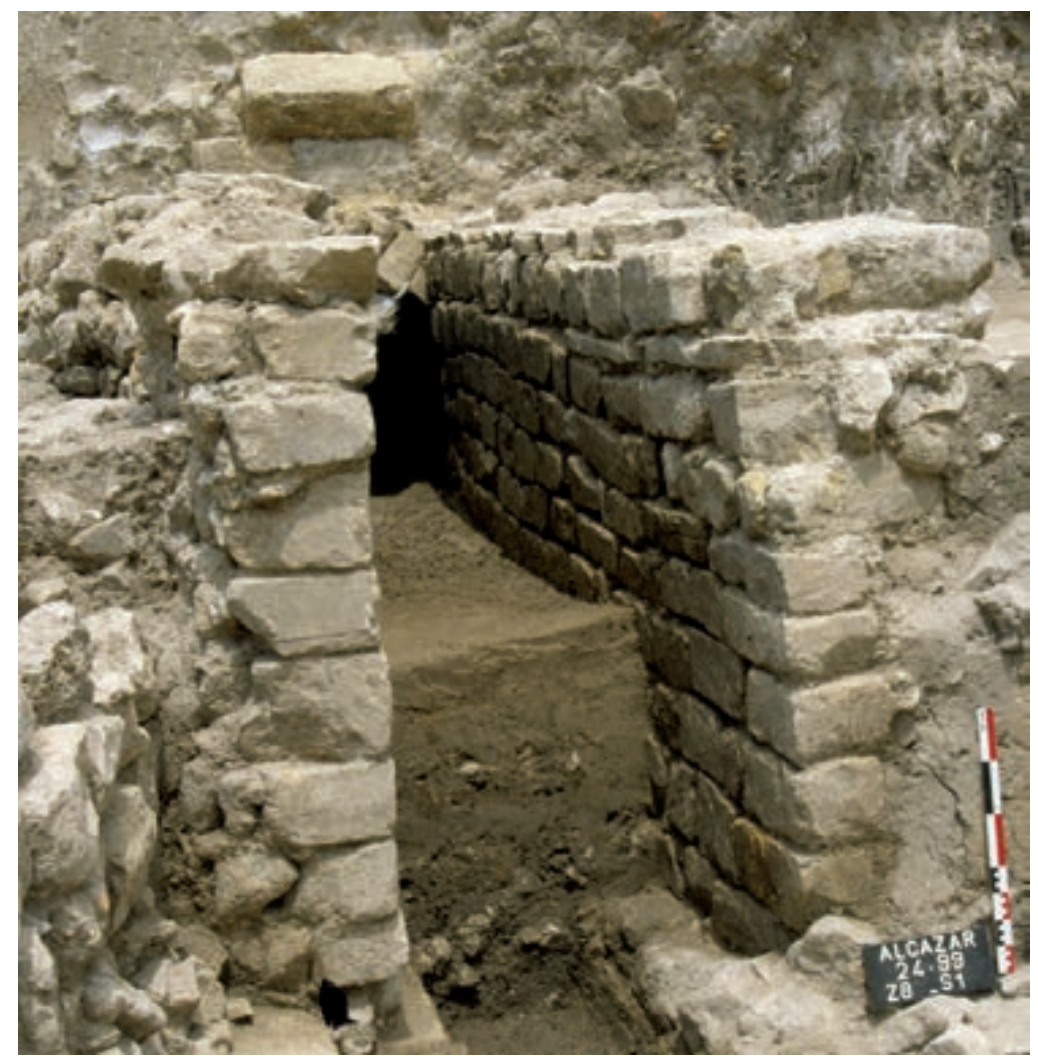

Fig. 243. Transformations du fossé (cl. T. Maziers/Inrap). au milieu. Cet aménagement, lié à la terre, fait la transition entre un sol en terre battue à l'ouest et une calade établie à l'est, $24 \mathrm{~cm}$ plus bas et très mal conservée.

Quinze mètres plus au sud et perpendiculairement à la voie de Morier, une impasse, large de $4 \mathrm{~m}$, sépare les bâtiments $4 \mathrm{~A}$ et $4 \mathrm{C} 1$ et permet d'accéder aux constructions et jardins orientaux. Cette venelle (4C4) semble cependant à usage privatif et parait utilisée comme espace de travail rattaché à l'îlot IV.

La trame médiévale perdure dans le tissu urbain moderne; on remarque en revanche que celle-ci se simplifie en s'aérant. Le réseau est-ouest est privilégié au détriment des voies nord-sud dont seul l'axe oriental est maintenu sur le site. On peut s'étonner de l'annexion par le domaine privé des deux axes de circulation, et notamment de la rue de Morier dont le tracé a été l'un des éléments déterminants dans l'urbanisation du secteur.

\subsubsection{De l'usage limité à la disparition du réseau hydraulique (E. Leal, N. Scherrer) ${ }^{857}$}

La disparition du complexe artisanal s'est accompagnée de l'envasement progressif de tout le réseau

857 D'après C. Aubourg, É. Leal, P. Reynaud, C. Voyez, in Bouiron 2001b, vol. 1-2, p. 349-351. hydraulique qui le faisait fonctionner. Les écoulements canalisés par le fossé oriental perdurent cependant, un nouvel aménagement se superpose à l'aqueduc et des travaux de curage sont à nouveau entrepris. Dans les derniers temps, le débit d'eau ralentit jusqu'à disparaître.

La persistance des circulations d'eau entraine une restauration de l'ancien aqueduc nord-sud qui sert de support alors à un nouveau conduit (fig. 243). Ses piédroits sont posés sur les montants de la canalisation sous jacente; la liaison s'effectue grâce à un rang de blocs calcaires bruts ou retouchés, liés au mortier, sur lesquels sont bâtis des parements en petit appareil régulier (sept assises de moellons en calcaire oligocène taillés) avec un liant à la terre. Cet aménagement se termine au sud par deux blocs de calcaire dur formant la transition avec un exutoire dont la bordure orientale alignée comprend deux rangs de moellons et de blocs en travertin, calcaire et poudingue. La limite ouest forme un évasement jusqu'à recouvrir le cuvelage de l'ancien puits-citerne. Elle s'accole au mur de bordure de la traverse septentrionale en formant un coude puis un léger décrochement.

Parallèlement, à partir de la fin du XIII ${ }^{e}$ s., le fossé est à nouveau curé mais l'évacuation des boues ne se fait pas de façon identique sur tout son tracé. Dans la partie nord, la purge forme un négatif en forme de $\mathrm{U}$ de $1,50 \mathrm{~m}$ de large, la profondeur du curage s'accentue 


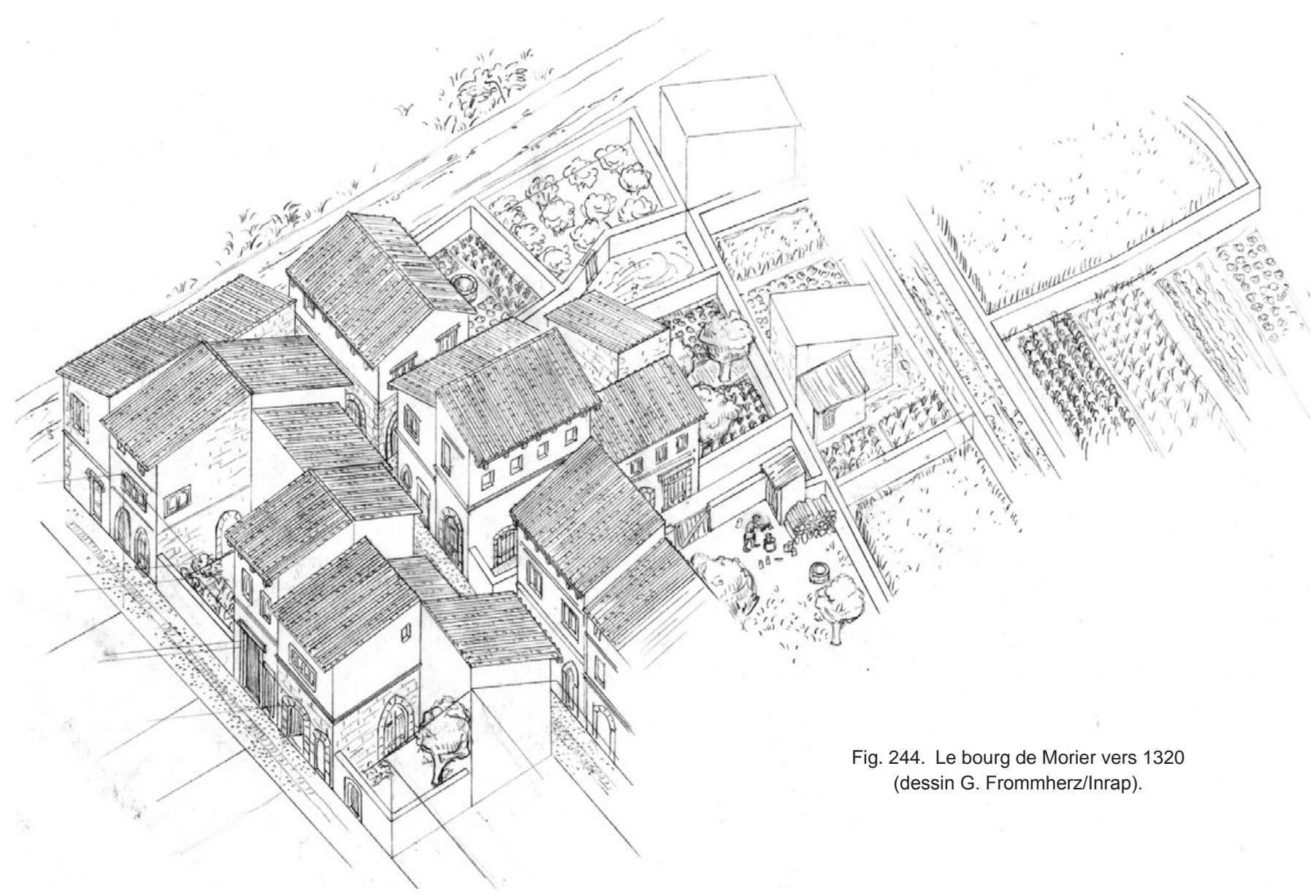

en partie centrale passant de $50 \mathrm{~cm}$ à $90 \mathrm{~cm}$. Enfin dans son extrémité méridionale, le curage a une emprise plus large $(1,80 \mathrm{~m})$ mais moins profonde $(30 \mathrm{~cm})$ maintenant ainsi un fond d'écoulement au pendage régulier. Suite à ces travaux, le colmatage du fossé se poursuit ; il se matérialise par des passées sableuses issues de dynamiques hydrauliques réduites. Lui succède une phase d'abandon caractérisée par un sédiment sombre incluant de nombreux fragments de blocs de pierres. Il subsiste cependant, après cette phase, une reprise d'écoulements sporadiques surcreusant la couche d'abandon.

Les aménagements du nouvel aqueduc sont détruits durant la seconde moitié du $\mathrm{XIV}^{\mathrm{e}} \mathrm{s}$. Le grand puits terminal est complètement abandonné et bouché. La portion du conduit de l'aqueduc qui se trouve désormais sous l'espace $2 \mathrm{E}$ est entièrement récupérée à partir du mur médian jusqu'au puits terminal. L'extrémité ouest de l'aqueduc, à l'aplomb de la façade de la pièce $2 \mathrm{E}$, est condamnée sur toute sa largeur par un muret. Le reste du tracé vers l'est est intégralement conservé. Les deux regards qui ponctuaient à l'origine la tracé du conduit sont conservés sans modification structurelle, dans la rue de Morier pour l'un et dans la traverse est-ouest pour l'autre. À l'origine destinés à l'entretien du conduit, il est possible que dans ce dernier état ils aient fait office de puits pendant quelque temps.

\subsubsection{La composition du faubourg (N. Scherrer)}

La création d'habitats dans les faubourgs est le marqueur de l'accroissement de la démographie urbaine, en liaison avec l'exode rural. Les unités de construction s'inscrivent entre des rues ou des traverses qui en assurent la desserte. La mise en place des six îlots d'habitation retrouvés sur le site est progressive, aussi la présentation des vestiges est-elle le reflet de cette chronologie relative des bâtiments les uns par rapport aux autres (fig. 244).

\section{L'îlot I $^{858}$}

L'îlot I, situé à l'ouest de la rue Sainte-Claire et en limite de la fouille, n'est que très partiellement conservé : seule une partie de la façade orientale sur rue et un mur de refend sont visibles (fig. 245). Les données relatives

858 D'après É. Leal in Bouiron 2001b, p. 351-352. 


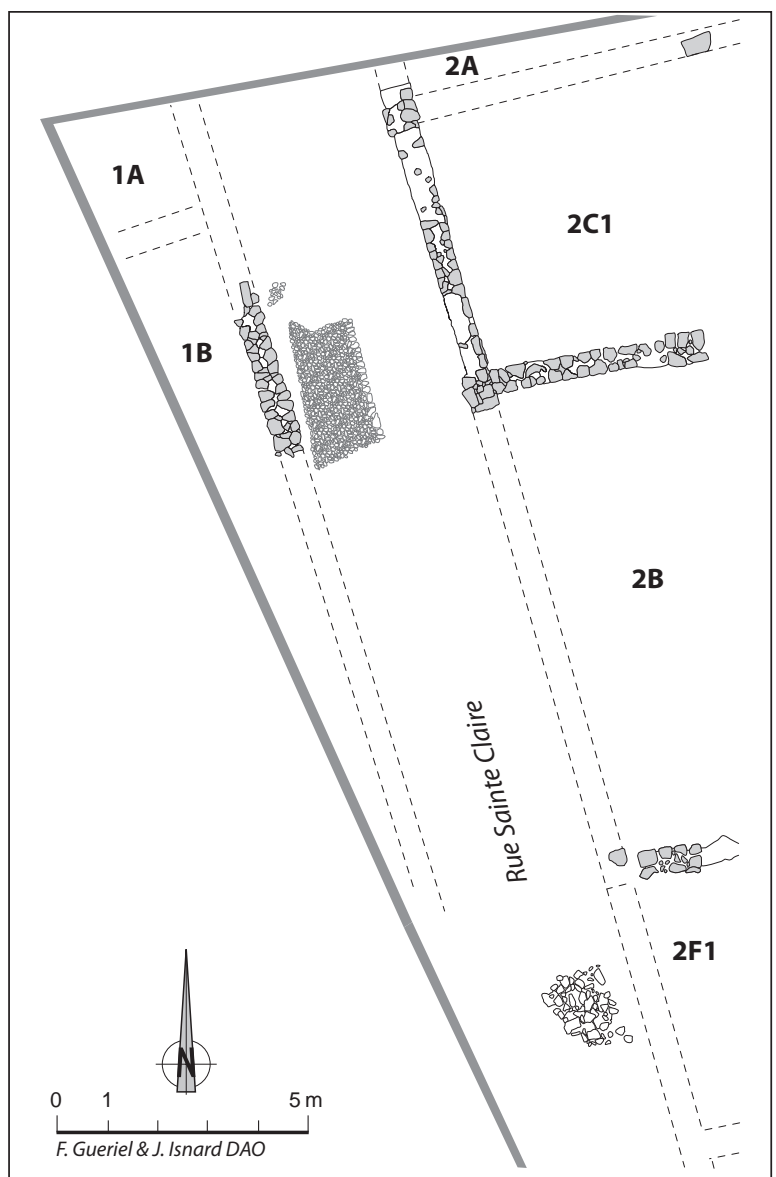

Fig. 245. Plan de l'îlot I (DAO F. Gueriel, J. Isnard/Inrap).

à l'organisation et à la datation de ce premier îlot sont par conséquent particulièrement succinctes. Le mur de façade sur la rue Sainte-Claire reprend en partie la limite de parcelle occidentale de la tannerie en la réalignant selon un axe nord-sud. Ce mur, conservé sur une longueur de 3,50 m, possède une fondation large de $53 \mathrm{~cm}$, conservée sur deux assises, à double parement de moellons équarris (poudingue, travertin, calcaire crayeux) et un blocage interne lié à la terre. La tranchée de récupération d'un mur perpendiculaire, large de $50 \mathrm{~cm}$, indique que l'espace derrière le mur de façade est subdivisé en deux pièces (ou bâtiments ?).

Seule la partie sud-est de la pièce 1A a été fouillée ; elle est remblayée par un épaisse couche de limons gris de manière à surélever le niveau d'occupation antérieur de près de $50 \mathrm{~cm}$ pour créer une nouvelle surface de terre battue. Dans la partie conservée, ce sol apparaît comme un niveau très damé et régulier avec par endroits la présence d'une fine couche de chaux. Au sud, la pièce 1B, dont seul l'angle nord-est est conservé, possède un sol de terre. La préparation du sol, d'environ $20 \mathrm{~cm}$ d'épaisseur, est constituée d'une première couche de limons sableux riches en cailloutis, recouverte par un niveau composé de limons plus fins et homogènes, dont la surface est régularisée et damée pour servir de sol. Aucun dispositif domestique particulier n'a permis de définir la fonction de ces deux pièces et les niveaux fouillés n'ont livré aucun élément de datation.

\section{L'îlot II ${ }^{859}$}

L'îlot II s'inscrit entre la rue Sainte-Claire à l'ouest et le chemin du Morier à l'est (fig. 246). Large de 17,50 m, il a été observé sur une longueur de $40 \mathrm{~m}$. Une opération d'assainissement préalable à la mise en place des sols sur l'arasement des structures artisanales de l'ancienne tannerie a été nécessaire à cause de la présence d'éléments insalubres, notamment les cuves de tannage. La progressive mise en place des édifices donne de l'îlot II une image de bâtiments hétéroclites accolés les uns aux autres. Les premiers espaces clos paraissent être ceux ouvrant sur la rue occidentale (les ensembles 2A, $2 \mathrm{~B}$ et 2C) contre lesquels s'accolent sans doute rapidement les unités $2 \mathrm{D}$ et $2 \mathrm{E}$, puis $2 \mathrm{~F}$. Parallèlement une unité importante, 2G, est établie plus au sud ; l'espace laissé au nord de celle-ci ne sera loti que plus tard $(2 \mathrm{H})$.

\section{L'ensemble $2 A$}

$\mathrm{Au}$ nord-ouest se développe la pièce $2 \mathrm{~A}$, identifiée sur une longueur de 9,50 m par un sol de terre battue. Le mur de façade sur la rue Sainte-Claire est hérité de la phase précédente, et le mur méridional vient s'appuyer contre. Large de $50 \mathrm{~cm}$, il présente une fondation à double parement de moellons équarris liés au mortier. Il n'est conservé que dans sa partie ouest, sur une longueur d'environ $2 \mathrm{~m}$. Le reste de son tracé étant totalement récupéré, le contact avec le mur oriental est détruit.

\section{- L'ensemble $2 B$}

Au sud de l'espace 2A, à plusieurs mètres de distance, une nouvelle parcelle est lotie ; elle est limitée par trois murs, au nord, à l'ouest et au sud. En l'absence d'autres éléments de clôture, il n'est pas possible d'en restituer la superficie exacte ou la partition intérieure. Sa superficie maximale en l'état atteint $85,50 \mathrm{~m}^{2}$ mais il est possible, au regard de l'organisation des autres espaces, qu'elle ait été divisée en deux pièces, d'une quarantaine de mètres carrés chacune, par un mur médian peut-être situé dans le prolongement du mur séparant des pièces $2 \mathrm{E} 1$ et $2 \mathrm{E} 2$.

Le mur nord est conservé en fondation et sur deux assises d'élévation. La première est constituée de deux

859 D'après É. Leal et N. Scherrer in Bouiron 2001b, p. 352-360. 


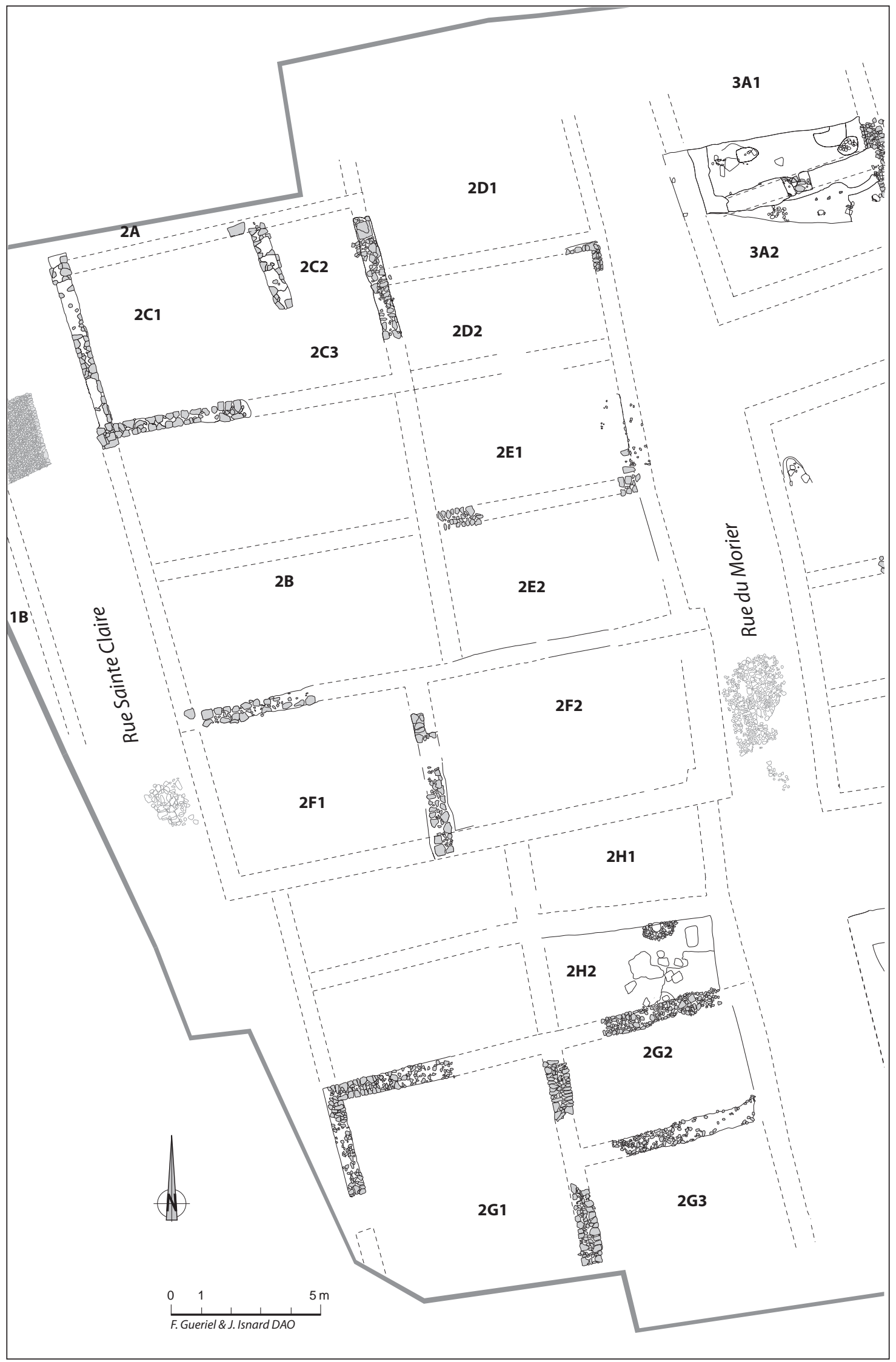

Fig. 246. Plan de l'îlot II (DAO F. Gueriel, J. Isnard/Inrap). 
assises, d'environ $50 \mathrm{~cm}$ de profondeur et la maçonnerie, à double parement de moellons équarris et blocage interne, est large de $65 \mathrm{~cm}$ avec un ressaut sur chacun des côtés. L'élévation, à parement double sans blocage interne, mesure $45 \mathrm{~cm}$ de large. L'ensemble de la construction est lié à la terre et forme un angle avec le mur de façade occidental. La fondation de ce dernier est constituée de deux assises (mesurant $50 \mathrm{~cm}$ de profondeur), de moellons équarris formant un double parement non débordant, de même largeur que les deux assises d'élévation conservées, soit $55 \mathrm{~cm}$. Les hauteurs de fondation et d'élévation de ce mur de façade entièrement lié à la terre sont identiques à celles du mur nord. Le mur sud n'est conservé que sur sa première assise de fondation, soit une profondeur de $25 \mathrm{~cm}$. La maçonnerie à double parement de moellons équarris et blocage interne de cailloux et galets est liée au mortier.

L'angle nord-ouest de l'espace conserve un fragment de sol suffisant pour qu'on puisse en lire la structure. Il se distingue des sols de terre battue identifiés dans les pièces adjacentes. En effet, il est constitué d'un premier remblai assez grossier associant graviers, sables et cailloux dans une matrice limoneuse. Lui succède une couche de limons bruns plus compacts et homogènes caractérisée par la présence d'éclats de calcaire dont la surface a été damée et régularisée.

\section{口 L'ensemble $2 C$}

Dans un premier temps, le terrain situé entre les espaces $2 \mathrm{~A}$ et $2 \mathrm{~B}$ n'est pas construit, mais il est rapidement investi. Ce nouvel espace, d'une superficie de $53,50 \mathrm{~m}^{2}$, s'ouvre sur la rue Sainte-Claire par un mur de façade accolé contre les deux pignons. C'est une solide construction entièrement liée au mortier, conservée sur la totalité de sa fondation et quatre assises d'élévation. La fondation comporte deux assises régulières à double parement de moellons équarris et blocage interne de cailloux, galets et fragments de tuile, d'une profondeur de $40 \mathrm{~cm}$. Le liant de mortier est épais et souvent débordant. La largeur de la fondation $(60 \mathrm{~cm})$ est sensiblement plus importante que celle de l'élévation qui est de $50 \mathrm{~cm}$. L'appareil de l'élévation, conservé sur une hauteur de $70 \mathrm{~cm}$, est constitué de moellons équarris, assisés, formant un parement double sans blocage interne.

La limite orientale de l'espace 2C est constituée par un piédroit prolongé au sud par un mur. Le piédroit, construction à double parement liée au mortier, large de $50 \mathrm{~cm}$ et long de $80 \mathrm{~cm}$, est conservé sur ses deux assises de fondation. Le mur qui lui est accolé est, en revanche, un mur lié à la terre. Large de $60 \mathrm{~cm}$, il est conservé sur deux assises de fondation, soit environ $40 \mathrm{~cm}$ de profondeur. Il se compose d'une maçonnerie assisée à double parement de moellons équarris et blocage interne de cailloux et galets. Il semble que dans un état initial, la pièce $2 \mathrm{C}$ communiquait à l'arrière sur un autre espace (les futures pièces 2D1 et 2D2), peut-être ouvert par une large ouverture dont le piédroit serait un témoin. Ce passage est par la suite condamné par le mur, au moment où l'on décide de construire les deux pièces ouvrant sur la rue de Morier.

L'espace $2 \mathrm{C}$ est subdivisé par un mur nord-sud et hérité d'un ancien bâtiment de la tannerie. La conservation de cette maçonnerie crée à l'intérieur de la pièce une subdivision en au moins deux pièces. Mais trois sols ayant été distingués, il est possible que le bâtiment ait été divisé en trois pièces. Dans la pièce $\mathbf{2 C 1}$, le long de la rue Sainte-Claire, le sol est constitué d'une mince couche de limons sableux bruns, compacts et homogènes, à la surface damée. Seul le creusement d'une fosse, postérieur à la mise en place du sol, a été observé. À l'est, le réduit $2 \mathrm{C} 2$ d'environ $7,50 \mathrm{~m}^{2}$ de superficie possède son sol propre, constitué d'une épaisse chape d'argiles jaunes (30 cm d'épaisseur) à la surface fortement damée et régulière. Ce sol a livré du mobilier céramique daté de la fin du XIII ${ }^{e}$ s. Enfin, la moitié sud de la pièce se présente comme un espace oblong d'une superficie de $23,75 \mathrm{~m}^{2}$, dont le sol est conservé de manière très partielle, sur environ $2 \mathrm{~m}^{2}$, en raison du creusement ultérieur d'une vaste fosse. Il est constitué d'un remblai de limons de $15 \mathrm{~cm}$ d'épaisseur formant une couche compacte et homogène et a livré du mobilier céramique daté de la première moitié du $\mathrm{XIV}^{\mathrm{e}} \mathrm{s}$.

L'absence de contact stratigraphique entre les différentes parties de cette pièce ne permet pas de savoir comment s'effectuait la transition entre les sols.

\section{口 L'ensemble 2D}

Cet ensemble occupe la partie nord-est de l'îlot II et donne sur la rue de Morier. Il est établi dans l'espace sur lequel s'ouvrait initialement le bâtiment 2C. Après l'obturation de cette communication par un mur, deux pièces, $2 \mathrm{D} 1$ et 2D2, ayant chacune leur façade sur rue sont créées. Le mur méridional de cet ensemble est attesté uniquement par sa tranchée de récupération, large de $65 \mathrm{~cm}$ et conservée sur $40 \mathrm{~cm}$ de profondeur. Il est situé dans l'axe du mur de limite sud de l'ensemble 2C. La pièce 2D1 est conservée sur une bande de $2 \mathrm{~m}$ de large; sa limite nord manque, car hors emprise du chantier. La pièce 2D2 possède une superficie totale de $22,75 \mathrm{~m}^{2}$. Un premier sol forme une surface damée et régulière de part et d'autre du mur qui sépare les deux pièces. Il est constitué d'un remblai de limons argileux bruns et gravillonneux servant de couche de préparation à une mince couche de sables et d'argiles jaunes 
mélangés. Il a livré du mobilier céramique daté de la première moitié du XIV ${ }^{\mathrm{e}} \mathrm{s}$.

Dans un second état, le mur de cloison est épierré et sa tranchée de récupération comblée de manière à mettre en place un nouveau sol de terre battue, qui occupe les deux espaces 2D1 et 2D2 et crée ainsi une vaste pièce d'une superficie minimale de $32 \mathrm{~m}^{2}$. Ce sol est installé sur une mince couche de préparation de limons.

\section{口L'ensemble $2 E$}

Situé au sud de l'ensemble 2D et à l'ouest de l'espace 2B dont il reprend la largeur, l'ensemble $2 \mathrm{E}$ est formé de deux pièces, 2E1 et 2E2, délimitées l'une de l'autre par un mur. Elles sont séparées de la rue de Morier par deux murs sans doute distincts ${ }^{\mathbf{8 6 0}}$. Totalement détruite, leur limite occidentale n'est pas restituable. Les murs largement récupérés n'apparaissent plus que par leur tranchée d'épierrement, exception faite du mur médian, conservé sur deux tronçons de 0,60 et $1,50 \mathrm{~m}$. Il se présente comme un mur à double parement et blocage interne, d'une largeur de $80 \mathrm{~cm}$. Il est conservé sur une unique assise de fondation, constituée de moellons équarris liés à la terre. La tranchée de fondation permet de restituer une hauteur de fondation initiale d'environ $50 \mathrm{~cm}$, soit au moins deux assises pour le type d'appareil observé sur le site.

La pièce $2 \mathrm{E} 1$ possède une superficie minimale de $29,25 \mathrm{~m}^{2}$. Un sol de terre battue très damé mais marqué par des irrégularités a livré du mobilier daté du début du $\mathrm{XIV}^{\mathrm{e}} \mathrm{s}$. Le sol de la pièce $2 \mathrm{E} 2$ est sensiblement identique.

\section{口 L'ensemble $2 F$}

Il s'agit d'une construction oblongue établie au sud des ensembles $2 \mathrm{~B}$ et $2 \mathrm{E}$. Toutes les maçonneries sont épierrées, à l'exception du mur qui constitue la limite entre les deux pièces. Les tranchées d'épierrement des limites sud et est sont remarquablement larges. Cet ensemble était bordé par la rue Sainte-Claire, la rue de Morier et une traverse qui sera ensuite occupée par l'espace $2 \mathrm{H}$. Sa position dans l'îlot et la largeur des tranchées laisse penser qu'il s'agit d'un bâtiment important.

À l'ouest se trouve la pièce $2 \mathbf{F 1}$, dont la superficie restituée est de $35 \mathrm{~m}^{2}$. Son sol de terre battue présente une surface irrégulière légèrement bosselée. Il est installé sur une chape constituée d'un remblai de mottes d'argiles grises et jaunes compactées, et sur un remblai de limons argileux compacts mais assez hétérogènes. La pièce 2F2 occupe, à l'est, une superficie de 42,50 m².

860 Les tranchées d'épierrements ne sont ni alignées, ni de la même largeur.
Son niveau de sol a également une surface assez irrégulière au-dessus d'un épais remblai de nivellement.

\section{口L'ensemble $2 G$}

Localisé à $6,50 \mathrm{~m}$ au sud du bloc $2 \mathrm{~F}$, l'ensemble $2 \mathrm{G}$ est un important corps de bâtiment, de $15 \mathrm{~m}$ de long et de $9 \mathrm{~m}$ de large au moins, formant la partie méridionale de l'îlot II. Il est très mal conservé en raison de l'installation ultérieure de deux caves d'Époque moderne.

Le mur septentrional, large de $80 \mathrm{~cm}$, est lié à la terre; l'élévation est conservée sur quatre assises vers l'ouest. À l'est, il ne subsiste que quelques pierres qui forment vraisemblablement le radier d'installation. Les murs nord et ouest sont chaînés entre eux. Le mur occidental, coupé par la paroi moulée, mesure au minimum $60 \mathrm{~cm}$ de large. Le bâtiment $2 \mathrm{G}$ se compose d'au moins trois espaces dont deux, les espaces $2 \mathrm{G} 2$ et $2 \mathrm{G} 3$, donnent sur la rue de Morier. Le mur séparant l'espace 2G1 des pièces $2 \mathrm{G} 2$ et $2 \mathrm{G} 3$, est partiellement conservé sur une assise de fondation, composée de moellons et blocs de calcaire liés à la terre, dont la largeur est de 70 à $80 \mathrm{~cm}$. Perpendiculaire à ce dernier, le mur entre les pièces $2 \mathrm{G} 2$ et 2G3 ne subsiste que par la tranchée d'épierrement qui mesure $60 \mathrm{~cm}$ de large. Au nord-est de l'ensemble 2G, contre le parement nord du mur, un sol chaulé compact de $6 \mathrm{~cm}$ d'épaisseur contenant des éclats de calcaire, est conservé sur 2,24 $\mathrm{m}^{2}$. Ce sol est lié à la mise en œuvre du bâtiment.

La pièce 2G1, localisée à l'ouest, s'ouvre probablement sur la rue Sainte-Claire située hors de l'emprise du chantier à cet endroit. L'espace semble donc présenter un plan rectangulaire orienté nord-sud. La surface de la pièce est d'au moins 47,5 m². Aucun sol n'a pu être observé.

L'espace 2G2 forme l'angle nord-est de l'ensemble. Un sol en terre battue est installé sur un remblai daté de la fin du XIII ${ }^{\mathrm{e}}$ s. ou du début du XIVe s. Il recouvre l'ensemble de l'espace et est marqué par la présence de poches de cendres et de taches rubéfiées. Un foyer est aménagé dans la partie centrale de l'espace. De plan circulaire, il se caractérise par de la terre rubéfiée et de la cendre (son diamètre mesure $24 \mathrm{~cm}$ ). Le sol est également recoupé par une fosse dont le comblement contient de la céramique du début du XIV ${ }^{\mathrm{e}} \mathrm{s}$.

L'espace 2G3 est conservé sur 19,2 m², mais il est possible que l'espace ait été plus important. Cette pièce fortement arasée n'a livré aucune trace d'occupation.

\section{L'ensemble $2 H$}

Cette construction est réalisée alors que les ensembles $2 \mathrm{~F}$ et $2 \mathrm{G}$ sont déjà construits. L'édifice doit s'adapter à 


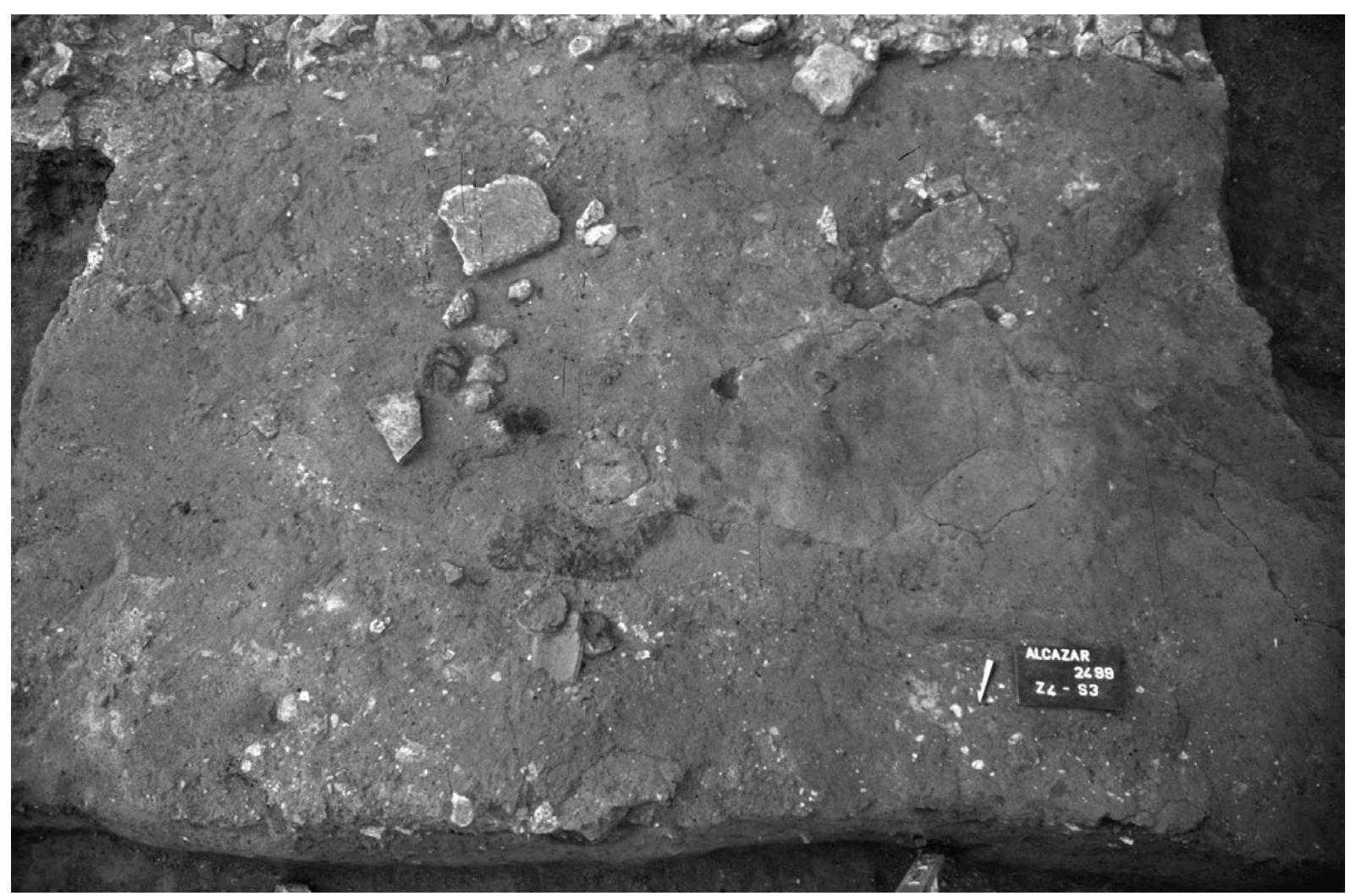

Fig. 247. Les bases de poteau de l'espace $2 \mathrm{H} 2$ (cl. T. Maziers/Inrap).

l'exiguïté de la surface restante et au bâti existant en faisant le lien entre le décrochement marqué des façades des deux immeubles entre lesquels il s'insère. L'ensemble $2 \mathrm{H}$ est fermé à l'est par un mur, dont ne subsiste que la tranchée d'épierrement large de $70 \mathrm{~cm}$. Ce dernier est axé en fonction des deux façades plus anciennes qui ne respectent pas exactement un même alignement sur la rue de Morier, ce qui rend son tracé légèrement oblique. Deux pièces sont édifiées, séparées par un mur de refend lui aussi épierré ; la tranchée mesure $60 \mathrm{~cm}$ de large.

De plan trapézoïdal, la superficie interne de la pièce 2H1 représente au minimum $16,50 \mathrm{~m}^{2}$. Un niveau de sol, et un foyer semi-circulaire, ont été observés dans la partie sud de l'espace. Le foyer matérialisé par un sédiment argileux rubéfié mesure $40 \mathrm{~cm}$ de diamètre; il se situe contre le mur médian.

Au sud de l'espace précédent, la pièce $\mathbf{2 H 2}$, d'une superficie de $17,10 \mathrm{~m}^{2}$, est également de plan trapézoïdal. Un premier sol se compose d'un sédiment sablo-limoneux (fig. 247). Deux poteaux, alignés selon un axe nord-sud, matérialisent sans doute un cloisonnement ou un support. À l'est, une fosse de forme rectangulaire et de faible profondeur $(8 \mathrm{~cm})$ présente au fond un lit de mortier; elle est peut-être le témoin de l'installation puis de la récupération d'un aménagement. Deux blocs de calcaire taillés, distants d'un mètre l'un de l'autre, dont l'un est sculpté, ont également été retrouvés sur ce niveau à $0,62 \mathrm{~m}$ du mur de limite sud. Le bloc sculpté, utilisé en réemploi, présente deux cannelures séparées par un creux et de l'autre côté, une nervure. Ces pierres ont pu servir de bases de poteau. Le sol rechargé d'une couche de limons sableux, est aménagé d'un foyer. De forme irrégulière, plutôt ovale ( $1 \mathrm{~m}$ de long), celui-ci est constitué de terre rubéfiée et de charbons de bois. Une corne d'animal a été retrouvée à sa surface et une poche de cendres était rejetée contre le mur méridional. Les blocs étant alors toujours apparents, ils ont pu servir de base à une crémaillère. Le sol et sa recharge sont datés du début du XIV ${ }^{\mathrm{e}} \mathrm{s}$.

Cet îlot est l'illustration parfaite d'un agencement successif de constructions mitoyennes. On en veut pour exemple l'annexion de la zone laissée libre entre les ensembles $2 \mathrm{~F}$ et $2 \mathrm{G}$, peut-être une traverse à l'origine, par le bâtiment $2 \mathrm{H}$ dont le plan traduit cette nécessité d'adaptation aux contraintes spatiales. La rationalité dans l'agencement du bâti est lisible au travers d'une répartition spatiale cohérente des maisons et des espaces ouverts. En effet, les unités d'habitations semblent être plus particulièrement disposées le long de la rue de Morier. Les espaces situés à l'ouest (à l'exception de l'ensemble 2C) constituent, semble-t-il, des secteurs ouverts, des cours ou des jardins. 


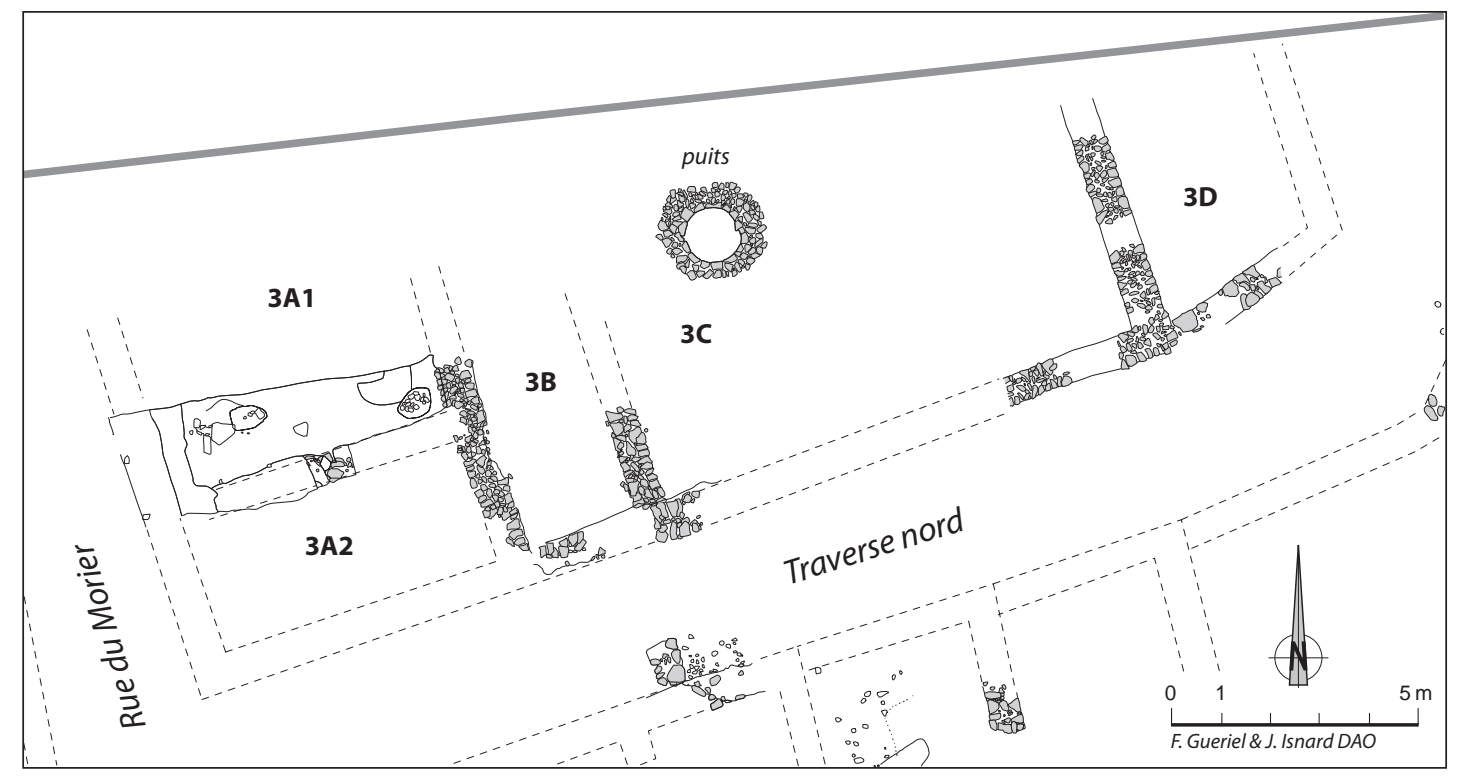

Fig. 248. Plan de I'îlot III (DAO F. Gueriel, J. Isnard/Inrap).

\section{L'îlot III ${ }^{861}$}

L'îlot III est situé à l'est de la rue de Morier et est bordé au sud par la traverse nord. Il réutilise un ensemble plus ancien, le bâtiment 2 de la tannerie, auquel s'ajoute un agrandissement vers l'est. Si les pièces $2 \mathrm{~A}$ et $2 \mathrm{~B}$ du bâtiment initial sont abandonnées pour le percement de la voie, l'emplacement et la superficie du corps principal sont conservés et intégrés dans le nouveau découpage parcellaire par un réalignement du mur de façade sur rue (fig. 248). À l'intérieur, les modifications interviennent sur le découpage interne et sur les niveaux de sols qui sont exhaussés.

Le mur ouest a été entièrement épierré et ne subsiste plus que par sa tranchée de récupération, large de $72 \mathrm{~cm}$ et profonde de $25 \mathrm{~cm}$. Le comblement contient du mobilier céramique daté de la première moitié du $\mathrm{XIV}^{\mathrm{e}} \mathrm{s}$. L'espace disposé le long de la rue de Morier est cloisonné en deux pièces, $3 \mathrm{~A} 1$ et $3 \mathrm{~A} 2$, par un mur transversal, appuyé contre les murs est et ouest. Il s'agit d'un mur à double parement de moellons de calcaire équarris et blocage interne hétérogène de galets et cailloux, liés par un mortier gris fin très compact. Il mesure $65 \mathrm{~cm}$ de large pour une longueur totale de $5,80 \mathrm{~m}$. Outre sa liaison au mortier, il se caractérise par une faible profondeur de fondation (une seule assise de fondation de $15 \mathrm{~cm}$ de profondeur). Le parement nord du mur est revêtu d'un enduit de chaux. Au nord, la pièce 3A1, largement tronquée par la mise en place d'une cave moderne, ne subsiste que sur une longueur de 1,70 m

861 D'après É. Leal in Bouiron 2001b, p. 360-363. pour une largeur totale de 5,80 m. Le sol de terre battue est installé sur une charge de limons sableux de $5 \mathrm{~cm}$ d'épaisseur. Il remonte légèrement contre les parements internes des murs qui le bordent à l'est et au sud. Deux foyers en fosses sont aménagés dans le sol. Le premier est situé dans l'angle sud-est de la pièce. Sa fosse, peu profonde, possède un profil en cuvette assez irrégulier, dont le fond est tapissé de blocs et de cailloux ; les parois sont fortement rubéfiées. Le second est aménagé le long du mur ouest. Sa fosse, au profil en cuvette, ne possède aucun aménagement intérieur. Le fond et les parois sont aussi fortement rubéfiés. Son comblement a livré du mobilier céramique du XIII ${ }^{e} \mathrm{~s}$. Au sud, la pièce $3 \mathrm{~A} 2$ a une surface de $14,50 \mathrm{~m}^{2}$. Son sol de terre battue est mis en place sur une charge de limons datée de la première moitié du XIVe s. À ceci s'ajoutent des galets qui comblent les irrégularités du sol sous-jacent et scellent les installations antérieures.

À l'est, l'organisation spatiale est inchangée par rapport à l'état précédent. La pièce $3 \mathbf{B}$ demeure un espace étroit de 2,50 $\mathrm{m}$ de large orienté nord-sud. Le mur occidental de la pièce est revêtu d'un enduit de chaux, conservé jusqu'à l'arase du mur. Le niveau d'occupation de cette pièce est un sol de terre battue qui scelle le précédent sol par une mince charge limoneuse de $4 \mathrm{~cm}$ d'épaisseur, datée de la première moitié du XIVe $\mathrm{s}$. Sur le sol, à l'angle nord-ouest de la pièce, ont été mis au jour les restes carbonisés d'un objet en fibres végétales tressées. Conservé sur un carré d'environ $50 \mathrm{~cm}$ de côté, il n'a pas été possible d'identifier cet objet, peut-être une natte de sol ou un sac?

Enfin, dans le vaste espace $\mathbf{3 C}$, on procède à une restauration du sol d'origine au moyen d'une mince 
recharge de limons homogènes et très compacts, sur laquelle s'installe le nouveau sol de terre battue. L'espace est en outre doté d'un puits. Il n'est pas possible de localiser avec précision la situation du puits au sein de l'espace, car on ne connaît que partiellement l'extension de ce dernier. Compte tenu de la superficie conservée, il n'apparaît pas installé dans un angle mais en un point plutôt central. Son diamètre interne est de $1,05 \mathrm{~m}$ et il a été observé sur neuf assises pour une profondeur de $1,30 \mathrm{~m}$. Son cuvelage présente une maçonnerie très soignée de moellons taillés dans le même calcaire tendre que les autres ouvrages hydrauliques observés sur le site. Le blocage se compose de blocs et de cailloux bruts. L'appareil régulier possède des trous de boulin de sections identiques, soit $12 \mathrm{~cm}$ de large pour $16 \mathrm{~cm}$ de haut. Leur répartition sur le cuvelage, partiellement conservé, présente au moins trois trous par assises, distantes les unes des autres d'une hauteur de cinq assises. En grande partie récupéré, il n'a conservé aucun contact avec les sols environnants et sa margelle est détruite.

L'espace oriental 3D est mal documenté car seule une partie des maçonneries qui le délimitent a été observée lors de la campagne de diagnostic de 1992. Il s'agit d'un mur, qui vient s'accoler à l'angle sud-est de la cour $3 \mathrm{C}$ et fermait au sud la pièce. Conservé sur une assise, il se compose essentiellement de moellons bruts de poudingue stampien liés à la terre.

\section{L'îlot $I V^{862}$}

Bordé au nord par la traverse nord et à l'ouest par la rue de Morier, cet îlot s'étend vers l'est jusqu'à l'emprise du fossé, soit sur une largeur de $28 \mathrm{~m}$ (fig. 249). Le cœur d'îlot est accessible par une impasse. Il se compose au nord de deux ensembles distincts $4 \mathrm{~A}$ et $4 \mathrm{~B}$, dont il est difficile d'établir la chronologie de construction. La partie méridionale est composée d'un bâtiment, $4 \mathrm{C}$, qui donne à l'est d'une zone ouverte dotée de quelques éléments construits (4D). Dans un second état, le nombre de constructions augmente et l'ensemble 4E est établi.

\section{口 L'ensemble 4A}

Cet ensemble forme l'angle nord-ouest de l'îlot. Il est constitué de trois espaces sur plan en lanières, orientés est-ouest et accolés les uns aux autres perpendiculairement à la rue de Morier. Le mur septentrional est partiellement conservé à l'est, sur deux assises de fondation, des blocs pour la première et une rangée de moellons au-dessus. L'ensemble est lié au mortier gris

862 D'après Duval et al. in Bouiron 2001b, p. 363-375. fin et mesure jusqu'à $75 \mathrm{~cm}$ de large. Contrairement aux autres murs est-ouest qui sont perpendiculaires à la rue de Morier, son axe biais est induit par la présence de la traverse nord. Le mur de façade sur la rue de Morier est entièrement épierré et il est difficile d'imaginer sa largeur car l'axe a été repris par une canalisation postérieure. Le mur oriental a été partiellement retrouvé sur trois assises de fondation qui forment un ressaut sous la seule assise d'élévation conservée. Il est constitué de blocs, moellons et cailloux de calcaire liés à la terre et mesure $50 \mathrm{~cm}$ de large. Le mur de limite sud est mal renseigné. L'ensemble est divisé par deux refends. Le premier, au nord, conservé sur trois assises d'élévation d'une largeur de $55 \mathrm{~cm}$ qui reposent sur une assise de fondation débordante de $68 \mathrm{~cm}$ de large. Ce mur est lié à la terre et il est enduit sur le parement nord. Son extrémité ouest traverse, au moins partiellement, le mur de façade oriental, mais ne se poursuit pas au-delà. Il semble bien, en fait, que lors de la construction, ils aient été chaînés. Le second mur de refend est constitué d'une fondation de $70 \mathrm{~cm}$ de large, composée de deux assises de moellons de calcaire et de travertin liés à la terre. L'élévation, conservée sur une assise de $53 \mathrm{~cm}$ de large, est également liée à la terre et très semblable à celle du mur nord.

L'espace 4A1, d'une superficie de $61,5 \mathrm{~m}^{2}$, est de forme trapézoïdale et sa largeur varie de 5 à $6,50 \mathrm{~m}$ d'ouest en est. Contre le mur méridional, la base d'un pilier de $57 \mathrm{~cm}$ de long sur $50 \mathrm{~cm}$ de large est conservée. Elle est constituée de blocs de calcaire taillés liés au mortier, contrairement au mur adjacent, qui est lié à la terre, mais comme le mur de limite nord, contre lequel devait également s'accoler un second pilier. En effet, la tranchée de récupération du mur s'élargit nettement en face du pilier méridional, ce qui permet de restituer un pilier contre son parement sud. Ces deux piliers en vis-à-vis se situent aux deux-tiers de la longueur de la façade sur rue, ménageant ainsi au fond de la pièce un petit espace. Le niveau d'occupation de celui-ci est installé sur une couche préparatoire de $10 \mathrm{~cm}$ d'épaisseur, constituée d'un sédiment limoneux contenant des nodules d'argiles jaune-orange et des nodules de mortier. Le sol est composé d'un sédiment limoneux à la surface irrégulière; il contient plusieurs objets métalliques qui sont peut-être issus de serrures ou huisseries. Une petite fosse ou dépression circulaire, d'un diamètre de $50 \mathrm{~cm}$ et creusée dans le sol, contient un bloc de calcaire retouché, des tuiles et des charbons de bois. Il s'agit peut-être d'une base de poteau comblée par la suite. Celui-ci est presque dans l'axe d'alignement des piliers. Ces piliers coïncident avec l'endroit où la largeur de l'espace est supérieur à $6 \mathrm{~m}$, c'est à dire difficilement couvrable par des poutres transverses. Ils portaient peut-être une poutre sur laquelle venaient ensuite reposer des traverses. 


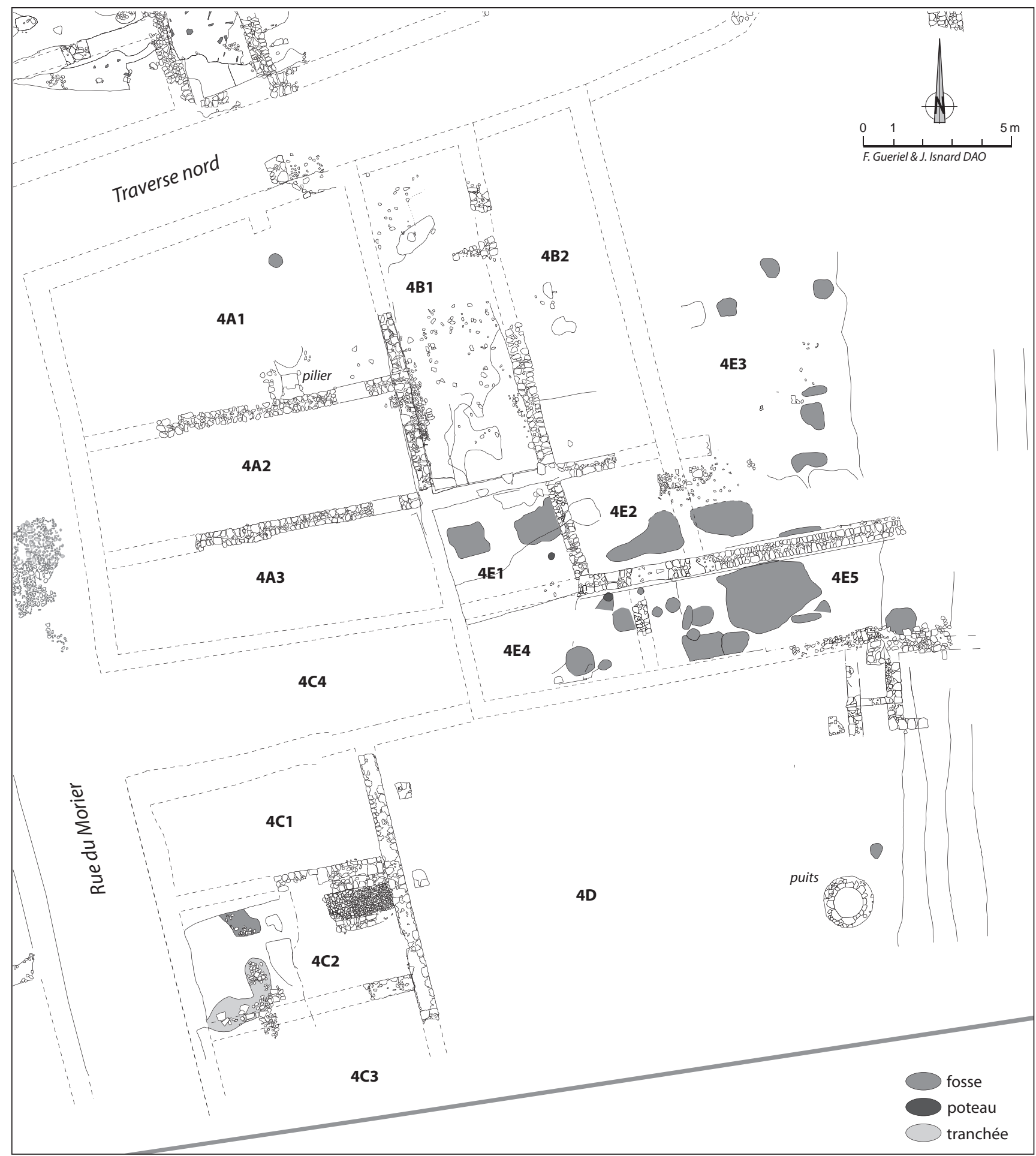

Fig. 249. Plan de l'îlot IV (DAO F. Gueriel, J. Isnard/Inrap).

Au centre, l'espace 4A2 a une superficie de $38,5 \mathrm{~m}^{2}$ et sa largeur sur rue est de 3,50 m. Contre le mur oriental, à $16 \mathrm{~cm}$ de l'angle nord-est, est installée une structure de $45 \mathrm{~cm}$ de long sur $30 \mathrm{~cm}$ de large, conservée sur une assise de moellons et cailloux de grès et calcaire, liés à la terre. Cet aménagement n'a pas pu être interprété. Une couche préparatoire de limons sableux mêlés de nodules argileux, datée du début du $\mathrm{XIV}^{\mathrm{e}}$ s., est recouverte par un sol sablo-limoneux.

$\mathrm{Au}$ sud, l'espace $\mathbf{4 A 3}$ est peu renseigné. L'espace a été couvert d'une couche préparatoire constituée de limons argileux jaunes mêlés de fragments de calcaire 
surmontée d'un sol composé d'une quinzaine de centimètres d'argiles jaunes mêlées de cailloutis. Ce niveau est structurellement proche du sol retrouvé dans l'espace mitoyen 4B1, et présente les mêmes caractéristiques que les sols observés dans les espaces extérieurs. Il s'agit donc peut-être d'une cour ou d'un appentis.

L'acquisition de l'ancien bâtiment du XII ${ }^{e}$ s. a été nécessaire à l'élaboration du bâtiment 4A à l'angle de la rue de Morier et de la traverse nord. Le soin apporté à sa réalisation (façade maçonnée, piliers et support intermédiaires) ainsi que l'étendue de son plan (deux grandes pièces plus une voire deux cours) en font l'une des constructions majeures du quartier et amènent à s'interroger sur l'identité du propriétaire qui n'appartient probablement pas à une population très modeste mais correspond plutôt à un notable.

\section{$\square$ L'ensemble 4B}

L'ensemble 4B se trouve à l'est de l'ensemble 4A et est desservi par la traverse nord ( $c f$. fig. 249). Il se compose de deux longs espaces orientés nord-sud, 4B1 et 4B2. À l'est, des terres ouvertes, friches ou jardins, sont simplement délimités par des murs.

L'espace 4B1, orienté du nord au sud, est mitoyen des pièces 4A1 et 4A2. Il est fermé à l'est par un mur dont il subsiste deux assises de fondation, avec un léger ressaut de moellons en travertin retouchés liés à la terre et une seule assise d'élévation enduite de mortier blanc sur sa face externe. Au sud, la limite a disparu : il n'en reste que la tranchée d'épierrement du mur, comblée de sédiment hétérogène contenant beaucoup de mortier. Au nord, la présence d'un petit fragment de mur permet d'envisager une fermeture de l'espace quelques mètres avant l'angle nord-est de la pièce 4A1, mais cet éventuel contact reste très hypothétique car le tracé du mur est interrompu par le creusement d'un sondage ancien. La seconde hypothèse est celle d'un espace ouvrant sur la traverse nord et qui se fermerait au même niveau que le mur nord de la pièce 4A1. Cette hypothèse semble validée par le fait que le mur oriental se prolonge vers le nord, au-delà du muret perpendiculaire, même si ce tronçon est d'orientation légèrement divergente vers l'est. Compte tenu de l'état de conservation de ces maçonneries, aucune ouverture n'a pu être décelée. Selon l'hypothèse retenue, la surface de cet espace va de 26,5 à $39,6 \mathrm{~m}^{2}$, sa longueur étant comprise entre 7,30 et $11 \mathrm{~m}$ pour une largeur de $3,50 \mathrm{~m}$.

Contre le mur ouest, un aménagement de 2,20 m de long pour une largeur maximale de $60 \mathrm{~cm}$ et une épaisseur de $15 \mathrm{~cm}$ forme peut-être une banquette ou une base d'escalier ; cet empierrement est bordé par un alignement de quatre cailloux plus gros. Le premier niveau d'occupation de cet espace est directement installé sur des sédiments d'origine alluviale. Le sol de terre battue est assez lacunaire mais relativement bien conservé dans la moitié nord de la pièce. La surface est compacte et lisse, de texture légèrement sableuse mêlée de nombreux nodules de chaux, et présente des traces brunes. Au nord, il reçoit un épandage de cendres mêlé de passées sableuses et il est marqué de deux traces rubéfiées circulaires de $25 \mathrm{~cm}$ de diamètre. Au sud-ouest de la pièce, le sol est ensuite recouvert par un niveau argileux jaune, parsemé de nodules de chaux et de charbons de bois. Un niveau assez comparable a été vu dans la partie nord. De même texture, il inclut de nombreux matériaux de construction (fragments de tuiles, de carreaux avec mortier d'accrochage, clous et mortier). Sa faible et constante épaisseur (5 à $10 \mathrm{~cm}$ ), son aspect damé et horizontal l'identifie à une recharge de sol, dont les matériaux de construction recyclés sont une matière de choix (drainage et isolation, qualités mécaniques de compactage).

Accolé à l'est de l'espace 4B1 et de même module, l'espace 4B2, est limité à l'est par un simple muret de $20 \mathrm{~cm}$ de large reconnu sur moins d'un mètre de longueur. Il est composé d'un alignement de cailloux liés par un mortier blanc solide. Le mur qui ferme l'espace 4B2 au sud, est conservé sur une seule assise de blocs de moellons calcaire relativement bien équarris. Dans cette pièce, le sol est formé de petits nodules de mortier et de débris de travertin.

\section{口 L'ensemble 4C}

À $3,50 \mathrm{~m}$ au sud de l'ensemble 4A, se trouve le bâtiment 4C ( $c f$. fig. 249). Il s'agit d'une construction établie au cours du XIII' s. (cf. supra § 2.2.4.). À la fin de ce siècle, elle subit des modifications, mais la continuité de l'occupation est attestée; en effet, aucune phase d'abandon ou de remblaiement ne s'intercale stratigraphiquement entre ces remodelages. Les murs nord et ouest sont maintenus, la limite orientale est légèrement décalée vers l'est par la construction d'un nouveau mur et le mur nord est alors prolongé jusqu'à cette nouvelle façade. La partie méridionale de l'îlot, proche de l'actuelle rue du Petit-Saint-Jean, a subi d'importantes destructions, par conséquent aucun vestige ne nous renseigne sur sa disposition. La construction de murs de refend divise le bâtiment en trois pièces rectangulaires $(4 \mathrm{C} 1,4 \mathrm{C} 2$ et $4 \mathrm{C} 3$ ) d'orientation est-ouest, perpendiculaires à la rue de Morier. Enfin un passage (4C4) entre l'ensemble 4A et le bâtiment donne accès aux jardins localisés à l'est. La façade orientale est conservée sur deux assises de fondation composée d'un double parement avec blocage interne. Sa longueur est d'environ $10 \mathrm{~m}$ et sa largeur de $60 \mathrm{~cm}$. Sa maçonnerie met en œuvre des cailloux et des 
moellons, le plus souvent équarris mais parfois bruts, majoritairement en grès, liés par un épais mortier de chaux. On remarque que le mur oriental antérieur était également constitué essentiellement de grès ; il est possible que les éléments de ce dernier aient été récupérés et retouchés pour la construction du mur de réalignement.

Le mur qui sépare les pièces $4 \mathrm{C} 1$ et $4 \mathrm{C} 2$, dont la construction est contemporaine de celle de l'autre mur de refend et du mur oriental, est conservé sur $2 \mathrm{~m}$ de long et sa largeur est à peine inférieure à $60 \mathrm{~cm}$. Il conserve deux assises en fondation et une assise d'élévation de facture similaire à celle du mur est. Le double parement de moellons de travertin et de calcaire brut ou équarri est lié au mortier. La présence d'un bloc de calcaire rectangulaire en position verticale posé sur un bloc quadrangulaire témoigne de l'existence d'une porte. Suite à la récupération de la majorité des éléments de la porte, l'ouverture est obturée par un tronçon de maçonnerie d'environ 1,50 m de long. La mise en œuvre diffère car les moellons sont liés à l'argile. Sa hauteur conservée n'excède pas $21 \mathrm{~cm}$. Un deuxième mur orienté est-ouest est construit au sud. Il est appuyé contre le mur de limite oriental; sa longueur conservée n'excède pas 1,5 m. Au-delà, la tranchée de récupération n'a pas été observée. Ce mur sépare les pièces $4 \mathrm{C} 2$ et $4 \mathrm{C} 3$.

La pièce 4C1, au nord, couvre une superficie de $3,80 \times 7 \mathrm{~m}$ soit d'environ $20 \mathrm{~m}^{2}$. Les niveaux d'occupation à l'intérieur de l'espace sont très mal conservés, particulièrement dans la partie orientale. Le sol et ses recharges sont ainsi localisés sur trois mètres à partir de la façade sur la rue de Morier; les trois mètres suivants, jusqu'au mur oriental, sont vierges de sol et d'aménagement. La limite entre les deux zones est perceptible à l'extrémité occidentale de la porte qui ouvre sur l'espace 4C2. Cette délimitation, qui scinde l'espace en deux, est peut-être le résultat de destructions ultérieures, ou plus vraisemblablement le témoin d'une cloison disparue. Un sol de terre battue est composé d'un sédiment limoneux jaunâtre mêlé à de nombreuses poches de sables, d'argiles, de chaux et de terre rubéfiée. Ce sol vient buter contre le mur méridional; il se perd vers l'est, où nous n'avons pas son contact avec le mur et où l'on constate une dépression importante. Le sol contient de la faune en grande quantité, dont des restes d'animaux de petite taille, de poissons et de coquillages. Divers autres éléments y ont été retrouvés, dont du corail et un fragment de fer d'équidé. Aucun foyer n'a été retrouvé. Un certain nombre de recharges ont été observées ; l'une d'elles est constituée d'une fine épaisseur de mortier de sables gris, de chaux et de petits cailloux, de 2 à 4 cm d'épaisseur. Des sables gris très meubles couvrent cette recharge et contiennent des objets en fer et en alliage cuivreux. Il sont surmontés d'une nouvelle recharge, à base de limons beiges plus ou moins épais qui contient beaucoup de charbons et de cendres et qui est rubéfiée par endroits. Elle contient notamment des clous, une lame avec soie, un élément en alliage cuivreux et des rebuts de fabrication de fer. Une poche de mortier gris clair épaisse de $10 \mathrm{~cm}$ vient combler une légère dépression dans cette recharge. On note aussi la présence d'un trou de poteau qui se situe précisément au centre de la moitié ouest de l'espace, ce qui tend à confirmer que cette division n'est pas fortuite. Il se matérialise par un creusement circulaire de $20 \mathrm{~cm}$ de diamètre et $18 \mathrm{~cm}$ de profondeur. Un calage constitué de trois pierres réduit le diamètre à $10 \mathrm{~cm}$. Le comblement contient de nombreux charbons de bois, qui proviennent sans doute de la combustion du poteau sur place. Ces niveaux qui révèlent peut-être une activité artisanale sont datés de la fin du XIII" ${ }^{\mathrm{e}} \mathrm{s}$. ou du début du XIV ${ }^{\mathrm{e}} \mathrm{s}$.

La pièce $4 \mathrm{C} 2$ est très mal conservée, mais sa surface peut être restituée à environ $25 \mathrm{~m}^{2}$. Une fosse est creusée dans le niveau de sol. De forme allongée, elle se situe contre le mur nord et est comblée de limons sableux contenant quelques pierres. Un grand creusement irrégulier forme sans doute la récupération d'une structure de type support, peut-être un piédroit en relation avec le mur sud. Une base de pilier est accolée à l'est de ce négatif. Constituée de moellons de calcaire lié à la terre, elle mesure $42 \mathrm{~cm}$ de long sur $39 \mathrm{~cm}$ de large. Cet ensemble de vestiges est certainement lié à des supports. Le matériel qui en est issu est daté de la fin du XIII ${ }^{\mathrm{e}} \mathrm{s}$. Dans l'angle nord-est de la pièce, un ensemble de maçonneries forme un aménagement particulier ( $c f$. fig. 91). Il comprend d'abord un mur à parement unique accolé au parement méridional du mur nord et constitué d'une rangée de blocs équarris et d'un blocage composé de cailloux liés à la terre. Il est conservé sur environ $2 \mathrm{~m}$ de longueur ; sa largeur maximale est de $40 \mathrm{~cm}$ et sa hauteur conservée de $20 \mathrm{~cm}$. Il s'arrête nettement à l'ouest, sans retour, ni tranchée de récupération. À $1 \mathrm{~m}$ de distance est établi un autre mur, parallèle au précédent, de $40 \mathrm{~cm}$ de large également. Il n'est que partiellement conservé, le contact avec le mur oriental, étant épierré. À l'ouest, il s'interrompt comme son pendant. L'observation de sa maçonnerie ne permet pas d'affirmer catégoriquement qu'il s'agisse de l'extrémité de la construction, mais tout porte à le croire dans la mesure où aucune tranchée de récupération n'a été observée dans son prolongement. Ce mur a été construit sur le principe du double parement de moellons bruts ou équarris avec un blocage interne ; l'ensemble est lié par un mortier de chaux. Un empierrement formé de cailloux et de galets liés par de l'argile se développe entre ces deux murs et couvre une surface légèrement supérieure à $2 \mathrm{~m}^{2}$. La fonction de cet ensemble est difficile à déterminer. Sa situation dans l'angle nord-est de la pièce et le fait qu'il ne se 
développe pas au-delà de la porte ménagée dans le mur nord sont des indices pour l'interpréter comme un soubassement d'un escalier.

La pièce $4 \mathrm{C3}$ a subi d'importantes destructions. Elle est conservée sur moins de $10 \mathrm{~m}^{2}$; aucun niveau d'occupation n'a résisté au dérasement général.

L'espace 4C4, au nord du bâtiment 4C, correspond à une zone ouverte qui établit une communication entre la rue de Morier et les jardins (4D) à l'est. Cet espace n'est pas simplement une desserte, mais correspond surtout à une zone fonctionnelle étroitement liée à une activité de petit artisanat déjà perceptible dans la pièce 4C1. Large de 3,50 m à l'ouest, il s'étend à l'est jusqu'au sud de l'ensemble 4B.

À l'ouest, un sol de terre battue très grossier a pu être partiellement observé aux abords de l'angle de la pièce 4C1. Il se compose d'un sédiment limoneux sur lequel on circulait. Un foyer a été installé sur ce niveau. Il est formé par un creusement en demi-cercle situé contre le parement nord du mur de la pièce $4 \mathrm{C} 1$; de contour régulier et de fond concave, il mesure 100 x 86 x $10 \mathrm{~cm}$. Un certain soin semble avoir été apporté à son élaboration. Une fine couche de charbons de bois, liée à l'utilisation de la structure, tapisse la cuvette du foyer. Un objet en métal qui a fortement subi l'action du feu a été dégagé dans les charbons ; il n'a pu être identifié. Au-dessus, une couche constituée exclusivement de mottes d'argiles pures jaunes, qui ne présente aucune trace de rubéfaction, comble partiellement le fond du foyer. Il est vraisemblable que nous sommes en présence d'une réparation du foyer, qui n'a finalement pas été utilisée. Au-dessus de ces argiles, une couche de sédiment limoneux beige comble définitivement le foyer. Un épandage de charbons de bois à l'ouest du foyer provient sans doute de vidanges de celui-ci. Dans cette lentille ont été retrouvés de nombreux éléments en métal : des clous, des fragments en alliage cuivreux et des rebuts de fabrication. Deux fosses ont été creusées dans la même couche. Une, de forme ovoïde $(90$ x $60 \mathrm{~cm})$, a un creusement irrégulier. Le comblement en est constitué essentiellement de gros cailloux de nature diverse et de galets d'environ dix centimètres de long pris dans un sédiment limoneux brun proche de celui du sol. Elle contient, en outre, un rebut de fabrication de fer et un objet, en fer également, non identifié. La deuxième fosse de forme oblongue $(110 \times 50 \times 30 \mathrm{~cm})$, est située à l'est du foyer. Les parois et le fond sont irréguliers, les bords sont droits. Le comblement a révélé un certain nombre de blocs plaqués contre les parois ; il n'est pas certain toutefois que nous soyons en présence d'un aménagement volontaire. La plupart des blocs portaient des traces de brûlé. L'utilisation de cette fosse est certainement à mettre en relation avec le fonctionnement du foyer sans que l'on comprenne exactement de quelle manière. Peut-être a-telle servi de feu secondaire avec dépôt de braises sur les pierres, ce qui pourrait expliquer qu'elles soient brûlées. Plus à l'est, de nombreuses fosses ont été retrouvées, parfois très grandes $(3,20 \times 2,40 \times 0,30 \mathrm{~m}$ pour l'une d'elles). Les comblements sont assez variés, mais la plupart contiennent des pierres, des fragments de tuiles, des charbons, des fragments métalliques. Certaines portent des traces de chauffe sur les parois. L'une d'elles contient des éléments et scories métalliques en grand nombre (clous, anneaux, plaques, petits morceaux de cuivre et de bronze, clous de sellerie, lamelles, anneaux), ainsi que de très nombreuses scories de verre et fragments de récipients en verre. À toutes ces fosses il faut ajouter la présence de quatre trous de poteaux dont trois sont sur le même axe et qui pouvaient former un petit appentis. Cet espace ouvert a certainement servi de zone de travail.

L'ensemble de ces observations démontrent l'existence dans ce secteur d'un petit artisanat du métal, peut être à usage quasi domestique.

\section{L'ensemble 4D}

Localisé au sud de l'espace 4C4 (cf. fig. 249), cet ensemble occupe une superficie minimale de $180 \mathrm{~m}^{2}$. Il est délimité à l'ouest par le mur oriental du bâtiment 4C, au nord par un cloisonnement dont la nature reste inconnue et au sud par la paroi moulée qui le recoupe. La limite orientale de cet ensemble est matérialisée par deux tranchées nord-sud parallèles, implantées sur le comblement du fossé dont elles reprennent la limite d'emprise au sol. La tranchée occidentale correspond vraisemblablement à un mur implanté dans les comblements d'abandon du fossé, le long de sa rive occidentale. Le comblement de la tranchée d'installation du mur disparu subsiste par endroits. La tranchée d'épierrement est comblée d'un sédiment jaunâtre mêlé à de gros fragments de mortier issus du démontage du mur. Vers le nord, son tracé disparaît et ne semble pas se poursuivre au-delà des limites repérées lors de la fouille. À l'est, distante de $90 \mathrm{~cm}$, la seconde tranchée est visible sur au moins $8,50 \mathrm{~m}$ de long. Sa largeur à la base du creusement est de $56 \mathrm{~cm}$ et sa partie supérieure, plus large, atteint 1,10 m. Le long de la paroi occidentale du creusement subsistent par endroits des lambeaux de mortier blanchâtre, témoins de la maçonnerie récupérée. La présence de ces plaques de mortier pourrait aller dans le sens de la récupération d'un mur ou d'une autre structure maçonnée telle qu'un caniveau. Il est possible de déterminer une chronologie entre les récupérations de ces deux structures : la tranchée ouest est scellée par une couche de remblai, elle-même recoupée par le creusement de la tranchée de récupération orientale. 


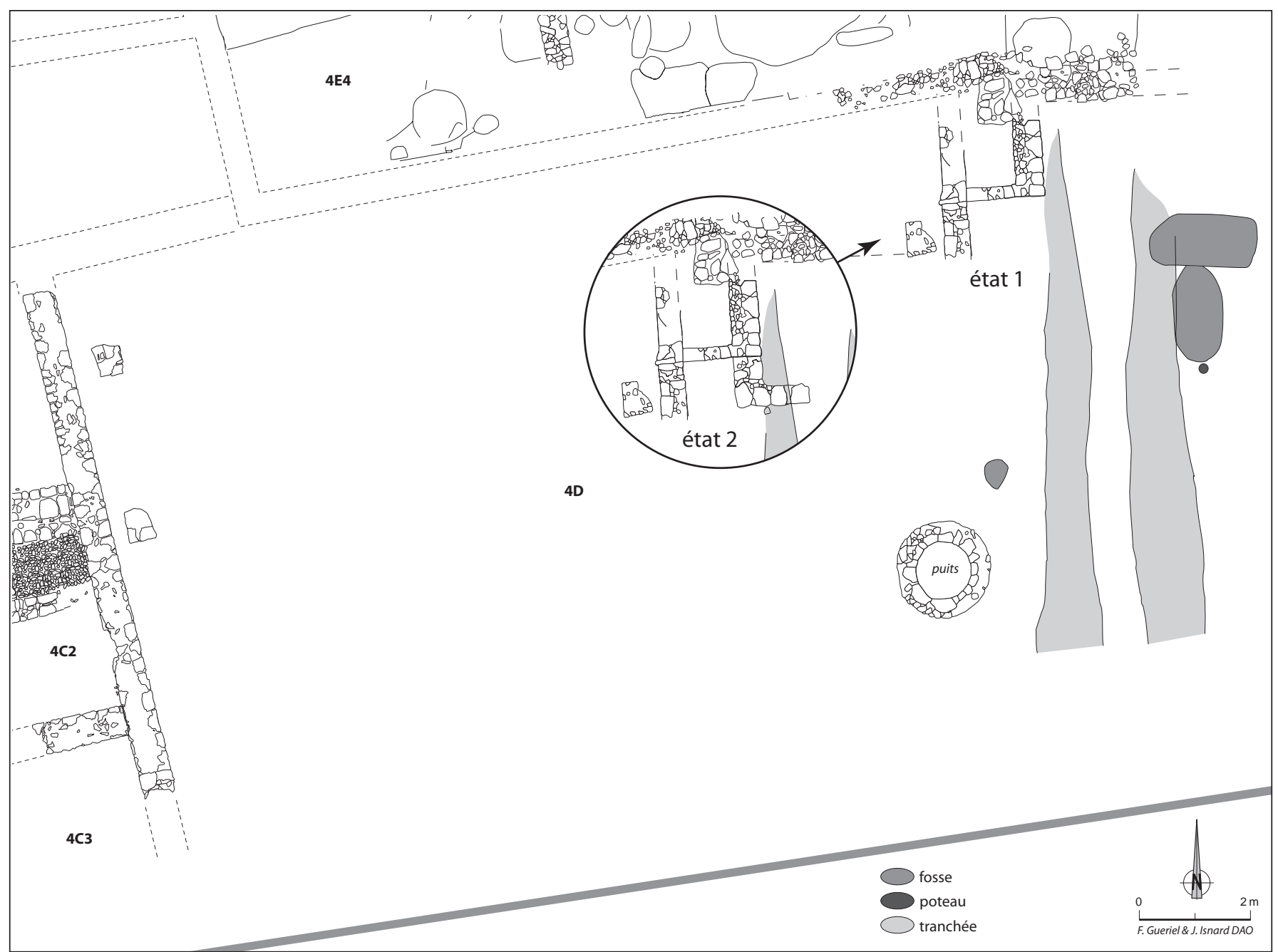

Fig. 250. Le petit édifice dans l'espace 4D (DAO F. Gueriel, J. Isnard).

Entre les tranchées et le bâtiment 4C, l'espace est recouvert par un remblai limono-sableux de couleur claire et chargé en charbons de bois, assimilable à des terres de jardins. Trois constructions s'apparentant à des bases de piliers ont été dégagées. Deux d'entre elles se situent le long du bâtiment $4 \mathrm{C}$ à $30 \mathrm{~cm}$ et $40 \mathrm{~cm}$ du mur ; la distance qui sépare ces deux maçonneries est d'environ $2,50 \mathrm{~m}$. Un troisième pilier se situe à un peu plus de 14 m à l'est des piliers occidentaux, près d'un petit édifice. Ces structures sont de forme quadrangulaire et de facture identique. Elles sont construites avec des cailloux et des moellons bruts et équarris de calcaire blanc et de calcaires rose, liés par un mortier blanc. Il s'agit d'un ensemble dont la structure même nous échappe, composant deux ensembles distincts aux extrémités du jardin.

$\mathrm{Au}$ sud-ouest, un puits est construit. D'un diamètre interne de $1,05 \mathrm{~m}$, il se compose d'un petit appareil régulier de moellons soigneusement taillés et posés à sec. Les assises supérieures sont composées de moellons plus grands. Aux quatre points cardinaux, on observe la présence de trous de boulins, ménagés pour construire le puits. Le blocage est constitué d'un mélange de cailloux calcaire et de mortier. Il n'a pas pu être fouillé jusqu'au fond. Deux petites fosses isolées ont été mises au jour et ont livré du mobilier du XIV es.

Un petit édifice a été observé dans l'angle nord-est de cette parcelle (fig. 250). Deux murs sont installés sur le comblement de la tranchée d'épierrement occidentale. La fondation du mur orientée nord-sud a été observée sur $1,75 \mathrm{~m}$ de long pour $48 \mathrm{~cm}$ de large. Elle n'est conservée que sur une seule assise. Son parement oriental est aménagé avec de gros moellons de poudingues posés à plat, et son parement ouest est constitué d'un blocage de cailloux de calcaire blanc liés à la terre. Complètement épierré à son extrémité septentrionale, il vient s'installer contre la partie occidentale de la fondation du mur de direction est-ouest. Ce dernier a été observé sur $1,20 \mathrm{~m}$ de long, pour une largeur moyenne de $45 \mathrm{~cm}$. Il ne conserve lui aussi, qu'une seule assise de fondation. 
Sa technique et ses matériaux de construction sont similaires à ceux du mur nord-sud. Bien qu'aucun chaînage d'angle n'ait été observé entre ces deux constructions, il semble bien que ces murs forment l'angle sud-ouest d'un petit bâtiment.

Au nord de ces deux fondations, on observe la présence d'un troisième mur, orienté est-ouest. Conservé sur deux assises, il a été observé sur 1,50 m de long, pour $60 \mathrm{~cm}$ de large. Il est lui aussi partiellement épierré. Cependant, même si la technique de construction de cette fondation est similaire à celles des deux précédentes, les matériaux employés sont quelque peu différents. En effet, ce mur est aménagé avec des moellons et des cailloux de travertin, de grès et de calcaire, liés à la terre. L'association de ces trois murs forme un petit espace d'environ $2 \mathrm{~m}$ de largeur. Aucun niveau de sol n'a été repéré.

Dans un second temps, le petit édifice est en partie épierré, et une nouvelle limite occidentale, ainsi qu'un retour vers l'est, sont bâtis ( $c f$. fig. 250). Le mur nord-sud est conservé sur 2,30 m de long, pour $50 \mathrm{~cm}$ de large ; il présente un double appareil de moellons et de cailloux posés à plat. Ces éléments, associant du grès, du calcaire et du travertin sont maçonnés à l'aide d'un mortier blanc gris relativement friable. Les deux extrémités de cette structure ont été récupérées. Le mur d'axe est-ouest mesure 1,40 m de long pour une largeur de $45 \mathrm{~cm}$. Il se compose d'une fondation maçonnée conservée sur une seule assise, construite avec des moellons et des cailloux de calcaire posés à plat. Son extrémité orientale est installée sur l'arase de la façade occidentale du petit édifice antérieur et est lié avec ce dernier en retour vers le nord tandis que la partie sud de cet ancien mur est rasée. Au nord, un massif de forme quadrangulaire $(80 \times 70 \mathrm{~cm})$, est construit avec des moellons et des cailloux de calcaire durs posés à plat et liés à la terre. Cet édifice, dont l'étroitesse de la pièce nord $(90 \mathrm{~cm})$ est remarquable, résiste à l'interprétation. A-t-on les vestiges de constructions agricoles, artisanales ? La conservation médiocre des structures rend difficile une interprétation de la fonction du secteur. Cet espace ouvert est peut-être un jardin avec un cabanon et un puits à rattacher au bâtiment 4C.

\section{口 L'ensemble $4 E$}

Suite à l'apport d'un remblai masquant certaines fosses dans la ruelle 4C4, de nouvelles constructions sont implantées ( $c f$. fig. 249). Elles se répartissent de part et d'autre d'un mur qui prolonge le mur de limite sud de l'îlot IV vers l'ouest. Cet ensemble se compose, au nord, de deux petites pièces (4E1 et 4E2) et d'un vaste jardin arboré (4E3) qui s'étend jusqu'en bordure de l'ancien fossé nord-sud. Au sud, deux autres espaces sont établis, 4E4 et 4E5.

L'espace 4E1 est situé au sud de l'espace 4B1. Il a une longueur de 3,80 m et une largeur de $3,40 \mathrm{~m}$, ce qui représente une surface de $13 \mathrm{~m}^{2}$. Des quatre murs qui l'enserrent, seul le mur oriental est conservé ; les trois autres n'existent que sous la forme de tranchée d'épierrement. Le mur est une construction hétérogène conservée sur deux assises de fondation de cailloux et moellons bruts ou retaillés, et une élévation, très lacunaire, de moellons retaillés. Il est chaîné au mur méridional de l'espace 4E2 et apparemment accolé à l'angle sud-est de la pièce. Le sol de la pièce est formé de lambeaux de couche argileuse jaune.

L'espace 4E2 est limité au nord par un mur constitué de deux parements sur une assise de moellons de calcaire et de grès. Cet espace reçoit un sol, composé d'une couche de limons sableux percée d'une fosse. Cet espace a sensiblement la même surface que l'espace 4E1; leur fonction reste énigmatique.

L'espace 4E3, d'une superficie d'un peu plus de $160 \mathrm{~m}^{2}$, est manifestement un espace ouvert. Il est vraisemblablement limité au nord par le mur qui borde la traverse et à l'est par l'ancien fossé. Une couche de limons jaunes, dont la surface semble constituer le sol, est ponctuellement affectée de poches de cailloutis et graviers manifestement issus de ruissellements. Cette surface est creusée de plusieurs fosses ovales peu profondes dont trois forment un alignement parallèle aux murs de bordure nord et sud. Ces creusements ont en commun leurs modestes dimensions et leurs comblements de terre noirâtre, tous identiques, qui évoquent de la terre amendée et lient ces fosses à une activité agricole. Le niveau encaissant montre en outre des caractéristiques de sol amendé et travaillé. En bordure du fossé à l'est de la parcelle, un épandage de limons sableux, très charbonneux par endroits et très compact, forme un niveau de circulation de 1,50 $\mathrm{m}$ de large. Le matériel céramique relevé dans ces couches permet de les dater du milieu du XIV e $\mathrm{s}$.

L'espace 4E4 a une superficie à peine supérieure aux deux premiers. Le mur septentrional est conservé sur $11 \mathrm{~m}$ de longueur pour une largeur moyenne de $55 \mathrm{~cm}$. Il se compose de moellons bruts (dont certains sont des réemplois) liés à la terre. Le long du parement sud, on note la présence d'un enduit de chaux et sable fin très mal conservé. Récupéré dans sa partie occidentale, il est chaîné avec le mur qui sépare les espaces 4E1 et 4E2. La jonction avec le mur qui sépare les espaces 4E4 et 4E5 a disparu, ce dernier est de mise en œuvre identique. L'espace est large de $3 \mathrm{~m}$ pour une longueur estimée à $6 \mathrm{~m}$ environ. Son occupation est matérialisée par une surface cendreuse sur laquelle on observe des tessons et 


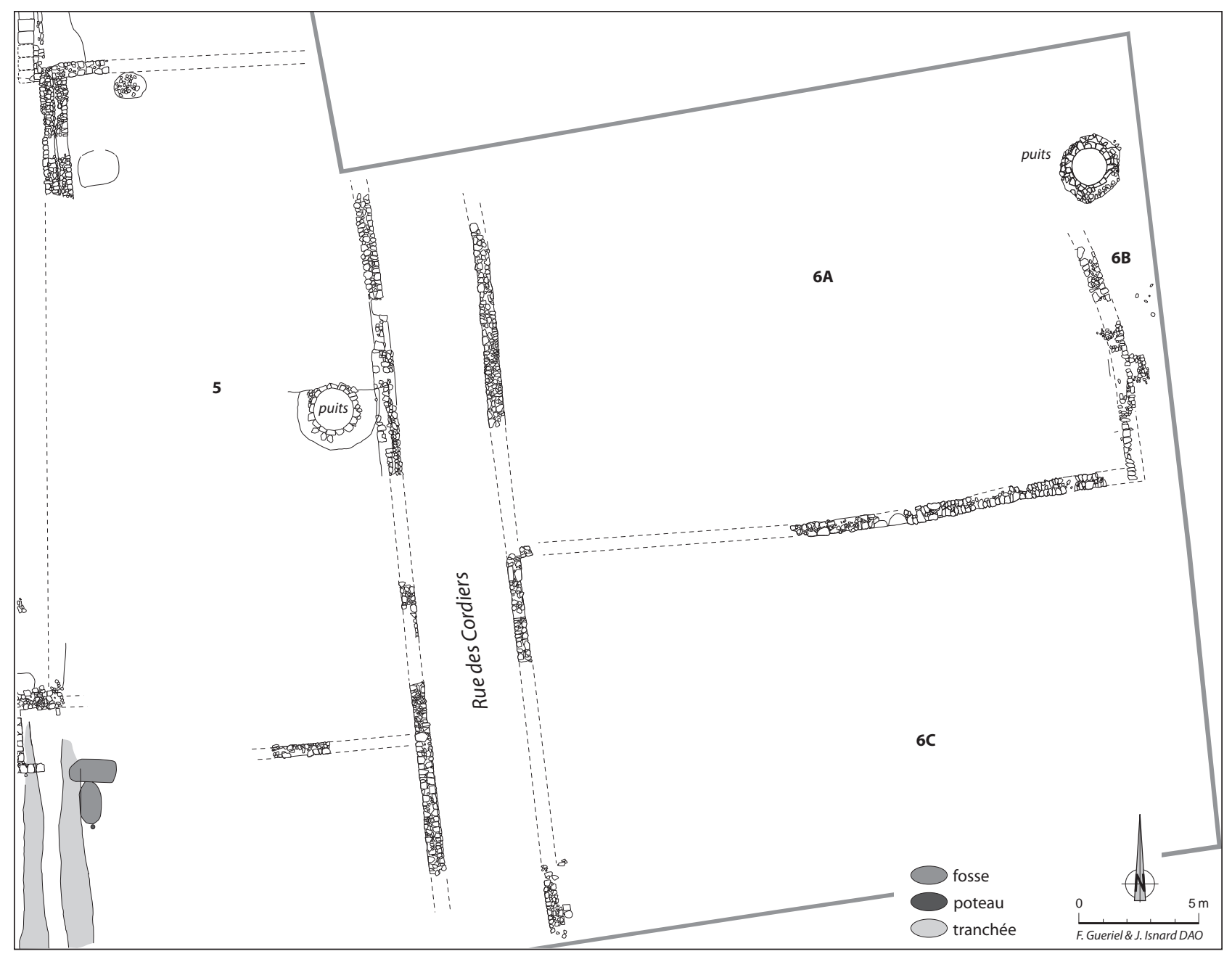

Fig. 251. Plan de la partie orientale du site (DAO F. Gueriel, J. Isnard/Inrap).

des tuiles à plat, et dans laquelle sont percés une fosse et un trou de poteau.

L'espace 4E5, de forme rectangulaire, a une longueur minimum de 9,50 m pour une largeur de $3 \mathrm{~m}$. Son sol de terre battue à la surface duquel subsistaient quelques tessons est perturbé par les creusements de plusieurs fosses et deux trous de poteaux.

L'orientation du parcellaire dans l'îlot IV s'est faite essentiellement à partir des voies nord-sud, mais quand la trame est lâche (comme c'est le cas ici), ce sont les venelles est-ouest qui conditionnent l'ordonnancement des parcelles, le petit côté s'ouvrant sur la rue. La parcelle standard mesure $4 \mathrm{~m}$ de large pour une longueur de $11,5 \mathrm{~m}^{863}$, soit une profondeur de près de trois fois la largeur. Ce gabarit concerne les espaces 4A2 et 4A3, 4B1 et 4B2, 4E5 ; l'impasse (4C4), dont la longueur n'est pas connue, respecte également la largeur de $4 \mathrm{~m}$. Au sud,

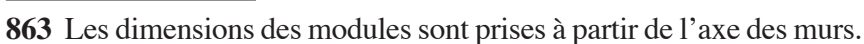

l'ensemble $4 \mathrm{C}$ correspond à une réutilisation d'un bâtiment ancien étendu à l'est pour atteindre $8 \mathrm{~m}$ soit deux largeurs standards. Un traitement particulier est apporté à la parcelle d'angle 4A1, son plan plus irrégulier résultant d'une transition entre deux rues non perpendiculaires. Dans cet îlot, une place assez importante est laissée aux espaces ouverts (cour, jardin ou verger) et clôturés (4A3, 4B1, 4D) qui sont toujours accessibles depuis une voie.

\section{L'îlot $V^{864}$}

Il s'agit, avec l'îlot VI, de l'un des secteurs les moins riches en vestiges (fig. 251). D'une largeur de $14 \mathrm{~m}$ et en grande partie détruit par le creusement de toute une série de caves à l'Époque moderne, il est limité, à l'ouest, par le fossé et, à l'est, par la rue des Cordiers. Seules sont préservées une partie des façades sur la rue et quelques 
maçonneries au nord. L'impossibilité de déterminer des espaces engendre une difficulté de désignation des diverses parties constituant cet îlot.

L'ancien fossé correspond toujours à une limite parcellaire. C'est dans son comblement que sont construits, au nord-ouest, deux murs orientés nord-sud, dont un est construit avec un retour vers l'est. Le mur intérieur, d'une largeur de $48 \mathrm{~cm}$ et conservé sur $4,90 \mathrm{~m}$ de longueur, ne comporte plus qu'une seule assise de fondation, en petit appareil de taille irrégulier. Les matériaux employés sont hétérogènes (cailloux, moellons en calcaire, travertin, poudingue ou tuf), parfois disposés en épis et liés à la terre. Le mur, disposé ultérieurement le long du parement ouest du précédent, comprend deux parements avec blocage interne, en petit appareil irrégulier, conservés sur trois assises. Il mesure de 0,45 à $0,60 \mathrm{~m}$ de large et est conservé sur $0,75 \mathrm{~m}$ de longueur. La nature des cailloux et moellons est aussi très diverse (travertin, calcaire tendre, poudingue et grès). Les pierres sont grossièrement retouchées, liées à la terre et posées à plat ou en épis; elles forment des assises en gradins du côté du parement oriental. Ces deux murs sont peutêtre destinés à renforcer, dans une ultime phase, la berge orientale du fossé. Le troisième mur, orienté est-ouest, a conservé en fondation une assise à deux parements et blocage, en petit appareil irrégulier de travertin lié à la terre. Il mesure $0,50 \mathrm{~m}$ de large et est conservé sur une longueur de 2,80 m. La présence de ce mur divise le secteur en deux espaces, dont les niveaux de sol ont disparu.

À l'est, la façade sur la rue des Cordiers présente plusieurs modifications et ajouts de maçonneries, reflets probables d'une mise en place progressive. Dans une première phase, la fondation de la partie nord du mur de façade conservée sur quatre assises, est caractérisée par l'emploi presque exclusif de poudingue. Dans un second temps, l'élévation du mur est remaniée ; elle est conservée sur deux assises composées de pierres en calcaire rose et de poudingue, liées au mortier sur une longueur de 7,80 m pour une largeur totale de $59 \mathrm{~cm}$. Vers le nord, un seuil est partiellement conservé ; il est construit au moyen de deux blocs taillés dans du calcaire rose. Dans le même temps, le mur est prolongé vers le sud : l'élévation, bâtie en petit appareil de taille de moellons irrégulièrement assisés (grès, poudingue et calcaire), repose sur une fondation ménageant un léger ressaut. Un mur de direction est-ouest forme un retour vers l'ouest, mais le lien stratigraphique avec le mur sur rue est perdu. Seule subsiste une assise de fondation observée sur une longueur de 2,30 m pour une largeur de $40 \mathrm{~cm}$. Il est essentiellement composé de galets et de cailloux de calcaire.

Un puits est situé près de la porte qui ouvre sur la rue des Cordiers. Il a fait l'objet d'une récupération partielle et la partie inférieure n'a pas été fouillée dans sa totalité. Le creusement d'installation de ce puits, d'un diamètre moyen de $3 \mathrm{~m}$, est de plan circulaire et comporte des parois verticales. Le cuvelage n'a été repéré que sur une hauteur de 1,25 m, soit douze assises. Celles-ci sont composées de petits moellons de calcaire blanc taillé présentant un léger cintre sur leur face apparente ; ils sont très régulièrement agencés et assisés. La hauteur des assises apparaît irrégulière et le profil interne de ce cuvelage est en léger tronc de cône. Les neuf assises supérieures présentent des faces internes artificiellement lissées tandis que sur les assises inférieures, des traces de layages obliques sont nettement plus marquées. L'espace interstitiel compris entre le creusement d'installation et le cuvelage est comblé au moyen d'un blocage de cailloux et moellons bruts en calcaire blanc et poudingue sans organisation perceptible. Le plus ancien niveau de remplissage qui a été fouillé peut être rattaché à son utilisation. Il s'agit d'un sédiment argileux brun foncé caractérisé par sa richesse en matériaux organiques (copeaux, sarments, paille). Le matériel contenu dans ce contexte est daté de la fin du $\mathrm{XV}^{\mathrm{e}} \mathrm{s}$. par un tesson, le reste de la céramique appartenant aux XIII ${ }^{\mathrm{e}}$ ou $\mathrm{XIV}^{\mathrm{e}} \mathrm{s}$. Il est à noter que parmi ces récipients il y a très peu de vases à liquide, ordinairement majoritaires dans les puits. Ce contexte est scellé par une couche d'abandon.

Enfin, deux fosses et un trou de poteau ont été découverts en bordure de la tranchée orientale. Les fosses ovales sont perpendiculaires l'une à l'autre. Les remplissages ne nous apportent aucune information sur leur utilisation. Au sud, a été creusé un trou de poteau d'un diamètre de $15 \mathrm{~cm}$, associé à des calages de pierres et de tessons. Ce creusement est isolé, aucune autre structure de ce type n'a été mise au jour dans ce secteur.

Dans cet îlot, la restitution d'un module de parcelle d'une largeur de $7 \mathrm{~m}$ pour $14 \mathrm{~m}$ de long, soit un rapport d'une profondeur pour deux largeurs, est envisageable. Cette hypothèse s'applique également à l'îlot VI.

\section{L'îlot VI ${ }^{865}$}

Cet îlot est situé à l'est de la rue des Cordiers, et mesure $27 \mathrm{~m}$ de large sur 32,80 $\mathrm{m}$ de long ( $c f$. fig. 251). Il est morcelé par des murs partageant l'espace en trois zones distinctes non loties.

La parcelle 6A mesure $25 \mathrm{~m}$ de longueur pour une largeur minimale de $15 \mathrm{~m}$, soit une superficie minimale de $375 \mathrm{~m}^{2}$. La limite occidentale de l'espace est matérialisée par un mur constituant la façade orientale de la rue des Cordiers. De ce mur, seule la fondation est

865 D'après Lefèvre-Gonzalès et al. in Bouiron 2001b, p. 378-380. 
conservée, sur trois assises; elle est construite en petit appareil régulier lié à la terre. Une assise médiane est formée essentiellement de plaquettes calcaires posées en épi $(15$ x 10 x $10 \mathrm{~cm})$ tandis que l'assise supérieure est faite de poudingue et de grès. Le mur méridional est conservé en deux fragments disjoints de mises en œuvre différentes. À l'ouest, un départ de maçonnerie est bâti en calcaire et poudingue formant quatre assises irrégulières liées au mortier. Il est chaîné à son extrémité occidentale au mur de façade sur rue de l'espace $6 \mathrm{C}$ au moyen d'un bloc de calcaire blanc. Vers l'est, le mur n'est conservé que sur une unique assise de fondation comportant des cailloux et moellons de calcaire, grès et travertin, disposés en épis pour une partie d'entre eux et liés à la terre. Il est sans doute contemporain du mur de direction nord-sud situé à l'est du chantier qui forme un retour vers le nord. Celui-ci, repéré sur une longueur de 10 m, est également composé de deux tronçons. La partie méridionale est construite au moyen de moellons de calcaire, grès et poudingue retouchés posés en carreau ou en boutisse alternant avec des petites dalles de calcaire ou de grès disposées en épis, l'ensemble étant lié à la terre. La partie nord du mur, composée de cailloux et moellons de calcaires et de poudingue est trop mal conservée pour préciser son type d'appareil.

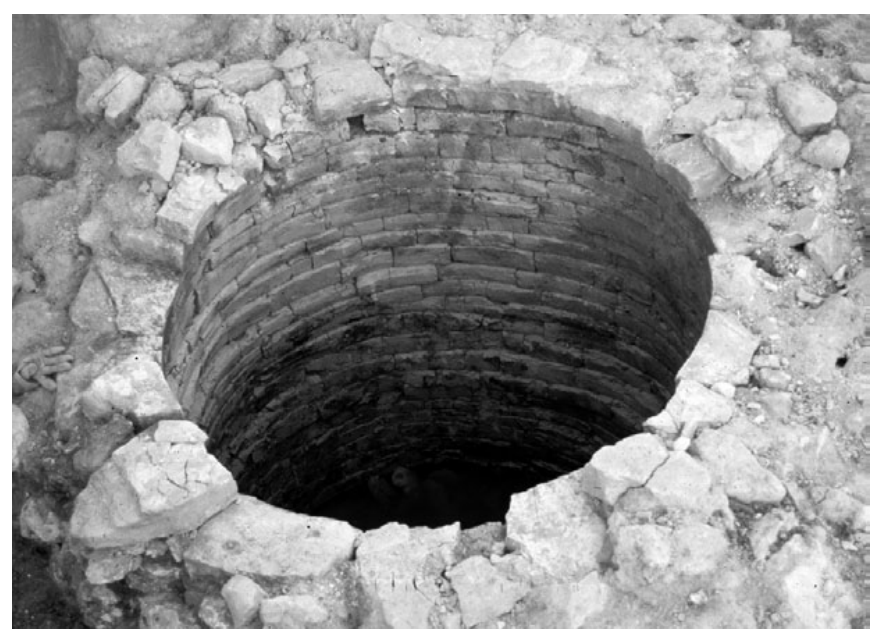

Fig. 252. Le puits l'espace 6B (cl. T. Maziers/Inrap).

Localisée dans l'angle nord-est, la parcelle 6B n'a été observée que sur une largeur de $2 \mathrm{~m}$ et une longueur de $6,70 \mathrm{~m}$. Un puits, d'un diamètre interne de 1,40 m, y est installé (fig. 252). Il n'a pas été fouillé dans sa totalité, seuls les cinq premiers mètres de comblement ont pu être retirés. Une couronne de dalles de calcaire soigneusement taillées en arc-de-cercle est surmontée d'une quarantaine d'assises irrégulières de moellons de calcaire. L'interstice situé entre ces moellons et le creusement d'installation est comblé au moyen de moellons et de blocs de calcaire et de travertin. La partie supérieure du puits a fait l'objet d'une réfection, caractérisée par un cuvelage nettement moins soigné, construit en cailloux et moellons de calcaire et de travertin à peine retouchés. Ce chemisage est calé contre le creusement au moyen de cailloux et éclats de même nature. Deux comblements différents en ont été extraits, correspondant tous deux à des niveaux de destruction et d'abandon datés du XIVe $\mathrm{s}$.

La parcelle 6C est accolée au sud de la parcelle 6A; elle est limitée à l'ouest par le mur qui borde la rue des Cordiers. Coupée au sud par la limite de chantier, elle mesure une longueur minimale de $27 \mathrm{~m}$ pour une largeur minimale de $15 \mathrm{~m}$. La fondation du mur sur rue est conservée sur 2,04 m de long pour une largeur de $54 \mathrm{~cm}$. Les matériaux utilisés, majoritairement du poudingue et du calcaire, sont disposés en épis. Cette fondation de mur est composée de deux assises qui présentent un léger ressaut de 2 à $3 \mathrm{~cm}$ par rapport à l'élévation formée de trois assises d'élévation liée à la terre. Une reprise partielle est observée dans l'élévation correspondant à un bouchage dont l'orifice pourrait être volontaire (un emplacement de porte) ou bien accidentelle (un effondrement). Au sud, le long du parement oriental sont accolées deux petites structures quadrangulaires bâties au moyen de moellons et cailloux liés à la terre. Dans le segment compris entre ces deux éléments, la largeur du mur est moindre. Il est possible que ce tronçon corresponde au bouchage d'une ouverture initialement limitée par deux piédroits maçonnés ou deux supports de piliers. Malheureusement, le degré d'arasement des vestiges est tel qu'il est impossible de conclure.

\subsubsection{Les aspects fonctionnels du faubourg ${ }^{866}$ (N. Scherrer)}

Malgré la destruction quasi totale du bâti, il est possible de dégager quelques aspects généraux concernant le bourg de Morier.

L'investissement des terres périphériques au rempart ne s'accompagne pas nécessairement de plan de lotissement codifié et rationnel comme cela a pu être observé dans le bourg Sainte-Catherine (Scherrer, Bouiron 2001), mais laisse ici place à une urbanisation qui semble moins maîtrisée, où les unités d'habitations s'accolent les unes aux autres et sont davantage l'œuvre d'initiatives individuelles. L'emprise des parcelles à bâtir était probablement délimitée par des clôtures et la construction des maisons restait à la charge des preneurs. Chaque parcelle est accessible par une rue ou une traverse, ce qui indique bien que l'implantation du bâti est néanmoins

866 D'après F. Paone. in Bouiron 2001b, p. 101-103 et F. Paone et N. Scherrer. in Bouiron 2001b, p. 13-107. 
rationalisée ( $c f$. supra $\S \mathrm{I}, 2,2.1 .2$.). Le phénomène de maison double est généralisé dans l'îlot II mais plus difficile à attester sur l'ensemble du faubourg. Les constructions sont bâties en adéquation avec des parcelles de plus petite taille, contrainte spatiale à laquelle sont moins soumis les autres îlots. Les maisons d'angles sont celles dont le plan et la mise en œuvre traduisent le plus d'ostentation, en corrélation avec des dimensions plus importantes.

\section{Les murs}

La majorité des fondations des murs mesurent entre 50 et $65 \mathrm{~cm}$ de large, les plus grandes largeurs sont comprises entre 70 et $80 \mathrm{~cm}$. Les dimensions inférieures se rencontrent pour des cloisons ou pour des petits cabanons. Il ne semble pas y avoir de corrélation entre la largeur des fondations et la fonction portante des murs, la qualité de la construction semble davantage résulter d'un soin global de mise en ouvre apporté à l'un ou l'autre des édifices. Par exemple, dans les maisons $2 \mathrm{~F}$ et $2 \mathrm{G}$, les murs qui donnaient sur le passage avant la construction du bâtiment $2 \mathrm{H}$ présentent de grandes largeurs ; il s'agit certainement d'une volonté ostentatoire plus que d'une nécessité. On rencontre deux types de liant, le mortier d'une part, mais c'est surtout l'emploi de la terre qui est généralisé. Le mortier de chaux reste donc marginalement employé ( $25 \%$ des cas) et on le rencontre plus particulièrement dans des constructions d'une certaine envergure comme, par exemple, les maisons d'angle. Des éléments disposés en épis ont été observés dans certains murs de l'îlot $\mathrm{V}$ et systématiquement dans les murs de l'îlot VI. Il est difficile de dire s'il s'agit d'une technique de construction plus spécifiquement réservée aux zones rurales ou simplement d'un maçon spécifique qui a œuvré sur ces parcelles.

Les élévations sont très mal documentées sur cette fouille. La prédominance de la pierre dans les fondations et dans les quelques élévations conservées n'est peut-être pas significative pour l'ensemble des superstructures. En effet, il semble qu'il faille envisager la présence d'un certain nombre d'élévations en terre comme tend à le démontrer l'observation des niveaux d'incendie des maisons. La plupart d'entre eux sont composés d'éléments de toitures, de fragments de tuiles canal et de bois de charpente associés à des argiles rubéfiées ou des limons. La présence d'argile, fondue ou sous forme de blocs, contraste avec la quantité moindre des blocs ou des moellons dans la démolition. Cette rareté toute relative s'explique aussi par la préoccupation des propriétaires de récupérer un maximum de matériaux (cf. infra § 2.3.5.).

\section{Les supports verticaux}

De façon générale la largeur des pièces (entre 4 et $5 \mathrm{~m}$ ) correspond à une longueur de poutraison classique ce qui ne nécessite donc pas de supports intermédiaires. Mais dans l'espace 4A1, les grandes dimensions et l'irrégularité du plan rendent indispensable l'ajout d'au moins deux piliers maçonnés et d'un poteau dans la partie orientale pour supporter les solives d'un probable plancher. Dans la zone 4D, trois piliers maçonnés dont deux sont disposés parallèlement à un mur indiquent l'existence possible d'une galerie (?) attenante à un jardin.

\section{Les sols}

Les sols rencontrés dans les espaces du faubourg sont de nature et de mise en œuvre différentes selon que l'on se situe à l'intérieur ou à l'extérieur des bâtiments. La majorité des sols trouvés dans les maisons sont en terre battue. Dans les espaces ouverts, la matrice est souvent constituée d'argiles jaunes mêlée à des apports plus grossiers et hétérogènes avec notamment la présence d'éclats de calcaire ou autres matériaux de construction tels que des fragments de tuiles de mortier. La diversité des inclusions rendent les surfaces de circulation irrégulière et bosselée.

L'identification de la fonction des rez-de-chaussée est problématique, rien ne permet de dire si ces derniers sont à usage domestique ou professionnel, même s'il est généralement admis que les espaces domestiques se situent à l'étage. L'usage des pièces de rez-de-chaussée pour les animaux ou à des fins artisanales ou commerciales est concevable car chaque espace ouvre sur la rue.

\section{Les aménagements intérieurs}

Bien peu d'aménagements utilitaires ont été découverts proportionnellement au nombre d'édifices dégagés. Ceci s'explique en grande partie par le soin apporté par les habitants à récupérer objets, meubles mais également matériaux de construction avant la destruction du quartier. Les multiples perturbations modernes ont contribué à la disparition des vestiges. Aussi c'est un bilan bien étiolé de ces aménagements qui peut être proposé avec l'impossibilité d'en établir la fréquence ou d'observer leur emplacement au sein de la maison.

Peu nombreux, les foyers sont pour l'essentiel dépourvus d'agencement ou dispositif particulier. Les feux sont allumés à même le sol, comme en témoigne l'existence de traces rubéfiées. Des fosses en cuvette de dimensions variable servent fréquemment de réceptacle au feu, sans préparation particulière à l'exception d'un lit de pierres posées sur le fond pour l'un d'eux. Le seul exemple 


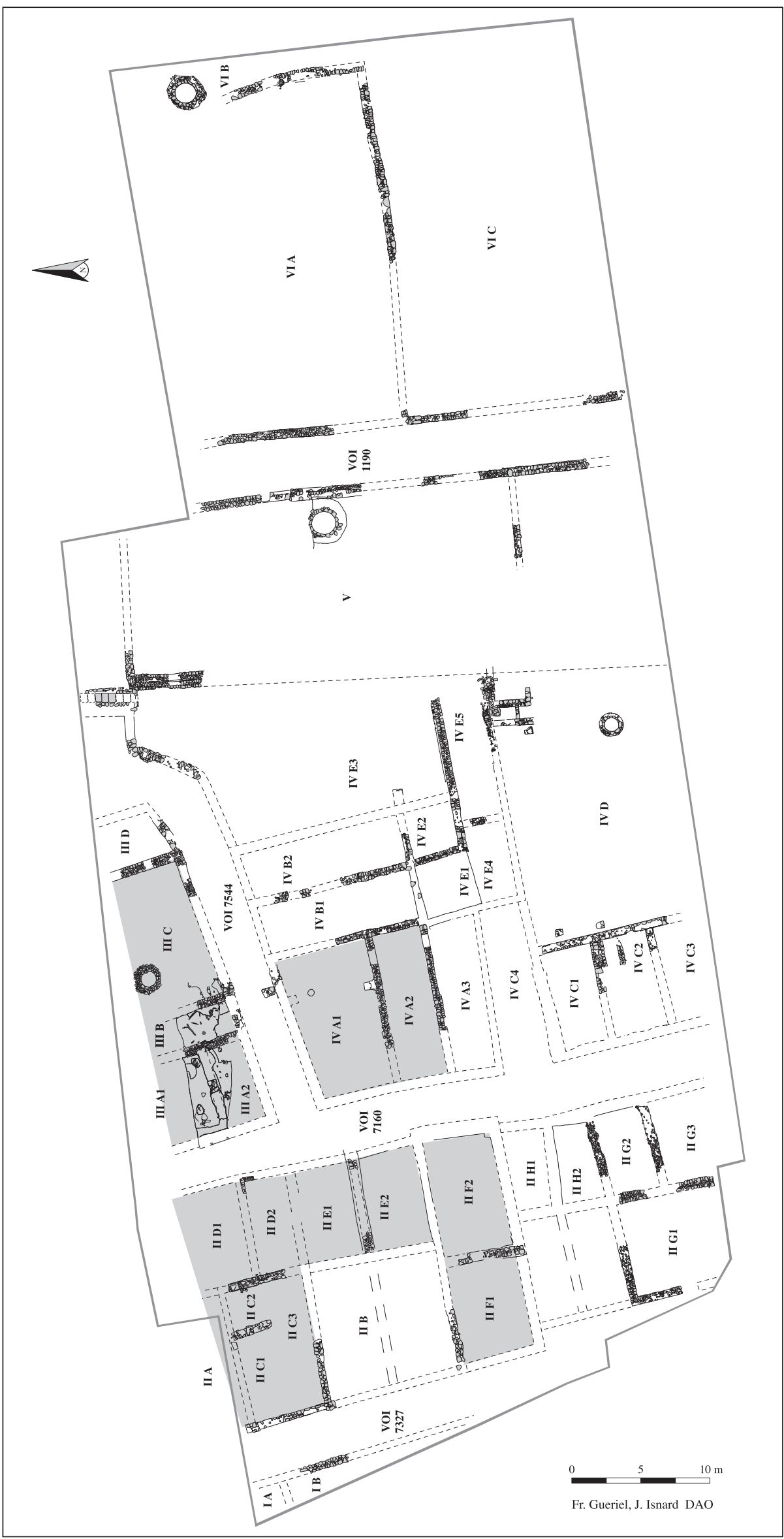

Fig. 253. Plan des

espaces incendiés

(DAO F. Gueriel, J. Isnard/ Inrap). 
de foyer central, découvert dans l'espace 2G2, mesure $24 \mathrm{~cm}$ de diamètre. Le plus souvent accolés le long d'un mur, ils sont alors oblongs ou semi-circulaires et de taille plus importante, $40 \mathrm{~cm}$ de diamètre pour le foyer en $2 \mathrm{H} 1$, 50 à $70 \mathrm{~cm}$ dans l'espace 3A1 dans lequel se trouve également un foyer d'angle. Les dispositifs d'évacuation des fumées restent inconnus, des systèmes d'évents ou de trémie suspendue sont concevables. On peut également envisager l'emploi de brasero ou de poêle comme systèmes de chauffage en l'absence de foyers.

Très peu de fosses sont creusées à l'intérieur ou à l'extérieur des maisons dans les espaces ouverts attenants. Rares sont celles ayant fait office de dépotoir domestique, aussi nous pensons qu'elles résultent parfois de spoliation de structures bâties. À l'exception notoire de l'ensemble $4 \mathrm{C}$ où une multitude de fosses renferment des déchets de forges, la plupart sont simplement colmatées d'un remplissage peu caractéristique de l'utilisation des lieux.

Le mauvais état de conservation des vestiges ne permet pas une analyse plus approfondie, que ce soit sur le mode de construction des élévations, sur les circulations intérieures (entre les pièces et avec d'éventuels étages) ou avec la rue, ou sur les aménagements des rez-dechaussée. En dehors d'un texte ${ }^{867}$ qui mentionne en 1322 quatre maisons de deux étages disposant d'un pati pour chacune d'elles dans la rue de Morier, le discours n'est guère plus alimenté par les textes sur ces problématiques.

\section{Les terres de jardin}

Bien peu d'éléments nous sont parvenus qui permettraient d'identifier précisément l'utilisation des terrains au sein des espaces de l'îlot VI. Différents apports volontaires de remblais ont été mis en évidence, mais ces niveaux ont été repérés en coupe sans livrer de matériel datant ; d'autres couches, intégralement fouillées ont été perturbées par l'activité agricole de l'Époque moderne et ont livré une forte proportion de matériel intrusif. Aucun sillon ou trace agraire ou trou de plantation d'arbres qui pourraient nous orienter vers des types de cultures particuliers n'a pu être identifié. Certains indices tendent à évoquer un amendement de ces terrains, et l'incohérence des datations céramiques plaident pour un travail de la terre qui a duré dans le temps.

La rareté des vestiges dans les îlots V et VI et l'absence de structures d'habitat dans les sondages de la place de la Providence (Bouiron et al. 1999) semblent confirmer que cette frange constitue la zone de transition entre un espace suburbain et le terroir véritable.

8671366 : AD13 351 E 28 fol. 143.
La pratique du maraîchage et de l'arboriculture apparaît régulièrement dans les censives, comme, mais de façon plus exceptionnelle, la mention de jardins d'agrément. Des études de prélèvements effectués dans les fosses ont permis de renforcer l'hypothèse d'un verger dans l'espace 4E3.

\subsubsection{La destruction du faubourg et la création de jardins (milieu du XIV ${ }^{e}$ s.) (N. Scherrer) ${ }^{868}$}

$\mathrm{Au}$ milieu du XIV e s. la destruction raisonnée du faubourg semble anticiper sur les mesures prises par le conseil de ville en 1357/1358 pour abaisser ou raser les maisons des quartiers extra muros en prévision des attaques des Routiers.

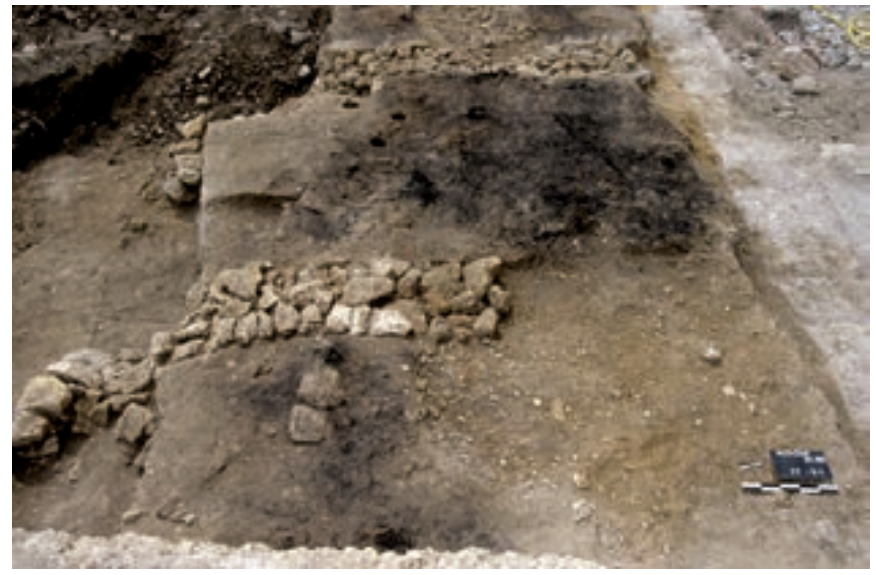

Fig. 254. Les niveaux d'incendie de l'îlot III (cl. F. Parent/Inrap).

Le faubourg est abandonné dans la première moitié du XIV e s. et méthodiquement détruit (fig. 253). Les maisons sont arasées et parfois incendiées les unes après les autres ou ensemble, et les murs sont épierrés quasi systématiquement. Les incendies touchent le centre et le nord du faubourg, tandis que le sud est épargné par le feu. Suite à un dérasement important lors d'une phase ultérieure, aucune trace de démolition n'est conservée dans la partie orientale du faubourg, où seules les tranchées de récupération des murs sont présentes. Les bâtiments ont sans doute été nettoyés avant démolition, comme le suggère la rareté du mobilier céramique et des objets domestiques en général.

Seules les maisons des îlots II, III et IV sont brûlées, les espaces ouverts, les cours ou jardins sont épargnés de même que les rues. Ces traces d'incendies dont l'importance reste limitée, indiquent que ce sont les matériaux irrécupérables tels des éléments de poutraison ou de

868 D'après M. Maurin et N. Scherrer in Bouiron 2001b, vol. 1-2, p. 381-385 et P. Rigaud in Bouiron 2001b, vol. 6, p. 14-15. 
toiture qui ont brûlé sur place après démontage, et que cette phase de destruction précède d'efficaces et massives campagnes d'épierrement, de récupération dont les tranchées sont comblées durant la seconde moitié du XIVe s.

Dans les voies, des épandages de tuiles, de limons issus des démolitions recouvrent les sols de circulation ; sur la rue des Cordier, une couche d'effondrement de la partie haute du mur de limite est matérialisée par un amas de calcaire, poudingue et travertin mêlés du cailloutis, des fragments de tuiles ainsi que des traces de mortier et de chaux lissés. S'ensuivent de nouveaux rejets de matériaux.

À travers l'observation des niveaux de destruction des îlots, des éléments importants pour la connaissance des élévations apparaissent et la répartition des espaces ouverts et fermés se dessine clairement. Si dans l'îlot I peu visible, aucune couche d'incendie n'apparaît, en revanche l'îlot II connaît plusieurs séquences de démolition localisées dans la moitié nord. Des couches de charbons de bois et d'argile rubéfiée scellent les sols des ensembles 2A, 2C, 2D, 2E parfois des poutres carbonisées sur place sont conservées et des éléments de tuiles rougies. Les murs des maisons une fois brûlées sont épierrés comme le montre l'étalement de blocs rejetés. L'ensemble $2 \mathrm{~B}$ qui renferme une cour est totalement dépourvu de traces d'incendie et de démolition, de même que la moitié méridionale de l'îlot, à l'exception de l'espace $2 \mathrm{G}$ comblé de matériaux de construction.

Dans l'îlot III, les niveaux d'incendie se caractérisent par l'omniprésence d'argile rubéfiée et de plaques d'enduit brûlés ainsi que par la quantité de charbons et morceaux de bois calcinés (fig. 254). Une telle spécificité des matériaux laisse penser que dans cet îlot les murs et cloisons étaient en pisé banché ce que confirme la présence de blocs de mortier mêlés à de limon brun, ainsi que l'absence de résidu de pierres. Seuls les solins de pierres sont donc récupérés. Dans la pièce $3 \mathrm{~B}$ est conservé un morceau de natte brûlé sur le sol, seul élément de mobilier découvert sur le site.

Enfin dans l'îlot IV, seules les pièces $4 \mathrm{~A}$ et $4 \mathrm{~B}$ sont incendiées; les constructions environnantes dérasées à l'Époque moderne ne comportent aucune trace de feu. Il ne subsiste que les tranchées de récupération partielles ou totales des maçonneries. Comme pour l'îlot nord, les pièces $4 \mathrm{~A}$ et $4 \mathrm{~B}$ sont recouvertes d'une épaisse couche (35 cm) de tuiles et de poutres carbonisées mêlées à de l'argile ce qui suppose qu'ici aussi les élévations sont en terre ; l'espace mitoyen 4A3 est en revanche comblé majoritairement de pierres. Le sol de la pièce $4 \mathrm{C} 1$ est recouvert d'une couche de démolition constituée de fragments de matériaux de construction et de résidus assez importants de charbons de bois et d'argile rubéfiée, datée de la première moitié du XIVe $\mathrm{s}$. Dans la pièce $4 \mathrm{C} 2$, le démontage de la structure d'un escalier n'a laissé que quelques pierres abandonnées sur le sol caladé. Enfin à l'est, dans la parcelle 4D, le puits est rempli de deux couches de destruction et d'abandon datées entre le $\mathrm{XIV}^{\mathrm{e}}$ s. et le $\mathrm{XV}^{\mathrm{e}} \mathrm{s}$.

Les zones orientales à vocation agricole sont décaissées, ne laissant en place que les structures en creux (fonds de fosse et fondations de murs en particulier). Le faubourg ainsi détruit laisse place à un terrain plat et déserté ou aucun monticule de matériaux ne subsiste.

Il semble que le bourg de Morier ait été l'un des premiers détruits car le mobilier issus des démolitions n'excède pas le milieu du $\mathrm{XIV}^{\mathrm{e}} \mathrm{s}$. Cette campagne de démolition méthodique des maisons des faubourgs commanditée par le conseil de ville en prévision du siège des Routiers d'Arnaud de Cervole a cependant été longue à mettre en place, la population des faubourgs étant hostile à la destruction des lieux et à leur déplacement. Au cours du mois de novembre 1357, le conseil ordonne par trois fois la destruction des ponts et maisons situés devant les remparts et décide de faire creuser des tranchées rejoignant les fossés. Jusqu'en février 1358, des réticences persistent et la ville veille que les places des maisons détruites soient exemptées de censes et qu'il n'en soit plus construit d'autres. Afin que l'ennemi ne puisse trouver de subsistance (victualia, pasture animalium) on décida de rapatrier en ville ce qui pourrait lui être utile. La situation politico-militaire s'étant redressée le siège de la ville craint et attendu n'eut finalement pas lieu alors que les destructions avaient été accomplies.

\section{Des faubourgs à l'agrandissement de Louis XIV (B. Sillano)}

La présentation qui suit fait référence à une numérotation indépendante de celle du parcellaire napoléonien (fig. 255).

\subsection{Les faubourgs peu avant Louis XIV}

L'occupation, peu avant l'Agrandissement, se limite à quelques demeures le long du Grand-Caire et aux possessions de la congrégation Saint-Hommebon (cf. fig. 222) puis, à partir de 1656, à des bâtiments le long de la rue du Petit-Saint-Jean. C'est ce qu'indique clairement le rapport d'expertise précédant l'Agrandissement, confirmé et complété par les données archéologiques. En revanche, ces dernières apportent un éclairage nouveau sur des parcelles situées en retrait, dont nous n'avons pas 


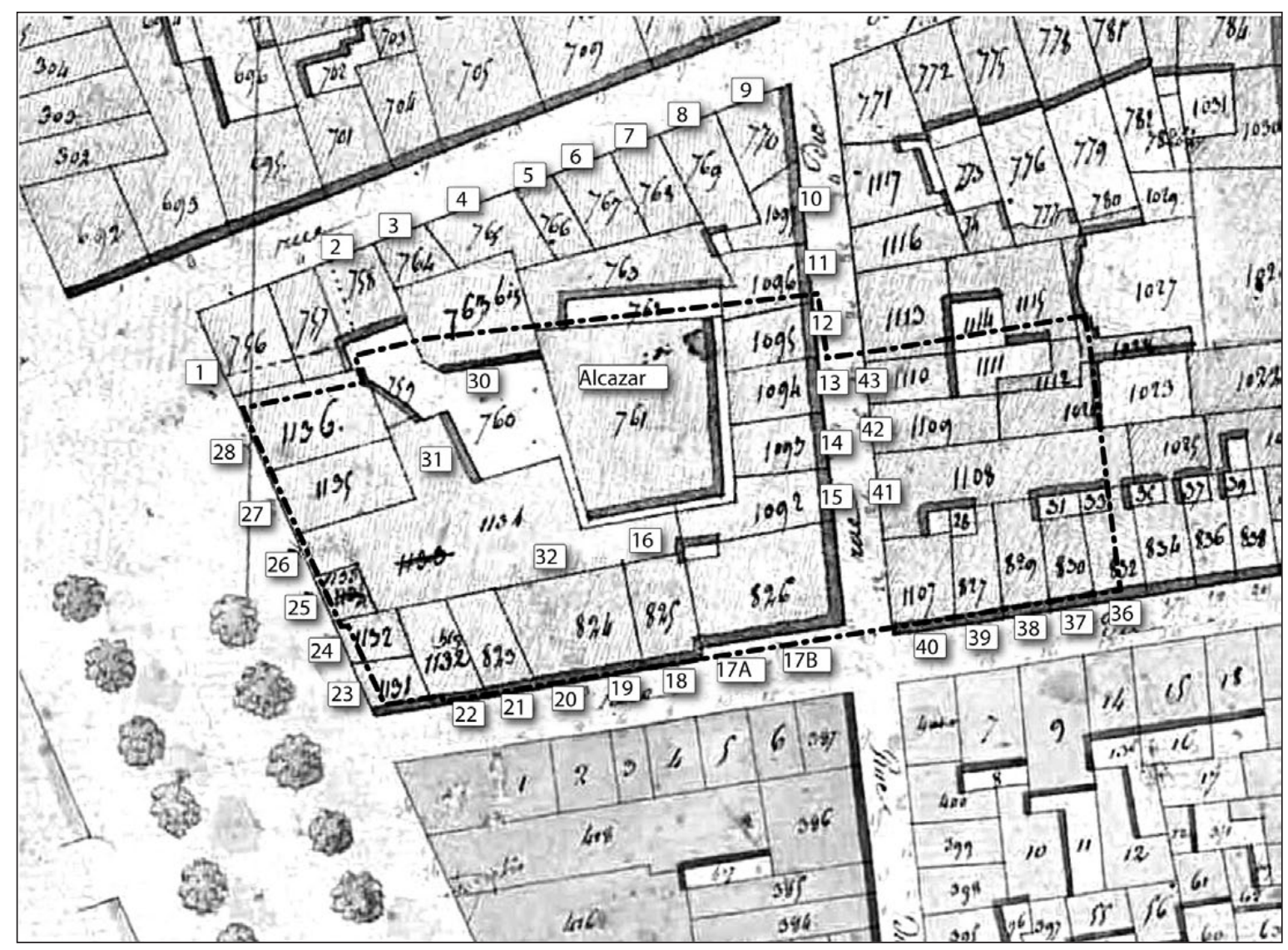

Fig. 255. Numérotation des parcelles sur fond de cadastre napoléonien (B. Sillano/Inrap d'après cl. AD13).

trouvé trace dans les rapports (elles ont déjà disparu ?). Il apparaît que les jardins sont parsemés de bâtiments de toutes dimensions.

\subsubsection{Nivellement des occupations antérieures}

Au début de la période moderne, une grande masse de remblais, épaisse de 0,50 à 0,70 m, est apportée afin de sceller les niveaux d'abandon du faubourg médiéval. Ils aplanissent un terrain à la surface duquel il ne semble plus rester de trace de l'occupation antérieure, mise à part la rue du Baignoir qui reste en usage. À l'ouest, les remblais, hétérogènes et mêlés de déchets de démolition, scellent l'occupation antérieure; ils ont été apportés dans le courant du XVI ${ }^{\mathrm{e}}$ s. De part et d'autre de la rue, ce sont des terres végétales qui ont été apposées durant le XVII ${ }^{\mathrm{e}} \mathrm{s}$. à la suite d'un arasement préalable.

\subsubsection{Les habitations le long du Grand-Caire}

C'est tout naturellement le long de la place du GrandCaire, aux portes de la ville, que s'édifient les premiers bâtiments modernes. Trois d'entre eux sont situés sur l'emprise de fouille, mais une partie des bâtiments, en façade, échappe à la fouille car ils ont subi un réalignement lors de la création du Cours.

Au nord, la parcelle 28, large de $9 \mathrm{~m}$, accueille le Logis des Trois Mulets qui se compose, d'après le rapport de 1668, d'un corps de bâtiment de trois étages ouvert sur la place, long de $17 \mathrm{~m}$, auquel est adossé un second, long de $9 \mathrm{~m}$ et aussi élevé. Le premier état d'occupation mis en évidence par la fouille, daté dans le courant du XVII ${ }^{\mathrm{e}}$ s., comprend trois espaces distincts (fig. 256). Le plus proche de la façade possède un sol en terre battue et une canalisation, qui le traverse d'est en ouest, faite de pierres diverses assez peu organisées et couverte de dalles de calcaire rose soigneusement découpées pour s'ajuster au conduit. Il s'agit du fond d'une des deux écuries qui occupent le rez-de-chaussée du bâtiment en façade. Le mur qui le sépare de l'espace central, détruit dans un second temps, reprend grossièrement la direction d'un mur du faubourg médiéval, récupéré peu avant, et son appareil, lié à la terre, est fait de moellons de calcaire blancs disposés de manière désordonnée. L'espace central, très dégradé, possède un puits au centre d'un diamètre interne de $0,80 \mathrm{~m}$ et dont le cuvelage est fait de moellons de calcaire tendre à peine assisés. Par sa position et la présence du puits, 


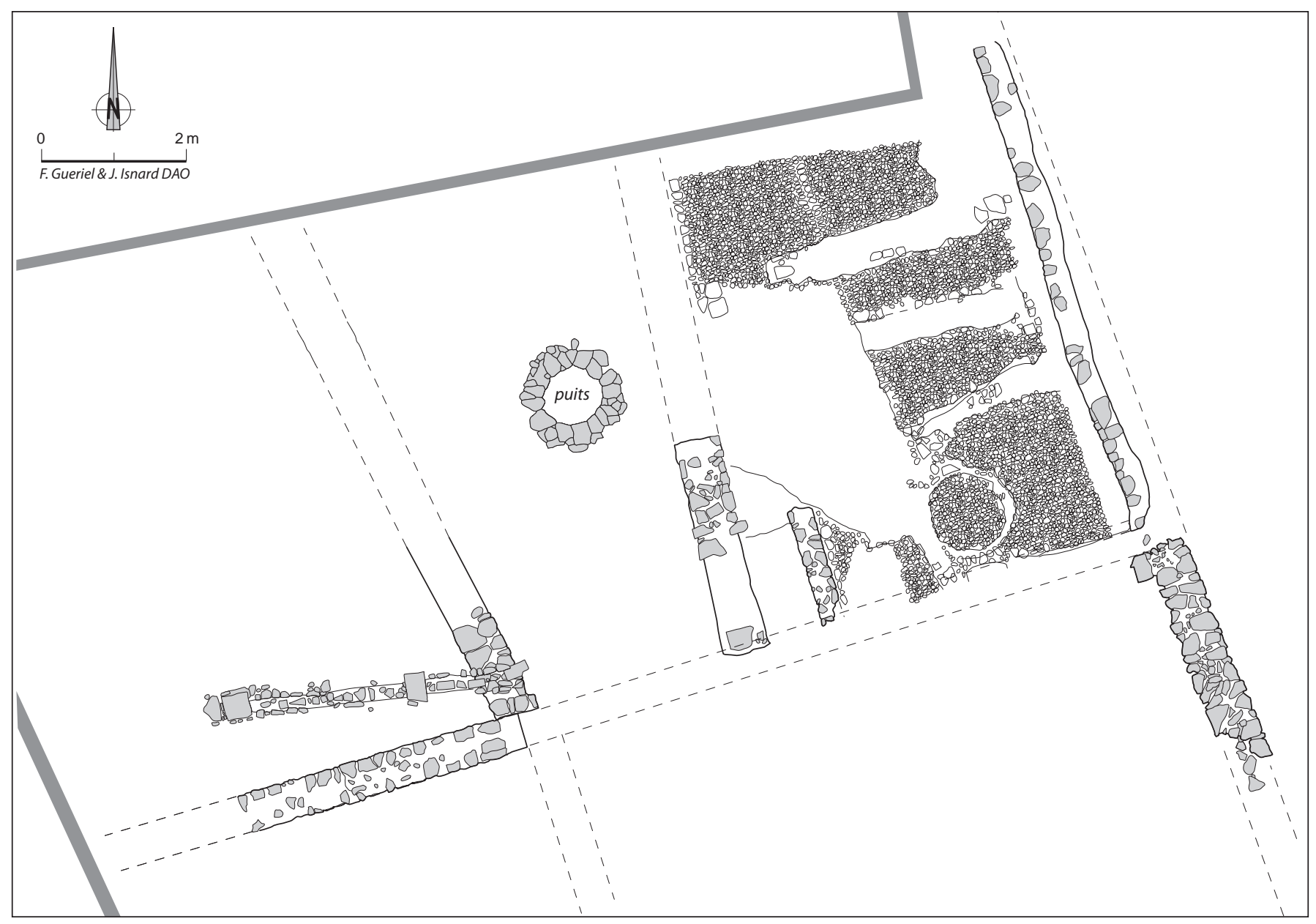

Fig. 256. Les vestiges modernes de la parcelle 28 (DAO F. Gueriel, J. Isnard/Inrap).

il pourrait correspondre à une cour intérieure, mais le rapport n'en fait pas mention ; il est possible que celle-ci ait été absorbée par le bâti dans un second temps. Enfin, l'espace oriental, le mieux conservé, a révélé, au fond d'un creusement d'environ $1 \mathrm{~m}$, un sol caladé subdivisé par trois tranchées. Il possède un fil d'eau d'axe nordsud et une empreinte circulaire en creux de 1,10 m de diamètre qui peut correspondre au vestige d'une cuve faite en matériaux périssables. Nous sommes, d'après le rapport d'estime, dans un cellier.

Au centre, la parcelle 27 est mentionnée dès 1634 dans un acte d'achat et porte pour enseigne Le Canard ${ }^{\mathbf{8 6 9}}$. En 1668, il ne s'agit plus d'une auberge et la parcelle, large de 8,25 m, est occupée par deux bâtiments, l'un de $12 \mathrm{~m}$ de long avec deux étages, l'autre de 5,25 m, séparés par une cour intérieure. Une cave récente nous prive des vestiges de sol du premier état, cependant la base de la fondation du mur mitoyen nord présente un piédroit correspondant à l'arrière du bâtiment de façade.
Ainsi, de grandes similitudes existent entre les premières parcelles, tout au moins dans un état antérieur au rapport d'estime. Elles se composent toutes deux d'un grand bâtiment en façade et d'une annexe en retrait, séparés par une cour. Ces observations nous permettent de mieux appréhender les textes qui concernent la parcelle 1, extérieure au chantier et située à l'angle de l'îlot. En 1636 , le lot n'est pas bâti ${ }^{870}$. En 1656, il contient une «petite maison et grand patti se joignant ${ }^{871}$, et le rapport d'estime de 1668 décrit un bâtiment en façade de $19 \mathrm{~m}$ de long pour $10 \mathrm{~m}$ de large, avec deux étages, une cour avec un puits, puis un autre bâtiment en fond de parcelle. Ces trois textes mettent en évidence le principe du lotissement des parcelles, d'abord en façade puis en fond de parcelle.

La parcelle 26, sur l'axe médian de l'îlot, n'est pas bâtie en 1668. Au sud, la parcelle 25 est de dimension plus modeste $(6 \mathrm{~m}$ par $7 \mathrm{~m}$ ) et ne comprend qu'une maison à deux étages dont la fouille n'a rien révélé.

870 AD13 380 E 127, fol. 1733.

871 AD13 364 E 267, fol. 1578v. 
La suivante, la parcelle 24, était à l'origine liée avec les parcelles voisines : 23 au sud et 22 à l'est. L'ensemble, qui formait un tout mentionné en 1638 par un acte de vente $^{872}$, se situait à l'angle de l'îlot et mesurait $11 \mathrm{~m}$ par 18 m. En 1668, les parcelles 24 et 23 sont dissociées et appartiennent à deux membres d'une même famille, la première restant associée à celle qui est sur la rue du Petit-Saint-Jean. Celle-ci est occupée par un bâtiment avec deux étages alors que l'autre possède un étage de plus. La fouille n'a rien révélé, mis à part un tronçon de mur lié à la terre, le renfoncement que forme la paroi moulée dans l'angle du chantier ayant trop réduit la surface d'observation.

\subsubsection{Les parcelles le long de la rue du Petit-Saint-Jean}

La rue du Petit-Saint-Jean, qui n'existe pas à l'époque médiévale, n'est, en 1636, qu'une traverse qui s'interrompt au niveau de la rue du Baignoir et qui se lotit à partir de 1656 lorsque l'auberge éponyme est construite à son extrémité. Avant cette date, l'étude des textes ne met en évidence, sur sa rive nord, que deux petites maisons situées en fond de jardin. La première, la «maison et cazal de François Gaillard » ${ }^{873}$, située sur la parcelle 21, n'a laissé aucune trace archéologique. L'autre, un bâtiment avec un étage de $7 \mathrm{~m}$ de long pour $4 \mathrm{~m}$ de large, construit «en pierre et terre » ${ }^{874}$, est situé sur la parcelle 20. Il est vendu en 1663 avec la parcelle 19 voisine. Nous avons effectivement retrouvé, au nord de la parcelle, un mur de refend, antérieur aux autres et qui isole un espace, orienté d'est en ouest, dont les dimensions sont conformes au texte. De plus, ce mur est épais de 0,60 m, ce qui est suffisant pour supporter un étage ; il est fait de moellons de calcaire tendre liés à la terre. À l'intérieur, un petit bassin carré de $0,60 \mathrm{~m}$ de côté a été dégagé alors que l'extérieur a révélé un lambeau de sol en terre battue.

En dehors de ces bâtiments, le reste des parcelles en rive nord de la rue du Petit-Saint-Jean n'est occupé, jusqu'en 1656, que par des jardins. La plupart des murs de clôture de cette période ont été entièrement repris plus tard; il n'en reste pas trace, hormis ceux situés à l'intérieur des parcelles qui ont été doublés ou encore qui sont légèrement obliques. C'est le cas du mur mitoyen entre les parcelles 19 et 20, fait de moellons de calcaire de Saint-Victor liés à la terre. Il en est de même pour un mur, également lié à la terre, qui traverse la parcelle $19 \mathrm{du}$ nord au sud. Distant de 1,40 m de la bordure de la parcelle, il délimite un accès aux jardins de

872 AD13 360 E 73, fol. 87.

873 AD13 360 E 73, fol. 87.

874 AD13 360 E 158, fol. 362v. la congrégation. Plus à l'est, deux murs perpendiculaires de même nature matérialisent l'angle nord-ouest de la parcelle 17. Plusieurs puits sont présents sur ces terrains, mais il nous est difficile de savoir s'ils sont ou non antérieurs à 1656. Celui de la parcelle 18 est situé en plein cœur du lot, ce qui est peu courant au sein d'un bâtiment. Il pourrait être lié aux jardins. En revanche, l'un d'entre eux, identifié uniquement par la fosse laissée par sa récupération, est certainement à rattacher à cette période. En effet, il est situé dans l'angle sud-ouest de la parcelle 17 et se voit chevauché par le mur de façade de l'auberge édifiée en 1656.

Le rapport d'estime de 1668 nous montre qu'en l'espace de dix ans toutes les parcelles situées au nord de la rue ont été bâties. Nous allons les examiner d'est en ouest.

La première, la parcelle 22, est, nous l'avons vu, liée à la parcelle 24 qui ouvre sur le Grand-Caire. Elle mesure $7 \mathrm{~m}$ de large pour $12 \mathrm{~m}$ de long; il s'agit, en 1668, d'une écurie sans étage. Les murs observés en fouille ne semblent pas correspondre à cet état, en revanche nous avons retrouvé un lambeau de sol caladé daté par la céramique de la première moitié du XVII ${ }^{\mathrm{e}} \mathrm{s}$. La parcelle suivante, un peu moins large, est également occupée par une écurie avec probablement un grenier à l'étage. Elle possède aussi un sol caladé qui est adossé à des murettes courant le long des murs, lesquelles sont faites d'un appareil irrégulier et hétérogène lié au mortier (fig. 257). Les parcelles 20 et 19 sont associées et occupent un espace trapézoïdal de $13 \mathrm{~m}$ de largeur minimale pour $12 \mathrm{~m}$ de profondeur. Le rapport d'estime parle d'une « grande escuyerie et deux greniers à foin par dessus » de $11 \mathrm{~m}$ de large. Nous devons déduire la largeur du passage, situé entre les parcelles 19 et 18, qui donne accès au jardin des Pères, ce qui prouve sa pérennité. Les vestiges de cette période sont très dégradés, néanmoins il semble que les murs antérieurs aient été

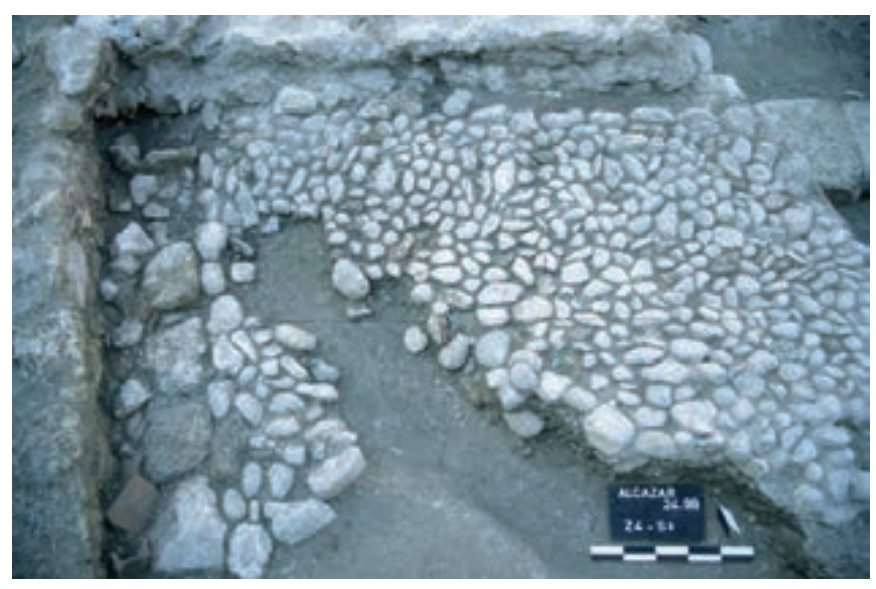

Fig. 257. Les vestiges du sol dans l'angle nord-ouest de la parcelle 22 (cl. T. Maziers/Inrap). 
conservés. La fouille a exhumé, au sud de la parcelle 20, un lambeau de sol avec une empreinte de carrelage sur du mortier (carreaux de $20 \mathrm{~cm}$ par $15 \mathrm{~cm}$ ). Il s'agit du seul exemplaire rencontré sur le site pour cette période. Citons également un mur qui divise la parcelle selon un axe nord-sud. Daté des années 1650 par la céramique, il repose sur une fondation de blocs taillés en calcaire blanc liés au mortier peu épais. Dans la parcelle 19, un sol caladé, associé (ou recoupé) à une murette le long du mur, a été observé partiellement.

L'auberge du Petit Saint-Jean occupe les parcelles 17 et 18. Elle est construite en 1656 sur un espace vierge, comme l'indique l'acte d'achat de deux «places à bâtir ${ }^{875}$. Elle n'est pas modifiée lors de l'agrandissement, en revanche le bâtiment est entièrement refait au XVIII ${ }^{e}$ s., ce qui a pour effet d'effacer toute trace du précédent. Seuls des négatifs permettent d'en imaginer la structuration. Les rapports d'estime de 1668 et de 1684 lui donnent une dimension de $27 \mathrm{~m}$ de long pour $12,50 \mathrm{~m}$ de profondeur. L'auberge se compose de deux bâtiments : à l'est, sur la parcelle 17, une écurie surmontée d'un étage ; à l'ouest, un grand immeuble avec deux étages et boutique au rez-de-chaussée.

Sur la parcelle 17, les plus anciennes structures observées en fouille, datées du milieu du XVII ${ }^{\mathrm{e}}$ s., sont un ensemble de fosses destinées au stockage de la chaux. Réparties sur l'ensemble du terrain, elles sont de forme rectangulaire, mais de dimensions variables comprises entre $1,40 \mathrm{~m}$ par $1,25 \mathrm{~m}$ pour la plus réduite et $3,70 \mathrm{~m}$ par $1,70 \mathrm{~m}$ pour la plus étendue. Le fond est généralement plat avec des parois verticales ou déversées. L'écrêtement de ces aménagements ne nous permet pas d'en connaître la profondeur. On note dans le bas des fosses la présence d'une couche plus ou moins épaisse de chaux grasse, caractérisée par un aspect induré et compact, parfois recouvert par du sable gris d'origine marine. Après récupération de la chaux, ces fosses sont comblées par des remblais constitués de matériaux de destructions. L'essentiel des sols de travail a été nivelé à une époque plus récente, sauf une portion dans la partie orientale de la zone, où il est matérialisé par une fine couche de chaux déposée sur une surface plane. Dans la partie centrale de la parcelle 17, quatre emplacements de piliers sont localisés (fig. 258). Ces structures ont été récupérées et seul subsiste, dans le fond d'une fosse, un reste de maçonnerie. Il s'agit seulement de la base de la fondation, composée de pierres de toutes natures et toutes dimensions. Les fosses sont de forme carrée, aux parois verticales et fond plat. Aux quatre angles et parfois contre les parois, on observe la présence de mortier induré constitué de sable marin avec des coquillages. Mesurant 1,20 m de côté, ces piliers sont profondément fondés sur une hauteur de $0,50 \mathrm{~m}$ à $0,80 \mathrm{~m}$. Ils subdivisent la parcelle en trois travées de $6 \mathrm{~m}$ de large et libèrent entièrement l'espace du rez-de-chaussée où se trouve l'écurie.

Les murs porteurs contemporains de ces structures ne sont pas conservés, mais les piliers sont centrés par rapport au bâtiment qui est édifié ultérieurement, en retrait par rapport à la rue. Ce réalignement paraît donc avoir une origine ancienne, peut-être pour mettre en valeur l'édifice. Dans le cas présent, comme il s'agit d'écuries, il est plus probable qu'il vise à faciliter les circulations. Aucun sol n'est conservé, le seul aménagement étant un amas de briques crues qui suppose un cloisonnement en adobes.

En conclusion, nous constatons que les parcelles 19 à 22 , bâties très rapidement juste après la construction de l'auberge du Petit Saint-Jean, ont subi une mutation de leur fonction. De simples jardins, elles sont toutes devenues des écuries, munies d'un étage pour y mettre le foin. La rapidité de leur mise en œuvre, qui réutilise en grande partie les murs de clôture insuffisamment fondés, les apparente à des constructions faites dans l'urgence. Peut-être s'agissait-il de répondre rapidement à une demande accrue dans ce quartier, aux portes de la ville, où abondent les auberges qui accueillent les voyageurs. La densification du bâti en centre ville a également contribué à l'impossibilité, voire à l'interdiction, d'y circuler avec des attelages, refoulant par là même les chevaux de trait. Enfin, la présence du marché aux fruits et légumes sur la place du Grand-Caire n'est pas non plus étrangère à la nécessité de remiser les chevaux, au moins pour la journée.

\subsubsection{L'occupation de part et d'autre de la rue du Baignoir}

À l'ouest de la rue du Baignoir, outre l'auberge du Petit Saint-Jean, nous n'avons repéré sur le terrain aucune construction antérieure à l'agrandissement. Le plan Razaud confirme par ailleurs que l'essentiel ne sera pas construit avant le XVIII ${ }^{e}$ s. En revanche, l'acte de 1636 mentionne une maison que la demoiselle de Guérin «se réserve avec l'allée outrelhais estant alentour dicelle maison ${ }^{876}$ et qui est située hors d'emprise de fouille, à l'angle de la rue du Baignoir et de la rue « tirant aux Augustins », au nord. Les textes nous indiquent qu'à l'est de la rue, avant que ne soit prolongée celle qui s'appellera Petit-Saint-Jean, se trouvaient en 1636 les jardins de Barnier. La fouille y a révélé des bâtiments antérieurs à l'Agrandissement. 
Le premier bâtiment construit à l'est de la rue du Baignoir est à l'emplacement de la future parcelle 40, mais n'occupe pas l'ensemble de cette dernière. En effet, en bordure de la rue, un mur a livré du mobilier du milieu du XVII ${ }^{e}$ s. et constitue un des rares témoins des constructions de cette période. Il est bâti au moyen de moellons de calcaire tendre blanc, liés par du mortier gris et disposés de manière irrégulière. Son épaisseur est de $0,60 \mathrm{~m}$ et sa fondation a été observée sur $2,70 \mathrm{~m}$. Il se termine au nord par un piédroit en grand appareil (fig. 259) difficile à interpréter, mais qui pourrait correspondre soit à une ouverture soit à la limite nord d'un bâtiment. Dans la parcelle 39 voisine, sous le sol de la cave, ont été retrouvés les vestiges de fondation de deux murs accolés d'axe nord-sud, ainsi qu'un retour d'axe est-ouest, matérialisé par une tranchée de récupération de mur, dans l'alignement du refend hypothétique de la parcelle 40. Ces témoins attestent de l'existence de murs fondés profondément, liés au mortier et constitués de moellons de calcaire blanc, tout comme le mur de façade, ce qui permet de les associer. Ainsi pouvonsnous restituer une parcelle perpendiculaire à la rue du Baignoir, de $12 \mathrm{~m}$ de profondeur et d'une largeur supérieure à $5 \mathrm{~m}$. La profondeur des fondations nous assure qu'il s'agit d'un bâtiment, dont aucun sol associé n'est conservé. Étant donné sa faible largeur, nous pouvons supposer qu'il était à l'origine plus large et dans l'axe de la traverse du Petit-Saint-Jean, puis qu'il a été recoupé par celle-ci lors de son prolongement vers l'est. Ce premier état de construction se traduit, dans les parcelles 41 et 42, par des aires et fosses de gâchage de mortier liées à la construction du bâti. Le décalage du mur de façade de la parcelle 40 par rapport au mur médiéval montre que la rue du Baignoir a été élargie avant l'agrandissement de Louis XIV.

La chronologie relative de construction des murs met en évidence, dans la parcelle 43, un espace antérieur aux autres. Aucun sol associé n'est conservé, à cause des caves, et les murs ne contiennent pas de céramique. Cependant, les datations des constructions qui lui font suite indiquent que cet espace a été mis en place avant la fin du XVII ${ }^{\mathrm{e}}$ s. Les fondations du mur sud sont composées d'une partie basse, débordante et installée en tranchée étroite, sur laquelle repose une fondation à double parement et blocage interne, épaisse de $0,60 \mathrm{~m}$ et conservée sur $0,80 \mathrm{~m}$ de hauteur. Ces constructions sont en moellons de calcaire blanc, disposés en assises irrégulières et liés par du mortier jaune. Le mur ouest n'a pas été étudié et son pendant a été arasé superficiellement par la cave. La profondeur des fondations atteste qu'il s'agit d'un bâtiment, de même longueur que son voisin et également recoupé, par la paroi moulée du chantier cette fois-ci.
En dehors de ces constructions, rien ne permet d'affirmer que le jardin de Barnier était déjà structuré en parcelles. Cependant, si l'on se réfère à la période médiévale, la partie concernée par la fouille était divisée en deux selon un axe est-ouest. Si on suppose que la parcelle nord s'étendait jusqu'à la rue «tirant aux Augustins », il est intéressant de constater que le bâtiment 42 est situé en son centre. De plus, le bâtiment 40 est approximativement à la même distance du mur de clôture $(11 \mathrm{~m})$ que son voisin. Il est possible d'imaginer des domaines de taille moyenne au centre desquels se trouve la maison du propriétaire.

\subsection{Les premières modifications liées à l'Agrandissement de Louis XIV}

La création de la Ville Nouvelle par Louis XIV, avec le tracé d'un nouveau plan du quartier, a eu, sur l'îlot concerné par les fouilles de l'Alcazar, un effet immédiat sur les constructions préexistantes, surtout à proximité du Cours (fig. 260). Ailleurs, après le traçage de nouvelles rues et parcelles, les constructions vont être plus lentes à se mettre en place, au cours du XVIII ${ }^{e}$ s. Nous distinguons donc dans notre étude ce qui est réalisé vers la fin du XVII ${ }^{e}$ s. de ce qui advient à partir du milieu du XVIII ${ }^{e}$ s., même si l'essentiel des sols conservés se rattache à cette dernière période.

\subsubsection{Reconstruction des immeubles le long du Cours}

La création du Cours a considérablement modifié les immeubles qui bordaient auparavant le Grand-Caire. Certes, ceux-ci ont profité de leur situation; cependant, non seulement ils ont été frappés d'un alignement sévère, mais en plus les reconstructions ont dû se plier à des normes strictes afin de préserver l'unité de la façade. Ainsi, les façades de l'îlot de l'Alcazar sont reculées de près de $10 \mathrm{~m}$ au nord pour $5 \mathrm{~m}$ au sud. Les premiers immeubles étant amputés de presque le tiers de leur superficie, il fût nécessaire de reculer les bâtiments vers l'arrière de la parcelle. Quatre devis de reconstruction nous sont parvenus, datés de 1675 , avec un même entrepreneur. La première façade réalisée est celle de la parcelle 26, non bâtie au moment de l'agrandissement. Elle sert ensuite de référence pour toutes les autres, de même que la façade de l'auberge de la Selle d'Or, sur l'îlot voisin au sud, sert de ligne de mire pour l'alignement. Nous allons voir en détail ces parcelles, du nord au sud de l'îlot, mis à part la première qui est hors emprise de fouille (fig. 261).

Pour la parcelle 28, le rapport de 1683 mentionne « la maison (...) où pend pour enseigne les trois mullets 


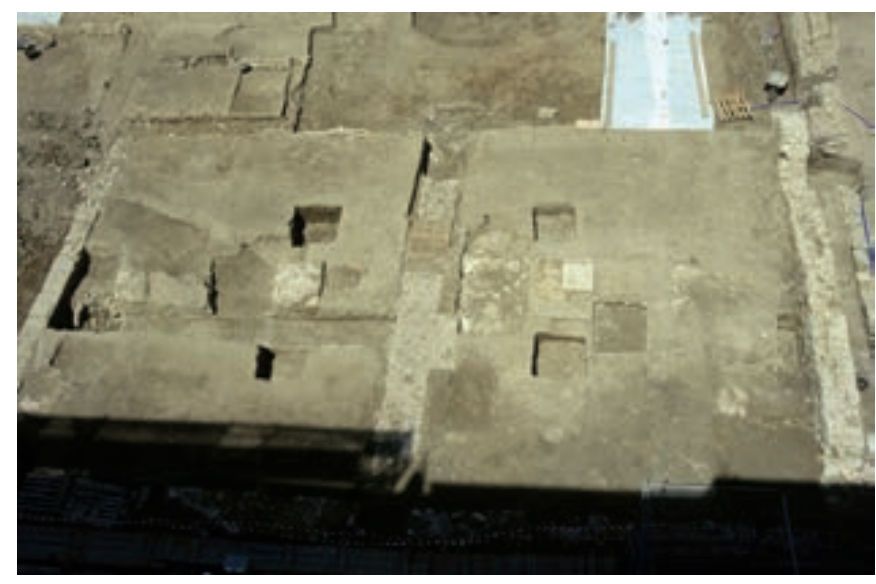

Fig. 258. Vue d'ensemble des vestiges de la parcelle 17 (cl. T. Maziers/Inrap).

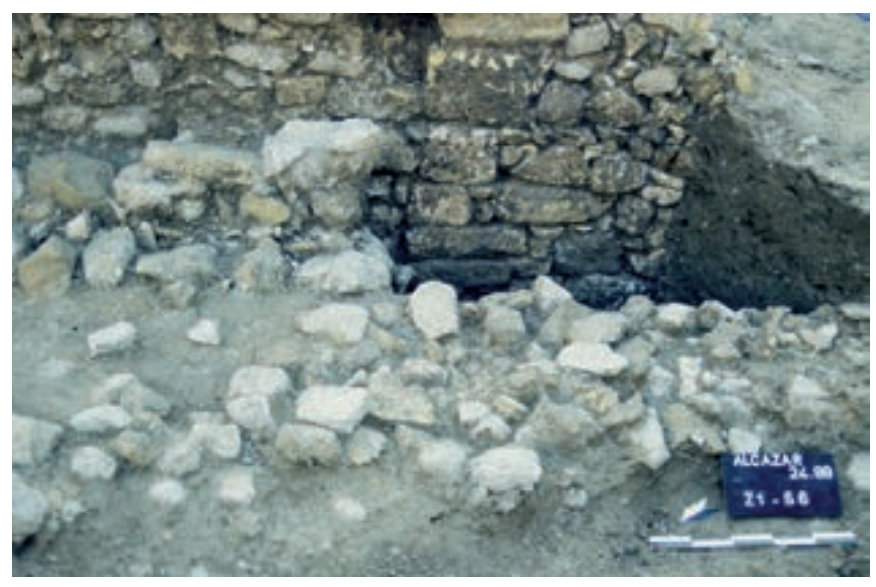

Fig. 259. Détail du piédroit dans la façade de la parcelle 40. Au premier plan, la façade antérieure (cl. T. Maziers/Inrap).

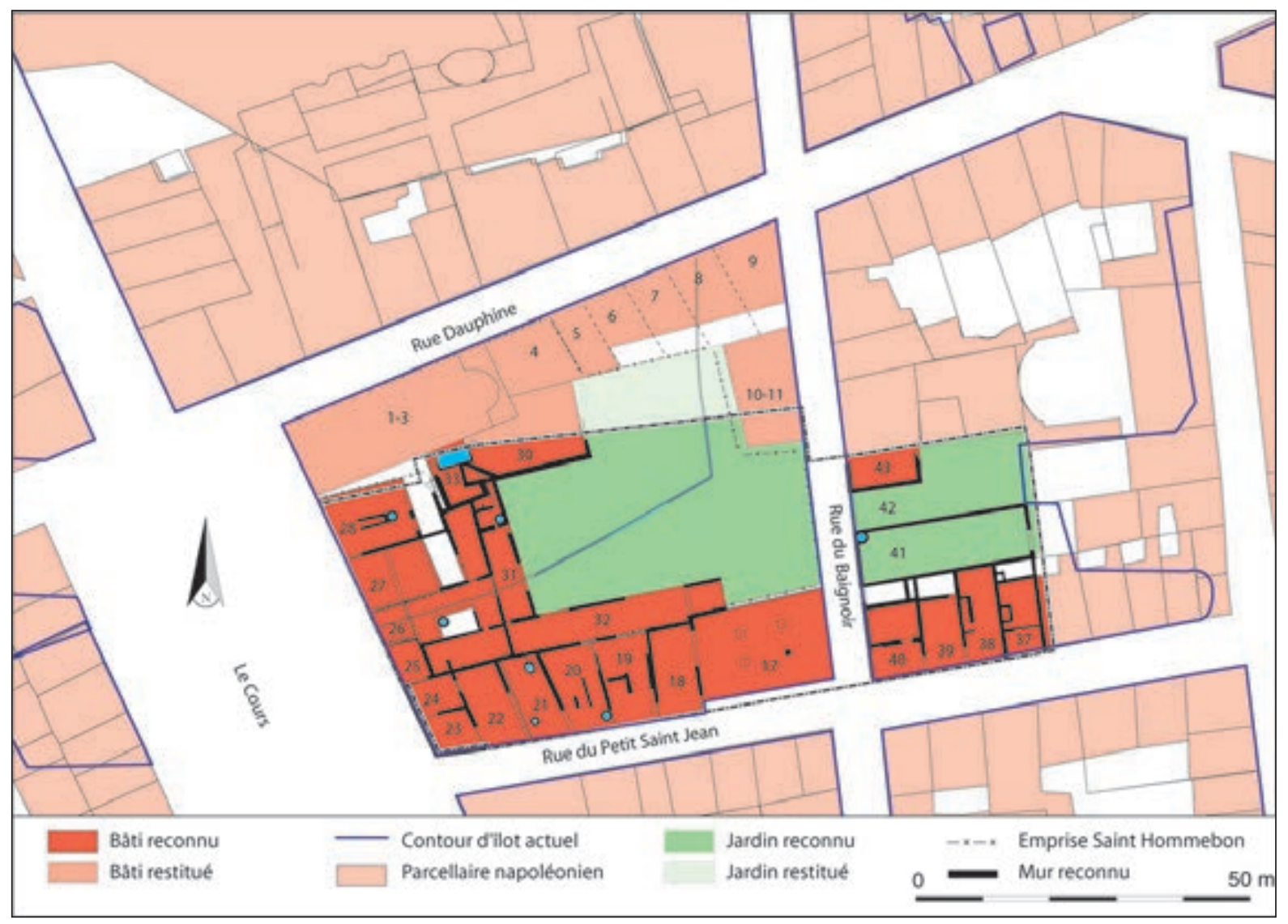

Fig. 260. Plan du secteur de l'Alcazar en 1682 (DAO B. Sillano /Inrap). laquelle a esté bastie après l'agrandissement sur les débris d'une maison ${ }^{877}$. Il montre clairement qu'elle a été entièrement reconstruite. Le nouveau bâtiment possède quatre étages et une boutique au rez-de-chaussée. Sur le terrain, nous constatons que le mur méridional est prolongé vers l'est par un mur de même largeur, fondé

877 ACM DD 164, fol. 104v. moins profondément et lié par du mortier gris. Son appareillage est irrégulier et les moellons sont essentiellement du calcaire blanc. Ce mur est lié à un petit retour, qui forme sans doute une base de pilier. Deux autres piliers, bâtis en blocs de calcaire de La Couronne soigneusement taillés, matérialisent ce retour. Cet ensemble constitue l'arrière du bâtiment principal, comme en témoigne le bâti encore en place avant le début du chantier de fouille. Ce recul montre la nécessité de déplacer la façade en 


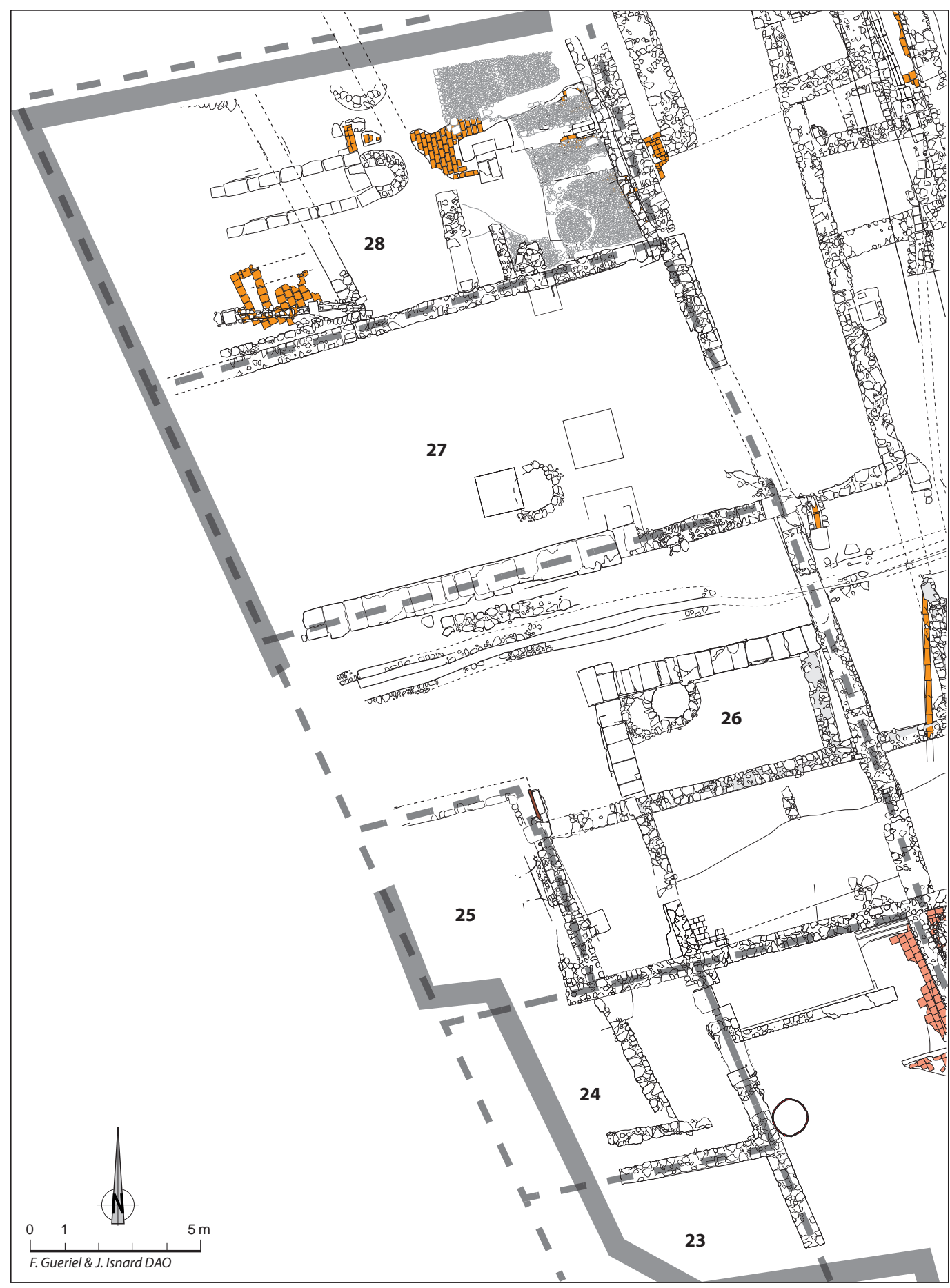

Fig. 261. Plan des vestiges modernes des parcelles 23 à 28 (DAO F. Gueriel, J. Isnard/ Inrap).

raison du réalignement sur le nouveau Cours dont l'amplitude est ici maximale, de près de 7,50 m. À l'intérieur du bâtiment, une construction en forme de «U», ouverte côté rue, est installée dans son axe et correspond à une montée d'escalier. Il s'adosse à l'ancien puits qui est toujours en fonction. Les trois murs d'échiffre sont constitués de gros blocs de calcaire jaune. Une murette en briquettes, d'axe nord-sud, prolonge le fond de l'escalier et son pendant au sud n'a pas été conservé mais devait exister. Elle permet de restituer trois pièces, deux d'axe est-ouest de part et d'autre de l'escalier et une derrière, d'axe nord-sud. À l'est, l'espace, couvert ou non, est limité à l'extérieur par une ossature de piliers. L'ensemble de ces niveaux de rez-de-chaussée est pavé de carreaux de terre cuite, comme l'indiquent les fragments conservés de manière lacunaire. Des bassins (dégradés) enduits de béton de tuileau sont également présents en fond de parcelle. 


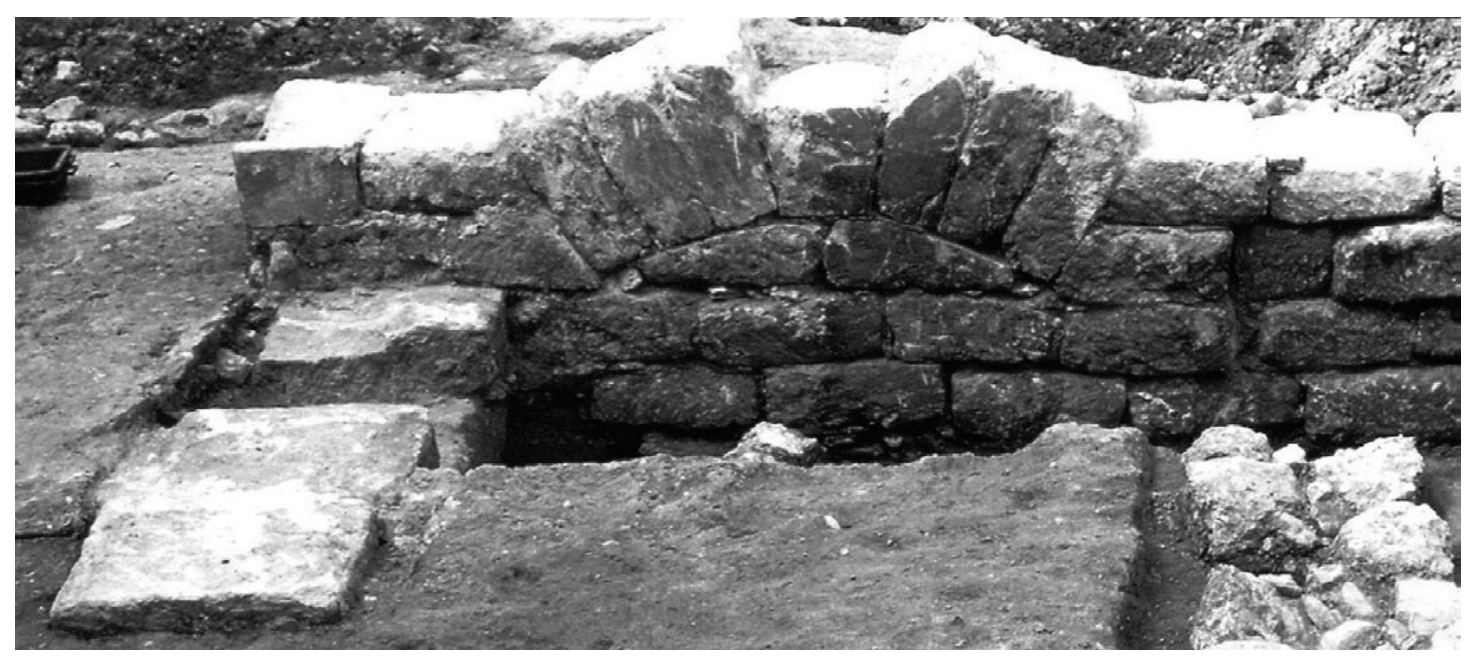

Fig. 262. Arc de décharge au-dessus du puits de la parcelle 26 (cl. T. Maziers/Inrap).

Le rapport d'expertise commence par la même remarque sur la reconstruction de la parcelle 27. C'est alors une maison d'habitation composée de quatre étages, avec une boutique, une écurie et une cave audessous. Un devis de $1675^{878}$ nous apporte des détails sur la nouvelle construction. On apprend ainsi que la cave s'étend «de la longueur despuis la muraille $d u$ derrière jusqu'au carage » et qu'elle mesure 4,50 m de large ; le puits est également creusé à cette époque. Malheureusement, l'extension de la cave à l'époque contemporaine a effacé les traces d'occupation antérieures. Seul le mur nord a été conservé car les autres, en grand appareil de taille, sont d'époque contemporaine. Contre celui-ci, l'empreinte d'une voûte abandonnée est le seul vestige de la cave primitive. Elle est faite avec des moellons de grès liés par un mortier jaune pulvérulent qui reposent sur un ressaut installé en sous-œuvre. Une voûte en berceau ne pouvant couvrir toute la largeur de la parcelle, on comprend pourquoi il est précisé dans le devis que la cave devait avoir $4 \mathrm{~m}$ de large. Cette cave est limitée à l'est au mur de confins de l'ancien bâtiment, mais le rapport d'expertise nous montre que le nouveau s'étend bien au-delà vers l'est, sur une superficie qu'il conserve jusqu'à l'époque actuelle. Enfin, sous le sol de cave, un puits a été mis en évidence qui, par sa localisation et sa conception, se rattache à l'Époque moderne. Il s'agit certainement du puits creusé en 1675, curieusement à l'intérieur du bâtiment.

La parcelle 26, qui n'était pas bâtie avant l'Agrandissement, est renseignée par deux textes écrits à un an d'intervalle. Le premier est le rapport d'estime de 1683, l'autre une déclaration de l'économe de la congrégation de Saint-Hommebon à qui elle appartient ${ }^{879}$. Ils

878 AD13 380 E 171, fol. 1411.

879 AD13 B 929, fol. 207v. décrivent un premier bâtiment, situé en façade sur le Cours, approximativement carré, de 5,50 m de côté, puis plusieurs écuries en retraits. La première occupe tout le fond de la parcelle à laquelle s'ajoute l'arrière de la parcelle voisine au sud, soit un carré de $12 \mathrm{~m}$ de côté ; les autres bordent les possessions de la congrégation, en cœur d'îlot ( $c f$. infra). Lors des fouilles, cette parcelle étant située sous l'accès au chantier, il a été décidé de faire un décapage massif des niveaux modernes pour ne conserver que les bases de fondation des murs. Ainsi, le mur arrière du bâtiment n'a pas été retrouvé ; en revanche, vers le fond, trois murs structurent l'espace. Ils doivent être mis en relation avec le cloisonnement du couvent. En effet, le fond de la parcelle n'est autre que le grand mur d'axe nord-sud qui s'aligne sur la façade de l'église, située au nord et le mur sud est l'arrière des parcelles qui bordent la rue du Petit-Saint-Jean, limite méridionale du domaine de la congrégation. Le mur axial se prolonge vers l'est à travers le cour d'îlot. Enfin, un court refend n'a d'autre retour que des murs en grand appareil plus récents. Au niveau du puits, un arc de décharge est pratiqué (fig. 262). Ces murs, élevés selon un mode de construction caractéristique du XVIII ${ }^{\mathrm{e}}$ s., ont dû prendre la place d'un prédécesseur trop peu fondé. Ainsi pouvons-nous restituer une cour intérieure avec un puits. La parcelle est traversée d'est en ouest par une canalisation d'époque contemporaine qui reprend l'axe d'un réseau plus ancien en provenance du coeur d'îlot. Un lambeau de sol pavé de terre cuite, daté des années 1680 - 1710 par le remblai sur lequel il repose, a été conservé au sud. Il s'agit de carreaux de $25 \mathrm{~cm}$ par $15 \mathrm{~cm}$ pour $3 \mathrm{~cm}$ d'épaisseur.

Le rapport d'estime mentionne pour la parcelle 25 un immeuble de quatre étages sur un magasin, de $6 \mathrm{~m}$ de large pour $4,75 \mathrm{~m}$ de long. Elle a été excavée à une période récente et il ne reste rien des niveaux d'occupation 
antérieurs. Le mur nord, repris en sous-œuvre, n'a été vu qu'en coupe. Large de $0,55 \mathrm{~m}$ et constitué d'un double parement de moellons de calcaire oligocène, il est relativement similaire au mur du fond de parcelle, mais ce dernier est constitué pour moitié de calcaire oligocène et pour moitié de calcaire de La Couronne. Le mur sud, dans le prolongement du mur de confins des parcelles le long de la rue du Petit-Saint-Jean, a une fondation en pierres liées par un mortier jaune, d'épaisseur irrégulière, qui contraste avec le liant blanc des autres murs. Il est certainement à relier à la parcelle suivante.

La parcelle 24 est mentionnée comme l'auberge du Cheval Rouge. Il s'agit encore d'un immeuble de quatre étages avec un magasin au rez-de-chaussée, toujours relié à la parcelle 22 sur la rue du Petit-Saint-Jean. La fouille a révélé la présence d'une ouverture dans le mur du fond, lequel est un reliquat de l'état précédent. Celle-ci, parementée de blocs de calcaire rose, mesure presque $2 \mathrm{~m}$ de large. Elle est excentrée vers le nord car un escalier, matérialisé par son mur d'échiffre très fruste, prend place contre le mur méridional.

Enfin, la parcelle 23, à l'angle du Cours, a la particularité d'avoir conservée sa façade, édifiée en 1675, dans la bibliothèque de l'Alcazar ( $c f$. fig. 37). Le rapport d'estime mentionne un immeuble de quatre étages avec boutique au rez-de-chaussée et une cave au-dessous. Effectivement, le terrain a révélé la présence d'une cave, bordée de murs aux fondations profondes ( $2 \mathrm{~m}$ ), épais de $0,60 \mathrm{~m}$ et faits de blocs équarris en calcaire tendre sur l'élévation. Les difficultés techniques rencontrées dans cet angle du chantier n'ont pas permis une meilleure observation. Pour cette raison, l'escalier, présent à l'angle, n'a pas été relevé car jugé trop dangereux.

\subsubsection{Mutation des bâtiments le long de la rue du Petit-Saint-Jean}

Nous ne possédons pas la façade des parcelles situées le long de la rue du Petit-Saint-Jean mais, si l'on se réfère aux données d'archives, elles ne semblent pas avoir été frappées d'alignement. Les transformations réalisées de manière systématique après l'agrandissement ne modifient donc pas la configuration des parcelles mais davantage leur vocation.

D'après le rapport d'estime de 1667 où elle est toujours associée à la parcelle 24, la parcelle 22 est occupée par une écurie surmontée de quatre étages. Un devis de $1674^{880}$ stipule cependant que la nouvelle maison aura deux étages, ce qui est plus compatible avec l'état actuel qui n'en présente que trois.

880 AD13 390 E 235, fol. 332v.
Seul le mur occidental a été refait, en liaison avec la réfection de la parcelle voisine (23) (cf. supra). Les autres sont hérités des périodes antérieures. Une cloison légère isole une petite pièce au fond, de part et d'autre de laquelle sont installés deux carrelages de terre cuite. De chaque côté de cette cloison sont installés deux carrelages, en carreaux de terre cuite rouge de forme carrée de $25 \mathrm{~cm}$ de côté. Le carrelage nord se caractérise par des carreaux plus fins $(1,8 \mathrm{~cm})$ que l'autre $(3 \mathrm{~cm})$, mais aussi plus indurés. Le plus curieux est cependant la nature de son radier de préparation, où abondent les tessons de bouteilles de couleur verte, de plusieurs modèles. Antérieurement à la destruction partielle de ce sol par la cave récente, ce radier était plus étendu encore, ce qui nous conduit à penser que plusieurs centaines, voire des milliers de tessons de bouteilles sont réunis là au même moment. On doit très certainement mettre cette présence de bouteilles en relation avec les auberges qui se trouvent dans le quartier à l'époque de cette construction. La parcelle est ensuite excavée sur sa moitié sud, les murs qui se mettent alors en place étant caractérisés par un mortier jaune foncé débordant. Enfin, la parcelle possède un puits, non relevé, construit contre le parement est du mur ouest et dans l'alignement de la cloison. Son cuvelage, de $1 \mathrm{~m}$ de diamètre interne, est, pour la partie conservée du moins, entièrement en briques cuites, de couleur jaune rouge, aux dimensions de $23 \mathrm{~cm}$ par $15 \mathrm{~cm}$ par $3 \mathrm{~cm}$. Conservées sur sept assises, elles sont disposées verticalement et de chant sur leur petit côté et maintenues en place par du mortier beige jaune friable. Rien ne permet de dater ces structures, mais nous émettons un doute sur l'utilisation des carreaux de terre cuite dans les écuries.

La parcelle 21 est occupée en 1684 par l'auberge de l'Escu d'Or et se compose, dans le rapport, d'un étage qui surmonte un grand magasin. Elle est «fort vieille et dans le mesme estat qu'elle estoit avant lagrandissement $\gg$. Cette maison n'a donc pas été refaite; en revanche, de simple écurie, elle est devenue auberge. La seule partie bien conservée, dans l'angle nord-ouest de l'espace, la calade, a été remplacée par un, puis deux carrelages, postérieurement à la seconde moitié du XVII $\mathrm{s}$. Un remblai préalable à la chape qui supporte le premier carrelage permet de niveler les inégalités de la surface de la calade. Seules les empreintes à sa surface nous permettent de restituer des carreaux de $24 \mathrm{~cm}$ par $16 \mathrm{~cm}$, récupérés par la suite. Le suivant est fait de carreaux carrés de $24,5 \mathrm{~cm}$ de côté disposés en quinconce. Ce dernier est complété, sur le parement est du mur occidental, par un revêtement de carreaux identiques mais moins épais. L'état de conservation du mur ne permet pas de dire si ces carreaux ont été disposés uniquement en plinthe, ou s'ils montaient sur toute sa surface, la première hypothèse étant la plus probable. La parcelle 21 comporte 
également deux puits qu'il est difficile de dater. L'un d'eux, au nord-est, est de forme ovoïde. Son cuvelage est fait de moellons retouchés en poudingue, ainsi que de cailloux bruts en poudingue et en calcaire blanc, de galets, et de fragments de carreaux en terre cuite. Le tout est lié par un mortier de couleur rose mêlé de terre, avec des joints d'épaisseur irrégulière, rentrants. La couleur du mortier indique sans doute la phase récente du site, plutôt qu'une phase ancienne. Le second est au sud-ouest et une partie de sa margelle est conservée. Le cuvelage, quasi-cylindrique et de $0,70 \mathrm{~m}$ de diamètre interne, est construit en éléments très diversifiés, avec un appareil irrégulier, voire chaotique. La margelle, en grands blocs de calcaire tendre sciés en remploi, comporte sans doute initialement quatre à cinq assises.

Les parcelles 19 et $\mathbf{2 0}$ sont toujours associées en 1672 lorsque deux devis de reconstruction sont établis. L'un d'eux ${ }^{881}$ concerne la reconstruction de la « murailhe moitinière », l'autre ${ }^{\mathbf{8 8 2}}$ le rehaussement du bâtiment. En 1684 , le rapport d'estime décrit une maison où pend pour enseigne Le Petit Paris composée de deux étages et une écurie. Elle est jointive avec l'auberge du Petit SaintJean ce qui indique que le passage qui permettait l'accès aux jardins de la congrégation est englobé, comme le confirme la largeur totale de la parcelle. En fouille, nous constatons effectivement la destruction de la bordure occidentale de ce passage, puis un nivellement de l'espace par un épais remblai d'argile pure, compact et homogène. Puis l'édification d'un mur axial oblique par rapport à l'ancien qui permet de compenser la forme trapézoïdale de la parcelle étendue. Il s'agit certainement de la «murailhe moitinière » puisqu'il divise l'ensemble des parcelles 19 et 20 en deux parties égales. Ce mur a une fondation assez hétérogène, tout comme l'élévation, conservée sur deux assises, en moellons et en blocs bruts et équarris de calcaire blanc, dont la disposition est désordonnée, et liés par un mortier épais jaunâtre. Une ouverture, large de $2 \mathrm{~m}$, est pratiquée dans la partie médiane de ce mur, matérialisée par deux piédroits faits de gros blocs de calcaire de La Couronne taillés.

La partie ouest, la parcelle 20, voit s'édifier un grand nombre de structures et de sols qu'il est souvent difficile de caler chronologiquement. On note la construction d'un mur, épais de $0,40 \mathrm{~m}$, parallèle et appuyé contre le mur nord, probablement pour en consolider l'élévation, qui n'est sans doute pas calculé au départ pour être le mur d'un bâtiment. Sa fondation, conservée sur deux assises, est faite de moellons équarris et de cailloux retouchés, en calcaire blanc, disposés en assises régulières. Une cloison reprend le mur qui séparait l'espace en deux selon

881 AD13 367 E 159, fol. 1182v.

882 AD13 367 E 159, fol. 930v. un axe nord-sud. À l'ouest, une calade est établie, séparée du mur occidental par une étroite murette adossée. Ce sol est remblayé puis remplacé par un pavement de carreaux carrés de $23 \mathrm{~cm}$ de côté. Le remblai contient du mobilier daté des années 1700. Dans l'angle nord-ouest, une fosse chaulée de forme carrée, de $2 \mathrm{~m}$ de côté et profonde de $0,60 \mathrm{~m}$, est creusée dans la calade. Comblée vers 1750 , elle atteste de travaux à cette période. À l'est de la cloison, un carrelage de type chantignole est conservé, recoupé ensuite par l'installation d'une canalisation faite de borneaux de terre cuite qui court le long de la cloison. Ce sol, qui semble correspondre à l'abandon de l'ouverture entre les deux parcelles, est très récent si on se réfère au bouchage en béton qui scelle la canalisation. Il correspond à la réfection du bâtiment lorsque les parcelles se sont individualisées. En résumé, les niveaux correspondant à l'écurie citée dans le rapport d'estime se réduisent à la calade. Nous constatons également que le rehaussement des murs se traduit par le doublage de leur base par une murette.

La partie est, la parcelle 19, connait tout d'abord le dérasement des murs centraux et occidentaux puis la mise en place d'un remblai, avant la construction de murs de refend. Le mur qui la borde à l'est possède une fondation profonde, assez similaire à son pendant à l'ouest. L'élévation, épaisse de seulement $0,40 \mathrm{~m}$, est composée de blocs sciés en calcaire divers formant un grand appareil de taille régulier, conservé sur un seul rang. Il est peut-être à mettre en relation avec la réfection de la parcelle voisine. Le mur nord est doublé d'une murette. Dans l'axe, le refend d'axe nord-sud a une fondation très épaisse $(0,75 \mathrm{~m})$ et hétérogène. Il semble ne pas aller jusqu' au fond de la parcelle, où une cloison qui le remplace pourrait indiquer la présence d'une ouverture primitive. Il est en relation avec un court refend perpendiculaire qui ferme deux espaces à l'ouest. Les niveaux de sol de cette parcelle sont implantés sur un nouveau remblai uniforme généralisé, daté du milieu du $\mathrm{XVIII}^{\mathrm{e}}$ s. Ils se caractérisent par l'usage de carreaux en terre cuite rouge, de forme carrée de $24 \mathrm{~cm}$ de côté.

\subsection{De l'Agrandissement à la Révolution : le lotissement de la Ville Nouvelle}

L'évolution du quartier jusqu'à la fin du XVIII ${ }^{\mathrm{e}} \mathrm{s}$. a pu être étudiée en détail grâce à la bonne conservation des vestiges de cette époque.

\subsubsection{Parcelles à l'est de la rue du Baignoir}

En 1675, Noble Thomas Riquetti revend, après les avoir divisés, les terrains qui bordent la « rue nouvelle », 
dans le prolongement de la rue du Petit-Saint-Jean ${ }^{\mathbf{8 8 3}}$. Les parcelles, sauf celle d'angle, mesurent $6 \mathrm{~m}$ de large pour $14 \mathrm{~m}$ de long. Elles sont ensuite loties selon un ordre que la fouille permet de reconstituer.

Tout d'abord, à l'angle des deux rues, la parcelle 40 remplace l'ancien bâtiment, arasé, tout en changeant son orientation d'un quart de tour. Sur le mur de façade de la rue du Baignoir, réutilisé, est adjoint un mur au nord, lui-même chaîné au mur oriental. Le bâtiment ainsi créé à l'angle des deux rues mesure $10,50 \mathrm{~m}$ par $7 \mathrm{~m}$; il n'occupe pas toute la longueur de la parcelle. Par la suite, c'est beaucoup plus loin, sur la parcelle 37, qu'est édifié un bâtiment de $11,50 \mathrm{~m}$ de long pour $5,50 \mathrm{~m}$ de large. Vient ensuite une construction qui occupe toute la parcelle 38 (14 m par 5,50 m). À ce stade est édifié le mur méridional de la parcelle voisine 41, aligné sur le fond du bâtiment de la parcelle 38. Dans la foulée sont bâtis les retours qui ferment les parcelles 41 et 37, délimitant ainsi des arrière-cours. Enfin, la parcelle 39 est dotée d'un bâtiment de 5,50 m de large pour 10,50 m de long construit tout simplement en fermant la parcelle par un mur adossé aux voisins. À ce moment, la parcelle 43 étant bâtie antérieurement, la façade orientale de la rue du Baignoir est presque entièrement constituée. Seule la parcelle 42 reste ouverte sur la rue jusqu'à ce qu'un mur vienne la fermer et que cette portion d'îlot acquierre ainsi une configuration qu'il conservera jusqu'à nos jours.

En limite de fouille, la parcelle 36 n'est conservée que sur moins d'un mètre de large. Seule une base de voûte en berceau a été vue. Nous supposerons qu'elle est relativement similaire à la parcelle voisine, comme semble l'attester le cadastre.

Les murs maîtres de la parcelle 37 sont constitués de cailloux et moellons de poudingue (mur ouest) ou de calcaire blanc (mur est), liés par du mortier grisâtre et disposés de manière irrégulière. Dans un second temps, l'espace est séparé en deux par un mur est-ouest qui délimite au sud un espace de plain-pied, tandis qu'au nord est creusée une cave dotée d'un sol aménagé de galets. Ce mur n'est pas daté, mais il recoupe entre autres une fosse dont le matériel le plus récent date des années 1670-1680. Au nord, à l'extérieur et dans un angle, est bâti un puits de plan carré. Un autre, circulaire, est également présent au sud. La cave est ensuite couverte d'une voûte en berceau et dotée d'un escalier à deux volées.

Le bâti de la parcelle 38, qui occupe toute la superficie, réutilise le mur de la parcelle précédente. À l'ouest, le mur édifié est épais de 0,65 m et constitué de moellons de calcaire ou de grès, disposés de manière irrégulière. Sa face orientale est enduite et il n'a pas été possible de

$\mathbf{8 8 3}$ AD13 380 E 171, fol. 49 et 380 ; AD13 E 170, fol. 1395v. savoir si la cave a été prévue ou non lors de la construction de ce mur. Au nord, il est chaîné avec la portion de mur qui forme le fond de la parcelle. Sur toute la superficie de ce bâti, une cave est creusée, mais nous ne savons pas si elle l'a été dès l'origine à cause d'un enduit trop induré qui en recouvre les parois. Elle est dotée d'un escalier d'accès central et comporte un triple système de voûtement : en berceau nord-sud pour la partie centrale et en voûtes d'arêtes pour les extrémités nord et sud. Ces voûtes en briques et petites dalles de calcaire retombent sur des impostes en calcaire rose qui sont insérées dans la maçonnerie du mur maître, postérieurement à sa construction.

Le refend qui permet de créer la parcelle 39 est large de 0,50 m et constitué de calcaire et poudingue. Il se termine à l'est par un piédroit délimitant une ouverture, face à laquelle un emmarchement permet l'accès, depuis le terre-plein au nord, à l'espace surcreusé au sud. Le reste de la parcelle est mal conservé et n'a rien révélé.

Les murs nord et est de la parcelle 40 sont épais de $0,60 \mathrm{~m}$ et ont un appareillage irrégulier. Le premier est hétérogène alors que l'autre est constitué exclusivement de moellons de calcaire. L'espace est ensuite recoupé, approximativement au centre par un mur est-ouest. Les deux pièces ainsi séparées communiquent par l'intermédiaire d'une ouverture, une porte en plein cintre construite au moyen de blocs de calcaire rose. Dans un second temps, l'espace tout au nord est réduit par adjonction d'un refend, puis la partie occidentale est excavée. Durant la période contemporaine, l'espace sud est doté d'un four à pain, lié à des aménagements dans l'espace nord.

La parcelle 41 est la plus grande observée sur le site de l'Alcazar. Elle mesure $26 \mathrm{~m}$ de long pour une largeur de $8 \mathrm{~m}$. Les murs qui l'entourent sont épais de $0,60 \mathrm{~m}$ et constitués de moellons de calcaire tendre disposés de manière irrégulière ; le mur de confins pourrait présenter une ouverture de $3 \mathrm{~m}$ de large. Deux puits y prennent place. Le premier, dans l'angle nord-ouest, a une forme de quart de cercle car il s'intègre aux murs. Il a un diamètre interne de $1,20 \mathrm{~m}$ et son cuvelage, constitué de moellons de calcaire tendre, a un appareillage irrégulier. Le second est sur l'axe médian de la parcelle, à l'extrémité orientale. Son diamètre interne est de $0,60 \mathrm{~m}$ et son cuvelage est constitué de moellons de calcaire tendre et dur. L'ensemble est scellé par un remblai de nivellement qu'il est possible de subdiviser en trois couches qui pourraient correspondre à une mise en culture. La grande dimension de cette parcelle suppose qu'il s'agisse d'un espace ouvert, ce qui est confirmé par l'absence de sol bâti. Dans l'angle sud-ouest de la parcelle, une petite construction, de 4,50 m par $2 \mathrm{~m}$, matérialisée par deux murs et un pilier, semble correspondre à un appentis. 
Durant la période contemporaine, cette construction est abolie et une cuve est construite en son sein, destinée à récolter les eaux usées provenant de la rue et de la cave de la parcelle 40 .

La parcelle 42 est la dernière à avoir été complètement fermée lorsque le mur de façade a été bâti. Ce mur, caractérisé par un mortier jaunâtre pulvérulent, est épais de 0,60 $\mathrm{m}$ et constitué de moellons de calcaire tendre disposés de manière irrégulière. Au nord, elle est limitée par le mur du bâtiment qui occupait la parcelle voisine (cf. supra) et son prolongement vers l'est où il est chaîné avec un retour, à $20 \mathrm{~m}$ de la façade. Le prolongement, épais de 0,50 m, est constitué de moellons de calcaire dur et tendre, le retour, épais de $0,80 \mathrm{~m}$, de moellons et blocs de calcaire gréseux. Les aménagements internes consistent en deux piliers supportant les retombées d'une voûte et deux murs de refend placés de part et d'autre d'un puits (ces deux murs ne sont pas forcément contemporains, mais leur mauvaise conservation ainsi que l'absence d'éléments de datation les concernant nous les ont fait regrouper ici). Le puits, d'un diamètre intérieur de $0,70 \mathrm{~m}$, a un cuvelage constitué de moellons de calcaire. Malgré l'absence de sols, les supports de voûte pourraient indiquer qu'il s'agit d'un bâtiment. En fond de parcelle, le mur nord est prolongé par un mur dont une assise en élévation est conservée, constituée de blocs taillés en calcaire détritique rose ou jaune. Au sein de l'espace ainsi délimité a été installée une structure bâtie circulaire dont la fonction reste inconnue. Peut-être s'agit-il d'un fond de puits ou de citerne.

Le bâtiment originel de la parcelle 43 est entièrement excavé et agrandi vers l'est. Cet agrandissement est divisé en deux par un mur de refend dont il ne reste que quelques éléments de la première assise de fondation. Il s'agit de blocs de calcaire détritique jaune, reposant sur un alignement de pieux. La faible profondeur des fondations est peu compatible avec un bâtiment. Il est possible que, avant que le bâti s'étende à toute la parcelle, parallèlement au creusement de caves à l'époque contemporaine, celui-ci se limitait à l'ancien bâtiment.

\subsubsection{Un programme de construction à l'ouest de la rue du Baignoir}

Postérieurement à la désaffection d'une portion du réseau de canalisations provenant du cœur d'îlot, daté de 1700-1750, une série d'immeubles s'implante en bordure ouest de la rue du Baignoir (fig. 263). L'ensemble des pièces dégagées correspond aux caves préservées de quatre bâtiments perdurant jusqu'à leur destruction en 1999. Les textes d'archives font état, dans le courant du XVIII ${ }^{\mathrm{e}}$ s., de l'édification d'immeubles sur des parcelles de jardins appartenant à la congrégation des pères du Saint-Sacrement, sises à l'ouest le long de la partie médiane de l'actuelle rue du Baignoir, jouxtant au sud l'auberge du Petit Saint-Jean.

L'ensemble de ces bâtiments forme un îlot homogène, caractérisé par une cohésion dans les volumes, la mise en œuvre et les matériaux employés. Son emprise totale, limitée au sud par l'auberge du Petit Saint-Jean et au nord par la parcelle 11, déjà bâtie et à l'extérieur du chantier de fouille, mesure 27,50 $\mathrm{m}$ du nord au sud pour 12,50 $\mathrm{m}$ de profondeur. Elle est divisée par les murs de refend est-ouest séparant les différents immeubles, de module presque similaire, soit une longueur interne de $11 \mathrm{~m}$ pour une largeur de $6 \mathrm{~m}$ à $6,50 \mathrm{~m}$. Toutefois le bâtiment le plus méridional se distingue des autres par la forme et la longueur, avec un décrochement sur sa façade arrière.

Tous les murs de façade, mitoyens et de cloisons sont bâtis avec des matériaux identiques, mis en œuvre selon un même appareil irrégulier et des dimensions comparables. La largeur moyenne est de $0,75 \mathrm{~m}$ pour les murs maîtres et 0,40 à $0,50 \mathrm{~m}$ pour les cloisons. Leurs matériaux consistent en une forte proportion de cailloux et de moellons de poudingue retouchés, associant des pierres en calcaire blanc ou beige à grain fin, en calcaire marneux et en grès retouchés, liés à un mortier maigre brun clair. Dans le détail, certains murs présentent de sensibles différences, notamment le long mur de façade, comprenant des portions de parements en appareil variable, petit à moyen, irrégulier ou assisé, probablement du fait de sa construction en plusieurs étapes. Les parements de la plupart des murs ont fait l'objet d'un traitement de protection avec un revêtement d'enduit de mortier hydraulique, couleur lie-de-vin, épais de $4 \mathrm{~cm}$ et résistant sur la face intérieure, en élévation, des murs de façade. La particularité des murs maîtres réside dans leur première assise de fondation particulièrement puissante, constituée d'un rang de gros blocs en calcaire coquillier taillés (L. : 0,78 m, 1. : 0,52 m, ép. : 0,28 m), disposés en boutisse.

Les espaces observés correspondent à des caves dont les implantations ont nécessité un décaissement général, effectué à l'aplomb de la rue du Baignoir, sur une profondeur d'environ deux mètres. La largeur des parcelles bâties correspond sensiblement à un axe constitué par l'aqueduc et le fossé médiévaux. Bien que des particularités de constructions, notamment dans les ouvertures et les pavements, soient similaires d'une pièce à l'autre, leur nombre, leur surface et leur disposition varient selon les immeubles. Les piédroits de portes sont tous caractérisés par des blocs en calcaire rose taillés avec des feuillures aux dimensions sensiblement identiques, et leurs sols sont pourvus de carreaux en terre cuite rectangulaires, au format standard $(24,5 \mathrm{~cm}$ par $15 \mathrm{~cm}$ pour $3 \mathrm{~cm}$ d'épaisseur) disposés en quinconce. 


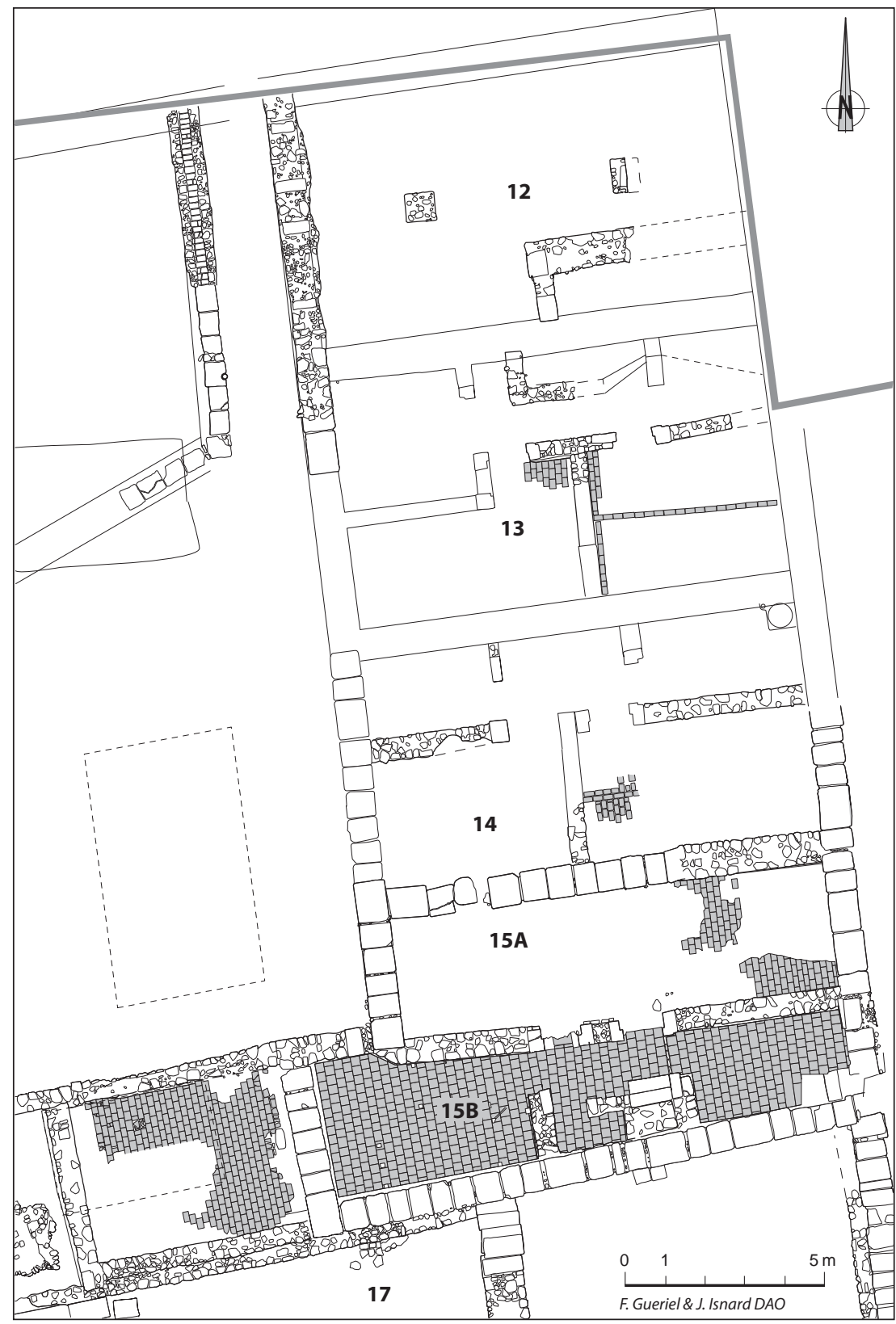

Fig. 263. Plan des vestiges modernes des parcelles 12 à 15 (DAO F. Gueriel, J. Isnard/Inrap).

En arrière de ces constructions, a été trouvée une fosse à chaux de $4 \mathrm{~m}$ de long pour 3,50 $\mathrm{m}$ de large et d'une profondeur minimale de $0,30 \mathrm{~m}$. Elle est comblée par un remblai contenant de nombreux nodules de chaux, des débris de mortier, d'enduits, quelques galets et un abondant mobilier céramique qui n'est pas antérieur à 1720-1730. Cependant, si les parcelles ont des modules et un mode de construction similaires, elles diffèrent au niveau de leur plan, tout au moins pour le sous-sol, la seule partie qui nous soit parvenue.

Au nord, la parcelle 12 est recoupée par la paroi moulée du chantier. Elle comprend au moins un espace conservé pourvu de trois sols successifs, dont à l'origine deux pavements de terre cuite (carreaux de $25 \mathrm{~cm}$ par $16 \mathrm{~cm}$, puis carrés de $23 \mathrm{~cm}$ de côté). Dans l'angle sud-est, deux fondations de murs, formées d'une assise de moellons, incluant à leur extrémité un gros bloc en calcaire rose, pourraient correspondre au soubassement d'un escalier.

Le sous-sol du bâtiment suivant (parcelle 13), d'un peu moins de $70 \mathrm{~m}^{2}$, se compose d'un couloir desservant quatre pièces et du soubassement d'un escalier d'accès. Le plan se découpe globalement en deux parties, avec au nord un secteur dévolu plutôt à la circulation et aux petits espaces, et au sud, en contrebas d'une vingtaine de centimètres, une surface occupée par de grandes pièces. La largeur des ouvertures varie de $0,84 \mathrm{~m}$ à $1 \mathrm{~m}$; elles comprennent deux piédroits conservés sur une à trois 


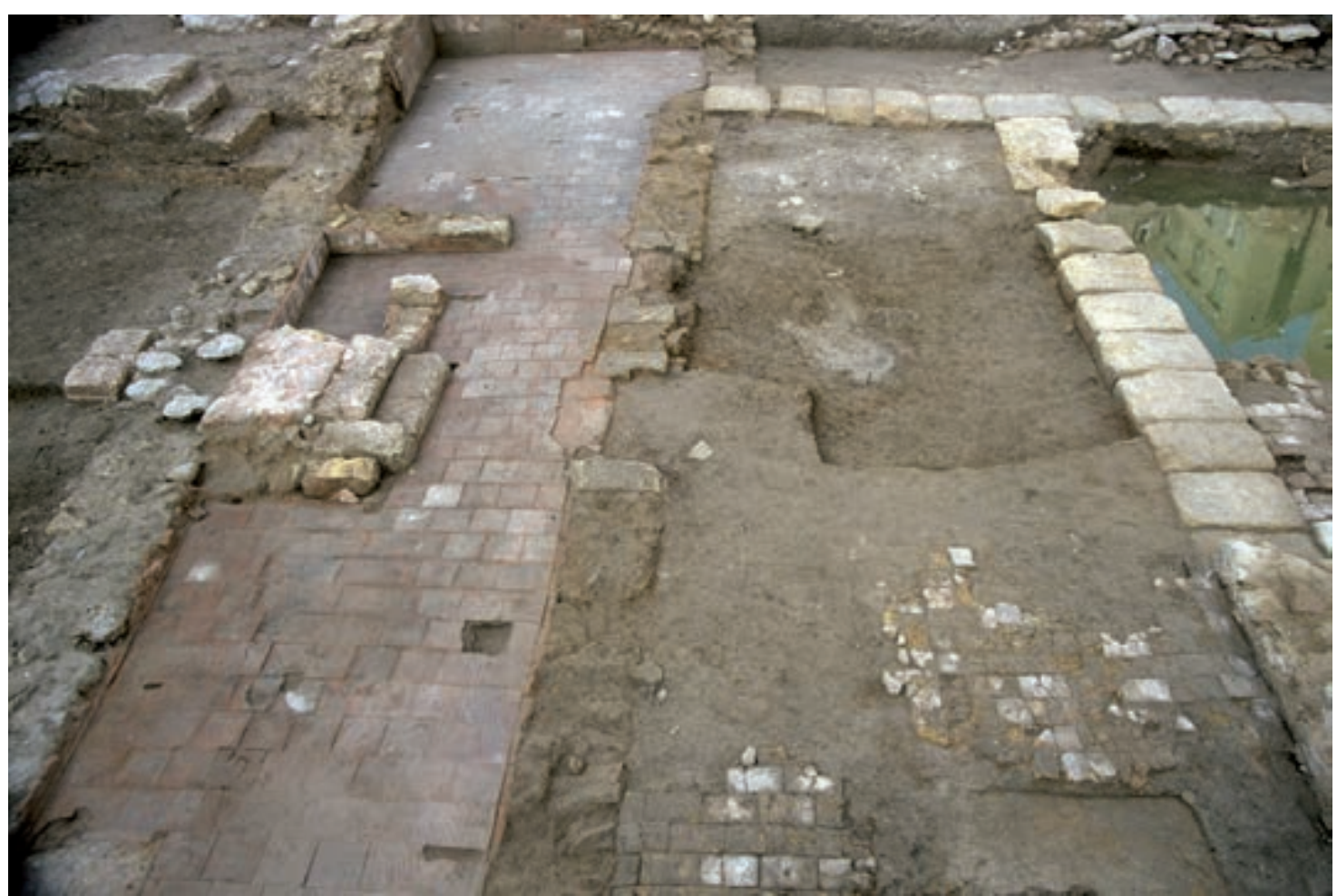

Fig. 264. Les vestiges modernes de la parcelle 15 vus de l'est (cl. T. Maziers/Inrap).

assises de blocs de module important mais variable selon les jambages (L. : 0,35 à 0,60 m, 1. : 0,24 à $0,44 \mathrm{~m}$, h. : 0,25 à 0,30 m), liés à un mortier maigre et mince, parfois complétés par une maçonnerie de briques ou de pierres en poudingue. Deux ouvertures seulement comportent une pierre de seuil, monolithe ou en cailloux de conglomérat. Les sols de carreaux sont similaires, l'un d'entre eux comportant sur son axe médian des carreaux disposés perpendiculairement pour faire un fil d'eau.

Le troisième immeuble (parcelle 14), d'environ $62 \mathrm{~m}^{2}$, est constitué de cinq pièces. Son plan se scinde aussi en deux parties avec, au nord, trois petits espaces, de 6 à 7,50 $\mathrm{m}^{2}$, agencés en enfilade et dont l'un sert de dégagement, et au sud, deux vastes pièces occupant plus de la moitié de la surface. Les portes ont une largeur moyenne de $1 \mathrm{~m}$ et les blocs des montants des dimensions distinctes. La grande pièce est aménagée avec un sol constitué également de deux panneaux, et d'une rangée de carreaux agencés dans l'axe central estouest de la pièce.

Le dernier immeuble (parcelle 15) présente, dans sa partie sud, un décrochement vers l'ouest (fig. 264). Il semble qu'en utilisant le bâtiment qui borde la cour du domaine de la congrégation, les pères ont légèrement augmenté la superficie de cette parcelle. La différence de mode de construction du mur nord de cette extension atteste par ailleurs de l'existence d'un bâti antérieur. En ce qui concerne la division du sous-sol, un acte notarié de 1783 dénombre deux grandes caves, une troisième petite et une quatrième «extrêmement petite ». Plusieurs caves ont été effectivement dégagées, mais le décompte ne coïncide pas avec le texte précité. Un mur est-ouest divise l'emprise de l'immeuble en deux longues pièces rectangulaires, chacune ayant été à son tour subdivisée. Celle qui est au nord couvre une superficie de 33,5 $\mathrm{m}^{2}$ et possède deux accès distincts d'une largeur de $1 \mathrm{~m}$. Leur présence et leur localisation suggèrent une subdivision de la cave en au moins deux espaces. L'autre pièce est de forme sensiblement trapézoïdale de $37,5 \mathrm{~m}^{2}$, découpée en trois espaces. Elle a fait l'objet, au cours d'une même campagne, d'une soigneuse réfection mettant en œuvre un nouveau carrelage (carreaux de $23 \mathrm{~cm}$ par $23 \mathrm{~cm}$ ), à la fois de pavement et mural, qui incite à l'appréhender comme une unité. Au sud, un escalier d'accès débouche au centre de la pièce. Son élévation, probablement composée à l'origine de deux volées droites séparées par un repos, ne comporte plus que les deux premières marches. Un espace exigu de 1,80 m sur 0,80 m de côtés, situé sous la volée d'escalier, semble correspondre à un réduit, à moins qu'il ne s'agisse de la cave «extrêmement petite » mentionnée dans l'acte du 28 avril 1783. Deux pièces rectangulaires se répartissent de part et d'autre de l'escalier. La pièce orientale comprend, dans son angle sud-est, un puits probablement antérieur à la cave et toujours en eau. Son cuvelage, d'environ 0,60 m de diamètre est de forme ovale, grossièrement appareillé 


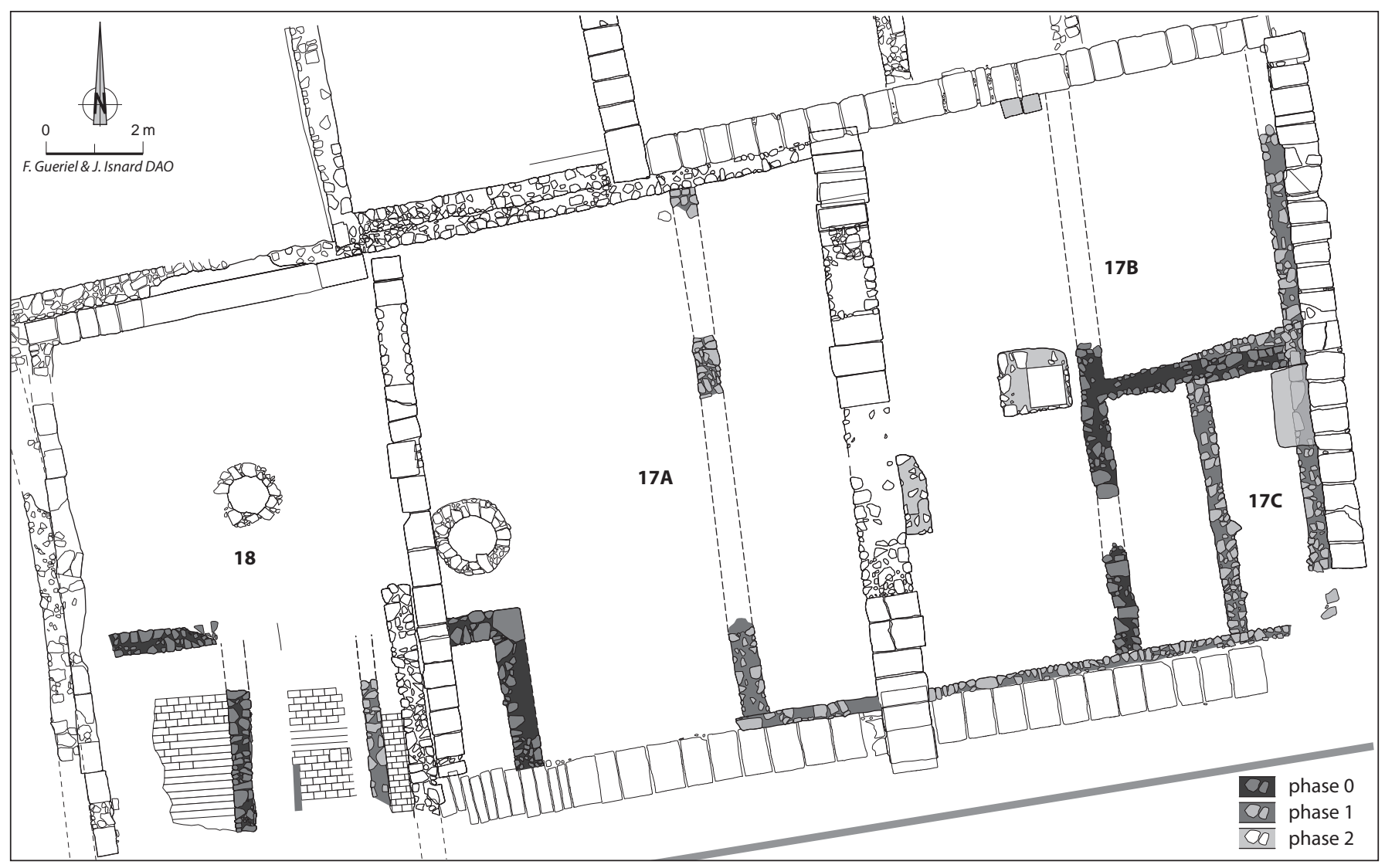

Fig. 265. Les vestiges modernes des parcelles 17 et 18 (DAO F. Gueriel, J. Isnard/Inrap).

de moellons et sa margelle aménagée à la hauteur du sol carrelé par une ouverture composée de trois blocs calcaires taillés avec des feuillures permettant la pose d'une pile d'évier rectangulaire, en pierre de Cassis, réemployée comme dalle de fermeture.

Les observations portant sur les pièces en sous-sol de ces différents immeubles mettent en évidence le peu de modification de leur plan initial, jusqu'à nos jours. Leur homogénéité se traduit aussi, à l'exception du bâtiment le plus au nord, par le découpage de chaque immeuble en deux grands volumes, se décomposant en deux ou trois espaces. L'attribution d'une date précise à leur construction est mal assurée, en raison notamment de la faible quantité de mobilier céramique. Toutefois la destruction du segment de canalisation situé dans le jardin des pères par l'implantation du mur de façade arrière, indique une mise en place dans le courant du XVIII ${ }^{\mathrm{e}} \mathrm{s}$. Cette datation, confortée par les documents d'archives, est aussi donnée par certains aménagements intérieurs, notamment les sols de carreaux en terre cuite.

\subsubsection{Transformation de l'auberge du Petit Saint-Jean}

Le Logis du Petit Saint-Jean est attesté jusqu'en 1754. C'est vers cette période que s'organise la subdivision de ce secteur en deux unités d'habitation distinctes, dont les parcelles cadastrales 17 et 18 fossilisent les limites (fig. 265).

Le bâtiment de la parcelle 18 a été mis en place dans la première moitié du XVIII ${ }^{\mathrm{e}} \mathrm{s}$. Il possède une longueur restituée de $13 \mathrm{~m}$ pour $8 \mathrm{~m}$ de large, hors œuvre. Le mur qui la sépare de sa voisine a été bâti à son profit non pas à l'aplomb mais contre l'ancienne limite. Les murs sont tous bâtis en pierre de taille de La Couronne, y compris celui de la façade qui a été observé avant l'ouverture du chantier archéologique. Les blocs, d'un module de 0,67 $\mathrm{m}$ par $0,60 \mathrm{~m}$ pour $0,20 \mathrm{~m}$ d'épaisseur, sont disposés en boutisse, en assises régulières. Le mur ouest réutilise une fondation qui justifie, par son étroitesse, la disposition en carreaux des blocs.

Dans un premier temps, le rez-de-chaussée est divisé en trois par un refend et une cloison d'axe nord-sud (fig. 266). L'un des espaces, particulièrement étroit $(0,60 \mathrm{~cm})$, correspond au couloir. Les autres sont pavés de carreaux de $25 \mathrm{~cm}$ par $15 \mathrm{~cm}$. Puis la mise en place postérieure de deux autres refends crée un nouvel espace de $4 \mathrm{~m}$ par $3 \mathrm{~m}$, ouvert sur la rue et qui n'a conservé aucun sol. La partie nord de la parcelle, explorée en sondage, n'a livré aucune structure excepté un puits de 0,90 m en œuvre. Son cuvelage, large d'environ 0,30 m, 


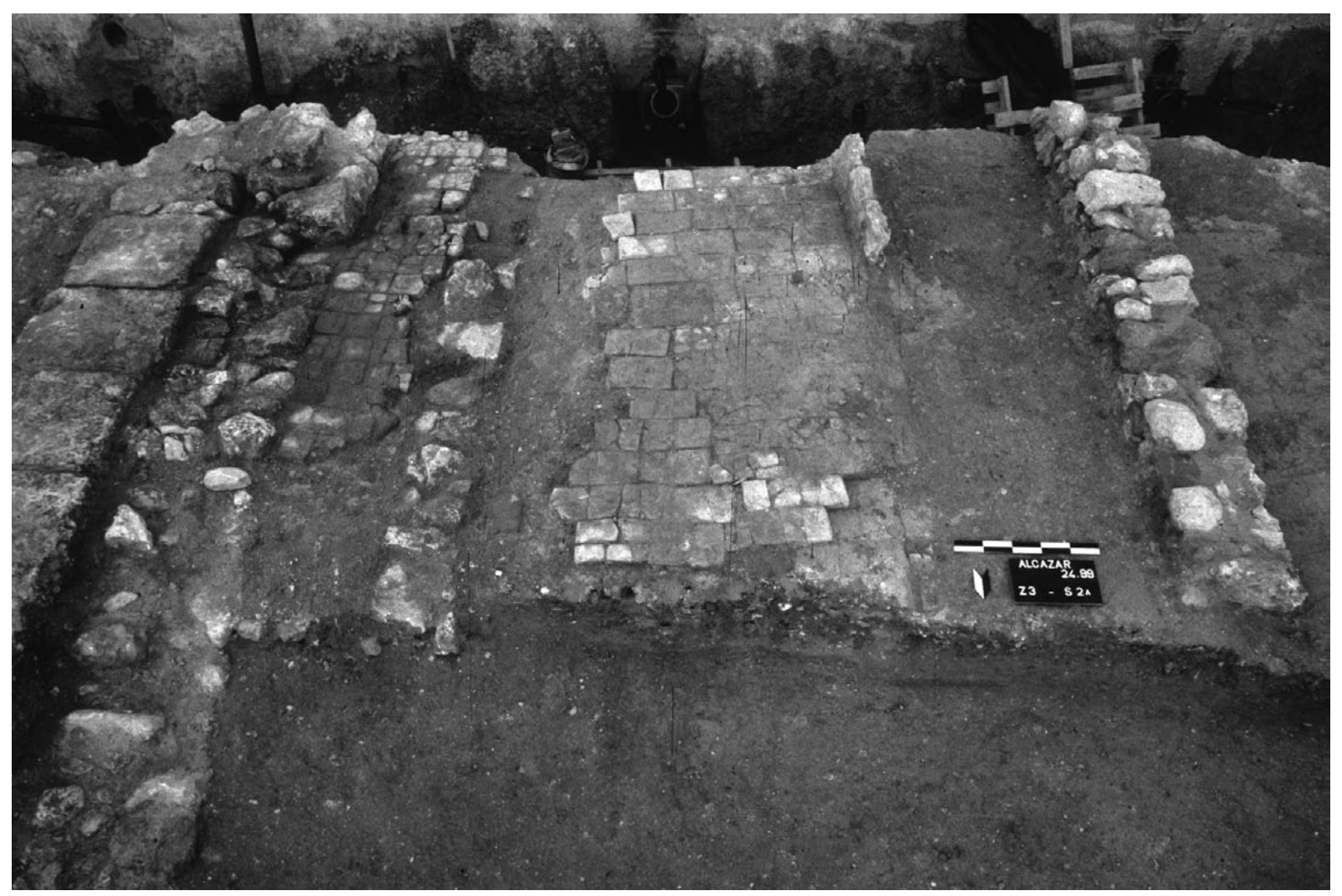

Fig. 266. L'espace sud-est de la parcelle 18 (cl. T. Maziers/Inrap).

est constitué de matériaux divers, sauf dans la partie basse où il est aménagé avec des briques. Nous pourrions restituer une grande pièce au fond, mais alors se pose le problème de son éclairage car le bâtiment est bordé au nord par les écuries de la Congrégation. L'hypothèse de l'existence d'une cour est également possible. Un plan $\mathrm{du} \mathrm{XX}^{\mathrm{e}} \mathrm{s}$. montre la présence d'une pièce au fond, avec un escalier dans l'angle sud-est.

La parcelle 17, autrefois occupée par une vaste écurie fondée sur quatre piliers, est entièrement reconstruite à partir de la seconde moitié du XVIII ${ }^{\mathrm{e}}$ s. Le bâtiment, qui forme la parcelle d'angle, diffère des autres constructions par la qualité et la diversité de sa mise en œuvre.

Le plan général est obtenu d'une part par le recul de la façade sur la rue du Petit-Saint-Jean et d'autre part par création d'un refend axial massif qui divise l'espace en deux parties égales de 11,50 m par 8,50 m. Ce plan est établi à partir de puissantes tranchées dans lesquelles sont disposées deux assises de parpaings placés en boutisse. Pour cela sont employés des blocs taillés en calcaire de La Couronne mesurant $1 \mathrm{~m}$ sur 0,60 m et ayant une épaisseur de 0,25 à 0,30 m, liés au mortier. Au-dessus, les fondations des murs de façades sont formées d'importantes maçonneries d'un mètre de large faites d'un blocage de moellons et cailloux ennoyés dans un mortier compact blanc. Un changement dans la composition du mortier, qui devient beaucoup plus sableux ainsi que la présence d'une assise de réglage en brique, témoigne de deux étapes successives de construction ou d'un arrêt de chantier. Seule la façade rue du Baignoir conserve une assise d'élévation en blocs de calcaire tendre disposée sur un lit de réglage de brique. Au sud-ouest, un arc de décharge est aménagé à cause de la présence d'un important puits obturé par du mortier. Au nord, le mur porteur semble avoir été détruit et remplacé par celui de l'immeuble mitoyen. Le refend, dont les deux premières assises sont identiques aux autres, diffère en revanche dans la suite de sa mise en œuvre. L'appareil mixte est formé de blocs de taille en calcaire de La Couronne placés en boutisse liés à l'aide du même mortier avec des joints gras et saillants. Ils sont accolés à des maçonneries de moellons et de blocs de poudingue retouchés liés à l'aide d'un mortier gris compact incluant des fragments de charbons de bois. Le rythme d'alternance entre ces appareils n'est pas régulier.

L'espace 17B possède en son centre un pilier ainsi que des pilastres accolés qui permettent de restituer un voûtement. Le pilier se compose d'une dalle carrée de 0,75 m de côté en calcaire rose de La Couronne, reposant sur une semelle de fondation bien plus large, aux matériaux hétérogènes, et dont le liant est un mortier gris clair dur, lié au sable marin. Deux pilastres, adossés 
aux murs est et ouest, sont désaxés par rapport au pilier central et leurs maçonneries, dont l'une est récupérée lors des travaux suivants, mesurent 1,70 par 0,60 m. Les deux autres, beaucoup plus petits, sont placés dans le même axe que le pilier et se composent d'un blocage de cailloux et moellons bruts noyés dans un mortier caractérisé par l'abondance de sable marin et de coquillages.

La construction de cet imposant bâtiment a laissé des traces ténues sur le terrain, matérialisées par un niveau de brasier et une succession de fosses à chaux appuyées contre le pilier. L'intérêt de ces dernières résident dans les traces circulaires d'extraction qui entament le remplissage de chaux.

Des murets viennent ensuite doubler les murs de façade. Leur largeur varie de $0,30 \mathrm{~m}$, au sud, à $0,40 \mathrm{~m}$ le long du mur oriental. Une petite pièce est conçue à l'angle sud-est du bâtiment 17B. À l'extérieur de celleci, le sol se caractérise par un fin niveau de mortier jaune irrégulièrement présent sur l'emprise du secteur. Au contact de cette couche, on note la présence d'un sol de terre battue. L'intérieur devait certainement être carrelé, comme le prouvent les carreaux de dallage conservés dans les niveaux de destruction qui scellent l'aménagement de cet espace. Parallèlement, l'espace occidental est divisé en deux parties par un mur d'axe nord-sud, puis les sols associés sont détruits et l'ensemble est nivelé par des remblais constitués de matériaux de destruction.

D'autres modifications interviennent par la suite, à une date incertaine, mais qui sort probablement du cadre de notre étude. Ce sont, dans l'espace 17A, la mise en place de ce qui a été interprété comme un escalier dans l'angle sud-ouest, et dans l'autre espace, le remplacement de l'espace 17C par un plus grand ainsi que la division en deux parties égales par une cloison nord-sud.

En conclusion, la reprise intégrale de la parcelle d'angle durant la seconde moitié du XVIII ${ }^{\mathrm{e}}$ s. s'illustre par la qualité de la mise en œuvre du bâtiment mais également par la réduction de l'emprise de l'immeuble. On remarque que les constructeurs ont été animés du souci de réaliser des fondations solides et stables. Le radier des blocs en boutisse, la présence d'un renfort au contact d'un mur de refend, la qualité du mortier relèvent d'une réelle maîtrise technique. Il semblerait que ces compétences soient indispensables à la réalisation d'un bâtiment «d'exception » dont la situation, à la jonction de deux rues, facilite l'implantation. Il apparaît qu'il faille rattacher à cette phase de travaux le retrait de la façade méridionale de l'immeuble sur la rue du Baignoir comme le prouve la localisation d'un puits antérieur colmaté par l'angle sud-ouest de la nouvelle construction. La mise en exergue de la façade méridionale passe alors par le non-respect à la conformité de l'alignement sur la rue.

\section{La congrégation Saint-Hommebon} (B. Sillano)

Du chapelet d'établissements religieux dont se parent les faubourgs de la ville au cours du XVII ${ }^{\mathrm{e}}$ s., seul celui de la congrégation Saint-Hommebon a été rencontré lors de fouilles récentes, sur le site de l'Alcazar. La frange septentrionale de la concession est hors emprise, mais nous pouvons néanmoins, avec l'aide des archives, en restituer une image complète.

La congrégation des prêtres du Saint-Sacrement ou de Saint-Hommebon, est fondée en 1632 ; la maison de Marseille est établie en 1638, après celles d'Aix et de Brignoles. Il ne s'agit pas d'un couvent au sens strict puisque son but est de réunir des ecclésiastiques séculiers pour des œuvres de missions et des directions de séminaires. À priori donc, il n'est nul besoin d'une infrastructure liée à la vie communautaire. Les bâtiments sont établis hors les murs, dans un secteur encore peu urbanisé, mais, 30 ans après leur construction, ils se retrouvent englobés dans la Ville Nouvelle de Louis XIV avec laquelle ils doivent composer. Nous verrons que, contrairement à ce qu'il advint de plusieurs autres couvents, la congrégation Saint-Hommebon sut tirer profit de l'Agrandissement.

\subsection{La confrérie du Saint-Sacrement avant l'Agrandissement}

Nous possédons l'acte d'arrentement perpétuel de Claire de Guérin ${ }^{884}$, daté de 1636 , qui nous donne un aperçu des terrains et bâtiments concédés. Il y est question d'un vaste jardin situé derrière les habitations qui bordent le Grand-Caire et qui s'étend depuis la «rue tirant aux Augustins » au nord jusqu'aux possessions du sieur de la Reynarde au sud ainsi que la rue du Baignoir à l'est. Nous vérifions ainsi qu'il ne reste plus rien du faubourg médiéval : c'est sur un terrain vierge de constructions que l'établissement religieux peut s'installer. Cet acte suscite cependant des interrogations car il concerne des places qui ne semblent pas appartenir à Claire de Guérin. Il en est ainsi de la parcelle 1, «que (...) Ambroise Bastide à présent possède », de la parcelle 26, «appartenant à Louis Girard», des parcelles 18, 19 et 20, «possédées icelles places par les hoirs du $S^{r}$ de la Reynarde » et de la parcelle 17, «possédée par lesdicts heoirs du $S^{r}$ de la Reynarde ». Il en va de même pour les parcelles situées au sud de la future

884 AD13 380 E 127, fol. 1733, cf. annexe 3.3. 
rue du Petit-Saint-Jean. De plus, si par la suite certaines de ces parcelles appartiennent encore à la Congrégation (parcelle 26), les actes montrent que ce n'est pas le cas de la plupart des autres. Ainsi, les parcelles 17 à 20 sont rachetées en 1656 et en 1659 , et plus curieusement, les vendeurs ne sont autre que les descendants du $\mathrm{S}^{\mathrm{r}}$ de la Reynarde. Tout se passe donc comme si la congrégation ne les avait jamais possédé. L'acte de 1636 a t-il été rendu caduc dans un second temps ? L'existence d'un accès au couvent au sein de la parcelle 19 ne matérialiserait-il pas une servitude héritée des acquisitions de 1636 ? Les terrains composeraient-ils une rente constituée ? La question mériterait d'être approfondie à la lumière du droit de l'époque.

Les premières constructions des pères ne sont renseignées que par la fouille car les textes suivants, les déclarations des Pères, sont postérieurs à l'agrandissement. Au nord, le long de la rue, un bâtiment de $20 \mathrm{~m}$ de

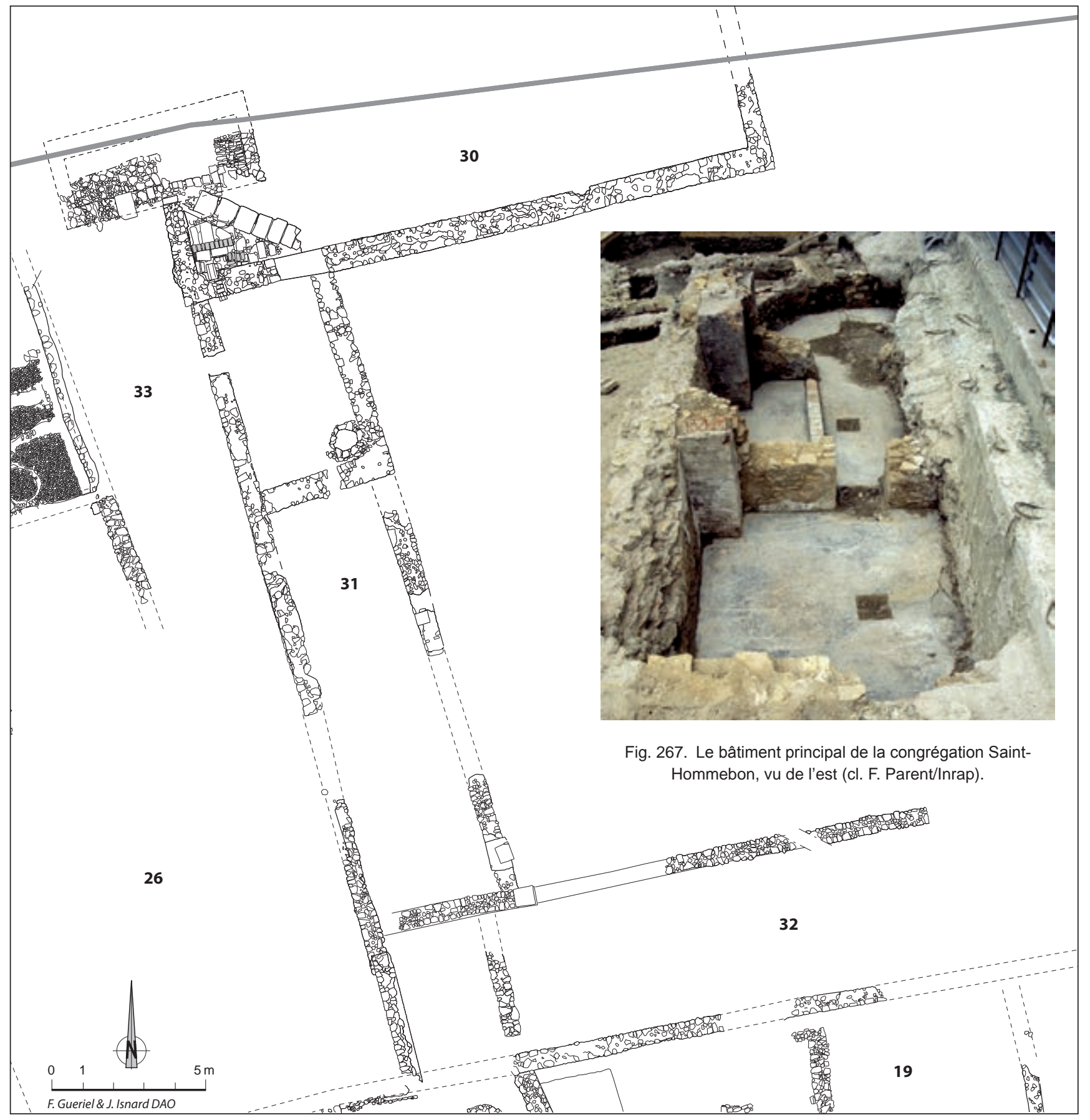

Fig. 268. Les bâtiments de la congrégation (DAO F. Gueriel, J. Isnard/Inrap). 


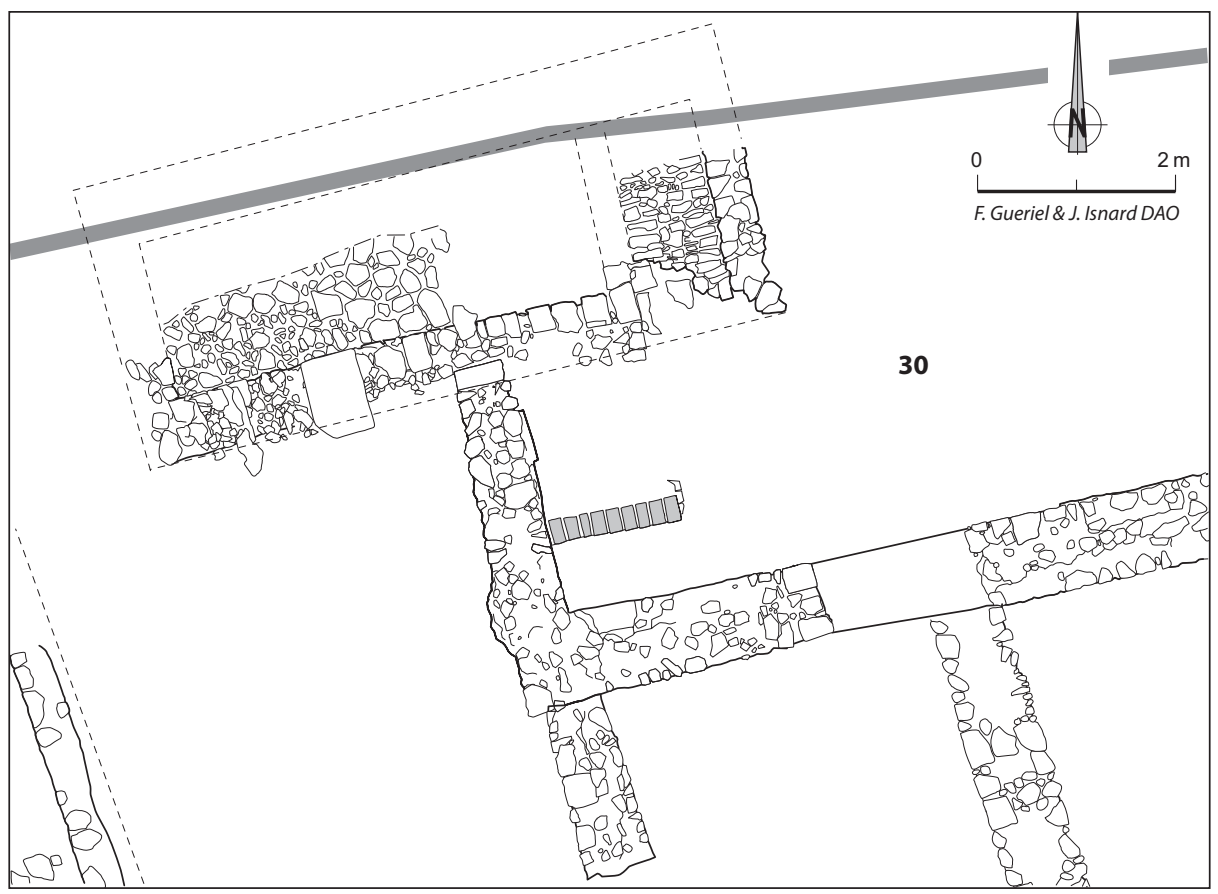

Fig. 269. Plan de la citerne et de la partie ouest du bâtiment 30, antérieurement à 1670 (DAO F. Gueriel, J. Isnard/Inrap). long (d'est en ouest) pour 12,50 m de large est installé directement sur les remblais qui scellent l'abandon du faubourg médiéval (fig. 267 et fig. 268). Nous l'identifions comme la première église, déplacée sur le Cours lors de l'agrandissement de Louis XIV. Seule sa partie méridionale est dans l'emprise fouillée ; ses fondations, profondes de $3 \mathrm{~m}$ et épaisses de $80 \mathrm{~cm}$, sont bâties en tranchée étroite par épandages de couches successives de pierres et de mortier très induré. Dans un second temps, des caves sont creusées ce qui nous prive des sols d'origine. Seuls quelques sols en terre battue, conservés de manière très lacunaire dans un angle et datés entre 1650 et 1670 , nous donnent une idée de la nature du revêtement de ces caves, en grande partie éliminés par les réaménagements postérieurs afin de préserver la hauteur disponible.

Le mur occidental de l'église chevauche une structure qui devait préexister puisqu'elle s'insère parfaitement dans la trame parcellaire médiévale. Il s'agit d'une citerne d'environ 5,80 $\mathrm{m}$ de long pour $2 \mathrm{~m}$ de large et profonde d'environ 5,60 m (fig. 269). L'importance de cette construction pourtant apparemment banale est attestée par sa pérennité (elle est toujours exploitée à l'époque contemporaine) alors même que, à cause de son emplacement, son maintien a de tout temps nécessité une mise en œuvre complexe. Ainsi, à son aplomb, le mur de l'église est soutenu par un arc doubleau fait de blocs de calcaire rose soigneusement taillés. Elle était couverte d'une voûte en berceau de pierres, probablement sur toute sa longueur à l'origine puis par la suite, partiellement rehaussé avec une voûte en briques. La couverture d'origine, conservée à l'intérieur du bâtiment, est dotée ensuite d'une ouverture bordée d'un garde corps afin de permettre un accès depuis les caves. Un ensemble de canalisations, pour partie dans le bâtiment voisin où se trouve un puits, est relié au bassin, probablement destiné à l'alimenter.

Le reste des bâtiments, en cœur d'îlot, est installé progressivement selon une chronologie que nous ne connaissons que de manière relative. Tout d'abord, dans le prolongement de la façade ouest de l'église un premier mur ferme le cœur d'îlot, à environ $4 \mathrm{~m}$ de distance de l'arrière des parcelles habitées. De même, un second le referme au sud, à la même distance des parcelles situées le long de la rue du Petit-Saint-Jean. Ces constructions isolent ainsi le couvent des habitations environnantes. Puis, un mur double le premier vers l'intérieur, délimitant ainsi une cour de $20 \mathrm{~m}$ par $30 \mathrm{~m}$, ouverte dans un premier temps vers la rue du Baignoir. La construction de murs de refend permet ensuite de délimiter entre ces murs des pièces allongées qui encadrent la cour. Deux accès devaient traverser ces locaux, l'un à l'ouest, qui aboutit au Grand-Caire par une parcelle non bâtie, l'autre au sud, vers la rue du Petit-Saint-Jean, par un passage étroit entre deux parcelles loties (cf. supra $§ 3.1 .3$.).

\subsection{Les réaménagements liés à l'agrandissement de Louis XIV}

Le plan de la Ville Nouvelle a eu pour conséquence d'agrandir l'îlot vers le nord par absorption de la rue «tirant aux Augustins » et la création de la rue 


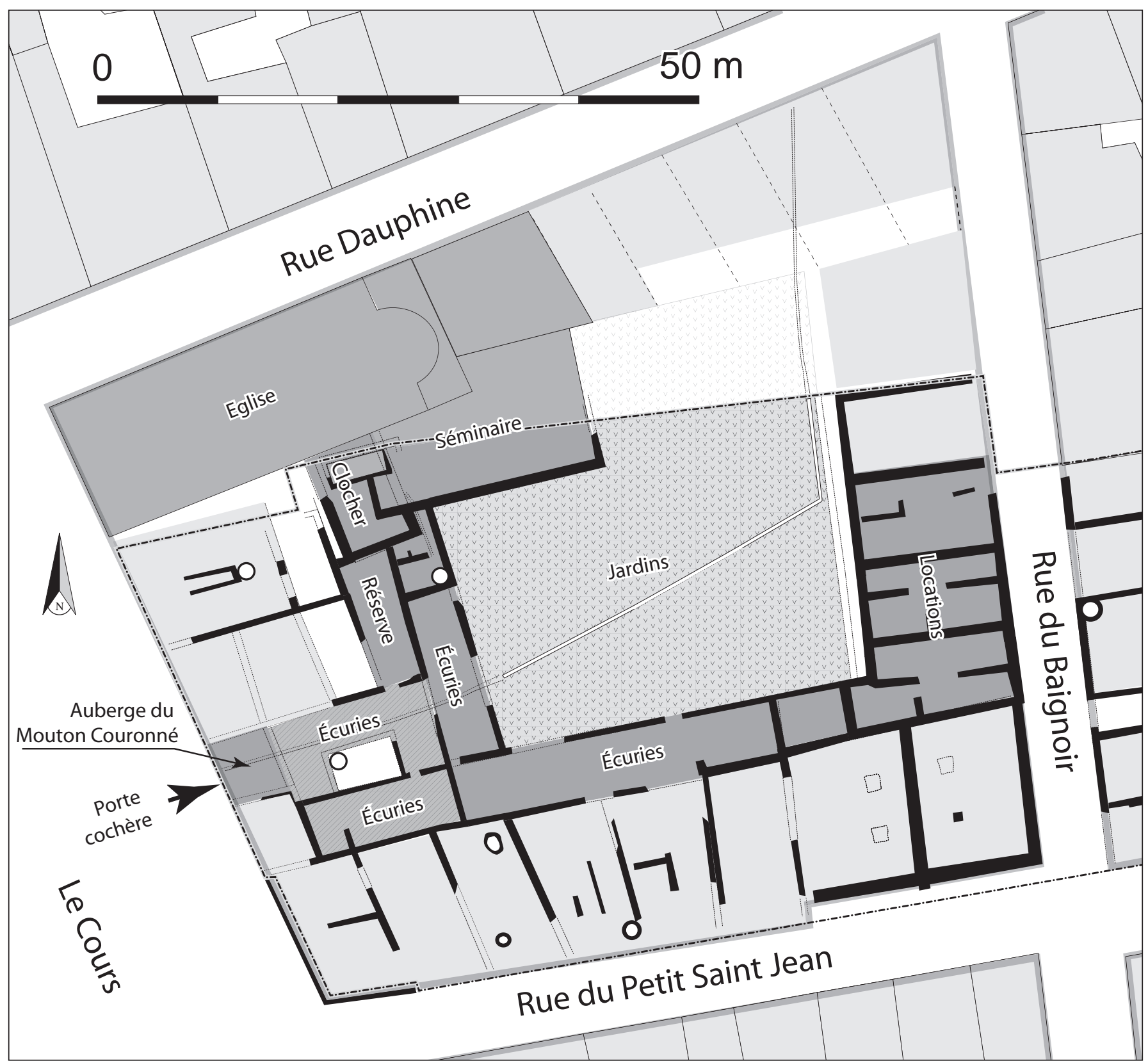

Fig. 270. Plan d'ensemble des bâtiments de la congrégation après l'agrandissement de Louis XIV (en gris foncé) (DAO B. Sillano/Inrap)

Dauphine. Selon une procédure dont nous n'avons pas de trace, les pères surent acquérir une partie des terrains gagnés sur les îlots voisins, particulièrement le long du tout nouveau Cours où l'espace dégagé fut suffisant pour y édifier une nouvelle église, plus vaste et mieux placée que l'ancienne. La différence d'orientation entre l'ancienne et la nouvelle rue nous permet de reconnaître sur le plan les murs bâtis après l'Agrandissement (fig. 270). Le texte de référence est une déclaration des Pères sur les possessions de la congrégation dans le rapport d'estime.

Nous possédons peu de renseignements sur l'église, détruite à la Révolution. Marchand a fait un petit croquis de la façade de style baroque, où il est précisé, en légende, qu'elle a été dessinée par P. Puget (fig. 271) et elle est visible, au fond, sur le tableau de M. Serre (Le Cours pendant la peste $\left.{ }^{\mathbf{8 8 5}}\right)$. Le rapport d'estime de 1686 nous en donne les dimensions, $34 \mathrm{~m}$ de long pour $12 \mathrm{~m}$ de large. Sa forme, en revanche, n'est pas connue. Razaud dessine une abside circulaire, mais nous ne connaissons pas la fiabilité de cette représentation. Le mur gouttereau de l'édifice a été aperçu (et détruit par la paroi moulée),

885 Musée des Beaux-Arts, Marseille. 


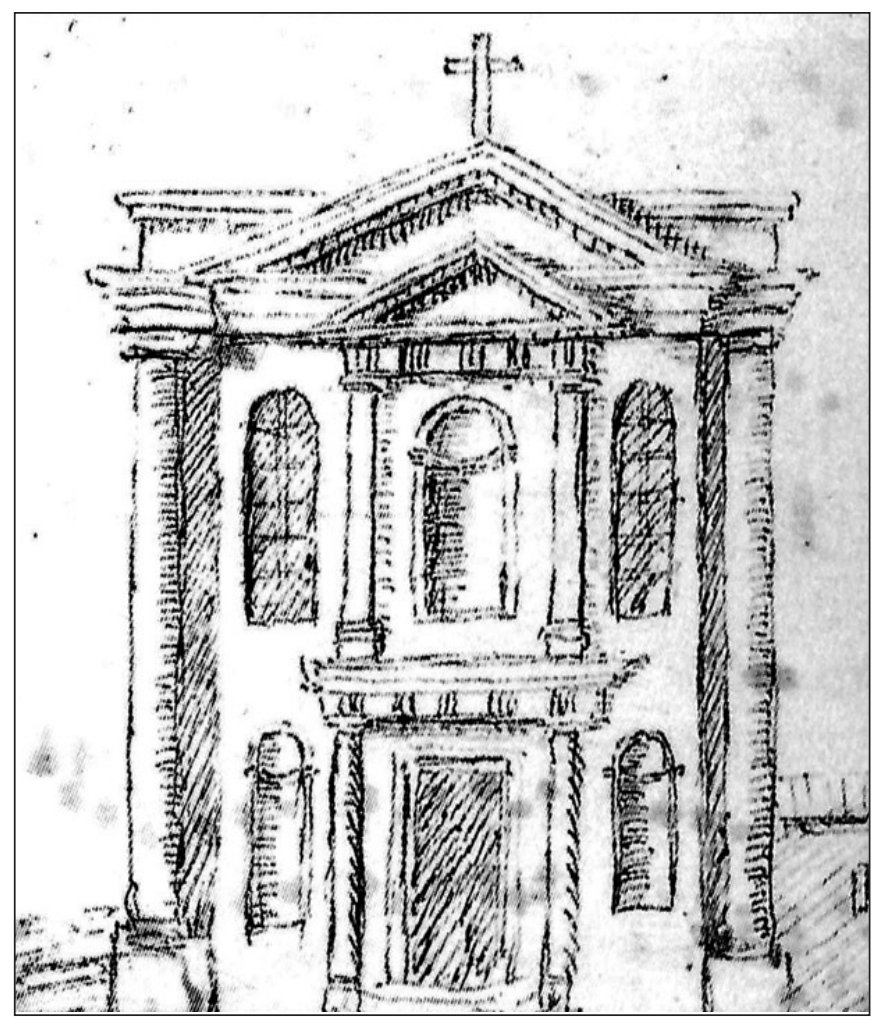

Fig. 271. Dessin de la façade de l'église Saint-Hommebon par Marchand (cl. AD13).

et un massif maçonné, repéré après la fouille au nord du chantier, pourrait en matérialiser l'angle. L'hypothèse de l'abside n'est pas exclue, mais des caves ont éliminé toute preuve absolue. Enfin, l'inventaire du mobilier par les commissaires de la Révolution, en 1792, nous donne indirectement quelques indications, comme le fait qu'elle « est éclairée par sept fenêtres avec leur vitrage à petit carreaux garnis de plomb ${ }^{\mathbf{8 8 6}}$.

Dans l'emprise des fouilles, nous avons retrouvé les substructions d'un édifice, visible sur le plan Razaud, qui lui est accolé et bâti pour partie sur l'ancienne église. Par ses dimensions modestes ( $7 \mathrm{~m}$ par $9 \mathrm{~m}$ ) en regard de la massivité des fondations, épaisses de $1 \mathrm{~m}$, nous pouvons supposer qu'il était très élevé et qu'il s'agissait peut-être du clocher. Il est situé à l'aplomb du bassin où un nouvel arc en pierre de taille de La Couronne, dont l'axe est légèrement oblique par rapport au précédent, a été édifié pour soutenir le mur oriental.

Dans la déclaration des pères, l'ancienne église semble être devenue la maison d'habitation. Pourtant, l'inventaire de la Révolution la qualifie de séminaire. Il mentionne des salons, un réfectoire, des bains, une

886 AD13 1 Q 664. cave, dans laquelle se trouvent des tonneaux de vin et d'huile. Dans la partie située dans l'emprise des fouilles et épargnée par les caves d'Époque contemporaine, nous avons relevé une construction d'angle, nantie de petits bassins, dont l'évacuation vers le collecteur axial se fait par l'intermédiaire d'une canalisation intégrée dans le mur (fig. 272 et fig. 273). Elle est reliée à une pièce extérieure, dans laquelle le puits est remplacé dans un second temps par une canalisation. Elle permet l'accès à un local adossé aux parcelles voisines qui est mentionné dans un prix-fait de $1675^{887}$ comme une «rézerve de quatorze pans ou environ sur le dernier » pour laquelle le maçon veillera à ce que «rien ne périsse et se fane», c'est-à-dire une réserve alimentaire.

Le reste des bâtiments, tout en longueur, qui bordent la cour du couvent, correspondent aux écuries citées dans la déclaration. On y accède depuis le Cours par une vaste porte cochère qui passe à travers (ou sous) l'auberge du Mouton Couronné, également propriété des Pères. L'essentiel du rez-de-chaussée de cette parcelle, débordant sur la parcelle voisine, est par ailleurs occupé par une écurie, de plan carré avec une cour et un puits au centre ( $f f$. supra). Ainsi la congrégation totalise près de $300 \mathrm{~m}^{2}$ d'écuries dont l'exploitation ne devait pas être exclusivement réservé au clergé mais plus probablement à l'adresse des usagers des auberges voisines qui en étaient dépourvues.

La cour centrale, dans laquelle s'installe le théâtre de 1'Alcazar deux siècles plus tard, est très perturbée par cet édifice. Aucune construction du XVII ${ }^{\mathrm{e}}$ s. n'y a été rencontrée et la seule représentation est celle du plan Razaud, qui montre une sorte de galerie (un cloître ?) qui borde les ailes est, sud et ouest. Des remblais de terre végétale, conservés de manière lacunaire, semblent cependant indiquer qu'il s'agit de jardins. Ceux-ci doivent rester invisibles du monde extérieur. C'est ce qu'indique un acte de 1672 qui précise qu'un voisin ne peut «prendre aucun jour ny voir dans le jardinet terremant desd. Pères de la Mission directement ny indirectement sous quelque cause et prétexte que ce soit $\gg{ }^{\mathbf{8 8} 8}$. Les murs de confins des parcelles le long de la rue Dauphine sont en effet aveugles. À l'ouest, les parcelles sont entièrement bâties et il est peu probable que, en l'absence de puits de lumière, les murs de confins soient aveugles. La bande d'isolement du théâtre de l'Alcazar ne tiendrait-elle pas son origine d'un mur-écran en avant des parcelles bâties ? Enfin, au sud et à l'ouest, les écuries, peut-être surélevées, peuvent remplir la même fonction.

Un réseau complexe de canalisations prend place dans le jardin. Jusqu'au $\mathrm{XX}^{\mathrm{e}}$ s., ce réseau s'est sans

887 AD13 380 E 171, fol. 1411.

888 AD13 362 E 126, fol. 1394. 


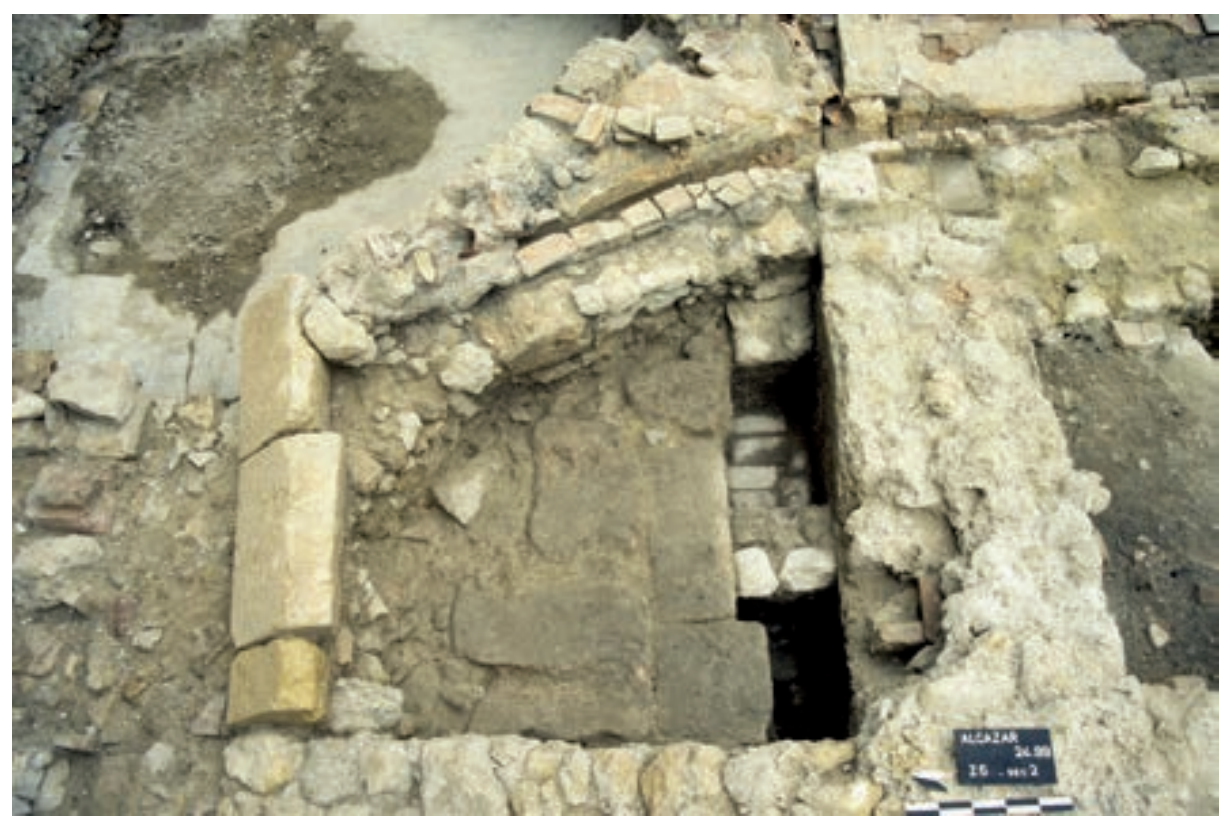

Fig. 272. Les structures hydrauliques une fois fouillées dans l'angle du bâtiment 30 (cl. F. Parent/Inrap).

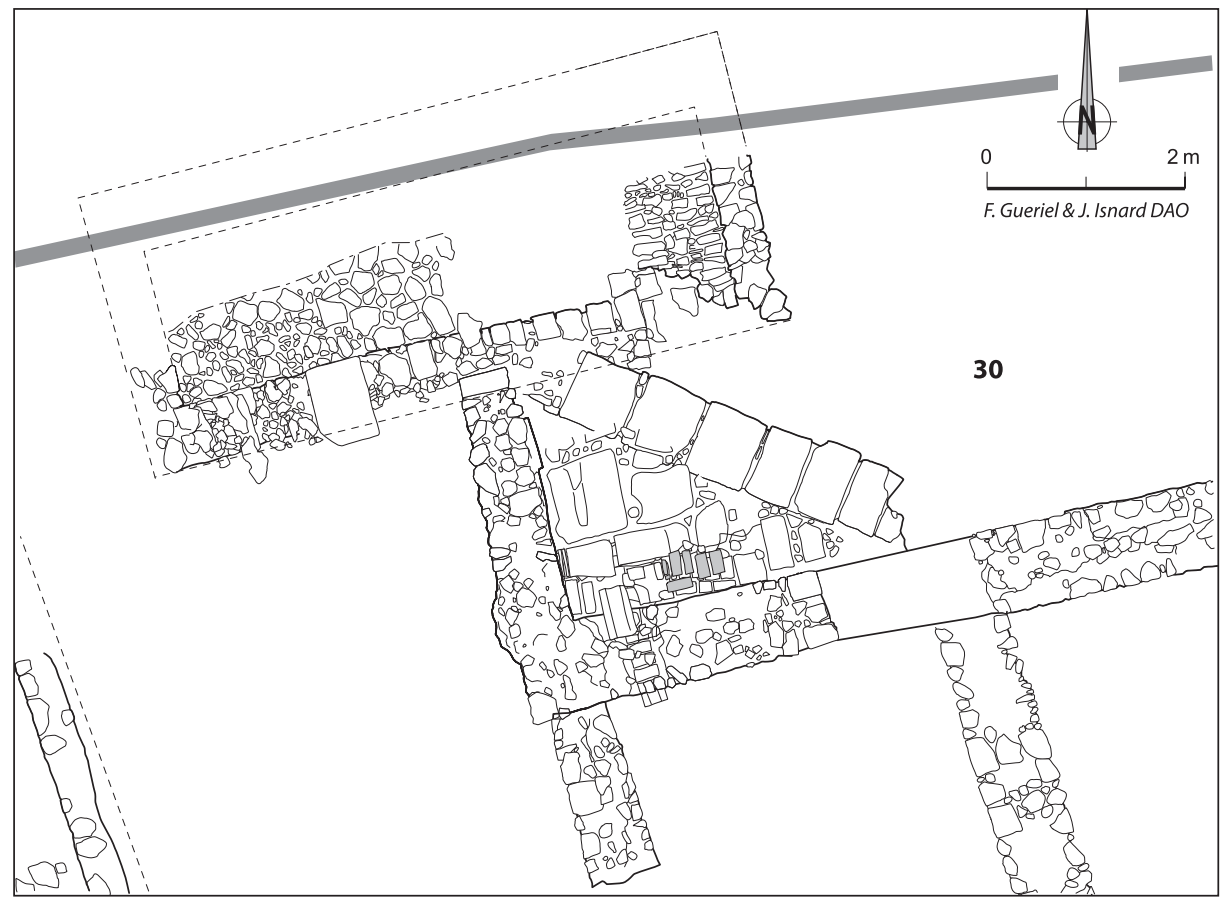

Fig. 273. Partie occidentale du bâtiment 30 (DAO F. Gueriel, J. Isnard/Inrap).

cesse enrichi de nouvelles conduites, les anciennes étant parfois refaites ou agrandies. C'est le cas pour la canalisation médiane, d'Époque contemporaine, qui recueille les eaux usées de toutes les habitations de l'îlot pour les acheminer vers le collecteur sous le cours Belsunce. Pour la période qui suit immédiatement l'Agrandissement de Louis XIV, les seuls réseaux hydrauliques présents sont l'adduction venant du nord et son embranchement vers l'ouest ( $c f$. supra $§ \mathrm{I}, 2,3.1 .2$.). Ils sont constitués de deux parements en petit appareil irrégulier de moellons retouchés et de fragments de tuiles, liés à un mortier maigre, d'un fond en briques cuites, et d'une couverture de dalles de calcaire coquillier taillées. Les parois du canal ont conservé dans leur partie inférieure un enduit hydraulique. Il s'agit certainement d'aqueducs, soit pour l'irrigation, soit pour un usage domestique. Construits après 1670 , ils sont abandonnés au plus tôt dans la première moitié du XVIII ${ }^{\mathrm{e}} \mathrm{s}$. 
La congrégation possède en périphérie du couvent une série de bâtiments qu'elle loue. Il s'agit d'abord de l'auberge du Mouton Couronné, sur le Cours avec, probablement, les multiples écuries qui en dépendent. Elle loue également les immeubles qu'elle fait construire, entre 1700 et 1720 , le long de la rue du Baignoir (cf. supra $\S$ 3.3.2.). Leur organisation prévoit en effet, dès l'origine, une subdivision du sous-sol en autant de caves que d'appartements. La congrégation possède également des maisons sur la rue Dauphine ${ }^{889}$ et des propriétés sont signalées en dans d'autres endroits de la ville ${ }^{890}$.

\subsection{Conclusion}

Dès le début du XVII ${ }^{\mathrm{e}}$ s., de nombreux couvents s'installent dans la périphérie orientale de la ville. Ainsi, l'installation des Augustins Réformés remonte à 1613. La congrégation Saint-Hommebon s'implante à peu près en même temps que les Recollets (dont l'église est bâtie à partir de 1648), les Recollettes (vers 1640) et la Mission de France (dont l'église est entreprise en 1667, mais qui tenait dès 1648 une place prépondérante). En 1673 , au nombre des charges de cette dernière, figurait la direction du Grand Séminaire, et en cela elle se présente comme une concurrente de la congrégation Saint-Hommebon.

Lors de leur mise en place, ces institutions étaient effectivement à l'extérieur de la ville, mais, avec l'agrandissement de Louis XIV, quelques dizaines d'années plus tard, elles ont été ennoyées dans un des quartiers les plus actifs. Disposées à l'origine le long de chemins importants, elles se sont retrouvées, pour la plupart, en cœur d'îlot dans le plan de la Ville Nouvelle. Ainsi, l'église des Recollettes, qui donnait à l'origine vers le Grand-Caire, a vu, lors de l'Agrandissement, s'édifier au-devant un îlot-masque, duquel elle est séparée par une ruelle secondaire. La supérieure de ce couvent s'en

$\mathbf{8 8 9}$ «Deux registres de comptabilité conservés aux archives de la Préfecture (de 1751 à 1791) nous apprennent que les prêtres du SaintSacrement possédaient deux maisons dans la rue Dauphine et six dans la rue du relais. L'une des maisons situées rue Dauphine portait alors le $\mathrm{n}^{\circ} 23$ et était arrentée au sieur Teissère pour six années, à raison de 800 livres, l'autre portait le $n^{\circ} 21$ et était arrentée pour sept années au sieur Achard, à raison de 720 livres » (Jaubert, 1888, p. 10). Il semble en tout cas que les propriétés de la congrégation n'ont cessé de croître durant le XVIII ${ }^{e}$ s. Ces deux maisons sont situées à l'angle sud-ouest de l'îlot au nord de l'îlot B (n 714 et 715 du cadastre napoléonien). 890 «Les mêmes registres désignent encore parmi les biens des Prètres du Saint-Sacrement une maison située rue de Rome Fonlongue, iscle 52, portant $n^{\circ} 6 »($ Jaubert, 1888, p. 10). plaint en $1684^{891}$. De même, l'église de la Mission de France se retrouva en retrait par rapport à l'actuelle rue Tapis-Vert, sur laquelle elle ne débouchait que par un porche. Seule la congrégation Saint-Hommebon a pu tirer profit de l'agrandissement (en exceptant les Recollets, dont l'église a eu la chance de conserver la rue sur laquelle elle donnait).

Mettant à profit un terrain qui leur appartenait, récupérant une portion de l'ancienne rue abandonnée, les prêtres du Très-Saint-Sacrement font édifier leur nouvelle église en bordure du Cours. Dès 1681, les messes y sont célébrées (Jaubert 1888, p. 9). Une telle rapidité d'exécution est révélatrice de l'état des finances de cette Congrégation qui devait, de surcroît, payer une taxe importante en raison de l'étendue de son domaine. A-t-elle bénéficié de compensations ou d'exonérations? La décision d'agrandissement est-elle survenue au moment où elle projetait de construire une nouvelle église, comme le suggère un achat de pierres en 1659 ?

Les dimensions de ce couvent sont somme toute relativement modestes si on les compare à la grande taille des terrains acquis en 1636. Au sud, le long de la rue du Petit-Saint-Jean, les parcelles « achetées » en 1636 sont bâties par des particuliers, et plus jamais, dans les textes les concernant, n'est mentionnée la congrégation. Représentent-ils pour celle-ci une rente constituée ? À l'est, les prêtres font construire une série d'immeubles le long de la rue du Baignoir afin de les louer. Sur le Cours, ils louent l'auberge du Mouton Couronné, avec les vastes écuries auxquelles elle donne accès, disposées autour du jardin. Bien que ce couvent soit essentiellement un séminaire, à l'adresse du clergé séculier, qui ne requiert pas beaucoup de place, on peut s'interroger sur la volonté de tirer un profit financier optimal des terres. L'installation de la puissante Mission de France à proximité a-t-elle modifié le projet de la Congrégation qui a préféré mettre à profit ses terres, d'autant plus rentables qu'elles ont été englobées dans la Ville Nouvelle, afin d'alimenter les caisses et de se développer dans d'autres régions ${ }^{892}$ ?

891 Dans un document de 1684, on peut lire: «La supérieure nous a représenté qu'elles ont reçu de grands dommages à l'occasion de l'agrandissement (...) ajoutant que cela leur sera beaucoup plus préjudiciable que le prétendu avantage qu'on peut croire qu'elles retirent d'être dans la nouvelle ville, disant aussi bien que leur église d'abord qu'on était à la porte Réale et à celle du marché, était alors d'une grande considération, au lieu qu'à prézsent le tout est de fort peu de valeur pour être situé à une méchante rue traverse qui reçoit tous les égouts et tous les immondices des maisons du Cours » (Durousseau, 1990, p. 51).

892 «La congrégation a tenu dans le dernier tiers du XVII ${ }^{e}$ s. un séminaire à Marseille. Mais elle semble avoir ensuite reporté dans celui de Valence les efforts de son modeste effectif » (Bertrand, à paraître). 


\section{Chapitre 4}

\section{Bilan de l'apport de l'archéologie à la connaissance de Marseille médiévale et moderne}

$\mathrm{L}$ e bilan que nous dressons à partir des données archéologiques couplées aux sources d'archives pour Marseille médiévale et moderne ne peut être qu'une ébauche bien partielle, soumise à l'actualité des nouvelles découvertes. Il n'en demeure pas moins qu'il s'agit là d'une présentation essentielle pour des périodes trop longtemps délaissées au profit d'une Antiquité si prestigieuse et attractive (Morel-Deledalle 1993, p. 8-11). D'un point de vue plus personnel, cela constitue également pour les auteurs de cet ouvrage un aboutissement de presque vingt ans de travail, d'investissement et d'interrogations.

Voici donc un aperçu de plus de dix siècles d'évolution urbaine commentée par le petit bout de la « lorgnette archéologique » qu'il est souvent bien difficile de mettre en parallèle avec les épisodes marquants de l'histoire de Marseille. La documentation présentée ici témoigne de périodes de renouveau urbain accompagnées d'évolution dans les modes de construction et les matériaux employés ; elle illustre également des phases de récession ou de destruction. Cette publication met également en évidence la prégnance de l'urbanisme médiéval partiellement remanié à partir du XVII ${ }^{\mathrm{e}}$ s. dans la ville ancienne, mais totalement repensé dans les anciens faubourgs appelés à devenir la Ville Nouvelle.

Le Moyen Âge connait depuis quelques temps déjà une véritable renaissance. De grandes monographies de site ont été publiées: fouilles de l'abbaye SaintVictor (Fixot, Pelletier 2004, Fixot, Pelletier 2009), des fouilles de Sainte-Barbe (Marchési et al. 1992) ou de la place Général-de-Gaulle (Bouiron 2001a). Les vestiges médiévaux dans leur ensemble ont été également l'objet de publications de synthèse, la plupart rédigés par M. Bouiron. Certains articles rassemblés dans les actes du colloque Trames et paysages urbains de Gyptis au Roi René (Bouiron et al. 2001a) constituent la première étape d'une lecture topographique des vestiges et édifices de la période médiévale, avec une présentation de la trame, des fortifications, des monuments religieux ou civils dont la plupart ont disparu. En 2009, durant la rédaction du présent ouvrage, une nouvelle impulsion est donnée par T. Pécout qui dirige la publication d'un livre de référence sur Marseille au Moyen Âge, entre Provence et Méditerranée (Pécout 2009a). Cet ouvrage, dans lequel sont rassemblées de multiples contributions d'historiens et d'archéologues, trouve son origine dans un projet d'exposition initialement programmé en 2009 et inaugurée en juin 2010 par S. Clair, directrice des Archives Municipales de Marseille. Pour cette occasion, la revue Marseille a consacré un numéro spécial à Marseille Médiévale.

Si les Temps Modernes marseillais ont jusqu'à présent bien peu inspiré la littérature archéologique, des études ponctuelles ont cependant été publiées comme celles de la Manufacture royale de Poudre et Salpètre (Castrucci 2007), et du Jeu de Paume (Sillano, Scherrer 2009). L'apport des historiens et historiens de l'art -et notamment R. Bertrand (Bertrand 2001b) et J.-J. Gloton (Gloton 1980)- est primordiale pour la compréhension de la parure monumentale de Marseille. Une analyse urbaine importante a, par ailleurs, concerné l'extension de la ville initiée par Louis XIV (Durousseau 1990). Enfin, le travail de l'Atelier du Patrimoine dirigé par D. Drocourt concerne le bâti civil sur tout le territoire marseillais en s'appuyant notamment sur l'ordonnancement des façades et les matériaux employés ${ }^{893}$.

Aussi pouvons-nous considérer que si le présent ouvrage est une étape supplémentaire pour la connaissance de Marseille médiévale, il constitue surtout la première pierre d'une étude de la ville moderne à partir de sources archéologiques et archivistiques.

\section{Synthèse chronologique (F. Paone, B. Sillano, M. Bouiron, N. Scherrer, C. Castrucci)}

Les onze siècles qui séparent les derniers rois mérovingiens de la Révolution Française sont irrégulièrement documentés par l'archéologie. Aux périodes d'expansion, parfois courtes et fructueuses pour l'archéologue, répondent des périodes de récession qui le laissent muet.

893 On signalera notamment la collection Centre historique de Marseille. Méthodes de diagnostic, banque de données ainsi que la publication sur le bâti ancien à Marseille réalisée en 1981. 
DEUXIÈME PARTIE : PRÉSENTATION DE QUELQUES QUARTIERS À LA LUMIÈRE DES FOUILLES ARCHÉOLOGIQUES

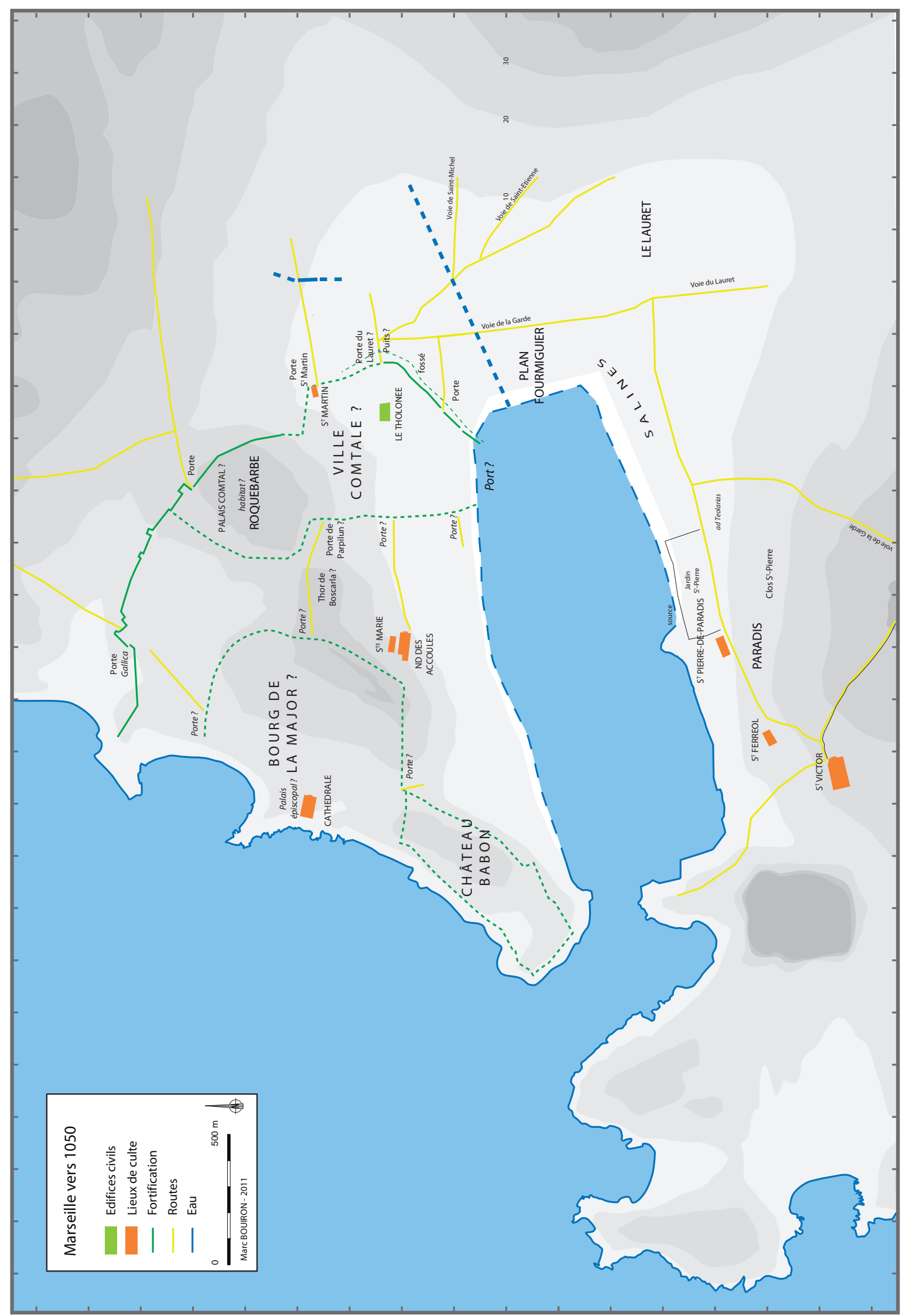

Fig. 274. Marseille vers 1050 (M. Bouiron/Ville de Nice). 
Aussi faire coïncider l'histoire du sol à l'historiographie relève de la gageure ; néanmoins, au terme de cette monographie, une confrontation est inéluctable. Nous avons choisi de l'étayer par des observations faites sur des chantiers récents que nous n'avons pu traiter dans ce recueil faute de temps.

Elle commence par un hiatus archéologique notoire à Marseille, le haut Moyen Age, qui, malgré l'attention grandissante portée à cette séquence, conservée surtout en pied de pente, vers le port, mais dénuée de vestiges tangibles, n'a certainement pas encore livré tous ses secrets ${ }^{894}$. L'un d'eux pourrait être cette mystérieuse transmission de la trame viaire antique, parfois du parcellaire, alors que tout semble avoir été épierré jusqu'aux fondations bien avant les premières reconstructions au XI' $\mathrm{s}$.

\subsection{Un haut Moyen Âge bien peu documenté par l'archéologie}

Notre connaissance de la Marseille antique tardive s'est étoffée au fil des fouilles, mais les $\mathrm{VIII}^{\mathrm{e}}$ et $\mathrm{IX}^{\mathrm{e}} \mathrm{s}$. nous livrent fort peu d'indices. Au Ve s., l'héritage prégnant du Bas-Empire se caractérise par le maintien du réseau viaire et de certains espaces et bâtiments publics tels le(s) forum(s) ou le théâtre. Durant la même période s'initie un renouveau urbain justifié par la présence des édifices de la nouvelle religion chrétienne : le monumental groupe épiscopal dominant la frange littorale en lisière de la ville et les nombreuses basiliques funéraires hors les murs (Guyon 2005, p. 291-302). Sur la rive nord du port, les entrepôts ou les thermes romains cèdent la place à des ateliers consacrés au travail des métaux mais aussi à l'habitat et la plupart des domus antiques, bien que modifiées, sont occupées jusqu'au VIe s. Aux confins de la ville, sur le versant nord des collines, l'habitat fait place très tôt à une occupation de type rural (Sillano et al. 2007a, p. 86), alors qu' a contrario dans les faubourgs, sur le comblement de la corne antique du port ou sur le site de l'Alcazar, les zones d'habitat se multiplient, parfois en lien avec une mise en culture des terres.

Au cours du VII ${ }^{\mathrm{e}}$ s., la croissance de Marseille, alors capitale de la Provence franque, se poursuit, mais la ville semble devoir répondre à plusieurs crises sanitaires lors des pestes de 643 et 689 (Guyon 1998, p. 63-64). Nous pensons que ces pandémies pourraient être en partie responsables d'une désertion partielle de certains quartiers de la ville antique et d'un éparpillement de la population.

894 Nous renvoyons pour cette période à l'article de M. Bouiron (2009b).
Sur les versants nord-ouest et est de la butte des Moulins ${ }^{\mathbf{9 9 5}}$ (Rothé 2005, p. 496-499), aux phases d'épierrement succèdent des apports de remblais. Lorsque de nouvelles implantations sont constatées, elles revêtent parfois un caractère rustique comme sur la butte des Carmes (Bizot, Gantès 2005, p. 511-530 et Paone 2008). Sur la rive nord du port (Mellinand 2005) ou dans le secteur de la butte Saint-Laurent, les reconstructions qui définissent de nouvelles orientations ne survivent pas à la fin du siècle ou au début du siècle suivant. Enfin, il est bien difficile pour nous de mesurer l'impact du « château Babon » sur la morphologie de cette ville et le rôle qu'il a pu tenir dans la protection de la population. Dans ses derniers travaux, M. Bouiron propose de remonter la construction de cette enceinte réduite dans le $3^{\mathrm{e}}$ quart du VII ${ }^{\mathrm{e}}$ s., et d'étendre son emprise au-delà de la butte Saint-Laurent, en englobant le quartier épiscopal jusqu'au sommet de la colline des Moulins (Bouiron 2009b, p. 13-42). Les fouilles du Tunnel de la Major ont montré que dans ce secteur où, pourtant, le renouvellement des constructions est régulier depuis le $\mathrm{V}^{\mathrm{e}} \mathrm{s}$., des campagnes de destruction sur l'ensemble des îlots s'échelonnent entre le VII ${ }^{\mathrm{e}}$ et le VIII' $\mathrm{s}$. malgré la présence de l'enceinte épiscopale (Barra et al. 2005, p. 446-452).

Alors, face à des paysages finalement contrastés où les secteurs désertés se généralisent, le haut Moyen Âge semble davantage se définir comme une accentuation significative du déclin urbain, dans une période de forte instabilité politique. Après la dislocation du pouvoir mérovingien, la ville est dirigée par les patrices qui mènent la Provence vers une indépendance de plus en plus affirmée. Cette dissidence conduit Charles Martel entre 737 et 739 à piller la région et Marseille. La Provence est alors mise au pas (Bouiron 2009b, p. 31-34). Ces attaques semblent constituer l'événement majeur qui précipite le destin de la ville, entraînant la disparition de l'habitat extra muros (site de l'Alcazar Bien 2004, p. 21-24). Une centaine d'années plus tard, la cité est de nouveau mise à sac par les Sarrasins puis dix ans plus tard, ce sont les pirates grecs qui pillent la ville et détruisent sa flotte, constituant ainsi un frein à l'activité portuaire. Alors que l'ouest de la cité est protégé par l'enceinte réduite du château Babon, la partie orientale, sous domination comtale, est délimitée par une enceinte réduite venant s'accoler au nord au rempart antique et se prolongeant jusqu'au port (Bouiron 2009b, p. 40). Établie durant les $\mathrm{IX}^{\mathrm{e}}-\mathrm{X}^{\mathrm{e}} \mathrm{s}$. (?), son tracé fossile justifie peut-être en partie le prolongement du réseau de rues depuis le port jusqu'au sommet de la colline des Carmes.

895 Fouilles des Pistoles et du Bon-Jésus. 
L'absence de vestiges archéologiques due en partie à la multiplication de ces destructions brutales, s'explique par d'autres facteurs. Lorsqu'elles sont présentes en fouille, ces séquences ténues, souvent dépourvues de vestiges construits et difficilement datables ${ }^{896}$, sont l'objet d'une attention moindre et désignées comme de « simples remblais » bien succinctement décrits. Ainsi, dans la fouille de l'Alcazar, il ne nous est pas possible d'interpréter avec assurance comme étant les fameuses «terres noires» (Galinié 2004), ces fines couches de limon argileux de couleur brun et gris sur lesquels des traces ténues de mise en cultures ont été observées uniquement en coupe (Maurin, Voyez 2001, p. 294). Mais le fait que ces séquences soient scellées par des épisodes alluviaux durant le haut Moyen Âge sur ce site mais également dans le bourg des Olliers confirme l'absence de constructions et d'infrastructures pouvant faire obstacles aux lessivages des terrains. Il semble dorénavant indispensable d'affiner l'étude de ces niveaux pouvant nous laisser entrevoir une relecture des «paysages urbains » marseillais.

Ne devons-nous pas également envisager pour le haut Moyen Âge à Marseille, mais peut être plus généralement, de nouveaux modes de constructions si rudimentaires qu'ils en seraient éphémères ? Dans la fouille de l'Esplanade de la Major (Paone et al. à paraître) réalisée en 2008 et donc non présentée ici, succèdent à l'imposante résidence épiscopale présente jusqu'au VIII ${ }^{\mathrm{e}} \mathrm{s}$., de bien rustiques constructions formées de quelques pierres liées à la terre et qui ont ponctuellement échappé à la mise en place du cimetière du XII ${ }^{e}$ s. Finalement, les indices de constructions sont bien minces pour le haut Moyen Âge marseillais, à l'exception d'une réparation du mur d'enceinte dans le secteur de la Bourse et sur les hauteurs des Carmes ${ }^{897}$.

Enfin, la rareté de ces niveaux du haut Moyen Age peut se justifier également par les phases de nivellement si fréquemment constatées lors des installations des bâtiments du XII ${ }^{e}$ s. Elles ont fait disparaitre ces occupations immédiatement antérieures.

896 Devant l'absence d'importation, les productions en pâte grise associées à ces contextes ne sont pas très précisément datées et restent méconnues. À noter également la rareté du mobilier médiéval par rapport à celui, pléthorique, de l'Antiquité tardive ; certains remblais sont datés par un unique tesson de céramique associé à des centaines de tessons résiduels et son absence peut faire basculer toute l'interprétation.

897 On signalera de façon plus «anecdotique » la réalisation de nouveaux aménagements liturgiques à l'intérieur de la cathédrale de la Major attestés par des fragments de chancel.

\subsection{La ville entre le $X^{e}$ et le $X I^{e} s$.}

Il faut attendre les $\mathrm{X}^{\mathrm{e}}$ et $\mathrm{XI}^{\mathrm{e}} \mathrm{s}$., pour qu'une reprise de la ville soit attestée par l'historiographie ; malheureusement l'archéologue perçoit encore ces transformations de façon bien lacunaire (fig. 274).

À partir du milieu du $\mathrm{X}^{\mathrm{e}}$ s., l'émergence de la famille d'Arlulf se manifeste par la nomination de l'un de ses fils, Honorat, à la tête de l'évêché et l'attribution du titre de vicomte de Marseille à son cadet Guillaume (Mazel 2009, p. 145-147). Le contrôle des pouvoirs épiscopal et vicomtal au sein d'une même famille entraîne une gouvernance conjointe de la ville jusqu'à la fin du XI $\mathrm{XI}^{\mathrm{e}} \mathrm{s}$, ce qui semble avoir favorisé la reprise des chantiers monumentaux dont les plus illustres exemples concernent les réédifications de la cathédrale de la Major et de l'abbaye de Saint-Victor. Et pourtant là encore, sur ces vastes ensembles étudiés lors de fouilles, l'archéologue n'a pas pu percevoir d'éléments significatifs attribuables à la première moitié du $\mathrm{XI}^{\mathrm{e}} \mathrm{s}$. A. Hartmann-Virnich constate également le décalage entre le caractère prestigieux de ces reconstructions sous-tendu par les sources (Hartmann-Virnich 2001, p. 279-292) et la moindre importance des travaux réalisés qui pourraient, selon lui, alors consister davantage en de simples rhabillages des édifices paléochrétiens, plutôt qu'à des reconstructions. Durant la même période, les églises paroissiales SainteMarie des Accoules et Saint-Martin sont créées, mais nous ne connaissons plus les édifices de cette période.

Les indices archéologiques restent rares pour cette période; ils sont tous en marge de la ville. Citons le mur de clôture littoral, sur lequel s'appuie par la suite la commanderie des Templiers, au fond du port (Sillano, Weydert, 2010) ; les aires d'ensilages, c'est-à-dire des structures en creux propices à la préservation, observées vers la butte des Carmes (site des Equipements publics et de la rue Trinquet - Paone 2009). Ou encore une probable activité de construction navale non loin de l'enceinte (sondages de la ZAC de la Bourse : Scherrer, Chevillot 2006). Ce constat confirme semble-t-il que la ville est encore peu densément lotie avec une probable concentration de l'habitat près des ensembles monumentaux. Dans la fouille du Tunnel de la Major, plusieurs maisons, bien que respectant la trame antique, redéfinissent les aménagements en terrasses de la butte Saint-Laurent ; elles sont établies entre le $\mathrm{X}^{\mathrm{e}}$ et le $\mathrm{XII}^{\mathrm{e}} \mathrm{s}$.

Pourtant ce constat archéologique est contredit par l'augmentation de l'emprise de la ville matérialisée par l'extension en 1040 de l'enceinte antique, mais dont la fouille de la Bourse n'a livré aucun vestige. Le développement urbain se justifie vraisemblablement par un 
accroissement de la population dans l'emprise de la ville sous domination comtale.

À partir du début du XII' s., une réoccupation de l'espace est ponctuellement perceptible sur la rive nord du port où des traces d'activités métallurgiques sont présentes, comme dans le bourg de Morier où l'on trouve alors un vaste bâtiment, qui reste cependant isolé.

\subsection{De la seconde moitié du XII ${ }^{\mathrm{e}}$ à la $1^{\text {re }}$ moitié du $\mathrm{XIII}^{\mathrm{e}} \mathrm{S}$. : division et reconquête de l'espace urbain}

La seconde moitié du XII ${ }^{e}$ s. marque pour l'archéologie marseillaise le début d'un renouveau urbain matérialisé par la multiplication des découvertes, et la densité des vestiges ne faiblit pas jusqu'au milieu du $\mathrm{XIV}^{\mathrm{e}} \mathrm{s}$.

Depuis la fin du $\mathrm{XI}^{\mathrm{e}}$ s., la réforme grégorienne polarise la scission entre les pouvoirs seigneuriaux de l'évêque et du vicomte qui n'ont alors de cesse d'affirmer leurs prérogatives, comme le montre la multiplication des procès entre les deux parties. Le conflit trouve sa pleine expression entre 1151 et 1164 , date à laquelle l'évêque obtient du comte de Provence le droit de fortifier la ville haute dont il a la seigneurie. Dans le même temps, une nouvelle partition de la ville épiscopale a lieu entre l'évêque et le chapitre qui obtient le partage des droits sur le temporel de l'Église (Pécout 2009b, p. 167-168). Il semble alors qu'il faille en partie attribuer à la rivalité de ces seigneurs laïcs et religieux, en quête de ressources et d'influences, le renouveau urbain si clairement perceptible à partir des données archéologiques. Mais il est le plus souvent bien difficile d'établir précisément, pour chaque secteur de la ville, quels sont les acteurs, les promoteurs de cet élan bâtisseur, l'enchevêtrement des seigneuries foncières étant régulièrement pointé lors des études d'archives (Teyssot 2003, p. 449-451). Ainsi, en 1178 dans l'emprise du château Babon, c'est la volonté conjointe du vicomte et des chanoines qui détermine la mise en place d'un lotissement (Mazel 2009, p. 145-148).

Dans la ville basse est créé un nouveau quartier marchand défini par un réseau dense de rues d'axe nord-sud disposées de part et d'autre de la Grand-Rue et à l'ouest par un maillage régulier de rues formant une transition entre l'ancien axe antique courbe de la rue Caisserie et le port ; cette trame définit un ensemble d'îlots dont les dimensions se répètent par endroit et dans lesquels un découpage parcellaire modulaire, sensiblement plus large que celui qui prévaut dans la ville haute, est réalisé. Ce qui apparaît d'autant plus intéressant est le rôle joué par l'abbaye Saint-Sauveur (Bouiron à paraître). Placée sous la sujétion de l'évêque, elle lotit de façon systématique les terrains qui lui appartiennent et qui correspondent à l'espace entre les anciennes fortifications réduites, au sud de la butte de la Roquette. Ce lotissement monastique est perceptible par les textes (certes difficilement, ce qui explique qu'il n'ait pas été identifié jusqu'à présent) et depuis peu par l'archéologie. L'opération César-Bargemon démontre en effet que la régularité des îlots participe d'une planification de l'urbanisme. Elle met également en évidence que les parcelles les plus larges sont situées à proximité immédiate du marché de bouche et du palais qui créé par la commune.

La gestion planifiée de l'espace semble également prévaloir dans les faubourgs où plusieurs établissements artisanaux sont élaborés. Ainsi, la conception de la vaste tannerie du bourg de Morier, peut-être due à une initiative vicomtale, intègre un réseau hydraulique complexe au sein de pièces réparties selon un schéma modulaire (Paone 2004, p. 25-32). Bien que la fouille des Olliers n'ait concerné qu'une surface réduite du bourg, il apparaît que les constructions dégagées étaient parfaitement adaptées à l'organisation du travail au sein de l'atelier des potiers. Les fouilleurs proposent d'attribuer à une décision de l'évêque détenteur de ces terres, la décision de faire venir un maître artisan d'Espagne ou de Sicile et pour cela lui fournir les infrastructures nécessaires à son art (Thiriot, Vallauri 2001, p. 369-374). Préalablement à l'installation des quartiers artisanaux dans les bourgs, la canalisation des eaux est réalisée sous la forme d'aqueduc, comme dans le bourg de Morier, alimenté par une dérivation du Jarret, et l'évacuation des eaux usées s'effectue grâce à des fossés dont celui de la Cuiraterie qui longe le Plan Fourmiguier est un bon exemple.

Le développement de zones d'habitats, la création d'établissements artisanaux et commerciaux et la mise en place de nouvelles infrastructures aboutissent vers 1190 à la nécessité d'agrandir la ville. Une nouvelle enceinte est établie vers l'est; elle a été en partie mise au jour lors des fouilles de l'îlot Puget III (Moliner 1993). Comme l'ont montré les fouilles de République-Surverse, des terrains sont également gagnés sur la mer, et accueillent un alignement d'îlots parallèles à la ligne du rivage.

La croissance démographique s'accompagne ou est justifiée par une activité portuaire grandissante alimentée par les consulats d'Arles et d'Aigues-Mortes. Les Marseillais, ayant participé à la seconde croisade, se voient également accorder l'octroi de comptoirs marchands en Terre Sainte. Le port, devenu alors une plaque tournante du transport de pèlerins, est bordé à l'ouest par la commanderie des Hospitaliers de Saint-Jean de Jérusalem et à l'est par celle des Templiers (Paone et al. 2009 , p. 37-44). Nous ne connaissons pas la nature des aménagements de rivage à cette époque ; ceux qui ont 


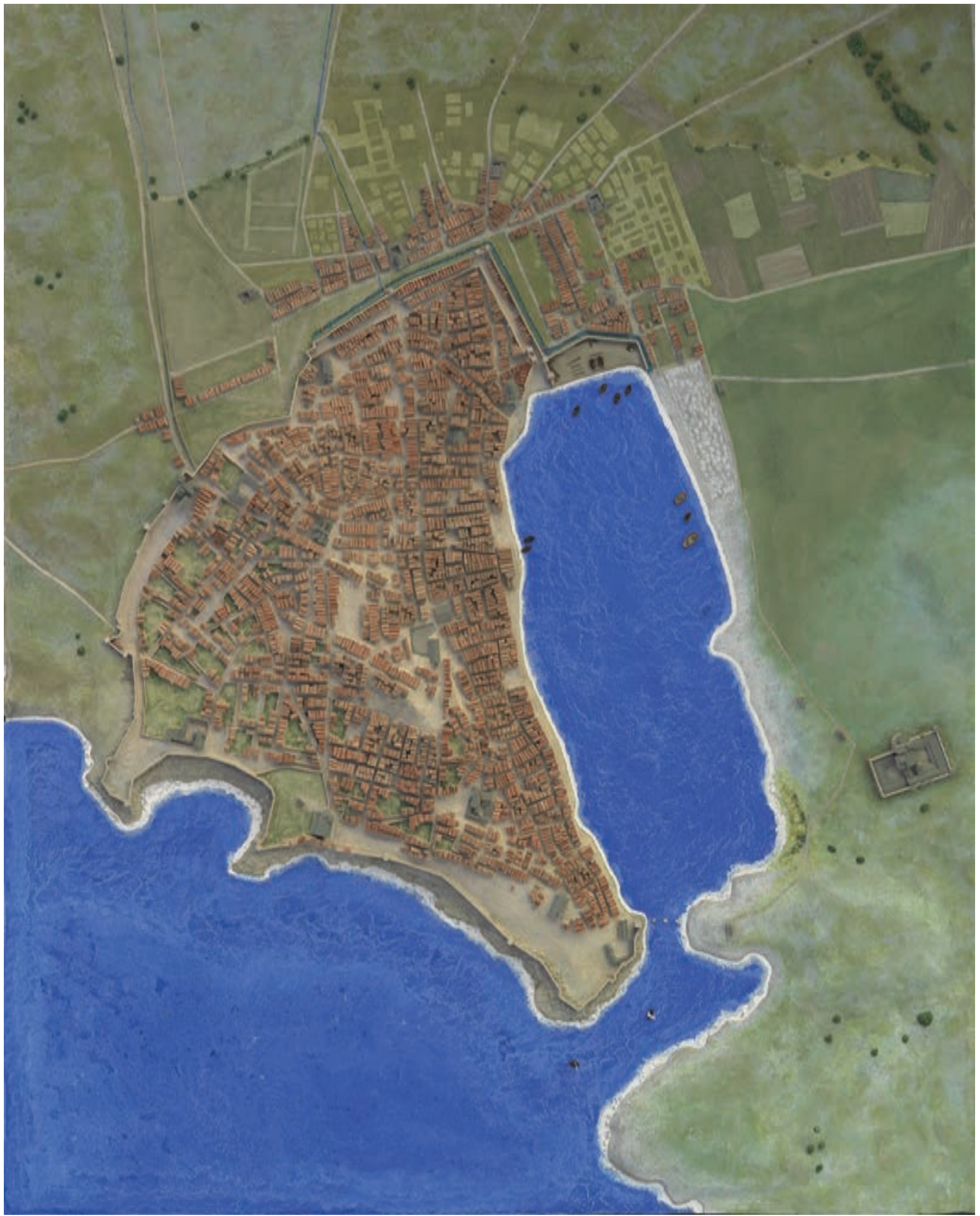

Fig. 275. Maquette de Marseille en 1350 (maquette Acte II, M. Bouiron et T. Pécout ; cl. O. Guillon/CICRP). 


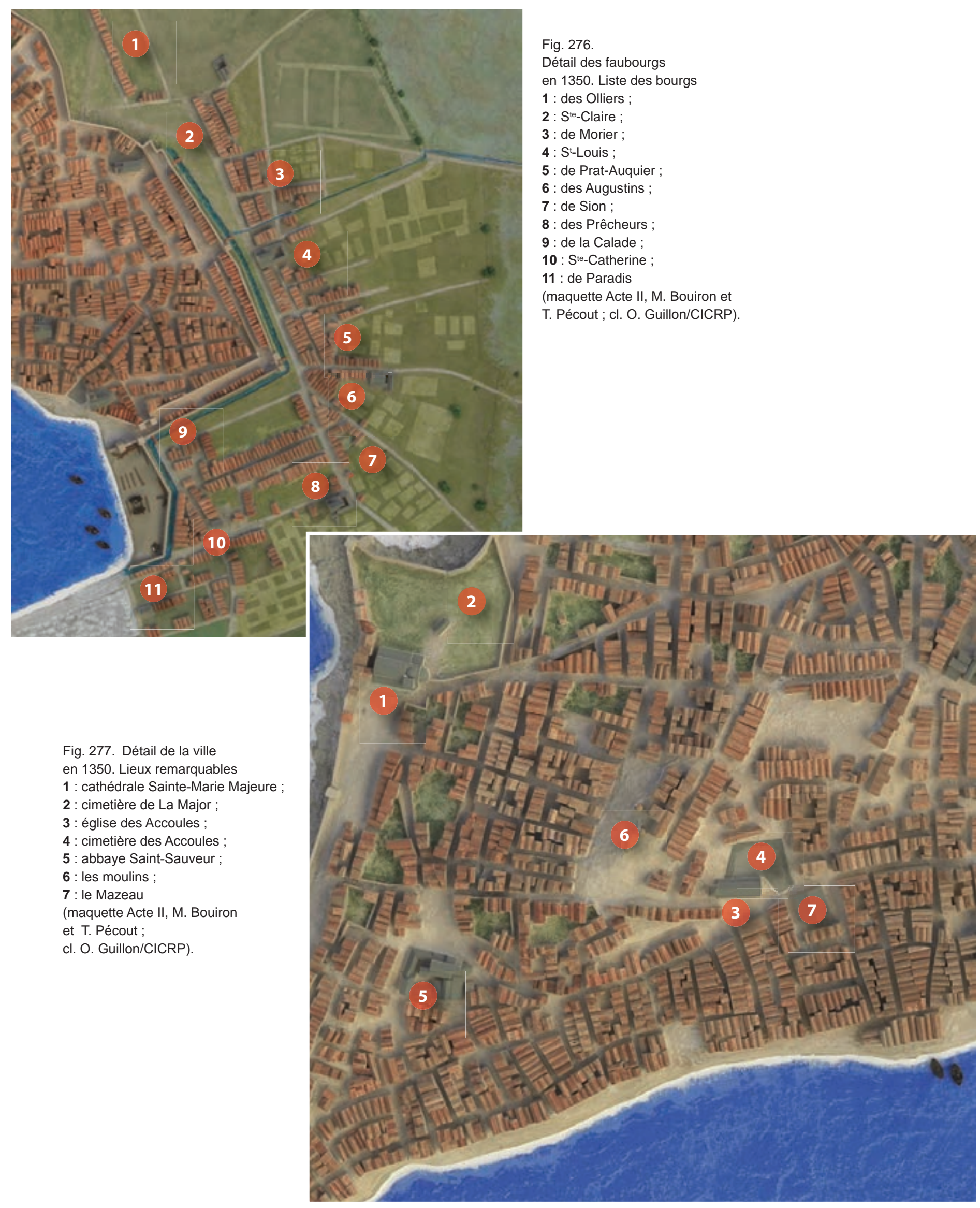


été observés rue de la République avaient été remplacés par des quais plus récents.

Le long des voies qui sortent de la ville s'établissent des hôpitaux qui deviennent très vite les catalyseurs de nouveaux pôles d'installation à l'origine de la création de véritables faubourgs d'habitation. L'hôpital du SaintSépulcre situé au plan Fourmiguier le long de la voie de la Calade en est un parfait exemple (Bouiron 1999). Dans le courant du XIII ${ }^{\mathrm{e}}$ s., la multiplication des couvents suburbains constitue autant de pôles de concentration de la population.

La forme de l'habitat à cette époque est difficile à appréhender car la fonction des pièces observées en fouille reste souvent indéterminée ; ainsi la répartition entre les espaces ouverts tels que les cours, les jardins et les maisons proprement dit n'est pas toujours très claire.

L'émergence de l'autonomie municipale (12291257) marque un tournant dans la gestion des affaires publiques avec la rédaction des Statuts municipaux. Elle accompagne entre autre la croissance urbaine et le développement économique en en fixant les règles. Nous pouvons certainement attribuer à des décisions communales l'amélioration du réseau viaire, l'entretien du port, ou l'interdiction de faire empiéter les constructions sur la rue ; autant de mesures qui peuvent être confirmées par les fouilles archéologiques. Doit-on expliquer l'absence totale sur les sites marseillais d'espaces-dépotoirs par l'interdiction de jeter tous déchets dans des zones vacantes, les cours, les jardins mais également les fossés, et bien sûr le port ? Cette ville, qui compterait au début du $\mathrm{XIV}^{\mathrm{e}}$ s. entre 10000 et 20000 habitants d'après Jacques Le Goff, conserve bien peu de traces de sa consommation, de ces rejets ; le contraste est significatif avec une ville comme Avignon où chaque fouille livre fosses et dépotoirs riches en faune et mobilier.

\subsection{7-1350 : poursuite et déclin de la croissance urbaine}

L'intégration de Marseille au royaume d'Anjou est un frein à l'indépendance communale. Charles I ${ }^{\text {er }} \mathrm{d}$ 'Anjou met un terme aux velléités d'autonomie des Marseillais et réussit, par une politique de rachat des droits seigneuriaux de l'évêque, à réunifier progressivement la ville. Aux lourdes taxes nécessaires aux guerres pour le maintien du royaume de Naples et de Sicile, s'ajoutent la réquisition des moyens maritimes et l'accueil d'une partie de la flotte angevine, dans les nouveaux arsenaux construits en rive sud du port par Charles II et le roi Robert. Mais si cette tutelle fut un lourd handicap pour l'économie de la ville, concurrencée par les ports d'Italie du Nord qui sont alors institués en communes indépendantes, elle n'entrave pas son développement. Au contraire, l'archéologie met en évidence la poursuite de la croissance démographique tout au long du premier siècle de domination angevine, que ce soit par la multiplication des faubourgs ou la densification du bâti intra muros (fig. 275).

Ces périodes nous livrent de nombreuses traces d'artisanat réparties indifféremment à l'intérieur ou à l'extérieur de la ville pour les ateliers ne nécessitant pas de grosses infrastructures ou ne générant pas de pollutions majeures comme le travail du corail ou celui des métaux, très souvent associés d'ailleurs. Mais dès la fin $\mathrm{du} \mathrm{XIII}^{\mathrm{e}} \mathrm{s}$. les grands établissements artisanaux périurbains tels la tannerie du bourg de Morier ou les potiers du quartier des Olliers disparaissent, pour être parfois transférés comme dans le cas des cuiratiers qui sont alors déplacés près du canal de Saint-Bauzille. Les terrains laissés vacants ne le restent naturellement pas et font rapidement l'objet de campagnes de lotissement.

À la fin du XIII et au début du XIVe s., une nouvelle phase d'expansion de l'urbanisation et de l'habitat se matérialise dans la couronne de lotissements qui se développent hors les murs (fig. 276). Le bourg de Morier se crée, selon une trame viaire dense, sur les vestiges de la tannerie, celui de Sainte-Catherine est établi en partie sur les anciennes salines de Saint-Victor et celui des Olliers reprend l'emplacement des ateliers de potiers. Ces fouilles nous livrent des informations essentielles sur l'organisation des maisons dont les unités simples côtoient des ensembles plus complexes pourvus de jardins ou de cours, ainsi que des parcelles cultivées. Ces espaces comportent des aménagements rudimentaires comme des foyers creusés à même les sols en terre battue. Dans le bourg Sainte-Catherine, ils sont alignés le long de rues rectilignes caladées.

Les mêmes caractéristiques se retrouvent intra muros dans le quartier excentré proche de la Joliette; sur le revers septentrional de la colline des Carmes se développe un lotissement serré à l'emplacement d'anciens jardins (Sillano 2007a). Dans la ville prévôtale, entre la fin du XIII et le début du $\mathrm{XIV}^{\mathrm{e}}$ s., le cimetière dont l'emprise s'étendait de l'anse de l'Ourse jusqu' au sud de la cathédrale, est en partie réduit pour laisser place à la maison du chapitre et aux logements de quelques clercs. Dans le quartier du Mazeau, d'anciennes placettes, dotées de puits, disparaissent au profit du bâti (îlots I et III) et des venelles sont abandonnées (fig. 277).

L'étude des vestiges de maisons indique que les matériaux employés sont tous issus de gisements du bassin marseillais et que leur sélection répond le plus souvent à des préoccupations architectoniques. Ainsi, le calcaire stampien de Saint-Victor généralement utilisé dans 
l'habitat se trouve privilégié également pour les structures d'eau comme les puits ou l'imposant complexe hydraulique de la tannerie de l'Alcazar. En revanche, le calcaire coquillier de La Couronne, dont l'utilisation est plus tardive, est presque exclusivement réservé pour les édifices en pierre de taille qu'ils soient religieux ou civils. Cependant la question de la gestion proprement dite de ces carrières et de l'approvisionnement en pierres reste posée. De plus, la fréquence des indices d'architecture de terre associée conjointement aux murs de pierres est maintenant clairement affirmée à Marseille. Les fouilles de la place Bargemon ou celle de la place des Pistoles (Reynaud 1998, p. 431-433) ont livré des murs en pisé ; c'est également le cas dans les faubourgs, sur les sites de l'Alcazar ou de Sainte-Barbe. L'usage de ces techniques mixtes finalement répandues entre la seconde moitié du XII ${ }^{\mathrm{e}}$ s. et le milieu du XIV ${ }^{\mathrm{e}}$ s. est probablement un facteur de fragilité et donc de disparition des élévations justifiant le faible nombre de vestiges conservés.

\subsection{Le hiatus archéologique de la fin du Moyen Âge}

Après le formidable essor démographique attesté par le développement des faubourgs, c'est une chute tout aussi vertigineuse qui caractérise la seconde moitié du XIVe s. (fig. 278). Les causes sont multiples : la famine, en partie liée à des conditions climatiques catastrophiques (comme en 1315-1317), les «Routiers », hommes d'armes sans emploi durant la guerre de Cent Ans qui vivent de pillages et rançons, la peste noire, qui arrive à Marseille à la fin de l'année 1347 avant de s'étendre à tout le royaume et décime près de la moitié de la population en vingt ans ${ }^{898}$, ou encore l'instabilité politique consécutive à la mort du roi Robert et au règne de Jeanne de Naples.

La fouille de l'Alcazar atteste de la destruction des habitations du faubourg à proximité des remparts, illustrant une ordonnance du conseil de ville, en 1357 , destinée à se protéger de l'attaque des Routiers ; néanmoins le mobilier céramique fait remonter l'abandon et l'incendie de plusieurs espaces à une date un peu antérieure. Cette mesure, en apparence autoritaire, pourrait n'avoir que très peu affecté un quartier déjà partiellement déserté et qui ne se relèvera pas avant la fin du $\mathrm{XVI}^{\mathrm{e}} \mathrm{s}$. Dans la ville intra muros, les datations les plus tardives pour le XIV e s. s'étalent entre le milieu et, plus rarement, comme pour les anciens Bains de la rue de la Guirlande, la fin du siècle. Après, c'est un hiatus, au moins du

898 La comptabilité du nombre de morts est variable selon les historiens, E. Baratier estime que sur les 25000 habitants, 10000 auraient péri. point de vue céramologique, de près d'un siècle. Les rares tessons proviennent de tranchées d'épierrement de murs médiévaux (Bargemon, parcelle 399), jamais de constructions.

Le sac des Catalans, en 1423, pendant lequel, diton, le quartier du port a été entièrement incendié, n'a laissé aucune trace dans la stratigraphie, là où elle est conservée. On pourrait s'interroger sur la densité de l'occupation à cette époque, mais les mesures incitatives prises par la suite par les autorités royales et municipales afin que la population réinvestisse le quartier (Maurel 2009, p. 415-418), ainsi que la grande taille des lots acquis par de riches négociants, tel les Vento, qui s'y installent au cours du XV ${ }^{\mathrm{e}}$ s., confirment l'impact de l'évènement. Sur la butte Saint-Laurent, la création de l'esplanade de la Tourette participe à la fois de la mise en valeur de la cathédrale de La Major, comme d'une réduction de l'espace habité.

Ce hiatus chronologique est d'autant plus troublant qu'il ne se manifeste pas dans d'autres fouilles urbaines du sud de la France. Que la cité soit rattachée au royaume de France, comme Nîmes ou Montpellier, ou à la papauté, comme Avignon, ou qu'elle soit port actif comme Arles, l'archéologie confirme le puissant essor qu'elle prend au XV ${ }^{\mathrm{e}} \mathrm{s}$., à l'instar des villes septentrionales. Marseille, source de revenus pour la maison angevine, ne semble pas se relever et sa population peine à retrouver le nombre d'habitants du début du $\mathrm{XIV}^{\mathrm{e}} \mathrm{s}$.

L'historiographie traditionnelle qui avait attribué au roi René une influence économique sur la Provence a été démentie depuis (Pécout, Roux 2009, p. 97) ; toutefois, dans le besoin criant de ressources et dans un souci de meilleur rendement fiscal, René tente de privilégier le développement du commerce (id., p. 82). L'immigration, en particulier ligure, relance la démographie qui, après une longue stagnation, ne reprend effectivement qu'à la fin du $\mathrm{XV}^{\mathrm{e}}$ s. A côté de la maison commune, le comte de Provence fait édifier sa résidence marseillaise, qu'il n'occupera sporadiquement qu'à partir de 1471. D'un point de vue archéologique, la reprise immobilière ne s'effectue pas avant l'extrême fin du $\mathrm{XV}^{\mathrm{e}} \mathrm{s}$.

\subsection{Marseille sous les Valois (1481-1589)}

Avec son rattachement au royaume de France, Marseille entre dans les Temps Modernes. Le port, nouvelle tête de pont vers le Levant, se substitue progressivement aux ports languedociens qui, tel Aigues-Mortes, s'ensablent. Vers 1511, le roi fait édifier une ligne de quais en pierre tout le long de la rive nord du port, construction définie par lettres patentes et dont la qualité et la solidité ont été confirmées par les fouilles. 
DEUXIÈME PARTIE : PRÉSENTATION DE QUELQUES QUARTIERS À LA LUMIÈRE DES FOUILLES ARCHÉOLOGIQUES

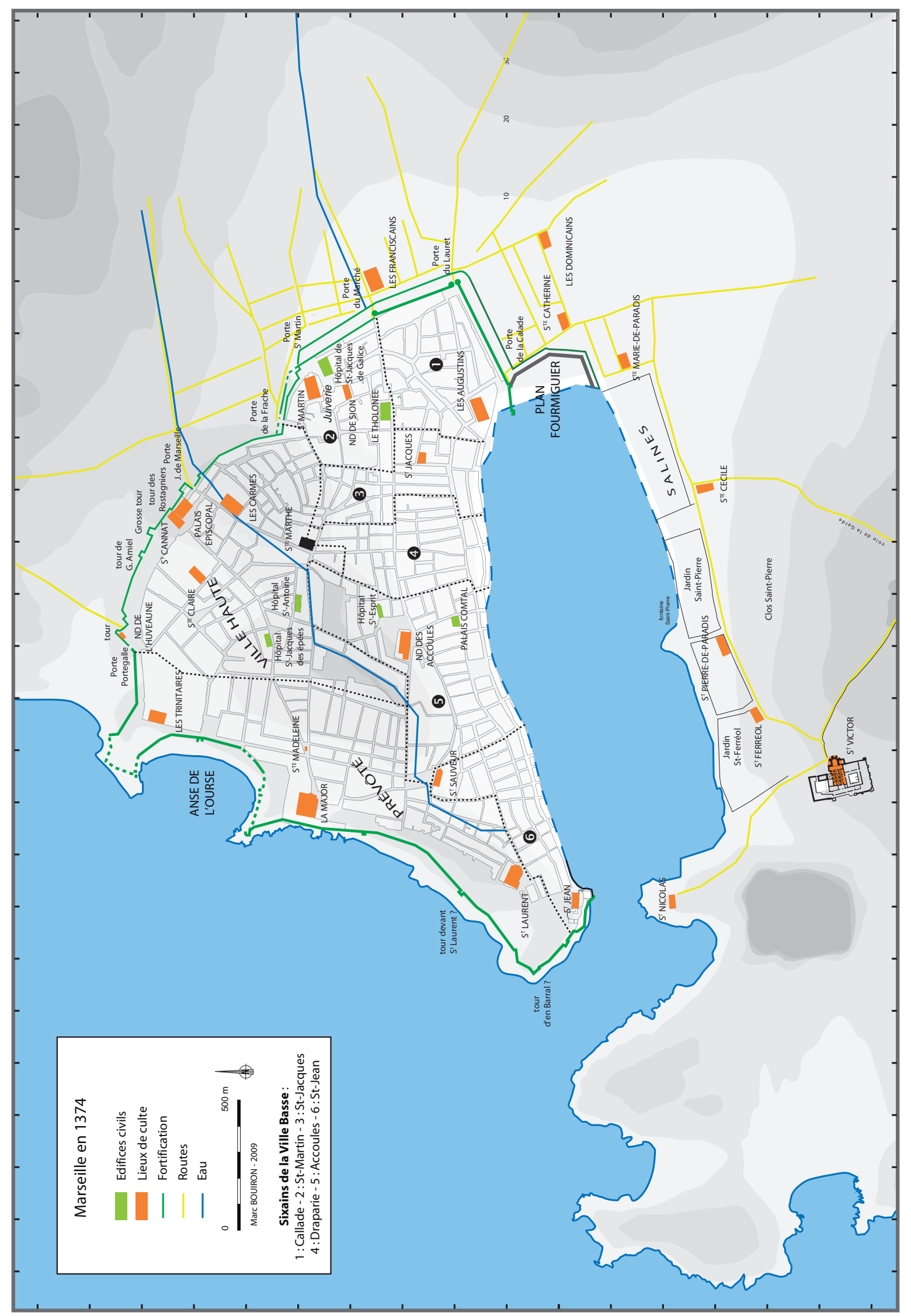

Fig. 278. Marseille en 1374 (M. Bouiron/Ville de Nice) 
La population passe de 15000 habitants en 1520 à 35000 en 1585 (Kaiser 1992, p. 36). Les conflits extérieurs persistants les contraignent à rester derrière des fortifications qui se dotent d'avant-corps et de bastions (probablement après 1524). Les fondations de la porte de l'Annonerie ont été retrouvées en fouille (Moliner 1986); elles remonteraient à 1585 (Fabre 1867-1869, p. 42) mais l'archéologie n'a pu confirmer cette date. Face à l'invasion de Charles Quint, si destructrice en Provence, Marseille bénéficie du soutien de l'État-Major et échappe ainsi aux destructions. Sous ces menaces persistantes, les lices, débarrassées des constructions médiévale au siècle précédent à des fins défensives, restent de larges aires ouvertes; sur le site de l'Alcazar, l'immense étendue de remblais qui couvre les vestiges du bourg de Morier atteste d'un gel de l'urbanisme jusqu'à la fin du siècle. Pour autant, audelà de cette couronne périphérique d'une centaine de mètres de large, les fouilles récentes sur le site du Jeu de Paume (Sillano, Scherrer 2010) mettent en évidence une succession de sols datés dans le courant du XVI ${ }^{\mathrm{e}} \mathrm{s}$. Malheureusement, pour cette période, et c'est le cas sur l'ensemble des fouilles marseillaises, le peu de mobilier retrouvé génère une imprécision dans la datation, ce qui est particulièrement pénalisant lorsqu'il s'agit de décomposer l'extraordinaire essor urbanistique que connaît le XVI' $\mathrm{s}$.

Cet essor est sensible dans de nombreuses villes du royaume, qui adoptent un plan plus régulier, traduisant la nouvelle esthétique urbaine (Loupiac 2005, p. 158). À Marseille, la création du Grand-Caire, cette place régulière ornée de fontaines sur laquelle se tient le marché aux fruits et légumes, située hors la ville, au débouché du chemin d'Aix, en est un exemple. L'étude du parcellaire un peu plus tardif sur le site de l'Alcazar montre que la conception de la place a produit des déformations tellement contraignantes que seule une volonté communautaire forte d'avoir des lices régulières peut les justifier. Grâce aux quelques vues cavalières de la ville antérieures à l'Agrandissement nous pouvons estimer que cette place remonte à fin du $\mathrm{XVI}^{\mathrm{e}} \mathrm{s}$.

Dans la ville intra muros, de tels aménagements de l'espace public sont difficiles par manque de place. En effet, si l'essor démographique n'a fait que compenser au début les pertes liées à la crise du $\mathrm{XIV}^{\mathrm{e}}$ s., par la suite la population dépasse de loin celle du Moyen Âge pour une superficie identique. Nous avons quelques exemples, que nous attribuons également à la fin du XVI ${ }^{\mathrm{e}} \mathrm{s}$, comme, en limite du site de Villeneuve-Bargemon, le haut de la rue de la Guirlande qui a été élargi de $2 \mathrm{~m}$ à 3,50 m. Cette opération s'est faite conjointement à la destruction des îlots situés à l'ouest afin d'installer les «bancs » des bouchers du marché du Petit Mazeau au sein d'un maillage serré de ruelles. Mais d'une manière générale, le réseau viaire médiéval reste en l'état, même si, parfois, des îlots trop petits sont regroupés, absorbant venelles et impasses. C'est plutôt le souci hygiéniste du $\mathrm{XVI}^{\mathrm{e}}$ s. que l'on retrouve à Marseille. Des collecteurs sont mis en place dans l'axe des rues qui descendent vers le port ; ceux de la rue de la Prison ou de la Guirlande se démarquent par la qualité de leur mise en œuvre. En 1582 un arrêté demande la destruction des saillies sur les rues afin de mieux les éclairer.

La reprise de l'immobilier près du port est en partie, comme cela a été évoqué, le fait de grandes familles qui acquièrent des terrains comprenant plusieurs parcelles. Ainsi trouvons-nous, à proximité des bancs du change et de la maison commune, de vastes demeures, précurseurs des hôtels particuliers du XVIII ${ }^{\mathrm{e}}$ s. Les Vento, négociants venu de Gênes vers 1425, construisent, entre autres, un hôtel place Vivaud au début du XVI ${ }^{\mathrm{e}}$ s. Les Remezan règnent également en maître sur le marché du négoce ; l'archéologie en révèle un hôtel, bordé de trois rues, daté d'après les éléments de fenêtre de style gothique en remploi (parcelles 374-373). L'Hôtel de Cabre, édifié par cette ancienne famille en 1535, possède un décor similaire mais plus flamboyant et probablement plus tardif. L'Hôtel de Saint-Victoret, qui occupe aussi toute une partie d'un îlot, apparaît au travers de l'étude d'archive. En 1545, il est bordé par le Palais comtal, avant d'être absorbé par la construction du pavillon Daviel. Également apparu dans la recherche archivistique, le somptueux hôtel de style classique que fit construire Casaulx près de la Maison commune et qu'il ne verra pas terminé. Le plus ancien, si on se réfère aux quelques tessons de céramiques exhumés, réoccupe une partie de l'établissement des Bains médiévaux de la rue de la Guirlande (parcelle 399). Le rhabillage de la façade en pierre de taille, plus tardif, le nombre exceptionnel de marches (24 degrés) pour atteindre le premier étage et la grande dimension du vestibule démontre le caractère prestigieux de l'édifice. Le plus vaste hôtel, propriété des Jarente au XVII ${ }^{\mathrm{e}}$ s. (parcelle 370), n'est pas daté. Il possède des latrines de grandes dimensions et, avec ses bâtiments disposés autour d'une cour intérieure, il reste le seul qui adopte une configuration plus conforme aux demeures de prestige d'alors, à la différence près que la cour est à l'opposé de la rue.

Néanmoins, comme l'illustre le démembrement de 1'Hôtel de Remezan à la fin du XVI' ${ }^{\mathrm{e}}$ s., les belles demeures ne sont rapidement plus l'apanage du quartier. Les plus riches négociants ont le regard tourné vers Aix, 
devenue capitale administrative depuis le roi René, puis vers le terroir. Ils abandonnent le quartier du Corps-deVille aux négociants de second rang (Dell'Umbria 2006, p. 90); on y retrouve alors tout le panel entre demeure patricienne et maison bourgeoise, mélangé aux maisons des artisans de la bouche.

C'est aux angles d'îlots que sont opérés les principaux remodelages parcellaires. Une maison d'angle de l'îlot III (parcelle 386) regroupe trois parcelles médiévales par de puissantes fondations, similaires à celles des bains médiévaux et à celles de l'Hôtel de Remezan, où l'alternance de blocs de grès à sec et de lits épais de mortier témoigne d'un soin particulier qui contraste avec l'hétérogénéité, liée aux remplois, de la plupart des fondations modernes. Les parcelles d'angle de l'îlot I acquièrent une organisation quadripartite stéréotypée. Dans tous les autres cas mis en évidence par l'archéologie, la forme de l'habitat compose avec le gabarit étroit des parcelles médiévales, à l'instar des autres villes du royaume (Saupin 2002, p. 52); nous ne trouvons pas à Marseille de terrains vierges, tels ceux nouvellement gagnés sur le Rhône à Lyon, qui ont laissé le champ libre

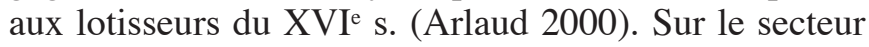
de la place Bargemon, les seules bâtisses qui ne tiennent pas compte du parcellaire antérieur sont les boutiques et habitations qui ont été rasées en 1784 lors de la création de la place du Petit-Mazeau. La confrontation du plan établi à cette occasion et des vestiges conservés montre que ces nouvelles constructions ne diffèrent guère de celles qui sont de l'autre côté de la rue de la Guirlande (parcelles 400 à 402), pourtant contraintes par le parcellaire médiéval qu'elles conservent.

Au rez-de-chaussée des immeubles du quartier de la Loge, la présence de boutiques, le plus souvent de magasins (dans le premier on vend, dans le second on stocke) est quasi-systématique. Généralement indépendantes de l'habitation, elles hébergent des artisans (rôtisseurs, boulangers) mais aussi des commerçants (huile d'olive, vin). Elles caractérisent ce secteur de la ville, proche du port et des accès charretiers (la Grand-Rue). Le creusement d'un puits privé semble être systématique à cette époque. Il se situe dans le ciel ouvert, cour à l'extérieur d'un bâtiment, ou au fond de la maison, à proximité ou sous l'escalier. Celui-ci, la vizette, est souvent disposé dans la maison, à l'opposé de l'entrée, plus rarement à l'extérieur, dans la cour, jamais du côté de la rue, comme il est d'usage dans d'autres villes comme Montpellier (Sournia Vayssette 1994). Il symbolise l'indépendance des étages, au nombre de deux ou trois, rarement plus, mais son accès, depuis la boutique du rez-de-chaussée, suggère que la résidence reste encore unifamiliale.

\subsection{Le début du XVII ${ }^{\mathrm{e}}$.}

Davantage que les guerres de Religion, ce sont leurs répercussions, avec la résistance de la Ligue et l'avènement de Casaulx en 1590, qui, selon l'historiographie, ont miné le commerce et fait augmenter les dépenses publiques. Celui que Ruffi présentera comme un tyran n'en a pas moins mis en œuvre nombre de constructions à caractère social dont l'Hôtel-Dieu, qui domine le quartier de la Loge. Ces temps de troubles ont conduit la ville à rester repliée derrière ses remparts, alors même qu'une foule d'immigrants, Gavots ou Italiens, est attirée par l'essor du port; la population passe de 35000 en 1585 à 65000 en 1650, dont un tiers hors les murs (Kaiser 1992, p. 36).

Avec la poussée démographique, la réduction de l'espace privé au profit de l'espace public est impensable. Les rues sont étroites (entre 2 et $4 \mathrm{~m}$ ) et le restent; aucun texte ne semble mentionner d'étages en surplomb sur la rue. Les collecteurs axiaux qui courent sous les rues aboutissant au port sont régulièrement entretenus et refaits. Nous n'avons aucune trace archéologique de la chaussée, hormis sur le site du Tunnel de la Major où les rues se pavent de «calades » avec rigole axiale à la fin du XVII ${ }^{\mathrm{e}}$ s. Il s'agit de ces rues secondaires « à chaussée fendue » interdites au charroi.

La poussée démographique se traduit par une densification de l'occupation de l'espace que les fouilles comme les archives illustrent bien. En effet, l'abondance des actes notariés au XVII ${ }^{\mathrm{e}}$ s., ainsi que celle du mobilier archéologique lié aux constructions des caves, les seules pièces complètes révélées par l'archéologie, font de ce siècle le cœur de l'étude des Temps Modernes.

La qualité de l'habitat marseillais est souvent décriée. Ainsi G. Rambert oppose l'esprit de municipalisme en Italie du Nord, fait d'orgueil collectif et de sentiment artistique, à celui des Marseillais qui ont longtemps négligé l'extérieur de l'habitation, refusant de «tapisser la rue » (Rambert 1938, p. 188). Pourtant, derrière le rempart d'hôtels particuliers de la via Garibaldi de Gênes, nous retrouvons les mêmes rues sombres aux bâtiments très hauts et étroits qu'à Marseille. Les façades restent certes modestes mais déjà l'utilisation de la pierre de taille, qui n'est pas encore de mise dans les villes plus septentrionales, leur donne un certain cachet. Vers la Loge se côtoient les anciennes fenêtres à croisées soulignées par un cordon continu et les nouvelles baies à recouvrement clavé, dont celles couvertes en plein cintre à l'arrière-voussure dite marseillaise, chef-d'œuvre de stéréotomie.

En 1668, le quartier de la Loge semble toujours apprécié puisque Catherine Vias fait entreprendre la reconstruction d'une ancienne demeure bourgeoise (parc. 386), parallèlement à l'édification de l'actuel 
Hôtel de Ville. Cependant il est clair qu'avec la poussée démographique contenue par les remparts, générant la surélévation des immeubles qui obscurcissent les rues trop étroites et la mauvaise qualité de l'habitat, le quartier commence une lente dégradation qui constituera la justification de sa destruction en 1943. Car la transformation de la maison élémentaire, à l'origine unifamiliale, en immeuble de rapport permettant d'augmenter la capacité d'hébergement se traduit, compte tenu de la petitesse des parcelles, par un habitat étriqué, avec des «maisons habitées depuis la cave jusqu'au grenier », "n'y ayant pas cent maisons où il y ait une cour » (lettres d'Arnoul à Colbert du 22 janvier 1667 et du 16 mars 1669). Toute transformation de bâti se révèle somme toute être un pis-aller très éloigné de la fonctionnalité qu'auront les immeubles de la Ville Nouvelle de Louis XIV.

Le bâti s'étend horizontalement, en absorbant l'arrière-cour et son bâtiment annexe, lorsqu'elle existe encore, parfois sur des lopins de terre en cœur d'îlot. Mais ces extensions sont limitées par les problèmes d'éclairage des circulations et des pièces en retrait, qui conduisent à une mise en commun des ciels ouverts, tout au moins de la possibilité d'ouvrir vers un voisin. Il s'étend aussi et de manière quasi systématique au soussol. Les caves occupent généralement l'ensemble de la parcelle et empiètent parfois sur le ciel ouvert. Nous avons bien observé leur construction en sous-œuvre, par panneaux, le puits étant alors chemisé et doté d'une ouverture à chaque niveau. Le couvrement, combinant la pierre de taille et la brique que l'on commence à fabriquer près des gisements d'argile de Séon, témoigne de nouvelles techniques de construction. Certaines caves empiètent sur la rue, sous la chaussée avec laquelle elles communiquent par une trémie. Cette originalité semble associée à la présence d'un four, chez les artisans rôtisseurs et boulangers du Petit Mazeau par exemple et correspond vraisemblablement à un besoin d'accès direct à la cave afin d'alimenter rapidement en combustible volumineux.

Les textes mettent bien en évidence un nombre croissant d'étages, jusqu'à cinq, surmontés d'une lauvisse, terrasse et pigeonnier. Les constructeurs semblent peu se soucier de la solidité des murs qui sont rarement refaits entièrement. Dans le cas contraire, nous avons constaté que les fondations ne sont pas toujours refaites, même si, parfois, le prix-fait exige de «creuser jusqu'au ferme ». Se pose le problème de la distribution des étages que l'on voudrait indépendants. Pour faire évoluer la maison unifamiliale, on assiste à la mise en place de couloirs latéraux au rez-de-chaussée permettant l'accès à la vizette sans passer par la boutique, à la création de paliers intermédiaires et à la multiplication des portes afin de rendre indépendants pièces et étages. Mais, pendant longtemps, l'immeuble ne possède qu'une cuisine, au premier étage, les autres niveaux restant assujettis pour «le pot et le feu », de même qu'ils partagent les lieux d'aisance situés au dernier étage. Si la distribution n'est plus commandée par une seule salle, nous sommes encore loin des « appartements » autonomes des immeubles de rapport.

Dans les faubourgs, sur le site de l'Alcazar, les premières constructions le long du Grand-Caire, les remblais du $\mathrm{XVI}^{\mathrm{e}}$ s. qui les supportent, les terres végétales du début du XVII ${ }^{\mathrm{e}}$ s. apposées dans les parcelles disposées le long des rues, la présence de petites masures, illustrent un état des lieux décrit dans l'acte de vente de $\mathrm{D}^{\text {lle }}$ de Guérin à la congrégation de Saint-Hommebon, en 1636. Nous avons retrouvé les auberges des Trois Mulets et du Canard, immenses bâtisses en bordure de la place, mentionnées par cet acte. Au-delà, ce sont des jardins avec quelques cazals, petites remises ou écuries. Plus loin est fait mention d'une vaste demeure «que se réserve la demoiselle de Guérin », une des premières bastides de la campagne marseillaise. Nous avons également retrouvé, amputée par le prolongement de la rue du Petit-Saint-Jean, une partie d'une bâtisse au cœur des «jardins Barnier», ensemble de larges parcelles amendées de terres végétales situées au delà de la rue du Baignoir. Curieusement, si le parcellaire et le viaire médiéval ont disparu sous les remblais, les constructions et jardins qui s'y implantent deux siècles plus tard s'inspirent encore de limites foncières anciennes. Regroupés par deux, voire quatre, les lots retrouvent leurs alignements, mais ils sont plus ou moins décalés, comme si on avait redessiné le foncier à partir de documents écrits.

Tout comme ceux du quartier intra muros mais excentré de la Joliette, les vastes terrains situés à l'est de la ville sont convoité dans le second tiers du XVII ${ }^{\mathrm{e}} \mathrm{s}$. par les ordres religieux qui se multiplient. La congrégation de Saint-Hommebon acquiert l'essentiel de ce qui deviendra l'îlot de l'Alcazar, puis, après avoir revendu des places à bâtir de part et d'autre de la traverse du Petit-Saint-Jean, fait édifier une première église, en partie dans l'emprise des fouilles. Sa fondation utilise la technique de la paroi moulée : un bourrage de pierres et mortier est compacté dans une tranchée très régulière, puis l'espace est excavé. Un bassin, probablement bien plus ancien (ses limites coïncident exactement, et c'est le seul du site, avec une parcelle médiévale), est partiellement intégré dans la construction. En cœur d'îlot, des bâtiments tout en longueur bordent un large jardin.

Ce n'est qu'à partir du milieu du milieu du XVII ${ }^{\mathrm{e}} \mathrm{s}$. que les places à bâtir vendues par la congrégation se lotissent. L'auberge du Petit Saint-Jean est édifiée au bout de la traverse qui prendra son nom, un bâtiment de quatre étages associé à une immense écurie à l'angle de deux rues. Les autres parcelles riveraines deviennent 


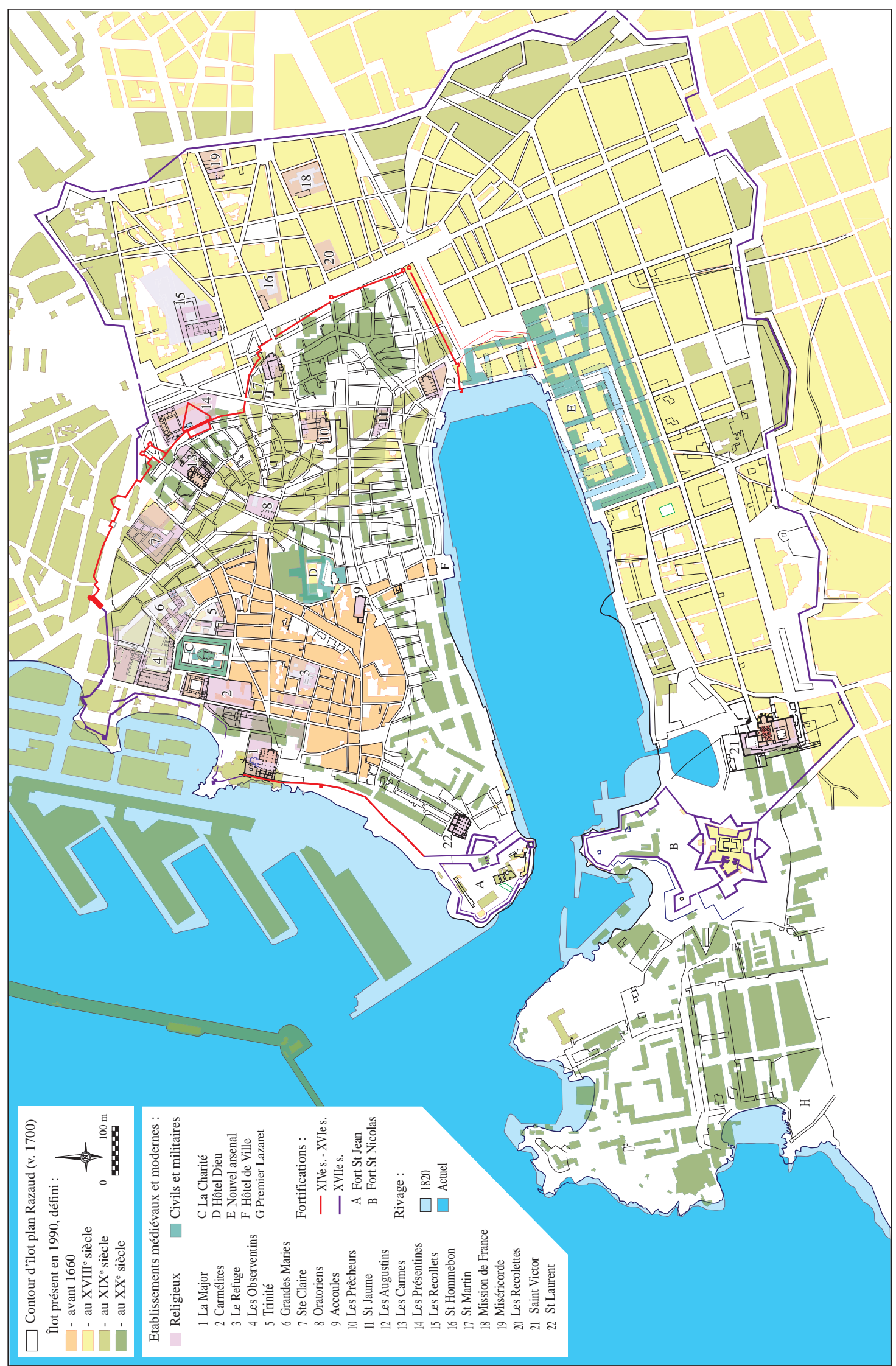

Fig. 279. Marseille à l'Époque moderne et l'évolution de la trame urbaine (B. Sillano/lnrap, M. Bouiron/Ville de Nice). 
également des écuries, au sol pavé de pierre, surmontées d'un grenier à foin. Les faubourgs portent en germe l'agrandissement de la ville qui les englobera sous Louis XIV mais, pour ce que nous avons pu en voir, il ne s'agit pas d'habitations, probablement plus nombreuses à proximité de la porte Réale, au sud, comme l'indique le rapport d'estime de 1667. Citons un petit pavillon de deux étages éclairé par de larges baies encore présent à proximité du site du Jeu de Paume, attenant à la place des Recollettes (Sillano, Scherrer 2009). Mentionnons enfin, sur le même site, une fabrique de cire, illustration de l'industrie qui, dans la lignée de la tannerie médiévale du site de l'Alcazar, occupe également les faubourgs, tout comme intra muros, le quartier de Cavaillon

\subsection{Le règne de Louis XIV}

C'est avec l'avènement de Louis XIV que la ville connait un de ses plus forts actes d'urbanisme: la création de la Ville Nouvelle (fig. 279). Le processus d'urbanisation a été largement étudié (Chancel 1978, Durousseau 1990, Hénin 1986) ; l'archéologie et l'étude en archives l'illustrent parfaitement.

Sous la houlette du Bureau de l'Agrandissement, le lotissement des terres nouvellement intra muros, particulièrement le tracé de rues, est le fruit de tractations entre le pouvoir royal, représenté par l'Intendant Arnoul, et l'échevinage. Il doit composer avec des faubourgs en partie gagnés par le bâti, qu'il convient de conserver, ainsi que les rues qui les desservent. Mais il n'hésite pas à sacrifier de grandes demeures, comme celle qui a été révélée par les fouilles, traversée par le prolongement de la rue du Petit-Saint-Jean. Les figures baroques, telles les pattes d'oies, n'ont été possible que sur des jardins, c'est-à-dire en périphérie. Seule la création du Cours, l'articulation avec la vieille ville dont on détruit les remparts, confiée aux architectes, aura des répercussions sur l'existant. Bien qu'il prenne place sur le Grand-Caire, il en rectifie les limites, ce qui se traduit pour les riverains soit par l'amputation d'une partie de leur propriété, soit par la disparition derrière des îlots écrans, comme ce fut le cas pour les religieuses des Recollettes (Sillano, Scherrer 2009). La fouille de l'Alcazar a montré comment les anciennes auberges situées au nord du Cours, amputées pour moitié, récupèrent la surface perdue sur l'arrière-cour tout en conservent leur grande dimension et en augmentant le nombre d'étages. Elles sont astreintes à la normalisation des façades; la première bâtie sur l'îlot, propriété de la congrégation de SaintHommebon, encore vierge de construction, sert ensuite de modèle aux autres.

Dans l'agrandissement vers l'est, en dehors du Cours, la largeur des rues reste modeste, environ $6 \mathrm{~m}$, alors que dans le quartier de Villeneuve à Aix, pourtant antérieur, elles sont de $8 \mathrm{~m}$. Ceci traduit en partie les difficultés de mise en œuvre des décisions royales; les transactions foncières connexes à la viabilisation sont souvent le fait des mêmes échevins qui participent à l'élaboration du projet. Ainsi le second échevin Barthélémy Couzinery acquiert et revend en lots de vastes terrains, surtout des jardins, sur lesquels sera tracée la rue Nationale, alors que Thomas Riquetti, le même qui héberge le roi dans son hôtel place de Lenche, possède les jardins de Barnier à travers lesquels sera prolongée la rue du Petit-SaintJean. À l'inverse, en 1656 et 1658, soit deux ans avant l'arrivée du roi, la famille de Félix, peut-être trop impliquée dans la Fronde, cède ses parcelles le long de la rue du Petit-Saint-Jean et d'une traverse, ignorant sans doute qu'elle deviendrait la rue d'Aix. Tous trois laisseront leur trace dans le parcellaire. Le premier en laissant l'acquéreur en définir la taille, le second en faisant un découpage régulier préalable, le troisième ne faisant rien, nous restituant ces maison étroites en rive est de la rue d'Aix.

En s'accaparant le tronçon proche du Cours de l'ancienne rue "qui menait aux Augustins », disparue dans l'Agrandissement, la congrégation de Saint-Hommebon gagne en superficie et en visibilité. La nouvelle église profilée dans l'alignement des façades uniformes du Cours, se distingue aisément. L'ancienne, située désormais en cœur d'îlot, devient séminaire. Le bassin qu'elle englobe pour partie se voit surmonté d'un clocher aux fondations puissantes au moyen d'une large voute en calcaire de La Couronne. La Congrégation met à disposition de grandes écuries, peut être des annexes conventuelles reconverties, aux nombreuses auberges qui monopolisent le quartier. En effet, toutes les écuries le long de la rue du Petit-Saint-Jean sont transformées en auberges, immeubles de trois à quatre étages. Nous avons un exemple de réfection de mur mitoyen, mais dans bien des cas, les anciennes fondations semblent conservées. Le contraste entre la façade sur le Cours et celles des rues adjacentes devait être saisissant.

Nous avons peu d'exemples archéologiques d'immeubles d'habitation de cette période. Les seuls connus sont sur les parcelles vendues par Thomas Riquetti, le long du prolongement de la rue du Petit-Saint-Jean. Curieusement, les places à bâtir, de largeur identique dans les actes de ventes, différent légèrement de l'une à l'autre, comme si les premiers acquéreurs avait pris la dimension comme étant hors œuvre. La taille et l'organisation diffèrent radicalement du modèle médiéval. Un escalier à noyau placé au centre, contre un mur mitoyen, dessert des pièces situées aussi bien sur la rue que sur la 
cour ménagée au fond. Mais la largeur reste insuffisante pour disposer deux pièces sur chaque façade.

\subsection{Le Siècle des Lumières}

Le Corps-de-Ville confirme son rôle administratif. Après l'Hôtel de Ville, achevé en 1673, avec au rezde-chaussée la Loge des marchands, c'est le pavillon Bargemon qui est l'objet de travaux, non achevés, puis le Palais de justice (l'actuel pavillon Daviel) qui remplace, en 1745, le palais comtal. Le marché du Petit Mazeau, situé à proximité, est détruit trente ans plus tard. Les artisans rôtisseurs disparaissent, en partie pour la Ville Nouvelle. C'est ce que suggère l'obturation des avancées de caves sous la rue, apparemment liées à la présence d'un four, ainsi qu'un exemple de démolition de four au XVIII' s. La Maison du roi, en ruine, fait place en 1713 à l'Hôtel de Rome d'Ardennes, construction qui adopte le seul exemple d'alignement que nous ayons observé. Les plans d'alignement abondent, mais ils ne s'appliquent qu'aux maisons bâties de neuf ; l'étroitesse des rues que dessine le cadastre est significative du peu de reconstructions totales dont fait l'objet la «vieille ville ».

La population croissante (90 000 habitants en 1716) trouve place dans la Ville Nouvelle, mais la démographie connait une baisse sensible au cours du XVIII"es. et les nouveaux remparts restent longtemps perdus au milieu des jardins. Les bâtiments construits le long de la rue Paradis, reconnaissables sur la fouille de la place Général-de-Gaulle par un semis de pieux, sont édifiés vers la fin du XVIII' ${ }^{\text {e }}$. (Bouiron 2001a, p. 131). Sur les îlots de l'Alcazar, nous distinguons aisément les parcelles précoces des autres; les parcelles vendues par Riquetti en 1674 sont de taille insuffisante pour y édifier l'immeuble qui sera légion dans la Ville Nouvelle : le «trois fenêtres» marseillais (Bonillo 1978). Les immeubles de rapport que fait construire la congrégation de Saint-Hommebon sur la rue du Baignoir avant 1720 en possèdent toutes les caractéristiques : caves divisées en quatre, correspondant aux quatre étages avec chacun leur appartement, deux pièces sur rue, deux sur l'arrière.

La construction au XVIII ${ }^{\mathrm{e}}$ s. voit l'utilisation massive du calcaire de La Couronne en fondation, parfois sur un semis de pieux, mais aussi un appauvrissement de la gamme des matériaux.

À l'aube de la Révolution, l'habitat à Marseille a acquis une qualité qui lui vaut sa reconduction tout au long des axes qui se développent au cours du XIX ${ }^{\mathrm{e}} \mathrm{s}$. Aujourd'hui encore, à l'heure où les appartements voient la taille de leurs pièces se réduire, l'immeuble « marseillais » est synonyme de confort.

\section{Quelques réflexions méthodologiques (M. Bouiron)}

Nous avons évoqué en introduction les «limites de l'archéologie». L'étude du terrain met en exergue le décalage qui existe entre faits historiques et faits archéologiques. Par exemple, nous constatons la lenteur des répercussions sur la culture matérielle des périodes de récession économique subie par la population. À l'inverse, des décisions royales ou communales qui peuvent paraître bien autoritaires s'appliquent en réalité à un état qui en porte les germes, comme la création de la Ville Nouvelle.

Au-delà de la seule difficulté d'établir une datation absolue (en particulier par le mobilier archéologique), cette constatation permet de mettre en évidence la trame invisible des évolutions sociétales, souvent clairement distincte des événements eux-mêmes. Rappelons-le, notre analyse se fonde sur ce qui a existé et qui n'a pas disparu par la suite. Ce rapport au réel est ce qui distingue le plus l'archéologue des autres spécialistes intervenant dans le champs historique. L'archéologue fait œuvre de scientifique lorsqu'il observe, d'historien lorsqu'il interprète.

Pour les périodes qui nous intéressent, on a vu toute l'importance de l'archéologie pour comprendre dans le détail l'évolution de la ville. Nous sommes ici évidemment sur un des aspects que l'archéologie explore le mieux, d'autant plus lorsque pouvons enrichir notre propos de textes d'archives. Cette dialectique qui s'instaure entre sources écrites et sources archéologiques est devenue en quelque années l'une des principales sources de renouvellement de l'histoire urbaine. Dans cette nouvelle formalisation de la recherche, c'est l'organisation même du chantier de fouille qui recrute l'historien archiviste chargé de dépouiller les actes anciens. Cet apport croisé a été mis en évidence dans d'autres villes de France comme à Lyon (Arlaud 2000). A Marseille, il a débuté en 1993 avec les fouilles de la place Jules-Verne et de la place Général-de-Gaulle. Si le premier chantier s'est très largement focalisé sur la période antique (il s'agissait avant tout de fouiller le port romain et grec), la seconde fouille a livré, pour la première fois depuis les travaux d'Eugène Duprat dans les années 1930, une lecture totalement renouvelée de l'évolution d'un espace suburbain de Marseille. Nous mesurons ici comment, en moins de vingt ans, toute une nouvelle réflexion sur l'évolution de Marseille médiévale a vu le jour.

L'intérêt de l'archéologie des Temps Modernes est souvent mis en doute car on suppose que les archives nous renseignent suffisamment. C'est oublier que les textes ne sont pas toujours le reflet de la réalité, qu'ils manquent 
souvent d'objectivité car ils sont faits à dessein. Il peut s'agir de projets, de vœux pieux, qui n'ont jamais été suivis des faits sans que nous le sachions. L'archéologie permet d'en vérifier l'exactitude, comme nous l'avons vu pour l'alignement des rues ou le non-respect des prixfaits. À l'inverse, l'archéologue, surtout pour le début de l'époque moderne, met en exergue des aménagements urbains dont les archives n'ont pas gardé trace ; les alignements des rues près du Change et du Grand-Caire en sont de bons exemples. Pour des époques anciennes, elle renseigne également sur un habitat dont les actes notariés ne font pas encore état. Enfin et surtout, la mise au jour des vestiges permet de recaler avec exactitude les textes avec la réalité. Si les études archivistiques menées par la méthode régressive et les localisations par les confronts permettent un exposé qualitatif, elles n'en comportent pas moins une part d'incertitude que l'archéologie parvient parfois à lever.

\section{Perspectives (M. Bouiron)}

Quelles perspectives peut-on proposer pour la prochaine décennie? Il faut d'abord noter combien est maintenant devenue naturelle la fouille des niveaux médiévaux et modernes. Nous espérons révolu ce temps où l'on ne fouillait à Marseille que les niveaux grecs ou romains. Désormais, chaque campagne de fouille étudie réellement la totalité des niveaux archéologiques.

Les pistes de recherche qui sont ouvertes sont nombreuses et dépendront bien sûr de la localisation des chantiers. Quelques points forts se dégagent cependant. Le premier concerne l'évolution des différentes lignes de fortification. Les rares fouilles qui en ont rencontré les vestiges l'ont toujours abordé depuis la zone suburbaine : place Général-de-Gaulle pour l'extension du Plan Fourmiguier, îlot Puget 3 pour la fortification de la fin du $\mathrm{XII}^{\mathrm{e}}$ s., ravelin du XVI ${ }^{\mathrm{e}}$ s. de la porte d'Aix. Il manque la fouille détaillée d'une tour ou d'une porte principale de la ville et ses renforcements modernes. Absence aussi cruelle de toute connaissance des lignes de fortification antérieures à celle de 1190 : la fouille de la Bourse n'a jamais signalé la présence de l'enceinte de 1040 et l'on connaît encore moins les fortifications intérieures du haut Moyen Âge ou l'enceinte attribuée à l'évêque Babon. Nous en sommes réduits à des hypothèses certes séduisantes et étayées par de rares textes mais qui auraient besoin d'une confirmation archéologique.

Autre nécessité, la redécouverte du port médiéval. Voici une ville qui est toute entière tournée vers la mer et dont on ne connaît actuellement qu'une petite partie du rivage rencontrée lors du percement d'une grosse canalisation, rue de la République. Les textes sont nombreux, mais ils mentionnent rarement les aménagements portuaires : le port fait partie d'un cadre de vie que l'on ne décrit pas. Il ne faudrait pas penser que le port moderne soit mieux connu que le port médiéval. Tout au plus peut-on bénéficier, à partir de la fin du XVI e s., d'une iconographie plus ou moins exacte qui illustre la ville et son port.

Autre manque dans la connaissance archéologique, les édifices religieux. En dehors de la cathédrale de La Major qui a fait l'objet de sondages archéologiques (malheureusement le rocher est quasiment au contact du sol actuel), aucun édifice n'a été fouillé. Or, de grands monuments sont probablement conservés dans le sol : l'église Saint-Martin sous la rue Colbert (on a certainement raté une occasion lors de la construction de la ligne du tramway), dont on ne sait pas si elle remonte à l'Antiquité tardive ou au haut Moyen Âge ; l'église des Accoules, dont l'emplacement, à peu près disponible (si l'on excepte les inévitables réseaux enterrés), pourrait donner lieu à une fouille particulièrement intéressante ; sans parler de toutes ces églises disparues, voire des grands couvents suburbains. Si certaines sont bien connues par les plans anciens, d'autres n'avaient pas de localisation précise avant nos recherches, ce qui n'a pas permis aux services de l'État d'exercer toute leur vigilance; on pense par exemple à la construction du «Faubourg Saint-Ferréol », espace commercial construit à l'emplacement exact du couvent des Dominicains, bâti au XIII ${ }^{\mathrm{e}}$ s. et détruit en 1524, dont la localisation n'a pu être restituée qu'avec la fouille de la place Général-de-Gaulle.

Autre aspect important, la poursuite de l'enrichissement du fond cartographique informatisé. Le long travail qui a été réalisé pour le colloque du 26e Centenaire, Trames urbaines ..., a été prolongé par l'intégration de toutes sortes d'informations : nouveaux chantiers, fonds de plans vectorisés issus de documents d'archives, ... Or ce travail de cartographie historique est absolument indispensable pour la réflexion sur l'histoire de la ville. Depuis dix ans, l'évolution des instruments informatiques et en particulier des SIG permet d'envisager un avenir particulier à ce travail. Mis à la disposition de tous les archéologues travaillant sur Marseille, il doit faire l'objet d'un minimum de centralisation régulière des couches d'information, chacune avec son degré de fiabilité afin que cet outil soit sans cesse réactualisé au profit de tous.

Les dépouillements d'archives doivent également être poursuivis. On l'a dit, Marseille dispose d'un fonds très riche qui est loin d'avoir été exploité. Les transcriptions systématiques réalisées ces dernières années dans le cadre des chantiers de fouille permettent de commencer à disposer d'une base importante de réflexion. 
Les textes que nous avons publiés dans l'ouvrage collectif dirigé par Thierry Pécout proviennent ainsi de ces travaux. Ils devront être poursuivis et systématisés, centrés bien évidemment autour de chaque fouille, dans une optique de compréhension du développement foncier d'une part et du bâti de l'autre.

Nous espérons également que se renforceront à l'avenir les liens avec les historiens médiévistes et modernistes. La collaboration depuis longtemps souhaitée a pris forme grâce à Thierry Pécout pour le Moyen Âge et à Régis Bertrand pour les Temps Modernes. Nos deux contributeurs dans le volume ont depuis longtemps déjà compris l'apport de l'archéologie à l'Histoire et favorisent le rapprochement avec leurs collègues. Il est vrai que le travail de l'archéologue sur sa fouille n'a à priori pas grand-chose à voir avec un travail d'historien «classique » dont la recherche est avant tout intellectuelle. Nos méthodes de relevé ou d'enregistrement des données, sans même parler d'une organisation basée avant tout sur le travail d'équipe, sont en effet de nature bien différente. Mais la connaissance de la matérialité du passé qu'apporte l'archéologie permet de bâtir le cadre dans lequel se déroule l'Histoire. Souhaitons donc pour l'avenir la multiplication de travaux croisés aussi bien pour le Moyen Âge et plus encore pour la période moderne, qui sera, n'en doutons pas, le grand enjeu de la prochaine décennie. 


\section{Annexes}

\section{Textes de la période médiévale : le quartier de la Major}

\section{Habitants payant le cens à l'CEuvre de la Major. Les censitaires sont classés par ordre alphabétique des prénoms, 1310.}

AD13 6 G 502 cahier (pergaminum). Transcription P. Rigaud.

Anno domini millo CCC X

Isti sunt census domorum qui debent et consueverunt servire operario ecclesie Majori Beate Marie sedis Massilia certum censum annuatim in peccunia, in festo beati Thome ante natale Domini, emphiteotis infra scriptis :

Aychardus Laurentii pro quadam domo que exit in duabus carreriis I s. I d.

Augerius Baussiani quondam pro quadam parva domo $\mathrm{V}$ d.

Aycharda Maystra pro quadam parva domo IIII d.

Arnaudus de Mausaco pro una domo que exit in duabus carreriis II s.

Audiarda de Aquis quondam pro quadam magna domo que est in carreria recta IIII s. $\mathrm{V} \mathrm{d}$.

Item, pro quadam parva domo que in dicta carreria

Item, pro tribus domibus et viridario contiguis in alia carreria superiori VII s.

Alazacia de Albis pro quadam parva domo VII d.

Amiella, uxor Raymundi Olivierii, pro quadam domo XII d.

Andreas Hugolini pro domo que fuit Bernardi de Sumidrio ${ }^{899}$ II s. VI d.

Aycharda, uxor Assaudi Mayo, pro domo quam erit ab Amigueta, uxore Johannis Mayo, VII s. VI d

Bertrandus de la Vouta pro quadam domo et quodam patuo illi domum contiguo que fuit Alazacie, uxoris Bertrandi Esmizol, II s. IIII d. $\left[\mathrm{f}^{\circ}\right]$ Bertrandus Baussiani, filius Baussiani juvenis quondam, pro quadam magna domo in qua manet III s. IIII d.

Item, pro quadam alia domo eidem domum contigua XXI d.

Item, pro quadam alia domo que est in carreria recta $\mathrm{XX} \mathrm{d}$.

Item, pro quodam magno patuo III d.

Bartholomeus Bonivini ${ }^{900}$ quondam pro quadam domo et patius retro sibi contiguis VIII s I d.

Bertrandus Blancardi pro duabus domibus contiguis XVII d.

Item, pro quadam alia domo XII d.

Bertrandus Mercerii, sacerdos, pro domo que fuit Ysnarde Besse VI d.

Berengueria Rayneria pro una domo sive casali X d.

Beatrix de Sumidrio pro domo magna paterna

Item, pro quodam magno viridario illi domum contiguo VII s.

Bernardus Ricardi quondam pro duabus domibus contiguis III s. VI d. $X \mathrm{~d}$.

Item, pro quodam casali retro contiguo illis domibus

Benedictus Anglicus, scriptor, pro domo que fuit uxoris Richardi Anglici VIII d.

Bartholomeus Textor pro domo que fuit Mellurade XII d.

Item, pro quadam alia parva domo VI d.

$\left[f^{\circ}\right]$ Colradus Cavallerii pro domo que fuit Guillelmi de Argilleriis, que est prope Petram Ymaginis II s. VIII d.

Item, pro domo que fuit Huge Sarde XVII d.

Colradus de Trievas et Beatrix, conjuges, pro quadam domo et patus retro sibi contiguis que fuerunt Jacobi Grati III s. II d.

Dominus Aymo de Burdegala pro quadam domo que fuit Marie, filie Poncii Marselles, V d.

Dulcia Thomasa pro domo materna XII d.

Dominus Amelius et Hugo Candola pro domo que fuit Thomasie de la Riba XII d.

900 Frère de Guilhem qui teste en sa faveur le 14 des calendes de mai 1281, AD13 6 G 25 n$^{\circ} 145$. 
Dulcia, uxor Petri Aycardi quondam, pro quadam domo cum patuo retro sibi contiguo III s.

Dulcia, uxor Pauli de la Carriera, pro domo que fuit Sibiude, matris sue, XI d.

Dulcia, uxor Guillelmi de Torrenes quondam, VIII d.

Durantus Massellarii pro quodam casali sive patuo quod fuit Guigonis de Castronovo VI s. VI d.

Elis de l'Espaza pro domo que fuit Galceri del Espaza XVI d.

Erminia Caguola pro quadam domo et viridario sibi contiguo VIII s.

Fererius de Bucco pro quadam XII d.

Item, per quadam alia parva domo $\mathrm{V}$ d.

Guillelmus Nielli pro quodam casali sive patuo quod est in principio vallis Beate Marie de Acuis VI d.

Giraudus Dalbatut pro domo que fuit Giraudi Civata XII d.

Item pro quadam domo que fuit Marquesii de la Sala XII d.

$\left[\mathrm{f}^{\circ}\right]$ Guillemus Franchi pro domo que fuit Esmengarde de Rodes, que exit in duabus carreriis II s. VIII d.

Item, pro quadam alia domo que est in carreria recta VII d.

Item, pro quodam casali quod fuit Bentrandi de la Vouta, que est in carreria superiori XV d.

Item, pro domo que fuit Guillelmi Bertrandi XII d.

Item, pro domo que fuit Petri Almozini VIIII d.

Item, pro domo que fuit Durante Franche VII d.

Guillelmus Guillisson pro quadam domo que habet postatam (?) VIIII d.

Galterius de l'Espaza pro domo qua erit ab heredum de Gerrin de la Rocha II s. VIII d.

Item, pro duabus domibus contiguis quas erit a Bernado Hugolini II s.

Item, pro duabus domibus qua erit ab herede magistri

Raholini, phisici, III s. II d.

Guillelmus Vigoros pro duabus domibus contiguis, crota in medio, VII d.

Item, pro quadam alia parva domo VI d.

Guillelma, uxor Berengarii Chaberti, pro quadam domo dotali que sita est in quad.... super Petram Ymaginis, que fuit Guillelmus Bernardi, VIII d.

Gaufridus Desderii pro quadam parva domo III d.

Guillelma Peiton pro domo que fuit Bernardi Nicholay, sacerdotis, XV d.

Hugo de Castronovo pro quadam domo magna paterna VIII s. V d.

Item, pro quodam magno viridario VIIII s. VI d.

Guillelmus de Montiliis pro domo quam erit a Petro Provinciale XII d.

$\left[\mathrm{f}^{\circ}\right]$ Guillelmus Bernardi pro quadam domo XII d.

Guillelmus Florentii pro domo que fuit Jacobi Bonduell XIII d.
Guillelmus de Monteolivo pro quadam domo dotali cum viridario sibi contiguo VI s. V d.

Item, pro duabus domibus cum casali sive patuis retro contiguis III s. VII d.

Item, pro quadam parva domo $\mathrm{V} \mathrm{d}$.

Guillelma Bedossa pro quadam parva domo que est in carreria recta VIIII d.

Item, pro duabus domibus et patuo retro contiguis III s. III d.

Item, pro quadam alia domo XII d.

Item, pro duabus domibus patuis contiguis VIIII d.

Item, pro domo que fuit Rextior (?) de la Vouta XVI d.

Guillelmus Bonivini pro domo que fuit Hugonis de Sumidrio XIIII d.

Guillelmus Berengarii quodam pro quadam parva domo $\mathrm{V}$ d.

Guillelmus Alamani pro quadam domo XV d.

Guillelmus Bonifilii pro domo qua erit a Nicholao Ranaudi, que (est) supra Petram Ymaginis, II s.

Girardus Alamani et Huga de Grezols, conjuges, pro quadam domo et patuo retro sibi contiguo II s. VI d.

Guillelmus Clari pro quadam domo dotali que fuit Aygline, uxoris Guiberti de Sancto-Quintino, VIII d.

Hugo Tenca pro quadam domo dotali cum patuo retro contiguo $\mathrm{XX}$ d.

$\left[\mathrm{f}^{\circ}\right]$ Hugo Martini pro quarta parte balneorum hominum et mulieri $\mathrm{V}$ s.

Item, pro quadam domo XII d.

Item, pro quadam alia domo XII d

Item, pro quadam alia domo $\mathrm{X} \mathrm{d}$

Item, pro quadam alia domo XII d

Item, pro domo que fuit Petrus Columbi, notarii, XI d.

Hugo Tenca pro quadam domo dotali cum patuo retro contiguo $\mathrm{XX}$ d.

Hugo Brifaci pro quodam domo XII d.

Huga Ymberta pro medietate duarum domorum contiguum que fuerunt Peirone Berarde XXI d.

Huga Palmiera pro domo que fuit Guillelmi Raymundi, que exit in duabus carreriis, XII d.

Hugo Cambal pro domo que fuit Raymundi Stephani, que domus est ante Petram Ymaginis XVI d.

Hugo Ancelmi, jurispertus, pro domo que fuit Perigrini Andree XX d.

Huga Calotiera et Huga, filia sua, pro domo quam emerunt ab Alazacia, uxore Guillelmi de Albis quondam, XXI d.

Johannes Garssias pro quadam domo dotali que est in carreria recta XVII d.

Item, pro quadam alia domo illi contigua XVII d.

Item, pro quadam alia domo in qua manebat XX d. Johannes Duranti quadam pro domo XVI d. 
Item, pro domo que fuit Johannis Marchi $\mathrm{V}$ d.

Jacobus d'Andusa et Marquesius d'Andusa, fratres, pro duabus parvis domibus contiguis XVIII d.

$\left[\mathrm{f}^{\circ}\right]$ Jacobus de Bossoneto pro quadam domo XV d.

Item, pro quadam alia domo XVI d.

Johanna Vigorosa pro quadam domo que est in carreria recta et exit in alia carreria superiori XVIII d.

Jacoba Bertranda, uxor Johannis Gavoti, pro medietate cujusdam domus que fuit Guillelmi Bertrandi XII d.

Johannes Garnaudi, notarii, pro domo que fuit Aychardi Jordani XVIII d.

Item, pro domo que fuit Hugonis de Sumidrio XII d. Item, pro domo que fuit Augerii Baussiani X d.

Item, pro domo que fuit heredum dicti Augerii Baussiani et pro quodam patuo illi domum contiguo II s. VII d.

Item, pro quadam parva domo que fuit Jacobi Cambal IIII d.

Item, pro domo que fuit Gaufrid Oliverii X d.

Item, pro quibusdam domibus sive patius et quodam viridario eis contiguo VI s. VI d.

Johannes Marcelli pro domo que fuit Baussiani de Bucco V s. IIII d.

Johannes de Savoya pro domo quam erit a Guillelmo

Vigoroso XIIII d.

Jordana, filia Guillelmi Aurifabri quondam, XII d.

Jacobus Cambal pro domo que fuit Mathei de

Bossoneto VIIII d.

Johannes de Bleys pro domo que fuit Agnetis Baussiane XIIII d.

Item pro domo quam erat a Bertrando Mercerii sacerdote VIIII d. XII d.

Item pro domo quam erat a Nicholao de la Balma

$\left[f^{\circ}\right]$ Jacobus de Lunello pro domo materna cum patuis sive casalibus sibi contiguis VII s.

Katherina de Valensa pro quadam domo VIII d.

Laurentus Vigoros pro quadam magna domo XII s.

Item, pro quadam alia domo a latere contigua IIII d.

Item, pro domo quam erat a Guillelmo Vigoros XX d.

Leonardus Guillisson pro quadam domo XVI d.

Laura Aycharda et Maria Aycharda, sorores, pro domo

Hugonis de Sumidrio, que fuit est extimata, XVIII d.

Martinus de Auriolo, filius Petri de Auriolo quondam, pro domo qua erat ab heredum Johannis de Alba II s.

Item, pro domo quam erat a Mabilia Cabestagna XVIII d.

Item, pro domo qua erat Sibyndia, uxore Gandulphi quondam, III d.

Item, pro domo qua erat a Matheo Barberii IIII d. et pictam.
Item, pro domo que fuit Baudoyni Sartoris XII d.

Item, pro domo que fuit Johannis Marinerii que est in carreria recta II $\mathrm{s}$.

Item, pro alia domo sibi contigua a parte inferiori XII d.

Item, pro quodam casali sive patuo illi dotarii contiguo a parte superiori XII d.

Item, pro domo quam erat a Plendoza, filia Guillelmi Guillissoni, XII d.

Item, pro domo que fuit Michaelis Sacerdotis III d. et pictam

Marquesius de la Sala quondam pro quaddam domo II s. VIII d.

Machelda de Gironda pro duabus domibus et patuiis retro sibi contiguis VIII s.

$\left[\mathrm{f}^{\circ}\right]$ Matheus de Bossoneto pro duabus magnus domibus contiguis II s.

Item, pro quodam magno viridario quod fuit Bernardi Boneti VI s.

Maria de Jherusalem pro exitu domus a parte inferiori II d.

Item, pro quodam viridario XXII d.

Maria Vassalla pro quadam magna domo IIII s. IIII d.

Magister Victor, phisicus ${ }^{901}$ quondam, pro casali sive patuo quod fuit Raynerii de Remis II s. IIII d.

Matheldis Atulpha pro quodam casali sive patuo quod emit a Guillelmo, quod est in carreria Raymundi Alberti quadam, VIII d.

Nicholaus de la Balma pro domo que fuit Gregorii Johannis, que exit in duabus carreriis, II s.

Payna pro quodam magno casali sive patuo IIII s. IIII d.

Petrus Mathin pro quadam domo dotali et quodam viridario domus retro contiguo IIII s.

Poncius de Aquis pro quadam domo XIIII d.

Petrus Martini pro quadam domo que exit in duabus carreriis XIIII d.

Paschalis de Mayraneguetas, notarii, pro quadam domo X d.

Item, pro quodam casali VI d.

Petrus de Bellaygua pro duabus domibus contiguis II s. VI d.

Petrus Paleta et Guanthelma, conjuges, pro domo que fuit Johannis Duranti XX d.

Petrus Provincialis pro tribus magnis domibus que fuerunt Kardinalis et Geguo, fratrum et sociorum eorum, VII s. VII d.

Petrus Gernasii sacerdos pro domo que fuit Bartolomei Franc, que est in carreria recta II s.

901 Fait son testament le 15 février 1296, AD13 6 G 31 nº 193 . 
$\left[\mathrm{f}^{\circ}\right]$ Petrus de Bas et Margarita Guiges pro domo que fuit Petrus Pellissoni XII d.

Petrus Columbii pro octava parte balneorum hominum et mulierum quam emit a Guillelmo de Caussio II s. VI d.

Item, pro quarta parte balneorum hominum et mulierum quam emit a Jacobo de Caussio V s.

Item, pro octava parte balneorum hominum et mulierum quam emit a Guillelma, filia Petri Boquerii, II s. VI d.

Item, pro quarta parte balneorum hominum et mulierum quam emit a Jordana, filia Guillelmi de Burgueto, aurifabri, V s.

Item, pro domo que est contigua illis balneis VIII d.

Item, pro quadam alia domo que est contigua illis balneis VIII d.

Raymundus de Nercio pro quadam domo XIIII d.

Item, pro alia domo que exit in duabus carreriis $\mathrm{XX} \mathrm{d}$.

Item, pro quadam alia domo XII d.

Item, pro alia domo $\mathrm{X}$ d.

Item, pro domo que fuit heredum Fulchonis Duranti XII d.

Item, pro tribus stagiis loquaticus et quodam casali illis contiguis IIII s. VIII d.

Raymundus Montagna pro quadam domo que exit in duabus carreriis II s. IIII d.

Rostagnus Baussiani pro quadam domo in qua manet III d.

Item, pro quodam magno viridario X s.

Rixenda de Mazalgis, uxor Arnaudi Robini quondam, pro quadam domo XII d.

Rostagnus Gibelini, boterii, pro quadam domo XII d. Item, pro domo que fuit Nicholay Aurioli VIIII d.

$\left[\mathrm{f}^{\circ}\right]$ Raymundus Faber sacerdos pro quadam domo XII d.

Raymudus de Sancto-Petro pro domo quam emit ab Hugone Cambal VIII d.

Item, pro quadam domo dotali que fuit Huge Martine VIII d.

Rostagnus de Monte Brurio, sacerdos, pro domo que fuit Petri de Sancto-Lazaro XX d.

Raymundus Viridi ${ }^{902}$, clericus sedis Massilie, pro quadam parva domo VII d. et pictam

Item, pro domo quam emit a Johanne lo Da..., carcator navium, II s.

Item, pro quadam alia domo eidem contigua XXI d.

Item, pro domo quam emit a Mabilia Cabestagna $\mathrm{XV} \mathrm{d}$.

Item, pro domo que fuit heredum Guilaberti ...

902 Devenu archidiacre, il fait son testament le 27 octobre 1330 (AD13 $6 \mathrm{G} 63 \mathrm{n}^{\circ} 415$ ) et le 27 octobre 1331 ( $1 \mathrm{~J} 210$ fol. 355, copie du 6 G 438, Livre Jaune du Chapitre ; 6 G 51, nº 334.
Richartz, uxor Guillelmi Sifren, pro medietate duarum domorum contiguum que fuerunt Peirone Berarde XXI d.

Raymundus Lobas pro quadam parva domo cum quodam patuo sive casali a latere contiguo, que fuit Hugonis de Sumidrio, XII d.

Bernardus Anglicis et Beatrix, conjuges, pro quadam domo que fuit Gaufridi Balbi XII d.

Item, pro quodam patuo eidem domus contiguo quod fui Hugonis de Sumidrio

Sebilia Jordana pro duabus domibus que fuerunt Bartolomei Atulphi III s. IIII d.

Item, pro domo quam emit ab Alazacia, uxore Guillelmi de Seguoyer,

Sancia Rostagna pro quadam domo XII d.

Simon de Rebes pro quibusdam domibus quas emit a Guidotie Tribolet, pistore nomine.

\section{Textes de la période médiévale : le bourg de Roubaud}

\subsection{Achat de cens à Bertrand de Marseille chevalier, seigneur d'Evenos et d'Olioulles, Raimond de Soliers damoiseau et Huguete sa femme (extrait), 22 octobre 1297.}

AD13 64 H 1 n 3. Albanès 1879 X, p. 266.

Phelippe Porcellette uxoris domini Fulchonis de Ponteves quondam et beguine domus Robaudi de Massilia.

(...) census infrascriptos (...) in transversia dicta Corderiorum :

(...) Johannis Olive, fusterius, (...) pro quodam orto sito in supradicta carreria sive Corderiorum ; confrontato ab una parte cum quibusdam domo et orto dictis Johannis Olive et ab alia parte cum orto G. Ysnardi, laboratoris, et $\mathrm{ab}$ alia parte cum bedali sive vallato et ab alia parte cum dicta transversia (...) (5 s. 7 d. 1 ob.).

Mabilia Novella seu ejus liberi pro quodam orto sito in dicta carreria Corderiorum ; confrontato ab una parte cum orto Guillelmi Ysnardi et ab alia parte cum edificio dominorum de Robaut et ab alia parte cum bedali seu vallato et ab alia parte cum dicta transversia (10 s. $11 \mathrm{~d}$. $1 \mathrm{ob}$.$) .$

(...) domina Dulcia de Cadaracha, beguine domus Robaudi Massilie, (...) pro eadem pro quibusdam domo et patuo simul contiguis, sitis in dicta transversia; que domus et quod patuum confrontantur ab una parte cum dicta transversia et ab alia parte cum domo et viridario sive patuo Raymundi Turelli et ab alia parte cum orto heredum Mabilie Novelle quondam (5 s. 4 d.). 
Raymundi Turelli, corderius, pro quibusdam domo et orto simul contiguis, sitis in dicta transversia; que et qui confrontantur $\mathrm{ab}$ una parte cum edificio domus dictarum dominarum de Robaut et ab alia parte cum orto Petri Bermundi, laboratoris, qui fuit Marine Pujole quondam et $a b$ alia parte cum vallato sive bedali et ab alia parte cum dicta transversia ( 5 s. 2 d. 1 ob.).

Petrus Bermundi, laborator, pro quodam orto sive patuo sito in dicta carreria transversia; confrontato ab una parte cum quibusdam domo et orto dicti Petri Bermundi et ab alia cum domo et orto Raymundi Turelli et $a b$ alia parte cum bedalli sive vallato et $a b$ alia parte cum dicta transversia; qui ortus fuit Marine Pujole quondam (4 s. 6 d.).

(...) Supradictus Petrus Bermundi, laborator, pro quibusdam domo et orto simul contiguis, sitis in dicta transversia; que domus et qui ortus confrontantur ab una parte cum domo et orto Raymundi Turelli et ab alia parte cum orto Bertrandi Terici et ab alia parte cum quodam alio orto dicti Petri Bermundi et ab alia parte cum bedalli sive vallato $(8 \mathrm{~s}$.).

Philippus Buezo, corderius, pro quibusdam domo et orto simul contiguis, sitis in dicta transversia; que domus et qui ortus confrontantur ab una parte cum domo Johannis Olive et ab alia parte cum orto Jacobi Nas de Vaca et ab alia parte cum orto sive patuo Calvini et ab alia cum orto sive patuo Petri Rigordi et retro cum bedali et $a b$ alia parte cum dicta transversia predicta $(5 \mathrm{~s}$.).

Johannis Olive supranominatus pro quibusdam domo et orteto simul contiguis, sitis in dicta transversia; confrontatis ab una parte cum domo et orto Philippi Buezo et ab alia parte cum quodam orto dicti Johannis super confrontato et ab alia parte cum bedalli sive vallato et cum dicta transversia ( $5 \mathrm{s.} 7 \mathrm{~d} .1 \mathrm{ob}$.).

Guillemus Ysnardi, laborator, pro quodam orto sito in dicta carreria transversia; confrontato ab una parte cum orto liberorum Mabilie Novelle et ab alia cum orto Johannis Olive supradicti et ab alia cum bedali (total $56 \mathrm{~s})$.

\subsection{Vente de cens par Hugues de Roquefort à Raymond Viridis sur des maisons situées au bourg de Roubaud, 5 mai 1326.}

AD13 6 G 56, charte $n^{\circ}$ 370. Transcription M. Bouiron.

In nomine Domini amen. Anno Incarnationis ejusdem millesimo trescentesimo vicesimo sexto, indictione nona, die quinto mensis madii, circa nonam. Notum sit cunctis presentibus et futuris quod Hugo de Rocaforti, domicellus, filius et heres testamentarius Raymundi de Rocaforti, domicelli quondam, civis Massilie, presente, volente, consentiente et ratum habente Petro
Lautandi, socero suo, (...) vendidit (...) venerabili viro domino Raymundo Viridis, archidiacono ecclesie sedis Massiliensis, ut domino Raymundo et non ut archidiacono, presenti (...) quinquaginta quinque solidos et tres obolos regalium seu Massiliensium minutorum censuales et jus et directum dominium et majorem seignoriam earumdem et jus laudandi trezenaque percipiendi et res infrascriptas (...) quos cerviebat (sic) eidem Hugonis et ab inde in antea cervierit (sic) dicto domino Raymundo et suis, annis singulis in festo sancti Michaelis, domina Ermessendis Porcelleta civis Massilie pro possessionibus inferius designatis.

Et primo cervit (sic) dicta domina Ermessendis, annis singulis in dicto festo, undecim solidos et tres obolos dicte monete pro quibusdam domo et viridario simul contiguis, totis cum suis juribus omnibus, sitis in carreria de Robaudo Massiliensis ; que confrontantur ab una parte cum domo Robaudi et a parte alia cum alia domo dicte domine Ermessendis et a parte alia cum viridario alio ipsius domine Ermessendis et a parte alia cum transversia et a parte ante cum carreria publica.

Item, et ex parte alia cervit ( $s i c$ ) dicta domina Ermessendis, annis singulis in dicto festo, viginti quatuor solidos predicte monete pro quadam alia domo ipsius domine Ermessendis sita ibidem; confrontata ab una parte cum viridario domini Raymundi de Monteolivo sacerdotis, et a parte alia cum carreria publica.

Item, et ex parte alia cervit (sic) dicta domina Ermessendis, annis singulis in dicto festo, viginti solidos dicte monete pro quodam viridario toto sito ibidem in transversia, quod viridarium fuit Bernardi de Cimiterio quondam; et confrontatur ab una parte cum alio viridario ipsius domine Ermessendis et a parte alia cum alio viridario ipsius domine Ermessendis et a parte bodii cum viridario Pontii Tisonis et a parte alia cum transversia publica (...).

\subsection{Vente de la directe sur une boutique d'Huguette Fausonerie par Hugues de Roquefort, 8 avril 1332.} AD13 6 G 69, charte $\mathrm{n}^{\circ}$ 454. Transcription M. Bouiron.

[In] nomine Domini amen. Anno Incarnationis ejusdem millesimo tricentesimo tricesimo secundo, die octavo mensis aprilis, quintedecime indictione. Notum sit cunctis presentibus et futuris quod ego Hugo de Rocaforti, domicellus, civis Massilie, (...) vendo (...) vobis domine Hugete Fausonerie, civi civitatis ejusdem, presenti ementi et recipienti per vobis et vestris juris [et] cum toto directo dominio et majori senhoria que est in laudimiis interponendis trezenis percipiendis et in jure retinendi in omnibus alienationibus quos nos dicta domina Hugueta servit et servire consuevistis, 
anno quolibet in predicto (festo) sancti Michaelis, pro quadam botiga vestra cum quodam viridario vestro contiguo dicte domus sitis in suburbiis Massilie, in traversia dicta Corderiorum;, confrontatur ab una parte cum botiga Johannis de Arco et retro cum orto seu viridario dominarum de Robaut et cum dicta traversia Corderiorum. Vendo inquam precio videlicet centum solidorum regalium (...).

\subsection{Vente de cens par Hugues de Roquefort à Raymond Viridis sur des maisons situées au bourg de Roubaud et reconnaissance, 29 juillet 1332.}

AD13 6 G 68, charte $n^{\circ}$ 453. Transcription M. Bouiron.

In nomine Domini amen. Anno Incarnationis ejusdem millesimo trecentesimo tricesimo secundo, die vicesimo nono julii, quintedecime indictione, circa terciam. Notum sit cunctis presentibus et futuris quod Hugo de Ruppefortis, domicellus de Massilia, bona fide et sine omni dolo et fraude non deceptus (...) vendidit et ex causa perfecte venditionis nostris et semper valiture tradidit (...) venerabili viro domino Raymundo Viridis, archidiacono Massiliensis, non ut archidiacono set ut domino Raymundo proprio, presenti ementi stipulanti et recipienti per se et suis, census infrascriptos et jus directum et majus dominium et senhoriam habendi eosdem annuatim laudandi retinendi et trezena percipiendi.

Primo videlicet illos decem et octo solidos et quatuor denarios regalios censuales quos ut ipse Hugo asserit sibi servit et servire tenetur Marita de Monteolivo, filia Johannis Boisserie quondam, pro duabus domibus et uno viridario et quodam patuo in quo est unus puteus et quoddam barquile simul contiguis, in burgo de Robaut civitatis Massilie ; confrontatis ab una parte cum domo helemosine ecclesie Beate Marie sedis Massiliensis et $\mathrm{ab}$ alia cum viridario Raymundi Rogerii et ab alia parte cum viridario domine Philippe Porcellette, beguiine de Robaudo, et cum carreria publica, annuatim in festo sancti Michaelis, scitis in carreria supradicta.

Item, illos quinque solidos decem denarios regalium censuales quos sibi servit annuo in predicto festo Bertranna Hugoneta pro domo quadam cum quodam patuo simul contiguis, scitis in carreria supradicta.

Item, illos octo solidos regalium censuales quos servit eodem anno in dicto festo Bertrandus de Volta pro domo quadam cum patuo et quodam viridario simul contiguis, dotalibus uxore dicti Bertrandi, scitis in carreria supradicta.

Item, illos octo solidos regalium censuales quos sibi servit annuo in dicto festo domina Johanna de Volta pro domo quadam et viridario simul contiguis, scitis in carreria supradicta.
Item, illos sex solidos et octo denarios regalium censuales quos ei servit annuo in dicto festo Hugo Cordella pro domo quadam scita in carreria supradicta.

Item, illos quatuor solidos et quatuor denarios regalium censuales quos sibi servit anno in dicto festo Guillelmus Arnaudi pro domo quadam dirruta scita ibidem.

Item, illos quatuor solidos et tres denarios regalium censuales quos eidem servit annuo in dicto festo Bertholomeo de Mosteriis pro domo quadam dirruta scita ibidem.

Vendidit inquam idem Hugo de Ruppefortis per se et suos jamdicto domino Raymundo Viridis presenti ementi, stipulanti et recipienti per se et suis census omnes supradictos cum omnibus juribus et pertinentiis suis, precio videlicet octuaginta libras regalium (...).

(à la suite)

Anno Domini $\mathrm{M}^{\circ} \mathrm{CCC}^{\circ} \mathrm{XXXII}^{\circ}$, die $\mathrm{XX}^{\circ} \mathrm{VIIII}^{\circ}$ julii. Notum sit cunctis quod Huga Cordella confessa fuit sollempniter et in veritate recognovit ut tutrix et tutorio nomine ut dicit Moneti et Romei Michaelis, fratrum, domino Raymundo Pichoni, presbitero, procuratorio domini Raymundi Viridis presenti stipulanti et recipienti, procuratorio nomine ipsius domini Raymundi Viridis et suorum, se tenere sub dominio directo et majori senhoria ipsius domini Raymundi Viridis, domum quandam scitam in civitatis Massilie, loco dicto in carreria de Robaudo ; confrontatis ab una parte cum domo Petri Rostagni et $\mathrm{ab}$ alia cum domo Hugete Falconerie, ad censum sex solidorum octo denariorum annuo solvendorum in festo sancti Michaelis (...).

(à la suite)

Anno Domini $\mathrm{M}^{\circ} \mathrm{CCC}^{\circ} \mathrm{XXXII}^{\circ}$, die $\mathrm{XX}^{\circ} \mathrm{VIIII}^{\circ}$ julii. Notum sit cunctis quod domina Johanna de Volta confessa fuit sollempniter et in veritate recognovit ut tutrix et tutorio nomine ut dicit Moneti et Romei Michaelis, fratrum, domino Raymundo Pichoni, presbitero, procuratorio domini Raymundi Viridis presenti stipulanti et recipienti, procuratorio nomine ipsius domini Raymundi Viridis et suorum se tenere sub dominio directo et majori senhoria ipsius domini Raymundi Viridis, domum quandam et viridarium simul contiguis scitis in civitatis Massilie, loco dicto in carreria de Robaudo, ad censum octo solidorum regalium annuatim solvendorum in festo sancti Michaelis (...) que domus cum ipso viridario confrontatis cum domo domine Ermessendis Porssellette et cum domo Bertrandis de Volta et cum carreria publica (...).

(à la suite)

Anno Domini $\mathrm{M}^{\circ} \mathrm{CCC}^{\circ} \mathrm{XXXII}^{\circ}$, die $\mathrm{XX}^{\circ} \mathrm{VIIII}^{\circ}$ julii. Notum sit cunctis quod Bertrandus de Volta confessa fuit sollempniter et in veritate recognovit ut tutrix et tutorio nomine ut dicit Moneti et Romei Michaelis, fratrum, 
domino Raymundo Pichoni, presbitero, procuratorio domini Raymundi Viridis presenti stipulanti et recipienti, procuratorio nomine ipsius domini Raymundi Viridis et suorum, se tenere sub dominio directo et majori senhoria ipsius domini Raymundi Viridis, domum quandam cum quibusdam viridario et patuo simul contiguis, scitis in civitatis Massilie, loco dicto in carreria de Robaudo ; confrontatis cum domo Helemosine ecclesie Beate Marie sedis Massiliensis et cum carreria publica, ad censum octo solidorum regalium annuatim solvendorum in festo sancti Michaelis (...).

(à la suite)

Anno Domini $\mathrm{M}^{\circ} \mathrm{CCC}^{\circ} \mathrm{XXXII}^{\circ}$, die $\mathrm{XX}^{\circ} \mathrm{VIIII}^{\circ}$ julii. Notum sit cunctis quod Bertranna Hugoneta confessa fuit sollempniter et in veritate recognovit ut tutrix et tutorio nomine ut dicit Moneti et Romei Michaelis, fratrum, domino Raymundo Pichoni, presbitero, procuratorio domini Raymundi Viridis presenti stipulanti et recipienti, procuratorio nomine ipsius domini Raymundi Viridis et suorum, se tenere sub dominio directo et majori senhoria ipsius domini Raymundi Viridis, domum quandam cum quoddam patuo contiguis, ad censum quinque solidorum et decem denariorum regalium annuatim solvendorum in festo sancti Michaelis; que domus cum dicto patuo scitis est in civitatis Massilie, loco dicto in carreria de Robaudo (...) et confrontantur cum domo Raymundi Aynardi et cum domo Johannis Francizii et cum carreria et cum viridario Raymundi Rogerii (...).

(à la suite)

Reconnaissance de Marita de Montolieu

\section{Textes de la période moderne}

\subsection{Rapport pour Jehan Boisselli contre Dangostine et demoiselle de Vento (1642, le 29 avril).}

AD13 357 E 133, fol. 462. Transcription C. Castrucci.

Satisfaisant nous Accassi Roux, Gaspar Sicardmarchands bourgeois et Jehan pierre Portal, me maçon de ceste ville de Marseille expertz comis et depputtes par decret de Monsieur le lieutenant prin[ci] pal au siege de cested. ville, randu le vingt sept[iesme] avril present mois au bas de la requeste presantee par Jehan Boisselli merchand aux fins de voir visiter extimer et rapporter de lestat et quallite des deux maisons quil a acquises de noble Marc Anthoine D'Angostine $\mathrm{s}^{\mathrm{r}}$ de Septemes mari et me des biens et droicts de dam[oise] lle Françoise de Vento assizes dans lenclos de cestd. Ville cartier du Corps de Ville rue des Ventes par contract riere me Lebon notaire le siziesme dud. presant mois davril, au commandement a nous faict par le (...) le landemain vingthuictieme mois ayant presté au preallable le serment en tel cas requis Certiffions nous estre ensamblement acheminés sur lesd. maisons assizes au lieu susd. joignantes et faisant canton amplement designes dans le susd. contract, ou arrives l'heure de lassigna[ti]on escheue et passée en presance dud. Boisselli et en deffault dud. $\mathrm{s}^{\mathrm{r}}$ de Septemes deuement assigne par le mesme exploit et apres avois icelles veues et visitees en tous ses endroitz les avons trouvés estre de la longueur du coste de $\mathrm{m}^{\mathrm{r}}$ de Gerente de cinquante pans tirant de midi a tremontane, et du coste du $\mathrm{s}^{\mathrm{r}}$ Anthoine Allamand quest par dernier de la largeur lesd. deux maisons de trante six pans tirant de levant à couchant, la fassade desd. deux maisons deubes midi ont quarante quatre pans et demy de large tirant aussi de levant a couchant et la fassade deube levant a de long quarante huict pans et demi tirant (fol. 462v) paraill[emen]t de midi a tremontane le tout franc de murailhes, estant lesd. maisons en deux corps separés ayant chascune maison son entree, ung ciel ouvert, sa visete et montee a deux meyneaux de plastre, et sa cave aussi chescune, dont la cave de la maison joignante la maison dud. $\mathrm{s}^{\mathrm{r}}$ de Gerente contient trante ung pans de long et seize pans de large, Et la cave de la maison faisant le coing contient aussi trante ung pan de long de midi a tresmontane touttes deux, et vingt huict pans de large estant lesd. deux caves seppares par une murette quest entre deux, Sur le dernier desquelles deux caves au dessoubz et fondz desd. maisons y a une petite cave de trante six pans de long et quinze pans de large que appartient aud. Allaman, A lad. Maison joignante celle dud. $\mathrm{s}^{\mathrm{r}}$ de Gerente y a deux estages soubz le couvert et toict et a laultre maison faisant le canton y a aussi deux estages soubz le toict et couvert vers la fassade du midi et ung petit demi soullier ou me[can] au dessoubz la salle, sur le dernier joignant la maison dud. $\mathrm{s}^{\mathrm{r}}$ Allaman y a une lauvisse au plus hault et dernier la traverse du coste de levant y a deux boutiques lune desquelles est au dessus la cave dud. $\mathrm{S}^{\mathrm{r}}$ Allaman cy dessus mentionnee. La fassade dud. coste de levant est de maçonnerie excepte le coing quest de pierre de tailhe de bas en hault jusques au toict ensamble la fassade du coste de midi desd. deux maisons est aussi de pierre de tailhe qui acompagne jusques a la premiere coudiere et le restant de maçonnerie le tout vieulx et corrompu sans aucun ordre et fenestres et voisures lesd. carages et fassades soubzplombant tant dung coste que daultre denviron ung pan, La murailhe mestresse et moittiniere dentre la maison dud. $\mathrm{s}^{\mathrm{r}}$ de Gerente et la maison la joignant, est vieilhe ruyneuse et grande[ment] corrompue laquelle a besoing destre desmollie et refaicte de neuf. Et la murailhe mestresse et moitiniere dentre lesd. (fol. 463) deux maisons et celle dud. Sr Allamand est descroustade en divers endroicts et corrompue en 
plusieurs parts, Les soulliers et planchers desd. maisons sont enfustas et entravettas aussi vieilhes corrompues et en fort mauvais estat. Comme de mesme les callamants, travettes, portes, fenestres, serrures à clefs, pallamelles, gonds, gaches, verrouilhes et vittres, pareilhes, les couvert, toict, visette, et en general le tout en tres piteux estat, attandu mesme lanciennette desdictes maisons Lesquelles par ainsi ont besoing destre bientôt reffaictes et rebasties veu quelles ne pourront estre commodement repparées ; et icelles en la quallité que se trouvent heu deue confiance entre nous extimons valloir la somme de six mil livres, Et comme dessus avons prouve sellon le deub de nos consciences estant deub pour nos prix et vacations cinq livres pour chescung que avons receu dud. Boisselli. Faict à Marseille le vingt neufiesme jour du mois davril mil six centz quarante deux Remis entre moy notere royal soubsigné ce sixiesme jour du mois de may aud. an.

\subsection{Prisfaict pour Pons Agnel a Jean Baptiste Gettin, Pierre Debarre, Pierre Amalbe et Michel Arnaud, $m^{e s}$ maçons (1636, le 23 janvier).}

AD13 373 E 271, fol. 102. Transcription C. Castrucci.

L'an mil six cens trente six et le vingt deux janvier apres midi, constitué en personne par devant moy $\mathrm{no}^{\mathrm{re}} \mathrm{e}$ tesmoings $\mathrm{s}^{\mathrm{r}}$ Pons Agnel, borgeois de ceste ville de Marseille, lequel a donne a prisfait a Jean Baptiste Gettin, Pierre Debarre, Pierre Amalbe et Michel Arnaud, mes maçons dudit Marseille present, stipullant, scavoir est la const[ruct]ion de ces deux maisons que le dit Agnel a acquis l'une de dlle Marguerite Alphante et Louis Petrot, mere et fils, et l'autre de son patrimoine, assizes dans l'enclos de cette ville, cartier de corps d'icelle fezant ung des quatre coings de Saint-Victor, confrontant d'une part maison de Joseph Louys, me orphevre, et d'autre part maison de Jean Baptiste Moutte, merchand, pour y faire la besogne suivante: Premierement lesdictz $\mathrm{m}^{\mathrm{es}}$ seront tenus de desmollir lesdictes deux maisons jusques aux fondements et tout ce que sera necessaire desmolir, Apontelleront suffisamment les maisons des voizins a leurs despens, perils et fortune, Forniront les etayes et eschafaux, ne pourront pretendre aulcune chose des desmollitions quelle qualité quil soit, feront place nette. Et pour tout ce que dessus leur (fol. 102v) sera paie la somme de cent livres, plus feront les murailhes qui sont sur les deux rues conformemant au dessain qui en a este fait, de bonne pierre de tailhe toutes portant parpain; et pour cest effect la requeront aux pereirons et les hornemans des croizieres seront de l'ordre de celles qui sont a la maison du sr Remondin, située a la place de Lenche sans y construire les flurs de lix qui sont au dessoubz. Les hornemants des boutiques et enrechissemans de la porte seront de l'ordre de celle de la maison de Sansson Napolon. Les coudieres regneront tout autour de lad. maison, l'antablemant et cornisse ce feront conformement a l'ordre qui est en la maison de monsr le comissere Darenne ou il habite de $\mathrm{p}^{\text {nt }}$, moyenant le prix de neuf livres pour cha[cu]ne canne carrée qui ce canegera tant plain que vuide sans pouvoir rien esperer des enrechissements des croizieres, coudieres portes, boutique, cornisse et gorges qui jettent l'eau sur la taulisse. Que la some de trante livres la vizette de la crote, aussi le premier tour de la vizette cousteront a (...) meneaux avec le parepied (...) premier estage, le tout de pierre de tailhe (fol. 103) ou sera fait les arquetz pour soubstenir lesd. vizette ou les coulones necessaires Et leur chapiteaux, ballustres, mains courantes, vazes dupui, pille, bassins, le bardat necessaire a l'entree et ciel ouvert le pozemant des gorges pour conduire les eaux a la rue pour deux artz dans la crotte avec leur pilliers de pierre de tailhe, les portes des crotes, la porte de l'estable et autres portes necessaires pour la commodite des crottes, le tout randu parfaict de pierre de tailhe jusques au premier estage pour le prix et somme de cent trante livres, moyenant lequel prix ne pourront lesd. $\mathrm{m}^{\mathrm{es}}$ rien prethandre du pozemant des gaches, gouffons, clefs necessaires a la liezon des murailhes quy seront de besoing a lad. maison ou telles que dezirera ledit $\mathrm{s}^{\mathrm{r}}$ Agnel de fere mettre. Davantage feront en lad. maison cinq fuguerons de cheminee, pozeront les bartz aux deux pilles, leur borneaux pour conduire l'eau dehors, le tout bien et deubemant travailhe pour le prix de quinze livres, La voulte de la crotte sera faite a croizilhons et crottee de mallons de lhauteur que ledit $\mathrm{s}^{\mathrm{r}}$ Agnel treuvera (fol. 103v) a propos, moyenant le prix de trois livres six soubz la canne carrée de lad. voulte sur lequel prix lesd. $\mathrm{m}^{\mathrm{es}}$ barderont le dabas de la crotte sans rien en pouvoir prethandre ni des sintres et autres bois neuf. Porter la facture de lad. crotte que lesd. $\mathrm{m}^{\text {es }}$ seront obligés de fournirt voullant le $\mathrm{s}^{\mathrm{r}}$ Agnel creuzer davantage lad. crotte fera fere a ces despans. Tous les malons que ce feront tant aux boutiques et cuisine payeront a raison de dix hit soubz la canne carrée, lesquelz ce feront a trelix la canne des murailhes maistresses a raison de deux pans d'espeisseur ce payera pour chaque canne carrée randue enduite a point de blanchir quarante soubz. La canne des murettes, randue aussi a point de blanchir d'ung pan despeisseur ce payera a raison de vingt six soubs la canne. Les solliers, entrevou, bugetz, cheminée, capes,taulisse, fere (...) prins avec ces caisses, les planchers d'espoisseur requise le tout a point de blanchir sera paye a raison de (...) soubz la canne carrée. Pour chaque (fol. 104) canne de blanchimant, sera paye sept soubz sy ce descroutte les vieilhes murailhes moitiniere 
d'entre monte et loup en cas quelle ce treuvassent bonnes ce payera pour chasque canne descrouttee enduite et blanchie a raison de dix soubz la canne carree. Feront en oultre lesd. mes quatre tours de vizette de giparie, trois avec ces vives arestes, cornisse, colones, chapiteaux, balustres et ces mains courantes, le tout blanchi de gip blanc et ce, pour le prix de cent livres. Et moyenant tous lesquelz prix de toute la susd. besogne, lesd. $\mathrm{m}^{\text {es }}$ seront tenus pozer tous les callamants, simas, rustes pour fere ces bugetz et pozer un bois dans la pierre de tailhepour claveller les travettes pour la fortiffication de lad. maison avec tous les pies, clef de fer et clavezon que plombz que ledit $\mathrm{s}^{\mathrm{r}}$ Agnel treuvera a propos estre besoing a lad. maison Retenir et pozer toutes croizieres, portes et fenestres dintre maison, gaches et gouffons fors l'enfustage des solliers et coridors sy mieux ilz nayment lesd. $\mathrm{m}^{\text {es }}$ fere led. enfustage et clouer les travettes ausd. solliers tant negats que plans a raison (fol. 104v) de huit soubz la canne carree. Clouer lesd. travettes a chasque callemantz d'une part et d'autre la ou est necessaire pour la fortification de lad. maison, lesquelz clavezon, clefz de fer et farr[am]ante seront fournis par led. $\mathrm{s}^{\mathrm{r}}$ Agnel, et lesdictz $\mathrm{m}^{\mathrm{es}}$ ne pourront employer aulcung cartier de pierre qui ne soit bon et rep[ce]vable, faizant la murailhe dessus la Grand Rue d'ung pan et demi d'espoisseur renforsant le pillier du milieu jusques a deux pans sy besoing est. La muraille sur l'autre rue sera de deux pans d'espoisseur jusques au premier estage. Les fondemantz d'icelle murailhe qui seront partie dans la rue seront de trois pans d'espoisseur. S'il fault soustraire des murailhe d'entre loup et monte lesd. mes ne pourront prethandre davantage que ra[is]on de quarante soubz la canne carrée et en cas que lesditz maistres ce servent de quelque personne qu'il ne soit capable et qu'il n'agrée aud ${ }^{t}$ $\mathrm{s}^{\mathrm{r}}$ Agnel ils seront tenus en mettre d'autres capab[les] ; et a faulte de ce, sera permis aud. $\mathrm{s}^{\mathrm{r}}$ Agnel d'en mettre telz autres qu'il treuvera a propos (fol. 105) aux despans desd. $\mathrm{m}^{\mathrm{es}}$, lesquelz seront tenus de commancer a mettre main a lad. œuvre dans trois jours prochains, et continuer icelle jusques a perfection qu'ils prometent sollideremant l'ung pour l'autre et l'ung d'eulx seul pour le tout avoir bien et deubemant parachever lad.œuvre dans la fin du mois d'aoust prochain affin d'estre arrantee et habita[ble] a la feste Saint Michel prochaine, a paine detous despans dommages, inthe[re]ts en cas que ce soit par le manque[men]t desd. mes attandu que led. sr Agnel leur doit en temps et lieu fournir les materiaux et tout ce qui est necessaire pour la constru[cti]on de lad. œuvre/ Et pour ce qui est du payemant de la susd. besoigne, ce payera scavoir de pr[esent] et par advance la somme de cent cinquante livres que lesd. $\mathrm{m}^{\mathrm{es}}$ maçons ont recu dud. $\mathrm{s}^{\mathrm{r}}$ Agnel reallemant en pistolles d'Espagne et autre monnaye au veu de moid. no ${ }^{\text {re }}$ et tesmoingz et le restant dud. prix ce payera en fezant la susd. besogne a condi[t] ion qu'ilz ne pourront res[e]pvoir aud.cinq paye[men]t (fol. 105v) qu'ilz ne soient tous quatre ensamblemant ainsin le tout entre lesd. parties acordes. Et pour l'observa[ti] on du contenu si dessus lesd. parties obligent leurs biens et personnes propres. Et l'ont juré. Fait et publie aud. Marseille dans la maison dud. $\mathrm{s}^{\mathrm{r}}$ Agnel, en $\mathrm{p}\left[\right.$ rese]nce de $\mathrm{s}^{\mathrm{r}}$ Cezard Goudard escuier et François Blanc, merchand dud. Marseille, t[esmoings] $\mathrm{s}$ [oubsignes], les parties ont dit ne scavoir escripre fors Debarre

Signé : Pierre Debarre, Godard, Blanc

et moy Jean Vachier no ${ }^{\text {re }}$ royal aud. Marseille soubsigne

\subsection{Arrentement perpétuel $D^{\text {Ile }}$ Claire de Guérin avec Achept de place et jardin pour la Congrégation de Pères de la Mission (1636, le 22 décembre).}

AD BDR 13: 380 E 127, fol. 1733. Transcription C. Castrucci.

(...) Damoyselle Claire de Guérin, femme séparée en biens de noble Jean-Baptiste de Fabre, de ladicte ville (...) a balhé (...) à titre d'arentement perpétuel (...) à la Congrégation des Pères de la Mission establie en la ville de Brignolles, à présent $\mathrm{M}^{\mathrm{e}}$ Jean Ofahy et vendeur au bien présent de la dicte congrégation (...) sçavoir est un jardin de la contenance d'une carteirade et demy et autres prenant tant que contient dans ses (b...) et limites avec tous les autres estans dans icelluy et autres ses droits et appartenances sur leuel laditte $d^{\text {lle }}$ de Guérin a esté colloquée pour la restitution de sa dot en suitte du arrest rendu par la souveraine cour du parlement et ce par actes du douze juin ou vingt aoust mil six cents vingt (...) scituée hors les murs dudit Marseille et au foubourg de la porte du marché, confrontant de levant une rue traverse et la maison bastie sur le cours dud. jardin que lad. dlle Guérin se réserve avec l'allée outrelhais estant alentour dicelle maison, de midy places de maison à vendre y après et maison et logis des trois Mulhets appartenant à (...) et du Cours, maison de Henry Geoffroy, et de trémontane les chemins allant aux Pères Augustins Refformés et autres ses meilheurs confrons sy point en y a, franche et libre de toute charge, directe (...). La dicte $d^{\text {lle }}$ de Guérin (...) la balhe moyennant la rente annuelle et perpétuelle $705 \mathrm{~L}$ tournois payables par lad. congrégation ainsy que lesd. $\mathrm{M}^{\text {res }}$ Ofahy et Aubert au nom d'icelle (...) à la charge que lad. congrégation sera tenue ainsi que lesdits messires Ofahi et Aubert promettent, de faire construire aux despans d'icelle une muraille que servira de sepparation dudit jardin davec la maison et allée outrelhas estans audevant dicelle que ladite $\mathrm{d}^{\text {lle }}$ de Guérin se réserve cy dessus. Laquelle construira, et fera 
sur les banquaus et petite murailhe quy soubstient et seppare les pilhiers dud. trelhas de telle autheur que bon semblera à lad. congrégation.

Et par ces mesmes ventes, lad. d ${ }^{\text {lle }}$ Guérin (...) a vendu (...) à lad. congrégation, lesdicts $\mathrm{m}^{\text {res }}$ Ofahi et Aubert acceptant et stippulant pour icelle (...) sçavoir est une place de maison et jardin que (...) ambroise Bastide à présent possède par $\mathrm{M}^{\mathrm{e}}$ Michaellis advocat en la cour, située au mesme faubourg et sur un coing, confrontant de levant le jardin cy dessus vandu, de midy maison de Claude Gaultier, hoste des Trois Mulletz, de couchant la place de la porte du marché, et de tresmontane les chemins tirant aux Pères Augustins Refformés, de la longueur de treize cannes et demy et de quatre cannes et demy de largeur comprins la place dung petit bastiment qu'il y a dans le (circuit) dans lequel il y a aussy la moitié d'une poze vague pour arrozer avec une grande pille de pierre de tailhe.

Plus une autre place de maison appartenant à Louis Girard, au mesme lieu, confrontant de levant le susdit jardin vandu, de midy maison de Guilhem Grimaud, de couchant lad. place du marché, et de tresmontane maison de Henry Geoffroy, contenant neuf cannes de long et deux et demy de large d'une part, plus un recoing de quatre cannes de long et trois cannes de large ou environ joignant lad. place.

Encore, trois autres places de maisons scituées au mesme lieu sur une traverse tirant à ladite place du marché vers les murailhes du jardin de Pierre Barnier, laquelle traverse est des despandances et tournant desd. places que lad. dlle de Guérin vend aussy, possédées icelles places par les hoirs du $\mathrm{S}^{\mathrm{r}}$ de la Reynarde, une desquelles estoit cy devans de Jean Gillet, $\mathrm{M}^{\mathrm{e}}$ masson, toutes trois joignantes et entourées de murailhes de dix à douze pans dhaulteur, et dans lune desquelles a une estable et basse cour, confrontant de levant avec place de maison possédée par lesd. heoirs cy apprès désignées, de midy maison de (...) Amphoux, dict «perroisse », lad. traverse au milieu, de couchant maison de François Gailhard et de trémontane, le jardin cy dessus vandu, en lune desquelles places y a une porte de maison de pierre de tailhe et deux fenestres bastardes aussi de pierre de taille trelissées de fer contenant chacune environ six cannes de longueur et trois cannes de largeur.

Davantage, une autre place de maison environnée de murailhe de la susd. hauteur ayant de largeur environ dix cannes et cinq cannes et demy longueur scituée sur la mesme traverse faisant le coing du derrière possédée par lesdicts heoirs du $\mathrm{S}^{\mathrm{r}}$ de la Reynarde, confrontant de levant jardin de Pierre Barnier, chemin traversier au millieu, de midy jardin tenu par François Pagi, $\mathbf{M}^{\mathrm{e}}$ de poste et rellaix, lad. traverse au millieu, de couchant les susdites places et de tresmontane ledict jardin vendu.

Plus une autre place à présent réduite de maison et basse-cour, possédée par (...) Amphoux, dict « peroisse », confrontant de levant place de maison qu'est cy devant de Pierre Barnier, de midy et couchant le logis de la Celle d'Or, tenu par Pierre Faure, dict «Alary », et de tresmontane, les susdictes places possédées par les heoirs du $\mathrm{S}^{\mathrm{r}}$ de la Reynarde, ladicte traverse vendue au milieu, contenant trois cannes de largeur en quarré tout comprins.

Comme aussy une autre place de maison joignant la précédente quy fust cy devant de Barnier ou de Jean Roman à présent possédée par led. Allary, confrontant de levant le jardin du rellaix, tenu par ledict Pagi, de midy ledict Logis de la Celle d'Or, de couchant ladicte maison de « peroisse », et de trémontane ladite traverse cy dessus vandue de pareille longueur et largeur que la précédente.

Et finallement, ung jardin tenu par ledict François Pagi, $\mathrm{M}^{\mathrm{e}} \mathrm{du}$ rellaix quest face cy devant des heoirs de Pierre Vidal, confrontant de levant avec jardin de Pierre Barnier, ledit chemin traversier entre deux, de midy la maison dud. Pagi, de couchant la place de maison de Allary, et de tresmontane ladite place de maison dudict $\mathrm{S}^{\mathrm{r}}$ de la Reynarde, ladicte traverse vandue au milieu, lequel jardin est denviron quinze cannes de longueur et six cannes et demy de largeur tout entouré de murailhe dans lequel y a un puis et puis six arbres fruitiers, et autres leurs plus vrais confrons sy point en y a (...) le tout franc et libre de toutes charges directes. Prix : 2550 livres tournois. 


\section{Bibliographie}

Abel 1995: ABEL (V.) - Marseille. Saint-Jean du Désert. IV Un petit édifice du XVIII' s. In: Bilan scientifique de la Région Provence-AlpesCôte d'Azur, 1994. Paris : Ministère de la Culture et de la Communication, 1995, p. 149.

Abel 1997: ABEL (V.) - Étude du mobilier céramique de l'époque moderne. In : Thernot (R.) dir., César médiéval et moderne. Marseille/Aixen-Provence: Afan/SRA-PACA, 1997. (Rapport de fouille archéologique préventive).

Abel 2001: ABEL (V.) - La céramique moderne et contemporaine de l'Alcazar. In: Bouiron (M.) dir., L'Alcazar, 26 siècles d'occupation suburbaine à Marseille. Marseille/Aix-en-Provence : Atelier du Patrimoine/ SRA-PACA/Afan, 2001, p. 451-495. (Document final de synthèse de fouille archéologique préventive).

Albanès 1865 : ALBANÈS (J.-H.) - Entrée solennelle du Pape Urbain V à Marseille en 1365. Programme de la fête, dressé par le conseil de la ville, texte provençal inédit du XIVe s., notes historiques et pièces justificatives. Marseille : Boy-Estellon, 1865, 79 p.

Albanès 1878 : ALBANÈS (J.-H.) - Jean Artaudi, dominicain, prieur de Saint-Maximin, évêque de Nice et de Marseille. Notice historique et documents inédits. Marseille : Lebon, 1878, 74 p.

Albanès 1879 : ALBANÈS (J.-H.) - La Vie de Sainte Douceline fondatrice des béguines de Marseille. Marseille : Étienne Camoin éd., 1879, 304 p.

Albanès 1884: ALBANÈS (J.-H.) - Armorial et sigillographie des évêques de Marseille, avec des notices historiques sur chacun de ces prélats, publiés sous les auspices de l'Évêque de Marseille. Marseille: M. Olive, 1884, $192 \mathrm{p}$.

Albanès Chevallier 1910: ALBANÈS (J.-H.), CHEVALIER (U.) éd. - Institutions liturgiques de l'Église de Marseille (XIII ${ }^{e}$ s.). Publiées d'après le manuscrit original des Archives de la Préfecture de Marseille, avec le Mortuologe de la même Église. Paris, 1910, 175 p. (Bibliothèque liturgique, 14)

Alexandre-Bidon 2006: ALEXANDRE-BIDON (D.) - Le confort dans la maison médiévale: une synthèse des données. In: AlexandreBidon (D.), Piponnier (F.), Poisson (J.-M.) dir., Cadre de vie et manières d'habiter (XII $\left.{ }^{e}-X V I^{e} s.\right)$. Actes du VIII ${ }^{e}$ Congrès international de la Société d'archéologie médiévale (Paris, 11-13 octobre 2001). Caen : CRAHM, 2006, p. 129-144.

Alexandre-Bidon, Lorcin 2003 : ALEXANDRE-BIDON (D.), LORCIN (M.-T.) - Le quotidien au temps des fabliaux. Paris: Éditions Picard, 2003, 303 p.

Alexandre-Bidon, Lorcin 2006 : ALEXANDRE-BIDON (D.), LORCIN (M.-T.) - La protection spirituelle. In : Alexandre-Bidon (D.), Piponnier (F.), Poisson (J.-M.) dir., Cadre de vie et manières d'habiter (XII ${ }^{e}-X V I^{e}$ s.). Actes du VIII Congrès international de la Société d'archéologie médiévale (Paris, 11-13 octobre 2001). Caen : CRAHM, 2006, p. 187-206.

Alibert 1966 : ALIBERT (L.) - Dictionnaire occitan-français d'après les parlers languedociens. Toulouse : IEO, 1966, 699 p. ( $2^{\mathrm{e}}$ éd.).

Amargier 1966: AMARGIER (P.-A.) - Benoît d'Alignan, évêque de Marseille, 1229-1268. Le contexte et l'esprit d'une théologie, Le Moyen Âge, LXXII (4e série, XXI), 1966, p. 443-462.

Amargier 1969 : AMARGIER (P.-A.) - Raimbaud, moine de Saint-Victor, archevêque d'Arles (1030-1070) et sa famille, de Reillanne. In : Rencontres d'Arles, 18 et 19 octobre 1968. Publication du Centre européen d'études burgondo-médianes, 11, 1969, p. 36-46.
Amargier 1972 : AMARGIER (P.-A.) - Évêques et prévôts languedociens de l'Eglise de Marseille. In: Les évêques, les clercs et le roi (1250-1300). Toulouse, 1972, p. 147-162. (Cahiers de Fanjeaux, 7).

Amargier 1987 : AMARGIER (P.-A.) - Politique de l'eau à Marseille au temps des premiers angevins (1260-1380). In: L'eau et les hommes en Méditerranée. Actes du colloque du G.I.S., Aix-en-Provence 1984. Paris : CNRS, 1987, p. 283-289.

Amargier 1996: AMARGIER (P.-A.) - Marseille au Moyen Âge. Marseille : Éditions La Thune, 1996. 121 p.

Amouric et al. 1997: AMOURIC (H.), BERNARDI (P.), VAYSSETTES (J.-L.) - Production et usages des céramiques architecturales en Provence et Languedoc du Moyen Âge à l'époque moderne. In : Démians d'Archimbaud (G.) dir., La céramique médiévale en Méditerranée. Actes du $V I^{e}$ congrès de l'AIECM2 (Aix en Provence, 13-18 novembre 1995). Aix-enProvence : Narration Éditions, 1997, p. 707-712.

Argan 1964: ARGAN (G. C.) - L'Europe des capitales, 1600-1700. Lausanne : Skira, 1964, 222 p.

Arlaud 2000: ARLAUD (C.) dir - Lyon, les dessous de la presqu'île. Bourse - République - Célestins - Terreaux. Sites Lyon Parc Auto. Lyon, 2000, 280 p. (Document d'Archéologie en Rhône-Alpes, 20).

Aubourg et al. 2001: AUBOURG (C.), COMBES (V.), LEAL (É.), MAURIN (M.), REYNAUD (P.), VOYEZ (Ch.) - Le complexe hydraulique, phase 4B1. In: Bouiron (M.) dir., L'Alcazar, 26 siècles d'occupation suburbaine à Marseille. Marseille/Aix-en-Provence : Atelier du Patrimoine/ SRA-PACA/Afan, 2001, vol. 1-2, p. 322-329. (Rapport de fouille archéologique préventive).

Aurell i Cardona 1986 : AURELL i CARDONA (M.) - Une famille de la noblesse provençale au Moyen Âge : les Porcelet. Aix-en-Provence : Éditions Aubanel, 1986, 217 p. (Archives du Sud).

Auzende et al. 1973 : AUZENDE (J.-M.), BONNIN (J.), OLIVET (J.-L.) - The origin of the western Mediterranean basin, Geological Society of London. 129, 6, Londres, 1973, p. 607-620.

Baldizzone 1954 : BALDIZZONE (J.) - La Major, cathédrale de Marseille du XI ${ }^{e}$ au XII ${ }^{e}$ s. Aix-en-Provence, 1954 (Mémoire de D.E.S, Université de Provence, dactylographié).

Baratier, Reynaud 1951 : BARATIER (É.), REYNAUD (F.) - De 1291 à 1480. In : Rambert (G.) dir., Histoire du commerce de Marseille. Tome II. Paris, 1951, $927 \mathrm{p}$.

Baratier 1957 : BARATIER (É.), REYNAUD (F.) - Le port de Marseille au Moyen Âge. Arts et livres de Provence - Bulletin, 31. Marseille, 1957, p. 29-40

Baratier et al. 1969 : BARATIER (É.), DUBY (G.), HILDESHEIMER (E.) éd. - Atlas historique. Provence, Comtat Venaissin, principauté d'Orange, comté de Nice, principauté de Monaco. Paris : Armand Colin, 1969, $208 \mathrm{p}$.

Barra 2002 : BARRA (C.) - 5/7 rue Leca à Marseille (Bouches-duRhône). Aix-en-Provence : Inrap/SRA-PACA, 2002. (Rapport de surveillance de travaux).

Barra et al. 2004 : BARRA (C.), GUILLAUME (M.), MAUFRAS (O.), VASSELIN (B.), VOYEZ (Ch.) dir., Les fouilles archéologiques du Tunnel de la Major (Marseille, Bouches-du-Rhône) : contribution à la connaissance de la topographie urbaine $d u V I^{e} s$. av. n. è. au XIX ${ }^{e}$. Marseille/Aix-enProvence: Inrap/SRA-PACA, 2004. (Rapport de fouille archéologique préventive). 
Barra et al 2005 : BARRA (C.), BIEN (S.), BLAISON (J.-L.) et al. - Notice 83 Tunnel de la Major. In : Rothe (M.-P.), Treziny (H.), Marseille et ses alentours. Paris, 2005, p. 446-452. (Carte archéologique de la Gaule, 13/3).

Barthelemy 1885 : BARTHELEMY (L.) - Les plafonds de l'hôtel de Vento à Marseille. In: Congrès archéologique de France. LII ${ }^{e}$ session. Séances générales tenues à Montbrison en 1885 par la Société Française d'Archéologie pour la conservation et la description des monuments. Paris/ Caen, 1886, p. 353-358.

Belsunce 1747-1751 : [BELSUNCE (Mgr. de)] - L'antiquité de l'Église de Marseille et la succession de ses évêques, Marseille, 1747-1751, 3 vol.

Ben Chaba, Leal 2001 : BEN CHABA (L.), LEAL (É.) - La desserte des bâtiments. In : Bouiron (M.) dir., L'Alcazar, 26 siècles d'occupation suburbaine à Marseille. Marseille/Aix-en-Provence : Atelier du Patrimoine/ SRA-PACA/Afan, 2001, vol. 1-2, p. 319-321. (Rapport de fouille archéologique préventive).

Ben Chaba et al. 2001 : BEN CHABA (L.), LEFÈVRE-GONZALES (L.), MELLINAND (Ph.), SCHERRER (N.) - Le réseau des rues. In: Bouiron (M.) dir., L'Alcazar, 26 siècles d'occupation suburbaine à Marseille. DFS. Marseille, 2001, vol. 1-2, p. 345-349. (Rapport de fouille archéologique préventive).

Benoit 1954 : BENOIT (F.) - Marseille. In : Villes épiscopales de Provence. $V^{e}$ congrès international d'archéologie chrétienne. Paris, 1954, p. 33-38.

Bernardi 1995 : BERNARDI (Ph.) - Métiers du bâtiment et techniques de construction à Aix en Provence à la fin de l'époque gothique (1400-1550). Aix en Provence : Publications de l'Université de Provence, 1995, 501 p.

Bernardi 1998: BERNARDI (Ph.) - Construction et politique en Provence. L'approvisionnement en matériaux : une affaire publique ? In : Coulet (N.) dir., Guyotjeannin (O.) dir., La ville au Moyen-Âge. $120^{e}$ congrès national des Sociétés Historiques et Scientifiques, Aix-en-Provence 1995, La ville au Moyen-Age, II. Paris, CTHS, 1998, p. 9-20.

Bernardi 2001: BERNARDI (Ph.) - Les fortifications médiévales de Marseille en 1374. In : Bouiron (M.), Tréziny (H.), Bizot (B.), Guilcher (A.), Guyon (J.), Pagni (M.), Marseille. Trames et paysages urbains à Marseille de Gyptis au Roi René, Actes du colloque international d'archéologie (Marseille, 3-5 novembre 1999), Marseille, 3-5 nov. 1999. Aix-en-Provence : Édisud, 2001, p. 93-98. (Études massaliètes, 7).

Bernardi 2005 : BERNARDI (Ph.) - Pierres réelles ou pierres de compte ? Notes sur la mesure d'un matériau de construction. In: Moulinier (L.), Sallmann (L.), Verna (C.), Weill-Parot (N.) dir., La juste mesure. Quantifier, évaluer, mesurer, entre Orient et Occident (VIII ${ }^{e}-X V I I I^{e}$ s.). Saint-Denis : PUV, 2005, p. 35-47.

Bernardi 2006 : BERNARDI (Ph.) - L'atelier : données provençales sur la place du travail au Moyen Âge. In : Alexandre-Bidon (D.), Piponnier (F.), Poisson (J.-M.), Cadre de vie et manières d'habiter (XII ${ }^{e}-X V I^{e}$ s.). Actes du VIII ${ }^{e}$ Congrès international de la Société d'archéologie médiévale (Paris, 11-13 octobre 2001). Caen : CRAHM, 2006, p. 117-124.

Bertrand 1992 : BERTRAND (R.) - L'entrée des manuscrits de Michel de Léon à la Bibliothèque de Marseille, Marseille, 162, 1992, p. 44-49.

Bertrand, Bernos 1993 : BERTRAND (R.), BERNOS (M.) - Des Marseillaises dans les cloîtres, les couvents féminins d'Ancien Régime, Marseille, 166, 1993, p. 42-49.

Bertrand 2001a : BERTRAND (R.) - Aux grands hommes, la mairie reconnaissante : hommes illustres et noms de rues à Marseille (vers 17701870), dans Bouvier (J.-Cl.) Guillon (J.-M.) dir., Les toponymes de l'espace urbain. Significations et enjeux. Paris : L'Harmattan, 2001, p. 65-73.

Bertrand 2001b : BERTRAND (R.) - Le patrimoine de Marseille. Une ville et ses monuments. Marseille : Jeanne Laffitte, 2001, 215 p.

Bertrand à paraître : BERTRAND (R.) - Le matériau des constructions marseillaises aux Temps Modernes. À paraître.

Bien 2004 : BIEN (S.) - Une occupation plus intensive, Ve ap. J.-C.-VII ${ }^{\mathrm{e}} \mathrm{s}$ In : L'Alcazar à ciel ouvert, revue Marseille, 204, mars 2004, p. 21-24.

Billioud 1957 : BILLIOUD (É.) - La voie publique à Marseille jusqu'à la monarchie de Juillet. Marseille, 1957, 263 p. (Thèse en droit dactylographié).

Billioud 1963 : BILLIOUD (J.) - Bibliographie, Provence historique, XIII, fasc. 54, 1963, p. 316-330.
Bizot, Gantès 2005 : BIZOT (B.), GANTÈS (L.-F.) - Notices 107 à 109. In : Rothe (M.-P.), Tréziny (H.), Marseille et ses alentours. Paris, 2005, p. 511-530. (Carte archéologique de la Gaule, 13/3).

Blanc 1953 : BLANC (J.-J.) - La sédimentation de lac Oligocène de SaintAndré (Marseille), Bulletin du musée d'histoire naturelle, Marseille, XIII, 1953, p. 19-37.

Blancard 1884-1885: BLANCARD (L.) - Documents inédits sur le commerce de Marseille au Moyen-Age. Marseille, 1884-1885, 2 vol, LX-417604 p. (Réimp. 1978).

Bonifay 1981 : BONIFAY (M.) - Fouilles récentes sur le chantier de la Bourse : niveaux de l'Antiquité tardive et du haut Moyen Âge, Archéologie du Midi Méditerranéen, 3, 1981, p. 37-48.

Bonifay 1984 : BONIFAY (M.) - Éléments d'évolution des céramiques de l'Antiquité tardive à Marseille d'après les fouilles de la Bourse (1980-1981), Revue archéologique de Narbonnaise, XVI (1983), Paris, 1984, p. 285-346.

Bonifay et al. 1984 : BONIFAY (M.), BOIRON (R.), NIN (N.) - Compterendu de la surveillance archéologique des travaux d'aménagement du jardin des Vestiges de la Bourse, 10 décembre 1983-30 avril 1984. Marseille/ Aix-en-Provence, 1984, 51 p. (Rapport de surveillance archéologique dactylographié).

Bonillo 1978 : BONILLO (J.-L.) - Types urbains et types domestiques : Analyse architecturales du « 3 fenêtres » marseillais, Marseille : I.N.A.M.A., 1978.

Bonillo 1981 : BONILLO (J.-L.) - Le 3 fenêtres marseillais, ordinaire de la ville et univers domestique au XIX ${ }^{\mathrm{e}}$ s., Marseille, 126, 1981, p. 116-123.

Bonillo, Roncayolo 1996: BONILLO (J.-L.), RONCAYOLO (M.) - Marseille. In : Pinol (J.-L.) éd., Atlas historique des villes de France, Paris : Hachette, 1996.

Bonnot 1988 : BONNOT (I.) dir. - Marseille et ses rois de Naples. La diagonale angevine 1265-1382. Aix-en-Provence, 1988, 181 p. (Archives municipales de Marseille).

Bory 1861 : BORY (J.-T.) - Recherches historiques sur la cantinella et l'oratoire de la Madeleine et sur la tradition marseillaise relative à l'apostolat de cette sainte, Revue de Marseille et de Provence, VII, 1861, p. 512-521, $567-580$

Bouiron 1994 : BOUIRON (M.) dir. - Les Fouilles de la place Généralde-Gaulle à Marseille. Marseille/Aix-en-Provence: Atelier du Patrimoine/ SRA-PACA/Afan, 1994, vol. 4, p. 620. (Rapport de fouille archéologique).

Bouiron 1999 : BOUIRON (M.) - La création de faubourgs (fouilles de la place Général de Gaulle et de l'Alcazar. In : Parcours de villes. Marseille : 10 ans d'archéologie, 2600 ans d'histoire. Marseille : Musées de Marseille. Édisud 1999, p. 132-150.

Bouiron 2001a : BOUIRON (M.) dir. - Marseille, du Lacydon au faubourg Sainte-Catherine ( $V^{e}$ s. av. J.-C.-XVIII ${ }^{e}$ s.). Les fouilles de la place Généralde-Gaulle. Paris : Éditions de la MSH, 2001, 340 p. (DAF, 87).

Bouiron 2001b : BOUIRON (M.) dir. - L'Alcazar, 26 siècles d'occupation suburbaine à Marseille. Marseille/Aix-en-Provence : Atelier du Patrimoine/ SRA-PACA/Afan, 2001, 2075 p. (Rapport de fouille archéologique préventive).

Bouiron 2001c: BOUIRON (M.) - Les fortifications médiévales de Marseille. In: Bouiron (M.), Tréziny (H.), Bizot (B.), Guilcher (A.), Guyon (J.), Pagni (M.), Marseille. Trames et paysages urbains à Marseille de Gyptis au Roi René, Actes du colloque international d'archéologie (Marseille, 3-5 novembre 1999), Marseille, 3-5 nov. 1999. Aix-en-Provence: Édisud, 2001, p. 75-92. (Études massaliètes, 7).

Bouiron 2001d: BOUIRON (M.) - La trame urbaine médiévale. In : Bouiron (M.), Tréziny (H.), Bizot (B.), Guilcher (A.), Guyon (J.), Pagni (M.), Marseille. Trames et paysages urbains à Marseille de Gyptis au Roi René, Actes du colloque international d'archéologie (Marseille, 3-5 novembre 1999), Marseille, 3-5 nov. 1999. Aix-en-Provence : Édisud, 2001, p. 147-156. (Études massaliètes, 7)

Bouiron 2001e: BOUIRON (M.) - Les espaces suburbains. In : Bouiron (M.), Tréziny (H.), Bizot (B.), Guilcher (A.), Guyon (J.), Pagni (M.), Marseille. Trames et paysages urbains à Marseille de Gyptis au Roi René, Actes du colloque international d'archéologie (Marseille, 3-5 novembre 1999), Marseille, 3-5 nov. 1999. Aix-en-Provence : Édisud, 2001, p. 319-335. (Études massaliètes, 7). 
Bouiron 2001f : BOUIRON (M.) - Histoire et topographie des monuments de Marseille médiévale. In: Bouiron (M.), Tréziny (H.), Bizot (B.), Guilcher (A.), Guyon (J.), Pagni (M.), Marseille. Trames et paysages urbains à Marseille de Gyptis au Roi René, Actes du colloque international d'archéologie (Marseille, 3-5 novembre 1999), Marseille, 3-5 nov. 1999. Aixen-Provence : Édisud, 2001, p. 255-276. (Études massaliètes, 7).

Bouiron 2002 : BOUIRON (M.) - Un acte régalien méconnu : l'extension urbaine de 1190. In: Marseille face au(x) pouvoir(s). Actes du colloque. Marseille - 4 et 5 février 2000. Marseille, 2002, p. 22-44.

Bouiron 2009a : BOUIRON (M.) - Marseille durant l'Antiquité tardive et le Moyen Âge: mille ans d'évolution urbaine, Revue Marseille, 225, Marseille, 2009, p. 12-19.

Bouiron 2009b: BOUIRON (M.) - De l'Antiquité au Moyen Âge. In : Pécout (Th.) dir., Marseille au Moyen Âge, entre Provence et Méditerranée : les horizons d'une ville portuaire. Méolans-Revel : Éditions Désiris, 2009, p. 12-43.

Bouiron 2009c : BOUIRON (M.) - L'évolution topographique de Marseille $\left(\mathrm{XI}^{\mathrm{e}}-\mathrm{XIV}^{\mathrm{e}} \mathrm{s}\right.$.). In : Pécout (Th.) dir., Marseille au Moyen Âge, entre Provence et Méditerranée : les horizons d'une ville portuaire. Méolans-Revel : Éditions Désiris, 2009, p. 46-88.

Bouiron à paraître : BOUIRON (M.) - Le lotissement de l'abbaye SaintSauveur de Marseille. De la reconquête de l'espace urbain à la création du palais communal $\left(\mathrm{XI}^{\mathrm{e}}-\mathrm{XIII}{ }^{\mathrm{e}} \mathrm{s}\right.$.), Mélanges de l'Ecole Française de Rome : Moyen Âge. Rome, à paraître.

Bouiron et al. 1995 : BOUIRON (M.), COLLINET (J.) coll., GANTÈS (L.-F.) coll., PARENT (F.) coll., POURNOT (J.) coll., RICHIER (A.) coll., SILLANO (B.) coll., VOYEZ (Ch.) coll. - Sondages Archéologiques.Tunnel de la Major (Marseille). Marseille/Aix-en-Provence : Atelier du Patrimoine/ Afan/SRA-PACA, 1995, 123 p. (Rapport de fouille archéologique préventive)

Bouiron et al. 1999 : BOUIRON (M.) dir., ABEL (V.) coll., BERTOMEU (E.) coll., COGNARD (F.) coll., DUCOUT (G.) coll., MAURIN (M.) coll., MOROLDO (F.) coll., PARENT (F.) coll., PASQUINI (R.) coll., SCHERRER (N.) coll. - Place de la Providence (Marseille -13). Marseille/ Aix-en-Provence : Atelier du Patrimoine/Afan/SRA-PACA, 1999, 106 p. (Rapport de diagnostic archéologique préventive)

Bouiron et al. 2001a : BOUIRON (M.), TRÉZINY (H.), BIZOT (B.), GUILCHER (A.), GUYON (J.), PAGNI (M.) - Marseille. Trames et paysages urbains de Gyptis au roi René : Actes du colloque international d'archéologie, Marseille, 3-5-novembre 1999. Aix-en-Provence: Édisud/Centre Camille Jullian, 2001. (Études Massaliètes, 7).

Bouiron et al. 2001b : BOUIRON (M.), MAURIN (M.), SCHERRER (N.), SILLANO (B.) - De la destruction du faubourg médiéval à la place actuelle. In : Bouiron 2001 : Bouiron (M.) dir., Marseille, du Lacydon au faubourg Sainte-Catherine ( $V^{e}$ s. av. J.-C.-XVIII ${ }^{e}$ s.). : Les fouilles de la place Généralde-Gaulle. Paris : Éditions de la MSH, 2001, p. 118-131. (DAF, 87).

Bouiron et al. 2001c : BOUIRON (M.), RIGAUD (Ph.), BLOESCH (P.) - La rive sud du port de Marseille. A propos d'une vue inédite de Marseille en 1662. In : Bouiron (M.), Tréziny (H.), Bizot (B.), Guilcher (A.), Guyon (J.), Pagni (M.), Marseille.Trames et paysages urbains de Gyptis au roi René : Actes du colloque international d'archéologie, Marseille, 3-5-novembre 1999. Aix-en-Provence: Édisud/Centre Camille Jullian, 2001, p. 375-393 (Études Massaliètes, 7).

Bouiron, de Candido 2009 : BOUIRON (M.), DE CANDIDO (M.) - Le premier plan de Marseille (c.1555 ?). Pietro Angelo Pelloia, un ingénieur au service de la France. In : Pécout (Th.) coord., Marseille au Moyen Âge, entre Provence et Méditerranée : les horizons d'une ville portuaire. Éditions Désiris, Méolans-Revel, 2009, p. 115-121.

Bouiron, De Luca 1994 : BOUIRON (M.), DE LUCA (B.) - Les fouilles de l'avenue Vaudoyer. Étude d'impact du souterrain de la Major. Marseille/ Aix-en-Provence: Atelier du Patrimoine/SRA-PACA/Afan, 1994. 32 p. (Rapport de fouilles dactylographié).

Bouiron, Gantès 2001 : BOUIRON (M.), GANTÈS (L.-F.) - La topographie initiale de Marseille. In : Bouiron (M.), Tréziny (H.), Bizot (B.), Guilcher (A.), Guyon (J.), Pagni (M.), Marseille.Trames et paysages urbains de Gyptis au roi René: Actes du colloque international d'archéologie,
Marseille, 3-5-novembre 1999. Aix-en-Provence: Édisud/Centre Camille Jullian, 2001, p. 23-34 (Études Massaliètes, 7).

Bouiron, Rigaud 2009 : BOUIRON (M.), RIGAUD (Ph.) - [Transcriptions et traduction de documents]. In : Pécout (Th.) coord., Marseille au Moyen $\hat{A} g e$, entre Provence et Méditerranée : les horizons d'une ville portuaire. Méolans-Revel : Éditions Désiris, 2009, p. 98-110.

Bourrilly 1925 : BOURRILLY (V.-L.) - Essai sur l'histoire politique de la commune de Marseille. Des origines à la victoire de Charles d'Anjou (1264). Aix-en-Provence, 1925, 2 vol, VIII-526 p.

Bouyala d'Arnaud 1959 : BOUYALA-D'ARNAUD (A.) - Évocation du vieux Marseille. Paris, 1959, $445 \mathrm{p}$.

Boyer 1987 : BOYER (J.) - Un peintre "vénitien" en Provence au XVI" s. : Antoine Ronsen alias "le Maître de la Prédication de la Madeleine", Gazette des Beaux-arts, (septembre), 1987, p. 55-60

Braunstein 1999: BRAUNSTEIN (P.) - Approches de l'intimité, $\mathrm{XIV}^{\mathrm{e}}-\mathrm{XV}^{\mathrm{e}} \mathrm{s} . \mathrm{In}$ : Duby (G.) dir., Histoire de la vie privée : de l'Europe féodale à la Renaissance. Paris : éditions du Seuil, 1999, p. 503-623.

Bresc 1985 : BRESC (H.) - Pêche et coraillage aux derniers siècles du Moyen Âge : Sicile et Provence orientale. In : L'Exploitation de la mer de l'Antiquité à nos jours. La mer, lieu de production (Actes des Ve rencontres internationales d'archéologie et d'histoire, Antibes, octobre 1984), Valbonne, 1985 , p. $107-115$.

Bresc 2000 : BRESC (H.) - Pêche et commerce du corail en Méditerranée de l'Antiquité au Moyen-Âge. In: Morel (J.-P.), Rondi-Costanzo (C.), Ugolini (D.) dir., Corallo di ieri, corallo di oggi (Atti del Convegno di Ravello, 1996), Bari 2000, p. 41-53 (Scienze e materiali del patrimonio culturale, 5).

Busquet 1945 : BUSQUET (R.) - Histoire de Marseille. Paris : Laffont, 1945 (réed. 1998), 477 p.

Busquet 1955 : BUSQUET (R.) - Bibliographie, Provence Historique, V, fasc. 20, 1955, p. 161-174.

Cabestan 1997: CABESTAN (J.-F.) - La naissance de l'immeuble d'appartements à Paris sous le règne de Louis XV. In : Rabreau (D.) dir., Paris, capitale des arts sous Louis XV. Paris-Bordeaux : Université de Paris I/ William Blake and Co, 1997.

Calderoni 2000 : CALDERONI (P.) - Rouen (76), 95/105 rue Martainville. Rouen : Afan, 2000 (Rapport de fouille archéologique préventive).

Carbonnier 2006: CARBONNIER (Y.) - Maisons parisiennes des Lumières. Paris : PUPS, 2006, 511 p.

Carozzi 1973 : CAROZZI (C.) - L'Estamen de sainte Douceline, Provence Historique, 23, 1973, p. 270-279.

Carrière et al. 1968: CARRIÈRE (C.), COURDURIÉ (M.), REBUFFAT (F.) - Marseille ville morte, la peste de 1720, Marseille : M. Garçon, 1968, $270 \mathrm{p}$

Carvais 1996 : CARVAIS (R.) - Le statut juridique de l'entrepreneur du bâtiment dans la France moderne, Revue historique du Droit, 74 (2), avril-juin 1996, p. 221-252.

Casal 1991 : CASAL (H.) - Marseille au XIII ${ }^{e}$ siècle, d'après les statuts municipaux, Marseille, 160, 1991, p. 70-73.

Castrucci 2001: CASTRUCCI (C.) - Étude bibliographique et archivistique de la période Moderne. In : Bouiron (M.) dir., L'Alcazar, 26 siècles d'occupation suburbaine à Marseille. Marseille/Aix-en-Provence : Atelier du Patrimoine/Afan/SRA-PACA, 2001, p. 168-179 (Rapport de fouille archéologique préventive).

Castrucci 2001 : CASTRUCCI (C.) - La maison du Roi. In: Bouiron (M.), Tréziny (H.), Bizot (B.), Guilcher (A.), Guyon (J.), Pagni (M.), Marseille. Trames et paysages urbains à Marseille de Gyptis au Roi René, Actes du colloque international d'archéologie (Marseille, 3-5 novembre 1999), Marseille, 3-5 nov. 1999. Aix-en-Provence : Édisud, 2001, p. 293-295 (Études massaliètes, 7).

Castrucci 2005: CASTRUCCI (C.) - Étude bibliographique et archivistique. In: Mellinand (Ph.) dir., Espace Bargemon à Marseille (Bouches-du-Rhône). Nîmes : Inrap, 2005, vol. 3, p. 555-563 (Rapport de fouille archéologique préventive).

Castrucci et al. 2007 : CASTRUCCI (C.), COLLINET(J.), DE LUCA(B.), MAURIN (M.) - Une raffinerie de soufre et de salpêtre aux portes de Marseille, Industrie en Provence, 15, 2007. 
Catzigras et al. 1979 : CATZIGRAS (F.), ANGLADA(R.), ARNAUD (M.), BABINOT (J.-F.), BRUNEL (P.), JACQUET (O.) - Les calcaires de Pied d'Autry-Allauch (Bouches-du-Rhône), Géologie méditerranéenne, VI, 3, 1979, p. 409-416.

Chabrol 1994 : CHABROL (J.-P.) - Les seigneurs de la soie : trois siècles d'une famille cévenole (XVI ${ }^{-}-X I X^{e}{ }^{e}$ s.). Montepellier : Presses du Languedoc, $1994,317 \mathrm{p}$

Chancel 1978: CHANCEL (J.-M.) - Urbanisme et morphologie architecturale : la génèse d'un processus moderne. Le quartier Belsunce: une étude de cas à Marseille. Marseille-Luminy, 1978 (Thèse INAMA, non publiée).

Chancel 1980 : CHANCEL (J.-M.) - La vie matérielle à Marseille. In : Marseille au XVII ${ }^{e}$ s.: Xe rencontres de Marseille, Marseille, 122, 1980, p. 105-115.

Chanterac 1837 : CHANTERAC (E. de) - Notice historique et statistique des établissements de bains à Marseille, Répertoire des Travaux de la Société de Statistiques de Marseille, Marseille, 1837, p. 460-473.

Chapelot, Fossier 1980 : CHAPELOT (J.), FOSSIER (R.) - Le Village et la Maison au Moyen Âge. Paris : Hachette, 1980, 358 p.

Chapon 2000 : CHAPON (Ph.) - Tunnel de la Major : notes et archives. Marseille, 2000 (Rapport de sauvetage archéologique).

Chardon 1806 : CHARDON - Tableau historique et politique de Marseille ancienne et moderne, Marseille, Chardon, 1806, $280 \mathrm{p}$.

Cherest 1879 : CHEREST (A.) - L'Archiprêtre, épisodes de la guerre de cent ans au XIVes. Paris : éd. Claudin, 1879, 414 p.

Chevallier 1930 : CHEVALLIER (U.) - Artaud, Jean, In : Dictionnaire d'histoire et de géographie ecclésiastiques, 4 (1930), col. 777-779.

Chiffoleau 1986: CHIFFOLEAU (J.) - Les mendiants, le prince et l'hérésie à Marseille vers 1260, Provence historique, XXXVI, 1986, p. 3-19.

Clair 2009 : CLAIR (S.) - La commune au XIIII s. In : Pécout (T.) coord.,

Marseille au Moyen Âge, entre Provence et Méditerranée. Les horizons d'une ville portuaire. Méolans-Revel : Éditions Désiris, 2009, p. 181-185.

Closson 1987: CLOSSON (M.) - Propre comme au Moyen Âge, Historama, 40, juin 1987, p. 7

Cocci 1997 : COCCI (A.) - Notizie su Benoît d'Alignan († 1268) ed il suo Tractatus fidei contra diversos errores (1261). In : Cacciotti (A.), Faes de Mottoni (B.) éd., Editori di Quaracchi 100 anni dopo. Bilancio e prospettive. Atti del colloquio internazionali, Roma 29-30 maggio 1995, Rome, 1997, p. 317-331.

Conard 1977 : CONARD (S.) - La Maison Diamantée, palais maniériste, Marseille, 1977, 110-111, p. 5-8.

Contamine 1985 : CONTAMINE (Ph.) - Les aménagements de l'espace privé $\mathrm{XIV}^{\mathrm{e}}-\mathrm{XV}^{\mathrm{e}} \mathrm{s}$. In : Duby (G.) dir., Histoire de la vie privée : de l'Europe féodale à la Renaissance. Paris : éditions du Seuil, 1999, p. 421-501.

Coron 2002 : CORON (J.) - Le monde de l'accueil et de la sociabilité sous l'œil de la police : ses lieux, ses acteurs, à Aix au XVIII' s. Aix-en-Provence, 2002 (Mémoire de maîtrise sous la direction de Wolfgang Kaiser).

Coste 1970: COSTE (J.-P.) - La ville d'Aix-en-Provence en 1695 : structure urbaine et société. Aix-en-Provence, 1970, 2 vol. (Thèse de $3^{\mathrm{e}}$ cycle, dact.)

Coulet 1976 : COULET (N.) - Un gîte d'étape : Les auberges à Aixen-Provence au quinzième siècle. Actes du colloque Voyage, quête, pèlerinage dans la littérature et la civilisation médiévale. Aix-en-Provence : Université de Provence, 1976. (Collection Sénéfiance n² 2 : Cahiers du CUER MA).

Coulet 1988: COULET (N.) - Aix-en-Provence: Espace et relations d'une capitale (milieu XIV ${ }^{e}$ s.-milieu XV $V^{e}$ s.), Aix-en-Provence : Presses de l'Université de Provence, 1988, $1238 \mathrm{p}$

Coulet 1991 : COULET (N.) - Hans von Waltheym, pèlerin et voyageur, Provence Historique, XLI, fasc. 166, 1991, p. 41-166.

Coulet 1993 : COULET (N.) - Voyageurs et aubergistes du Moyen Âge, L'Histoire, 163, 1993, p. 14-19.

Crémieux 1917 : CRÉMIEUX (A.) - Le VIe livre des Statuts de Marseille publié d'après un Manuscrit des Archives Communales de Marseille avec une introduction et un Commentaire. Aix-en-Provence, 1917. LVI-219 p. (Publication de la société d'études provençales, IV).
Cuzon 2007: CUZON (J.) - Les aménagements portuaires et les Augustins à l'époque moderne, d'après les textes. In: Sillano dir. 2007 : Sillano (B.) dir., Parent (Fl.), Weydert (N.), D'un quai à l'autre, Bassin de stockage Sadi-Carnot, Surverse Vieux-Port, rue de la République à Marseille (Bouches-du-Rhône). Nîmes : Inrap, 2007, p. 150 (Rapport de fouille archéologique préventive).

Daumalin et $\boldsymbol{a l} .2003$ : DAUMALIN (X), GIRARD (N) et RAVEUX (O) - Du savon à la puce, l'industrie marseillaise du XVII siècle à nos jours, Marseille : Jeanne Laffitte, 2003, 379 p.

De Chazelles, Leal 2003 : DE CHAZELLES (C.-A.), LEAL (É.) - Les murs en terre crue d'un faubourg médiéval de Narbonne (XIII ${ }^{\mathrm{e}}-\mathrm{XIV}^{\mathrm{e}} \mathrm{s}$ s.). In : De Chazelles (C.-A.), Klein (A.) dir., Échanges transdisciplinaire sur les constructions en terre crue, Montpellier, 2003, p. 247-262.

Deborde $\boldsymbol{e}$ t al. 2002 : DEBORDE (G.), MONTEMBAULT (V.), YVINEC (J.-H.) - Les ateliers de tanneurs de la rue du Moulinet à Troyes (Aude). In : Audouin-Rouzeau (F.), Beyries (S.) dir., Le travail du cuir de la préhistoire à nos jours. Antibes, 2002, p. 283-314.

Dell'Umbria 2006: DELL'UMBRIA (A) - Histoire universelle de Marseille : De l'an mil à l'an deux mille. Marseille : Éditions Agone, 2006, $756 \mathrm{p}$.

Démians d'Archimbaud et al. 1972 : DÉMIANS D'ARCHIMBAUD (G.), ALLAIS (J.-M.), FIXOT (M.) - Découvertes récentes à Saint-Victor de Marseille, Archéologia, 44, 1972, p. 14-21.

Démians d'Archimbaud et al. 1974 : DÉMIANS D'ARCHIMBAUD (G.), ALLAIS (J.-M.), FIXOT (M.) - Fouilles récentes et nouvelles interprétations architecturales, Académie des Inscriptions et Belles-Lettres, compte-rendu, 1974, p. 313-345.

Deperet 1889 : DEPERET (C.) - Note Stratigraphique sur le bassin tertiaire de Marseille. Bull. Serv. Cart. géol. France, I, 5, 1889, p. 1-19.

Dolan 1981 : DOLAN (C.) - Entre tours et clochers : les gens d'Église à Aix-en-Provence au XVI ${ }^{e}$ s. Aix-en-Provence : Édisud, 1981, 433 p.

Drocourt 1981: DROCOURT (D.) dir. - Le bâti ancien à Marseille. Connaissance de l'habitat existant. Paris, 1981.

Drocourt 1996: DROCOURT (D.) - La place royale de Pierre Puget, Marseille, 177, 1996, p. 70-75.

Dupanloup 1966 : DUPANLOUP (M.) - La corporation des cuiratiers à Marseille au début du XIVe s. vue à travers les registres de Maître Raymond Rougier notaire. Aix-en-Provence, 1966, 130 p. (Mémoire de DES dactylographié, Université de Provence).

Dupanloup 1969 : DUPANLOUP (M.) - La corporation des cuiratiers à Marseille dans la première moitié du XIV ${ }^{\mathrm{e}} \mathrm{s}$., Provence historique, XIX, fasc. 77, 1969, p. 189-213.

Dupire 1985 : DUPIRE (S.) - Étude cartographique $1 / 25000^{\circ}$ de la zone sud de Marseille, les travertins de Marseille, aperçu géomorphologique et néotéctonique. Marseille, 1985. (Thèse de $3^{e}$ cycle, Université d'AixMarseille I).

Duprat 1922 : DUPRAT (E.-H.) - Notes d'archéologie marseillaise. III Documents relatifs aux remparts de Marseille au XIV e s., Provincia, II, 1922, p. $92-105$.

Duprat 1940 : DUPRAT (E.-H.) - Notes d'archéologie marseillaise. (I)V - I. Les fouilles de S. Clastrier au couvent des Grandes Maries et à la rue Rouge - II. Fragments de mosaique marseillaise et objets antiques provenant sans doute de Marseille, Mémoires de l'Institut historique de Provence, XVII, 1940, p. 15-36.

Duprat 1941 : DUPRAT (E.-H.), Un évêque inconnu du $\mathrm{X}^{\mathrm{e}} \mathrm{s}$. à Marseille, Revue d'histoire de l'Église de France, 27, 1941, p. 165-179.

Duprat, Rambert 1935 : DUPRAT (E.-H.), RAMBERT (G.) - L'évolution urbaine. Chapitre IV : Marseille aux XII ${ }^{e}$ et XIII ${ }^{e}$ s. In : Masson (P.) dir., Les Bouches-du-Rhône. Encyclopédie départementale. Tome XIV. Marseille : 1935 , p. $78-106$

Durousseau 1990 : DUROUSSEAU (T.) - Belsunce, une figure de ville : un quartier de l'agrandissement de Marseille au XVII ${ }^{e}$ s. Aix-en-Provence : Édisud, 1990, $121 \mathrm{p}$

Duval 2005: DUVAL (L.) - Le lapidaire de la cave CAV3064. In : Mellinand (Ph.) dir., Espace Bargemon à Marseille. Nîmes : Inrap, 2005, vol. 3, p. 663 (Rapport de fouille archéologique préventive). 
Duval, Mellinand 2001: DUVAL (L.), MELLINAND (Ph.) - Les terres non loties, phase 4B1. In : Bouiron (M.) dir., L'Alcazar, 26 siècles d'occupation suburbaine à Marseille. Marseille/Aix-en-Provence : Atelier du Patrimoine/Afan/SRA-PACA, 2001, vol. 1-2, p. 341-343 (Rapport de fouille archéologique préventive).

Espeut 1953 : ESPEUT (P.) - Aperçu sur les Clarisses de Marseille au Moyen-Age, Provincia, 216, 1953, p. 103-104.

Esquieu 2006 : ESQUIEU (Y.) - La baie : Ostentation et hiérarchisation dans la demeure médiévale. In: Alexandre-Bidon (D.), Piponnier (F.), Poisson (J.-M.). Cadre de vie et manières d'habiter (XII ${ }^{e}-X V I^{e}$ s.). Actes du VIII Congrès international de la Société d'archéologie médiévale (Paris, 11-13 octobre 2001). Caen : CRAHM, 2006, p. 229-238.

Fabbri 2003: FABBRI (F.) - L'hôtel de Noailles, le plus bel hôtel particulier de Marseille à l'âge baroque, Marseille, 201, 2003, p. 28-31.

Fabre 1862 : FABRE (A.) - Notice historique sur les anciennes rues de Marseille démolies en 1862 pour la création de la rue Impériale. Marseille, $1862,312 \mathrm{p}$.

Fabre 1867-1869 : FABRE (A.) - Les rues de Marseille. Marseille, 18671869, 5 vol. (rééd. Librairie Frézet, 1970).

Famin 1859-1860 : Famin (F.) - Des anciennes possessions de l'Église de Marseille, Revue de Marseille, 5, 1859, p. 537-549 et 6, 1860, p. 217-233.

Feniello, Boisseuil 2002 : FENIELLO (A.), BOISSEUIL (D.) - Un aspect du paysage napolitain au Moyen Age : les bains dans la ville du $\mathrm{X}^{\mathrm{e}}$ au XIII ${ }^{\mathrm{e}} \mathrm{s}$, Médiévales, 43, 2002, p. 71-81.

Fixot, Pelletier 2004 : FIXOT (M.), PELLETIER (J.-P.) - Saint-Victor de Marseille, de la basilique paléochrétienne à l'abbatiale médiévale. Marseille, 2004, $115 \mathrm{p}$.

Fixot, Pelletier 2009 : FIXOT (M.), PELLETIER (J.-P.) dir. - Saint-Victor de Marseille, I, Étude archéologique et monumentale ;II, Études archéologiques et historiques. Actes du colloque Saint-Victor de Marseille, Nov. 2004. Turnhout : Brepols, 2009, 688 p. (coll. Bibliothèque de l'Antiquité tardive, 12 et 13).

Galinié 2004: GALINIÉ (H.) - L'expression terres noires, un concept d'attente, Les petits cahiers d'Anatole, 15, 2004, p. 2-29.

Garden 1970 : GARDEN (M.) - Lyon et les Lyonnais au XVIII $s$. Paris : Les Belles Lettres, 1969, $773 \mathrm{p}$.

Garden 1984: GARDEN (M.) - Quelle histoire pour la ville. In: Garden (M.), Lequin (Y.) dir., Habiter la ville $X V^{e}-X X^{e}$ s. Actes de la Table ronde organisée avec l'aide de DGRST et de la Mission de Recherche Urbaine. Lyon : PUL, 1984 (Histoire et populations, 1).

Garrigou Grandchamp 1992: GARRIGOU GRANDCHAMP (P.) - Demeures médiévales. Cour de la cité. Paris: Remparts, 1992. 128 p. (Patrimoine vivant. Notre histoire)

Garrigou-Grandchamp et al. 1997 : En collaboration avec JONES (M.), MEIRION-JONES (G.), SALVEQUE (J.-D.) - La ville de Cluny et ses maisons (XI ${ }^{e}-X V^{e}$ s.), Paris, Picard, 1997, $248 \mathrm{p}$.

Gascon 1971 : GASCON (R.) - Grand commerce et vie urbaine au XVI ${ }^{e}$ s. Lyon et ses marchands (environs de 1520 - environs de 1580). Paris : EPHE, 1971, 999 p. (Civilisations et société, 22).

Gaudant 1975 : GAUDANT (J.) - Intérêt paléoécologique de la découverte de Gobius Aries (poisson téléostéen, Gobioidei) dans l'Oligocène des bassins de Marseille et de Saint-Pierre-Les-Martigues (Bouches-du-Rhône), Géologie méditerranéenne, 2, 1975, p. 111-114.

Gauthiez 2003: GAUTHIEZ (B.) - Espace urbain, vocabulaire et morphologie. Ed du Patrimoine. Tours 2003, 493 p.

GCNN Marseille: ALBANÈS (J.-H.), CHEVALIER (U.) - Marseille (évêques, prévôts, statuts). In: Gallia Christiana Novissima. Histoire des archevêchés, évêchés \& abbayes de France d'après les documents authentiques recueillis dans les registres du Vatican et les archives locales. Valence : Impr. Valentinoise, $1899,955 \mathrm{p}$.

GCNN Toulon : ALBANÈS (J.-H.), CHEVALIER (U.) - Toulon : évêques, prévots. In : Gallia Christiana Novissima. Histoire des archevêchés, évêchés et abbayes de France, d'après les documents authentiques recueillis dans les registres du Vatican et les archives locales. Valence : Impr. Valentinoise, 1911, XXVIII p.-940 col.

Gérin-Ricard, Isnard 1926 : GÉRIN-RICARD (H. de), ISNARD (É.) - Actes concernant les vicomtes de Marseille et leurs descendants. Monaco/
Paris, 1926, LXX-331 p. (Collection de textes pour servir à l'histoire de Provence).

Giordanengo 1988 : GIORDANENGO (G.), Le droit féodal dans les pays de droit écri L'exemple de la Provence et du Dauphiné, XII -début XIVes., Rome, 1988, 331 p. (Bibliothèque des écoles françaises d'Athènes et de Rome, 266).

Giraud 1962: GIRAUD (P.) - Marseille, l'Hôtel de Ville, la Loge les Maisons du Roi, Nice, [P. Giraud], 1962, 85 p.

Glessgen 1989: GLESSGEN (M.-D.) - "Lo Thesaur del hospital de Sant Sperit". Edition eines Marseiller Urkundeninventars (1399-1511), mit sprachlichem und geschichtlichem Kommentar unter besonderer Berücksichtigung des Rechtswortschatzes. Tübingen, 1989, XI-596 p. (Beihefte zur Zeitschrift für romanische Philologie, 226).

Gloton 1979 : GLOTON (J.-J.) - Renaissance et baroque à Aix, recherches sur la culture architecturale dans le Midi de la France de la fin $d u X V^{e}$ au

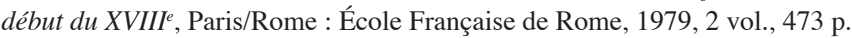

Gloton 1980 : GLOTON (J.-J.) - L'architecture à Marseille. Culture et création. In : Marseille au XVII ${ }^{\mathrm{e}} \mathrm{s} ., \mathrm{X}^{\mathrm{e}}$ Rencontres de Marseille, Marseille, 122,1980 , p. 163-174.

Gloton 1992 : GLOTON (J.-J.) - L'urbanisme marseillais de l'âge baroque, Marseille, revue culturelle de la ville, 164, 1992.

Gloton 1996: GLOTON (J.-J.) - Pierre Puget architecte à Marseille, Marseille, 177, 1996, p. 48-59.

Grabmann 1941: GRABMANN (M.) - Der Franziskanerbischof Benedictus de Alignano († 1268) und seine Summa zum Caput Firmiter des Vierten Laterankonzils. In : I.-M. Freudenreich dir., Kirchengeschichtliche Studien P. Michael Bihl O.F.M. als Ehrengabe dargeboten. Colmar, 1941, p. $50-64$

Grosson 1773: GROSSON (J.-B.-J.) - Recueil des antiquités et des monumens marseillois qui peuvent intéresser l'histoire et les arts. Marseille, 1773 , p. $296,47 \mathrm{pl}$.

Guieu 1968 : GUIEU (G.) - Étude tectonique de la région de Marseille. Aix-en-Provence, 1968, 604 p. (Thèse Scientifique, Université de Provence)

Guieu 1977: GUIEU (G.) - La tectonique du bassin de Marseille à l'Oligocène, Géologie méditerranéenne, Marseille, 1977, IV, n 1, p. 9-24.

Guyon 1998: GUYON (J.) - Les temps obscurs. In : Joutard (P.). dir., Histoire de Marseille en treize événements. 2002, p. 63-64.

Guyon 2005: GUYON (J.) - le culte chrétien : naissance et affirmation d'une église. In : Rothe (M.-P.), Tréziny (H.), Marseille et ses alentours. Paris, 2005 (Carte archéologique de la Gaule 13/3).

Harouel 1993 : HAROUEL(J-L) - L'embellissement des villes. L'urbanisme français au XVIII ${ }^{e}$ s. Paris : Picard, 1993, 335 p. (Villes et sociétés).

Hartmann-Virnich 2001: HARTMANN-VIRNICH (A.). et coll. -L'architecture religieuse médiévale à Marseille. In : Bouiron (M.), Tréziny (H.), Bizot (B.), Guilcher (A.), Guyon (J.), Pagni (M.), Marseille.Trames et paysages urbains à Marseille de Gyptis au Roi René, Actes du colloque international d'archéologie (Marseille, 3-5 novembre 1999), Marseille, 3-5 nov. 1999. Aixen-Provence : Édisud, 2001, p. 279-292 (Études massaliètes, 7).

Heers 1989 : HEERS (J.) - En Italie centrale : les paysages construits, reflets d'une politique urbaine. In : Maire-Vigueur (J.-C.) éd., D'une ville à l'autre: structures matérielles et organisation de l'espace dans les villes européennes (XIII ${ }^{-}-X V I^{e}$ s.), Actes du colloque organisé par l'École française de Rome avec le concours de l'Université de Rome (1986). Rome : École française de Rome, 1989 (Collection de l'École française de Rome, 122).

Henin 1986 : HENIN (B.) - L'agrandissement de Marseille (1666-1690) : un compromis entre les aspirations monarchiques et les habitudes locales. Annales du Midi, 98, $\mathrm{n}^{\circ}$ 173, 1986, p. 7-21.

Hesnard et al. 2001 : HESNARD (A.), BERNARDI (Ph.), MAUREL (Ch.) - La topographie du port de Marseille de la fondation de la cité à la fin du Moyen Âge. In: Bouiron (M.), Tréziny (H.), Bizot (B.), Guilcher (A.), Guyon (J.), Pagni (M.), Marseille. Trames et paysages urbains de Gyptis au Roi René, Actes du colloque international d'archéologie de Marseille (1999). Aix- en Provence : Édisud, 2001, p. 159-202 (Études Massaliètes, 7).

Honnorat 1846-1847 : HONNORAT (S.-J.) - Dictionnaire provençalfrançais ou dictionnaire de la langue d'oc ancienne et moderne, suivi d'un vocabulaire franco-provençal. Digne, 1846-1847, 3 vol. 
Jandot 1996 : JANDOT (C.) - Marseille, site de l'Hôtel de Ville, Interventions archéologiques sur les pavillons Bargemon, Puget, Maison diamantée. Marseille/Aix-en-Provence : Afan/SRA-PACA, 1996 (Rapport de sauvetage urgent).

Jaritz 2006: JARITZ (G.) - Entre espace public et espace privé : le décor de la maison urbaine (Europe centrale, $\mathrm{XIV}^{\mathrm{e}}-\mathrm{XV}^{\mathrm{e}} \mathrm{s}$.). In : AlexandreBidon (D.), Piponnier (F.), Poisson (J.-M.). Cadre de vie et manières d'habiter (XII ${ }^{e}-X V I^{e}$ s.). Actes du VIII ${ }^{e}$ Congrès international de la Société d'archéologie médiévale (Paris, 11-13 octobre 2001). Caen : CRAHM, 2006, p. 249-254.

Jaubert 1888 : JAUBERT (Dom H.) - Saint-Hommebon : notes sur les Missionnaires de Provence ou Pères du Saint-Sacrement. Marseille, 1888, 24 p.

Joly à paraître : JOLY (D) - Formes et fonctions des caves des maisons médiévales dans le sud de la France. In : La maison au Moyen-Âge dans le midi de la France. Actes du colloque, Cahors, 6-8 juillet 2006, Société archéologique du Midi de la France, à paraître.

Jousse 1642: JOUSSE (M.) - Le secret de l'architecture découvrant fidèlement les traits géométriques, couppes et dérobemens nécessaires dans les bâtiments. La Flèche : Georges Griveau, 1642, 235 p.

Joutard 1988 : JOUTARD (Ph.) dir. - Histoire de Marseille en treize événements. Marseille : éditions Jeanne Laffitte, 1988.

Jouve 1962 : JOUVE (L.) - Le temporel de l'Église de Marseille avant 1257. Aix-en-Provence, 1962 (D.E.S., université de Provence dactylographié).

Jouvet 2006 : JOUVET (L.) - L'évêque et la commune : Marseille, 12301257. Aix-en-Provence, 2006 (mémoire de Master 1, université de Provence dactylographié).

Kaiser 1992 : KAISER (W)-Marseille au temps des troubles. Morphologie sociale et luttes de faction 1559-1596, Paris : Éditions de l'EHESS, 1992, $411 \mathrm{p}$.

Laroche 1999: LAROCHE (M.-L.) - Le corail et les corailleurs en Provence, Annales de la Société scientifique et littéraire de Cannes et de l'arrondissement de Grasse, 44, 1999, p. 163-176.

Leal 2001: LEAL (É.) - Un ensemble artisanal, phase 4B1. In: Bouiron (M.) dir., L'Alcazar, 26 siècles d'occupation suburbaine à Marseille. Marseille/Aix-en-Provence : Atelier du Patrimoine/Afan/SRA-PACA, 2001, vol. 1-2, p. 330-339 (Rapport de fouille archéologique préventive).

Leal 2001b : LEAL (É) - Disparition de la vocation artisanale du secteur, phase 4B2. In: Bouiron (M.) dir., L'Alcazar, 26 siècles d'occupation suburbaine à Marseille. Marseille/Aix-en-Provence : Atelier du Patrimoine/ Afan/SRA-PACA, 2001, vol. 1-2, p. 343-344 (Rapport de fouille archéologique préventive).

Leal, Paone 2001a : LEAL (É.), PAONE (F.) - La maîtrise de l'eau. In : Bouiron (M.) dir., L'Alcazar, 26 siècles d'occupation suburbaine à Marseille. Marseille/Aix-en-Provence : Atelier du Patrimoine/Afan/SRA-PACA, 2001, vol. 7, p. 97-100 (Rapport de fouille archéologique préventive).

Leal, Paone 2001b : LEAL (É.), PAONE (F.) - Un quartier à vocation artisanale de la fin du XII ${ }^{\mathrm{e}}$ s. au XIII' ${ }^{\mathrm{e}}$ s. In : Bouiron (M.) dir., L'Alcazar, 26 siècles d'occupation suburbaine à Marseille. Marseille/Aix-en-Provence : Atelier du Patrimoine/Afan/SRA-PACA, 2001, vol. 7, p. 89-96 (Rapport de fouille archéologique préventive).

Leguay 1984 : LEGUAY (J.-P.) - La rue au Moyen Âge. Rennes : Ouest France, 1984, $253 \mathrm{p}$

Leguay 1999: LEGUAY (J.-P.) - La pollution au Moyen Âge. Paris : Edition Jean-Paul Gisserot, 1999, $127 \mathrm{p}$

Léonard 1932-1936 : LÉONARD (É.-G.) - Histoire de Jeanne Ire, reine de Naples, comtesse de Provence. Monaco/Paris, 1932-1936, 3 vol. (Mémoires et documents historiques publiés par ordre de S.A.S. le prince Louis II de Monaco)

Leroy 1847 : LEROY (V.) - Notice sur les constructions des maisons à Marseille (au XIXe s.). Marseille : 1847, 124 p. (réed. 1989).

Levy 1980 : LEVY (E.) - Petit dictionnaire provençal-français. Raphèleles-Arles : Culture provençale et méridionale, 1980, 387 p.

Loupiac 2005 : LOUPIAC $(\mathrm{C})$ - La ville entre représentations et réalités, CNDP, Paris, 2005, 395 p.

Mabilly 1905 : MABILLY (Ph.) - Les villes de Marseille au Moyen Âge. Ville supérieure et ville de la Prévôté 1257-1348. Marseille, 1905, 289 p.
Manselli 1989: MANSELLI (R.) - Spirituels et béguins du Midi. Toulouse : Editions Privat, 1989, 333 p.

Marchesi et al. 1992 : MARCHESI (H.), THIRIOT (J.), VALLAURI (L.) - Marseille Sainte-Barbe, vestiges médiévaux et modernes. Aix-en-Provence : LAMM, avril 1992 (Rapport de fouille de sauvetage).

Marchesi et al. 1997: MARCHESI (H.) dir., THIRIOT (J.) dir., VALLAURI (L.) dir., LEENHARDT (M.) coll. - Marseille, les ateliers de potiers du XIII ${ }^{e}$ et le quartier Sainte-Barbe (V ${ }^{e}-X V I I^{e}$ s.). Paris : Éditions de la Maison des Sciences de l'Homme, 1997, 389 p. (DAF, 65).

Marseille au XVII ${ }^{e} s$. (sous la direction d'A. Ramière de Fortanier), Marseille : Archives communales, 1980 (catalogue d'exposition).

Marseille en Révolution (sous la direction de C. Badet), Marseille, éd. Rivages/Musées de Marseille, 1989 (catalogue d'exposition).

Massot 1992 : MASSOT (J.-L.) - Art de restaurer en Provence. Volume 2. Architecture et décoration du XVI ${ }^{e}$ au XIX ${ }^{e}$ siècle. Aix-en-Provence : Edisud, 1992, 339 p.

Maurel 2009: MAUREL (Ch.) - Le sac de la ville en 1423 et sa renaissance. In : Pécout (Th.) coord., Marseille au Moyen Âge, entre Provence et Méditerranée. Les horizons d'une ville portuaire. Méolans-Revel : Éditions Désiris, 2009, p. 415-418.

Maurin et al. 2001a: MAURIN (M.), MOERMAN (M.), MOROLDO (F.), SCHERRER (N.), SILLANO (B.), VILLEMEUR (I.) - L'urbanisation progressive. In: Bouiron (M.) dir., Marseille, du Lacydon au faubourg Sainte-Catherine ( $V^{e}$ s. av. J.-C.-XVIII ${ }^{e}$ s.). : Les fouilles de la place Généralde-Gaulle. Paris : Éditions de la MSH, 2001, p. 43-82 (DAF, 87).

Maurin et al. 2001b: MAURIN (M.), MOERMAN (M.), MOROLDO (F.), SCHERRER (N.), SILLANO (B.), BÉRARD (G.) coll., BOUIRON (M.) coll. - Le faubourg Sainte - Catherine dans la première moitié du XIV ${ }^{\mathrm{e}} \mathrm{s}$. In : Bouiron (M.) dir., Marseille, du Lacydon au faubourg Sainte-Catherine ( $V^{e}$ s. av. J.-C.-XVIII ${ }^{e}$ s.). : Les fouilles de la place Général-de-Gaulle. Paris : Éditions de la MSH, 2001, p. 83-116 (DAF, 87).

Maurin, Reynaud 2001: MAURIN (M.), REYNAUD (P.) - Une extension possible de la zone artisanale à l'est du puits citerne PT8177 et de l'aqueduc AQ8220. In: Bouiron (M.) dir., L'Alcazar, 26 siècles d'occupation suburbaine à Marseille. Marseille/Aix-en-Provence : Atelier du Patrimoine/Afan/SRA-PACA, 2001, vol. 1-2, p. 339-340 (Rapport de fouille archéologique préventive).

Maurin, Scherrer 2001: MAURIN (M.), SCHERRER (N.) - La destruction du faubourg et la création de jardins (milieu $\mathrm{XIV}^{\mathrm{e}} \mathrm{s}$.). In : Bouiron (M.) dir., L'Alcazar, 26 siècles d'occupation suburbaine à Marseille. Marseille/Aix-en-Provence : Atelier du Patrimoine/Afan/SRA-PACA, 2001, vol. 1-2, p. 381-385 (Rapport de fouille archéologique préventive).

Maurin, Sillano 2001 : MAURIN (M.), SILLANO (B.) - Transformation de la frange littorale de l'âge du Bronze au haut Moyen Âge. In : Bouiron (M.) dir., Marseille, du Lacydon au faubourg Sainte-Catherine (Ve s. av. J.-C.$X V I I I^{e}$ s.). : Les fouilles de la place Général-de-Gaulle. Paris : Éditions de la MSH, 2001, p. 17-42 (DAF, 87).

Maurin, Voyez 2001: MAURIN (M.), VOYEZ (Ch..) - L'époque romaine. In : Bouiron (M.) dir., L'Alcazar, 26 siècles d'occupation suburbaine à Marseille. Marseille/Aix-en-Provence : Atelier du Patrimoine/Afan/ SRA-PACA, 2001, vol. 1-2, p. 113-232 (Rapport de fouille archéologique préventive).

Mazel 2002: MAZEL (F.) - La noblesse et l'Église en Provence, fin $X^{e}$-début XIV s. L'exemple des familles d'Agoult-Simiane, de Baux et de Marseille. Paris, 2002, 803 p.

Mazel 2009 : MAZEL (F.) - Les vicomtes de Marseille. In : Pécout (T.) coord., Marseille au Moyen Age, entre Provence et Méditerranée. Les horizons d'une ville portuaire. Méolans-Revel : Éditions Désiris, 2009, p. 145-148.

Mellinand 2005 : MELLINAND (Ph.) - Espace Bargemon à Marseille (Bouches-du-Rhône). Marseille/Aix-en-Provence : Inrap/SRA-PACA, 2005 (Rapport de fouille archéologique préventive).

Métamorphoses d'une ville, Marseille 1789-1989 (sous la direction de M. Morel). Marseille : Musée d'Histoire de Marseille, 1989 (catalogue d'exposition).

Mellinand 2007 : MELLINAND(Ph.) dir,CHAPPUIS(C.), FROMMHERZ (G.), GUERIEL (F.), MOROLDO (F.), VASSELIN (B.) - Zac de la Source 
du Pré à la Ciotat (Bouches-du-Rhône). Nîmes : Inrap, 2007 (Rapport de fouille archéologique préventive).

Melquiond 1882: MELQUIOND (G.) - Étude sur l'aqueduc de l'Huveaune et les autres anciennes eaux de la ville de Marseille. Marseille, 1882,98 p.

Meynier 1866: MEYNIER (F.) - Les anciens chemins de Marseille. Description historique et topographique du territoire. Marseille: imp. V. Olive, $152 \mathrm{p}$.

Michel 2001 : MICHEL (D.) - Catalogue du verre du site de l'Alcazar. In : Bouiron (M.) dir., L'Alcazar, 26 siècles d'occupation suburbaine à Marseille. Marseille/Aix-en-Provence : Atelier du Patrimoine/Afan/SRA-PACA, 2001, vol. 3, p. 45-92 (Rapport de fouille archéologique préventive).

Michel 2004 : MICHEL (D.) - Bilan périodisé de l'étude du verre. In : Barra (C.), Guillaume (M.), Maufras (O.), Vasselin (B.), Voyez (Ch.) dir., Les fouilles archéologiques du Tunnel de la Major (Marseille, Bouches-duRhône) : contribution à la connaissance de la topographie urbaine du VI ${ }^{e}$. $a v . n$. ̀̀. au XIX ${ }^{e}$ s. Marseille/Aix-en-Provence : Inrap/SRA-PACA, 2004, vol. 2, p. 187-199 (Rapport de fouille archéologique préventive).

Mistral 1878 : MISTRAL (F.) - Lou tresor dóu Felibrige ou dictionnaire provençal-français. 1878 (réed. Marcel Petit éditions, Raphèle-lès-Arles, 1979).

Moermanetal. 1989 : MOERMAN(M.), MOLINER(M.), GANTES(L.-F.) - Marseille, aqueduc de l'Huveaune. Marseille/Aix-en-Provence : Atelier du Patrimoine/Afan/SRA-PACA, 1989 (rapport de fouilles de sauvetage urgent).

Moliner 1986 : MOLINER (M.), BOIRON (R.) - Marseille, Grands Carmes, îlot N. Marseille/Aix-en-Provence : Atelier du Patrimoine/SRAPACA, 1986 (Rapport de diagnostic archéologique).

Moliner 2001 : MOLINER (M.) - Orientations urbaines dans Marseille antique. In : Bouiron (M.), Tréziny (H.), Bizot (B.), Guilcher (A.), Guyon (J.), Pagni (M.), Marseille. Trames et paysages urbains à Marseille de Gyptis au Roi René, Actes du colloque international d'archéologie (Marseille, 3-5 novembre 1999), Marseille, 3-5 nov. 1999. Aix-en-Provence : Édisud, 2001, p. 101-120 (Études massaliètes, 7).

Moliner à paraître : MOLINER (M.) - Un autre regard, l'aqueduc romain de Sainte-Barbe à Marseille. à paraître.

Moliner et al. 1993 : MOLINER (M.), MARTIN (L.), MOERMAN (M.) - Marseille, Puget III. Marseille/Aix-en-Provence : Atelier du Patrimoine/ Afan/SRA-PACA, 1993 (Rapport de fouille archéologique).

Mollat 1964 : MOLLAT (G.) trad. - Bernard Gui, Manuel de l'Inquisiteur. Paris : Les Belles Lettres, 1964, 2 vol.

Morel-Deladalle 1993 : MOREL-DELEDALLE (M.) - Le Moyen Âge et le patrimoine de Marseille. In : Le temps des découvertes, Marseille de Protis à la reine Jeanne. Musées de Marseille, 1993.

Morhange 2001 : MORHANGE (C.) - Les variations relatives du niveau de la mer à Marseille depuis 5000 ans. In : Bouiron (M.), Tréziny (H.), Bizot (B.), Guilcher (A.), Guyon (J.), Pagni (M.), Marseille.Trames et paysages urbains de Gyptis au roi René: Actes du colloque international d'archéologie, Marseille, 3-5-novembre 1999. Aix-en-Provence: Édisud/ Centre Camille Jullian, 2001, p. 35-42 (Études Massaliètes : 7)

Mortreuil 1872 : MORTREUIL (J.-A.-B.) - Dictionnaire topographique de l'arrondissement de Marseille, Bouches-du-Rhône, comprenant les noms anciens et modernes. Marseille, 1872, $470 \mathrm{p}$.

Napoléone 2002 : NAPOLÉONE (A.-L.) - L'équipement domestique dans l'architecture civile médiévale. In : La maison au Moyen-Age dans le midi de la France. Actes des journées d'études de Toulouse, 19-20 mai 2001. Toulouse : MSAMF, 2003, p. 239-263.

Nury 1977 : NURY (D.) - Le bassin oligocène de Marseille ; stratigraphie, évolution paléogéographique, Géologie méditerranéenne, Marseille, 1977, IV, 1.

Nury 1979 : NURY (D.) - Attribution au stampien supérieur du calcaire de l'Estaque et au stampien inférieur des argiles et conglomérats de Saint-Marcel (Bassin de Marseille et de l'Huveaune, Bouches-Du-Rhône) : premières implications structurales, Bull. Soc. Géol. France, (7), 21, 1979, p. 121-124.

Nury, Raynaud 1986: NURY (D.), Raynaud (S.) - Etude tectonosédimentaire du fosse oligocène de Marseille (Bouches-du-Rhône). Evolution postérieure, Géologie de France, 4, 1986, p. 377-397.
Palanque 1967 : PALANQUE (J.-R.) dir. - Le diocèse de Marseille, Paris, 1967, 332 p. (Histoire des diocèses de France).

Panerai et al. 1999 : PANERAI (P.), DEPAULE (J.-C.), DEMORGON (M.) - Analyse urbaine. Marseille, 1999, 189 p. (Eupalinos, Architecture et Urbanisme)

Paone 1997a: PAONE (F.) - Les données de terrains: les rues. In : Thernot (R.) dir., César médiéval et moderne. Marseille/Aix-en-Provence : Afan/SRA-PACA, 1997, p. 4-7 (Rapport de fouille archéologique).

Paone 1997b : PAONE (F.) - Le secteur 1. In: Thernot (R.) dir., César médiéval et moderne. Marseille/Aix-en-Provence : Afan/SRA-PACA, 1997 (Rapport de fouille archéologique).

Paone 1997c: PAONE (F.) - Zone 7 et MCR zone 2, secteur 11. In: Thernot (R.) dir., César médiéval et moderne. Marseille/Aix-en-Provence : Afan/SRA-PACA, 1997, p. 6 (Rapport de fouille archéologique).

Paone 2001 : PAONE (F.) - Une approche topographique. In : Bouiron (M.) dir., L'Alcazar, 26 siècles d'occupation suburbaine à Marseille. Marseille/ Aix-en-Provence : Atelier du Patrimoine/Afan/SRA-PACA, 2001, p. 81-88 (Rapport de fouille archéologique).

Paone 2004: PAONE (F.) - De la relance artisanale du faubourg de Morier à celui de Roubaud. XII ${ }^{\mathrm{e}}$ au $\mathrm{XIV}^{\mathrm{e}} \mathrm{s}$. In : L'Alcazar à ciel ouvert. Revue Marseille, 204, 2004, p. 25-32.

Paone 2005: PAONE (F.) - Synthèse de la période médiévale. In : Mellinand (Ph.) dir., Weydert (N.), Monteil (K.), Thernot (R.), Chappuis (C.), Parent (F.), Paone (F.), Sillano (B.), L'Espace Bargemon, Marseille. Nimes/Aix-en-Provence : Inrap/SRA-PACA, 2005 (Rapport de fouille archéologique).

Paone 2008 : PAONE (F.) dir. - 14 rue Trinquet à Marseille (Bouchesdu-Rhône). Nîmes/Aix-en-Provence : Inrap/SRA-PACA, 2008 (Rapport de fouille archéologique).

Paone 2009: PAONE (F.) - De la carreria del Morier à la carreria de Crota vielha: présentation de quelques rues de Marseille au Moyen Âge à la lumière des fouilles archéologiques. In: Pécout (Th.) coord., Marseille au Moyen Âge, entre Provence et Méditerranée. Les horizons d'une ville portuaire. Méolans-Revel : Éditions Désiris, 2009, p. 88-92.

Paone, Bouiron 1999 : PAONE (F.), BOUIRON (M.) - La cathédrale. In : Morel (M.) dir., Parcours de villes. Marseille : 10 ans d'archéologie, 2600 ans d'histoire. Marseille/Aix-en-Provence: Musées de Marseille/Édisud, 1999, p. 103-105.

Paone, Bouiron 2001 : PAONE (F.), BOUIRON (M.) - Le groupe épiscopal de Marseille. In: Bouiron (M.), Tréziny (H.), Bizot (B.), Guilcher (A.), Guyon (J.), Pagni (M.), Marseille.Trames et paysages urbains de Gyptis au roi René: Actes du colloque international d'archéologie, Marseille, 3-5-novembre 1999. Aix-en-Provence : Édisud/Centre Camille Jullian, 2001, p. 225-234 (Études Massaliètes, 7).

Paone et al. 1999: PAONE (F.), PARENT (F.), THERNOT (R.) - La création d'un quartier à Marseille à la fin du XII ${ }^{\mathrm{e}}$ s. In : Morel (M.) dir., Parcours de ville. Marseille : 10 ans d'archéologie, 2600 ans d'histoire. Marseille/Aix-en-Provence: Musées de Marseille/Édisud, 1999, p. 75-76.

Paone et al. 2007 : PAONE (F.), SCHERRER (N.), VASSELIN (B.) - Fort Saint Jean MUCEM à Marseille (Bouches-du-Rhône). Inrap, 2007 (Rapport d'opération archéologique)

Paone et al. 2009 : PAONE (F.), SCHERRER (N.), SILLANO (B.)-Aperçu de Marseille médiévale d'après trois fouilles archéologiques récentes. In : Marseille médiévale. Revue Marseille, 225, 2009.

Paone et al. à paraître : PAONE (F.), MELLINAND (Ph.), PARENT (F.) dir. - La fouille de l'Esplanade Major (Marseille). Nîmes/Aix-en-Provence : Inrap/SRA-PACA, 2011 (Rapport de fouille archéologique).

Paone, Sillano 1997 : PAONE (F.), SILLANO (B.) - Les données de terrains : îlot sud. In : Thernot (R.) dir., César médiéval et moderne, rapport de fouille. Marseille/Aix-en-Provence : Afan/SRA-PACA, 1997 (Rapport de fouille archéologique).

Paone, Thernot 2005 : PAONE (F.), THERNOT (R.) - L'époque moderne et contemporaine. In : Mellinand (Ph.) dir., Espace Bargemon à Marseille (Bouches-du-Rhône). Nîmes/Aix-en-Provence, Inrap/SRA-PACA, 2005, vol. 1b, p. 324-367 (Rapport de fouille archéologique). 
Pardailhé-Galabrun 1988: PARDAILHE-GALABRUN (A.) - La naissance de l'intime : 3000 foyers parisiens $X V I I^{e}-X V I I I^{e} s$. Paris : PUF, $1988,583 \mathrm{p}$

Parent 2001: PARENT (F.), VALLAURI (L.) coll. - Le mobilier céramique de la période médiévale. In : Bouiron (M.) dir., L'Alcazar, 26 siècles d'occupation suburbaine à Marseille. Marseille/Aix-en-Provence : Atelier du Patrimoine/Afan/SRA-PACA, 2001, vol. 2-3, p. 393-450 (Rapport de fouille archéologique).

Parent 2005 : PARENT (F.) - Aperçu des céramiques en usage à Marseille au XII et au début du XIII ${ }^{e}$ s. In : Mellinand (Ph.) dir., Espace Bargemon. Nîmes/Aix-en-Provence : Inrap/SRA-PACA, 2005, vol. 4, p. 845-868 (Rapport de fouille archéologique).

Pécout 2009a : PÉCOUT (Th.) coord. - Marseille au Moyen Âge, entre Provence et Méditerranée. Les horizons d'une ville portuaire. MéolansRevel : Éditions Désiris, 2009, 429 p.

Pécout 2009b : PÉCOUT (Th.) - L'évêque et le chapitre de la Major. In : Pécout (Th.) coord., Marseille au Moyen Âge, entre Provence et Méditerranée. Les horizons d'une ville portuaire. Méolans-Revel : Éditions Désiris, 2009, p. 167-177.

Pécout à paraître : PÉCOUT (Th.) - L'évêque de Marseille Benoît d'Alignan (1229-1267), la dîme et l'institution épiscopale. In: Dîme, biens d'Église et territoire ecclésial dans l'Occident du Moyen Âge, Table ronde de l'UMR CÉPAM, Université de Nice, 6-7 juin 2008, à paraître dans Cahiers du Cépam.

Pécout, Roux 2009 : PÉCOUT (Th.)., ROUX (C.) - Le Roi René en Provence. In : Matz (J.-M.), Verry (E.), Le roi René dans tous ses États. Paris : Éditions du Patrimoine, 2009, p. 77-85.

Pernoud 1935 : PERNOUD (R.) - Essai sur l'histoire du port de Marseille des origines à la fin du XIII' ${ }^{\mathrm{e}}$ s. Paris, 1935, 334 p. (Thèse de doctorat).

Pernoud 1949 : PERNOUD (R.) - Les Statuts municipaux de Marseille. Paris-Monaco, 1949, $289 \mathrm{p}$

Pérouse de Monclos 1983 : PÉROUSE DE MONCLOS (J.-M.) - La voûte de l'Hôtel de Ville d'Arles est-elle le produit de la tradition locale ou une importation parisienne? In: Culture et création dans l'architecture provinciale de Louis XIV à Napoléon III. Travaux et colloques de l'Institut d'Art. Aix-en-Provence: Publications de l'Université de Provence, 1983, p. 123-125.

Pillorget 1972: PILLORGET (R) - Luttes de factions et intérêts économiques à Marseille, de 1598 à 1618, Annales économie sociétés et civilisations, 27, 1972, p. 705-730.

Poly 1976 : POLY (J.-P.) - La Provence et la société féodale (879-1166). Contribution à l'étude des structures dites féodales dans le Midi. Paris : Bordas, 1976, VIII-431 p.

Pringle, Saba 1981 : PRINGLE (J.-K.) et SABA (S.-S.) - Langage médical et politique locale: l'urbanisme et la santé à Marseille à la fin de 1'Ancien Régime, Annales du midi, 93, n 154, 1981, p. 397-417.

Rambert 1931 : RAMBERT (G.) - Nicolas Arnoul, intendant des galères à Marseille (1665-1674) ses lettres et mémoires relatifs à l'agrandissement de la ville et à l'entretien du port. Marseille : Les éditions de Provincia, 1931, 345 p.

Rambert 1934 : RAMBERT (G.) - Marseille, la formation d'une grande cité moderne. Étude de Géographie Urbaine. Marseille : impr. du Sémaphore, 1934, 531 p.

Rambert 1949-1966 : RAMBERT (G.) dir., Histoire du commerce de Marseille, Plon, 1951-1966, 7 vol.

Ramière de Fortanier 1978: RAMIERE DE FORTANIER (A.), Illustration du Vieux Marseille. Avignon, Aubanel, 1978, 279 p.

Renaud et al. 2007 : RENAUD (B.), FRASSON-COHET (Dominique), POTTE (Marie-Blanche) - Riom, une ville à l'œuvre. Enquête sur un centre ancien, $X I I I^{e}-X X^{e}$ siècle. Lyon : Lieux-dits éditions, 2007, $191 \mathrm{p}$.

Reynaud 1988: REYNAUD (G.) - L'hôtel de Pesciolini (1673): une nouvelle identité pour la « maison aux cariatides » du cours Belsune à Marseille, Provence historique, 38, fasc. 154, 1988, p. 377-401.

Reynaud, 1998: REYNAUD (P.) - Marseille (Bouches du Rhône), première moitié $\mathrm{XIV}^{e} \mathrm{~s}$. Maison en pierre et en pisé, rue de la Charité. In : Esquieu (Y.), Pesez (J.-M.) dir., Cent maisons médiévales en France (du XII ${ }^{e}$ au milieu du XVI $s$.). Un corpus et une esquisse. Paris : CNRS éditions, 1998, p. 431-433. (Monographie du CRA, 20).
Riani 1982 : RIANI (A.) - Pouvoirs et contestations. La prostitution à Marseille au XVIII ${ }^{e}$ s. (1650-1830). Aix-en-Provence, 1982 (thèse de doctorat en histoire, Université de Provence)

Richarté, Bouiron 1995 : RICHARTÉ (C.), BOUIRON (M.) - Zélige. In: Le vert et le brun, de Kairouan à Avignon, céramiques du $X^{e}$ au $X V^{e} s$. Catalogue d'exposition. Musées de Marseille, Réunion des Musées Nationaux. Marseille, 1995, p. 212-213.

Rigaud 2001 : RIGAUD (Ph.) - La destruction du faubourg de Roubaud (hiver 1357-1358). In : Bouiron (M.), Tréziny (H.), Bizot (B.), Guilcher (A.), Guyon (J.), Pagni (M.), Marseille. Trames et paysages urbains à Marseille de Gyptis au Roi René, Actes du colloque international d'archéologie (Marseille, 3-5 novembre 1999), Marseille, 3-5 nov. 1999. Aix-en-Provence: Édisud, 2001, p. 365-367 (Études massaliètes, 7).

Rigaud 2004 : RIGAUD (Ph.) - Étude d'archives : synthèses, inventaires et transcriptions. In : Barra (C.), Guillaume (M.), Maufras (O.), Vasselin (B.), Voyez (Ch.) dir., Les fouilles archéologiques du Tunnel de la Major (Marseille, Bouches-du-Rhône) : contribution à la connaissance de la topographie urbaine du VI ${ }^{e}$ s. av.n. è. au XIXe s. Marseille/Aix-en-Provence : Inrap/SRAPACA, 2004, annexe 8 (Rapport de fouille archéologique).

Rigaud, Bouiron 2001 : RIGAUD (Ph.), BOUIRON (M.) - Le bourg de Roubaud: l'évolution d'un quartier péri-urbain marseillais du Moyen Âge au $\mathrm{XVI}^{\mathrm{e}} \mathrm{s}$. d'après les archives. In : Bouiron (M.) dir., L'Alcazar, 26 siècles d'occupation suburbaine à Marseille. Marseille/Aix-en-Provence : Atelier du Patrimoine/Afan/SRA-PACA, 2001, vol. 6, p. 7-138 (Rapport de fouille archéologique).

Rigouleau 2004: RIGOULEAU (C.) - Hôtes et logis à Marseille au $X V I^{e} s$. Aix-en-Provence, 2004 (Mémoire de DEA sous la direction de Monsieur Gabriel AUDISIO).

Rinalducci 1997 : RINNALDUCCI (V.) - L'îlot nord et l'îlot est, zones 5, 6 et 8. In : Thernot (R.) dir., César médiéval et moderne. Marseille/Aix-enProvence : Afan/SRA-PACA, 1997, p. 16 (Rapport de fouille archéologique).

Rinalducci 1997 : RINALDUCCI (V.) - La fouille. In : Thernot (R.) dir., César médiéval et moderne. Marseille/Aix-en-Provence : Afan/SRA-PACA, 1997, p. 81-101 (Rapport de fouille archéologique).

Roberty 1937 : ROBERTY (B.) - Marseille : Quelques notes sur SaintJean, son fort et ses alentours. Marseille : Impr. méridionale, 1937, 47 p. Roche 1981 : ROCHE (D.) - Le peuple de Paris. Paris : Aubier, 1981, 286 p.

Roche 2000 : ROCHE - La ville promise : mobilité et accueil à Paris (fin XVII ${ }^{e}$-début XIX ${ }^{e}$ s.). Fayard, Paris, 2000, 438 p.

Roncayolo 1996: RONCAYOLO (M.) - Marseille. Les territoires du temps, Éditions locales de France, 1996, 135 p. (Patrimoine et territoires).

Rothe 2005 : ROTHE (M.-P.) - Notice 101. In : Rothe (M.-P.), Tréziny (H.). Marseille et ses alentours. Paris, 2005, p. 496-499. (Carte archéologique de la Gaule, 13/3).

Ruffi 1696 : RUFFI (A. et L.-A. de) - Histoire de la ville de Marseille, ... recueillie de plusieurs auteurs ... Seconde édition, reveuë, corrigée, augmentée et enrichie de quantité d'inscriptions, sceaux, monnoïes, tombeaux et autres pièces d'antiquité. Marseille, 1696, 2 vol., 496-482 p. (2éd.).

Saupin 2002 : SAUPIN (G.) - Les villes en France à l'époque moderne (XVIe-XVIII' s.). Paris : Belin, 2002, 270 p.

Sauze 1983 : SAUZE (É.) - La vie de château en Provence au Moyen-

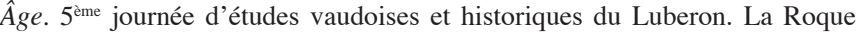
d'Anthéron, 1983.

Scherrer 2008 : SCHERRER (N.) - Le Moyen Âge. In : Paone (F.) dir., 14, rue Trinquet à Marseille (Bouches-du-Rhône). Nîmes/Aix-en-Provence : Inrap/SRA-PACA, 2008, p. 131-138 (Rapport de fouille archéologique).

Scherrer, Bouiron 2001 : SCHERRER (N.), BOUIRON (M.) coll. - Les aspects fonctionnels du faubourg médiéval. In : Bouiron (M.) dir., Marseille, du Lacydon au faubourg Sainte-Catherine (Ve s. av. J.-C.-XVIII ${ }^{e}$ s.) : Les fouilles de la place Général-de-Gaulle. Paris : Éditions de la MSH, 2001. 340 p. (DAF, 87).

Scherrer, Chevillot 2006: SCHERRER (N.), CHEVILLOT (P.), CHANTANT (R.) coll., CHAPPUIS (C.) coll., COGNARD (F.) coll. - ZAC de la Bourse à Marseille (Bouches-du-Rhône). Marseille/Aix-en-Provence : Inrap/SRA-PACA, Nîmes, 2006, 175 p. (Rapport de diagnostic archéologique). 
Scherrer, Yebdri 2001 : SCHERRER (N.), YEBDRI (É.) - Le bâtiment 3, phase 4B1. In: Bouiron (M.) dir., L'Alcazar, 26 siècles d'occupation suburbaine à Marseille. Marseille/Aix-en-Provence : Atelier du Patrimoine/ Afan/SRA-PACA, 2001, vol. 1-2, p. 340-341 (Rapport de fouille archéologique).

Segonne 1960 : SEGONNE (M.), Moine, prélat, croisé : Benoît d'Alignan, abbé de La Grasse, seigneur-évêque de Marseille, 1190-1268. Marseille, 1960, $100 \mathrm{p}$.

Sillano 1997: SILLANO (B.) - Zones 11 et 12 de l'îlot sud. In : Thernot (R.) dir., César médiéval et moderne. Marseille/Aix-en-Provence : Afan/SRA-PACA, 1997, p. 6 (Rapport de fouille archéologique).

Sillano 2001 : SILLANO (B.) - L'eau. In : Bouiron (M.) dir., L'alcazar, 26 siècles d'occupation suburbaine à Marseille (Bouche-du-Rhône). Document final de synthèse. Marseille/Aix-en-Provence : Atelier du Patrimoine/Afan/ SRA-PACA, 2001, vol. 7, p. 137-141 (Rapport de fouille archéologique).

Sillano 2004a : SILLANO (B.) dir. - Avenue de la République - Surverse Vieux-Port. Tranche de ville: du quai romain à l'église Saint-Jaume à Marseille (Bouches-du-Rhône). Marseille/Aix-en-Provence : Inrap/SRAPACA, 2004 (Rapport de fouille archéologique).

Sillano 2004b : SILLANO (B.) - De la naissance du quartier Belsunce à l'Alcazar (XVI ${ }^{\mathrm{e}}$ au XIX ${ }^{\mathrm{e}} \mathrm{s}$.), Marseille, 204, 2004, p. 33-39.

Sillano 2005 : SILLANO (B.) - L'habitat moderne. In : Mellinand dir., Espace Bargemon. Nîmes/Aix-en-Provence : Inrap/SRA-PACA, 2005, vol. 2, p. 463-478 (Rapport de fouille archéologique).

Sillano et al. 2007a : SILLANO (B.), PARENT (F.), CHAPPUIS (C.) - Rue de la République (Nord), Rapport final d'opération, Inrap, Marseille, 2007.

Sillano et al. 2007b : SILLANO (B.), PARENT (F.), WEYDERT (N.) - D'un quai à l'autre, bassin de stockage Sadi-Carnot, surverse Vieux-Port, rue de la République à Marseille. Nîmes/Aix-en-Provence : Inrap/SRAPACA, 2007 (Rapport de fouille archéologique).

Sillano, Scherrer 2009 : SILLANO (B.), SCHERRER (N.) - Le jeu de Paume de la rue Thubaneau, à Marseille, dans l'agrandissement de Louis XIV. Mélanges XVe-XXe s., Provence historique, LIX, 2009, p. 175-191.

Smail 2001 : SMAIL (D.-L.) - La topographie socioprofessionnelle de Marseille au XIV e s. In : Bouiron (M.), Tréziny (H.), Bizot (B.), Guilcher (A.), Guyon (J.), Pagni (M.) - Marseille. Trames et paysages urbains à Marseille de Gyptis au Roi René. Actes du colloque international d'archéologie (Marseille, 3-5 novembre 1999), Marseille, 3-5 nov. 1999. Aix-en-Provence : Édisud, 2001, p. 307-316 (Études massaliètes, 7).

Sournia, Vayssettes 1994: SOURNIA (B.), VAYSETTES (J.-L.) - Montpellier : la demeure classique. Paris : Imprimerie nationale, 1994. 336 p. (Cahiers du Patrimoine, 38).

Stouff 1970 : STOUFF (L.) - Ravitaillement et alimentation en Provence aux XIV e et XV $V^{e}$ s. Paris-La Hayes : EPHEE, 1970, 507 p. (Civilisations et Sociétés, 20).

Stouff 2009 : STOUFF (L.) - Marseille et Arles. In : Pécout (Th.) dir., Marseille au Moyen Âge, entre Provence et Méditerranée : les horizons d'une ville portuaire. Méolans-Revel : Éditions Désiris, 2009, p. 358-363.

Tavernier 1976 : TAVERNIER (F.) - Aspects de Marseille sous la royauté, Marseille : Centre régional de documentation pédagogique, 1976, $117 \mathrm{p}$.

Teissier 1891: TEISSIER (O.) - Marseille au Moyen-Age. Institutions municipales, topographie, plan de restitution de la ville 1250-1480. Marseille, 1891, $203 \mathrm{p}$.

Teyssot 2003 : TEYSSOT (J.) - Les promoteurs de l'urbanisme. In : Gauthiez (B.), Zadora-Rio (E.) et Galinié (H.). Village et ville au Moyen Age : les dynamiques morphologiques. Tours, 2003, p. 449-451 (Perspectives «Villes et Territoires », 5).

Thernot 1997: THERNOT (R.) dir. - César médiéval et moderne. Marseille/Aix-en-Provence : Afan/SRA-PACA, 1997. (Rapport de fouille archéologique).

Thernot, Vecchione 2003 : THERNOT (R.), VECCHIONE (M.) - Les murs en terre banchée dans l'habitat de Marseille au Moyen-Âge (fin XII ${ }^{e}$ début XIII ${ }^{\mathrm{s}}$.), fouilles de la place Villeneuve-Bargemon. In : De Chazelles (C.-A.), Klein (A.), Accetta (A.) dir., Échanges transdisciplinaires sur les constructions en terre crue. Actes de la table ronde, Montpellier 17-18 novembre 2001, Montpellier, 2003, p. 439-449.
Thiriot, Vallauri 2001 : THIRIOT (J.), VALLAURI (L.) - Le bourg des Olliers à Marseille : conception d'un espace artisanal périurbain au XIII ${ }^{e} \mathrm{~s}$. In : Bouiron (M.), Tréziny (H.), Bizot (B.), Guilcher (A.), Guyon (J.), Pagni (M.). Marseille. Trames et paysages urbains à Marseille de Gyptis au Roi René, Actes du colloque international d'archéologie (Marseille, 3-5 novembre 1999), Marseille, 3-5 nov. 1999. Aix-en-Provence : Édisud, 2001, p. 369-374. (Études massaliètes, 7)

Vacca-Goutoulli 1997 : VACCA-GOUTOULLI (M.) - Étude du mobilier lapidaire, Étude des matériaux et des techniques. In : Thernot (R.) dir., César médiéval et moderne. Marseille/Aix-en-Provence : Afan/SRA-PACA, 1997, p. 60 (Rapport de fouille archéologique).

Vacca-Goutoulli 2001: VACCA-GOUTOULLI (M.) - L'étude diachronique du lapidaire du site de l'Alcazar: analyse des observations techniques relevées sur une partie du mobilier lapidaire. In : Bouiron (M.) dir., L'alcazar, 26 siècles d'occupation suburbaine à Marseille (Bouchedu-Rhône). Marseille/Aix-en-Provence : Atelier du Patrimoine/Afan/ SRA-PACA, 2001, vol. 4, p. 159-224 (Rapport de fouille archéologique).

Valbelle 1985: VALBELLE (H. de) - Histoire journalière d'Honorat de Valbelle (1498-1539). Journal d'un bourgeois de Marseille au temps de Louis XII et de François I. 2 t., Marseille, 1985, 622 p.

Vallauri, Leenhardt 1997: VALLAURI (L.), LEENHARDT (M.) - Les productions. In : Marchesi (H.), Thiriot (J.), Vallauri (L.) dir., Marseille, les ateliers de potiers du XIII' s. et le quartier Sainte Barbe (Ve $\left.-X V I I^{e} s.\right)$. Paris : MSH, 1997, p. 389 (DAF, 65).

Vasseur 1894 : VASSEUR (G.) - Compte-rendu d'excursions géologiques aux Martigues et à l'Estaque (Bouches-Du-Rhône), Bulletin de la Société Géologique de France, 22, 1894, p. 413-444.

Vecchione 1997: VECCHIONE (M.) - La fouille. In: THERNOT (Robert) dir. - César médiéval et moderne. Marseille/Aix-en-Provence : Afan/SRA-PACA, 1997 (Rapport de fouille archéologique).

Vecchione, Rinalducci 1997 : VECCHIONE (M.), RINALDUCCI (V.) - Les données de terrains : les îlots nord et est. In : Thernot (R.) dir., César médiéval et moderne. Marseille/Aix-en-Provence : Afan/SRA-PACA, 1997 (Rapport de fouille archéologique).

Verdin 2008: VERDIN (P.) - Rapport d'analyse des phytolithes. In : Paone (F.) dir., 14, rue Trinquet à Marseille (Bouches-du-Rhône) RFO, 2008, p. 131-138.

Vergé-Franceschi 2004: VERGE-FRANCESCHI (M.) - Les Lenche de Morsiglia et la Magnifique Compagnie du Corail à Marseille XVI- $\mathrm{XVII}{ }^{\mathrm{e}}$ s. In : Vergé-Franceschi (M.), Graziani (A.-M.) dir., Le corail en Méditerranée, Cinquièmes Journées Universitaires d'histoire maritime de Bonifacio, 2004, p. 65-95.

Villard 1999: VILLARD (M.) - Fruits à Marseille aux XVe et XVI e s., Provence historique, 49, 195-196, 1999, p. 511-522.

Villard, Villard 1970 : VILLARD (A.), VILLARD (M.) - Les fonds des archives départementales des Bouches-du-Rhône. Premier volume, Deuxième partie. Dépôt principal de Marseille. Séries anciennes $G$ et $H$. Marseille, 1970, 325 p.

Villate 1992 : VILLATE (D.) - L'équipement hôtelier parisien au milieu $d u$ XVIII $s$. Paris, 1992 (Thèse de doctorat sous la direction de Pierre Chaunu Université de Paris IV-Sorbonne).

La Ville figurée. Plans et vues gravées de Marseille, Gênes et Barcelone (sous la direction de M. Morel), Marseille : Éditions Parenthèses/Musées de Marseille, 2005, 144 p. (Catalogue d'exposition).

Vovelle 1980 : VOVELLE (M.) - De la cave au grenier. Un itinéraire en Provence au $18^{e}$ s. : de l'histoire sociale à l'histoire des mentalités, Québec : Serge Fleury, 1980, 484 p. (La mesure du temps).

Willaume et al. 1983 : WILLAUME (M.), GANTES (L.-F.), CARDUNER (M.), SINTES (C.), BATUT (L.), LAMBERT (N.), BOIRON (R.), BONIFAY (M.), GREGORCZYCK (E.), LABARRE (R.), PUTZOLA (J.-C.) - Marseille. Équipements Publics, août 1982-février 1983. [Aix-en-Provence], [1983], 113 p. (Rapport de fouille archéologique).

Wolff 1978 : WOLFF (Ph.) - Les hôtelleries toulousaines au Moyen Âge. In : Regards sur le Midi médiéval, Toulouse : Privat, 1978, p. 93-107.

Zysberg 1983 : ZYSBERG (A.) - Marseille au temps des galères : 16601748, Marseille : édition rivages, $1983,115 \mathrm{p}$

Zysberg 2007 : ZYSBERG (A.) - Marseille au temps du Roi-Soleil, la ville, les galères, l'arsenal. Marseille : Jeanne Laffitte, 2007, 304 p. 


\section{Bibliothèque d'archéologie méditerranéenne et africaine}

Volumes parus :

1, 2009 - M. Segard : Les Alpes occidentales romaines.

2, 2009 - P. Thollard : La Gaule selon Strabon.

3, 2010 - Grecs et indigènes de la Catalogne à la Mer Noire.

4, 2010 - Archéologie de la montagne européenne.

5, 2010 - Apollonia du Pont (Sozopol) : La nécropole de Kalfata (Ve-III ${ }^{e}$ s. av J.-C.).

6, 2010 - L. Rivet : Recherches archéologiques au coeur de Forum Iulii.

7, 2011 - Fouilles à Marseille. Approche de la ville médiévale et moderne (ÉtMassa 10).

8, 2011 - P. Excoffon : Ville et campagne de Fréjus romaine. La fouille préventive de «Villa Romana ».

On trouvera la liste des publications du Centre Camille Jullian sur le site :

http://sites.univ-provence.fr/ccj/spip.php?rubrique79

Les volumes 1 à 9 des Etudes massaliètes sont accessibles en ligne en format pdf, grâce au soutien du Centre de conservation du livre à Arles (e-corpus).

Achevé d'imprimer en juin 2011 par Printer Portuguesa

à Rio de Mouro

Dépôt légal : juillet 2011

$\mathrm{n}^{\circ} \mathrm{d}^{\prime}$ imprimeur :

Imprimé au Portugal 